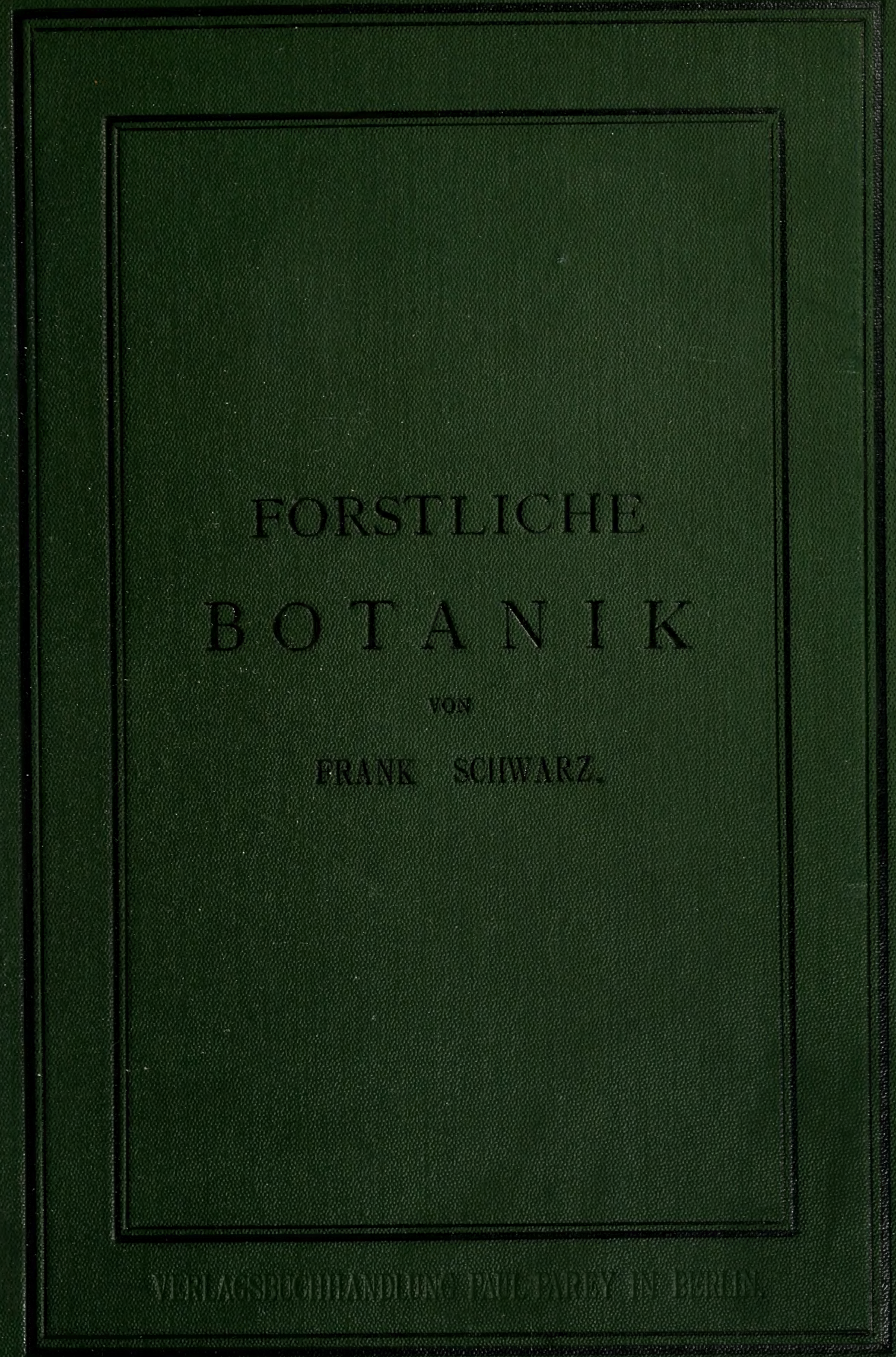




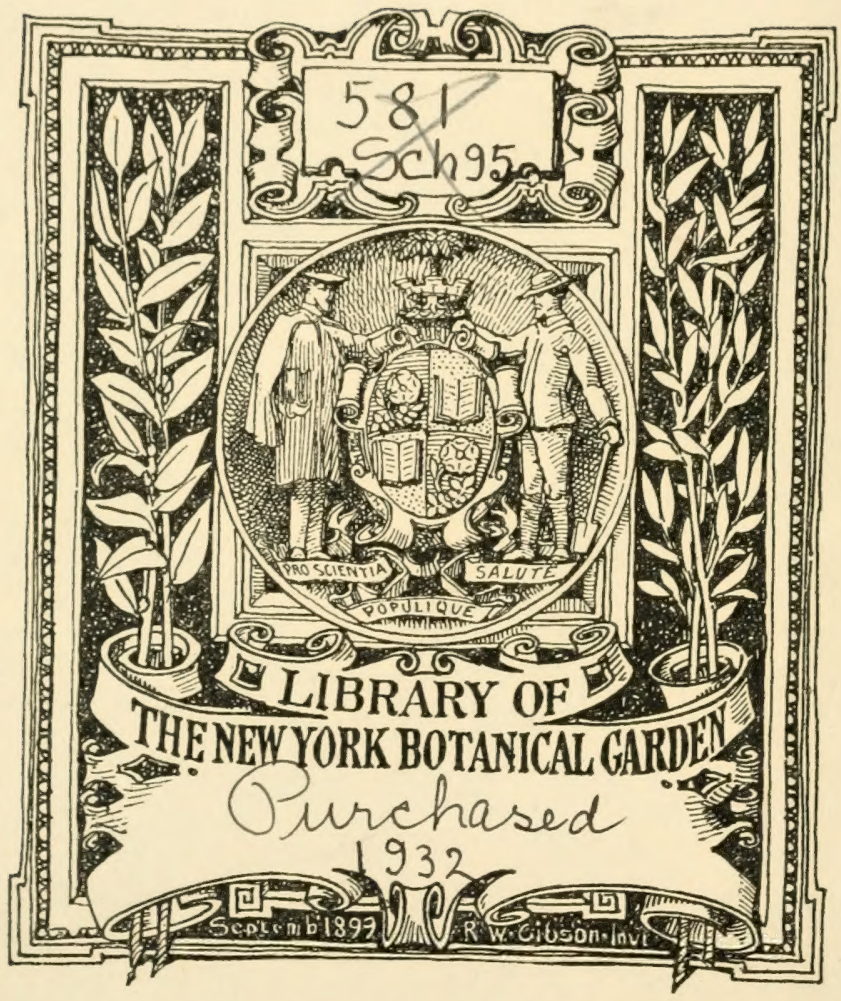




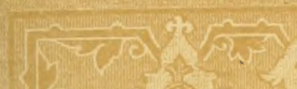

$\left[\begin{array}{l}3 \\ 3\end{array}\right.$

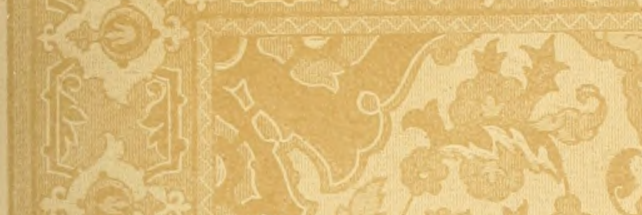

(a)

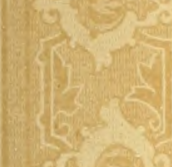

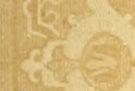

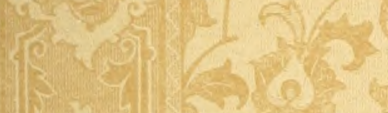

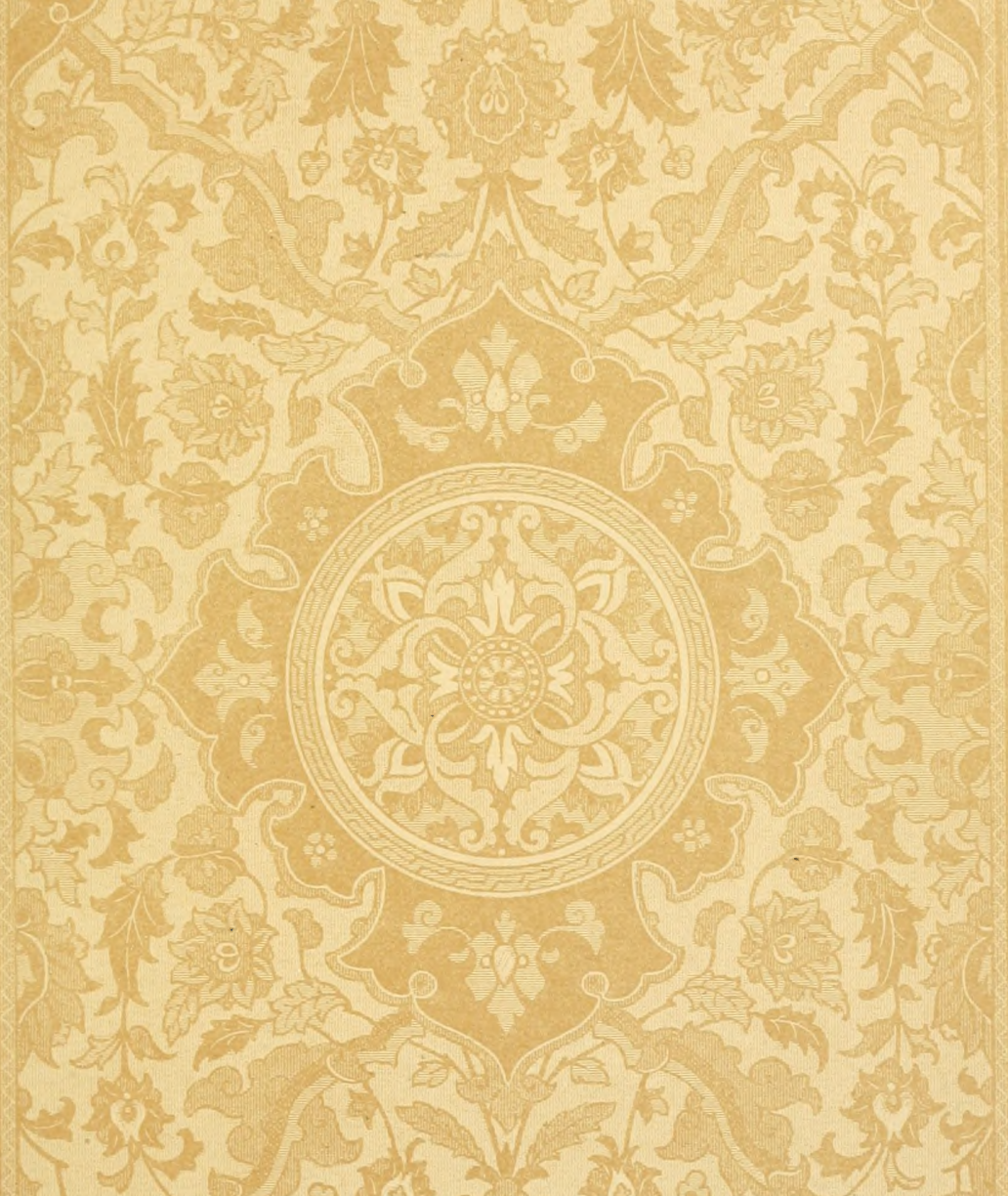

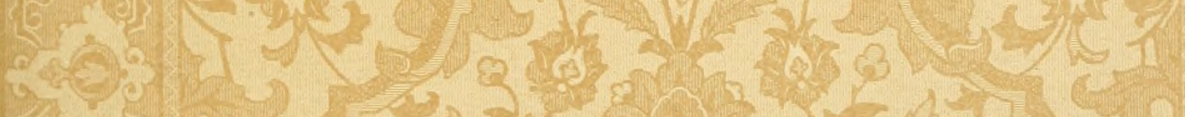

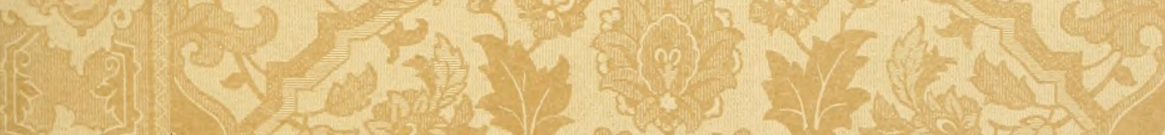

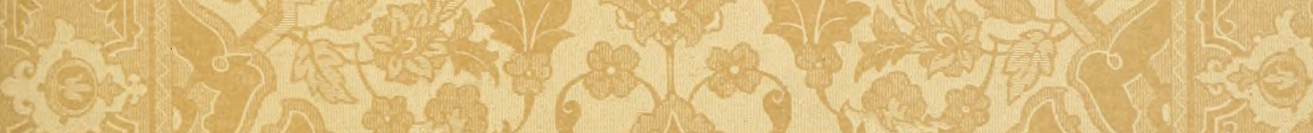

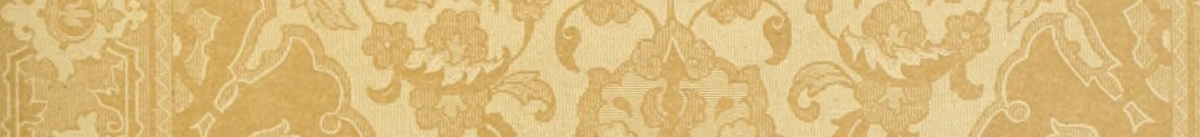

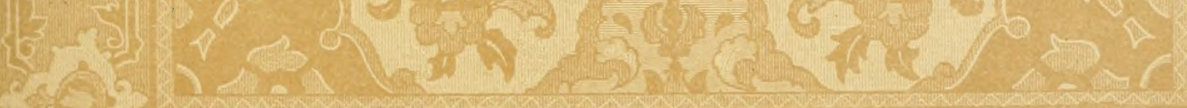

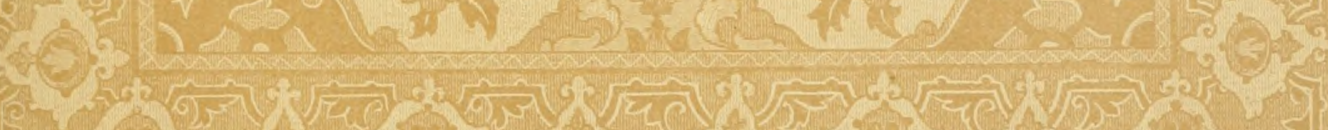

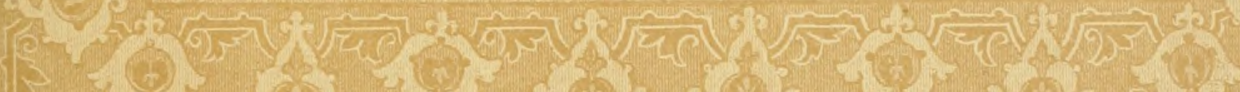

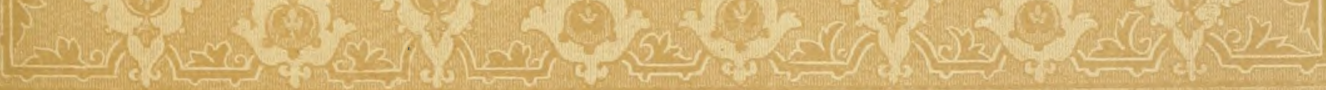




$$
425
$$




\section{Forstliche Botanik.}





\section{Forstliche Botanik.}

Von

\section{Dr. Frank Schwarz}

Professor an der Kgl. Forstakademie in Eberswalde.

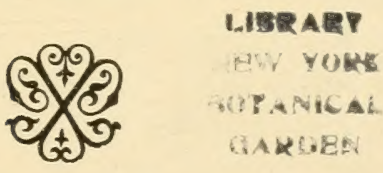

Mit 456 Textabbildungen und zwei Lichtdrucktafeln.

BERLIN.

VERLAG VON PAUL PAREY. Ferlarshandlung fir Landwirtschaft, Gartenbau und Porstresen. SW., 10 Hedemannstrasse. 
QK475

$$
.526
$$




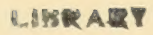 \\ GiHW YORE \\ BCTANICAL \\ GALOEE: \\ Vorwort.}

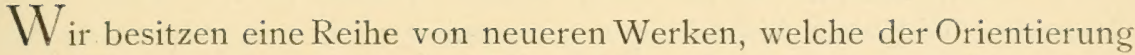
und dem Unterrichte auf forstlich-botanischem Gebiete dienen. Zu nennen wären unter vielen anderen Willkomms „,Forstliche Flora von Deutschland und Österreich,“ sowie „Deutschlands Laubhölzer im Winter" von demselben Autor, R. Hartigs „Lehrbuch der Anatomie und Physiologie der Pflanzen“, „Lehrbuch der Baumkrankheiten“ und die „Unterscheidungsmerkmale der wichtigeren in Deutschland wachsenden Hölzer", ferner v. Tubeufs „Samen, Früchte und Keimlinge" und das Buch von Hess „Die Eigenschaften und das forstliche Verhalten der wichtigeren in Deutschland vorkommenden Holzarten." Die Anschaffung aller dieser Werke, welche zur allgemeinen Übersicht noch durch ein Lehrbuch der Botanik, sowie durch eine Flora zum Bestimmen der Pflanzen zu ergänzen wären, kann von dem Einzelnen, sobald er sich nicht die Botanik als Specialstudium gewählt hat, nicht verlangt werden. Wenn nun auch das vorliegende Buch die übrigen Specialwerke nicht vollständig ersetzen kann, so soll es doch dem in der Praxis stehenden Forstmann und dem Studierenden jene Übersicht über die gesamte Botanik bieten, welche geeignet ist als Grundlage für die praktische Erfahrung, sowie für den akademischen Unterricht zu dienen. Sollte das Buch nicht einen die gegebenen Grenzen weit übersteigenden Umfang annehmen, musste ich auf die nähere Behandlung von Details verzichten, besonders da ich die für das allgemeine Verständnis notwendigen Gebiete nicht ausser Acht lassen durfte, wenn sie auch mit dem forstlichen Beruf nicht direkt in Verbindung stehen. Hierher gehören die Abschnitte über Zellenlehre und gewisse Teile der Anatomie, welche etwas ausführlicher behandelt wurden, um zu gleicher Zeit als Hilfsmittel für die zum Studium der Botanik so notwendigen mikroskopischen Übungen dienen zu können. Bei der Behandlung der Systematik wurde auf den Aufbau des Systems und die genetische Verwandtschaft der einzelnen Gruppen Wert gelegt und nur die forstlich wichtigen Gewächse wurden eingehender besprochen. Bei der Überbürdung der Studierenden der Forstwissenschaft mit den verschiedenartigsten Gegenständen scheint mir jede wenn auch noch so kleine Erleichterung des Studiums von Vorteil zu sein und ich hoffe, dass die einheitliche Bearbeitung des vorliegenden Stoffes zu diesem Zwecke beiträgt. Nament- 
lich dürften in dieser Hinsicht auch die Bestimmungstabellen in Betracht kommen, die den unnützen Zeitaufwand, welcher den Bestimmungen an unseren preussischen Akademien gewidmet wird, vielleicht etwas einschränken.

Zu besonderem Danke bin ich dem Verleger, Herrn Paul Parey, für die vortreffliche Ausstattung des Buches verpflichtet, indem er mir nicht nur die Holzschnitte seines Verlages zur Verfügung stellte, sondern auch in der Anfertigung von Originalzeichnungen jederzeit in der liberalsten Weise entgegen kam. So konnte ich aus den Lehrbüchern von Reinke (bezeichnet mit R.), Kienitz-Gerloff (K.), Döbner-Nobbe (DN.), Schubert (Sch.), Wossidlo (W.) viele Abbildungen verwenden. Die neuen Holzschnittzeichnungen wurden fast ausschliesslich von Fräulein E. Raatz nach der Natur aufgenommen, während die Tafeln mit den Holzquerschnitten von Herrn Forstassessor Dr. K. R. G. Schumann, die Karten mit der Verbreitung der Holzgewächse von Herrn Forstassessor Böhm herrühren. Allen diesen Nitarbeitern sage ich hiermit meinen verbindlichsten Dank.

Eberswalde im Herbst I89I.

F. Schwarz. 


\section{Inhalt.}

Einleitung

Seite

\section{Organographie.}

\section{Erster Abschnitt: Zellenlehre.}

$\S$ I. Begriff und Teile der Zelle . . . . . . . . . . . . . . . . . . .

$\S$ 2. Protoplasma (Übersicht) . . . . . . . . . . . . . . . . . . . 5

\& 3. Cytoplasma . . . . . . . . . . . . . . . . . . . . . 6

$\$$ 4. Zellkern (nucleus) und Zellvermehrung . . . . . . . . . . . . . . . 9

§ 5. Chromatophoren . . . . . . . . . . . . . . . . . . . . I 3

§ 6. Zellsaft. Aleuronkörner . . . . . . . . . . . . . . . . . . I7

§ 7. Ungelöste im Plasma abgelagerte Stoffwechselprodukte . . . . . . . 20

§ 8. Osmose und Turgor . . . . . . . . . . . . . . . . . . . . . 22

§ 9. Zellwand (Zellmembran) . . . . . . . . . . . . . . . . . . . 23

$\S$ ro. Chemische Beschaffenheit der Zellwand . . . . . . . . . . . . . 27

§ I I. Physikalische Eigenschaften der Zellwand . . . . . . . . . . . . . 3 I

§ 12. Wachstum der Zellwand . . . . . . . . . . . . . . . . . . . 32

Zweiter Abschnitt: Morphologie und Gewebelehre der Vegetationsorgane.

§ 13. Arbeitsteilung in der Pflanze. . . . . . . . . . . . . . . . . . 34

$\S$ I4. Die Vegetationsorgane der Algen, Pilze und Moose . . . . . . . . . 35

I5. Entstehung der Organe und Gewebe aus den Vegetationspunkten . . . . is

§ I6. Normale und adventive Bildung von Seitenorganen . . . . . . . . . it

17. Morphologischer Aufbau der Axen und Stellung der Scitenorgane . . . . 46

$\S$ 18. Beschreibung der Blätter . . . . . . . . . . . . . . . . . . . 51

$\S$ 19. Anatomie der Blätter . . . . . . . . . . . . . . . . . . 57

\$ 20. Beschreibung der Sprossaxen . . . . . . . . . . . . . . . . . 65

$\$ 2$ r. Primärer anatomischer Aufbau der Sprossaxen . . . . . . . . . . 7 I

\$ 22. Sekundäres Dickenwachstum der Sprossaxen . . . . . . . . . . . . . $s_{3}$

$\S$ 23. Die Elementarorgane des sekundären Holzes . . . . . . . . . . . . $\$_{5}$

\$ 24. Jahresringbildung, Verschiedenheiten des Holzes nach Alter und Baumhöhe. Kernholz und Schutzholz . . . . . . . . . . . . . . . . 94

$\S 25$. Holzqualität . . . . . . . . . . . . . . . . . . . . . 100

$\S 26$. Anatomie des sekundären Bastes . . . . . . . . . . . . . . . . 104

\$ 27. Beschreibung der Wurzeln . . . . . . . . . . . . . . . . . . 107

$\S$ 28. Primärer anatomischer Aufbau der Wurzeln . . . . . . . . . . . . II I

$\S 29$. Sekundäres Dickenwachstum der Wurzeln. Wurzelholz . . . . . . . II7 
s. 3o. Periderm- und Borlicbildung. Lenticellen . .

ธ. 3. Wundheilung, Überwallung, Astung . . . . . . . . . 125

\section{Physiologie.}

\$32. Dic Nilirungsstoffe der Pflanzen . . . . . . . . . . . . . . 135

\$. 3. Kohlenstiureassimilation . . . . . . . . . . . . 136

\$. 3. Dic Aufnahme von Stickstoff bei den grünen Pflanzen. . . . . . . . I39

\$. 35. Aufnahme organischer Nahrung . . . . . . . . . . . . . . . . 141

36. Aschenbestandteile der Pllanzen . . . . . . . . . . . . . . 144

$\$$ 37. Wasserabgabe, Wasseraufnahme und Wasserleitung . . . . . . . 149

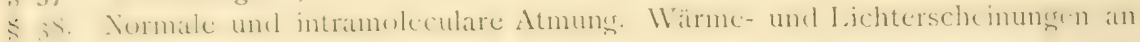

Plimzen . . . . . . . . . . . . I5t

\$ 39. Wachstumserscheinungen der Pflanzen. Allgemeines . . . . . . . 156

\$ 40. Periodicität des Wachstums . . . . . . . . . . . . . . 159

\$ 41. Einwirkung äusserer Faktoren auf das Wachstum . . . . . . . . 166

$\$ 42$. Autonome Bewegungen . . . . . . . . . . . . . . . . . . 168

43. Reizerscheinungen und inducierte Bewegungen . . . . . . . . . . 169

$\$$ 44. Beschädigung und Tötung durch äusscre Faktoren . . . . . . . . . 173

\section{Systematik.}

\$ 45. Übersicht über das System . . . . . . . . . . . . . I83

46. Schizophyceae Algae . . . . . . . . . . . . . . . . I86

5 ti. Myxomycetes. Reproduktions- und Vegetationsorganc der echten Pilze a Ind

$\$ 4$. Oomycetes . . . . . . . . . . . . . . . . . 202

\$ 49. Zygomycetes . . . . . . . . . . . . . . . . . . . 204

50. Ascomycetes . . . . . . . . . . . . . . . . . 204

51. Lichenes, Flechten . . . . . . . . . . . . 213

52. Ustilagineae, Brandpilze . . . . . . . . . . . . . . 215

\$5. Uredineac, Rostpilze . . . . . . . . . . . . . . . . . 216

\$54. Basidiomycetes . . . . . . . . . . . . . . . . . . . 223

$\$ 55$. Bryophyta oder Muscineae, Moose . . . . . . . . . . . 23 I

$\$ 56$. I'teridophyta, Farnpfianzen oder Gefisskryptogamen . . . . . . . 236

$\$$ 57. Fortpflanzung der Gymnospermen und Angiospermen. Anschluss dersclben an die Pteridophyten . . . . . . . . . . . . . . . . . . 242

$\$ 5$ S. Gymnospermae, Nacktsamige. Typus . . . . . . . . . . . . . $25 \mathrm{I}$

\$ 59. Cycadeae . . . . . . . . . . . . . . . . . . . $25 \mathrm{I}$

§6. Coniferae, Nadelhölzer . . . . . . . . . . . . . . . . . 251

\$ 61. Gnetaceae . . . . . . . . . . . . . . . . 268

$\$ 62$. Angiospermae, Bedecktsamige. Typus . . . . . . . . . . . . . 268

\$63. Morphologie von Blüte und Frucht . . . . . . . . . . . . . . . 268

5 64. Bestäubungseinrichtungen. Verbreitungsmittel der Samen und Früchte 27 I

§ 65. Monocotyledones, Einkeimblättrige. Typus . . . . . . . . . . . 275

$\$ 66$. Helobieae . . . . . . . . . . . . . . . . 275

\$ 67. Glumiflorae, Spelzblütige . . . . . . . . . . . . 276

\$ 68. Spadiciflorae . . . . . . . . . . . . . . . . . 285

\$ 69. Enantioblastae. . . . . . . . . . . . . . . . . 286

\$ 70. Liliiflorae . . . . . . . . . . 286

71. Scitamineae . . . . . . . . 288

\$ 71. Scitamineae 288

72. Gynandrae. Dicotyledones, Zweikeimblättrige. Typus . . . . . . . . . . . . 289 
$\$ 74$. Choripetalae: Saliciflorae

\$ 75. Ouerciflorae . . . . 290

\$ 76. Juglandiflorae . . . . . . . . . . . . .

§ 77. Urticiflorae . . . . . . . . . . . . . . . 3II

§ 7 \&. Polygoniflorae . . . . . . . . . . . . . 314

\$ 79. Curvembryae. . . . . . . . . . . . . . 314

§ so. Cactiflorae . . . . . . . . . . . . . . 315

\$ \$. Polycarpicae . . . . . . . . . . . . . . . . 316

§ \$2. Rhoeadinae . . . . . . . . . . . . . . . 318

$\S \$_{3}$. Cistiflorae . . . . . . . . . . . . . . . . . . 319

$\$ \$ 4$ Gruinales . . . . . . . . . . . . . . 320

$\$ \$_{5}$. Columniferae . . . . . . . . . . . . . . . . . $32 \mathrm{I}$

\$ \$6. Tricoccae . . . . . . . . . . . . . . . . . 322

$\$ 87$. Terebinthinae . . . . . . . . . . . . . . . 323

§ SS. Aesculinae . . . . . . . . . . . . . . . . . 325

§ \$. Frangulinae . . . . . . . . . . . . . . . . . 329

§ 90. Thymelaeinae . . . . . . . . . . . . . . . . . 33 I

§ 9r. Saxifraginae . . . . . . . . . . . . . . . . . . 333

\$ 92. Rosiflorae . . . . . . . . . . . . . . . . . . . 335

\$ 93. Leguminosae . . . . . . . . . . . . . . . . . . . . . 344

\$ 94. Passiflorinae . . . . . . . . . . . . . . . . 349

§ 95. Myrtiflorae . . . . . . . . . . . . . . . . . 349

§ 96. Umbelliflorae . . . . . . . . . . . . . . . . . 350

\& 97 . Hysterophyta . . . . . . . . . . . . . . . . . . . . 353

§ 9 \$. Sympetalae: Bicornes . . . . . . . . . . . . . . . . . . . 353

§ 99. Diospyrinae . . . . . . . . . . . . . . . . . . . $\quad 355$

\$ 100. Primulinae . . . . . . . . . . . . . . . . . . . . . . 355

§ гог. Tubiflorae . . . . . . . . . . . . . . . . . . . . . . 355

$\S$ 102. Personatae . . . . . . . . . . . . . . . . . . . . . . . . . 356

§ 103. Nuculiferae . . . . . . . . . . . . . . . . . . . . . . . . 358

$\S$ ro4. Contortae . . . . . . . . . . . . . . . . . . . . . . 360

$\S$ 105. Rubiales . . . . . . . . . . . . . . . . . . 363

$\S$ ro6. Campanulinae . . . . . . . . . . . . . . . . . . . . 366

§ 107 . Aggregatae . . . . . . . . . . . . . . . . . 367

\section{Pflanzengeographie.}

$\$$ 108. Die pflanzengeographische Einteilung der Erde in Florenreiche und Vegetationsformationen . . . . . . . . . . . . . . . . . 371

ऽ rog. Die Florenreiche . . . . . . . . . . . . . . . . . . . . 377

$\S$ I 10. Vegetationslinien und Regionen . . . . . . . . . . . . . . 385

§ III. Elemente der wichtigsten Vegetationsformationen Mitteleuropas . . 395

$\S$ I12. Bodenanzeigende Pflanzen. Nutzen und Schaden der Bodenflora . . . 407

\section{Bestimmungstabellen.}

§ II3. Bestimmung der wichtigsten Bäume und Sträucher nach den Blättern • 4I3

§ I I4. Bestimmung der Laubhölzer im Winterzustande. . . . . . . . . . 427

$\S$ II 5 . Bestimmung der wichtigsten Keimpflanzen . . . . . . . . . . . . 462

$\S$ IÍ. Bestimmung der Hölzer nach den mit freiem Auge sichtbaren Merkmalen 



\section{Einleitung.}

Bei der wissenschaftlichen Forschung kommt es im allgemeinen darauf an, die Bedeutung der einzelnen Erscheinung für das Ganze zu erfassen. Ebenso müssen wir bei der Untersuchung der Pflanzen die Bedeutung der einzelnen Teile derselben, ihre Funktionen im Auge behalten, wollen wir den ganzen Organismus verstehen, wir müssen von den Eigenschaften, von der Form und Entwickelung des Individuums ausgehn, um die natürliche systematische Verwandtschaft der Pflanzen in ihrer Gesamtheit zu erkennen.

Die Pflanzenmorphologie, die Lehre von der Gestalt der Pflanzen, zergliedert die Pflanzen der Form nach, untersucht die Entwicklung und Bedeutung der einzelnen Glieder, während die Pflanzenanatomie auf den inneren Bau derselben eingeht und besondere Rücksicht auf die Eigenschaften der Zellen nimmt, welche den Pflanzenkörper zusammensetzen (Zellenlehre). Da wir bei der Betrachtung der Gestalt und des inneren Aufbaues den Zusammenhang mit der Funktion in den Vordergrund stellen wollen, ergeben sich zwischen Morphologie und Anatomie eine Reihe von Berïhrungspunkten, welche es praktisch erscheinen lassen, diese beiden Gebiete nicht zu trennen, sie vielmehr nach dem Vorgange Anderer unter dem gemeinsamen Namen der Organographie zusammenzufassen, wozu naturgemäss auch die Zellenlehre zu rechnen ist.

Die Pflanzenphysiologie sucht die Lebensvorgänge durch mechanisch-chemisch wirkende Ursachen zu erklären. Obgleich uns das Leben an und für sich wohl immer ein unergründliches Rätsel bleiben wird, dürfen wir bei diesem ,,ignorabimus" nicht stehen bleiben, wir müssen vielmehr versuchen die Phänomene auf die zunächstliegenden causalwirkenden Ursachen zurückzuführen, wir müssen die Abhängigkeit der Erscheinungen von äusseren oder inneren Faktoren feststellen, das Substrat dieser Lebensvorgänge ermitteln und die einzelnen Phasen der Erscheinung beschreiben.

Die Systematik der Pflanzen hat nicht nur die Aufgabe die specielle Kenntnis der für uns wichtigen Pflanzen zu vermitteln, sie soll uns auch einen Eimblick gewähren in den Zusammenhang und die Entwickelung 
der grösseren Gruppen und Pflanzenreihen. Die Morphologie der Pflanze, speciell der Blüten, sowie die Fortpflanzungsorgane überhaupt bilden die Grundlage einer natürlichen Systematik.

Die Pflanzengeographie berücksichtigt die Verbreitung und Verteilung der Pflanzen auf der Erde.

Insofern es sich nicht um normale, sondern um krankhafte Lebensvorgänge handelt, spricht man von Pflanzenpathologie. Einerseits

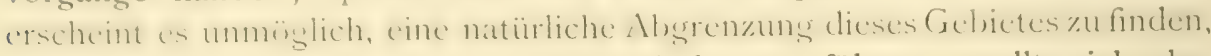
anderseits würde es leicht zu Wiederholungen führen, wollte ich den Pflanzenkrankheiten einen besonderen Abschnitt in diesem Buche widmen, ich habe daher vorgezogen, die Krankheitserscheinungen im Anschluss an die normalen Bildungsvorgänge zu behandeln, die durch Pilze verursachten Krankheiten aber bei der Systematik der Pilze zu befprechen.

In Anwendung der wissenschaftlichen Resultate und Untersuchungsmethoden auf bestimmte Gebiete des praktischen Lebens kann man auch ven ciner landwirtschaftlichen, technischen, pharmaceutischen Botanik, einer Forstbotanik sprechen, wir dürfen dabei aber nicht vergessen, dass es sich hierbei nur um Teile der verschiedenen Zweige unserer Wissenschaft handelt, die mit Rücksicht auf den bestimmten Zweck zusammengestellt sind.

Orsanosraphic (Anatomie, Morphologie) und Physiologie wird häufig als Allgemeine Botanik bezeichnet, im Gegensatz zur speciellen Botanik, welche die Systematik umfasst. 


\section{Organographie.}

\section{Erster Abschnitt: Zellenlehre.}

\section{§ 1. Begriff und Teile der Zelle.}

Ein Schnitt durch einen Teii einer höheren Pflanze mit dem Mikrosliop betrachtet zeigt uns zahlreiche Kammern, die einer Bienenwabe nicht unähnlich sind. Es sind die Zellwände der zu einem Gewebe verbundenen zahlreichen Zellen, welche das Zelllumen (den Innenraum) umschliessen. Dieses Zelllumen ist bei lebenden Zellen mit Zellinhalt erfüllt, bei abyestorbenen Zellen mit Wasser, Luft oder Exkretstoffen.

Während höhere Pflanzen von einem Komplexz zahlreicher Zellen gebildet werden, können niedere Pflanzen (Algen und Pilze) auch aus einer einzigen oder wenigen Zellen bestehen, womit in der Regel eine geringere Ausbildung ihrer äusseren Gestalt verbunden ist.

Es gilt dies nicht ausnahmslos, wie uns z. B. die Neeresalge Caulerpa prolifera zeigt, welche in Fig. I in natürlicher Grösse abgebildet ist. Wir sehen hier sowohl blattartige Flächen, als wurzelähnliche $\mathrm{Ge}$ bilde, die von einer gemeinsamen Axe ausgehen, auch den analogen Funktionen dienen, aber doch nur Ausstülpungen einer einzigen Zelle sind.

Die Zell-

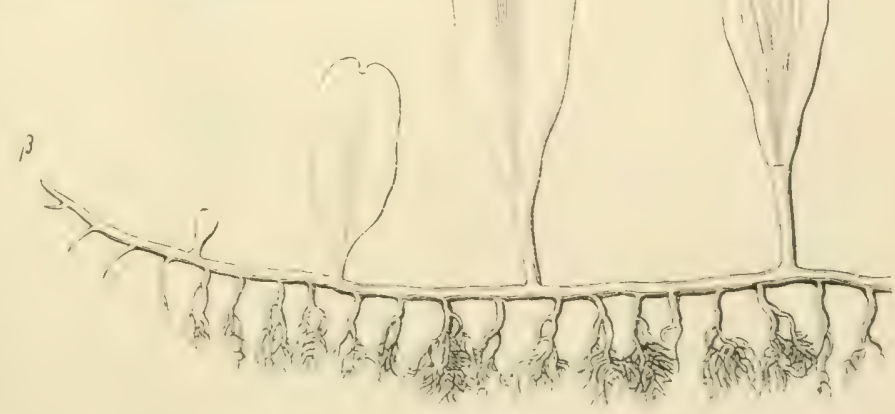

Fig. I. Caulerpa prolifera, (R.)

wand oder Zellmembran bildet die feste Hülle, welche den teils weichen, teils flüssigen Inhalt einschliesst und so die Gestalt der ganzen 
Pflanze festhält. Der Zellinhalt besteht, absesehen von verschiedenen Produkten des Stoffwechsels, aus Protoplasma und Zellsaft. Das Protoplasma ist der aktive Träger des Lebens, in welchem sich die Vorsänge der Ernährung abspielen, von welchem Neubildungsprozesse ausgehen und dem die Fähigkeit innewohnt auf äussere Reize in bestimmter Weise zu reasieren. Beim Absterben des Protoplasmas kann die Zellwand noch erhalten bleiben, so z. B. in dem älteren Narke vieler Phanerogamen, oder in den alten Holzzellen der
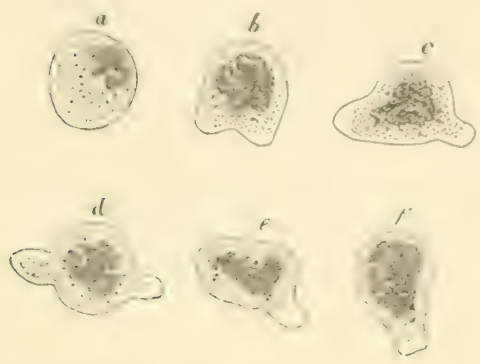

Fig. 2 .

Kriechende Spore von Bangia atro. purpurea. (R.)

Bäume. Es können noch chemische Umwandlunesen und Stoffeinlasserungen in der Zellwand eintreten, es kann durch Wasseraufnahme oder Abgabe das Volumen der Zellwände auch an toten Pflanzenteilen (z. B. Rose von Jericho) verändert werden, so dass sogar Bewegungen enstehen, aber Lebensvorgänge sind für immer ausgeschlossen, sobald das Protoplasma fehlt.

Der Zellsaft ist eine Lösung verschiedener Stoffe, die von dem Protoplasma produziert sich unter Umständen in grosser Menge darin anhäufen können.

Wir sehen also, dass der wesentliche Teil der Zelle das Protoplasma ist. Es kann auch für sich bestehen ohne Zellwand. So stellen die nack-

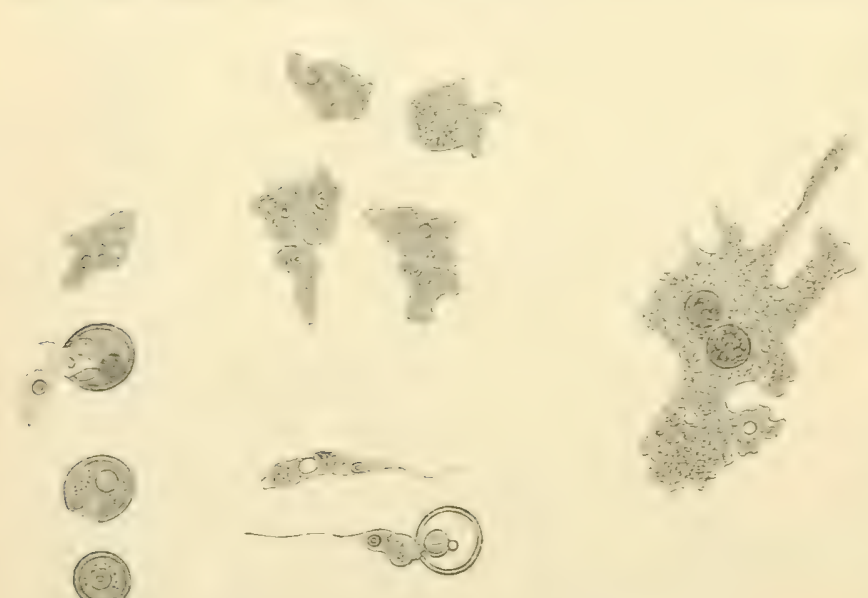

Fig. 3. Didymium Libertianum.

Keimung der Sporen, Schwärmer- und Plasmodienbildung. ten Fortpflanzungszellen (Sporen) von Bangia atropurpurea, einer Meeresalge ( Fig. 2) cin Klümpchen Protoplasma dar, welches unter mannigfachen Formveränderungen über das Substrat kriecht. Die unter dem Namen Amöben zusammengefassten Entwickelungszustände verschiedener niederer Lebewesen zeigen dieselbe Beschaffenheit. Sie können sich zu grösseren Protoplasmaklumpen (Plasmodien) vereinigen (Fig. 3), ohne durch eine Zellwand eine feste Form zu erhalten.

Nach dem Gesagten können wir uns der Definition anschliessen, welche Zimmermann von der Zelle giebt, er bezeichnet als Zelle jeden 
isolierten lebensfähigen Plasmakörper mit Einschluss der die äussere Begrenzung bewirkenden Membran - wenn eine solche vorhanden ist mag derselbe nun im Innern einer hoch differenzierten Pflanze auftreten oder mag er den gesamten Organismus einer Pflanze bilden. Es sagt diese Definition mehr, als wenn man die Zelle als Elementarorganismus bezeichnet.

Wir dürfen dabei nicht vergessen, dass die Zelle und das Protoplasma immer noch sehr komplizierte Organismen sind, in denen nur durch das Zusammenwirken ron sehr verschiedenen Faktoren Erscheinungen zu Tage treten, die wir als Leben bezeichnen.

\section{§ 2. Protoplasma (Übersicht).}

Wir unterscheiden im Protoplasma die Grundmasse, Cytoplasma gsenannt, und die in demselben liegenden geformten plasmatischen Elemente, den Zellkern (nucleus) und die Chromatophoren. Die letzteren sind wieder zu gliedern in Chlorophyllkörper (Chloroplasten), Farbstoffbildner (Chromoplasten) und Stärkebildner (Leucoplasten). Diese Gebilde zeigen alle eine zähflüssige, an das frische Hühnereiweiss oder an eine Gallerte erinnernde, Konsistenz. Sie sind zusammengesetzt aus Proteinstoffen, d. h. stickstoffreichen Verbindungen von Kohlenstoff, Sauerstoff und Wasserstoff, Schwefel und Phosphor, welche einen sehr komplizierten molekularen Aufbau besitzen.

Diese protoplasmatische Grundlage ist bei Chlorophyllkörpern und Farbstoffbildnern durch bestimmte Farbstoffe tingiert, der Kern und die Stärkebildner, ebenso fast immer das Cytoplasma, sind farblos.

Gewisse Reaktionen erleichtern uns das Erkennen der Proteinstoffe, resp. des Protoplasmas in den Zellen: Gerinnung bei höherer Temperatur (daher die schädliche Wirkung derselben auf das Leben der Pflanze), Fällung durch Metallsalze, iz. B. Quecksilberchlorid) oder gewisse organische Verbindungen (Alkohol, Gerbsäure, Pikrinsäure etc. bei höherer Konzentration). Hierzu treten noch gewisse Farbstoffeaktionen: Salpetersäure und Ammoniak geben eine orangerote Färbung (Nanthoproteinreaktion), Jodlösungen eine Braunfärbung, Millons Reagenz, ein Gemisch von salpetersaurem Quecksilberoxydul und salpetersaurem Quecksilberoxyd, ergibt eine schmutzig rötliche Färbung. Gewisse Proteinstoffe zeigen eine charakteristische Violettfärbung, sobald sie mit sehr wenis schwefelsaurem Kupfer und konzentrierter Kalilauge versetzt werden.

Wir dürfen uns das Protoplasma jedoch nicht als eine einheitliche chemische Verbindung vorstellen, es ist ein Gemenge sehr verschiedenartiger Substanzen. Das beweist uns einerseits die Thatsache, dass Cytoplasma, Kern etc. aus differenten Proteinstoffen bestehen, die sich gegen Salzlösungen und Säuren verschieden verhalten, anderseits ist durch die 
chemische Analyse die Existenz sehr verschiedenartiger Stoffe nachstewiesen. Ausser den Proteinstoffen sind als wesentliche Bestandteile das Wasser und die Aschenbestandteile, d. h. die beim Verbrennen zurückbleibenden anorganischen Stoffe hervorzuheben.

Ausserdem kommen im Protoplasma eine grosse Menge von Stoffwechselprodukten

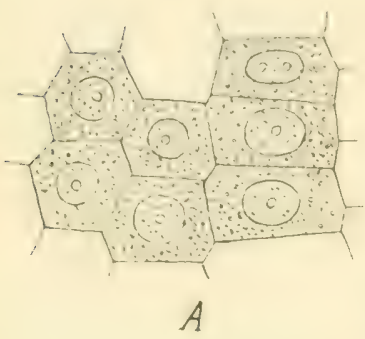

Fig. 4 .

Zea mais. Junge Zelle der Wurzelspitze. Die Zellwändesind sehr dünn, in der Mitte des feinkörnigen Cytoplasmas der relativ grosse Zellkern. (K.) vor, wie Amide, Fette, Kohlenhydrate wie Stärke, Zucker etc., ferner Harze, Fermente und andere Stoffe, die nicht unmittelbar zur Konstitution des Protoplasmas gehören.

Sehr wichtig ist es festzuhalten, dass das Protoplasma eine äusserst feine innere Organisation besitzt, durch welche es befähigt ist Lebensfunktionen aufzuweisen, die von einer einfachen Mischung ähnlicher Substanzen nicht hervorsebracht werden könnten.

Das Protoplasma erfüllt nur in jungen Zellen (Fig. 4) das ganze Zelllumen, in einem

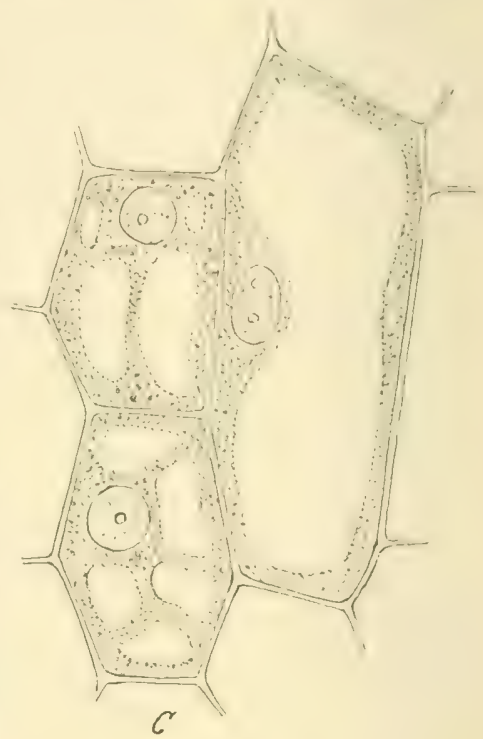

Fig. 5 .

Zea mais. Zellen einige mm unterhalb) der Wurzelspitze. Zellwände dicker, Cytoplasma feinkörnig, Zellsaft vorhanden. $\left(K_{\text {. }}\right)$ etwas älteren Zustande (Fig. 5) bilden sich in dem Cytoplasma Flüssigkeitstropfen, V a cuolen, die sich vergrössernd und vereinigend dasselbe $z u$ einem mehr oder weniger dünnen Wandbelag zurückdrängen, welcher den Zellsaft umgiebt. Der letztere ist durch das Zusammenfliessen solcher Vacuolen entstanden.

\section{Cytoplasma.}

Das Cytoplasma bildet eine zähflüssige, weiche, durchsichtige, feinkörnige Masse, die selbst bei der stärksten Volumzunahme des Zellsaftes die 1 and der Zelle vollständig wie ein allseitig geschlossener Sack auskleidet. In weniger plasmaarmen Zellen gehen von dem Wandbelag noch feine Stränge durch den Zellsaft (Fig. 6).

Fixiert man das Cytoplasma, d. h. behandelt man die unverletzten Zellen mit Substanzen, welche wie Osmiumsäure, Alkohol, verdünnte Essigsäure das Protoplasma schnell töten und unlöslich machen, so 
erscheint es wie aus Körnchen, Stäbchen und Fibrillen zusammengesetzt, welche zur Annahme einer gerüstähnlichen Netzstrulitur Veranlassung ggegeben haben. Es sind dies jedoch kïnstliche Fällungsprodukte, die erst durch die Fixierung entstehen. Nichtsdestoweniger kann man bei Behandlung mit verschiedenen Lösungsmitteln und Verdauungsfermenten eine schwerer lösliche Substanz, das Cytoplastin unterscheiden. Ausserdem finden sich kleine Körnchen und Tröpfchen (Mikrosomen) auch im lebenden Cytoplasma vor, die jedoch eine verschiedene chemische Beschaffenheit besitzen und hauptsächlich zu den oben crwähnten Stoffwechselprodukten gehören.

Eine bemerkenswerte Eigenschaft des Cytoplasmas ist seine Bew egungs fähişkeit. Wir unterscheiden Rotation und Cirkulation, je nachdem ob die ganze Cytoplasmamasse rotierend an der Zellwand dahinfliesst (Rotation bei Blattzellen von Vallisneria spiralis, Elodea canadensis), oder ob die cinzelnen Plasmapartien und Körnchen um die Vacuolen herum in den durch den Zellsaft ausgespannten Fäden nach verschiedenen Richtungen hingleiten (Cirkulation bei den Staubfadenhaaren von Tradescantia virginica). Die Strömungsgeschwindigkeit ist eine sehr geringe, bei Vallisneria spiralis $z$. B. ca. I, $5 \mathrm{~mm}$ in der Minute, doch können an sich unbewegliche Körper wie Zellkern und Chloro-

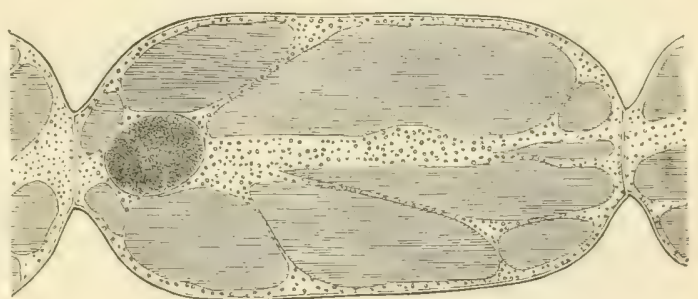

Fig. 6.

Zelle aus einem Staubfadenhaar von Tradescantia virginica. (R.) plasten durch das strömende Cytoplasma mit fortbewegt werden. An freien Protoplasmamassen tritt noch die sog. amöboïde Bewegung auf. Es handelt sich hierbei um Formveränderungen protoplasmatischer Körper, mit denen häufig Ortsbeweşung verbunden ist, indem Plasmafortsätze ausgesendet werden, in welche das übrige Plasma einwandert. Diese Bewegungen werden von äusseren Faktoren beinflusst, Wärme und Sauerstoffzutritt wirken wie auf andere Lebenserscheinungen auch auf die Bewegung des Protoplasmas ein.

Zu erwähnen ist ferner noch die Schwimmbewegung einzelner Zellen, wie der Schwärmzellen von Algen und Pilzen und der Spermatozoiden der Gefässkryptogamen. Dieselbe wird durch geisselartig schwingende, äusserst feine, fadenförmige Cilien bewirkt.

Bei einseitiger Beleuchtung von Stengeln sammelt sich Protoplasma in grösserer Menge an der beleuchteten Seite an, es muss also hier und in ähnlichen Fällen ein Wandern des Protoplasmas durch die IVand hindurch angenommen werden. Ebenso ist ein Auswandern von Plasma aus den älteren Teilen in die jüngeren Zellen fortwachsender Pflanzenteile 
nicht unwahrscheinlich. Auch bei dieser Translokation mïssten Zellwände passicrt werden. Es ist daher nicht unwichtig zu konstatieren, dass die Protoplasmakörper benachbarter Zellen durch ganz ausserordentlich feine Fäden untereinander verbunden sein können. Tangl wies diese Verbindungsfäden zuerst für das. Endosperm von Strychnos nux vomica (Fig. 7), nach, Russow für die Rinde verschiedener Holzsewächse (Fraxinus, Rhamnus, Aesculus, Alnus). Ausserdem haben sich noch verschiedene andere Forscher mit dieser Frage beschäftigt, welche das häufigere Vorkommen dieser durch die Zellwände gehenden Plasmastränge an verschiedenartigen Zellgeweben nachgewiesen haben. Hierher gehört auch das Vorkommen von Protoplasma in den Hohlräumen zwischen den Zellen, den sog. Intercellular-

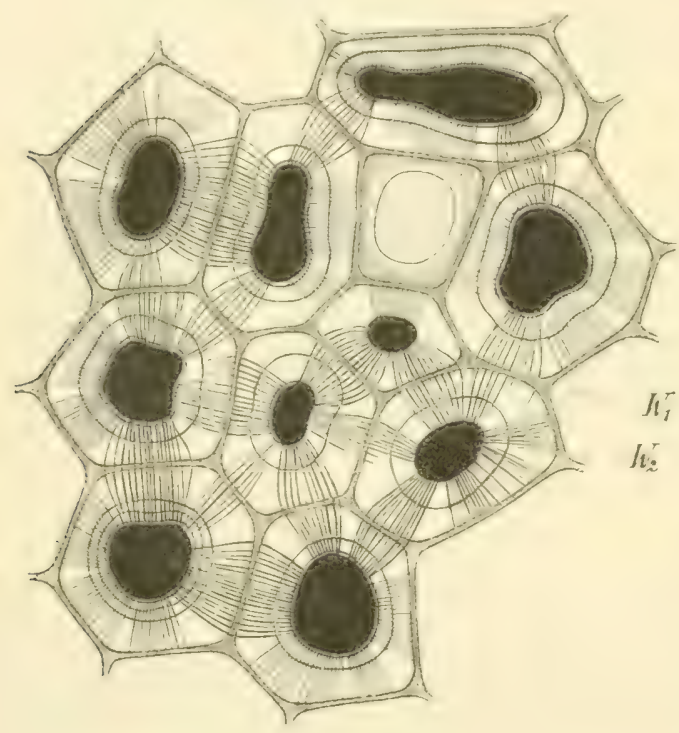

Fig. 7.

Zellen aus den Endoeperm von Strychns nux vomicn, nach der Behandlung mit Jod. Inhalt und Plasmafäden sind in der Figur schwarz, $\mathrm{W}_{1}$ Mittellamelle, $\mathrm{W}_{2}$ Verdickungsschichten der Zellwand (n. Tangl). räumen. Es kann sich dort bei normalem Wachstum vorfinden (Rindenzellen von Cornus mas, Ligustrum vulgare) oder erst nach Verletzungen auftreten, wie z. B. bei Allium Cepa nach Abtragen der äussersten Hautschicht.

Der Zusammenhang der Protoplasmakörper benachbarter Zellen durch feine, die Zellwand durchsetzende Fäden kann eine besondere Bedeutung dadurch gewinnen, dass Veränderungen, welche durch äussere Ursachen, einen Reiz (vgl. \$ 43) in einer Zelle hervorgerufen werden, durch die Protoplasmafäden auf andere Zellen übertragen werden. In der That können wir infolge von Verwundungen nicht nur in den der Wunde unmittelbar angrenzenden Zellen Veränderungen wahrnehmen, sondern auch in weiter abliegenden Zellen Wanderungen des Plasmas und Lageveränderungen von Zellkern und Chlorophyllkörpern beobachten, welche auf eine Fortleitung des durch die Verwundung hervorgerufenen Reizes hinweisen. Sollte diese Fortleitung des Reizes auch vielleicht in anderer Weise zu erklären sein, so bleibt doch noch eine weitere Bedeutung dieser Plasmaverbindungen bestehen, indem durch dieselben die Möglichkeit gegeben ist, dass auch unlösliche Stoffe von einer Zelle zur anderen wandern. 


\section{\$. Zellkern (nucleus) und Zellvermehrung.}

Der Zellkern fehlt wohl in keiner Zelle, wenn sein Nachweis bei den niedersten Algen und Pilzen auch auf Schwierigkeiten stösst. Der Zellkern besitzt eine rundliche bis kugelige Gestalt, ist in langgestreckten Zellen häufig spindelig ausgezogen, in älteren Zellen, wo er sich in dem dünnen Cytoplasmabelag vorfindet, oft stark abgeplattet. In den meisten Zellen findet sich nur e in Kern. Nur bei gewissen Pflanzen mit grossen schlauchförmigen Zellen treten mehrere Kerne auf, so z. B. bei den Algen Cladophora, Vaucheria, Caulerpa, bei den Pilzfamilien der Mucorineen, und Myxomyceten. Ausserdem kann eine grössere Anzahl von Kernen in mehr oder weniger alten Zellen auftreten (Parenchymzellen von Phajusknollen, Bastfasern von Urtica urens, Weichbastzellen von Tradescantia zebrina), desgleichen in den sog. Zellfusionen d. h. in Vereinigungen von Zullen, deren Kontaktfächen gelöst sind (z. B. in gegliederten Wilchröhren).

Der Kern zeichnet sich dem Cytoplasma gegenüber durch eine grössere Dichtigkeit aus, sowie durch die Fähigkeit nach der Fixierung (vgl. S. 6) Farbstoffe in höherem Masse festzuhalten. Ausserdem zeigt der Zellkern eine kompliziertere innere Struktur und damit im Zusammenhang einen Aufbau aus verschiedenen Proteinstoffen, die sich durch ihre Löslichkeit in anorganischen Salzen, in Såuren, Alkalien und in Verdauungsfermenten (Pepsin und Trypsin) unterscheiden.

In Zellen, welche nicht in Teilung begriffen sind, zeigt der Kern folgende Strukturelemente:

I) Das Kerngerüst, gebildet aus netzförmig anastomosierenden Fäden, welche aus Lininsubstanz bestehen.

2) Die dem Kerngerüst eingelagerten zahlreichen Chromatinkörnchen, welche sich durch grosse Tinktionsfähigkeit auszeichnen.

3) Die Kernkörperchen der Nucleolen, grössere, sehr dichte Körnchen, bestehend aus Pyreninsubstanz.

4) Der Kernsaft, welcher die Lücken zwischen dem Kerngerüst ausfüilt.

5) Die Kernmembran, bestehend aus einem den Nucleolen verwandten Stoff. Dieselbe umgrenzt den ganzen Kern, bildet sich möglicherweise aus dem Cytoplasma.

Eine wesentliche Veränderung erleidet der Kern bei der Vermehrung der Zellen.

Die Vermehrung der Zellen geschieht entweder durch Zellteilung oder durch sog. freie Zellbildung. Bei der Zellteilung entstehen aus dem einen Kern der Mutterzelle durch Umwandlungen, welche wir weiter unten erörtern wollen, zwei Tochterkerne, zwischen diesen bildet sich eine neue Zellwand, welche das Cytoplasma und das ganze Zelllumen in zwei Hälften scheidet, wodurch zwei neue Zellen, die Tochterzellen, ent- 
stehen. Der Kernteilung geht zumeist eine Volumzunahme der Mutterzelle voraus.

Bei der freien Zellbildung erfolgt eine Teilung des Kernes der Mutterzelle in zwei Kerne, welche sich weiter teilen, ohne dass zunächst zwischen denselben eine Zellwand gebildet wird. Ist auf diese WVeise cine grössere Anzahl von Kermen entstanden, so wird nachträglich zwischen denselben Zellwand gebildet, die ganze Mutterzelle in so viel Tochterzellen kammernd, als Zellkerne vorhanden sind. In Fig. 8 sehen wir eine derartige Vermehrung der Zellkerne eingetreten, der nächste Schritt der freien Zellbildung würde sein, dass sich in den mittleren Abständen zwischen den Kernen Membranlamellen bilden, die stumpfwinklich aufeinander stossen.

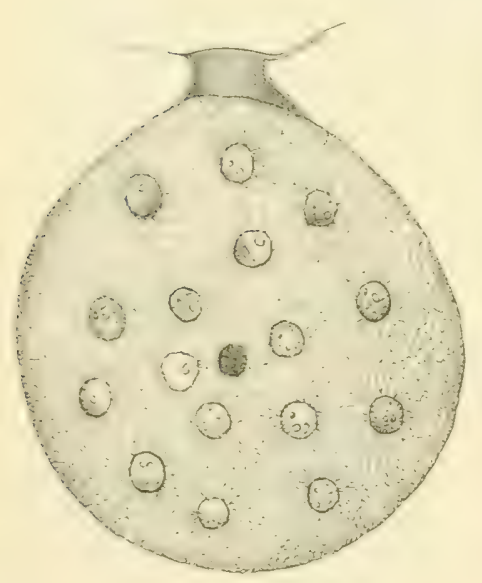

Fig. 8.

Embryosack von Gingko biloba mit zahlreichen Kernen (n. Strasburger).
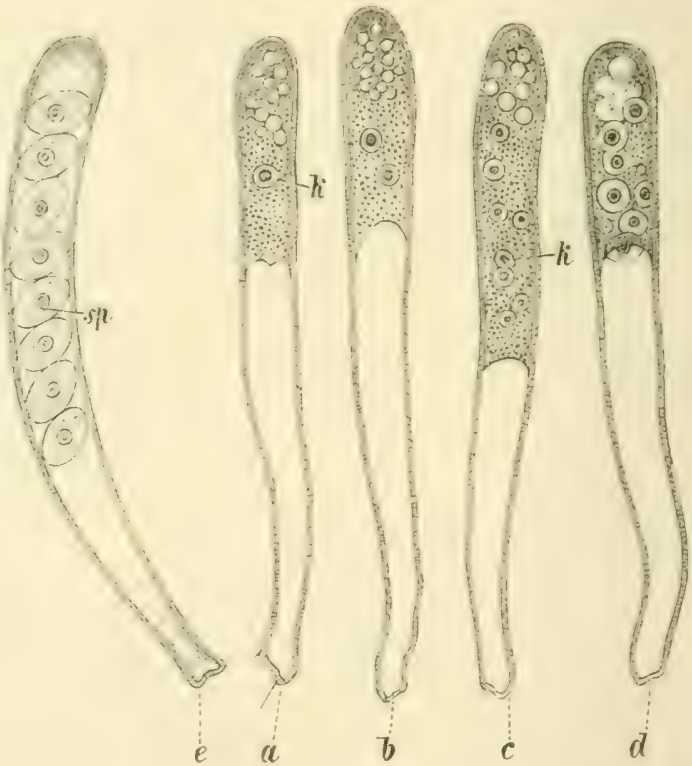

Fig. 9. Peziza confluens, Bildung der Ascosporen (n. De Bary).

In ähnlicher Weise geht die Sporenbildung in den Schläuchen (asci) der Pilzfamilic der Ascomyceten vor sich. Das feinkörnige, mit zahlreichen Vacuolen versehene Protoplasma (Fig. 9) sammelt sich am oberen Ende des Schlauches an, der Kern (K) teilt sich zu wiederholten Malen (Fig. 9 a his c), jeder einzelne Tochterliern umsiebt sich mit dichterem Cytoplasma (Fig. 9 d) und schliesslich wird um diese dichteren Plasmaballen eine Zellhaut gebildet, wobei also unter Zurückbleiben eines kleineren Cytoplasmarestes eine grössere Anzahl von Zellen entsteht (Fig. 9 e). Dieselben werden hier entsprechend ihrer Funktion als Fortpflanzungszellen Sporen genannt.

Als Vollzellbildung wird schliesslich jener Vorgang bezeichnet, bei welchem sich das gesamte Protoplasma einer Zelle unter Aus- 
stossung von Wasser zusammenzieht und sich nun entweder in der Zelle selbst mit einer neuen Zellhaut umgiebt (Bildung der Eizelle von Oedogonium) oder durch eine Öffnung der Zellwand heraustretend, sich durch Bildung einer neuen Wand in eine neue Zelle umwandelt (Bildung der Schwärmsporen bei Oedogonium, Fig. IO).

Die Zellteilung ist der weitaus häufigste Fall der Zellvermehrung, insofern dieselbe überall dort auftritt, wo es sich um das Wachstum vegetativer Zellen handelt. Freie Zellbildung ist häufig bei der Bildung der Fortpflanzungszellen, besonders im Embryosack der Phanerogamen zu beobachten.

Die Veränderungen des Kernes bei der Teilung bestehen nun darin, dass das feine Gerüstwerk desselben sich zu einem Faden umordnet, in welchem sich unter gleichzeitiger Lösung der Kernmembran (Fig. I I A.) die Chromatinmenge be-
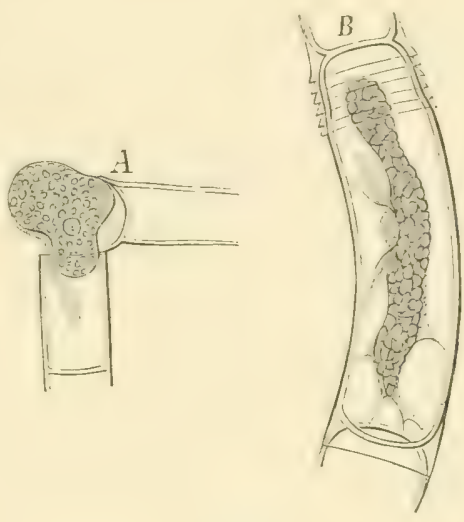

Fig. 10

Entstehung einer Schwärmspore bei Oedogonium; dieselbe ist bewimpert und kann infolgedessen nach dem Austritt aus der Zelle (A) im Wasser schwimmen. (Nach Pringsheim.) deutend vermehrt. Dieser Faden zerfällt in eine bestimmte Anzahl von Segmenten, die sich zu der sog. Kernplatte anordnen und zwar in der Mitte von spindelförmig ausgespannten Fäden
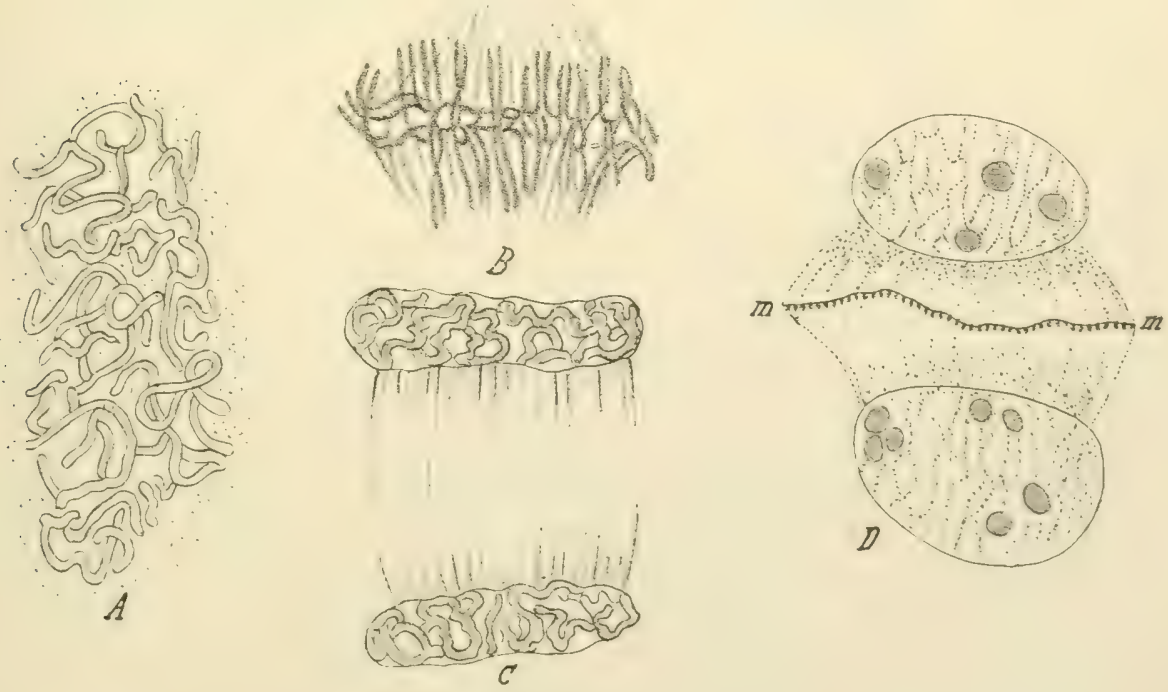

Fig. I I A-D.

Frittillaria imperialis. Kernteilungsstadien aus dem Endosperm (nach Strasburger). 
(Fig. II B). Jedes Sesment spaltet sich der Länge nach in zwei Hälften, ron denen die eine nach dem einen Pol, die andere nach dem anderen Pol der Spindelfasern wandert. Dort findet ein Zusammenlegen der Sesmente statt, es entsteht ein lockeres Knäuclstadium, das sich allmählich verdichtet und mit einer Kernmembran umgiebt. Die Spindelfasern sind an den Polen auscinander gewichen, so dass die Kernfigur nun ein tonnenförmiges Aussehen gewährt (Fig. I I C). In der Mitte dieser

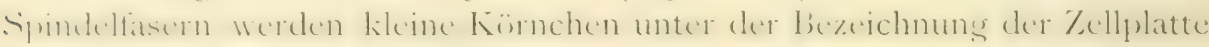
(Fig, I I D mm) ausgeschieden, die sich aneinander legend zur Zellwand werden. Zugleich bilden sich in den neuen Tochterkernen die Nucleolen aus, welche während der Teilung verschwunden waren.

Die Kernteilung verläuft abgesehen von Verschiedenheiten in Form, Zahl und Grösse der Segmente im wesentlichen bei den Pflanzen in gleicher Weise. Diese Erscheinungen gewinnen noch dadurch eine grössere Bedeutung, dass sich diese Analogie auch auf die Zellkernteilungen im Tierreich erstreckt.'

Die eben beschriebene Art der Kernteilung wird als die sog. indirekte Kernteilung oder Karyokinese bezeichnet. Im Gegensatz zu derselben steht die direkte Kernteilung. Der in die Länge gestreckte oder lappig ausgebuchtete Kern zerfällt hierbei in einzelne Portionen, ohne dass ein Kernfaden, eine Kernplatte etc. gebildet würde. Diese Art der Kernteilung besitzt eine geringere Bedeutung, indem sie nur in alternden Zellen auftritt, nicht mit Zellteilung verbunden ist und nur ausnahmsweise bei der freien Zellbildung beobachtet worden ist.

Man hat dem Kern eine höhere Organisation zugeschrieben als dem Cytoplasma, und die kompliziertere Struktur weist zweifellos darauf hin. Im Anschluss daran sieht man in dem Kern den Sitz der vererbbaren Eigenschaften einer Zelle resp. eines Organismus, wobei der Vorgang der indirekten Kernteilung als ein Mittel anzusehen wäre, diese der Materie inne wohnenden vererbbaren Eigenschaften in gleicher oder in bestimmt verschiedener Weise auf die Tochterzellen zu übertragen. Die Ansicht wird dadurch gestützt, dass die Spermatozoiden bei Tieren und niederen Pflanzen, sowie die befruchtende Substanz bei den Phanerosamen fast ausschliesslich aus Kernsubstanz bestehen. Es sind dies Hypothesen, zu deren näherer Ausführung mir hier der Raum fehlt. Es sei jedoch noch darauf hingewiesen, dass Plasmapartien, welche von dem übrigen Protoplasma abgetrennt werden, und unter Umständen, z. B. bei der Alge Spirogyra, noch weiter fortleben können, nur dann fähig sind neue Zellhaut zu bilden, wenn sie einen Kern enthalten. In Zellen mit starker lokaler Wandverdickung befindet sich der Kern in der Nähe dieser in die Dicke wachsenden Häute oder ist doch mit ihnen durch stärkere Cytoplasmastränge verbunden.

Ob der Zellkern direkt mit der Funktion der Zellwandbildung in Ver- 
bindung $\mathrm{zu}$ bringen ist, und welche Funktionen er sonst noch besitzt, bleibt vorläufig zweifelhaft. Jedenfalls ist er ein sehr wichtiger Bestandteil des Protoplasmas.

\section{Chromatophoren.}

Unter diesem gemeinsamen Namen werden, wie schon Seite 5 ausgesprochen, Chlorophyllkörper (Chloroplasten), Farbstoffbildner (Chromoplasten) und Stärkebildner (Leucoplasten) zusammengefasst, denen sich die auf bestimmte Algenfamilien beschränkten bramen Phaeoplasten (bei den Phaeophyceen) und die roten Rhodoplasten (bei den Rhodophyceen) anschliessen. Die Chromoplasten bestehen aus einer die Form bestimmenden protoplasmatischen Grundlage, die bei den Chlorophyllkörpern durch den grünen Farbstoff das Chlorophyll, bei den Farbstoffbildnern durch gelbe oder rote Farbstoffe tingiert ist. Die Stärkebildner sind farblos, können jedoch unter Bildung ron Chlorophyll ergrünen (Grünwerden der Kartoffeln), wie denn auch Chlorophyllkörper und Leucoplasten in Farbstoffbildner übergehen können.

Die Chlorophyllkörper dienen der Aufnahme von Kohlensäure und Bildung von Stärke unter Einwirkung des Lichtes (vgl. Kohlenstoffassimi-

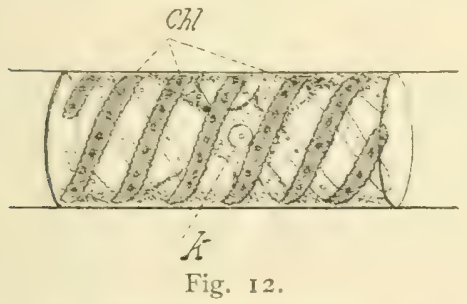

Zelle aus einem Faden von Spirogyra. (K.)

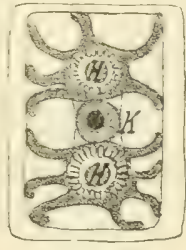

Fig. I 3 .

lation § 33). Wegen dieses Zusammenhanges mit der Lichtwirkung finden sich dieselben fast immer nur in Organen, welche dem Lichte ausgesetzt sind. Die Blätter und oberirdischen Axen erhalten durch die Chlorophyllkörper die bekannte Grünfärbung, während den nicht assimilierenden Pflanzenteilen, sowie den Pilzen und den meisten Schmarotzern die Chlorophyllkörper fehlen.

Bei den Algen ist die Gestalt der Chloroplasten eine sehr mannigfaltige. Sie bilden dort spiralige (Spirogyra Fig. I2) oder längsstreifige zusammenhänģende Bänder, grüne Sterne (Zysgnema Figs. I3), kompalite (Mesocarpus) oder netzförmig durchbrochene Platten (Cladophora arcta). Eine grössere Oberflächenentwichlung und damit ein gesteigerter Effeht der Lichtwirkung wird bei den Moosen, Gefässkryptogamen und Phanerogamen dadurch erzielt, dass hier sehr zahlreiche, kleine rundliche Chlorophyllkörperchen gebildet werden. Die Zahl der Chlorophyllkörper in 
einer cinzigen Blattzelle betragt nicht selten 50-90, so dass schon auf I qmm Blattfläiche, z. B. bei Ricinus communis, ungefähr 400,000 solch kleiner kugeliser oder linsenförmiss abgeplatteter Körperchen kommen können. Eine Abbildung solcher Chloroplasten sehen wir in Fig. I4 g, die hier wie sonst hauptsächlich dem cytoplasmatischen Wandbelag der Zelle eingebettet sind.

Die Ansichten über die feinere Struktur der Chlorophyllkörper gehen bei den verschiedenen Forschern noch ziemlich weit auseinander. Sicher ist, dass man in schr vielen Fällen bei den stärksten Vergrösserungen im

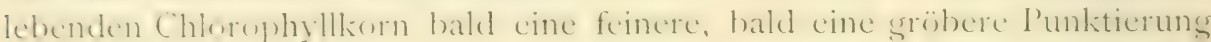
wahrnehmen kann, welche auf eine be-

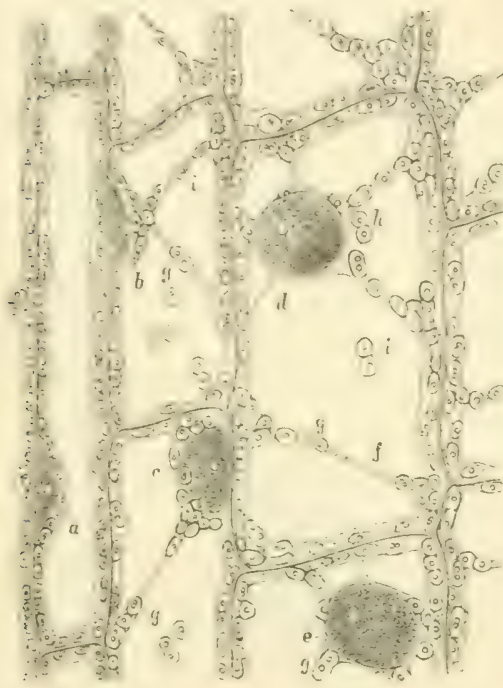

Fig. 14.

Blattzelle von Elodea canadensis, a-e Zellkerne, g Chlorophyllkörper, f Cytoplasmastränge. (KIV.) stimmte Struktur und Verteilung des Chlorophylls hinweist. Der Chlorophyllfarbstoff kann durch Alkohol oder andere Lösungsmittel extrahiert werden, es bleibt sodann eine protoplasmatische Grundlage zurück (Stroma), die wie das Verhalten gegen Lösungsmittel zeigt, aus zwei Proteinstoffen besteht, dem Chloroplastin (sehr nahe verwandt dem Cytoplastin) und dem Metaxin, einem leichter löslichen Stoffe.

Als erstes sichtbares Produkt der Assimilation treten in den Chlorophyllkörpern Stärkekörnchen auf, die sich nach Extraction des Chlorophylls durch ihre Blauschwarzfärbung bei Jodzusatz nachweisen lassen. Stärkekörnchen können sich aus Zucker auch ohne direkte Assimilation in den Chloroplasten bilden, wenn den betreffenden Zellen Zucker in genügender Menge zugeführt wird. Als besondere Einschlüsse der Chloroplasten sind Öltröpfchen zu erwähnen, die sich nur bei alternden Blattzellen z. B. bei (Funkia, Ulmus campestris, Stelitzia) oder auch schon im jugendlichen Zustande (Irisarten) vorfinden. Da dieselben nicht weiter verbraucht werden, muss man sie als Auswurfsstoffe ansehen, welche auf eine gewisse Degeneration schliessen lassen. Chemisch sind diese Öltröpfchen sowohl von fetten als ätherischen Ölen verschieden.

In den Chlorophyllkörpern einzelner Pflanzen treten auch Eiweisskrystalle auf (in Parenchymzellen der Phajusknollen, im Stengel von Cephalanthera pallens, bei Boragineen etc.), die Bedeutung derselben ist jedoch unbekannt. Eine bemerkenswerte Erscheinung sind ausserdem 
noch die sog. Pyrenoide oder Stärkeherde, deren Vorkommen auf gerrisse Algenfamilien beschränkt ist und welche, wie in Fig. I3 zu sehen ist, aus einem dichteren plasmatischen Kern bestehen, um den sich rings herum die Stärke bildet. Die plasmatische Substanz des Pyrenoids kann in einzelnen Fällen Krystallform annehmen.

Die Bildung und Natur des Chlorophyllfarbstoffes siehe $\$ 33$.

Zum Schluss sei noch darauf hingewiesen, dass sich die Chlorphyllkörper ebenfalls durch Teilung vermehren und, da sie sich niemals aus der Grundmasse des Cytoplasmas differenzieren, müssen sie schon in der Eizelle der Pflanzen vorkommen. Allerdings sind sie dort ebenso wie in den jüngsten Pflanzenteilen farblos.

Verfärbungen von Blättern können auf verschiedene Weise entstehen. Entweder verändern die Chloroplasten ihre Farbe oder es findet eine Ansammlung ron Farbstoff im Zellsaft statt. Beim Gelbwerden der Blätter im Herbste verschwindet das Chlorophyll, die Chloroplasten sind durch Xanthophyll, einen gelben Farbstoff, tingiert. Die bräunliche Missfärbung der Nadelhölzer im Winter z. B. bei Thuja, Picea, entsteht durch das Auftreten zahlreicher kleiner roter Körnchen in den Chloroplasten. Im Frühjahr verschwinden diese Körnchen, die Nadeln werden wieder rein grün. Die herbstliche Rotfärbung, die namentlich an gewissen Eichen, wildem Wein etc. zu beobachten ist, beruht auf einer Ansammlung von rotem Farbstoff (Anthocyan) im Zellsaft. Dieser Farbstoff ist bei Anwesenheit ron Säure rot, neutral violett, alkalisch blau. Es können dementsprechend je nach der Reaktion des Zellsaftes verschiedene Nüancen vorkommen, was besonders an einjährigen Kiefern oft zu beobachten ist, wie denn überhaupt Mischfarben entstehen, welche von der Färbung der Chloroplasten s grün oder gelbi und der Nuancierung des Zellsaftes abhängen. Dabei sind die Zellen noch lebendig. Beim Absterben von Pflanzenteilen sind ebenfalls Verfärbungen zu beobachten, die teilweise auf der dabei eintretenden Wirkung des sauren Zellsaftes auf das Chlorophyll, teilweise auf dem Braunwerden von Zellinhalt und Zellwand beruhen.

Chromoplasten. Die normale Buntfärbung von Blättern, Blüten, Früchten etc. kann entweder durch plasmatische Gebilde, die Chromoplasten oder durch einen im Zellsaft gelösten Farbstoff bewirkt werden.

Die Chromoplasten zeigen eine grössere Mannigfaltigkeit als die Chlorophyllkörper, indem der Farbstoff in verschiedener Weise verteilt ist, und durch das Auftreten von langgestreckten Eiweisskrystallen oder nadelfirmigen Farbstoffkrystallen die Form der plasmatischen Grundlaye. verändert wird. Hier einige Beispicle: Stroma farblos, Farbstoff als gselbe (Oncidium amictum) oder rote (Aloë verrucosa) Körnchen, weder Eiweissnoch Farbstoffkrystalle vorhanden. Im farblosen Stroma befinden sich gelbe Kïrnchen und farblose nadelförmige Eiweisskrystalle iChryanthemum phoeniceum). Im gelben oder farblosen Stroma befinden sich wenige 
orangegelbe oder rote Farbstoffkrystalle in Form von Tafeln, Stäbchen, hobelspanähnlichen Bändern (Wurzeln von Daucus carota) oder das Stroma ist durch dichte Krystallaggregate gefarbt (Früchte von Sorbus aucuparia und Rosa arvensis). Rote Farbstoffkrystalle und gelbe sehr feine Körnchen sind bei den Frïchten von Solanum dulcamara vorhanden. Farblose Eiweisskrystalle und braune Farbstoffnadeln zugleich treten bei Neottia nidus avis auf.

Die Chromoplasten können entweder aus farblosen Leucoplasten oder aus mehr oder weniger stark gefärbten Chloroplasten entstehen. Stärkekörnchen sind in denselben unter Umständen ebenfalls zu beobachten.

Die blaue und rote Färbung des Zellsaftes an den verschiedenen Pflanzenteilen geschieht in den meisten Fällen durch einen Stoff, der entweder mit dem bei der herbstlichen Verfärbung der Laubblätter auftretenden Anthocyan identisch oder doch sehr nahe verwandt ist. Auch hier tritt blaue oder rote Färbung auf, je nachdem, ob der Zellsaft schwach alkalisch oder sauer reagiert. Auch schwärzliche Beeren erhalten ihre Farbe durch Ansammlung einer grösseren Menge des blauen Farbstoffes im Zellsaft. Die Färbung des Zellsaftes durch Anthocyan ist sehr verbreitet.

Einen abweichenden Farbstoff bietet der Zellsaft der roten Rübe, welcher mit Alkalien nur missfarbig wird. Der gelbe Farbstoff des Zell-

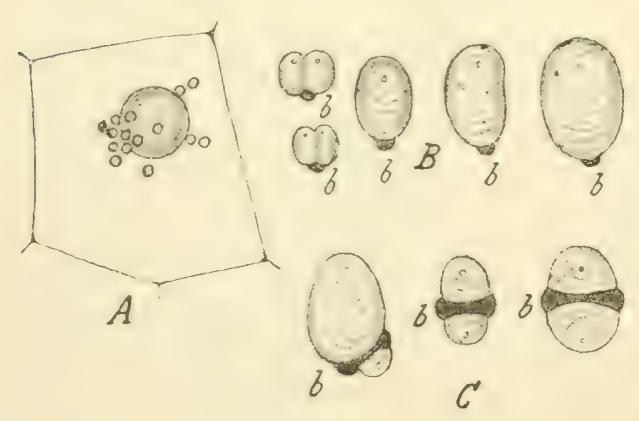

Fig. I 5 .

A. Zelle einer Kartoffel, um den grossen Zellkern bleine stïkebildner. B. C. Die substanz der Iartoffel--iärkebildner (b) ist schwarz gehalten (n. Schimper). saftes wird als $\alpha$-Anthoxanthin oder Anthochlor bezeichnet. Er findet sich bei gelben Rosen, Dahlia variabilis, Astragalus vulpinus, der gelbblühenden Opuntia Rafinesquiana u. a. vor.

Die grosse Mannigfaltigkeit der Färbung der Blüten wird also hauptsächlich durch das Zusammenwirken von Zellsaftfarbstoff und Chromatophoren bewirkt, doch kommen dabei noch durch die Zellwand und eventuell durch andere Inhaltsbestandteile hervorgerufene Lichtbrechungserscheinungen in Betracht.

Die Leucoplasten oder Stärkebildner sind überall dort zu finden, wo Stärke aber kein Chlorophyll gebildet wird, also in unterirdischen Stengeln, in Trurzeln, in der Epidermis oberirdischer Pflanzenteile, in Stärke führenden Samen. Sie sind von sehr verschiedener Grösse, farblos, bei geringen Stärkemengen kugelig (Fig. I5 A). Die Stärke wird meist an der Peripherie gebildet, die plasmatische Substanz ist dann hauptsächlich an einer Seite des grösseren Stärkekorns angesammelt und nur ein dünnes 
Häutchen plasmatischer Substanz überzieht den übrigen Teil des Stärkekorns. (Fig. I5 B. C.). Es können auch mehrere Stärkekörnchen zu sleicher Zeit im Innern der Stärkebildner auftreten (Batatas edulis, Stengel von Phaseolus multiflorus und Pisum sativum), die sich dann gegenseitig abplatten, oder der ganze Leucoplast ist auf ein dünnes, das Stärkekorn überziehendes Häutchen reduziert.

\section{Zellsaft. Aleuronkörner.}

Der Zellsaft ist von dem Protoplasma nur durch eine Niederschlagsmembran getrennt, welche sich überall dort bildet, wo das Plasma mit Wasser oder wässerigen Lösungen in Berührung kommt. Diese feine Membranschicht kann bei Bewegungen des Plasmas, bei Veränderungen der Form des Zellsaftraumes ohne weiteres wieder vom Protoplasma aufgenommen werden. Sie schützt das Protoplasma vor der direkten Einwirkung jener Stoffe des Zellsaftes, welche wie organische Säuren und Gerbstoff dem Protoplasma bei etwas höherer Konzentration schädlich sind.

Der Zellsaft dient als Reservoir für Stoffe, die vom Protoplasma produziert werden oder auf der Wanderung von Zelle zu Zelle begriffen sind. Allgemeiner verbreitet sind anorganische Salze, organische Säuren resp. deren Salze, so Apfel-

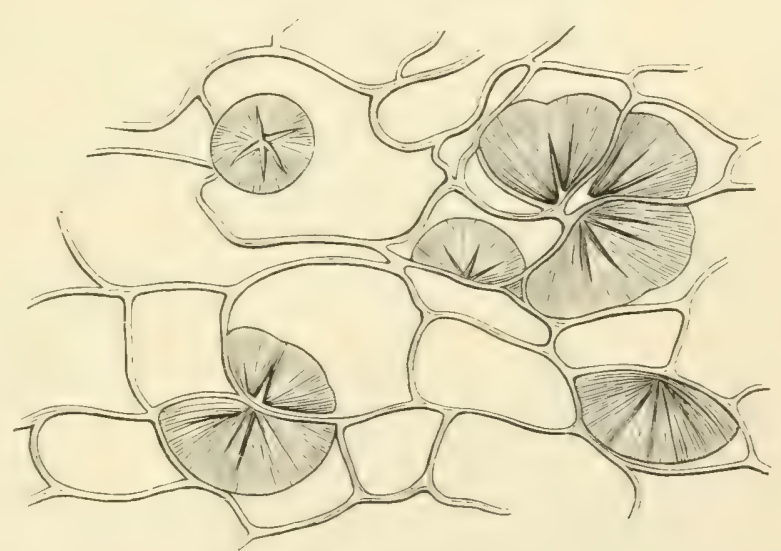

Fig. 16, säure, Weinsäure, Oxalsäure, ferner Zersetzungsprodukte von Proteinstoffen, Asparagin, Leucin, und gelöste Proteinstoffe sehr häufig auch Gerbstoff, besonders aber unelöste Kohlenhydrate: Traubenzucker (Glykose) Rohrzucker, Dextrin und gummiartige Stoffe, selten Inulin.

Fällungsprodukte, die bei der Einwirkung von Alkohol auf Zellen enstehen, sind die sog. Sphaerokrystalle des Inulins (Fig. I6) und des phosphorsauren Kalks. Diese Stoffe finden sich in der lebenden Zelle gelöst im Zellsaft vor, werden dann bei der Behandlung mit Alkohol an beliebigen Stellen ausgeschieden. Inulin findet sich z. B. in den Knollen von Dahlia variabilis und Helianthus tuberosus, in den 
Wurzeln von Cichorium Intybus, Taraxacum officinale, phosphorsaurer
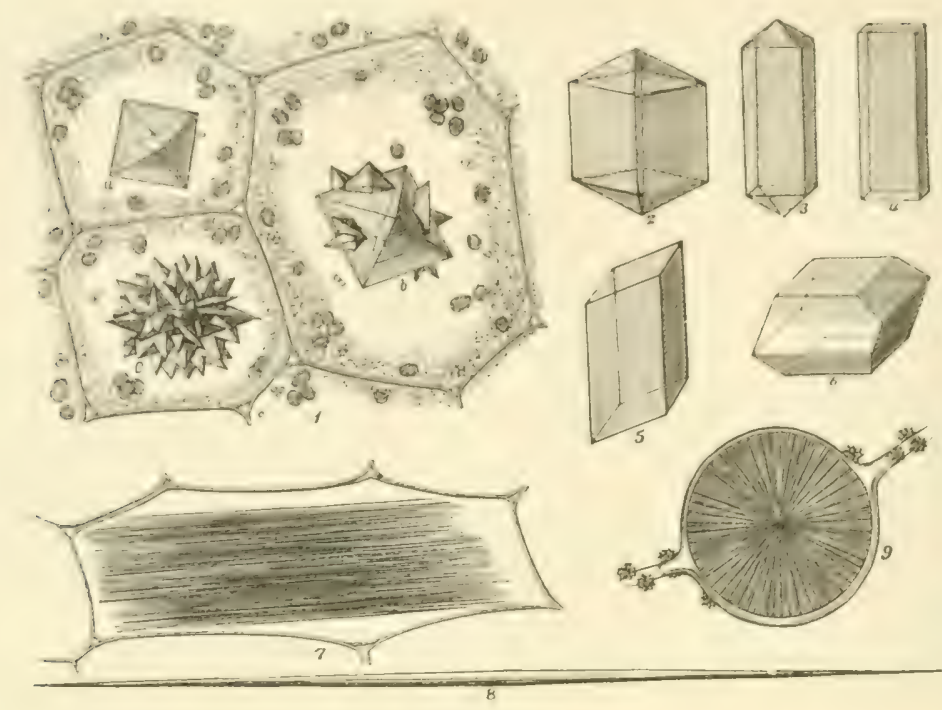

Fig. I 7 .

1. Zellen aus dem Blattstiel einer Begonia. 2-6. IVeitere Krystallformen. 7, 8, Krystallnadeln, 1. Raphiden aus den Zellen vun Lemna. 9. Sphärokrystall aus dem Mycel von Phallus. (KIV.)

Kalk in dem Sprossende von Euphorbia caput Medusae. Bei Anwendung wasserentziehender Substanzen

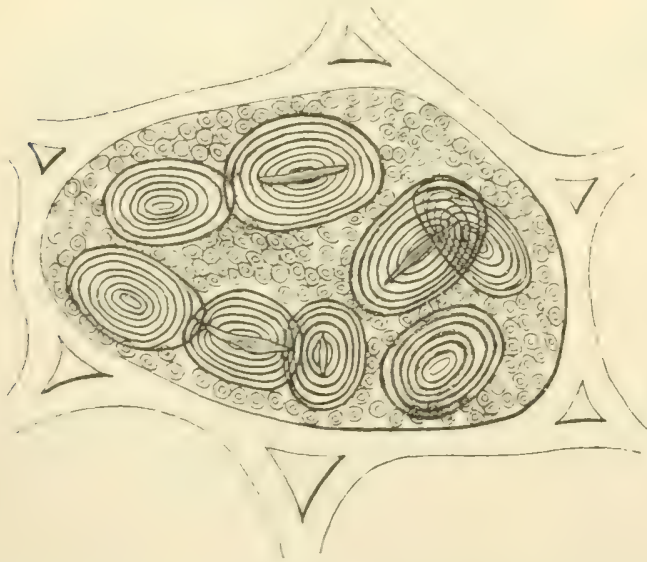

Fig 18.

Zelle aus einem Cotyledo der Erbse. Die grossen geschichteten Körper sind Stärkekörner, die kleineren Proteinkörner. (K.) entstehen im Zellsaft inhaltsreicher Zellen häufig gummiartige Kugeln oder feinkörnige Niederschläge, die bei Anwesenheit von Farbstoff im Zellsaft denselben rasch an sich ziehen. Ähnliche Gebilde entstehen, wenn durch Einwirkung verdünnter Lösungen von kohlensaurem Ammoniak die Säure des Zellsaftes neutralisiert wird, ein Beweis, dass durch die Säure des Zellsaftes verschiedene Stoffe in Lösung erhalten werden.

In der lebenden Zelle findet sich der Gerbstoff fast immer gelöst im Zellsaft vor, ausnahmsweise z. B. in der Rinde von Salixarten, in den Blattgelenken von Mimosa pudica sind jedoch Gerbstoftkugeln zu beobachten. 
Ausserordentlich verbreitet sind in den lebenden Zellen Krystalle von oxalsaurem Kalk, welche durch ihre Löslichkeit ohne Gasentwickelung in Salzsäure und ihre Unlöslichkeit in Essigsäure charakterisiert sind. Der oxalsaure $\mathrm{Kalk}\left(\mathrm{C}_{2} \mathrm{O}_{4} \mathrm{Ca}+\mathrm{H}_{2} \mathrm{O}\right)$ krystallisiert entweder mit 3 Molekülen Krystallwasser im tetragonalen System (Fig. I7, I-4) oder mit I Molecül Krystallwasser im monosymmetrischen System (Fig. I7, 5-9).

Ausser dem Kalksalze ist noch das saure Kalisalz der Oxalsäure $\left(\mathrm{C}_{2} \mathrm{O}_{4} \mathrm{HK}\right)$ in Pflanzensäften (Oxalis, Rumexarten) zu finden.

Eine besondere Behandlung erfordern die sog. Protein- oder Aleuronkörner der Samen. Es handelt sich hierbei um kugelige oder eiförmige Gebilde, die entweder aus gleichmässig verteilten Proteinstoffen bestehen, oder besondere Einschlüsse von Eiweisskrystallen und anorganischen Bestandteilen aufweisen. In die erste Kategorie gehören die Proteinkörner der stärkehaltigen Samen. Die beistehende Fig. Is bringt derartige Proteinkörner tus einer Zelle der Cotyledonen von Pisum sativum zur Anschauung. Diese Aleuronkörner finden sich immer in grosser Menge in den betreffenden Zellen und sind relativ klein. Ob dieselben thatsächlich in kleinen Zellsafträumen entstehen und erst beim Austrocknen des Samens als körnige Gebilde ausgeschieden werden, oder ob es sich um eine direkte Ansammlung festerer Proteinkörper im Cytoplasma handelt, ist noch nicht vollkommen sicher gestellt.

Die Proteinkörner der ölhaltigen
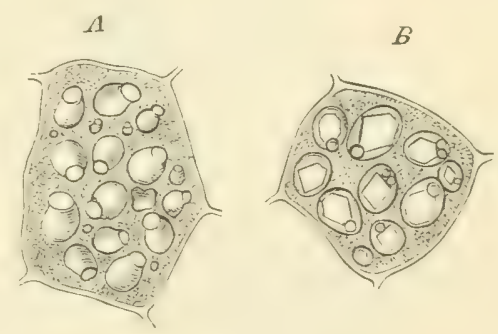

Fig.r. I9.

Zellen aus dem Samen von Ricinus communis (n. Pfeffer). Samen sind in der Regel wesentlich grösser. Wir sehen in Fig. Ig A Zellen aus dem trockenen Samen von Ricinus. Die Proteinkörner sind hier von dem feinkörnig gehaltenen, stark ölhaltigen Cytoplasma umgeben. Lassen wir Wasser auf diese Zellen einwirken, oder behandeln wir dieselben mit geeigneten Fixierungsmitteln wie sublimathaltisem Alkohol, welcher das Öl löst und die Proteinstoffe fixiert, so erkennen wir (Fig. I9B), dass die Proteinkörner aus einer gleichartigen Grundsubstanz bestehen, in welche erstens ein kantiger Eiweisskrystall, zweitens ein hellglänzender kugeliger Körper, das sog. Globoid eingelagert ist. Das letztere besteht aus einer gepaarten Verbindung von phosphorsaurer Kalk-Magnesia, ist also anorganischer Natur. An Stelle des Globoids kommen im Samen von Scorzonera hispanica und Tragopogon pratense Krystalle von oxalsaurem Kalk vor.

Nie durch entwickelungsgeschichtliche Lntersuchungen festgestellt ist, entstehen diese grossen Aleuronkörner aus Vacuolen. Das Erhärten der Grundsubstanz, welche den Vacuolenraum zuerst in selüster Form erfüllte, 
erfolgt beim Austrocknen der Samen, während sich Eiweisskrystalle, Globoide- und Oxalatkristalle schon vorher in diesen kleinen Zellsafträumen gebildet hatten.

Bei der Keimung der Samen werden die Proteinkörper gelöst.

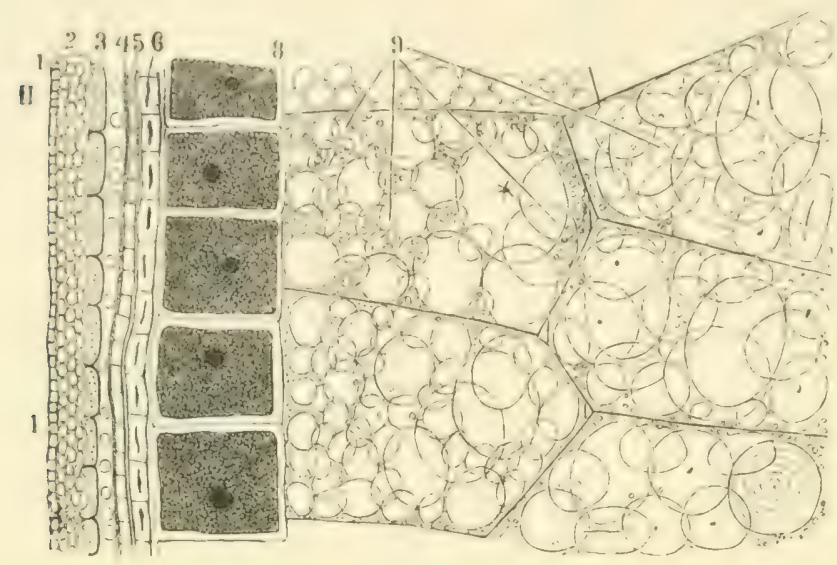

Fig. 20.

Secale cereale, Teil eines Querschnittes aus dem Samen. Schichten I-6 Frucht- und Samenhüllen, $S$ Kleberschicht, 9 stärkehaltige Endospermzellen (n. Harz).

Bei den Gräsern sind die Proteinkörner auf eine äussere stärkefreie Schicht des Endosperms beschränkt, die sog. Kleberschicht (Fig. 20), während die übrigen Zellen hauptsächlich Stärke führen.

\section{$\$$ 7. Ungelöste im Plasma abgelagerte Stoffiwechselprodukte.}

Hier ist zunächst die Stärke, Amylum $\left(\mathrm{C}_{6} \mathrm{H}_{10} \mathrm{O}_{5}\right) n$ zu nennen. Dieselbe kommt in Form von hellglänzenden farblosen Körnchen vor, die je nach der Pflanzenart rundliche oder eckige Gestalt, sowie verschiedene Grösse besitzen. In den Chloroplasten der Blätter sind sie meist sehr klein, in den Samen wesentlich grösser. Die mannigfaltige Form ist aus der beigefügten Fig. 2 I ersichtlich.

Die Stärke quillt in heissem Wasser zu Kleister auf, färbt sich mit Jod blau, wird durch Kochen mit verdünnten Mineralsäuren in dextrinartige Stoffe, dann in Zucker umgewandelt. Diese Übergangsprodukte färben sich mit Jod rot, sind in unreifen Samen (Paeonia) zeitweise leicht nachzuweisen, desgleichen im sog. Klebreis. In der Pflanze wird die Stärke durch das Diastaseferment in Zucker umgewandelt, um durch dic Zellwände diffundieren und wandern zu können. 
An sehr vielen, namentlich den grösseren Stärkekörnern findet man eine Schichtung der Substanz, hellere und dunklere konzentrische oder exzentrische Linien wechseln miteinander ab (Fig. 2I, a, k, m). Dieselben hängen mit der Art des Wachstums zusammen, indem auf die zuerst gebildeten kleinen Stärkekörnchen neue Substanzlamellen aufgelagert werden.

Ölartige Körper (Fette und ätherische Öle) entstehen als kleine, stark lichtbrechende helle Tröpfchen im Cytoplasma. In den an fetten Ölen so reichen Samen vereinigen sich diese Tröpfchen zu hellglänzenden
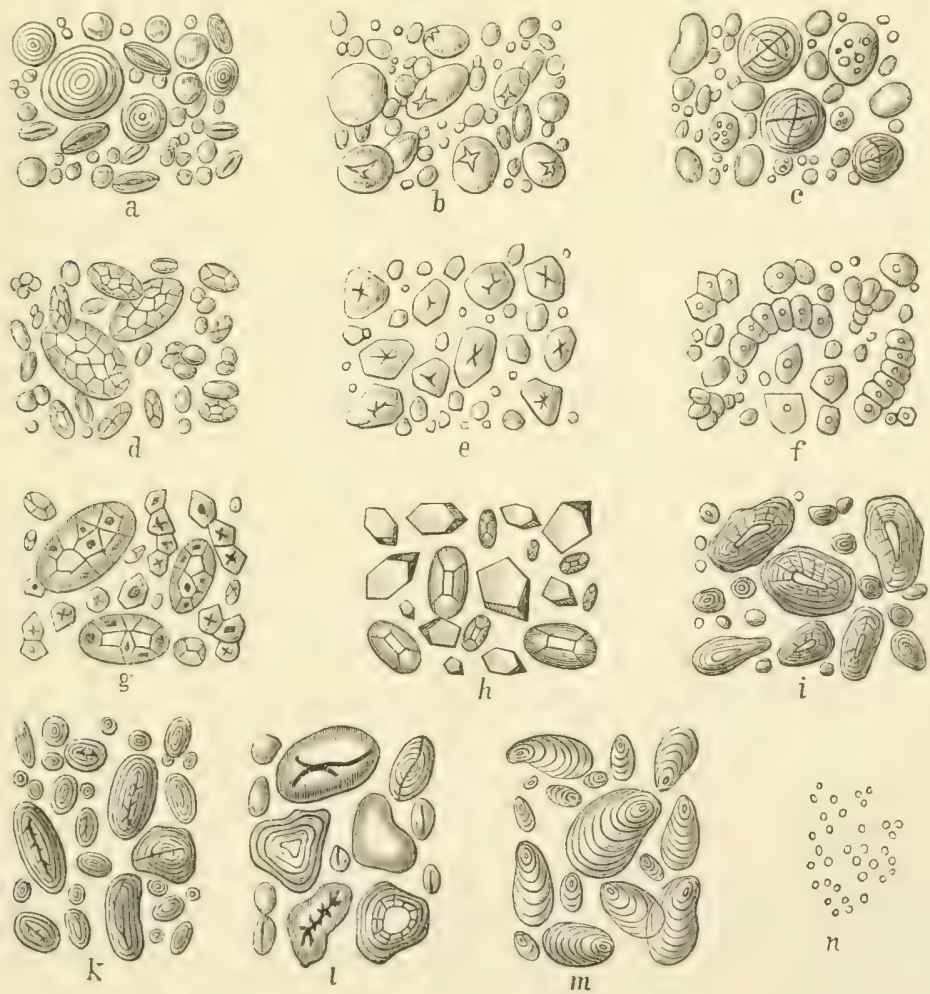

Fig. 2 I.

Formen der Stärke aus folgenden Samen: a Weizen, b Roggen, c Gerste, d Hafer, e Mais, f Buchweizen, g Reis, h Hirse, i Erbse, k Bohne, l Wicke, m Kartoffel, n Möhre. (Sch.)

Massen, welche das ganze Zelllumen ausfüllen. In Sekretbehältern (vgl. $\S 2$ I) werden durch fein verteiltes Öl Emulsionen gebildet. Abgesehen ron dem hellglänzenden homogenen Aussehen, kann man ölartige Körper unter dem Mikroskop durch ihre Löslichkeit in Benzol, Chloroform, Äther, meist auch in Alkohol erkennen.

Die Harze verhalten sich ähnlich wie die Öle.

Die hier genannten Stoffe werden wohl zumeist im Plasma produziert, 
sic kïnnen jedoch später von demselben ausgeschieden werden, sich in besonderen Schläuchen und Gänęen ansammeln oder wie z. B. das Harz die Zellmembranen durchtränken.

\section{Osmose und Turgor.}

Schichten wir vorsichtig eine Zuckerlösung und reines Wasser übereinander so wird nach einiger Zeit Wasser in die Zuckerlösung und umgekehrt Zuckerlösung ins Wasser übertreten, diffundieren. Sind beide Flüssigkeiten durch eine nur mit feinen Molckularinterstitien versehene Membran getrennt, so wird der Stoffaustausch durch die Beschaffenheit der Membran beeinflusst. Das Wasser wird durch diese Membran leichter hindurch gehen als der Zucker und sich infolgedessen das Volumen der Zuckerlösung vermehren, das des reinen Wassers vermindern. Hätten wir eine allseitig geschlossene, mit Zuckerlösung gefüllte Blase, die für Zucker undurchlässig, für Wasser durchlässig wäre, so würde, sobald wir dieselbe in reines Wasser bringen, kein Zucker austreten (Exosmose) wohl aber Wasser eintreten (Endosmose). Die Folge davon würde sein, dass die Blase ihr Volumen vergrössert und stärker gespannt wird. Wenn wir umgekehrt eine mit destilliertem Wasser gefüllte Blase in Zuckerlösung hängen, wird sich das Volumen der Blase allmählich verringern. Der Zucker wirkt gewissermassen wasseranziehend.

Analoge Vorgänge haben wir nun in der Pflanzenzelle. Der mit gelösten Stoffen reichlich versehene Zellsaft wirkt wie der Inhalt einer mit Zucker- oder Salzlösung gefüllten Blase wasseranziehend, das Cytoplasma und zwar besonders die äusserste Schicht desselben verhindert wie die Wand der Blase ein Hinausdiffundieren der wasseranziehenden Substanzen des Zellsaftes. Kommt eine Zelle in reines Wasser oder in Lösungen geringerer Konzentration als der Zellsaft, so wird der Zellsaft sein Volumen vergrössern. Nun ist aber die weiche Cytoplasmamasse eingeschlossen in die feste elastische Zellwand, welche dem Durchtritt von Lösungen keinen (oder nur geringen) Widerstand entgegensetzt. Diese Zellwand wird durch das Ausdehnungsbestreben des Zellinhaltes gespannt, sie wird ausgedehnt, und da sie elastisch ist, wird sie einen Gegendruck auf den Zellinhalt ausüben. Der hydrostatische Druck, welcher durch diese osmotischen Kräfte zu stande kommt, wird als Turgor bezeichnet, Zellen, in denen ein solcher Druck besteht, turgeszent genannt. Bei fehlendem Turgor der Zellen werden die Pflanzenteile, soweit sie nicht durch dicke Zellmembranen gefestigt sind, welk.

Man kann den Turgor aufheben, wenn man die Zellen in eine Lösung bringt, die konzentrierter ist, oder besser gesagt stärker wasseranziehend wirkt als der Zellsaft, welchen Vorgang man als Plasmolyse bezeichnet.

Hat die Spannung der Zellwand durch den Turgor eine gewisse Grösse erreicht, wird die Masseraufnahmsfähigheit des Zellsaftes schliesslich 
aufhören, es tritt ebensoviel Wasser in die Zelle ein, als durch den Druck der Zellwand ausgepresst wird, womit ein Gleichgewichtszustand erreicht ist, der nur durch die veränderte Dehnbarkeit der Zellwand oder durch Umwandlungen der in Zellsaft gelösten Stoffe verändert wird.

\section{§ 9. Zellwand (Zellmembran).}

Die Form der Zellen und die Ausbildung der Zellwand ist, wie uns die Anatomie der Gewebe zeigen wird, eine sehr verschiedene. An dieser
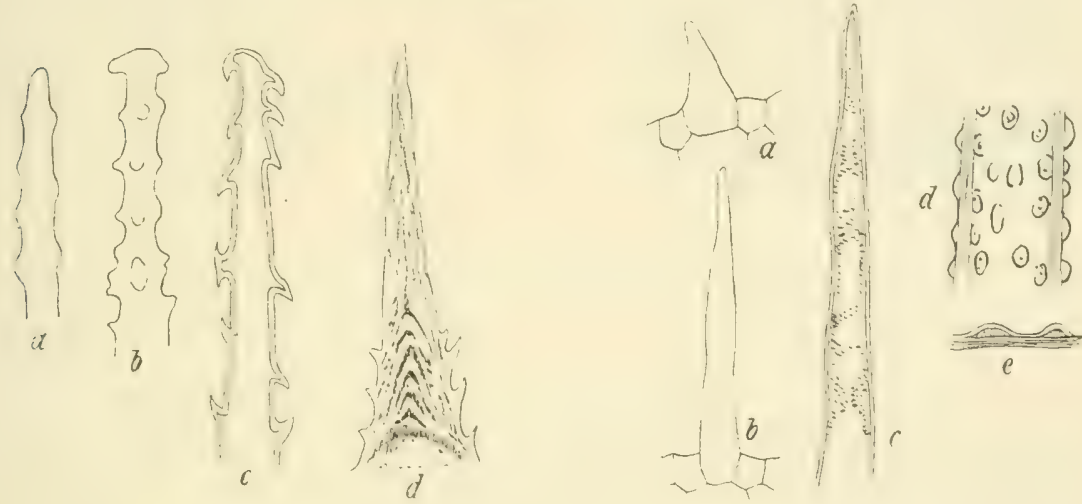

Fig. 22.

Haare von Campanula medium in verschiedenem Alter (n. Schenk).

Stelle sollen nur die allgemeinen Eigenschaften der Zellwand besprochen werden.

Sehr junge Zellwände sind dünn, homogen, durchsichtig. Beim Älterwerden erleiden dieselben unter Dickenzunahme mannigfaltige Veränderungen. An Zellen mit freier Oberfläche können sich nach aussen vorspringende Höcker und Warzen bilden (zentrifugale Verdickung), so an den Lufthaaren verschiedener Pflanzen (Fig. 22), an den Pollenkörnern der Phanerogamen und Sporen der Kryptogamen (Fig. 23). Zunächst werden dabei auf die primäre Membran eine oder mehrere sekundäre Schichten im Innern aufgelagert, durch Einwanderung von Substanzen aus dem Plasma nimmt dann das Volumen der äusseren Schichten zu, wodurch an derselben Vorsprünge, Warzen etc.

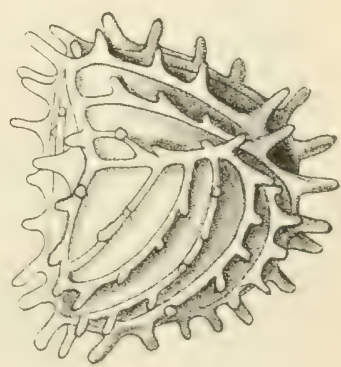

Fig. 23.

Spore von Aneimia phyllitidis, einem Farnkraut (K.) entstehen. Es sei hier, ohne auf Details einzugehen, noch erwähnt, dass auch auf andere Weise z. B. durch Falten- 
bildung, oder durch Auskrystallisieren bestimmter Stoffe ähnliche zentrifugale Verdickungen entstehen können.

Die weitaus häufigere Verdickungsform ist die zentripetale, bei welcher neue Wandschichten im Innern der primären Zellmembran auf-

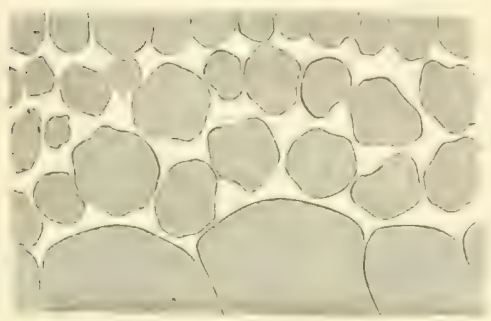

Fig. 24 .

Querschnittt aus den subepidermalen Collenchymschichten des Stengels von Solanum tuberosum. (R.)

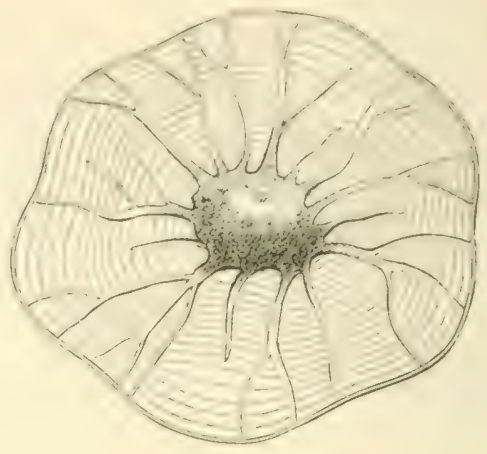

Fig. 25 .

Sclerenchymzelle der Wallnussschale mit verzweigten Tiipfeln. (R.)

gelagert werden. Die Verdickung kann gleichmässig erfolgen oder nur an bestimmten Stellen der Wand vor sich gehen.

An Zellen, welche die Oberfläche von

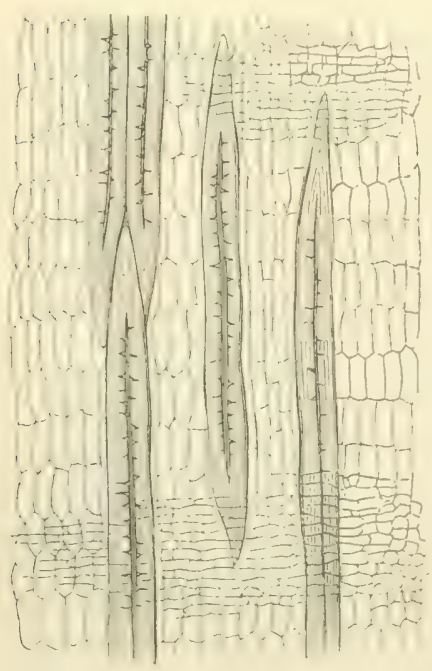

Fig. 26

Bastzellen, Kindenjarenchym und Markstrahlgewebe (die kleineren Zellen) von Cinchona calysaya. (R.) Pflanzenteilen bekleiden wie die Epidermiszellen, finden wir häufig die Aussenseite stärker verdickt (Fig. 30 und 67), ebenso bei den Korkzellen der Rinde ron Salix, Sorbus u. a. Bei Samenschalen, welche Schutz gegen Druck gewähren sollen, sind ausserdem häufig die auf der Oberfläche senkrechten Wände verdickt. Bei densog. me chanis chen Zellen, d. h. Elementen, welche der Festigung von Organen dienen, ist die Zellwandwerdickung die unerlässliche Bedingung einer genügenden Leistungsfähigkeit. Hierher gehören die Collenchymzellen (Fig. 24), bei welchen nur die Ecken der Zellen verdickt sind, während durch die dünneren Teile der Zellwand noch der Austausch von Wasser und anderen Stoffen vor sich gehen kann. Bei den sclerenchymatischen Zellen ist die rerdickte Wandmasse sehr mächtig und nur wenige Stellen bleiben unverdickt, welche als feine Kanäle, sog. Tüpfel, in der Verdickungsmasse sichtbar sind, (Fig. 25). Bei den 
durch ihre langsestreckte Form ausgezeichneten Bastfasern Sclerenchymfasern । ist die Zellwand oft bis auf ein enses strichförmiges Lumen verdickt Fis. 26).

Wo sich die zentripetale Verdickung auf den grössten Teil der Zellwand erstreckt, bleiben bestimmte, meist kleine Stellen unverdickt, es entstehen hierdurch die sog. einfachen Tüpfel (Fig. 27) oder wenn die dünngebliebene Wandlamelle nachträglich resorbiert wird, eigentliche Poren.

Die Verdickung kann auf bestimmte Stellen der Zellwand beschränkt bleiben. Beispiele hierfür

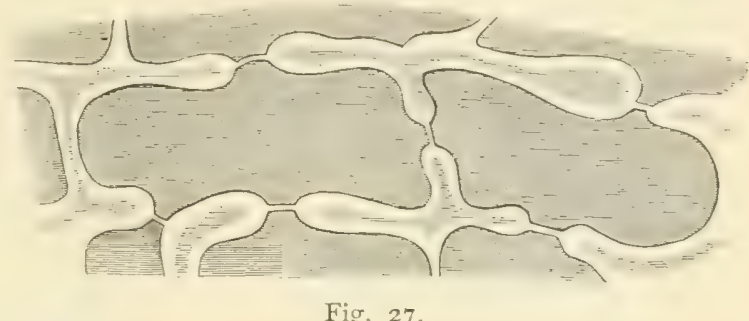

Fucus vesiculosus. Einfache Tüpfel. (R.) liefern die Gefässzellen des Holzes (Fig. 28). Die Ringgefässe zeigen verdickte Ringe, die Spiralgefässe verdickte Spiralen, die sich in anderen Fällen zu netzförmig oder leiterförmig zusammenhängenden Verdickungen vereinigen können, (Netz- und Treppengefässe).

Diese Verdickungen der Zellwand dienen hier als Aussteifungen, indem bei den etwas älteren Gefässzellen der plasmatische Inhalt und mit ihm der Turgor fehlt, welcher die Zellwand ausgespannt erhalten kann.

Eine besondere Erwähnung erfordern die in Holzkörpern so verbreiteten gehöften Tüpfel (Fig. 29). Eine dünner bleibende kreisförmige Scheibe der Membran (die sog. Schliesshaut, wird von sekundären V'erdickunssschichten überwölbt (Quer-

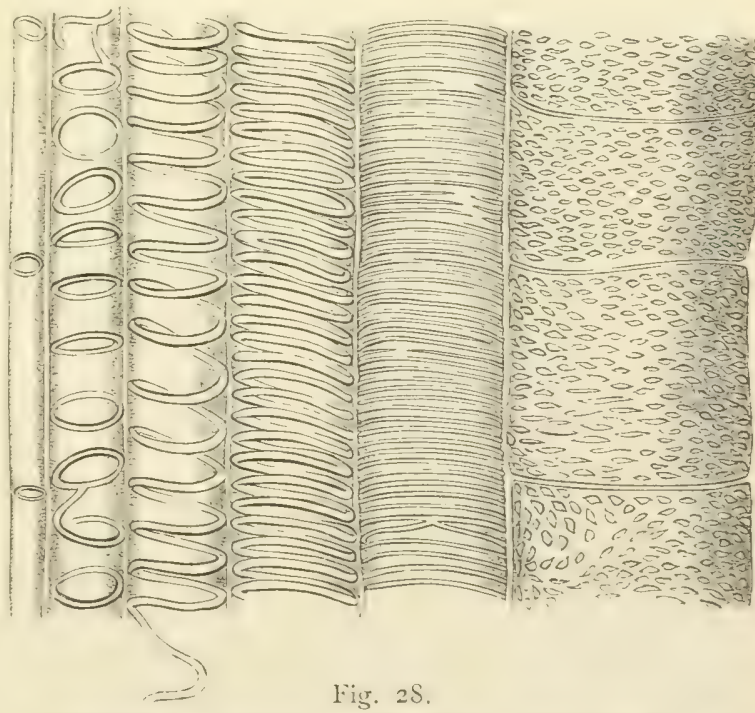

Ringformige, spiralige. netzfömige Verdickungen an den Holzgefäisen von Cucurbita I'epo. (K.)

schnitt hiervon Fis.s. 29 B), so dass ein linsenfömiger Hohlraum , Tüpfelhof , über der dünnen Scheibe entsteht, welcher durch den Porus in das Lumen der Zelle führt. Von der Fläche betrachtet (Fig. 29 A) erscheint der gehöfte Tüpfel als ein doppelter Kreis. Der äussere Kreis ist die Ansatzstelle der uhrglasförmigen Verdickung, der innere Kreis ist der 
Porus, der häufies auch Spaltenform annimmt. Die Schliesshaut zeigt in der Nitte eine geringe Verdickung, Torus genannt (Fig. 29 B, C), welche den Porus verschliesst, sobald sich die Schliesshaut seitlich den sekundären Verdickungsschichten anlegt.

Hoftüpfel finden sich besonders in den Gefässen und Tracheïden des Holzkörpers.

Unter Zellfusionen versteht man dic Vereinigungen benachbarter Zellen durch Auflösung der trennenden Membranteile. Die ver-
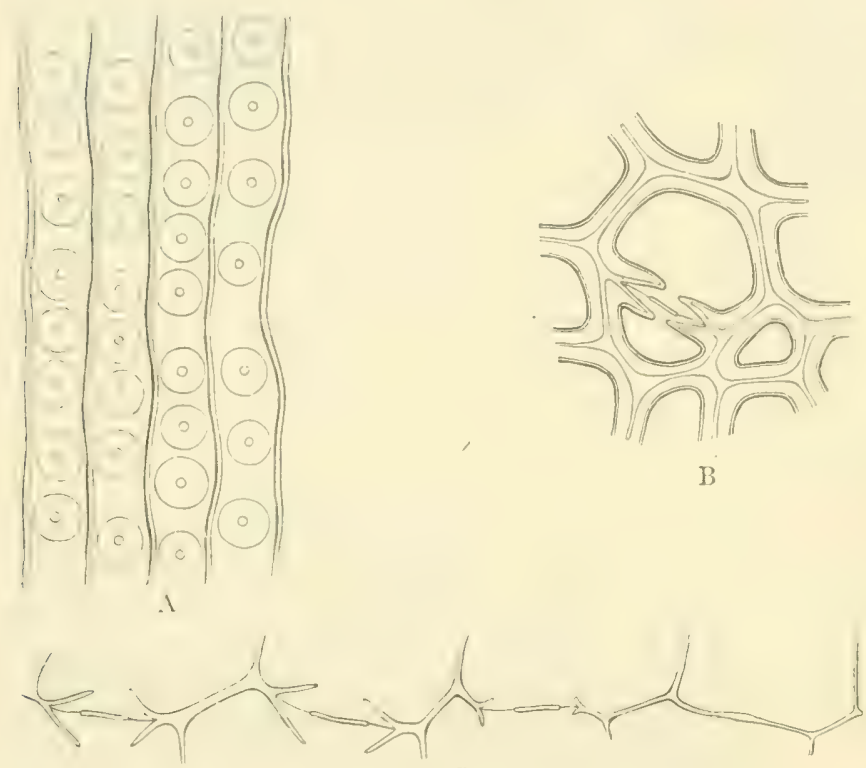

C

Fig. 29.

Gehöfte Tüpfel der Tracheiden von Pinus silvestris. A Flächenansicht, B Ouerschnit, C Entwicklung der Tüpfel (n. Sanio).

breitetsten Zellfusionen sind die sog. Tracheen oder echten Gefässe, welcheeinen wesentlichen Bestandteil der Gefässbündel (s. diese) ausmachen. Sic entstehen aus Längsreihen von Zellen, deren Querwände nachträglich resorbiert werden, deren Längswände jene oben besprochenen charakteristischenVerdickungen aufweisen. Dieselben Verdickungsformen finden sich auch bei den Tracheïden, hier hat jedoch keine Resorption der Berührungsflächen stattgefunden. Bei den sog. Siebröhren (vergl. Phloëm) ist die Durchbrechung der Membran benachbarter Zellen eine siebartige, die durchlöcherten Stellen werden als Siebplatten bezeichnet.

Nur die jüngsten Membranen sind homogen. Bei stärker verdickten Zellwänden kann man zumeist mehrere Membranschichten unterscheiden. Wie wir in Fig. 29B sehen, ist die sog. Mittellamelle oder primäre Membran zwei benachbarten Zellen gemeinsam. Es folgt die breite sekundäre Verdickungsschicht und schliesslich im Innern die tertiäre Verdickungsschicht (das Grenzhäutchen). Aus der homogenen Mittellamelle lässt sich cine dünne Schicht herauslösen, indem wir Schnitte von Pflanzenteilen mit Salpetersäure und chlorsaurem Kali (Schulzes Nacerationsgemisch) erwärmen, oder mit konzentrierter Chromsäure be- 
handeln. Es werden hierdurch die einzelnen Zellen isoliert, was namentlich an dickwandigen Geweben gut auszuführen ist und beim Studium des Holzkörpers mit Vorteil angewendet wird.

In den sekundären Verdickungsschichten finden wir häufig ausserdem noch feinere Strukturdifferenzen, die darin bestehen, dass dunklere und hellere Schichten miteinander abwechseln. In Fig. 30 ist ein Beispiel

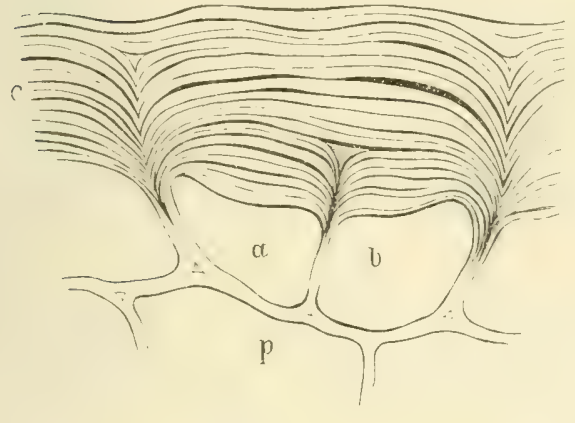

Fig. 30 .

Membranschichtung an älteren Epidermiszellen von Viscum album. (DN.)

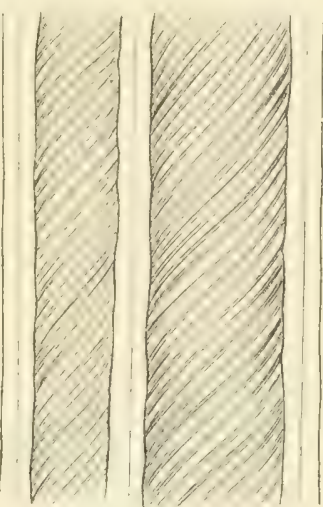

Fig. 3 I.

Larix europaea. Teil zweier Holzzellen in Flächenansicht. (R.) 츨

der sog. Schichtung abgebildet, bei welcher die Schichten einen der Oberfläche der Zelle parallelen Verlauf aufweisen. Die sog. Streifung entsteht dadurch, dass in ein und derselben Membranschicht hellere und dunklere Streifen miteinander abwechseln, die natürlich auf der Flächenansicht der Zellen am besten hervortreten, hierfür ist als Beispiel die spiralige Streifung der Holzzellen von Larix europaea (Fig. 3I) abgebildet, sie findet sich sehr schön auch bei andern Holzzellen, sowie bei Bastzellen verschiedener Planzen vor.

\section{§10. Chemische Beschaffenheit der Zellwand.}

Junge Zellwände bestehen aus reiner Cellulose, $\left(\mathrm{C}_{6} \mathrm{H}_{10} \mathrm{O}_{5}\right) \mathrm{n}$, die sich in der Pflanze wahrscheinlich aus den chemisch nahe verwandten Stoffen wie Stärke, Zucker, Dextrin (?) bildet.

Die Cellulose ist sehr widerstandsfähig gegen Zersetzungen, wodurch sie befähigt ist, das gegen äussere Einwirkungen sehr empfindliche Protoplasma zu schützen. Sie ist unlöslich in Wasser, Alkohol, Salzen, verdünten Säuren und Alkalien, lüslich in Kupferoxyd-Ammoniak und quillt in konzentrierter Schwefelsäure zu vegetabilischem Pergament auf. Sie färbt sich mit Jodlüsung braun, mit Jod und Schwefelsäure blau, mit Chlorzinkjod violett. 
Bei der Verdickung und dem Älterwerden der Zellwand nimmt nicht nur der Cellulosegehalt zu, sondern es werden auch andere Stoffe zwischen die Celluloseteilchen cingelasert.

Die Verholzung der Zellwände trifft besonders die Zellen des Aylems, aber auch Bastfasern und andere Zellen verholzen. Der Cellulose sind in diesem Falle noch andere Stoffe beigemengt, die man mit dem Sammelnamen Lignin, inkrustierende Substanz oder Holzstoff bezeichnet. Als regelmässige Begleiter der cingelagerten Substanzen treten in verholzten Wänden Coniferin und Vanillin auf, welche an besonderen Farbenreaktionen erkannt werden, aus deren Vorhandensein man auf Verholzung schliessen kann.

Sowohl auf Coniferin als Vanillin reagieren: Schwefelsaures Anilin und etwas Schwefelsäure (gicbt Gelbfärbung), Phloroglucin und Salzsäure (giebt Rotfärbung).

Nur mit Vanillin, nicht mit Coniferin reagiert: Schwefelsaures Thallin (orangegelbe Färbung).

Nur mit Coniferin reagieren: Phenol-Salzsäure (blaugrüne Färbung), Thymol-Kaliumchlorat-Salzsäure (himmelblau).

Verholzte Membranen färben sich mit Jod, Chlorzinkjod, Jod-Schwefelsäure braun, durch konzentrierte Schwefelsäure werden sie geschwärzt.

Ausser Coniferin und Vanillin kommen im Holz noch gummiartige Substanzen (Holzgummi) sowie ein mit Salzsäure sich gelbfärbender Stoff vor.

Ein Teil der inkrustierenden Substanz löst sich in siedendem Wasser, ein anderer unmittelbar in Alkalien, der Rest erst nach vorheriger Wirkung von Chlorwasser. Nit Eau de Javelle behandelte Holzmembranen zeigen die Holzstoffreaktionen nicht mehr oder nur sehr schwach, trotzdem unterbleibt bei nachheriger Einwirkung von Chlorzinkjod die für Cellulose charakteristische Violettfärbung, was uns anzeigt, dass ausser den die Holzstoffreaktion gebenden Substanzen (Coniferin, Vanillin) noch andere Stoffe der Cellulosemembran eingelagert sind, welche die eigentliche Cellulosereaktion verdecken.

Die Mittellamelle an Holzzellen (Fig. 29B) ist stärker verholzt als die sekundären Verdickungschichten. Das Grenzhäutchen zeigt Cellulosereaktion.

Die Verholzung erhöht die Festigkeit der Membran, ohne die Wasserbewegung in derselben zu hemmen.

Der Verholzungsprozess geht nux in lebenden Zellen vor sich, weshalb es sehr wahrscheinlich ist, dass die Verholzung durch Einwanderung von Substanzen, die vom Protoplasma produziert werden, geschieht.

Die Verkorkung der Membran beruht auf der Einlagerung von Suberin, einer fettähnlichen Substanz (bei Quercus suber Glycerinester der Stearinsäure und Phellonsäure, $\left.\mathrm{C}_{20} \mathrm{H}_{42} \mathrm{O}_{3}\right)$, wodurch die Wand un- 
durchlässig für Wasser und Gase wird. Die verkorkte Wand ist ein schlechter Wärmeleiter.

Reaktionen der verkorkten Membran: Gelbfärbung in konzentrierter Kalilauge, Umwandlung in ölartisge Tropfen beim Kochen in Salpetersäure und chlorsaurem Kali, Unlöslichkeit in konzentrierter Chromsäure, Widerstandsfähigkeit gegen konzentrierte Schwefelsåure.

Auch bei verkorkten Membranen kann man eine Zusammensetzung aus mehreren Teilen konstatieren, die Mittellamelle ist verholzt, die folgende sekundäre Schicht suberinhaltig und im Innern kann noch eine Celluloseschicht vorkommen.

Den verkorkten Membranen schliessen sich die cutinisierten an. Das hier eingelagerte Cutin ist ebenfalls ein fett- oder richtiger ein wachsartiger Körper, welcher die damit infiltrierten Membranen für Gase und Wasser in hohem Grade undurchlässig macht. Auf der Aussenseite der oberirdischen Pflanzenteile befindet sich eine zusammenhängende homogen erscheinende Schicht, die Cuticula, welche ausserordentlich reich an Cutin ist, die darunter befindlichen cutinärmeren Schichten werden als cutinisiert oder cuticularisiert bezeichnet, sie grenzen meist nach innen an Celluloseschichten (Epidermiszellen, Lufthaare).

Ebenso ist die Aussenschicht der Pollenkörner, die Exine, mit einem dem Cutin sehr nahestehenden Körper infiltriert.

In den Reaktionen stehen die cutini-

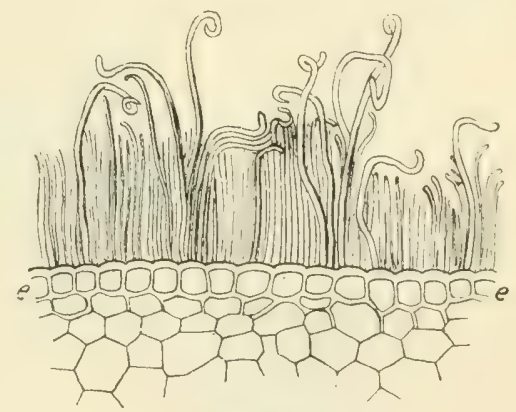

Fig. 32.

Epidermis des Zuckerrohrs mit Wachsüberzug (n. De Bary). sierten Membranen den verkorkten sehr nahe (sind identisch?). Die Cuticula widersteht der konz. Schwefelsäure am längsten, färbt sich mit Chlorzinkjod, mit Jodschwefelsäure gelb, während die cutinisierten Membranteile mit letzterem Reagenz eine grünliche oder blaue Farbe annehmen.

Den Cuticularbildungen schliessen sich unmittelbar die leicht abwischbaren Wachsablagerungen auf der. Oberfläche von Pflanzenteilen an. Es können Stäbchen sein (Sacharum officinarum Fig. 32, Canna, Strelitzia) Körnchen (Gramineen, Liliaceen, Irideen), oder Krusten (Thujanadeln, Sempervivum).

In harzreichen Pflanzenteilen, z. B. bei verschiedenen Nadelhölzern, können die Zellwände mit Harz infiltriert werden.

An den Wundstellen von Laubhölzern vermehrt sich die Menge des Gummis sehr bedeutend, auch die Zellmembranen werden hier mit Gummi durchtränkt. Die z. B. bei den Kirschen nicht seltene abnorme Gummibildung (Gummosis) ist noch nicht genügend aufgeklärt. 
Bei der Kernbildung vieler Holzplanzen wird in den Membranen Farbstoff absclasert (rgl. S 24).

Ausser organischen Substanzen können auch anorganische Stoffe in der Zellwand abgelagert werden, namentlich Kalk und Kieselsäure, wodurch die Festigkeit der Wände wesentlich erhöht wird. Beim Einäschern derartişer Pfanzenteile kann ein vollständiges Aschenskelett der Zellwände zurückbleiben.

Oxalsaurer Kalk findet sich $u$. a. bei vielen Coniferen, bei Dracaenaarten, Mesembryanthemum, Sempervivum calcareum, meist in Form von kleinen Körnchen oder Krystallen. Grössere Drusen kommen im Mark von
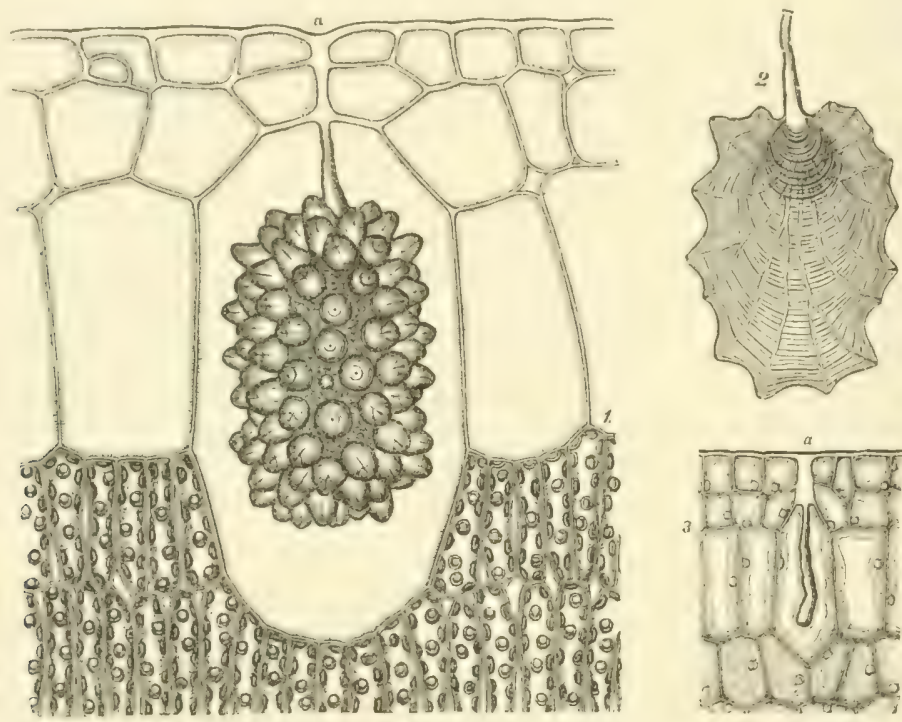

Fig. 33 .

Ficus elastica. I. Blattepidermis mit Cystolith. 2. Cystolith nach Entfernung des Kalkes. 3. Jüngeres Stadium. (KW.)

Kerria japonica, im Phloem von Vitis vor, ferner in den Blattstielen von Tilia, Popolus, Fagus, Morus etc., in der Rinde von Salix aurita, Fagus, Rhamnus frangulua, Platanus orientalis etc.

Calciumcarbonat kommt vielfach in oberflächlichen Krusten auf der Membran vor, (Farne, Saxifrageen, gewisse Kalkalgen), ist ferner in grosser Menge gleichmässis rerteilt in den Membranen vieler Haare, Boragineen, Compositen etc.) zu finden. In gewissen Familien (Acanthaceen, Urticaceen, Moreen) giebt es besondere Zellwandgebilde, die mit kohlensaurem Kalk durchsetzt sind, die sog. Cystolithen (Fig. 33).

Bei unseren Laubhölzern ist ausserdem das Lumen der Zellen des Kernholzes sehr reich an Calciumkarbonat (Llmus campestris, Acer, Fagus), während sich im Holz von Tectona grandis Calciumphosphat vorfindet. 
Ob der Kalk in der Membran als Celluloseverbindung vorkommt, ist fraglich.

Die Kieselsäure ist in den Membranen ganz ausserordentlich verbreitet, doch sind gewisse Pflanzen besonders bevorzugt: Diatomeen, die sogr. Kieselalgen liefern den Kieselguhr, Equiseten, Gramineen, Cyperaceen Ericaceen, unter den Bäumen Populus tremula, Betula, Ulmus, Fraxinus, Quercus, Picea, Pinus. Namentlich sind die Blätter und in diesen wieder die Epidermiszellen kieselsäurereich.

Kieselsäure kann ausserdem noch an der Oberfläche der Zellen (im hohlen Mark von Bambusa Arundinacea das sog. Tabaschir) oder im Zelllumen vorkommen.

\section{$\S$ 11. Physikalische Eigenschaften der Zellwand.}

Das specifische Gewicht der Membranen (nicht ganzer Pflanzenteile) beträgt nach Sachs und Hartig I,56, nach Henze I,60-1,63, stark verkieselte Membranen z. B. der Buchenrinde sind schwerer.

Bei den mechanischen Eigenschaften der Membran kommt deren Trasfähiglicit, absolute Festigkeit und Dehnbarkeit in Betracht. Dic Tragfähigkeit wird ausgedrückt durch den Tragmodul d. h. die maximale Belastung (in $\mathrm{Kg}$ ausgedrückt), welche ein Stab von I qmm Querschnitt aushält, ohne die Elastizitätsgrenze zu überschreiten, d. h. eine dauernde Verlängerung zu erfahren. Der Festigkeitsmodul repräsentiert das Gewicht (in $\mathrm{Kg}$ ), welches das Zerreissen eines Stabes von I qmm bewirkt. Die Dehnbarkeit wird ausgedrückt (in $\mathrm{mm}$ ) durch die Verlängerung, welche kurz vor dem Zerreissen eines $1000 \mathrm{~mm}$ langen Körpers eintritt.

Die grösste Tragfähigkeit und Festigkeit besitzen die sog. mechanischen Zellen: das Collenchym (S. 24) und die Bastfasern (S. 25), deren Tragfähigkeit der des Schmiedeeisens gleichkommen kann. Ebenso sind die mechanischen Leistungen der Epidermiszellen und des Holzkörpers bedeutend.

Festigkeitsverhältnisse bei den Bastzellen folgender Pflanzen:

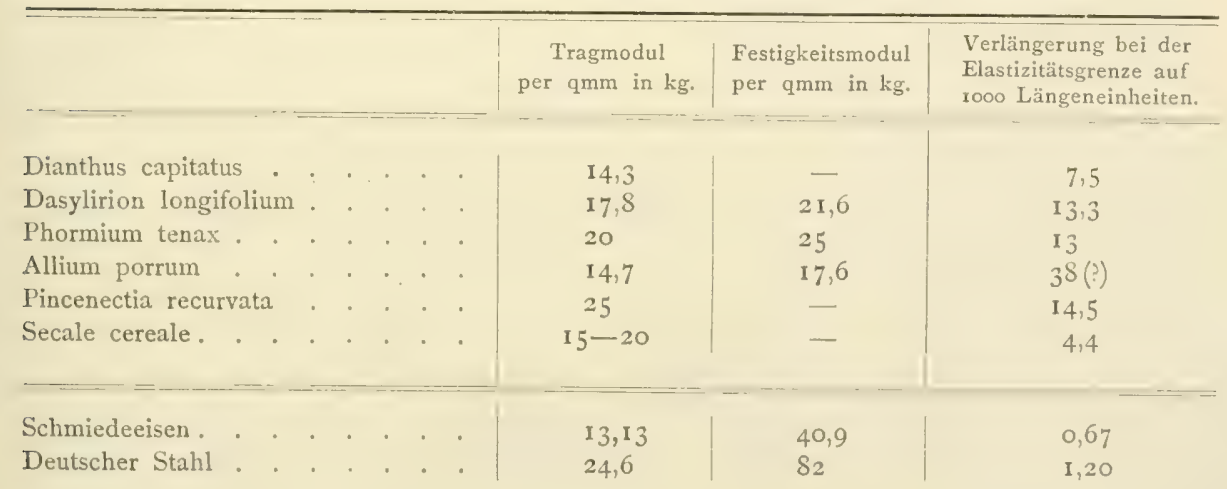


Vercleicht man wasserhaltige und und trockene Zellwände, so stellt sich heraus, dass dic Dehnbarkeit mit dem Austrocknen der Membran abnimmt, dic Tragfähigkeit und Festigkeit aber zunimmt.

Was dic optischen Eigenschaften der Membran anbelangt, so sind ganz junge Membranen isotrop oder ganz schwach anisotrop, ältere Zellwände anisotrop, was wahrscheinlich auf Spannungen zwischen den cinzelnen Membranschichten zurückzuführen ist.

Bezüglich der Wärmeleitungsfähigkeit, Quellungsfähigkeit, Orienticrung der optischen Elastizitätsaxen und vielleicht auch hinsichtlich der Wasserleitungsfähigkeit ist zu bemerken, dass dieselben in verschiedenen Richtungen ungleiche sind.

Die Quellung der Membran besteht in einer Aufnahme von Wasser zwischen die einzelnen Moleküle oder, wie man meist annimmt, Molekülgruppen (Micellen). Derartige mit Wasser durchtränkte Zellwände bezeichnet man als imbibiert. Ebenso wie Wasser können natürlich auch in Wasser gelöste oder flüssige Stoffe von der Membran aufgenommen werden. Beim Austrocknen der Zellwände verkleinert sich der mit Wasser erfüllte Raum zwischen den Micellen, wodurch das Volumen des ganzen Holzstückes vermindert wird, welche Erscheinung man als Schwinden bezeichnet. Je schneller das Austrocknen vor sich geht, desto leichter entstehen Risse im Holz.

\section{Wachstum der Zellwand.}

Nach der Anlegung der ersten Zellwandlamelle bei der Zellteilung (vgl. S. I2) wächst die Zellwand weiter, u. z. können wir dabei Flächenwachstum und Dickenwachstum unterscheiden. Das Flächenwachstum der Zellwand erfolgt mit der Volumzunahme der Zelle, das Wachstum in die Dicke kann gleichzeitig mit der Vergrösserung der Zellwandfläche vor sich gehen oder nachdem das Flächenwachstum abgeschlossen ist.

Das Dickenwachstum geschieht in sehr vielen Fällen durch Apposition d. h. durch Auflagerung neuer Membranlamellen, wovon man sich z. B. an der dickwandigen Meeresalge Caulerpa überzeugen kann, indem man vor der vollständigen Verdickung der Zellwände dieselben mit Berliner Blau imprägniert, und sie in reinem Meerwasser weiter wachsen lässt. Die neu aufgelagerten Schichten sind farblos, was nicht der Fall sein könnte, wenn sich die Membranen durch Intussusception verdickt hätten, d. h. durch Zwischenlagerung neuer Celluloseteilchen zwischen die schon vorhandenen.

Es werden hierbei die äussersten Schichten des Cytoplasmas durch Einwanderung von stickstofffreien Substanzen in Membranschichten umgewandelt und der schon vorhandenen Zellwand aufgelagert.

In anderen Fällen, namentlich bei Pollenkörnern, lässt sich nachweisen, dass (protoplasmatische:) Substanz in Zellwandschichten einwandert, welche 
durch eine Zellwandlamelle von der direkten Berührung mit dem Cytoplasma ausgeschlossen sind. Durch Vermittlung dieser lebenden Substanz wird die Verdickung und Ausgestaltung bewirkt. Man kann diesen Vorgang ebenfalls als Intussusceptionswachstum bezeichnen. Von diesem Gesichtspunkte aus erscheint der Nachweis von Proteinstoffen oder deren Derivaten in der Zellwand von besonderem Interesse.

Das Flächenwachstum kann durch Dehnung oder Sprengung der alten und Auflagerung von neuen Nembranlamellen geschehen, ob auch Einschaltung neuer Substanzteile zwischen die schon vorhandenen eine Flächenvergrösserung bewirkt, ist nicht unwahrscheinlich, aber nicht sicher festgestellt. 


\section{Zweiter Alsschnitt: Morphologie und Gewebelehre der Vegetationsorgane.")}

\section{S. Arbeitsteilung in der Pflanze.}

Bei den niedersten Pflanzen verrichtet cin und dieselbe Zelle alle Funktionen. Der erste Schritt zur Teilung der Arbeit besteht darin, dass die zur Ernährung dienenden vegetativen Zellen sich von den zur Fortpflanzung dienenden reproduktiven Zellen unterscheiden. Auf einer höheren Stufe stehen jene Pflanzen, welche nicht mehr aus gleichartigen Zellen bestehen, sondern schon eine Übertragung einzelner Funktionen auf verschiedene Zellen erkennen lassen. Je höher eine Pflanze steht, desto vollkommener ist im allgemeinen die Trennung der einzelnen Funktionen. Die äussere Gestalt der Pflanzen wird mannigfaltiger, wodurch die höheren Pflanzen zur Ausbildung typischer Glieder, auch Organe genannt, gelangen. Wir können an den höheren Pflanzen, abgesehen von den Fortpflanzungsorganen folgende Organe unterscheiden: I. den Laubspross bestehend aus Blatt und Sprossaxe, 2. die Wurzel. Ebenso wie die äussere Gestalt unterliegt auch der innere Aufbau der Pflanze einer desto weitergehenden Differenzierung, je höher eine Pflanze im System steht. Es kommt zur Ausbildung der mannigfaltigsten Gewebe, ohne dass jedoch die Arbeitsteilung eine so vollkommene wird, als im Tierreich.

Wenn wir den Laubspross und die Wurzel einander gegenüber stellen, so sind für deren Unterscheidung nicht nur die morphologischen, sondern auch die physiologisch-biologischen Beziehungen, welche die Lebensfunktionen der Pflanzen betreffen, zu beachten. Der Laubspross umfasst die Assimilationsorsane (Blätter) und deren Träger (Sprossaxen), während die Wurzeln zur Aufnahme von Wasser und gelösten Stoffen, sowie zur Befestigung der Pflanze im Boden dienen.

Man geht einen Schritt weiter und subsumiert alle jene durch Entwickelung und Stellung verwandten Organe unter diese beiden Begriffe, auch wenn sie durch die Anpassung an verschiedene andere Funktionen

1) Die der Vermehrung dienenden Fortpflanzungsorgane (reproduktive oder Fruktifikationsorgane) werden in der Systematik behandelt. 
eine abweichende Ausbildung erlangt haben. Eine scharfe allgemein gültige Definition des Begriffs Spross und Wurzel ist nicht möglich, da die Natur nicht nach derartigen schematischen Begriffen arbeitet. Trotzdem werden wir die gewünschte Übersicht über die Pflanzenformen gewinnen, wenn wir bei den höheren Pflanzen zunächst die typischen Formen von Laubspross und Wurzel betrachten und uns sodann zu den abgeleiteten metamorphosierten Formen wenden. Ausserdem werden wir bei den niederen Pflanzen (Algen, Pilzen, Moosen) ähnliche Organe finden, jedoch in unvollkommener morphologischer und anatomischer Ausbildung.

Wir müssen die morphologischen Begriffe von Sprossaxe und Blatt als korrelative bezeichnen: Sprossaxe ist, was Blätter trägt, Blatt ist, was an einem Axengebilde seitlich entsteht (Sachs, Lehrbuch der Botanik). Man ist daher auch berechtigt, Blatt und Stammaxe als ein Ganzes zu betrachten und als Laubspross zu bezeichnen.

Wenn wir im folgenden einige Eigentümlichkeiten von Spross und Wurzel angeben, so geschieht dies mit dem Bemerken, dass Ausnahmen von diesen Regeln vorkommen.

Der Spross: produziert Blätter, dieselben entstehen ebenso wie die Seitenaxen als Auswüchse oberflächlicher Schichten (exogen), der Vegetationspunkt d. i. die fortwachsende Spitze trägt keine sog. Haube.

Die Wurzel: trägt keine Blätter, die Seitenaxen, d. h. die Nebenwurzeln, bilden sich im Innern dèr Wurzelkörper (endogen), an dem Vegetationspunkte befindet sich eine sog. Wurzelhaube.

Da diese Kennzeichen nicht für niedere Pflanzen gelten, möge die Gestalt derselben eine besondere Besprechung erfahren.

\section{§ 14. Die Vegetationsorgane der Algen, Pilze und Moose.}

Die einfachste Form des Vegetationskörpers ist die einzelne, frei lebende Zelle (einzellige Algen, viele Bakterien). Die nächst höhere Ausbildung der Form sind Fäden und Flächen aus gleichartigen Zellen (Spirogyra, Confervaceen, niedere Pilze). Es können sich einzelne Zellen oder Teile derselben (Ulothrix, Oedogonium Fig. 34) unter Reduktion der Chlorophyllkörper zu Haftorganen ausbilden: die erste Andeutung der Trennung von Spross und Wurzel. Ferner können die Randzellen einer Zellfläche (Fig. 35) anders gestaltet sein, wodurch die Form der betreffenden Pflanze genauer fixiert wird.

Bei der Algenfamilie der Siphoneen besteht jedes Individuum nur aus einer grösseren Zelle, welche jedoch die Form von Algen annimmt, welche aus vielen Zellen bestehen. Hier zu nennen ist Vaucheria (Fig. 36); aus der Spore (sp) entwickelt sich ein Keimschlauch, der an einer mit der Erde in Berührung stehenden Stelle farblose wurzelartige Ausstülpungen treibt (v). Bei höheren Siphoneen z. B. Caulerpa (Fig. I) bringt es die 
cine Zelle zu blatt-, stengel- und wurzelartigen Ausstülpungen. Dabei ist die Arbeitsteilung eine unvollständise, da die ganze Oberfläche der Pflanzen Stoffe aufnimmt und die Wurzelschläuche nur als Haftorgane dienen.

Unter den Meeresalgen finden wir häufig eine

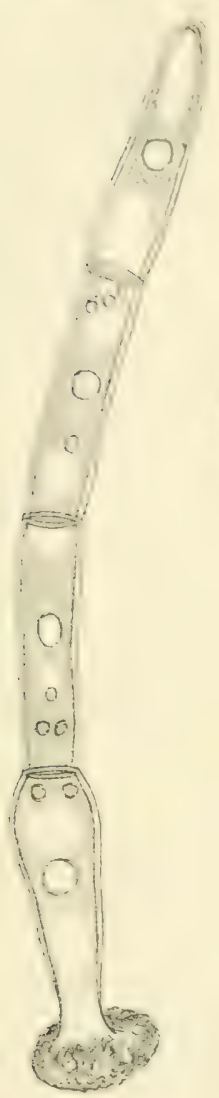

Fig. 34 .

Junger Faden von Oedogonium $\mathrm{m}$. Haftscheibe. (K.)

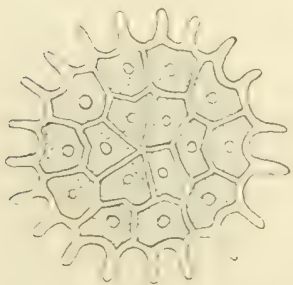

Fig. 35 .

Pediastrum granulatum (Alge) (n. Braun). hochentwickelte Gliederung, z. B. bei vielen Phaeophyceen und Rhodophyceen, so dass wir an die Laubsprosse höherer Pflanzen erinnert werden (vgl. Fig. 37), auch das Haftwurzelsystem wird weiter ausgebildet (Fig. 38). Der kompakte Körper dieser manchmal viele Meter langen Pflanzen (z. B. Macrocystis pyrifera) entsteht entweder durch Teilung der Zellen, wie bei den höheren Pflanzen, oder durch

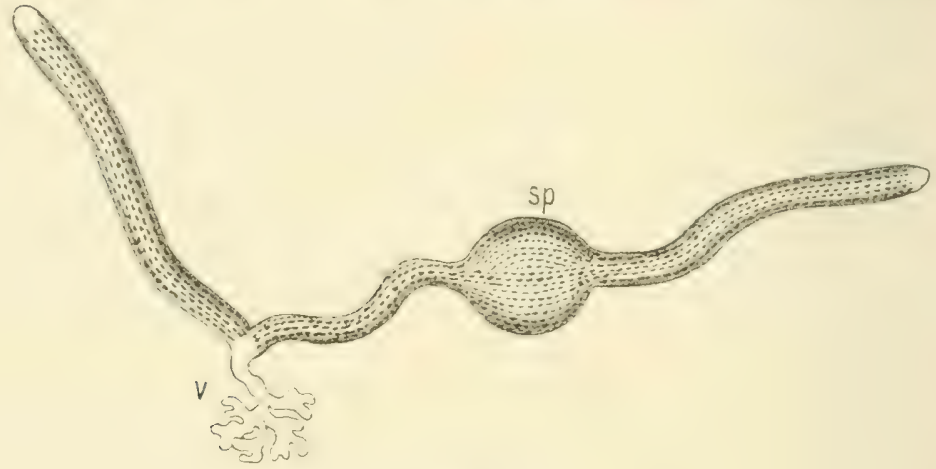

Fig. 36 .

Vaucheria sessilis (n. Sachs).

Aneinanderlegen und Verschmelzen einzelner Fäden, wodurch ein sog.

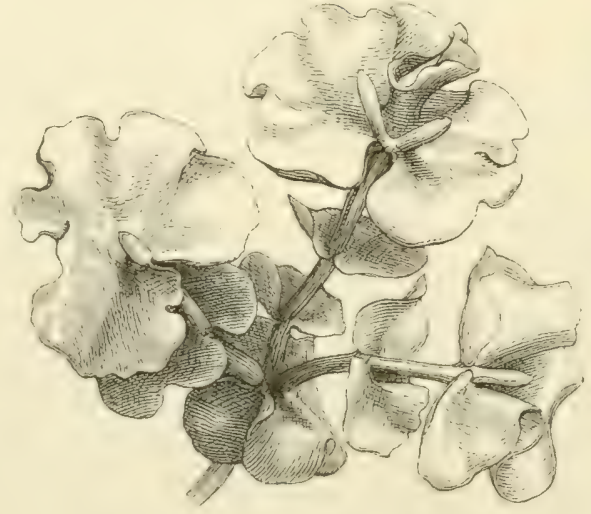

Fig. 37 .
Pseudoparenchym entsteht. Es können auch einzelne Zellen in der gallertigen Wand weiter wachsen (Fig.38). Von den Geweben sind ausser gleichartigen Parenchymzellen noch collenchymatische und geConstantinea reniformis (Rhodophyceae). (R). tüpfelte Zellen zu beobachten, aber keine Gefässe. Die Rindenzellen sind häufig von den Innenzellen ver- 
schieden. Sekundäres Dickenwachstum ist bei Laminariasprossen zu konstatieren.

Bei den Pilzen (vgl. §47) haben wir allgemein einen einfacheren morphologischen Aufbau der vegetativen Organe, indem ein aus feinen Fäden gebildeter Körper (Mycel) am besten zur Aufnahme der organischen Nahrung geeignet ist (Fig. 39), doch finden hier sehr mannigfaltige Differenzierungen statt, welche sich als ein Angepasstsein an bestimmte Nährsubstrate darstellen. Die Träger von Fortpflanzungs-

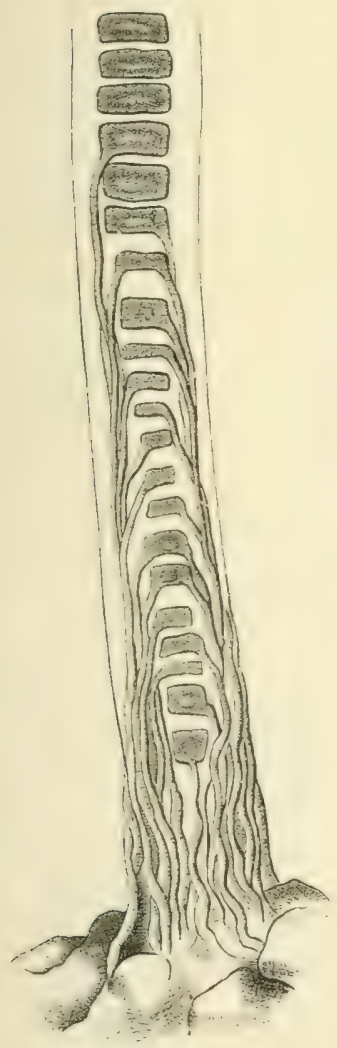

Fig. 38 .

Bangia fusco-purpurea. Im Gestein haftendes Ende. (R.) zellen können kompakte pseudoparenchymatische Gewebe darstellen (Basidiomycetes, die sog. Schwämme).

In anbetracht der weniger scharfen Abgrenzung der einzelnen Organe bei Algèn und Pilzen hat man deren Vegetationsorgane als Thallus, Lager bezeichnet, sie selbst als Thallophyten.

Bei den Moosen ( $v g l . \S 55$ ) finden wir Übergänge von

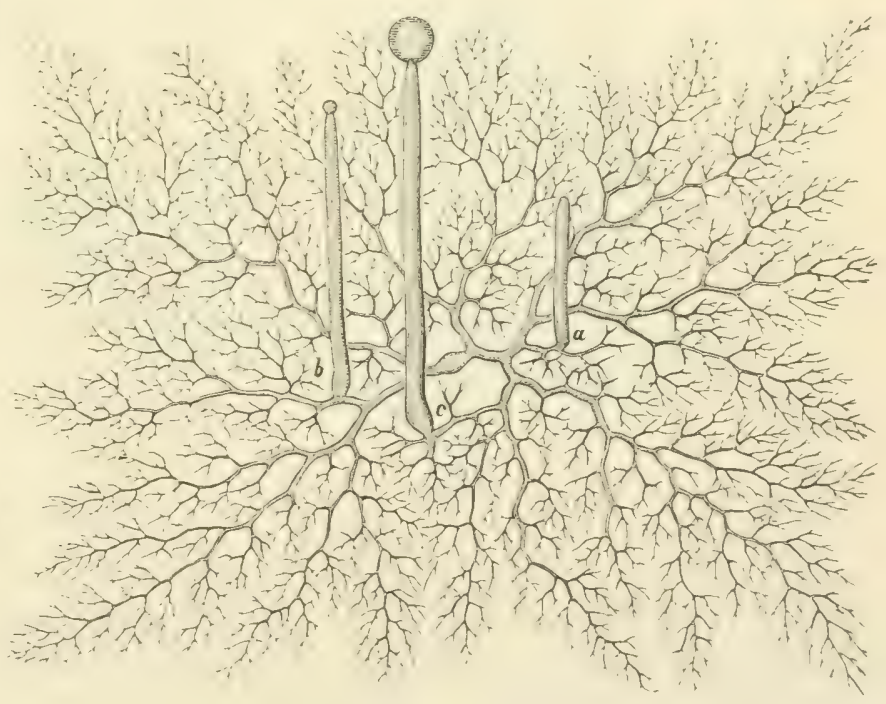

Fig. 39 .

Mucor Mucedo, Mycel und Sporangienträger.

einfachen oder gabelig verzweigten Flächen (Marchantia) zu beblätterten Sprossen (ein Teil der Lebermoose und die Laubmoose). Als Wurzeln fungieren Haare, sog. Rhizoiden, welche an der Unterseite des Thallus oder am Stämmchen durch Auswachsen von Oberflächenzellen entstehen. Es werden jedoch gelöste Stoffe auch noch durch die Blätter und das Stämmchen aufgenommen. An der Unterseite mancher auf dem Substrat 
kriechender Iungermanniaceen sind die Blätter zusammengerollt oder in Blasen umgewandelt, Amphigastrien genannt, welche als Wasserreservoire 7.1 dienen haben.

Die Differenzierung der Gewebe steht auf einer wesentlich höheren Stufe als bei den Algen und Pilzen. Es werden dickwandige mechanische Zellen gebildet (ja selbst Bastfasern mit Tüpfeln), welche die peripherischen Teile des Stämmchens oder bestimmte Stellen der Blätter einnehmen, zur Festigung und zum Schutz dienen. Die assimilierenden Organe sind im Vergleich zu den höheren Pflanzen sehr einfach gebaut, oft nur eine Zellschicht dick, doch ist häufig sowohl in der Blattmitte als im Stamm ein aus langgestreckten Elementen bestehendes Gewebe gebildet, welches zur Fortleitung von Stoffen dient. Als Wasserreservoir können mit Löchern versehene tote Zellen dienen (Sphagnum). Die Fortleitung von Wasser kann ausser im Stamm in gewissen Fällen durch Capillarität an der Oberfläche der Axen geschehen.

Bei den Gefässkryptogamen und Phanerogamen tritt an Stelle der Rhizoiden ein kompakter typischer Wurzelkörper, die Gewebe werden komplizierter und namentlich treten typische Gefässe auf.

\section{Entstehung der Organe und Gewebe aus den Vegetationspunkten.}

An keimenden Samen von Phanerogamen können wir die Cotyle-

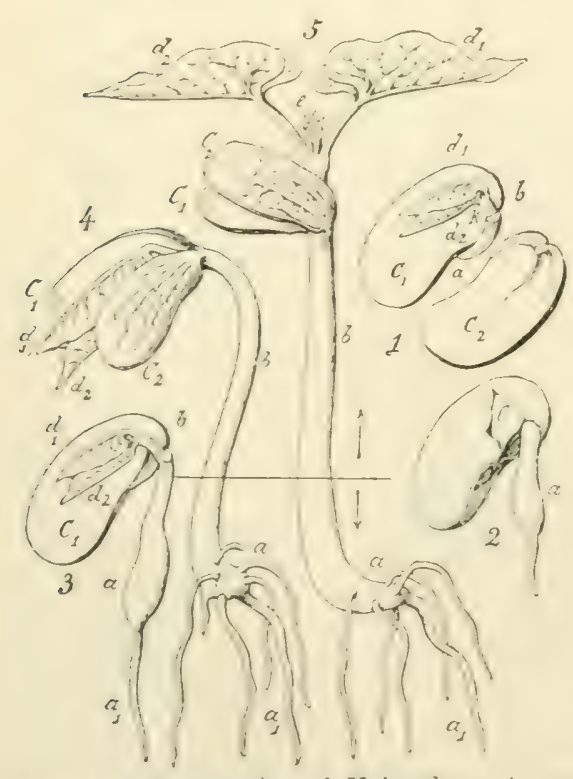

Fis. 40. Same (I) und Keimptlanze $(2-5)$ von Phaseolus. (IV.) donen oder Keimblätter (Fig. 40, I $C_{1} C_{2}$ ) so wie die Anfänge von Wurzel (a) und Stengel (b) wahrnehmen. An Samen, deren Cotyledonen bei der Keimung über die Erde emporgehoben werden, befindet sich unter den Cotyledonen, zwischen diesen und der Wurzel ein Stengelglied, welches als Hypocotyl bezeichnet wird (Fig. 40, 4 und 5 b), durch dessen Streckung die Cotyledonen über die Erde gehoben werden. Bleiben die Cotyledonen jedoch unterirdisch (Quercus, Corylus), so bezeichnet man die erste Strecke der jungen Sprossaxe als das Epicotyl.

Die Spitzen von Laubspross und Wurzel werden zuerst angelegt, von ihnen geht die Bildung der Vegetationsrorgane aus, man bezeichnet sie deshalb als Vegetationspunkte. Bei der 
Entstehung von Seitensprossen und Nebenwurzeln bilden sich (vgl. weiter unten) an den schon vorhandenen Organen neue Vegetationspunkte, welche den zuerst angelegten in Funktion und Aussehen gleichen. Den zuerst zwischen den Cotyledonen auftretenden Vegetationspunkt, welcher häufig von schuppenartigen Blattgebilden bedeckt ist, bezeichnet man auch als „Plumula" und die auf die Cotyledonen folgenden Blätter als Plumulablätter. Sie zeigen oft eine von den Laubblättern abweichende Form (z: B. bei Fraxinus excelsior).

Zwischen den Vegetationspunkten der Laubsprosse und der Wurzeln bestehen gewisse Unterschiede. Die ersteren sind kegelförmige (Fig. 4I) oder flachgewölbte. Gebilde, an denen sich in unmittelbarer Nähe der

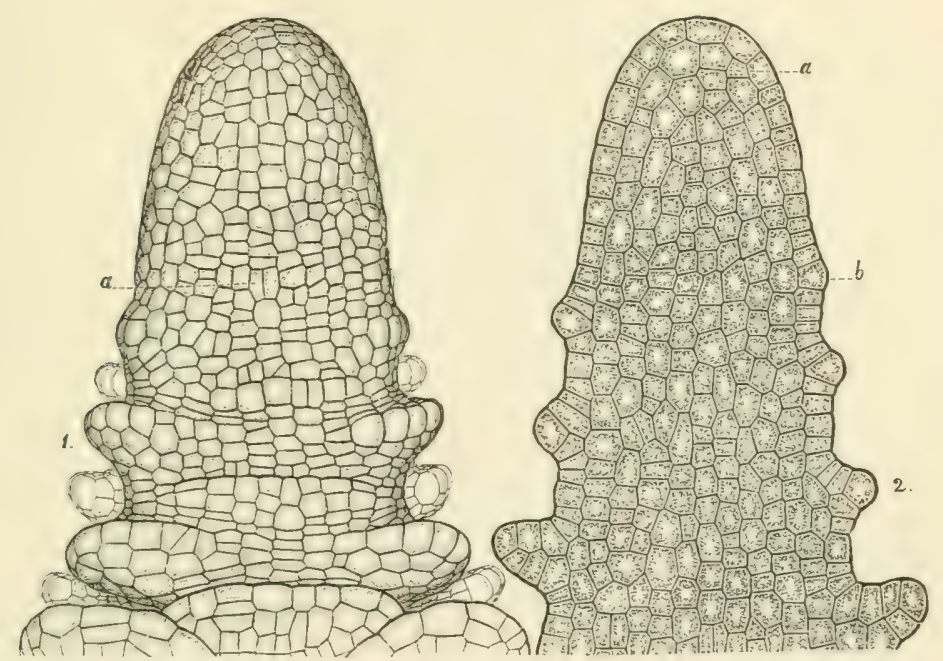

Fig. 41 .

Sprossspitze von Elodea canadensis, links Oberflächenansicht, rechts Längsschnitt. (KW.)

Spitze Höcker und Wülste erheben, die später zu Blättern oder zu neuen Vegetationspunkten auswachsen. An Stelle der einzelnen Höcker können auch ringförmige Wülste auftreten (z. B. bei Asperula, Galium), aus denen sich die einzelnen Blattanlagen entwickeln. Wächst dieser ringförmige Teil weiter, so erhalten wir sog. durchwachsene Blätter, wie z. B. bei Lonicera caprifolium (vgl. § I05).

Dieselbe Entwickelung zeigen die sog. verwachsenen Kelch- und Blumenblätter, deren einzelne Zipfel sich ebenfalls als Höcker auf einem gemeinsamen Ringwulste bilden.

Bei der jungen Blattanlage kann man Blattgrund und Oberblatt unterscheiden. Der Blattgrund entwickelt sich nicht weiter oder bildet die Nebenblätter (Stipulae) oder wird zur Blattscheide 
(|gl. IS). Aus dem Oberblatt geht die Blattfläche (Blattspreite) hervor. Der Blattstiel entwiclielt sich zuletzt, er wird gewissermassen zwischen Blattgrund und Oberblatt eingeschoben. Die in der Form fertig atussebildeten aber noch kleinen Blätter, wie sic in den Knospen vorkommen, sind entweder cingefaltet (Prunus avium, Corylus avellana) oder cinserollt (Prunus spinosa). Bei Laubausbruch sind die Zellteilungen in den Blättern zumeist schon abgeschlossen, es findet nur Zellstreckung und die Ausbildung der inneren Gewebe statt, was uns die schnelle Entwickelung der Blätter im Frühjahr erklärlich macht.

Die Knospen sind Vegetationspunkte mit Blattanlagen und jungen

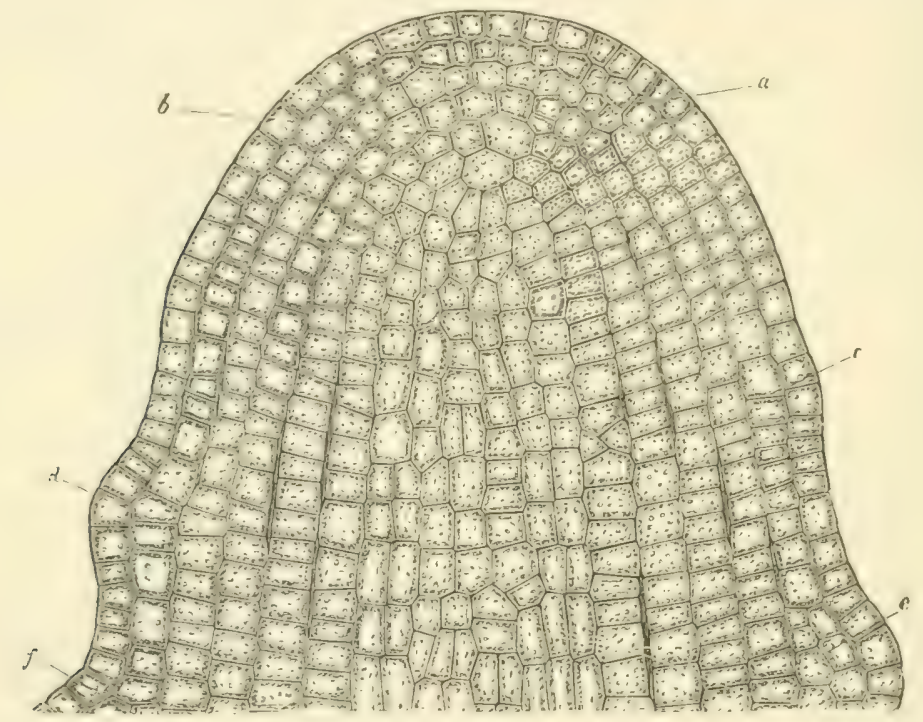

Fig. 42.

Hippuris vulgaris. Längsschnitt durch den Vegetationspunkt des Stengels. a Peribleminitialen, b Plerominitialen, c-f Blattanlagen. (KW.)

Blättern, die meist ron schützenden Knospenschuppen (rol. \$ 18 ) umgeben sind. In analoger Weise wie bei den Laubknospen finden wir bei den Blütenknospen Vescetationspunkte mit jungen Blïtenanlasen. Auch hier sind Blumenblätter, Staubblätter und Fruchtblätter aus Wülsten und Höckern hervorgegangen.

Ähnliche Vegetationspunkte finden wir bei den Gefässkryptogamen und den Moosen vor, ja auch bei höheren Algen geht das Wachstum, den Vegetationspunkten gleich, von gewissen Stellen aus, die an der Spitze von Fäden oder am Rande von Flächen liegen.

In anatomischer Beziehung sei bemerkt, dass die Spitze der Vegetationspunkte aus ziemlich gleichartigen, parenchymatischen, dünnwandigen 
Zellen besteht, die auch als Urmeristem bezeichnet werden. Entsprechend ihrem embryonalen Zustande zeichnen sich diese Zellen durch ihre grosse Teilungsfähigkeit aus, wodurch eben das Wachstum des Laubsprosses eingeleitet wird.

Dieses Urmeristem weist bei den Phanerogamen die Initialzellen für drei zunächst entstehende Gewebeschichten auf, welche Hanstein als Dermatogen (äusserste Zelllage) Periblem (mittlere Schicht) und Plerom (Centralcylinder) bezeichnet hat (Fig. 42). Eine derartige Differenzierung kann jedoch auch ganz unterbleiben.

Bei dem Vegetationspunkt des Laubsprosses überzieht die Dermatogenschicht die Oberfläche, und da sie schon in der Jugend mit einer Cuticula bedeckt ist, dient sie wohl als Schutz. Das Periblem ist häufig reich an Luftgängen, welche den Gasaustausch erleichtern, ausserdem wird in demselben Stärke zum Verbrauch angesammelt. Die langgestreckten Pleromzellen führen dem Vegetationspunkte plastisches Material zu, das selbstverständlich bei der Zellteilung und der Entstehung neuer Zellen in erheblichem Masse verbraucht wird. Die Aus-

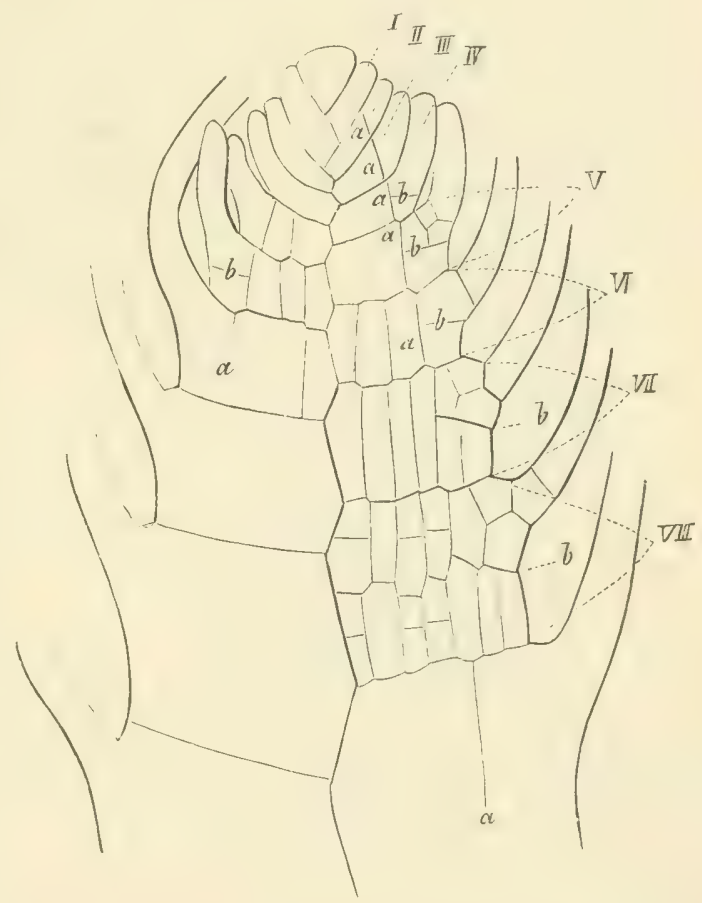

Fig. 43 .

Lägsschnitt durch die Sprosssjitze des Laubmooses Fontinalis antipyretica (n. Leitgeb).

\section{bildung dieser jungen Ge-}

webe ziclt dahin, die Zellteilung und das Wachstum am Vegetationspunlit zu unterstützen.

Bei vielen Moosen und den Pteridophyten tritt an der Spitze des Vegetationspunktes eine sog. Scheitelzelle auf (Fig. 43) d. h. sämtliche Zellen des Vegetationspunktes und des Laubsprosses lassen sich entwickelungsgeschichtlich auf diese eine Zelle zurückführen.

Bei Algen mit Spitzenwachstum haben wir Vegetationspunkte mit verschiedenem Teilungsmodus (Fig. 44 und Fig. 45).

Der Vegetationspunkt der Wurzeln (Fig. 46) ist stumpfkegelförmig, unterscheidet sich jedoch von dem der Sprosse durch das Fehlen der höckerartigen Blattanlagen. 
Die endogene Bildung der Nebenwurzeln siehe \$ 28 .

Bei den Wurzeln wird von dem Urmeristem aus nicht nur der Wurzelkörper ergänzt, sondern nach aussen zu die Wurzelhaube gebildet (Fig. 46). Die letztere entsteht aus einer besonderen Schicht,

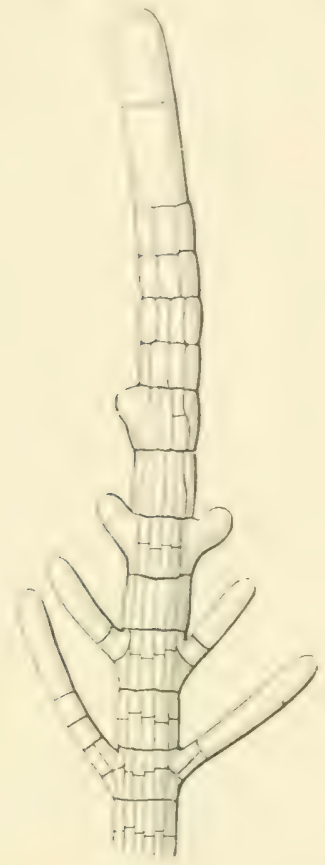

Fig. 44.

Scheitelwachstum des Thallus von Chaetopteris plumosa (n. Magnus).

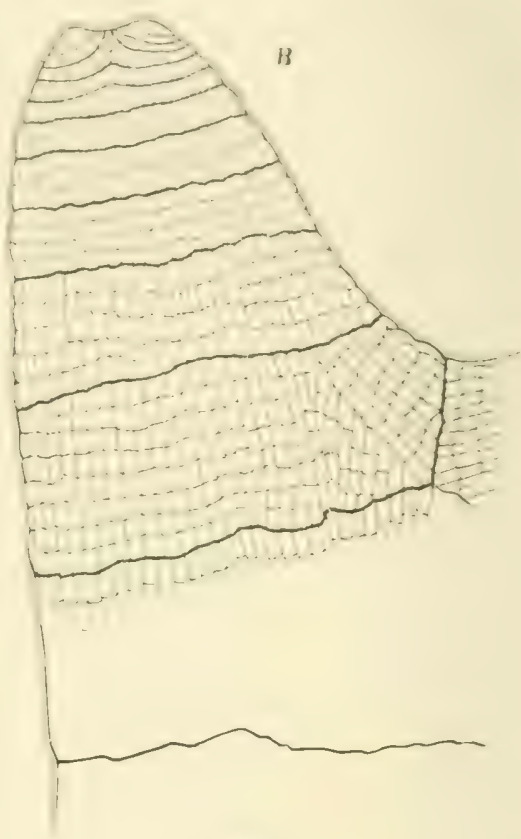

Fig. 45 .

Thallusspitze von Dictyota dichotoma, Die ersten Zellteilungen sind durch stärker gehaltene Linien markiert. (R.)

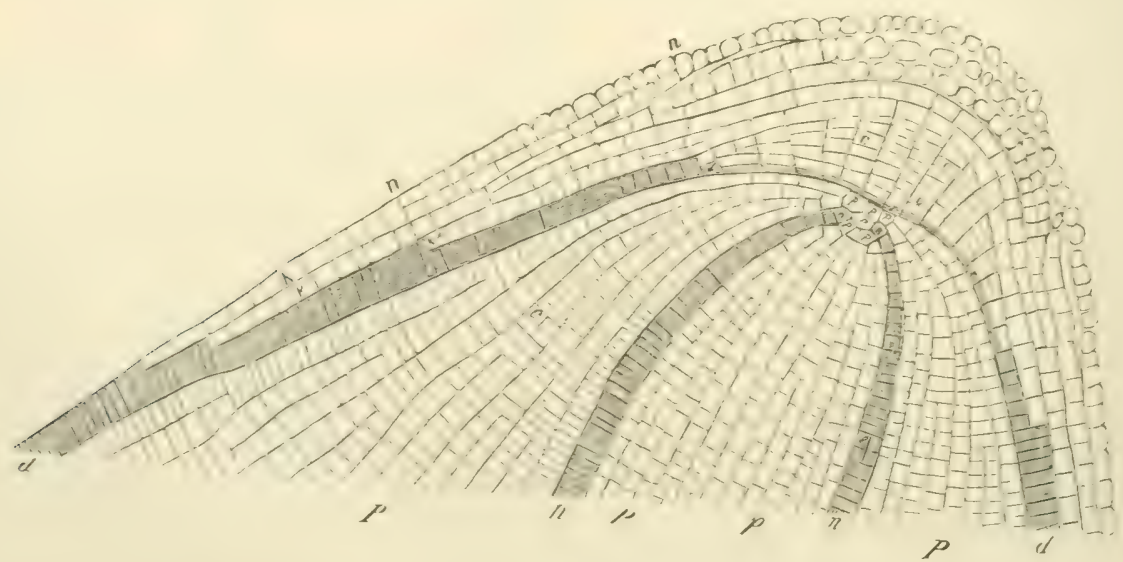

Fig. 46.

Helianthus annuus. Längsschnitt durch die Wurzelspitze. p n Plerom, P Periblem, d Dermatogen, c $\mathrm{k}$ n Wurzelhaube, aussen mit den sich ablösenden Schichten, (R.) 
der Calyptrogenschicht, welche bei den verschiedenen Pflanzen in ungleicher Weise mit den übrigen Geweben zusammenhängt.

Die Wurzelhaube dient zum Schutz für die in der Erde vorwärts dringenden Wurzeln. Die äusseren Zellschichten derselben lösen sich los, indem die Mittellamellen der Zellwände verschleimen, weshalb die Haube trotz der Neubildung am Vegetationspunkt ungefähr gleich gross bleibt (Fig. 47).

Aus dem in hervorragender Weise teilungsfähigen Urmeristem der Vegetationspunkte gehen, indem sich die einzelnen Zellen different ausbilden, die verschiedenen Gewebe hervor. Mlan bezeichnet diese Bildung durch Zellteilung als echte Gewebebildung. Dieselbe findet sich bei sämtlichen Moosen und höheren Pflanzen.

Dünnwandige Gewebe, welche aus Zellen bestehen, deren Durchmesser nach den verschiedenen Richtungen hin ungefähr gleich ist, werden als parenchymatische bezeichnet. Prosenchymatisch werden die Gewebe resp. die Zellen genannt, wenn die Zellen in einer Richtung stark verlängert sind.

Pseudoparenchym oder unechtes Gewebe entsteht durch das Aneinanderlegen einzelner ursprünglich getrennter Fäden (Fig. 48), ein Vorgang, den man namentlich bei Pilzen und Flechten häufig findet.

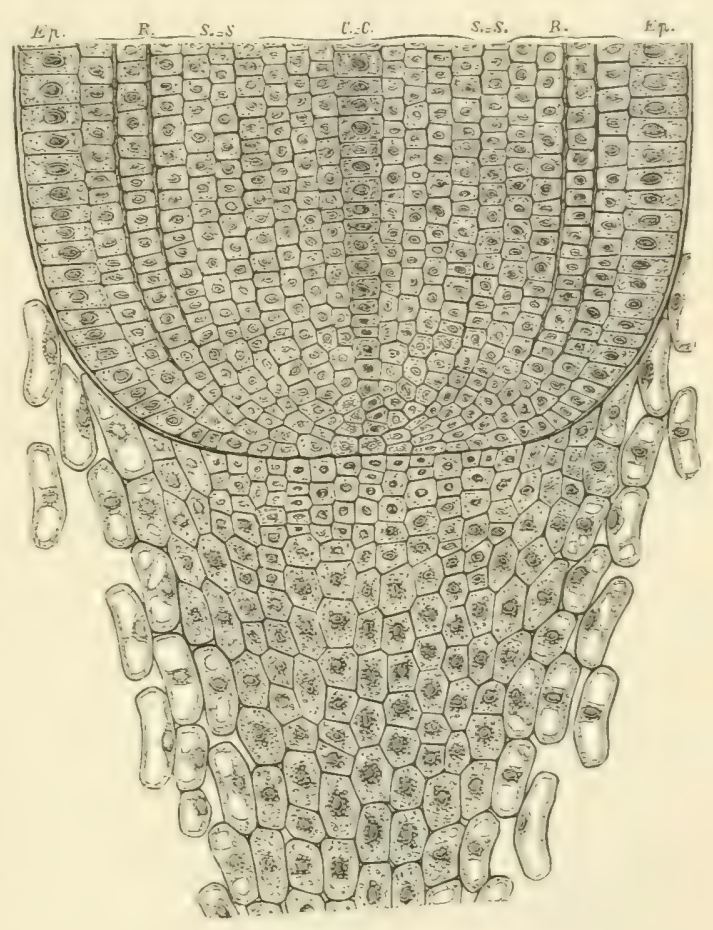

Fig. 47 .

Secale cereale. Längsschnitt durch die Wurzelspitze. C. C. Plerom, S. R. Periblem, Ep. Dermatogen, darunter die Haube. (KW.)

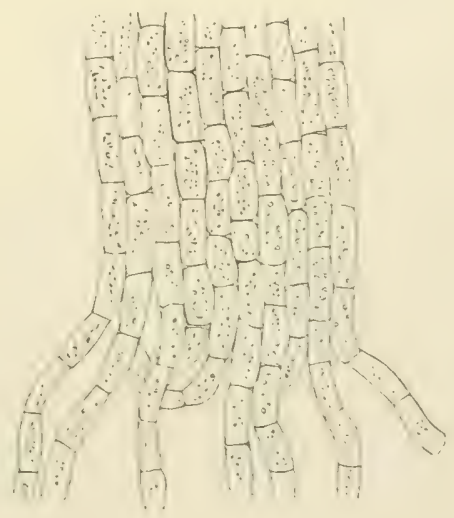

Fig. $4 \mathrm{~S}$.

Mycelfäden von Nectria cinnabarina, ein Pseudoparenchym bildend. (R.) 
L̈bergänge zu der unechten Gewebebildung finden wir atuch bei den höheren Pflanzen, indem einzelne Zellen wie z. B. Gefässe, Bastfasern und Libriformzellen zwischen andere Zellen ihres Gewebeverbandes hineinwachsen, an denselben vorbeigleitend und sie auseinanderdrängend. Krabbe hat diese Art des Vachstums als das gleitende bezeichnet. Es erinnert uns daran, dass der einzelnen Zelle cine sewisse Selbständigkeit zukommt und der anatomische Aufbau bis zu einem gewissen Grade ron dem W Vachstum der einzelnen Zellen abhängt.

\section{s. Normale und adventive Bildung von Seitenorganen.}

Aus dem im vorigen Paragraphen Gesagten erfahren wir, dass die normale Organbildung von den Vegetationspunkten ausgeht und zwar kann es sich hierbei um Verzweigung oder Neubildung handeln. Bei der Verzweigung entstehen gleichartige Organe, Seitenaxen an der Hauptaxe, Teilblätter an Blättern, Nebenwurzeln an Hauptwurzeln. Bei der Neubildung werden ungleichartige Organe, also z. B. Blätter an den Sprossaxen, Sprosse an Wurzeln etc. produziert.

Bei der normalen Verzweigung der Sprossaxen bilden sich die Seitenzweige in der Achsel von Blattorganen, den Trag-oder Stützblättern aus, welche Verzweigung man auch als die axilläre bezeichnet. Die Stellung dieser Sprosse ist demnach von der Stellung der Blätter abhängig. Teilt sich der Vegetationspunkt selbst in zwei oder mehrere neue Vegetationspunkte (rgl. Fig. 45), wie bei der Dichotomie und Polytomie, so fällt dieser Zusammenhang der nun entstandenen Zweige mit den Blättern natürlich fort.

$\mathrm{Da}$ die Bildung von Seitenwurzeln hauptsächlich in der Nähe der Encler wn radialstrahlenfoirmis ansererdneten Gefässbündeln der Wurzeln (rgl. \$2S) stattfindet, sehen wir die Seitenwurzeln häufig den einzelnen (jefisisbündelstrahlen entsprechend in Länssicihen anseordnct, ohne dass jedoch die Seitenwurzeln eine so regelmässige Verteilung aufweisen würden wie dic axillär entstehenden Laubsprosse.

Bei der normalen Verzweigung stehen die jüngsten Seitenglieder an der Spitze der sie tragenden Axe, je älter die Seitenglieder sind, desto weiter sind dieselben vom Vegetationspunkte entfernt. Man bezeichnet eine derartige Entwickelung als die akropetale. Bleiben Zonen in bestimmter Entfernung rom Vegetationspunkte noch längere Zeit bildungsund wachstumsfähig, während die oberhalb derselben liegenden Strecken ihr Wachstum eingestellt haben, so dass die basalen Teile jünger sind als die Spitzen, spricht man von einer Entwickelung in basipetaler Reihenfolge.

Im Gegensatz zur normalen Verzweigung stehen die Adventivbildungen. Die Adventivsprosse entstehen unabhängig von der Blatt- 
bildung an beliebigen Stellen der Sprossaxe, also auch nicht in bestimmter akropetaler oder basipetaler Altersfolge. Ihre Bildung wird in vielen Fällen durch Verletzungen und äussere Eingriffe hervorgerufen, kann jedoch auch ohne dieselbe vor sich gehen.

Schneiden wir einen Weidenzweig ab und stecken ihn in feuchte Erde, so wird dieser Steckling Adventivwurzeln treiben und, indem die Zweigknospen auswachsen, sich zu einer vollkommenen Pflanze ergänzen; ein auf feuchten Sand gelegtes Begonienblatt (Blattsteckling) entwickelt in grösserer Anzahl junge Adventivsprosse. Ebenso ist die sog. Wurzelbrut verschiedener Holzpflanzen eine Adventivbildung, indem bei Weisserlen, Pappeln, Ulmen, aus den flachstreichenden Wurzeln, gleichgültig ob verletzt oder unverletzt, junge Sprosse entstehen. Brombeersträuche dringen von selbst in die Erde, bewurzeln sich dort und wachsen aufs neue wieder über die Erde empor, wodurch jene schwerdurchdringbaren Brombeerdickichte entstehen. Zweige der Haselnuss können künstlich herabgebogen und mit Erde bedeckt werden, um nach Bildung von Adventivwurzeln ein dichtes Unterholz zu liefern.

Die Adventivbildungen gehen aus verschiedenartigen Geweben hervor, sie können exogen oder endogen entstehen und sind nicht immer an die in lebhafter Zellteilung befindlichen Gewebe, (Cambium, Urmeristem) gebunden. Es ist sogar bis zu einem gewissen Grade charakteristisch für Adventivbildungen, dass hierbei Zellen im Dauerzustande durch Verletzungen, durch lokale Einwirkung von Feuchtigkeit etc. in teilungsfähiges, embryonales Gewebe umgewandelt werden, welches sodann die Vegetationspunkte der neuen Organe bildet.

Von den Adventivbildungen ist das Auswachsen der sog. schlafenden Augen oder schlafenden Knospen zu unterscheiden. Es sind dies normal angelegte Knospen, welche nicht ausgewachsen, sind und dabei die Fähigkeit
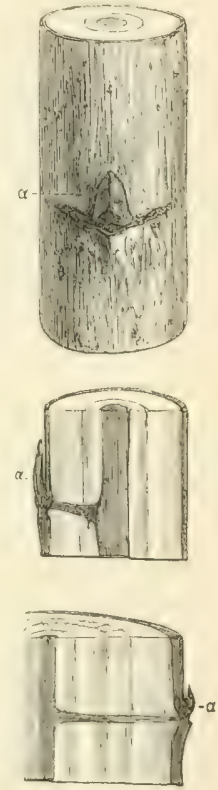

Fig. 49.

Schlafende Knospe von Salix fragilis, Aussenansicht, sowie zwei- und vierjähr. Längsschnitt. (DN.) der Weiterentwickelung behalten haben. Eine solche Knospe sehen wir in Fig. 49 a. Sie bleibt an der Oberfläche des Zweiges trotz des Dickenwachstums des letzteren: Sie verlängert sich jahrelang an der Basis um so viel, als das Dickenwachstum des betreffenden Zweiges beträgt.

Die schlafenden Knospen entwickeln sich vielfach nach Verletzungen des Stammes, sei es nun durch mechanische Beschädigung oder durch Frost und andere elementare Einwirkungen. Ausserdem wachsen die Knospen namentlich an plötzlich freigestellten Stämmen aus, welche Erscheinung als die Bildung von Wasserreisern bezeichnet wird. Die Ursache hiervon liegt in der plötzlichen Vermehrung des Lichtzutrittes und einer dementsprechend vergrösserten Nahrungszufuhr. 
Die Ausschlagsfahigkeit der einzelnen Pfanzen nach Verletzungen, welche entweder auf der Bilduns adventiver Sprosse oder der Weiterentwickelung schlafender Knospen beruht, ist sehr verschieden.

Reichlichen Stockausschlag weisen auf:

Quercus sessiliflora und pedunculata, Carpinus betulus, Ulmusarten, Acer campestre, Fraxinus excelsior in der Jugend, Castanea vesca, Alnus glutinosa und incana, Robinia Pseudacacia, Tilia grandifolia und parvifolia, Populus nigra, die Salixarten, Juglans regia, Corylus avellana (sehr tief am Wurzelstock).

Reichliche Wurzelloden bilden: Ulmusarten, Acer campestre, Alnus incana, Robinia Pseudacacia, Populus tremula.

Geringe Ausschlagsfähigkeit zeigen Fagus silvativa, Betula verrucosa, etwas besser Acer pseudoplatanus und platanoides, in allen Fällen nur Stockloden.

Die Nadelhölzer schlagen fast niemals aus, nur wenn die Stöcke mit den Wurzeln anderer Stämme verwachsen sind, treten Ausnahmen ein.

Pinus rigida und Pinus excelsa zeigen Ausschlagsvermögen.

\section{Morphologischer Aufbau der Axen und Stellung der Seitenorgane.}

Die verschiedenen Sprossaxen einer Pflanze sind zu einem Sprosssystem verkettet. Die Entwickelungseseschichte des sanzen Sprosssystems zeigt uns, auf welche Weise dasselbe aus Haupt- und

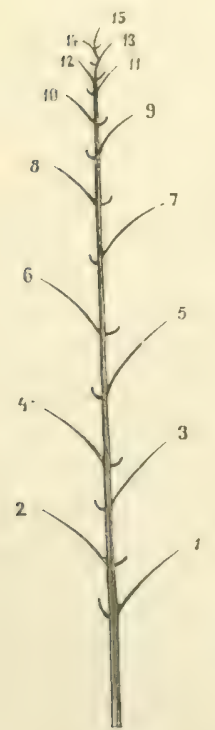

Fig. 50.

Schema eines sympodial-cymösen Aufbaues. (K.) Nebenaxen zusammengesetzt ist.

Bei der dichotomischen, dichopodialen Verzweigung (Sprossverkettung) gabelt sich der Vegetationspunkt des Organes in zwei neue, welcher Vorgang sich an den entstandenen Seitenaxen wiederholt (Fig. 45). Sind beide Äste gleich stark ausgebildet, entsteht die gabelige Dichotomie (meist nur bei gewissen Moosen und Pteridophyten, z. B. Lycopodium); wächst dagegen abwechselnd nur der linke und rechte Seitenarm weiter, so entsteht die wickelähnliche Dichotomie (Stamm von Selaginella); bei der schraubelähnlichen Dichotomie bildet sich immer nur der auf der einen Seite liegende Gabelast weiter aus (Blatt von Adiantum pedatum).

Bei der seitlichen, monopodialen Verzweigung geht der Vegetationspunkt nicht in der Bildung der Seitenaxen auf, die letzteren bilden sich vielmehr seitlich, unterhalb der Spitze. Specialfälle dieser Art der Sprossverkettung sind die racemöse und cymöse Verzweigung.

Bei der racemösen Verzweigung bildet sich die primäre 
Axe (= Hauptaxe, Mutterspross) stärker aus als die sekundären Axen (Seitenaxen, Seitensprosse), diese wieder stärker, als die an den letzteren

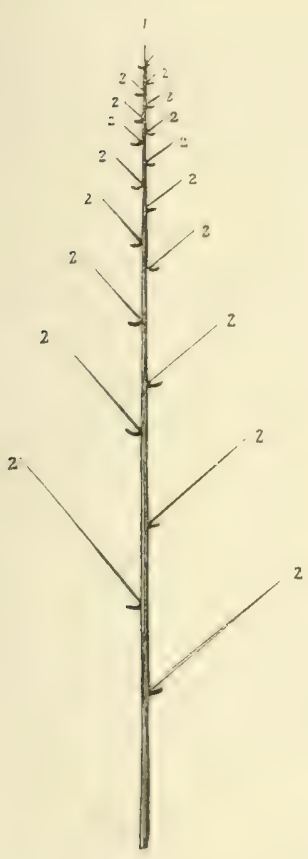

Fig. 5I.

Schema eines monopodialracemösen Aufbaues. (K.)
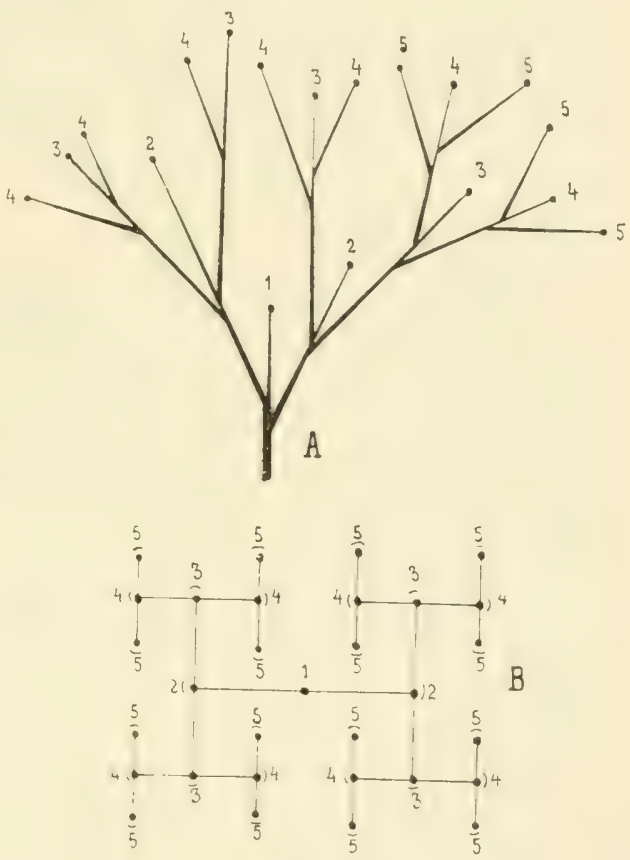

Fig. 52 .

Schema eines Dichasiums. (K.)

befindlichen tertiären Axen (vergl. Fig. 51). Diese Verzweigung ist bei den Laubsprossen der höheren Pflanzen die weitaus verbreitetste. Als eklatantes Beispiel seien hier Tanne und Fichte genannt. Von Blïtenständen gehören hierher Traube (Berberis), Ähre (Gräser), Rispe (Gräser), Dolde (Umbelliferen), Köpfchen (Compositen), Kätzchen (Amentaceen).

Bei cymöser Verzweigung wachsen die Seitenaxen stärker, als die sie tragenden Hauptaxen. Der Vegetationspunkt der letzteren wird zur Seite gedrängt,

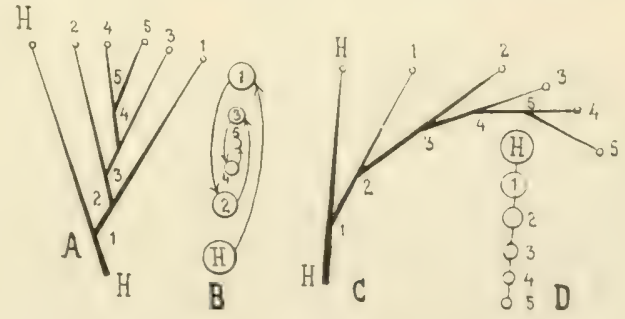

Fig. 53 .

A Aufriss, B Grundriss des Fächels; C Aufriss, D Grundriss der Sichel, H H Hauptaxe, I, 2. 3. Die Nebenaxen erster, zweiter, dritter Ordnung. (K.) in seiner Entwickelung mehr oder weniger unterdrückt. (Fig. 50.)

Auch hier sind verschiedene specielle Fälle zu unterscheiden. Bei der sog. falschen Dichotomie (Dichasium) und beim Polychasium entwickeln 
sich unterhalb des Vegetationspunktes auf gleicher Höhe zwei, resp. mehrere Äste. Beispicle von Dichasien: Zweige von Viscum, Syringa, Rhamnus cathartica (vergl. Schema in Fig. 52), eines Polychasium: die Trugdolde des Blïtenstandes von Sambucus nigra.

In anderen Fällen (Monochasien) entsteht eine Scheinaxe, indem der Seitenast, den Mutterspross zur Seite drängend, die ursprüngliche Axe scheinbar weiter fortsetzt, während die vermeintlichen Seitensprosse die abgelenkten Muttersprosse sind. Fig. 50).

Hierher gehören:

Fächel, die Verzweigungen liegen in einer Ebene, gehen abwechselnd nach rechts und links (Verzweigung von Birke und Ulme, wo die Spitze der Axe am Ende jeden Jahres abstirbt und eine Seitenknospe die Führung übernimmt. (Fig. 50 und Fig. 53 A, B.)

Sichel, die Verzweigungen liegen in einer Ebene, die Seitenaxen entwickeln sich alle nach ein und derselben Seite (Juncus bufonius, Fig. 53 C, D).

Wickel, die Verzweigungen liegen in gekreuzter Ebene, gehen abwechselnd nach rechts und links (Boragineen, Fig. 54 C).

Schraubel, die Verzweigungen liegen in gekreuzter Ebene, die Seitenaxen fallen alle nach derselben Seite (Commelinaceen, Fig. 54 D).

Entsteht eine derartige Scheinaxe aus Sprossen verschiedener Ord-

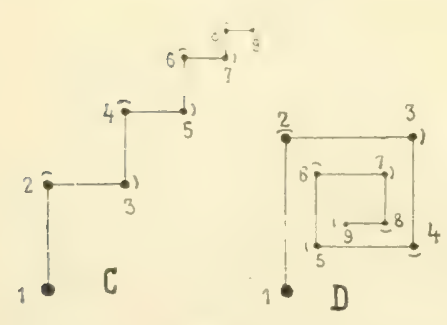

Fig. 54.

C Grundriss der Wickel. D Grundriss der Schraubeln. (K.) nung, gleichgültig ob dichotomische oder seitliche Verzweigung vorliegt, so bezeichnen wir die Sprossverkettung als ein Sympodium. ${ }^{1}$ )

Die Stellung der Blätter und der Seitenaxen kann insofern gemeinschaftlich behandelt werden, als die Seitenaxen bei der normalen Verzweigung der Phanerogamen in den Axen der Blätter entstehen.

Sind die Blätter resp. Seitenzweige an einem cylindrischen Organe gleichmässig verteilt, so sprechen wir von einer $r$ a diä ren Anordnung resp). Aufbau eines Organes. Radiär aufgebaute Organe können durch eine grössere Anzahl von schneidenden Ebenen in zwei spiegelbildlich gleiche Hälften zerlegt werden; Beispiele hierfür bieten viele kreisrunde Laubsprosse und Wurzeln der Phanerogamen, ferner die sog. regelmässigen (actinomorphen) Blüten.

Diese und andere Blattstellungsverhältnisse können schematisch durch die sog. Diagramme dargestellt werden, d. h. durch Grundrisse, bei welchen die basalen Organe die äusseren Kreise, die der Spitze am näch-

1) Sympodium und Monopodium sind keine sich ausschliessenden Gegensätze. 
sten liegenden Seitenorgane die innersten Kreise einnehmen. Fig. 55 zeigt uns das Diagramm eines radiär gebauten Organes mit gekreuzt gregenständigen Seitenorganen, Fis. 56 mit spiralig gestellten Seitenorganen.

An bilateralen oder symmetrischen Organen finden wir eine vordere und hintere, oder eine rechte und linke unter sich jeweils gleiche Seite. Diese Organe können nur durch eine oder höchstens zwei schnei-

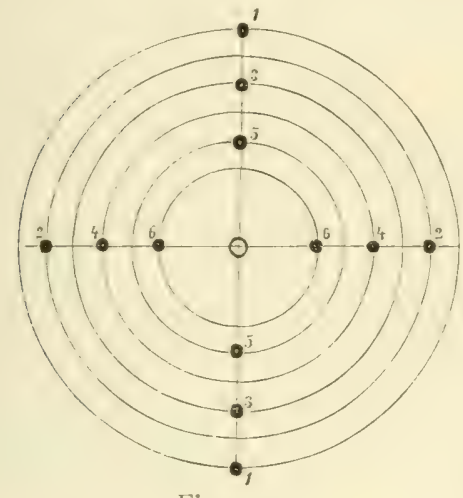

Fig. 55 .

Diagramm mit gekreuzt gegenständigen (decussierten) Seitenorganen.

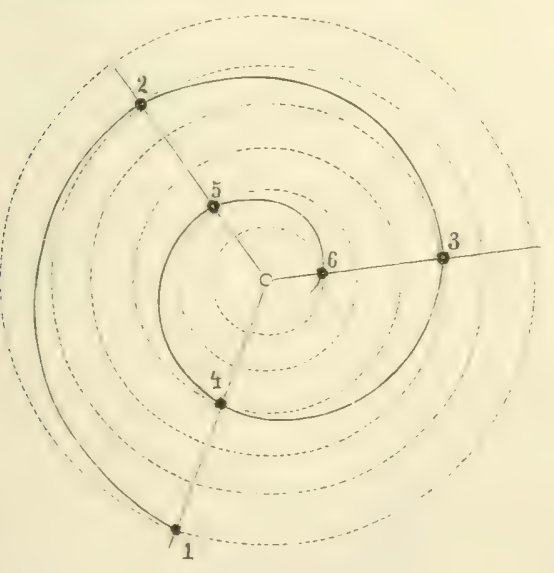

Fig. 56.

Diagramm mit spiraliger Blattstellung.

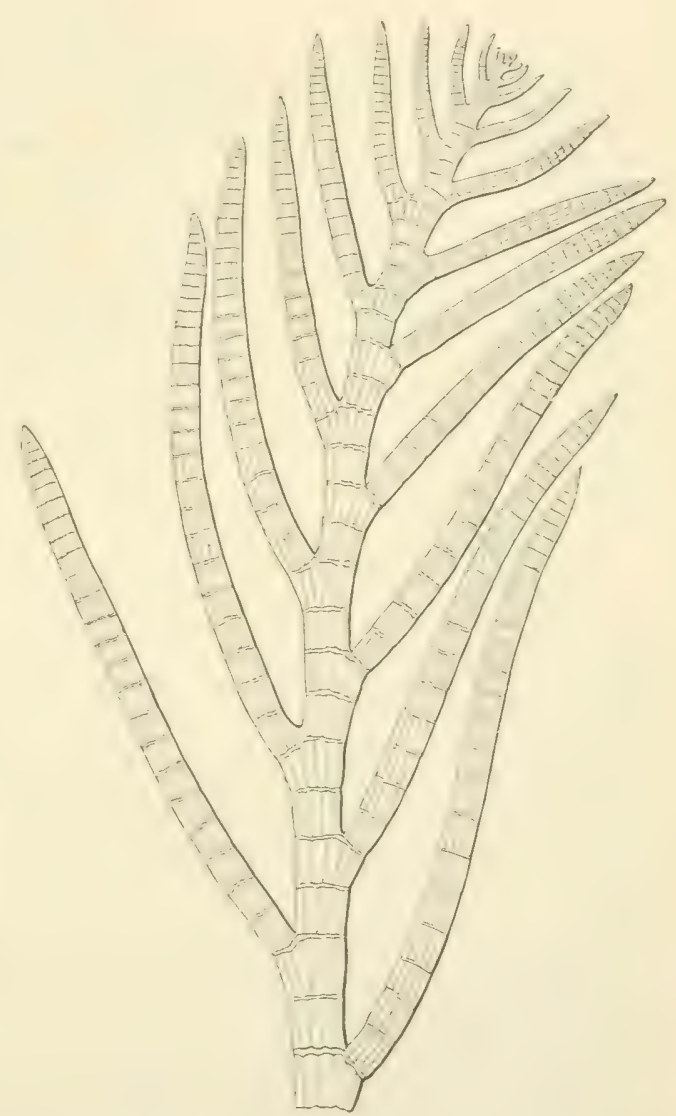

Fig. 57 .

Spross von Polysiphonia. (R.)

dende Ehenen in spiegselbildlich sleiche Hälften zerlest werden. Hierher gehören Sprosse mit zwei Reihen von Blättern oder Seitenorganen. (Fig. 57 Spross der Alge Polysiphonia und Fig. 58 dessen Diagramm.) Bilateral sind auch die zygomorphen Blüten, welche meist nur durch einen Schnitt in zwei symmetrische Hälften zerlegt werden können (Papilionaceen, Labiaten).

Die dorsiventralen Sprosse besitzen verschieden gestaltete VorderSchwarz. 
und Rücksciten (Bauch- und Rückenseiten). Dic Verzweigung kann auf der einen Seite sanz fehlen, oder die Organe auf Bauch- und Rückenseite sind verschieden. So schen wir, dass der Spross von Caulerpa (Fig. 1, S. 3) dorsiventral gebaut ist, da er auf der Unterseite wurzelartige, auf der Oberseite blattartige Organe hervorbringt.

Entstehen zwei oder mehrere Seitenorgane gleichzeitig (simultan) auf sleicher Höhe, so bezeichnen wir ihre Stellung als zwei- resp. mehrglied-

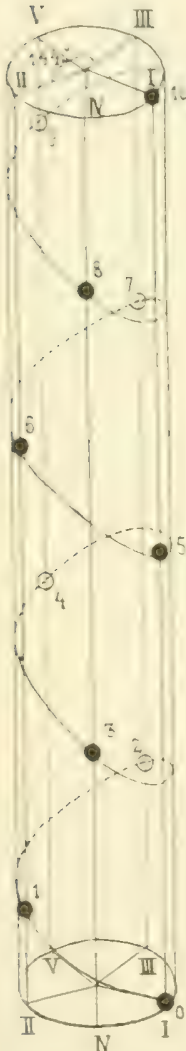

Fig. 59.

Schematische Darstellum spiralig sestellter Blätter mit $\because$ Divergenz. (I.) verbunden werden (Fig. 59). Wollen wir die Blattstellung eichnen, so bestimmen wir die Zahl der Umgänge dieser Spirale welche notwendig sind, um von einem Seitenorgan zu dem senkrecht über ihm liegenden Seitenorgan zu gelangen, und ferner die Zahl der einzelnen Seitenorgane in diesen Lmgängen. Die spiralige Stellung wird dann durch einen Bruch ausgedrückt, bei welchem der Zähler die Anzahl 
der Umgänge, der Nenner die Zahl der durchlaufenen Seitenorgane enthält.

Diesen Bruch bezeichnet man als die Divergenz.

Häufig vorkommende Divergenzen:

$1 / 2$ (Fig. 58) Blätter von Gramineen, Tilia, Fagus, Ulmus.

$1 / 3$ (Fig. 55) Blätter von Cyperaceen, Alnus, Betula.

$2 / 5$ Blätter vieler Dicotyledonen, Salix, Pirus, Ribes.

$3 / s$ Blätter von Raphanus, Brassica.

$5 / 13$ Zapfenschuppen von Pinus Strobus.

\$/21 Zapfenschuppen von Abies pectinata.

13/34 Zapfenschuppen von Pinus Laricio.

Es ist dies eine Reihe, bei welcher die Summe der beiden vorausgehenden Zähler und Nenner die nächste Divergenz ergiebt und welche noch weiter fortgesetzt werden kann.

Diese Blattstellungen sind von Schwendener mechanisch-geometrisch erklärt worden, es kommt dabei hauptsächlich auf den gegenseitigen Druck an, welchen die jungen Blatthöcker am Vegetationspunkt aufeinander ausüben, und der wieder von dem Wachstum und der Volumvergrösserung der Axe abhängt.

\section{$\$$ 18. Beschreibung der Blätter.}

Aus den Blattanlagen (vgl. S. 39) können assimilierende und nicht assimilierende Blattorgane hervorgehen. Die ersteren dienen der Ernährung der Pflanze, bei den letzteren ist diese Funktion mehr oder weniger vollständig unterdrückt, es sind rudimentäre oder metamorphosierte Organe, welche anderen Funktionen angepasst sind.1)

Bei den assimilierenden Blättern handelt es sich um die zur Kohlensäureassimilation (vgl. \$ 33) geeigneten Organe, welche sich schon äusserlich durch ihre grüne Farbe, resp. durch den Gehalt an grünem Chlorophyllfarbstoff auszeichnen. Die grosse Oberflächenentwickelung dieser Blätter ist einerseits vorteilhaft zur Aufnahme von viel Licht, das zur Assimilation notwendig ist, anderseits nützlich, wo es sich darum handelt, eine grössere Menge von Wasser zu verdampfen, welches aus dem Boden die für das Leben der Pflanze notwendigen anorganischen $\mathrm{Be}$ standteile in den Laubspross transportiert. Die Oberflächenvergrösserung wird entweder durch die flächenartige Entwickelung der Blattspreite (Laubbäume und die meisten krautigen Pflanzen) oder durch eine nadelförmige Gestalt (Nadelhölzer) erreicht.

1) Man kann die Blätter auch in Niederblätter, Laubblätter und Hochblättereinteilen. Die Niederblätter sind schuppenförmige, häufig nicht assimilierende Blätter an der Basis der Sprossaxen, die Hochblätter kommen an der Spitze der Triebe, hauptsächlich in der Blütenregion vor, sind häufig bunt gefärbt. 
Dic zur Assimilation seeisneten Lichtstrahlen werden von einem Blatte mehr oder weniser vollständig absorbiert, es muss daher eine gegenscitise Deckung möglichst vermieden werden. Dies wird erreicht teils durch die Stellung der Blätter an der Axe, teils durch Krümmungen und Längsdifferenzen der einzelnen

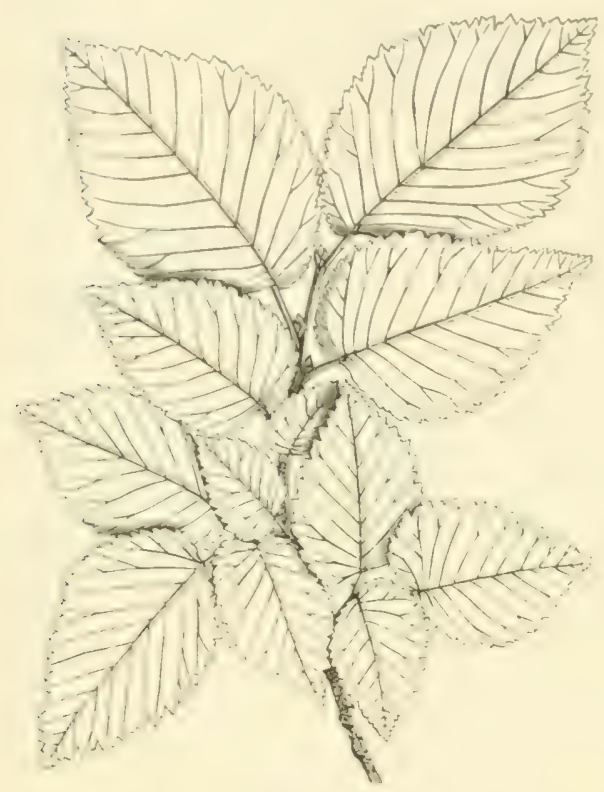

Fig. 60 .

Blattmosaik aus den ungleich grossen asymmetrischen Blättern einer Ulme (n. Kerner). Blattsticle. Auch die Ausbuchtungen und Teilungen der Blattspreite sind in dieser Bezichung rom IVichtiskit, indem durch die gegebenen Lücken eine hinreichende Lichtmense zu den wnteren Blättern gुelangsen kamn.

Bei dichtstehenden Blättern wird eine Blattmosaik gebildet, indem die kleineren Blätter manchmal auch die Nebenblätter in die Lücken zwischen die grösseren Blätter treten (vgl. Fig. 60 und Fig. 6I). Bei Verkiirzung der Sprossaxe entstehen an der Basis oft Blattrosetten (Geranium molle, Saxifragaarten etc.).

Die Beschaffenheit der Blätter bietet zu gleicher Zeit einen Schutz gegen verschiedene äussere schädliche Einwirkungen.

Gegen mechanisches Zerreissen, etwa durch heftige Windstösse, an-

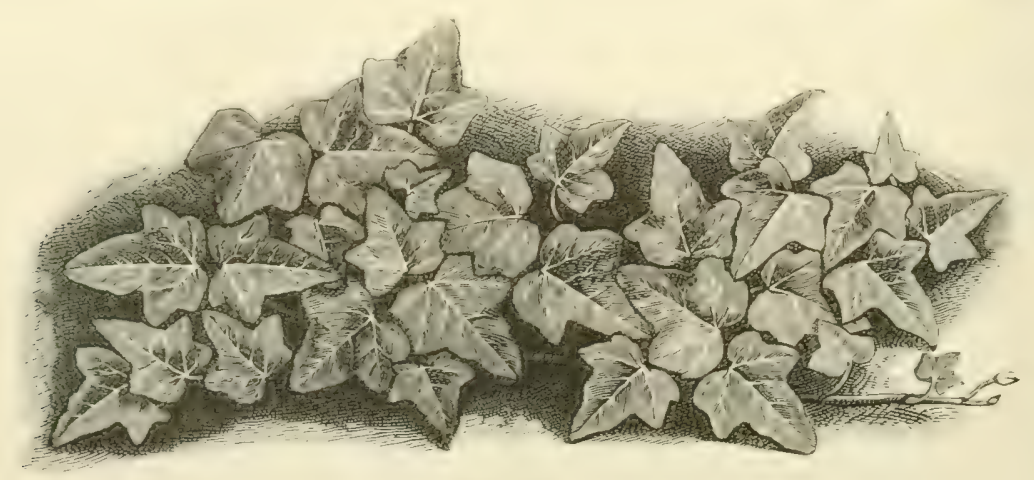

Fig. 6r.

Blattmosaik von Hedera Helix (n. Kerner).

prallenden Regen, sind die lederartigen und starren nadelförmigen Blätter durch die Ausbildung zahlreicher dickwandiger Zellen an der Peripherie 
des Blattes geschützt. Bei dünnwandigen Blättern wird einem Zerreissen durch die Nachgiebigkeit und Elasticität des Blattstiels vorgebeugt, während ein Einreissen am Rande durch sklerenchymatische Zellen, sowie durch bestimmte Verteilung der festeren Blattnerven verhindert wird.

Derbe lederartige Blätter sind meist sowohl gegen zu starke Verdunstung als gegen Kälte geschützt, wir finden sie daher vorzüglich bei immergrünen Gewächsen. Fleischige Blätter stellen eine Anpassung an einen trocknen Standort dar, indem sie selbst gewissermassen ein Wasserreservoir bilden. In seltneren Fällen werden an dünnwandigen Blättern Falten und Höhlungen gebildet, in welchen sich Wasser ansammelt, das

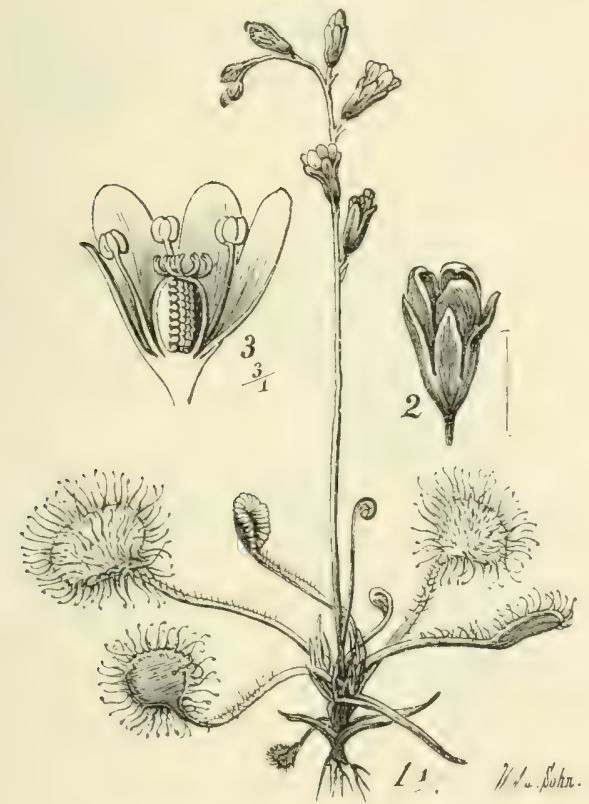

Fig. 62.

Drosera rotundifolia (W.)

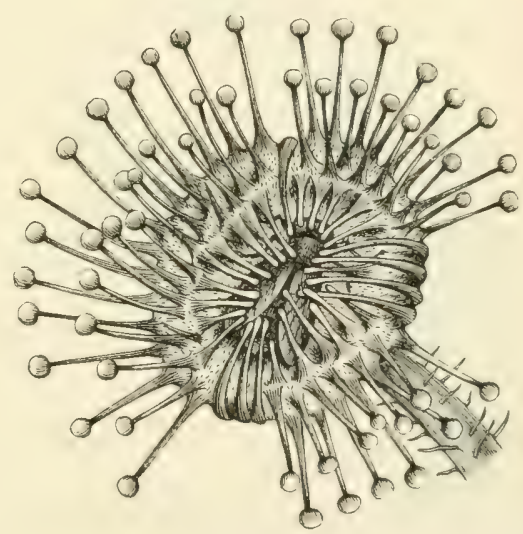

Fig. 63 .

Blatt von Drosera rotundifolia (W.)

direkt durch dünnwandige Stellen der Blätter aufgenommen wird (Dipsacus laciniatus und silvestris, Stellaria media), und eventuell auch Nährstoffe enthält.

Über die Bedeutung der Behaarung vgl. § I9.

Angriffe von Tieren werden teils durch den Gehalt an giftigen oder widerlich riechenden Stoffen (Euphorbia, Colchicum autumnale, Datura strammonium), teils durch feine Nadeln von oxalsaurem. Kalk, welche auf die Schleimhäute der Tiere reizend wirken (Oxalis acetosella) abgewehrt. Denselben Vorteil gewähren stechende Blattspitzen und stachelige Blattränder (Picea excelsa, Ilex aquifolium, Cirsium arrense, Carduus nutans). Die Scheiden assimilierender Blätter sind manchmal stark entwickelt. 
Sie können wie bei den Gräsern zugleich assimilieren und zur Festigung des Stengels beitrasen, indem sie denselben röhrenartig umhüllen. In anderen Fällen, z. B. bei Rheum, dienen sie zum Schutze der noch un(ntwickelten Bilitter, sie werelen dann später trockenhäutig und funktionslos.

Die Nebenblätter an der Basis des Blattstiels können zum Schutze der jungen Blätter in der Knospe dienen und dann abfallen (Fagus silvatica) oder erhalten bleiben und assimilieren, in geringem Grade auch die junge Achselknospe schützen (vgl. Abbildung von Salix aurita).

Die Blattorgane der insektenfressenden Pflanzen sind dem Fange der Insekten, sowie der Aufnahme organischer Nahrung besonders angepasst. Hierfür einige Beispicle.

Bei Drosera rotundifolia (Fig. 62) stehen auf einem Blatte zahlreiche I) rüsenhare (Tentakel), welche mit einem durchsichtigsen, klebrigen Köpf-

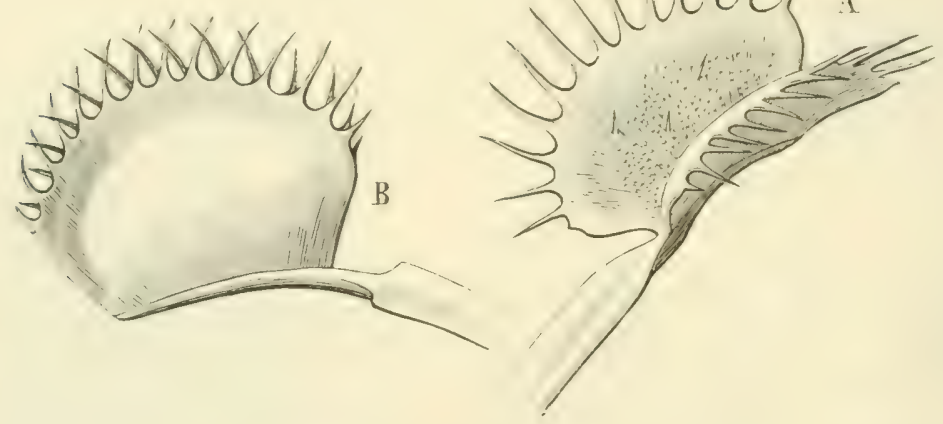

Fig. 64 .

Blätter von Dionaea muscipula. (R.)

chen versehen, zum Festhalten und späteren Aussaugen des Insekts bestimmt sind.

Durch die Ausscheidung von Säure und Ferment aus den Drüsenköpfehen wird die Aufnahme der organischen Stickstoffverbindungen bewirkt, nachdem durch allmähliches Zusammenbiegen ein möglichst vollständiger Kontakt mit dem gefangenen Insekt erzielt worden war (Figs. 63).

Bei Dionaea muscipula befinden sich auf einem besonderen Abschnitt der Blattspreite 3 reizbare Haare (Fig. 64 A). Sobald ein Insekt mit denselben in Berührung kommt, klappen die Blattspreiten schnell zusammen (Fig. $64 \mathrm{~B}$ ), durch die Wimpern des Blattrandes wird die Flucht des Insekts verhindert.

Pinsuicula rulgaris (Figs. 65 ! besitzt auf seiner Blattoberfäche mikroskopisch kleine Verdauungsdrüsen. Insekten, Reste von Samen und andere organische Stoffe werden durch Einrollen des Blattrandes festgehalten und durch die Drüsen verdaut. 
Bei Nepenthes- und Sarraceniaarten werden aus Blattteilen Kannen gebildet (Fig. 66), in welche die Insekten hineinfallen. Die Innenseite dieser Kannen ist meist mit nach abwärts gerichteten Haaren besetzt, wodurch das Herauskriechen der Insekten erschwert wird. Am Grunde der Kannen wird Verdauungsflüssigkeit ausgeschieden.

Bei Utricularia vulgaris, einer insektenfangenden Wasserpflanze, sind Blasen vorhanden, welche mit einem Ventil versehen sind, das die Insekten herein aber nicht heraus herauslässt.

Von den nicht assimilierenden Blättern seien zunächst die reduzierten Formen genannt, welche sich durch ihre geringere Grösse

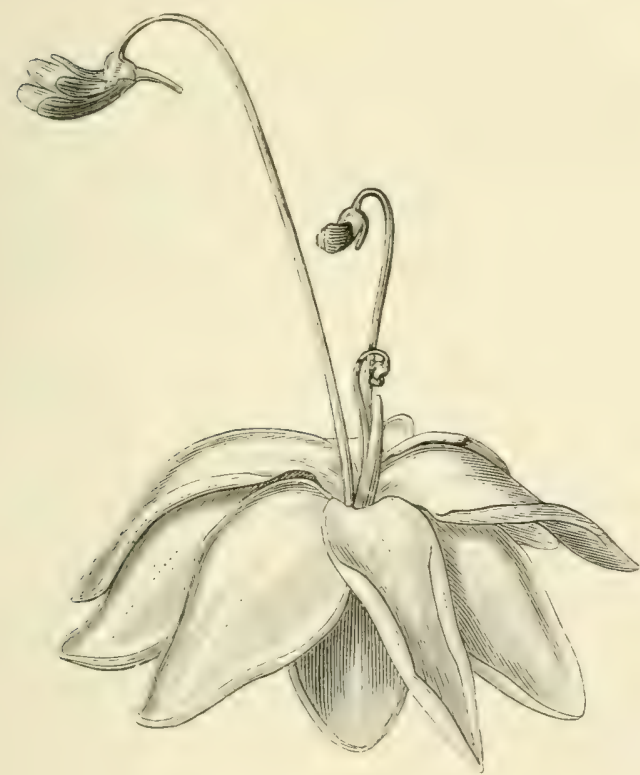

Fig. 65 .

Pinguicula vulgaris, (R.)

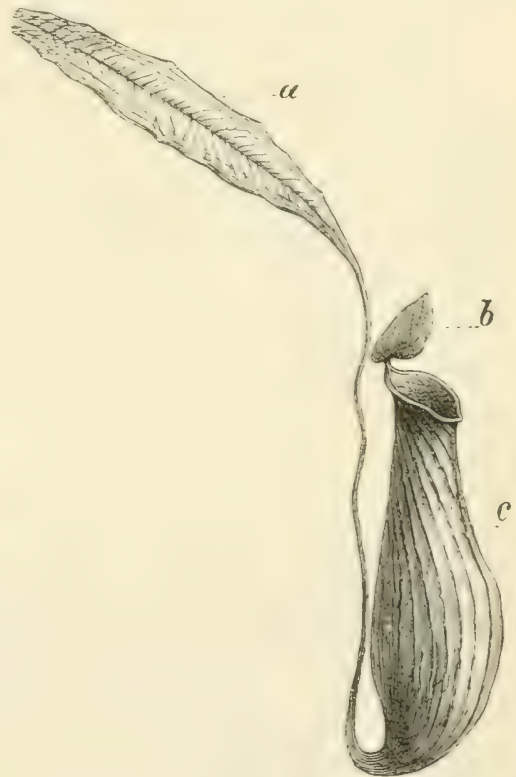

Fig. 66.

Blatt von Nepenthes destilatoria (DN.)

und meist schuppenartige Entwickelung auszeichnen. Sie sind in den meisten Fällen chlorophyllfrei, daher fahl, selblich oder bräunlich gefärbt. IVir finden solche schuppenförmige Blätter an unterirdischen Sprossaxen, z. B. an den Rhizomen von Carex arenaria (Fig. 8I), an den Ausläufern von Circaea, Adoxa u. a., welche der Ausbreitung und Erhaltung der Pflanze dienen. Mit dem Wegfall der Assimilation unterbleibt auch die Bildung assimilierender, mit grosser Oberfläche versehener Blätter. Ebenso treten die Blattsgebilde zurück, sobald die Assimilationsfunktion von der Sprossaxe übernommen wird, z. B. bei den Kaktusgewächsen und verschiedenen tropischen Wolfsmilcharten.

Aus ähnlichen Gründen entwickeln sich die Blattanlagen bei den Schmarotzergewächsen nur unvollständigs, weil bei diesen Pflanzen durch 
Aufnahme von orsanischen Verbindungen aus dem Substrat die Assimilationsfunktion der Blätter ïberflüssig wird (Monotropa Hypopitys, Lathraca Squammaria).

In einem gewissen Gegensatze zu diesen mehr oder weniger funktionslosen Blättern stehen jene Blattgebilde, welche zwar zur Assimilation untauslich sind, aber im Haushalte der Pflanze eine andere Funktion erhalten haben und einen dementsprechenden anatomischen Aufbau zeigen.

Hier sind zunächst die Knospenschuppen zu nennen, welche den jungen Blättern während des Winters zum Schutze dienen. Gewisse Teile der embryonalen Blattanlagen werden zur Knospenschuppe, während die übrigen Teile der Blattanlage nicht zur Entwickelung kommen.

Die Knospenschuppen gehen hervor:

Aus der ganzen Blattanlage (Primordialblatt vor Sonderung in Spreite und Sticl) bei den Monokotylen, Abietineen. Aus der embryonalen Blattspreite bei Syringa, Ligustrum. Aus der Anlage des Blattgrundes mit Verkrümmung der Spreite und der Nebenblätter bei Prunus, Acer, Fraxinus. Aus den Nebenblättern mit Verkïmmerung der Spreite bei Quercus, Fagus.

Diese Knospenschuppen sind infolge der Dickwandigkeit, sowie der häufigen Verkorkung ihrer Zellen schlechte Wärmeleiter, sowie undurchlässig für Wasser. Die einzelnen Schuppen schliessen sehr dicht aneinander oder werden durch Ausscheidung harziger Stoffe (Aesculus hippocastanum) verklebt. Der Schutz gegen Frost wird häufig noch durch Haare an den jungen Blättern erhöht, wodurch die letzteren wie in Watte eingewickelt erscheinen. Zur Vervollständigung des Bildes sei an dieser Stelle darauf hingewiesen, dass ein ähnlicher Schutz erreicht werden kann, indem die Knospen in die Basis des Blattstieles (Platanus), oder in das Rindengewebe des Stengels (Robinia Psendacacia, Philadelphus coronarius) versenkt werden.

Innerhalb der Blütenregion ist die Schutzfunktion der Blätter, in deren Achseln die Blüten stehen (Vorblätter, Tragblätter, Deckblätter), zumeist weniger vollkommen ausgebildet. Diese Deckblätter der Blüten nähern sich in Form und Aufbau häufig den Laubblättern. Sie können für die Pflanze von Vorteil sein, indem sie auffallende Färbungen annehmen und so die Verrichtung der Blumenblätter, die bestäubenden Insekten anzulocken, vervollständigen.

In anderen Fällen werden die Anlagen dieser Vorblätter in der Blütenresion jedreh zu entschiedenen Schutzorganen ausgebildet, sie sind schuppenförmig, chlorophyllarm und bestehen aus dickwandigen Zellen. Die Kätzchenschuplen der überwinternden männlichen Blüten von Corylus, Alnus, Betula, wie die Spelzen der Gramineen mögen als Beispiele genannt werden.

In der Blütenregion finden sich ausserdem vielfach feine, pfriemen- 
oder schúppenförmige Blätter, die gewissermassen mit der Ausbildung der Blïten in Correlation stehen. Durch die Entwickelung der Blüten wurde die Weiterausbildung der Blattanlagen gehemmt.

Aus Blattanlagen können auch dornige Gebilde hervorgehen. Bei Ulex europaeus, Berberis vulgaris geht die ganze Blattanlage in der Bildung der Dornen auf. Bei Robinia Pseudacacia, Caragana arborescens, Euphorbia splendens gehen die Dornen nur aus den Anlagen der Nebenblätter hervor. Diese Dornen sind Schutzmittel gegen Angriffe von Tieren.

Die Ranken der Cucurbitaceen, welche durch Umfassen von Stützen das Klettern des Stengels ermöglichen, gehen ebenfalls aus Blattanlagen hervor. Bei Pisum sativum, Lathyrus pratensis, Vicia cracca ist nur ein Teil des Blattes, d. h. einzelne Fiederblättchen, zu Ranken umgewandelt (vgl. $§ 43$ mechanische Reize).

Die Zwiebeln sind umgeben von dünnen, hautartigen, vertrockneten, reducierten Blättern, den Zwiebelschalen. Die letzteren umhüllen die sog. Nährblätter der Zwiebel, welche dickfleischig und zur Speicherung von Nährstoffen bestimmt sind. Die äusseren Nährblätter der meisten Zwiebeln (Allium cepa, Hyacinthus orientalis, Frittillaria imperialis) sind spreitelose Blattgebilde, während die innersten Nährblätter häufig die Scheiden der grundständigen Laubblätter sind.

\section{§ 19. Anatomie der Blätter.}

Es interessiert uns hier vor allem der innere Aufbau der assimilierenden Blätter. Wir können an denselben folgende Gewebe unterscheiden: Epidermis oder Oberhaut.

Parenchymatisches Gewebe oder Mesophyll (bestehend aus assimilierendem Parenchym und Schwammgewebe).

Gefässbündel.

Mechanische Zellen.

Harz und sekretführende Intercellularräume und Zellen.

Die Epidermis ist die äussere Zellschicht, welche Blatt und Blattstiel umgiebt. Sie schützt das unterliegende Gewebe, und dient besonders zur Regelung und Beschränkung der Wasserverdunstung. Obgleich die Epidermis in den weitaus meisten Fällen nur einschichtig ist, vermag sie die Wasserverdunstung doch sehr bedeutend herabzudrücken, da die nach aussen gerichteten Wände (Fig. 30) an den etwas älteren Blättern stark verdickt und mit der Cuticula versehen sind (vgl. S. 29). Die Seitenwände (Fig. 67) der Epidermiszellen sind oft dünn, es kann auf diese Weise ein Stoff- und Wasseraustausch zwischen den einzelnen Epidermiszellen stattfinden, ebenso eine durch lokale Erhitzung herbeigeführte zu starke Verdunstung ausgeglichen werden. In anderen Fällen sehen wir (Fig. 68) die Wand bis auf enge Tüpfel verdickt. Die Epidermis übernimmt hier 
zugleich mit dem Schutz gegen zu starke Verdunstung die weitere Funktion, die Nadeln widerstandsfahiger und fester zu machen.

Chlorophyllkïrper finden sich bei den Landpflanzen in den Oberhautzellen (abseschen von den Schliesszellen der Spaltöffnungen, siehe unten) nicht vor, indem dieselben leicht durch $2 u$ intensives Licht geschädigt werden könnten.

Da die cutinisierten Epidermiszellen Wasserdampf nur sehr wenig durchlassen, sind für die Abgabe einer grösseren Menge von Wasserdampf
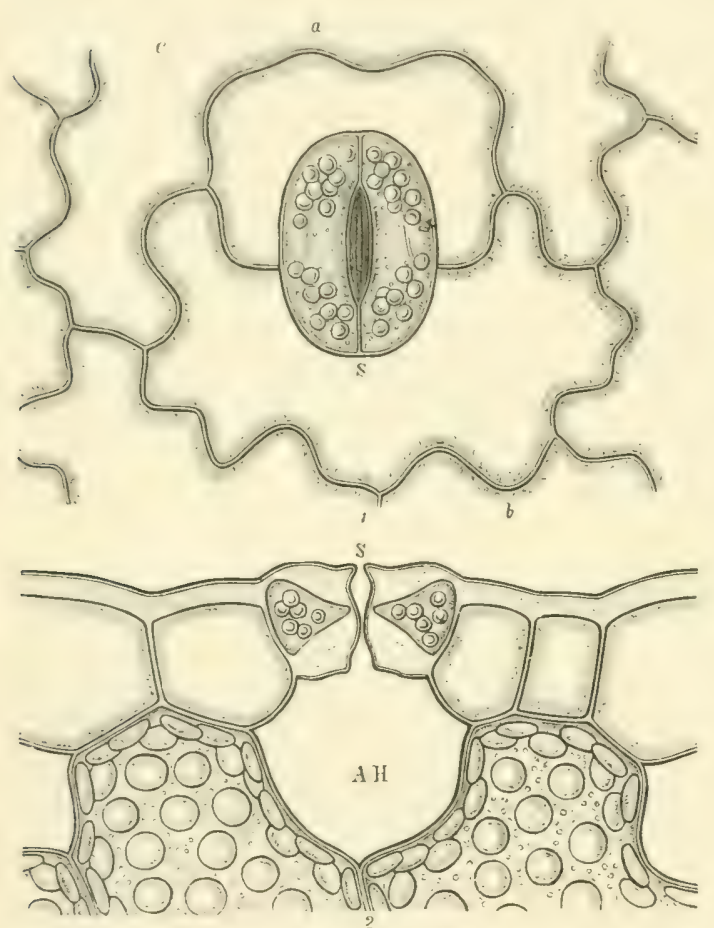

Fig. 67 .

Thymus Serpyllum. 1. Epidermis und Spaltöffnung von der Fläche gesehen. 2. Dasselbe im Querschnitt, unter der Epridermis Teile von zwei Chloruphyllkörper führenden Zellen. (KIV.) (vgl. \$ 37) Durchtrittsstellen in der Epidermis notwendig. Diese sind gegeben durch die sog. Spaltöffnungen (Stomata) der Epidermis, welche zu gleicher Zeit innerhalb gewisser Grenzen die Wasserverdunstung regulieren. Zwischen zwei meist halbmondförmigen Zellen, den Schliesszellen, befindet sich ein Spalt, der Porus (Fig. $67 \mathrm{~s})$, welcher in einen grösseren Intercellularraum, die sog.Atemhöhle (A H), mündet. Diese Atemhöhle steht mit den übrigen Intercellularräumen des Blattes in Verbindung, die letzteren enthalten Luft und Wasserdampf, welcher von den inneren Zellen ausgeschieden, durch den Porus der Spaltöffnungen entweicht. Da der Spalt sich durch Formveränderung der Schliesszellen erweitern oder ganz schliessen kann, wird die Wasserabgabe durch die Thätishleit der Schliesszellen erleichtert oder sehr bedeutend herabsedrücht werden. Ein Verschluss des Porus tritt ein, sobald die Turgescenz in den Zellen des Blattes und auch in den Schliesszellen bis zu einem gewissen Grade abnimmt, d. h. bevor noch das Blatt zu welken beginnt. Das von den Wurzeln zugeführte Wasser kann nach Verschluss des Porus zur Sättigung der Zellen verwendet werden ohne durch Transpiration verloren zu gehen.

Die Spaltöffnungen sind zwar sehr klein, dafür aber in grosser Menge 
vorhanden, oft IOO-300 auf den Quadratmillimeter Blattfläche, sodass sie eine hinreichende Wirksamkeit entfalten können. Bei Pflanzen mit geringerer Transpirationsgrösse, die einem trockneren Standorte angepasst sind, in hervorragender Weise bei Steppenpflanzen, sehen wir an den häufig

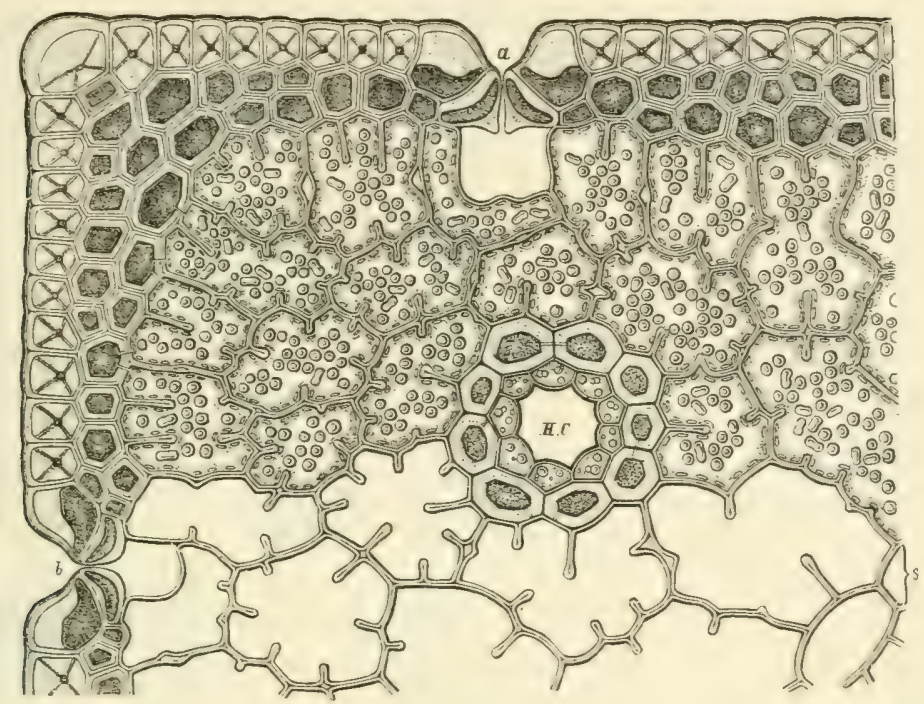

Fig. 68.

Querschnitt durch den Teil einer Nadel von Pinus Laricio. (KW.)

lederartigen, starken Blättern und Nadeln die Schliesszellen durch das Wachstum der benachbarten Epidermiszellen nach innen gedrängt, der Porus mündet dann nach aussen in einen sog. Vorhof (vgl. Fig. 68 a, b), der die Schliesszellen vor zu grosser Turgorverminderung schützt, wodurch ihre regelmässige Funktion leicht gestört werden könnte.

Den Spaltöffnungen reihen sich die Wasserspalten an, welche wir an den Blättern einiger Pflanzen (Fuchsia globosa, Saxifragaarten) finden und die zur Ausscheidung von Wassertropfen dienen. Es sind Spalten in der Epidermis (Fig. 69), die einen Intercellularraum abschliessen, an welchen Gefässe und ein stark wasserhaltiges Parenchym grenzen. Bei manchen Gräsern (Triticum vulgare, Zea Mais) wird das Wasser durch einfache Risse der

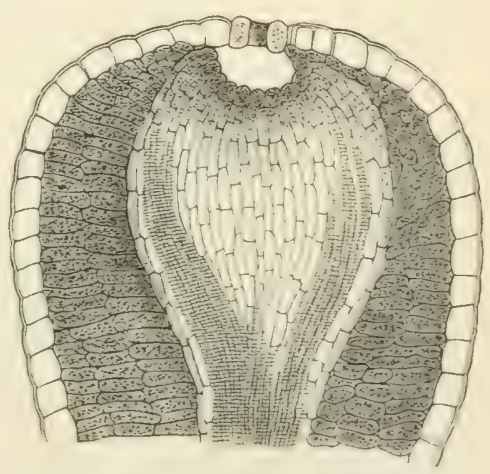

Fig. 69.

Längsschnitt durch die Spitze eines Blattzahns von Fuchsia globosa. (R.) Epidermis ausgeschieden.

Aus Epidermiszellen gehen die $\mathrm{Ha}$ are (Trichome) hervor, denen 
sich die Emerenzen anschliessen, an deren Bildung nicht nur die Epidermiszellen, sondern auch das darunter befindliche parenchymatische Gewebe teilnimmt. Während die Haare meist feine, oft hinfällige Gebilde sind, erreichen die Emergenzen eine derbere Gestalt, wofür die Stacheln der Rosen als Beispiel angeführt sein mögen.

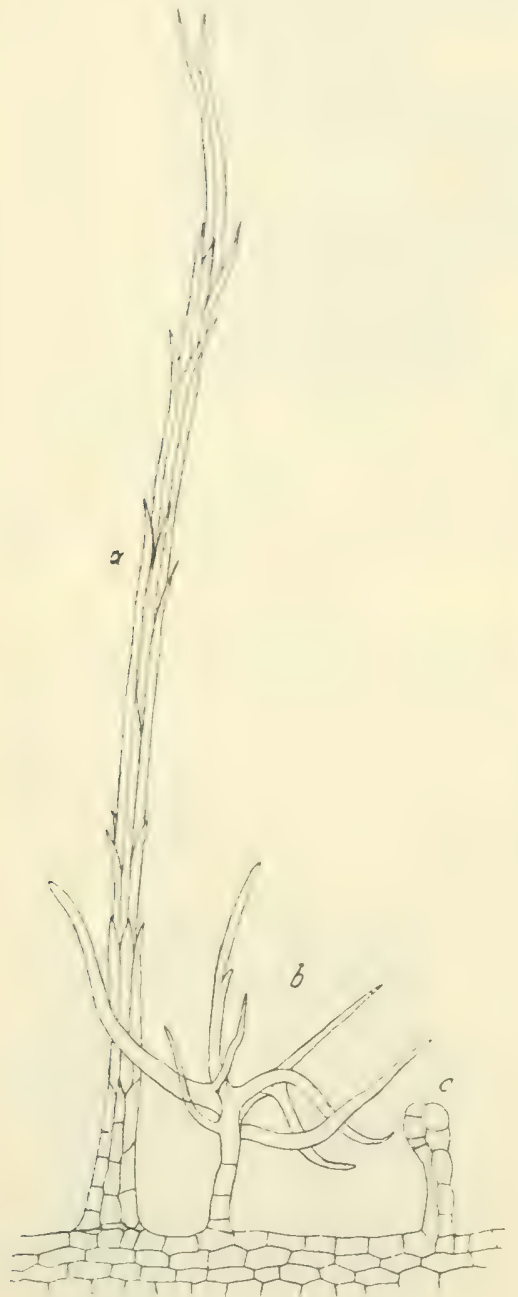

Fig 71.

Verschiedene Haarformen des Blattes von Hieracium piliferum (n. De Bary).
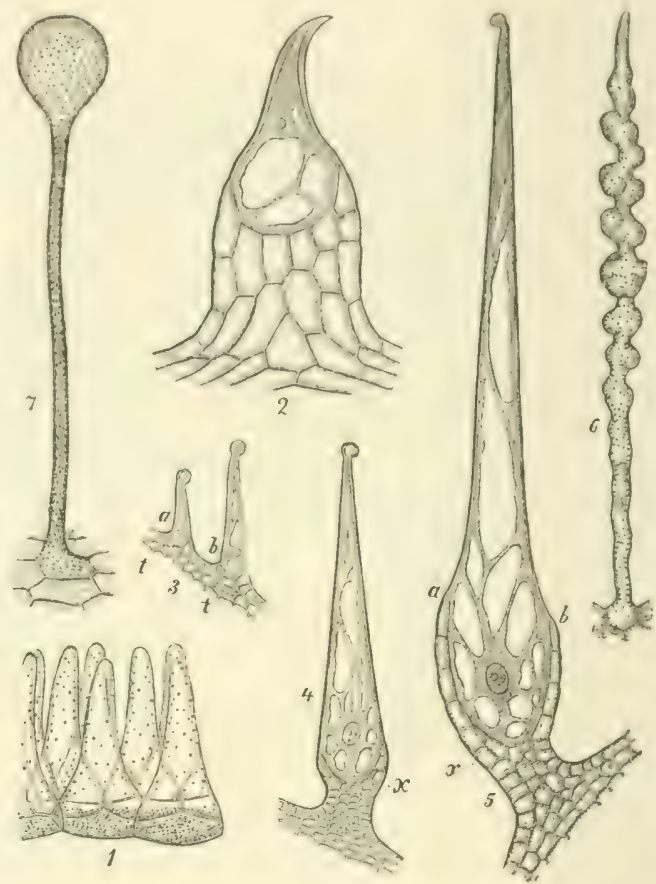

Fis. 70.

Verschiedene Haarformen. I. Aus dem Schlund der Blumenkrone von Primula chinensis. 2. Vom Stengel von Rubia tinctorum. 3-5. Brennhaare von Urtica. 6. Haar aus der Blüte von Viola altaica. 7. Dsgl. von Antirrhinum. (KW.)

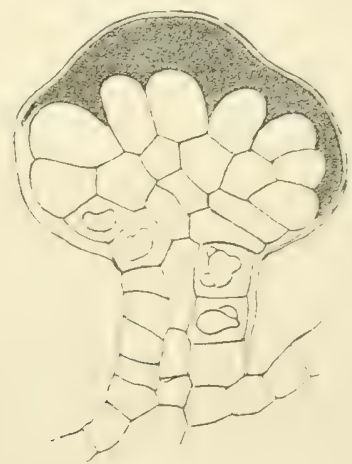

Fig. 72.

Drüsenhaar von Ribes rubrum (n. Hanstein).

Die Form der Haare ist eine ausserordentlich mannigfaltige, es gilt dies sowohl für die Haare an Blättern, als an Axen und Blütenteilen 
(vgl. Fig. 70 und Fig. 7 I). Sie schützen die betreffenden Pflanzenteile vor zu starker Verdunstung, Ausstrahlung resp. Abkühlung, eventuell auch vor zu intensiver Beleuchtung, indem sie einem dichten Filze gleich die betreffenden Pflanzenteile einhüllen.

Eine besondere Form stellen die Drüsenhaare dar. Durch die Absonderung eines Sekretes, das die jungen Pflanzenteile umfliesst, vervollständigen sie den Schutz gegen äussere schädliche Einflüsse. Als Beispiel seien die Drüsenhaare an der Knospe von Ribes rubrum angeführt, (Fig. 72), bei welchen sich zwischen Cuticula und Zellwand das

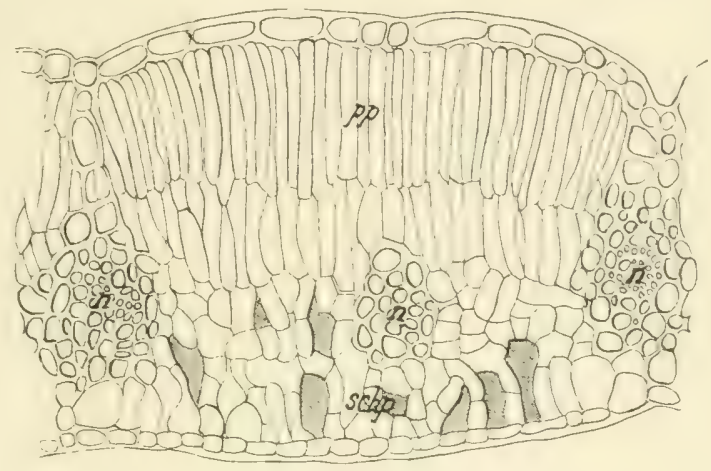

Fig. 73 .

Querschnitt durch ein in der Sonne gewachsenes Buchenblatt (n. Stahl). Sekret in grösserer Menge anhäuft und durch Zerreissen der Cuticula frei wird. Ähnliche Drüsen-

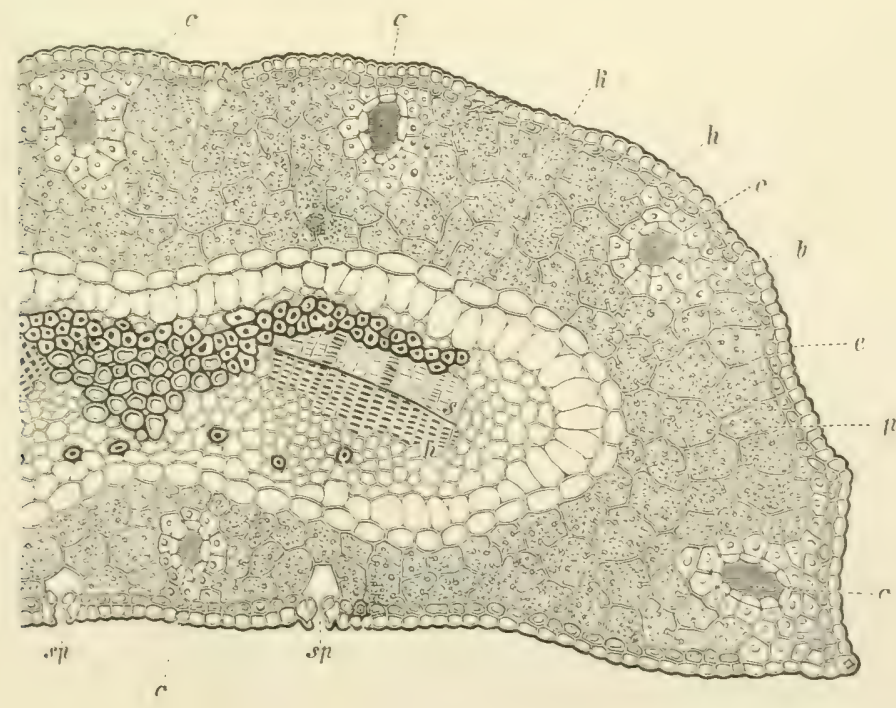

Fig. 74 .

Querschnitt durch eine Nadel von Pinus silvestris. h Holzteil, s Siebteil der Gefässbündel, p Assimilationsparenchym, o Harzgänge, $k$ Parenchymscheide um die Gefässbündel, e Epidermis. (Nach Tschirch.)

haare finden wir bei den Laubknospen des Flieders, der Rosskastanie, an der Zweigepidermis der Birke. 
Als Schutzmittel gegen Verletzungen durch Tiere dienen viele scharfe, spitze Haargebilde, denen sich auch dic Brennhaare der Brennnessel anreihen, welche mit einem bei Berührung leicht abbrechenden Köpfchen versehen sind (Fig. 70, 3-5), nach dessen Entfernung aus dem Haare sich in die kleine Wunde, die durch die zurückbleibende Spitze entstanden ist, ein scharfes Sekret ergiesst.

Als Mesophyll bezeichnet man das zwischen den Blattnerven befindliche, dünnwandige Gewebe. Die Zellen desselben sind entweder chlorophyllhaltig oder nicht. Die chlorophyllhaltigen Zellen dienen zur Assimilation und weisen sehr häufig eine bestimmte Form auf; sie sind dann langgestreckt, stehen pallisadenförmig nebeneinander (Fig. $73 \mathrm{pp}$ ) und werden deshalb als Pallisadenzellen bezcichnet.

Das chlorophyllführende Gewebe ist entweder centrisch angeordnet, d. h. an allen Seiten des Blattes gleichmässig verteilt, wie bei nadelförmigen oder allseitig beleuchteten Blättern (z. B. bei Pinus silvestris Fig. 74, Yucca filamentosa, Iris, Ranunculus aquatilis) oder es macht sich ein Unterschied zwischen Ober- und Unterseite geltend, wobei die dem Lichte zusewendete Site eine grössere. Ilenge won chlorephyllhaltigen Zellen besitzt, während die Schattenseite nur wenig oder gar kein Chlorophyll aufweist. Diese Anordnung finden wir in der Regel bei den flächenartig ausgebreiteten Laubblättern. Indem die Längsaxe der Pallisadenzellen auf der Blattfläche senkrecht steht und die Chlorophyllkörper an die Längswände rücken, wird eine geeignete Beleuchtung der Chlorophyllkörper erzielt, ohne dass die inneren von den äusseren volllständig beschattet und dadurch in ihrer Funktion gestört würden. Durch die Schmalheit der Pallisaden im Zusammenhang mit ihrer grossen Anzahl wird eine grosse Wandfläche zur Placierung der Chlorophyllkörper gewonnen, ein Vorteil, der bei isodiametrischen Zellen durch die Bildung von Zellwandfalten erreicht wird (Fig. 68, Nadel von Pinus Laricio).

Die Ableitung der durch die Assimilation producierten Stoffe wird durch die Dünnwandigkeit der Zellen und durch die Hinneigung und direkte Verbindung der Pallisaden zu den Leitungsbahnen, d. h. den Blattnerven begünstigt.

Unter dem assimilierenden Gewebe liegen Zellen, zwischen welchen sich grössere Intercellularräume (vgl. Fig. 73, die dunklen punktierten Stellen) befinden, weshalb man diesem Gewebe den Namen des Schwammparenchyms beilegt. Es dient einerseits dazu, den Assimilationszellen kohlensäurehaltige Luft zuzuführen, anderseits zur Aufnahme und Ableitung des Wasserdampfes, welcher von den Zellen ausgeschieden wird. Die Zellen sind chlorophyllfrei oder doch nur mit geringen Ilengen ron Chlorophyllkörpern versehen, sie können bei bestimmten Pflanzen auch ganz fehlen, in welchem Falle das Assimilationsparenchym reicher an Intercellularräumen ist. 
Die Gefässbündel des Blattes sind schon äusserlich als Blattnerven (Adern, Rippen) sichtbar, wobei jedoch zu bemerken ist, dass die stärkeren Blattrippen sowie der Blattstiel oft eine grössere Anzahl von Gefässbündeln enthalten. Dieselben dienen in erster Linie zur Leitung der verschiedenen Nahrungsstoffe der Pflanze, seien es nun Assimilationsprodukte, plastisches Material, oder anorganische Stoffe und Wasser. Ausserdem bilden die Blattnerven ein Gerüst, welches die mechanische Festigung der Blätter unterstützt, dem Einreissen und der Formveränderung der Blätter entgegen wirkt. Die Verteilung der Blattnerven entspricht beiden Funktionen in vorteilhafter Weise, die mechanisch stärkeren Blattrippen bilden zugleich die Hauptleitungskanäle, welche einerseits mit den feineren Endigungen der Blattnerven, welche alle Mesophyllteile durchziehen, anderseits durch den Blattstiel mit den Gefässbündeln der Sprossaxe in kontinuierlicher Verbindung stehen. Bei den Dicotylen finden wir meist zwischen Primärnerven (Mittelrippe) und Sekundärnerven (grössern Seitenrippen) ein feineres Netz von Gefässen ausgespannt, während bei den Nonocotylen die Nerven in der Regel parallel oder bogig von der Basis zur Blattspitze laufen. Bei den feineren Blättern der Nadelhölzer finden wir häufig (vgl. Fig. 74) nur zwei central verlaufende Gefässbündel.

Die Gefässbündel ${ }^{1}$ ) sind in den Blättern wie im Stamme aus den Elementen des Xylems (Holzteils) und Phloëms (Bastteils) zusammengesetzt, die, der Dicke der Blattnerven entsprechend, in verschiedener Anzahl zusammentreten. Diese Teile sind zumeist von einem chlorophyllfreien oder doch chlorophyllarmen grosszelligen Parenchym umgeben, sodass die Gefässbündel in der Mitte des Blattquerschnittes verlaufen.

Zur mechanischen Festigung der Blätter tragen verschiedene Faktoren bei. Die dickwandigen mechanischen Zellen, die Epidermis, die Gefässbündel und der Turgor der dünnwandigen Parenchymzellen. Dass der letztere nicht unwesentlich ist, sehen wir an dem Collabieren welkender, d. h. nicht mehr turgescenter Blätter. Das turgescente Parenchym wirkt als Schwellgewebe, welches die Blätter ausgebreitet erhält. Aus der Elasticität der Epidermis und mechanischen Zellen in Verbindung mit dem Turgor der Parenchymzellen resultiert eine Gewebespannung, welche, abgesehen von lederartigen Blättern notwendig ist, um die Blattfäche ausgespannt zu erhalten. Eine Verstärkung wird durch die derberen Blattrippen sewonnen. Die Widerstandsfähiskeit der Epidermis wird nicht selten durch das sog. Hypoderma erhöht, d. h. durch Gewebeschichten mehr oder weniger derbwandiger chlorophyllfreier Zellen, die unmittelbar unter der Epidermis liegen. Eine weitere Verstärkung (vgl. Fig. 85) bieten die Stränge mechanischer Zellen (Collenchym- und Sklerenchymzelleni welche

1) Das Nähere vgl. $§ 21$, Xylem und Phloëm der Sprossaxen, sowie Fig. 93. 
häufies über den Gefissbiundeln liesen und auf dem Querschnitt die Form von Trägern (I) annchmen, wobei die zwischen den beiden Gurtungen liegende Fïllung meist durch die Gefaissbündel oder durch Parenchymgewebe hergestellt ist. Es wird hierdurch eine srössere Festigleit gegen Druck und Zus erreicht und in Verbindung mit den zahlreichen Gefassbïndeln eine Querschnittsveränderung des Blattes, eine schädliche Verschicbung und Dehnung des mechanisch schwächeren Gewebes verhindert. Ausserdem kann der Blattrand durch dickwandige Zellen vor dem Zerreissen geschützt sein.

Harzgänge, Milchsaftbehälter wic bei der Sprossaxe (vgl. \$2I).

Bei schuppenförmigen Blättern ist das Chlorophyllparenchym reduciert und dementsprechend auch die zur Ableitung von Assimilationsstoffen

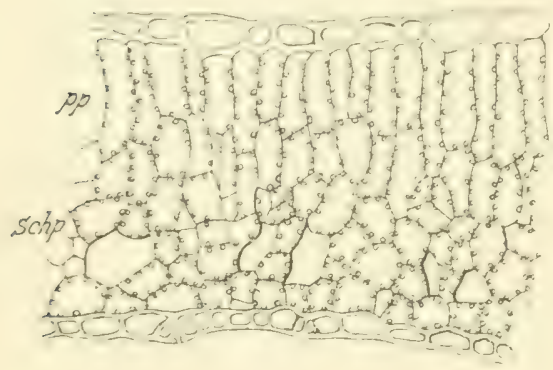

Fig. 75 .

Querschnitt durch ein Buchenblatt aus halbschattiger Lage. pp Pallisadenzellen, schp Schwammparenchym (n. Stahl).

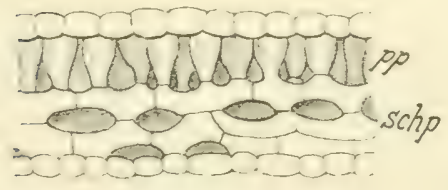

Fig. 76.

Querschnitt durch ein Buchenblatt von sehr schattigem Standort (n. Stahi). bestimmten Gefässbündel auf Stränge von geringerem Umfang beschränkt. An Knospenschuppen sind die Zellwände vielfach stark verdickt, eventuell auch verkorkt, die Sklerenchymzellen treten stark in den Vordergrund, was mit der Schutzfunktion dieser Gebilde zusammenhängt.

Eine Reduktion des Blattgewebes findet auch bei geringer Beleuchtungsintensität statt, was durch die Figuren 73,75 und 76 veranschaulicht wird. Die ganze Blattmasse nimmt ab, die Pallisaden werden in weniger typischer Weise ausgebildet, die Blattnerven zeigen nur schwache Gefässbündelstränge. Da ausserdem auch die Knospen in dichtem Bestande an beschatteten Ästen kleiner bleiben, die Zahl der Blattanlagen demnach wohl eine geringere ist, so wird sich bei plötzlicher Lichtstellung von Beständen nicht unmittelbar ein der vermehrten Lichtintensität entsprechendes Wachstum einstellen.

Die herbstliche Verfärbung der Blätter wurde schon S. I5 berührt. Die Zersetzung des Chlorophylls, sowie die Ansammlung von Farbstoff im Zellsaft wird durch Frost begünstigt. Violettrote Keimlinge von Pinus silvestris können unter günstigen Bedingungen im Frühjahr wieder ergrünen. Sind dieselben gelbrot, so ist von einer Verpflanzung abzuraten.

Bei dem Abfall der Blätter perennierender Pflanzen entsteht 
an der Basis des Blattstiels eine schmale Trennungsschicht, deren Zellen anschwellen, sich abrunden, und sich durch Lösung der Mittellamelle der Zellwände voneinander trennen (Fig. 7\%). Unter der Trennungsschicht wird die Wunde durch Kork abgeschlossen. Bei manchen Bäumen (Ahorn,

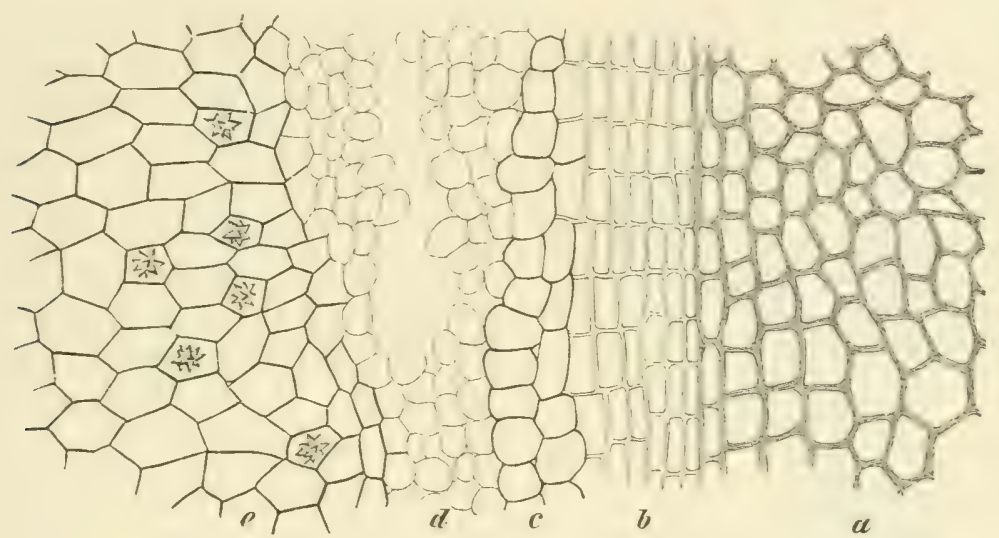

Fig. 77.

Längsschnitt durch die herbstliche Trennungsschicht (d) des Blattes von Aesculus Hippocastanum. a Rindenparenchym des Zweiges, b Korkschicht, c und e Blattstielparenchym. (DN.)

Nussbaum u. a.) bildet sich bei Frost innerhalb der Trennungsschicht Eis, welches einen plötzlichen Abfall des Blattes bewirken kann.

\section{Beschreibung der Sprossaxen.}

Die Sprossaxe (Stengel, Stamm) funktioniert vor allem als Träger der Blätter, sowie der Blüten und Früchte, sie führt die Assimilationsorgane dem Lichte zu. Ausserdem dienen die Sprossaxen zur Fortleitung und eventuell auch zur Speicherung von Nahrungsstoffen, während die Assimilationsfunktion mit Ausnahme von jenen Fällen, wo die Blätter fehlen (z. B. bei Kaktusgewächsen), zurücktritt.

Gemäss der Anpassung an eine specielle Funktion kann die Sprossaxe in bestimmter Weise modificiert werden und von der bekannten typischen Form abweichen.

An den Sprossaxen wird jede Querscheibe, an welcher ein oder mehrere Blätter inserirt sind, als Knoten (nodus) bezeichnet, das zwischen zwei aufeinander folgenden Knoten liegende Stück als Internodium oder Stengelglied. Dem grösseren oder geringeren Abstande der Blätter entsprechend bezeichnet man die Internodien als gestreckt oder verkürzt 
(gestaucht). Relativ lange Internodien bieten z. B. die Schäfte von Scirpus lacustris, Juncus conglomeratus, wie denn auch der Blütenschaft von Leontodon Taraxacum ein cinziges Internodium darstellt. In der Regel sind die Sprossaxen jedoch aus zahlreichen Internodien zusammengesetzt.

Bei der Betrachtung der typischen oberirdischen Sprossaxen haben wir zunächst jene Formen zu betrachten, welche stark genug sind, das ganze Gewicht der Blattmasse und Zweige zu tragen, wozu selbstverständlich eine grosse Festigkeit notwendig ist. Die Axen werden oft ungleichmässig belastet, bei den Bewegungen durch den Wind wird ihre Festigkeit in verschiedenen Richtungen in Anspruch genommen, eine rundlichwalzise, oder liegelfömige Gestalt wird diesen mechanischen Anforderungen am besten entsprechen. Der sich vermehrenden Blattmasse gemäss werden die Sprossaxen im Verlaufe der Vegetation dicker und stärker.

Ist die Axe zu schwach, um das Gewicht der Blätter zu tragen, wird der Stengel sich durch Umwinden einer Stütze (Phaseolus, Convolvulus, Humulus) emporarbeiten, oder durch Ranken (vgl. S. 57 und 70) an anderen Pfanzen oder leblosen Gegenständen festgehalten werden (Bryonia dioica, Ampelopsis hederacea, Vicia cracca). Bei gewissen Wasserpflanzen (z. B. Ranunculus aquatilis, Potamogeton crispus) wird nicht das ganze Gewicht der Blattmasse von der Axe getragen, es unterbleibt daher die starke mechanische Festigung des Stengels. Ebenso tritt bei sehr verkürzten Axen, wie z. B. bei den Blattrosetten tragenden Pflanzen, sowie bei den kriechenden Arten das mechanische Moment in den Hintergrund, die Pflanze wird mit geringerem Aufwand für die Ausbildung der Axe auskommen, dafür aber auch Gefahr laufen, von anderen Pflanzen überschattet und überwachsen $\mathrm{zu}$ werden.

Die Stärke der Axen eines Sprosssystems und die Verteilung des Gewichtes der Blattmasse ist eine verschiedene, ob wir es mit einem Baume, Strauche, Halbstrauche oder einer krautigen Pflanze zu thun haben. Die drei zuerstgenannten Pflanzengebilde zeichnen sich durch ihre starke Verholzung der Axen aus. Sie unterscheiden sich in der Form der Verzweigung und der Grösse. Bei den Bäumen ist eine starke Hauptaxe gebildet mit hochansetzenden Ästen, bei den Sträuchern ist der Stamm von unten her verästelt, die Äste bleiben erhalten, während bei den Halbsträuchern (z. B. Vaccinium Myrtillus, Genista pilosa) nach einiger Zeit ein Teil der Triebe abstirbt. An Bäumen unterscheiden wir je nach der Grösse Bäume erster Grösse, welche über $25 \mathrm{~m}$ hoch werden, zweiter Grösse zwischen $10-25 \mathrm{~m}$ Höhe und Bäume dritter Grösse, welche eine Höhe von IO $\mathrm{m}$ nicht erreichen.

Die für die vorteilhafteste Beleuchtung geeignete Verteilung der Blattmasse wird teilweise schon durch die Blattstellung (vgl. S. 48 ff.) geregelt, 
ausserdem ist jedoch die rerschiedene Ausbildung der Axen von Einfluss. So unterscheidet man zwischen Lang- und Kurztrieben, von denen die ersteren mehr der Ausbreitung des ganzen Sprosssystems, die letzteren der Produktion von Blättern und Blüten dienen. Ja wir sehen, dass z. B. bei Apfelbäumen die Blütenbildung sogar auf diese kurzen Seitentriebe beschränkt bleibt (sog. Tragholz). In extremen Fällen, wie z. B. bei den Kiefern, besteht ein Kurztrieb nur aus Blättern, welche die im Zustande des Vegetationspunktes verharrende Sprossaxe umgeben. Ein Abbrechen der Spitzenteile des Zweiges oder eine Verletzung derselben durch Hagel, Frost etc. kann ein Auswachsen der Kurztriebe zu Langtrieben bewirken, wodurch der hervorgerufene Schaden wieder ausgeglichen wird (Fig. 78). Aber auch ohne Verletzungen kann ein Kurztrieb zu einem Langtriebe auswachsen, wie dies bei der Lärche häufig zu finden

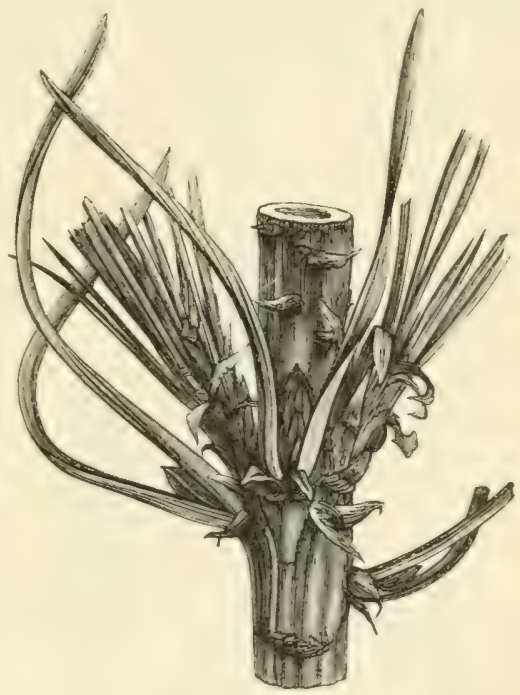

Fig. 78 .

Pinus silvestris mit auswachsenden Kurztrieben. (DN.)

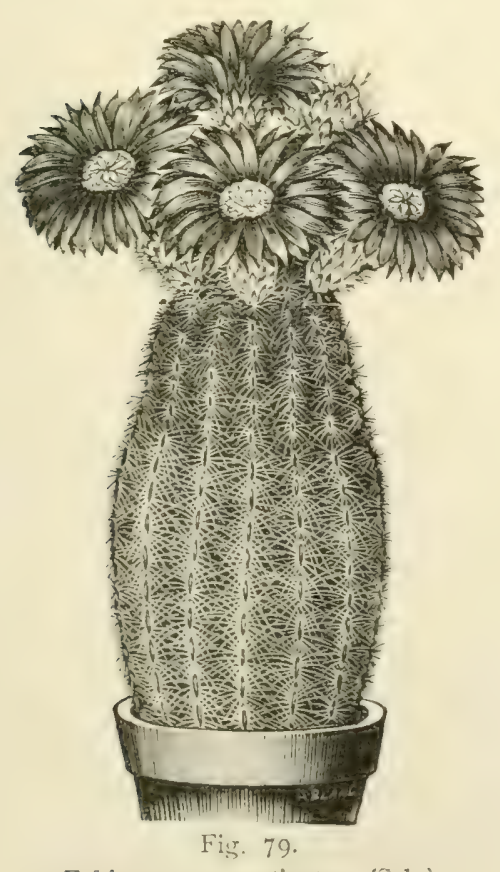

Echinocereus pectinatus. (Sch.)

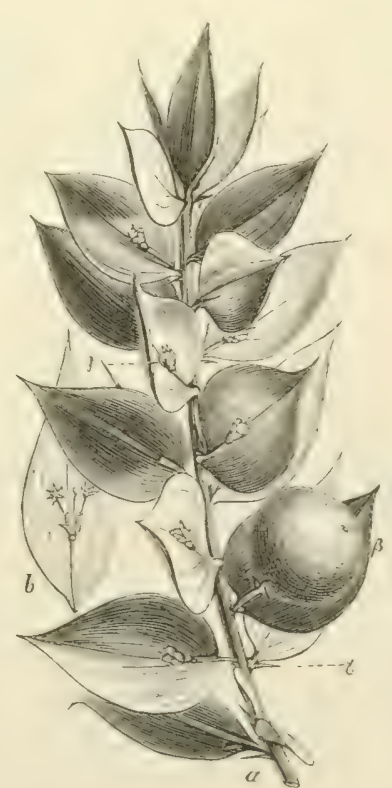

Fig. So.

Ruscus aculeatus. « Blätter, $\beta$ Frucht, $\gamma$ Blüte, b einzelner Flachspross mit Blüten. (K.) 
ist. Die Kurztriche der Laubbäume weisen meist sehr dicht stehende Blattnarben auf (verl. die Knospenbilder von Pirus malus, Sorbus etc.), und verlïngern sich in jedem Jahre nur um eine kurze Strecke. Eine scharfe Grenze zwischen Kurztrieben und Langtrieben ist nicht bei allen Bäumen vorhanden, indem die Seitenzweige im Vergleich zu den Haupttricben immer

mehr oder weniger zurïck-

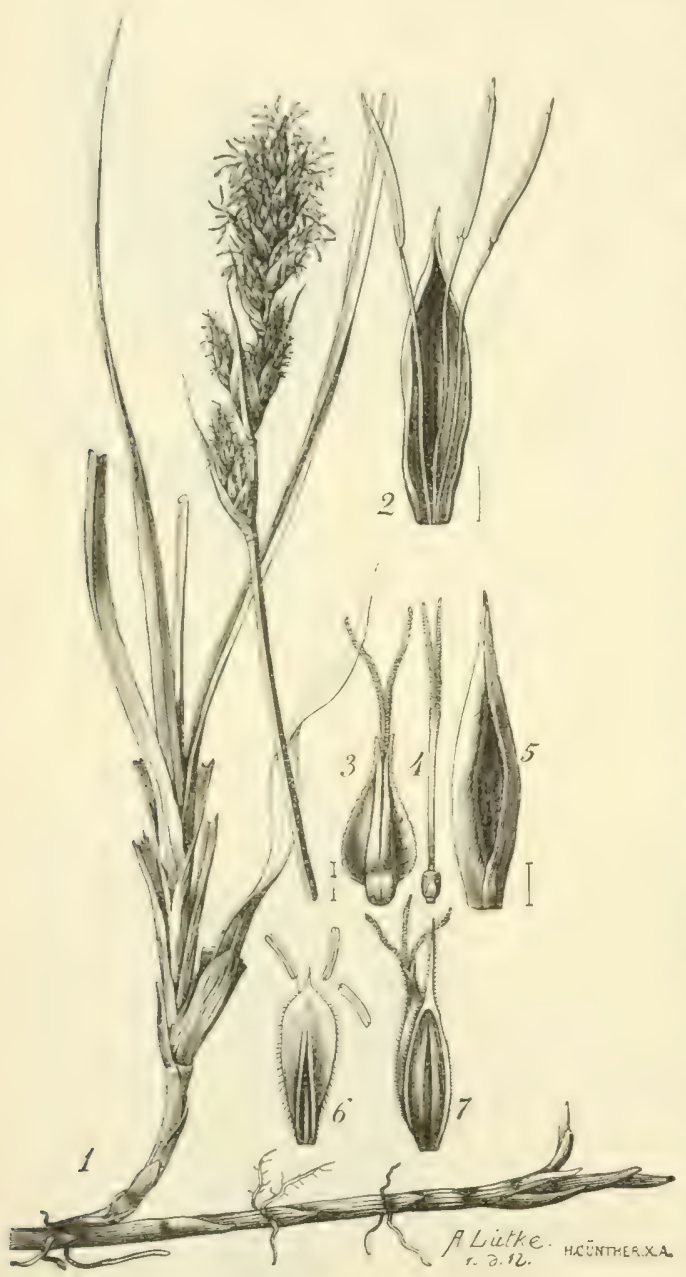
bleiben, und wir nur bei grösserer Beschränkung des Längenwachstums der Zweige von Kurztrieben reden können.

Einen wesentlich anderen Habitus erhält der Spross, sobald die Axe die Assimilationsfunktion der Blätter ïbernimmt. Die letzteren werden zu Schuppen oder Stacheln reduciert, während der Stamm seine Oberfläche vergrössert, um mehr Licht aufnehmen zu können. Es kann dies, wie bei gewissen Euphorbien und Cacteen, durch eine kugelige Auftreibung der Sprossaxe erreicht werden, deren Oberfläche durch Rillen, Leisten(Echinocereus pectinatus, Fig. 79, Melocactus communis, Euphorbia grandicornis), oder durch rundliche Wülste (Mamillaria elephantidens) vergrössert wird. Im anderen Falle werden die Sprosse flach und breit (Epiphyllum, Opuntia vulgaris), welche Umwandlung so weit geht, dass sie vollständis sewöhnlichen Laubblättern ähnlich werden. Man Fig. 81 . bezeichnet dies als Phyllocladienoder Cladodienbildung, wofür die Blüten resp. Früchte tragenden Zweige von Ruscus aculeatus (Fig. 80) als Beispiel angeführt sein mögen. Die Oberflächenvergrösserung, kann auch dadurch gewonnen werden, dass die Zweige dünn, oder wie z. B. beim Spargel, nadelförmig werden.

Die Mittel, welche die Blätter vor Angriffen von Tieren schützen, 
gewähren natürlich auch der Sprossaxe eine gewisse Sicherheit. Die holzige Beschaffenheit vieler Axen, sowie giftige oder bitter schmeckende Stoffe der Rinde können einen gewissen Schutz gewähren, der jedoch,

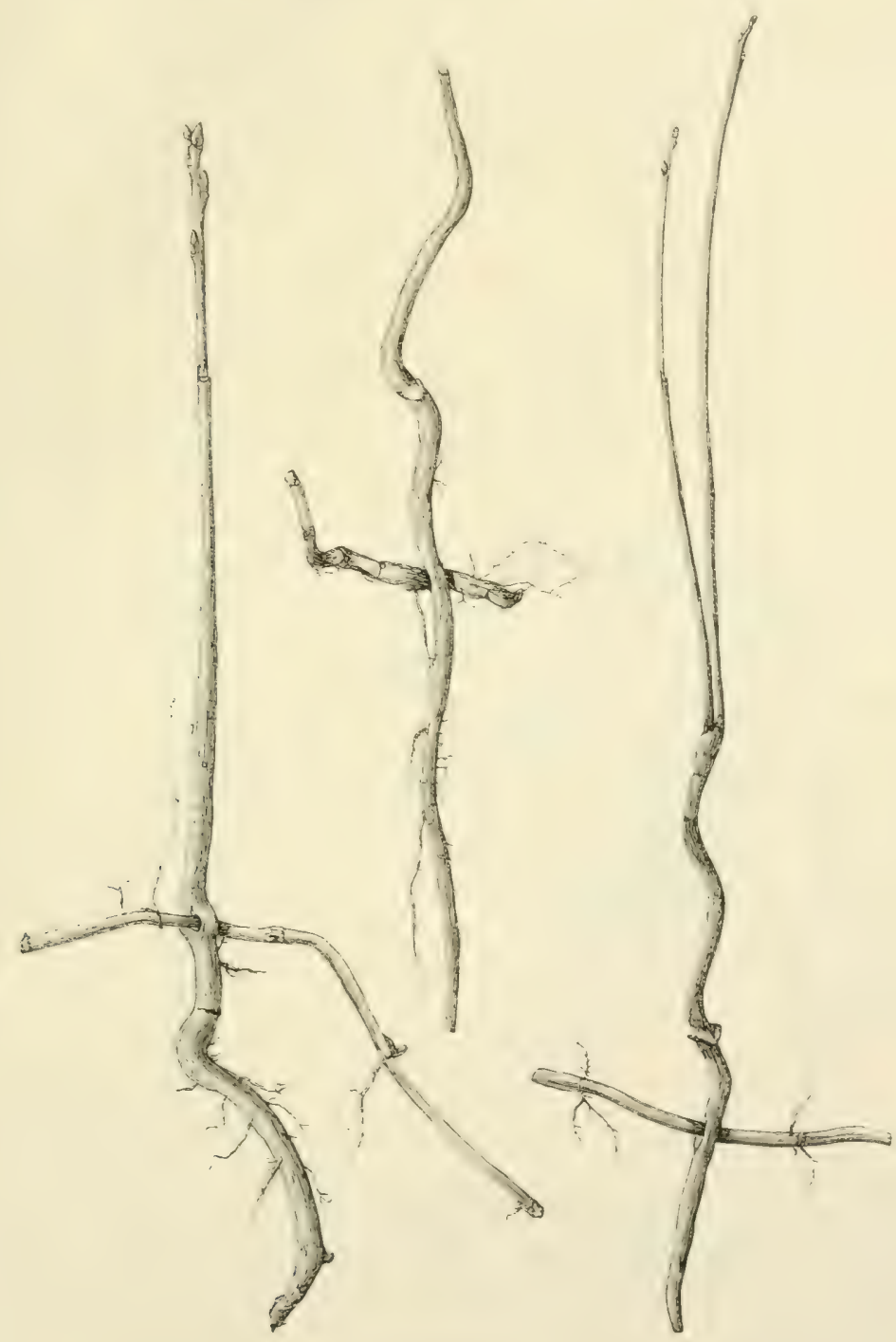

Fig. 82.

Rhizome von Triticum repens junge Eichen durchbohrend.

wie die zahlreichen Beschädigungen durch Wild, Insekten etc. beweisen, in den meisten Fällen nicht ausreicht.

Nanche Pflanzen sind gegen die Angriffe grösserer Tiere durch die Ausbildung von Dornen, d. h. zu stechenden Gebilden umgewandelte 


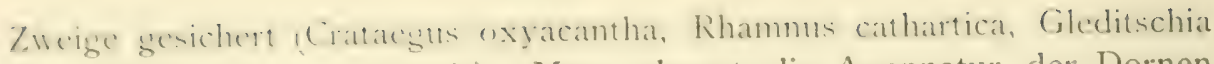
triacanthos, Pirus communis). NIan erkennt die Axennatur der Dornen an der Stellung in der Achsel von Blättern, sowie an der Produktion ron Knospen, Blättern, eventuell auch von Blüten (Prunus spinosa). Vgl. Stacheln S. 60 .

Für dic Erhaltung des Individuums nach Verletzungen ist auch die Reproduktionstahiskeit der Sprossaxen und IVurzeln, das sous. Ausschlass-

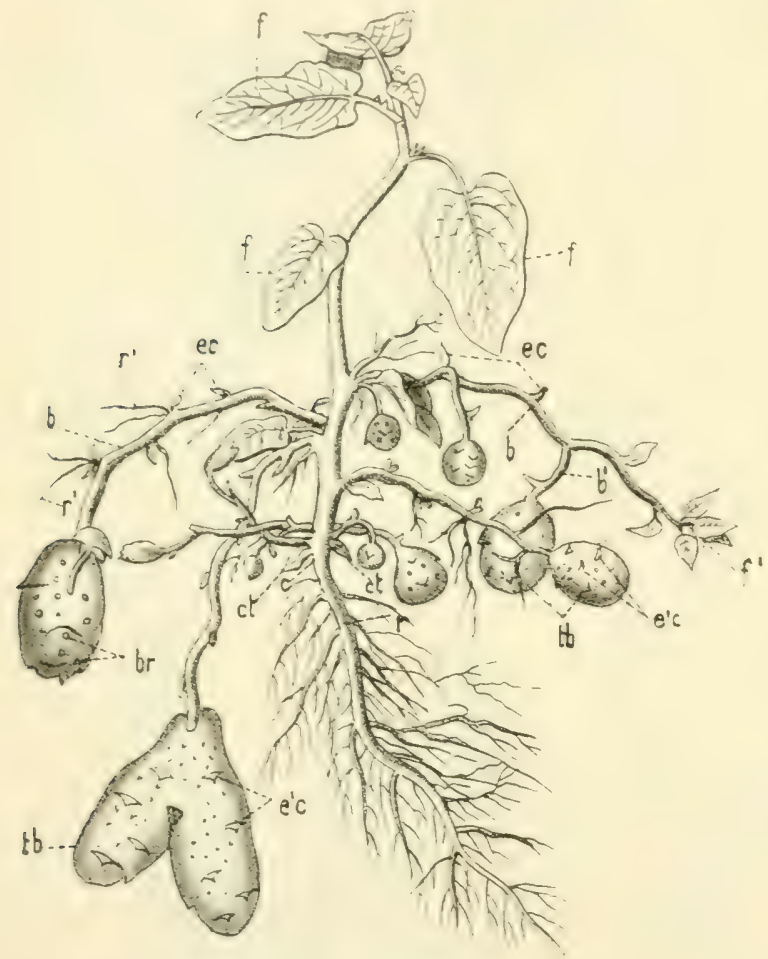

Fig. 83 .

Eine aus dem Samen erzogene Kartoffelpflanze; r Hauptwirzel, ct Cntylednnen, f Laubblätter, bb unterirdische Ausliiufer mit schuppenfömigen Blättern ec, an ihren Enden die Knollen tb, auf diesen die Knospen br ( $\mathrm{n}$. Duchartre). vermögen von Wichtigkeit (vgl. S. 46)

Zu Ranken umgewandelte Sprosse finden sich bei Vitis und Passiflora.

Die Ausbreitung mancher Pflanzen wird durch die Bildung von Ausläufern (stolones) unterstützt. Es sind dies langgestreckte am Grunde den Axen entspringende, meist wenig oder gar nicht beblätterte Triebe, welche auf dem Boden fortkriechend sich bewurzeln und neue Individuen bilden (Fragaria vesca, Ranunculus repens).

Was die unterirdischen Axengebilde anbelangt, so haben wir zwischen Rhizom, Zwiebel und Knolle zu unterscheiden. Die Rhizome sind schief oder horizontal im Boden verlaufende Stengelorgane, die, mit schuppenförmigen Blättern besetzt, jedes Jahr blatt- und blütentragende Sprosse über die Erde entsenden. Während letztere am Ende einer Vegetationsperiode absterben, perenniert das Rhizom in der Erde und verlängert sich durch Endknospen (Polygonum bistorta), oder falls diese zu oberirdischen Sprossen werden, durch Auswachsen von Seitenknospen (Convallaria polygonatum, Triticum repens, Listera ovata). An den Rhizomen werden meist zahlreiche Wurzeln gebildet, die, wenn sie 
in grösserer Menge vorhanden sind, zur weiteren Festigung des Bodens beitragen. Man verwendet daher solche rhizombildende Pflanzen bei Flugsandkulturen (Elymus arenarius, Ammophila arenaria, Carex arenaria (Fig. 8r).

Bei der Zähigkeit und Festigkeit solcher kriechender, dicht verwirrter unterirdischer Sprosse ist es leicht begreiflich, dass dieselben häufig das Durchpflügen des Bodens sehr erschweren. Die Quecke (Triticum repens) kann noch in anderer Weise schädlich werden, indem die Rhizome dieser Pflanze im stande sind, junge Holzpflanzen zu durchbohren (Fig. 82).

Knollen sind lokale Anschwellungen der unterirdischen Axe, die meist nur mit trockenhäutigen oder schuppenförmigen Blättern besetzt sind (Solanum tuberosum, Fig. 83, Helianthus tuberosus). Sie sind besonders zur Speicherung von Reservestoffen geeignet, welche in der nächsten Vegetationsperiode in die aus den Knospen (Augen) der Knolle hervorgehenden Sprosse übergeleitet werden.

Die Zwiebeln weisen eine sehr verkürzte Axe auf, die von fleischigen Blattorganen vollständig eingehüllt wird, in deren Achseln neuc Zwiebeln, d. h. neue Laubblätter tragende, verkürzte Sprosse entstehen (Allium cepa, Lilium candidum). Vgl. S. 57.

\section{$\S 21$. Primärer anatomischer Aufbau der Sprossaxen.}

Wie wir im $\S$ I 5 gesehen, entwickelt sich aus dem teilungsfähigen Urmeristem des Vegetationspunktes ein Dauergewebe, das in seiner mannigfaltigen Zusammensetzung aus verschiedenen Gewebearten den primären Aufbau des Laubsprosses darstellt. Während nun bei den Blättern die aus der Blattanlage hervorgehenden fertigen Gewebe keine weiteren Veränderungen erleiden (abgesehen von Desorganisationserscheinungen und anormalen Bildungen), können bei den Sprossaxen durch gewisse teilungsfähig bleibende Gewebepartien (Folgemeristeme, Cambium) sekundäre Veränderungen eingeleitet werden, unter denen vor allem das sekundäre Dickenwachstum der Sprossaxen zu nennen ist. Wir haben also zwischen den direkt aus dem Urmeristem des Vegetationspunktes hervorgehenden primären Geweben und den Geweben des sekundären Zuwachses zu unterscheiden. An dieser Stelle sollen die ersteren betrachtet werden.

Wir finden bei den Sprossaxen dieselben Gewebearten, wie bei den Blättern. Die Epidermis umschliesst parenchymatisches Gewebe, in welchem dic Gefässbündel, die mechanischen Zellen, Sekretions - und I_citungsgänge liegen.

Wie bei den Blättern (vgl. S. 63) herrscht zwischen dem turgescenten Parenchym und den festeren dickwandigeren mechanischen Zellen eine 
Gewebespannung, welche zur Festigung des Stengels notwendig ist. Diese dickwandigen Elemente sind so verteilt, dass unter möglichst geringer Aufwendung von Material die grösste Biegungsfestigkeit erreicht wird, ein Umknicken und Zerreissen des Stengels, eine Veränderung seines Querschnittes nach Möglichkeit verhindert wird. Bei der Verwendung der gleichen Stoffmenge wird cine Röhre eine grössere Biegungsfestigkeit aufweisen, als ein massiver Stab. Ebenso sehen wir bei den oberirdischen Sprossaxen ${ }^{1}$ ) die festen Elemente an die Peripherie gerückt. Den grössten Nutzeffelt würde die l.aterumg eler me chanischen \%ellen unmittellar unter der Epidermis bieten. 1) a die \% dhen unter der Ejpidermis weesen des reichlichen l ichtzutrittes jedoch auch zur Assimilation dienen können, findet ein Ausgleich der sich gegen-

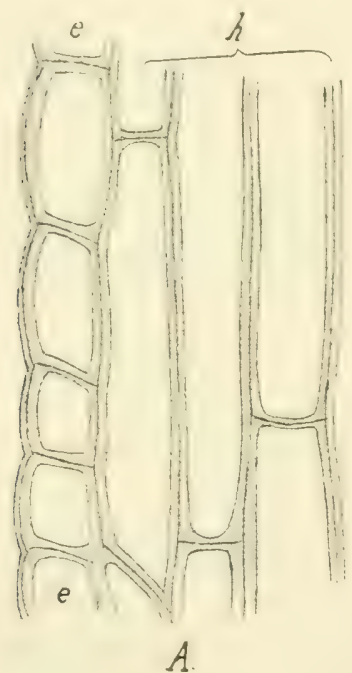

A

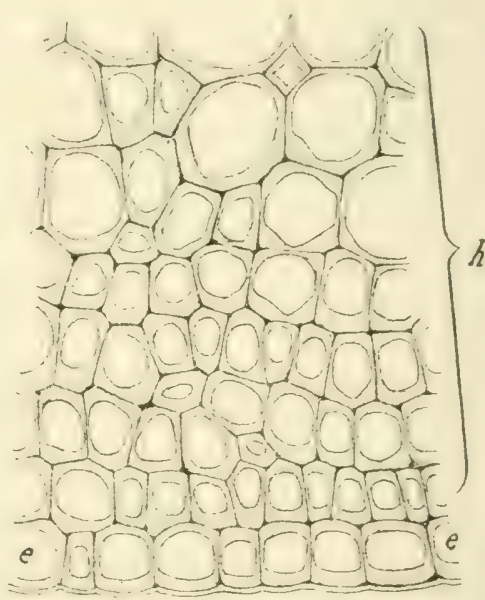

B.

Fig. 84.

Epidermis (e) und Hypoderm (h) aus dem Stengel von Helianthus annuus; A Längsschnitt, B Querschnitt. (K.)

seitis ausschliessenden Funktionen statt, indem die mechanischen Elemente etwas nach innen rücken oder das Assimilationsparenchym zwischen Iändern und Komplexen ron mechanischen Zellen liest, welche unmittelbar unter der Epidermis verlaufen. Da die Assimilationsfunktion beim Stengel überhaupt zurücktritt, kann auch auf die Assimilation der Axe ganz verzichtet werden. An Stelle des assimilierenden Rindenparenchyms finden sich dann unter der Epidermis mehrere Lagen verdickter, häufig collenchymatischer oder verholzter Zellen, welche Schichten man als Hypoderma bezeichnet (Fig. 84).

1) Man beachte, dass es sich hier nur um den primären Aufbau der Sprossaxen handelt. 
Zur Festigung der Axen tragen einerseits die dickwandigen Elemente der Gefässbündel bei, anderseits die nicht mit dem Gefässbündel direkt zusammenhängenden Stränge, Ringe, Complexe von dickwandigen

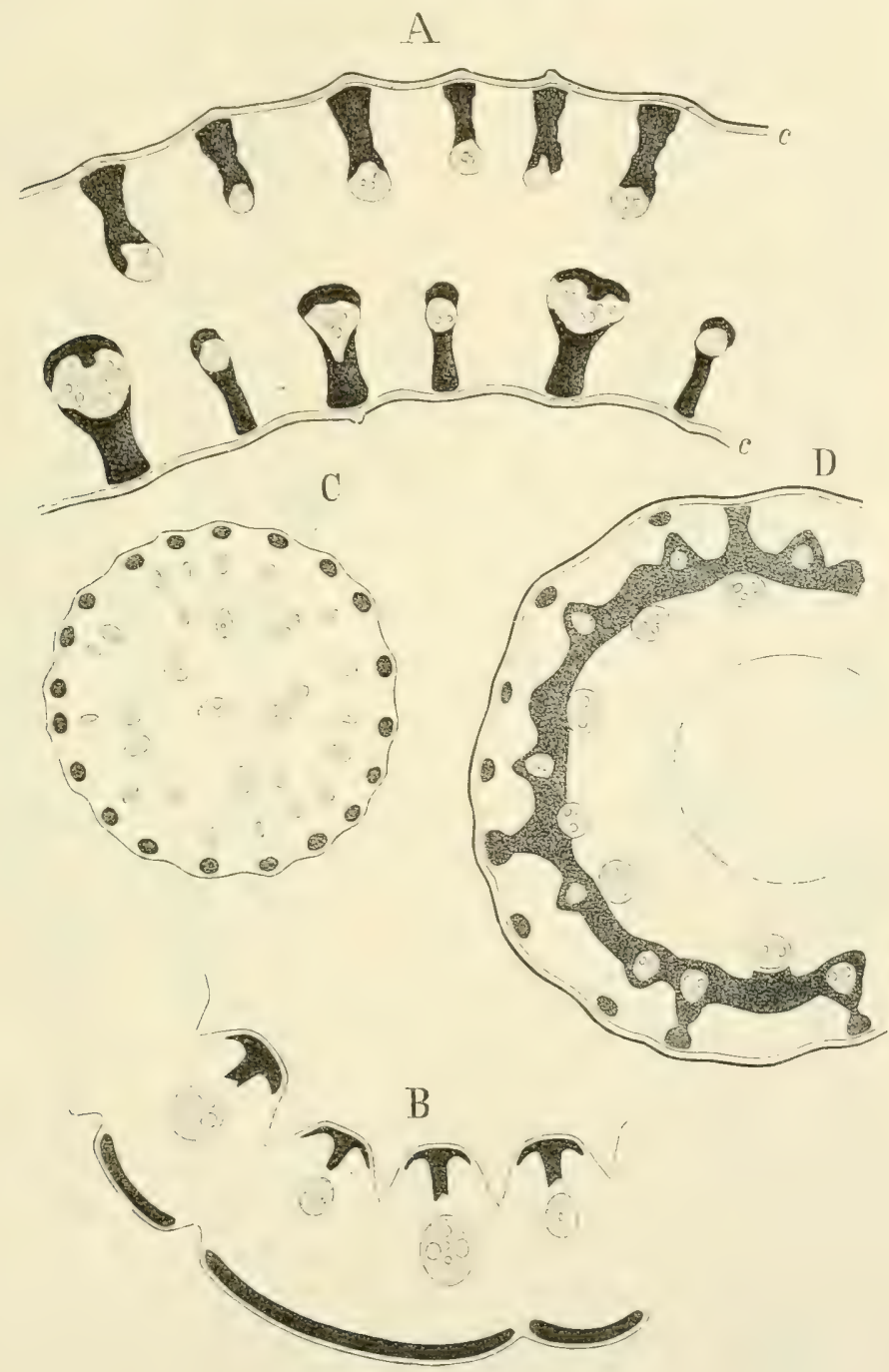

Fig. S5.

A Querschnitt aus dem Blatte von Dasylirion acrotiche, B aus dem von Gynerium argenteum, C aus dem Blütenschaft von Atherurus ternatus, D aus dem Stengel von Bromus inermis. Die schwarzen Partien stellen das Sklerenchym, die helleren rundlichen Figuren die Gefässbündel dar. Bei D eine grosse centrale Luftlïcke. (R.)

Zellen (Sklerenchymfasern, isodiametrischen Sklerenchỵmzellen, Collenchym), wofür an Blättern und Stengeln einige wenige Beispicle angeführt sein mögen (Fig. 85 A-D). 
Da die Gefissbündel mechanische Elemente enthalten, so fügen sie sich dem auf Festigung zielenden Bauplane ein, ausserdem kommt für den Verlauf derselben ihre Funktion der Stoffleitung in Betracht.

Die meisten Gefissbündel des Stammes sind sog. "Blattspuren ", d. h. Verlängerungen der durch den Blattsticl in die Sprossaxe über-

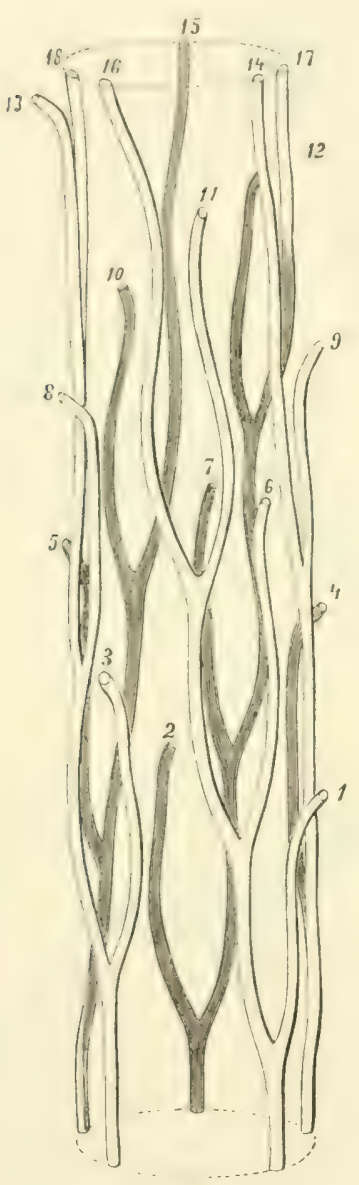

Fig. S6.

Schema des Gefässbündelverlaufs im Stengel von Iberis amara. Blattstellung mit $5 / 13$ Divergenz. (R.)

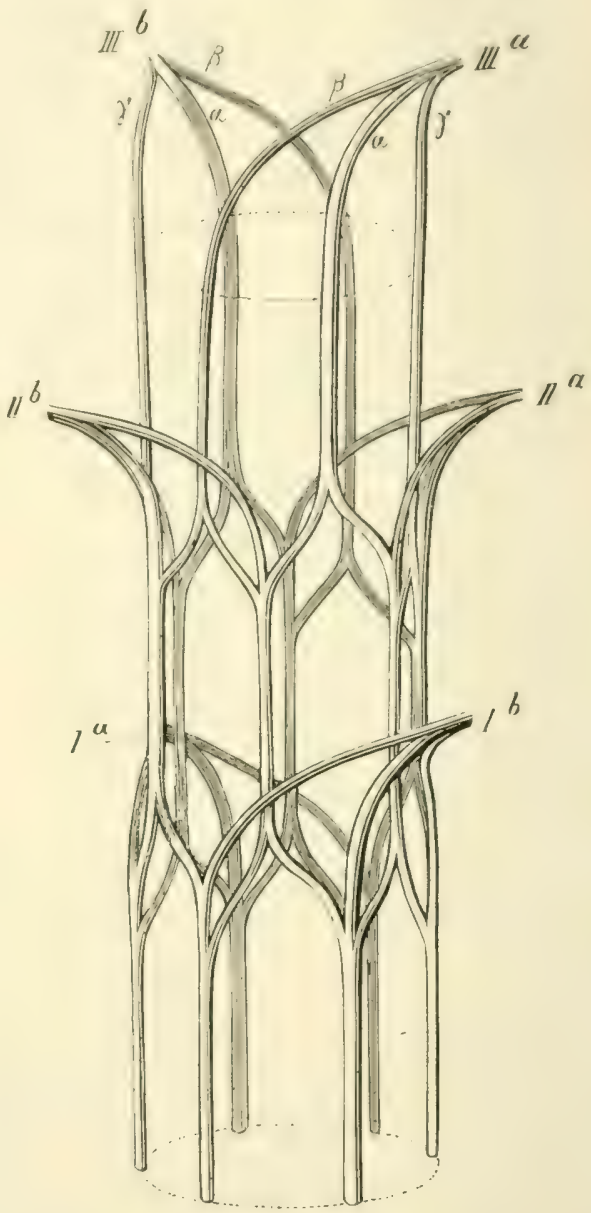

Fig. 87.

Schema des Gefässbündelverlaufs in der Sprossaxe von Clematis integrifolia. Blattstellung gekreuzt gegenständig. (R.)

tretenden Gefässbündel der Blätter. Durch dieselben wird die Leitung von Stoffen in der Längsrichtung der Sprossaxe bewirkt und der Stoffaustausch zwischen Blatt und Axe vermittelt. Die aus den Blättern übertretenden Blattspuren vereinigen sich im Stengel mit anderen Blattspuren, um dann in der Längsrichtung des Stengels weiter zu verlaufen. Zur Erläuterung des Gesagten sind einige Modelle abgebildet, welche den 
Gefässbündelverlauf im Stengel darstellen; die Zahlen bedeuten die Ansatzstellen der Blätter: Iberis amara (Fig. 86), Clematis integrifolia (Fig. 87) und Aspidistra elatior (Fig. 90).

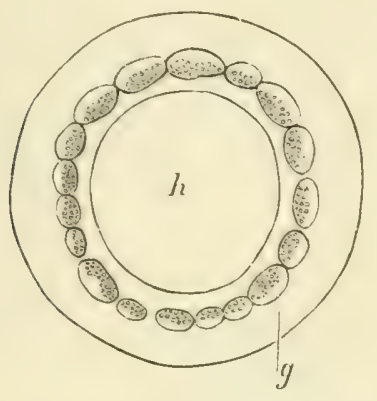

Fig. 88 .

Querschnitt durch die Sprossaxe von Lychnis Viscaria; g Gefässbündel, $h$ die centrale Lufthöhle. (R.)

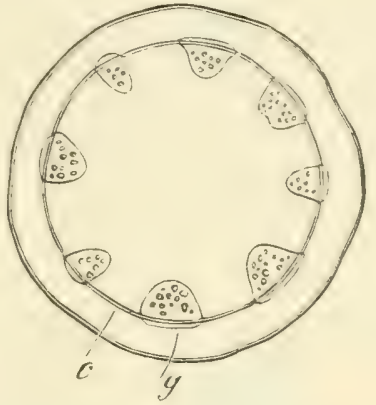

Fig. 89.

Querschnitt durch ein junges Internodium von Impatiens parviflora; g Gefässbündel, c Cambiumring. (R.)

Ausserdem sind bei bestimmten Pflanzen (manche Begonien, Orobanchen, Melastomaceen, Ripsalideen), noch besondere stammeigene Gefässbündel vorhanden, welche nur der Stoffleitung innerhalb der Axe dienen.

Die Anordnung der Gefässbündel ist je nach der systematischen Stellung der betreffenden Ordnungen verschieden.

Bei dem Dicotylentypus sind die Gefässbündel auf dem Querschnitte des Stengels in einen Kreis gestellt (Fig. 88 und 89). Ein Querschnitt durch die schematischen Fig. 86 und 87 zeigt uns, wie diese Kreisstellung zu stande kommt. Das Parenchym innerhalb des Gefässbündelkreises wird als Mark, ausserhalb desselben als Rinde bezeichnet. Wir finden den Dicotylentypus, ausser bei den meisten Dicotyledonen, noch bei den Coniferen, und einzelnen Gefässkryptogamen, wie Equisetum und Osmunda.

Eine Abweichung von diesem normalen Dicotylentypus bilden jene Fälle, wo ausser dem Blattspurkreise noch mark- oder rindenständige Gefässbündel vorhanden sind.

Bei dem Palmentypus, welcher die meisten Mlonocotyledonen umfasst, dringen zahl-

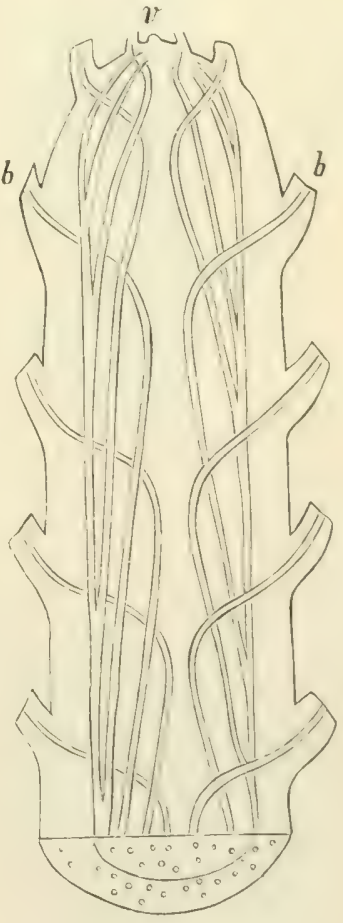

Fig. 90 .

Schema des Gefässbündelverlaufs von Aspidistra elatior; v Stammscheitel, b Blattbasen (n. Falkenberg). 
reiche Blattspuren (Figs. 90) in das Innere der Axe und verlaufen von da schräs nach abwärts, um sich an der Peripherie mit anderen Strängen zu vereinisen. Auf einem Querschnitt durch die Sprossaxe finden wir daher die Gefassbündel zerstreut, an der Peripherie mehr oder weniger schäuft. Die äusseren Partien des Parenchyms werden auch hier als Rinde, die inneren als Mark bezeichnet, obwohl die Trennung oft keine scharfe ist. Für den Fall, dass ein innerer Raum frei von Gefassbündeln bleibt, kann das Mark in den älteren Stengelteilen austrocknen, der Stengel selbst hohl werden (Gramineen).

Ohne auf weitere Specialfälle cinzugehen, sei noch auf die Gefässbïndel monocotyler und dicotyler Wasserpflanzen verwiesen, bei welchen ein axiler Strang in der Mitte des Stengels ausgebildet ist

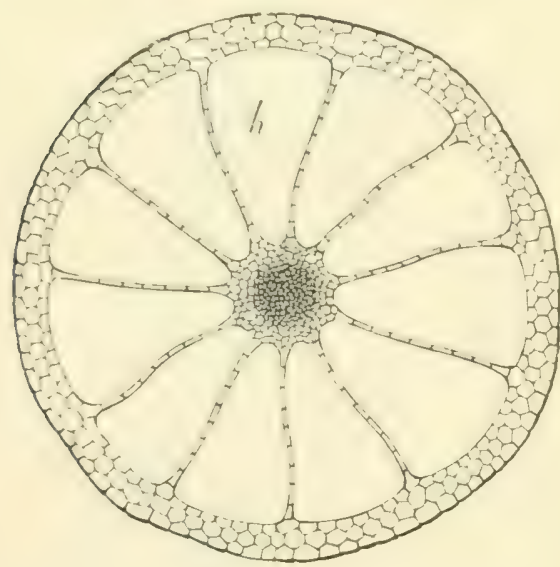

Fig. 91 .

Querschnitt durch den Stengel von Elatine Alsinastrum, h Lufthöhle. (R.)

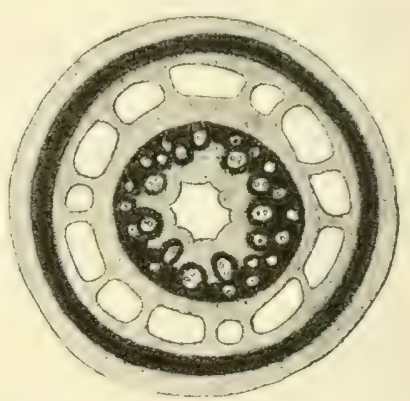

Fig. 92 .

Rhizom von Carex. Die schwarzen Stellen sind Sklerenchym, die punktierten Parenchym, dazwischen die Luftlücken. Im innern Sklerenchymringe die Gefässbündel (n. Schwendener).

(Fig. 9I). Es ist dies insofern bemerkenswert, als die Wasserpflanzen mehr auf Zug- als auf Biegungsfestigkeit in Anspruch genommen werden und hierbei eine Vereinigung in einen centralen Strang grössere Vorteile bietet als zerstreute peripherische Gefässbündel. Ausserdem ist als Anpassung an das Leben im Wasser eine Verminderung der Gefässbündelmenge zu konstatieren, indem hier die bei den Landpflanzen von der Wurzel aufgenommenen und in der Sprossaxe weiter transportierten, anorganischen Bestandteile, sowie das Wasser direkt vom Stengel aufgenommen werden können, mithin keine so grosse Zahl von Leitungsbahnen notwendig ist.

Auch bei unterirdischen Sprossaxen rücken die Gefässbündel und mechanischen Elemente mehr in die Mitte, dafür bildet sich jedoch häufig (vgl. Carex, Fig. 92) cin peripherischer Mantel dickwandiger Zellen aus, welcher dem Druck des umgebenden Erdreichs entgegenwirkt. 
Was die Zusammensetzung der einzelnen Gefässbündel anbelangt, können wir zunächst zwischen dem Gefässteil, Xylem oder Holzteil und dem Siebteil, Phloëm oder Bastteil unterscheiden. Xylem und Phloëm werden häufig von einer besonderen Scheide stärkehaltiger Zellen (Stärkescheide) oder dickwandiger Zellen (Schutzscheide) umgeben.

Der wesentlichste Teil des Xylems sind die Gefässe (Fig. 93 b, c, d, g, vgl. auch S. 25). Dieselben sind im ausgewachsenen Zustande frei von lebendem Inhalt, mit Luft, Wasserdampf und Wasser erfüllt. Sie stellen capillare Leitungsbahnen für Wasser und gelöste Stoffe dar. Den Gefässen schliessen sich die Trachëiden an (S. 26). Zweitens

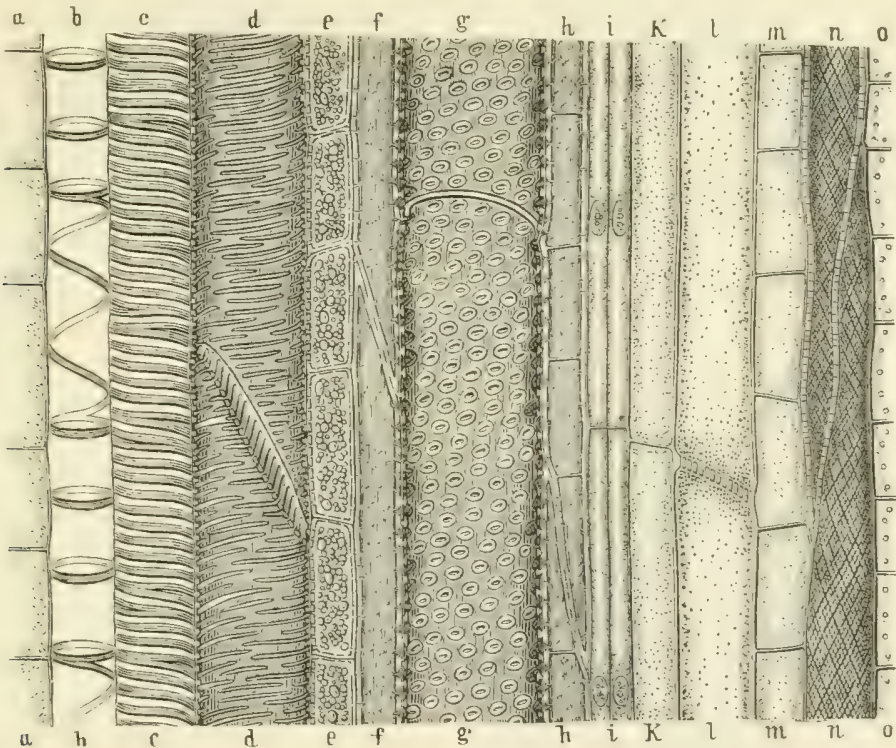

Fig. 93 .

Längsschnitt durch ein ideales dicotyles Gefässbündel. a Mark-, o Rindenparenchym, i Cambium. Die anderen Bezeichnungen vgl. Text, (KIV.)

haben wir das Holzparenchym (Fig. 93 e), d. h. parenchymatische verholzte Zellen, deren Plasma und Inhalt länger erhalten bleibt. Drittens sind die Holzfasern (Fig. 93 f) oder Libriformzellen zu nennen, welche die specifisch mechanischen Elemente des Xylems darstellen. Es sind dickwandige, langgestreckte Zellen, deren Inhalt vor der Verdickung der Wand zurücktritt.

Im Phloëm haben wir die Siebiöhren (Fig. 93 1), welche mit ihren siebfürmis durchlöcherten Querwänden gewisscrmassen den Gefässen des Xylems entsprechen. Die Cambiformzellen (Fig. $93 \mathrm{k}$ ) sind langgestreckte, dünnwandige Elemente, die den kürzeren Phloëmparenchymzellen (Fig. 93 m) sehr ähnlich sind. Die genannten Elemente des 
Phloëms enthalten Plasma und leiten vorzïglich plastische Stoffe, wic Kohlenhydrate, eiweissartige Substanzen und deren Zerfallsprodukte. Sehr Wahrscheinlich leiten sie auch anorganische Stoffe in grösserer Menge. Die eigentlichen Bastfasern (Fig. 93 n) sind dic mechanischen Elemente des Phlö̈ms und werden wegen ihrer Dickwandigkeit wohl auch

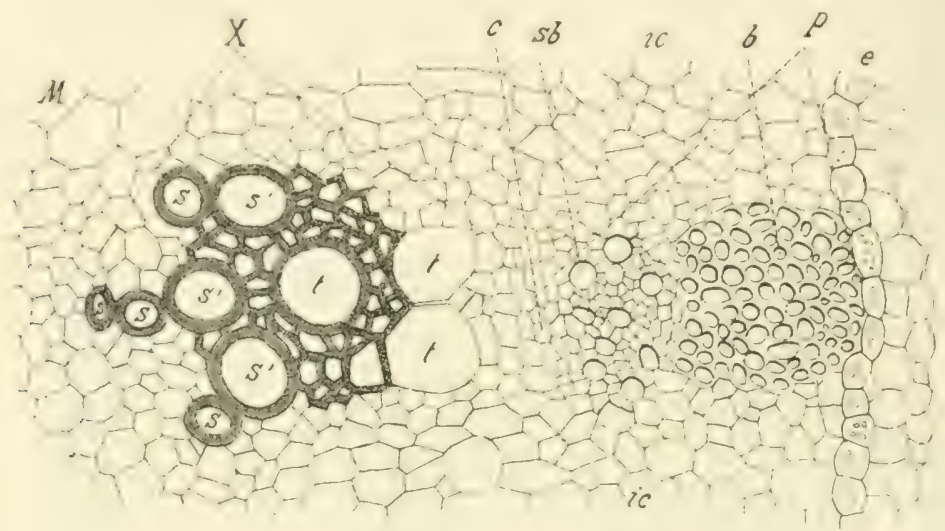

Fig. 94.

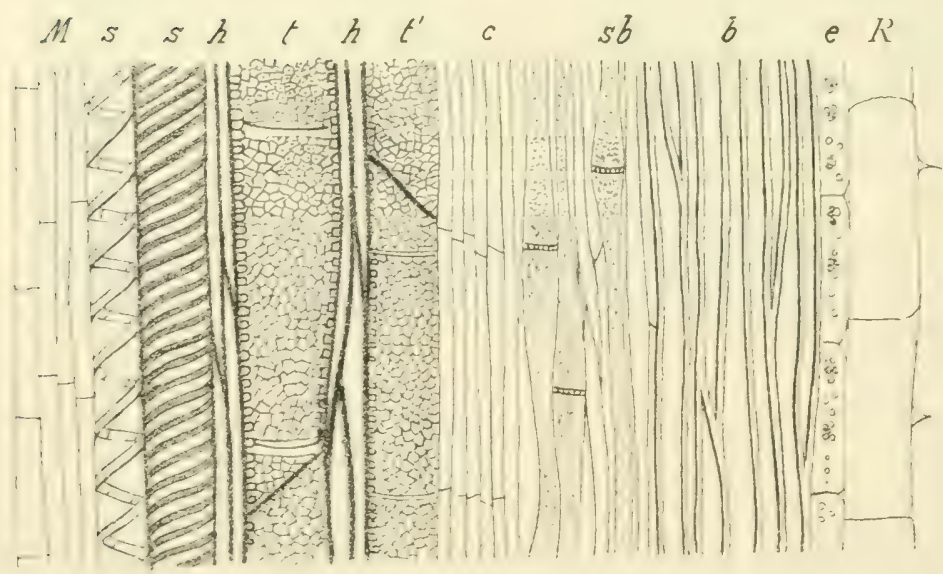

Fig. 95 .

Fig. 94 Querschnitt, Fig. 95 radialer Längsschnitt durch ein Gefässbündel von Helianthus annuus. II Jark; X XYlem, c Cambium, P Phloëm. R Rinde, ss' Spiralgefässe, tt' Tüpfelgefässe, hh Holzfasern, sb Siebröhren, die kleinen Zellen dazwischen Cambiformzellen, b Bastfasern, e Stärkescheide (n. Prantl).

als Hartbast den dünnwandigen Elementen des Phloëms gegenübergestellt, die mit dem Collektivnamen des Weichbastes bezeichnet werden. Man vergleiche ferner auch die Erklärung von Fig. 94 und Fig. 95 .

Bei den collateralen Gefässbündeln liegt Xylem und Phloëm 
seitlich nebeneinander (Fig. 94), eventuell kann ein Gefässteil von zwei Siebteilen flankiert sein (bicollateral). Bei den concentrischen Gefässbündeln liegt Xylem oder Phloëm in der Mitte, rings herum der andere Teil des Gefässbündels. Die radialen Gefässbündel der Wurzeln vgl. \& 28 .

Bei dem Laubspross der Dicotyledonen finden sich in den weitaus meisten Fällen collaterale Bündel, und zwar liegt der Gefässteil nach innen, er grenzt an das Mark, der Siebteil liegt in radialer Richtung nach aussen und grenzt an das Rindenparenchym.

Über das zwischen Gefässteil und Siebteil liegende Cambium vgl. § 22.

Wenn nun auch die Gefässbündel die schnellere Fortleitung von Stoffen übernehmen, so ist an der Stoffleitung in geringerem Grade auch das Parenchym beteiligt. Da die Parenchymzellen in gewissen Stadien reich an Stärke sind, wird man annehmen müssen, dass sie den aus der Stärke entstehenden Zucker fortleiten. Die Zellschicht an der Peripherie der Gefässbündel, welche man wegen ihres Stärkereichtums die Stärkescheide nennt (Fig. 94 e) und die bei sehr vielen Pflanzen vorkommt, ist gewissermassen nur eine dem Gefässbündel anliegende Schicht des umgebenden Parenchyms, in welcher sich diese Stärke, resp. Zuckerleitung concentriert. Ebenso werden die in dem assimilierenden Rindenparenchym entstandenen Stoffe durch das Parenchym zu den Gefässbündeln abgeleitet. Neuerdings hat Schimper darauf hingewiesen, dass auch die anorganischen Salze in hervorragender Weise ausserhalb der Gefässbündel wandern.

Zwischen den Parenchymzellen von Rinde und Mark befinden sich immer Intercellularräume, die mit Luft und Wasserdampf erfüllt sind. Ebenso stelit der durch das Collabieren des Markes in hohlen Stengeln entstehende Raum einen Kommunikationsweg für Luft, resp. den zum Leben notwendigen Sauerstoff dar, in welchen auch aus den benachbarten Zellen Wasserdampf abgegeben werden kann. Besonders grosse Intercellularräume sind bei den Wasserpflanzen ausgebildet (Fis. 91 ), die hier zu gleicher Zeit die Bedeutung haben, die ganze Pflanze specifisch leichter zu machen.

Schliesslich sind noch die zur Aufnahme oder Fortleitung bestimmter Stoffe dienenden Sekretbehälter zu erwähnen.

Hierher gehören die bei verschiedenen Pflanzen auftretenden $\mathrm{Milch}$ röhren. Die sog. gegliederten Milchröhren (Milchsaftgefässe) entstehen dadurch, dass sich Reihen junger Zellen, unter Resorption der Querwände, zu einem Kanalsystem vereinigen, bei welchem die Längsstränge, durch Einbeziehung querverlaufender Zellen, zu einem anastomosierenden Netz verbunden sind (Fig. 96). Gegliederte Milchröhren finden sich bei den Cichorieen, Campanulaceen, Papaveraceen etc., wo sie entweder die Gefässbündel begleiten oder im Parenchym liegen. Die ungegliederten Milchröhren (Milchzellen) entstehen aus einigen wenigen Zellen, die, dem Längenwachstum der ganzen Pflanze folgend, 
zwischen die Zellen von Stengel und Blatt eindringen und sich dort durch Verzweigung zu cinem ähnlichen Kanalsystem ausbilden, wie die sesliederten Nilchröhren (Fig. 97). Wir finden dieselben bei den Euphorbiaceen, Noreen, Artocarpeen, Apocyncen. Dic Milchröhren dienen zum Transport von Kohlenhydraten und Eiweissstoffen, sie führen aber auch der Ernährung nicht mehr dienende Ausscheidungsprodukte wie Kautschuk und Alkaloide (z. B. Opium). Insofern diese kautschukartigen Stoffe an der Luft erhärten, kann der ausfliessende Milchsaft zum Wundverschluss dienen, die giftigwirkenden Alkaloide bieten einen Schutz gegen Angriffe von Tieren.

Den Milchsaftzellen schliessen sich jene Sekretbehälter an, welche

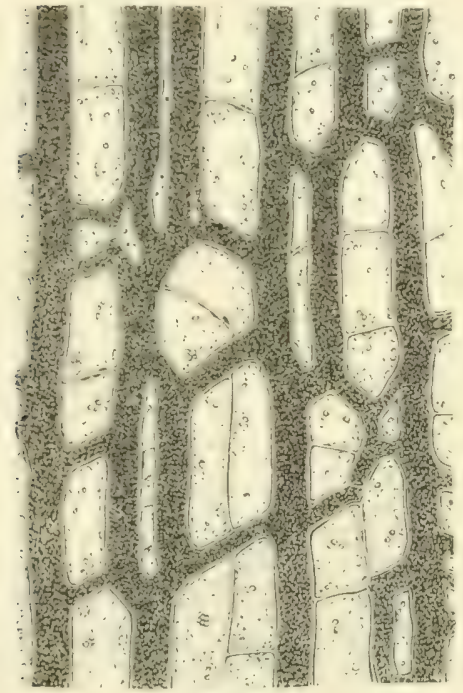

Fig. 96.

Gegliederte Milchröhren aus dem Rindenparenchym des Salats. (KIV.)

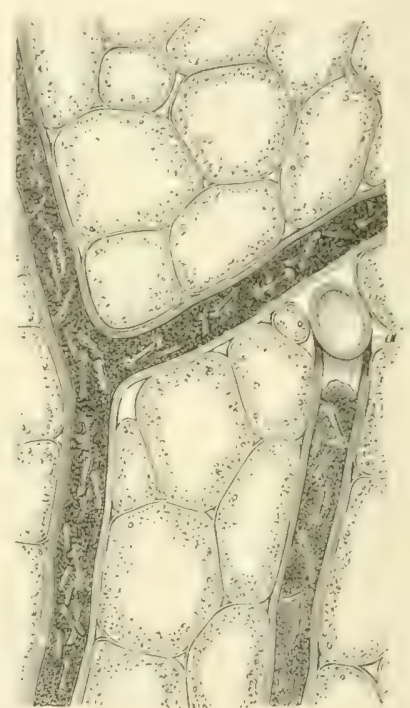

Fig. 97.

Teil einer ungegliederten Milchröhre von Euphorbia splendens (n. Kuy).

eine reichliche Menge von Gummischleim, ätherischen Ölen, Harzen oder ein Gemisch dieser verschiedenen Stoffe enthalten. Ferner sind an dieser Stelle jene Zellen zu erwähnen, die Gerbstoff, Kalkoxalatkrystalle in grösserer Menge führen. Wenn auch eine teilweise Wiederverwendung dieser Stoffe zur Ernährung der Pflanze nicht ausgeschlossen ist, so sind dieselben in der Hauptsache Abfalls- und Nebenprodukte der Stoffwechselvorgänge, die von der Pflanze nicht weiter umgewandelt werden.

Die Stoffe können abgelagert sein:

I. in Zellen oder übereinander stehenden Zellreihen,

2. in Intercellularräumen.

In die erste Gruppe gehören: die Schleimbehälter der Malvaceen, 
Cactaceen, die Harz- und Ölbehälter der Lauraceen, Magnoliaceen, von Rheum und Lysimachia, die Gerbstoffbehälter im primären Gefässbündel von Robinia Pseudacacia, Phasenlus multiflorus, die Gerbstoffschläuche in der Rinde von Sambucus, die Krystallbehälter (oxalsaurer Kalk) bei Liliaceen, Orchideen, in der Rinde von Aesculus Hippocastanum, Ulmus campestris, Acer, Quercus, Betula und vielen anderen Holzgewächsen. Auch die nach ihrem milchisen Inhaltssemenge fälschlich als Milchsaftgefässe bezeichneten Sekretschläuche von Acerarten (namentlich bei Acer platanoides in reichlicher Menge vorhanden) sind hierher zu rechnen. Durchschnittlich I mm lange Zellen stehen übereinander in Reihen, ohne dass die Querwände resorbiert würden.

In der zweiten Gruppe der Sekretbehälter haben wir zwischen lysigener und schizogener Entstehung der Intercellularräume zu unterscheiden. Die ersteren bilden sich durch Auflösung der Zellwände in bestimmten Gewebekomplexen, die schizogenen Intercellularräume bilden sich dagegen durch das Auseinanderweichen der Zellen resp. durch Trennung der Wände.

Lysigen entstandene, kugelige Sekretbehälter findet man bei den Myrtaceen, Rutaceen, Hypericumarten. In der sekundären Rinde von Prunusarten, z. B. bei Prunus avium, werden öfter
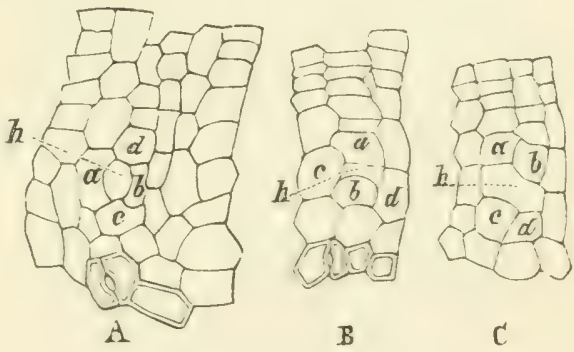

Fig. 98 .

Entstehung eines Harzganges (n. Sanio). grössere Gewebepartien unter Auflösung der Zellmembranen desorganisiert und in gummierfüllte Lücken verwandelt, aus welchen durch die aufbrechende Rinde das sog. Kirschgummi hervortritt. Ebenso entstehen in der Rinde älterer Coniferen öfter grosse Harzlücken, bei welchen Desorganisationserscheinungen möglicherweise Pilze thätig sind.

Häufiger kommen schizogen entstandene Gänge vor, die bei Lycopodiaceen, Cycadeen, Canna und Opuntiaarten, schleimige und summiartige Substanzen, bei Coniferen, Umbelliferen, Terebinthaceen, vielen Araliaceen, Compositen, äterische Öle, Harze oder Gummiharzemulsionen führen.

Da die Entwickelung dieser Sekretbehälter im primären und sekundären Gewebe gleich ist, sei es erlaubt, schon an dieser Stelle auf die Bildungsweise eines Harzsanges im sekundären Coniferenholze hinzuweisen. Zwischen vier jungen Zellen (Fig. 98, a b c d) bildet sich ein Intercellularraum h, der sich mit dem Wachstum des betreffenden Pflanzenteils vergrössert und durch die Ausscheidung der umliegenden Zellen, 
der Sekretzellen, mit Harz erfüllt wird. Die letzteren können sich noch weiter teilen, wobei sic aber in lüekenlosem Verbande bleiben. Dic Sckretzellen sind häufig durch sklerenchymatische Zellen umgeben, welche den Harzang segen das umsebende Parenchym abschliessen (Nadel von Pinus Iaricio, Fiss. $68, \mathrm{HC}=$ Harzkanal).

Derartige Harzgänge stehen untereinander in Verbindung, bei Verletzungen fliesst daher cine grössere Menge von Harz aus der Pflanze

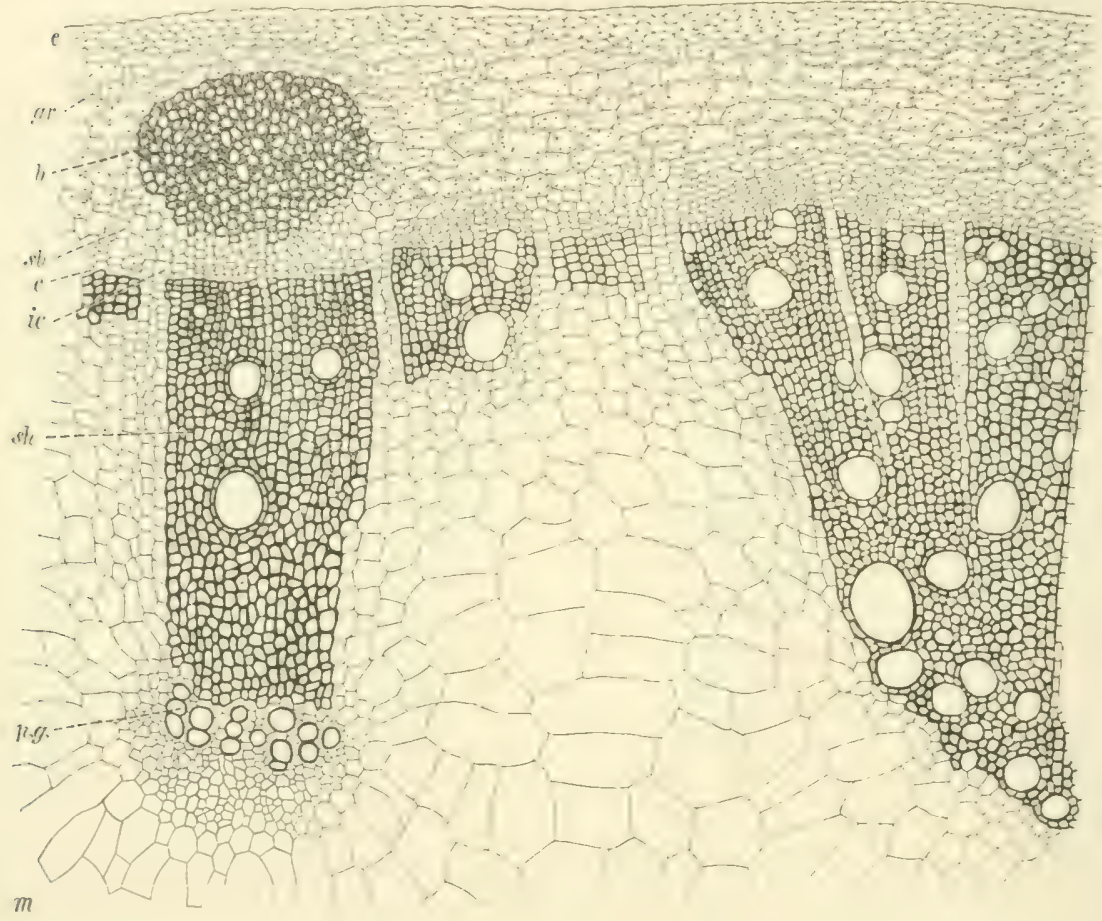

Fig. 99 .

Stück eines Querschnittes durch den erwachsenen Stengel einer Sonnenrose, nach dem Beginn der sekundären Verdickung. pg Primäre Gefässe, sh sekundäres Holz, ic und c Cambium, sb Siebteil der Gefässbündel mit b Bastfasern, gr grünes Rindenparenchym, e Epidermis.

(Frank und Tschirch, Wandtafeln.)

an der Wundstelle zusammen, welche Thatsache bei der Harznutzung von Wichtigkeit ist.

Die Sekretbehälter im allgemeinen können in den verschiedensten Teilen der Pflanzen vorkommen, sowohl im primären Gewebe, als im sekundären Zuwachs, im Phloëm wie im Xylem. Ebenso findet man sie häufig im Parenchym, namentlich in dem Rindenparenchym. 


\section{$\S 22$. Sekundäres Dickenwachstum der Sprossaxen.}

Ein Dickerwerden der Sprossaxen durch sekundäres Dickenwachstum, d. h. durch die Thätigkeit eines bestimmten, vom Vegetationspunkte nicht unmittelbar abhängigen Gewebes (Cambium), finden wir bei den Gymnospermen und Dicotylen in ausgedehntem Masse. Bei den Monocotylen dagegen ist nur ausnahmsweise sekundäres Dickenwachstum vorhanden.

Bei den typisch gebauten Gymnospermen und Dicotylen, also auch bei unseren Nadelhölzern und Laubhölzern, sind die Gefässbündel auf dem Querschnitt im primären $\mathrm{Zu}-$ stande in einen Kreis gestellt (vgl. Seite 75). Wir haben hier sog. offene Gefässbündel, d. h. Xylem und Phloëm sind durch das Cambium getrennt, durch jenes zartwandige, kleinzellige Gewebe, welches durch seine andauernde Teilungsfähigkeit ausgezeichnet ist (Fig. 93 i, Fig. 94 und $95 \mathrm{c}$ ). Diese Cambiumzellen haben entweder die Form eines rechteckigen Prismas, dessen längste Axe parallel der Längsrichtung des betreffenden Stammgebildes orientiert ist und dessen radialer Querdurchmesser kleiner als der tangentiale ist, oder sie sind faserförmig mit schief gestellten Querwänden.

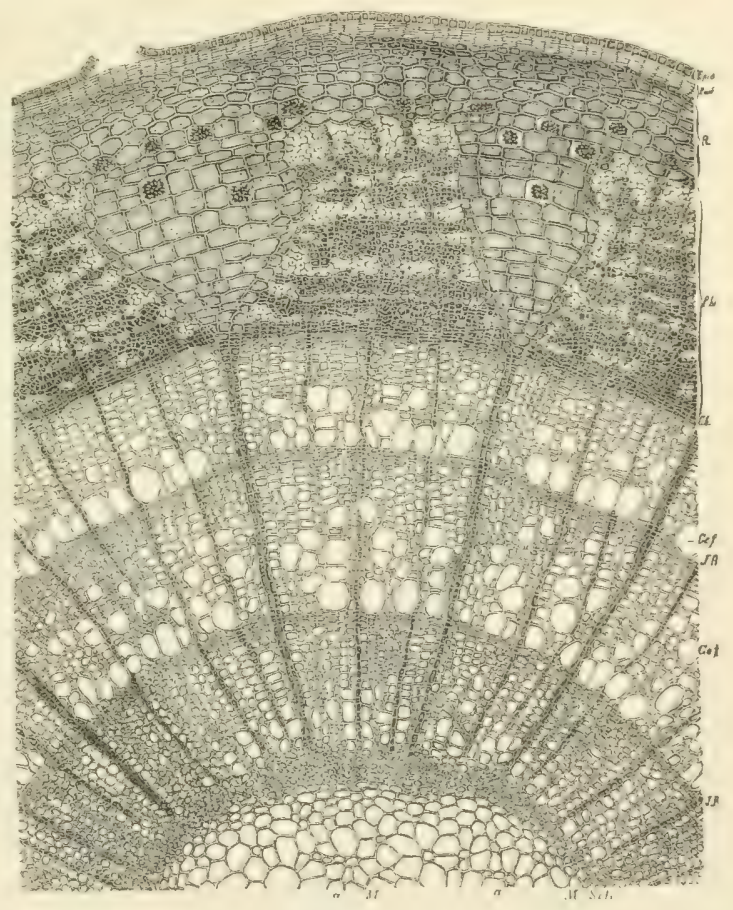

Fig. 100.

Querschnitt aus einem dreijährigen $\mathrm{Zweige}$ von Tilia parvifolia. Epid. Epidermis, Peri Kork, R Rindenparenchym, Phl Phloëm, Cb Cambium, Gef. Gefässe, JR Jahresringgrenze, M Mark. (KW.)

Während in dem primären Stadium des Laubsprosses, das Cambium nur auf die Gefässbündel beschränkt ist (Fascicularcambium), bildet sich bei dem Eintritt in das sekundäre Stadium auch noch zwischen den Gefässbündeln durch Teilungen der dazwischen liegenden Parenchymzellen eine cambiale Zone aus, welche als Überbrückungs- oder Interfascicularcambium bezeichnet wird. Es entsteht auf diese Weise ein vollständiger Cambiumring, wie dies durch Fig. 89 in schematischer Weise dargestellt ist. 
An der Innenseite des Cambiumringes liegen primäres Xylem und Mark, an der Aussenseite Phloëm und Rindenparenchym. Der Cambiumring durchschneidet dic aus Parenchymzellen bestehende Verbindung von Mark und Rinde, die sog. Markverbindungen.

Bei dem normalen Dickenwachstum werden durch die Teilung der Cambiumzellen nach innen zu, neue Xylemelemente, nach aussen zu neue Phlö̈m- und Rindenelemente gebildet. Zu gleicher Zeit bilden sich die Markverbindungen zu den Markstrahlen um (Fig. 99), indem an Stelle der Parenchymzellen teilweise Gefässbündelelemente auftreten.

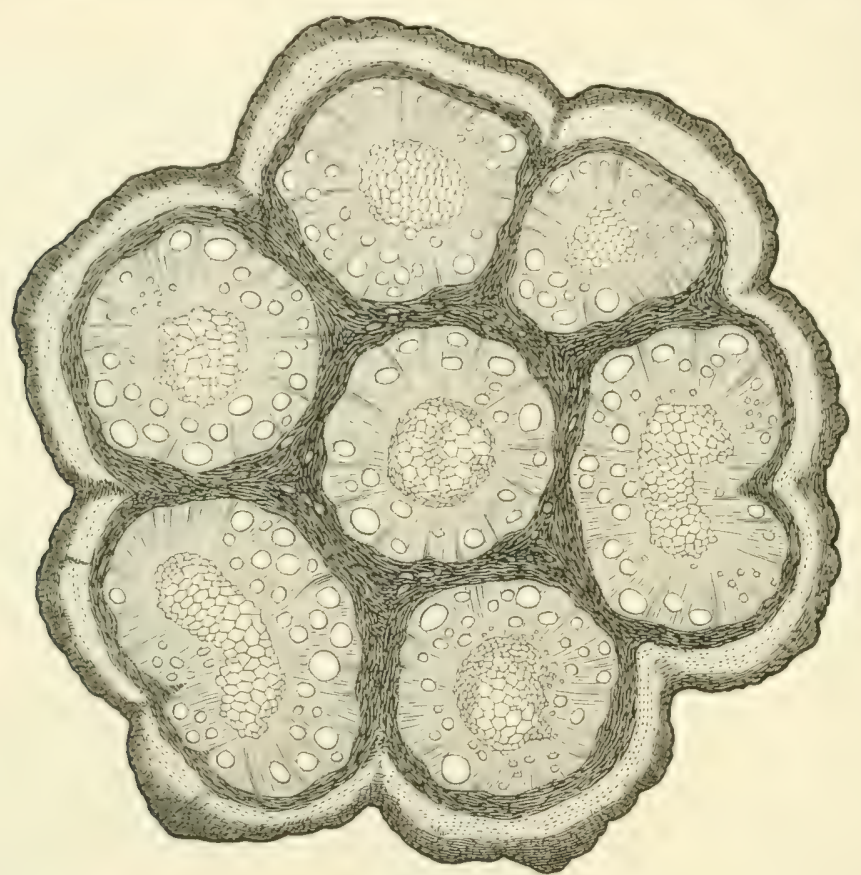

Fig. IOI.

Querschnitt durch den Stamm von Serjania. (R.)

Der vom Gefässbündel eingenommene Raum vergrössert sich auf Kosten des Parenchyms, welches auf mehr oder weniger schmale, radial verlaufende Strahlen, die Markstrahlen eingeschränkt wird (vgl. Fig. 99 und 100). Was im gewöhnlichen Leben als Holz bezeichnet wird, umfasst demnach alles Gewebe, welches zwischen dem Marke und dem Cambiumringe liegt (Fig. IOO). Dieses durch sekundäres Dickenwachstum entstandene Holz, auch sekundäres Holz genannt, schliesst unmittelbar an die primären Holzteile an (Fig. 99), welch letztere häufig als in das Nark vorspringende Ausbuchtungen (die sog. Markkrone) kenntlich sind. Während nun der sekundäre Holzkörper, wie bekannt, bei den Holzgewächsen durch jahrelang andauerndes Dickenwachstum grosse Dimensionen annehmen kann, bleibt das Rindenparenchym mit dem Phloëmteil 
relativ im Wachstum zurück, indem an der Aussenseite des Cambiumringes eine geringere Anzahl von Zellen abgeschieden wird und ausserdem diese Rindenparenchym- und Phloëmteile an der Peripherie in Borkebildung übergehen.

Bei den anomalen Dicotylen wächst der Stamm durch Bildung neuer Cambiumringe in die Dicke (Phytolacca, Wisteria, Bauhiniaarten), während die älteren Cambiumringe funktionslos werden. Es können auch mehrere Cambiumringe zugleich thätig sein, wodurch Gebilde, wie sie Fig. IOI darstellt, zu stande kommen.

Unter den Monocotylen zeigen nur einige baumartige Liliaceen, so Dracaena, Yucca, Aloë sekundäres Dickenwachstum, welches dadurch zu stande kommt, dass in dem die Gefässbündel umgebenden Parenchymcylinder bestimmte Zellcomplexe in ein teilungsfähiges Gewebe (Folgemeristem) übergehen und neue Gefässbündel und Parenchymzellen hervorbringen. Die Gefässbündel besitzen hier kein Cambium, man bezeichnet sie als geschlossene Gefässbündel.

\section{\$23. Die Elementarorgane des sekundären Holzes.}

Zum näheren Studium des anatomischen Aufbaus des sekundären Holzes sind drei in verschiedener Richtung geführte Schnitte notwendig (vgl. Fig. IO2): Der Querschnitt (senkrecht auf die Längsaxe), der radiale Längsschnitt (in der Ebene des Radius einer Holzscheibe) und der tangentiale Längsschnitt (parallel der Tangente einer Holzscheibe).

Auf dem Querschnitte (Fig. IOO und Fig. IO2 Q) erscheinen die Markstrahlen als radialstrahlenförmig verlaufende Zellreihen. Sind dieselben, wie z. B. bei den Nadelhölzern (Fig. IO3 und Taf. I, Fig. 4 und 7), bei Salix, Populus etc. nur eine oder wenige Zellen breit, so können sie mit freiem Auge nicht mehr oder nur undeutlich wahrgenommen werden. Bei sehr

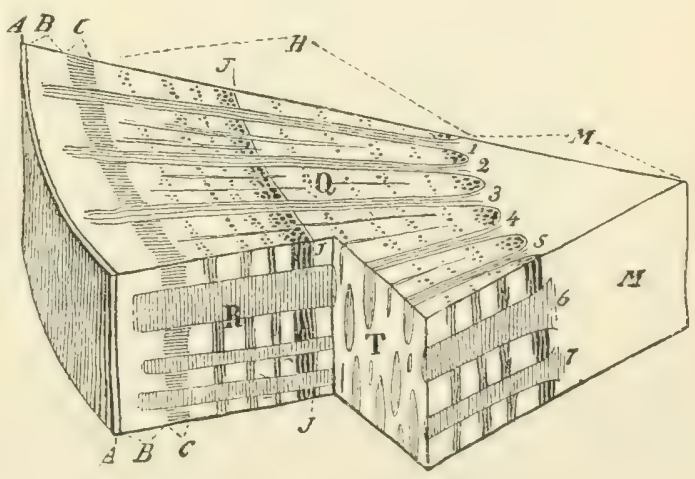

Fig. 102.

Q Querschnitt, $\mathrm{R}$ radialer Längschnitt; $\mathrm{T}$ tangentialer Längsschnitt durch ein Holzstück. A Epidermis, B l'hloëm und Rindenjarenchym. C Cambiumzone (hier relativ viel zu breit), $\mathrm{H}$ Holz, M Mark, I-7 Markstrahlen. (W.) vielen Hölzern kommen breite und schmale Markstrahlen zugleich vor, z. B. bei Carpinus, Taf. I, Fig. 5. Auf dem radialen Längsschnitt (Fig. $102 \mathrm{R}$, und I04) stellen die Markstrahlen radial verlaufende Bänder dar (Fig. IO4, 1, q), welche von den 
Technikern, wegen ihres etwas glänzenden Aussehens, als Spiegelfasern bezeichnet werden.

Auf dem Tangentialschnitt erkennen wir ihre Breite und Höhe, sie haben hier die Gestalt von langgestreckten, ellipsenartigen Figuren (Fig. IO2 T und Figs. 105 c), deren längere Axe (Höhe der Markstrahlen) fast immer mit der Längsrichtung der Sprossaxe zusammenfällt.

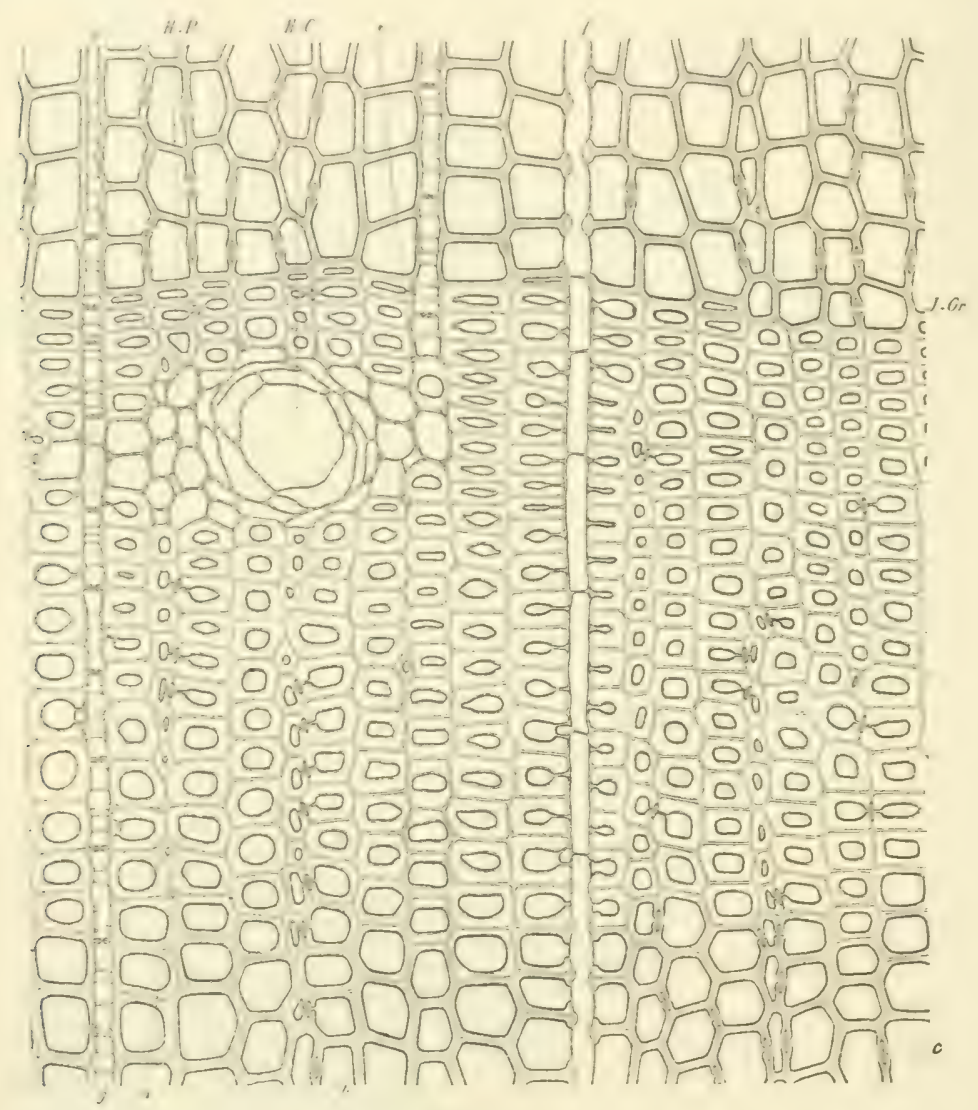

Fig. 103.

Querschnitt durch Kiefernholz. f Markstrahl, g Quertracheïden des Markstrahls, H.-P. Holzparenchym, um H.-C. einen Harzkanal, bc gehöfte Tüpfel, J.-G. Jahresringgrenze. (KW.)

Die von der Rinde bis zum Mark verlaufenden Strahlen bezeichnet man als die primären Markstrahlen. Da sich jedoch der Umfang eines Stammes mit seinem Dickenwachstum vergrössert, werden zwischen die älteren Markstrahlen neue eingeschaltet, die, von aussen gerechnet, nur bis zu gewissen Jahresringen reichen und sekundäre Markstrahlen genannt werden.

Der Raum zwischen den Narkstrahlen wird von den Elementen des 
sekundären Xylems eingenommen, zwischen welchen ausserdem noch Harz- und Gummigänge vorkommen können (vgl. S. 81).

Um die Bedeutung der Elemente, welche den sekundären Holzkörper zusammensetzen, besser verstehen zu können, ist es notwendig, kurz auf die physiologischen Funktionen desselben zu verweisen.

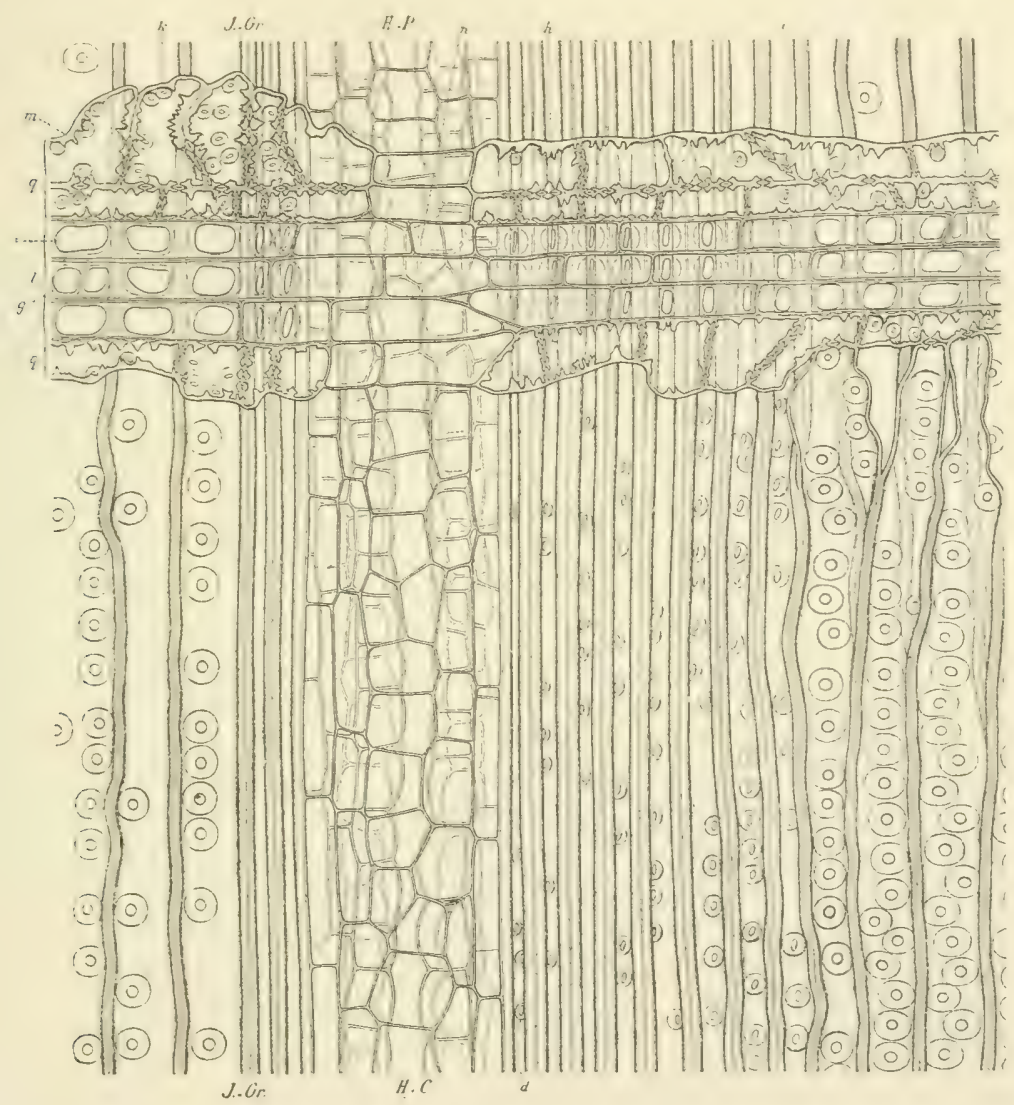

Fig. 104.

Radialer Längsschnitt durch Kiefernholz, I Parenchymatische Zellen, q Quertracheïden des Markstrahls. H.-C. Harzkanal von H.-P. Holzparenchym umgeben. Die behöften Tüpfel an den Tracheiden in Flächenansicht. J.-Gr. Jahresringgrenze. (KWV.)

I) Dient derselbe zur schnellen Fortleitung der für die Wasserverdunstung der Blätter notwendigen Wassermassen, so wie der im Wasser gelösten anorganischen Salze;

2) muss der Holzkörper eine genügende Festigkeit besitzen, um das Gewicht der Blattmasse, sowie der oberen und seitlichen Teile der Sprossaxen zu tragen;

3) ist derselbe zur Speicherung der in einer Vegetationsperiode producierten plastischen Stoffe bestimmt, die bei dem Austreiben der Knospen, 
der Ausbildung neucr Tricbe und der Produltion von Samen weitere Verwenduns finden.

Diesen Funktionen sind in hervoragender Weise gewisse Kategorien ron Holzelementen angepasst, die von Sanio auch als Systeme bezcichnet werden.

Das tracheale System dient in erster Linic dem Wassertransport, das bastfaserähnliche System der Festigung, das parenchyma-

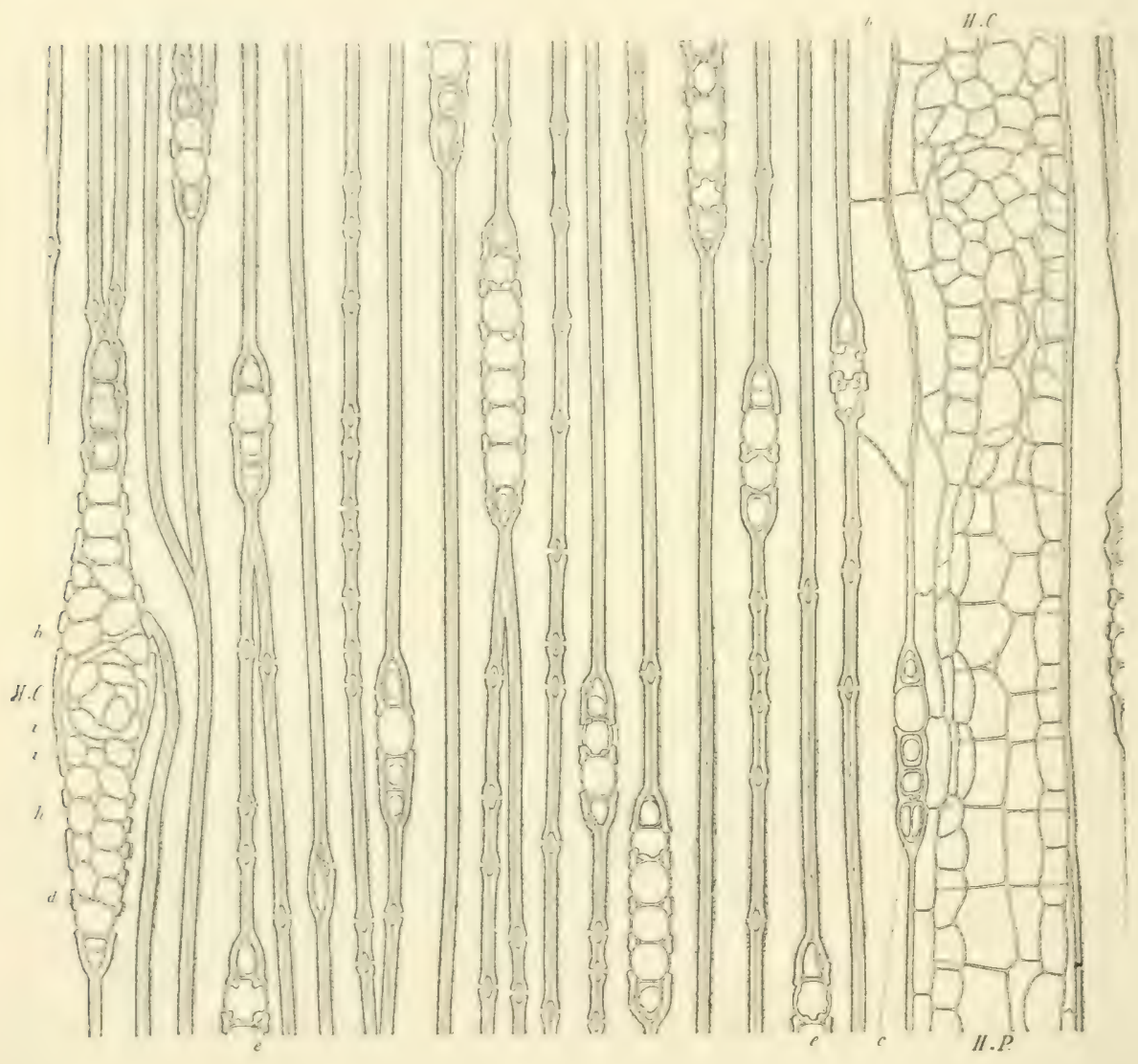

Fig. 105.

Tangentialer Längsschnitt durch Kiefernholz. e Markstrahlen, links ein grösserer Markstrahl mit einem Harzkanal (H.-C.). H.-C. und H.-P. wie bei Fig. IO4. (KW.)

tische System der Aufnahme und Leitung plastischer Substanzen. Die Arbeitsteilung ist in Wirklichkeit keine so scharfe, indem jedes System an den Funktionen der anderen mehr oder weniger beteiligt sein kann.

Zum trachealen System gehören die echten Gefässe ( Tiracheen) und die Trachëiden oder gefässartigen Holzzellen. (Unterschied siehe Seite 26.) 
Die Tracheen sind entweder relativ dünnwandig und mit spiraligen, ring- oder netzförmigen Verdickungen versehen, oder sie zeigen, und dies ist das weitaus häufigere Vorkommen, sehr zahlreiche kleine Hoftüpfel bei etwas stärkerer Verdickung der Zellwand. Spiralig-netzförmigc Verdickung kann zugleich mit behöften Tüpfeln vorkommen, z. B. bei Ulmus campestris, Tilia grandifolia.

Bei den einzelnen Hölzern herrscht in Bezug auf die Gestalt der Tüpfel, die Grösse des Hofes, die Form des Porus (vgl. S. 25) eine grosse Mannigfaltigkeit, die noch dadurch erhöht wird, dass die grossen und kleinen Gefässe desselben Holzes nicht vollständig übereinstimmen.

Der Hof ist an beiden Seiten der Membran gleich ausgebildet, wo die Gefässe an andere Gefässe, behöftgetüpfelte Tracheïden oder behöftgetïpfelte Libriformzellen grenzen. Ist das benachbarte Libriform einfach setïpfelt, so sind die Berührungsflächen ebenfalls einfach getüpfelt , Sambucus nigra, Populus nigra), oder der Hoftüpfel ist ausserordentlich klein (Syringa vulsaris, Hedera helix). IVo getüpfelte Gefässe an Holzparenchym, Ersatzzellen oder Markstrahlen grenzen, ist nur auf der Gefässseite ein weiter Tüpfelhof ausgebildet, der eine unverholzte Schliesshaut umgiebt. Es sind dies Erscheinungen, welche mit dem Wasser- und Stoffaustausch der einzelnen Gewebesysteme zusammen hängen.

Die Tracheiden gleichen bis auf die Perforation der Querwand den echten Gefässen. Sie können ebenso kurz sein wie die einzelnen Glieder der Tracheen, und wie diese in deutlichen Längsreihen angeordnet sein (Moreen, Ulmaceen etc.), oder sie sind mehr in die Länge gestreckt, an beiden Enden scharf zugespitzt und greifen prosenchymatisch zwischen einander ein (Quercus sessiliflora, Ribesarten, Pomaceen, Coniferen). Man bezeichnet derartige langgestreckte Formen als Fasertracheiden.

Tracheen und Tracheïden einerseits, Tracheïden und Libriformzellen anderseits können durch Übergangsformen miteinander verbunden sein. So sehen wir in Fig. Io6 bei a ein normales Element einer Trachee mit vollständig perforierter Querwand. Bei b ist die Trachee englumiger, die Perforation ist nur eine leiterförmige; bei c fehlt die Perforation, weshalb wir diese Zelle als Tracheïde aufzufassen haben. Ebenso ist $d$ eine Tracheide, obgleich die Tüpfel hier schief gestellt und wesentlich enger sind; d bildet den Übergang zu den typischen Libriformzellen e und f.

Die Zellen des trachealen Systems enthalten nur in der Jugend Protoplasma, später Wasser, Wasserdampf und Luft. Sie stellen demnach enge Capillaren dar, welche, wie man annehmen muss, in hervorragender Weise beim Wassertransport beteiligt sind.

Zum bastfaserähnlichen System gehören die einfachen und gefächerten Libriformzellen (= bastartigen Holzzellen oder Holzfasern). Dieselben sind langsestreckt, an beiden Enden mehr oder weniger zugespitzt. Sie besitzen eine sehr dicke Wand mit meist einfachen, sehr schmalen schiefgestellten Tüpfeln (Fig. I06e, f). Behöfte Tüpfel sind 


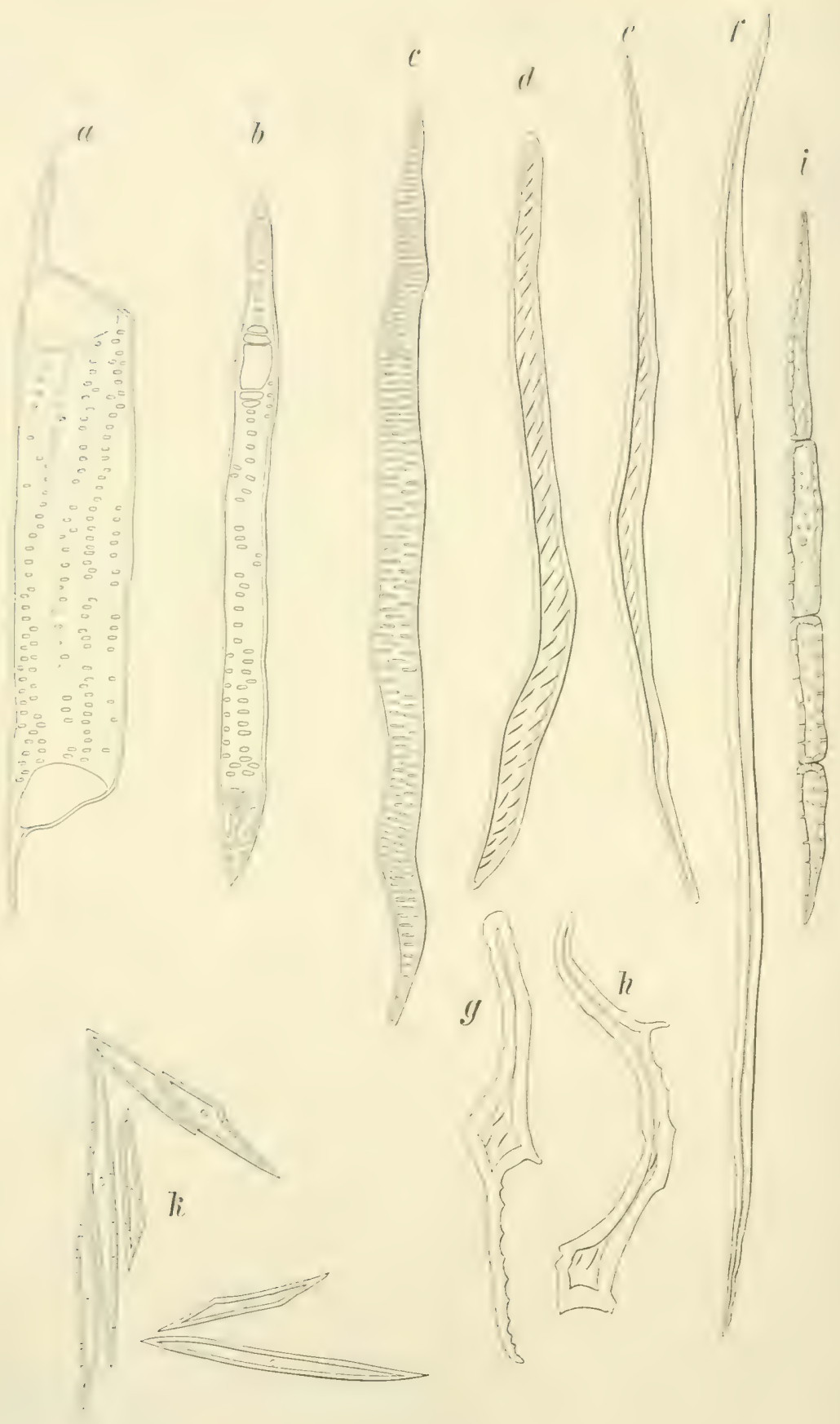

Fig. 106.

Isolierte Elemente aus dem alten Holze von Fagus silvatica. a und b Gefässzellen, c und d Tracheïden, e-h Libriformzellen, i Holzparenchym, k Markstrahlzellen. 
selten, spiralige Verdickungsleisten fehlen in der Regel. Die innerste Wandschicht ist bei manchen Hölzern (Cytisus Laburnum, Caragana arborescens, Ulmus campestris, Morus alba etc.) von gelatinös-knorpeliger Beschaffenheit, und zeichnet sich durch Blaufärbung mit Chlorzinkjod aus.

Die gefächerten Libriformzellen gleichen den einfachen in Form und Wandverdickung, sind jedoch durch zarte Querwände in zwei oder mehrere übereinander liegende Zellen geteilt.

Die Libriformzellen enthalten, nachdem die Verdickung der Wand vollzogen ist, in dem oft sehr engen Lumen entweder Luft, Wasser und einige Plasmareste, oder sie können das Protoplasma noch etwas länger behalten und dann zur Speicherung von Stärke verwendet werden. Es ist dies jedoch nur eine Nebenfunktion dieser Zellen.

Die Hauptfunktion der Libriformzellen ist die Festigung des Holzes, wozu sie durch ihre grössere Länge (bis zu I,3 mm), ihre Dickwandigkeit, sowie durch die feste keilförmige Verbindung untereinander besonders geeignet sind. Der feste Zusammenhang mit den übrigen Elementen kann eventuell (Fig. I06e, g, h) durch vorspringende Kanten und Ecken der Zellwand erhöht werden.

Die Spaltbarkeit des Holzes dürfte durch derartig unregelmässige Formen, wie Fig. Io6g und h, wesentlich vermindert werden.

Ebenso wie es Übergänge zwischen Tracheïden und Libriformzellen giebt (vgl. S. 89), kann man eine Annäherung der Libriformzellen an die Holzparenchymzellen konstatieren, indem bei den ersteren das Protoplasma erhalten bleibt. Namentlich unterscheiden sich die gefächerten Libriformzellen nur durch den Grad der Wandverdickung von den Holzparenchymzellen. Die zu dem parenchymatischen Systeme gehörigen Ersatzfasern (vgl. unten) besitzen ebenfalls eine langgestreckte Form, wenn auch mit weiterem Lumen und geringerer Wandverdickung. Bei Cytisus Laburnum kommen Zellen vor, die zur Hälfte Ersatzfasern, zur anderen Hälfte Libriformzellen sind.

Zum parenchymatischen System gehören die Holzparenchymzellen und die Ersatzzellen oder Ersatzfasern. Diese beiden Elemente zeichnen sich durch relativ schwach verdickte Wandungen aus, die weder spiralige Verdickungen noch behöfte Tüpfel aufweisen, sondern nur mit einfachen Tüpfeln versehen sind. Das Protoplasma bleibt bei denselben meist viele Jahre erhalten, wodurch sie befähigt werden, plastische Substanzen, namentlich Stärke zu speichern.

Die Holzparenchymzellen (Fig. I06i) entstehen durch Querteilungen der Cambiumzellen, wobei die Endzellen häufigs zussespitzt bleiben, während die mittleren Zellen auf dem Längsschnitt die Form eines Rechteckes aufrueisen.

Die Ersatzzellen stimmen sonst in ihren Eigenschaften mit den Holzparenchymzellen überein, die Querteilungen der Cambiumzellen sind jechel unterblieben, weshalb die ganze Zelle eine faserförmige Gestalt aufweist. 
Ersatzzellen finden sich sehr häufig im Herbstholz, d. h. sie werden zu ciner Zeit sebildet, wo die Teilungsfahiskeit der Zellen im ganzen nachliisst (z. B. bei Betula alba, Juglans regia). Doch siebt es Hölzer, Wo nu. Ersatzfasern, kein Holzparenchym gebildet wird; \%. B. Viscum album, Carasana arborescens.

In Funktion und Beschaffenheit stehen die Elementaroryanc der Markstrahlen dem parenchymatischen Systeme sehr nahe. Es handelt sich auch hier um stoffleitende und speichernde Organe, um Zellen, deren Protoplasma mehrere Jahre hindurch erhalten bleibt.

In den meisten Fällen bestehen die Markstrahlen aus Parenchymzellen, deren radialer Durchmesser am grössten ist, entsprechend der Fortleitung ron Stoffen in radialer Richtung, während die übrigen Holzelemente zumeist in der Längsrichtung des Stammes gestreckt sind. Die Markstrahlen haben entweder die Form eines rechteckigen Prismas oder sind, wic dies Fig. I06k zeigt, an zwei Seiten in Spitzen ausgezogen. Beide Formen können nebeneinander vorkommen, wie dies auch bei Fagus silvatica der Fall ist. Ausnahmsweise sind die Markstrahien in der Längsrichtung des Stammes stärker gestreckt (Periploca, Hoja, Nerium, Drimys Winteri), oder es kommen zweierlei Zellen nebeneinander vor wie bei Salix, Populus. Bei den letztgenannten Pflanzen wird die Mitte der Markstrahlen von radialgestreckten Zellen eingenommen, die nach oben und unten von höheren, in radialer Richtung verkürzten Zellen begleitet werden. Eine grössere Differenz zwischen den Bestandteilen der Markstrahlen ist bei gewissen Coniferen zu finden, so bei Pinus, Cedrus, Larix, Tsuga canadensis, Picea excelsa, Abies balsamea. Hier finden sich einerseits leitende Parenchymzellen (Fig. IO4l), anderseits Tracheïden, die wegen ihrer von den übrigen Tracheïden abweichenden Lage als Quertracheïden (Fig. IO4 q) bezeichnet werden. Sic enthalten Wasser und Luft, während die plastischen Stoffe nur durch das leitende Parenchym gespeichert werden.

Die Markstrahlzellen zeigen, abgesehen von den Quertracheïden, nur cinfache Tüpfel, niemals Hoftüpfel. Besonders gross sind die Tüpfel dort, wo der Markstrahl an Gefässe stösst, wodurch die Wasseraufnahme aus den Gefässen für die Markstrahlen erleichtert wird. Die an Holzparenchym und Ersatzfasern stossenden Wandpartien haben kleine, aber zahlreiche Tïpfel.

Die Wand der Markstrahlen ist bis auf wenige Ausnahmen verholzt.

Bemerkenswert ist noch, dass zwischen den Markstrahizellen zahlreiche mit Luft erfüllte Intercellularräume vorkommen, die einerseits durch die Lenticellen (vgl. \$ 30) mit der Aussenluft, anderseits mit den zwischen Holzparenchymzellen rorkommenden Intercellularräumen in Verbindung stehen.

Was die Zusammensetzung des Holzkörpers der verschiedenen Pflanzen aus den Elementarorganen anbelangt, so ist zu- 
nächst zu bemerken, dass jede Pflanze nur bestimmte Elementarorgane zu bilden im stande ist. So beruht der so scharfe Unterschied zwischen Laubhölzern und Nadelhölzern darauf, dass bei den Nadelhölzern nur Tracheiden vorkommen, die echten Gefässe jedoch fehlen. Eine Ausnahme bildet nur der erste Jahresring, in welchem auch bei den Nadelhölzern echte Gefässe zu finden sind. Die einzige dicotyle Pflanze, welche mit den Nadelhölzern in der Abwesenheit von Gefässen übereinstimmt, ist Drimys Winteri.

Die Nadelhölzer enthalten, abgesehen von den Markstrahlen, entweder nur Tracheïden (z. B. Taxus baccata), oder Tracheïden und Holzparenchym (z. B. Pinus silvestris, Picea excelsa), wobei jedoch zu bemerken ist, dass das Holzparenchym nur im Zusammenhang mit den Harzkanälen vorkommt (Fig. IO3-IO5).

Ebenso stellte Sanio für die Laubhölzer verschiedene Reihen auf, je nach der Kombination von Elementarorganen, welche in dem betreffenden Holze zu finden sind. Als Beispiele greife ich heraus:

Gefässe, Tracheiden und Ersatzzellen bei Kerria japonica, Elaeagnus argentea, Hippophaë rhamnoides u. a.

Gefässe, Tracheïden und Libriform bei Berberis vulgaris, Mahonia aquifolium.

Gefässe, Libriform und Erzatzzellen bei Viscum album.

Gefåsse, Libriform, Holzparenchym und Ersatzzellen bei Fraxinus excelsior, Fraxinus ornus, Platanus occidentalis u. a.

Gefässe, Tracheiden, Libriform und Holzparenchym bei Sambucus racemosa und nigra, Acer platanoides, Pseudoplatanus, campestre u. a.

Sämtliche Elemente kommen zugleich vor bei Tectoma grandis, Rhus Cotinus, Ceratonia Siliqua u. a.

Die Trennung dieser Gruppen ist insofern nicht immer prägnant, als es schwer ist, bei den Übergängen von Tracheen zu Tracheïden, von Tracheïden zu Libriformzellen genau festzustellen, welche Gewebeelemente hier vorliegen.

Ferner unterscheiden sich die einzelnen Hölzer durch die verschiedenartige Wandverdickung der betreffenden Elemente, indem wir bald getüpfelte, bald spiralige Tracheen etc. vorfinden. Für die Erkennung der Hölzer mit freiem Auge ist die Grösse der Gefässe von Wichtigkeit, sowie die Anordnung bestimmter Elementarorgane und die Deutlichkeit der Markstrahlen. Die Grundmasse bei den meisten Hölzern bildet das Libriform, in welchem dann die Gefässe, Tracheïden etc. zu grösseren Gruppen, helleren Bändern oder radialen Streifen vereinigt sind.

In der Tabelle zur Bestimmung der Hölzer sind unsere wichtigsten einheimischen Hölzer nach derartigen mit freiem Auge sichtbaren Merkmalen zusammengestellt, und durch die bei schwacher Vergrösserung entworfenen Tafeln I und II erläutert. 
\$2. Jahresringbildung, Verschiedenhoiten des Holzes nach Alter und

\section{Baumhöhe. Kernholz und Schutzholz.}

Wie bekannt, kann man den in einem Jahre gebildeten Zuwachs bei den meisten einheimischen Hölzern sehr deutlich erkennen, indem das Holz im Frühjahre und im Spätsommer in verschiedener Weise ausgrebildet wird. Man bezeichnet die oft allmählich ineinander übergehenden Zonen innerhalb eines Jahresringes einem ältern Sprachgebrauche gemäss als Fribjahrsholz und Herbstholz, obgleich Herbstholz schon im Hochsommer sebildet wird, und demnach korreliter dasselbe als Sommerholz zu bezeichnen wäre. Für alle Fälle passt diese Bezeichnung jedoch auch nicht, indem z. B. in Wurzeln das Dickenwachstum erst Ende Oktober oder noch später erlischt, wir halten demnach an dem älteren so gebräuchlichen Ausdrucke „Herbstholz" fest.

Zwischen Herbstholz und Frühjahrsholz kömnen folgende Unterschiede bestehen:

I) Im Herbstholz und Frühjahrsholz werden dieselben Elementarorgane gebildet, sie sind jedoch anders gestaltet. So finden wir bei den Nadelhölzern im Frühjahr (Fig. IO3) weitlumige, dünnwandige Tracheïden, während im Herbstholz englumige, in radialer Richtung abgeplattete, dickwandige Tracheiden vorkommen. Den Übergang bilden häufig Tracheïden, welche nicht wesentlich kleiner sind als die Frühjahrstracheiden, aber mit einer dickeren Wand versehen sind. Ebenso können bei den Laubhölzern die Tracheiden und Libriformzellen, sowie das Holzparenchym dickwandiger ausgebildet werden, mit oder ohne Verkürzung des radialen Durchmessers.

2) Im Frühjahre werden ausserordentlich weite, im Herbstholze dagegen sehr enge Gefässe gebildet, wodurch das Frühjahrsholz ein mehr grossporiges Aussehen erhält (z. B. bei Fraxinus excelsior, Taf. II, Fig. I I). Auch die Markstrahlzellen sind in den meisten Fällen im Herbstholz stark verkürzt.

3) Die hellere Färbung des Frühjahrsholzes kommt dadurch zu stande, dass in demselben zahlreichere, wenn auch nicht weitere Gefässe gebildet werden als im Herbstholz (z. B. bei Prunus domestica, Rhamnus cathartica).

Im Frühjahrs- und Herbstholz werden nicht immer dieselben Elemente gebildet. Während bei Beginn der Vegetation die Bildung von Gefảssen vorherrscht, treten im Herbstholz mehr Libriformzellen auf. Die Gefässe können, z. B. bei Betula verrucosa, Alnus glutinosa, Populus tremula u. a., im Herbsholz direkt durch Tracheïden ersetzt werden. Es werden im Frühjahr zunächst die zur Wasserversorgung notwendigen Bahnen geschaffen und erst wenn dies vor sich gegangen ist, treten die mecha- 
nischen Elemente in den Vordergrund. Von der Regel, dass die Herbstholzgrenze von englumigeren und dickwandigeren, d. h. mechanisch wirksameren Elementen eingenommen wird, giebt es jedoch Ausnahmen, indem z. B. bei Morus alba, Fraxinus excelsior, Fraxinus ornus, Robinia Pseudacacia, Gleditschia triacanthos u. a., die Jahresringgrenze im Herbste durch relativ dünnwandiges Holzparenchym eingenommen wird. Es mag dies mit einer besseren Versorgung des Cambiums mit Nahrungsstoffen zusammenhängen.

Die Ursachen der Jahresringbildung sind noch nicht vollständig aufgeklärt. Sachs nahm an, dass während der Bildung des Herbstholzes infolge der Vergrösserung des ganzen Holzkörpers die Rinde stärker gedehnt wäre und demnach ein grösserer Druck auf die jungen Holzzellen ausgeübt würde, wodurch stärker abgeplattete und verdickte Elemente entständen. Während des Winters soll dieser Rindendruck verschwinden, so dass im Frühjahre wieder weitere Elemente gebildet werden könnten. Von Krabbe wurde nachgewiesen, dass der Rindendruck keine derartigen Differenzen aufweist. Man muss vielmehr annehmen, dass die Jahresringbildung durch den Wasserbedarf der Pflanze indirekt beeinflusst wird, obwohl man nicht weiss, wie dieser Einfluss mechanisch vermittelt wird. Werden z. B. Laubhölzer im Sommer entlaubt, so sinkt der Wasserverbrauch plötzlich sehr stark. Zugleich wird statt des Frühjahrsholzes Herbstholz gebildet. Schlägt der entlaubte Baum wieder aus, so entsteht aufs neue Frühjahrsholz. Auf diese Weise können bei Entlaubungen durch Raupenfrass oder vorübergehende starke Trockenperioden in einem Jahre zwei Jahresringe gebildet werden. Da zu jeder Zeit genügende Mengen von Reservestoffen zur Verfügung stehen, kann ich die verschiedene Ernährung des Cambiums nicht als Ursache der Jahresringbildung ansehen.

Bei manchen Holzpflanzen, deren Wachstum sehr lange andauert, reifen die Spitzen der Triebe nicht vollständig aus, so z. B. bei Robinia Pseudacacia, Gleditschia triacanthos, Morus alba, Salix und Populusarten. Die Zweige sind, wenn der Winter bei uns eintritt, noch zu wasserreich, weshalb sie leicht erfrieren. Diesem Erfrieren kann man durch vorzeitige Entlaubung entgegenwirken. Es erscheint daher nicht unwahrscheinlich, dass auch hier infolse der Entlaubung derbwandigere und infolgedessen widerstandsfähigere Holzelemente gebildet werden.

Beim Vergleich der Elementarorgane des Holzes der verschiedenen Jahresringe finden wir ebenfalls Differenzen.

Die Grösse der. Holzzellen nimmt in den Stamm- und Astteilen überall von innen nach aussen durch eine Anzahl von Jahresringen hindurch zu, bis eine bestimmte Maximalgrösse erreicht ist, welche für die folgenden Jahresringe konstant bleibt, eventuell aber auch eine kleine Abnahme erfährt. 
Als Beispiele mögen folgende Angaben dienen:

Pinus silvestris 1 IOjähriger Stamm, I1,3 m über dem Boden (n. Sanio).

\begin{tabular}{|c|c|c|c|c|c|}
\hline Nummer & Mittl. Breite & Miul, Lïnge & \multirow{2}{*}{$\begin{array}{c}\text { Nummer } \\
\text { des Jahresringes. }\end{array}$} & Mittl. Breite & Mittl. Lünge \\
\hline des Jahresringes. & \multicolumn{2}{|c|}{ der Tracheïden in $\mathrm{mm}$} & & \multicolumn{2}{|c|}{ der Tracheïden in $\mathrm{mm}$} \\
\hline I (innen) & 0,017 & 0,95 & 39 & - & 4,00 \\
\hline 17 & - & $2,7+$ & 40 & 一 & 4,04 \\
\hline 19 & - & 3,13 & 43 & 一 & 4,09 \\
\hline 31 & - & 3,69 & 45 & - & 4,2 I \\
\hline 37 & - & 3,87 & 46 & - & 4,21 \\
\hline $3^{S}$ & 一 & 3,91 & 72 (aussen) & 0,032 & 4,21 \\
\hline
\end{tabular}

Fagus silvatica I50jähriger Stamm; I,3 $\mathrm{m}$ über dem Boden (n. R. Hartig).

\begin{tabular}{|c|c|c|c|}
\hline Lebensjahr. & $\begin{array}{c}\text { Länge } \\
\text { der Gefässe. }\end{array}$ & $\begin{array}{c}\text { Länge } \\
\text { der Traclieïden. }\end{array}$ & $\begin{array}{c}\text { Länge } \\
\text { der Libriformzellen. }\end{array}$ \\
\hline $\begin{array}{l}30 \\
60\end{array}$ & $\begin{array}{l}0,512 \mathrm{~mm} \\
0,610 \quad \%\end{array}$ & $\begin{array}{l}0,723 \mathrm{~mm} \\
0,940\end{array}$ & $\begin{array}{l}\mathbf{1}, 058 \mathrm{~mm} \\
\mathbf{1}, \mathbf{I} 88 \quad,\end{array}$ \\
\hline 90 & $0,616 \quad n$ & $0,943 \quad n$ & $1,123 \quad$, \\
\hline 120 & 0,653 & $0,950 \quad$ & $1,264 \quad$ \\
\hline 140 & $0,633 n$ & $0,882 \quad "$ & $1,177 \quad$ \\
\hline 150 & $0,488 \quad "$ & ? & I, I $34 \quad$, \\
\hline
\end{tabular}

Die Grösse der Holzzellen der Stammes nimmt von unten nach oben zu, erreicht in bestimmter Höhe ein Naximum um dann nach dem Wipfel zu wieder abzunehmen. Das Maximum scheint jedoch unter Umständen sehr tief zu liegen.

Nach Sanio beträgt die Länge der Tracheiden bei Pinus silvestris (I IOjähriger Stamm) in den äussersten Jahresringen:
über dem Boden (I05. Jahresring von Innen) 2,65 $\mathrm{mm}$
in I I, $3 \mathrm{~m}$ Höhe (72. Jahresring)
$4,21 \mathrm{~mm}$
im unteren Wipfel (35. Jahresring)
$2,78 \mathrm{~mm}$
im oberen Wipfel (2 I. Jahresring)
$2,82 \mathrm{~mm}$

Nach R. Hartig zeigten die Zellen des I40. Jahres bei der oben als Beispiel angeführten Buche folgende Längen:

\begin{tabular}{|c|c|c|c|}
\hline Baumhöhe. & Gefässe. & Tracheïden. & Libriformfasern. \\
\hline $\mathrm{I}, 3 \mathrm{~m}$ & $0,633 \mathrm{~mm}$ & $0,882 \mathrm{~mm}$ & $1,177 \mathrm{~mm}$ \\
\hline $5,5 \mu$ & $0,532 \quad$ & 0,773 & $1,010 \quad "$ \\
\hline 10,7 & $0,547 \quad$, & $0,773 \quad n$ & $\mathbf{1}, 0 \mathbf{1} \mathbf{2} "$ \\
\hline I 5,9, & $0,564 \quad n$ & 0,823, & 1,002, \\
\hline 21,1 & $0,453 \quad n$ & $0,640 \quad$, & $0,838 \quad "$ \\
\hline $24, I$, & 0,437, & $0,627 \quad "$ & $0777 "$ \\
\hline
\end{tabular}


Auf welche Weise diese Differenzen zu erklären sind, bleibt dahingestellt. Vielleicht werden gerade an jenen Teilen des Stammes die Libriformzellen und Tracheïden am längsten ausgebildet, welche mechanisch am stärksten in Anspruch genommen werden, indem derartige lange Zellen mit möglichst grossen (schief gestellten) Berührungsflächen am wenigsten leicht auseinander gerissen werden. Die wechselnde Grösse der Gefässe hängt vielleicht mit quantitativ verschiedenen Ansprüchen an die Wasserleitungsfähigkeit zusammen.

Die Zahl der Markstrahlen ist ebenfalls nach Stammhöhe und Alter des Jahresringes auffallend verschieden. Hierfür ein Beispiel an einem alten Stamme von Pinus silvestris (n. Essner). Auf I qmm des Tangentialschnittes kommen:

\begin{tabular}{|c|c|c|c|}
\hline im $\quad r$. & esr & 76 & str \\
\hline$" \quad 5$. & ", & 54 & $"$ \\
\hline "IO. & ", & 46 & $"$ \\
\hline$\Rightarrow 20$. & ", & 36 & $"$ \\
\hline , 40. & ", & 30 & $"$ \\
\hline$", 50$. & $"$ & 27 & ", \\
\hline 60. & $"$ & 27 & $"$ \\
\hline So. & $"$ & 30 & ", \\
\hline , 90. & ," & 30 & $"$ \\
\hline 125. & $"$ & 34 & $"$ \\
\hline 160. & ", & 37 & , \\
\hline
\end{tabular}

Wesentliche Veränderungen erleidet das Holz bei seinem Älterwerden. In vielen Fällen lässt sich an der Farbe das junge Holz, der Splint, von dem älteren Holz, dem Kern unterscheiden.

Die jüngeren Jahresringe enthalten eine grössere Menge mit Protoplasma versehener, d. h. lebender Zellen (Holzparenchym und Ersatzfasern), welche sich zu gewissen Zeiten durch ihren Stärkegehalt auszeichnen. Nit dem Älterwerden des Holzes, namentlich mit der Bildung des Kernes wird die Zahl der lebenden Zellen reduciert, bis schliesslich das ganze Holz nur aus toten Elementen besteht, welcher Zustand jedoch auch erst im hohen Alter eintreten kann.

Die Gefässe, die in den jüngeren Jahresringen mit Luft, Wasser und Wasserdampf erfüllte Röhren darstellen, werden in dem älteren Holze verstopft. Diese Verstopfung geschieht entweder durch sog. Thyllenbildung oder durch gummiartige Substanzen.

Unter Thyllen (Fig. IO7 a) versteht man Auswüchse lebender, an die Gefässe anstossender Holzparenchymzellen, deren Wand sich an den getüpfelten Stellen in das Innere des Gefässes vorstülpt, bis durch eine grössere Menge derartiger Blasen der Verschluss erreicht wird.

Die gummiartigen Substanzen werden ebenfalls von den Holzparenchymzellen gebildet, aus denen ein in den Gefässen erhärtendes 
summiartiges Sekret übertritt. Diese Substanz unterscheidet sich durch ihre Unveränderlichkeit in Wasser von anderen Gummiarten. Diese Eisenschaft ist wesentlich, da die Gefässe ja für den Wasserdurchtritt undurchlässigs semacht werden sollen.

Dic auffallende Färbung, welche das Kernholz (vgl. die Holz-

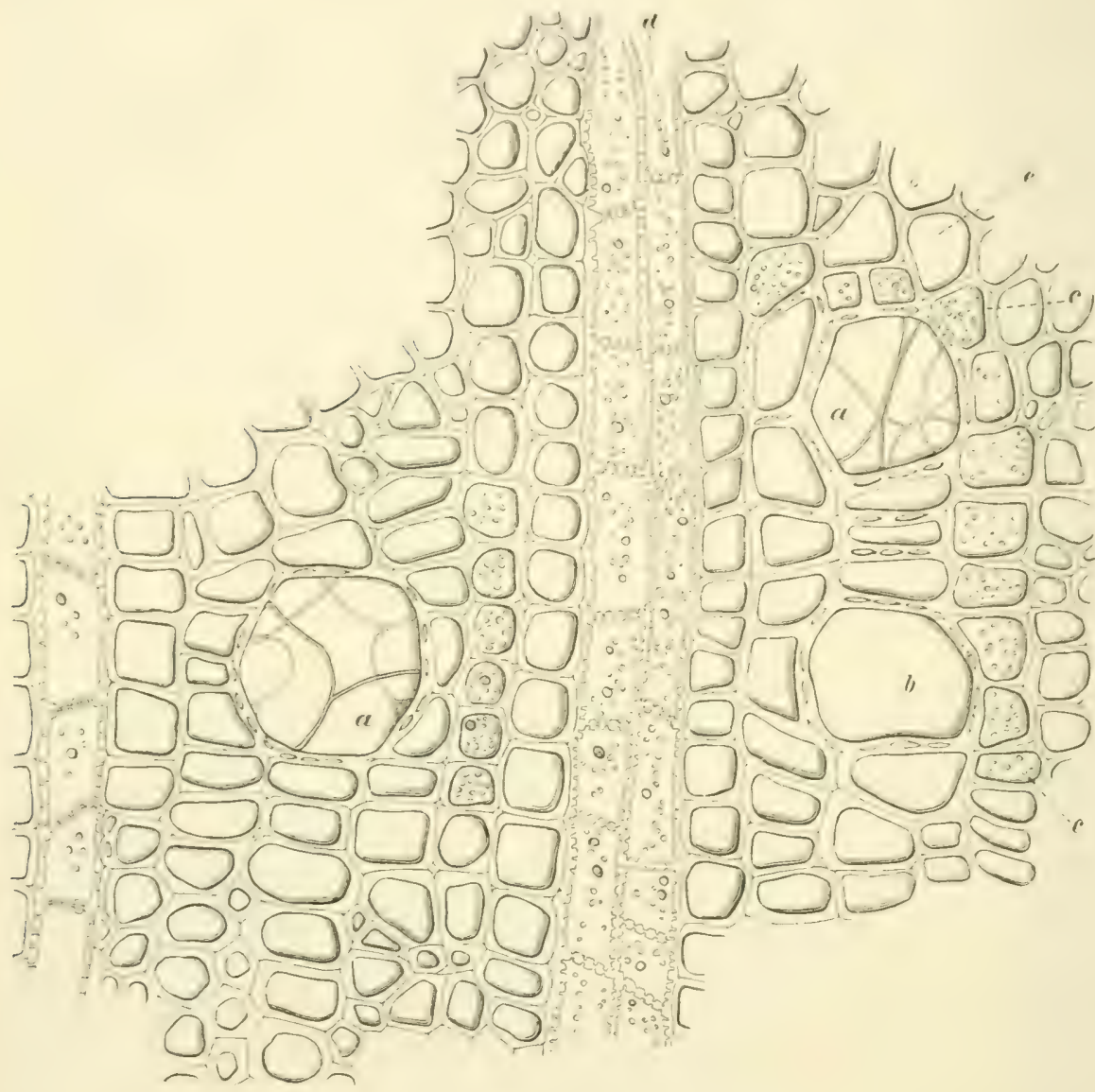

Fig. 107

Querschnitt durch einen einjährigen Zweig von Robinia Pseudacacia. a Gefäss mit Thyllen, b Gefäss ohne Thyllen, c Holzparenchym, d Markstrahlen, e Libriformzellen. (DN.)

bestimmungstabellen) a ufweist, ist einerseits durch die Fárbe des die Zellen ausfüllenden summiartigen Körpers, anderseits durch die Färbung der Zellmembran verursacht. Es handelt sich um Ausscheidungsprodukte der lebenden Zellen, welche das Kernholz durchtränken. Sehr charakteristisch sind die bei den technisch verwendeten Farbstoffhölzern auftretenden Farbstoffe. Als Beispiele mögen hierfür angeführt werden: 
Haematoxylon campechianum, Campesche- oder Blauholz, Caesalpinia echinata, Fernumbuk- oder Rotholz, Caesalpinia sappan, ostindisches Rotholz, Pterocarpus Santalin, rotes Sandel- oder Caliaturholz, Physocalymna floribundum, echtes Rosenholz, Diospyros ebenum, echtes Ebenholz.

Auffallend ist der wesentlich höhere Gerbstoffgehalt des Kernholzes, wofür ich einige Beispiele nach G. Kraus anführe, wobei zu erwähnen ist, dass im alten Kern der Gerbstoffgehalt wieder etwas abnimmt.

Gleditschia triacanthos. Splint gelbweiss, Kern rotbraun.

\begin{tabular}{l|c|c|c|c|c}
\hline & Rinde. & $\begin{array}{c}\text { Äusserer } \\
\text { Splint. }\end{array}$ & $\begin{array}{c}\text { Innerer } \\
\text { Splint. }\end{array}$ & $\begin{array}{c}\text { Äusserer } \\
\text { Kern. }\end{array}$ & $\begin{array}{c}\text { Innerer } \\
\text { Kern. }\end{array}$ \\
\hline Gerbstoffgehalt & $0,6 \%$ & $0,36 \%, 0$ & $0,40 \%$ & 4, So $\%$ & $4,00 \%$
\end{tabular}

Morus alba. Splint weiss, Kern gelbbraun.

\begin{tabular}{|c|c|c|c|c|}
\hline & Rinde. & Splint. & $\begin{array}{c}\text { Äusserer } \\
\text { Kern. }\end{array}$ & $\begin{array}{c}\text { Innerer } \\
\text { Kern. }\end{array}$ \\
\hline Gerbstoffgehalt & $\mathbf{I}, \mathbf{O}^{0} \%_{0}$ & $0,64^{\circ} \cdot 0$ & $3,84 \%$ & $2,75 \%$ \\
\hline
\end{tabular}

Bei den sog. Splinthölzern, d. h. den Hölzern ohne abweichend gefärbten Kern, ist der Gerbstoffgehalt der älteren Jahresringe nur um weniges grösser, als in den jüngeren Jahresringen (Acer, Aesculus, Tilia).

Das Kernholz hat im allgemeinen ein grösseres specifisches Gewicht, als das Splintholz. Wir sehen dies z. B. an einer von R. Hartig untersuchten 235 jährigen Kiefer.

\begin{tabular}{c|c|c}
\hline $\begin{array}{c}\text { Nummer der } \\
\text { Jahresringe. }\end{array}$ & $\begin{array}{c}\text { Beschaffenheit } \\
\text { des Holzes. }\end{array}$ & $\begin{array}{c}\text { Specifisches } \\
\text { Trockengewicht. }\end{array}$ \\
\hline 62-73 & Kern & 55,7 \\
$74-100$ & Kern & 56,6 \\
100-135 & Kern & 55,2 \\
136-17I & Ubergang & 48,2 \\
I72-235 & Splint & 42,7
\end{tabular}

Älteres Kernholz kann auch z. B. bei der Kiefer ein geringeres specifisches Trockengewicht zeigen. Dabei müssen jeduch die zur Zeit der Bildung dieses Holzes herrschenden äusseren Bedingungen berücksichtigt werden, welche möglicherweise dahin gewirkt haben, dass ein an und für sich leichteres Holz gebildet wurde. Man kann aus diesem Befunde also nicht olne weiteres sagen, dass das Kernholz mit dem Alter wirklich leichter wird. Ähnliche Differenzen wie für die ganzen Holzstïcke dürften sich auch für das specifische Gewicht der Zellmembran herausstellen, wenn die vorliegenden Zahlen in dieser Richtung einander auch noch widersprechen.

1) Specifisches Trockengewicht siehe S. IOI. 
Durch die Verkernuns soll die Fähigkeit, beim Trocknen zu schwinden, bedentend verringert werden, wofuir K. Hartig als Beispiel anführt, dass 100 Volumina Eichenhol\% im Splintzustande $4 m 16 \%$ schwinden, als Kernholz jedoch nur um 10,7 "/1. Ein allgemein gültiges Gesetz dahingehend, dass das Splintholz immer stärker schwindet, als das dazugehörige Kernholz, dürfte sich jedoch nicht aufstellen lassen, da die Zahlen je nach den Verhältnissen, unter denen das Holz gewachsen ist, schwanken.

Dieselben Veränderungen, welche das Holz bei dem Übergange vom Splintholz in Kernholz erleidet, finden wir an Wunden, welche durch das Splintholz gehen. Auch hier tritt Veränderung der Farbe ein, die Gefisse und Holzzellen werden verstopft, so dass hierdurch eine das innere Holz schützende Schicht entsteht, weshalb man diesem Holze den Namen des Schutzholzes gegeben hat. Wie wir später sehen werden, besitzt die in den Gefässen befindliche Luft einen geringeren Druck, da bei Verwundungen die Gefässe geöffnet werden, gleichen sich diese Druckdifferenzen aus und erst nach der Bildung des für Luft und Wasser undurchlässigen Schutzholzes kann in den Gefässen des gesunden Holzes wieder ein luftverdünnter Raum entstehen.

Unter der Bezeichnung ,falscher Kern" werden einerseits Schutzholzhildungen, anderseits Zerset zungserscheinungen \#usammengefasst, welche durch das Auftreten von Pilzmycel im Holz verursacht werden. Derartige falsche Kerne treten bei Hölzern mit oder ohne normale Kernbildung auf, und zeichnen sich meist dadurch aus, dass sie sich nicht an bestimmte Jahresringgrenzen halten, sondern mehr unregelmässig durch das Holz verlaufen. Sie stehen wohl immer mit Astwunden, Rissen und anderen Verletzungsstellen in Verbindung. Das bei der Rotbuche auftretende falsche Kernholz soll minderwertig sein.

\section{§25. Holzqualität.}

Es ist bei dem jetzigen Stande der Wissenschaft unmöglich, über die Wirkungsweise der verschiedenen Faktoren, welche die Qualität eines Holzes becinflussen, genügende Auskunft zu geben. Ich muss mich daher darauf beschränken, die allgemeinen Gesichtspunkte geltend zu machen.

Vor allem kommt es darauf an, in welcher Weise das Holz in Anspruch genommen werden soll. Soll der Stamm zu Säulen, Pfosten, Speichen, Schwellen verwendet werden, so hat derselbe einem gewissen Drucke zu widerstehen, welcher auf den Querschnitt des Stammes, also in der Faserrichtung oder senkrecht auf diese wirkt. Die Grösse des Widerstandes wird als Druckfestigkeit bezeichnet.

Bei Balken, Gerüsthölzern, Deichseln, Leiterbäumen kommt es dagegen auf die Biegungsfestigkeit des Holzes an, d. h. auf die Widerstandsfähigkeit gegen Zerbrechen bei einer rechtwinklig gegen die Faser- 
richtung des Stammes wirkenden Kraft. Bei längeren und relativ dünneren Stäben wird die Biegungsfestigkeit auch dann in Anspruch genommen, wenn ein Druck auf die Querschnittsfläche des Holzes, also parallel der Faserrichtung einwirkt, da derselbe leicht ein Ausbiegen des Stabes hervorruft.

Suchen mechanische Kräfte die kleinsten Teilchen eines Körpers aufeinander zu verschieben, so bezeichnet man sie als scherende Kräfte und den Widerstand, welchen ein Körper diesem Vorbeischieben seiner Teile entgegensetzt, als Scherfestigkeit oder Schubfestigkeit. Ist ein Körper auf einer sehr widerstandsfähigen Unterlage so angebracht, dass ein Teil von ihm darüber hervorragt, und sucht eine Kraft das überstehende Stück durch Niederdrücken loszureissen, so wird die Scherfestigkeit des Körpers in Anspruch genommen.

Wirkt ein Zug in der Längsrichtung der Fasern, so bezeichnet man den Widerstand, welchen ein Körper dem Auseinanderreissen, der Trennung seiner Teilchen entgegensetzt, als seine $\mathrm{Zugfestigkeit.}$

Für die in verschiedener Art in Anspruch genommene Festigkeit sind folgende Eigenschaften wichtig:

Die Dickwandigkeit der Zellen,

die Qualität der Zellwandung und der Wassergehalt derselben,

die Form der Zellen und der Zusammenhang der Zellen untereinander,

die Art der Verteilung der mechanisch leistungfähigeren Elemente.

Die mechanisch leistungsfähigsten Elemente sind, wie schon oben angegeben, die Libriformzellen und die dickwandigen Fascrtracheiden, die einen um so grösseren Effekt hervorbringen werden, je länger sie sind, je inniger sie ineinander greifen, je dicker und fester ihre Wandung und je enger ihr Zelllumen ist. Das Holz wird demnach um so fester sein, je mehr die mechanischen Elemente die übrigen Zellen überwiegen; und desto gleichmässiger dieselben verteilt sind. Der letztere Punkt ist wichtig, weil bei schichtweiser Anordnung fester und weniger fester Elemente grössere Flächen geringeren Widerstands eine Verschiebung der Elementarorgane und eine Zerstörung des Zusammenhangs des Holzes sehr erleichtern werden.

Für das Verhältnis der dickwandigen, mechanisch wirksameren Elemente zu den dünnwandigen, weniger festen Holzelementen hat man das sog. specifische Trockengewicht als Mass herangezogen.

Man erhält dasselbe, wenn man das bei höherer Temperatur getrocknete Holz wiegt, und die erhaltene Zahl durch das Volumen des trockenen Holzstückes dividiert, also

$$
\text { Specifisches Trockengewicht }=\frac{\text { Absolutes Trockengewicht }}{\text { Trockenvolumen. }}
$$

Nimmt man an, dass die Wandung der Holzzellen immer das specifische Gewicht von I,56 hat, so erhält man: 
Volumen der trockenen Holzsubstanz pro Frischvolumen Substanzerewicht in 100 Frischvolumen

$$
1,56 \text {. }
$$

Ob es serechtfertigt ist, für alle Hölzer und Holzqualitäten das specifische Gewicht von I,56 anzunehmen, erscheint fraglich. Man geht dabei von der Voraussetzung aus, dass alle in die Zellwände bei der Verkernung abgelagerten Substanzen das specifische Gewicht der Wand nicht verändern, was z. B. bei der Verharzung kaum der Fall sein dürfte. Ausserdem besteht die als trockene Holzsubstanz bestimmte Masse nicht nur aus den Zellwandungen, sondern auch aus den im Zelllumen ausgeschiedenen Substanzen, wie Gummi, Harz, Kalk etc. und es muss sehr fraglich erscheinen, ob diese Substanzen für die Festigkeit eine grössere Bedeutung haben.

Abgesehen von diesen Bedenken können Hölzer von gleichem specifischem Trockengewicht - man denke auch an das Holz verschiedener Species - dennoch verschiedene mechanische Eigenschaften haben, insofern die Natur und die Form der Elemente hierbei eine grosse Rolle spielt. Bei gleicher Wandmasse werden z. B. Libriformzellen eine grössere mechanische Leistung hervorbringen, als die mit senkrechten Querwänden aufeinanderstossenden Zellen, oder Gewebe, die, durch Luftlücken unterbrochen, weniger innig zusammenhängen.

Ich muss daher meine Ansicht dahin aussprechen, dass für die verschiedenen Arten von Festigkeit specifisches Trockengewicht und Holzsubstanzmenge noch keinen exakten Massstab geben, höchstens Annäherungswerte, deren Genauigkeit noch nicht bestimmt ist. Immerhin sind diese Zahlen wichtig, wo es sich um die Masse der producierten I olzzellwand handelt, $u m$ die Abhängigkeit derselben von äusseren Faktoren. Ebenso werden für die Brennkraft des Holzes die genannten Zahlen ein gutes Mass liefern.

$\mathrm{Zu}$ bemerken ist ausserdem noch, dass die Festigkeit durch eingewachsene Äste, durch Harzlücken, partiell zersetzte oder gar faulende Stellen sehr bedeutend herabgedrückt wird, es sind dies Punkte, auf welche die Holzerziehung in erster Linie ihr Augenmerk zu richten hat.

Es ist unzweifelhaft, dass die Beschaffenheit des Holzes ein und derselben Species in hohem Grade von den äusseren Verhältnissen und der Holzerziehungsmethode abhängig ist, welche die Art der Ernährung des ganzen Baumes und die Holzbildung beeinflussen. Es kommt dabei auf die Ausbildung der Blattmasse an, von welcher die Menge der dem Cambium zugeführten Assimilationsprodukte abhängt, ebenso auf die Menge der aus dem Boden aufgenommenen mineralischen Bestandteile. Ferner ist die dem Baume zur Verfügung stehende Wassermenge von Wichtigkeit, wobei einerseits die Menge des aus dem Boden aufgenommenen Wassers, anderseits die Menge des von den Blättern abgegebenen Wassers in Betracht kommt. Licht und Wärme werden in erster Linie mittelbar 
einwirken, indem sie sowohl die Assimilation als die Wasserabgabe und Aufnahme beeinflussen, ausserdem aber können sie auch unmittelbar die Wachstumsfähigkeit der Holzzellen modificieren.

Innerhalb gewisser Grenzen ist das besser ernährte Holz (grössere Krone, mineralisch reicherer Boden) von besserer Qualität, es besitzt ein höheres specifisches Trockengewicht, und mit dem specifischen Trockengewicht steigt und fällt auch z. B. die Druckfestigkeit. Nit der besseren Ernährung ist auch ein grösserer Flächenzuwachs, eine grössere Breite der Jahresringe verbunden, so dass, je grösser der Flächenzuwachs, desto besser die Holzqualität.

Dies hat jedoch seine Grenze, indem bei sehr starkem Zuwachs, also bei übermässiger Verbreiterung der Jahresringe, das dünnwandigere Frühjahrsholz besonders stark zunimmt, und so das Verhältnis zwischen dem mechanisch leistungsfähigeren Herbstholz und dem mechanisch weniger wirksamen Frühjahrsholz ein ungünstiges wird. Ausserdem können wir unter Umständen auch bei sehr geringem Flächenzuwachs, d. h. bei sehr engen Jahresringen vortreffliches $\mathrm{Holz}$ beobachten, wofü uns die im Hochgebirge erwachsenen Bäume ein Beispiel geben. Die Vegetationszeit, in welcher die Neubildung von Holzzellen stattfindet, ist hier durch die niedrige Temperatur verkürzt, die Assimilation dagegen wird nicht in demselben Nasse durch die geringere Temperatur herabgemindert, zumal die Beleuchtung auf den Bergen eine intensive, für die Assimilation günstige ist. Es sind demnach reichliche Assimilationsprodukte vorhanden, welche zur Verdickung und besseren Ausbildung der Zellwand verwendet werden, so dass das Herbstholz dem Frühjahrsholz gegenüber relativ mächtiger ist. Ist der geringe Dickenzuwachs durch sehr ungünstige Bodenverhältnisse bedingt, so kann die Qualität auch eine geringe sein.

Die im geschlossenen Bestande erwachsenen Nadelhölzer sollen bei sunst gleichen Lmständen ein feinringigeres und besseres Holz liefern, als die im lichten Stande gewachsenen. Das Längenwachstum wird bei engem Stand auf Kosten des Dickenwachstums berorzugt, die Feuchtigheit des Bodens wird auf eine grössere Zahl von Stämmen verteilt, die Erwärmung des Bodens tritt später ein und demnach wird, wie im Hochsebirge, die Zeit der Holzbildung verküirzt, bei genügender Bodenqualität und längerer Assimilationsdauer. Aníangs sehr dicht stehende Bestände, mit allmählich stärker werdender Durchforstung, werden ein ggutes Holz liefern, das ausserdem noch den Vorzug hat, vermöge des durch die Durchforstung gesteigerten Flächenzuwachses eine sehr gleichmässige Jahresringbreite aufzuweisen.

Bei sonst vollständig gleichen Verhältnissen liefert der mineralisch kräftigere Boden ein besseres Holz, rorausgesetzt, dass nicht bei zu starler Vergrösserung der Jahrestinge ein ungünstiges Verhältnis zwischen Herbstund Frühjahrsholz entsteht. 
Dass geringere Fenchtigkeit der Umgebung ein dichteres, libriformreiches Holz liefert, wurde durch direkte Versuche erwiesen. Junge Zweige von Robinia und Quercus zeigten, sobald sie lokal angefeuchtet und diese Stellen in feuchter Luft erhalten wurden, eine bedeutend seringere Ausbildung von Libriformzellen, ebenso blieben die Zellwände dünner, so dass diese Sprossaxen sich dem Wurzelholz näherten. Es hat sich dabei herausgestellt, dass aus denselben Cambiumzellen je nach den ätsseren Verhältnissen sehr verschiedene Elemente hervorgehen können, was insofern wesentlich ist, als durch die äusseren Verhältnisse, also nicht nur die Wandstärke und Länge der Holzelemente verändert wird, sondern auch andere Holzelemente produciert werden, und damit die Holzqualität noch in höherem Masse veränderlich wird. Die Abhängigkeit der Holzbildung von der Feuchtigkeit, die namentlich an krautigen Pflanzen konstatiert wurde, besteht sicherlich auch für Holzpflanzen, doch fehlen hierüber genügende Untersuchungen.

$\mathrm{Zu}$ erwähnen ist noch der auffallende Unterschicd, welchen die Qualität des Holzes in verschiedener Baumhöhe darbietet. Das specifische Trockengewicht nimmt mit zunehmender Höhe im Schafte ab. Ausgenommen hiervon sind die obersten Teile des Baumes, welche wiederum ein etwas höheres specifisches Trockengewicht aufweisen. Ebenso sinkt die Druckund Biegungsfestigkeit mit zunehmender Höhe im Schafte. Ob man als Ursache dieser Erscheinung den früheren Beginn der Cambialthätigkeit annchmen kann, erscheint mir fraglich, da hier doch auch andere Faktoren zur Geltung kommen. Jedenfalls wären hierbei die im vorhergehenden Paragraphen besprochenen Verschiedenheiten im anatomischen Aufbau zu berücksichtigen und causal zu erklären.

\section{Anatomie des sekundären Bastes.}

Die junge primäre Rinde (Fig. 99) hat an ihrer Peripherie die Epidermis, das darunter befindliche Rindenparenchym und die primären Phloëmteile. Infolge der Thätigkeit des Cambiums werden den primären Elementen sleichartige sckundäre Elemente angefürst, ohne dass zwischen beiden eine Grenze sichtbar wäre, oder wie bei dem sekundären Holze der jährliche Zuwachs in Form bestimmt begrenzter Jahresringe sich abheben würde. Die vom Cambium abgeleiteten Gewebe (Bastparenchym, Siebröhren, Bastfasern und Steinzellen) bezeichnet man auch in Analogie zum sekundären Holzkörper als sekundären Bast oder Bastkörper, sekundäres Phloëm.

Da die Epidermis der mit dem Dickenzuwachs des Holzkörpers verbundenen Umfangszunahme nicht zu folgen vermag, sowie für dickere holzige Pflanzenteile keinen genügenden Schutz bietet, wird dieselbe durch Korkschichten (Periderm) ersetzt. Diese Korkschichten gehen auch 
(vgl. Fig. I22) durch den sekundären Bastkörper, dessen peripherische Teile absterben, wodurch die Borke gebildet wird.

Ohne an dieser Stelle auf Periderm- und Borkebildungen (vgl. \$ 30) einzugehen, betrachten wir zunächst die Elementarorgane des sèkundären Phloëms.

Das sekundäre Phloëm besteht aus Bastparenchym, Bastfasern, Steinzellen und Siebröhren.

Bastparenchym fehlt keiner Rinde. Die Zellen haben entsprechend ihrer Entstehung aus den Cambiumzellen eine langgestreckte Gestalt, sind vorwiegend parenchymatische Fasern durch horizontale Querwände geteilt, ähnlich wie das Holzparenchym (vgl. Fig. I06i). Ungeteilte Fasern, den Ersatzfasern des Holzes entsprechend, sind selten (Gujacum, Caragana). Tüpfel finden sich an den radialen und an den Querwänden vor, fehlen an den tangentialen Wänden, die Fortleitung der in diesen Zellen wandernden Stoffe ist dementsprechend in radialer und in der Längsrichtung begiinstigt. Seltener ist die Wandung dieser Parenchymzellen etwas stärker verdickt.

Bastfasern (Fig. Io8g, g'), durch Wandverdickung und langgestreckte Form ausgezeichnet, finden sich

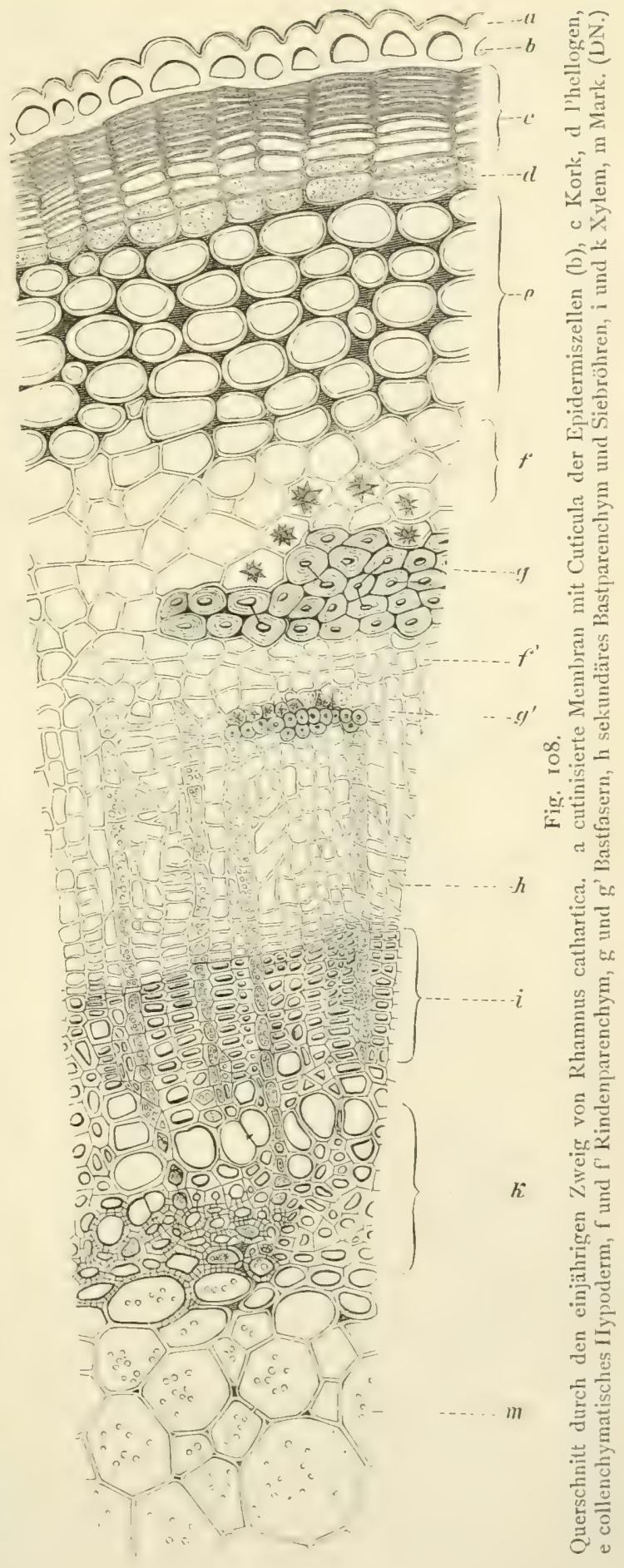




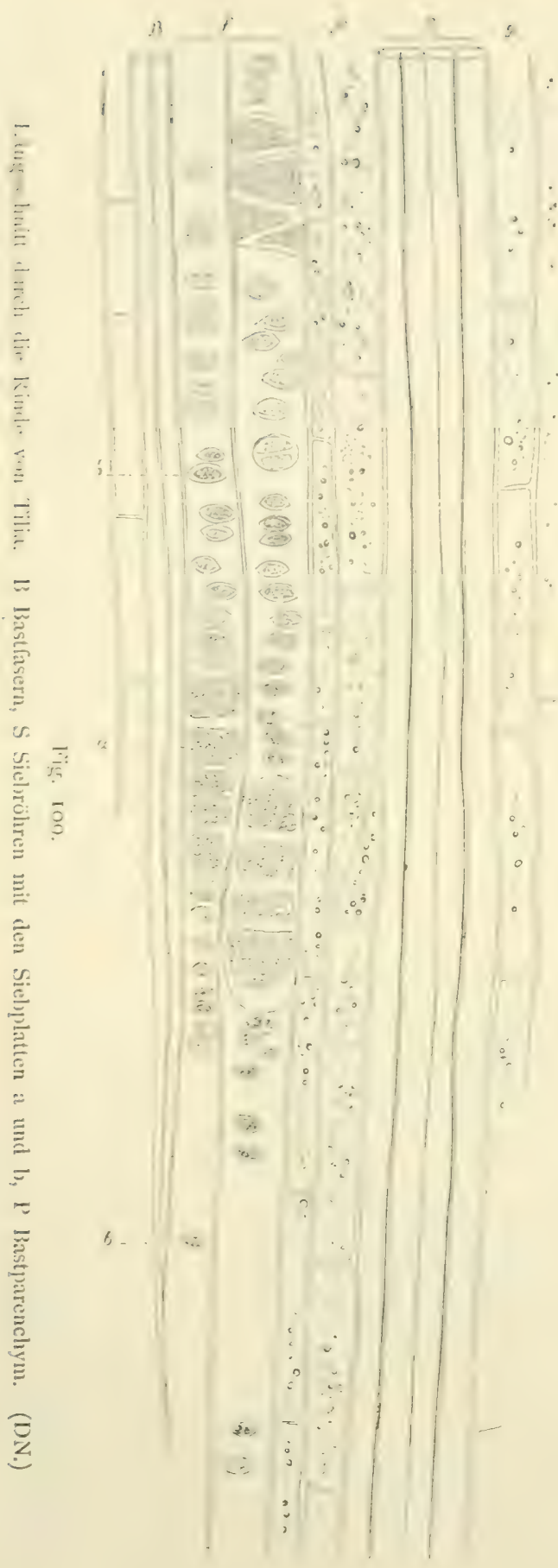

unter sleichzeitigem Fehlen der Steinzellen bei Cupressineen, Taxineen, Ulmaceen, Lonicereen, Rhamnaceen u. a.

Steinzellen, durch stark verdickte Wandung und isodiametrische form ausgezeichnet, finden sich, ohne dass Bastfasern vorkommen, bei Abies, Picea, Larix, Betulaceen, Fagus, Platanus, Olea, Ligustrum u. a.

Bastfasern und Steinzellen zugleich enthalten: Sequoia, Corylaceen, Quercus, Castanea, Morus, Salicaccen, Fraxinus, Syringa u. a. Frei von Bastfasern und Steinzellen ist die Rinde bei Pinus, Laurus, Lycium, Ampelopsis, Cornus u. a.

Was die Verteilung der dickwandigen Elemente anbelangt, so haben wir zwei Typen zu unterscheiden. Bei dem ersten Typus wechseln resclmässiskencentrische Sichich. ten von sklerenchymatischen Zellen mit Schichten von dünnwandigen Zellen (Parenchym, Siebröhren). Hierher gehören z. B. Cupressineen, Taxineen, Betulaceen, Ulmaceen und Tilia (Fig. IOO, die hellen Zellen in Phl.). Bei dem zweiten Typus sind die dickwandigen Elemente unregelmässig zerstreut, isoliert oder zu grösseren oder kleineren Bündeln vereinigt (Abies, Picea, Larix, Ligustrum, Evonymus, Amygdalaceen, Rhamnaceen (Fig. I08 g, g').

Ein wesentlicher Unterschied zwischen Dicotylen und Coniferen besteht darin, dass bei den ersteren die Bastfasern 
allseitig von Parenchym umgeben sind, während bei den Coniferen die Bastfasern von Siebröhren begleitet sind, und das Parenchym erst an die Siebröhren grenzt.

Die Siebröhren fehlen nur wenigen Gattungen mit anomalen Fibrovasalsträngen (Salvadora, Strychnos, Calycanthus?'). Einfache Querplatten haben Fagus, Ulmaceen, Celtis, Acerineen, Rhamneen u. a. Siebröhren mit Plattensystemen zeigen Abietineen, Taxineen, Corylaceen, Cornaceen, Tiliaceen (Fig. Iogs), Pomaceen, Juglandaceen u. a.

Die Markstrahlen des Bastes sind Fortsetzungen der im Holze verlaufenden Strahlen, sie treten jedoch bei Beobachtung ohne Mikroskop nicht so deutlich hervor. Vielfach sind dieselben nach aussen erweitert, so bei Corylaceen, Carya, Amygdalaceen, Papilionaceen, Tiliaceen (Fig. IOO).

In den Markstrahlen und Bastparenchymzellen kommen ausserordentlich häufig Krystalle von oxalsaurem Kalk in verschiedener Krystallform vor, und besonders sind die den sklerenchymatischen Elementen benachbarten Zellen bevorzugt. Ausserdem ist die Rinde gewisser Pflanzen reich an Sekretbehältern mit specifischen Inhaltsstoffen.

Von praktischer Bedeutung ist der Gerbstoffgehalt gewisser Rinden, der jedoch nach Alter und Standort ziemlich bedeutenden Schwankungen unterworfen ist. Unter unseren einheimischen Rinden besitzt die borkearme Eichenrinde (Spiegelrinde) den grössten Gerbstoffgehalt. Es mögen hier einige Zahlen für den mittleren Durchschnittsgehalt der gebräuchlichen Rinden folgen:

Beste Eichenspiegelrinde

Gute Spiegelrinde

$16-20 \%$

Geringe Spiegelrinde

Alte Eichenrinde von Borke befreit .

I $2-15 \%$

$7-9 \%$

$8-10 \%$

Schwarzerlenrindo

Junge Weidenrinden

8 I $15^{\prime \prime} .0$

$8-\mathrm{I} 2 \%$

Fichtenrinde von 30-60jährigen Bäumen . $8-10 \%$

Fichtenrinde von 60-Ioojährigen Bäumen . 6- $7 \%$

Lärchenrinde . . . . . . . . 6- $6 \%$

Tannenrinde . . . . . . . $4-8 \%$

Birkenrinde $3.5^{\prime \prime}$

Ulmenrinde . . . . . . . . . 4 $4-5 \%$

Buchenrinde . . . . 3 - . . . . $4^{\prime \prime}$

Rosskastanienrinde . . . . . . . 2- $2-3 \%$

\section{S 27. Beschreibung der Wurzeln.}

Das Wurzelsystem entwickelt sich entweder aus der schon am Embryo vorhandenen Wurzel, oder es besteht aus Adventivwurzeln. Im ersten Falle, den wir bei den meisten Dicotylen antreffen, wird die Wurzel 
des Lmbryos zur l'fahlwurzel (Primärwurzel, Hauptwurzel), an welcher scitlich die Wurzeln höherer Ordnung (Sekundär-Tertiärwurzeln etc.) entstehon. Bei perennierenden Pflanzen, namentlich unseren Bäumen, zeist dic Hauptwurzel, sowie die grösseren Seitenwurzeln ein dem Stammo analoges Dickenwachstum, während zugleich jährlich immer neue feine Wurzelaweige (Zaserwurzeln) sebildet werden. Bei diesem Wurzeltypus übertrifft entweder die Pfahlwurzel dauernd das Wachstum der Seitenwurzeln, oder die letzteren entwickeln sich später stärker, als die primärc Pfahlwurzel.

Beispiele ron stark entwickelten Pfahlwurzeln bieten uns: Quercus, Ulmus, Juglans, Abics, Pinus silvestris, Pinus strobus. Pfahlwurzel und Seitenwurzel sind stark entwickelt bei Fraxinus excelsior, Tilia, Larix. Die Pfahlwurzel ist kurz und dick (Herzwurzel) bei Acer, Fagus, Taxus baccata. Die Seitenwurzeln überwiegen bei Carpinus, Alnus, Betula, Robinia, Populus, Salix, Picea, Pinus austriaca.

Bei dem zweiten Wurzeltypus entstehen die Wurzeln adventiv, d. h. sic bilden sich an Sprossaxen, nachdem die Wurzel des Embryos zu Grunde gegangen oder nicht zur Entwickelung gelangt ist. Ein derartiges adventives Wurzelsystem finden wir vielfach bei den Monocotylen, so z. B. bei den Gräsern, wo zahlreiche gleichartige Wurzelbüschel unterhalb der Grasknoten entstehen. Ebenso werden an unterirdischen Rhizomen, sowie an Zweigen, die auf der Erde liegen oder in dieselbe eindringen, Adventivwurzeln gebildet. Die Entstehung des Wurzelsystems an Zweig - und Blattstecklingen ist selbstverständlich eine adventive. Ebenso gehören hierher die Haftwurzeln des Epheu und die Luftwurzeln der tropischen Orchideen und Aroideen.

Zwischen beiden Wurzeltypen giebt es Übergänge, bei welchen die Funktion der normalen Wurzeln durch die Bildung vōn Adventivwurzeln unterstützt wird.

Die Wurzeln sind dazu bestimmt, erstens die Pflanzen in dem Boden zu befestigen, zweitens Wasser und in demselben gelöste Nahrungsstoffe, namentlich anorganische Salze aufzunehmen. Nur in den ersten Stadien nach der Keimung dient das ganze Wurzelsystem der Nahrungsaufnahme und der Befestigung, im darauf folgenden Entwickelungsstadium macht sich eine Arbeitsteilung dahin geltend, dass die grösseren Wurzeln zur Ausbreitung des ganzen Wurzelsystems und zur Festigung der Pflanze dienen, während nur die jüngst gebildeten Wurzelteile, namentlich die feinen Zaser- oder Saugwurzeln, zur Nahrungsaufnahme geeignet sind. Die letzteren sterben beim Älterwerden des sie tragenden Wurzelzweiges ab.

Interessant ist der Zusammenhang zwischen der Ausbildung des Laubsprosses und der Ausbreitung des Wurzelsystems. Wir sehen in Fig. IIO, I ein Calladium, dessen schräg nach abwärts gerichtete Blätter den auffallenden Regen in centrifugaler Richtung ableiten. Dement- 
sprechend ist das Wurzelsystem horizontal ausgebreitet und die aufsaugenden Wurzelspitzen kommen unter die Traufe zu liegen. Bei der Rhabarberpflanze (Fig. IIO, 2) wird der Regen centripetal abgeleitet, die Wurzeln wachsen dementsprechend vertikal nach abwärts. Ähnliche Verhältnisse haben wir bei den Bäumen, bei welchen sich die aufsaugenden feinen Wurzelendigungen ebenfalls unter der Traufe der Blätter befinden. Es ist daher praktisch, Düngemittel in einem der Grösse der Krone entsprechenden Kreis, von dem Stamme entfernt anzubringen.

Die Ausbildung des Wurzelsystems wird ausserdem noch durch die Bodenbeschaffenheit modificiert, indem in mineralisch sehr armen oder

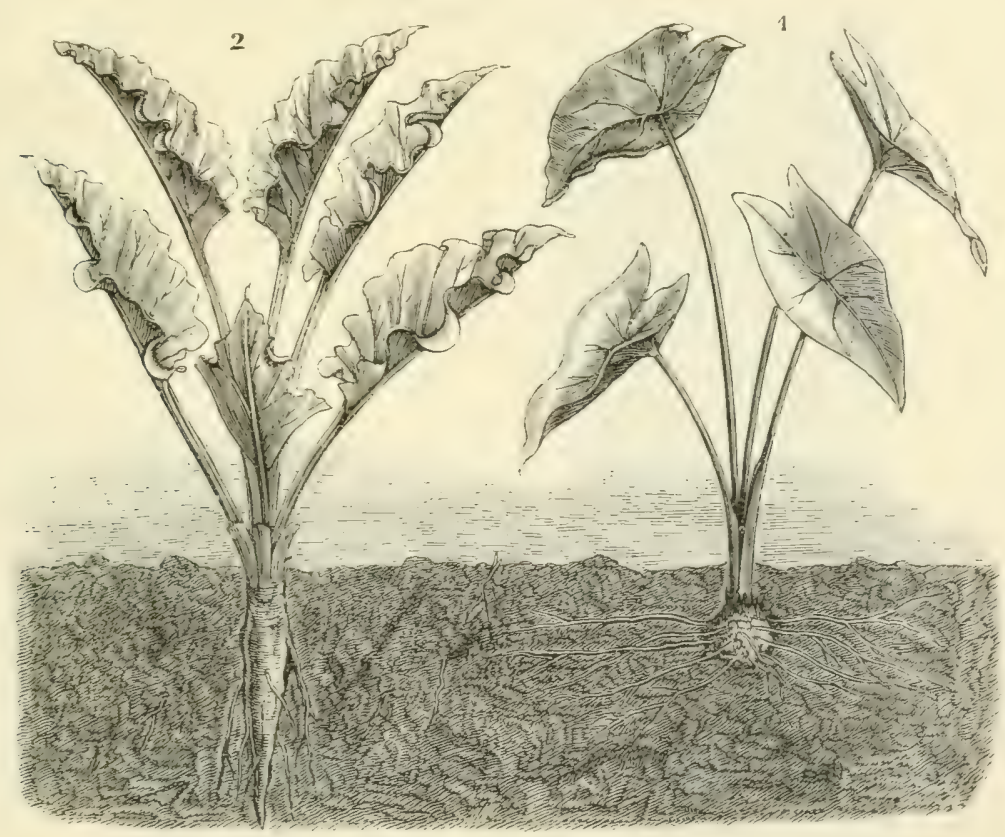

Fin. 110.

Centrifugale und centripetale Ableitung des Wassers, I an einem Calladium, 2 an einer Rhabarberpflanze (n. Kerner).

trockenen Schichten die Seitenwurzeln zwar zur Ausbildung gelangen, später aber absterben, während die Seitenwurzeln in passenden Bodenschichten erhalten bleiben und sich dort mannigfaltiger verzweigen.

Bei Wasserpflanzen sind die Wurzeln meistens reduciert, da die Blätter und Sprossaxen entweder selbst Wasser und wasserlösliche Nahrungsstoffe aufnehmen, oder wenn sie über die Wasserfläche emporsteigen, in der feuchten Luft weniger Wasser verdunsten.

Die Luftwurzeln sind derber gebaut, sie legen sich vielfach an Baumstämme oder feste Gegenstände an und können direkt mit diesem Substrat verwachsen. In den Tropen finden wir oft starke Luftwurzeln, 
die in den Boden eindringen und so dem Laubspross als Stïtze dienen (Rhizophora Mangle).

Bei bestimmten Pflanzen Werden die Wurzeln knollis, spindelis oder handförmis verdickt und so zur Aufnahme von Reservestoffen geeignet (Orchis morio, Orchis maculata, Daucus carota, Spiraea filipendula, Ranunculus ficaria und Raphanus sativus var. radicula das Radieschen).

Eine besondere Ausbildung erfahren ferner die Wurzeln der Schmarotzergew ï hse. Bei Melampyrum pratense, Euphrasia offici-
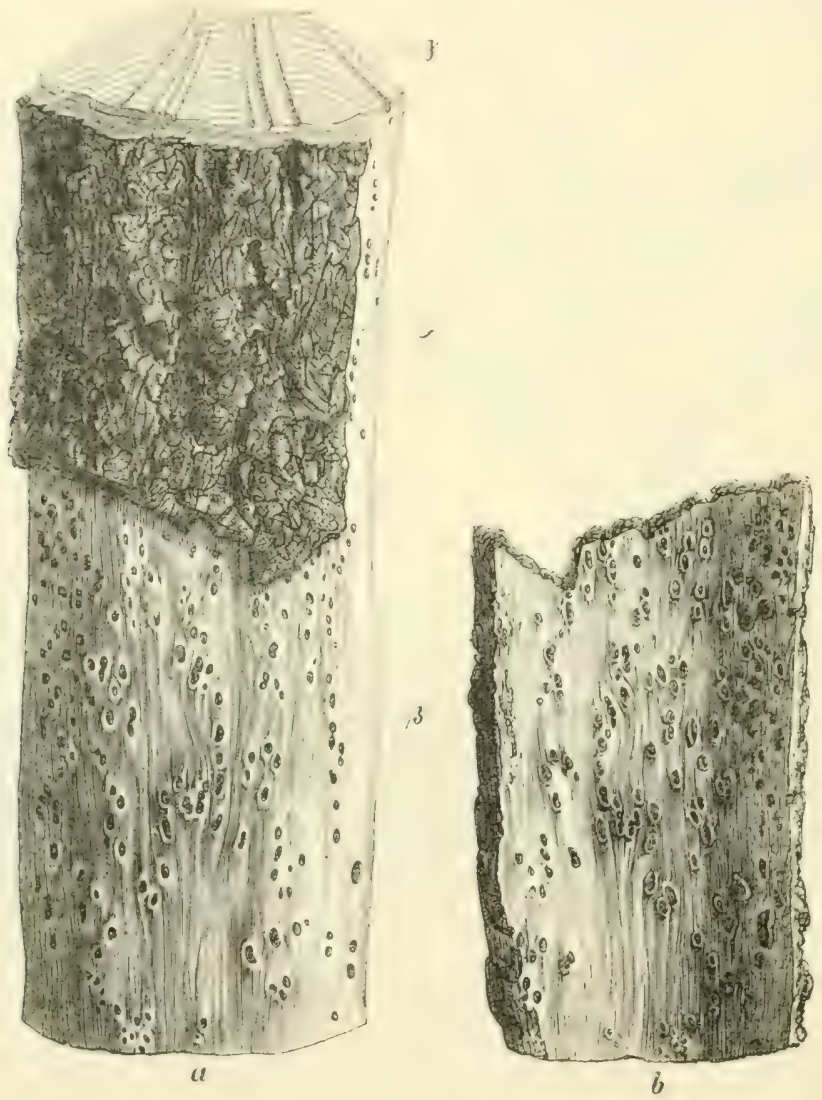

Fig. I I I

Abies pectinata mit Senkerspuren von Viscum album. a Aussenansicht, b von der Innenseite. (DN.)

nalis, die auf Wurzeln von Gräsern schmarotzen, bilden sich an den Berührungsstellen mit der Graswurzel kleine kugelige Haftscheiben, welche als Saugapparate funktionieren. Ähnliche Haftscheiben oder Haustorien bilden sich an dem fadenförmigen Stengel der Kleeseide (Cuscuta europaea), welche ebenfalls in die befallene Pflanze eindringen.

Bei der auf verschiedenen Bäumen schmarotzenden Mistel, Viscum album, werden die Samen durch Vögel, namentlich Drosseln auf die 
Wirtpflanzen verschleppt. Bei der Keimung bildet der Mistelsame eine haftscheibenförmige Wurzel, welche durch die Rinde bis zum Holze einen sog. Senker treibt. Von diesem primären Senker gehen später in der Längsrichtung des Zweiges Wurzeln ab, die an der Grenze von Holz und Bast weiter wachsen und als Rindenwurzeln bezeichnet werden. An diesen Rindenwurzeln bilden sich sekundäre, radial verlaufende Senker. Diese Senker verlängern sich jedes Jahr an ihrer Basis um soviel, als der betreffende Jahresring breit ist. Ohne aktiv in das Holz einzudringen, werden sie unter gleichzeitiger Verlängerung von dem Holze umwachsen. Sie hinterlassen an den befallenen Stellen zahlreiche Löcher, die auf dem Querschnitte als radial verlaufende Kanäle erscheinen (Fig. I I I).

\section{§ 28. Primärer anatomischer Aufbau der Wurzeln.}

Wir unterscheiden an den Wurzeln:

I) die Epidermis,

2) die Wurzelrinde,

3) den Centralcylinder mit den Gefässbündeln.

Die Verteilung dieser Gewebe ersehen wir aus Fig. I I 2. Die äusserste Schicht ist die Epidermis, es folgt die breite Rinde, welche den Centralcylinder umschliesst.

Die Epidermis ist der Funktion der Nahrungsaufnahme entsprechend eingerichtet. Die Zellen derselben bestehen, soweit es sich um junge zur Nahrungsaufnahme geeignete Wurzelteile handelt, aus dünnwandigen Zellen, deren Aussenseite garnicht oder doch nur ganz unbedeutend verdickt ist. Diese Epidermiszellen sind bei sehr vielen Pflanzen befähigt zu Haaren, den sog. Wurzelhaaren auszuwachsen (Fig. II3), welche den möglichst innigen Kontakt mit den Bodenpartikelchen herstellen und zu gleicher Zeit die aufnehmende Oberfläche um ein vielfaches vergrössern. Da die Aussenseite dieser Wurzelhaare gallertartig ist, haften bei trockner Erde die einzelnen Bodenpartikelchen sehr fest an den Haaren, wofür uns Fig. II $3 \mathrm{C}-\mathrm{D}$ deutliche Beispiele abgeben. Diese Haare sind immer einzellig und dünnwandig, besitzen keine undurchlässige Cuticula wie die Lufthaare. Sie finden sich besonders dort, wo die Wurzel in trocknem Boden oder in feuchter Luft wächst, wo die Wasseraufnahme erschwert und eine grössere aufnehmende Oberfläche notwendig ist. Bei leichter Wasserzufuhr (so bei Wasser- und Sumpfpflanzen, wie Butomus umbellatus, Caltha palustris, Hippuris vulgaris, Nymphaea alba) oder bei geringerem Wasserbedarf für die Transpiration (Abies und Pinusarten, Cupressus, Thuja) kann die Wurzelhaarbildung gänzlich unterbleiben.

Die Wurzelhaare dienen zugleich zur Befestigung der Wurzel im Boden, um beim Vorwärtsdringen der Wurzelspitze die rückwärtigen Teile zu fixieren. 
An älteren Wurzelteilen sterben dic Haare ab, ebenso geht die Epidermis 20 Grunde. Die letztere wird entweder durch Korkschichten in der Vurzelrinde ersetzt oder die Wurzelrinde stirbt ebenfalls mit ab.

Eine cigentïmliche Veränderungs erleidet die Wurzeloberfläche vieler Waldpflanzen durch die Umhüllung mit Pilzgeflecht, durch die sogs. Mycorhizenbildung. Die Mycorhiza oder Pilzwurzel besteht aus der IVurzel der Phanerogamenpflanze und aus Pilzfäden, welche einen Pilzmantel namentlich um die Saugwurzel bilden. Frank, der zuerst die Bedeutung der Mycorhiza erkannt hat, unterscheidet eine endotrophische

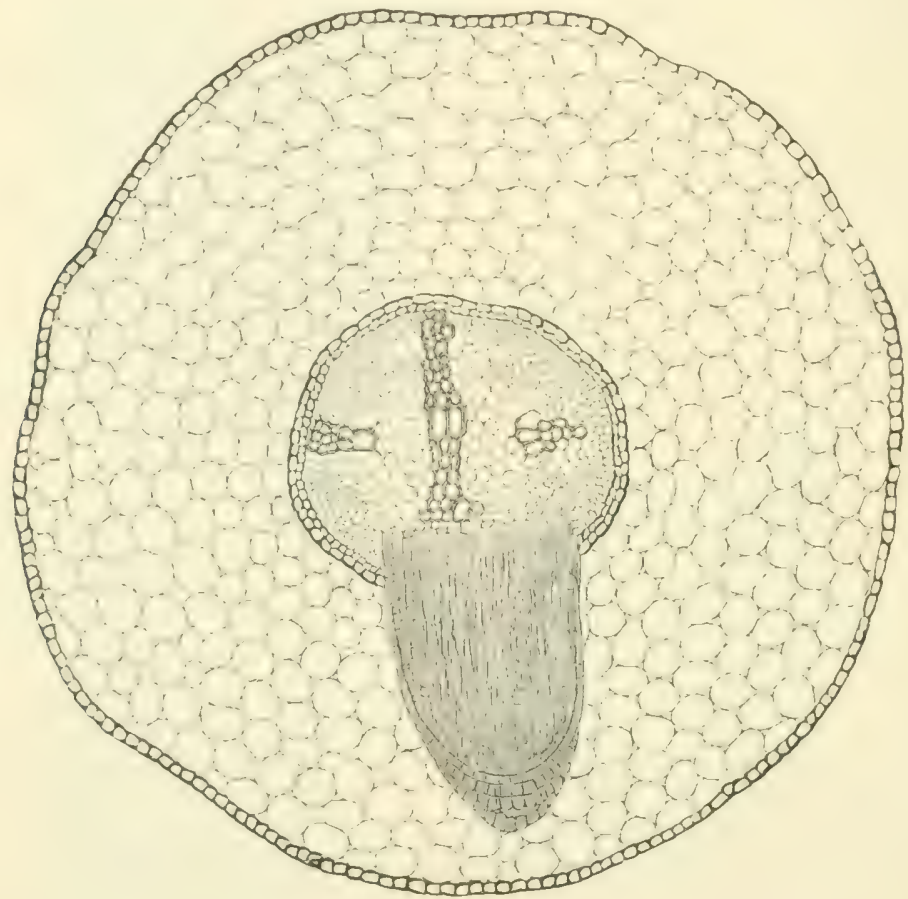

Fig. I1 12.

Querschnitt durch eine junge Hauptwurzel von Helianthus annuus mit der Anlage einer Seitenwurzel, welche das Rindengewebe noch nicht durchbrochen hat.

und eine ectotrophische Form. Bei der endotrophischen Form befindet sich der Pilz innerhalb der Wurzelrinde oder, wo diese fehlt, nur in den Epidermiszellen. Aus dem Pilzknäuel im Innern der Zellen werden feine Fäden an die Oberfläche entsendet, welche sich im Waldhumus verbreiten. Hierher gehören die chlorophyllfreien Humusbewohner wie Monotropa Hypopitys, Neottia Nidus avis, Corallorhiza innata.

Bei der ectotrophischen Mycorhiza (Fig. I I 4 B) bilden die Pilzfäden eine einfache oder aus mehreren Zelllagen bestehende pseudoparenchymatische Schicht um die Wurzel (Fig. I I4 B unten bei p), welche 
auch die Epidermiszellen umspannt (Fig. II4 rechts unten bei e) eventuell auch zwischen die äusseren Rindenschichten eindringen kann, seltener im Zelllumen selbst vorkommt. Von dem Pilzmantel gehen zahlreiche Fäden

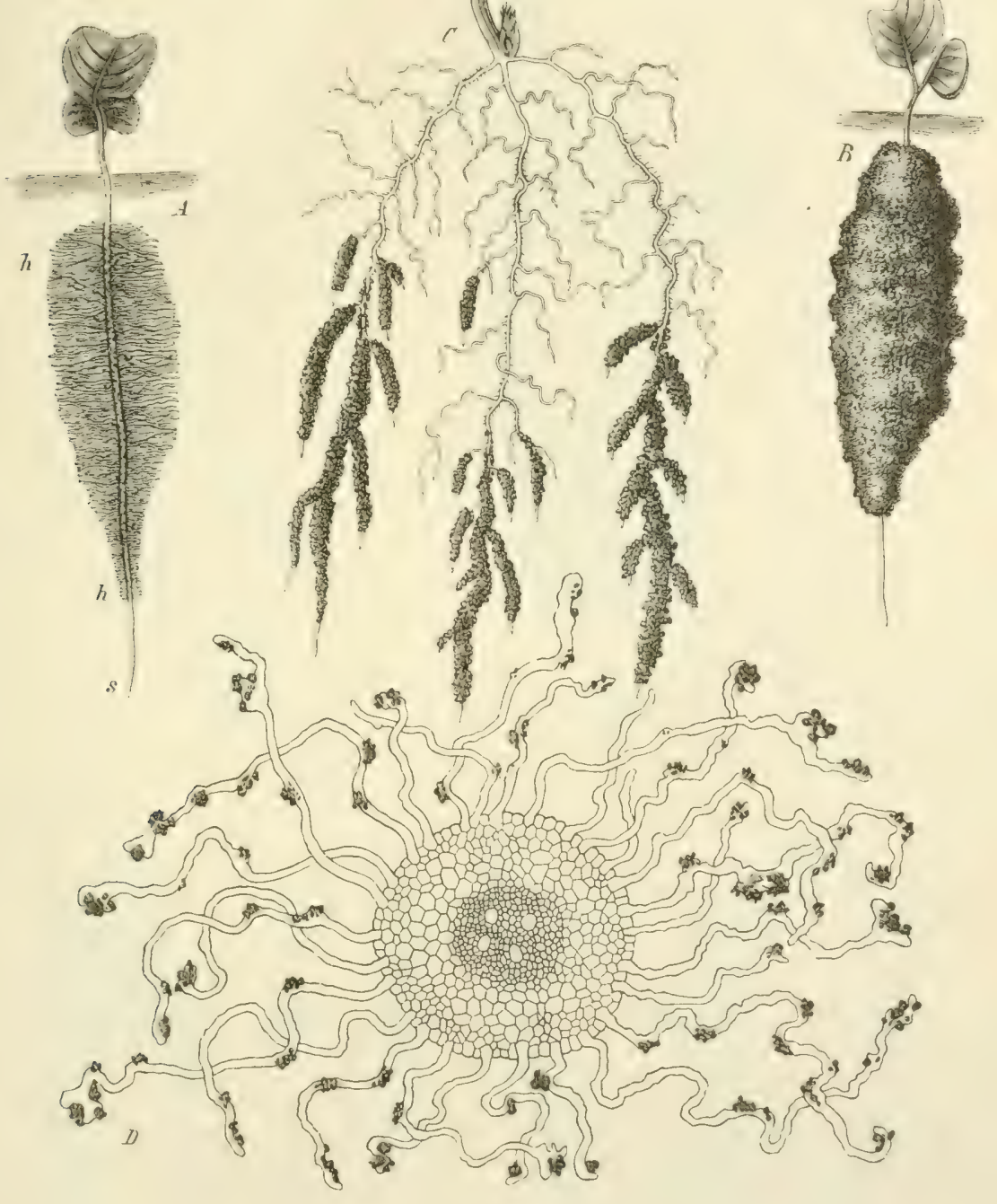

Fig. 113 .

Die Wurzel mit den Wurzelhaaren. A und B Keimpflanzen des Raps, C Vurzelsystem einer jungen Getreidepflanze, D Wurzelquerschnitt (n. Frank und Tschirch).

und Pilzstränge aus (Fig. I I 4 B 1 ), die mit den Erdteilchen in ähnlicher Wéce verschmelzen wie die Wurzelhaare (Fig. II3). Da das Längenwachstum und die Verzweigung der Wurzeln durch den Pilzmantel gehemmt wird, 
sind die mit dem Pilze versehenen Wurzeln oft dichotomisch verzweist oder traubig angeschwollen (Fig. I15). Dic Wurzelhaarbildung wird
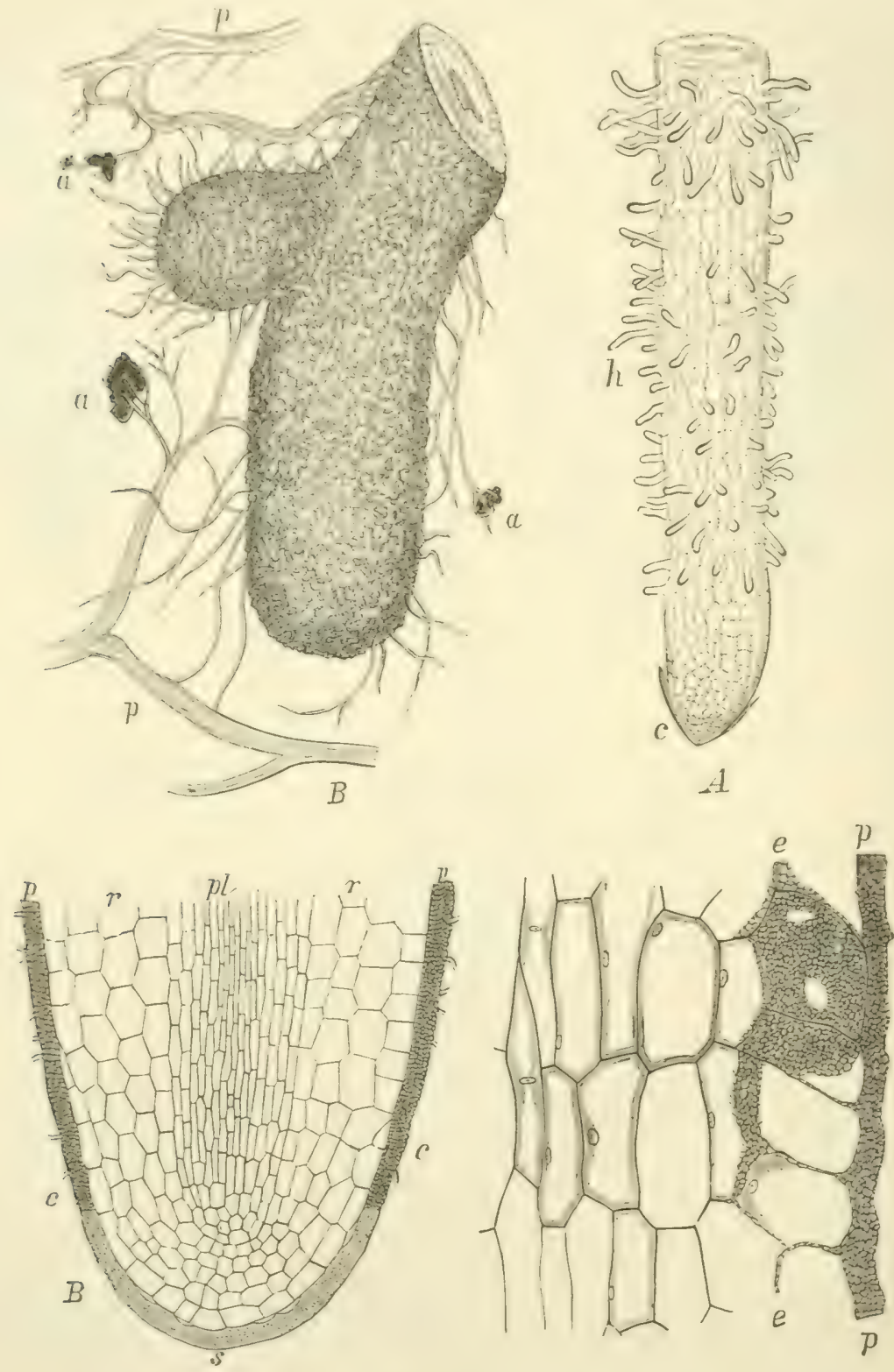

Fig. II 4 .

A Buchenwurzel in sterilisiertem Waldhumus, B Ectotrophische Mycorhiza der Buche (nach Frank und Tschirch). 
durch den Pilz unterdrückt, kann aber bei pilzfreien Wurzeln auftreten (Fig. II 4 A h).

Die ectotrophische Form tritt auf bei allen Cupuliferen, und waldbildenden Coniferen, bei den Salicaceen, Tilia, bei den Heide- und Moorboden bewohnenden Ericaceen und Empetraceen. Ebenso findet sich dieselbe bei sehr vielen Kräutern, die im Waldhumus, oder auf humusreichen moorigen Wiesen vorkommen, so bei den meisten Orchideen, bei verschiedenen Liliaceen, Smilaceen, Ranunculaceen, Rosaceen, Leguminosen, Labiaten, Compositen etc.

Das Vorkommen der Mycorhiza ist an das Vorhandensein von organischen Stoffen (Humusbestandtheilen) im Boden gebunden, welche mit Hülfe des Pilzes verarbeitet und zur Ernährung verwendet werden.

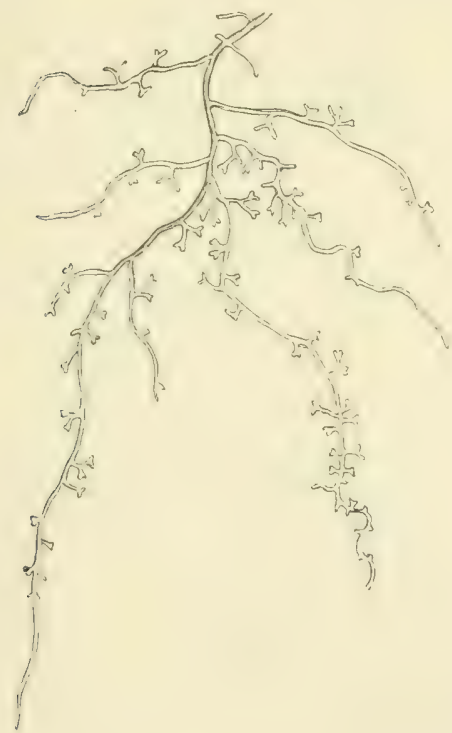

Fig. II 5 .

Mycorhiza von Pinus silvestris. (DN.)

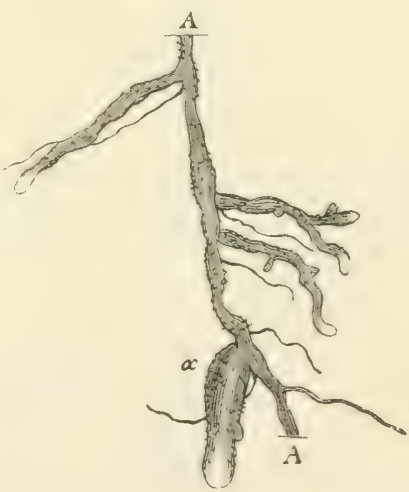

Fig. I 16 .

Jüngere u. ältere Wurzelteile der Fichte. (DN.)

Die Wurzelrinde besteht aus parenchymatischen, dünnwandigen Zellen (Fig. II2), die im jugendlichen Zustande häufig Stärke führen. Die äusseren Rindenzellen sind lückenlos miteinander rerbunden, während die inneren vielfach Intercellulargänge aufweisen. Da die Rinde später absterben und collabieren kann, während der Centralcylinder am Leben bleibt, sind die jüngeren mit lebender Rinde versehenen Wurzeln oft wesentlich voluminöser als die etwas älteren Teile (Fig. II6). Ausserdem tritt an älteren W'urzeln eine Bräunung der äusseren Schichten ein, wodurch sich dieselben leicht von den frisch entstandenen weisslichen Wurzelteilen unter- 
scheiden lassen. Bei den Luftwureln der tropischen Orchideen und mancher Aroiden sind der parenchymatischen Rinde noch mehrere äussere Zellschichten aufgelasert, deren Inhalt in einiger Entfernung von der Wurzelspitze abstirbt. Diese toten, luft- und wasserhaltigen, mit Lö̈hern versehenen

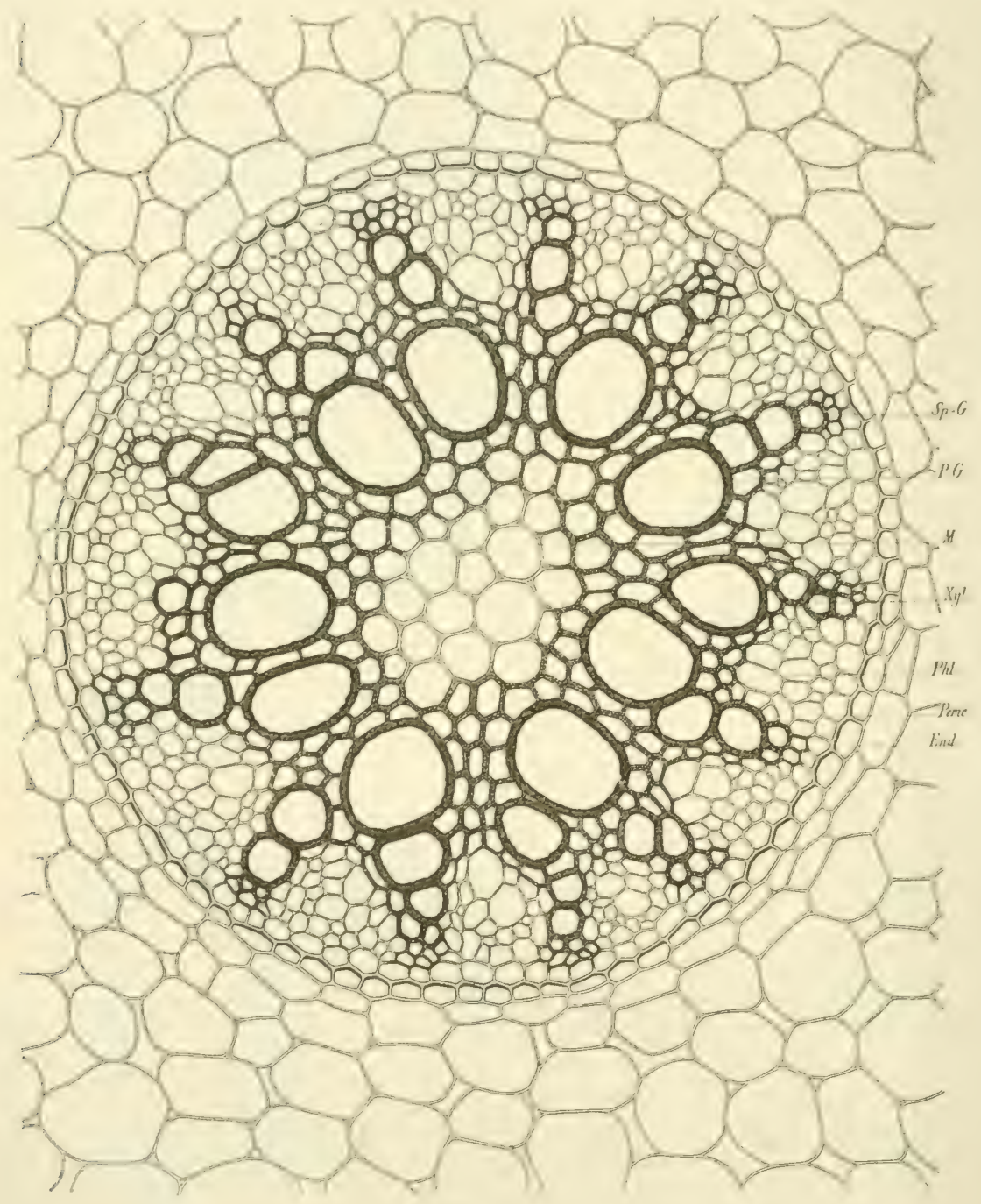

Fig. II 7 .

Centraler Teil eines Querschnittes durch eine Wurzel von Asparagus officinalis. Sp.-G. Spiralgefässe, P.G. Tüpfelgefässe, M. Mark, Xyl. Xylem, Phl. Phloëm, Peric. Pericambium, End. Endodermis. (KW.)

Zellen haben die Aufgabe, das herabrieselnde Wasser wie ein Schwamm aufzusaugen. Sie sind spiralig oder netzförmig verdickt, da beim Fehlen des Turgors die Zellen sonst leicht collabieren würden. 
Eine besondere Berücksichtigung verdient die innerste Schicht der Rinde, welche als Schutzscheide um den Centralcylinder ausgebildet ist und als Endodermis bezeichnet wird (Fig. I 7 End.). Die Endodermis selbst oder die angrenzenden Rindenschichten sind verdickt, eventuell auch teilweise verkorkt, es ist auf diese Weise möglich, dass nach Absterben der Rinde der Centralcylinder wie durch eine Epidermis abgeschlossen und geschützt wird.

Der Centralcylinder enthält die Gefässbündel, die Leitzellen und das Pericambium. Die Gefässbündel sind in den Wurzeln radial gebaut d. h. die Xylemteile bilden Strahlen (Fig. I I7 Xyl.), zwischen denen die Phloëmbündel liegen (Fig. I 7 Phl.), welch letztere von Leitzellen umgeben sind. Die Xylemteile können 2, 3, 4 oder viele Strahlen darstellen und werden dementsprechend als diarch, triarch, tetrarch oder polyarch bezeichnet. Diese Xylemstrahlen, deren jüngste Elemente an der Peripherie liegen, deren ältere Elemente der Mitte zugewendet sind, können in der Mitte zusammenstossen (Fig. I I8) oder es kann ein parenchymatisches Mark vorhanden sein (Fig. I I7 M). Das Phloëm besteht meist nur aus Phloëmparenchym und Siebröhren, doch können auch Bastfasern gebildet werden (Fig. I I Scler.).

Das Perica m bium liegt unmittelbar unter der Endodermis (Fig. I I Peric.), ist einschichtig (die meisten Angiospermen) oder mehrschichtig (Gymnospermen) und besteht aus länģer teilungsfähig bleibenden, parenchymatischen Zellen.

Eine wesentliche Bedeutung erhalten Pericambium, Endodermis und eventuell auch die innersten Rindenschichten durch die Bildung der Seitenwurzeln. Dieselben entstehen endogen, d. h. im Innern der Hauptwurzeln. Die betreffenden Gewebe bilden einen neuen Wurzelvegetationspunkt, welcher die äusseren Rindenpartien, sowie die Epidermis zu durchbrechen hat, um an die Oberfläche der Wurzeln zu gelangen (Fig. I I2); dabei sind verschiedene Modifikationen möglich: Wurzelhaube und Epidermis gehen aus der Endodermis, der übrige Teil des Vegetationspunktes aus dem Pericambium hervor (Pistia); sämtliche Teile des neuen Vegetationspunktes gehen aus dem Pericambium hervor (Sagittaria, Zea, Alisma, Helianthus, Faşopyrum); das Pericambium bildet die Gefässbündel, die Endodermis und $\mathrm{I}-2$ Rindenschichten bilden die übrigen Teile (Cucurbitaceen und Papilionaceen).

\section{S 29. Sekundäres Dickenwachstum der Wurzeln. Wurzelholz.}

Sekundäres Dickenwachstum wird in der Regel nur bei Gymnospermen und Dicotylen beobachtet. Es bildet sich hier in den Zellen, welche sich zwischen Xylem und Phlö̈m befinden, eine Cambiumschicht aus, die zunächst den Strahlen und Auszackungen des primären Xylems folgt (Fig. I I 8 Camb). In derselben Weise wie bei den Spross- 
axen werden von den Cambialzellen nach innen neue Xylemelemente, nach aussen neue Phloëmelemente abseschieden (Fig. I I 8 sek. Xyl.). Das Dickenwachstum ïberwiegt zunächst in den Buchten zwischen den primären Xylemstrahlen, wodurch die Bastelemente nach aussen gedrängt

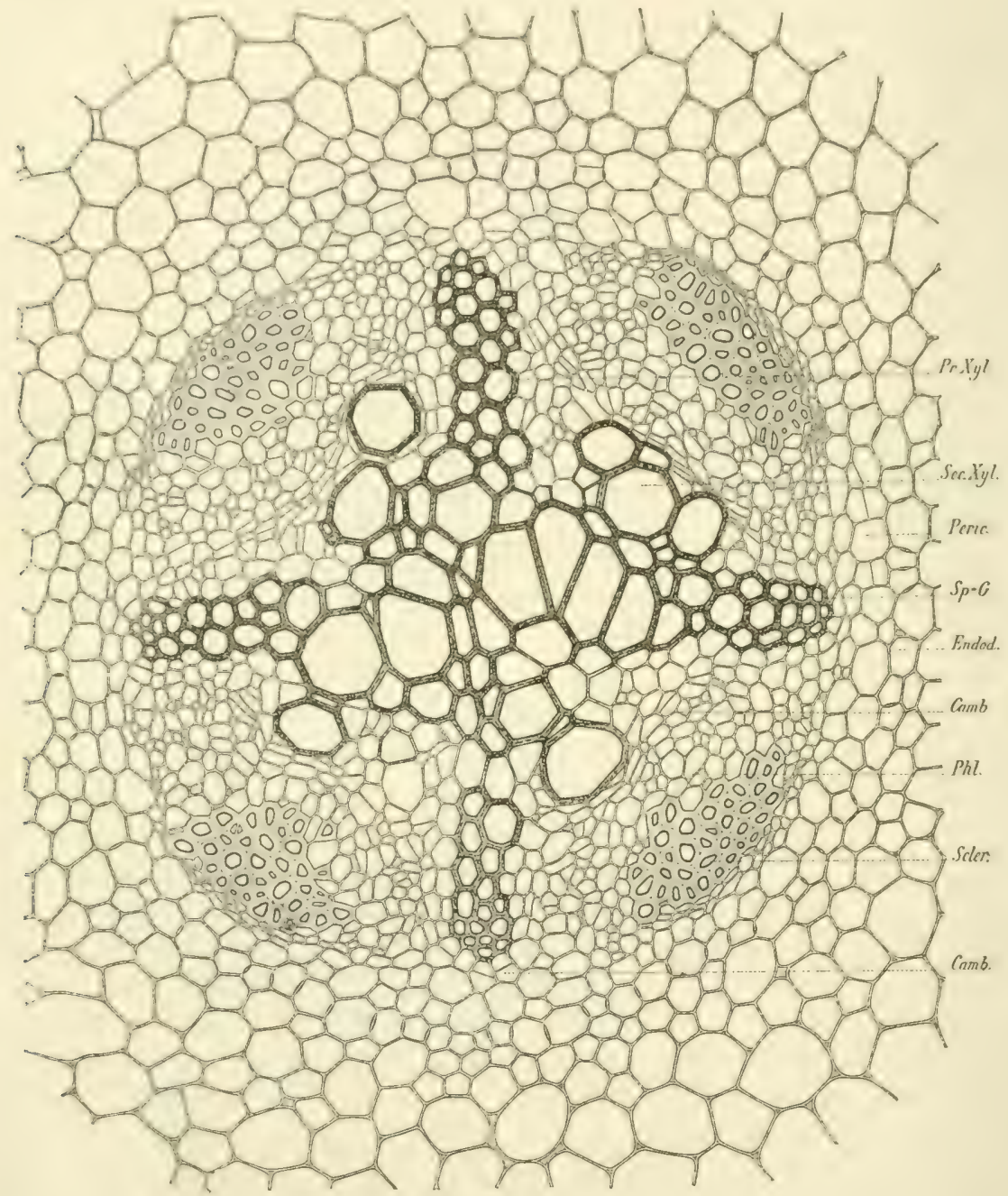

Fig. II 8 .

Querschnitt durch die centralen Teile der Wurzel von Vicia Faba. Pr. Xyl. primäres, Sec. Xyl. sekundäres Xylem, Camb. Cambium, Scler. Bastfasern, sonst die Bezeichnungen wie bei Fig. I I 7 (KW)

werden, während sich die zuerst şezackte Cambiumzone zum vollständigen Cambiumringe umbildet. Ist dies geschehen, so findet das Dickenwachstum in derselben Weise statt, wie bei den Sprossaxen.

Bei den Monocotylen tritt Dickenwachstum nur in seltenen Ausnahmen auf (Dracaena Draco und andere Dracaenaarten, Aletris fragrans). 
Durch Teilung in den Pericambialzellen werden neue Gefässbündel gebildet, die sich den schon früher vorhandenen anschliessen. Die Regel ist, dass die Wurzeln am Vegetationspunkt in derselben Dicke angelegt werden, wie sie weiter wachsen.

Trotz der gleichartigen Entstehungsweise durch die Thätigkeit eines Cambiumringes weicht das Wurzelholz von dem Holze der Stämme und Äste sehr wesentlich ab. Das Holz der Wurzeln ist im allgemeinen weicher und leichter. Bei den Nadelhölzern sind die Tracheïden dünnwandiger, das Herbstholz ist bedeutend reduciert oder fehlt gänzlich. Die Tüpfel sind hier vielfach in zwei Längsreihen geordnet, während die Stammholztracheïden meist nur eine Tüpfelreihe aufweisen. Bei den Laubhölzern ist die Zahl der Gefässe und Tracheïden eine relativ sehr grosse, bei sleichzeitigem Zuriüktreten der dickwandigen Libriformzellen, so dass z. B. vieljährige daumendicke Eichenwurzeln im Querschnitt wie ein Sieb aussehen können. Die Holzzellen sind im allgemeinen, z. B. bei der Rosskastanie und Erle, in der Wurzel dünnwandiger als im Stamm, bei der Aspe ist die Differenz dagegen unbedeutend, da hier der Stamm schon ziemlich dünnwandige Elemente aufweist. Bei der Esche und Eiche sind die Gefässe in der Wurzel durchschnittlich enger, bei der Buche und in geringerem Grade auch bei der Birke und Aspe durchschnittlich weiter als im Stamm. Ausserdem können noch Tracheïden und Holzparenchym an Weite beträchtlich zunehmen, unter entsprechender Abnahme der Zellwandverdickuns (Berberis, Fraxinus, Betula, Quercus).

Bemerkenswert ist ausserdem die Längenzunahme der Holzelemente, die im Verein mit der Geschmeidigkeit der Wand eine grössere Biegsamkeit des Wurzelholzes zulassen.

Die Jahresringgrenzen sind in der Wurzel häufig sehr undeutlich. Das Zählen der Jahresringe wird sowohl durch die geringeren Unterschiede von Frühjahrs- und Herbstholz, als durch die geringe Breite der Jahresringe erschwert, ja, sie kann bei der Ausbildung zahlreicher gleichgrosser Gefässe zur Unmöglichkeit werden (Eiche).

Die basalen Teile starker Seitenwurzeln zeigen häufig (z. B. bei Fichte und Buche) ausserordentlich excentrische Jahresringe. Die Irurzeln sind seitlich stark zusammengedrückt, die Oberseite der Wurzeln weist sehr breite, die Unterseite sehr feine Jahresringe auf, die sich bis zur Unkenntlichkeit verschmälern können.

Inwieweit die abweichende Ausbildung des Wurzelholzes von äusseren Umständen bedingt ist, muss noch näher untersucht werden, namentlich scheint die umgebende Feuchtigleeit die Beschaffenheit des Wurzelholzes stark zu beeinflussen (vgl. S. I04). Über der Erde wachsende Wurzeln sollen sich der Beschaffenheit des Stammholzes nähern. 


\section{$\$$ 30. Poriderm- und Borkebildung. Lenticellen.}

Bei Verletzung lebender Gewebe wird an der Wundstelle Korkgewebe sebildet. Ebenso wird die Epidermis beim Älterwerden der Sprossaxen und Wurzeln durch Kork ersetzt.

Der Kork ist ein Dauergewebe, das aus der teilungsfähigen Phellogenschicht (Korkcambium) hervorgeht, beide zusammen bezeichnet man als Periderm.

Betrachten wir zunächst die ohne Verletzungen auftretenden Peridermbildungen.

Periderm kann aus verschiedenartigen, natürlich nur lebenden Geweben hervorgehen. In den betreffenden Zellen treten zur Oberfläche parallele Teilungen auf. Die eine Tochterzelle wird zur Phellogenschicht

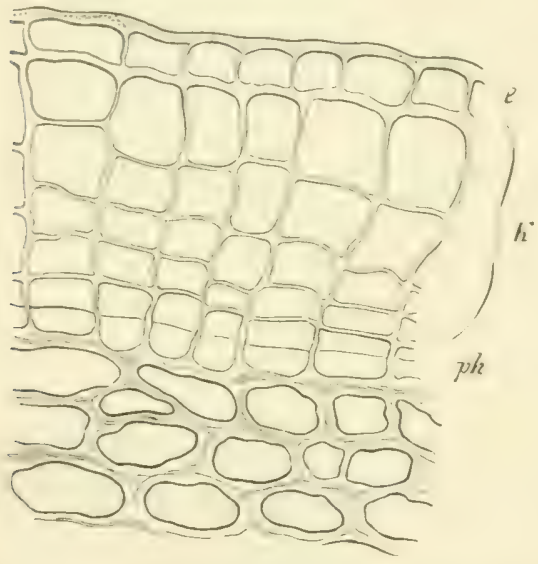

Fig. 119.

Cuerschnit aus der l'eripherie eines jungen Zweiges von Acer campestre; e Epidermis, k Korkzcllen, ph Phellogenschicht, darunter verdickte Zellen des Rindenparenchyms. (R.)
(Fig. II9 ph), die andere Tochterzelle wird zur Korkzelle. Die zum Phellogen gewordene Zelle bleibt teilungsfähig, und fügt den schon vorhandenen Korkzellen neue hinzu (Fig. I I $\mathrm{k}$ ).

An der Innenseite der Phellogenschicht können ausser Korkzellen auch parenchymatische Zellen entstehen, welche gemäss ihrem Ursprung aus der Phellogenschicht als $\mathrm{P}$ helloderm bezeichnet werden, und zur Vermehrung des Rindenparenchyms beitragen.

Bei Sprossaxen geht die Phellogenschicht entweder aus der Epidermis herror (Salix, Pomaceen, Rosa), oder aus der der Epidermis unmittelbar anliegenden Rindenparenchymschicht (der weitaus häufigste Fall, so bei Abies, Tiliaceen, Rhamnaceen, Amygdalaceen etc.). Aber auch tiefere Zelllagen können zur Phellogenschicht werden, so eine Rindenschicht bei Pinus, Larix, Ribes, Berberideen 'der eine Region des Gefässbündels bei Taxus, Ericaceen, Titis. Die Peridermbildung beginnt häufigs an einzelnen Stellen, um sich später allseitig auszubreiten.

An Blättern können sich lokale Korkwucherungen bilden, die namentlich an immergrünen Arten, z. B. bei Ilex auftreten. Sie stellen äusserlich graue oder braune Flecken dar.

Bei Wurzeln finden wir schon sehr zeitig Korkbildungen, wodurch die Aufnahme von Nahrungsstoffen auf die jüngsten, nicht verkorkten 
Wurzelteile beschränkt wird. Bei den Dicotylen und Coniferenwurzeln geht die Phellogenschicht am häufigsten aus den unter der Endodermis liegenden Pericambiumzellen hervor (vgl. S. I I 7 ). Da die Korkzellen für Wasser und Nahrungsstoffe undurchlässig sind, stirbt in der Regel die ausserhalb der Korkschichten gelegene Rinde bald ab. Die Phellogenschicht kann auch bei den Wurzeln nach aussen Kork, nach innen Phelloderm abscheiden.

In anderen Fällen, z. B. bei Ononis spinosa, Aconitum Napellus, sowie bei den Monocotylen, findet die Peridermbildung in der primären Rinde dicht unter der Epidermis statt. Die primäre Rinde wird dann nicht abgeworfen.

Das Korkgewe be besteht aus etagenförmig übereinander liegenden Zellreihen (Fig. IOS C, I2 I und I22), die dadurch zu stande kommen, dass die in der Phellogenschicht auftretenden Teilungswände parallel verlaufen, und die neugebildeten Zellen ihre Form nicht wesentlich verändern. Grosslumige Korkzellen werden als Schwammkork, englumige als Plattenkork bezeichnet. Die Korkzellen können entweder dickwandig oder dünnwandig sein, Tüpfel sind im typischen Periderm nicht vorhanden, was mit der Schutzfunktion des Korkes, der undurchlässig für Wasser und Gase sein soll, zusammenhängt. Das Phelloderm besitzt bei stärkerer Wandverdickung deutliche Tüpfel.

Über die Verkorkung der Zellwand, welche die Undurchlässigkeit für Wasser und Luft bedingt, siehe S. 28. Zu bemerken ist jedoch, dass nicht in allen Zellen des Periderms, welche aus dem Phellogen hervorgehen, die Wände verkorken, es befinden sich in gewissen Fällen zwischen den verkorkten Zellen auch noch verholzte Elemente in grösserer Anzahl, so bei den Korkleisten von Ulmus campestris var. suberosa und Evonymus europaeus irgl. die Abbildungen dieser Pflanzen im TVinterzustand.

Eine eigentümliche Korkbildung der Rotbuche ist in Fig. I20 abgebildet. Es sind dies knollenförmige, verschieden grosse Gebilde, die in grosser Anzahl an Rinden auftreten können und zu grösseren Knollenkomplexen miteinander verschmelzen. Sie bestehen aus Plattenkork, sind sehr fest und lösen sich von der Rinde nicht los. 1)

Die Korkzellen sind entweder mit Luft oder mit einem homogenen braunen oder gelben Inhalt versehen. Lebendes Protoplasma fehlt im fertigen Zustande.

Die zuerst angelegte Phellogenschicht kann bei gewissen Pflanzen (Fagus, Carpinus, Corylus, Ligustrum, Ailanthus u. a.) sehr lange Zeit in Thätigkeit bleiben, und Jahr für Jahr neue Korkzellen bilden; diese Gewächse bilden demnach keine Borke oder doch nur in höherem Alter. Hierher gehört auch die Birke, bei welcher sich das Oberflächenperiderm

1) Dieselben sind, nicht zu verwechseln mit den an Buchen häufig vorkommenden Holzkugeln (Sphaeroblasten), welche schlafende Augen darstellen, deren Basis kugelig aufgetrieben ist. Dieselben bestehen aus Holz, welches von normaler Rinde bedeckt ist. 
viele Jahre hindurch vergrössert, um erst später der Borlicbildung Platz zu machen. Bei der Birke wechseln dickwandige und dünnwandige Korkzellen ab (Fier. 121), die letzteren zerreissen bei dem Abblättern des Birkenperiderms.

Anders verhält es sich bei der Mehrzahl der Holzgewächse, bei denen äussere Rindenteile und Bastpartien als Borke abgetrennt werden. Innerhalb des zuerst gebildeten Periderms bilden sich neue Periderm-

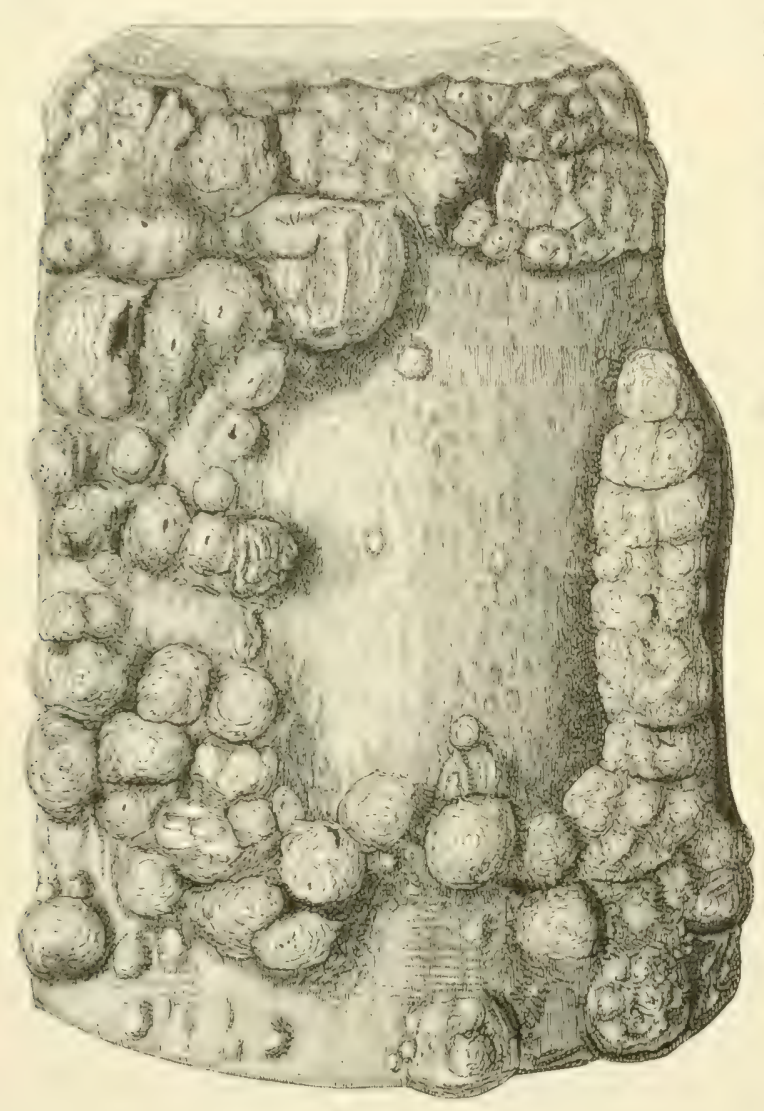

Fig. 120 .

Korkbildungen an einem älteren Stamme von Fagus silvatica. schichten, welche das Absterben der peripherischen Teile von Rinde, primärem und sekundärem Bast bewirken. Wir erhalten eine Ringelborke, wenn durch die zu der Oberfläche parallel verlaufenden Peridermschichten periphere Cylinder abgetrennt werden, die sich

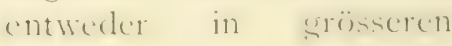

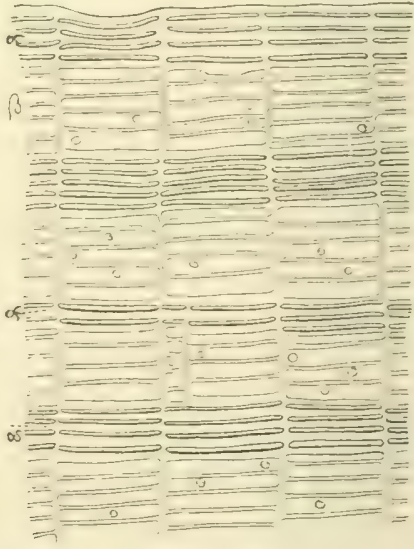

Fig. 121 .

Birkenkork im Querschnitt. « dickwandige, $\beta$ dünnwandige Korkzellen. (DN.)

Blättern (Prunus avium) oder in Längsfasern (Cupressineen, Taxineen) ablösen. Bei der Schuppenborke (Fig. I22) werden schuppenförmige oder uhrylasförmige Gewebepartien durch spitzwinklich an die vorhergehenden Periderme anschliessende Schichten abgetrennt I Robinia Pseudacacia, Picea, Platanus). Da die Borkeschichten als totes Gewebe nicht mehr wachsen, werden sie bei dem Dickenwachstum des Holzkörpers gesprengt, wobei die Längsrisse vorwiegen. Werden die durch Längsrisse entstandenen 
Borkestreifen durch Querrisse in echige Tafeln zerlegt, entsteht die sog. Tafelborke.

An den Wurzeln erreicht die Borke im allgemeinen eine geringere Mächtigkeit. Hiervon kommen jedoch auch Ausnahmen vor. In Fig. I23 ist eine Kiefernwurzel abgebildet, bei welcher die Borkemassen mächtiger sind als der Holzkörper.

Dicke Borkeschichten schützèn den Stamm gesen zu intensive Be-

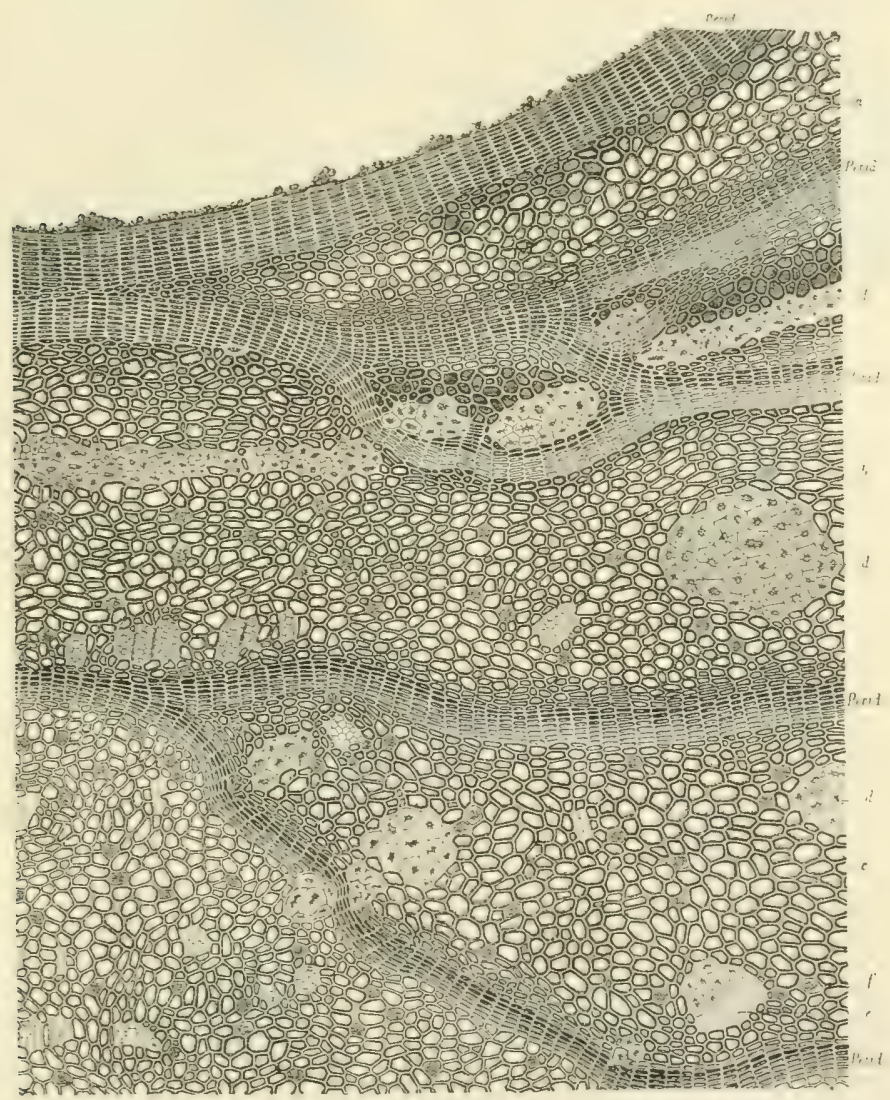

Fig. !22.

Querschnitt durch den äusseren Teil der sekundären Rinde einer jungen Wintereiche. a b c Rinden- und Bastparenchym und Siebröhren, d Steinzellen, e Bastfasern, f Zellen mit oxalsaurem Kalk. Perid. Peridermzonen, welche die Borkeschuppen nach innen zu abgrenzen. (K. W.

strahlung (Rindenbrand), ebenso gegen das auf dem Erdboden sich ausbreitende Lauffeuer, unter Umständen auch gegen Treibeis. Ausserdem dürfte noch der Schutz gegen das Schälen des Wildes zu erwähnen sein.

Die Lenticellen oder Rindenporen sind lokale Wucherungen, welche sich unter Spaltöffnungen oder Peridermschichten bilden. Durch die 
Thätigkeit einer Meristemschicht (Fig. 12+v) werden zahlreiche Zellen gebildet, die mari als Füllzellen bezeichnet (Fig. I24f). Die Bildung dieser Füllzellen kann länsere Zeit andauern, wodurch sich die Lenticellen selbstverständlich vergrössern. Die Lenticellen dienen zum Ersatz der Spalt-

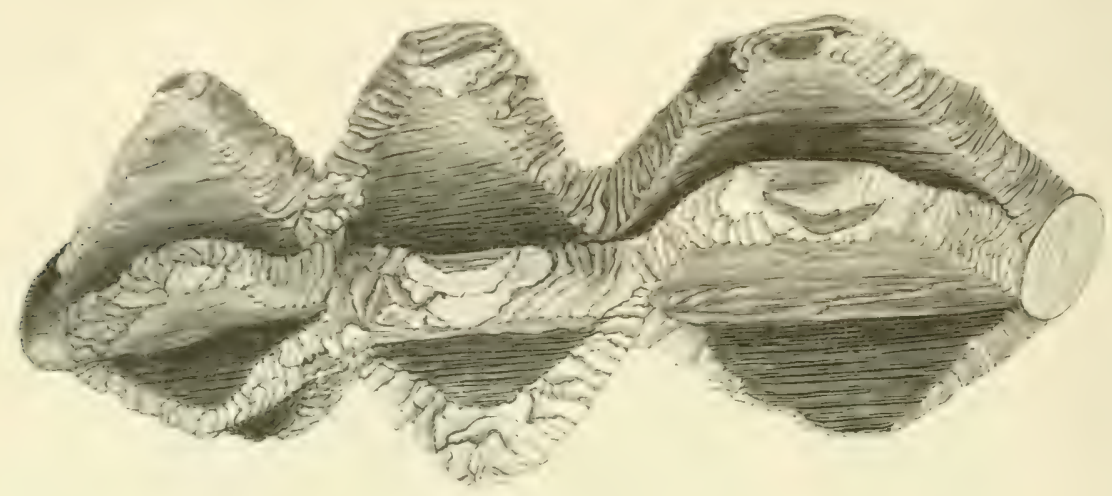

Fig. 123 .

Abnorme Borkebildung an einer Kiefernwurzel.

öffnungen bei älteren Zweigen, indem die Intercellularräume der Rinde durch die Lenticellen mit der Aussenluft in Verbindung stehen.

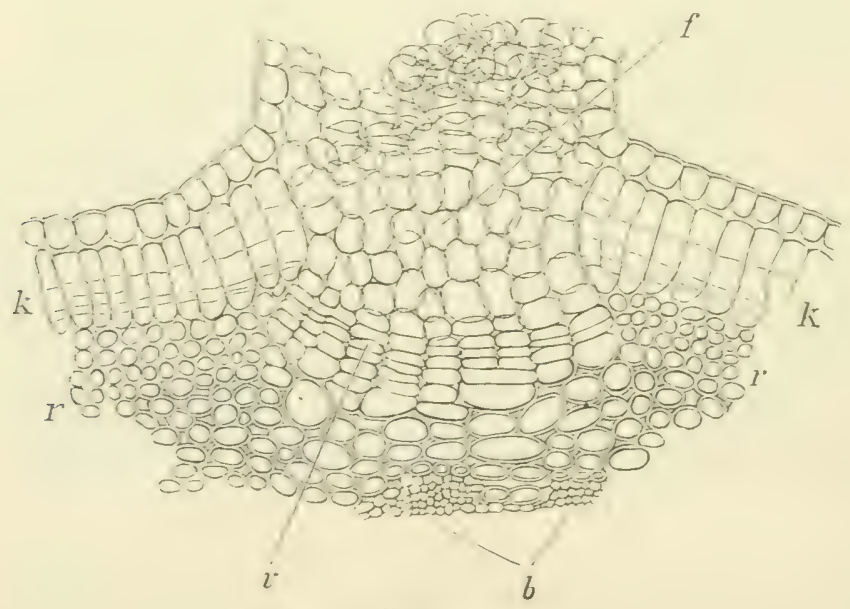

Fig. I24.

Lenticelle von Sambucus nigra im Querschnitt. $k$ Periderm, v Meristemschicht, f Füllzellen, r primäre Rinde, b Phloëm ( $\mathrm{n}$. Stahl).

Sie fehlen nur wenigen Holzpflanzen, so z. B. bei Vitis vinifera, Philadelphus coronarius, Rubus odoratus, Clematis Vitalba. Das Periderm zeigt hier in der Verlängerung der Markstrahlen einfache Intercellularräume, welche den Gasaustausch vermitteln. 


\section{§ 31. Wundheilung. Überwallung. Ästung.}

Triffteine Verletzung lebendes Gewebe, so wird die Wunde entweder durch Wundkork verschlossen, oder es entsteht ein sog. Callus.

Der Wundkork bildet sich zumeist in parenchymatischen Zellen, gleichgültig, ob dieselben schon in den Danerzustand übersegangen sind oder nicht. Indem die oberflächlichen Zellschichten der Wunde vertroclenen, entsteht in den zunächst liegenden lebenden Zellen eine Phellogenschicht, welche den Wundkork bildet.

Zur Illustration dieses Vorgangs diene Fig. I25, in welcher die Bildung von Wundkork (c, d) an einer Kartoffelknolle dargestellt ist. Die neugebildete Peridermschicht schliesst bei $\mathrm{c}$ an die alten Kork-

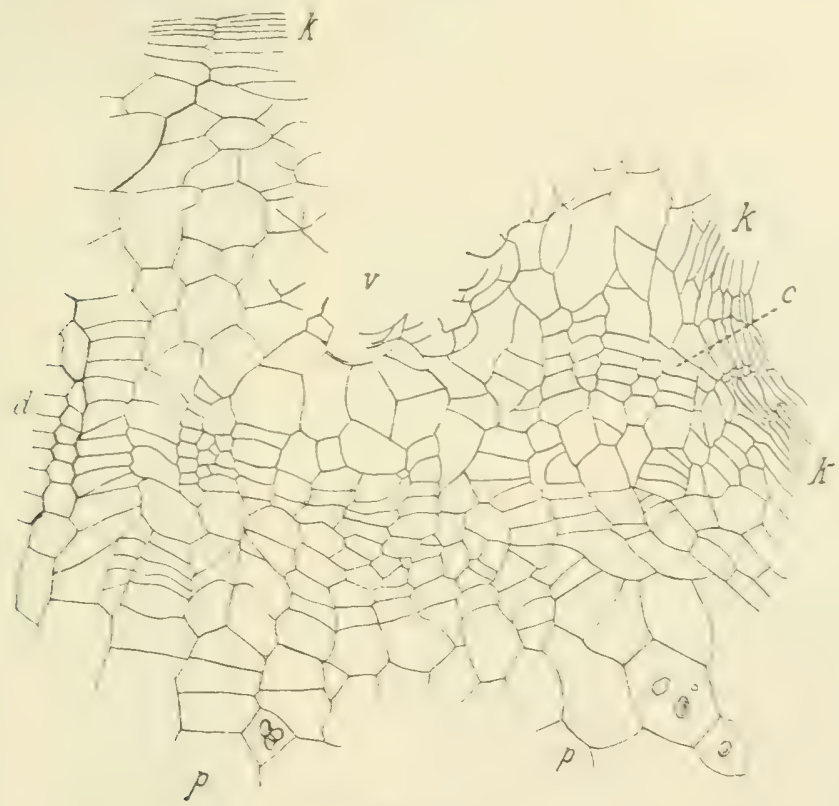

Fig. 125 .

Wundkorkbildung an einer Kartoffelknolle (n. Frank).

schichten der Kartoffelschalen ( $k$ ) an. In derselben Weise werden die Wunden geschlossen, die sich beim Abfall von Blättern, Blüten etc. bilden.

Als Callus bezeichnet man jenes aus wenig verdickten Zellen bestehende Gewebe, das durch Auswachsen der an der Wunde liegenden Zellen entstanden ist (Fig. I26, I B und $2 \mathrm{~g}$ ). Er bildet sich aus Parenchymzellen, Cambium, Weichbastzellen, während Holz-. Sklerenchym- und Korkzellen unverändert bleiben. Nachdem dieser Callus durch Bildung von Korkschichten nach aussen abgeschlossen ist, können sich im Innern Holzund Bastelemente differenzieren.

Derartige Callusbildungen treten z. B. an der in der Erde befindlichen Schnittfläche von Stecklingen auf, es gehen aus denselben neue Wurzeln 
hervor. Ebenso wird eine Schailwunde an Zweigen von Holzpflanzen mit Callus bedeckt, sobald noch Cambiumzellen oder junge Rinden- und Bastzellen erhalten geblieben sind und durch eine schützende Hülle oder eine feuchte Atmosphäre vor dem Austrocknen bewahrt wurden. Es bildet sich dann aus dem in Fig. 126 dargestellten Callus eine neue Rinde. In analoger Weise können z. B. bei Mäusefrass lokale Cambium-

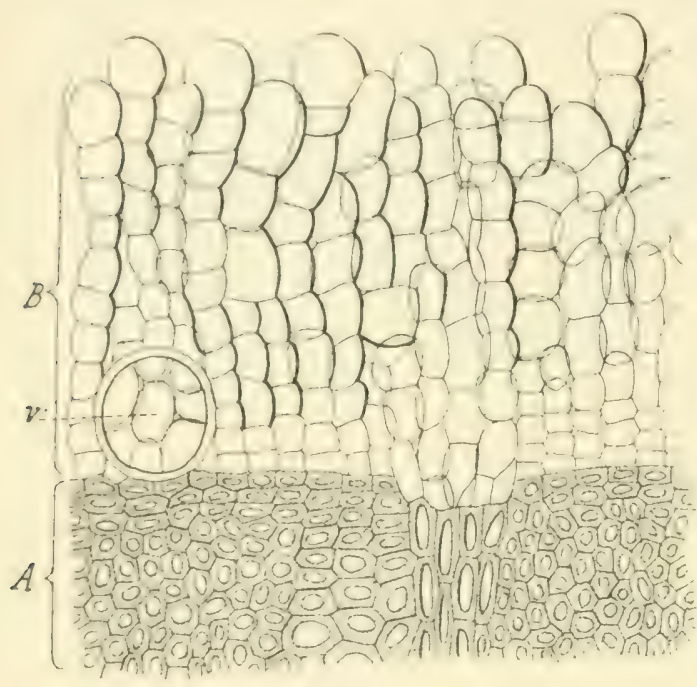

I

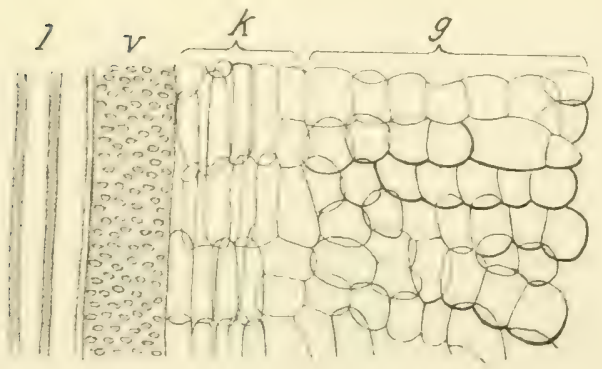

2.

Fig. 126.

Callusbildung an einer Schälwunde des Holzkörpers von Robinia Pseudacacia. I. Querschnitt. A altes Holz, v Gefäss vor der Verwundung gebildet, B Callus. 2. Längsschnitt. 1 Libriformzellen, v Gefäss, k Cambium, g Callus (n. Trecul.).

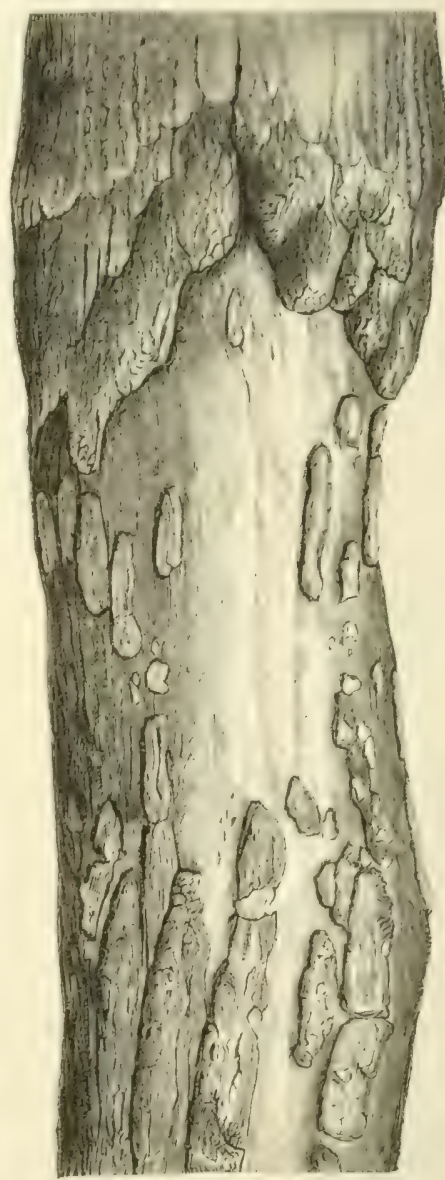

Fig. 127 .

Beschädigung einer Buche durch Mäuse. An den Stellen wo das Cambium vertrocknete hat keine Rindenbildung stattgefunden.

partien erhalten bleiben (Fig. 127), denen vom Holz aus Nahrungsstoffe zugeführt werden.

Geht die Verletzung durch Gewebe, welche tote Elemente in grosser Menge enthalten, so kann eine Reproduktion an der Wundfläche nicht eintreten. Der vorläufige Verschluss der Wunde wird bei vielen Nadelhölzern durch Harzausfluss, bei den Laubhölzern durch Gummiaus- 
scheidung oder Thyllenbildung (vgl. S. 97) in den Gefässen mehr oder weniger vollständig erreicht. Das freigelegte $\mathrm{Holz}$ wird, ohne dass Reproduktionserscheinungen auftreten, in das dem Kernholz sleiche Sichutzholz (vgl. S. IOO) umgewandelt. Der definitive Wundverschluss wird durch Überwallung angestrebt, d. h. durch gesteigerte Wachstumsthätigkeit der lebenden Gewebe des Wundrandes.

Bei einem sehr schmalen Ringelschnitt, auch wenn er das Holz der äusseren Jahresringe verletzt, wird von dem Cambium und der jungen Bastzone zunächst Callusgewebe gebildet, das die Wunde vollständig ver-

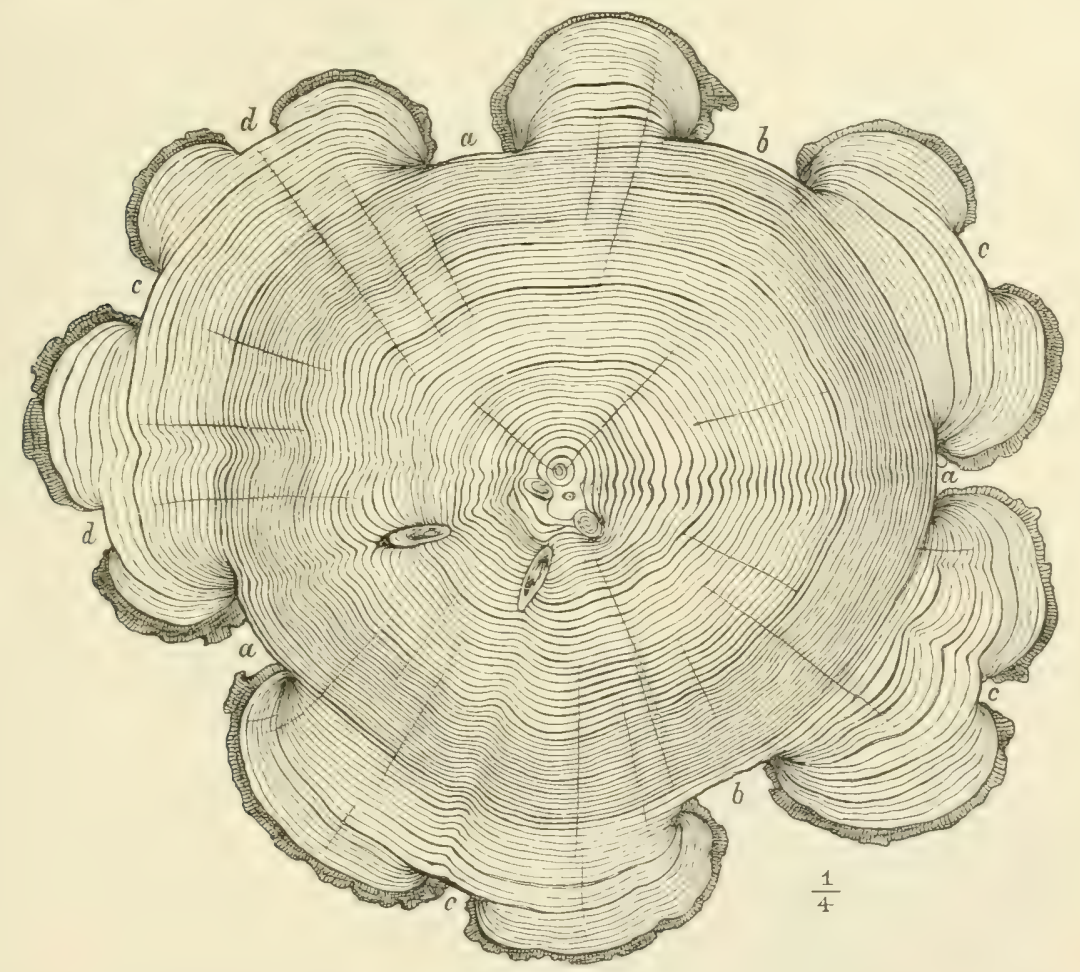

Fig. 128 .

Picea excelsa. Querscheibe eines 70 jährigen Stammes, der im 50. (a) 5 1. (b) 62. (c) 65. (d) Jahre der Harznutzung tinterzogen wurde. (DN.)

schliessen kann. Wenn die Wundränder aufeinander stossen, werden die den Callus umgebenden Peridermschichten nach aussen gedrängt, das von den cambialen Zonen der Wundränder gebildete Holz sowie der Bast vereinigen sich, wodurch die unterbrochene Leitungsbahn wieder hergestellt ist.

Bei grösserer Breite des Ringelschnittes werden ebenfalls an den Wundrändern vom lebenden Cambium aus neue Holz- und Bastwülste gebildet, namentlich an dem oberen, der Krone zugewendeten Rande, welchem die von den Blättern gebildeten, nach abwärts wandernden 
Assimilationsprodukte zuerefibrt werden. Die inneren durch den Schnitt nicht unterbrochenen Holzpartien sind nicht im stande, auf dic Dauer den oberen Pflanzenteilen die senügende Wassermenge zuzuführen und sic sterben nach ein oder mehreren Jahren ab, bevor noch eine Vereinisung des oberen und unteren Überwallungswulstes eintreten konnte.

Läinswunden sind insofern weniser sefählich, als die liortleitungs der Nahrungsstoffe und des Wassers durch dieselben nicht unterbrochen wird. In Fis. I $2 S$ ist der Querschnitt eines Fichtenstammes darsestellt, welcher wiederholt bei der Harznutzung mit Längswunden versehen worden war. Die Überwallung geht auch hier von dem erhalten gebliebenen jungen Holze aus. Bemerkenswert ist, dass der vollständige Verschluss der IVunde bei Bäumen erschwert ist, die eine sehr dicke Borke bilden, indem diese Borkeschichten der Vereinigung aufeinander stossender Überwallungsränder sehr grossen Widerstand entgegensetzen. Längswunden entstehen im Walde am häufigsten durch das Schälen des Wildes, welches die Rinde von unten nach oben vom Holze abreisst. Im Winter ist das Schälen weniger gefährlich, da das ruhende Cambium, d. h. die Schicht, an welcher die Lostrennung der Rinde erfolgt, dem Abreissen einen grössern Widerstand entgegensetzt als das thätige Cambium im Sommer. Ausserdem kommt dabei noch in Betracht, dass die Infektion durch holzzerstörende Pilze weniger leicht vor sich gehen wird, wenn die Wunde im Winter durch Harz verschlossen war, bevor noch die für die Pilzkeimung vorteilhafte Sommertemperatur cintrat.

Selbstverständlich kann das durch die Überwallung gebildete Holz nicht mit dem toten Holz der Wunde verwachsen, es kann sich jedoch allen Biegungen und Vertiefungen anschmiegen. Auf diese Weise wird von Inschriften und Zeichen, die in freigelegtes Holz eingeschnitten waren, ein vollständiger Abdruck auf dem Überwallungsholze gebildet, der später in den Baum vollständig eingeschlossen wird. In ähnlicher Weise können leblose Gegenstände, wie Knochen, eiserne Ringe, Nägel etc. umwachsen und von äusseren Holzschichten bedecht werden.

Die Astwunden der Stämme werden ebenfalls ron den Wundrändern aus überwallt. Sie entstehen entweder durch das Absterben unterdrückter, dem Lichte entzogener Äste, die später vermöge ihrer eigenen Schwere abfallen oder durch Entfernung lebender noch beblätterter Äste durch den Menschen (Grünästung), Schnee, Sturm etc. Bei dem natürlichen Reinigen des Stammes von den Ästen bleiben bei Fichte und Tanne die verharzten Aststumpfe lange erhalten, sie werden überwallt und fallen aus Brettern als sog. Hornäste leicht aus.

Bei Laubbäumen, an denen namentlich bei den kleineren Ästen der Aststumpf leichter zersetzt wird, fehlen die Aststümpfe an dem Stamm. Dickere, kernholzhaltige Äste werden auch hier in den Stamm eingeschlossen (Fig. I29). 
Die Überwallung wird um so leichter vor sich gehen, je kürzer der Aststumpf ist, ein längerer Aststummel dagegen verzögert die Überwallung, die Zersetzung des Holzes wird bei der längeren Zeit eine voll-

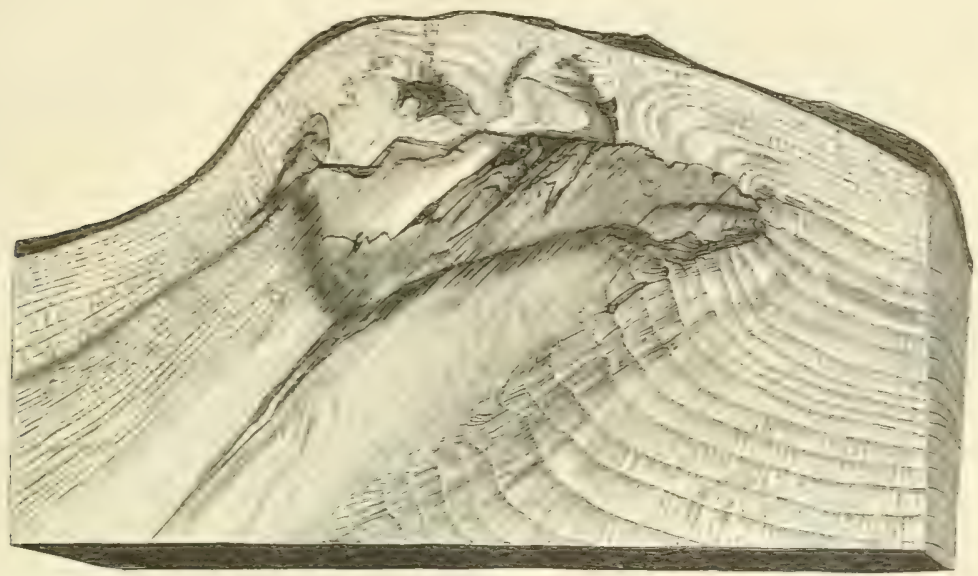

Fig. I 29 .

Tberwallung eines Buchenastes mit geringer Zersetzung des Aststumpfes,

ständigere sein und sich leicht auf weitere Strecken in das Stammholz fortsetzen, bevor noch ein Verschluss der Wunde erreicht ist. Es können

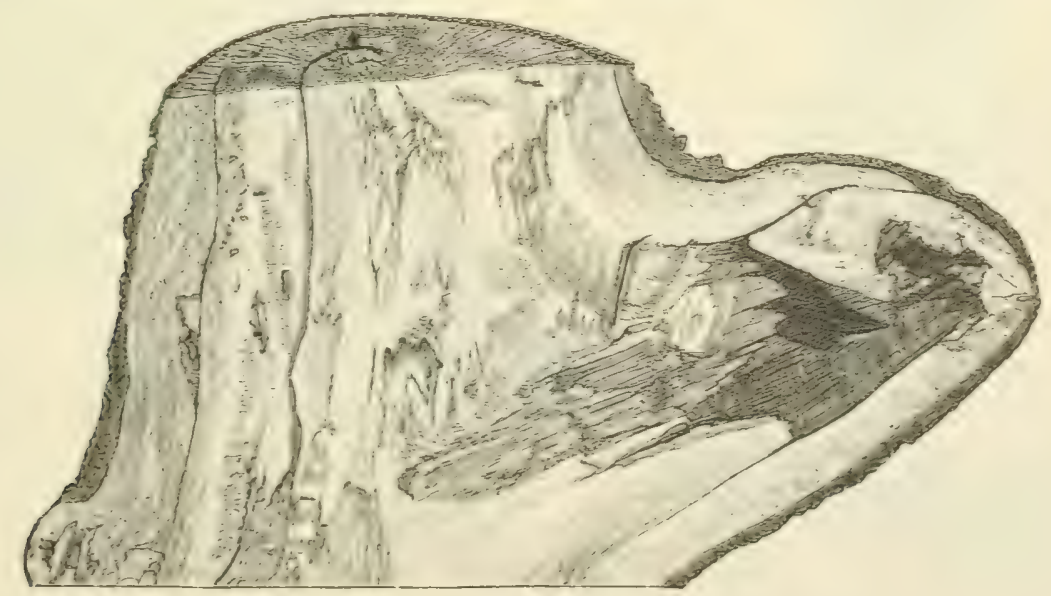

Fig. 130 .

Weitgehende Zersetzung eines längeren, später überwallten Eichenastes.

dann, wie Fig. I 30 zeigt, vollständige Hohlräume unter der Überwallungsstelle entstehen.

An der unteren Seite grösserer Astwunden bleibt häufig die Überwallung zurück, da einerseits dem oberen Rande mehr Nahrungsstoffe 
zusefuiht werden, anderseits der Rindenkërper bei der Ästung leicht lossedriekt und somit das reproducierende Cambialgewebe verletzt wird. An jungen Bäumen mit breiten Jahresringen, sowic an reich belaubten äteren Bäumen wird die Überwallung schneller vor sich sehen, weil die Überwallungsräinder infolge der reichlicheren Nahrungszufuhr schneller wachsen. Die VVinter- und Herbstästung ist der Sommer- und Frühjahrsästung vorzuzichen, da im Winter die Pilzinfektion weniger gefährlich ist als im Sommer (vol. S. 128).

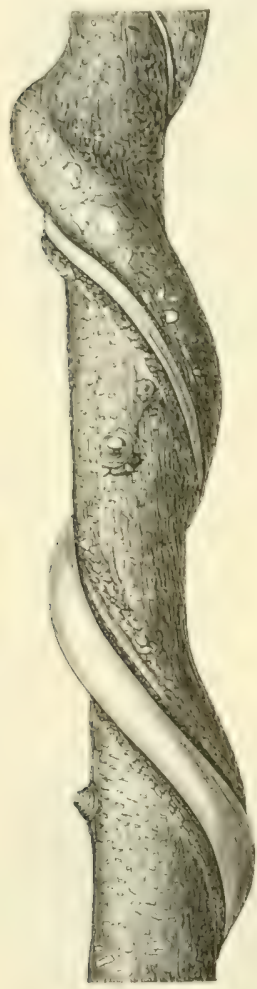

Fig. I3I.

Junges Birkenstämmchen durch Lonicera Periclymenum umwunden. Die Überwallung ist an der oberen Region weiter vorgeschritten als an der basalen.

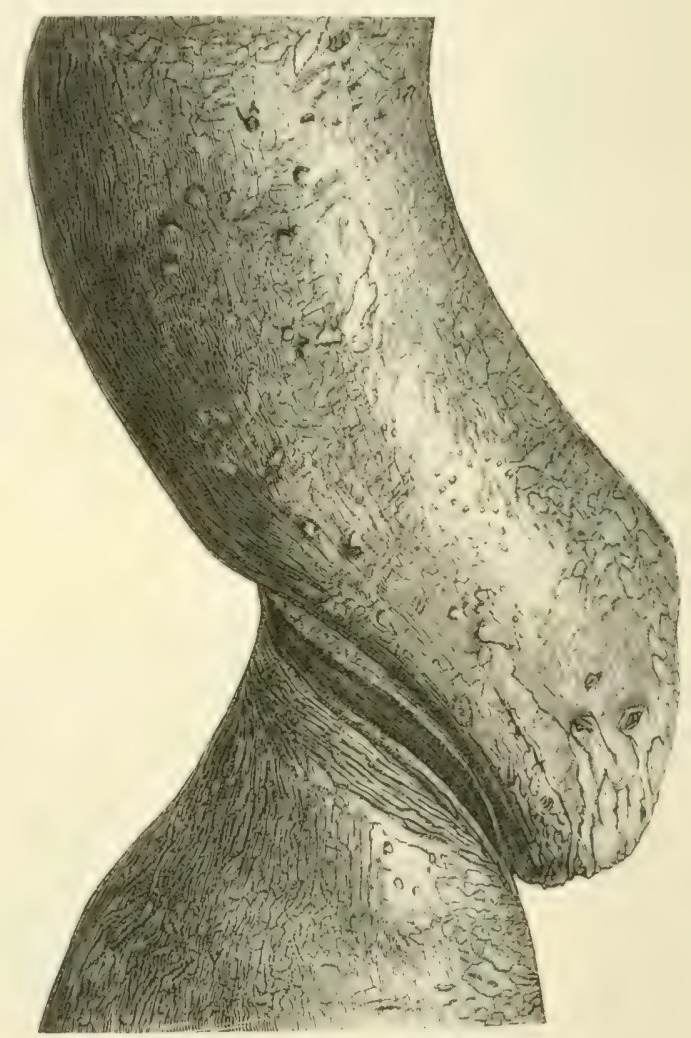

Fig. 132 .

Abschnitt eines von Lonicera Periclymenum umwundenen Buchenstammes in der Flächenansicht.

Die Harzausscheidung der Nadelhölzer gewährt einen vollkommeneren Schutz gesen die Pilzinfektion, als die Wundholzbildungs der Laubhölzer, doch sind auch hier kernhaltige Wunden dickerer Äste gefährlich, da aus dem Kern nur wenig Harz austritt. Es ist daher notwendig, dic Äste der Laubhölzer, sowie die stärkeren Äste der Nadelhölzer durch Überstreichen mit Theer, Baumwachs oder ähnlichen Stoffen gegen die Infektion und ihre Folgen zu schützen. Das Theeren wird einen um so 
besseren Erfolg haben, je trockner das Holz ist, und je besser der Theer in die Holzwandungen und Zelllumina eindringt. Im Frühjahr und Sommer nehmen die mit Wasser getränkten Holzzellen den Theer nur schlecht auf.

Eine geringere $\mathrm{Be}-$ deutung besitzt die Üb er wallung der Stümpfe abgehauener Stämme. Die Überwallung wird hier nur langsam vor sich gehen, da die assimilierenden Organe fehlen, und der Überwallungswulst sich nur auf Kosten der im Wurzelsystem gespeicherten Nahrungsstoffe bilden kann. Eine Überwallung findet bei den Nadelhölzern in der Regel überhaupt nicht statt, nur wenn die zum Stammrudiment gehörenden Wurzeln mit einem anderen unverletzten Stamme verwachsen sind, kann der letztere als Nährstamm die zur Überwallung nötigen Nahrungsstoffe liefern.

Überwallungswülste können auch ohne äuss ere Verletzungen entstehen, wenn die Stämme durch Draht oder durch Schlingpflanzen, wie LoniceraPericlymenum (Fig. I 3 I bis I33), Celastrus scandens, umwunden werden. Das Dickenwachstum ist an den Stellen gehemmt, an

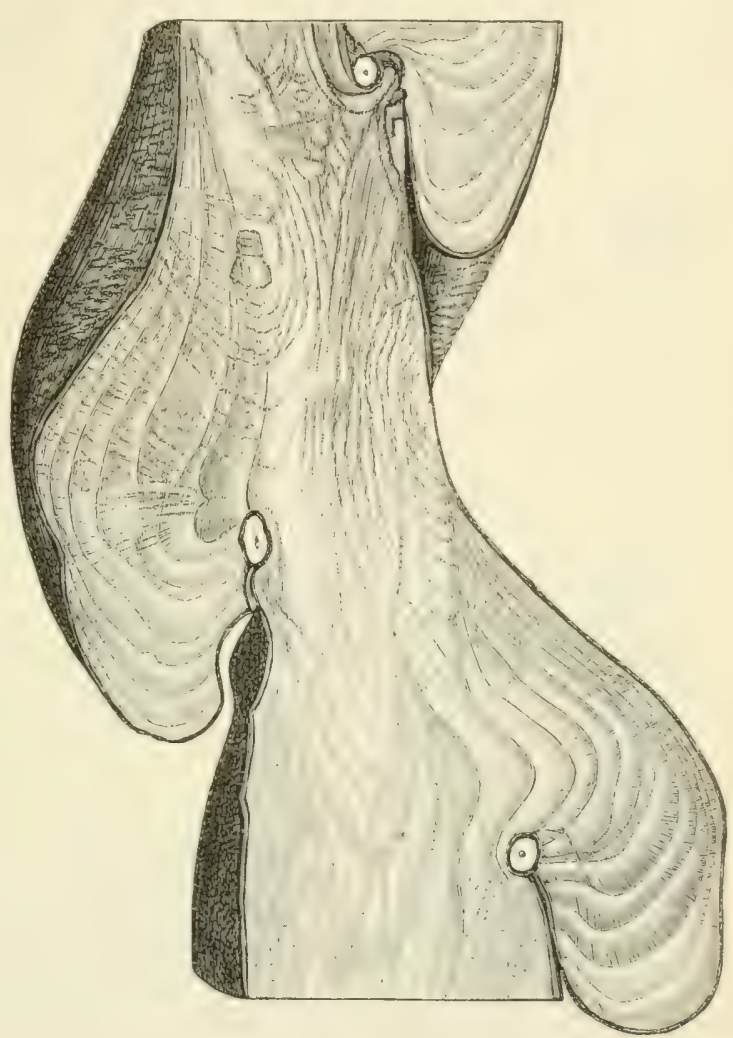

Fig. I33.

Dasselbe wie Fig. I 32 in Längsschnitt.

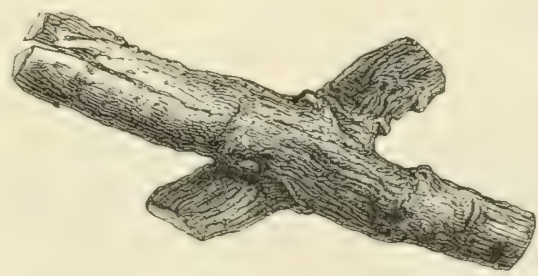

Fig. 134 .

Verwachsung zweier Buchenwurzeln. (DN.) welchen der Draht resp. die Schlingpflanzen auf den Stamm drücken, dafür werden, wie wir in den Figuren I3I-I33 sehen, die benachbarten Partien auf der der Krone zugewendeten Seite zu erhöhtem Wachstum angeregt, es bildet sich ein Überwallungswulst, welcher schliesslich den fremden Gegenstand einschliesst. Es ist dies interessant, weil man für 
gewöhnlich die Bildung des Überwallungswulstes auf die Bescitigung des Rindendrucks an der Wundstelle zurückführt. In dem gesebenen valle tritt jedoch eine Steigerung des Wachstums an der Überwallungsstelle ein, olme dass eine Aufhebung des Rindendrucks stattgefunden hätte, ja der Rindendruck dürfte sogar infolge des vermehrten Wachstums eine Steigerung erfahren. Später kann wohl die Rinde aufreissen, dies scheint mir aber nicht von Wichtigkeit zu sein.

In ähnlicher Weise, wic sich die Holzkörper der Über-

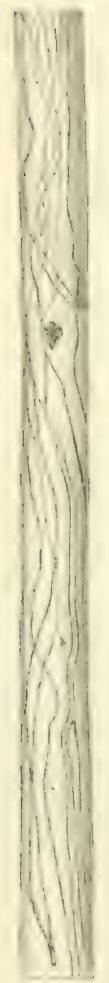
wallungswülste beim Schluss der Wunde unter Herausdrücken der Rinde vereinigen, können auch gleichartige Pflanzenteile miteinander verwachsen. Wir sehen in Fig. 134 zwei miteinander verwachsene Wurzeln, die ursprünglich nur fest aufeinander lagen, ebenso können zwei Stämme oder im jugendlichen Zustande absichtlich hervorgerufene Stammschlingen verwachsen. Wir können derartige Vereinigungen z. B. an Büschelpflanzungen von Fichten oder an Eichenkulturen beobachten, wo zwei Eicheln nebeneinander gekeimt hatten. Diese Erscheinung kann gefährlich werden, wenn der eine Stamm unterdrückt wird und abstirbt, oder durch Sturm gebrochen wird. Es entsteht eine grosse Wunde, von welcher aus die Zersetzung auf den erhalten gebliebenen Stamm übergreift. Eine Verwachsung wird absichtlich hervorgerufen bei dem Pfropfen und Okulieren von Edelreisern auf Wildlinge derselben Art oder nahe verwandter Arten, wobei sich an den in verschiedener Weise hergestellten Schnittflächen Rinde mit Rinde, Cambium mit Cambium vereinigt, unter gleichzeitiger Ausfüllung der Zwischenräume mit callösem Gewebe.

Eine Ausfüllung durch lockeres Zellgewebe findet auch bei den sog. Zellgängen statt, welche sich in dem Stammholze mancher Bäume (Salix, Alnus Tafel I, Figs. I, Betula, Tafel II, Fig. I6, Crataegus und Sorbusarten) vorfinden. Es sind dies feine Gänge, welche Tipulalarven in dem thätigen His. 1.35. Cambium fiessen. Man kann dieselben im Mai und Nnfans

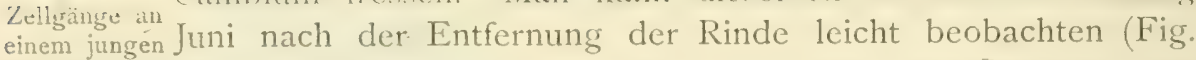
Weidenzweig 135). Diese Frassgänge werden im Verlauf des Sommers von

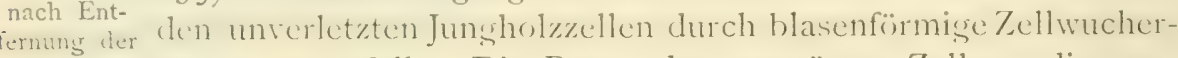
Rinde. ungen ausgefüllt. Die Reste der zerstörten Zellen, die neugebildeten Füllzellen, sowie die Kotmassen färben sich allmählich dunkler, und rufen die gelbbraune oder rotbraune Färbung der Zellgänge hervor, wodurch dieselben im Holzkörper auffallen.

Auf welche Weise die Zellgänge der Nadelhölzer entstehen, ist noch nicht aufgeklärt.

Manche Käferlarven, die ebenfalls im Cambium und der jungen Rinde fressen, zerstören eine so grosse Menge von Zellen, dass die Stoffwan- 
derung unmöglich gemacht wird, wodurch schliesslich die Bäume absterben.

Bei Quetschwunden, die durch Anprällen mit dem Axtrücken beim Raupensammeln, oder durch Anschlagen eines Stammes beim Baumfällen entstehen, findet in der Regel keine Ausheilung statt. Ebenso ist bei dem durch die Sonnenhitze hervorgerufenen Rindenbrand kein Ersatz der abgestorbenen Teile zu beobachten. Die Rinde vertrocknet allmählich, es treten Risse auf, welche der Pilzinfektion Thür und Thor öffnen. Die Überwallung derartiger Wunden soll nach den bisherigen Anschauungen unterbleiben, weil die Rindenspannung nicht aufgehoben sei, ich möchte diesem Umstande jedoch keine so grosse Bedeutung beimessen, da die

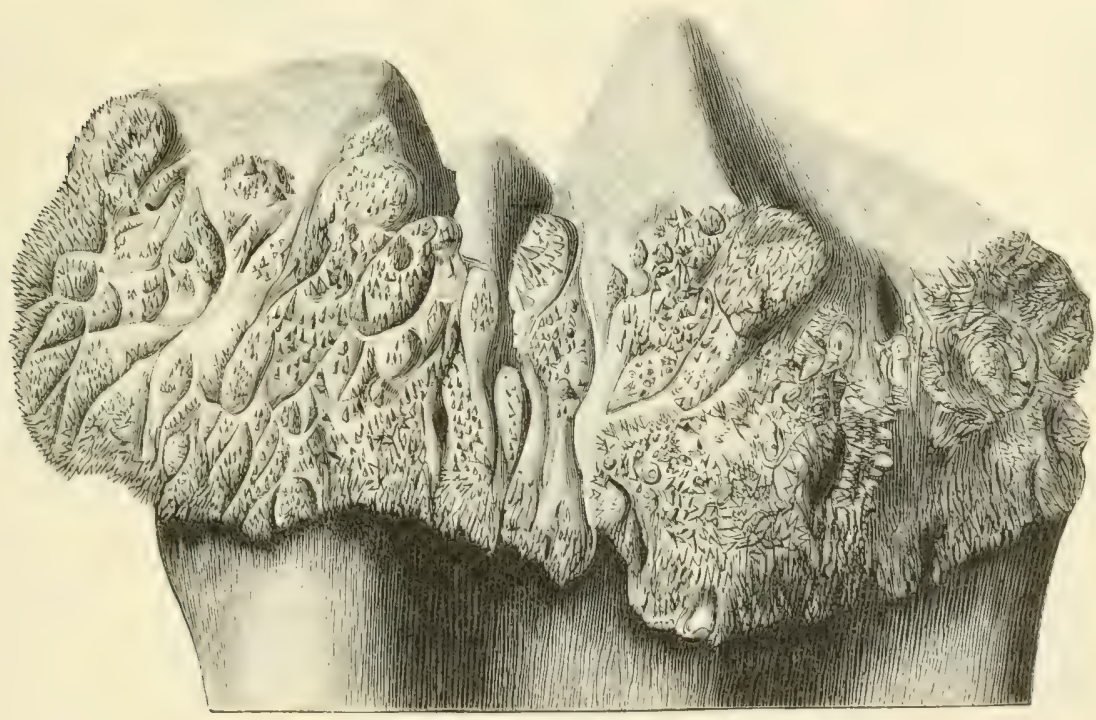

Fig. 136 .

Maserbildung an der Erle nach Entfernung der Rinde.

Verhältnisse bei Quetsch - und Sonnenbrandwunden doch auch in anderer Beziehung verschieden sind. Es wäre sehr leicht möglich, dass nur bei dem Vorhandensein einer Wunde mit scharf abgegrenzten Wundrändern jener Reiz auf das gesunde Gewebe ausgeübt wird, welcher zur Überwallung führt.

Ebenso handelt es sich beim Auftreten zahlreicher Knospen an Stammwunden um einen Reiz, und nicht etwa um eine Differenz der Rindenspannung. Häufig wachsen derartige Knospen nicht zu Zweigen aus. Sie bilden untereinander zusammenhängend grosse Auswüchse an Stämmen, eine Erscheinung, die man namentlich an Erlen, Linden, Birken und Buchen beobachten kann. Die Unregelmässigkeit im Verlaufe der Holzfasern, sowie die Häufung der Knospen lässt das Holz dieser Aus- 
wïchse schön semasert erscheinen. Wir sehen in Fig. 136 einen derartigen Auswuchs eines Erlenstammes, der mit zahlreichen vorstehenden Spitzen, dem Holzkörper der Knospen, bedeclit ist.

Schliesslich mögre noch jene Erscheinung erwähnt werden, die man als Verbänderung (Fasciation) bezeichnet. Man versteht darunter

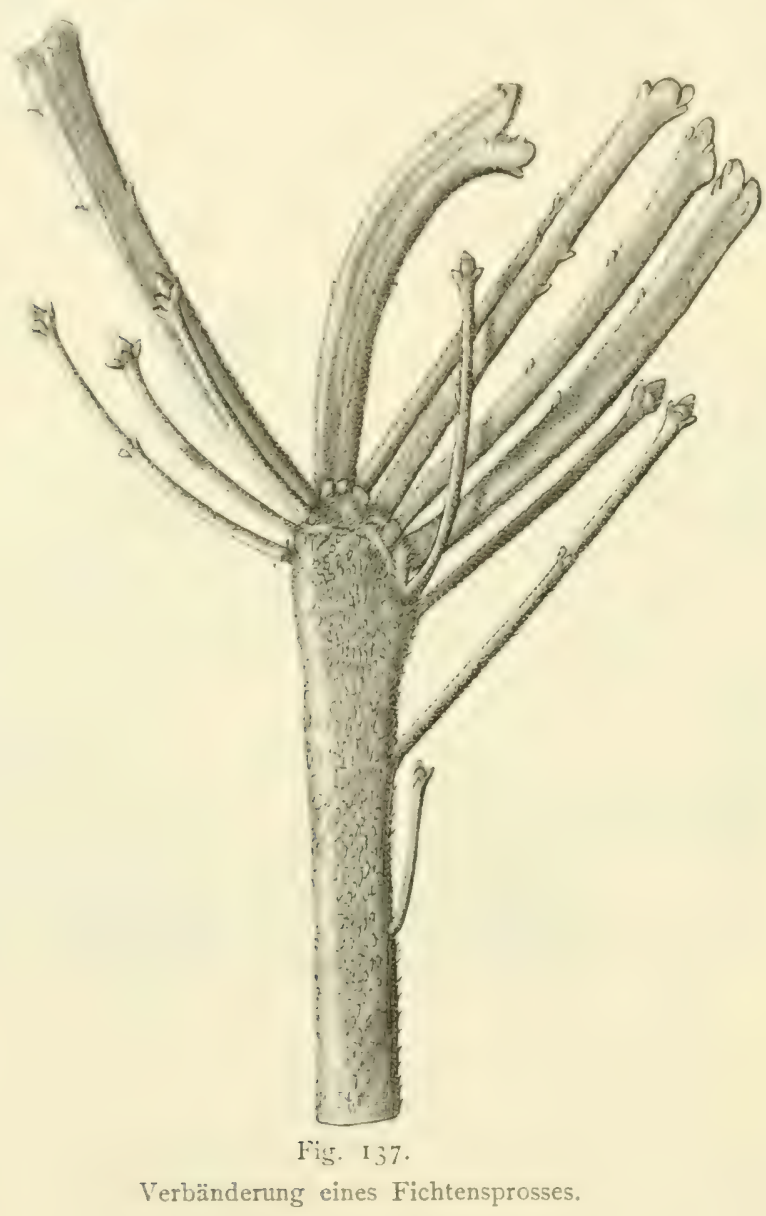

eine bandförmige, flache Ausbildung der sonst runden Sprosse (Fig. 137), die meist mit abnormer Verzweigung verbunden ist. Man findet diese Verbänderung sowohl bei Holzpflanzen (z. B. Erlen, Kirschen, Kiefern, Fichten, Akazien etc.), als bei krautigen Gewächsen (z. B. Leontodon Taraxacum). Die Erscheinung kann durch Stecklinge oder sogar durch Samen iz. B. bei Celosia cristata, dem Hahnenkamm) fortgepflanzt werden. Wir müssen daher annehmen, dass es sich um eine Veränderung des Prritoplasmas am Veugetationspunlite handelt, welche zu der Fasciation führt. 


\section{Physiologie.}

\section{S32. Die Nahrungsstoffe der Pflanzen.}

Zum Aufbau der Pflanzen sind gewisse Stoffe notwendig, die als Nahrungsstoffe in einfachen chemischen Verbindungen aufgenommen und weiter verarbeitet werden. $\mathrm{Zu}$ dieser Umwandlung, sowie zum Leben und Wachsen überhaupt sind Kräfte notwendig, welche die Pflanze teils als Licht und Wärme von der Sonne empfängt, teils durch die molekularen, mechanischen und chemischen Kräfte gewinnt, welche den als Nahrung aufgenommenen Pflanzensubstanzen inne wohnen.

In der Pflanze haben folgende Elemente allgemeine Verbreitung: Kohlenstoff, Wasserstoff, Sauerstoff, Stickstoff, Schwefel, Phosphor, Kalium, Natrium, Calcium, Nagnesium, Eisen, Mangan, Chlor, Silicium. Die übrigen Elemente fehlen entweder vollständig, sind mehr zufällig vorhanden oder ihr Vorkommen ist auf bestimmte Pflanzen beschränkt. So kommt Jod und Brom in den Meeresalgen, Aluminium in den Lycopodiumarten, Fluor in den Samenschalen des Getreides vor.

Da die Kohlenstoffverbindungen die sog. organischen Verbindungen in der Pflanze sehr überwiegen, ist der Bedarf an Kohlenstoff naturgemäss ein sehr bedeutender. Derselbe wird bei den grünen Pflanzen ausschliesslich oder doch in ganz überwiegendem Masse durch die Kohlenstoffassimilation gedeckt, wobei aus der Kohlensäure der Luft und dem Wasser durch die Nitwirkung von Chlorophyll und Sonnenlicht zunächst stickstofffreie organische Verbindungen entstehen (Stärke). Die letzteren werden mit stickstoffhaltigen Substanzen (salpetersauren Salzen, Asparagin, Leucin etc.) verarbeitet, wodurch unter Aufnahme von Schwefel und Phosphor die für das Protoplasma so wichtigen Proteïnsubstanzen entstehen. Bei den Stoftwechselvorsängen ist die Mitwirkung gewisser anorganischer Salze notwendig, die nach dem Verbrennen der organischen Verbindungen als sog. Aschenbestandteile zurïckbleiben.

Bei den chlorophyllfreien Pflanzen, den Pilzen und phanerogamen Schmarotzern findet keine Kohlensäureassimilation statt, diese Pflanzen decken vielmehr ihren Kohlenstoffbedarf durch die Aufnahme organischer Verbindungen aus lebendem oder totem Substrat. Der Stickstoff wird hier in Form organischer oder anorganischer Verbindungen aufgenommen. Aschenbestandteile bedürfen die Pilze ebenfalls. 
Zum Aufbati der Zelle, bei der bildung sewisser I'flanzensubstanzen (z. B. entsteht Stärle aus Kohlensäure und Wasser), sowic zum Transport der Pflanzenstoffe ist Wasser notwendig, wir werden daher im Folsenden Gelesenheit haben, nicht nur die Bildung der Trockensubstanz, sondern auch dic Wasserversorgung der Pflanze zu besprechen.

In der Pflanze vollzichen sich jedoch nicht nur synthetische Prozesse, bei denen aus den einfacheren Nahrungsstoffen die komplicierteren Bcstandteile der Zellen sebildet werden, sondern es findet auch eine Zerlesung der in den Zellen enthaltenen Stoffe statt. So wird bei der Atmun@ der Pflanzen Stärke und Öl unter Aufnahme von Sauerstoff schliesslich zu Kohlensäure und Wasser verbrannt, ein Vorgang, durch Welchen die Pflanze cine gewisse Menge lebendiger Kraft für die Arbeit der Zellen sewinnt.

\section{Kohlensäureassimilation.}

Unter Kohlensäureassimilation oder einfach Assimilation versteht man die Bildung organischer Substanz aus Kohlensäure und Wasser unter Vermittlung der Chlorophyllkörper durch die Energie der Lichtstrahlen. Bei diesem Vorgang wird Kohlensäure aus der Luft a ugenommen und das gesamte Volumen Sauerstoff ausgeschieden, welches in der aufgenommenen Kohlensäure enthalten war. Dieser Prozess kann durch folgende Gleichung dargestellt werden:

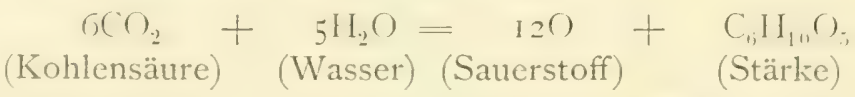

oder da die Stärke wahrscheinlich ein höheres Moleculargewicht besitzt, richtiger durch:

$$
{ }_{12} \mathrm{CO}_{2}+\mathrm{IOH}_{2} \mathrm{O}=24 \mathrm{O}+\mathrm{C}_{12} \mathrm{H}_{20} \mathrm{O}_{10} .
$$

Es ist auf diese Weise die Entstehung der Stärke als erstes sichtbares Produkt der Assimilation verdeutlicht.

Da man jedoch aldehydartige Substanzen in grünen Pflanzen nachgewiesen hat, könnte der Vorgang der Assimilation auch nach folgender Formel verlaufen:

$$
\mathrm{CO}_{2}+\mathrm{H}_{2} \mathrm{O}=\mathrm{O}_{2}+\mathrm{CH}_{2} \mathrm{O}
$$

(Kohlensäure) (Wasser) (Sauerstoff) Formaldehyd)

Hierbei könnte aus dem Formaldehyd durch Polymerisierung ${ }^{1}$ ) Stärke oder ein anderes Kohlenhydrat entstehen.

Der Nachweis der Assimilation gelingt, indem man das Vorhandensein ronStärle durch die Blaufärbuns mit Jod in Chlorophyllkörpern constatiert, die vorher durch länseren Aufenthalt im Dunkelnstärliefrei gemacht

1) Z. B. : $12\left(\mathrm{CH}_{2} \mathrm{O}\right)=\mathrm{C}_{12} \mathrm{H}_{20} \mathrm{O}_{10}+2\left(\mathrm{H}_{2} \mathrm{O}\right)$. 
worden waren. An Wasserpflanzen kann man aus der Ausscheidung von Sauerstoff in Blasenform auf Assimilation schliessen. Genauere gasometrische Methoden zeigen, dass in einem abgeschlossenen Raume bei Beleuchtung die Kohlensäure verschwindet und ein gleiches Volumen Sauerstoff dafür ausgeschieden wird.

Der zur Assimilation notwendige Chlorophyllfarbstoff absorbiert die verschiedenfarbigen Strahlen des weissen Lichtes nicht gleichmässig. Die spektroskopische Untersuchung grüner Blätter oder einer alkoholischen Chlorophylllösung zeigt, dass die ganze rechte Hälfte des Spektrums vom Blau an absorbiert wird, ebenso erscheinen auf der linken Hälfte vier an bestimmten Stellen liegende dunkle Bänder, von welchen das in Rot zwischen den Frauenhoferschen Linien B und C liegende Band am deutlichsten ist und schon bei sehr verdünnten Lösungen hervortritt. Nach der Ansicht von Sachs dienen der Assimilation nur die absorbierten Strahlen der roten Hälfte, während die blauen Strahlen zwar auch in Energie umgesetzt werden, aber mit anderen Prozessen zusammenhängen.

Das Chlorophyll ist kein einheitlicher Farbstoff, es kann vielmehr in einen reingrünen bis blaugrünen Farbstoff, das Kyanophy 11, und in einen gelben Farbstoff, das Xanthophy11, zerlegt werden. Wird eine alkoholische Chlorophylllösung mit Benzin geschüttelt, so nimmt das Benzin den gelben Farbstoff auf. Die Assimilationsfähigkeit des reingrünen Farbstoffes ist nicht anzuzweifeln, doch scheint auch der gelbe Farbstoff für sich allein assimilieren zu können, wie die genügende Ernährung und das Wachstum gelber Varietäten verschiedener Pflanzen zeigt.

Die Bildung des Chlorophylls ist an gewisse äussere Faktoren gebunden. Erstens ist Licht hierzu notwendig, eine Ausnahme hiervon machen die Coniferenkeimlinge (aber nicht Larix europaea) und gewisse Farnpflanzen, die auch im Dunkeln ergrünen. Die übrigen Pflanzen etiolieren bei Lichtmangel, d. h. sie bleiben farblos oder schwach gelblich. Ebenso unterbleibt die Chlorophyllbildung bei Mangel an Eisen. Man bezeichnet derartige schwachgelbliche Pflanzen als bleichsüchtig oder chlorotisch. Bei sehr niedrigen Temperaturen crgrünen die Pflanzen ebenfalls nicht, eine Erscheinung, die man namentlich an Frühjahrspflanzen beobachten kann, die zwar über die Erde hervorwachsen, aber erst bei etwas höherer Temperatur Chlorophyll bilden.

Die Intensität der Assimilation ist einerseits von der Menge des vorhandenen Chlorophylls, anderseits von äusseren Umständen abhängig.

Weder zu intensives $\mathrm{L}$ icht, welches das Chlorophyll zerstört, noch zu schwaches Licht ist zur Assimilation geeignet. Die meisten Pflanzen assimilieren in hellem, diffusem Tageslicht am besten, doch zeigen nicht 
alle Pfanzen die sleiche Empfindlichkeit für verschiedene Lichtintensitäten. Schattenpflanzen, wie Oxalis acetosella, Majanthemum bifolium, verschiedene Moose, Daphne Mezereum, verlangen ein gemässigteres Licht, während Fettpflanzen wie Sedum und Sempervivumarten, unsere landwirtschaftlichen Kulturplanzen und die an stark besonnten Felsen vorkommenden Pflanzen eine ziemlich hohe Lichtintensität ertragen können. Dabei kommt allerdings auch noch in Frage, invieweit die betreffenden Pflanzen die mit der Insolation gesteigerte Wasserverdunstung ertragen können.

In forstlicher Beziehung ist wichtig, dass gewisse Baumspecies schr lichtbedürftig sind, andere Beschattung gut ertragen können. Zu den Schattenhölzern gehören Abies pectinata, Picea excelsa, Taxus baccata, Juniperus communis, Fagus silvatica, Carpinus Betulus, Tilia. Lichthölzer sind Pinus silvestris, Pinus maritima, Larix curopaea, Betula verrucosa, Robinia Pseudacacia, Quercus pedunculata noch mehr als sessiliflora, Acerarten. Halbschattenhölzer sind Fraxinus, Alnus, Ulmus, Pinus strobus. Bei gutem, mincralisch kräftigem Boden ertragen die Pflanzen eine grössere Beschattung. Ein Bestand kann daher auf gutem Boden dichter sein.

Die durch verschiedene Lichtintensität hervorgerufenen Bewegungen der Chlorophyllkörper sind $\$ 43$ (Lichtwirkung) besprochen.

Über die Ausbildung von Licht- und Schattenblättern vgl. S. 64.

Die Assimilation ist ferner abhängig von der Temperatur. Die untere Grenze der Temperatur (Temperaturminimum), bei welcher noch Assimilation stattfindet, liegt für unsere einheimischen Pflanzen sehr tief $\left(0,5-3,5^{\circ} \mathrm{C}\right.$, die günstigste Temperatur (Optimum) bei circa $30^{\circ} \mathrm{C}$, das Maximum, bei welchem noch Assimilation stattfindet, wohl meist über 50 $\mathrm{C}$. Diese Zahlen sind bei den einzelnen Pflanzen bedeutenden Schwankungen unterworfen. Die immergrünen Pflanzen, namentlich die Nadelhölzer, zeigen bei den Temperaturverhältnissen unserer Gegenden im Winter keine nennenswerte Assimilation, wobei aber nicht nur die geringe Temperatur, sondern auch die geringere Lichtintensivität im Winter in Betracht kommt. Ausserdem leidet die Assimilation unter dem geringen Wassergehalt der Blätter.

Der Kohlensäuregehalt der Luft ist ein sehr geringer, in I0000 Liter Luft sind erst 3-6 Liter Kohlensäure enthalten, demnach enthält die Luft $0,03-0,06 \%$ Kohlensäure. Am Boden ist der Kohlensäuregehalt meist etwas grösser, als in den oberen Luftschichten. Die Luft ist über grossen Wasserflächen, und nach Regen, wegen der Kohlensäureabsorption durch Wasser weniger kohlensäurehaltig. Diese in der Natur vorkommenden Differenzen sind für die Pflanze ohne Bedeutung, da erst bei viel grösserem Kohlensäuregehalt eine Steigerung der Assimilationsthätigkeit zu beobachten ist. Das Optimum des Kohlensäurcgehalts liegt erst bei $5-10 \%$. Darüber hinaus wirkt eine grössere Kohlensäuremenge schädlich auf die Pflanzen ein. 


\section{S34. Die Aufnahme von Stickstoff bei den grünen Pflanzen.}

Der Pflanze zu Gebote stehende Stickstoffquellen sind:

I. Salpetersaure Salze (Nitrate).

2. Ammoniaksalze.

3. Organische Stickstoffverbindungen.

4. Freier Stickstoff der Luft.

Die beste Stickstoffnahrung für die grünen Pflanzen sind die salpetersauren Salze, die von der Pflanze leicht aufgenommen werden und im Boden, sowie im Wasser, in leicht löslicher Form und hinreichender Menge vorhanden sind.

Mit Ammoniakverbindungen kann die grüne Pflanze ebenfalls ernährt und zur Samenbildung gebracht werden, doch stellen sich hierbei, namentlich in Kulturen mit wässriger Lösung, leicht Fäulnis und Zersetzungserscheinungen ein, welche das Wurzelsystem und somit die ganze Pflanze schädigen. Ausserdem ist hervorzuheben, dass im Boden durch die Mitwirkung von Bakterien eine Nitrifikation stattindet, d. h. eine Umwandlung von Ammoniakverbindungen in Nitrate, so dass sich in den unteren Bodenschichten überhaupt keine Ammoniakverbindungen vorfinden. In der Luft befindliche Ammoniakmengen können auch durch die Blätter aufgenommen werden, reichen aber nicht zur vollständigen Ernährung der Pflanze aus.

Der Boden erhält durch die Verwesung stickstoffhaltiger organischer Substanzen, wie Laub, Wurzeln, Mist etc. eine bedeutende Menge von Ammoniak - und salpetersauren Salzen, wozu noch die im Regen enthaltenen Stickstoffverbindungen kommen. Der Verwesungsprozess, welcher hauptsächlich durch die Bakterien des Bodens verursacht wird, schafft zunächst einfachere orsanische Stickstoffierbindunsen, aus denen schliesslich die salpetersauren Salze resultieren.

Schliessen wir vorläufig die Aufnahme organischer Stickstoffrerbindungen von unseren Betrachtungen aus, so bleibt noch die Aufnahme und Assimilation des freien Stickstoffs der Luft.

Es ist noch nicht lange her, dass man an der Ansicht festhielt, der freie Stickstoff könne überhaupt nicht von der Pflanze als Nahrungsstoff verwendet werden. Nach den neueren Untersuchungen ist jedoch sicher festgestellt, dass die Fähigkeit, freien Stickstoff zu assimilieren einer grösseren Anzahl von Leguminosen (Lupine, Erbse, Bohne, Klee, Seradella etc.) in hohem Grade zukommt. In viel geringerem Masse dürften auch Pflanzen anderer Familien, selbst Algen, den freien Stickstoff unter Umständen verwenden können, doch ist dies noch nicht sicher festgestellt.

Ich verweise bezüglich der Verarbeitung des freien Stickstoffs zunächst auf die im grossen angestellten Versuche von Schultz in Lupitz. 
Derselbe entnahm cinem lehmhaltisen Sandboden hintereinander zwanzig I.upinenernten, ohne dass dem Boden iryend welcher Stickstoffdiunger zuseführt worden wäre. Fö̈r das Vorhandensein genügender Aschenbestandteile, namentlich Kali und Phosphorsäure, war gesorgt. Die zwanzigste Lupinenernte repräisentierte noch immer eine Stickstoffprodulition von 148,37 keg pro Hektar. Da dieses Quantum dem Boden schon zwanzigmal entzorgen war, ohne dass Stickstoffdüngungs stattgefunden hatte, müsste der Boden am Anfang des Versuches rund $3000 \mathrm{~kg}$ Stickstoff po Hektar enthalten haben, was nicht möglich ist. Es ist auch durch Bodenanalysen nachsewiesen, dass in den letzten fünf Jahren der Stickstoffsehalt des Bodens nicht verringert wurde. Es hat demnach von aussen eine Stickstoffzufuhr stattgefunden und da die durch den Regen aus der Luft zugeführte Stickstoffmengen relativ sehr unbedeutend sind, bleibt kein anderer Schluss, als dass die Lupine stickstoffanreichernd gewirkt hat, d. h. den freien Stickstoff der Luft in gebundenen übergefuhrt hat.

Sehr wichtig scheinen für diese Bindung des freien Sticlistoffs die an den Leguminosenwurzeln auftretenden Knöllchen zu scin. Dieselben enthalten einen Pilz, der von Frank Rhizobium leguminosarum genannt wird. ') Ist die Infektion durch einen derartigen Pilz ausgeschlossen, wie z. B. in vorher erhitztem Boden, wodurch die Pilzkeime setötet worden sind, oder in pilzfreien Wasserkulturen, so findet keine Knöllchenbildung an den Wurzeln statt, und auch die lebhafte Assimilation des freien Stickstoffs unterbleibt. Während Hellriegel dem Pilze selbst die Fähigkeit, den Stickstoff zu verarbeiten, zuschreibt, nimmt Frank an, dass durch Infektion mit demselben nur alle Funktionen der Pflanze eine Steigerung erfahren, sowohl die Kohlensäureassimilation, als die Fähigkeit freien Stickstoff zu assimilieren, welche der Pflanze auch ohne Pilzinfeltion nur in seringerem Masse, zukomme.

Auch an verschiedenen Holzpflanzen aus der Familie der Leguminosen finden sich Wurzelknöllchen, so bei Robinia Pseudacacia, Colutea arborescens, ferner bei dem im Walde vielfach vorkommenden Spartium scoparium. Es wäre möglich, dass derartige Pflanzen für den Waldbau dieselbe Bedeutung erhielten, wie die Lupinen für die Landwirtschaft, nämlich dem Boden Stickstoffverbindungen zuzuführen, welche den übrigen Bäumen des Bestandes zu gute kämen. Frank hat an Robinia Pseudacacia direkt nachgewiesen, dass sich diese Pflanze mit freiem Stickstoff als einziger Stickstoffquelle vollständig normal entwickelt. Leider macht das grosse Lichtbedürfnis dieser Pflanze es unmöglich, dieselbe als Unterholz zum Zwecke der Bodendüngung zu ziehen. Es ist dies aber eine Frage, welche weitere Berücksichtigung verdient. Vielleicht sind perennierende Lupinenarten für die Praxis von grösserer Bedeutung,

1) Prazmowski bezeichnet den Pilz als Bacterium Radicicola. 
zumal dieselben rom Wilde gern angenommen werden und ein gutes Wildfutter abgeben.

Die Überführung des freien Stickstoffs der Luft in Sticlistoffverbindungen gewinnt dadurch eine besondere Bedeutung, dass im Boden verschiedene Prozesse thätig sind, welche demselben Stickstoff entziehen. So entweicht bei Zersetzungen organischer Stickstoffverbindungen ein Teil des Stickstoffs im freien Zustande in die Luft, ausserdem findet durch das Wasser konstant ein Auswaschen der salpetersauren Salze statt. Auf diese Weise müsste schliesslich jeder Boden im Laufe langer Zeiträume vollständig an Stickstoff verarmen und für die Vegetation unbrauchbar werden, wenn nicht durch stickstoffbindende Prozesse der freie Stickstoff der Luft wieder verwertet wïrde.

\section{Aufnahme organischer Nahrung.}

Wenn bei grünen Pflanzen auch der ganze Bedarf an Kohlenstoff durch die Assimilation aus der Kohlensäure der Luft gedeckt werden kann, so ist damit noch keineswegs gesagt, dass den grünen Pflanzen die Fähigkeit abgeht, organische Verbindungen aufzunehmen und zu verarbeiten.

Bei der Keimung ernährt sich die junge Keimpflanze, bevor sie noch selbständig assimiliert, auf Kosten der in den Samen befindlichen Reservestoffe. Dies sind sowohl stickstofffreie organische Verbindungen wie Stärke, Öl, Cellulose, als stickstoffhaltige Verbindungen wie die Proteinstoffe. Diese Reservestoffe werden bei der Keimung in eine lösliche Form übergeführt, um zu den Verbrauchsstellen der jungen Keimpflanze wandern zu können.

In analoger Weise wandern die in früheren Vegetationsperioden gewonnenen Reservestoffe aus ihren Ablagerungsorten in Stamm, Wurzeln, Rhizomen nach den Stellen, wo Neubildung von Organen und Verbrauch von Nahrungsstoffen stattfindet. Der Verbrauch kann unter Umständen in einem Jahre ein bedeutend stärkerer sein, wie dies z. B. für die Mastjahre der Buche nachgewiesen wurde, wo eine grössere Menge von Reservestoffen zur Samenbildung aufgebraucht wird. Der Eintritt eines Samenjahres scheint von der Ansammlung einer gewissen Reservestoffmenge abhängig zu sein.

Aber auch von aussen können die grünen Pflanzen organische Verbindungen aufnehmen. So bilden Moose auf Zuckerlösung gelegt aus dem aufgenommenen Zucker in den Chlorophyllkörpern auch im Dunkeln, also ohne Assimilation, Stärke. Maispllanzen konnten mit "rsanischen Stickstoffrertindungen I Iarnstoff, Hiprusäure, Glycucoll, Kreatin. Asparagin, Ieucin als einziger Stickstoffnahrung zu guter Entwickelung und Körnerbildung gebracht werden. Der Ernährung der grünen Pflanze mit von aussen aufgenommenen organischen Verbindungen ist jedoch in 
der Natur eine Grenze sezogen, einerseits durch die schwierigere Aufnahme dieser Stoffe, anderseits dadurch, dass dieselben im Boden zersetzt werden.

Die mit Mycorhizen versehenen Waldpflanzen (vesl. S. I I 2) werden die organischen Substanzen des Humus besser ausnützen können. Eine genïgend zersetzte Humusschicht ist daher nicht nur wegen der darin vorkommenden Ammoniak- und Salpetersäureverbindungen vorteilhaft, sondern auch wegen des Gehaltes an direkt aufnehmbaren organischen Verbindungen.

Dic Mycorhizenernährung bildet den Übergang zu den echten Saprophyten oder Fäulnisbewohnern, welche jedoch den gesamten Kohlenstoff aus leblosen, organischen, in Fäulnis übergehenden Tier- und Pflanzenkörpern gewinnen, ohne selbständig Kohlensäure zu assimilieren.

Eine nicht unbeträchtliche Menge organischer Nahrung, namentlich organische Stickstoffverbindungen, nehmen die insektenfressenden Pflanzen durch ihre dem Inselitenfange angepassten Blätter auf (vgl. S. 54). Die verdaubaren Teile der Insektenleiber, ebenso kleine absichtlich auf die Blätter gebrachte Fleischstückchen werden durch Verdauungsfermente und schwache Säuren, welche die Pflanzen ausscheiden, in eine lösliche und aufnehmbare Form gebracht. Die Insektennahrung hat, wie bei Drosera nachgewiesen ist, eine reichlichere Fruchtbildung zur Folge.

Die chlorophyllfreien Pflanzen sind daraut angewiesen sämtlichen Kohlenstoff in Form organischer Verbindungen aufzunehmen. Als Stickstoffquelle können salpetersaure Salze, Ammoniaksalze oder organische Stickstoffverbindungen dienen. Die nicht grünen Pflanzen ernähren sich entweder saprophytisch oder parasitisch. Die Parasiten befallen lebende Pflanzen und Tiere, während die Saprophyten aus leblosem organischem Material, Humus, abgestorbenen Pflanzen und Tierkörpern ihre Nahrung ziehen. Selbstverständlich sind zwischen beiden Formen der Ernährung Übergänge vorhanden, die schon dadurch gegeben sind, dass die Parasiten das Substrat ihrer Ernährung töten können und dann auf dem toten Nateriale weiter leben.

Unter den Phanerogamen finden wir häufig Saprophyten und Parasiten, welche entsprechend ihrem Chlorophyllgehalte einen Teil ihrer organischen Nahrung durch Assimilation gewinnen, so z. B. Viscum album, Loranthus europaeus, Euphrasia und Melampyrumarten.

Echte Saprophyten sind Monotropa Hypopitys, Corallorhiza innata, Epipogon aphyllum, bei deren Ernährung jedoch (vgl. S. I12) der in den unterirdischen Teilen vorkommende Pilz eine wesentliche Rolle spielt. Von echten phanerogamen Parasiten wären zu nennen: Lathraea Squamaria auf Erlen- und Haselwurzeln, Orobanche minor auf Klee, Orobanche rubens auf Luzernen, Cuscuta europaea, C. Trifolii, C. Epilinum, die Kleeseidenarten auf Klee, Lein, Hopfen, Brennnesseln und den Stengeln anderer Pflanzen. 
Die Pilze sind sämtlich Parasiten oder Saprophyten. Sie besitzen als Krankheitserreger an pflanzlichen und tierischen Organismen eine besondere Bedeutung. Während bei den Menschen und Tieren hauptsächlich die Bakterien Krankheiten erzeugen, sehen wir bei den Pflanzen parasitäre Krankheiten nur durch höhere Pilze hervorgerufen. Dieselben können entweder als echte Parasiten unverletzte Pflanzen angreifen, wie z. B. Phytophthora omnivora; Hysteriumarten, Agaricus melleus etc., oder sie sind Wundparasiten und wirken nur dann schädlich, wenn ihnen durch eine Wunde der Eingang in das Innere der Pflanze geöffnet wurde (viele Polyporeen, Nectria ditissima u. a.).

Die Pilze scheiden bestimmte Substanzen, Fermente aus, welche die unlöslichen Verbindungen ihres Nährsubstrates in eine lösliche, für sie aufnehmbare Form überführen. So können Pilze Holzsubstanz und Cellulosewände auflösen, die anderen Lösungsmitteln einen kräftigen Widerstand entgegensetzen.

Manche Pilze rufen in der Pflanze, ohne sie zu töten, Deformationen und lebhafte Verzweigung hervor, wie uns die Bildung der Hexenbesen an Abies pectinata durch Aecidium elatinum (vgl. § 53), oder an Carpinus Betulus durch Exoascus carpini (vgl. \$ 50) zeigt.

Die Pilze können jedoch auch nützlich wirken, indem sie die Tier- und Pflanzenreste des Bodens zersetzen und Verbindungen bilden, welche von den grünen Pflanzen aufgenommen werden können. Ohne diese Thätigkeit der Bacterien und saprophytisch lebenden Pilze würden sich die Reste abgestorbener Pflanzen und Tiere in ungeheurer Menge ansammeln.

Die Konservierungsmethoden organischer, der Fäulnis ausgesetzter Körper beruhen auf der Tötung und Fernhaltung sämtlicher Pilzkeime. Die letzteren können durch Kochen oder durch Hinzufügung desinficierender Substanzen vernichtet werden. Ebenso verhindert eine koncentrierte Salz- oder Zuckerlösung die Weiterentwickelung der Pilze, von welcher Thatsache man bei der Konservierung von Lebensmitteln Gebrauch macht.

Es ist gelungen, auch parasitäre Pilze auf saprophytischem Wege zu ernähren, indem man dieselben auf Gelatine, die mit anderen organischen Substanzen und den nötigen Aschenbestandteilen versetzt war, oder in Lösungen bestimmter organischer Substanzen gezogen hat. Diese Pilzkulturen leisten namentlich beim Studium des Entwickelungsganges der Pilze und bei der Reinzüchtung einer Species sehr wesentliche Dienste.

Im Anschluss an die Erörterung über Saprophyten und Parasiten möchte ich noch den Begriff der Symbiose erläutern. Es handelt sich hierbei um ein „Zusammenleben“ verschiedener Organismen, welche zu einer Ernährungsgemeinschaft verbunden sind. Das eclatanteste Beispiel bilden die Flechten (vgl. § 5I), welche aus Pilz und Alge bestehen. Die 
Alse assimiliert vermöge ihres Chlorophyllgehaltes, der Pilz gewährt der Alse Schutz segen äussere ungünstige Beeinflussungen und nimmt aus dem Substrat verschiedene Stoffe auf, welche teilweise auch der Alge zus sute kommen.

In grewissen Moosen, z. B. in Blasia, kommen Kolonien von Nostocalsen in bestimmten Höhlungen vor. Ob die Alge von dem Moose Stoffe bezicht, ist zweifelhaft, jedenfalls findet sie in den Höhlungen genügende WVassermengen vor und schadet nichts. Auch Symbiose zwischen niederen Tieren und Algen kann vorkommen, wie das Gedeihen von grimen Alsen in Hydra viridis beweist. Die Symbiose von Wurzel und Pilz (Mycorhiza) wurde schon S. II 2 besprochen.

\section{Aschenbestandteile der Pflanzen.}

Bei der vollständigen Verbrennung von Pflanzenteilen werden die organischen Verbindungen zu Kohlensäure und Wasser verbrannt, ebenso werden die Stickstoffverbindungen zersetzt, so dass in der Asche nur die feuerbeständigen mineralischen Stoffe zurückbleiben. Der Schwefel und Phosphor der organischen Substanzen des Pflanzenkörpers werden zu Schwefelsäure resp. Phosphorsäure oxydiert, wie denn auch die organischen Kali- und Calciumverbindungen in feuerbeständige Salze übergeführt werden.

Ein Teil der Aschenbestandteile ist für die Pflanze unentbehrlich, insofern als beim Fehlen e in es e in zi ge $n$ dieser Stoffe dauerndes Wachstum und Gedeihen nicht möglich ist. Unentbehrliche Aschenbestandteile sind:

Phosphorsäure;

Schwefelsäure ;

Kali ;

Magnesia;

Kalk;

Eisenoxyd.

Die übrigen Aschenbestandteile, von denen Kieselsäure, Chlor und Natron in den Aschen regelmässig vorkommen, sind für das Wachsen und Leben der Pflanze entbehrlich.

Soweit die Versuche an Schimmelpilzen Schlüsse zulassen, kommen dic Pilze mit weniger Stoffen aus. Sie bedürfen folgende vier Elemente:

I. Schwefel.

2. Phosphor.

3. Ein Element Alkalien (Kalium, Rubidium, Caesium, können einander vertreten).

4. Ein Element alkalischer Erden (Calcium, Magnesium, Baryum, oder Strontium).

Man überzeugt sich von der Unentbehrlichkeit eines Stoffes durch die sog. Wasserkulturen oder durch die Sandkulturen. Bei den Wasserkulturen werden der keimenden Pflanze alle übrigen Stoffe in 
Form gelöster Salze in Wasser geboten bis auf das fragliche Element. Ist dies unentbehrlich, so wird die Pflanze sich nur so weit entwickeln, als dies auf Kosten der in den Samen vorhandenen organischen und anorganischen Nahrungsstoffe möglich ist, wird aber immer kümmern. Bei der Sandkultur wird reiner, durch Auswaschen mit Salzsäure von den Aschenbestandteilen befreiter Sand mit den Samen beschickt, nachdem dem Sande die bestimmten Aschenbestandteile beigemengt waren.

Die Aschenbestandteile werden aus dem Boden oder bei Wasserpflanzen aus dem Wasser in Form von löslichen Salzen aufgenommen, als Chloride oder phosphorsaure, schwefelsaure, salpetersaure oder kohlensaure Salze: Da die Wurzeln jedoch eine Säure ausscheiden, können auch unlösliche Verbindungen in Lösung und zur Aufnahme gebracht werden.

Die Pflanze nimmt die Salze nicht in demselben Verhältnisse auf, als sie ihr im Boden oder im Wasser dargeboten werden, sie besitzt vielmehr das sog. Wahlvermögen, welches sie befähigt, einen Stoff, der im Substrat nur in geringer Nenge vorhanden ist, eventuell auch stärker aufzunehmen, als ein in grosser Menge vorhandenes Salz.

Die einzelnen Pflanzenarten bedürfen zu ihrem Gedeihen verschiedene Mengen von mineralischen Bestandteilen, sie machen daher sehr verschiedene Ansprüche an den Mineralsehalt des Bodens. Ein Massstab hierfür ist der Aschengehalt der Pflanzen. Als Beispiei führe ich die Mineralstoffmengen an, welche in dem Jahreserträgnisse eines Waldes durchschnittlich pro Hektar enthalten sind:

im Buchenwald (bei I 2ojähr. Umtriebszeit) 2 I5, I4 Kilogramm

im Fichtenwald (bei I2ojähr.

im Kiefernwald (bei Ioojähr.

I 58,48

63,06

Wir ersehen aus diesem Beispiel, dass die Jahresproduktion der Kiefer viel weniger Aschenbestandteile enthält als bei Fichte und Buche. Bei ihren geringeren Ansprüchen wird daher die Kiefer auch auf einem mineralisch ärmeren Boden noch gedeihen können, wo anspruchsvollere Holzarten ausgeschlossen sind.

Ebermayer stellt folgende nach dem Bedürfnis an Mineralbestandteilen bestimmte Reihen auf, die mit den begehrlichsten Holzarten beginnen und mit den genügsamsten schliessen.

\begin{tabular}{|c|c|c|c|c|c|}
\hline $\begin{array}{l}\text { a. nach dem Ge- } \\
\text { samtbedarf an } \\
\text { Mineralstoffen. }\end{array}$ & $\begin{array}{l}\text { b. nach dem Be- } \\
\text { darf an Kali und } \\
\text { Phosphorsäure. }\end{array}$ & $\begin{array}{l}\text { c. nach dem Be- } \\
\text { darf an Kalk. }\end{array}$ & $\begin{array}{l}\text { a. nach dem Ge- } \\
\text { samtbedarf an } \\
\text { Mineralstoffen. }\end{array}$ & $\begin{array}{l}\text { b. nach dem Be- } \\
\text { darf an Kali und } \\
\text { Phosphorsäure. }\end{array}$ & $\begin{array}{l}\text { c. nach dem Be- } \\
\text { darf an Kalk. }\end{array}$ \\
\hline $\begin{array}{l}\text { Haselnuss } \\
\text { Apfelbaum } \\
\text { Ulme } \\
\text { Aspe } \\
\text { Ahorn } \\
\text { Eichenschäl- } \\
\text { wald } \\
\text { Eichenhoch- } \\
\text { wald }\end{array}$ & $\begin{array}{l}\text { Esche } \\
\text { Ahorn } \\
\text { Haselnuss } \\
\text { Apfelbaum } \\
\text { Aspe } \\
\text { Eichenschäl- } \\
\text { wald } \\
\text { Ulme } \\
\text { Elzbeere }\end{array}$ & $\begin{array}{l}\text { Haselnuss } \\
\text { Apfelbaum } \\
\text { Ulne } \\
\text { Aspe } \\
\text { Hainbuche } \\
\text { Eichenschäl- } \\
\text { wald } \\
\text { Eichenhoch- } \\
\text { wald }\end{array}$ & $\begin{array}{l}\text { Hainbuche } \\
\text { Esche } \\
\text { Elzbeere } \\
\text { Rotbuche } \\
\text { Fichte } \\
\text { Weisstanne } \\
\text { Lärche } \\
\text { Kiefer } \\
\text { Birke. }\end{array}$ & $\begin{array}{l}\text { Weisstanne } \\
\text { Rotbuche } \\
\text { Hainbuche. } \\
\text { Eichenhoch- } \\
\text { wald } \\
\text { Lärche } \\
\text { Fichte } \\
\text { Birke } \\
\text { Kiefer. }\end{array}$ & $\begin{array}{l}\text { Ahorn } \\
\text { Elzbeere } \\
\text { Esche } \\
\text { Rotbuche } \\
\text { Fichte } \\
\text { Lärche } \\
\text { Kiefer } \\
\text { Weisstanne } \\
\text { Birke. }\end{array}$ \\
\hline
\end{tabular}


Fiir das Gedeihen und Fortkommen der verschiedenen Species ist besonders der Bedarf an Kali und Phosphorsäure von Wichtigkeit, da diese Stoffe niemals in so grossen Mengen im Boden vorhanden sind, und in armen Bodenarten gerade an diesen Stoffen leicht Mangel eintritt.

Im grossen und ganzen kann man annehmen, je grösser die Aschenmenge in einem cbm Holz ist, desto mineralisch reicheren Boden verlangt der betreffende Baum. Nan muss jedoch bei derartigen Folgerungen vorsichtig sein, wie z. B. das Verhalten der Akazic lehrt, die noch auf sehr armen Sandböden fortiommt, und doch einen relativ sehr grossen Kalisehalt aufweist. So enthiclt I cbm Holz mit Rinde im 40jährigen Alter folgende Mengen von Kali:

Akazic vom Diluvialsand

Rotbuche vom Muränenschutt

Esche von feuchtem Diluvialsand

Hainbuche vom Diluvialsand

Weisstanne

Gem. Kiefer vom Diluvialsand

Lärche vom Muschelkalk

\section{Diluvialsand}

Weymuthskiefer vom Diluvialsand

Fichte vom Diluvialsand

\begin{tabular}{|c|c|c|}
\hline $90 \mathrm{I}$ & ¿' & ", \\
\hline 887 & , & ", \\
\hline 710 & ," & ", \\
\hline 573 & ", & $"$ \\
\hline 362 & , & ", \\
\hline 318 & " & ", \\
\hline 248 & ", & ", \\
\hline 295 & ", & ", \\
\hline 215 & ," & ", \\
\hline
\end{tabular}

Wir sind zur Annahme gedrängt, dass die Akazie vermöge ihres umfangreichen Wurzelsystems das Kali aus einem grossen Umfang des Standraumes aufnimmt, und deshalb auch mit geringwertigen Bodenarten zufrieden ist.

Der Wassergehalt des Bodens ist insofern von Wichtigkeit, als bei grösserem Wassergehalt desselben die mineralischen Nahrungsstoffe leichter aufgenommen und besser ausgenutzt werden können, als auf trockenem Boden. Auch in dieser Beziehung ist die Erhaltung der Bodenfrische durch die Waldkultur von der grössten Wichtigkeit.

Durch die Entnahme der Ernte wird, sowohl bei dem landwirtschaftlichen als bei dem forstlichen Betriebe, dem Boden eine nicht unbeträchtliche Nenge ron mineralischen Nahrungsstoffen entzogen. Bei den landwirtschaftlichen Kulturgewächsen reichen die durch Verwitterung des Bodens wicder disponibel werdenden Mineralstoffe in der Regel nicht aus, um auf die Dauer ein freudiges Gedeihen zu erzielen, es müssen dem Boden daher durch die Dünsung neue Aschenbestandteile zugeführt werden.

Bei dem forstlichen Betriebe kann der jährliche Bedarf an Aschenbestandteilen und Stickstoff den jährlichen Bedarf der landwirtschaftlichen Kulturgewächse erreichen. Durch den Abfall der Blätter (Streu), werden jedoch bei einem Holzbestande dem Boden jährlich wieder eine grosse Menge von Aschenbestandteilen und Stickstoff zu- 
geführt; die nach der Zersetzung der organischen Substanzen für die Pflanze wieder disponibel werden. Nur bei Streuentnahme oder beim Verwehen der Streu, wird allmählich eine Verarmung des Bodens eintreten, die um so schneller erfolgt, je ärmer der Boden überhaupt war.

Auf die Entnahme von Aschenbestandteilen aus dem Boden hat die Betriebsart einen sehr wesentlichen Einfluss. Jüngere Waldpflanzen enthalten relativ mehr Aschenbestandteile (bezogen auf die Trockensubstanz), als die älteren Waldbäume. Der Boden der Saatbeete wird daher, wenn nicht eine Düngung mit frischer Walderde, mit phosphorhaltigen oder kalihaltigen Substanzen stattfindet, bei dauernder Benutzung leicht verarmen. Da das Reisig, die Äste und das junge Stammholz mehr Aschenbestandteile enthalten, als das alte Stammholz, werden dem Boden um so mehr Aschenbestandteile entzogen, je jünger die Bestände genutzt werden. Dieser letzte Satz erfährt dadurch eine gewisse Einschränkung, dass der Gehalt namentlich an den so wichtigen Kali- und Phosphorsäuremengen nicht gleichmässig mit dem Älterwerden des Holzes abnimmt. $\mathrm{R}$. Weber hat an der Buche gezeigt, dass der prozentische Kali- und Phosphorsäuregehalt in dem ersten Decennium relativ sehr hoch ist, er fällt aber rasch bis zum 60. Jahre, worauf dann vom 80. bis I0o. Jahre eine Periode der Zunahme folgt. Auf diese Periode des zweiten Maximums folgt dann wieder eine Periode des Sinkens bezw. des Gleichbleibens. Weber bringt das Auftreten des zweiten Maximums mit der Vergrösserung der Standraumflächen, d. h. des Ernährungsraumes der einzelnen Bäume, nach den Durchforstungen in Verbindung.

Über die Bedeutung der einzelnen Aschenbestandteile für die Ernährung und die Stoffbildung herrscht noch ziemliche Unklarheit

Das Eisen steht unzweifelhaft mit der Chlorophyllbildung im Zusammenhang, indem Pflanzen, welche in einer eisenfreien Lösung erzogen werden, nicht ergrünen (vgl. S. I37).

Schwefelsäure und Phosphorsäure liefern Schwefel und Phosphor zur Bildung von Proteïnsubstanzen. Der Phosphor scheint besonders bei der Bildung der. Zellkernsubstanzen beteiligt zu sein, der Verbrauch an Phosphorsäure wird daher besonders in den Vegetationspunkten und Meristemen ein bedeutender sein, da hier die Zellen sehr grosse Kerne enthalten.

Zur Synthese der Kohlenhydrate und der Proteinsubstanzen des Protoplasmas scheint das Vorhandensein grösserer Mengen von $\mathrm{K}$ a li und Magn $\mathrm{n}$ s ia notwendig zu sein, wie dies durch das reichliche Vorkommen dieser Stoffe an den Vegetationspunkten wahrscheinlich gemacht wird.

Der Kalk scheint zu den eben erwähnten Processen nicht unbedingt notwendig zu sein. Der Kalk ist nichtsdestoweniger für das Leben der Pflanze unentbehrlich und zwar nicht bloss zum Transport scwisser Stoffe (Zucker, Phosphorsäure), sondern auch zur Neutralisation der im Stoffwechsel entstehenden organischen Säuren. So entsteht namentlich in 
Meristemen, wo zusgleich mit der Zellteilung und dem Wachstum eine Vermehrung des Protoplasmas und der Proteinsubstanzen stattfindet, als Nebenprodukt Oxalsäure, die sich zunächst als oxalsaures Kali in den Zellen ansammelt. Kalkverbindungen finden sich nur in einer gewissen Entfernung von den Vegetationspunkten, sie geben dort ihre gebundene Säure $a b$ und rerbinden sich mit der Oxalsäure zu dem sehr schwerlöslichen oxalsauren Kalk (vol.S. I9). Hierdurch wird einerseits die, in (sö̈sserer Menge giftige, Oxalsäure unschädlich gemacht, anderseits das an die Oxalsäure sebundene Kali für weitere Stoffwechselvorgänģe disponibel.

Der Kalk findet sich vielfach in Geweben, welche dem unmittelbaren Bildungsgewebe von Proteinsubstanzen und von Kohlenhydraten entrückt sind, so in dem älteren Parenchym des Stengels, in dem Schwammparenchym der Blätter, in der Rinde unserer Holzgewächse. Die Rinde der Buche z. B. ist sehr reich an Asche, ein I jo jähriger Stamm enthielt I,3 m über der Erde in der Rinde 5,44 "1/ Reinasche, während der Holzkörper im Baumalter

$$
\begin{array}{ccccc}
\text { von } & \text { I } 50-120 & \text { Jahren } & 0,2 S_{3} \% \\
. & 120-90 & , & 0,2 S_{3} \% \\
. & 90-60 & , & 0,332 \% \\
. & 60-30 & , & 0,394 \% \\
, & 30-0 & , & 0,349 \%
\end{array}
$$

Bei der Buchenrinde beträgt der Kalkgehalt im höheren Alter S2-S7 \% der Asche. Da die äusseren Rindenteile, ohne ihren Kalk zu

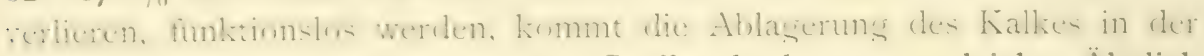
Rinde einem Ausscheiden aus dem Stoffwechselprocesse gleich. Ähnlich verhalten sich die Blätter, die sich ebenfalls durch ihren hohen Kalksehalt auszeichnen. Kali und Phosphorsäure dagegen wandern vor dem Laubfall in grosser Menge in den Stamm zurüch, um später aufs neue wieder am Stoffwechsel teilzunehmen.

An der Buche wurde constatiert, dass Phosphorsäure, Schwefelsäure und Nagnesia in der Asche des Stammholzes eine deutliche und konstante Abnahme von aussen nach innen aufweisen. Es könnte dies bei lum Zu-ammenhans dieser Sitrife mit den protrpla-matischen sub-tanzen durch die Abnahme lebender Zellen in dem centralen Teil des Holzkörpers erklärt werden. Auffallend ist jedoch, dass das Kali eine ausgesprochene Steigerung von der Stammperipherie zum Centrum zeigt. E: ist dic sine Er-cheinung, die mägicher Wise damit zusammenhängst. dass zur Lösung der in den centralen Stammteilen vorhandenen und verschwindenden Stärke eine grössere Menge von Kali notwendig ist, doch bleibt dies nach dem jetzigen Stande unserer Kenntnisse eine gewagte Hypothese. 


\section{\$37. Wasserabgabe, Wasseraufnahme und Wasserleitung.}

Jede Pflanze besteht aus Trockensubstanz (organische Stoffe + Aschenbestandteile) und Wasser. Der Wassergehalt kann unter Umständen ein sehr grosser sein, so enthalten frische Champignons $93 \%$, Spargel $92 \%$, Waldhimbeeren $\delta_{1,2} \%$ Wasser. Samen sind relativ wasserarm, es enthalten Weizen $13,16 \%$, Roggen $14,94 \%$, frische Eicheln $50,68 \%$, Kastanien 48,75\% Wasser. Im Holze unserer Waldpflanzen schwankt der Wassergehalt sehr bedeutend, je nach Alter, Bestandeserziehung und Jahreszeit, doch lassen sich gewisse Grenzwerte aufstellen, die unter Umständen jedoch auch überschritten werden. Nadelhölzer enthalten im frischgefällten Zustande meist $52-65 \%$, weiche Laubhölzer 45-55\%, harte Laubhölzer $38-45 \%$ Wasser.

Viel grösser als der Wassergehalt ist die Menge von Wasser, welche bei der Wasserverdunstung, Transpiration von einer Pflanze ausgehaucht wird und durch Aufnahme aus dem Boden wieder ersetzt werden muss.

Um zu vergleichbaren Zahlen zu gelangen, bestimmte v. Höhnel die Verdunstungsgrösse einer Blattmasse, welche je 100 gr Blatttrockensubstanz aufwies. Diese betrug während einer Vegetationsperiode bei:

$\begin{array}{lrl}\text { Betula verrucosa } & 67,98 \mathrm{~kg} \text { Wasser } \\ \text { Tilia grandifolia } & 6 \mathrm{I}, 52, ", \\ \text { Fraxinus excelsior } & 56,69, ", \\ \text { Carpinus Betulus } & 56,25, ", \\ \text { Fagus silvatica } & 47,25, ", \\ \text { Acer Pseudoplatanus } & 43,57, ", \\ \text { Ulmus campestris } & 40,73, ", \\ \text { Quercus pedunculata und sessiliflora } & 28,34, ", \\ \text { Quercus cerris } & 25,33, ", \\ \text { Acer campestre } & 24,68, ", \\ \text { Picea excelsa } & 5,84, ", \\ \text { Pinus silvestris } & 5,80, ", \\ \text { Abies pectinata } & 4,40, ", \\ \text { Pinus Laricio } & 3,20, ",\end{array}$

Aus diesen Zahlen könnte man direkt das Wasserbedürfnis der einzelnen Holzarten entnehmen, wenn nicht bei verschiedenen Pflanzen ein bedeutendes Anpassungsvermögen an die Feuchtigkeitsverhältnisse des. Bodens zu konstatieren wäre. So können z. B. Pinus silvestris, Alnus incana, Betula verrucosa auf sehr verschieden feuchtem Boden vorkommen und dementsprechend verschiedene Wassermengen aufnehmen. Besonders erweckt die für Betula verrucosa angegebene Zahl Bedenken, da die Birke auch auf trockenem Sandboden vorkommt. Immerhin sind die Zahlen für das Wasserbedürfnis von Laub- und Nadelhölzern charakteristisch.

Die Transpiration ist abhängig einerseits von der Beschaffenheit der 
Blätter, anderseits von äusseren Faktoren. Junge Blätter mit unvollständig cuticularisierter Membran verdunsten mehr Wasser als ältere Blätter, die Unterseite der Blätter transpiriert stärker als die Oberseite.

Licht und Wärme vermehren die Wasserabgabe, Sättigung der Luft mit Wasserdampf vermindert die Transpiration.

Immerhin bleibt die ausgehauchte Wassermenge hinter der Regenmenge eines Jahres zurück.

Die Pflanze kann noch einem staubtrockenen Boden Wasser entzichen, wobei allerdings die aufgenommene Wassermenge den Transpirationsverlust nicht immer vollständig zu decken vermag, so dass bei sehr trockenem Boden die Pflanze zu welken beginnt.

Die Temperatur des Bodens ist für die Wasserversorgung von sehr wesentlichem Einfluss, indem die Pflanzen aus sehr kaltem Boden, ohne dass derselbe etwa gefroren wäre, bedeutend weniger Wasser aufnehmen als aus einem wärmeren Boden. Lebhaft transpirierende Topfpflanzen können durch Abkühlung der Erde zum Welken gebracht werden.

Vgl. ferner den Einfluss des Wassers auf das Wachstum, S. I67.

Die Hauptmasse des Wassers wird bei den Landpflanzen durch die Wurzeln aufgenommen, dem gegenüber die Aufnahme von Regen durch die Blätter nur eine sehr geringe Bedeutung hat.

Wie schon früher (S. 87) erwähnt, wird das Wasser auf weitere Strecken durch den Holzteil der Gefässbündel fortgeleitet. Bei den mit sekundärem Dickenwachstum versehenen Pflanzen sind es besonders die jüngsten Jahresringe, in denen das Wasser wandert, während die älteren Teile des Holzes mehr als Reservoire für den Notfall anzusehen sind. Nach Wieler leiten bei:

$\begin{array}{llc}\text { Robinia Pseudacacia } & \text { I-2 Jahresringe } \\ \text { Quercus pedunculata } & 2 & , \\ \text { Sorbus aucuparia } & 2 & ", \\ \text { Juglans cinerea } & 2-3 & " \\ \text { Prunus mahaleb } & 2-3 & " \\ \text { Fraxinus excelsior } & 3-4 & " \\ \text { Acer platanoides } & 5 & ", \\ \text { Pirus malus } & 5 & , \\ \text { Fagus silvatica } & 3-6 & ,\end{array}$

Die von Sachs geltend gemachte und eine Zeitlang fast allgemein acceptierte Anschauung, dass das Wasser in den Zellwandungen des Holzes wandere, hat man jetzt fallen lassen. Man nimmt vielmehr an, dass sich das Wasser in dem Lumen der Zellen weiter bewege, ohne dass hierdurch ein Passieren der Wandung ausgeschlossen ist.

Welche Kräfte heben nun das Wasser bis in die höchsten Baumspitzen? Bei der Beantwortung dieser Frage haben wir zunächst die Saugung durch die verdunstenden Blätter, und ferner den Druck von der Wurzel aus zu berücksichtigen. 
Die Saugung der Blätter kann durch den in Fig. I3 8 abgebildeten einfachen Apparat veranschaulicht werden. Eine circa meterlange Glasröhre, mit einer Erweiterung an der oberen Seite, wird an dieser Seite mit feuchter Schweinsblase verschlossen, und sodann mit Wasser gefüllt. Man stellt sie mit dem offenen Ende in Quecksilber und kann nun beobachten, dass an der Schweinsblase Wasser verdunstet, austritt ohne dass hierfür Luft eintritt. Dem Verschwinden des Wassers entsprechend kann das Quecksilber durch den Luftdruck in der Glasröhre bis auf die Höhe des Barometerstandes gehoben werden, wenn nicht kleine Poren in der Schweinsblase ein so bedeutendes Steigen verhindern.

In ähnlicher Weise wird Wasser von den Blattzellen verdunstet, ohne dass dafür Luft in die Zellen eintreten würde. Die transpirierenden Blattzellen entnehmen das Wasser aus den Gefässen und Tracheïden, deren Wandung für Wasser, aber nicht für Luft durchlässig ist. Wird nicht dieselbe Menge Wasser nachgeschafft, als durch die Verdunstung verloren geht, so entstehen in den Gefässen und Tracheïden luftverdünnte Räume, die sich bei dem kontinuierlichen Zusammenhang des trachealen Systems von Blatt- und Sprossaxe auch in die Sprossaxe fortsetzen.

Im Sommer enthält das tracheale System, entsprechend der lebhaften Transpiration, neben Wasser luftverdünnte Räume. Es entsteht in den Capillaren, welche Tracheen und Tracheïden darstellen, eine sog. Jaminsche Kette, indem Luftblasen und Wassersäulchen miteinander abwechseln.

Durch die luftverdünnten Räume in den oberen Teilen der Pflanze wird Wasser aus den unteren Teilen nachgesaugt. Das .Steigen des Wassers

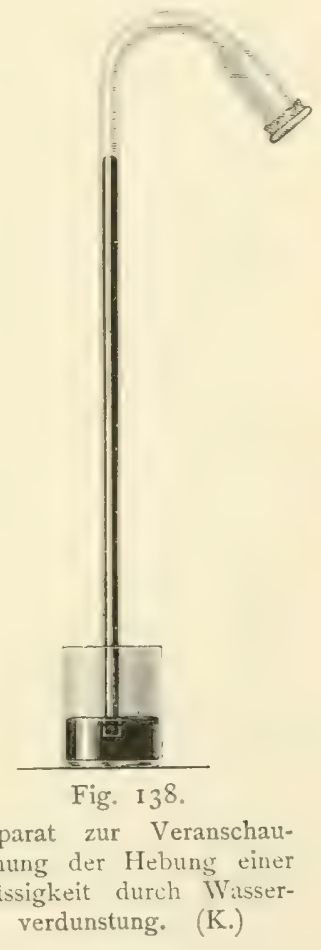
durch Saugung ist jedoch begrenzt, indem das Wasser nur auf eine dem Luftdruck entsprechende Höhe sehoben werden kann. Da das Wasser durch den Luftdruck nur circa Io $\mathrm{m}$ hoch gehoben wird, ist es ausgeschlossen, dass dasselbe durch Saugung bis in die Krone hoher Bäume geschafft wird.

Die Annahme, dass das Gewicht einer längeren Wassersäule in den Gefässen und Tracheiden durch die Reibungswiderstände der Jaminschen Kette gehalten werden könnte, ist falsch. Ebenso hält ein Atmosphärendruck keine längere Wassersäule als Io $\mathrm{m}$, wenn dieselbe durch permeable Membranen, wie die Zellwände es sind, in zahlreiche kleinere Stïcke geteilt wird.

Durch die Capillarkraft kann, entsprechend der grösseren oder 
geringeren IVeite der Gefasse, nur cine Wassersäule von $2-3 \mathrm{~m}$ Höhe gehalten werden. Es ist demnach weder die Capillarkraft allein, noch in Verbindung mit der saugenden Wirkuns der Blätter im stande, das Wasser auf cine bedeutende Höhe steigen zu lassen. Zu dem kommt noch, dass die Jaminsche liette der Fortbewesung von Wasser einen bedeutenden Viderstand entegesensetzt, so dass die Capillarität der Gefässe beim Aufsteigen des Wasserstromes nicht als bewegende, sondern nur als haltende Kraft in Betracht kommt.

Der Wurzeldruck oder Blutungsdruck ist die Ursache des schon seit langem bekannten Blutens mancher Pflanzen im Frühjahre. Werden Zweigse rom Weinstock, der Birke oder Hainbuche im Frühjahre abgeschnitten, so fliesst tagelang cin sehr verdünnter Saft aus den Gefässen aus. Ebenso findet ein Bluten aus den mit der Wurzel zusammenhängenden Stümpfen statt, wenn man junge Pflanzen von Zea Mais, Cheiranthus Cheiri oder Dahlia variabilis, über der Erde abschneidet. Die ausfliessende Wassermenge ist bedeutend grösser als das Wurzelvolumen, es muss also zu gleicher Zeit eine Aufnahme von Wasser aus dem Boden, und eine Abscheidung an der Schnittfläche stattgefunden haben.

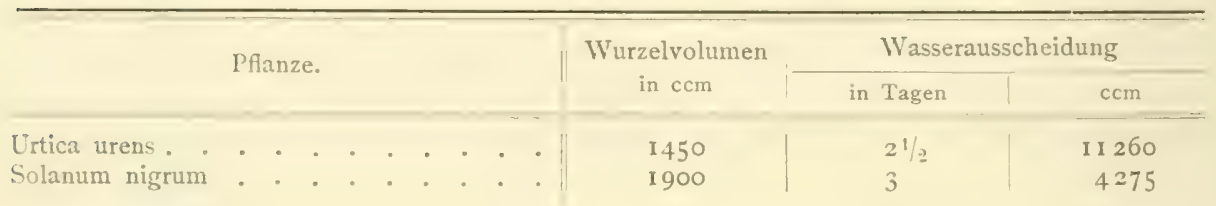

Das Wasser wird aus dem Wurzelstumpf mit einer gewissen Kraft herausgepresst. Von Hales wurde schon im Jahre I748 am Weinstock ein Blutungsdruck von IO7 cm Quecksilber beobachtet. Ausgedrückt durch die gehobene Quecksilbersäule ergab Morus alba I,2 cm, Atriplex hortensis 6,5 cm, Papaver somniferum $21,2 \mathrm{~cm}$, Digitalis media $46,1 \mathrm{~cm}$ Blutungsdruck. Der Blutungsdruck kann so gross werden, dass an der unverletzten Pflanze aus den Blättern Wassertropfen ausgeschieden werden.

Abgeschnittene und in Wasser gestellte Zweige können unter Umständen ebenfalls Blutung zeigen. Es beweist dies, dass analoge Druckkräfte, wie in der Wurzel, auch in den Sprossaxen thätig sein können.

Wie die für den Blutungsdruck angegebenen Werte beweisen, reicht die Kraft des von der Wurzel ausgehenden Druckes nicht aus, das Wasser bis in die Krone hoher Bäume zu pressen. Ausserdem kommt noch in Betracht, dass die Menge des Wassers, welche vermöge des Wurzeldruckes aus dem Stumpfe ausfliesst, bedeutend geringer ist, als die durch die Transpiration verbrauchte Wassermenge. Zur Zeit lebhafter Transpiration im Sommer kann der Wurzeldruck vollständig fehlen, ja ein Zweigstück, oder ein Wurzelstumpf, kann sogar Wasser einsaugen. Der 
Wurzeldruck kann demnach nicht die alleinige Ursache der Hebung des Wassers in den Pflanzen sein.

Wir sehen, dass wir ohne die Annahme anderer Kräfte die Wasserbewegung nicht genügend erklären können. Diese Kräfte liegen nun in den lebenden Zellen der Markstrahlen und des Holzparenchyms der Wurzeln und des Stammes.

Godlewski, dem wir diese Anschauung verdanken, fasst seine Theorie in folgenden Worten zusammen: „Im allgemeinen stellen wir uns diese Wirkung so vor, dass die Markstrahlzellen auf osmotischem Wege das Wasser aus den Gefässen und Tracheïden aufnehmen, und indem sie es wieder ausstossen, pressen sie es in die höher liegenden Gefässe und Tracheiden hinein, wo es wieder durch andere Markstrahl- und Holzparenchymzellen aufgenommen und dann weiter gepresst wird, und so immer höher, bis zu den transpirierenden Blättern. Auf diese Weise können wir die Markstrahl- und Parenchymzellen als Saugdruckpumpen betrachten, welche das Wasser in den Tracheïden und Gefässen bis zu den Baumgipfeln aufwärts treiben."

Thatsächlich finden wir überall Gefässe und Tracheïden in Berührung, oder umgeben von lebenden Markstrahl- oder Holzparenchymgewebe. Die Tüpfel an diesen Berührungsstellen sind besonders gross, so dass auch dies auf einen lebhaften Wasseraustausch zwischen trachealen und parenchymatischen Elementen hinweist. Durch Umsetzungen in der lebenden Zelle kann der Turgor bedeutend schwanken. Durch Zersetungen von Verbindungen wird die osmotische wasseranziehende Kraft sehr bedeutend erhöht, die Zellwand dementsprechend stärker gespannt, indem die wasseranziehende Kraft der im Zellsaft gelösten Stoffe der Anzahl der Noleküle proportional ist. Wenn durch Vereinigung der Zersetzungsprodukte die Zahl der Moleküle vermindert wird, und die wasseranziehende Kraft herunter geht, so wird durch die Spannung der Wand Wasser aus der Zelle ausgepresst werden und zwar an der Stelle des geringsten Widerstandes. Es ist auf diese Weise in der That möglich, dass abwechselnd von den Markstrahl - und Holzparenchymzellen Wasser aus den Gefässen und Tracheïden aufgenommen und wieder ausgestossen wird.

Da der Luftdruck in den Tracheïden im Stamme von unten nach oben sinkt (R. Hartig), so wird bei dem Einpressen des Wassers in eine Tracheïde das Wasser nicht nach der nächst unteren, sondern nach einer nächst oberen Tracheïde, da in dieser ein geringerer Luftdruck herrscht, durchgepresst werden. Bei den Gefässen kommt die Bildung der Jaminschen Kette vielleicht einer Bildung von Tracheïdenreihen gleich.

In derselben Weise, wie die eben besprochene Saug- und Druckwirkung, kann auch der Blutungsdruck in Wurzel und Sprossaxe erklärt werden.

Die Einzelheiten des anatomischen Aufbaus des Holzes entsprechen ganz den Anforderungen der Godlewskischen Theorie. 


\section{Normalo und intramoloculare Atmung. Wärme und Licht- orscheinungon an Pflanzen.}

Die Atmung (Respiration) der Pflanzen entspricht der Atmuns der Tiere. Bei den Pflanzen haben wir jedoch zwei verschiedene Formen der Atmung zu unterscheiden: die normale und die sog. intramoleculare Atmung.

Bei der normalen Atmung wird Sauerstoff aus der Luft aufgenommen und auf bestimmte Pflanzensubstanzen übertragen, wobei dieselben zu Kohlensäure und Wasser verbrannt werden. Kohlensäure und Wasser sind die Endprodukte der Verbrennung lebloser organischer Substanz, wir können demnach die normale Atmung als einen Verbrennungsprozess bezeichnen.

Die Pflanze zeigt jedoch auch analoge Kohlensäure abspaltende Stoffwechselvorgänge in einem sauerst offfreien Raume, welchen Prozess man als intramoleculare Atmung bezeichnet. Normale und intramoleculare Atmung sind Funktionen des lebenden Protoplasmas, die untereinander zusammenhängen.

Durch die Sonne erhält die Pflanze bei der Assimilation Kraft, welche zur Trennung der Atome in der Kohlensäure und dem Wasser, und zur Bildung der Stärke verbraucht wird. Diese Kraft erscheint bei der Atmung wieder, indem die durch die Assimilation gewonnenen Stoffe verbrannt werden. Assimilation und Atmung sind dementsprechend zwei entgegengesetzte Prozesse, was sich auch aus den Anfangs- und Endprodukten ergiebt, indem bei der Assimilation Kohlensäure und Wasser aufgenommen und Sauerstoff ausgeschieden, bei der Atmung Sauerstoff aufgenommen, und Kohlensäure und Wasser abgeschieden wird.

Das Auftreten von Kohlensäure bei der normalen Atmung lässt sich leicht nachweisen, wenn man in ein abseschlossenes mit keimenden Samen, Bliiten oder Blättern beschicktes Gefäss kohlensäurefreie Luft einleitet und clie abgeleitete Luft durch Kalkwasser streichen lässt. Es bildet sich in dem letzteren vermöge der Kohlensäureausscheidung der Pflanzen ein Niederschlag von kohlensaurem Kalk. Ebenso lässt sich die Abnahme des Trockengewichtes und die Zumahme des Wassers in verdunkelten Pflanzenteilen (um die Assimilation auszuschliessen) nachweisen. So enthielten 22 Maiskörner ungekeimt $8,636 \mathrm{gr}$ Trockensubstanz, 20 Tage nach der Keimung nur 4,529 gr Trockensubstanz.

Veratmet werden besonders die Kohlenhydrate (Stärke, Zucker etc.) und Fette. Doch können auch Proteïnstoffe die Atmung unterhalten.

Die intramoleculare Atmung lässt sich an Pflanzen nachweisen, die man in reinem, sauerstofffreiem Wasserstoff oder Stickstoff hält.

Es werden bei der intramolecularen Atmung ähnliche Stoffe verbraucht, wie bei der normalen Atmung, es treten jedoch ausser Kohlensäure und 
Wasser noch andere organische Substanzen auf, namentlich Alkohol und organische Säuren, besonders Essigsäure.

Die Intensität der Atmung ist von dem Entwickelungszustand des betreffenden Pflanzenteiles abhängis. Lebhaft wachsende Pflanzenteile atmen im allgemeinen energischer, als ältere ausgewachsene oder ganz junge Organe. Je höher die Temperatur, desto intensiver der Atmungsprozess.

Es lässt sich bis jetzt nicht sagen, durch welche Vorgänge im Protoplasma es ermöglicht wird, dass der passive Sauerstoff (aktiver Sauerstoff, Ozon, kommt in der lebenden Zelle nicht vor) oxydierend auf die zu veratmenden Stoffe einwirkt. Ebenso ist der Vorgang der intramolecularen Atmung noch nicht näher aufgeklärt. Pfeffer sagt über das Verhältnis der normalen Atmung zur intramolecularen Atmung folgendes: „Dieselben primären Ursachen, welche in der normalen Atmung den oxydierenden Eingriff des Sauerstoffs veranlassen, machen bei Abwesenheit des freien Sauerstoffs fortgesetzt Sauerstoffaffinitäten geltend und bewirken hierdurch Umlagerungen, welche zuvor ganz oder teilweise nicht zu stande kamen, Umlagerungen, aus welchen Kohlensäure, sowie die andern Produkte der intramolecularen Atmung hervorgehen."

Durch die Atmung werden Kräfte frei gemacht, welche die Pflanze zu bestimmten physiologischen Leistungen bedarf. Hierbei kann die normale Atmung nicht ohne weiteres durch die intramoleculare Atmung ersetzt werden. Die Empfänglichkeit der Pflanzen für Reize (§ 43), die Bewegung des Protoplasmas, die Schwimmbewegung mancher Algenschwärmzellen ist an die Gegenwart von Sauerstoff gebunden.

Das Vorhandensein der intramolecularen Atmung erklärt uns jedoch, wieso die Pflanzen ohne Sauerstoff so lange am Leben bleiben können, während höhere Tiere ohne Sauerstoff alsbald ersticken. Bei Fröschen konnte übrigens ebenfalls intramoleculare Atmung nachgewiesen werden.

Schliesslich ist noch zu bemerken, dass der Pflanze ausser der durch die Atmung gewonnenen Energie noch andere bedeutende Kräfte zu Gebote stehen. Es sind dies die Molecularkräfte der Pflanzensubstanzen. Eine Äusserung derselben haben wir z. B. in den osmotischen Leistungen der im Zellsaft gelösten Stoffe bei der Entstehung des Turgors.

Einen speciellen Fall der intramolecularen Atmung bilden die Gärungserscheinungen ron Hefezellen und Spaltpilzen, bei denen je nach dem Gährungserreger verschiedene Produkte gebildet werden.

Die bekannteste Gärungserscheinung ist die alkoholische Gärung, bei welcher die Hefezellen aus Zucker neben geringen Mengen von Bernsteinsäure, Glycerin und anderen Produkten hauptsächlich Kohlensäure und Alkohol bilden, d. h. jene Stoffe, welche auch bei der intramolecularen Atmung der höheren Pflanzen entstehen.

Milchsäuresärungs, Buttersäuregärung, faulisge Gärung (Fäulnis) wird durch verschiedene Spaltpilzarten hervorgerufen. 
Ehonso wie bei der Verbrennung lebloser orsanischer Körper treten bei der Atmung der I'flanzen Wärme und unter Umständen auch Lichterscheinungen auf. Dic Pflanze nimmt im allsemeinen die Tempertur ihrer Umgebung an, bei lebhaften Atmungs- oder Gärungsvorgängen tritt jedoch eine nicht unbeträchtliche Temperaturerhöhung auf. Zusammengehäuft keimende Samen, bei denen keine genügende Abkïhlung durch die umescbende Luft bewerkstelligt wird, können sich um IO- $5^{\text {" }} \mathrm{C}$. und mehr erwärmen. Nadelholzsamen erwärmen sich auch im ungekeimten Zustande bei ungenügender Durchlüftung so bedeutend, dass eine Schädisung der Keimfähigkeit hierdurch herbeigeführt werden liann.

Bei Sauerstoffabschluss ist die Erwärmung nur unbedeutend.

Lichterscheinungen wurden an verschiedenen Pilzen (Mycel von Agaricus melleus, Agaricus olearius) beobachtet. Doch tritt die Erscheinung nur auf, wenn Sauerstoff vorhanden war. Eine höhere Temperatur ist für das Leuchten vorteilhaft, aber keine unerlässliche Bedingung, da

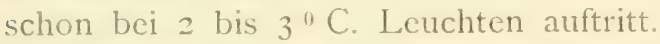

Ebenso dürften die an faulenden Fischen und Fleisch auftretenden Lichterscheinungen hierher gehören.

\section{S 39. Wachstumserscheinungen der Pflanzen. Allgemeines.}

Der Laie verwechselt vielfach Wachstum und Ernährung. Unter Wachstum verstehen wir eine Volumvergrösserung der Pflanze, während die Ernährung die Aufnahme und Bildung von Pflanzensubstanz darstellt. Ernährungsvorgänge können sich auch in nicht mehr wachsenden Pflanzenteilen abspielen, umgekehrt kann das Wachstum, wie z. B. bei der Keimung von Samen auf Kosten von Reservestoffen, also ohne Aufnahme von Pflanzennahrung von aussen, vor sich gehen.

Die Form der sich bildenden Organe, sowie die Geschwindigkeit und die Grenzen des Wachstums werden einerseits durch innere, anderseits durch äussere Faktoren bestimmt.

Von der inneren Beschaffenheit einer Eizelle hängt es $a b$, ob sich daraus eine Rose oder eine Eiche entwickeln wird. Ein Zweig der Buchenvarietät mit zerschlitzten Blättern wird auch fernerhin zerschlitzte Blätter bilden, ein Steckling der sog. Pyramideneiche wird wiederum zur Pyramideneiche werden. Ebenso hängt es von inneren Ursachen ab, wie die Pflanze auf Kälte und Wärme oder andere äussere Faktoren reagiert.

In Form dieser inneren Ursachen machen sich die durch Vererbung erlangten Eigenschaften geltend, zu denen jedoch vermöge der Variation gewisse dem Mutterorganismus nicht zukommende Eigenschaften hinzutreten können.

Die äusseren Ursachen beeinflussen das Wachstum entweder mittelbar dadurch, dass sie in die Ernährungsvorgänge eingreifen, oder 
unmittelbar, indem sie die Geschwindigkeit und Energie des Wachstums bestimmen und Bildungsvorgänge auslüsen, die beim Fehlen dieser äusseren Einwirkung in anderer Weise verlaufen würden. Als Beispiel will ich die Lichtwirkung anführen, von welcher erstens die Assimilation, ein Ernährungsvorgang abhängig ist, von welcher jedoch auch die Intensität des Wachstums, sowie die innere Ausbildung der Organe - ich erinnere an Licht- und Schattenblätter (S: 64$)$ - abhängt.

Die erste Stufe des Wachstums bilden in der Regel Zellteilungen, nur einzellig bleibende Organismen können auch ohne Zellteilungen wachsen. Die zweite Stufe bildet die starke Volumvergrösserung der Zellen, im dritten Stadium erfolgt die innere Ausbildung der Gewebe, bis schliesslich im ausgewachsenen Zustand die vierte Stufe erreicht ist.

Entsprechend der Volumzunahme in der Längsrichtung oder Dicke der Organe haben wir zwischen Längenwachstum und Dickenwachstum zu unterscheiden. Aus beiden resultiert die Massenzunahme der Pflanze. Die Vergrösserung der Querschnittfäche eines Stammes bei der Dickenzunahme wird als Flächenzuw a chs bezeichnet. Je nach der Örtlichkeit, wo das Wachstum erfolgt, kann man Spitzenwachstum, basales Wachstum oder, wenn die wachsende Zone zwischen ausgewachsenen Teilen liegt, intercalares Wachstum unterscheiden. Flächenartig ausgebreitete thallöse Organismen können sich am Rande durch Rand-oder Marginalwachstum oder gleichmässig durch Flächenwachstum vergrössern.

Die Messungsmethode des Wachstums wird sich selbstverständlich den Objekten anzupassen haben. Bei sehr geringen Zuwachsgrössen werden wir das Mikroskop zu Hilfe nehmen, sonst passende Massstäbe oder andere Messinstrumente verwenden. Der in Fig. I39 abgebildete Apparat, der sog. Zeiger am Bogen dient ebenfalls zur Bestimmung einer relativ geringen Längenzunahme. Der Faden $f$ ist an der Pflanze und an der Rolle $r$ befestigt, welch letztere mit dem Zeiger $z$ und dessen Gegengewicht $\mathrm{k}$ fest verbunden ist. Bei der Verlängerung des Pflanzenteils wird die Rolle $r$ gedreht und der Zeiger $z$ giebt einen seiner Länge entsprechenden grossen Ausschlag.

$\mathrm{Zu}$ länger andauernden Messungen dienen die Wachstumsregistrierapparate. Ein derartiger Apparat, von W. Pfeffer konstruiert, ist in Fig. I 40 abgebildet. Der an der Pflanze befestigte Faden läuft durch ein Gewicht gespannt über eine kleine Rolle, welche mit einem etwas grösseren Rade fest verbunden ist. An dem letzteren ist ein Zeiger mit seinem Gegengewicht aufgehängt. Beim Längenwachstum der Pflanze wird Rolle und Rad gedreht, wobei sich der Zeiger in gerader Linie nach abwärts bewegt. Er schleift auf einer berussten Trommel, welche mit Hilfe eines Triebwerks in dem darunter befindlichen Kasten, einer Batterie und einer Uhr jede Stunde um ein kleines Stückchen gedreht wird. Es entsteht durch diese Drehung auf der Trommel jedes- 
mal cin Horizontalstrich, welcher die Abwärtsbeweguns des Zeigers in ciner Stunde markiert. Die I änese der Vertikalstriche auf der Trommel entspricht dem Wachstum der Pflanze, das im Verhältnis der Radien von Rolle und Rad versrössert aufgeschrieben wird.

Mechanik des Wachstums. Die Zellteilungsvorgänge künnen wir noch nicht mechanisch erklären, dasegen ist die Zellstreckung einer Erklärung zugänglicher. Hierbei kommt einerseits der Turgor, anderseits

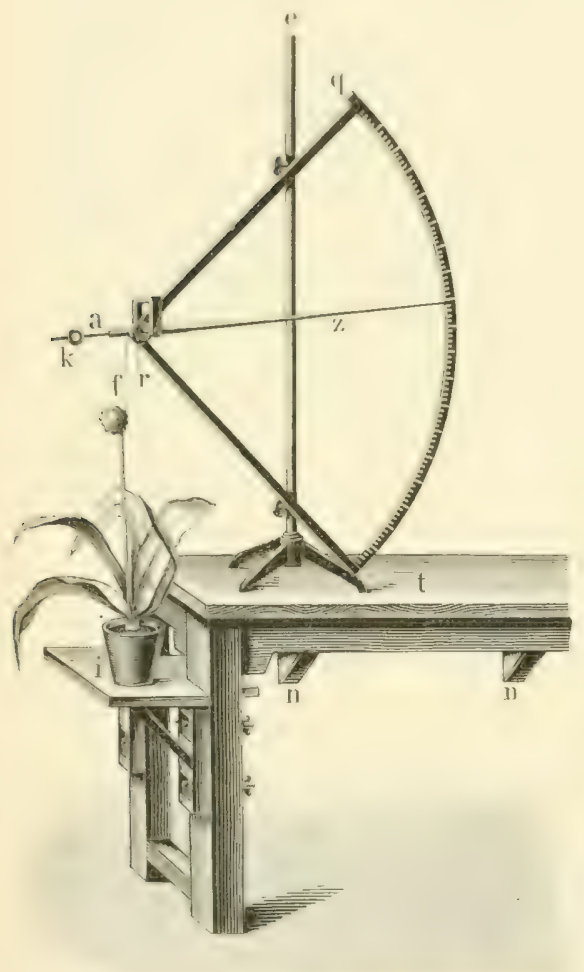

Fig. 139.

Zeiger am Bogen (n. Pfeffer).

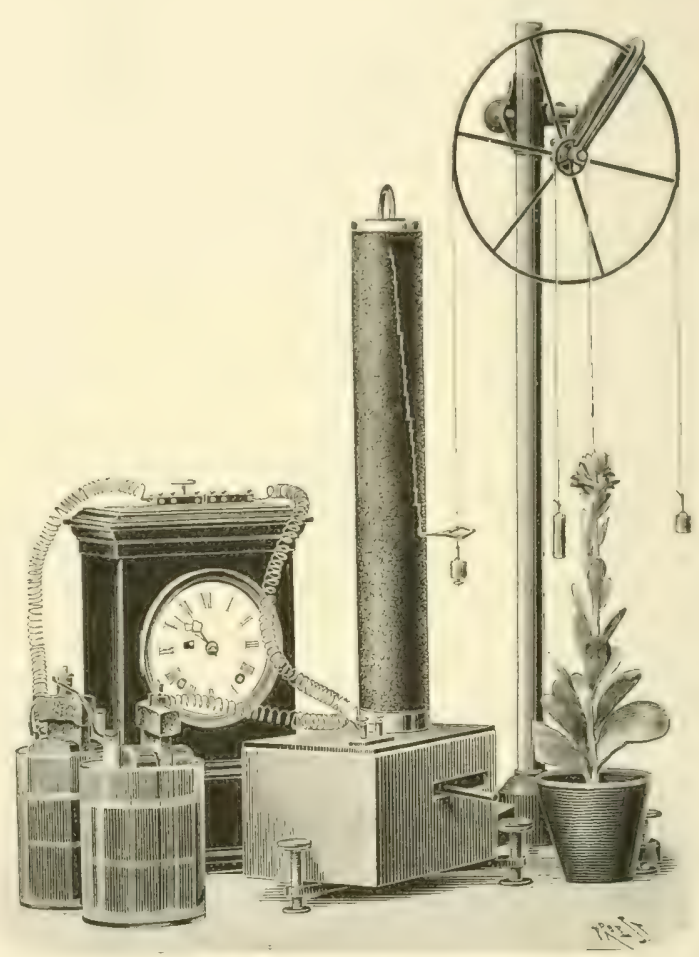

Fig. 140.

Wachstumsregistrierapparat von Pfeffer.

die Dehnbarkeit der Zellwand in Betracht. Durch den Turgor wird eine Volumvergrösserung der Zellen angestrebt, die um so grösser ausfällt, je dehnbarer die Zellwand ist. In einzelligen Pflanzen, wie z. B. bei Caulerpa (Fig. I) und Mucor (Fig. 39), ist der Turgor überall gleich, und doch kann Wachstum nur an der Spitze oder an bestimmten anderen Teilen stattfinden, wenn hier die Wandung dehnbar ist. Bei Pflanzen, welche aus verschiedenen Geweben bestehen, werden nur bestimmte Gewebe ein aktives Ausdehnungsbestreben zeigen, während die übrigen Gewebe passiv gedehnt sind. Rinde und Holz werden in fortwachsenden Sprossen zumeist durch das Mark gedehnt, werden daher die genannten Teile isoliert, 
d. h. aus dem Verbande gelöst, so tritt bei dem Mark eine Verlängerung, bei Holz und Rinde, die vorher passiv gedehnt waren, eine Verkürzung ein. Zwischen den einzelnen Geweben bestand demnach, solange sie miteinander fest verbunden waren, eine Spannung, die man als Gewebespannung bezeichnet. Dieselbe beruht auf der Turgescenz und der grösseren Dehnbarkeit gewisser Gewebe, und ist für das Wachstum der höheren Pflanzen von der grössten Wichtigkeit. Alle Faktoren, welche den Turgor, die Dehnbarkeit der Wandung und die Gewebespannung beeinflussen, verändern auch die Wachstumsgeschwindigkeit. Trotz Turgor und Dehnbarkeit der Wandung kann jedoch das Wachstum unterbleiben, wenn wie z. B. bei Abwesenheit von Sauerstoff die Stoffwechselvorgänge in dem Protoplasma gehemmt sind. Turgor und Dehnbarkeit der Wand sind demnach nicht die einzigen für das Wachstum massgebenden Faktoren.

Wachstum der Zellwand vgl. S. 32.

\section{S40. Periodicität des Wachstums.}

Lassen wir eine $3-4 \mathrm{~cm}$ lange Keimlingswurzel von Vicia Faba unter günstigen Umständen weiterwachsen, nachdem wir dieselbe durch feine Tuschstriche in Millimeterzonen geteilt haben, so sehen wir, dass nur in der Nähe der Wurzelspitze die Tuschmarken infolge des Längenwachstums auseinandergerückt sind. So zeigten während 24 Stunden bes $20,5^{\circ}$ C. die an der Spitze befindlichen zehn Millimeterzonen folgende Verlängerung resp. Wachstum.

\begin{tabular}{c|c}
\hline Zone & Zuwachs in mm \\
\hline I. (Spitze) & $\mathbf{I}, 5$ \\
II. & 5,8 \\
III. & $\mathbf{8 , 2}$ \\
IV. & 3,5 \\
VI. & $\mathbf{1}, 6$ \\
VI. & $\mathbf{1}, 3$ \\
VII. & 0,5 \\
VIII. & 0,3 \\
IX. & 0,2 \\
X. & 0,1 \\
Ältere Zonen & 0 \\
\hline Gesamtzuwachs & $23,0 \mathrm{~mm}$. \\
\hline
\end{tabular}

Die Zellen an der Wurzelspitze haben sich nur wenig gestreckt, das Längenwachstum hat in der zweiten Zone ziemlich schnell zugenommen, um in der dritten Zone das Maximum zu erreichen.

Die Verlängerung der Zellen in den ältern Zonen ist geringer und bildet den allmählichen Übergang zu den nicht mehr wachsenden Streclien, die hier bei Io mm Entfernung von der Wurzelspitze beginnen. Mit dem Weiterwachsen der Wurzel verschieben sich diese Zonen verschiedenen 
IVachstums, indem niher an der Spitze liesende Zonen in das Stadium des maximalen VVachstums treten, die am stärksten Wachsenden Zonen sich lanssamer strecken, und die zuerst noch schwach wachsenden Zonen ( III bis $\mathrm{X}$ ) in den aussewachsenen Zustand übersehen.

Bei den Sprossaxen sind die wachsenden Zonen zumeist ausgedehnter, und erstreclien sich häufigs über mehrere Internodien, sonst lassen sich jedoch auch hier dieselben Verhältnisse konstatieren.

Was für die oben angeführten Zonen sesagt wurde, gilt selbstverständlich auch für die einzelnen Zellen, welche diese Zonen zusammensetzen. Jede Zelle beginnt langsam in die Länge zu wachsen, erreicht ein Wachstumsmaximum und wächst sodann wieder langsamer. Dieselbe Periodicität des Längenwachstums können wir auch an jedem Internodium, an jedem Organe und an der ganzen Pflanze beobachten.

Man bezeichnet diesen Wachstumsgang der ganzen Pflanze als die sog. grosse Periode.

Zur Veranschaulichung der betreffenden Verhältnisse bei der Kiefer, Buche, Fichte und Tanne führe ich in der beifolgenden Tabello die Höhe der Bestände in Metern an, und zwar für verschiedene Bestandsbonitätsklassen. Die Höhen der ganzen Bestände geben uns auch Mittelwerte für den Wachstumsgang der einzelnen Bäume.

Kiefer nach Schwappach.

\begin{tabular}{|c|c|c|c|c|c|c|c|c|c|c|c|c|c|c|c|}
\hline itte & - & . & - & 11 & 20 & 30 & & & ? & , & 2 & 90 & 0 & 110 & $? 0$ \\
\hline onit: & & . & & & & 3.3 & 16,9 & 8 & 3 & 24,4 & 26,2 & 27 & 2 & 30,4 & \\
\hline II & . & . & - & 2 & 7, & $\mathbb{1}, 1$ & I 4 & & & 2 & 0 & & & & \\
\hline$"$ & - & : & . & $\mathrm{I}$, & 3 & $\begin{array}{l}9, \\
6\end{array}$ & $\begin{array}{r}12 \\
9\end{array}$ & II & 12, & $\begin{array}{l}17,5 \\
\text { I } 4,2\end{array}$ & $\frac{1}{5}$ & $\begin{array}{l}20 \\
16\end{array}$ & 17 & & 20,0 \\
\hline ", & & & & 0,7 & 2,0 & 4,5 & 6,4 & 7,9 & 9,2 & 10,4 & I 1,6 & 12,6 & 13,5 & & \\
\hline
\end{tabular}

Buche nach Baur.

\begin{tabular}{|c|c|c|c|c|c|c|c|c|c|c|c|c|c|c|c|}
\hline Alte & & . & . & 10 & 20 & 30 & 40 & 50 & 60 & 70 & 80 & 90 & 100 & 110 & 120 \\
\hline & nitä & . & . & & & & I 4,9 & & 2 & 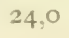 & 0 & 28,0 & 8 & & \\
\hline II & $"$ & . & . & I, & & 8,2 & 12 & 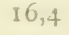 & o & 21 & 23,0 & 25,0 & 6 & 7,6 & 20 \\
\hline II & $"$ & . & . & 0, & & 6,0 & 10,0 & 14,0 & I & 9 & 20,9 & 22,0 & o & 0 & 25,0 \\
\hline Y & $"$ & . & . & o & 2, & 5. & 8,0 & & & & & I 8,6 & & 20,6 & I, 6 \\
\hline V & $"$ & & . & 0,2 & 1,2 & 3,0 & 5,5 & 8,0 & 10,0 & $\mathrm{I} 2, \mathrm{O}$ & 14,0 & $1_{5,0}$ & 16,0 & 17,0 & I, 0 \\
\hline
\end{tabular}

Fichte nach Baur.

\begin{tabular}{|c|c|c|c|c|c|c|c|c|c|c|c|c|c|c|c|}
\hline Alter & & & & 10 & 20 & 30 & 40 & 50 & 60 & 70 & 80 & 90 & 100 & 110 & 120 \\
\hline I Bonität & & . & & 1,0 & 4,4 & 10,3 & 15,1 & 18,9 & 21,9 & 24,9 & 27,9 & 29,9 & 31,9 & 33,9 & 35,0 \\
\hline II & . & & & 0.7 & 2.9 & 0.7 & 10.7 & 13.0 & 16,5 & 19.8 & 22.0 & 24.0 & 25.1 & $2(1,0)$ & 25.0 \\
\hline III & & . & & 0,5 & 2,0 & 4,8 & 8,0 & I I, 0 & $\left|I_{3}, 4\right|$ & 15,4 & $|17,4|$ & I $\$, 8$ & 19,8 & 20,5 & 21,0 \\
\hline IV & & . & & 0,4 & $\mathbf{I}, 4$ & 3,6 & $6, \mathbf{I}$ & $S, \mathbf{I}$ & IO, 1 & 12,1 & 13,1 & $\mathrm{I}_{3}, \mathrm{~S}$ & 14,6 & 15,5 & 16,0 \\
\hline
\end{tabular}

Tanne nach Schuberg.

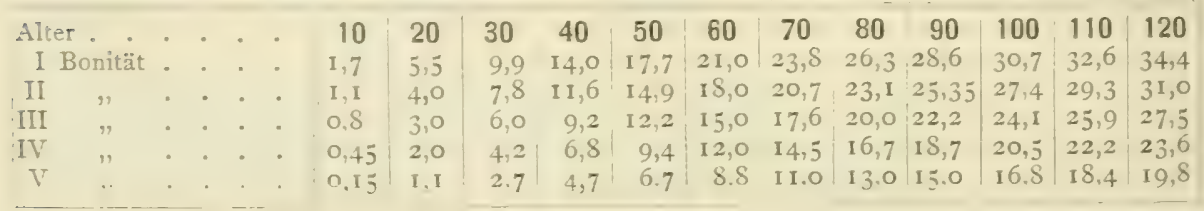


Um die grosse Periode leichter zu übersehen, dürfte es vorteilhaft sein, wenigstens für Kiefer und Tanne die Zuwachsgrössen in den Iojährigen Perioden zusammenzustellen.

\begin{tabular}{|c|c|c|c|c|c|c|c|c|c|c|c|}
\hline \multicolumn{6}{|c|}{ Längenzuwachs der Kiefer (in Metern). } & \multicolumn{6}{|c|}{ Längenzuwachs der Tanne (in Metern). } \\
\hline \multirow{2}{*}{ In den Jahren } & \multicolumn{5}{|c|}{ Bonität } & \multirow{2}{*}{ In den Jahren } & \multicolumn{5}{|c|}{ Bonität } \\
\hline & I & II & III & IV & $\mathrm{V}$ & & $\mathrm{I}$ & II & III & IV & V \\
\hline $1-10$. & 3,7 & 2,7 & 1,7 & 1,0 & 0,7 & $1-10$. & I,7 & $\mathrm{I}, \mathrm{I}$ & 0,8 & 0,45 & 0,15 \\
\hline $10-20$. & 5 & 4,3 & & 2,7 & 1,3 & $10-20$. & & 2,9 & 2,2 & $\mathbf{I}, 55$ & 0,95 \\
\hline $20-30$. & 4 & 4,1 & & & 2 & $20-30$. & 4 & 3 & 0 & 2 & I, 6 \\
\hline $30-40$. & 3 & 3,4 & 2 & 2 , & 1,9 & $30-40$. & 4 & 3,8 & & 2 & 2,0 \\
\hline $40-50$. & 2 & 2,7 & 2 , & $\mathbf{I}$, & $\mathbf{I}, 5$ & $40-50$. & 3 & 3,3 & & 2 & 2,0 \\
\hline $50-60 \ldots$ & 2 & 2,3 & I, & I & 1,3 & $50-60$. & 3 & 3 , & 8 & 2,6 & 2,1 \\
\hline $60-70 \ldots$ & 2,1 & $\mathbf{1}, 9$ & I, & I, & $\mathbf{I}, 2$ & $60-70$. & 2 & 2,7 & 2,6 & 2,5 & 2,2 \\
\hline $70-$ So. & $\mathbf{1}, 8$ & $\mathbf{1}, 6$ & 1,6 & I, & 1,2 & $70-80$ & 2, & 2,4 & 2.4 & 2 , & 2,0 \\
\hline So- 90. & $\mathbf{I}$ & I, 4 & I, 4 & I, & $\mathrm{I}, \mathrm{O}$ & So- 90. & 2 & 2,25 & 2 & 2 & 2,0 \\
\hline $90-100$. & I & 1,3 & $\mathbf{I}$ & 1 & 0,9 & $90-100$. & $2, I$ & 2,05 & 9 & $\mathbf{I}, 8$ & I, 8 \\
\hline $100-110$. & $\mathrm{I}, 2$ & $\mathbf{I}, 2$ & $\mathbf{I}$ & $\mathbf{I}, \mathbf{I}$ & - & $100-110$. & $\mathbf{I}, 9$ & $\mathrm{I}, 9$ & $\mathbf{I}, 8$ & $\mathrm{I}, 7$ & $\mathrm{I}, 6$ \\
\hline $110-120$. & 1,0 & $\mathrm{I}, \mathrm{O}$ & $\mathrm{I}, \mathrm{O}$ & $\mathrm{I}, \mathrm{O}$ & - & $110-120$. & I, 8 & $\mathbf{I}, 7$ & $\mathbf{I}, 6$ & $\mathbf{I}, 4$ & $\mathrm{I}, 4$ \\
\hline Gesamtzuwachs & $3 \mathrm{I}, 4$ & 27,9 & $24, \mathrm{I}$ & 20,0 & I 3,5 & Gesamtzuwachs & 34,4 & 31,0 & 27,5 & 23,6 & 19,8 \\
\hline
\end{tabular}

Trotzdem die Ernährungsverhältnisse bei den einzelnen Bestandsbonitätshlassen sehr verschiedene waren, lässt sich die grosse Periode überall gut erkennen. Das Längenwachstum nimmt bis zu einem gewissen Zeitpunkte zu, erreicht sein Maximum und nimmt allmählich wieder ab.

Das Maximum wird unter günstigen äusseren Verhältnissen früher erreicht, als bei den schlechten Waldbeständen. So fällt das Wachstumsmaximum der Kiefer bei Bonität I und II zwischen das IO. und 20. Jahr, bei den übrigen geringeren Bonitäten zwischen das 20. und 30. Jahr. Bei der Fichte liegt das Maximum bei der Bonität I zwischen dem 20. und 30. Jahr, bei den übrigen Bonitäten zwischen dem 30. und 40. Jahr. Die Tanne verhält sich in der ersten Bonität gleich der Fichte, durch die Ernährungsverhältnisse kann jedoch das Maximum bis in den Zeitraum von 60 bis 70 Jahren hinausgeschoben werden. Dic Buche verhält sich nach Baur analog wie die Fichte, das Maximum tritt jedoch erst um IO Jahre später ein. Nach R. Hartig liegt das Maximum des Höhenzuwachses bei der Annahme von drei verschiedenen Bonitätsklassen bei I. Bonität im IO.-30. Jahre, bei II. Bonität im 20.-30. Jahre, bei III. Bonität im 30.-40. Jahre.

Einzelne Pflanzen und ganze Holzarten, bei denen das Wachstum in der Jugend sehr schnell ansteigt, so z. B. die Kiefer werden im Vergleich zu anderen Holzarten als vorwüchsig bezeichnet. Solche Vorwüchse können später von Pflanzen überflügelt werden, deren Maximum in einen späteren Zeitraum fällt.

Bei älteren Pflanzen können sich die Differenzen im Zuwachs auf verschieden gutem Boden mehr ausgleichen, ja es kann sogar vorkommen, dass die Bäume in höherem Alter (über roo Jahre) auf schlechtem Boden 


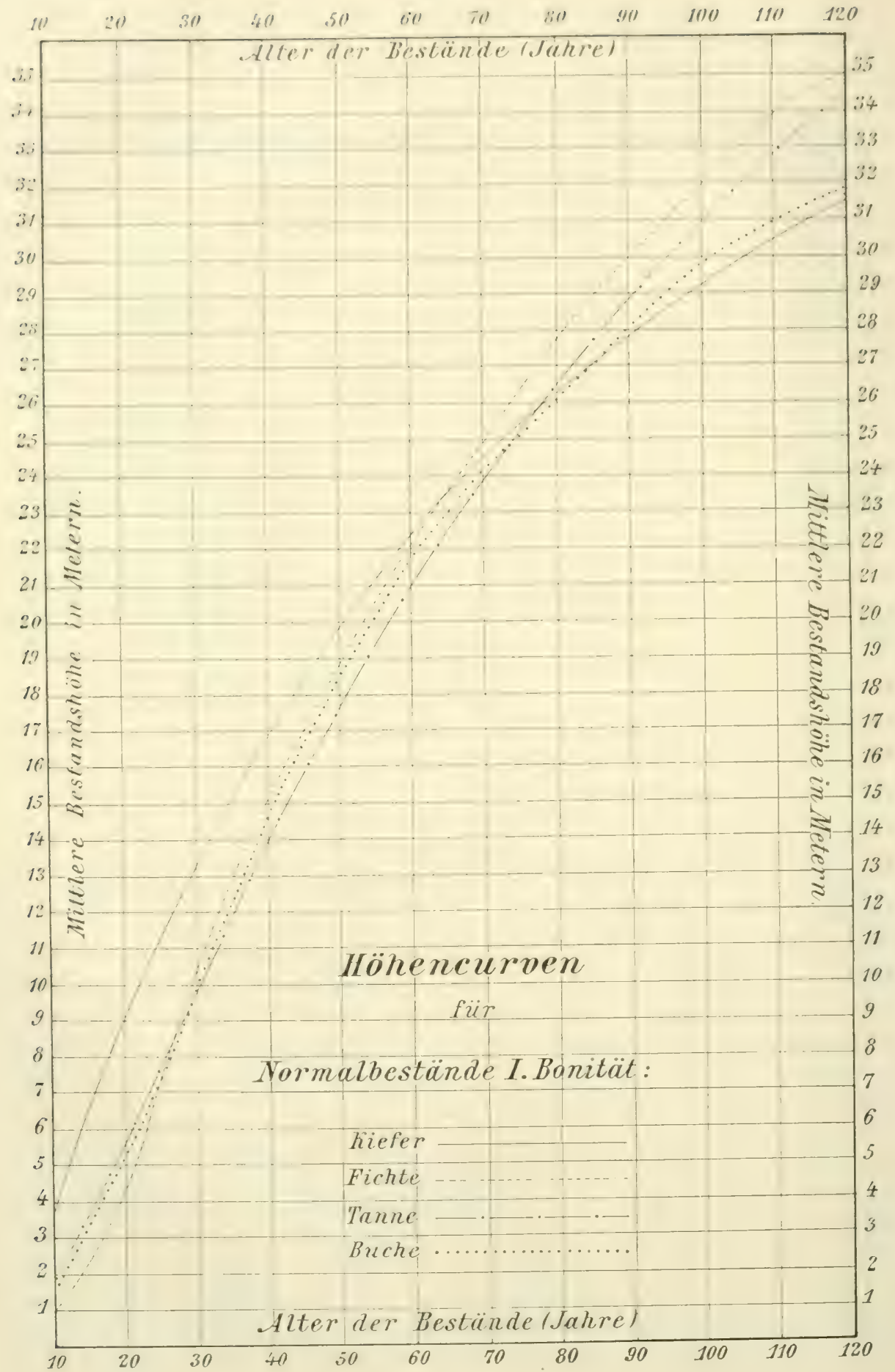


einen grösseren Längenzuwachs aufweisen, als auf gutem Boden. So zeigten Buchen nach R. Hartig in Zeiträumen von IO Jahren folgende Verlängerung :

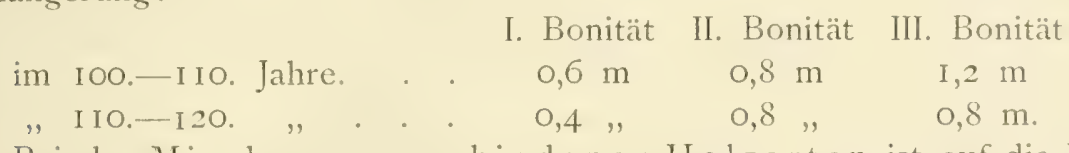

Bei der Mischung verschiedener Holzarten ist auf die Vorwüchsigkeit einer Holzart Rücksicht zu nehmen, doch kommen dabei hauptsächlich die absoluten Höhen in Betracht, welche eine Pflanze innerhalb eines gewissen Zeitraumes erreicht. Zur Veranschaulichung dieses Gegenstandes sind in der Tafel auf S. I62 ohne Rücksicht auf das Vorkommen solcher Mischungen in der Praxis die Baumhöhen als Curven aufgezeichnet. Hierzu sind die auf Seite 160 für die I. Bonität angegebenen Längen benutzt. Wir sehen, wie sich mit dem Alter die Höhenfolge der einzelnen Holzarten verschiebt. In der Praxis kommen nur bestimmte Mischungen vor und ausserdem werden die Verhältnisse dadurch geändert, dass die Bonitätsklassen der einzelnen Holzarten nicht miteinander übereinstimmen. Ein Boden, welcher z. B. Kiefern II. Bonität liefert, wird einen Buchenbestand III. Bonität tragen. Ferner wird das Wachstum der anfangs zurückbleibenden Holzart durch die Beschattung der vorwüchsigen Holzart modificiert werden.

Durch die Betrachtung der absoluten Höhe des Bestandes, welche in einem bestimmten Zeitraume erreicht wird, kann man auch ein Urteil über die Bonität des Bodens erhalten, man muss dabei jedoch in Betracht ziehen, dass ein an und für sich mineralisch reicher Boden durch Verwilderung, durch Austrocknen etc. bedeutend an Qualität verlieren kann; in welchem Falle die Bestandeshöhe noch keinen genügenden Aufschluss über den Mineralgehalt des Bodens gewährt.

Vergleichen wir das Längenwachstum von Sprossaxe und Wurzel, so lässt sich in der ersten Jugend meist ein Vorauseilen der Wurzelentwickelung, ein schnelleres Ansteigen der grossen Periode konstatieren, oder wenn wir einen für die Stämme gebräuchlichen Ausdruck auf die Wurzeln übertragen wollen, können wir sagen, die Wurzeln sind vorwüchsig. So erreichte z. B. die Pfahlwurzel einer jungen. Eiche in derselben Zeit eine Länge von vier Fuss, während die Länge der oberirdischen Teile erst 6 Zoll betrug. In ähnlicher Weise sehen wir bei dem Wintergetreide die Ausbildung des Wurzelsystems bevorzugt.

Bei dem Dickenzuwachs der Stämme besteht sicherlich eine analoge Periodicität wie beim Längenwachstum. Die einzelnen Zahlen werden jedoch durch Nebenumstände derartig alteriert, dass wir von einem näheren Eingehen auf diesen Punkt Abstand nehmen.

Innerhalb der grossen Periode, welche sich auf das ganze Leben des Individuums erstreckt, ist bei mehrjährigen Pflanzen das Wachstum jährlichen Schwankungen unterworfen, die man als Jahresperioden bezeichnet. 
Dieselben sind in hohem Grade von äusseren Faktoren abhängig, indem Wärme, Feuchtigkeitsverhältnisse und Licht das Wachstum becinflussen.

In unseren Breitengraden ist die Jahresperiode der Sprossaxen durch den Gang der Temperatur bedingt. Ähnlich wirkt in den Tropen grosse Trockenheit. Durch die genannten Ursachen treten in der Vegetation Ruheperioden ein, in denen die Pflanze nicht wächst und sich häufig auch gewisser Organe entledigt. Dic Entlaubung unserer Hol\%sewächse ist bekannt, ebenso können jedoch bei bestimmten Arten Zweige abseworfen werden. Derartige „Absprünge" sind bei Eichen, Pappeln, Weiden, Linden, bei Robinia, Prunus Padus, Evonymus und Taxodium distichum zu beobachten. Bei Eichen und Pappeln werden auch ältere (bis sechsjährige) Äste abgeworfen, sonst meist nur jüngere Triebe.

Die durch äussere Verhältnisse hervorgerufenen Ruheperioden können sich auch dann noch geltend machen, wenn die hemmenden Wirkungen hinwegfallen. So werfen Eichen, Buchen und manche Obstbäume in Madeira ihre Blätter regelmässig zu bestimmten Zeiten ab und zeigen eine Ruheperiode, trotzdem auf Madeira im kältesten Monat eine Mitteltemperatur von $+I 5^{0} \mathrm{C}$. herrscht. Bei anderen Pflanzen, z. B. den Weinreben, Kirschen, fehlen unter denselben Verhältnissen die in unseren Gegenden vorkommenden Ruheperioden.

Nach den Ruheperioden beginnt das Wachstum zuerst langsam, später erreicht die Wachstumsgeschwindigkeit ein Maximum, um schliesslich wieder abzunehmen.

Die Länge der Vegetationsperiode wird ebenfalls durch äussere Faktoren, namentlich durch die geographische Lage bestimmt. Aus dem Süden stammende Arten besitzen zumeist längere Vegetationsperioden. Werden diese Arten in Gegenden mit kürzerer Vegetationsperiode kultiviert, so reifen die Äste vielfach nicht aus und erfrieren, eine Erfahrung, die man namentlich bei der Kultur von Ausländern machen kann.

Die Länge der Vegetationsperiode kann, obwohl sie durch äussere Bedingungen induciert ist, vererbt und durch Samen übertragen werden. So durchlaufen die aus dem Norden stammenden Getreidearten ihre Entwickelung in kürzerer Zeit, sie tragen frühzeitiger reife Samen, als dieselben Arten aus wärmeren Klimaten. Ebenso dürften die Samen von Holzpflanzen, welche in einem kalten Klima gewachsen sind, Bäume liefern, dic ihre Jahresentwickelung früher abschliessen, wobei die Triebe besser ausreifen und somit weniger der Frostgefahr unterworfen sind. Doch kann hierbei auch eine verschiedene Empfindlichkeit der Pflanzen für höhere Kältegrade vererbt worden sein.

Der regelmässige Gang der Jahresperiode kann Unterbrechungen erleiden, wie uns die Ausbildung der sog. Johannistriebe zeigt, welche sich z. B. bei der Eiche am Ende des Sommers aus diesjährigen Knospen bilden, die eigentlich erst zum Auswachsen im nächsten Frühjahr bestimmt sind. Da sie häufig nicht genügend ausreifen, erfrieren sie leicht. 
Die Ruheperioden vieler Samen sind durch innere Veränderungen veranlasst, deren Natur uns unbekannt, ist. Wir können demnach auch nicht sagen, warum gewisse Samen, wie z. B. Carpinus, Fraxinus, Tilia, Taxus, in der Regel auch Ulmus montana länger als ein Jahr brauchen (ïberliegen), um zu keimen.

Die Jahresperiode jder Wurzeln stimmt nicht mit der Jahresperiode der Sprosse überein. An den näher untersuchten Laubhölzern, z. B. bei Fagus, Tilia, Alnus, Quercus, Acer campestre, Fraxinus, Syringa, Mespilus findet die lebhafteste Wurzelentwickelung zumeist im August und September statt, bei milder Witterung kann sogar während der Wintermonate die Entwickelung andauern. Die zu starke Abkühlung des Bodens führt auch hier einen Stillstand des Wachstums herbei, welches jedoch im Februar oder März aufs neue beginnt. Während der Laubentwickelung hört das Wachstum der Wurzeln auf, um, wie gesagt, erst im August wieder zu beginnen. Bei Quercus Robur findet man auch im Juni neugebildete Wurzeln, welche Erscheinung vie!leicht mit dem Johannistriebe zusammenhängt.

Bei den Nadelhölzern haben wir einen ähnlichen Herbst - und Frühjahrstrieb, der erstere scheint jedoch früher (Oktober) zum Stillstand zu kommen, so dass hier eine ausgesprochene Winterruhe vorliegt. Die Frühjahrsentwickelung dauert bis Mitte Mai.

Wir haben bei den Wurzeln demnach eine Jahresperiode, welche zwei Maxima aufweist, die durch die Winterruhe mehr oder weniger scharf getrennt sind.

Die hier erörterten Verhältnisse sind bei dem Umsetzen und der Pflanzung zu berücksichtigen, dabei ist jedoch zu bemerken, dass durch das Umsetzen und Verschulen eine Neubildung von Wurzeln angeregt wird, die mit dem periodischen Entwickelungsgang der Wurzeln nicht identisch ist.

Die jährlichen periodischen Schwankungen im sekundären Dickenwachstum des Holzkörpers wurden schon bei der Jahresringbildung berührt. Der Begginn des sekundären Dickenwachstums differiert bei den verschiedenen Pflanzenteilen sehr bedeutend. Im allgemeinen wird eine stark besonnte, freistehende Pflanze früher ihre Thätigkeit aufnehmen, als eine stark beschattete Pflanze. In der Krone kann das Wachstum bei dichtem Bestandesschluss um vier Wochen früher beginnen, als an der Stammbasis. In der Wurzel ist Beginn und Ende der Cambiumthätigkeit noch bedeutend mehr hinausgeschoben. So kann die Ausbildung der Jahresringe in der Wurzel bei der Eiche erst Ende Februar, bei der Esche im März, bei Kirsche und Apfel sogar erst im April des nächsten Jahres beendigt sein, wenn auch in vielen Fällen das Dickenwachstum schon im Oktober aufhört. Im Stamme 50-I 50jähriger Rotbuchen war bis Mitte Juni das erste Drittel, bis Ende Juli das zweite Drittel, bis Mitte August das letzte Drittel des Jahresringes gebildet. 
Innerhalb der Jahresperioden sind beim Längenwachstum noch tägliche Schwankunsen zu beobachten, die man als die Tagesperioden bezcichnet. Diesclben sind hauptsächlich von Licht und Wäame abhängig.

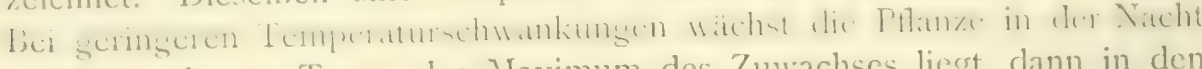
schneller als am Tage, das Maximum des Zuwachses liegt dann in den ersten Morenstunden, bevor die hemmende Wirkung des Lichtes sich scltend machen kann. Ist dic Temperatur am Tage wesentlich höher als in der Nacht, so wird das Tageswachstum überwiegen.

\section{ธ41. Einwirkung äusserer Faktoren auf das Wachstum}

Nachdem wir schon früher den Einfluss äusserer Faktoren auf die

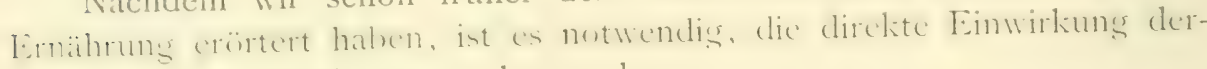
selben auf das Wachstum zu besprechen.

\section{Temperatur.}

Zum Vachstum der Pflanzen ist ein gewisses Minimum an Temperatur netwendis, das für die cinzelnen I'flanzen sellostressändlich nicht

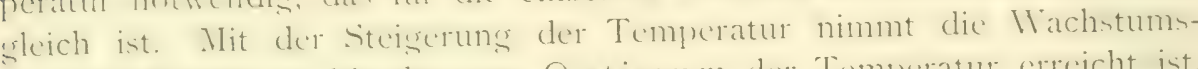
geschwindiglieit zu, bis das sog. Opt im un der. Tempratur erreicht ist, bei welchem die Pflanze am schnellsten wächst. Eine weitere Temperaturerhühung bewirlit eine Verlangsamung des Viachstums, his dasselbe bei dem Temperaturmaximum aufhört. Dieser Grenzwert liegt unterhalb der Tötungstemperaturen.

\begin{tabular}{|c|c|c|c|}
\hline & Minimum & Optimum & Maximum \\
\hline A vulga & $5^{\circ} \mathrm{C}$. & $28,7^{\circ} \mathrm{C}$ & $42,5^{\circ} \mathrm{C}$. \\
\hline Lea 1$]$ & $9.511 C$. & $33.7^{\circ} \mathrm{C}$. & $4^{r}, 2^{n}$ \\
\hline & $\mathrm{I}_{3}, 7^{\circ} \mathrm{C}$. & $33,7^{\circ} \mathrm{C}$. & $46,7^{0}$ \\
\hline icillium (Mycel) & $2,5-3^{\circ} \mathrm{C}$ & - & \\
\hline
\end{tabular}

Auf Wurzel und Spross wirken die Temperaturen nicht in derselben Weise ein, namentlich ist bemerkenswert, dass bei niederen Temperaturen das Wurzelsystem sich relativ stärker entwickelt als die oberirdischen Teile, so dass sehr zeitig im Friihjah ausgesäete Samen wohl ein relativ grösseres Wurzelsystem haben dürften, als spät ausgesäete Pflanzen.

\section{Licht.}

Gegen Licht rerhalten sich nicht alle Teile der Pflanzen gleich. Die Axenureane werden durch Licht meist im Wachstum sehemmt. Wechseln Beleuchtums und Terdunkelung ab, so wachsen die Syrosse und Tirzeln während der. Dunkeiperioden schneller. Durch sehr startie Beleuchtung kann das Längenwachstum sougar sistient werden. Pflanzen, die, mit senügenden Reservestoffen versehen, unter dauerndem Lichtabschluss (Etir)lement) wachsen, künnen eine bedeutende L̈berverlänserung der Sprossaxen zeisen , Kartoffel. Wicke, Erbse, doch gicbt es auch Pflanzen, die hierbei keine atssersewöhnliche Terlängerung aufweisen i Bryonia dioica, Humulus Lupulus, Dioscorea Batatas). 
Die Blätter bleiben bei dauerndem Lichtabschluss bedeutend kleiner (Fraxinus excelsior, Picea vulgaris), oder sie werden nur als schuppenförmige Organe ausgebildet (Gingko biloba, Vicia Faba).

Dass das Chlorophyll sich bei Dunkelheit in der Regel nicht ausbildet, wurde schon S. I37 erwähnt, ebenso unterbleibt teilweise die Verdickung der Zellmembranen, was namentlich an sklerenchymatischen Elementen, Bastfasern und dem Hypoderm auffällt.

Ferner wird durch das Licht die Anlegung und Neubildung von Organen beeinflusst. Adventivwurzeln bilden sich besonders an der Schattenseite, wie denn auch die Rhizoïden bei Marchantia, nur an der weniger beleuchteten Seite entstehen.

\section{Schwerkraft.}

Die Schwerkraft beeinflusst das Längenwachstum nicht, sobald dieselbe in normaler Richtung einwirkt (Wirkung des Geotropismus rol. S. I69). Die Anlage von Adventivbildungen, sowie das Auswachsen von Knospen wird in der Weise beeinflusst, dass die erdwärts gerichteten Teile vornehmlich Wurzeln bilden, während auf der entgegengesetzten Seite die Knospen zur Entwickelung gelangen. Dabei kommen jedoch noch innere Kräfte zur Wirkung, indem die basalen Teile von Zweigen, Stecklingen etc. leichter Wurzeln, die Spitzenteile leichter Knospen ausbilden.

\section{Wassergehalt.}

Zum Wachsen ist der Turgor notwendig (vgl. S. I58), Wasserentziehung, welche den Turgor herabsetzt, muss demnach das Wachsen vermindern oder schliesslich ganz sistieren. In sehr trockener Erde kann das vorhandene Wasser zwar noch zum Ersatz des verdunstenden Wassers ausreichen, aber trotzdem das Wachstum so bedeutend gehemmt werden, dass die Pflanzen sehr klein bleiben, welche Erscheinung man als Nanismus bezeichnet. Nach der Verpflanzung von Holzşewächsen bleiben die Blätter im ersten Jahre häufig kleiner, da das Wurzelsystem nicht die zum normalen Wachstum notwendigen Wassermengen aufzunehmen vermag. Der Umstand, dass viele Pflanzen einen sehr feuchten Standort meiden, dürfte hauptsächlich auf die srösseren Ansprüuche derselben an die Durchlüftuns des Bodens zurückzuführen sein.

\section{Sauerstoff.}

Die höheren Pflanzen können ohne Sauerstoff nicht wachsen, doch reichen noch sehr geringe Sauerstoffmengen hin, um wenigstens ein langsames Wachstum zu unterhalten. Wurzeln, die in schlecht durchlüfteten Bodenschichten wachsen, fallen leicht der Fäulnis anheim.

$\mathrm{Zu}$ tief liegende Samen keimen nicht, was zum grössten Teil wohl auch auf der ungenügenden Zufuhr von Sauerstoff beruht.

\section{Correlationswachstum.}

Zwischen den einzelnen Gliedern einer Pflanze besteht eine gewisse Wechselwirkung oder Correlation. So können nichtblühende Kartoffelvarietäten dadurch zur Blütenbildung veranlasst werden, dass man die 
Knollenbildung unterdrïckt. Werden die Blätter im Sommer durch Raupenfrass, Hagel etc. vernichtet, so treiben die vorhandenen Knospen aus. Eine Wechselwirkung besteht auch zwischen der Entwickelung des Samens und der Fortbildung der Fruchtteile. Nur wenn Befruchtung erfolgte und die Samenanlagen sich zum Samen entwickeln, wachsen die Fruchtteile weiter. Bei Nadelhölzern wird einer der oberen Astquirle zu erhöhtem Wachstum angeregt, wenn der Gipfeltrieb vernichtet ist. Teilweise lassen sich diese Vorgänge durch die vermehrte Nahrungszufuhr erklären, doch kommen dabei auch Reize in Betracht, welche auf die betreffenden Organe ausgeübt werden und innere Veränderungen hervorrufen, die sich unserer Kenntnis entziehen.

\section{\$ 42. Autonome Bewegungen.}

Die Erörterungen über das Wachstum müssen noch durch die Besprechungen jener Faktoren ergänzt werden, welche die Wachstumsrichtung der Pflanzenteile bestimmen. An dieser Stelle soll auf jene Bewegungen von Pflanzenteilen — die Krümmung eines wachsenden Organs ist ja auch eine Bewegung - verwiesen werden, welche durch innere Ursachen bedingt sind, und die man daher als autonome oder spontane Bewegungserscheinungen bezeichnet.

Das Wachstum selbst, soweit es durch innere Ursachen bestimmt wird, ist eine autonome Vorwärtsbewegung. Eine Spross-oder Wurzelspitze wächst jedoch nicht in gerader Linie weiter, sondern zeigt verschiedenartige Bewegungen, die man als Nutationen bezeichnet. Dieselben kommen dadurch zu stande, dass eine Seite des Organes stärker wächst, die hierbei entstehende Krümmung kann im weiteren Verlaufe des Wachstums wieder ausgeglichen werden, indem nun die entgegengesetzte Seite im Wachstum gefördert wird. Die Spitze vieler Stengel ist gekrümmt (Vicia Faba, Pisum sativum, Humulus Lupulus), die Krümmung wird später durch das stärkere Wachsthum der konkaven Scite aufgehoben (pendelartige Nutation. Dasselbe kann man bei jungen Blättern, Farnwedeln und gewissen Blïten beobachten. Wachsen der Reihe nach die verschiedenen Seiten des Stengels etwas stärker, so beschreibt die Spitze mehr oder weniger unregelmässige Kreise, welche Erscheinung man als rotierende Nutation oder Circumnutation bezeichnet.

Derartige Nutationen machen sich bei windenden Pflanzen (vgl. S. 66) in erhöhtem Masse geltend (Phaseolus multiflorus, Humulus Lupulus, Convolvulus), doch ist hier die autonome Bewegung der circumnutierenden Pflanze mit dem Geotropismus derselben, d. h. mit der Empfindlichkeit für Schwerkraftwwirkung, kombiniert. Diese windenden Pflanzen vermögen nämlich nur nach aufwärts zu wachsen, sind aber nicht im stande, eine horizontale oder nach abwärts gerichtete Stütze zu umschlingen.

Autonome Bewegungen können auch ohne Wachstum zu stande 
kommen. So bewegen sich ausgewachsene Blättchen von Trifolium pratense, Oxalis acetosella auf und ab nur durch wechselnde Expansion der gegenüberliegenden Hälften an den Blattgelenken.

\section{Reizerscheinungen und induzierte Bewegungen.}

Die Pflanze erreicht die für sie günstigen Lebensbedingungen dadurch, dass sie mit der Aussenwelt in Verbindung tritt. Licht, Schwerkraft, mechanischer Druck oder Stoss, chemische Einwirkungen und andere äussere Faktoren, welche man in diesem Falle als Reize bezeichnet, lösen Vorgänge in der Pflanze aus, welche für dieselbe nützliche Bewegungen, Krümmungen und Wachstumserscheinungen zur Folge haben.

Man bezeichnet als Reizbarkeit die Fähigkeit des lebenden Organismus in bestimmter Weise auf äussere Einwirkungen, welche denselben treffen, zu reagieren. Der ausgelöste Effekt ist die Reizerscheinung.

Wird eine geheizte Dampfmaschine durch die Drehung eines Hahnes in Gang gesetzt, so ist die durch die Maschine erzielte Leistung unabhängig von der zum Drehen des Hahnes notwendigen Kraft. In derselben Weise ist es möglich, dass durch einen kleinen äusseren Anstoss - den Reiz - in der Pflanze eine bedeutendere, diesem äusseren Anstoss nicht proportionale Leistung ausgelöst wird.

Durch Sauerstoffentziehung, Chloroform, niedere Temperaturen, dauernden Lichtmansel können in der Pflanze Starezustände hervorgerufen werden, so dass die Pflanze nicht mehr auf äussere Reize reagiert, d. h. die in dem Organismus vorhandenen Kräfte müssen sich in einem gewissen labilen Gleichgewichte befinden, damit der äussere Anstoss eine Reaktion erzielt.

\section{Schwerkraftswirkung.}

Als Geotropismus wird die Fähigkeit der Pflanzenorgane bezeichnet, sich in eine bestimmte Lage zur Richtung der einwirkenden Schwerkraft zu stellen. Werden die Hauptaxen oberirdischer Laubsprosse oder Hauptwurzeln horizontal gelegt, so krümmen sie sich so lange, bis sie in der Richtung der Schwerkraft weiter wachsen. Die Wurzeln sind positiv geotropisch, die oberirdischen Sprossaxen sind negativ geotropisch, d. h. die Wurzeln folgen der Anziehungskraft der Erde, während die Stengel als negativ geotropische Organe in entgegengesetzter Richtung weiter wachsen. Pflanzenteile, welche unter einem gewissen Winkel zur Schwerkraftsrichtung weiter wachsen, werden als diageotropisch bezeichnet (Rhizome, Seitenaxen, Nebenwurzeln).

Schwärmzustände niederer Algen (Chlamydomonas, Euglena) können durch die Schwerkraft in der Weise gerichtet werden, dass sie nach aufwärts schwimmen (Negative Geotaxis).

\section{Lichtwirkung.}

In analoger Weise wie die Schwerkraft kann auch das Licht richtend 
einwirken, welche Erscheinung man als Heliotropismus bezeichnet. Dic Sprossaxen sind zumcist positiv heliotropisch, sie krümmen sich der Lichtquelle zu, die Wurzeln negativ heliotropisch, sie wenden sich vom I.ichte ab. Die Blätter stellen sich mit wenigen Ausnahmen senkrecht zur Einfallsrichtung des diffusen Tageslichtes, wodurch die beste Ausnutzung des für die Assimilation notwendigen Lichtes erreicht wird (Diaheliotropismus). Die Stellung der Organe ist von der Einfallsrichtung des Lichtes abhängies.

Der negative Geotropismus und der positive Heliotropismus der Sprossaxen wirken gleichsinnig, indem beide das Aufsteigen der Axen, welche die Blätter dem Lichte zuführen sollen, veranlassen. Ebenso bewirkt der Heliotropismus und Geotropismus der Wurzeln das Eindringen in die Erde.

Durch den WTechsel der Lichtintensität werden an Blättern verschiedener Pflanzen (Oxalis, Robinia, Astragalus, Lotus, Passiflora,

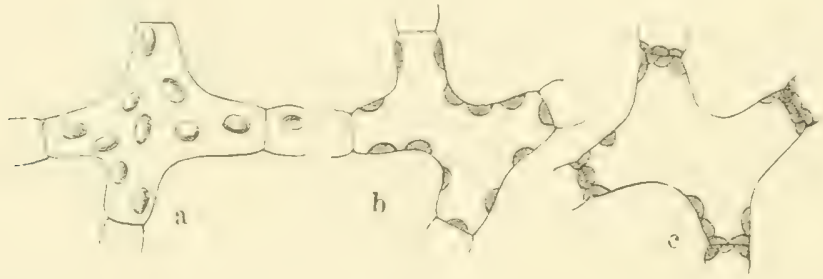

Fig. 141

Schwammparenchymzellen aus dem Blatte von Oxalis acetosella. Ansicht von der Blattfläche aus (n. Stahl).

Trifolium u. a.) Bewegungen hervorgerufen, welche darauf hinzielen, dic Blätter bei günstiger Beleuchtung horizontal, bei Verdunkeluug vertikal (aufwärts oder abwärts) zu stellen. Diese Erscheinung, Nyctitropismus genannt, ist unter dem Namen des Pflanzenschlafes schon lange bekannt. Der Wechsel der Lichtintensität bewirkt, dass sich die eine Hälfte des Gelenkpolsters an der Basis der Fiederblättchen der genannten Pflanzen stärker ausdehnt als die entgegengesetzte Seite. Sind diese Expansionsänderungen, resp. diese Bewegungen der Blätter einmal durch den Wechsel von Tag und Nacht induciert, so können sie auch noch längere Zeit bei kontinuierlicher Beleuchtung oder sleichmässiger Dunkelheit forthestehen, sie werden demnach zu periodischen Bewegungen.

Bemerkt sei noch, dass durch zu intensives Licht, z. B. bei Oxalis acetosella, ähnliche Bewegungen hervorgerufen werden können wie durch Verdunkelung.

Innerhalb der Zellen zeigen die Chlorophyllkörper Bewegungen, welche sowohl von der Lichtintensität, als von der Einfallsrichtung der Lichtstrahlen abhängig sind. Bei diffusem Licht wandern die Chlorophyll- 
körper an die der Aussenseite des Blattes parallelen Wände (Fig. I4I a), Bei stärkerem Licht bedecken sie die zu der Aussenfläche der Blätter senkrechten Wände (Fig. I4I b). Wirkt sehr starkes Licht längere Zeit ein, so ziehen sich die Chlorophyllkörper auf die vom Licht am wenigsten getroffenen Stellen zurück (Fig. I4I c). Zu gleicher Zeit erleiden die Chlorophyllkörper Formveränderungen, welche ebenfalls darauf hinzielen, eine für die Assimilation günstige Lichtintensivität zu erlangen und dem schädlichen Einfluss des sehr intensiven Lichtes auszuweichen. Schwärmende Algen werden durch das Lichtzu Ortsbewegungen veranlasst, um eine günstigeBestrahlung zu erlangen (Phototaxis).

\section{Chemische Reize.}

Dieselben kommen in sehr interessanter Weise bei den insektenfressenden Pflanzen zur Geltung. So wird bei Droseraarten durch die organischen Substanzen des Insektenleibes, aber auch durch andere Stoffe, namentlich Ammoniaksalze eine Einkrümmung der Tentakel (Fig. 63) hervorgerufen, welche zum Festhalten des Insektes und zur Aufnahme der organischen Nahrung notwendig ist. Eine weitere Folge des Reizes ist die Ausscheidung eines

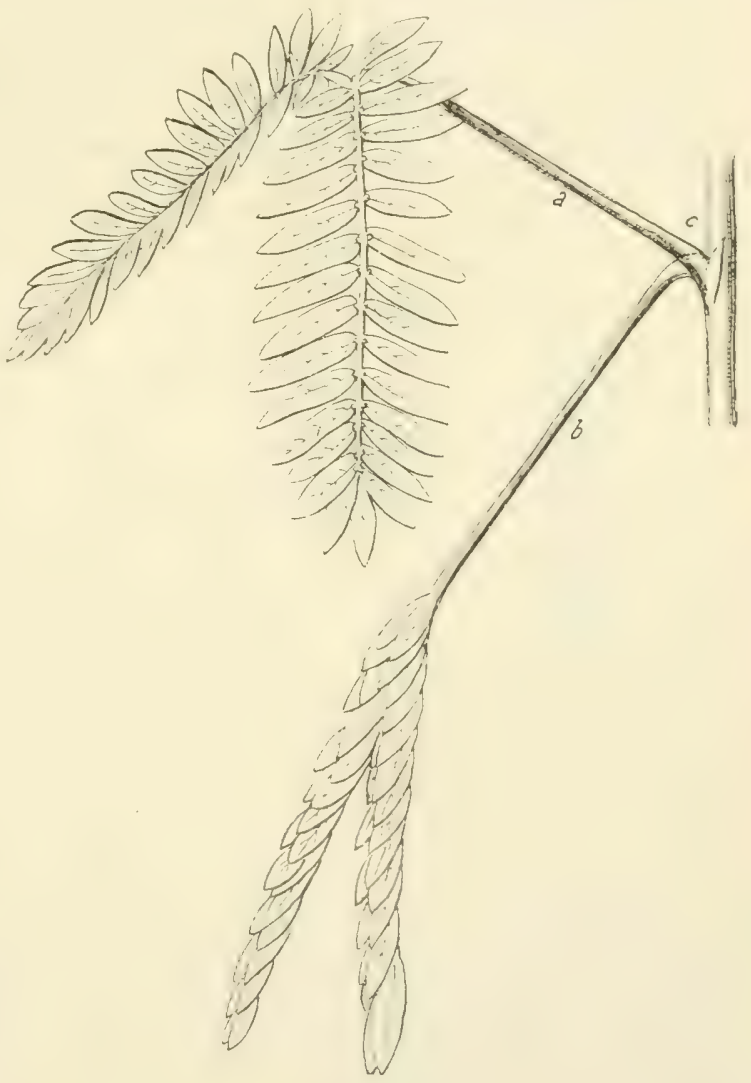

Fig. 142.

Mimosa pudica. a im ungereizten, . b im gereizten Zustand, c Blattgelenk (n. Pfeffer).

Verdauungsfermentes und

einer zur Wirksamkeit des letzteren notwendigen Säure. Diese Erscheinung ist nicht bloss bei Drosera, sondern auch bei anderen insektenfressenden Pflanzen Sarracenia, Nepenthes, Pinguicula etc. zu beobachten.

In anderer Weise wirken chemische Reize auf die Spermatozoiden von Moosen und Farnkräutern ein. Bestimmte, aus den Archegonien in sehr geringen Mengen austretende Stoffe, z. B. Apfelsäure, Zucker, lenken die Bewegungsichtung der vor den Archesenien vorbeischwimmenden 
Spermatozoiden in der Weise ab, dass die letzteren in der Richtung der höheren Konzentration dieser Stoffe abbiegen und so in den sehr feinen, engen Archegonhals und zum Ei gelangen.

Die Wurzeln wachsen nach dem einseitis zutretenden Sauerstoff hin, wenden sich jedoch von schädlichen Gasen, z. B. Leuchtgas ab (Aërotropismus).

\section{Mechanische Reize.}

Das bekannteste Beispiel bieten die Blätter der Sinnpflanze, Mimos a p) udica (Fis. I 42). Die Blattsticle sind im ungereizten Zustande nach aufwärts gerichtet, die Fiederblättchen ausgebreitet, durch einen Stoss klappen die Letzteren zusammen, die Blattstiele senken sich (Fig. I42 b). Es tritt

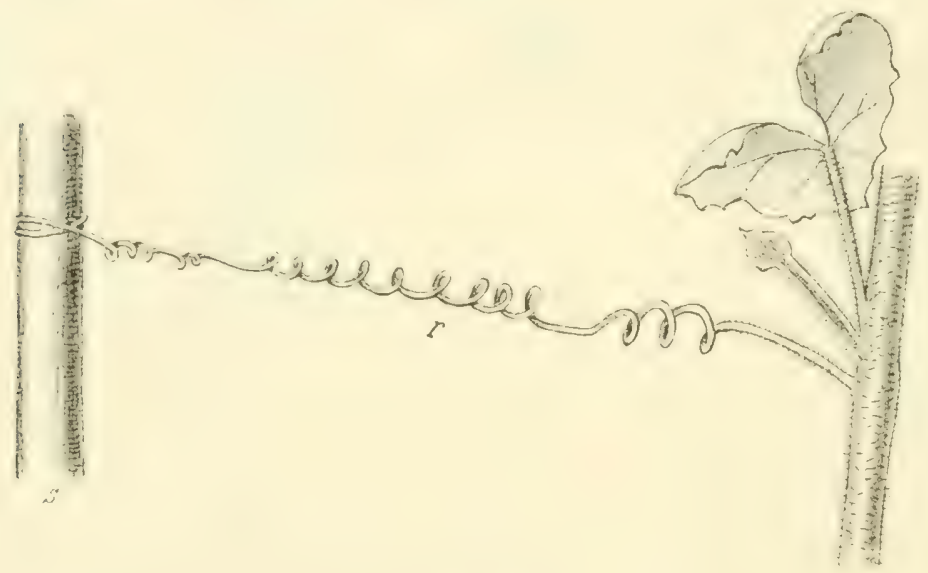

Fig. 143 .

Ranke von Bryonia dioica nach Ėfassen der Stütze (n. Pfeffer).

hier sehr deutlich hervor, dass derselbe Effekt durch verschiedene Reize ausgelöst werden kann, so durch den elektrischen Strom, plötzliche Verdunkelung oder Temperaturwechsel, ebenso durch schnelle Transpirationsänderungen oder dadurch, dass man ein Fiederblättchen in den Brennpunkt einer Linse bringt.

Die Staubgefässe von Sparmannia, Berberis, Cistusarten krümmen sich bei Berührung, ebenso treten infolge eines leichten Stosses bei Centaurea jacea Verkürzungen der Staubgefässe auf. Die genannten Bewegungen werden im Freien durch die blütenbesuchenden Insekten ausgelöst, welche hierdurch mit Pollen bestäubt werden, den sie auf andere Blüten übertragen.

Die Ranken der Pflanzen (vgl. S. 57 und 70) werden durch einen länger andauernden Kontakt mit einem festen Gegenstand zum Einkrümmen veranlasst. Zunächst krümmt sich das mit der Stütze in Berührung gekommene Rankenende ein und nachdem auf diese Weise der feste Gegenstand erfasst ist, rollt sich der übrige Teil der Ranke zu- 
sammen (Fig. I43), um die Pflanze an die betreffende Stütze heranzuziehen.

Bei Ampelopsisarten entstehen infolge des Kontaktes an der Spitze der Ranken Haftscheiben, die mit der Unterlage innig zusammenhängen und so die Pflanze an derselben befestigen.

\section{Andere Reize.}

Die Reizwirkungen im Pflanzenleben sind so zahlreich, dass wir dieselben hier. nicht erschöpfend behandeln können. Ich möchte daher nur kurz noch auf die Ablenkung der Wurzeln durch Feuchtigkeitsdifferenzen, durch VIasserströmungen, durch galranische Ströme hinweisen. Durch strahlende Wärme werden Bewegungen an Stengeln ausgelöst, ebenso wird das Öffnen und Schliessen der Blüten von Crocus und Tulipa durch Steigerung und Abfall der Temperatur hervorgerufen. Das Auswachsen schlafender Augen nach Verletzungen (vgl. S. I33) ist ebenfalls auf einen durch die Wunde ausgeübten Reiz zurückzuführen.

\section{S 44. Beschädigung und Tötung durch äussere Faktoren.}

Wir haben schon früher Gelegenheit gehabt, auf die Abhängigkeit der Ernährung von äusseren Bedingungen hinzuweisen. Sobald die gegebenen Verhältnisse für die Ernährung ungünstig sind, wird die Pflanze kränkeln, missfarbiş werden, eine unvollständige Ausbildung erfahren und unter Umständen vorzeitig absterben. Auf dieses Kränkeln einzugehen, liegt nicht in meiner Absicht, da ich schon im Vorhergehenden die Ernährungs - und Wachstumsbedingungen erläutert habe, es soll hier vielmehr auf die direkte schädliche Wirkung äusserer Faktoren eingegangen werden. Pilzkrankheiten vgl. \$ $47-54$.

\section{Frost.}

Die schädliche Wirkung des Frostes beruht einerseits auf dem Auskrystallisieren von Wasser aus den Zellen, anderseits auf einer Zerstörung der Protoplasmastruktur, ohne dass sich jedoch diese beiden Vorgänge genau trennen lassen. Es scheiden sich in den Intercellularräumen, oder in dem Lumen der Gefässzellen des Holzes, eventuell auch unter der Epidermis der Blätter Eiskrystalle aus. Nur bei sehr schneller Abkühlung kann in den lebenden Zellen selbst Eis gebildet werden. Durch diese Wasserabgabe, namentlich wenn die Temperatur nach der ersten Bildung von Eis noch weiter sinkt, können empfindliche Pflanzenteile direlit setëtet werden, indem mit dieser Wasserausscheiduns eine Zerstörung der Protoplasmastruktur Hand in Hand geht (Phajus grandifolius, Cucurbita Pepo, Impatiens balsamina etc.). Andere Pflanzen ertragen die Ausscheidung von Eis besser, sie werden eventuell durch den Wasserverlust welk (Hyacinthus), büssen ihr Leben jedoch erst dann ein, wenn sie schnell aufgetaut. werden. Die Wiederaufnahme des aus- 
seschiedenen Wassers geht in diesem Falle nur unvollständig vor sich, wodurch das Protoplasma in Mitleidenschaft gezogen wird. In strengen Wintern (z. B. I $879 / 80$ ) kann es vorkommen, dass sonst frostharte Bäume (Fichte, Weymuthskiefer) an Nordabhängen unversehrt bleiben, während sic an Süd- und Südwestabhängen geschädigt werden. Dieser sogs. Wintersonnenbrand diurfte auf das schnelle Auftauen gefrorener Pflanzenteile bei intensiver Sonnenwirkung zurückzuführen sein. Auch in normalen Wintern dïrfen frostempfindlichere Pflanzen auf diese Weise zu Schaden kommen. Für Frost sehr wenig empfindliche Pflanzen, so namentlich die im Hochsebirge oder im hohen Norden vorkommenden Arten, können auch wiederholtes Gefrieren und schnelles Auftauen ertragen. Die Nadelhölzern können bei lang andauernder Winterkälte, geringen Niederschlagsmengen und grösserer Lufttrockenheit auch durch Austrocknen leiden. Es gehen dann zumeist dic älteren Nadeln zu Grunde.

Die mit dem Frost verbundenen Wasserverschiebungen in den Zellen lassen es begreiflich erscheinen, dass wasserarme Pflanzenteile, wie Samen, Knospen nur wenig oder gar nicht durch Frost leiden. Die Winterkälte, welche dic Pflanzen zur Zeit der Vegetationsruhe trifft, ist daher im allgeminen wenig schädlich (Ausnahmen hiervon Juglans regia, Morus alba, Robinia, Pinus maritima).

Am empfindlichsten sind wasserreiche Pflanzenteile, besonders wenn sie, wie die Jugendzustände der Organe, mit zarten, unvollständig verdickten Membranen versehen sind. Am schädlichsten sind daher die im Frühjahre auftretenden Spätfröste. Tannen, Fichten, Buchen, Eichen, Eschen, Edelkastanien, Nkazien, Nussbäume, Naulbecrbätme sind segen Spätfröste sehr empfindlich, Ahorne, Ulmen und Linden leiden selten, während die Kiefernarten, Hainbuchen, Erlen, Birken gar nicht oder nur in sehr geringem Masse beschädigt werden. Je später eine empfindliche Holzart ausschlägt, desto leichter wird sie der Wirkung des Spätfrostes entgehen, ein Beispiel hierfür ist das günstigere Verhalten der Eichen (besonders von Quercus sessiliflora) gegenüber der früher ausschlagenden Buche.

Die Frühfröste (September - Oktober) werden besonders jene Holzpflanzen treffen, deren Wachstum sehr lange andauert, so dass der Frost noch ungenügend ausgereifte Triebe antrifft. Als empfindlich sind zu nennen: Pinus maritima, Robinia, Morus, Catalpa speciosa, Ailanthus glandulosa, in geringerem Grade auch Salix- und Populusarten. Ebenso werden die Johannistriebe (s. S. 164) leicht durch Frühfröste beschädigt.

Schliesslich seien noch die Barfröste erwähnt. Indem das im Winter und Frühjahre im Boden reichlich vorhandene Wasser gefriert, werden Bodenteile und mit ihnen schwache junge Pflanzen emporgsehoben. Nach dem Auftauen und dem Zurücksinken des Brodens liesen die Wurzeln entblösst auf der Oberfläche desselben. Diesem Ausfrieren sind die schon im ersten Jahre mit einer kräftigen Pfahlwurzel versehenen Pflanzen, 
wie Eiche, Kiefer etc. nicht ausgesetzt, während bei den schwächer bewurzelten Fichten und Tannen die Gefahr eine wesentlich grössere ist. Ebenso kann die Schwarzerle, welche besonders auf sehr feuchtem, lockerem, zum Auffieren geneigten Boden wächst, in der Jugend durch Barfrost leiden.

Im Stammholze verlieren die Zellwandungen durch den Frost einen Teil ihres Imbibitionswassers (vgl. S. 32), das Holz schwindet, und wenn die inneren Schichten des Holzes noch wenig durch den Frost berührt

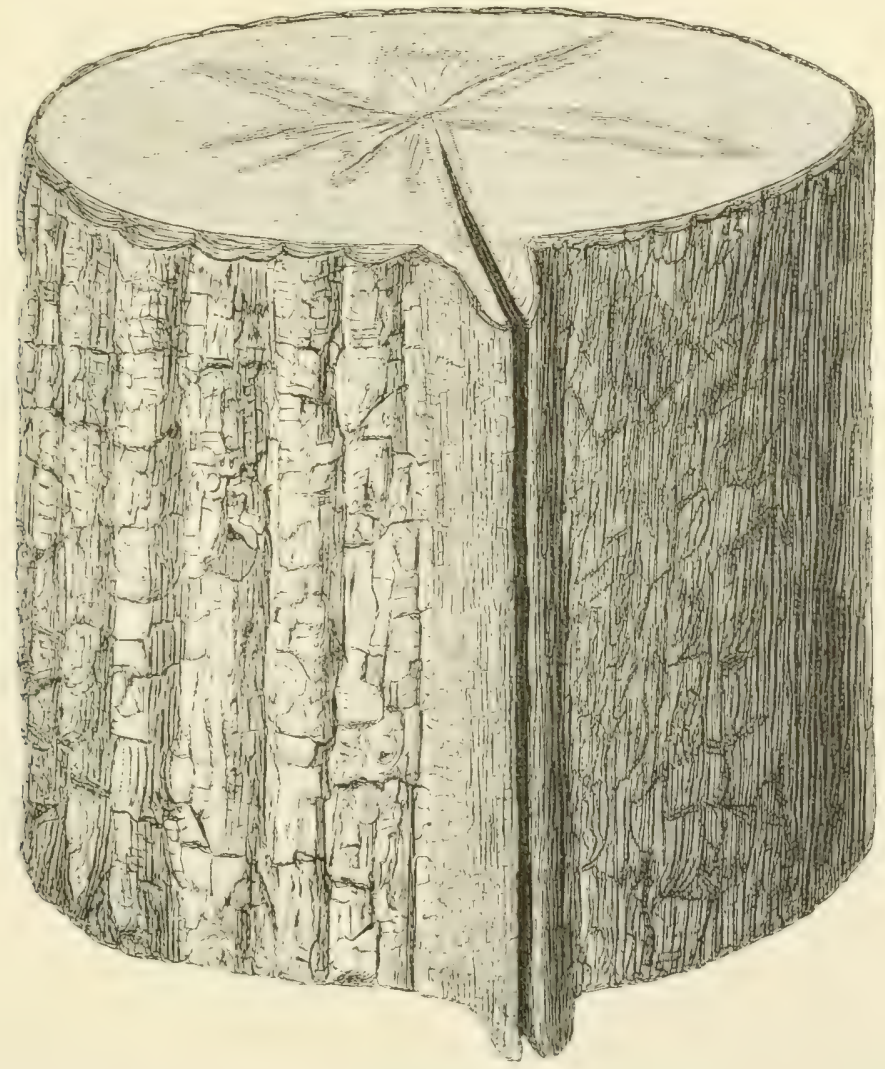

Fig. 144.

Frostleiste an einem Stamme von Acer campestre.

sind, so entstehen hierdurch Spannungen, die schliesslich zum Zerreissen der äusseren Schichten und zur Bildung der radial verlaufenden Frostrisse oder Frostspalten führen. Die letzteren schliessen sichjwieder, sobald die äusseren Schichten wasserreicher werden. Folgen mehrere milde Winter aufeinander, so wird der Frostriss durch Überwallung geschlossen, tritt jedoch wiederholt ein Aufreissen der dünnen Überwallungsschichten durch erneute Frostwirkung ein, so entstehen die sog. Firostle isten (Fig. I44). 
Durch den Frost kann die Rinde zum Abheben gebracht werden, wodurch peripherische Risse entstehen, die später durch Überwallung geschlossen werden. An Zweigen und Ästen, die während der Vesctationszeit von Spätfrösten ggetroffen werden, können derartige Lü̈cken mit Wucherungen des Jungholzes erfüllt werden, wodurch unter Umständen wulstige oder knollenartige Gebilde entstehen, eine Krankheit, die auch als Brand oder Krebs bezeichnet wird. Dabei ist jedoch zu bemerken, dass in den meisten Fällen wohl erst durch die Mitwirkung von Pilzen (rgl. Nectria ditissima) dic starke Wucherung der Wundränder hervorgerufen wird.

Das Aufrichten der Zweige bei Acer-Negundo, Pterocarya caucasica, ebenso wie die Senkung der Zweige bei Larix, Pinus Laricio, Pinus Strobus und Tilia parvifolia infolge des Winterfrostes hat keine nachteiligen Folgen. Die Zweige von Aesculus, Carpinus, Rhamnus cathartica senken sich bei scringerer Kälte und richten sich bei intensiverer Kälte auf.

Die Frostbeschädigungen treten besonders auf der Süd- und Südostseite auf. Es hat dies seinen Grund darin, dass diese Seiten früher erwärmt und zur Vegetation angeregt werden, daher wasserreicher sind und den Spätfrösten leichter unterliegen. Ausserdem sind die Pflanzen besonders an bestimmten Örtlichkeiten, auf den Frostlöchern und auf moorigfeuchtem Boden dem Erfrieren ausgesetzt.

Im Anschluss an die Frostwirkungen möge noch die Krankheit junger Kiefern besprochen werden, welche unter dem Namen der Kiefernschütte bekannt ist. Im Frühjahre oder zu Beginn des Sommers werden die Nadeln junger Kiefern rotbraun und sterben ab. An schwächlichen Kiefern und bei starkem Auftreten der Krankheit kann auch die ganze Pflanze eingehen. Ebenso können durch mehrjährige Wiederholungen der Schütte die Kiefern zu Grunde gerichtet werden. Das gefährlichste Alter ist das zweite bis vierte Jahr, doch können auch an älteren Exemplaren die Nadeln absterben.

Da die Ursachen der Schütte noch nicht genügend experimentell festgestellt sind, so führe ich im Folgenden die drei zur Zeit aufgestellten Hypothesen über die Entstehung an.

I. Es kann sich um eine direkte Wirkung des Frostes handeln (Nördlinger). Infolge von Frühfrösten (im September) färben sich die Kiefernnadeln häufig violettrot bis gelblichrot, ohne jedoch dabei abzusterben (vgl. S. I 5 und 64). Ich halte diese Färbung bei Pinus silvestris in sehr vielen Fällen für ein Symptom schlechter Ernährung, derartige Pflanzen dürften daher für die schädlichen Wirkungen der Atmosphäre und auch für Pilzinfektion empfindlicher sein, als besser genährte Kiefern, sie gehen aber nicht zu Grunde, wenn sie unter günstigen Bedingungen weiter wachsen. Junge Kiefernnadeln können allerdings auch durch Spätfröste getötet werden, da sie jedoch erst relativ spät austreiben, ist diese Gefahr von sehr geringer Bedeutung. 
2. Gefährlicher ist für die jungen Kiefern eine starke Besonnung im Frühjahre, solange noch der Boden gefroren ist und demnach die Wasseraufnahme (vgl. S. I 50) sehr erschwert ist. Durch die direkte Insolation wird die ITasserverdunstung sehr sesteigert, es kann deshalb bei unsenügender Wasserzufuhr der Tod durch Vertrocknen herbeigeführt werden (Ebermayersche Theorie). Die.Spitzenteile der Nadeln leiden stärker als die basalen Teile, doch bleibt eine an der Spitze vertrocknete Nadel nicht am Leben. Die rotbraune Färbung der Nadeln tritt erst später bei längerer Besonnung auf. Pilzmycel oder Sporenfrüchte sind hier anfangs noch nicht vorhanden, können sich jedoch nach dem Absterben einstellen, da der Pilz der Kiefernnadeln Lophodermium (Hysterium) Pinastri, ausserordentlich verbreitet ist.

3. Die dritte Erklärung der Schütte, von Göppert herrührend, führt diese Krankeit auf die Infektion durch den oben genannten Pilz Lophodermium Pinastri zurück. Durch künstliche Infektionsversuche ist allerdings dargethan, dass unter Umständen die Nadeln durch den Pilz getötet werden können. Es ist daher sehr wahrscheinlich, dass auch in der Natur Kiefernnadeln durch den Pilz direkt zum Absterben gebracht werden können. Die Infektionsgefahr ist bei der grossen Verbreitung des Pilzes an den alten Kiefern eine sehr bedeutende. Wenn daher die Schütte an den jungen Kiefernpflanzen überhaupt fehlt, darf man wohl annehmen, dass dieselben nur unter bestimmten Bedingungen der Infektion zugänglich sind. Das Absterben der vom Pilze ergriffenen Nadeln wird durch Besonnung und stärkere Erwärmung beschleunigt, so dass dasselbe unter ähnlichen Bedingungen wie bei 2 auftreten kann.

Die Entwickelung des Pilzes siehe § 50.

Solange die Ursachen der Schütte noch nicht genügend aufgeklärt sind, dürfte auch den Vorbeugungsmassregeln gegen dieselbe kein allzugrosser Wert beizumessen sein.

\section{Höhere Temperatur. Austrocknen von Pflanzenteilen.}

Wasserreiche Organe werden bei Temperaturen zwischen $45-52^{\circ} \mathrm{C}$. schon nach IO-30 Minuten getötet. Auf ganz kurze Zeit kann eventuell eine etwas höhere Temperatur ohne Schaden ertragen werden. Trockne Samen, sowie Pflanzen, welche durch das Austrocknen nicht leiden (manche Flechten und Moose) können ohne Schaden auch einer noch stärkeren Erwärmung ausgesetzt werden. Gewisse Bakteriensporen werden selbst durch Siedehitze nicht getötet.

Gegen die bedeutende Temperaturerhöhung, wie sie eine intensive Bestrahlung oder ein Brand des Bodengestrüppes mit sich bringt, sind die Stämme mit dicker Borke besser geschützt als die dünnrindigen Holzpflanzen. Die dünne Rinde von Fagus, Carpinus, Acer, Picea, Abies, Pinus strobus kann infolge intensiver Sonnenwirkung absterben, welche Erscheinung man als Rindenbrand bezeichnet (vgl. S. I33). Derselbe tritt namentlich an der Südwestseite der Stämme auf. Besonders em- 
pfindlich sind plötzlich freisestellte Stämme. Durch die Sonne können anch Risse in der Rinde entstehen, die sich jedoch nur selten wie die Frostrisse ins Holz fortsetzen. Bei intensiver Besonnung erwärmt sich die Rinde der Bäume sehr bedeutend, trotzdem wäre es möglich, dass das Absterben der Rinde durch Austrocknen und nicht allein durch die Temperaturerhöhung herbeigefuhrt würde. Das Absterben der Blätter und die vorzeitige Entlaubung der Bäume bei starker Besonnung dürfte weniser durch die Erwärmung als durch den starken Wasserverlust herbeigefuhrt werden. Da die Blattnerven Wasser zuführen, so vertrocknen zunächst die Randpartien des Blattes und die zwischen den Blattnerven liegenden Teile. Herrscht während der Blütezeit Trockenheit, so fallen namentlich an Obstbäumen die Blüten in grösserer Menge ab.

Für Hitze und die damit zusammenhängende Trockenheit der Luft sind besonders empfindlich Abies, Pinus cembra, Fagus, Tilia, Fraxinus, Alnus glutinosa. In geringerem Masse leiden Pinus maritima, Larix, Acer, Carpinus.

Junge Wurzelteile, welche noch nicht mit einer Korkschicht bedeckt sind, vertrocknen sehr leicht. Die Pflanze verliert hicrdurch die wasseraufnehmenden Organe und kann bei grösserer Trockenheit leicht zu Grunde gehen. Keimlinge von Bäumen werden daher mit Vorteil zeitig im Frühjahr verpflanzt, weil dann der Boden noch sehr wasserhaltig ist, die Wasserverdunstung durch die oberirdischen Teile noch nicht so gross ist und ausserdem (vgl. S. 165) die Neubildung von Wurzeln besser vor sich geht. Bei dem Pflanzen selbst muss jedes längere Verweilen der jungen Wurzeln in trockner Luft vermieden werden.

Ebenso wirkt das Austrocknen angekeimter Samen, namentlich wenn sie vorher sehr feucht gehalten wurden, schädlich.

\section{Gifte.}

Die meisten Stoffe können, sobald sie reichlich in Wasser löslich sind, schädlich wirken, wenn sie der Pflanze im Übermasse zugeführt werden. Dies gilt auch von Düngemitteln (z. B. frischer Jauche) und sonst der Pflanze zuträglichen Nahrungsstoffen, wie mineralischen Bestandteilen oder Kohlensäure. Als Gifte können wir Substanzen jedoch erst dann bezeichnen, wenn sie schon in geringer Menge das Leben der Pflanze gefährden.

Praktisch grössere Bedeutung gewinnt die giftige Wirkung des von industriellen Anlasgen ausgehenden Rauches. Derselbe wirkt hauptsächlich nur durch den Gehalt an schwefliger Säure giftig. Schon bei einem Gehalt von $1 / 50000$ des Luftvolumens an schwefliger Säure tritt eine Zerstörung der Blätter ein, welche sich zunächst als eine Gelbfärbung namentlich der Randpartien seltend macht. Die siftige Mirliung steigert sich, je länger die Blätter dem Rauch ausgesetzt sind. Aus diesem Grunde leiden die Nadelhölzer mehr als die Laubhölzer, welche jedes 
Jahr ihre Blätter abwerfen. Bei längerer Einwirkung kann Luft, die nur 1/1000000 schweflige Säure enthält, şiftig wirken. Eine Beschädigung durch Rauch kann durch den Nachweis der schwefligen Säure in den Blättern constatiert werden.

In geringerem Grade kann auch der Chlorgehalt des Steinkohlenrauches für die Vegetation gefährlich werden.

Trotzdem behauptet wird, dass die Russteilchen des Rauches den Pflanzen nicht schädlich sind, ist doch zu bedenken, dass bei grösseren Rauchmengen die Spaltöffnungen des Blattes verstopft werden, wodurch die Funktion der Blätter eine Störung erfahren muss, wenn auch hierdurch allein der Tod nicht herbeigeführt wird.

Bei manchen Fabrikationszweigen können auch kleine Teilchen von kohlensaurem Natron in die Umgebung gelangen. Die Blätter der getroffenen Pflanzen werden hierdurch fleckig.

\section{Schnee, Duft, Eis, Hagel.}

Es handelt sich hier um die mechanischen Beschädigungen durch die genannten atmosphärischen Einflüsse.

Ein flockiger, wässeriger Schnee, der während einer milden Wintertemperatur und bei geringer Luftbewegung fällt, haftet leichter auf den Bäumen, als ein feinkörnig nadelförmiger Schnee. Ist einmal eine Schneedecke über die Bäume ausgebreitet, so kann die Schneelast durch weitere Niederschläge, sei es nun Schnee, Reif oder Eis vergrössert werden. Fest gefrorene Bäume sind spröder und brechen höher oder tiefer unter der Schneelast zusammen (Schneebruch). Bestände, die häufig von Schneebruch heimgesucht werden (in Schneebruchregionen) zeigen krüppelhaften Wuchs und zahlreiche Wipfel, indem (besonders bei Nadelhölzern) Seitenäste aufrecht weiter wachsen, nachdem der ursprünglich vorhandene IVipfel abgeknickt ist. Sind die Bäume infolge des höheren W'assergehaltes bei geringeren Kältegraden biegsamer, so werden sie durch den Schnee zur Erde gezogen ( $\mathrm{Schneedruck}$ ) oder umgeworfen. Das letztere tritt namentlich ein, wenn der Boden noch nicht stark gefroren ist oder die Pflanze nur flach wurzelt. Bei Jungbeständen ist Schneedruck häufiger als Schneebruch. Die Gefahr des Brechens ist von der Beschaffenheit des Holzes und der Belaubung abhängig. Nadelhölzer sind durch den Schnee mehr gefährdet, weil ihre Benadelung ein Haften des Schnees erleichtert. Sehr stark werden Pinus silvestris, Pinus Laricio, Picea excelsa beschädigt, weniger Abies pectinata, während Pinus strobus, Pinus cembra und nach vollständiger Entlaubung auch Larix europaea dem Schnee- und Eisanhang gut widerstehen. Unter den Laubhölzern leiden Akazien und Erlen am meisten, doch werden auch Hainbuchen, Rotbuchen, Eichen, Pappeln und Obstbäume nicht verschont. Eine relativ umfangreiche Ausbildung der Krone, sowie das Verbleiben abgestorbener Blätter an den Bäumen kommt ebenfalls für die Gefahr des Schneebruchs in Betracht. Dichtere gleichaltrige Bestände leiden mehr als gemischte. 
Duftanhang (Winterreif, Rauhreif, Haarfrost) schlägt sich vorzugsweise aus feuchter, nebeliger Luft auf den Zweigen in Form feiner Eiskiryställchen und Nadeln nieder. Derselbe kann namentlich in engen Thälern, sowic im Gebirge ein so bedeutendes Gewicht erlangen, dass ähnliche Erscheinungen wie bei den Schneebeschädigungen auftreten.

Eis anhang bildet sich dann, wenn aus höheren, wärmeren Luftschichten ein wässeriger Niederschlag auf Pflanzen fällt, die sich in einer flachen, kalten, ruhig lagernden Luftschicht befinden. Für gewöhnlich bilden sich nur dünne, durchsichtigse Eiskrusten. Unter Umständen können jedoch die feinsten Ästchen mit so viel Eis umhüllt sein, dass sie den Umfang derber Schiffstaue erreichen. Eine derartige, viele Zentner betragende Last stürzt und bricht einen Baum, wenn sie nur an der einen Seite des Baumes gebildet wird, so an Randbäumen von Beständen. Die von den Ästen herabhängenden, schweren Eiszapfen können jedoch mit darunter liegenden Ästen verschmelzen und sich auf die Erde stützen, so dass ein derartig vereister Bestand das Aussehen einer Tropfsteinsrotte erlangt. Eine derartige hochgradige Vereisung tritt jedoch nur äusserst selten auf.

Der Hagel kann an Bäumen und krautigen Pflanzenteilen ziemlich bedeutenden Schaden anrichten. Blätter und krautige Stengel werden durchlöchert und geknickt und zwar leiden sie um so stärker, je weniger sie durch Ausbiegen dem Schlage ausweichen können. Junge Zweige ron Holzpflanzen werden entweder geknickt oder es entstehen rundliche Wunden, die Rinde wird aufgerissen oder doch durch das Hagelkorn gequetscht und lokal zum Absterben gebracht. Wenn offene Hagelwunden auch später überwallen, so bieten sie doch eine Eingangspforte für Pilze, wie denn auch der Holzkörper an diesen Stellen meist gebräunt ist.

\section{Sturm.}

Flachwurzelige Bäume, wie z. B. die Fichte, oder zähholzige Arten wie Birke, Hainbuche, Rotbuche, werden durch einen starken Sturm entwurzelt und geworfen (Windwurf), an Bäumen mit Pfahlwurzeln dagegen wird der Wipfel in geringerer oder grösserer Höhe abgebrochen (Windbruch). Ausserdem werden durch den Wind besonders in höheren exponierten Lagen Äste abgeknickt, und zwar sind die der herrschenden Windrichtung entgegengesetzten Äste am meisten gefährdet. Da bei uns zumeist von Westen kommende Winde vorherrschen, so bleiben in Regionen mit starkem Wind häufig nur die Äste der Ostseite erhalten, wodurch die Bäume ein fahnenartiges Aussehen erlangen. Ausserdem wird an freistehenden Bäumen durch andauernde Wirkung von Winden der Stamm gebogen, er wird säbelwüchsig oder er nimmt, wie z. B. viele Obstbäume an Chausseen, ein schiefe Lage an.

\section{Blitzschlag.}

Trifft der Blitz nur einzelne Bäume, so wird häufig die Rinde rinnen- 
förmig aufgerissen, einzelne Streifen und Fetzen losgelöst. Verlaufen die Holzfasern in spiraliger Richtung, so kann auch die Blitzrinne spiraliss den Baum umfassen, denn der Blitz wird vorzugsweise in der Längsrichtung der Holzelemente fortgeleitet, wenn hierdurch auch radiale und tangentiale Zerklüftungen nicht ausgeschlossen sind (z. B. bei der Eiche).

Ebenso wie der Blitz sich auf eine grössere Anzahl von Zweigen verteilen kann, werden manchmal auch ganze Baumgruppen vom Blitze getroffen. Sind dieselben durch den Blitz weniger beschädigt, so gehen sie oft erst nach mehreren Jahren zu Grunde. Der Blitz kann demnach den sofortigen Tod eines Baumes zur Folge haben oder nur einzelne Partien, namentlich des Cambiums und der Rinde, zum Absterben bringen.

Andere mechanische Beschädigungen sowie die Bedeutung und Ausheilung der Wunden siehe $\S 3$ I. 


\section{Systematik.}

\section{\$4. Übersicht über das System.}

Die Species, Art, ist die Vereinigung der einander ähnlichen, in allen wesentlichen Merkmalen übereinstimmenden Pflanzenindividuen. Die verschiedenen Species werden unter den nächst höheren Begriff des Genus, der Gattung, zusammengefasst. Bei der wissenschaftiichen Benennung wird der Gattungsname (z. B. Quercus) dem Speciesnamen (z. B. pedunculata) vorangesetzt.

Das Pflanzensystem, welches aus Reihen, Klassen, Ordnungen, Familien, Gattungen und Arten besteht, kann nach verschiedenen Prinzipien aufgestellt werden. Die künstlichen Systeme berücksichtigen nur einzelne besonders auffallende Eigenschaften, um die verschiedenen Abteilungen zu bilden. So könnte man die Pflanzen nach der Färbung der Organe in Ordnungen etc. bringen, diese wieder nach dem Umfang der Organe oder einem anderen Merkmal in Familien einteilen u. s. w. Derartige künstliche Systeme sind nur dann wertvoll, wenn es gilt, eine möglichst leichte C̈bersicht über den ganzen Formenreichtum der Pflanzen zu gewinnen. Das bekannteste und beim Bestimmen von Phanerogamen gute Dienste leistende künstliche System ist das von Linnée, bei welchem die Zahl und Stellung der Staubgefässe als Einteilungsprinzip verwendet wurde.

Im Gegensatz zu den künstlichen Systemen soll das natürliche System den natürlichen Zusammenhang der einzelnen Pfanzen, ihre innere Verwandtschaft darstellen. Im Verlaufe ausserordentlich langer Erdperioden haben sich die höheren Pflanzen aus niedriger stehenden Formen entwickelt. Durch das natürliche System soll nun diesem genetischen Zusammenhang Rechnung getragen werden. Die uns vorliegenden Familien und Ordnungen sind vielfach die Endglieder von Entwickelungsreihen, die auf einen gemeinsamen Ursprung hinweisen, deren Zwischenglieder uns aber verloren gegangen sind, es ist daher nicht immer leicht, die wirkliche innere Verwandtschaft zu erkennen, auch wenn wir alle Eigenschaften und die Entwickelungsgeschichte der Organe berücksichtigen. 
Um den Gang der Entwickelung und den Zusammenhang der einzelnen Abteilungen zu verstehen, müssen wir aus den auf niedrigerer Stufe stehen gebliebenen Familien auf ähnliche Ursprungsglieder schliessen.

Die eben angedeuteten Umstände bringen es mit sich, dass dem subjektiven Ermessen jedes einzelnen Systematikers ein ziemlich bedeutender Spielraum gelassen ist. Wir haben daher statt des einen theoretisch nur möglichen natürlichen Systems in der Wissenschaft eine ganze Anzahl sog. natürlicher Systeme.

Unter vielen anderen stellten natürliche Systeme auf: Bernard de Jussieu (I759), Antoine Laurent de Jussieu (I789), Aug. Pyrame Decandolle (I813), Endlicher (1836), Bentham und Hooker (1862). Das System von Bentham und Hooker entspricht im wesentlichen unseren heutigen Anschauungen, wurde jedoch im einzelnen vielfach verändert und verbessert.

Ich folge in der Anordnung der Hauptgruppen des Pflanzensystems der von De Bary gegebenen Übersicht, wobei jedoch die Pilze ausgenommen wurden, die nach $\mathrm{Brefeld}$ in anderer Weise zu natürlicheren Gruppen vereinigt werden müssen. Im übrigen acceptiere ich das von Eug. Warming ausgearbeitete, und in seinem Handbuch der Botanik (Berlin I890) niedergelegte System.

\section{Reihe. Thallophyta, Lagerpflanzen.}

I. Klasse. Schizophyceae, Spaltpflanzen.

I. Ordn. Schizomycetes, Spaltpilze oder Bakterien.

2. Ordn. Cyanophyceae, Spaltalgen.

2. Klasse. Chlorophyceae, Grünalgen.

I. Ordn. Confervaceae.

2. Ordn. Volvocaceae.

3. Ordn. Cladophoraceae.

4. Ordn. Siphoneae.

3. Kiasse. Conjugatae.

4. Klasse. Diatomeae, Kieselalgen.

5. Klasse. Phaeophyceae, Braunalgen.

6. Klasse. Rhodophyceae oder Florideae, Rotalgen.

7. Klasse. Characeae, Armleuchtergewächse.

8. Klasse. Myxomycetes, Schleimpilze.

9. Klasse. Oomycetes.

I. Ordn. Peronosporaceae.

2. Ordn. Saprolegniaceae.

3. Ordn. Chytridiaceae.

4. Ordn. Entomophthoraceae.

Iо. Klasse. Zygomycetes.

I. Ordn. Mucoraceae.

2. Ordn. Chaetocladiaceae.

3. Ordn. Piptocephalideae. 
11. Klasse. Ascomycetes, Schlauchpilze.

I. Gymnoasceac.

2. Perisporiaceac.

3. Pyrenomycetes, Kermpilze.

4. Ordn. Discomycetes, Scheibenpilze.

Anhang: Lichenes, Flechten.

12. Klasse. Ustilaginea e, Brandpilze.

13. Klasse. Uredineae, Rostpilze.

14. Klasse. B a s idiom y cetes.

I. Ordn. Protobasidiomycetes.

2. Ordn. Autobasidiomycetes.

I. Unterordn. Hymenomycetes.

2. Unterordn. Gastromycetes.

2. Reile. Bryophyta oder Muscineae, Moose.

I. Klasse. Hepaticae, Lebermoose.

I. Ordn. Marchantieae.

2. Ordn. Anthoceroteae.

3. Ordn. Jungermannieac.

2. Klasse. Musci frondosi, Laubmoose.

I. Ordn. Sphagna, Torfmoose.

2. Ordn. Schizocarpae, spaltfrüchtige Laubmoose.

3. Ordn. Cleistocarpae, schliessfrüchtige Laubmoose.

4. Ordn. Stegocarpae, deckelfrüchtige Laubmoose.

3. Reihe. Pteridophyta, Farnpflanzen oder Gefässkryptogamen.

I. Klasse. Filic inae, Farne.

I. Ordn. Filices, eigentliche Farne (isospor).

2. Ordn. Hydropterides, Wasserfarne (heterospor).

2. Klasse. Equisetinae, Schachtelhalme (isospor).

(Heterospore Schachtelhalme ausgestorben.)

3. Klasse. Ly c o p od in a e, Bärlappgewächse.

I. Ordn. Lycopodiaceae (isospor).

2. Ordn. Selaginelleae (heterospor).

\section{Reihe. Gymnospermae, Nacktsamige.}

I. Klasse. Cycadeae, Cycadeen.

2. Klasse. Coniferae, Nadelhölzer.

I. Ordn. Taxoïdeae.

2. Ordn. Pinoïdeae.

3. Klasse. Gnetaceae. 


\section{Reihe. Angiospermae, Bedecktsamige.}

I. Klasse. Monocotyledones. Einkeimblättrige.

I. Ordn. Helobieae.

2. Ordn. Glumiflorae.

3. Ordn. Spadiciflorae.

4. Ordn. Enantioblastae.

5. Ordn. Liliiflorae.

6. Ordn. Scitamineae.

7. Ordn. Gynandrae.

2. Klasse. Dicotyledones. Zweikeimblättrige.

I. Unterklasse. Choripetalae. Freikronblättrige.

I. Ordn. Saliciflorae. Weidenblütige.

2. Ordn. Querciflorae. Eichenblütige.

3. Ordn. Juglandiflorae. Wallnussblütler.

4. Ordn. Urticiflorae. Nesselblütige.

5. Ordn. Polygoniflorae. Knöterichblütler.

6. Ordn. Curvembryae. Gekrümmtkeimige.

7. Ordn. Cactiflorae. Kaktusblütler.

8. Ordn. Polycarpicae. Vielfrüchtige.

9. Ordn. Rhoeadinae. Mohnblütige.

Io. Ordn. Cystiflorae. Cystusblütige.

II. Ordn. Gruinales. Storchschnabelgewächse.

12. Ordn. Columniferae. Säulenblïtler.

I3. Ordn. Tricoccae.

I4. Ordn. Therebinthinae.

15. Ordn. Aesculinae.

I6. Ordn. Frangulinae.

17. Ordn. Thymelaeinae.

I8. Ordn. Saxifraginae.

19. Ordn. Rosiflorae. Rosenblütige.

20. Ordn. Leguminosae. Hülsenfrüchtige.

21. Ordn. Passiflorinae. Passionsblütige.

22. Ordn. Myrtiflorae. Myrtenblütige.

23. Ordn. Umbelliflorae. Doldengewächse.

24. Ordn. Hysterophyta.

2. Unterklasse. Sympetalae. Vereintkronblättrige.

A. Pentacyclicae. Fünfkreisige.

I. Ordn. Bicornes.

2. Ordn. Diospyrinae.

3. Ordn. Primulinae.

B. Tetracyclicae. Vierkreisige.

4. Ordn. Tubiflorae. Röhrenblütige.

5. Ordn. Personatae. Maskenblütler. 

6. Ordn. Nuculiferac. Nussträser.
7. Ordn. Contortae. Gedrehtkronige.
S. Ordn. Rubiales. Krappblütige.
9. Ordn. Campanulinae. Glockenblïtler.
Io. Ordn. Aggregatae. Dichtblütigse.

In anderen Systemen wird bei den Thallophyten auf die Ernährungsweise ein grösseres Gewicht gelegt und die Thallophytenreihe demnach in Algae, Algen und Fungi, Pilze geteilt. Zu den Algen rechnet man in diesem Falle die Ordnung der Cyanophyceac, und die Klassen der Conjusatal, Diatomeac, Chlorephyceac, Phacophyceac, Rhodophyceac, da sie selbständig assimilieren (\$ 33), als Pilze werden Schizomycetes, Myxomycetes, Oomycetes, Zygomycetes, Ascomycetes, Ustilagineae, Uredineae und lasidiomectes zusammensefasit, welche sich nur durch die Aufnahme organischer Verbindungen ernähren (s. S. I43).

\section{§ 46. Schizophyceae. Algae.}

Für die Beurteilung der Verwandtschaftsverhältnisse ist in erster Linie die Ausbildung der Fortpflanzungsorgane von Wichtigkeit.

Sehen wir vorläufig von den Pilzen ab, so kann man sechs Stufen der Ausbildung dieser Organe aufstellen, welche durch die Tabelle auf der folgenden Seite veranschaulicht werden sollen.

Bei der untersten Stufe, den Agamae, fehlt die geschlechtliche Fortpflanzung vollständig. Bei den Isogamen sind die sich vereinigenden Geschlechtszellen gleich gestaltet. Als Beispiel hierfür sei der Entwickelungsgang der zu den Chlorophyceen gehörigen Ulothrix zonata (Fig. I45) angeführt. Der Inhalt der Zellen eines Algenfadens (A) kann sich in mehrere (2-8) Portionen teilen (B). Die letzteren treten nach Aufreissen der Mutterzellwand aus und bilden Schwämsporen (Zoosporen) (C), die sich mit Hilfe von vier Wimpern im Wasser fortbewegen, bis sie zur Ruhe gelangen und zu einer neuen Algenpflanze auswachsen (D, E). Ausser diesen Makrozoosporen können sich durch fortsesetzte Teilungen auch kleinere zweiwimperige Schwärmsporen in grösserer Anzahl bilden (Mikrozoosporen oder Gameten, F). Dieselben sind ebenfalls direkt keimfähig $(\mathrm{H})$, können aber auch mit den Mikrozoosporen anderer Zellen kopulieren $(G)$. Das Vereinigungsprodukt beider Gameten wird als Zygospore $(G)$ bezeichnet, die sich mit einer Haut umgiebt $(J)$ und zunächst in einen Ruhezustand übergeht. Bei der Keimung zerfällt der Inhalt der Zygospore, es bilden sich (K) mehrere Makrozoosporen, welche zu Algenfäden auswachsen. Diese Kopulation gleichgestalteter Zellen repräsentiert die niedrigste Form eines Geschlechtsaktes. Erstens ist noch kein Unterschied zwischen männlichen und weiblichen Produkten vorhanden, zweitens besitzen die Geschlechtszellen noch die Fähigkeit, auch ohne Kopu- 


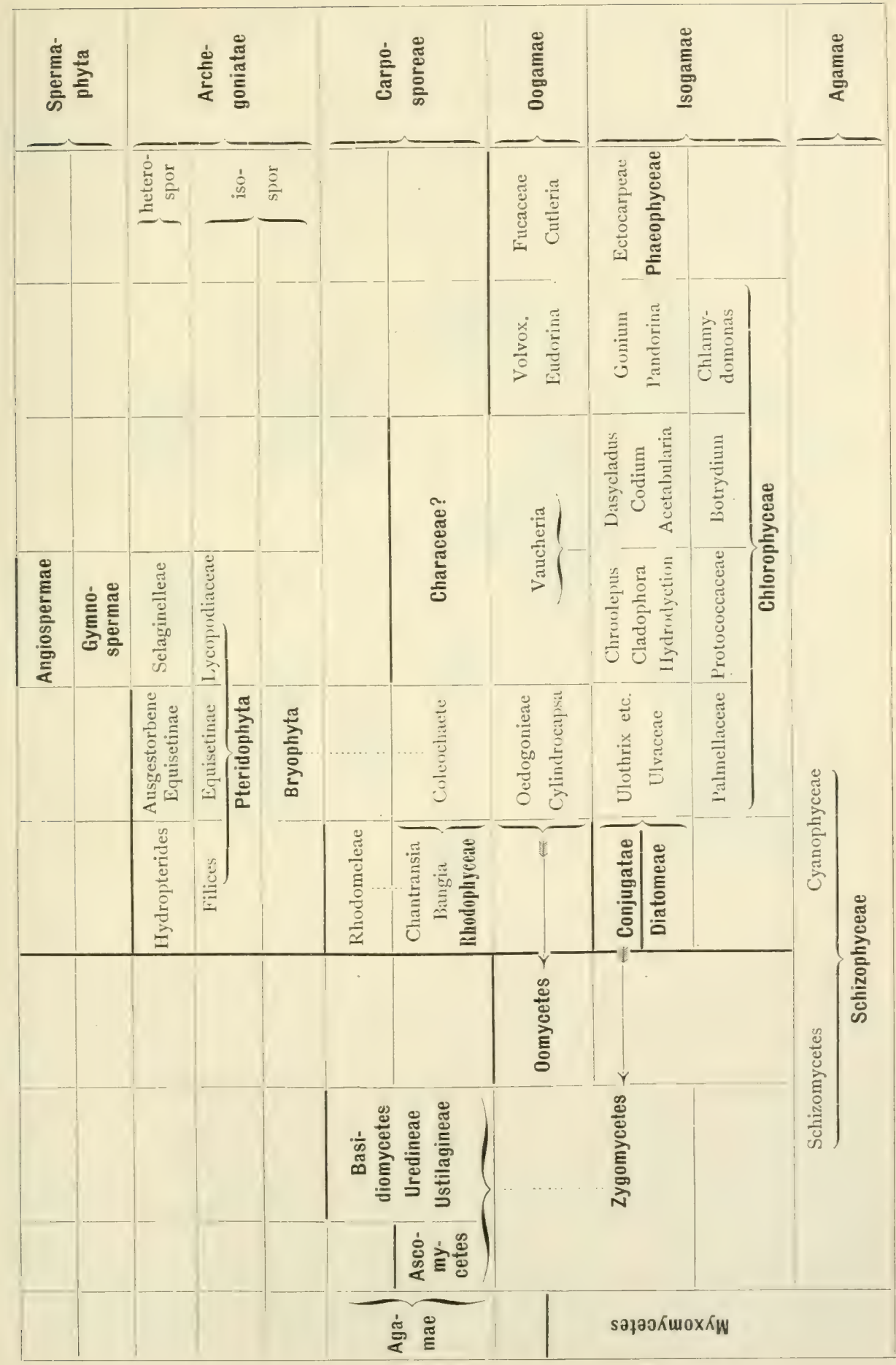


lation weiter zu wachsen. Ferner ist hervorzuheben, dass die auf ungeschlechtlichem Wege entstandenen Makrozoosporen (B, C) von den Geschlechtszellen nur sehr wenigs abweichen.

Bei anderen isogamen Pflanzen bilden sich die Zygosporen durch Kopulation unbeweglicher Zellen, wofür Spirogyra als Beispiel angeführt werden möge (Fig. 146). Zwei Algenfäden legen sich hicr aneinander, zwischen denselben wird cine Verbindungsbrücke gebildet, durch welche dic Kopulation des Inhaltes beider Zellen ermöglicht wird.
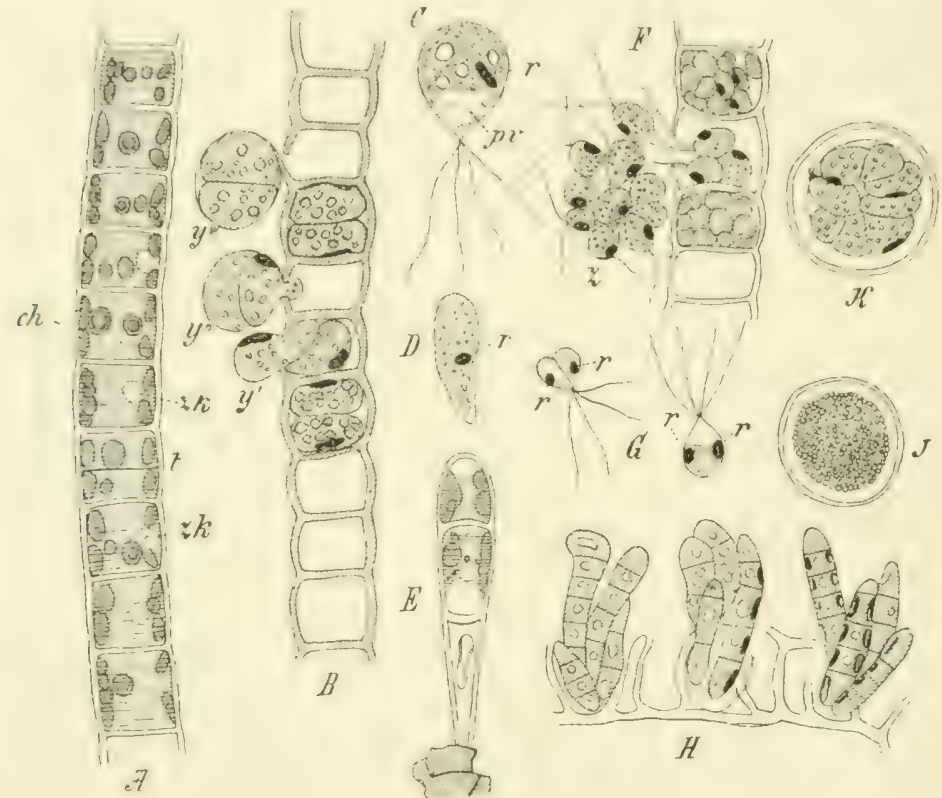

Fig. I 45 .

Fortpflanzung von Ulothrix zonata (n. Dodel).

Bei den Oogamen sind männliche und weibliche Zellen verschieden ausgebildet. Das meist grössere Ei entsteht in dem Oogonium, die Samenliörper bilden sich in Antheridien. Der befruchtende Stoff ist entweder der Inhalt einer im Vergleich zum Oogonium kleineren Zelle (Antheridium) oder der Inhalt dieser Antheridienzelle teilt sich in zahlreiche kleinere Portionen, d. h. bewegliche Spermatozoiden. Nach der Befruchtung umgiebt sich das Ei mit einer festen Haut und wird so zur Oospore. Diese Oospore kann direkt nach der Keimung zu einer neuen Pflanze werden (Fucaceen), häufiger jedoch teilt sich ihr Inhalt in einige oder zahlreiche Zellen, welche als Schwärmzellen austreten und nun erst zu neuen Individuen heranwachsen. Diese Schwärmzellen sind im Gegensatz zu den Oosporen auf ungeschlechtlichem Wege entstanden. Hierdurch ist das Vorhandensein zweier Generationen angedeutet, ein Um- 
stand, der bei der Ableitung der höheren Pflanzen von den niedrigeren Pflanzen von der grössten Wichtigkeit ist. Wir haben eine geschlechtliche Generation, die Oogonien und Antheridien produzierende Algenpflanze und eine ungeschlechtliche Generation, die Oospore, welche durch einfache Zellteiluns, also auf ungeschlechtlichem VTegse Schwärmzellen bildet. Nicht bei allen Oogamen sind zwei derartige Generationen vorhanden.

Bei den Carposporeen (vgl. Tabelle S. I 87 ) wird eine Sporenfrucht (Sporocarpium) gebildet, die aus fertilen, sporenbildenden und sterilen Zellen besteht. Die niederen Formen der Carposporeen (z. B. Coleochaete) weisen eine den Oogamen ähnliche Eizelle auf, die jedoch mit einer Hülle von sterilen Zellen umgeben ist. Bei Coleochaete (Fig. I47) zeigt die Eizelle (o) einen langen Schlauchfortsatz, welcher zur Aufnahme des Spermatozoids dient. Die letzteren werden in Antheridien (a) gebildet, und gleichen Schwärmzellen, diesich durch das Schwingen ihrer Wimpern fortbewegen. Nach der Befruchtung wird die Eizelle durch das Auswachsen benachbarter Zellen ( $k$ ) mit einer Rinde versehen. In dieser Sporenfrucht (Fig. I 47 C) teilt sich die

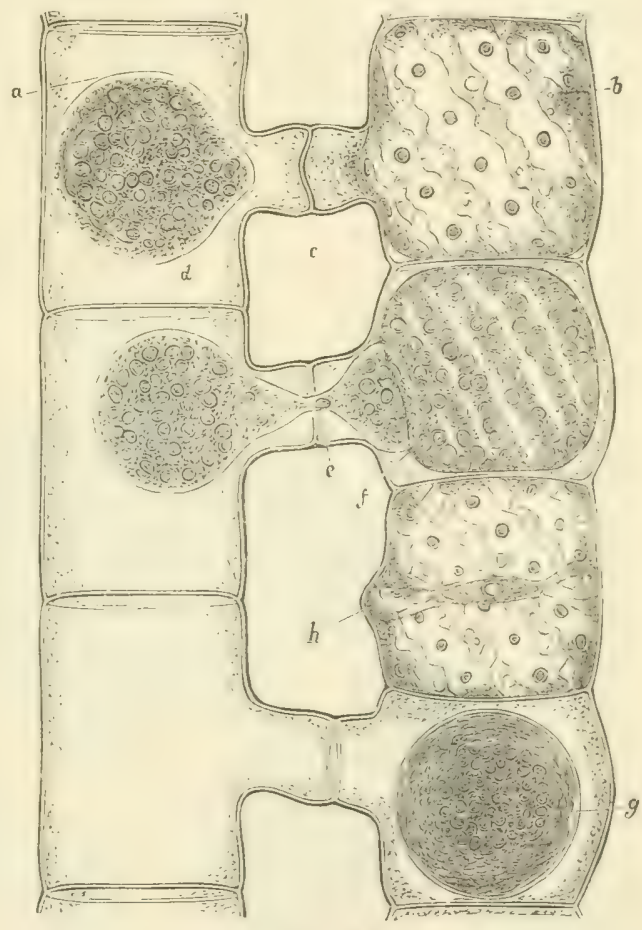

Fig. 146.

Kopulation von Spirogyra. (KIV.) befruchtete Eizelle mehrmals, die Teilzellen isolieren sich bei der Keimung (Fig. I47 D) und bilden Schwärmzellen, analog den oben erwähnten Vorgängen bei gewissen Oosporcen.

Bei den Carposporeen anderer Reihen, z. B. den höheren Rhodophyceen, entsteht als weibliches Organ zunächst ein Procarpium, das einoder mehrzellig ist (Fig. I4S, 2 c). An diesem Procarp befindet sich eine Zelle (oder Zellreihe), welche zur Aufnahme der männlichen Samenkörper dient, das Trichogyn (Fig. 148, 2, 3, 4). Die Spermatozö̈den (hier auch Spermatien genannt) entstehen in grösserer Anzahl an besonderen Organen, den Antheridien. Sie besitzen keine selbständige Bewegung, werden vielmehr durch Wasserströmungen zu dem Trichogyng geführt, mit welchem sie verschmelzen. Die Folge dieses Befruchtungsaktes ist eine 
weitere Zellteilung und dic Sporenbildung im Procarpium. Bei den höheren Formen entwickelt sich um die Sporen eine Hülle (Fig. 148, 3-7), die jedoch bei den ticfer stehenden Rhodophyceen fehlt.

Trotzdem es schr interessant wäre, auf die so überaus mannigfaltigen Geschlechtsvorgänge der Algen näher einzugehen, muss ich der Tendenz dieses Buches entsprechend hierauf verzichten. Es sollte nur auf die einzelnen Stufen der Entwickelung der Geschlechtsvorgänge hingewiesen werden.

Ausser den auf geschlechtlichem Wege entstehenden Sporen können dic Algen auch noch auf ungeschlechtlichem Wege, wie schon oben

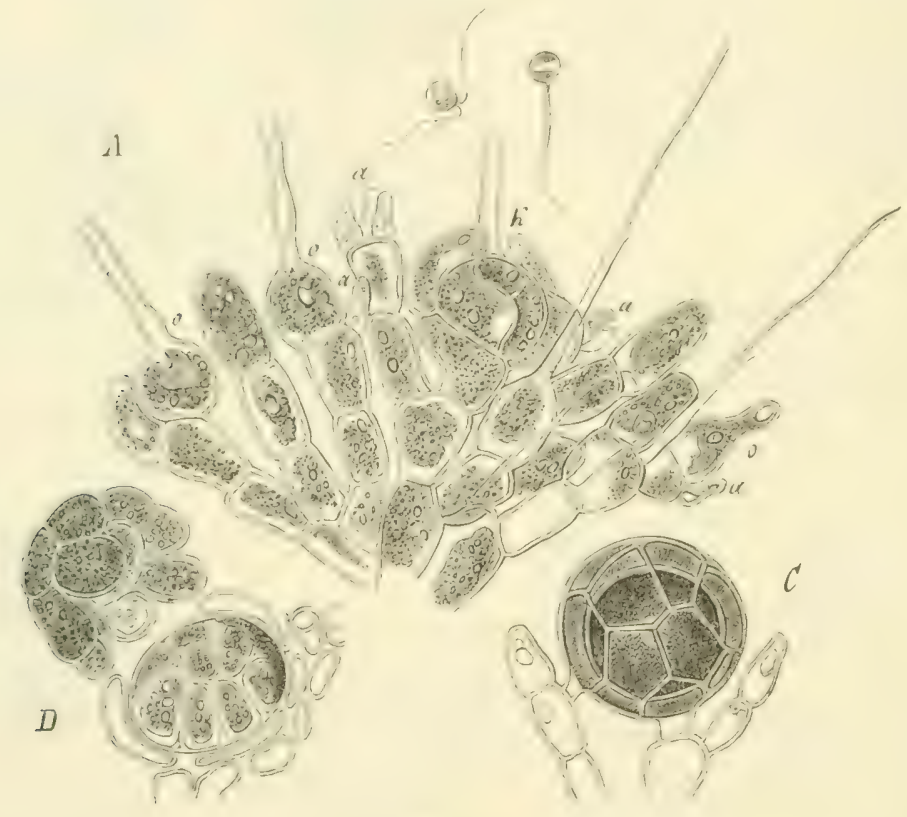

Fig. 147

Sexuelle Fortpflanzung von Coleochaete pulvinata (n. Pringsheim).

angedeutet wurde, besondere Zellen producieren, welche der Fortpflanzung dienen, doch haben dieselben bei den Algen keine so weitgehende Ausbildung erfahren als bei den Pilzen (vgl. \$ 47).

Betrachten wir die Tabelle auf S. I87), so sehen wir, dass, abgesehen von gewissen Pilzklassen, nur die Klasse der Schizophyceen auf der Agamenstufe steht, es fehlt ihr zugleich ein Anschluss an höhere Formen.

In den eigentlichen Algenklassen müssen wir verschiedene Entwickelungsreihen erblicken, die mit niederen isogamen Formen beginnen und zu oogamen eventuell auch carposporen Formen aufsteigen. Die Ordnung der Confervaceen, mit den Palmellaceen beginnend, mit Coleochacte endigend, setzt sich weiter zu den Bryophyten (Moosen) und Pteri- 
dophyten (Gefässkryptogamen) fort, um schliesslich mit den Phanerogamen zu endigen.

Das Ende einer derartigen Verwandtschaftsreihe ist in der oben angeführten Tabelle jedesmal durch einen dickeren Strich markiert.

\section{Klasse, Schizophyceae, Spaltpflanzen.}

Dieselben zeichnen sich durch die Isolierung ihrer Teilzellen aus (Spaltung). In den Zellen können Sporen endogen gebildet werden. Geschlechtliche Vorgänge fehlen.

\section{Ordnung. Schizomycetes, Spaltpilze oder Bakterien.}

Die Spaltpilze assimilieren keine Kohlensäure, ernähren sich ganz wie Pilze. Die einzelnen Zellen sind ausserordentlich klein. Über die Verschiedenheit der Form giebt Fig. I 49 Auskunft. Man bezeichnet als Kokkus (Mikrokokken) kleine Körnchen, als Bacterium und Bacillus, kurze und etwas längere gerade Stäbchen, als Spirillumoder Spirochaete kurze oder mehrfach spiralig gewundene Formen. Dazu kommen noch feine Fäden (Leptothrix, Cladothrix), die unter Umständen in Stäbchen und Kokken zerfallen können. Spaltpilzkolonien können zu Gallerten vereinigt sein (Zoogloeaform).

Bacillus tuberculosis erzeugt Tuberkulose, Bacillus anthracis Milzbrand, Leptothrix buccalis Zahncaries, Spirochaete Ober-

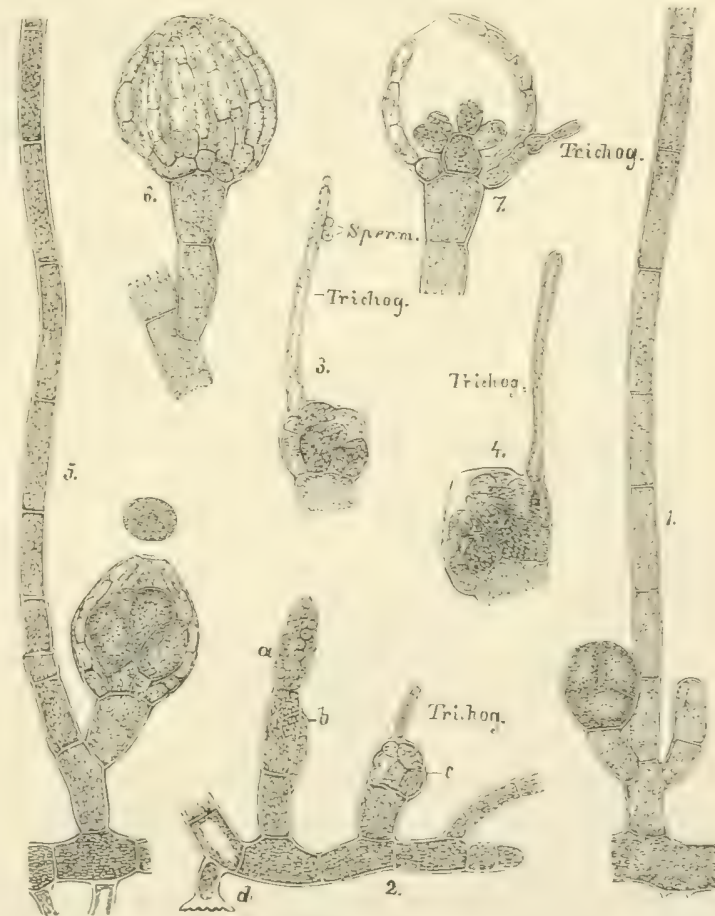

Fig. ItS. meieri Rückfalltyphus.

Mikrokokkus prodigiosus ist rotgefärbt, Mikrokokkus pyocyanus kommt im blauen Eiter vor.

Bacterium aceti, Pilz der sog. Essigmutter, Essigkahmhaut, oxydiert den Alkohol in gegorenen Flüssigkeiten zu Essigsäure (nicht zu verwechseln mit der Kahmhaut von Saccharomyces mycoderma). Fäulnis und Zersetzungen werden durch verschiedene, namentlich bewegliche 
Spaltpilzformen hervoreserufen. Crenothrix Kühniana in schlechtem Brunnenwasser. Beggratoa alba scheidet Schwefelwasserstoff aus.

Gewisse Spaltpilze können auch dadurch cine Bedeutung erlangen, dass sie verheerende Raupen- und Insektenepidemien hervorrufen. Eine derartise Krankheit ist unter dem Namen der Flacherie oder Schlaffsucht bekannt, welche sowohl die nützlichen Seidenraupen

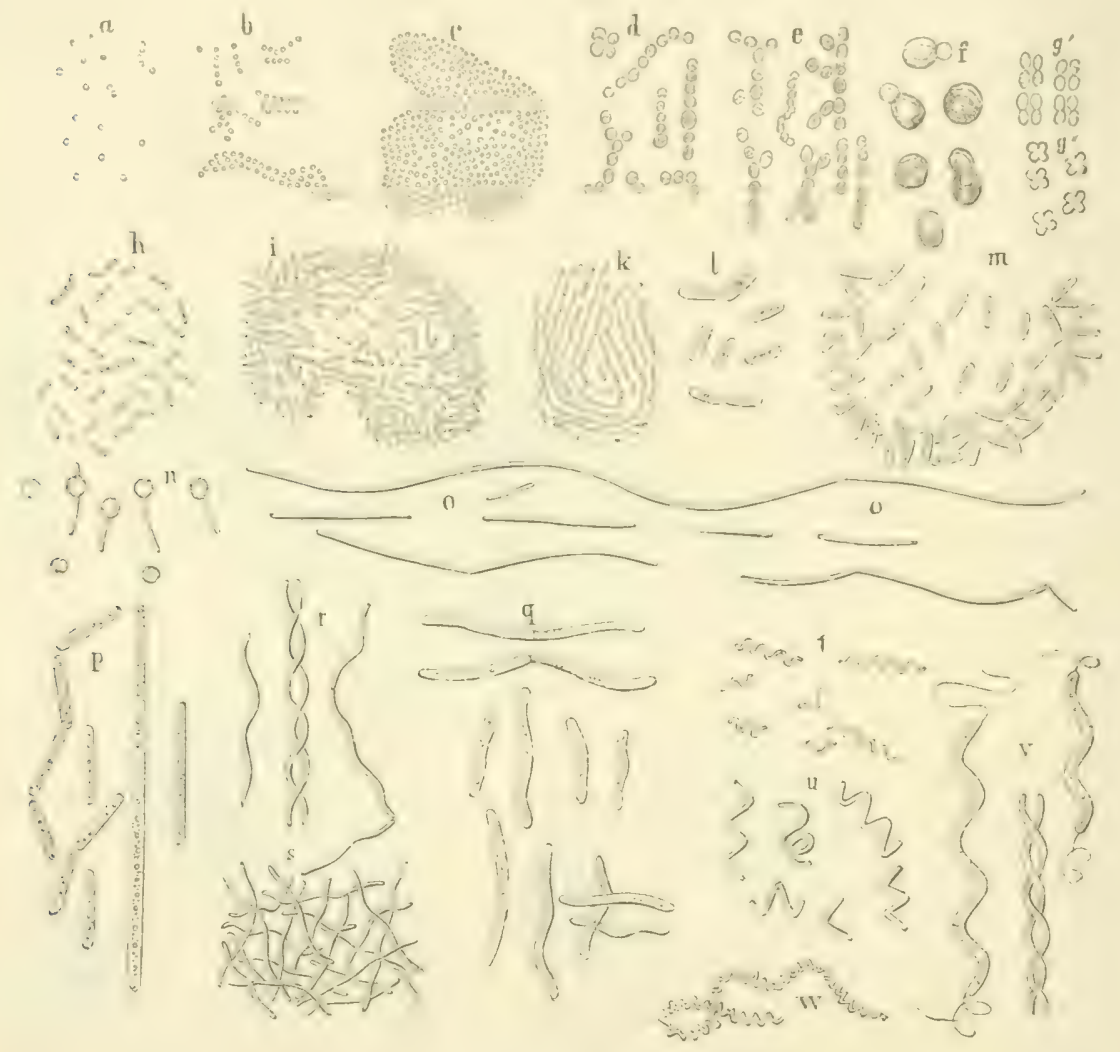

Fig. 149.

Spaltpilzformen, bis auf $\mathrm{f}$, welches Hefezellen (Saccharomyces cerevisiae) darstellt. (Sch.)

als die schädlichen Kaupen des kleinen Kohlweisslings, Picris Rapae dahinrafft. Aus Mund und After der Raupe fliesst eine übelriechende Flüssigkeit aus, welche häufig die Afteröffnung verklebt. Die Raupen hören auf zu fressen, werden matt, bis schliesslich die in eine fast leere schwarze Haut verwandelte Raupe nur noch mit ein oder zwei Bauchfüssen am Substrat haftet. Ich erwähne diese Krankheit besonders aus dem Grunde, weil dieselbe im Jahre I 890 an den Raupen von Liparis monacha (Nonne) aufgetreten ist und vielleicht zur Vertilgung dieses Schädlings beiträgt. Man entferne also kranke oder tote Raupen nicht aus dem Walde, da man hierdurch die Infektionsgefahr herabmindern 
würde (vgl. $\S 48$ Entomophthoraceae und $\S 50$ Pyrenomycetes, Familie der Hypocreaceae).

An Nadelhölzern, welche auf undurchlässigem Boden wachsen, kann die Pfahlwurzel absterben und dann der Zersetzung durch Bakterien anheim fallen. Bei dieser Wurzelfäule bleiben die flachstreichenden Seitenwurzeln erhalten, während bei der durch Polyporus annosus (s. S. 227) bedingten Wurzelhrankheit auch die Seitenwurzeln angegriffen werden. Kiefern, deren Hauptwurzel abgefault ist, werden leicht vom Sturme geworfen.

\section{Ordnung. Cyanophyceae, Spaltalgen.}

Diese Algen zeichnen sich durch den Gehalt an blaugrünem Farbstoff aus, sie assimilieren Kohlensäure. Zellwand häufigs gallertig gequollen. Oscillaria, Nostoc, Gloeocapsa auf feuchtem Boden, an feuchten Wänden, Brettern etc.

\section{Klasse. Chlorophyceae.}

Algen mit rein grünem Farbstoff.

\section{Ordnung. Confervaceae.}

Der Thallus besteht aus Zellfäden oder Zellflächen, seltener aus einzelnen Zellen; nur die Schwärmsporen und bei den höchsten Formen die Spermatozoiden zeigen Eigenbewegung.

I. Fam. Palmellaceae, Zellen einzeln oder zu Kolonien verbunden.

Palmella, Pleurococcus vulgaris bilden grüne Überzüge auf Baumrinden und anderen Körpern.

2. Fam. Ulvaceae. Zellen zu Flächen vereinigt ohne Eigenbewegung.

3. Fam. Ulothrichaceae. Zelläden. Vgl. Fortpflanzung von Ulothrix zonata S. I 88 .

4. Fam. Oedogon ia cea e. Unverzweigte und verzweigte Zellfäden. Fortpflanzung oogam. Oedogonium. Bulbochaete.

5. Fam. Coleochaetaceae. Fäden zu Scheiben und Polstern vereinigt. Bildung von Sporocarpien S. 190.

Coleochaete.

\section{Ordnung. Volvocaceae}

Einzellige Algen oder Zellfamilien, welche sich durch Wimpern fortbewegen.

Chlamydomonas, Gonium, Stephanosphaera, Pandorina, Eudorina, Volvox.

Die niederen Formen sind mit niederen Tierformen sehr nahe verwandt, was übrigens auch von einzelnen Palmellaceen gesagt werden kann. 


\section{Ordnung. Cladophoraceae.}

Einzellige Algen, Zellnetze oder Fäden. Die Zellen häufig mit vielen Zellkernen.

Protococcaceac, Hydrodictyeac, Cladophoreae, Sphacropleaceae.

\section{Ordnung. Syphoneae.}

Schlauchförmise, vielkernige Zellen, die sich beim Wachstum nicht in cinzelne kleinere Zellen teilen.

Botrydium, Acetabularia, Caulerpa (Fig. I), Vaucheria.

Wic schon oben angedeutet, stellen die Chlorophyceen, speciell dic Ordnung der Confervaceen den untersten Abschnitt der Hauptreihe dar, in welche sich die Mehrzahl der grossen Abteilungen des Pflanzenreiches ihrem Entwickelungsgange nach einordnen.

\section{Klasse. Conjugatae.}

Die Conjugaten sind in der Isogamenstufe von den Chlorophyceen abgezweigt. Sie zeichnen sich durch die Kopulation unbeweglicher Zellen aus ivel. Fïg. Ifor, Schwärmzellen fehlen vollständis.s. Diese Familie ist wichtis, weil sie das Überganssslicd zu der Pilzfamilie der Zygromyceten bildet, von denen ein grosser Teil der Pilze abgeleitet wird.

Spirogyra, Zygnema, Cosmarium, Closterium.

\section{Klasse. Diatomeae, Kicselalgen.}

Sie zeigen einen analogen genetischen Zusammenhang wie die Conjugaten (vgl. Tabelle S. I87). Es sind einzellige Algen, in deren Zellwand Kieselsäure eingelasert ist. Ihre Nandung besteht dabei nicht aus einem Stück, sondern aus zwei sleich sebildeten, schachtelförmigs in-
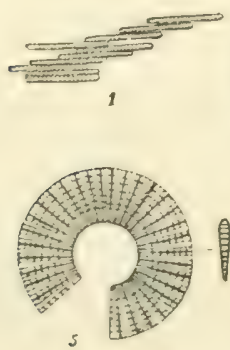
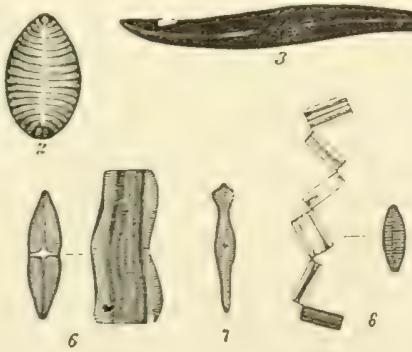

Fig. 150 .

Verschiedene Diatomeenformen.

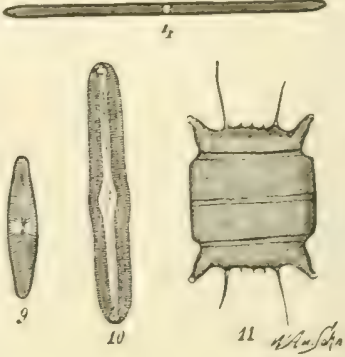

(W.)

cinander greifenden Schalen. Der Chlorophyllfarbstoff ist durch einen braunen Farbstoff (Diatomin) verdeckt. Abgesehen von der Vermehrung durch Zellteilung werden sog. Auxosporen gebildet. Sie können entweder ungeschlechtlich entstehen, indem das Protoplasma einer Zelle nach dem 
Abwerfen der Zellwand an Volumen zunimmt und sich mit einer neuen Wand umgiebt oder auf seschlechtlichem Wege, durch die Kopulation des Protoplasmas zweier Individuen.

Fossile Lager von Diatomeen liefern den sog. Kieselguhr.

Pillularia, Navicula, Gomphonema, Pleurosigma. Circa I 500 Arten.

\section{Klasse. Phaeophyceae, Bramalgen.}

Sie zeichnen sich durch den Gehalt an einem braunen Farbstoff aus (Phycophaeïn). Die niedriger stehenden Formen sind durch die Cladophoraceen mit den Chlorophyceen verwandt. Die höheren Formen sind zum Teil mächtige Pflanzen, z. B. Laminaria oder Macrocystis pirifera, der Birntang, dessen Thallus über $300 \mathrm{~m}$ lang werden soll. Meeresbewohner, bekannt als sog. Tange.

Ectocarpus, Sargassum, Fucus vesiculosus (Fig. I 5 I).

\section{Klasse. Rhodophyceae oder Florideae.}

Sie sind fast immer rot, violett oder rotbraun, sie enthalten Chlorophyll, das jedoch durch einen roten Farbstoff verdeckt ist (Erythrophyll), daher der Name Rotalgen. Die niedersten Formen dieser Klasse sind mit den Coleochaetaceen verwandt. Die Rhodophyceen sind demnach von der Chlorophyceenreihe abgezweigt, schliessen sich jedoch nur an sehr hochentwickelte Formen an (vgl. Tabelle S. I 87). Die

höheren Glieder der Rhodophyceen zeichnen sich durch komplicierte Sporocarpienbildung aus (S. I 89). Der höheren Stellung im System entspricht auch der komplicierte Aufbau des Thallus, an welchem blattund stengelartige Teile, sowie Haftorgane ausgebildet werden.

Bangia, Chantransia, Polysiphonia, Ceramium, Delesseria, Lejolisia. Fast ausschliesslich Meeresbewohner. 


\section{Klasse. Characeae. Armlenchtergenuächse.}

Dic Characeen sind hochentwickelte Algen, deren Anschluss an die Chlorophycen zweifelhaft ist. Sie bilden Stengel mit blattartigen Organen und besitzen hochentwickelte Geschlechtsorgane.

Nitella. Chara.

\section{Myxomycetes. Reproduktions- und Vegetationsorgane der echten Pilze.}

Wir können zwei Gruppen von chlorophyllfreien Thallophyten unterschciden: I) Myxomycetes, Schleimpilze, 2) Fungi, echte Pilze.

\section{Klasse. Myxomycetes, Schleimpilze.}

Die Verwandtschaft dieser Klasse mit gewissen Formen des Tierreichs (Rhizopoden) ist eine wesentlich grössere, als mit den eigentlichen Pilzen und Algen. Man hat diesem Umstande Rechnung getragen, indem man dieselben als Mycetozoën, Pilztiere bezeichnete. Mit den Pilzen haben sie die Eigenschaft gemeinsam, dass sie chlorophyllfrei sind und Sporen producieren.

Sie stellen nackte Protoplasmamassen dar (Fig. 3), die auf Humus, Lohe, verfaultem Holz vegetieren. Das Plasmodium verwandelt sich bei der Sporenbildung in Sporen, welche von erstarten Plasmapartien zusammen gehalten werden. Aus den Sporen entwickelt sich entweder eine Amöbe oder eine Schwärmzelle.

Fuligo varians (syn. Aethalium septicum) Lohblüte auf Gerberlohe, Dictyostelium, Arcyria, Lycogala auf Humus und moderndem Holz.

Plasmodiophora Brassicae erzeugt an Kohlwurzeln sehr starke Auftreibungen, die sog. Kohlhernie.

Schinzia Alni, der Pilz, welcher die traubenartigen Anschwellungen an Erlenwurzeln hervorruft, mag an dieser Stelle genannt werden, obgleich er kaum mit den übrigen Myxomyceten zu vergleichen ist.

$\mathrm{Zu}$ den echten Pilzen gehören sechs Klassen, die sich in zwei Abteilungen gruppieren lassen: Die Phycomyceten, Algenpilze, umfassen die Klassen der Oomyceten und Zygomyceten, die Mycomyceten oder höheren Pilze, die Klassen der Ascomyceten, Ustilagineen, Uredineen und Basidiomyceten.

Die Phycomyceten zeigen geschlechtliche Vorgänge, welche direkt an gewisse Algenfamilien anschliessen, während die Mycomyceten sich nur auf ungeschlechtlichem Wege fortpflanzen.

Bei den Oomyceten werden Oogonien und Antheridien gebildet, welche an die entsprechenden Fortpflanzungsorgane der oogamen Con- 
fervaceen erinnern. Die Oomyceten müssen also von dieser Algengruppe abgeleitet werden (vgl. Tabelle S. I 87). In Fig. I52,5 ist die grössere Zelle das Oogonium, die kleinere Zelle das Antheridium. Nach der Befruchtung entwickelt sich in dem Oogonium eine Oospore (Fig. I 52,6), welche direkt zu einem neuen Mycel auswächst. Ausser der geschlechtlichen Fruktifikation haben wir noch die Produktion ungeschlechtlicher Sporangien. Bei Peronospora, dem von uns angeführten Beispiele, befinden sich die Sporangien (Fig. I 52,2) an verzweigten Trägern. Diese Sporangien bilden in Wasser zahlreiche Schwärmsporen, oder wachsen direkt zu einem neuen Mycel aus. Der aus der Spore hervortretende Keimschlauch

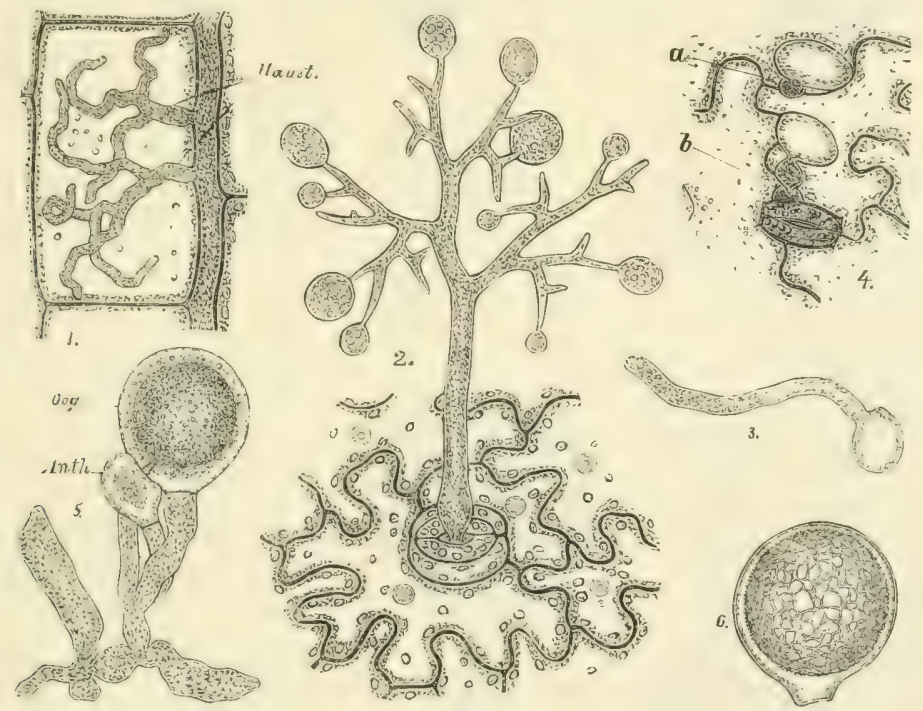

Fig. 152.

Fortpflanzungsorgane von Peronospora calotheca im Gewebe von Asperula odorata. No. 4 von Peronospora parasitica. No. I Haustorienbildung des Mycels, (KW.)

durchbricht die Aussenwand der Wirtspllanze oder dringt durch die Spaltöffnungen in das Innere derselben ein (Fig. I 52, 3, 4).

Bei einem Teil der Oomyceten sind die Antheridien funktionslos geworden, es zeigt sich hier also eine Reduktion der Geschlechtsvorgänge, welche wohl teilweise mit der parasitischen Lebensweise dieser Pflanzen zusammenhängt.

Die ungeschlechtliche Fortpflanzung nimmt bei den einzelnen Oomymycetenfamilien eine verschiedene Gestalt an.

Etwas abweichend verhalten sich die hier zu den Oomyceten gestellten Chytridiaceen, welche vielleicht von der Algenfamilie der Protococcaceen abstammen.

Bei den Zygomyceten entsteht durch die Kopulation zweier 
ruhender, sleichartiger Zellen eine Zygospore, So schen wir in Fig. 153,5 zwei rundliche Zellen aufeinander stossen, welche nach ihrer Vereinigung zu der Zygospore (Fig. I53,6) heranwachsen. In Fig. 153, 7 ist die Keimung derselben dargestellt. Das Nycel hat in diesem falle ein Sporangium produciert, welches die ungeschlechtliche Form der Fortpflanzung repräsentiert. Dieses Sporangium (Fig. I53, I, stark ver(srössert) enthält zahlreiche Sporen, die hier nach dem Platzen der spröden Sporangienmembran frei werden (Fig. I53,2) und zu neuen Pilzfiden auswachsen können (Fig. I 53, 3, 4).

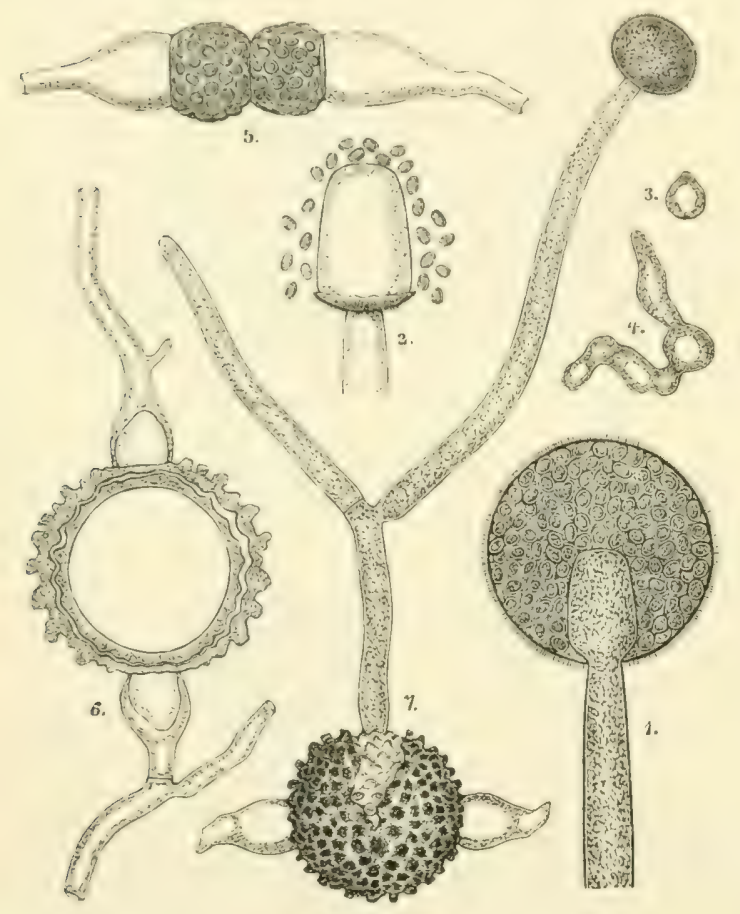

Fig. 153 .

Fortpflanzungsorgane von Mucor Mucedo. (KW.)

Andere Zygomyceten bilden keine Sporangien mit endogen entstehenden Sporen, sondern schnüren exogen Fortpflanzungszellen, Conidien ab.

Die Kopulation zweier ruhender Zellen lässt es geboten erscheinen, die Klasse der Zygomyceten von der Algenklasse der Conjugaten abzuleiten (vgl. Tabelle S. I87). Es hat sich demnach der Übergang von der assimilierenden Lebensweise zur parasitischen und saprophytischen Ernährung an verschiedenen Stellen des Algensystems vollzogen.

Die höheren Pilze, die Mycomyceten sind von den Zygomyceten abzuleiten, die geschlechtliche Fortpflanzung hat sich nicht weiter ausgebildet, ist vielmehr bei den Mycomyceten gänzlich verschwunden. Hierdurch unterscheiden sich die Pilze sehr wesentlich von den Algen, bei welchen die Geschlechtsorgane immer höhere und kompliziertere Formen annehmen, je höher die betreffende Alge im Systeme steht.

Es wurde schon hervorgehoben, dass bei den Zygomyceten sowohl endogene Sporangienfruktifikation, als exogene Conidienfruktifikation vorkommt. Die Fähigkeit, derartige Organe hervorzubringen, hat sich nun bei den höheren Pilzklassen weiter ausgebildet, und zwar zeigen die Ascomyceten eine weitere Differenzierung in Bezug auf die Sporangienfruktifikation, während bei den Ustilagineen, Uredineen und Basidiomyceten 
die Conidienfruktifikation weitergebildet wurde. Ausserdem finden sich bei den Pilzen noch verschiedene Formen von Conidien und Sporenbildung aus Mycelfäden, die man als Nebenfruktifikationen bezeichnen kann.

Wir geben im Folgenden eine Übersicht der so ausserordentlich mannigfaltigen Fortpflanzungszellen der Pilze:

A. Exosporen oder Conidienfruktifikation.

B. Endosporen oder Sporangienfruktifikation.

C. Zygosporenfruktifikation.

D. Chlamydosporen oder Gemmenfruktifikation.

Die Exosporen oder Conidien entstehen an der Spitze oder seitlich von Mycelfäden, die man als Tragzellen oder Conidienträger bezeichnet. Die Conidien sind demnach besonders gestaltete Zellen,

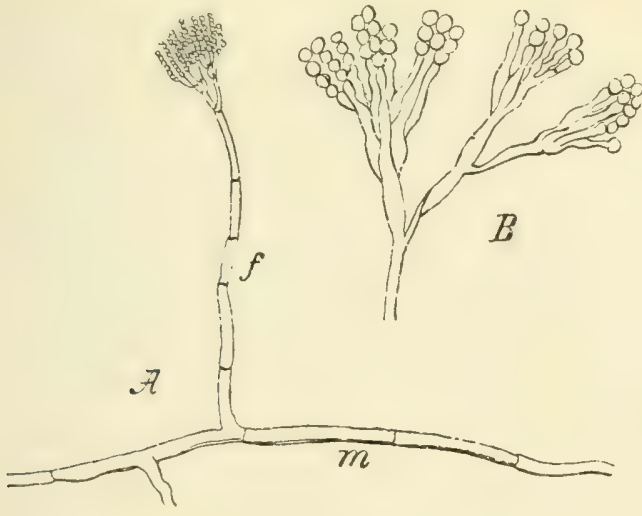

Fig. I 54 .

Conidienbildung von Penicillium glaucum. B stärker vergrössert. (Sch.)

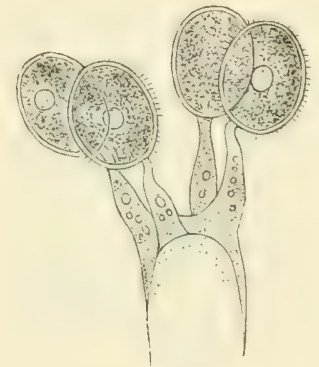

Fig. I 55 .

Basidiosporen von Corticium amorphum (n. De Bary).

oder da sie mehrzellig sein können, eventuell Zellgruppen, welche sich von Mycelfäden loslösen und nun direkt $z u$ einem neuen Mycel auswachsen. Die Conidienträger sind fädige Gebilde, an denen einzelne Conidien und Conidienketten stehen, häufig sind die Träger verzweigt oder bündelartis vereinigt (Penicillium glaucum, Fig. I54). Es liommen ferner Conidienlager vor, welche aus pallisadenartig nebeneinander stehenden Conidienträgern zusammengesetzt sind; dieselben können entweder unmittelbar aus den Mycelfäden hervorsprossen oder aus einem dichteren Mycelpolster, dem ,Stroma“, entspringen. Dieses Stroma kann krustenförmig (Diatrype), polsterförmig (Nectriaarten) sein, hirschgeweihartige grössere Körper bilden (Xylaria Hypoxylon) und fleischige, lederartige, holzige oder gallertartige Konsistenz haben. Die conidienbildende Zone, welche dem Stroma aufliegt, bezeichnet man als Hymenium. Dasselbe überzieht entweder das ganze Stroma (Ascomyceten, Clavarien), oder ist 
auf bestimmte Stellen beschränlet (Unterseite des Hutes bei den hutbildenden Basidiomyeten). Bei der höheren Form der Conidienausbildung ist die Zahl der abseschnürten Conidien eine bestimmte, so z. B. bei den Autobasidiomyecten, wo fast immer vier Conidien auf einer Trägerzelle gebildet werden. Die Conidien (= Basidiosporen) stehen hier auf Sterigmen, das sind feinere Fortsätze der gemeinsamen Trägerzelle, welche man hier als Basidie bezeichnet (Fig. 155).

Die Conidien können auch in seschlossenen oder mit einem Aus-

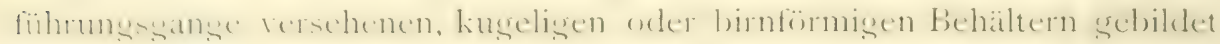
werden. Man kann dieselben mit dem allgemeinen Namen der Conidien-

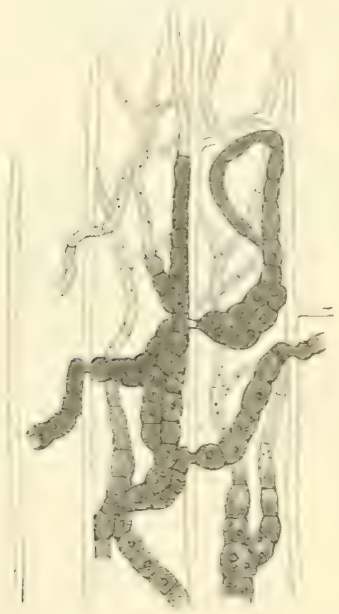

Fig. 156

Dunkler gefärbte Gemmen am helleren Mycel von Verticillium alboatrum im Gewebe eines Kartoffelstengels. (R.)

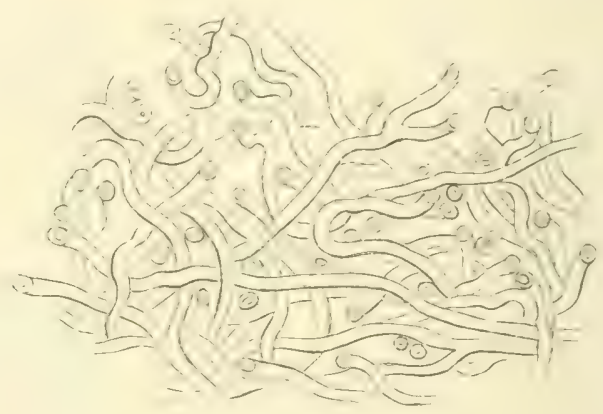

Fig. 157 .

Verfilzte Pilzhyphen aus dem Thallus der Flechte Cetraria islandica. (R.)

früchte bezeichnen. Sehr kleine, oft punktförmige Conidienfrüchte der Ascomyceten nennt man Pycniden. Bei den Gasteromyceten erreichen die Conidienfrüchte Erbsen- bis Kinderkopfgrösse. Sehr kleine Conidienfrüchte werden auch als Spermogonien bezeichnet, da man annahm, dass die in denselben producierten sehr kleinen Conidien (früher Spermatien, jetzt auch Mikroconidien genannt) bei geschlechtlichen Vorgängen als Befruchtungskörperchen zu fungieren hätten. Diese Spermatien sind jednch für sich keimfähiss, haben daher wohl mit Geschlechtsrorgängen nichts zu thun.

Die Endosporenfruktifikation zeichnet sich durch die Bildung von Sporen im Innern von Mutterzellen aus, die als Sporangien zu bezeichnen sind. Man hat mit Bewegungsorganen versehene Sporen, Schwärmsporen oder Zoosporen und unbewegliche Sporen. Die auch zu den 
Endosporen gerechneten Oosporen (vgl. Oomyceten) verdanken einem Geschlechtsakt ihre Entstehung, die übrigen Endosporen bilden sich ungeschlechtlich. Eine besondere Form stellen die Ascosporen oder Schlauchsporen dar (vgl. Fig. 9), sie werden in besonderen Schläuchen (Asci) gebildet, und sind für die Familie der Ascomyceten charakteristisch.

Den Conidienfrüchten entsprechen die Sporangienfrüchte oder Schlauchfrüchte der Ascomyceten. Dieselben bestehen aus der Hülle (Peridie) und dem die Schläuche tragenden Hymenium. Scheiben- oder becherförmige Fruchtformen bezcichnet man als Apothecien (rgl. Discomycetes।. geschlossene oder mit enger Mündung verschene, birnförmige Früichte als Perithecien (vgl. Pyrenomycetes). Auch diese Schlauchfrüchte können auf einem Stroma gebildet werden, oder in dasselbe eingesenkt sein. Aus ihrer Entwickelungsgeschichte ist hervorzuheben, dass die Asci aus besonders gestalteten fertilen Zellen entstehen, die man früher für Geschlechtszellen gehalten hat.

Zygosporen vgl. S. 198 .

Chlamydosporen oder Gemmen sind Zellen verschiedener Pilzhyphen, welche Inhaltsstoffe den benachbarten Hyphenteilen entziehen und aufspeichern (Fig. I56). Sie können auch an der Spitze ron Pilzhyphen entstehen (Uredineen), sie unterscheiden sich dann nicht mehr von Conidien. Die Bezeichnung als Chlamydosporen kann dann nur durch den Versleich mit analogen Gebilden anderer Familien gerechtfertigt werden. Ihre häufig mit Farbstoffen durchtränkte Membran ist zumeist dick, wodurch sie befähigt sind, die übrigen Pilzhyphen zu überdauern. Unter geeigneten Bedingungen wachsen sie direkt zu neuen Mycelien aus. Chlamydosporen finden sich bei Phycomyceten und Mycomyceten.

Was die Vegetationsorgane der echten Pilze anbelangt, so sehen wir, dass der Pilzthallus in seiner typischen Ausbildung aus mehr oder weniger dünnen langen Zellfäden besteht, den Pilzhyphen oder Mỵcelfäden (Fig. I 56 und 157 ). Die Mycelfäden sind bei den höheren Pilzen fast immer in zahlreiche Zellen geteilt, sie können jedoch auch nur einen vielfach verzweigten Schlauch darstellen (Mucor, Fig. 39).

Die Pilzzellen sind immer frei von Chlorophyll oder einem anderen Assimilation vermittelnden Farbstoff. Sehr häufig sind sic überhaupt farblos.

Der verschiedenen Lebensweise der Pilze entspricht auch die nähere Ausbildung des Aycels. Dasselbe kann auf der Oberfläche ron Organen vegetieren, in das Innere der Zellen eindringen oder in den Zellwänden weiter wachsen. Es kommen ferner Pilze vor, welche zwischen den Zellen der befallenen Pflanze leben, und nur Saugorgane (Haustorien) in die Zellen derselben treiben (Fig. 152, 1).

Die Mycelien vergrössern sich durch Zellteilungen, häufig zeigen sie auch Spitzenwachstum. Bei gewissen Pilzzellen bilden sich sackartige 
Ausstïlpungen (Fig. I 58 ), die zu neuen Zellen heranwachsen. Derartige durch Sprossung entstandene Zellen können zu Sprossmycelien vereinigt bleiben, oder sich isolieren (Saccharomyces, Bier- und Weinhefe, Mucor racemosus, Tremellaarten, Ustilago Carbo, Ustilago Maydis, Empusa Muscae u. a.).

Die Pilzhyphen können auch ein Pseudoparenchym bilden (vgl. S. 43, Fig.48), wodurch Zellkomplexe entstehen, welche wie Gewebe höherer Pflanzen aussehen (Fruchtträger von
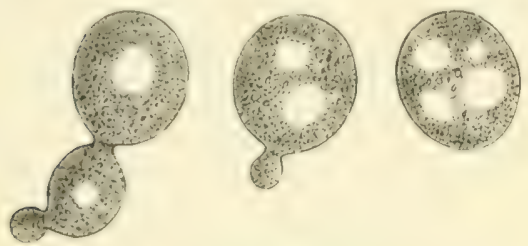

Fig. 158.

Sprossung an Saccharomyceszellen. Hutpilzen, Flechten etc.). Nanche Pilze bilden Sclerotien (Dauermycelien), es sind dies rundliche festere Körper, welche durch dichte Verflechtung von Pilzhyphen entstehen, und die nach aussen durch meist dunkelgefärbte, widerstandsfähigere Mycelschichten begrenzt sind (Claviceps purpurea, das Mutterkorn, Sclerotinia sclerotiorum,

Rosellinia quercina u. a.). Die Vereinigung von Pilzhyphen zu festeren Strängen, die von einer dichten gefärbten Mycelrinde umgeben sind, bezeichnet man wegen der Ähnlichkeit mit dunklen Wurzelsträngen als Rhizomorphen (vgl. Agaricus melleus).

\section{9. Klasse. Oomycetes.}

Geschlechtliche Fortpflanzung durch Oosporen. Ausserdem Vermehrung durch Conidien, Endosporen oder Schwärmsporen.

\section{Ordnung. Peronosporaceae.}

Parasiten, deren Mycel zumeist in den Intercellularräumen höherer Pflanzen lebt und Haustorien in das Innere der Zellen entsendet.

Phytophthora omnivora De Bary (syn. Phytophthora Fagi R. Hartig) Ursache der Buchenkeimlingskrankheit. Tritt ausser an Buchen noch an den Keimlingen von Acer, Fraxinus, Robinia, Picea, Pinusarten, Larix, Abies, sowie an den Pflanzen von Fagopyrum, Sempervivum auf. Äussere Anzeichen der Krankheit: Schwarzwerden der Würzelchen, Auftreten von missfarbigen Flecken an den Cotyledonen. Bei feuchtem Wetter verfaulen die Pflanzen, bei grösserer Trockenheit werden sie rotbraun, wie vom Feuer versengt. Die Sporen erhalten sich mehrere Jahre im Boden.

Phytophthora infestans, der Pilz der Kartoffelkrankheit, zerstört die Blätter, welche lokal gebräunt werden. An der Übergangsstelle zu den gesunden Teilen treten weissliche Conidienmassen auf. Die Krank- 
heit ergreift auch die Knollen, welche bei grösserer Feuchtigkeit verfaulen, im trocknen Zustande die sog. Trockenfäule aufweisen.

Pythium Debaryanum vernichtet Keimpflanzen von Zea Mays, Panicum, Trifolium repens. Cystopus candidus auf Capsella bursa pastoris.

\section{Ordnung. Saprolegniaceae.}

Leben zumeist im Wasser auf toten organischen Körpern (Fliegen, Insekten, den sog. Ameiseneiern), sie können jedoch auch lebende Fische in Teichen und Brutanstalten befallen und zu Grunde richten (z. B. Goldfische, Forellen, Stachelbarsche, Lachse). Gewisse Arten kommen auf Algen und Moosen vor.

Oogonien ähnlich wie bei den Peronosporaceen, Antheridien können fehlen oder funktionslos sein. Der Inhalt der Oogonien teilt sich mit oder ohne Befruchtung in mehrere Portionen, die zu Sporen werden. Endosporen sind Schwärmzellen.

Achlya, Saprolegnia.

\section{Ordnung. Chytridiaceae.}

Sehr unscheinbare Schmarotzer auf Algen, Infusorien, Nematoden, seltener auf phanerogamen Wasserpflanzen. Mycel wenig umfangreich oder ganz fehlend. Es kommt im letzteren Falle nur zur Bildung von Sporangien, welche zahlreiche Schwärmsporen enthalten. Oosporen sind ebenfalls beobachtet.

Polyphagus Euglenae, Synchitrium, Chytridium.

\section{Ordnung. Entomophthoraceae.}

Die Oosporenfruktifikation nähert sich bei manchen Formen sehr der Zyosporenbildung. Diese Familie ist daher mit den Zygomyceten näher verwandt. Ähnliche Sporen werden auch ohne vorausgegangene Kopulation gebildet (Entomophthora radicans). Es handelt sich also auch hier um den Verlust geschlechtlicher Vorgänge, ähnlich wie bei den Saprolegniaceen.

Die hierher gehörigen Pilze dringen in die Leibeshöhle lebender Insekten ein und zehren die inneren Teile derselben fast vollständig auf. An der Aussenfläche der getöteten Tiere werden an hervorgewachsenen Pilzhyphen Conidien abgeschnürt, welche wieder andere Insekten inficieren. Es werden besonders Fliegen, Schmetterlinge, Blattläuse, seltener Cicaden, Heuschrecken, Wespen und Blattwespen angegriffen.

Empusa muscae verursacht die im Herbst auftretende Krankheit der Stubenfliegen, bei welcher ein Hof ron weissen staubfömisen Conidien die erstarrten Fliegen umgiebt. Entomophthora radicans in Raupen des Kohlweisslings. Eine andere Entomophthora decimiert die Raupen ron Trachea piniperda. 


\section{10. Klasse. Zygomycetes.}

Bildung von Zysosporen durch Kopulation ruhender Zellen. Keine Schwärmsporen. Ungeschlechtliche Fortpflanzung durch Endosporen oder Conidien.

\section{Ordnung. Mucoraceae.}

Schimmelpilze, die saprophytisch auf Mist, Brod, Früchten etc. leben. Zysosporen und Sporangien vgl. S. igs.

Mucor mucedo, Pilobolus crystallinus auf Pferdemist. Mucor racemosus, MI. spinosus, M. circinelloides bilden hefeartige Gemmen, welche wic die echten Hefearten (Saccharomyces) alkoholische Gärung hervorrufen.

\section{Ordnung. Chaetocladiaceae.}

Zygosporen und einzeln abgeschnürte Conidien.

Chaetocladium auf grösseren Mucorarten schmarotzend.

\section{Ordnung. Piptocephalideae.}

Zygosporen und Conidien, die durch Quergliederung reihenweise gebildet werden.

Piptocephalis und Syncephalis parasitieren auf grösseren Mucoraceen.

\section{11. Klasse. Ascomycetes, Schlauchpilze.}

Charakteristisch für diese ausserordentlich formenreiche Klasse ist die Entstehung der Sporen in schlauchförmigen Sporangien, Asci genannt. Die letzteren können entweder frei auf der Oberfläche vorkommen oder in besonderen Schlauchfrüchten eingeschlossen sein. Bei vielen Schlauchfrichten bilden sich die Asci aus einem besonders gestalteten Hyphenkomplex, dem Ascogon.

Conidienfruktifikation und Pycnidenbildung ausserordentlich mannigfaltig.

\section{Ordnung. Gymnoasceae.}

Um die Asci keine gewebeartige Hülle. Bei gewissen Vertretern (Saccharomyces, manche Taphrinaarten) rerwandeln sich sämtliche Pilzzellen direkt in die Asci.

I. Fam. Saccharomycetes, Hefepilze.

Die Hefepilze treten häufig als einzellige Gewächse auf, welche sich durch die Aussprossung neuer Zellen (vgl. S. 202) auszeichnen, sie werden daher auch als Sprosspilze bezeichnet. Ausserdem bilden sie jedoch bei geeigneter Kultur kurze, gegliederte durch Sprossung entstandene Mycelien. 
Verschiedene Arten sind befähigt, in den vegetativen Zellen, ähnlich wie in einem Schlauche, eine geringe Anzahl Sporen zu bilden.

Saccharomyces cerevisiae, Bierhefe und S. ellipsoideus, Weinhefe rufen alkoholische Gärung unter Spaltung des Zuckers hervor. Kommen gärungserregende Hefen mit der Nahrung in den Darmkanal von Raupen, können sie Erkrankungen dieser Tiere zur Folge haben.

Äusserliche Ähnlichkeit der vegetativen Zellen besitzen folgende Pilze, die man jedoch wegen ungenügender Kenntnis des Entwickelungsganges nicht in das System einreihen kann: Mycoderma cere-

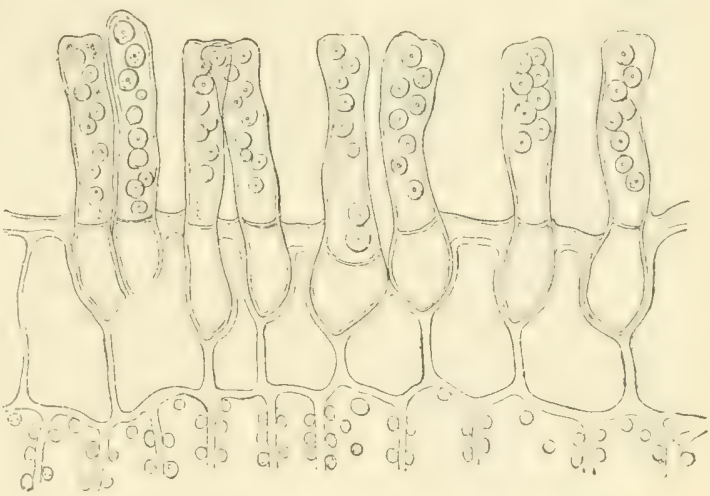

Fig. I 59.

Querschnitt durch ein Stück eines Erlenblattes mit reifen Schläuchen von Taphrina Tosquinetii (n. Sadebeck). visiae, Pilz der Kahmhaut auf Bier, dem Mycoderma vini sehr ähnlich ist. Monilia albicans, Schwämmchenkrankheit der Kinder.

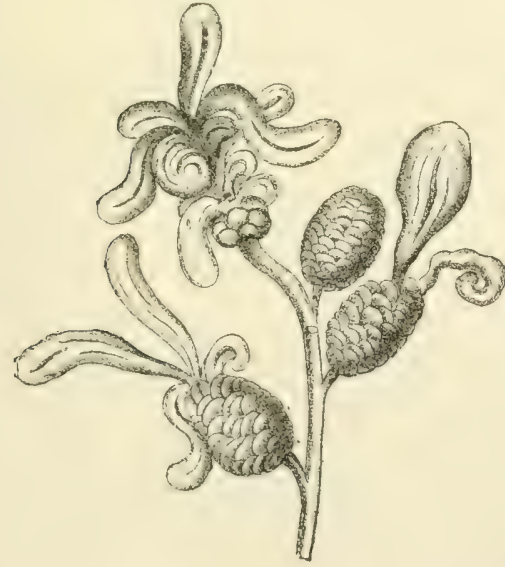

Fig. 160.

Kätzchen von Alnus incana durch Taphrina Alni incanae verändert (n. Hartig).

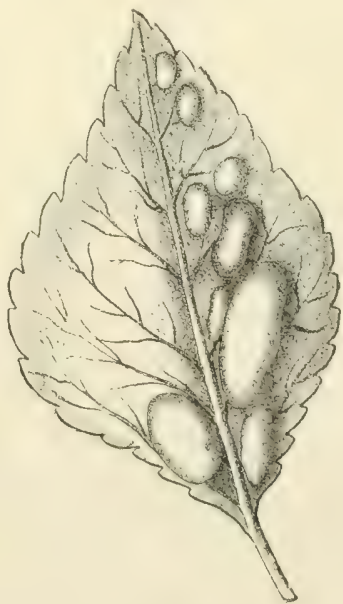

Fig. $16 \mathbf{I}$

Auftreibungen durch Taphrina aurea (n. Hartig).

2. Fam. Exoasci.

Die meisten hierhergehörigen Arten sind Parasiten auf Laubholzgewächsen, wo sie Deformationen an Zweigen, Blättern, Blüten oder Früchten hervorrufen. Das Mycel ist schwach entwickelt, perenniert nur 
in den Knospen, Asci nackt, unmittelbar auf den Zweigen des Mycels (Fis. 159).

Hicrher gehört die Gattung Ta ph rin a (syn. mit Exoascus), welche nach Sadebeck die folgenden nach den Wirtpflanzen geordneten Arten umfasst:

Alnus glutinosa: Taphrina Tosquinetii, Deformation der jungen Zweige und einzelner Blatteile. Taphrina Alni incanae, Deformation der weiblichen Kätzchen. T. epiphylla var. maculans, grauweisse runde Flecken auf den Blättern. T. Sadebeckii, gelbe Flecken auf den Blättern.

Alnus incana: T. epiphylla, Flecken auf den Blättern, blasige Auftreibungen derselben und Reifbildungen auf den Blättern, Deformation junger Zweige und Hexenbesenbildung. T. Alni incanae, Deformation der weiblichen Kätzchen (Fig. I60).

Betula verrucosa: Taphrina turgida, Hexenbesen. T. Betulae, weisse bis gelblich weisse Flecken auf den Blättern. T. flava, intensiv gelbe Flecken.

Betula pubescens: T. betulina, Deformation ganzer Sprosssysteme und Hexenbesenbildung.

Carpinus betulus: T. Carpini, Hexenbesen.

Quercus Robur und Qu. pubescens: T. coerulescens, mehr oder weniger grosse Flecken, welche oft $1 / 3$ des Blattes einnehmen.

Populus nigra und P. pyramidalis: T. aurea, blasige Auftreibungen der Blätter und gelbe Flecken (Fig. I6I).

Populus tremula: T. Johannsonii, Hypertrophie der Früchte.

Populus alba: T. rhizophora, Hypertrophie der Früchte.

Ulmus campestris: T. Ulmi, mehr oder weniger grosse blasige Auftreibungen und Flecken an den Blättern.

Crataegus oxyacantha: T. Crataegi, Auftreibungen und Flecken an Blättern.

Pyrus communis: T. bullata, blasige Auftreibungen und Flecken an Blättern.

Persica vulgaris: T. deformans, Kräuselkrankheit der Blätter.

Prunus avium und P. cerasus: T. cerasi, Hexenbesen.

Prunus insititia und P. domestica: T. insititiae, Hexenbesen.

Prunus domestica, P. Padus, P. virginiana: T. Pruni, Deformation der Fruchtknoten, Bildung der sog. Narren oder Taschen der Pflaumen.

\section{Ordnung. Perisporiaceae.}

Die Schläuche werden von einer allseitig geschlossenen, pseudoparenchymatischen, kugeligen bis ellipsoïdischen Hülle umgeben, welche keinen Ausführungsgang enthält. Die Sporenschläuche und Sporen werden durch Zerreissen der Hülle frei. Die Schläuche entstehen aus einem Ascogon. Paraphysen, d. h. unfruchtbare fadenförmige Zellen zwischen den Sporenschläuchen, fehlen vollständigs. Ausgiebige Conidienbildung. 
I. Fam. Erysipheae, Mehltaupilze.

Parasiten auf höheren Pflanzen, deren Mycel sich auf der Oberhaut ausbreitet und einen weissen mehligen Überzug bildet. Die Schlauchfrüchte erscheinen mit blossem Auge als dunkle Pünktchen.

Sphaerotheca Castagnei auf Hopfen, Sphaerotheca pannosa auf Zweigen und Blättern von Rosen. Podosphaera Oxyacanthae auf Weissdorn. Erysiphe communis auf verschiedenen Pflanzen. Erysiphe Tuckeri, Ursache der Traubenkrankheit. Uncinula salicis auf verschiedenen Weiden, Uncinula Aceris auf Ahornarten. Phyllactinia suffulta auf Blättern von Alnus, Corylus, Fagus, Quercus, Carpinus, Fraxinus, Cornus, Pirus u. a. Microsphaeraarten auf Rhamnus, Berberis, Viburnum, Evonymus, Syringa, Alnus, Lonicera etc.

2. Fam. Aspergilleae. Pinselschimmel.

Charakterisiert durch die pinselförmigen Conidienketten (Fig. I 54).

Saprophytische Formen: Aspergillus glaucus auf feuchten Pflanzen-
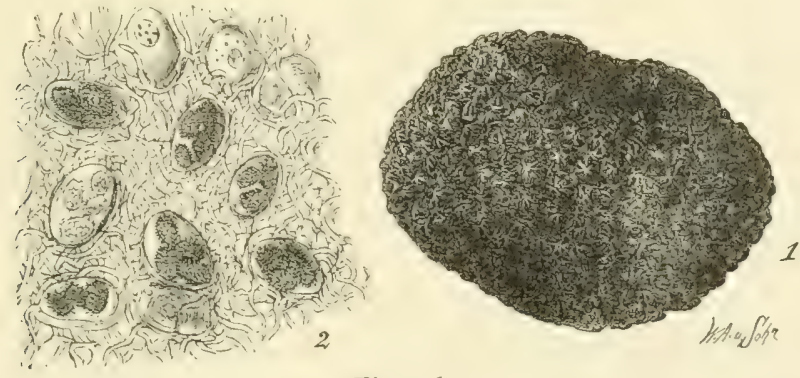

Fig. I62.

Tuber melanosporum. I. Aussenansicht. 2. Durchschnitt. (W.)

teilen, eingemachten Früchten, Brot etc., Penicillium glaıcum, der gemeinste Schimmelpilz, auf Brot, alten Knochen, Früchten blaugrüne Überzüge bildend (Fig. I 54). Pathogene Formen: Aspergillus fumigatus und andere nicht genau bestimmte Aspergillusarten rufen bei verschiedenen Vögeln Lungenkrankheiten hervor.

3. Fam. Tuberaceae. Trüffelartige Pilze.

Mycelium unterirdisch in humusreichem Waldboden, wobei sie Wurzeln von Laubhölzern (Eiche, Rosskastanie, Hainbuche, Rotbuche, Haselnuss etc.) oder Nadelhölzern (Kiefer) umspinnen. Der Pilz der Mycorhizen wird von Rees dieser Familie zugeschrieben. Sporenfrüchto sehr gross, knollenförmig, eventuell kleidet das Hymenium grössere Kammern aus.

Sporen mit stacheliger Aussenhaut: Tuber melanosporum (syn. T. cibarium) Perigordtrüffel (Fig. I62). Das Innere dieser Trüffel ist rötlich oder violett schwarz. Tuber brumale, innen schwärzlich aschgrau, weiss marmoriert. Sporen mit netzförmig gezeichneter Aussenhaut: Tuber aestivum, eigentliche deutsche Trüffel, innen blassbraun, wird im Reg.-Bez. 
Hildesheim mit Hunden im Boden sesucht. Tuber mesentericum, dunkelbraun, an der Basis oft gehöhlt.

Elaphomyces granulatus und $E$. variegatus, Hirschtrüffel, vom Wilde scsucht.

\section{Ordnung. Pyrenomycetes, Kernpilze.}

Dic Schlauchfrucht (Perithecium) besitzt fast immer eine Mündung, ans welcher die Sporen heraustreten. Häufig sind Paraphysen gebildet. Conidienfrüchte vorhanden. Mit oder ohne Stroma. Es ist eine Ordnung, die nach Saccardo circa 5 Soo Species umfasst. Wir finden ihre Conidienlager, Pycniden und Perithecien sehr häufig an abgestorbenen Zweigen von Holzpflanzen, sowie an den Blättern der verschiedensten Pflanzen, in Form von schwarzen, braunen oder anders gefärbten Flecken oder sehr kleinen Kügelchen. Grössere Formen sind seltener. Echte Parasiten, Wundparasiten, Saprophyten.

I. Fam. Sphaeriaceac.

Perithecien mit deutlicher Mündung, nicht fleischig, sondern lederartig, holzig, kohlig, oft spröde, dunkel bis schwarz gefärbt. Stroma wenn vorhanden, nicht in das Perithecium übergehend. Auf Kot verschiedener Tiere, auf lebenden oder toten Zweigen, Früchten von Holzpflanzen und krautigen Gewächsen. Vielfach sind nur Conidien, Pycniden oder Spermogonien bekannt.

Fumago salicina Tulasne (syn. Capnodium salicinum Montagne) bildet auf den Blättern von Weiden, Linden, Ahornen, Eichen, Hopfenpflanzen schwarze Überzüge, die als Russtau bezeichnet werden. Der Pilz tritt auf, wenn die Blätter durch Blattläuse mit Honig besprengt sind (sog. Honigtau). In die Blattzellen dringt Fumago nicht ein, die schwarzen Krusten vermindern jedoch die Assimilation.

Apiosporium pinophylum (Conidienformen als Antennaria pinophila und Torula pinophila bekannt), bildet schwarze Überzüge auf Zweigen und Blättern von Abies pectinata.

Trichosphaeria parasitica R. Hartig, auf Nadeln von Abies, Picea, Tsuga. Die absterbenden Nadeln werden durch das Pilzmycel an dem Zweige festgesponnen. Andere Arten auf Ästen von Pinus silvestris, Corylus, Betula. Herpotrichia nigra R. Hartig, das braune Mycel umspinnt sehr dicht die Zweige von Fichten und Krummholzkiefern.

Rosellinia quercina, R. Hartig, an den Wurzeln I-3 jähriger Eichen. Die Pflanzen verfärben sich und sterben ab. Die Wurzeln sind von dichten Mycelsträngen umgeben, später treten die wie schwarze Körner aussehenden Sclerotien an denselben auf. Im Innern des Gewebes lassen sich durch das Mikroskop auch noch gefächerte Sclerotien nachweisen.

Dematophora necatrix R. Hartig. Tötet Wurzeln von Vitis, Acer, bildet rhizomorphenartige Stränge. 
Diatrype stigma Fr. auf abgestorbenen Ästen verschiedener Holzpflanzen, namentlich an Crataegus, Prunus, Quercus, Fagus. An dürren Zweigen brechen als Pusteln hervor: Valsa salicina Fr. an Weiden, Valsa stellulata Fr. an UImen, Hercospora Tiliae Fr. an Linden, Cryptospora suffusa Tul. an Erlen, Diaporthe Carpini Fuckel an Weissbuchen. Quaternaria Persoonii auf Fagusästen und Stämmen ist leicht an den in Form goldgelber Ranken entleerten Conidienmassen, welche aus der Rinde hervortreten, zu erkennen.

Gnomonia erythrostoma auf Prunus avium. Die Blätter werden infolge der Pilzinfection fleckig, sterben ab, die Früchte verkrüppeln oder gehen zu Grunde. Nach einigen Jahren stirbt der Baum ab. Perithecien auf dem Laube in Form schwarzer Punkte.

Otthia-, Nassaria-, Linospora-, Phyllostictaarten befallen Blätter verschiedener Laubholzgewächse. Sphaerelia Fragariae, Mori, Pseudacaciae Fraxini, Evonymi, fagicola bilden Flecken auf den Blättern, Stigmatea Mespili Blattflecken auf Cotoneaster, Mespilus, Pirus communis. Fusicladium tremulae bringt die Blätter von Populus tremula zum Schrumpfen. Fusicladium dendriticum, Ursache der Rostflecke auf Äpfeln und Birnen, auch auf Blättern.

Phoma ist eine auf toten Zweigen sehr verbreitete Pycnidenform, zu welcher die übrigen Entwickelungszustände fehlen. Phoma abietina R. Hartig, findet sich an absterbenden Weisstannenzweigen, aus deren Rinde Pycniden bis zur Grösse eines Stecknadelkopfes hervortreten.

Pestalozzia Hartigii an jungen Fichtenpflanzen. Die Rinde stirbt über dem Boden $a b$, während die etwas höher gelegenen Teile noch weiter in die Dicke wachsen. Nur Conidienpolster und Pycniden bekannt. Die Krankheit wurde früher auf Frostwirkung zurückgeführt. Septoria curvata zerstört Blätter von Robinia Pseudacacia, kann einjährigen Pflanzen gefährlich werden.

Diplodia sp. soll an Populus tremula haselnuss- bis taubeneigrosse Holzkröpfe verursachen.

2. Fam. Hypocreaceae.

Perithecien häutigfleischig oder fleischig, lebhaft gefärbt oder farblos. niemals schwarz. Conidien farblos oder in roten Tönen gefärbt.

Nectria ditissima Tul. Ursache des Krebses an den Stämmen verschiedener Laubhölzer, so an Fagus, Carpinus, Quercus, Corylus, Fraxinus, Alnus, Acer, Pirus u. a. Der Pilz inficiert Wunden, die sich infolgedessen vergrössern, während das umliegende Gewebe wulstige Überwallungsränder bildet (Fig. I63). Das Mycel wandert im Holzkörper, wodurch ein inficierter Stamm ganz mit Krebswunden bedeckt wird. An den Krebsstellen weisse Conidienpolster (früher Fusidium candidum genannt) und rote bis braune Perithecien.

Nectria cucurbitula, Wundparasit auf Fichten, namentlich an Frassstellen von Grapholitha pactolana. Nectria cinnabarina, sehr gemeiner 
Wundparasit an den verschicdensten Laubholzgewächsen, besonders auffallend sind die orangeroten Conidienpolster (früher als Tubercularia vulgaris bezeichnet).

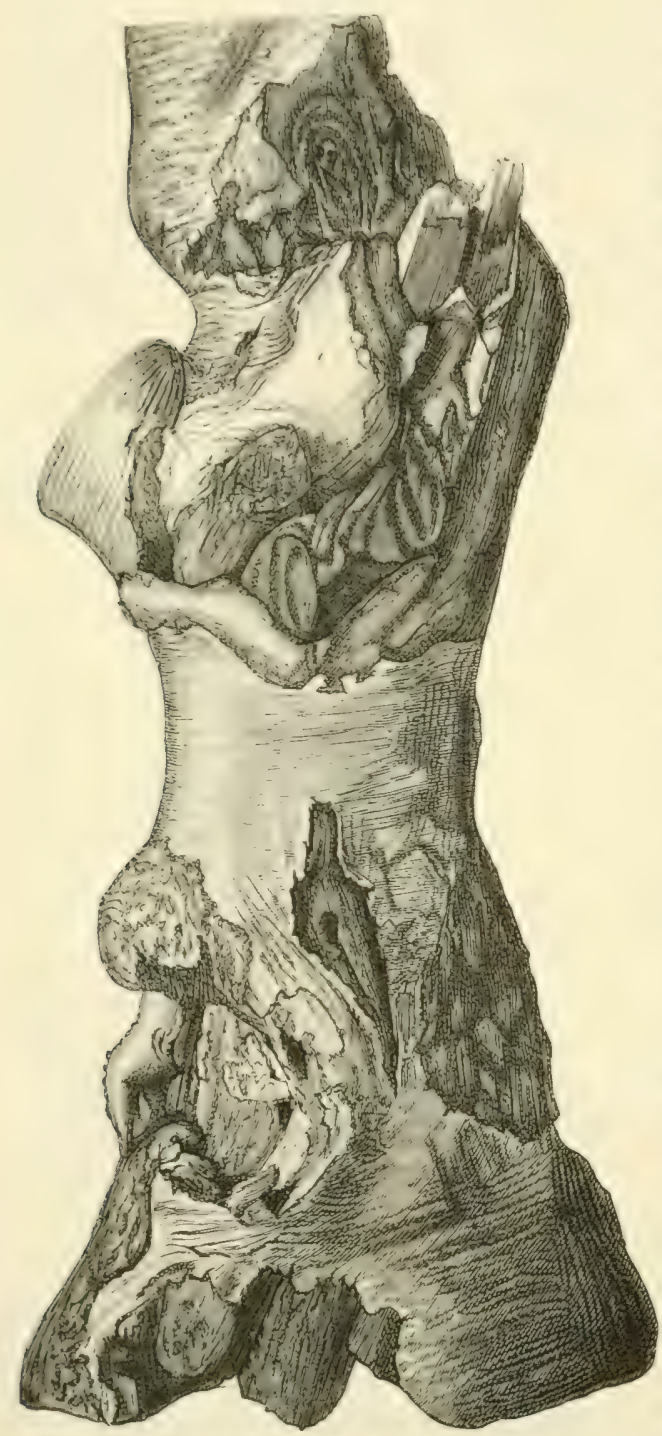

Fig. 163 .

Hainbuche von Nectria ditissima befallen.

Claviceps purpurea Tul. im Fruchtknoten verschiedener Gräser, namentlich des Roggens. Die grossen dunkelvioletten Sclerotien sind als das sog. Mutterkorn bekannt.

Die ebenfalls hierher gehörigen Cordicepsarten sind wichtig, weil sie grosse Epidemien unter forstlich schädlichen Raupen resp. Schmetterlingen anrichten. Die Schlauchfrüchte entstehen auf keulenförmigem, gestieltem Stroma. Die stattlichen Conidienbündel wurden früher als besondere Art aufgefasst (Isaria) bevor ihr Zusammenhang mit der Schlauchfruchtform bekannt war. Cordiceps militaris in Raupen resp. Puppen von Fidonia piniaria (Kiefernspanner), Trachea piniperda (Forleule), Gastropacha Pini (Kiefernspinner), Orgyia pudibunda (Rotschwanz). Auf verschiedenen Sphingiden kommt Cordiceps Sphingum vor. Die Muscardinenkrankheit der Seidenraupen wird durch einen Pilz Botrytis Bassiana hervorgerufen. Es handelt sich hier um eine Conidienform, welche möglicherweise zu einer Cordicepsart gehört. Ein mit Botrytis Bassiana wahrscheinlich identischer Pilz wurde an toten Raupen von Liparis monacha, der Nonne, gefunden.

3. Fam. Iylarieac.

Das Stroma ist entweder krustenförmig oder besitzt Keulenoder Hirschgeweihgestalt. Xylaria Hypoxylon L. sehr häufig auf faulendem Holz. 
4. Fam. Dothideaceae.

Perithecien fehlend, durch Höhlungen im Stroma ersetzt, in denen sich die Schläuche befinden.

Polystigma rubrum DC. ruft rote Flecken an den Blättern von Prunus domestica und Prunus spinosa hervor.

\section{Ordnung. Discomycetes, Scheibenpilze.}

Die Schlauchfrüchte (Apothecien) sind offene, häufig scheibenförmige oder becherförmige Gebilde. Das Hymenium kann aber auch die Oberfläche hutpilzähnlicher Fruchtträger (z. B. bei Morchella) überziehen. Bei den Hysteriaceen reisst die Schlauchfrucht erst später auf. Paraphysen, d. h. unfruchtbare Zellfäden neben den Schläuchen vorhanden (Fig. I65, 3). Ausser den Schlauchfrüchten werden Conidien in freier Abschnürung, Pycniden und Spermogonien gebildet.

I. Fam. Hysteriaceae.

Die Schlauchfrüchte öffnen sich lippenartig mit einem Längsspalt. Hülle häutig oder von kohlenartiger Beschaffenheit. Bei einzelnen Arten sind Pycniden bekannt, einfache Conidienträger fehlen.

Lophodermium pinastri Chev. (syn. Hysterium pinastri Schrad.) Ritzenschorf. Überall auf Nadeln von Pinus silvestris, ferner auf Pinus Laricio, P. cembra, P. Strobus, Picea (?), Abies (?). Auf die Bedeutung dieses Pilzes für die Schüttekrankheit der Kiefer wurde schon S. I77 hingewiesen. Das Mycel desselben wuchert in den Nadeln, kommt jedoch auch oberflächlich auf Nadeln und Rinde vor. Die Infection geht von einzelnen Stellen aus, die sich gelb bis rotbraun färben. Später sind die durch den Pilz befallenen Stellen durch schwarze Querstriche begrenzt, was besonders an der getöteten Nadel hervortritt. Von Fortpflanzungsorganen erscheinen zunächst Pycniden als kleine schwarze Punkte, später die Apothecien in Form von grösseren, schwärzlichen Längsstrichen. Die Apothecien entwickeln sich an den jungen Keimlingen ca. ein Jahr nach der Infection, bei älteren Pflanzen nach 2-4 Jahren. An den Nadeln erwachsener Pflanzen erscheinen sie zumeist erst nach dem Abfall.

Nach Rostrup soll bei der Schwarzkiefer das Pilzmycel auch in den Holzkörper eindringen, was bei Pinus silvestris bisher noch nicht nachgewiesen wurde. Die derartig inficierten Schwarzkiefern sterben ab, es tritt dies jedoch nicht wie bei der Schütte der gemeinen Kiefer in den ersten Lebensjahren ein, sondern erst im Alter von ca. 20 Jahren. Da diese Krankheit besonders in Dänemark und dem nördlichen Deutschland auftritt, in dem natürlichen südlicheren Verbreitungsgebiete der Schwarzkiefer fehlt, dürften klimatische Einflüsse die Wirkung des Pilzes unterstützen.

Lophodermium macrosporum Rehm an Picea excelsa. Befällt die grünen Nadeln, tötet sie und entwickelt die Schlauchfrüchte (in Form schwarzer Striche) an den abgefallenen Nadeln. 
L. ophodermium nervisecuium auf Tannennadeln, L. laricinum auf Lärche, L. juniperinum auf Juniperus communis, J. Sabina, J. nana, Lophodermium bachysporum tütet Nadeln und junge Triebe von Pinus

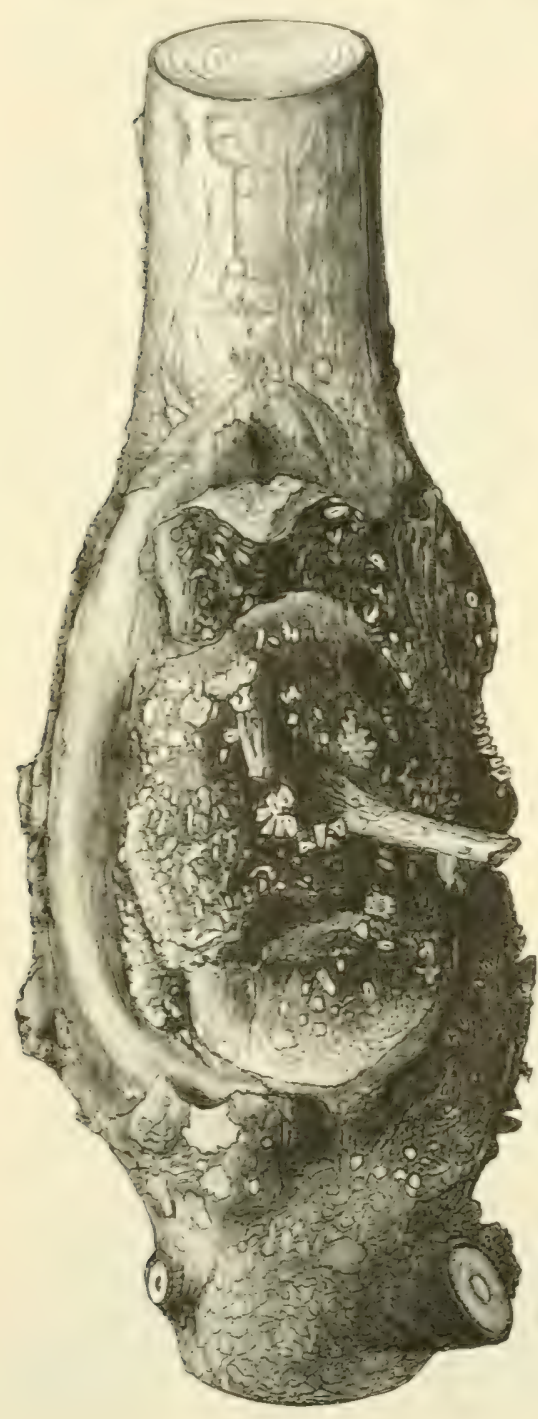

Fig. 164 .

Larix europaea mit Krebsstelle durch Peziza Villkommii verursacht. Strobus.

\section{Fam. Pezizeac.}

Fruchtschicht flach in einem schüsselförmigen, anfangs geschlossenen und dann weitgeöffneten Gehäuse.

Den Ubergang zu den Hysterieen bildet die Lnterfamilie der Phacidieae. Hierher gehört Rhyt is ma a c r in u m, Runzelschorf auf Acer platanoides, seltener auf anderen Ahornarten, bildet braune, später schwarze, grosse runzelise Flecke an den Blättern. Rhytisma salicinum auf $1 V^{\prime}$ eiden, namentlich auf Salix Caprea, S. aurita, S. purpurea.

Phacidium abietinum, Klappenschorf auf Tannenästchen.

Peziza IVillkommii R. Hartig, die Ursache des Lärchenkrebses. Sehr gefährlicher Wundparasit in der Rinde und dem Holzkörper der Lärche. Nach Absterben der Rinde, die an der befallenen Stelle eingesunken und häufig mit ausgeflossenem Harze bedeckt ist, treten am Wundrande weiss-rote Schüsselchen, die Apothecien, auf (Fig. I64). Der Pilz greift besonders in dumpfen Lagen und feuchten Sommern um sich. Das Absterben der Lärchen erfolgt ziemlich langsam, doch können sowohl junge als alte Pflanzen davon ergriffen werden.

Sclerotinia Libertiana (Peziza Sclerotiorum) zerstört Hanfpflanzen, Rüben von Brassica und Daucus, Stöcke von Phaseolus, Vicia Faba, Petunia und vielen anderen Pflanzen.

Sclerotinia Fuckeliana De Bary mit der häufig rorkommenden Conidienform Botrytis cinerea tötet in feuchten Gewächshäuscrn etc. die verschiedensten Pflanzen. An Trauben ruft der Pilz die Edelfäule hervor. Botrytis Douglasii auf Zweigen von Pseudotsuga Douglasii. Cenangium Ulmi, Parasit auf Zweigen. 
Pyronema confluens, rote Schüsseln auf Meilerboden, Bulgaria inquinans, grosse schwarzbraune Apothecien auf gefälltem Eichen- und Buchenholz.

3. Fam. Helrellaceac.

Fruchtschicht frei, die Aussenseite meist grosser, fleischiger und aufrechter Träger überziehend.

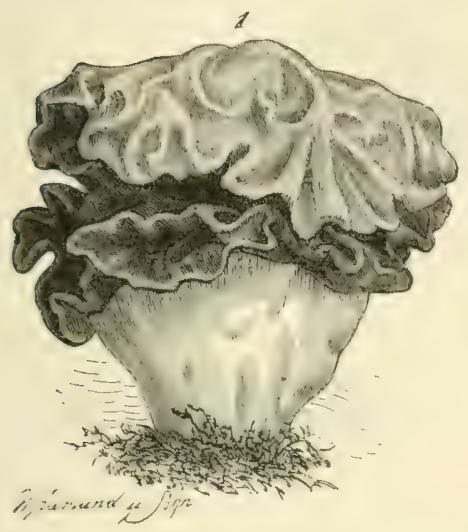

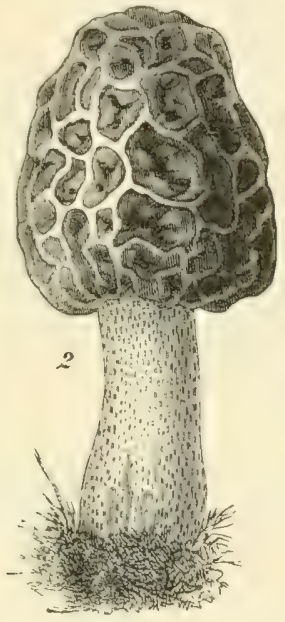

Fig. 165.

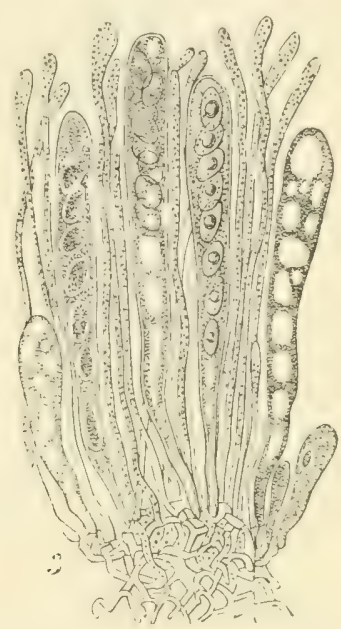

2. Morchella esculenta. 3. Sporenschläuche aus dem Apothecium von Peziza convexula. (IV.)

Helvella esculenta, Faltenmorchel oder Lorchel, (Figur I65, I) das Wasser der ersten Abkochung giftig, sonst essbar. Morchella esculenta, Speisemorchel (Fig. I65,2), Morchella conica, Spitzmorchel, beide essbar.

\section{$\S 51$. Lichenes, Flechten.}

Der Thallus der Flechten besteht aus symbiotisch vereinigten Algen und Pilzen (vgl. S. I43), welche sich auch isoliert weiter kultivieren lassen. Der Pilz bildet in den meisten Fällen eine festere Rinde (Fig. I66 a, d), wobei sich an der Unterseite oft Haftfasern (Fig. i66 e) entwickeln. Im Innern ist die Flechte aus locker verwebten Pilzhyphen (c) und den Algen (b) zusammengesetzt. Seltener ist die Filzwand gallertig. Da der Pilz Fruktifikationsorgane bildet, können wir konstatieren, dass unsere einheimischen Flechten alle zu den Ascomyceten gehören. In den Tropen kommen einige Flechten mit Basidiomycetenpilzen vor. Die Pilzsporen können direkt mit den Algen einen neuen Flechtenthallus bilden. Ausserdem vermehren sich die Flechten durch die sog. Soredien. Dic Flechte zerfällt hierbei in staubförmige Partikelchen, welche aus wenigen Algen und Pilzhyphen bestehen und durch den Wird leicht verbreitet auf Ästen, Stämmen, Brettern etc. zu neuen Flechtenüberzügen heranwachsen. 
Die Flechten schmarotzen nicht, trotzdem können gewisse sich masser:haft ausbreitende Arten, \%. B. Usnea barbata, Parmelia saxatilis, Evernia

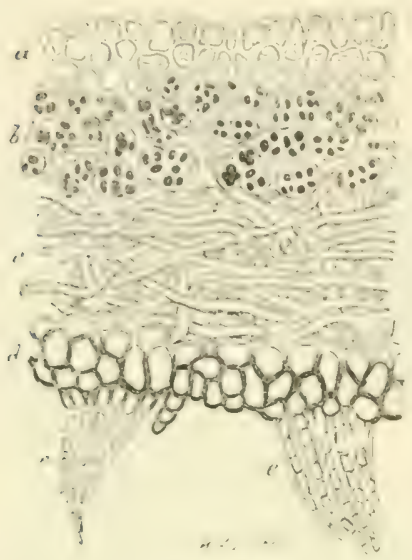

Fïg. 160

Suhnitt durch den Thallus von Sticta fuliginosa. (IV.)

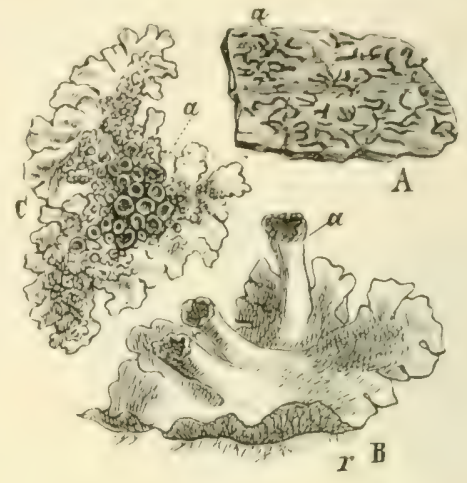

Fig. 167.

A Graphis scripta, B Peltigera canina, C l'hyscia parietina. (DN.)

prunastri, namentlich den Nadelhölzern dadurch gefährlich werden, dass sie die Blätter bedecken und ihnen das zur Assimilation notwendige

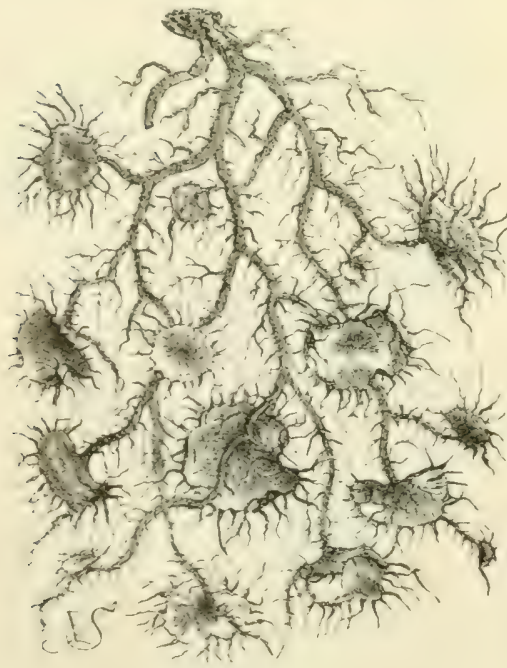

Fig. 16S.

Usnea barbata, mit zahlreichen Apothecien. (W.)

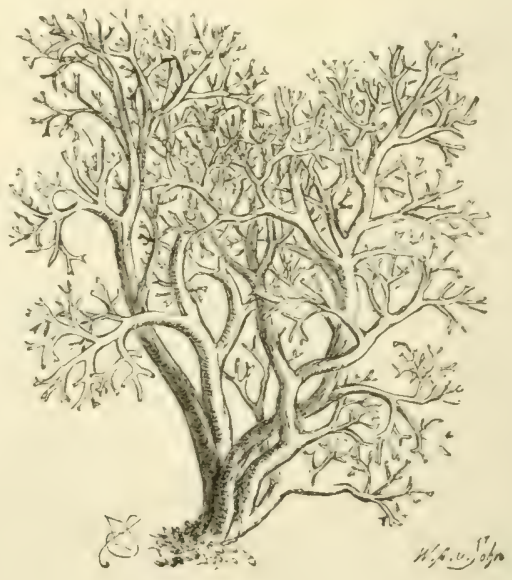

Fig 169 .

Cladonia rangiferina. (W.)

Licht wegnehmen. Die Nadeln und sodann auch die Äste sterben vorzeitig ab. Diese Flechten entwickeln sich besonders bei grösserer Luftfeuchtigkeit, sowie in schlecht wachsenden Beständen. 
Einteilung der Flechten:

I. Ascolichenes, Pilzsporen in Schläuchen.

A. Thallus homöomer d. h. Algen und Pilze nicht auf bestimmte Schichten beschränkt. Ephebe, Thallus nicht gallertig, Collema, Thallus gallertig.

B. Thallus heteromer Algen und Pilze auf bestimmte Schichten verteilt.

a. Pilz gehört den Pyrenomyceten an, Thallus krustenförmig: Pertusaria, laubig: Endocarpon, strauchig: Sphärophoron.

b. Pilz gehört den Discomyceten an, Thallus krustenförmig: Graphis scripta, Schriftflechte (Fig. I67 a), Lecanora, Lecidea, laubartig: Sticta, Parmelia saxatilis, Peltigera canina (Fig. I67 b), Physcia parietina (Fig. I67 c), strauchartig: Usnea barbata, Bartflechte (Fig. I68) Bryopogon jubatum, Evernia prunastri; Cladonia rangiferina Renntierflechte auf sehr schlechtem Boden, (Fig. I69), Cetraria islandica, Isländisches Moos.

II. Hymenolichenes, Sporen auf Basidien, Tropische Formen: Cora, Laudatea, Rhipidonema.

52. 12. Klasse. Ustilagineae, Brandpilze.

Parasiten auf höheren Pflanzen, deren Sporenmassen sich zumeist in Blüten und Früchten, seltener in Blatt- und Stengelteilen entwickeln.

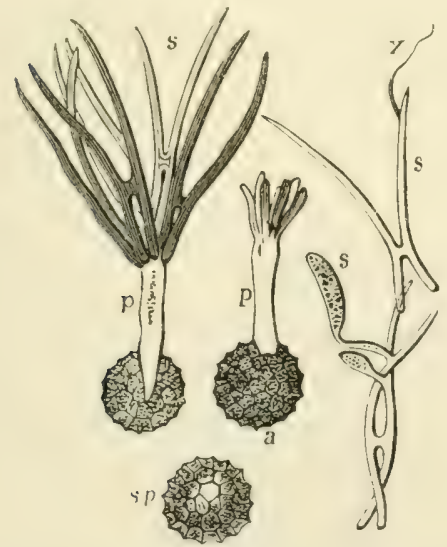

Fig. I 70.

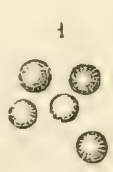

Fig. 17 I.

Sporen, Promycel und Sporidien von Tilletia Ustilago carbo. A Brandsporen, B keimende caries (n. Tulasne). Sporen mit Sporidien s (n. Frank).

Die Pilzfäden leben zwischen den Zellen der Gewebe, die schliesslich aufgezehrt werden. Aus dem Mycel entwickeln sich später braune bis schwarze Brandsporen (Chlamydosporen), die schliesslich das ganze be- 
fallene Oresan, meistens den Fruchtknoten, in eine schwarze Sporenmasse rerwandeln. Seltener stellen die Fruktifikationsorte bloss dunkle Flecken dar. Aus den Brandsporen (Figs. 170 s p und a, Fig. I I A.) entwickelt sich bei der Keimuns ein Promycel (Fig. I 0 P, Fig. I7 I B), welches sog. Sporidien trägt. Diese Sporidien können entweder seitlich (bei (L'stilago carbo, Fig. I I I Bs, Ustilago Maydis) oder an der Spitze (bei Tilletia Fig. I 70 s, Urocystis, Tuburcinia) entstehen. Eventuell können sich an den Sporidien (Fig. I jo rechts unten bei s.) sckundäre Sporidien ausbilden. Brefeld sicht in dem Promycel ein der Basidie der Basidiomyceten homoloses Gebilde, welches Conidien, hier Sporidien genannt, trägt. Durch diese Deutung wird die Verwandtschaft der Ustilagineen mit den Basidiomyceten und auch mit den Uredineen, wo sich ähnliche Gebilde rorfinden, festgestellt.

In guten Nährstofflösungen, in frischem Dünger erzeugen viele Ustilagineen durch lange fortgesetzte Sprossung der Conidien hefeartige Zellen, durch welche der Pilz leicht auf neue Pflanzen übertragen wird. Auch spätere Entwickelungszustände des Mycels können Pflanzenteile schimmelpilzähnlich ïberziehen. und Conidien abschnüren.

Geschlechtliche Vorgänge fehlen, ebenso ist keine endogene Sporenbildung vorhanden, abgesehen von Protomyces, welcher Pilz jedoch mehr ein Übergangsglied zu den Ascomyceten darstellt.

Tilletia caries. Steinbrand, Schmier- oder Stinkbrand. Die Fruchtlnoten von Triticum vulgare, Poa pratensis werden in eine ziemlich harte Sporenmasse verwandelt.

Ustilago carbo. Staubbrand. Der Fruchtknoten verschiedener Gramineen wird in eine schwarze, staubige Masse verwandelt. Ustilago Maydis, Maisbrand. Urocystis occulta bildet auf den Halmen von Secale cercale schwarze Rinnen.

\section{13. Klasse. Uredineae, Rostpilze.}

Das Mycel entwickelt sich im Innern lebender Blätter und Stengelteile, auf denen Sporenlager rotbraune oder schwarze Flecken und Striche, den sog. Rost, hervorrufen. Charakteristisch ist die Bildung verschiedenartiger Fortpflanzungszellen, die zum Teil auch auf verschiedenen Wirtspflanzen vorkommen.

Wir haben Uredos poren, Teleutos porenund Aecidiosporen, welche $\mathrm{in}$ besonderen Lagern rorkommen. Brefeld deutet dieselben als drei rerschiedene Chlamydosporenformen, welche demnach in ihrer Mannigfaltigkeit eine Weiterentwickelung der Chlamydosporenfruktifikation bei den Ustilagineen darstellen würde. Aus den Teleutosporen entwickelt sich ein Promycel, welches ebenfalls Sporidien trägt. Auch hier dürfte die Deutung des Promycels als Basidie, der Sporidie als Conidie, wie sie 
Brefeld vornimmt, zutreffend sein. Ausser diesen Fortpflanzungszellen finden wir noch Spermogonien, welche sehr kleine Conidien produzieren, deren Keimfähigkeit vielfach angezweifelt wurde, die eventuell als reducierte Organe anzusehen sind.

Einzelne dieser Fortpflanzungszellen können auch fehlen, doch sind Teleutosporen mit Promycelien immer vorhanden. Die einzelnen Fortpflanzungsformen hielt man frühei für gesonderte Arten und belegte sic demnach mit besonderen Namen. Zur Bezeichnung der Art verwendet man jetzt den Namen für die Teleutosporenform.

Zur Erläuterung des Gesagten möge der Entwickelungsgang von $\mathrm{P}$ u c c i nia graminis, dem Getreideroste angeführt werden, welche Uredinee mit den verschiedenartigen Fortpflanzungszellen versehen ist. An der Unterseite der Blätter von Berberis vulgaris erscheinen im Frühjahr rote Flecke, welche die Aecidien des Pilzes darstellen (Fig. I72). Umgeben von einer einschichtigen, becherförmigen Hülle (Peridie) bilden sich zahlreiche Sporenreihen, welche am Grunde des Aecidiums entspringen. Etwas vorher bilden sich an der Blattoberseite Spermogonien

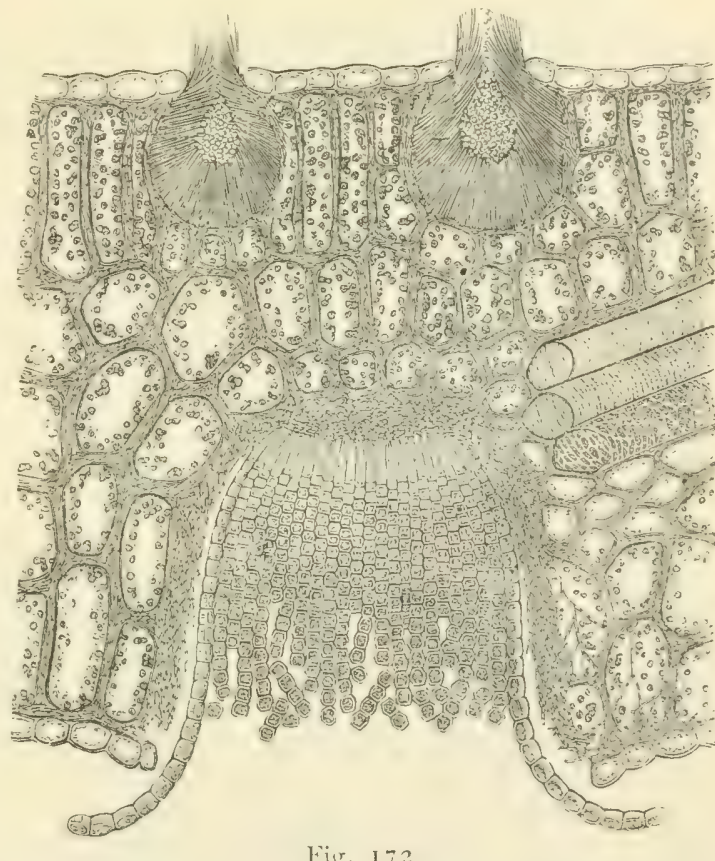

Fig. 172.

Blattquerschnitt von Berberis vulgaris auf der Oberseite zwei Spermogonien, auf der Unterseite ein Aecidium. (KW.)

(Fig. I72), die den entsprechenden Organen der Ascomyceten gleichen und sehr kleine Conidien liefern.

Die Aecidiosporen entwickeln sich auf Berberisblättern nicht weiter, sie keimen jedoch auf Stengeln und Blättern verschiedener Gräser, z. B. des Roggens (Fig. I73, 3) und dringen in das Gewebe dieser neuen Wirtspflanze ein. Im Laufe des Sommers brechen hier rostfarbige, länsliche Polster von Sporen hervor, die sog. Uredosporen (Fig. I73,5 U), welche direkt keimfähig sind (Fig. I73, 4) und neue Pflanzen inficieren können. Gegen Ende der Vegetationsperiode erscheinen an Stelle der einzelligen Uredosporen, zweizellige, schwarzbraun gefärbte Sporen, die Teleuto- oder Wintersporen (Fig. 173, $5 \mathrm{~T}$ ), welche überwintern und im Frïhjahr zu dem Promycelium auskeimen (Fig. I73, I). Das letztere 
schnürt die Sporidien ab (Fiss. 173, I Sp), welche sich erst auf Berberis rulgaris weiter entwickeln (Fig. $173,2 \mathrm{Sp}$ ). Das von ihnen gebildete Mycel erzeugt hier wiederum Accidien, wodurch der Entwickelungscyclus geschlossen ist.

Diejenigen Arten, welche zu ihrer vollständigen Entwickelung verschiedene Wirte brauchen, bezeichnet man als heteröcisch, im Gegensatz zu den autöcischen Formen, welche ihren ganzen Entwickelungscyclus nur auf einer Pflanze durchlaufen. Dieser Wirtswechsel bringt

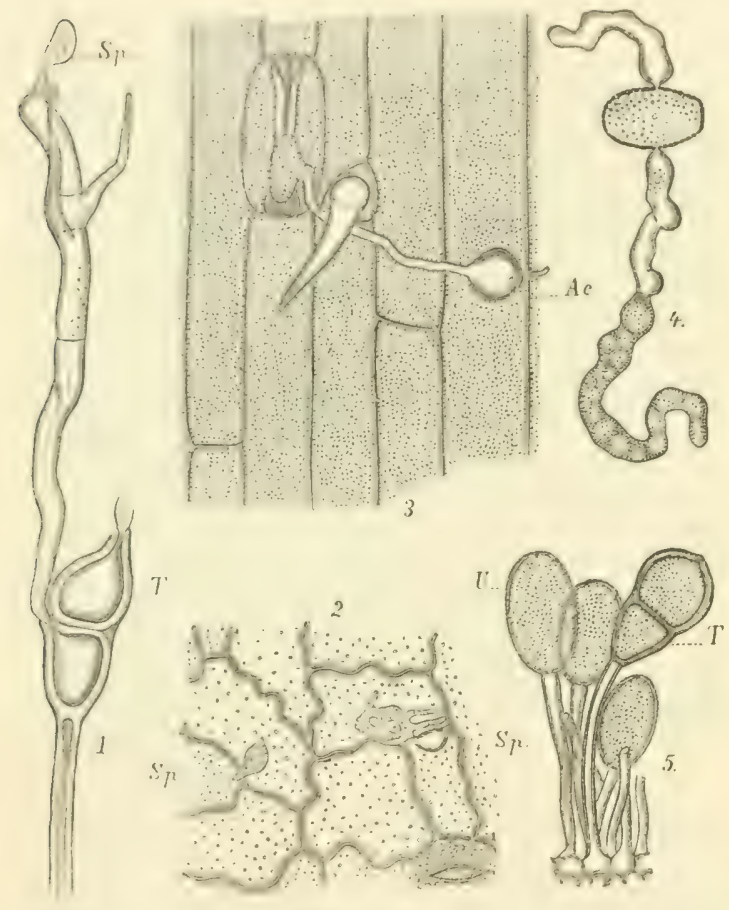

Fig. 173 .

Verschiedene Sporenformen von Puccinia graminis.

(KW.) es mit sich, dass wir noch nicht bei allen Pflanzen dic zu den Teleutosporen schörigen Aecidien kennen. Puccinia graminis (mit der Aecidienform Aecidium Berberidis und der Uredoform Uredo linearis). Puccinia straminis, Rost auf Roggen, Weizen, Gerste, dazu Aecidium auf Anchusa, Borago etc. Puccinia coronata auf Getreide, Hafer, Aecidien goldgelbe Anschwellungen auf Rhamnus frangula und Rhamnus cathartica.

Uromyces Pisi, Erbsenrost mit Aecidien auf Euphorbia Cyparissias, welche Pflanze durch den Pilz an der Verzweigung und normalen Ausbildung der Blätter gehindert wird.

Phragmidium subcorticium Rosenrost.

Gymnosporangium: Teleutosporen perennieren in der Rinde von Juniperusarten, sie quellen im Frühjahr als gelbe oder braune Gallerte aus der Rinde hervor. Das Vorhandensein von Uredosporen ist zweifelhaft. Aecidien unter dem Namen Roestelia auf Sorbus-, Pirus-, Crataegusarten. Der Pilz schädigt die befallenen Pflanzen häufis nur in geringem Grade.

Gymnosporangium fuscum, syn. G. Sabinae (Fig. I74): Teleutosporen auf Zweigen von Juniperus Sabina, J. virginiana, J. phoenicea, Pinus halepensis. Aecidien (früher Roestelia cancellata) auf Blättern von Pirus communis (Gitterrost der Birne), P. Nichauxii Bosc., P. tomentosa, Mespilus germanica, Crataegus monogyna. Gymnosporangium clavariaeforme: Teleutosporen auf Juniperus communis, Aecidien auf 
Crataegus oxyacantha und anderen Crataegusarten, Sorbus torminalis, Sorbus latifolia, Sorbus aucuparia, Cydonia vulgaris, Pirus malus seltener auf Pirus communis. Gymnosporangium conicum, syn. G. tremel-

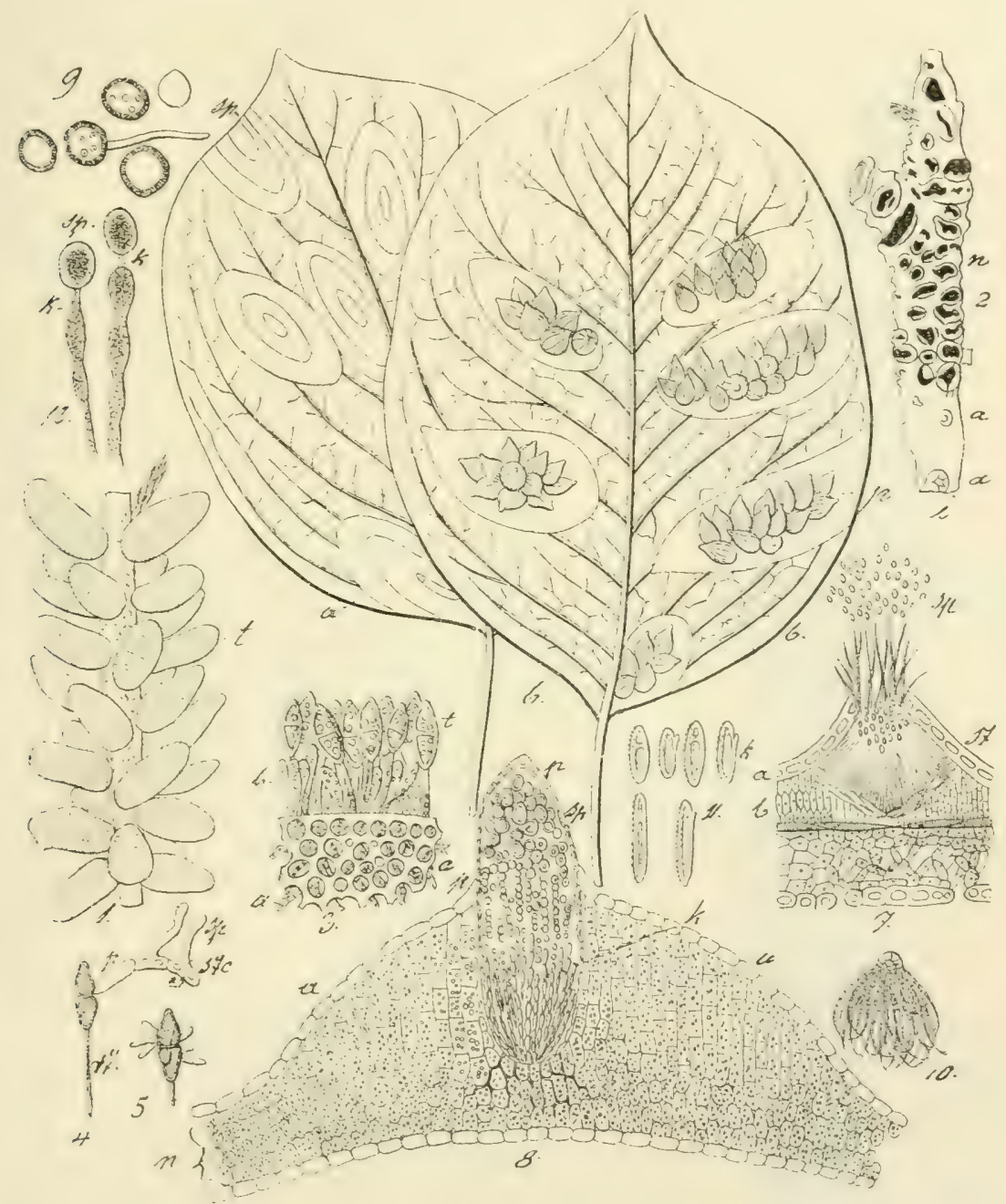

Fig. 174 .

Gymnosporangium fuscum. 1. Teleutosporenlager auf Juniperus Sabina. 2. Narben, welche der Pilz auf der Rinde dieser Pflanze hinterlässt. 3. Teleutosporen vergr. 4, 5. Keimung derselben. p Promycel, sp Sporidien. 6. Aecidien auf Pirus communis, a Oberseite, b Unterseite der Blätter. 7. Spermogonien mit sp Spermatien. S. Aecidium vergr. 9. Aecidiosporen. Io. Hülle des Aecidiums, I I. Zeilen der Hülle. I2. Abschnürung der Aecidiosporen (n. Sorauer).

loides R. Hartig, G. juniperinum: Teleutosporen auf Juniperus communis, Aecidien auf Sorbus aucuparia (Ebereschenrost) Sorbus torminalis, Sorbus Aria, Sorbus Chamaemespilus, Pirus Nalus, Cydonia vulgaris, Aronia rotundifolia, Amelanchier canadensis. 
Calyptospora Goeppertiana J. Kühn. Die Telentosporen bilden weit ausurebreitete Laser in den Epidermiszellen der Preisselbecre. Der Stengel derselben wird durch die Einwirkung des Pilzes abnorm verdickt. Die Aecidien entwickeln sich auf der Unterseite der Nadeln von Abies pectinata, wo sie zwei Reihen

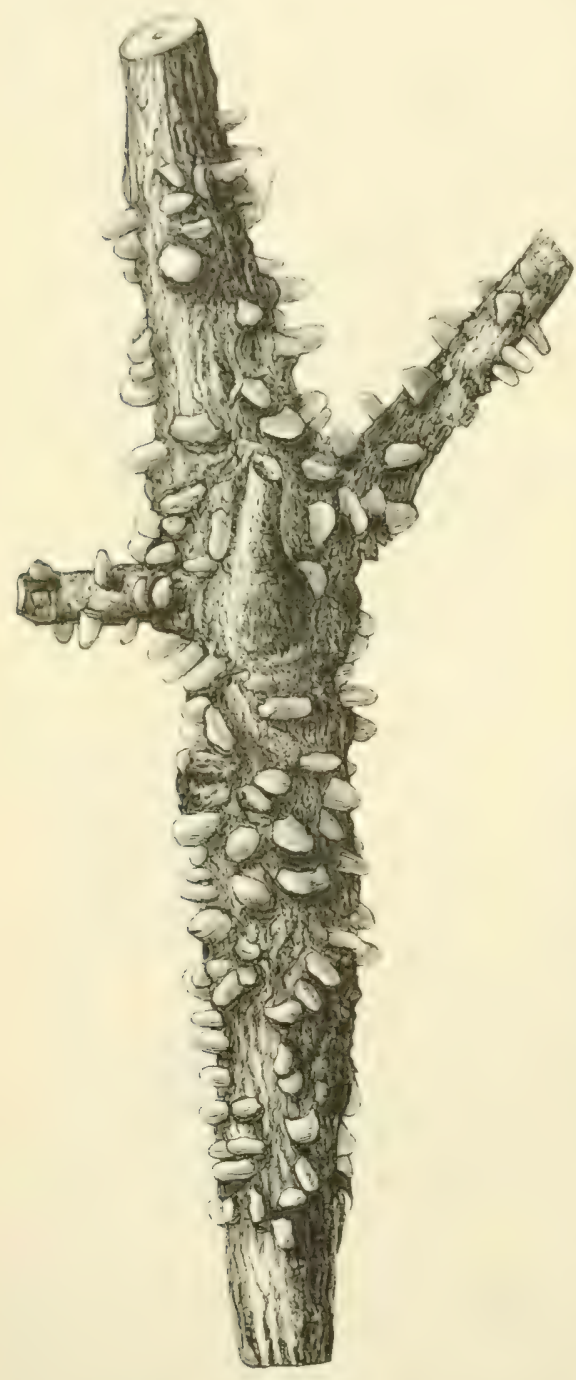

Fig. 175 .

l'inus silve-tris nit Aecidien von Coleusporium Senecionis f. corticola. kileiner Säulchen bilden (daher Säulenrost). Da die Nadeln noch längere Zeit am Leben bleiben, ist die Krankheit nicht so gefährlich. Die Accidienfruktfikation kann fehlen, dic Sporidien der Teleutosporen können direkt wieder Preisselbecren inficieren. Uredosporen fehlen.

Melampsora Tremula Tul. Auf den Blättern von Populus tremula erscheinen zuerst rundliche, lockere, gelbe bis rostfarbige Uredohäufchen, später schwarzbraune, kleine, scharf begrenzte Flecke, welche die Teleutosporen enthalten. Die Aecidien, fruher als die Gattung Caeoma bezeichnet, erscheinen auf Pinus silvestris, Larix europaea, Clematis vitalba und Mercurialis annua. Dic Kiefern werden besonders im jüngeren Alter befallen (I.-IO. Jahr). Im Juni treten an den Axenorganen derselben $\mathrm{I}-3 \mathrm{~cm}$ grosse blassselbe Stellen auf, welche zuerst Spermogonien, später die Aecidien tragen. Das Gewebe der eincr Infektionsstelle gegenüberliegenden Seite der Sprossaxe bleibt lebendig und indem die gesunde Seite weiter wächst entstehen an den Kiefernzweigen Krümmungen, weshalb man die an den Kiefern auftretende Aecidienform früher Caeoma pinitorquum genannt hat. Bei der Lärche entstehen Spermrgonien und Aecidien auf der Nadeln.

Ausser Populus tremula werden noch andere Pappelarten (Pop. nigra, P. balsamifera) durch Melampsoraarten befallen, deren Identität mit dem zuerst genannten Pilze nicht bewiesen ist. Aushieb ron Pappeln beseitigt diese Erkrankung von Kiefern und Lärchen. 
Melampsora Hartigii Uredosporen als rotgelbe Häufchen auf Blättern von Salix pruinosa, S. daphnoides, S. viminalis u. a. Teleutosporen ebenda, schwarze, stecknadelkopfgrosse Polster. Aecidien auf Ribesarten, können auch übersprungen werden, die Teleutosporen keimen sodann direkt wieder auf Weidenblättern. Die Weiden werden durch den Pilz vorzeitig entlaubt. Me la m p s or a c a prea ru m Uredosp. und Teleutosporen auf Salix caprea, S. cinerea, S. aurita, S. longifolia, S. repens, S. reticulata, Aecidien auf Evonymus europaeus. Melampsora epitea, auf

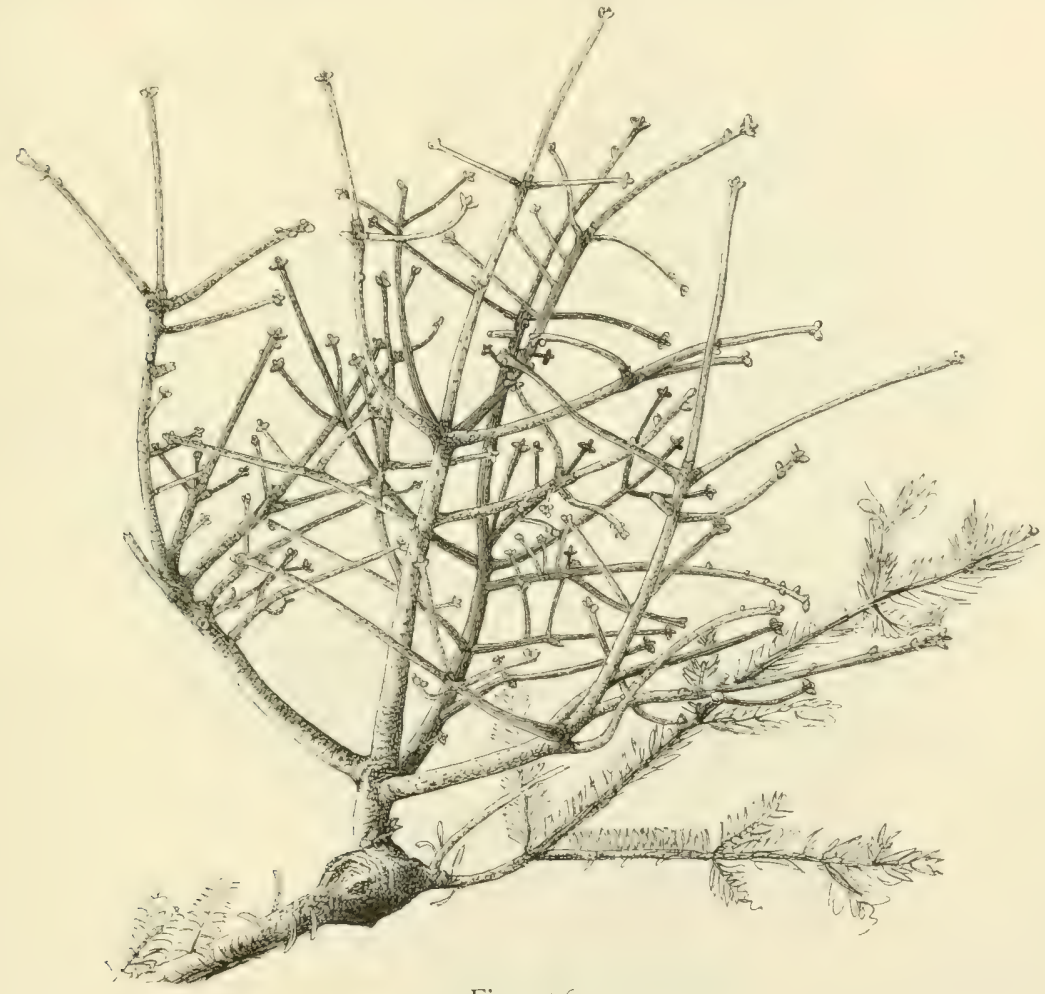

Fig. 176 .

Junger Hexenbesen von Abies pectinata (n. K. R. G. Schumann).

Salix alba, S. incana, S. purpurea, S. nigricans, S. retusa. Melampsora mixta auf Salix triandra, S. hastata, S. silesiaca. Ausserdem werden von Melampsoraarten befallen: Carpinus, Sorbus Aria, Sorbus aucuparia, Sorbus torminalis, Prunus Padus und Vacciniumarten.

Coleosporium Senecionis Teleutosporen bestehen aus Zellreihen, kommen ebenso wie die Uredosp. auf Senecioarten vor. Die Aecidien entwickeln sich auf verschiedenen Kiefernarten, Pinus silvestris, P. strobus u. a. (früher als Peridermium Pini bezeichnet). Das in dem Stamm lebende Mycel, forma corticola, ist die Ursache der als Kienzopf, Brand, Krebs bezeichneten Krankheit. Rinde und Cambium sterben ab, 
der Holzkörper verhar\%t. Der Gipfel der Kiefern scht zu Grunde, sobald das Pilzmyeel den sanzen Umfang des Kiefermstammes umfasst hat. Die

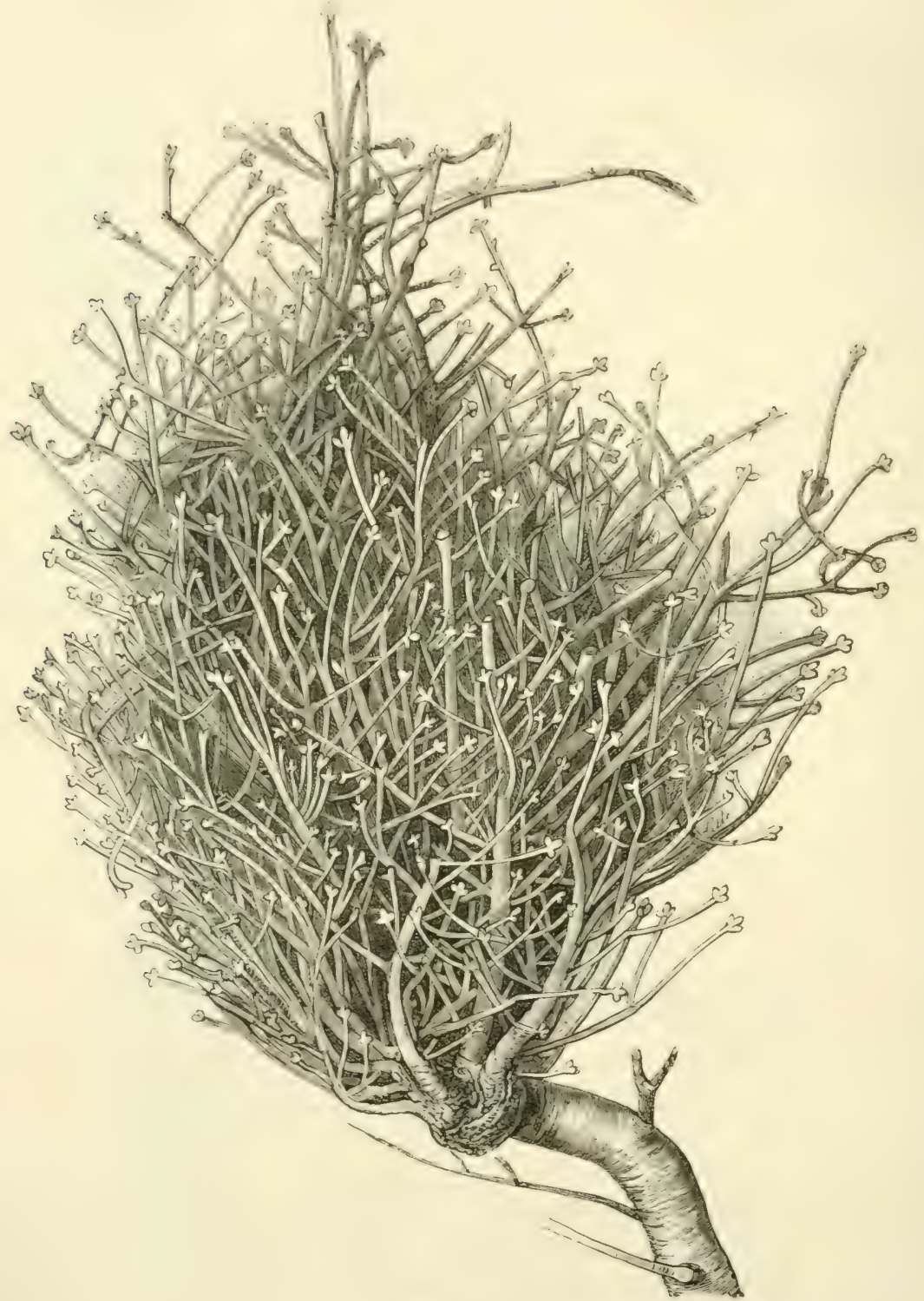

Fig. $17 \%$.

Alter Hexenbesen von Abies pectinata (n. K. R. G. Schumann).

Aecidien bilden fleischfarbige Blasen an den dünneren Sprossaxen (Fig. I75). Die zweite Form, acicola bildet Blasen auf den Nadeln.

Cronartium asclepiadeum Uredosporen und Teleutosporen auf 
Vincetoxicum officinale, Aecidien an der Rinde von Pinus silvestris. Cronartium Ribicolum Uredosporen und Teleutosporen auf Ribes nigrum, R. rubrum, R. aureum u. a. Aecidien auf Pinus strobus (Peridermium Strobi).

Chrysomyxa Abietis, Fichtennadelrost, nur Teleutosporen bekannt. Das Mycel färbt die Fichtennadeln goldgelb, doch bleiben teilweise grüne Binden erhalten. Teleutosporen in braunen, strichförmigen Lagern. Das Mycel überwintert in den Nadeln. Chrysomyxa Rhododendri Uredo- und Teleutosporen auf Rhododendron ferrugineum und Rh. hirsutum, Aecidien auf Fichtennadeln, die in dem Jahre der Infektion abfallen. Chrysomyxa Ledi Uredo- und Teleutosporen auf Ledum palustre, Aecidien auf Picea excelsa.

Isolierte Aecidienformen, Teleutosporen unbekannt:

Aecidium elatinum auf Abies pectinata. Mit dem Wuchern des Pilzes in Rinde und Jungholz ist entweder eine Steigerung des Dickenwachstums verbunden, wodurch Krebsbeulen entstehen, oder die Verzweigungsfähigkeit der Wirtspflanze wird vermehrt, es bilden sich dann sog. Hexenbesen. Die Verzweigung wird wie wir an Fig. I76 sehen unregelmässiger, die Richtung der Zweige ist eine abnorme. Nach längerem Wachstum erhalten wir schliesslich ein dichtes Gewirr von schwächlichen Ästen (Fig. 177).

Aecidium strobilinum. Zahlreiche, halbkugelige Aecidien auf Fichtenschuppen. Aecidium conorum Piceae, ebenda, jedoch nur je zwei Aecidien.

Aecidium coruscans macht Fichtennadeln und Triebe fleischig. Aecidium (Caeoma) Abietis pectinatae auf Tannennadeln bildet zahlreiche Spermogonien, sowie längliche, gelbe Sporenlager.

\section{$\S$ 54. 14. Klasse. Basidiomycetes.}

Diese Pilze producieren auf besonders gestalteten Tragzellen, den Basidien, eine bestimmte Anzahl (meist vier) Conidien, die man als Basidiosporen bezeichnet. (vgl. Fig. I55). Ausserdem kommen weniger bestimmt geformte Conidienträger vor, welche Conidien in unbestimmter Anzahl hervorbringen. Ferner sind Chlamydosporen bekannt, welche entweder in Form hefeartig sprossender Mycelien (Oidienform) auftreten oder sich Conidien ähnlich durch ihre Gestalt und Grösse, sowie durch die Färbung der Wand auszeichnen. Geschlechtliche Vorgänge fehlen vollständig.

\section{Ordnung. Protobasidiomycetes.}

Die Basiden sind mehrzellig. Ausserdem Conidien. Mit wenigen Ausnahmen sind die Basidienlager gallertig.

I. Fam. Auriculariaceae. Basidien lang, quer geteilt, Basidiosporen seitlich. Auricularia sambucina Judasohr, ohr- bis muschelförmige 
sallertige Fruchträger auf alten Stämmen von Sambucus nigra. Tachaphantium Tiliae an Lindenzweigen schwarze Gallerten bildend.

2. Fam. Tremellineac, Gallertpilze. Basidien rundlich, durch schräse Wände geteilt. Tremella lutescens, Gelber Zitterpilz auf abgefallenen Zweigen von Birken, Buchen, Hainbuchen etc. im Winter.

3. Fam. Pilacrecn. Basidien wie bei den Auriculariacen. Basidien im Innern eines geschlossenen Fruchtkörpers (angiocarp) Pilacre Petersii auf trockenen Hainbuchen.

\section{Ordnung. Autobasidiomycetes.}

Basidien ungeteilt, keulig, mit zumeist vier Sporen an der Spitze.

\section{Unterordnung. Hymenomycetes.}

Meist grosse Pilze, wie die sog. Hutpilze oder Schwämme. Das Basidien tragende Hymenium nicht in geschlossenen Behältern, es überzieht

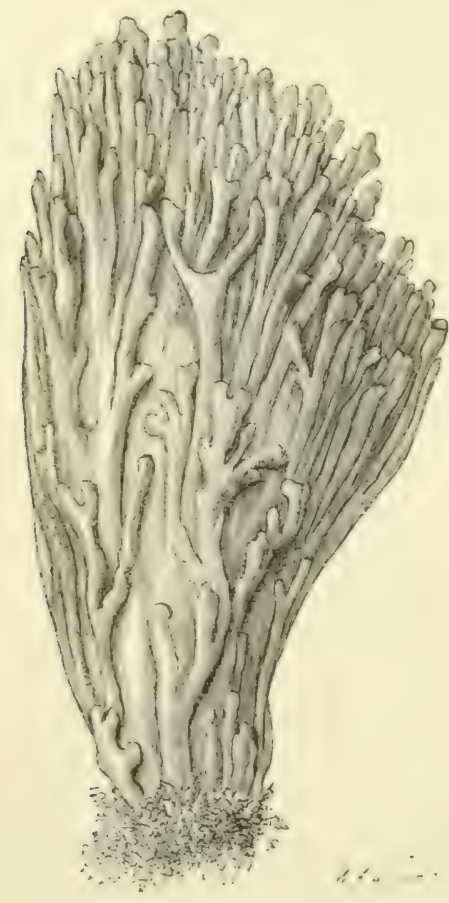

Fig. 178.

Clavaria flava. (IW.) Röhren, Blätter, Stacheln von Fruchtkörpern. Die letzteren sind entweder schirmförmig, keulenförmig verzweigt oder stellen Konsolen und ausgebreitete Polster dar. Das Mycel vegetiert in humoser Erde, faulendem Holz, seltener parasitisch in Bäumen. In Europa circa 2700 Arten.

I. Fam. Tomentelleac. Basidien lagerartig, keine eigentlichen Fruchtkörper.

Exobasidium Vaccinii bewirkt Deformationen an Preiselbeer- und Heidelbeersträuchern. Corticium quercinum und C. giganteum, lederförmige Krusten an gefällten Eichen- resp. Kiefernstämmen.

2. Fam. Clavarieae. Fruchtträger fleischig, dendritisch verzweigt, essbar. Clavaria (Sparassis) crispa Ziegenbart, Clavaria flava ebenfalls als Ziegenbart bezeichnet. (Fig. I78.) Clavaria botrytis, Bärentatze, roter Hirschschwamm.

3. Fam. Dacryomyceteae, Fruchtträger gallertig, Basidien lang, keulenförmig.

Dacryomyces deliquescens, gelbe oder rote gallertige Tropfen auf totem Holz.

4. Fam. Tele phoreae. Hymenium gleichförmig glatt, auf flach ausgebreiteten, dem Substrat aufliegenden cder becherförmigen Fruchtkörpern.

Telephora laciniata Fruchtträger blattartig, zerschlitzt, rotbraun, umschliesst und erstickt eventuell junge Fichten, Tannen, Weymouthskiefern 
und Pflanzen von Chamaecyparis Lawsoniana, seltener an Rotbuchen. Telephora terestris in Kiefernwäldern auf dem Boden. Telephora perdix, das Mycel entwickelt sich im Eichenholz, das tief rotbraun gefärbt wird, später treten weisse, scharf umgrenzte Höhlungen auf (Rephuhnholz).

Stereum hirsutum auf verschiedenen Laubbäumen, besonders Eichen, Buchen, Pappeln, auch an Brettern etc. An Eichen entsteht durch

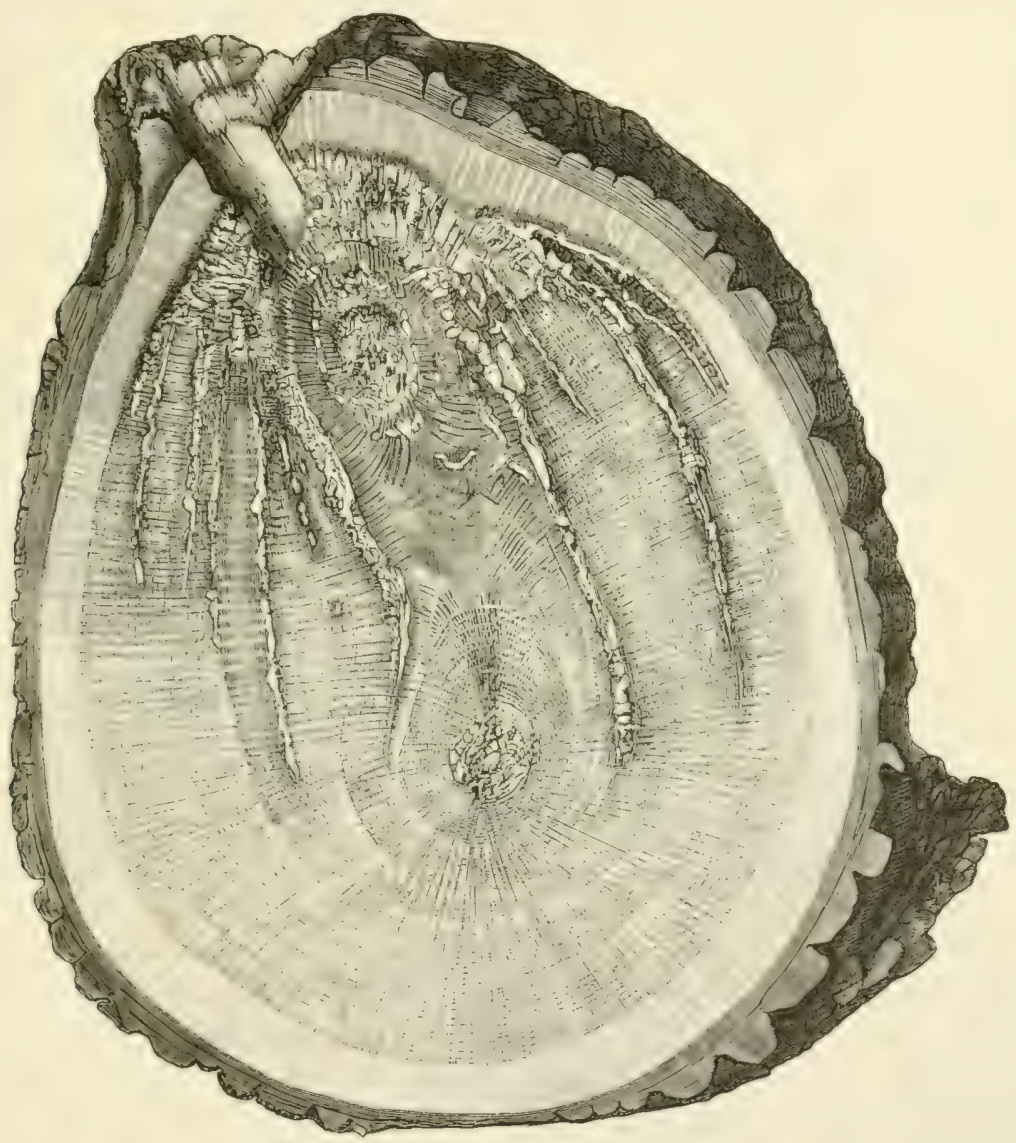

Fig. 179.

Eichenholz durch Mycel von Polyporus sulfureus zersetzt.

diesen Pilz gelb- und weisspfeifiges Holz, auf dem Querschnitt weisse Flecke, später grössere rein weisse Pilzmassen aus äusserst feinen Fäden bestehend. Fruchtträger krustenförmig.

5. Fam. Hy d n a c e e, Stachelschwämme. Fruchtträger schirmförmig, oder krustenförmig. Das Hymenium überzieht Zähne, Stacheln, Warzen.

Hydnum diversidens auf Eichen und Rotbuchen. Holz wird gelblich aschgrau, anfangs hellbräunlich. Fruchtträger gelbweiss. 
Hydnum imbricatum, Iabichts- oder Stachelschwamm und Hydnum repandum, Stoppelschwamm essbar.

6. Fam. Polyporeac, Löcher-oder Porenschwämme. Fruchtträger hut- oder konsolenförmig, seltener als Krusten. In denselben lïcher oder Röhren, welche ron dem die Sporen producierenden Iymenium ausgekleidet werden.

Polyporus igniarius, falscher Fenerschwamm, gemeinster Parasit der meisten Laubhölzer, besonders an Weiden. Eichenhol\% wird zunächst rotbraun, erhält helle Streifen, bis sich schliesslich eine gleichmässig gelbweisse Färbung einstellt. Die Ränder der Infelitionsstellen sind dunkelbraun. Fruchtkörper erst beulen-, dann konsolenförmig, hart, oben grauschwärzlich, Unterseite (Hymenium) braun.

Polyporus fomentarius, Zunderschwamm, echter Feuerschwamm. An Laubholzstämmen, besonders an Buchen. Fruchtkörper unter der rauchgrauen harten Rinde weich flockig, Holz weissfaul.

Polyporus sulphureus, an Eichen, Akazien, Erlen, Weiden, Pappeln, Nussbäumen und Birnbäumen, Lärchen. Erkranktes Eichenholz wird erst fleischrot, dann hell rotbraun (Rotfäule), später werden radiale und tangentiale Risse mit derben Mycelmassen erfüllt. In Fig. I 79 sehen wir den Querschnitt durch einen Eichenstamm, welcher von der Astwunde aus inficiert worden ist. Der Pilz ist verschieden tief in die Stammscheibe eingedrungen. Fruchtträger weich, schwefelgelb, stehen meist zahlreich übereinander.

Polyporus dryadeus an Eichen. Im festeren Holz treten weisse, unregelmässige Striche und Flecke auf.

Polyporus betulinus an Birken, bewirkt Rotfäule. Fruchtträger erst kugelig, später konsolenförmig, hellbraun.

Polyporus laevigatus an weissfaulen Birken. Fruchtträger dunkelbraune Krusten.

Polyporus fulvus an Tannen und Fichten. Das Holz wird schmutzig hellgelb, mit wenig scharf hervortretenden weissen Flecken. Mycel und das Innere der Fruchtträger gelb, die Rinde der letzeren aschgrau.

Polyporus borealis an Fichten. Holz in der Farbe wenig verändert, wird durch horizontale Mycelplatten in kleine Würfel zerlegt. Fruchtträger weisslich, vergänglich.

Polyporus vaporarius an Fichten und Kiefern. Holz anfangs hellbraun, später dunkel rotbraun, mit verticalen und horizontalen Rissen. Die Fruchtträger bilden weisse, krustenförmige Überzüge.

Polyporus mollis an Kiefern. Krankes Holz rotbraun, mit Rissen, doch nicht so mürbe wie bei $P$. vaporarius, besitzt einen scharfen Terpentingeruch. Fruchtträger rotbraun, die Hyphen daran teilweise srünlich.

Polyporus officinalis an Lärchen, hauptsächlich in Russland, enthält einen purgierenden Bestandteil.

Trametes Pin i, in den Kiefernbeständen Norddeutschlands sehr ver- 
breitet, in Süddeutschland mehr an Fichten, sonst rech an Lärchen und Tannen. Das Holz der Kiefern wird zunächst rotbraun, sodann treten unregelmässig geformte Löcher auf (Fig. I SO), die sich namentlich in dem Frühjahrsholze ausbreiten, während das Herbstholz zunächst noch erhaiten bleibt. Diese ringförmige Zersetzung des Holzes hat die Bezeichnun als Ringfäule veranlasst. Die Flecke und Löcher sind weiss und heben? sich deutlich von dem übrigen rötlichen Holze ab. Das Splintholz wird vom Pilzmycel nicht angegriffen. Die Infektion mit Pilzsporen erfolgt an Astwunden, älteren Stämmen (vom 40. Jahre ab), Fruchtträger nur an

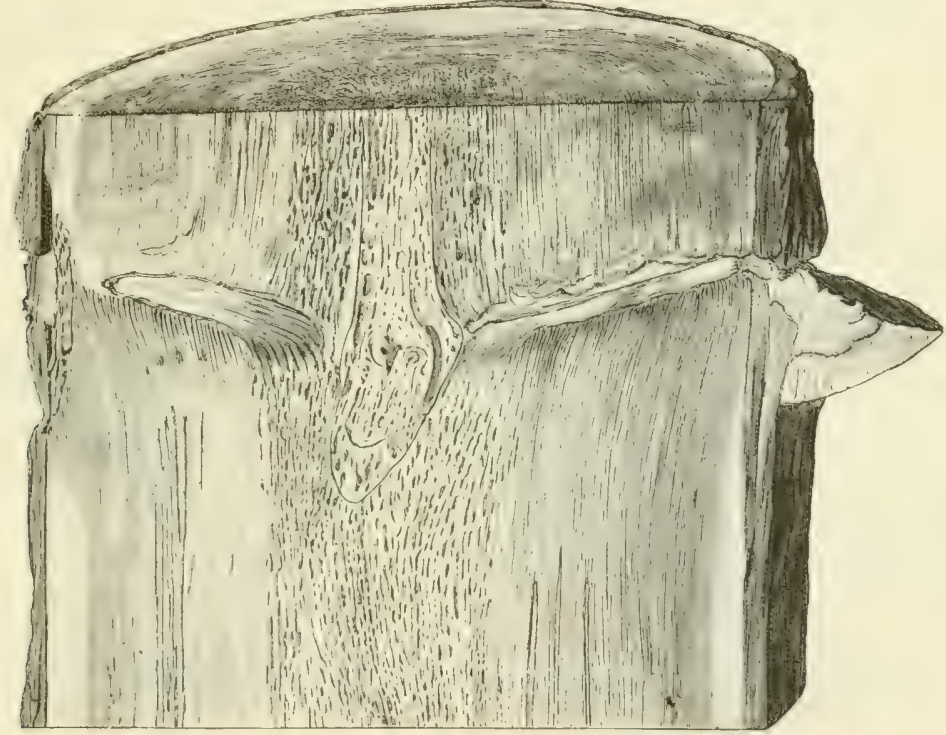

Fig. I 80 .

Theil eines Stammes von Pinus silvestris durch Trametes Pini zersetzt.

älteren Stämmen, sie treten häufig an Astwunden hervor (Fig. ISO). Es sind derbe holzige, weiter wachsende Konsolen oder unregelmässig vorgewölbte, wulstige Lager, die anfangs hell rotgelb, später schwärzlichgrau gefärbt sind.

Polyporus annosus Fries (syn. Heterobasidion annosum Brefeld, Trametes radiciperda R. Hartig). Eine der gefährlichsten und verbreitetsten Krankheiten der gewöhnlichen Kiefer, ferner noch an Weymouthskiefern, Fichten, Wachholder, Tannen, Birken, seltener an Erlen, Rotbuchen, Weissdorn. Sowohl 5-Iojährige als ganz alte Kiefern werden von der Krankheit ergriffen. Das Pilzmycel breitet sich in der Erde aus, inficiert die Wurzeln und dringt von hier aus in den Stamm. Zwischen Holz und Bast zeigt sich gar kein oder nur ein äusserst feines Mycel (Unterschied von Agaricus melleus). Von einem Krankheitsheerde aus 
entstehen grosse Bestandeslieken, deren Vergrösserung man durch Anbringung von Isoliergräben nicht verhindert. Die noch grünen Bäume sterben plötzlich ab, wenn das Myeel die Wasser fïhrenden Gewebe zerstört hat. Das Holz wird hellbräunlichgelb, zeigt kleine schwarze Flecken, welche sich später mit einer weissen Zone umgeben. Das zersetzte Holz ist hell braungelb, rotfaul, nic schwarzbraun. Fruchtträger zumeist unterirdisch, an der Basis des Stammes (Fig. I8I) oder an Wurzeln, krustenförmigs mit wulstigen Rändern, gelblich weiss. In Skandinavien sind oberirdische Fruchtträger am häufigsten.

Polyporus annosus ist durch die Bildung eigentümlicher Conidien ausgezcichnet, die in grosser Anzahl auf köpfchenförmig gestielten Trägern

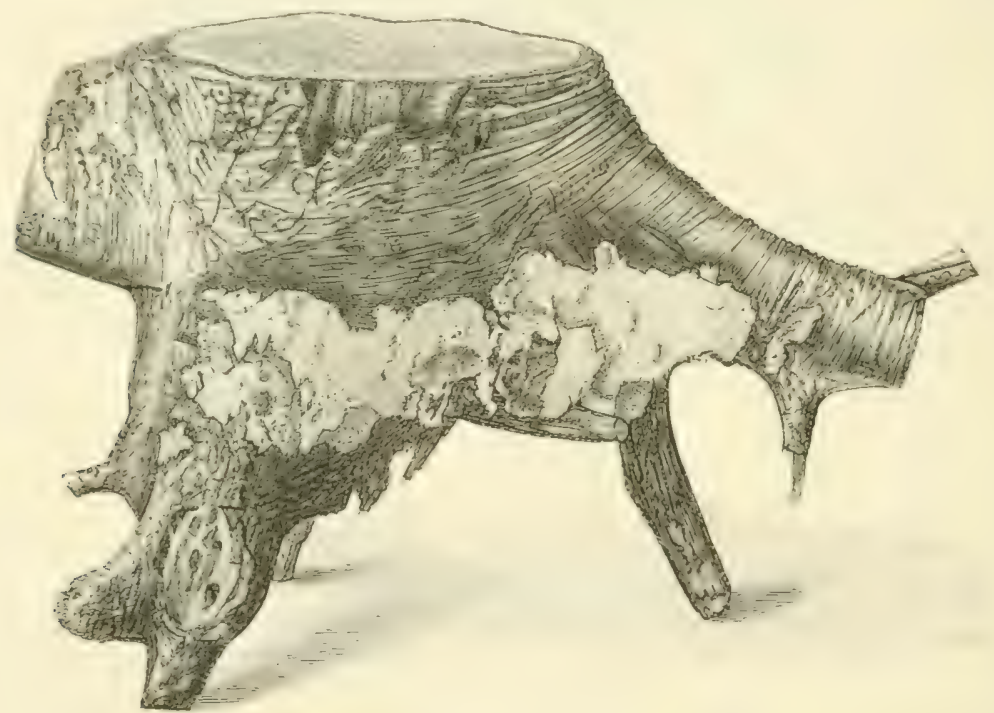

Fig. $\mathbf{I} \mathbf{I}$.

Fruchtträger von Polyporus annosus an einer Kiefer.

entstehen, sobald das aus den Basidiosporen hervorgegangene Mycel in geeigneter Weise ernährt wird (daher der Name Heterobasidion). Da die Laubhölzer durch den Pilz wenig oder gar nicht leiden, sind einmal inficierte Flächen mit Laubhölzern zu bepflanzen.

Daedalea quercina an Eichen. Hymenium in weiten Löchern oder gewundenen Gängen an den konsolenförmigen Fruchtträgern.

Merulius lacrimans, Hausschwamm. Im feuchten Holz der Häuser, im Freien sehr selten. An den grossen weissen Mycelüberzügen und dem fleischigen rotbraun-weisslichen, geaderten Hymenium zu erkennen.

Mit den bisher behandelten Polyporeen ist die Zahl der holzzerstörenden Pilze dieser Familie keineswegs erschöpft. Die Anführung der 
genannten Arten genügt jedoch um die Gefährlichkeit dieser Pilzgruppe nachzuweisen. Da die Pilze fast immer Wundparasiten sind, hat man vor allem Verletzungen hintanzuhalten. Es ist dies jedoch leichter gesagt, als gethan. Ist ein Stamm einmal inficiert, so sollte er, wenn es wirtschaftlich irgend wie zulässig ist, sobald als möglich entfernt werden. Das Holz dieser Schwammbäume wird mit der Zeit immer minderwertiger, entsprechend dem weiteren Umsichgreifen des Mycels im Stamme. Ausserdem wird die Gefahr der Ansteckung durch Aushieb der Fruchtträger producierenden Stämme wesentlich vermindert.

$\mathrm{Zu}$ den Polyporeen gehört ferner noch die auf humoser Erde lebende Gattung Boletus mit gestielten, hutförmigen, fleischigen Fruchtträgern. Die Hymenialschicht kleidet wie bei Polyporus feine Kanäle aus, welche sich auf der Unterseite des Hutes befinden. Die mit einem Ringe am Stiel versehenen Arten sind essbar. Diejenigen Arten, welche keinen Ring am Stiel haben sind giftig, sobald die Röhrenfläche von aussen rostbraun oder rot ist, oder der gelbliche Stiel rotgeadert ist und beim Anschneiden blau wird. Am bekanntesten ist Boletus edulis, der Steinpilz (essbar).

7. Fam. Agaricineae, Lamellen-

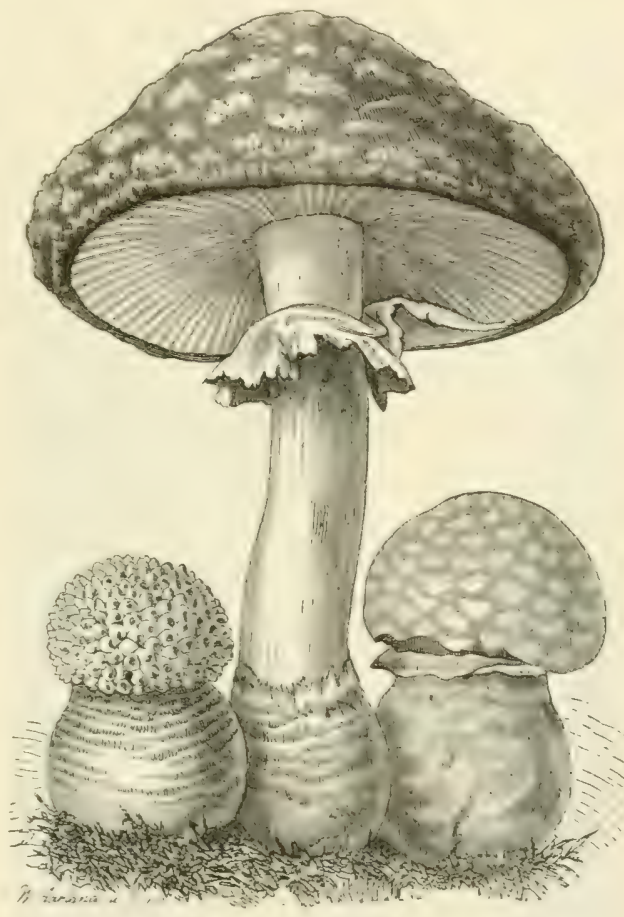

Fig. I82.

Agaricus r.uscarius, Fliegenpilz. (W.)

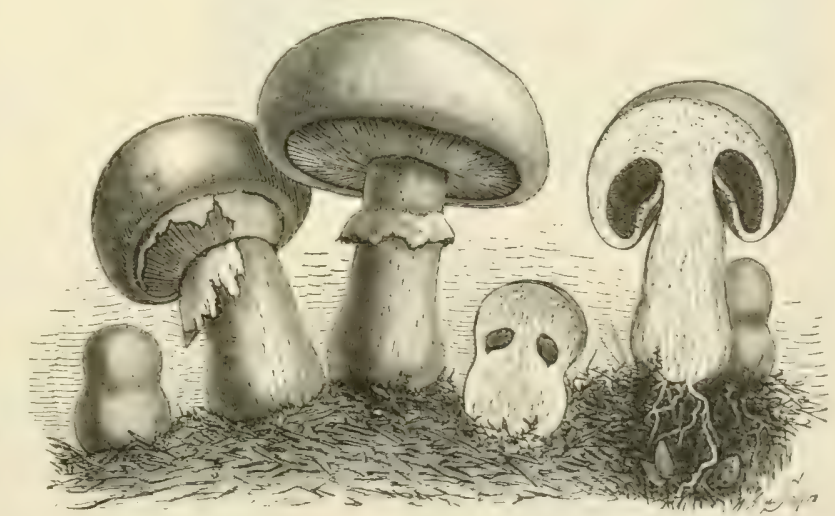

Fig. ${ }_{1} S_{3}$.

Agaricus campestris, Feldchampignon. (WV.) o der Blätterschwäm m e.

Das Hymenium überzieht dünne Lamellen (in der Pilzsystematik viel- 
fach Blätter semannt), welche sich auf der Unterseite des hutförmigen Fruchttrïgers befinden und strahlenförmig vom Sticle ausgehen.

Die Fruchtträger lïnnen anfangs von einem häutigen Hyphengewebe cingeschlossen werden (Velum universale oder Volva, Schleier), das spöiter zerreisst, dessen Reste am Grunde des Stieles (unterer Ring) oder als Warzen auf der Hutfläche (Fis. I \$2) zurüickbleiben. Andere Gattungen haben ein Velum partiale, das bei der Ausbreitung des Hutes am Stiele selbst sitzen bleibt (Fig. I82

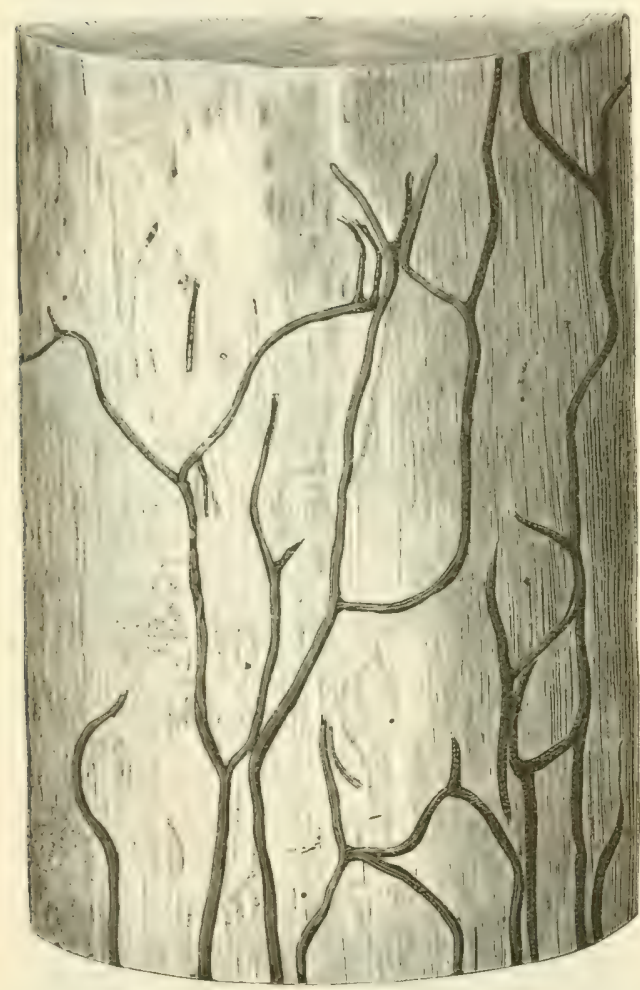

Fig. 184 .

Rhizomorphen von Agaricus melleus einen Holzklotz uiberziehend. und Fis. I 83 ). Das Velum kann auch ganz fehlen. An die 2000 Arten, die fast sämtlich auf humosem Boden vorkommen.

Asaricus melleus (Armillaria mellea) Hallimasch, Honigpilz. Sehr verbreiteter

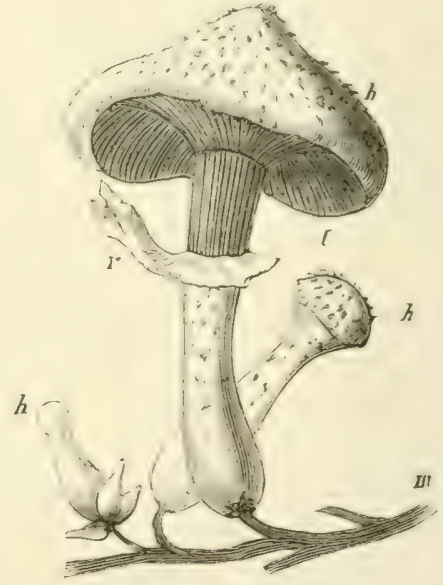

Fig. 185 .

Fruchtträger von Agaricus melleus aus Rhizomorphen hervorgegangen.

Parasit, der sämtlichen Nadelhölzern, unter den Laubhölzern den Kirschen- und den Pflaumenbäumen, gefährlich wird. Saprophytisch auf Humus, toten Wurzeln und Wurzelstöcken, Bergwerkshölzern etc. Er crgreift sowohl ganz junge als alte Bäume. Der Pilz ist durch die Bildung von Rhizomorphen ausgezeichnet, die sowohl in der Erde, als zwischen Rinde und Holz (Fig. I 84) als schwarze Stränge vorkommen. Die Rhizomorphen können in die Wurzeln der lebenden Pflanze eindringen und sich dort unter der Rinde in ein derbes flächenartig aussebreitetes weissliches Mycel auflösen, das am Stamm hinaufwächst und 
die Zerstörung der peripherischen Teile des Holzkörpers bewirkt. Die letzteren füllen sich mit Harz, das zum Teil auch aus der Pflanze austritt, sodass die Erdpartikelchen ganz mit dem Stamm und den Wurzeln verklebt werden. Die Krankheit wurde daher früher als Harzsticken oder Harzfülle bezeichnet. Nachdem durch die Thätigkeit des Pilzes die wasserleitenden Gefässe zerstört sind, stirbt der Baum schnell ab. Das Holz wird meist faul, die durch den Pilz inficierten Stellen sind durch eine schwarzbraune Linie begrenzt.

Die Fruchtträger (Fig. I 85) erscheinen meist gesellig an der Basis des Stammes. Die Oberfläche des Hutes ist honiggelb und mit schwarzen Schuppen versehen. Die Fruchtträger sind essbar.

Agaricus velutipes, ebenfalls rhizomorphenähnliche Stränge bildend, beschädigt Ulmen.

Agaricus campestris (Fis. Is3), A. silraticus, A. arrensis, Champignonarten. Die Lamellen werden rötlich-violett, während sie bei dem ähnlichen giftigen Agaricus (Amanita) phalloides immer weiss bleiben.

Agaricus Prunulus, Mousseron, Lactuarius volemus, Brätling, Lactuarius deliciosus, Reitzker. Cantharellus cibarius, Pffferling, Agaricus (Tricholoma) gambosum, Maischwamm, auch Mousseron, Agaricus (Tricholoma) graveolens, echter Mousseron, alle essbar. Agaricus caesarius, Kaiserling, fast gelbe Blätter, essbar, zu verwechseln mit dem schr giftigen Agaricus muscarius, Fliegenpilz (Fig. I82), Lamellen weiss.

\section{Unterordnung. Gasteromycetes. Bauchpilze.}

Das Hymenium liegt in dem Innern eines kammerigen Fruchtkörpers, der von einer festeren Hülle umgeben ist, die später aufreisst. Saprophyten.

Phallus impudicus Gichtschwamm, Stinkmorchel. Cyathus striatus, Becherpilz. Scleroderma vulgare, Hartbovist. Lycoperdon bovista, Riesenstäubling. Lycoperdon gemmatum, Warzenstäubling.

\section{Bryophyta oder Muscineae, Moose.}

Wie wir schon früher gesehen haben (vgl. S. I 88 und I89), besitzen die Algengattungen Ulothrix und Coleochaete $z$ wei Generationen, eine geschlechtliche und eine ungeschlechtliche. Diese beiden Generationen werden bei den Moosen weiter ausgebildet und finden sich, wenn auch in mannigfaltiger Gestalt bei den farnartigen Pflanzen und Phanerogamen wieder. Durch die Verfolgung dieser Generationsverhältnisse wird es erst möglich, die Verwandschaft der einzelnen Abteilungen der höheren Pflanzen zu erkennen.

Bei der Keimung einer Moosspore entwickelt sich ein sog. Vorkeim (Protonema, Fig. I 86 , Vk), welcher das Moospflänzchen trägt. Das letztere produciert weibliche Geschlechtsorgane, Archegonien (Fig. I87) 


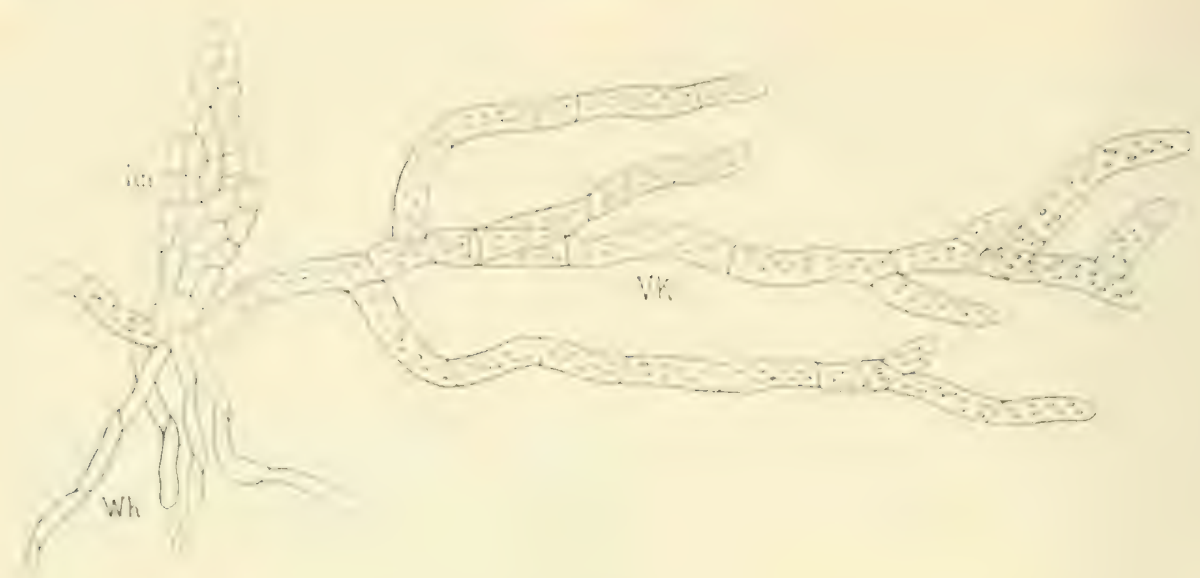

Fig. $x \$ 6$.

Tk Moosvorkeim, Kn die junge Anlage einer Moospflanze, Wh Rhizoïden. (Sch.)

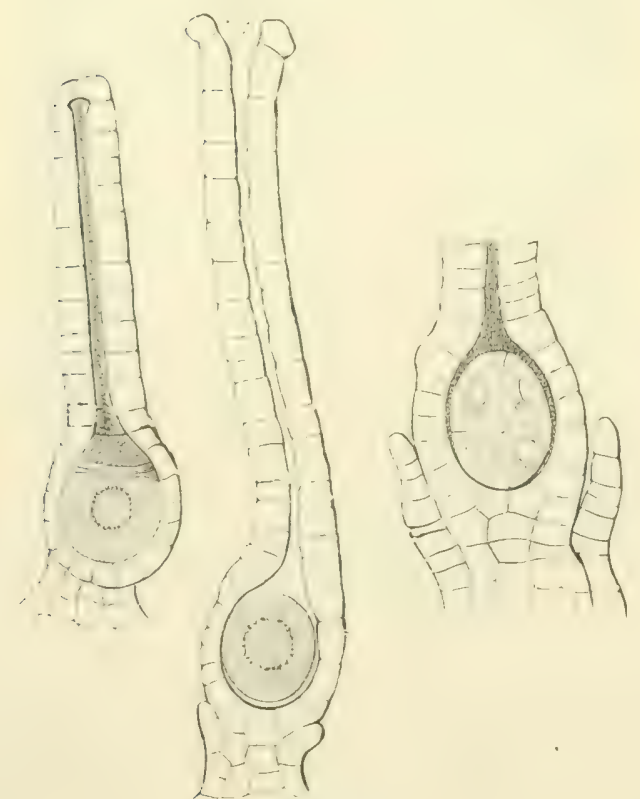

Fig. 187 .

Marchantia polymorpha, Längsschnitt durch Archegonien mit befruchteter und unbefruchteter Eizelle (n. Strasburger).

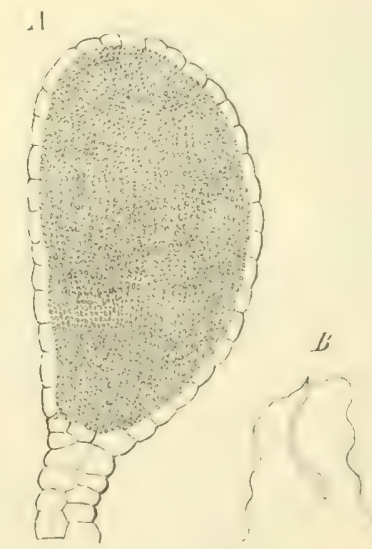

Fig. 188 .

Marchantia polymorpha. A. Antheridium mit Spermatozoïdmutterzellen erfüllt.

B. Spermatozoïd. (R.)

und männliche Geschlechtsorgane, Antheridien (Fig. I88). Im Archegonium entsteht die Eizelle, in den Antheridien zahlreiche mit Eigenbewegung versehene Spermatozoïden (Fig. 188, B). Die Eizelle wird be- 
fruchtet, indem ein Spermatozoïd durch den Hals des Archegoniums eindringt und mit der Eizelle verschmilzt.

Das die Geschlechtsorgane tragende, grüne Moospflänzchen ist die geschlechtliche Generation (Fig. I89). Aus der befruchteten Eizelle geht nun ein Sporogon hervor, dessen unterer Teil (Fuss) die Verbindung mit der Mutterpflanze (dem Moospfänzchen) herstellt, dessen mittlerer Teil zum Stiel und dessen oberer Teil zu dem eigentlichen sporenbildenden Behälter, der Mooskapsel wird. Dic letztere wird auch im reifen Zustande noch von den Resten des Archegons bedeckt (Calyptra). Das die Sporen auf ungeschlechtlichem Wege hervorbringende Sporogon mit seinen Teilen ist die ungeschlechtliche Generation (Fig. IS9). Die letztere ist gewissermassen ein Anhangsgebilde der geschlechtlichen, hier überwiegenden Generation.

Von geringerer Bedeutung sind die bei einzelnen Moosen noch vorkommenden Brutzellen, d. h. sich isolierende Zellkomplexe, aus denen ebenfalls neue Moospflänzchen hervorgehen können.

\section{Klasse, Hepaticae, Lebermoose.}

Das Moospflänzchen ist entweder ein unbeblättertes Lager oder ein niederliegender, beblätterter, dorsiventraler Stengel. peripheren Teil (Wand) und centralen Teil (Endothecium). Fast immer wird das ganze Endothecium zur Bildung von Sporen und sterilen Elateren (Schleuderzellen) aufgebraucht. Meist keine Columella in der Kapsel.

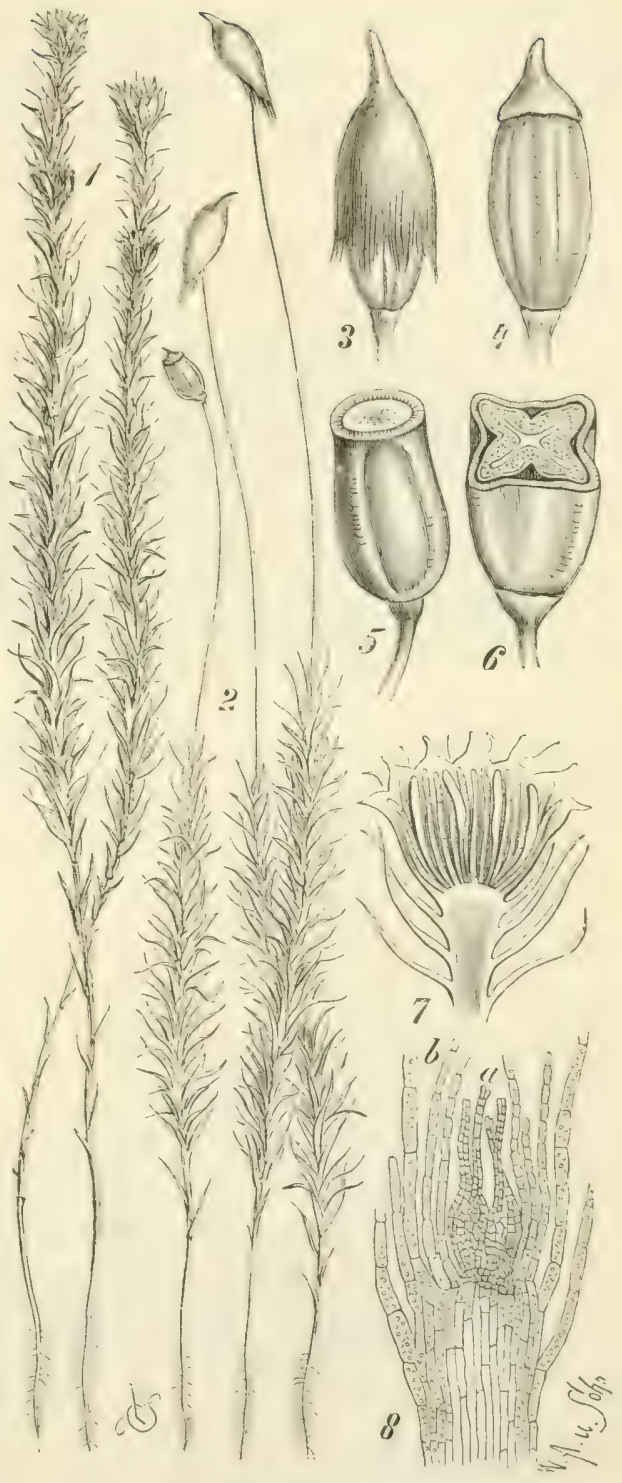

Fig. 189 .

Polytrichum commune. I. Männliche Pflanze. 2. Weibliche Pflanze mit reifer Kapsel. 3. Kapsel mit Calyptra, 4. desgl. ohne Calyptra, 5. Kapsel nach dem Abwerfen des Deckels. 6. Querschnitt. 7. Antheridienstand. 8. Archegoniumstand. (W.) 
Riccia slauca auf feuchten Äckern. Marchantia polymorpha (Fics. 190 und 191 ) an feuchten Stellen semein, Fegetella conica in feuchten Schluchten, Anthoceros laevis ebenda. Pellia epiphylla, Jungermannia incisa, J. bicuspidata u. a. auf feuchter Erde, Baumstämmen. Radula

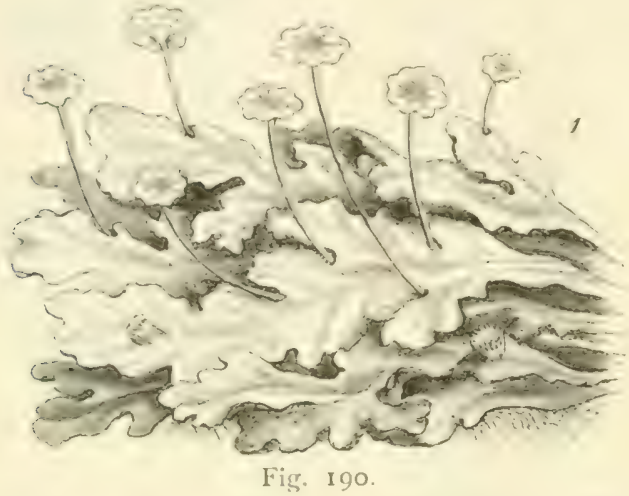

Marchantia polymorpha, männliche PHanze. (IV.)

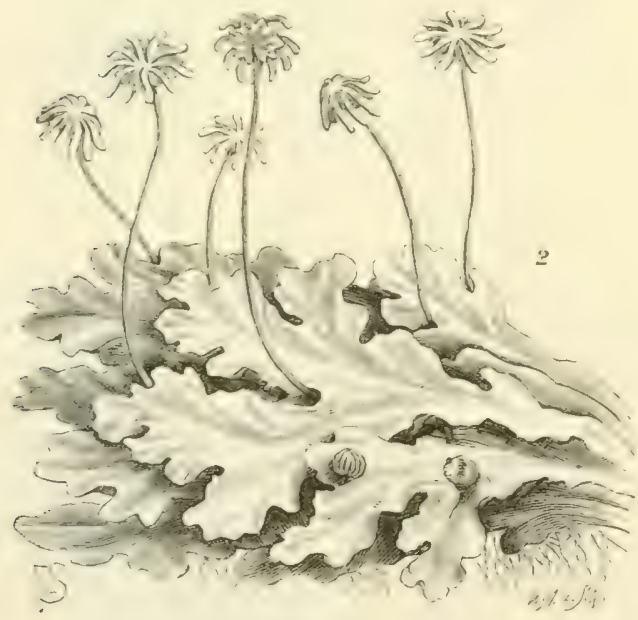

Fig. I9I.

IIarchantia polymorpha, weibliche Pflanze. (W.)

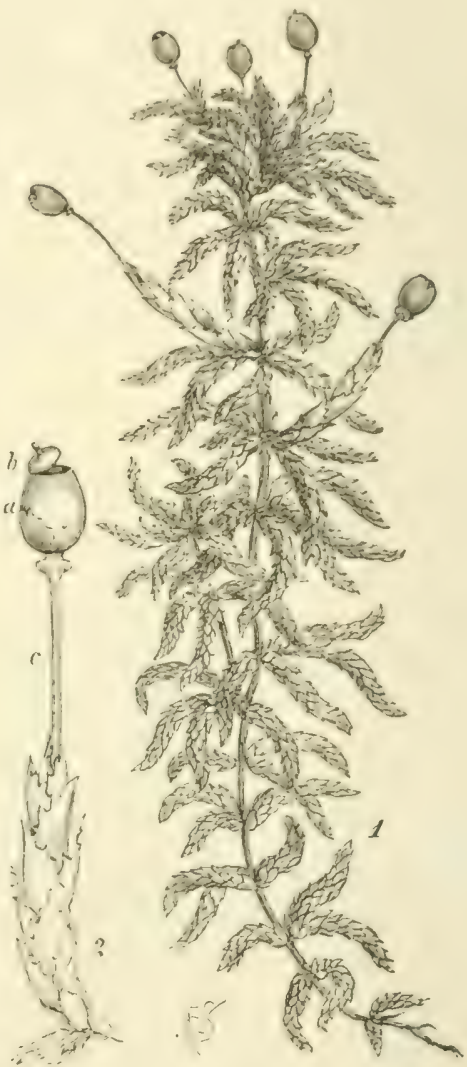

Fig. 192.

Sphagnum cymbifolium. I. Kapsel tragende Blüte. 2. Kapsel vergr. (IV.)

complanata und Frullania dilatata an Baumrinden und feuchten Steinen. Lepidozia reptans auf feuchtem Holz, Steinen.

\section{Klasse. Musci frondosi, Laubmose.}

Geschlechtliche Generation fast stets ein aufrechter, beblätterter Stengel. Im Endothecium des Sporogons bleibt ein centraler Strang steril (Columella), welchen die sporenbildenden Schichten umgeber. Elateren fehlen. 
Die Ordnung der Sphagna besitzen Kapseln, die sich mit einem Deckel öffnen, haben keinen Mundbesatz (Peristomium) an der Mündung der Kapsel (Fig. I92, 2). Einzige Gattung Sphagnum, Torfmoos. Bei den Schizocarpae öffnet sich die Kapsel mit vier Klappen (Andraea). Die Kapsel der Cleistocarpae öffnet sich nicht, die Sporen werden durch Verwesung der Kapselwand frei (Phascum, Ephemerum, Pleuridium).

Die Stegocarpae, die Ordnung, welche die meisten Arten umfasst, besitzt einen Deckel und einen Mundbesatz (Fig. I93).

Die Sphagna finden sich nur an sehr feuchten Orten, sie tragen zur Bildung der
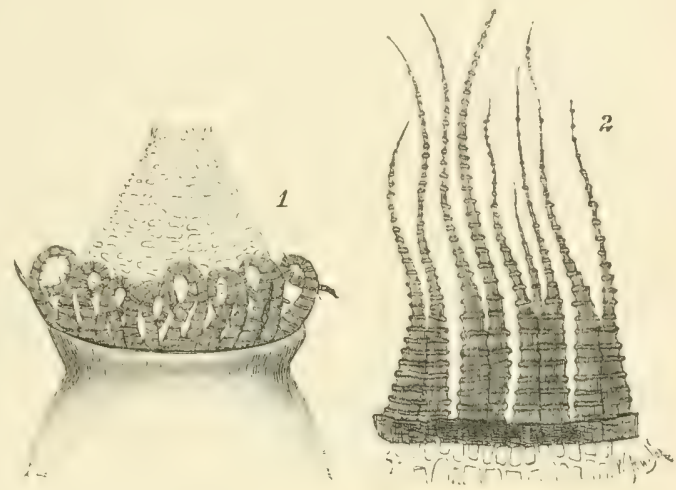

Fig. I') 3 .

Fontinalis antipyretica, r. Doppelter Mundbesatz, 2.Zähne des äusseren Besatzes, ausgestreckt. (W.)

Hochmoore bei. Sphagnum

acutifolium, Sp. cymbifolium (Fig. I92, I) Sp. subsecundum, Sp. squarrosum, Sp. rigidum u. a.
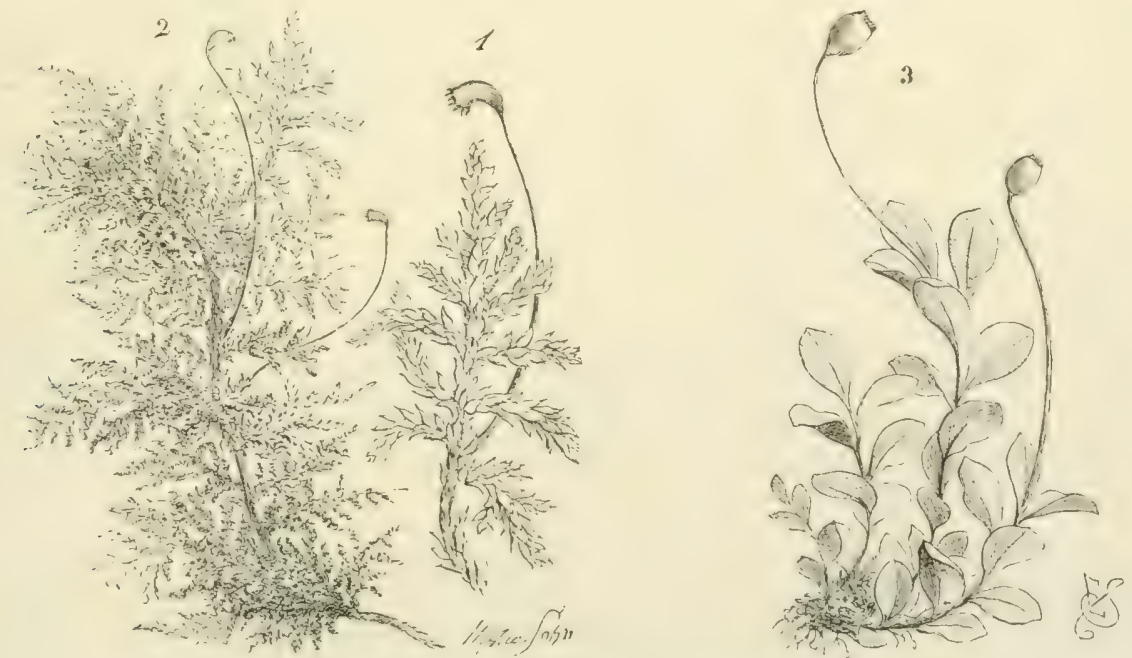

Fig. 194.

I. Hypnum triquetrum, 2. Hypnum splendens, 3. Mnium punctatum. (W.)

In Wasser flutend: Fontinalis antipyretica.

An Sümpfen, sowie in sumpfigen Wiesen: Gymnocybe palustris, Hypnum cuspidatum, Hypnum scorpioides, Polytrichum juniperinum, Philonotis montana, Climacium dendroides. 
Auf moorigem und humusreichem Boden: Mnium cuspidatum, Mnium punctatum (Fig. 194, 3) Mnium hornum, Mnium undulatum, Amblystegium serpens.

Auf feuchtem Thon-, Lehm- und Mergelboden: Barbula unguiculata, Hypnum molluscum, Hypnum chrysophyllum.

Auf feuchtem Sandboden: Funaria hysrometrica, Mnium undulatum, Polytrichum commune (Fig. I 89), Polytrichum juniperinum.

In sandigem Waldboden: Dicranum scoparium, Hypnum triquetrum (Fig. 194), Hypnum Schreberi, Hypnum purum, Hypnum splendens, Leucobryum glaucum. Verschied. Bryumspecies.

Auf trocknem Sandboden: Phascum cuspidatum, Ceratodon purpureus, Barbula ruralis.

An Baumrinde: Orthotrichum speciosum, Orthotrichum obtusifolium, Pylaisia polyantha, Isothecium myurum, Homalothecium sericeum.

Auf Mauern, Steinen: Barbula muralis, Grimmia pulvinata, Hedwigia ciliata.

\section{Pteridophyta, Farnpflanzen oder Gefässkryptogamen.}

Wie bei den Moosen ist eine geschlechtliche und eine ungeschlechtliche Generation vorhanden. Die Geschlechtsgeneration, welche Archegonien und Spermatozoïden bildende Antheridien trägt, ist verhältnismässig reduciert. Sie besteht aus einem kleinen thallösen Gebilde, dem Prothallium (Fig. I95, I), das um so unbedeutender ist, je höher die betreffende Ordnung steht. Das Prothallium entspricht dem Mruspflänzchen. Aus der befruchteten Eizelle des Archegoniums(Fis. I95, 3) geht die ungeschlechtliche Generation hervor, welche aber nicht ein einfaches, kurzlebiges Sporogon ist, sondern eine anatomisch und gestaltlich hochentwickelte Pflanze mit vollkommener Ausbildung von Stamm, Blatt- und Wurzelorganen (Fig. I96, I). Was der Laie als Farnkraut, Schachtelhalm, Bärlapp etc. bezeichnet, ist diese ungeschlechtliche Generation. Dieselbe produciert auf ungeschlechtlichem Wege in besonderen Sporangien die Sporen. Die letzteren liefern bei der Keimung das Prothallium.

Innerhalb der drei Klassen der Pteridophyten (Filicinae, Equisetinae und Lycopodinae) sind isospore und heterospore Formen zu unterscheiden. Bei den erșteren werden in den Sporangien nur einerlei Sporen produciert, aus denen Prothallien hervorgehen, welche zugleich Archegonien und Antheridien tragen. Bei den heterosporen Pteridophyten dagegen haben wir zweierlei Sporen, weibliche Makrosporen und männliche Mikrosporen, welche in Makro- und Mikrosporangien entstehen. Aus den Makrosporen gehen weibliche Prothallien, aus den Mikrosporen männliche Prothallien hervor. 
Unter Berïcksichtigung der bei den Moosen und Farnpflanzen gleichartigen Ausbildung von Archegonien erscheint es gerechtfertigt, diese beiden Reihen als eine besondere Entwickelungsstufe des Pflanzenreiches zusammenzufassen und sie gemeinsam als Archegoniaten zu bezeichnen (vgl. Tabelle auf S. I87).

Wegen der bei den Pteridophyten auftretenden Gefässbündel (Leitbündel) werden dieselben auch als Gefässkryptogamen oder Leitbündel-

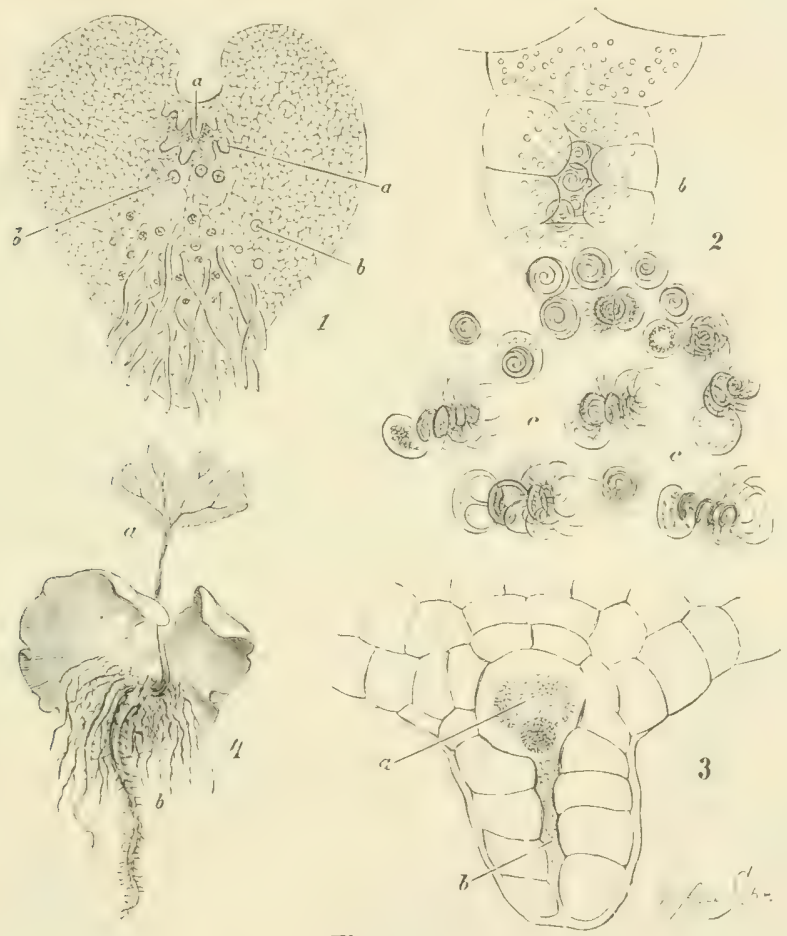

Fig. 195 .

Adiantum capillus veneris. I. Prothallium, a Archegonien, b Antheridien (Iomal vergr.). 2. b Antheridium, c Spermatozoïden. 3. Archegonium, a Eizelle, b Halskanal. 4. Junge Farnpflanze am Prothallium, a erstes Blatt, b Wurzel. (W.)

kryptogamen bezeichnet. Sekundäres Dickenwachstum fehlt (mit Ausnahme von Isoëtes).

\section{Klasse, Filicinae, Farne.}

Blätter im Vergleich zum Stamm gross, in der Jugend oft eingerollt (Fig. 196, 1). Die Sporangien sitzen auf dem Rande oder der Unterseite der Blätter. Die sporangientragenden Blätter sind nicht auf bestimmte Regionen oder Zweige des Stammes beschränkt.

\section{Ordnung. Filices, eigentliche Farne.}

Sporen alle gleich. Prothallium ein grünes, selbständig lebendes Pflänz- 
chen (lig. 195, 1). Nach der Befruchtung der Eizelle bildet sich am l'rothallium cine Farnplanze (Fis. 195, 4), das Prothallium geht sodann

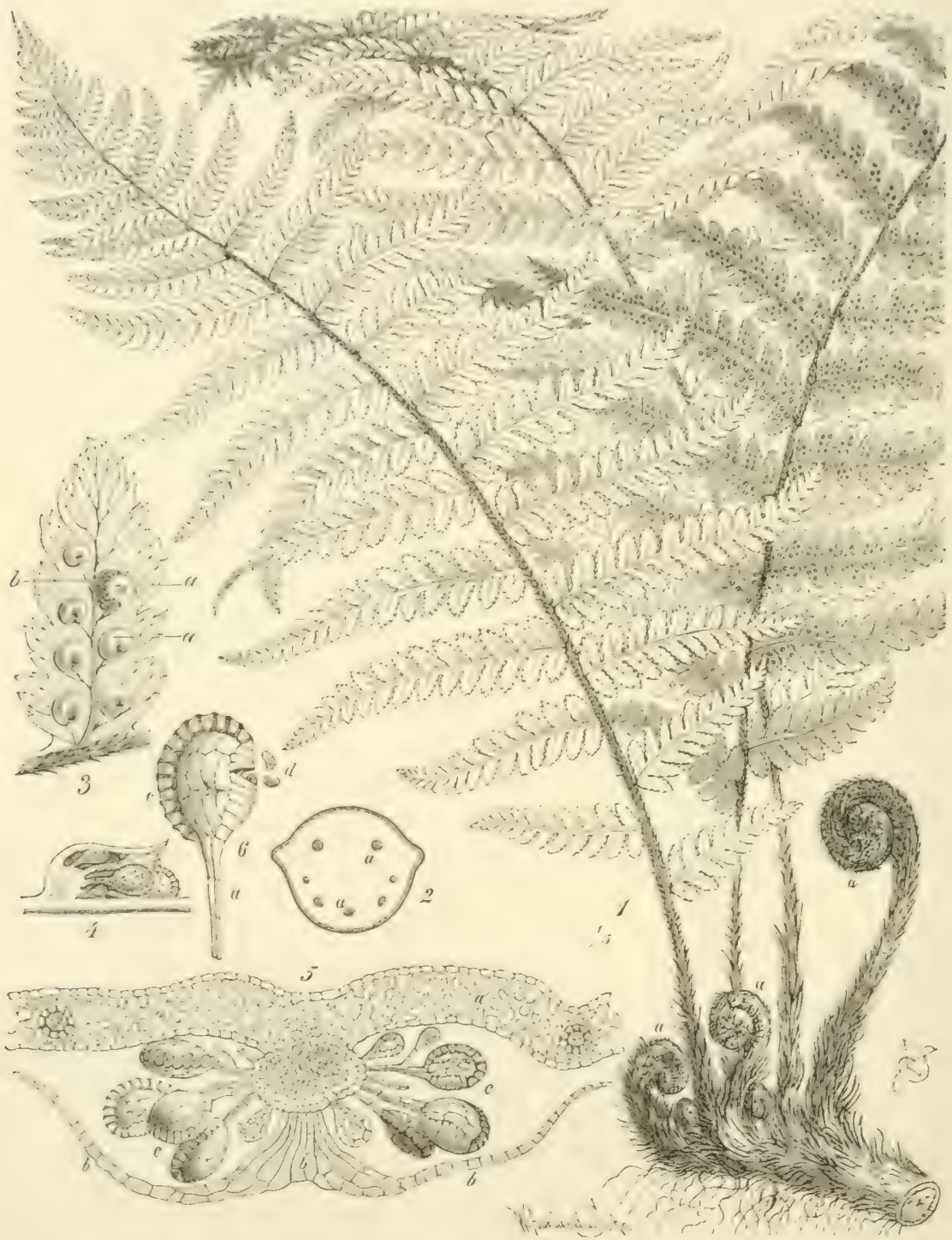

Fig. 196.

Aspidium filix mas. I. Farnpflanze, 2. Querschnitt durch den Stamm. 3. Unterseite eines F̈iederchens mit den Sori, a Indusium, b Sporangien. 4. Sorus der Länge nach, 5. desgl. quer durchschnitten. 6. Sporangium, d Sporen. (IV.)

zu Grunde. Wenn die Farnpflanze herangewachsen ist, bilden sich an den Blättern die Sporangien (Fig. 196), welche zu Häufchen (sori) vereinigt sind. Bei vielen Gattungen sind die Sori von einem schuppen- 
förmigen Gebilde, dem echten Indusium bedeckt. Sic können jedoch auch durch Einrollung des Blattrandes gedeckt werden (falsches Indusium).

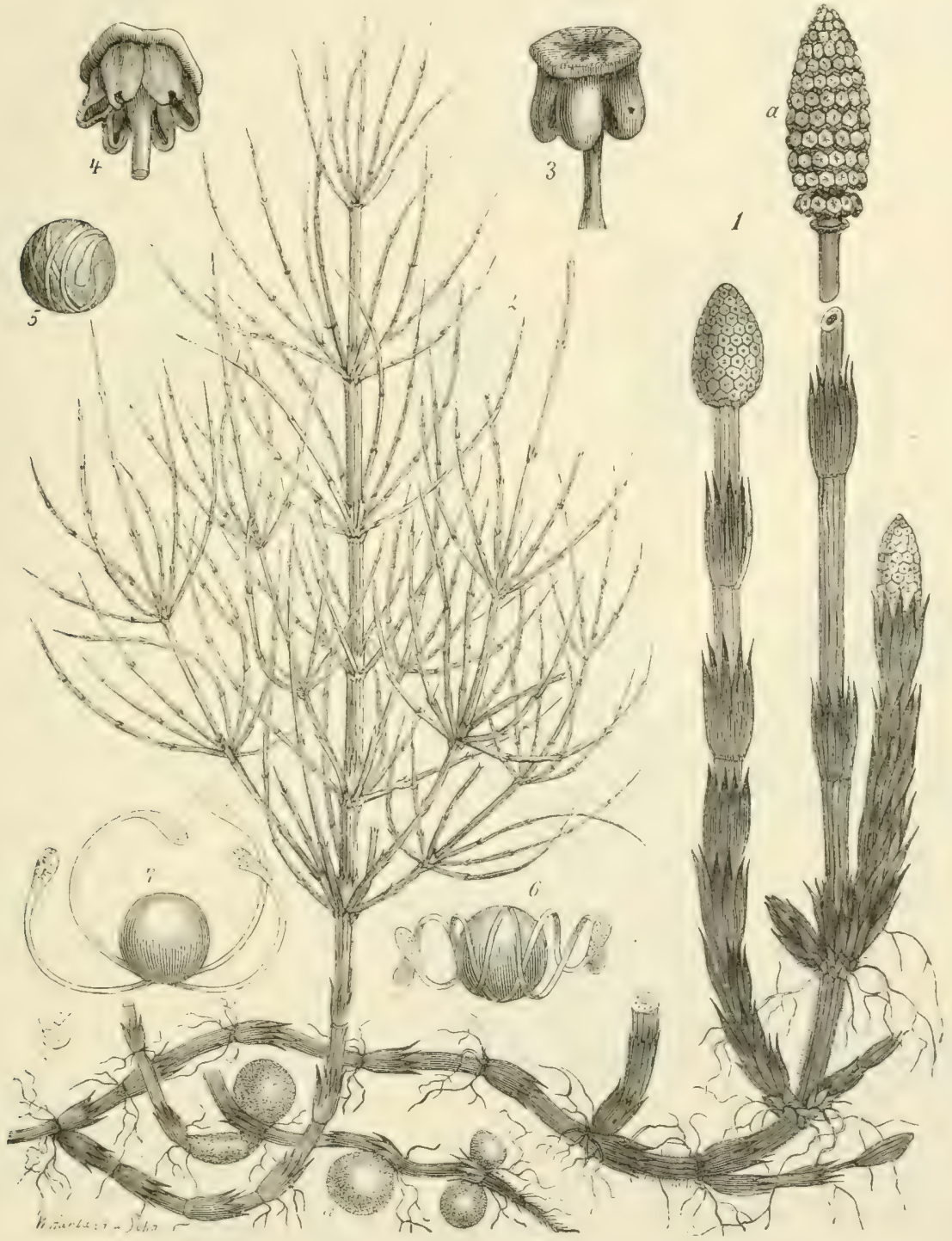

Fig. 197.

Equisetum arvense. (W.)

Die Farnkräuter beanspruchen fast sämtlich feuchte Luft, sie gedeihen im Halbschatten der Wälder am besten. Polypodium vulgare, Tüpfelfarn. Phegopteris Dryopteris, Eichenfarn und Phegopteris polypodioides, Buchenfarn. Pteris aquilina, Adlerfarn. Aspidium filix mas, Wurmfarn, Aspidium 
spinulosum, Dornfarn. Asplenium filix femina, Milzfarn. Bei Onoclea Struthiopteris und Blechnum Spicant, dem Rippenfarn, sind die sterilen und die fertilen, d. h. Sporangien tragenden Blätter verschieden gestaltet. Osmunda resalis, Könissfarn. Ophioslossum vulgatum, Natterzunge. Botrychium Lunaria.

\section{Ordnung. Hydropterides, Wasserfarne.}

Mikrosporangien mit zahlreichen Mikrosporen und Makrosporangien

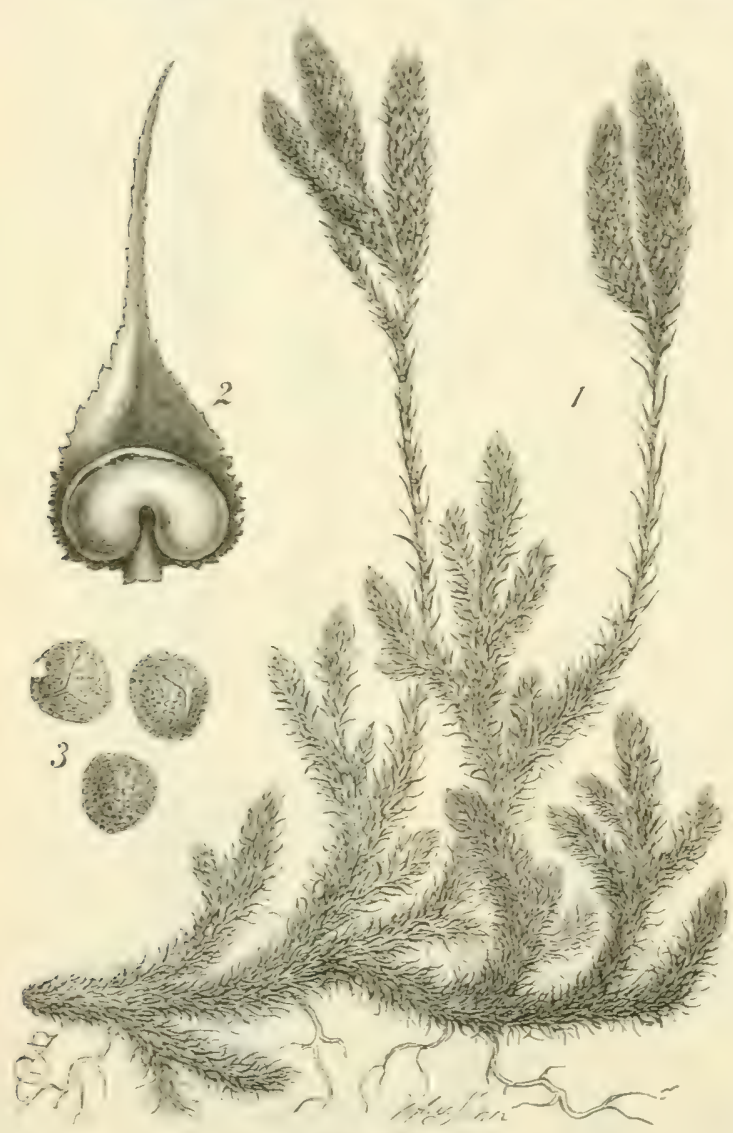

Fig. $19 \mathrm{~S}$.

Lyepodium clavatum. IW. mit je ciner Makrospore. Die Sporangiengruppen von einem Indusium oder von einem Blatteil eingeschlossen. Männliches und weibliches Prothallium sehr klein, bilden gewissermassen nur Anhängsel ihrer Sporen. Salvinia natans. Marsilla quadrifolia. Pilularia globulifera.

\section{Klasse.}

\section{Equisetinae, Schachtelhalme.}

Blätter klein, scheidenförmig verwachsen, an quirlig gestellten Ästen (Fig. 197). Sprossaxen teilweise unterirdisch. Die jetzt lebenden Equiseten sind isospor. Dic Sporangien stehen auf der Unterseite metamorphosierter, schildförmiger Blätter (Fig. I97, 3, 4), welche zu einem eigenen Stande (Fig. 197, I a) vereinigt sind. Die äussere Haut der Sporen wird zu zwei hysgroscopischen Bändern (Fig. I97, 5-7), welche der Verschleppung der Sporen dienen. Das Prothallium ist grün, blattartig zerschlitzt, selbständig.

Unfruchtbare Sprosse verzweigt, fruchtbare unverzweigt und blassbraun: Equisetum arvense (Fig. I97), E. Telmateja. Fruchtbare Sprosse, später grün werdend: E. silvaticum, E. pratense. Beiderlei Sprosse gleich: E. palustre, E. limosum, E. hiemale.

Heterospore Equiseten ausgestorben. 


\section{Klasse. Lycopodinae, Bärlappgewächse.}

Blätter relativ klein; einfach. Sporangien meist einzeln auf dem Grunde der Blattoberseite, in der Blattachsel oder über der Achsel am Stamme. Die sporentragenden Blätter oft zu blütenartigen Ständen vereinigt.

\section{Ordnung. Lycopodiaceae.}

Sprosse dünn, Blätter zugespitzt (Fig. 198, I). Nur eine Art von
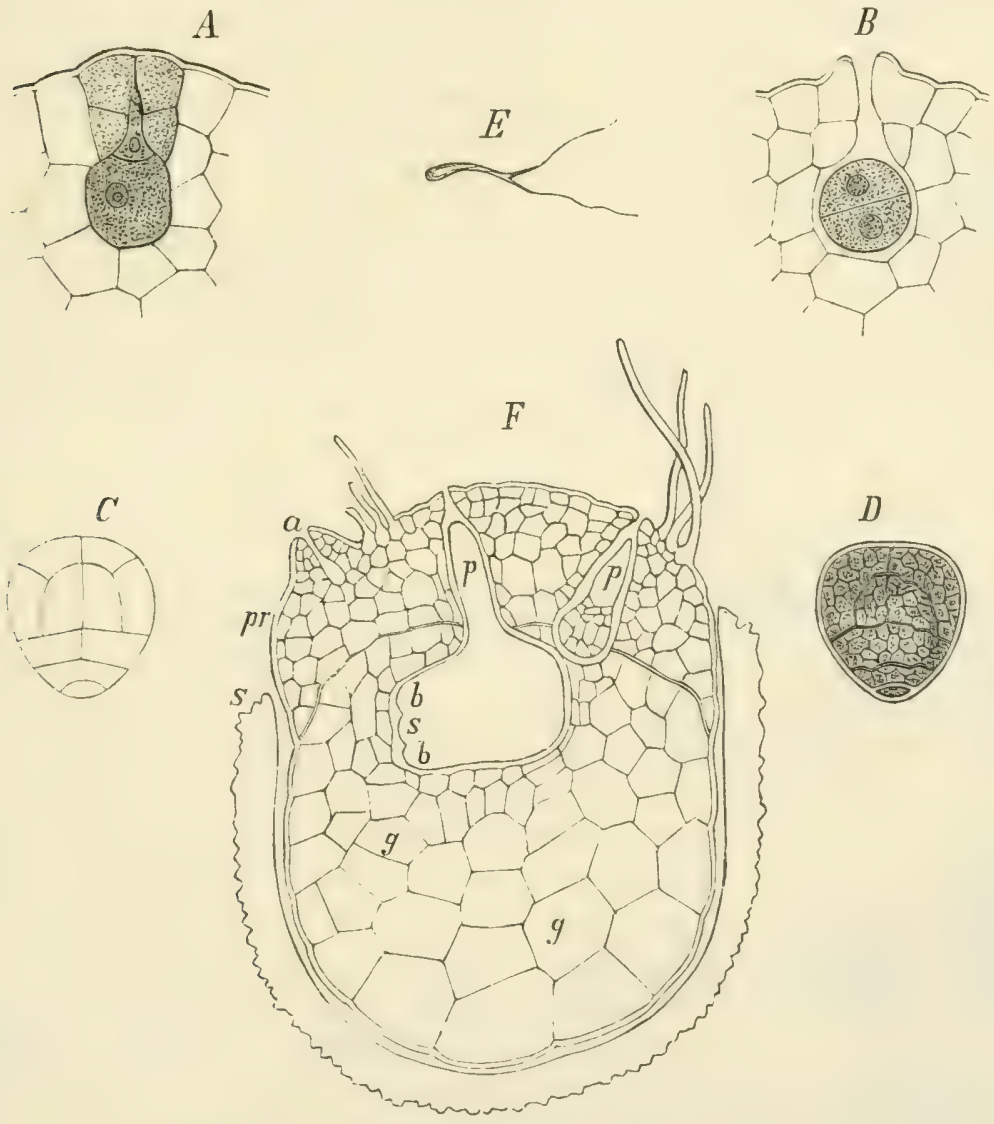

Fig. 199.

Geschlechtliche Generation von Selaginella (n. Pfeffer).

Sporangien (Fig. 198, 2), demnach eine isospore Ordnung. Sporen tetraëdrisch (Fig. 198, 3). Prothallien mehr weniger chlorophyllfrei. Lycopodium clavatum. L. Selago. L. annotinum. L. inundatum.

\section{Ordnung. Selaginelleae.}

Sprossaxen bei Isoëtes knollig, Blätter pfriemenförmigr. Bei Selasinella ist der Stengel dichotomisch verzweigt, mit eiförmigen, kleinen 
Blättern verschen. Mikro- und Makrosporangien (heterospore Ordnung). Die Mikrosporen producieren ein einzelliges, rudimentäres männliches Prothallium und ein Antheridium, welche beide nicht aus der Spore heraustreten. In Fig. I99 C und $\mathrm{D}$ ist dic unterste Zelle das Prothallium, die oluen \%ellen sind Antheridiumzellen, welche Sipermatozoïlen (Figs. I99 E) bilden. In der Makrospore entsteht das weibliche Prothallium (Fig. 199 Fpr.), welches die Archegonien (a) trägt. Etwas später bildet sich im Sporenraum ein grosszelliges Gewebe, das man als sekundäres Prothallium bezcichnet (Fig. I99 Fg). Im Archegonium (Fig. I99 A) liegt die Eizelle, die nach der Befruchtung (B) zum Embryo (Fig. I99 F psb) wird. Der Embryo zeigt wie bei den Phanerogamen einen Embryoträger (F p), ferner zwei Cotyledonen (b). Derselbe wächst zur beblätterten Pflanze heran.

Wie wir sehen, ist die sporangientragende Pflanze (ungeschlechtliche Generation) hoch entwickelt, während die Geschlechtsgeneration stark reduciert und zum Teil in der Spore eingeschlossen ist.

Isoëtes lacustris. Selaginella eine vorzugsweise tropische Gattung (S. Kraussiana, S. Martensii u. a.). In Deutschland nur S. helvetica, S. spinulosa.

\section{Fortpflanzung der Gymnospermen und Angiospermen. Anschluss} derselben an die Pteridophyten.

Bei den Phanerogamen (Gymnospermen und Angiospermen) sind ebenso wie bei den Kryptogamen zwei Generationen vorhanden.

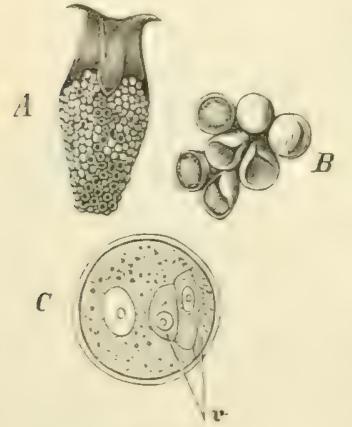

Fig. 200

Ceratozamia longifolia. A Staubblatt. B Pollensäcke. C Querschnitt eines Pollenkorns. v vegetative Zellen. (R.)

Die ungeschlechtliche Generation ist die in Laubspross und Wurzel gegliederte Pflanze, welche die Blüten trägt, die Geschlechtsgeneration ist in den Pollenkörnern und Samenknospen eingeschlossen.

Die sporangientragenden (fertilen) Blätter der Pteridophyten können den sterilen Laubblättern gleichen (die meisten Filices), sie können aber auch wesentlich metamorphosiert, zu dichtblätterigen, ährenartigen Ständen am Ende von Sprossaxen vereinigt sein, deren Wachstum hierdurch abschliesst (Equisetum, manche Selaginellen). Bei Selasinellen und Isoëtes haben wir sogar männliche und weibliche Sporangien auf rerschicden gestalteten Blattorganen. Bei den Gymnospermen und Angiospermen ist diese Trennung noch weiter ausgebildet.

Die Staubblätter (Staubgefässe, Stamina) tragen Pollensäcke, 
welche die Pollenkörner. (Blütenstaub) producieren. Die Pollensäcke entsprechen den Mikrosporangien der Pteridophyten, die Pollenkörner den Mikrosporen.

Bei den am niedrigsten stehenden Gymnospermen (gewissen Cycadeen) befinden sich zahlreiche Pollensäcke auf der Unterseite von Blattorganen (Fig. 200, A), bei anderen Cycadeen und den Coniferen stehen 2-8 Pollensäcke an der. Unterseite schildförmiger (Taxus, Fig. 210, 4-6) oder gestielt schuppenförmiger (Picea, Fig. 2 I 3.5, 6, Pinus, Fig. 2 I6, z) blattartiger Organe. Die Angiospermen haben mannigfaltig gestaltete Staubblätter, welche fast immer vier Pollensäcke tragen. Man kann an diesen Staubblättern den Staubfaden (Filament), das Connectiv und die Staubbeutel (Antheren) unterscheiden. Der Staubfaden ist entweder dünnfadenförmig oder bandartig, bei den sitzenden Staubblättern sehr kurz. In seiner Verlängerung liegt das Connectiv, das Verbindungsstück zwischen den Staubbeuteln, welches bald schmal (Fig. 2OI A) oder stärker verbreitert, selten geteilt ist (Fig. 20I B, C). Die Staubbeutel bestehen meist aus zwei nebeneinander liegenden Antherenhälften. In jeder der letzteren befinden sich durch eine Scheidewand getrennt zumeist zwei mit Blütenstaub erfüllte Kammern, die Pollensäcke; derartige Staubbeutel bezeichnet man als vierfächerig. Seltener sind die zweifächerigen Antheren (Orchidaceen und Asclepiadeen), welche im ganzen
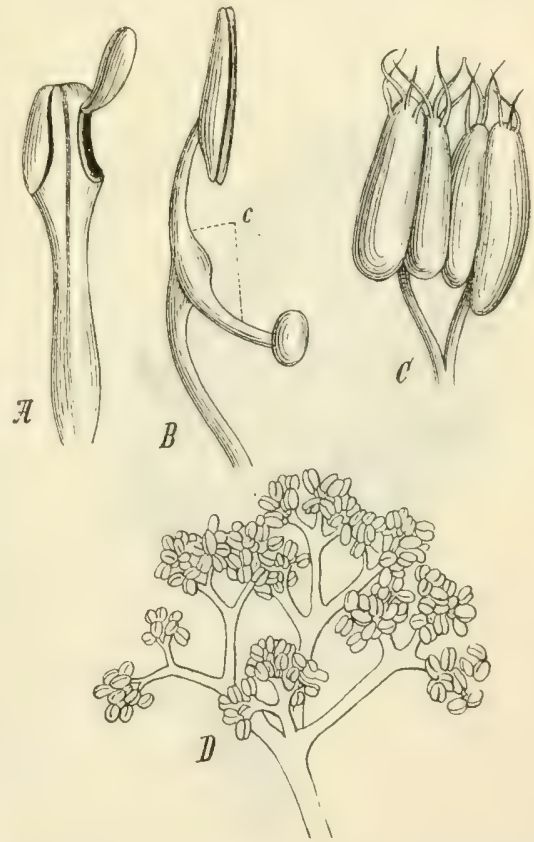

Fig. 201 .

Staubblätter: A von Berberis, B von Salvia, C von Corylus, D von Ricinus; c Connectiv. (K.) nur zwei Pollensäcke enthalten. Die introrsen Staubbeutel sind dem Innern der Blüte zugewendet, die extrorsen Staubbeutel stehen auf der Aussenseite der Staubblätter. Die verzweigten Staubblätter (Fig. 2OI D) entsprechen den verzweigten Laubblättern.

Die Fruchtblätter tragen die sog. Samenknospen (Samenanlagen, Ovula), welche später zu dem Samen, einem den Kryptogamen fehlenden Organe, umgewandelt werden.

Bei den Gymnospermen stehen: die Samenknospen frei auf der Oberfläche der Fruchtblätter, während dieselben bei den Angiospermen in die zum Fruchtknoten verwachsenen Fruchtblätter (Carpelle) e in geschlossen sind. Den einfachsten Fall zeigt die Gymnospermen- 
sattung Cycas, bei welcher die Samenknospen (Fig. 202, o) an laubblattartigen Organen stehen. Die, Samenknospen von Ceratozamia bilden sich auf der Unterseite schildförmig metamorphosicrter Blattorgane. Bei den Coniferen sitzen die Samenknospen in der Regel auf dem Rande oder der Oberseite dick schuppenförmiger Fruchtblätter (Pinus, Fig. 2 I6, 3), seltener kommen sie direkt auf der Axe vor (Taxus Fig. 2I0, 8).

Die Bildung des Fruchtknotens bei den Angiospermen vgl. $\$ 3$.

Die Samenknospen bestehen aus dem Knospenkern (Nucellus) und aus ein oder zwei Integumenten. Die letzteren umwachsen den

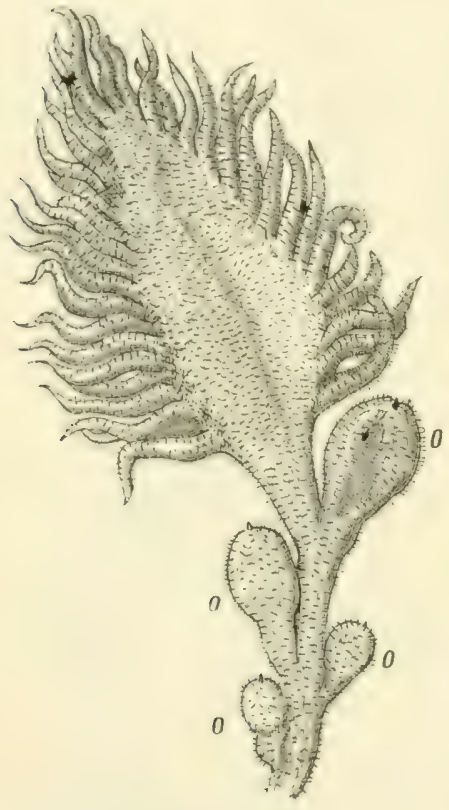

Fig. 202.

Fruchtblatt von Cycas revoluta.

Knospenkern und bilden am Scheitel desselben einen kanalartigen Zugang, die Mikropyle (Fig. 203). Sehr häufig ist die Samenknospe an dem Tragorgan, der Placenta, durcheinen Stiel, Funiculus, befestigt, welcher von einem Gefässbündel durchzogen wird (Fig. 203). Das letztere endigt an der Basis des Knospenkernes, dem sog. Knospengrunde oder Chalaz a ende.

Eine bestimmte Zelle des. Knospenkerns vergrössert sich auf Kosten der anderen Zellen und wird zum Embryo$\mathrm{sack}$, welcher in den Bildern der Fig. 203 dunkel gehalten ist. Man unterscheidet folgende Samenknospenformen: I) gerade (atrope oder orthotrope), die Mikropyle liegt in der geraden Fortsetzung des Funiculus (Fig. 203, I). 2) u $\mathrm{mge}$ wendete (anatrope), der Knospenkern und die Integumente sind an der Basis (R.) umgewendet und seitlich mit dem Funiculus verwachsen. Der Embryosack ist gerade (Fig. 203, III bis VI, VIII). 3) gekrümmte (campylotrope), der Knospenkern selbst, der Embryosack und die Integumente sind gekrümmt (Fig. 203, II, VII, IX).

Der Knospenkern entspricht dem Makrosporangium, er ist hier durch die indusienartigen Integumente eingeschlossen. Der Embryosack ist ein der Makrospore homologes Organ.

Die Blüte ist demnach ein Spross oder Sprossende, an welchem Sporangien tragende Blätter, die Staubblätter und Fruchtblätter stehen, mit deren Entwickelung das Längenwachstum des Sprosses abschliesst. Die Blüte ist nur die höhere Ausbildungsstufe von den schon bei gewissen Pteridophyten (vgl. Equisetinae und Lycopodinae) vorhandenen Ständen sporentragender Blätter. Bei den Angiospermen sind Staub- und 
Fruchtblätter noch von dem aus besonders gestalteten Blattorganen bestehenden Perianthium umgeben, das entweder ein einfaches Perigon sein kann oder aus Kelch (Calyx) und Krone (Corolle) besteht. Seltener fehlt das Perianthium ganz. Derartige Blüten nennt man nackt.

Das Perianthium nimmt die Basis der Blütenaxe ein, es folgen die Staubblätter, die man unter dem gemeinsamen Namen des Androec e ums zusammenfasst, am Scheitel der Blütenaxe stehen die Fruchtblätter, die in ihrer Gesamtheit das Gynaeceum bilden.

Eingeschlechtliche (diklinische) Blüten sind männlich ( $\sigma^{*}$ oder weiblich $(\subseteq)$, je nachdem ob sie Staubblätter oder Fruchtblätter enthalten. In den

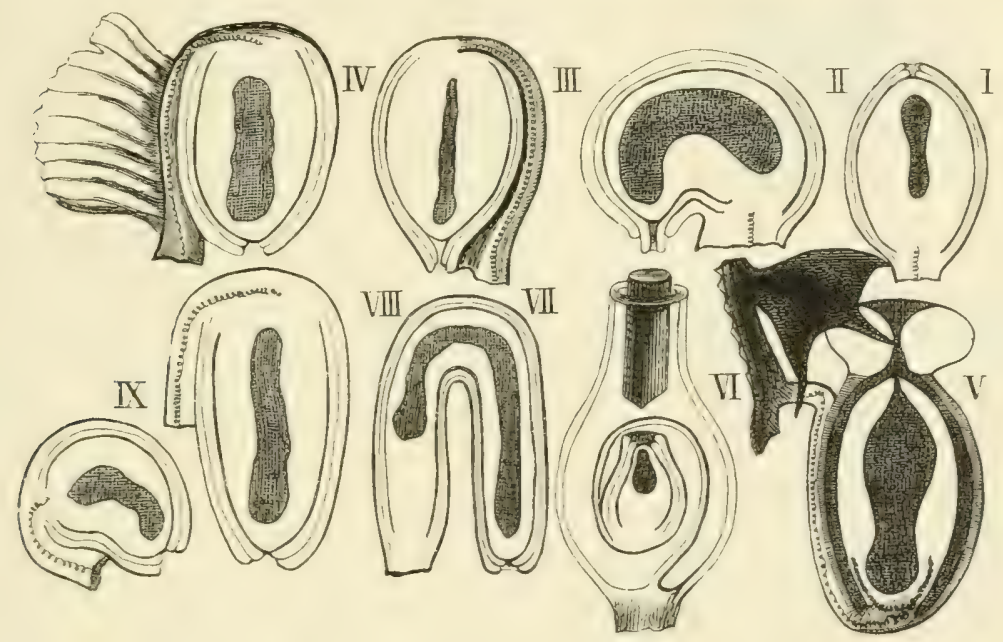

Fig. 203.

Verschiedene Samenknospen (n. Harz).

zweigeschlechtigen Zwitterblüten, hermaphroditen Blüten (s) sind Staub- und Fruchtblätter sleichzeitig vorhanden. Kommen weibliche und männliche Blüten auf derselben Pflanze vor, so nennt man die Art monöcisch (einhäusig), bei diöcischen (zweihäusigen) Arten dagegen sind männliche und weibliche Blüten auf verschiedene Individuen verteilt. Sind neben den eingeschlechtigen Blüten noch Zwitterblüten vorhanden, wird die Pflanze als polygam bezeichnet.

Die Befruchtungsvorgänge und hiermit die Ausbildung der geschlechtlichen Generation sind bei Gymnospermen und Angiospermen verschieden.

Bei den Gymnospermen teilt sich der Inhalt der Pollenkörner in zwei bis vier Zellen; die $\mathrm{I}-3$ kleineren sog. vegetativen Zellen (Fig. 200, v) repräsentieren das rudimentäre männliche Prothallium, die grössere sog. generative Zelle entspricht dem Antheridium der Gefässkryptogamen. Die generative Zelle wächst zum Pollenschlauche aus, einer langgsestreckten Zelle, welche nach der C̈bertragungs auf die weib- 
liche Blüte bis zur Mikropyle des Ovulums und zum Embryosack vordringt.

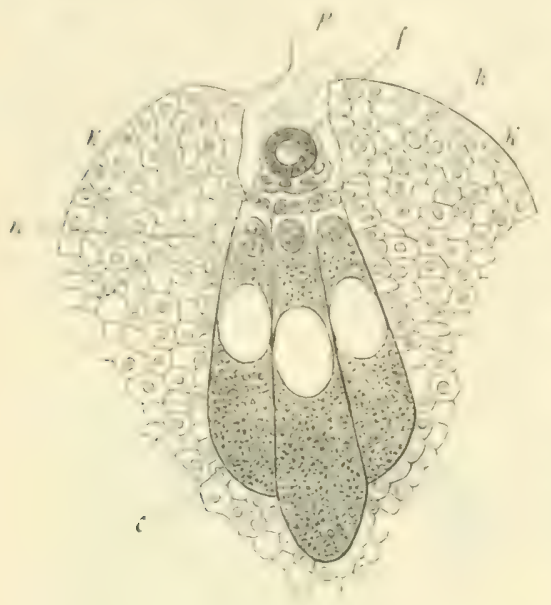

Fig.'204.

Längsschnitt durch den Scheitel eines Embryosackes von Juniperus comnunis. K Endosperm c Centralzelle, h Halszellen der Archegonien, n Zellkern der Centralzelle, p Pollenschlauchende (n. Strasburger).
Die Samenknospen der Gymnospermen sind fast immer gerade und meist nur mit einem Integument versehen. Der Embryosack, eine relativ grosse Zelle im Innern des Knospenkerns, bleibt bis zur Befruchtung von einer dicken Lage des Knospenkerngewebes umgeben. Längere Zeit vor der Befruchtung füllt sich der Embryosack durch freie Zellbildung mit einem gleichartigen Gewebe, dem Endosperm. Das Endosperm ist ein in die Makrospore (Embryosack) eingeschlossenes weibliches Prothallium, es trägt, wie bei den Pteridophyten, auch hier Archegonien und zwar in ve:schiedener Anzahl. So sind bei den Abietineen 3-5, bei den Cupressineen 5-I5, bei Taxus baccata 5-8 Arche-

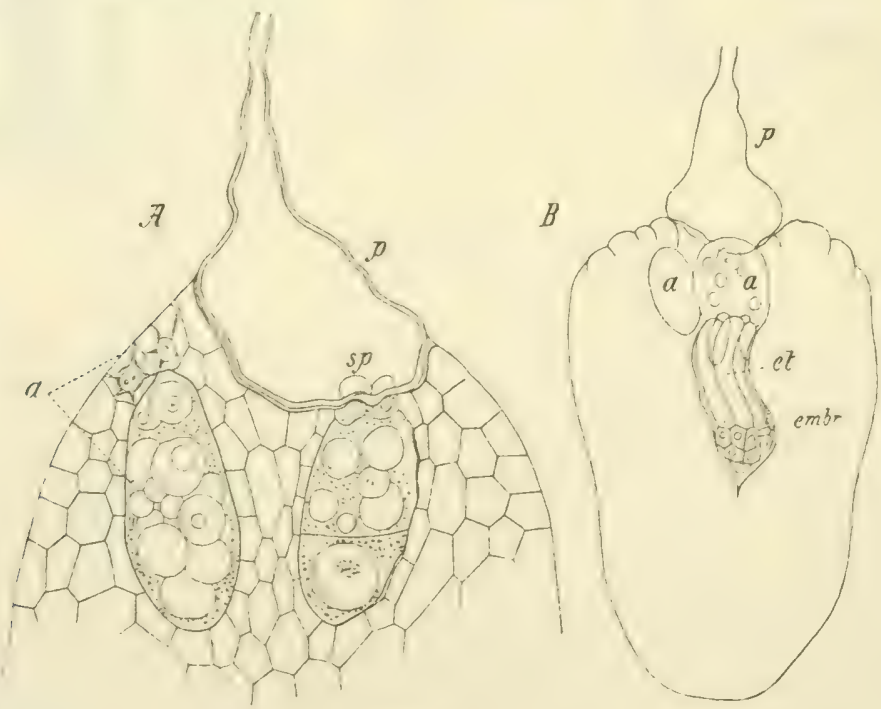

Fig. 205 .

A Taxus canadensis. Längsschnitt durch den Embryosack unmittelbar vor der Befruchtung. Im Gewebe des Embryosackes zwei Archegonien (a). p erweitertes Ende des Pollenschlauches. sp Zellkerne der generativen Zelle. B Taxus baccata. a und $p$ wie bei A. et Suspensor, embr Embryoanlage (n. Hofmeister).

gonien vorhanden. Bei den Cupressineen stehen sie nebeneinander zu 
Gruppen vereinigt (Fig. 204, c, h). Die Archegonien bestehen aus Halszellen (Fig. 204, h) und der Centralzelle (c), von welcher vor der Befruchtung zumeist noch eine sog. Bauchkanalzelle abgeschnürt wird, während der übrige Teil der Centralzelle zur Eizelle wird. Diese Zellteilungen bei der Archegonbildung sind interessant, weil sich die analnesen Vorgänge bei den Archegronien der Pteridophyten und Bryophyten wiederfinden, und die Homologie dieser Organe noch weiter sicher gestellt wird.

Nachdem der Pollenschlauch durch die Nikropyle bis zum Knospenkern vorgedrungen ist, durchwächst er das Gewebe des letzteren und legt sich an das Archegonium an (Fig. 205, Ap). Aus dem Pollenschlauche tritt die befruchtende Substanz in die Eizelle ein und zwar rerschmilzt ein aus dem Pollenschlauche übertretender ,Spermakern" mit dem Zellkern der Eizelle zu einem neuen Zellkern (Keimkern). Der Keimkern wandert in die der Mikropyle gegenüberliegende Seite der Eizelle und teilt sich dort mehrmals, wodurch mehrere Zelletagen entstehen. Die hinterste Zelletage wird zum Embryo, die übrigen Etagen wachsen zu mehreren schlauchförmigen Zellreihen aus, den Suspensoren oder Vorkeimen, welche den Embryo vor sich her in das Endospermgewebe hineindrängen. Da an der Spitze eines jeden Suspensors eine Embryoanlage entstehen kann, ausserdem mehrere Archegonien befruchtet werden können, so werden innerhalb einer Samenknospe mehrere Embryonen angelegt, von denen sich jedoch nur ein einziger weiter entwickelt. Das Endosperm füllt sich während der weiteren Vergrösserung des Embryos mit Reservestoffen, vergrössert sich und verdrängt das Knospenkerngewebe. Die Integumente der Samenknospe werden zur Samenschale. Der reife Same besteht demnach aus: I) der Samenschale, 2) dem Endosperm, 3) dem Embryo.

Der Same ist ein Gebilde, welches den Kryptogamen vollständig fehlt und durch dessen Vorhandensein sich die Gymnospermen und ebenso die Angiospermen von den niedriger stehenden Pflanzen sehr wesentlich unterscheiden. Man bezeichnet die ersteren deshalb auch als Spermaphyten (Sperma $=$ Same). Es ist dies noch ein prägnanterer Unterschied als die Bildung einer Blïte, indem wir bei einem Teil der Gymnospermen (Cycadeen) eine specifische Blüte nur unvollkommen entwickelt finden.

Zur besseren Übersicht der Homologien zwischen Kryptogamen und Gymnospermen diene folgende Zusammenstellung:

\section{Kryptogamen}

Sporangientragende Pflanze.

Makrosporangium.

Makrospore.

VVeibl. Prothallium.

Archegonium.

Eizelle.

\section{Gymnospermen}

Pollensäcke und Samenknospen tragende Pflanze. Knospenkern.

Embryosack.

Endosperm.

Archegonium.

Eizelle. 


\section{Kryptogamen}

Embryo, aus dem wiederum die sporentragende Ptlanze hervorgeht.

Mikrosporangium.

Mikrospore.

Männl. Prothallium.

Antheridium.

Spermatozoïd.

\section{Gymnospermen}

Embryo der Pollensäcke und Samenknospen tragenden Pflanze.

Pollensack.

Pollenkorn.

Vegetative Zelle.

Generative Zelle.

Spermakern.

Die Bildung der Sporangien, die Entwickelung der geschlechtlichen Generation, sowie die paläontologischen Funde weisen darauf hin, dass sich die Gymnospermen aus Pflanzen ent-

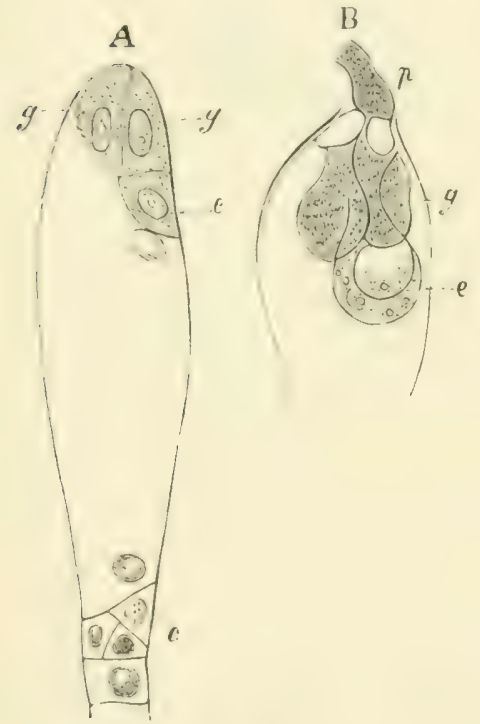

Fig. 206.

A Embryosack von Monotropa Hypopitys. B Spitze des Embryosacks von Torenia asiatica (n. Strasburger). wickelt haben, welche heterosporen Pteridophyten ähnlich waren und wahrscheinlich speciell den Selaginellen nahe standen (vgl. Tabelle S. I87).

Bei den Angiospermen geht die Reduktion einzelner Teile der Geschlechtsgeneration noch weiter als bei den Gymnospermen. In dem Pollenkorn der Angiospermen, das ebenfalls einer Mikrospore gleich $z u$ achten ist, bildet sich eine vegetative und eine generative Zelle, welche jedoch nur durch eine Hautschicht, keine feste Zellwand geschieden sind. Die generative Zelle wächst zum Pollen$\mathrm{schlauch}$ aus, ihr Zellkern teilt sich in zwei neue Zellkerne, von denen einer die Befruchtung vollzieht. Bezüglich der Bildung von Samenknospen, Knospenkern und Embryosack unterscheiden sich Gymnospermen und Angiospermen nicht wesentlich. Im Embryosack wird jedoch vor der Befruchtung kein Endosperm, und ebenso keine Archegonien gebildet. Der Kern des Embryosacks teilt sich zuerst in zwei Kerne, jeder derselben wiederum in zwei Kerne, und diese vier Kerne nochmals, so dass wir im Embryosack acht Kerne haben, aus welchen sich der sog. Eiapparat bildet. An dem Mikropylenende umgeben sich zwei Kerne mit einer dünnen Haut, sie werden zu den Gehilfinnen (Fig. 206 A und B, g), ein Kern mit Plasma umgeben wird zur Eizelle (Fig. 206 A und B,e). Drei Kerne wandern an das der Mikropyle gegenüberliegende Ende, umgeben sich mit einer Zellwand und bilden so drei Zellen, die man als Ge gen füssler (Antipoden) bezeichnet (Fig. $206 \mathrm{Ac}$ ). Die übrig bleibenden zwei Zellkerne vereinigen sich zu dem sekundären Kern des Embryosacks. 
Bei der Bestäubung gelangt der Pollen auf die Narbe der Blüte (Fisg. 20\%). Nachdem der Pollenschlauch den Griffel durchwachsen, dringt er bis zum Embryosack vor, der eine Zellkern desselben (Spermakern) tritt

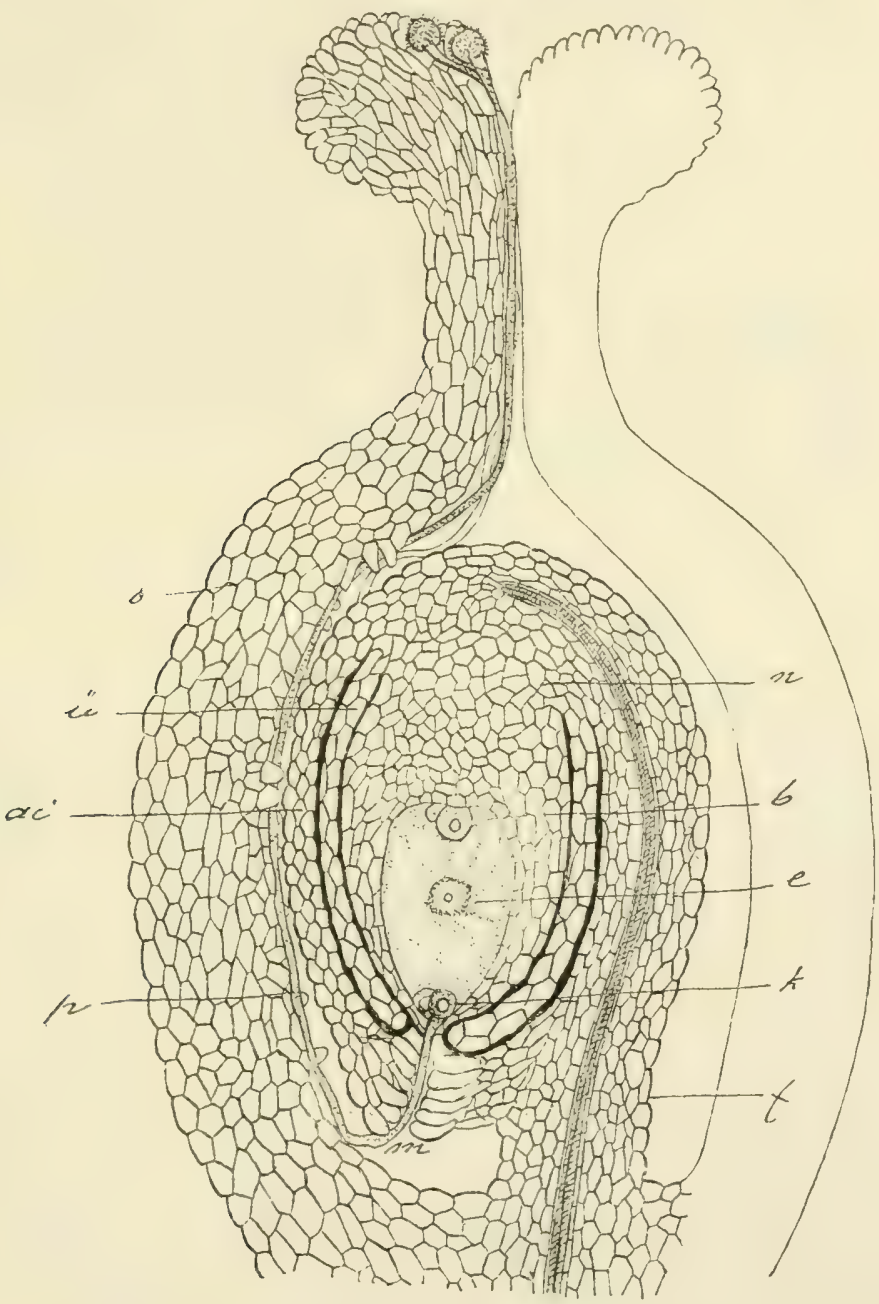

Fig. 207.

Schematische Darstellung eines Fruchtknotens mit einer Samenknospe, p Pollenschlauch, o Fruchtknoten, ii und $\mathrm{a} i$ inneres und äusseres Integument, m Mikropyle, n Chalazaende, $f$ Funiculus. Im Embryosack k Eizelle und Gehilfinnen, b Gegenfüsslerinnen, e sekundärer Embryosackkern. (K.)

an der Stelle, wo sich die Gehilfinnen befinden, in den Embryosack über und verschmilzt mit dem Kerne der Eizelle. Hierdurch ist der Befruchtungsakt vollzogen. Nachdem sich die Eizelle mit einer Cellulosewand umseben hat, treten Zellteilungen in der Eizelle ein, durch welche dieselbe 

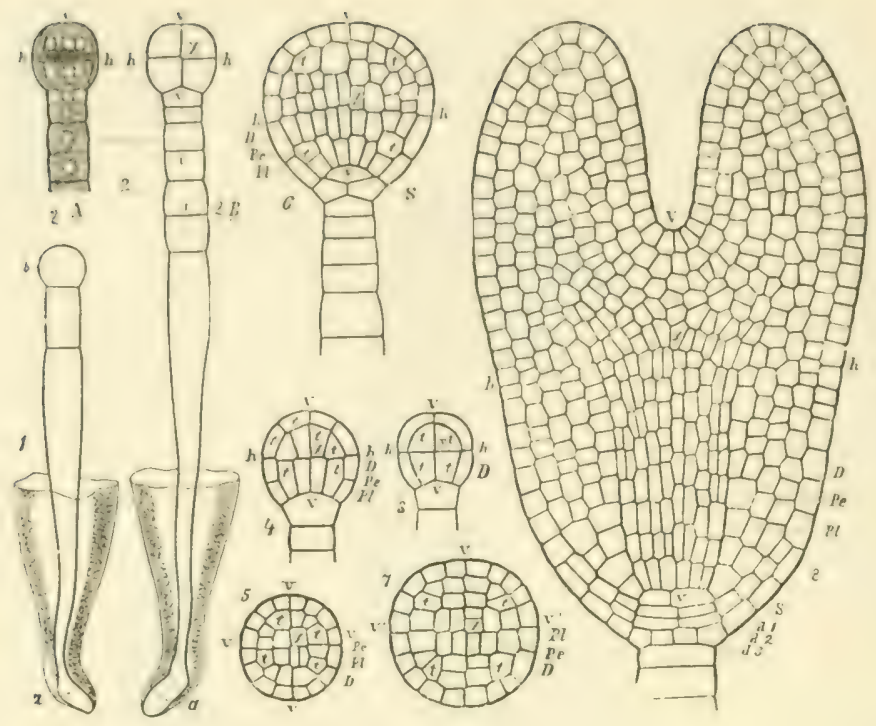

Fig. 208.

Embryoentwickelung von Brassica Napus. In I und 2 ist auch der Vorkeim abgebildet, welcher die kugelige Embryoanlage trägt. (KW.)

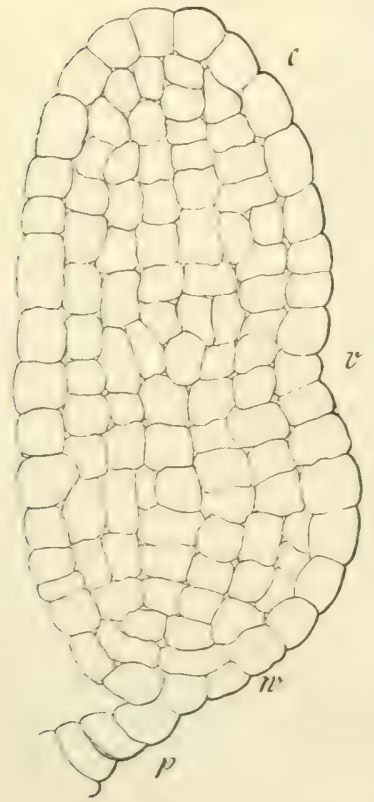

Fig. 209.

Embryo von Alisma Plantago (n. Hanstein). in einen Embryoträger (Vorkeim) und den Embryo geteilt wird (Fig. 208). Es kann jedoch auch die ganze Eizelle direkt zum Embryo werden. Ausserdem teilt sich der sekundäre Kern des Embryosacks weiter. Es entsteht aus demselben, sei es nun durch freie Zellbildung oder durch Zellteilung im Embryosack das Endosperm, welches hier aber nicht wie bei den Gymnospermen vor der Befruchtung, sondern erst nach der Befruchtung gebildet wird. Diese zeitliche Verschiebung lässt es zweifelhaft erscheinen, ob es gerechtfertigt ist, das Endosperm der Angiospermen mit dem Endosperm der Gymnospermen zu vergleichen.

Das Endosperm kann sich weiter entwickeln, das Knospenkerngewebe verdrängen und sich mit Reservestoffen füllen. Der Embryo bleibt dann relativ klein (Endospermhaltige Samen der Labiaten, Campanulaceen, der meisten Monocotylen).

Der Embryo kann jedoch auch sehr stark wachsen und in seinen Cotyledonen Reservestoffe speichern, so dass 
schliesslich sowohl Endosperm als Knospenkerngewebe durch den Embryo zusammengedrückt und verdränģt werden (Leguminosen). Seltener werden die Reservestoffe im Knospenkerngewebe abgelagert (sog. Perispermbildung bei Scitamineen, Piperaceen, Nymphaeaceen).

In allen Fällen geht die Samenschale aus den Integumenten hervor.

Bezüglich der Ausbildung des Embryos ist zu bemerken, dass die Gymnospermen 2-I5 Cotyledonen aufweisen, welche kranzförmig um den primären Vegetationspunkt herum entstehen.

Unter den Angiospermen besitzen die Embryonen der Dicotylen zwei Cotyledonen, zwischen denen sich der Vegetationspunkt (Fig. 208, v) befindet.

Bei den Monocotylen ist nur ein Cotyledo vorhanden, der Vegetationspunkt des Stengels (Fig. 209, v) entsteht zumeist seitlich.

Bei gewissen Pflanzen (z. B. Funkia ovata, Citrus aurantium, Coelebogyne ilicifolia) entwickelt sich das Ei nicht weiter. Dem Embryosack benachbarte Zellen des Knospenkerngewebes wachsen hier, ohne dass Befruchtung notwendig wäre, zu Embryonen aus, die man als Adventivembryonen bezeichnet.

\section{4. Reihe. Gymnospermae, Nacktsamige. Typus.}

Samenanlagen nackt, Pollenkörner vom Winde verstäubt. Narben und Fruchtknoten fehlen. Endosperm vor der Befruchtung gebildet. Archegonien vorhanden. Pollenkörner mit deutlich geschicdenem männlichen Prothallium. Perianthium nur bei Gnetaceen vorhanden. Cotyledonen in rerschiedener Anzahl. Bäume und Sträucher, welche sekundäres Dickenwachstum zeigen.

\section{§ 5. 1. Klasse. Cycadeae.}

Stamm sehr selten oder garnicht verzweigt, knollen- oder säulenförmig. Laubblätter gross, fiederförmig verzweigt, ähnlich den W'edeln gewisser Farne.

Blüten diöcisch. Fruchtknoten bei Cycas (Fig. 202) am Laubblätter bildenden Stamme, also keine eigentliche Blüte. Sonst bilden Fruchtblätter und Staubblätter sehr einfache zapfenförmige Blüten. Circa 90 Arten.

Nur tropische Arten: Cycas revoluta, C. circinalis. Zamia. Ceratozamia. Dioon.

\section{S6. 2. Klasse. Coniferae, Nadelhölzer.}

Stamm reich verzweigt mit lang andauerndem Dickenwachstum: Blätter relativ klein, unverzweigt, nadel- oder schuppenförmig. Blüten 
monöcisch, seltener diöcisch. Perianthium nicht vorhanden. Pollensäcke zu 2-5, seltener mehr auf der Unterseite der Staubblätter. Weibliche Blïten bei den zwei Ordnungen verschieden. In den meisten Fällen geht aus denselben cin Zapfen hervor. Circa 350 Arten.

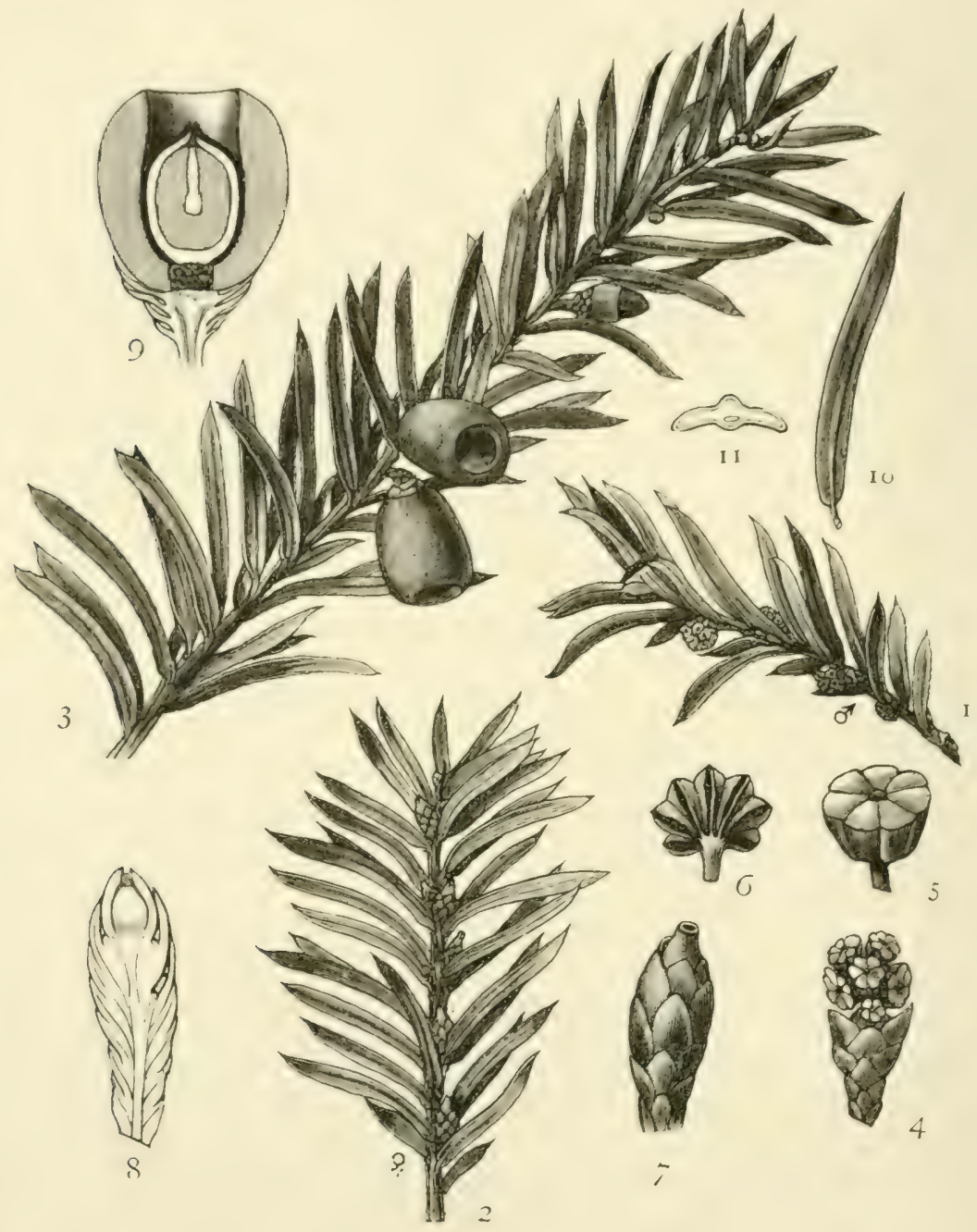

Fig. 210.

Taxus baccata. I Zweig mit männlichen, 2 mit weiblichen Blüten, 3 mit jungen und reifen Samen, 4 männliche Blüte, 5, 6 Staubblätter, 7, 8, weibliche Blüte, 9 reifer Samen, 10, II Blatt und Blattquerschnitt (Beissner).

\section{Ordnung. Taxoideae.}

Zapfenbildung unvollkommen oder fehlend. Samen nackt oder von einem fleischigen Samenmantel (Arillus) umgeben. Fruchtblätter unterdrückt oder fleischig. 
1. Fam. Taxacea e, Eiben.

Samen aufrecht. Wenn das Fruchtblatt fehlt, entstehen die Samenknospen direkt auf der Sprossaxe (Taxus, Fig. 2 IO, 7, 8). Blüten immer diöcisch.

Taxus baccata, פEibe (Fig. 2IO). Strauch oder Baum III. Grösse, wird bis 1500 Jahre alt. Blüten an der Unterseite vorjähriger Triebe. Weibliche Blüte aus einer Samenknospe bestehend (Fig. 210, 7, 8). Blüht April, Mai. Arillus rot (Fig. 210, 9). Samen liegen über.

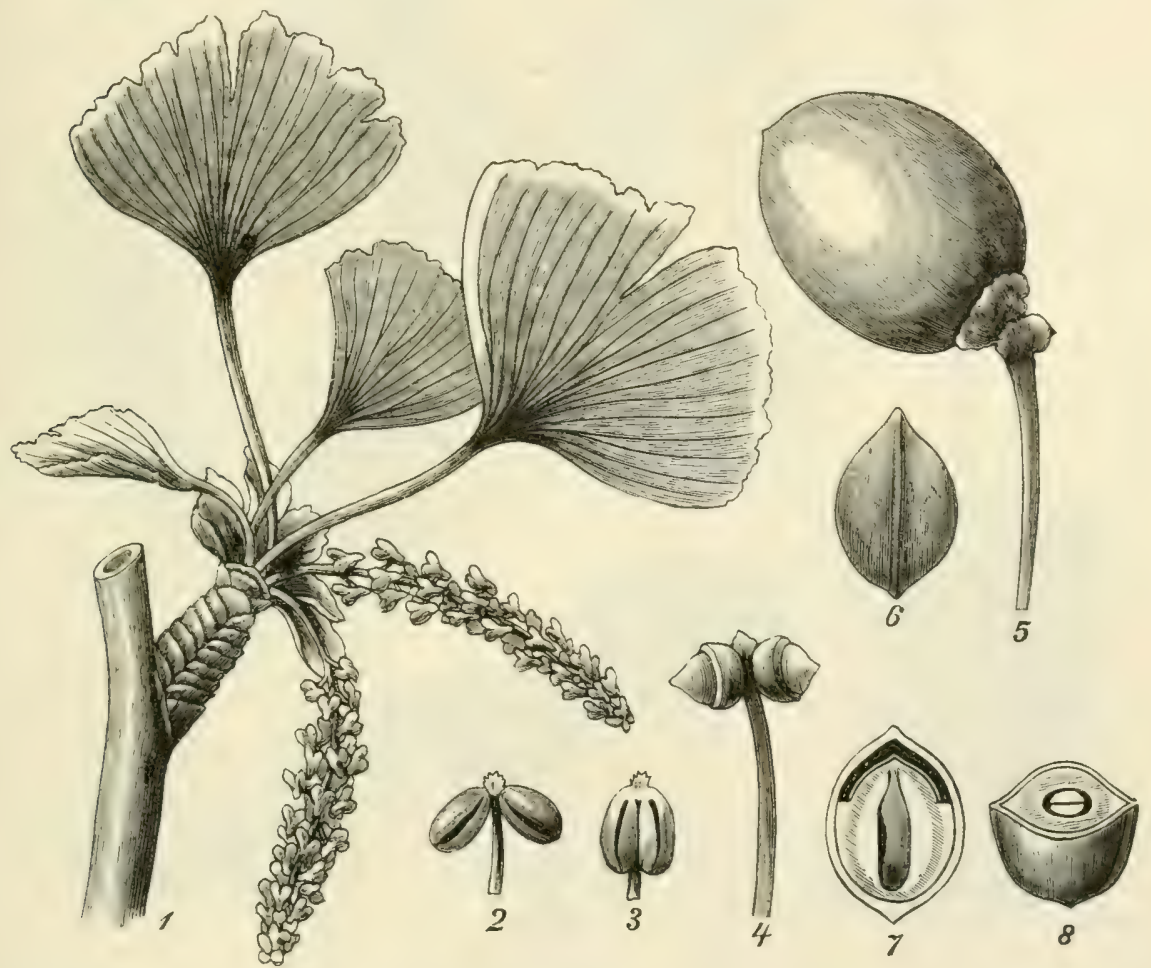

Fig. 211 .

Ginkgo biloba, I Kurztrieb mit männlichen Blïten. 2, 3 Staubblätter. 4 Weibliche Blüte. 5-8 Samen. (Beissner.)

Ginkgo biloba L. (syn. Salisburia adiantifolia Smith). Blätter laubartig (Fig. 2I I). Cephalotaxus, Phyllocladus, Torreya.

2. Fam. Pod oc a r a c e a .

Same mehr weniger umgewendet, Fruchtblatt immer vorhanden. Arillus vorhanden. Podocarpus. Dacrydium.

\section{Ordnung, Pinoideae.}

Vollkommene Zapfenbildung. Samen zwischen den Zapfenschuppen 
versteckt. Samenschale holzig, leder- oder knochenartig. Kein Arillus. An der Zapfenspindel stehen Deckschuppen, in deren Achsel sich die Fruchtschuppen befinden. Deckschuppe und Fruchtschuppe mit einander verwachsen oder nicht. Die Fruchtschuppen tragen die Samenknospen.

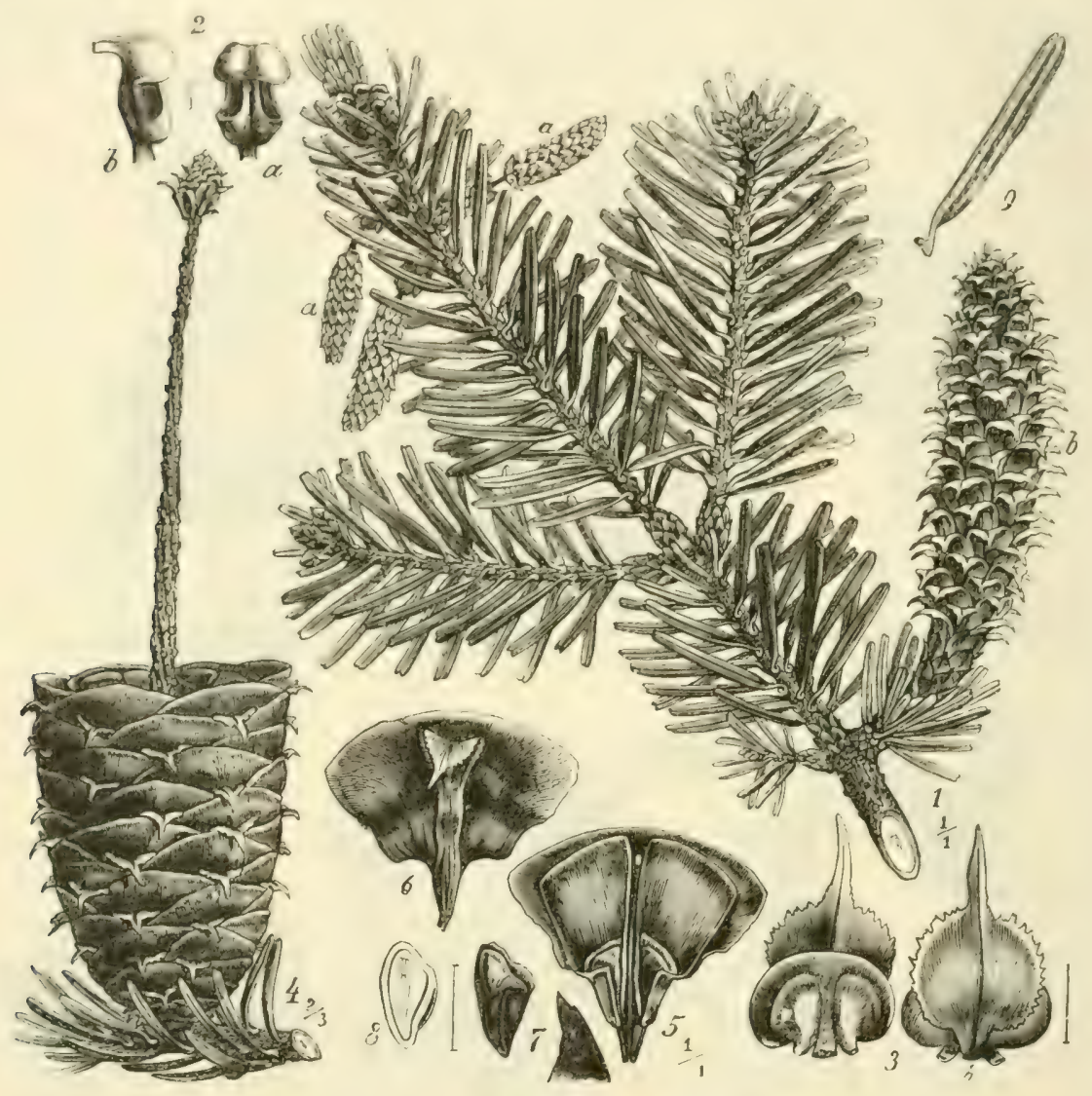

Fig. 212 .

Abies pectinata. I Zweig mit ठ Blüte (a) und $q$ Blüte (b). 2 Staubblatt mit je zwei Pollensäcken. 3 Fruchtblatt von vorn (a), von rïckwärts (b). 4 halbentblätterter Zapfen. 5 Fruchtschuppe mit den geflügelten Samen. 6 Fruchtschuppe und Deckschuppe. 7 Same ohne Flügel. 8 Samenlängsschnitt. 9 Nadel von der Unterseite. (W.)

\section{Fam. Abietaceae.}

Blätter und Zapfenschuppen spiralig gestellt. Zwei umgewendete Samenknospen. Fruchtschuppe und Deckschuppe nur an der Basis verwachsen. Same fast immer geflügelt. Der Flügel ist eine oberflächliche Zellschicht der Fruchtschuppe. Blüten monöcisch. § Blüten kätzchenartig, mit vielen Staubblättern, welche je zwei Pollensäcke tragen. Pollenkörner oft mit zwei blasenförmigen Auftreibungen der äusseren Haut, den sog. Exineblasen. Keimlinge mit mehr als zwei Cotyledonen. 
Abies pectinata DC. (syn. Pinus abies DR. Pinus picea L) Weisstanne, Edeltanne (Fig. 2I2). Baum I. Grösse (30-65 m hoch) gerade, vollholzig. Alter 200 Jahre und darüber. Zweige flach. Rinde der jungen Zweige glatt, mit kurzen Haaren versehen. Pfahlwurzel mit vielen starken Seitenwurzeln. Nadeln flach, an der Spitze eingekerbt, auf der Unterseite mit zwei weisșen Streifen, spiralig inseriert, kammförmig gestellt, bis acht Jahre alt werdend, manchmal noch älter.

Männl. Blüten länglich cylindrisch, gelblich grün bis rot, mit der Quere nach aufspringenden Antheren; weibl. Blüten bleichgrün, walzenförmig, erscheinen Mitte April (im Süden) bis Ende Mai; beide an vorjährigen Trieben. Zapfen $75-170 \mathrm{~mm}$ lang, aufrecht stehend. Deckschuppe länger als Fruchtschuppe. Fruchtschuppen flach, fallen mit den Samen bei der Reife von der Spindel ab. Samenreife Ende September des I. Jahres: Samen verkehrt kegelförmig, von dem glänzend braunen Teil des Flügels umhüllt, $\bar{\gamma}-9 \mathrm{~mm}$ lang. Keimung bei Frühjahrsaussaat in $3-5$ Wochen. Mannbarkeit mit 60-70 Jahren.

Varietäten: Schlangentanne, Seitenäste wenig verzweigt. (selten), Hängetanne, Zweige herabhängend.

Verlangt frischen, entsprechend tiefgründigen Boden. Empfindlich für Spät- und Frühfröste. Leidet durch Dürre. Sturm, Schnee, Eisanhang schadet weniger als bei der Fichte.

$\mathrm{Zu}$ Anbauversuchen werden verwendet:

Abies Nordmanniana Lk. Nadeln der jüngeren. Seitensprosse bürstenförmigg aufwärts gerichtet, dunkelgrün, länger und breiter als bei A. pectinata. Krim. Kausasus.

Abies firma Sieb. et Zucc. Zweige stark, hellbraun, junge Triebe kurz, braunhaarig. Nadeln derb lederartig, steif, fast zweizeilig, 20 bis $30 \mathrm{~mm}$ lang, $21 / 2-3 \mathrm{~mm}$ breit, lang zweispitzig oder abgerundet. Japan. Abies amabilis Forb. Zweige durch die länglich-rhombischen Blattkissen runzelig, dunkel behaart. Nadeln. ähnlich wie bei Abies Nordmanniana, aber kürzer, über der Mitte des. Zweiges drehen die kürzeren Nadeln die weiss gestreifte Seite nach oben. Östliches Nordamerika. Abies concolor Lindl. et Gord. Junge Triebe glatt, gelblich, Nadeln meist stumpf, beiderseits matt, blassgrün und mit Spaltöffnungsreihen versehen, in der Jugend länger $(5-7 \mathrm{~cm})$ als im Alter. Kalifornien. Abies grandis, junge Triebe glatt, gelbbraun. Nadeln oben rinnenförmig und glänzend dunkelgrün, $3-5 / 2 \mathrm{~cm}$ lang. Westl. Nordamerika. Abies nobilis Lindl. Junge Tricbe rotbraun, weichhaarig. Nadeln aufwärts gekrïmmt, dunkel blaugrün, beiderseits mit Spaltöffnungslinien versehen, $2^{1} / 2-3^{1}, 2 \mathrm{~cm}$ lang. Blattquerschnitt flach, nicht viereckig wie bei der ähnlichen Abies magnifica. Höhere Gebirge im Oregon.

In Deutschland häufige Parkbäume:

Abies balsamea Mill. Nadeln sichelförmig nach oben gebogen, ziemlich kurz. Knospen von Harz umflossen. Nordamerika. Abies 
sibirica Ledeb. (syn. A. Pichta Forb.) Sibirische Tanne. Deckschuppen kïrzer als Fruchtschuppen. Ural, Sibirien. Abies Pinsapo, Andalusische Tanne. Nadeln spitz, rings um die Zweige gestellt.
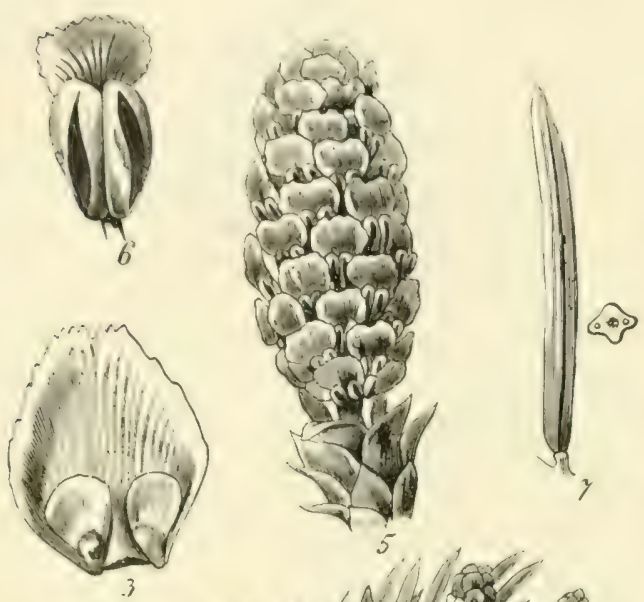

5

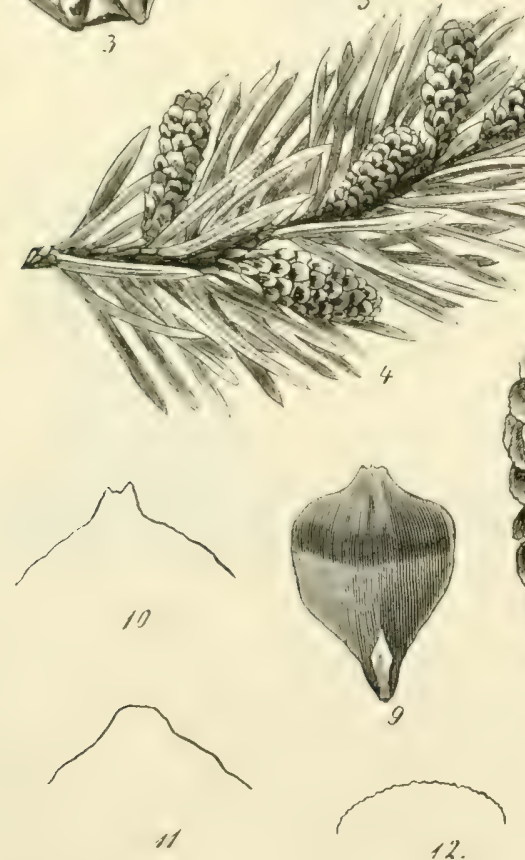

12.
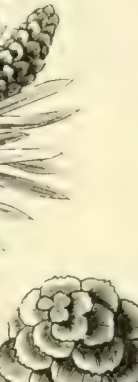
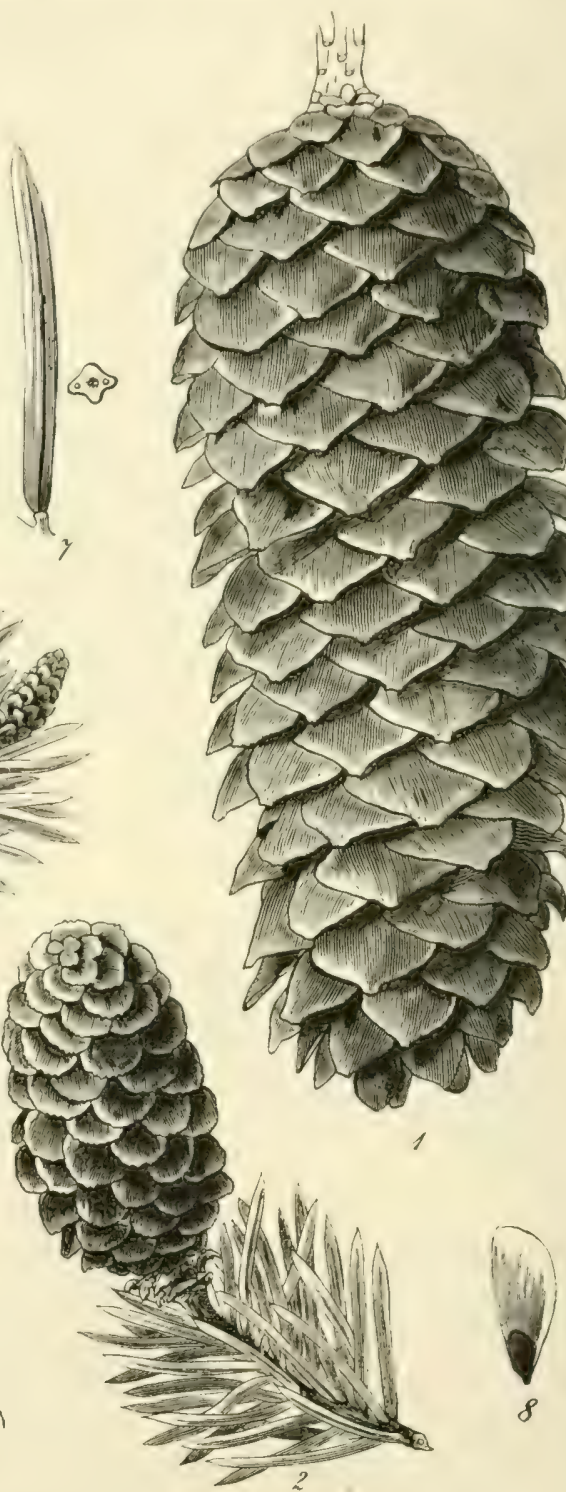

Fig. 213 .

Picea excelsa. I Reifer Zapfen. 2 Weibliche Blüte. 3 Zapfenschuppe von Innen. 4 Männliche Blüten. 5 Männliche Blüte vergr. 6 Staubblatt vergr. 7 Nadel. 8 Same. 9 Deckschuppe und Fruchtschuppe von aussen. 10-12 Fruchtschuppen. (Beissner.)

Picea excelsa Lk. (syn. Abies excelsa DC, Pinus abies L., Pinus excelsa Lam.). Fichte, Rottanne, Pechtanne (Fig. 2I3). Baum I. Grösse 
(30-50 m), schnurgerader Stamm, nach oben stark abfällig. Äste bogenförmig. Bewurzelung flach. Nadeln vierkantig, $5-7$ Jahre alt werdend. Die Blïten stehen an vorjährigen Trieben. Staubblätter rot, Pollensäcke gelb, mit einem Längsspalt aufspringend. Blüht Ende April bis Mitte Juni. Fruchtschuppen flach, Deckschuppen kleiner als diese (Fig. 2 I3, 9). Fruchtschuppen fallen nicht von der Spindel ab. Zapfen Io- $16 \mathrm{~cm}$ lang, auch kürzer, später herabhängend, reifen im Oktober des ersten Jahres, Der Same fliegt Februar, März aus. Samen dunkelrostfarbiş, Flïgel dreimal länger als der Same. Der Same liegt in einer löffelartigen Verticfung des

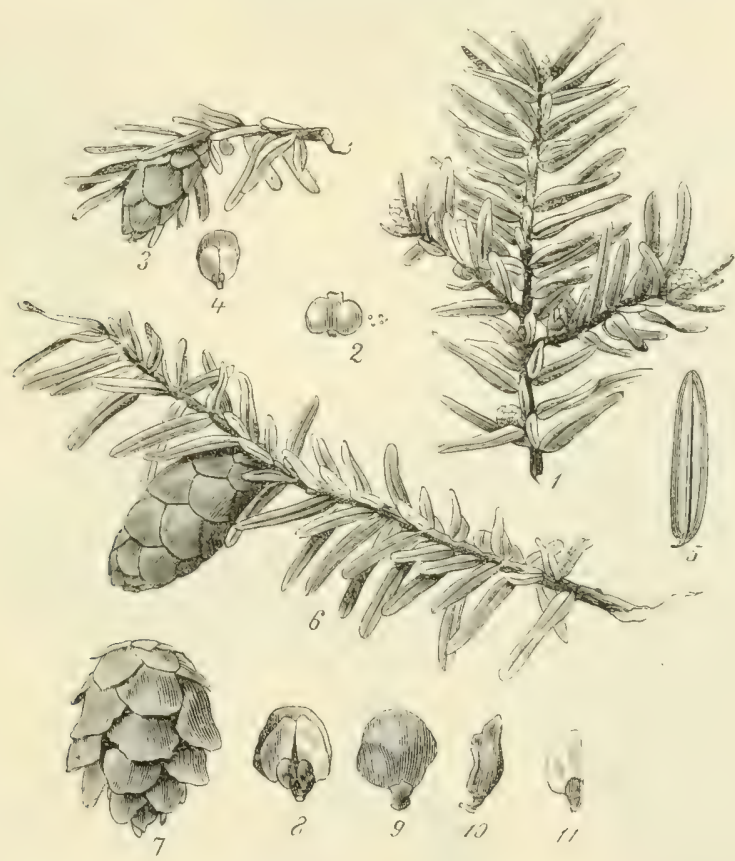

Fig. 214 .

Tsuga canadensis. I Männliche Blütẹn. 2 Staubblatt. 3, 4, 6-I I Weibliche Blüte, Zapfen, Zapfenschuppen, Samen. 5 Blatt von der Unterseite. (Beissner.)

Flügels. Keimung 3-5 Wochen nach der Aussaat im Frühjahr. Mannbarkeit mit 50-60 Jahren.

Varietäten: rotzapfige Fichte (var. erythrocarpa), grünzapfige Fichte (var. chlorocarpa). In Skandinavien und Russland die kleinzapfige Fichte (var. medioxima), ähnlich die in der Schweiz vorkommende var. alpestris. Hänge- und Schlangenfichten (var. pendula und virgata).

Die Fichte liebt frische Böden mit genügender Feuchtigkeit, Tiefgründigkeit nicht verlangt. An mineralische Bodenkraft stellt sie mittlere Ansprüiche. Standort hauptsächlich Gebirge, Spätfröste und Dürre schaden leicht. Windwurf.

$\mathrm{Zu}$ forstlichen Anbauversuchen werden verwendet: Picea sitchen- 
s is Trautr. et Mey. (syn. Picea Menziesii Carr.). Nadeln zweiflächig, starr, stechend, 12-18 mm lang, auf der Oberfläche mit zwei weissen Streifen, die jedoch in den ersten Jahren gar nicht oder nur schwach hervortreten. Zapfen 5-S cm lans. Sehr wenig wählerisch in Bezug auf den Stand-

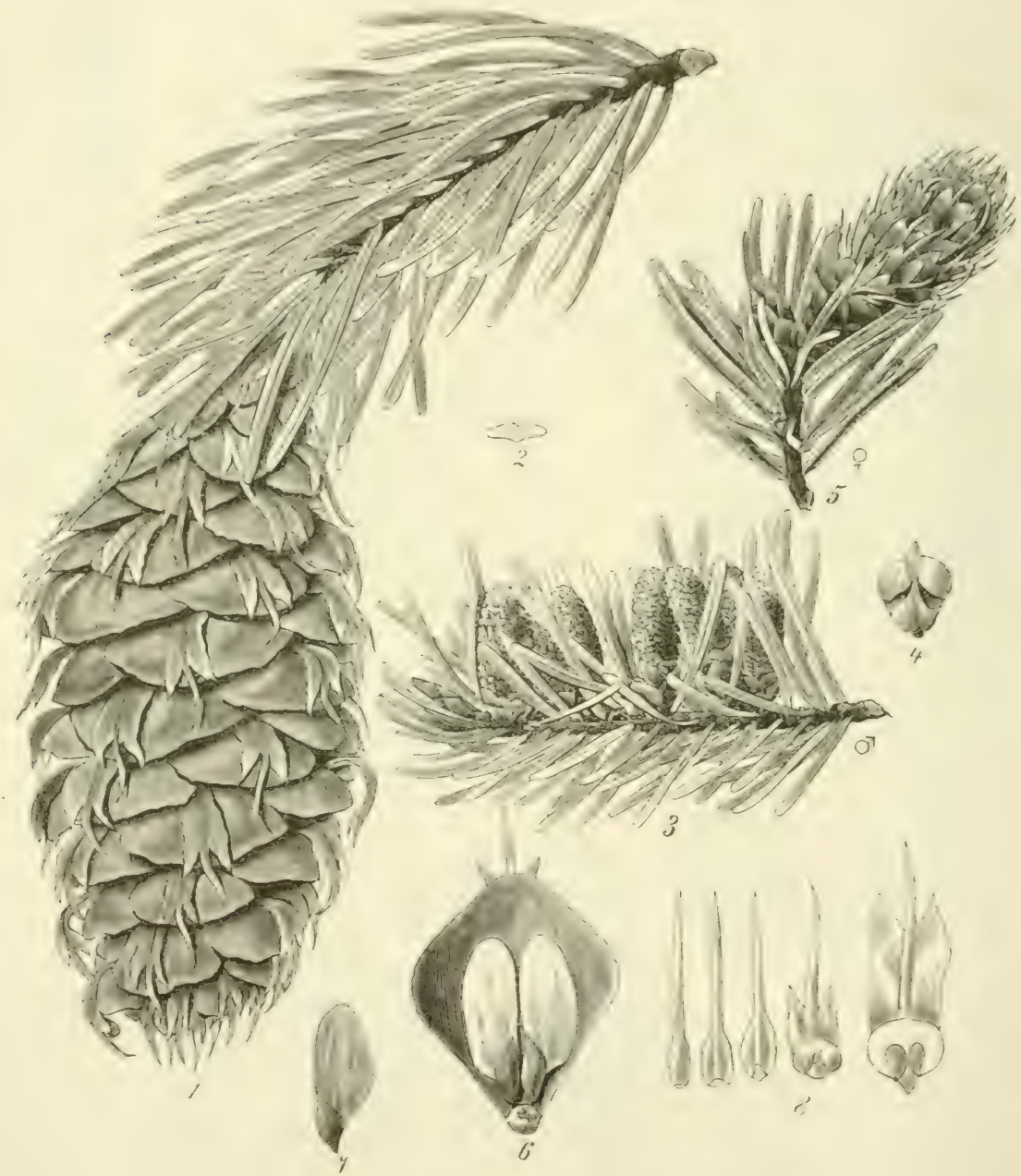

Fig. 215.

Pseudotsuga Douglasii. I Zapfen. 2 Nadelquerschnitt. 3 Männliche Blüten. 4 Staubblatt. 5 Weibliche Blüten. 6 Fruchtschuppe mit Samen von innen. 7 Samen. 8 Übergang der Nadeln in Zapfenschuppen (n. Eichler).

ort. Nur junge Pflanzen leiden etwas durch Frost oder auch durch Vertrocknen im Winter. Forstlich wertvoll. Nordwestliches Nordamerika. Picea pungens Engelm. (syn. Picea Parryana Barron.). Nadeln vierkantig, stechend, besonders in der Jugend stark blau bereift. Die Endknospen mit breiten, zurückgeschlagenen Schuppen. Nordamerika. Picea Engel- 
mannii Engelm. Junge Triebe fein behaart, Nadeln stechend, ziemlich weich, blaugrün, vom Zweige weniger abstehend. Die Nadeln der Keimpflanze nicht gezähnt. Knospenschuppen gelb, fest anliegend. Gebirge des westlichen Nordamerika. Picea polita Carr. Nadeln stechend, etwas nach aufwärts sekrümmt, frisch srün, mit bläulichen Spaltöffnunssicihen. Zapfen 8 - I $2 \mathrm{~cm}$ lang. Japan. Picea bicolor Mayr (syn. Picea Alcockiana Carr.). Nadeln steif, stechend, sehr dichtstehend, gebogen, oberseits bläulich grün. Japan.

Andere bemerkenswerte Arten sind: Picea obovata Ledeb. Sibirische Fichte. Steht der Picea excelsa sehr nahe, vielleicht nur eine klimatische Abart. Picea nigra Lk., Nadeln stechend, dunkelgrün, bläulich bereift, Zweige fein behaart. Nordamerika. Picea rubra Lk., Zweige filzig, rotbraun, Nadeln sehr dicht stehend, kleiner als bei der gemeinen Fichte. Picea alba Lk. Zweige unbehaart, weisslich, $\mathrm{Na-}$ deln nicht stechend, blaugrün erscheinend. Nordamerika. Picea orientalis Lk. et Carr. Nadeln sehr kurz und stumpf. Kaukasus. Picea Omorica Pan., Nadeln zweiflächig. Serbien.

Tsuga canadensis

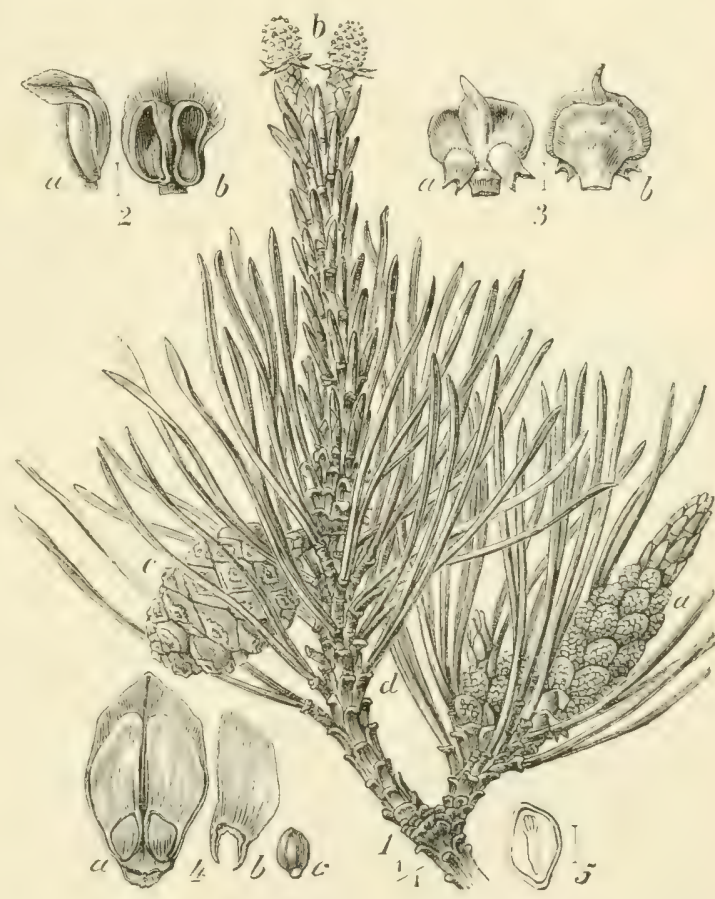

Fig. 216.

Pinus silvestris, I a $\delta^{\nearrow}$ Blütenstand, I b 을 Blüte. I c Zapfen im Frühjahr des zweiten Jahres. 2 Staubblatt. 3a Samenknospen und Fruchtschuppen. 3 b Deck- und Fruchtschuppe. 4 a Samen auf der Fruchtschuppe. $4 \mathrm{l}$ Flügel. $4 \mathrm{c}$ Same. 5 Längsschnitt durch den Samen. (W.) Carr. (syn. Abies, Pinus, Picea canadensis) Hemlockstanne, Schierlingstanne (Fig. 2I4). Baum II. Grösse. Nadeln zweiflächig, kammförmig stehend, an der Spitze abgerundet, 6-I4 mm lang, also wesentlich kürzer als bei der Tanne. Blattbasen hervorstchend. Zapfen $1,5-2,5 \mathrm{~cm}$ lang. Zapfenschuppen dünn, lösen sich nicht von der Spindel, Deckschuppe kïrzer als die Fruchtschuppe. Samen $4 \mathrm{~mm}$ lang, kantig, hellbraun. Nordamerika.

$\mathrm{Zu}$ Anbauversuchen verwendet: Tsuga Mertensiana Carr. Zweige in der Jugend lang behaart. Nadeln $\mathrm{I}-2 \mathrm{~cm}$ lang. Westliches Nordamerika. Tsuga Sieboldii Carr. Junge Zweige glatt, Nadeln an der Spitze ausgerandet. Japan.

Pseudotsuga Douglasii Carr. (syn. Abies, Picea, Pinus Dou- 
glasii), Douclasfichte oder Douglastanne (Fis. 215). Baum 1. Grösse, in der Heimat bis $90 \mathrm{~m}$ hoch. Nadeln schmal, $18-30 \mathrm{~mm}$ lans, stumpf, an den Seitentricben kammförmis, wohlriechend. Zapfen hängend, $5-9 \mathrm{~cm}$ lang. Schuppen bleiben an der Spindel, Dechschuppen längser als Fruchtschuppen. Samen hellrötlich braun, 6-7 mm lang, etwas kantigs. Sehr wertvolle nordanerikanische Art, die bei uns auffrischem, mildem humosem, lehmisem Sandboden sut sedeiht, rasch wächst und grosse Massen hochwertiges Holz produciert.

Bei der Gattung Pinus stehen $2-5$ (ausnahmsweise bis 7 ) Nadeln in Kurztrieben. Nan unterscheidet vier Scktionen dieser Gattung:

I. Sektion. Pinaster. Kurztricbe zweinadelig. Zapfen kugelig oder kesgelförmig. Die Apophyse, das viereckige Schild an der Spitze der Fruchtschuppen, stark verdickt. Nabel in der Mitte.

Pinus silvestris L., gemeine Kiefer, Forche, Föhre (Fig. 2I6). Baum 1. Grösse, $20-35 \mathrm{~m}$ hoch. Reinigt sich leicht von den Ästen. Krone im Alter (nach Ioo Jahren) schirmförmig. Bei freiem Stande entwickeln sich starke Seitenäste, im Gebirge leicht krummschäftig, sonst gerader Stamm. Kann mehrere hundert Jahre alt werden. Pfahlwurzel, zahlreiche Nebenwurzeln. Nadeln meist $4-5$, seltener $6-7 \mathrm{~cm}$ lang; $21 / 2-4$ Jahre dauernd. Nännliche Blüten dicht gedrängt an der Basis junger Triebe. Weibliche Blüten erbsengross, rot an der Spitze junger Triebe, im Mai. Zapfen reifen im Oktober des zweiten Jahres. Der Same fliegt im März und April ab. Zapfen 3-5 cm lang. Flügel der schwarz-grau melierten Samen zangenartig. Keimung 2-4 Wochen nach Aussaat. Mannbarkeit meist mit 30-40 Jahren, auf sehr feuchtem Boden erst später.

Variiert mit veränderten Standortsverhältnissen (Strand- und Moorkiefer). Die Zapfen können flach, konvex oder in Haken ausgezogen sein.

Baum des Flachlandes, wo er sich sehr verschiedenen Feuchtigkeitsverhältnissen anpasst. In jeder Hinsicht genügsam. Leidet durch Hagel, Schnee, Waldbrände.
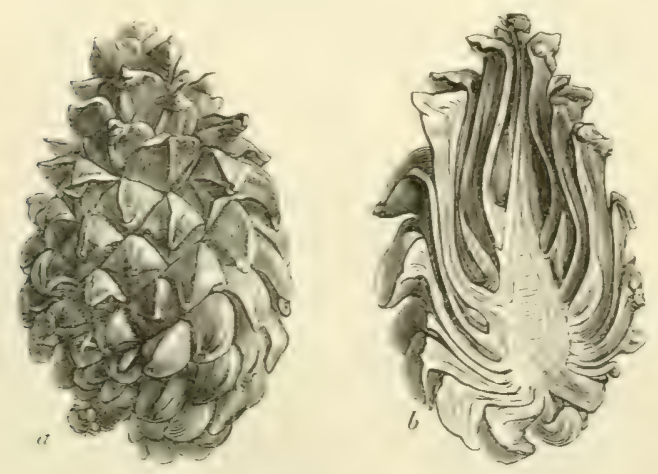

Fig. 217 .

Pinus montana var. uncinata. Zapfen. (DN.)
Pinus montana Mill. Krummholzkiefer, Bergkiefer, Knieholz, Latsche. Die einzelnen Formen dieser Art von sehr verschiedenem Habitus, strauchig, niederliegend, bogig aufstrebend, höchstens Baum III. Grösse. Nadeln beiderseitig grün, weibliche Blüten violett. Apophysen grauweiss, matt, bei manchen $\mathrm{Va}-$ rietäten braun. Nabel von schwärzlicher Linie umsäumt. Pinus montana ist speciell dem Vorkommen im Gebirge angepasst. 
Nach der Zapfenbildung kann man folgende Hauptformen unterscheiden: var. uncinata, Hakenkiefer, Zapfen stets ungleichseitig, am Grunde schief, Apophysen hakig gekrümmt (Fig. 217); var. Pumilio, Zapfen gleichmässig, eiförmig, fast kugelig, anfangs violett, blau bereift, reif dunkelbraun bis scherbengelb, Nabel meist eingedrückt; var. Mughus, Zapfen kegel- oder eikegelförmig, im ersten Herbst hell gelbbraun, reif hell bis dunkelzimmtbraun, niemals bereift, Nabel central mit stechendem Dorn.

Pinus Laricio Poir. (syn. P. corsicana Poir., P. Pinaster Besser) Schwarzkiefer. Dicknadelige Formen: var. austriaca, var. Poiretiana, var. Pallasiana; dünnnadelige Formen: var. cebennensis, var. pyrenaica.

Für unser Gebiet ist nur von Wichtigkeit:

Pinus Laricio var. austriaca (syn. P. austriaca Höss, P. maritima Koch, P. nigricans Host). Die österreichische Schwarzkiefer wird unter günstigen Verhältnissen circa $30 \mathrm{~m}$ hoch, auf sehr trocknem Kalkboden kann sie auch Strauchform annehmen. Jüngere Äste regelmässig quirlständig. Krone später schirmförmig, dicht. Starke, weitstreichende Horizontalwurzeln. Nadeln $8-16 \mathrm{~cm}$ lang, dunkelgrün. Knospen spitz, mit silberweissen Schuppen bedeckt. Zapfen 5-8 cm lang, glänzend gelbbraun oder scherbengelb mit fleischfarbigem Nabel (Fig. 2I8), Samen nebelig grau, ohne

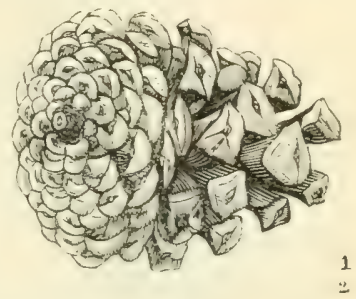

Fig. 2 I 8 .

Pinus Laricio var. austriaca. Zapfen $1 / 2$ der nat. Grösse. (DN.) Glanz.

Ansprüche an den Boden gering, verlangt jedoch grössere Luftwärme. In Dänemark, Norddeutschland, Thüringer Wald, leidet dieselbe vom zwanzigsten Jahre ab sehr bedeutend (vgl. S. 2 I I).

Pinus Pinaster Sol. (syn. P. maritima, Poir.). Sternkiefer, Igelföhre, Seekiefer, Strandkiefer. Baum II.-I. Grösse. Kann krummschäftig und buschig werden. Knospen bis $2 \mathrm{~cm}$ lang, stumpf, mit weiss gewimperten Schuppen, Nadeln IO-20 cm lang, abstehend am Ende der Triebe gebüschelt, Zapfen glänzend zimmtbraun, 8 - I9 $\mathrm{cm}$ lang, mit sleichfarbigem Nabel. Samen einerseits kohlschwarz glänzend, anderseits grau, grosses Wärmebedürfnis, leidet in Deutschland sehr durch Frost, Anbau daher aufgegeben.

Pinus pyrenaica La Peyr., die Pyienäenkiefer und Pinus halepensis Mill., die Aleppokiefer besitzen dünne, zarte Nadeln. Pinus Pinea L., die Pinie hat fast ungeflügelte, dicke Samen.

$\mathrm{Zu}$ Anbauversuchen verwendet: Pinus Banksiana Lamb. Nadeln 4--6 cm lang, sehr dicht, am Rande rauh, etwas sichelförmig gebogen. Knospen mit Harz bedeckt. Kälteres Nordamerika. Pinus Thunbergii Parl., der P. Laricio ähnlich. Erfriert in Deutschland. Japan. Pinus densiflora Sieb. et Zucc, ebenfalls eine japanische Art, hat sich in Deutschland nicht bewährt. 
11. Sektion Tacda, Kurztriche, dreinadelis, Zapfen wie bei der Sektion Pinaster.

Pinus risida Mill. Pechkicfer. Bis $15 \mathrm{~m}$ hoch, häufig krummschäftis. Nadeln 6-I2 cm lang. Zapfen eiförmig, oft quirlständigs, 6- IO cm lans, Apophyse mit scharfem Querkiel und donigem, zurückgebogenem Nabel (Fig. 219). Samen $4 \mathrm{~mm}$ lang.

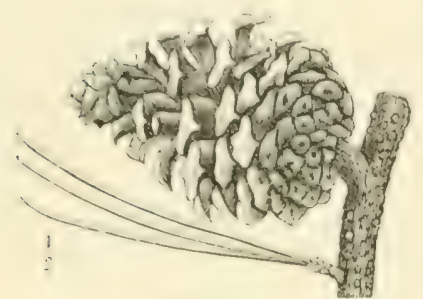

Fig. 219.

Pinus rigida. Zapfen. (DN.)

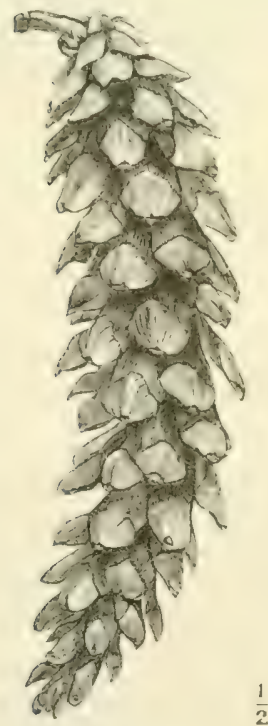

Fig. 220.

Pinus Strobus. Zapfen. (DN.) Nordamerika. Stellt ausscrordentlich geringe Ansprïche an den Boden, die Triebe reifen auf besserem Boden sehr oft nicht aus. Liefert nicht das wertvolle Pitch-pine-Holz des Handels, welches von den im Südosten Nordamerikas vorkommenden Kiefernarten Pinus mitis und Pinus australis stammt. Pinus Jeffreyi Murr. Nadeln IO- $20 \mathrm{~cm}$ lang, wie dic jungen Triebe weissblau bereift. Hat keine wesentlichen Vorzüge vor der gemeinen Kiefer. Pinus ponderosa Dougl. Gelbkiefer. Nadel $10-20 \mathrm{~cm}$ lang. Junge Triebe bräunlich, der vorigen Art sehr ähnlich. Hat sich in Deutschland forstlich nicht bewährt. Pinus taeda, Pinus Sabiniana, Pinus Coulteri. Die letztere Art hat mächtige Zapfen.

III. Sektion Strobus. Kurztriebe fünfnadelig, Zapfen langwalzig, nach der Samen reife nicht zerfallend. Flache kiellose Apophyse. Nabel an der Spitze der Fruchtschuppe.

Pinus Strobus L. Weymouthskiefer. Baum I. Grösse. Gerader Stamm. Pfahlwurzel mit weit ausstreichenden Nebenwurzeln. Nadeln 6- IO,5 cm lang, sehr dünn. Scheitel des Staubblattes aufrecht, zweispitzig. Zapfen IO-I $5 \mathrm{~cm}$ lang, hängend (Fig. 220). Samen 5-6 $\mathrm{mm}$ lang, violettgrau und dunkelbraun marmoriert, auf einer Seite glänzend, reifen im September des zweiten Jahres und fliegen sodann aus. Mannbarkeit mit 30-35 Jahren.

Im ganzen genügsam, bevorzugt tiefgründigen, feuchten, lehmigen Boden. Aus dem östlichen Nordamerika seit I 705 eingeführt.

Pinus excelsa Wall. (syn. P. Peuce Grieseb.). Nadeln IO-I $5 \mathrm{~cm}$ lang, Zapfen I4-I7 cm lang. Erfriert leicht. Himalaya, Balkan.

IV. Sektion Cembra. Kurztriebe fünfnadelig, Zapfen bei der Reife zerfallend. Samen ungeflügelt.

Pinus Cembra L. Arve, Zirbelkiefer. Baum II. Grösse. Stamm stark abholzig, mit tief angesetzter Krone. Jüngste Triebe mit rost- 
farbigem Filz. Nadeln stark, 5-8 cm lang, oberseits weiss. Zapfen eiförmig, 5-8 cm lang, Fruchtschuppen dick (Fig. 22I). Samen gross, nussartig, IO-I2 $\mathrm{mm}$ lang. Gebirgsbaum, besonders auf sandig-thonigen, kalireichen Böden. Bedarf feuchte Luft.

Die Gattung La rix besitzt Kurztriebe mit zahlreichen sommergrünen Nadeln.

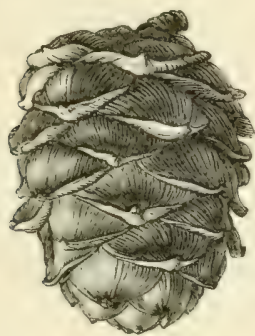

Fig. 221.

Pints Cembra. Zapfen. (DN.)

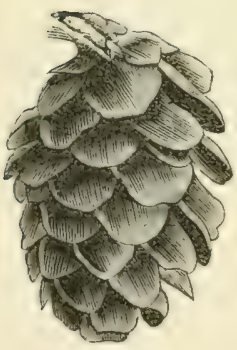

Fig. 223.
Larix europaea. Zapfen. (Beissner.)

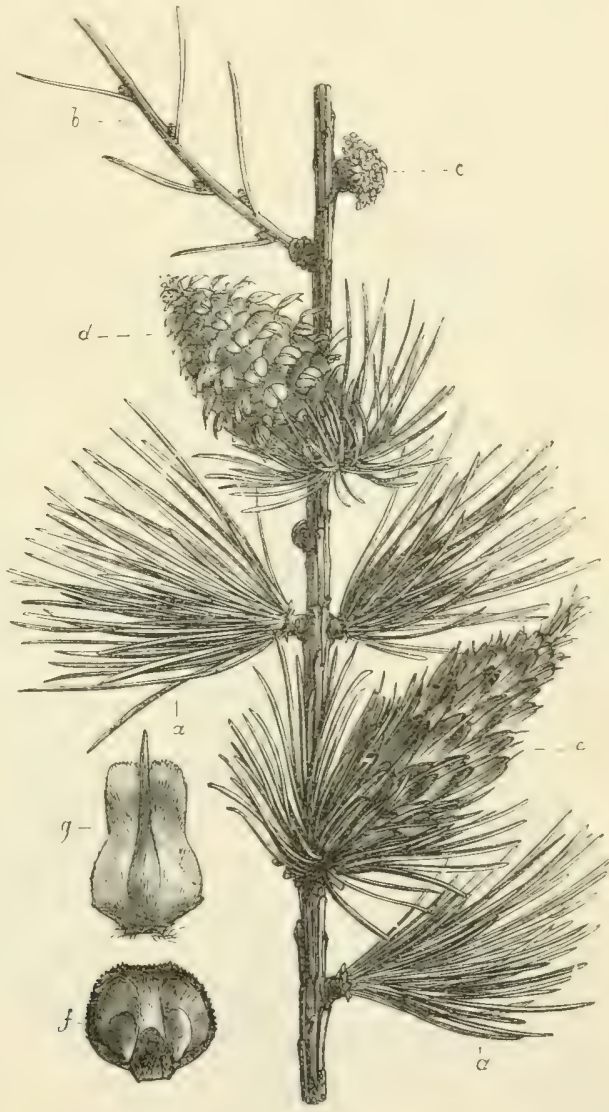

Fig. 222.

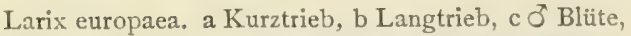
d Q junger Zapfen, mit beginnender Durchwachsung. f Fruchtschuppen mit 2 Samen, g Deckschuppe. (DN.)

Larix europaea DC. (syn. Larix decidua Mill., Pinus Larix L. Lärche (Fig. 222 und 223), Baum I. Grösse, Säbelwuchs häufig. Die feinen Seitenzweige hängend. Pfahlwurzel, später Herzwurzel. Nadeln an den Kurztrieben sehr zahlreich, gebüschelt, an Langtrieben einzeln. Männliche Blüten kugelige, gelbe Kätzchen, weibliche Blüten eiförmišs, rot, beide an vorjährigen oder älteren Trieben. Blïht März, April. Zapfen (Fig. 223) eiförmig, I,5-2,5 cm lang. Fruchtschuppen flach. Deck- 
schuppen ungefähr so langwic fruchtschuppen. Samen 3-4 mm lang, rötlichsraubraun, mit dem Flügel verwachsen. Reifen im Oktober des ersten Jahres, Abfall im darauf folgenden Frïhjahr. Keimung nach 3-5 Wochen.

Kommt hauptsächlich im Gebirge und als besondere Abart in den Ebenen Russlands vor. Vermeidet wegen der Empfindlichkeit der jungen Nadeln gegen Frost ein Klima, welches im Frühjahr häufige Temperaturschwankungen aufweist. Leidet durch Hitze.

Zu Larix europaea gehören der geographischen Verteilung entsprechend verschiedene Varietäten, die auch als besondere Arten beschrieben wurden, so Larix europaea var. sibirica in der Jugend mit behaarten Fruchtschuppen, var. rossica, var. pendula.

Die zu Anbauversuchen verwendete japanische Art Larix leptolepis Nurr. (syn. L. japonica Carr.), verhält sich wie die gewöhnliche Lärche. Die Zweige sind nicht herabhängend, Nadeln dunkelgrün-bläulich.

Die Gattung Cedrus hat wie Larix Kurztricbe mit zahlreichen Nadeln, die jedoch immergrün sind. Samenreife zweijährig. Cedrus Deodara aus dem Himalaya und Cedrus atlantica aus Nordafrika halten in den wärmeren Teilen Deutschlands im Freien aus. Cedrus Libani, Libanonceder.

2. Fam. Araucariaceae, Schmucktannen.

Blätter und Zapfenschuppen spiralig stehend. Fruchtschuppe und Deckschuppe vollständig verwachsen. Samenknospen umgewendet. Araucaria imbricata. Chile. Araucaria excelsa, Norfolktanne. Agathis Dammara. Malayische Inseln.

3. Fam. Taxodiaceac.

Blätter und Zapfenschuppen spiralig. Fruchtschuppe und Deckschuppe verwachsen. Die 2-8 Samenknospen aufrecht.

Taxodium distichum Rich. Virginische Sumpfcypresse. Die dünnen Zweige, mit den zweizeilig abstehenden Blättern. werden abgeworfen. Taxodium mexicanum wird 4000-6000 Jahre alt. Sequoia gigantea Torr. (syn. Wellingtonia gigantea Lindl.), Nammuthbaum über $100 \mathrm{~m}$ hoch. Californien. Leidet in Deutschland bei strenger Winterkälte. Cryptomeria japonica Don. Nadeln sichelförmig, zugespitzt, an dem Zweige herablaufend, stehen fünfreihig. Sciadopitys verticillata Sieb. et Zucc. Nadeln gross, breit, in Scheinquirlen. Japan.

4. Fam. Cupressaceae.

Blätter und Zapfenschuppen gegen- oder quirlständig. Frucht- und Deckschuppe vollständig verschmolzen. Samenknospen aufrecht.

Die Blüten bestehen aus einer kurzen Spindel, an welcher die schuppenförmigen Staubblätter, sowie Samenknospen tragenden Fruchtschuppen stehen. Die Staubblätter zeigen meist mehrere Pollensäcke. Samenknospen aufrecht, zu zwei bis mehreren, selten nur je I an der Basis der Fruchtschuppe. Holzige Zapfen oder Beerenzapfen, welche durch die Verschmelzung der fleischig werdenden Zapfenschuppen entstanden sind. 
i. Lnterfam. Cupressinae.

Zapfen holzig. Fruchtblätter schildförmig gestielt (Fig. 224, 1, 3). Quirle aller Blätter zweizählig. Die Zweige der unten angeführten Arten sind nicht so flach und so stark zusammengedrückt wie bei den Thujopsidinengattungen Thuja und Thujopsis.

$\mathrm{Zu}$ Anbauversuchen werden verwendet:

Chamaecyparis Lawsoniana Parl. (syn. Cupressus Lawsoniana

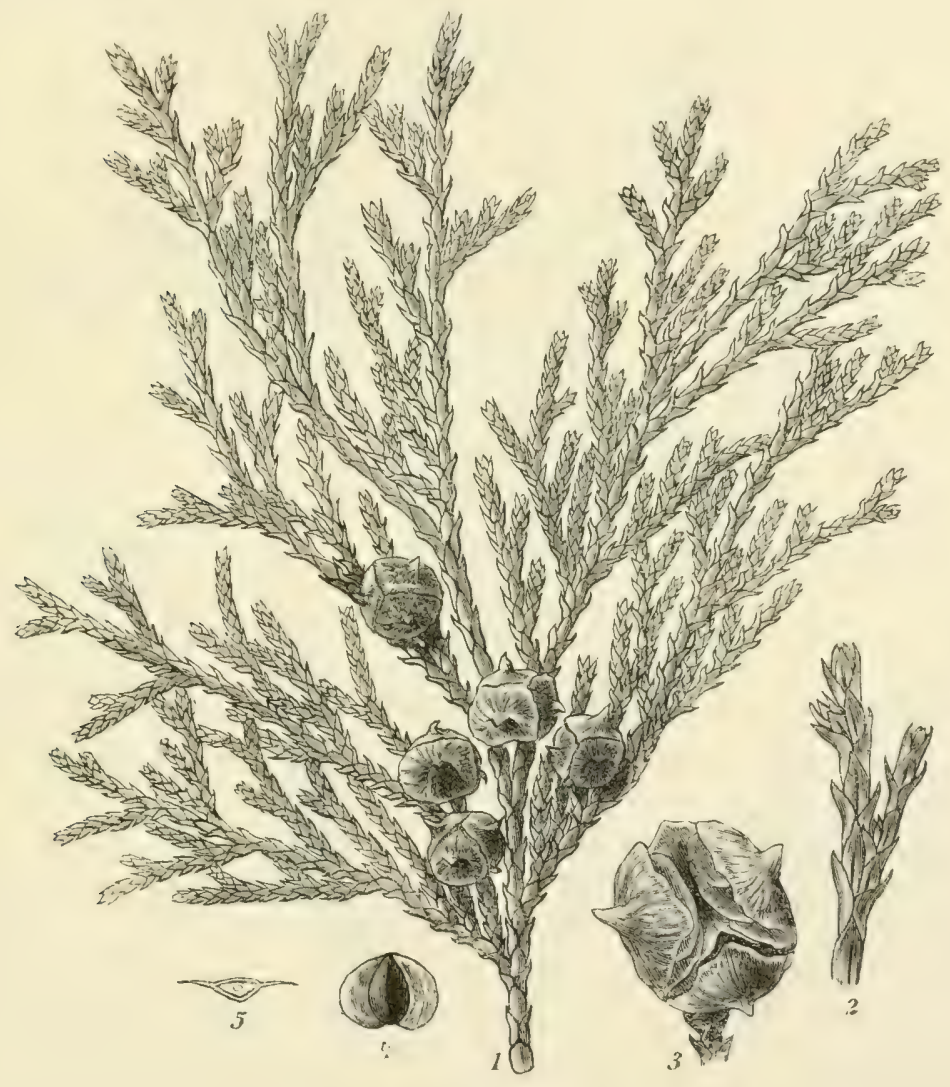

Fig. 224 .

Chamaecyparis nutkaënsis. I Zweig mit Zapfen, 2 Zweigstück, vergrössert, 3 Zapfen, 4 Samen, 5 Zweigdurchschnitt. (Beissner.)

Murr.). Gipfeltriebe überhängend. Die einzelnen Triebe flach. Die Blätter wie bei den anderen Chamaccyparisarten am Zweige teilweise herablaufend. Die Blätter sind stumpf zugespitzt, die Zweige fühlen sich daher nicht stachelig an. Seiten- und Rückenblätter mit rundlicher Öldrïse '). Auf der Unterseite der Zweige sind die Nadeln an der Basis

1) Man erkennt die Öldrüsen am besten, wenn man einen gegen das Licht gehaltenen Zweig mit der Lupe betrachtet. 
zumeist mit einer weissen Linic rersehen. Californicn. Chamaecyparis pisifera Sich. et Zucc., ähnlich wie die vorhergehende Art, die Nadeln jedoch stachelspitzig. Die Weisse Zeichnung tritt weniger hervor. Japan. Chamacyparis obtusa Sicb. et Zucc., Nadeln fast bis zur Spitze angewachsen, stumpflich, mit rundlicher Öldrüise, unterseits mit silberweissen

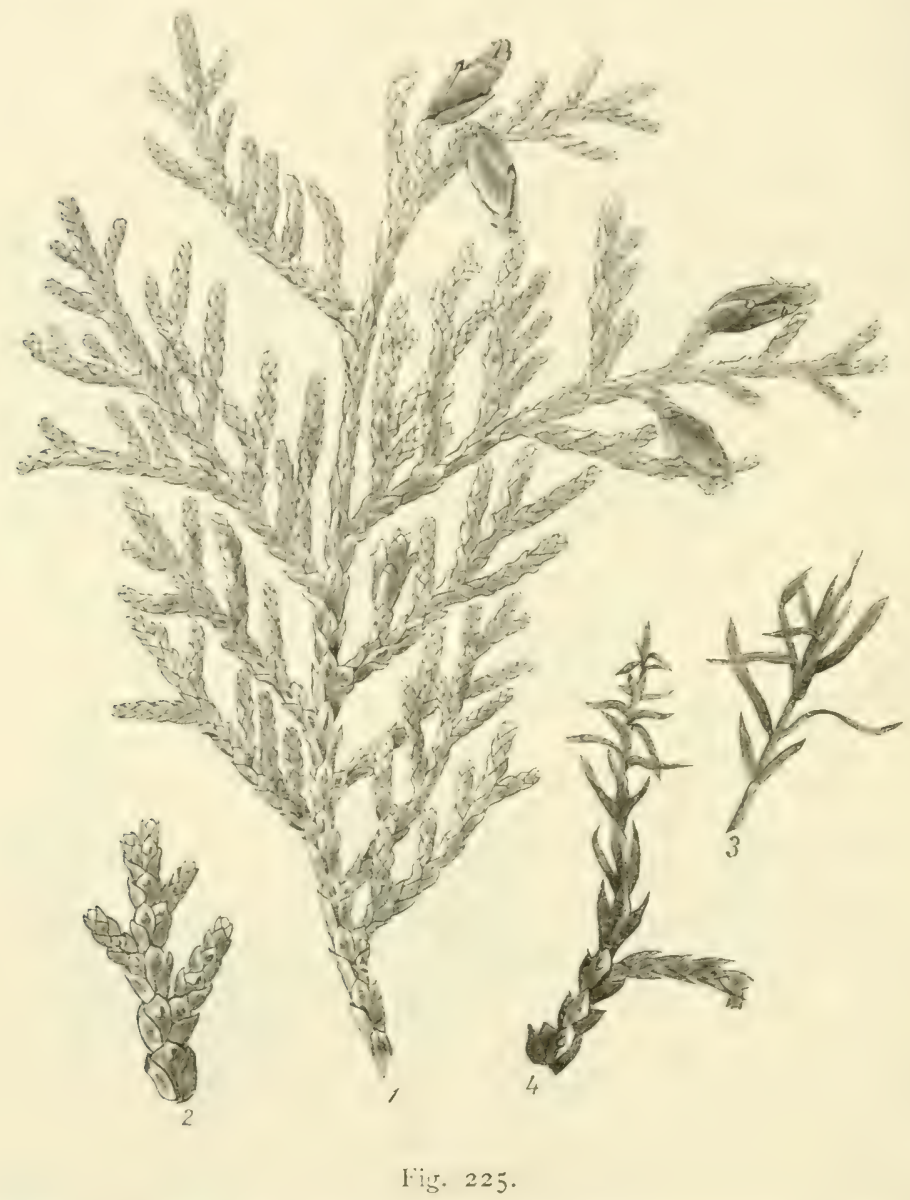

Thuja occidentalis. I Zweig mit jungen Früchten, 2 Zweigspitze vergr., 3 und 4 Übergänge zu var. Ellwangeriana und ericoïdes. (Beissner.)

Spaltöffnungsreihen. Randblätter fast sichelförmig. Japan. Chamaecyparis nutkaënsis Spach. (Fig. 224). Die jüngsten Zweige mehr vierkantig. Rückenblätter mit strichförmiger Drüse (Fig. 224, 2), die an den Seitenblättern nicht wahrzunehmen ist. Westl. Nordamerika.

Die echte Cypresse Cupressus sempervivens L. (mit deutlich vierkantigen Zweigen) kann in Deutschland im Freien nicht mit Erfolg kultiviert werden. 
2. Unterfam. Thujopsidinae.

Zapfen holzig, Fruchtblätter dachig (Fig. 225, I), Quirle aller Blätter zweizählig. Die Zweige der hier aufgeführten Arten stark zusammengedrückt.

Thuja occidentalis L., Lebensbaum (Fig. 225). Unterseite der Zweige hellgrün, nicht weisslich. Öldrüse höckerig, rundlich. Bei gewissen Garten-Varietäten (Fig. 225, 3,4) sind die Blätter dem Zweige nicht angewachsen. Nordamerika. Biota orientalis L., Lebensbaum, wie die vorige Art, jedoch mit vertiefter Öldrüse, die Blätter daher auf der Rückenseite mit einer Längsfurche. Stammt aus China und Japan.

$\mathrm{Zu}$ forstlichen Anbauversuchen verwendet: Thuja gigantea Nutt. ${ }^{1}$ ) (syn. Thuja Menziesii Dougl.). Jüngste Zweige sehr flach, auf der Unterseite weisslich. Die Rückenblätter nur mit einer rundlichen Öldrüse, die Seitenblätter mit ein oder zwei Drüsen. Westl. Nordamerika. Thuja japonica Maxim. (syn. Thuja Standishi Carr.). Wie die vorhergehende Art, unterseits weiss, die Zweige sind jedoch etwas weniger flach, dic Blïtter mit einer strichförmigen Mitteldrüse und mehreren kleineren rundlichen Seitendrüsen versehen. Japan. Thujopsis dolabrata Sieb. et Zucc. Zweige und Blätter bedeutend breiter als bei den anderen Arten, Blätter unterseits weiss, mit strichförmiger, nicht erhabener Öldrüse. Japan.

3. Unterfam. Juniperinae.

Zapfen Beeren oder steinfruchtartig.

Juniperus communis L. Gem. Wachholder. Klein- oder Grossstrauch. Nadeln in dreigliedrigen Quirlen, sehr stechend, IO-I $5 \mathrm{~mm}$ lang, oberseits weiss. Blüten diöcisch. Männliche Blüten mit breit eiförmigen, schildförmigen Staubblättern. Weibliche Blüten den Laubknospen ähnlich. Beerenzapfen (Fig. 226) im zweiten Jahre reifend, erst grün, später schwarzblau.

Juniperus Sabina L. Sadebaum, Sevenbaum. Blätter vierreihig, an jungen Trieben $\mathrm{I}-2 \mathrm{~mm}$, an älteren Trieben $4-7 \mathrm{~mm}$ lang.

Juniperus nana W. Zwergwachholder. Nieder-

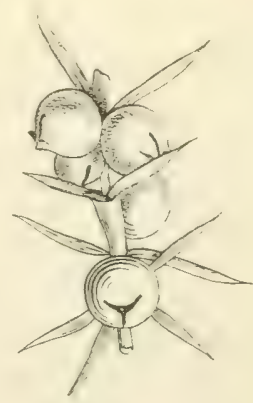

Fig, 226 . Juniperus communis. Beerenzapfen. (K.) liegender Gebirgsstrauch, Nadeln gebogen.

Juniperus virginiana L. Baum III.-II. Grösse. Nadeln vieroder sechsreihig, schuppen- oder nadelförmig, oberseits blauweiss, auf dem Rücken mit buckeliger Öldrüse. Die nadelförmigen Blätter sind ungefähr halb so lang, wie bei Juniperus communis. Bleistiftholz. Stammt aus Nordamerika.

1) Bei Librocedrus decurrens Torr, auch als Thuja gigantea Carr. bezeichnet, ist die Oberund Unterseite der Zweige gleichmässig grün gefärbt, die Blätter sind mit einer strichförmigen Öldrüse versehen, zugespitzt, etwas stechend. 


\section{3. Klasse. Gnetaceae.}

Un die Samenknospen eine Hülle vorhanden (Perianth oder Fruchtknoten?). Blüten monöcisch oder diöcisch. Der Holzkörper enthält echte Gefisse. Habitus verschieden.

Welwitschia mirabilis Hook, knolliger Stamm Südwestafrikas, an welchem nur die zwei Cotyledonen entwickelt werden. Ephedia distachya L.,. im Habitus den Schachtelhalmen ähnlich. Gnetum Gnemon L.

\section{sิ 62. Angiospermae, Bedecktsamige. Typus.}

Die Fruchtblätter (Carpelle) schliessen die Samenknospen ein und bilden auf diese Art einen Fruchtknoten. In demselben befinden sich die Samenknospen, aus welchen die Samen hervorgehen. Ein Teil des Fruchtblattes wird zur Narbe und zum Griffel, welche zur Aufnahme des Pollens resp. zur Fortleitung des Pollenschlauches dienen. In den weitaus meisten Fällen ist ein Perianthium vorhanden. Befruchtung vgl. S. 248. Archegonien fehlen. Am Embryo ein oder zwei Cotyledonen.

\section{Morphologie von Blüte und Frucht.}

Für die nähere systematische Einteilung ist die Ausbildung der Blüte von der grössten Wichtigkeit. Zunächst sind die Stellungsverhältnisse der Blätter des Perianths, der Staubblätter (Androeceum) und der Fruchtblätter (Gynaeceum) zu berücksichtigen (vgl. auch die Stellungsverhältnisse der Vegetationsorgane, § I7). Bei quirlständigen Blättern werden die Blüten als cyclisch (eucyclisch), bei spiraliger Stellung als acyclisch, bei teilweiser quirlblättriger Stellung als he micyclisch bezeichnet. Bei cyclischen Blüten ist die Zahl der einzelnen Quirle oder Kreise im Perianth, Androeceum und Gynaeceum zu beachten. Die Zahl der einzelnen Glieder eines Kreises wird, je nachdem ob 3, 4, 5 Blätter vorhanden sind, als trimer, tetramer, pentamer, oder als 3-, 4-, 5 zählig bezeichnet. In den weitaus meisten Fällen alternieren die einzelnen Glieder der aufeinander folgenden Kreise. Besteht das Androeceum nur aus einem Kreise und alternieren alle Kreise der Blüten (Kelch, Krone, Androeceum und Gynaeceum), so bezeichnet man die Blüten als haplostemonisch. Sind zwei Kreise von Staubblättern vorhanden und ist die regelmässige Alternation festgehalten, so nennt man die Blüten diplostemonisch. Die über dem Kelche stehenden (episepalen) Staubgefässe bilden hier den äusseren Kreis, die über den 
Kronenblättern stehenden (epipetalen) Staubgefässe den inneren Kreis des Androeceums. Bei den obdiplostemonischen Blüten ist die Reihenfolge eine umgekehrte, die epipetalen Staubblätter bilden den äusseren, die episepalen Staubblätter den inneren Kreis, wodurch natürlich die regelmässige Alternation der Staubblattkreise mit der Blumenkrone aufgehoben wird.

Durch Abort oder Spaltung ganzer Kreise oder cinzelner Glieder können die Verhältnisse ausserordentlich mannigfaltig werden. Am besten werden dieselben durch das Diagramm der Blüte (vgl. S. 48) veranschaulicht. Ebenso kann der Anschluss der Blüten an die Tragblätter durch das Diagramm ausgedrückt werden.

Das Perianthium kann gänzlich fehlen (apetale oder nackte Blüten), die Blumenkronenblätter können miteinander verwachsen (sympetale, gamopetale oder vereintkronblättrige Blüten) oder frei sein (choripetale, dialypetale oder freikronblättrige Blüten). Die actinomorphen oder regelmässigen Blüten sind radial, die zygomorphen Bliiten bilateral (vgl. S. 49) gebaut.

Die Staubblätter stehen entweder frei oder sind mit den Kronenblättern verwachsen (der Blumenkrone eingefügt). Bei den Compositen sind die Filamente der Staubblätter frei und nur die Antheren (Staubbeutel) untereinander verwachsen. Beschreibung des Staubblattes vgl. S. 242 .

Das Gynaeceum (vgl. S. 245) kann aus getrennten Fruchtblättern resp. Fruchtknoten bestehen, es heisst dann apocarp z. B. bei den Ranunculaceen), oder mehrere Fruchtblätter sind zu einem gemeinsamen syncarpen Fruchtknoten verwachsen, in dessen Höhlung die Samenknospen stehen. Nach der Zahl der Fruchtblätter, welche das Gynaeceum bilden, bezeichnet man dasselbe als monokarpisch, dikarpisch, polykarpisch.

Der Fruchtknoten kann bei der Zusammensetzung aus mehreren Fruchtblättern ein- oder mehrfächerig sein, je nachdem ob die Samenknospen in einer gemeinsamen Höhlung oder in verschiedenen Fächern stehen. Durch unvollständige Abteilung der einzelnen Fächer erhalten wir zwei-, drei-, mehrkammerige Fruchtknoten. Scheidewände, welche nicht aus den eingeschlagenen Rändern der Fruchtblätter hervorgehen, werden als ,falsche" bezeichnet.

Die Gewebeteile, welche die Samenknospen tragen, werden, wie schon oben erwähnt wurde, Placenta genannt. Die Samenknospen können nun auf den Fruchtblättern selbst entstehen (carpellbürtig sein) oder auf die Blütenaxen hinaufrïcken (axenbürtig).

Bei gleichmässigem Fortwachsen der Blütenaxe ist das Gynaeceum der oberste Teil der Blüte, der Fruchtlnnoten ist oberständig (Fig. 227, A), die Blüte (d. h. Perianthium und Staubblätter) hypogyn. Wächst dagegen der untere Teil der Blütenaxe stärker, so dass Perianthium 
und Androeceum höher zu stehen kommen als das Gynaceeum, so erhalten wir den unterständiesen Fruchknoten (Fiss. 227, B). Hierbei kann der becherförmis sewordene Axenteil mit den Fruchtblättern vollständig verwachsen, so dass die übrigen Blïtenorgane dem Fruchtknoten eingefügt erscheinen, eine solche Blüte heisst epigyn (Fig. 227, B). Tritt eine derartige Verwachsung nicht ein oder doch erst viel später, so wird die Blüte als perigyn bezeichnet. Die Familie der Rosifloren (rgl. Fig. 329) liefert hierfür zahlreiche Beispiele.

Den Teil der Axe, welcher die Blätter der Blüte trägt, bezeichnet man als Blütenboden oder Receptaculum.

Die Blütenaxe kann auch an der Fruchtbildung beteiligt sein, es

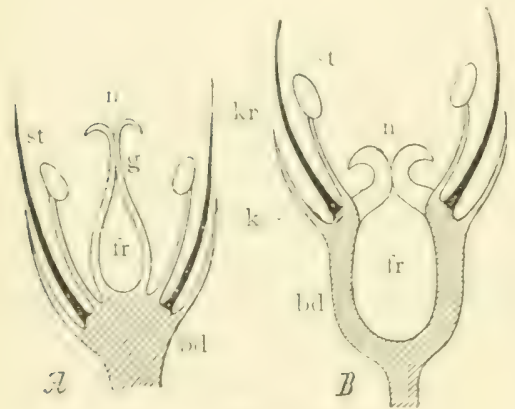

Fig. 227.

Schematische Blütenlängsschnitte. A Hypogyne Blüte, oberständiger Fruchtknoten. I) Eligyne lilite, unterstindiger Fruchtknoten. bd (schraffiert) Blütenaxe, $k$ Kelch, kir Plumenkrone, st Staulshlatt, fo Fruchkn,ten, g Grifiel, "l larbe,

(K.)

(z. B. bei Caltha, Ranunculus). Fruchtähnliche Gebilde, die aus einem Blütenstande hervorgegangen sind, nennt man Fruchtstände (Maulbeere, Ananas, Hopfen). Dieselben können auch zu den Scheinfrüchten gerechnet werden.

Mit Warming kann man vier Hauptformen von Früchten unterscheiden:

Frucht gewöhnlich vielsamig; Frucht ein-(selten mehr-) samig die Samen bleiben nicht von | Der Same bleibt von der Fruchtder Fruchtwand eingeschlossen. | wand umschlossen.

Fruchtwand trocken, unansehnlich gefärbt (bräunlich, gelblich etc.).

Fruchtwand gänzlich oder nur im äusseren Teil fleischig, gewöhnlich auffallend gefärbt. (z. B. Apfel, Birne), während die echte F r ucht sich nur aus den Fruchtblättern entwickelt. Die Wandung des Fruchtknotens wird zur Fruchtwand (Pericarp), bei welcher man häufig drei Schichten (Epikarp, Mesokarp, Endokarp) unterscheiden kann. Dic Fruchtwand dient teils zum Schutze der Samen, teils trägt sic, indem die Früchte von Tieren gesucht werden, zur Verbreitung der Samen bei.

Sind zahlreiche apocarpe (vol. S. 26g) Fruchtknoten vorhanden, so entwickeln sich aus diesen einzelne zahlreiche Früchtchen, die auf gemeinsamen Axen stehen und als Sammelfrucht bezeichnet werden entsteht dann eine sog. Scheinfrucht 
sich nur an der Bauchnaht (Helleborus, Caltha), die letztere öffnet sich an Rücken- und Bauchnaht (Robinia, Colutea). Ferner die Schote, welche äusserlich der Hülse ähnlich, aber aus zwei Fruchtblättern entstanden ist. Die Büchse öffnet sich durch einen ringförmigen Querspalt (Plantago). Die übrigen Kapseln können sich durch Löcher, Zähne, Spalten etc. öffnen.

Eine besondere Form der Nuss ist die Spaltfrucht, welche aus einem Fruchtknoten gebildet ist, mehrere Samen enthält, aber in mehrere einsamige Teilfrüchte zerfällt (Labiatae, Boraginaceae, Asperula).

Bei der Beerenfrucht wird die ganze Fruchtknotenwandung fleischig, oder eine derbere Aussenschicht umgiebt die fleischigen Innenschichten (Apfelsine, Spanischer Pfeffer).

Die Steinfrucht ist charakterisiert durch eine dünne, festere Aussenschicht, eine fleischige Mittelschicht und eine knochenharte Innenschicht, den Steinkern (Pflaume, Kirsche, Wallnuss, Sambucus).

Schliesslich sei noch darauf hingewiesen, dass man den Aufbau der Blüte kurz durch eine Formel ausdrücken kann: $\mathrm{K}$ bedeutet Kelch, $\mathrm{C}$ Blumenkrone, $\mathrm{P}$ einfaches, nicht in Kelch und Krone differenziertes Perigon, A Androeceum, G Gynaeceum. So sagt z. B. die Formel $\mathrm{P}_{3}+3 \mathrm{~A}_{3}+3 \mathrm{G}_{3}$, dass die Blüte aus zwei dreigliedrigen Perigonkreisen, zwei dreigliedrigen Staubblattkreisen und einem aus drei Fruchtblättern zusammengesetzten Fruchtknoten besteht. Vollständiger Abort eines Kreises wird durch ein o, Verdoppelung eines Kreises durch einen besonderen Index $\left(z . \mathrm{B} \mathrm{A}_{3}{ }^{2}\right)$ bezeichnet. Die Zeichen * und $\downarrow$ vor einer Blütenformel drücken aus, dass die Blüte actinomorph (regelmässig) resp. zygomorph ist. Durch Einklammern der betreffenden Buchstaben und Zahlen werden Verwachsungen angedeutet. Die Unter- oder Oberständigkeit des Fruchtknotens wird dadurch angezeigt, dass man die Zahlen für $G$ unter oder über einen horizontalen Strich stellt (z. B. G 3 ). Ein vertikaler Strich zwischen zwei Kreisen bedeutet, dass die normale Alternation der einzelnen Glieder an dieser Stelle unterbrochen ist.

\section{64. Bestäubungseinrichtungen. Verbreitungsmittel der Samen und Früchte. 1)}

Bei der Bestäubung, d. h. der Übertragung des Pollens auf die Narbe, kann es sich um Selbstbestäubung oder um Fremdbestäubung (Kreuzbestäubung) handeln. Bei der ersteren gelangt der Pollen einer Blüte auf die Narbe derselben Blüte, bei der letzteren wird zur Bestäubung Pollen einer anderen Blüte desselben Individuums oder cines anderen Individums verwendet. Die Bestäubung geht selbstverständlich der Befruchtung voraus, welch letztere darin besteht, dass von dem Pollenkorn aus der Pollenschlauch bis zur Samenknospe vordringt und Substanz zur

1) In diesem Paragraph sind auch Beispiele von Gymnospermen angefïhrt. 
Eizelle iblertritt. Zwischen Bestätbung und Befuchtung können nur wenise Stunden, aber auch Tage, Wochen und Monate liegen (Orehideen, Colchicum autumnalis, l'inus).

Dic grïnstigen Folgen der Kreuzbestäubung resp. Kreuzbefruchtung machen sich darin scltend, dass cine grössere Anzahl von Samen produziert wird, die aus diesen Samen hervorgegangenen Pflanzen sind liräftiger und fruchtbarer, sowie widerstandsfähiger gegen äussere schädliche Einflüsse.

Nach der Art und Weise, wie fremder Blütenstaub auf die Narbe gelangt, kann man unterscheiden:

Windblütler, der Pollen wird durch den Wind befördert. Die hichher gehörigen Pflanzen besitzen ein unscheinbares, wenigs auffallend gefurbtes oder gar kein Perianthium. Es wird eine grosse Menge von Pollen produziert, eventuell besitzen die Pollenkörner, wie z. B. bei vielen Coniferen besondere Flugapparate. Die Narben sind gross und gewöhnlich reich verzweigt. Hierher gehören (ausser den Gymnospermen) Gramineen, Typhaceen, Urticifloren, Quercifloren u. a.

Wasserblütler, der Pollen schwimmt auf dem Wasser zur Narbe. Vallisneria, Zostera.

Tierblütler resp. Insektenblütler. Die Übertragung des Pollens geschieht durch Ticre und zwar in den weitaus meisten Fällen durch Insekten (Hummeln, Bienen, Schmetterlinge, Fliegen, Käfer) nur selten durch kleine Vögel oder Schnecken. Die Insekten besuchen die Blüten, um Pollen oder den Honig zu sammeln, welcher in besonderen Drüsen produziert wird. Sie werden durch die lebhaften Farben der Blüten aufmerksam gemacht, sei es nun, dass sie durch grosse Blumenblätter einzelner Blüten oder durch ansehnliche Blütenstände kleinerer Blüten angelockt werden. Ebenso wirkt der Geruch der Blüten günstig auf den Insektenbesuch. Die weniger hochorganisierten Blüten gewähren sehr vielen Insekten, auch den kurzrüsseligen, Zugang zum Honig, oder bieten den Insekten überhaupt nur Pollen (z. B. Hepatica, Clematis, Papaver). Bei höher organisierten Blüten ist der Insektenbesuch durch die Form und Stellung der Blumenblätter und Antheren auf bestimmte intelligente und langrüsselige Arten beschränkt, welche zur Übertragung des Pollens besonders geeignet sind und die Blüten derselben Pflanzenspecies andauernd besuchen. I)urch die Rauhiglicit oder Klebrigkeit, durch Vorsprïnge und Stacheln des Pollens wird das Anhaften des Bliitenstaubes am Insektenleibe begünstigt, wie denn auch die Narben vielfach Einrichtungen (Warzen, Haare, Klebflüssigkeit) aufweisen, um das Hängenbleiben des Pollens herbeizuführen.

Als Beispiel für die ausserordentlich komplizierte Anpassung der Blüten an den Insektenbesuch möge hier Salvia pratensis erwähnt werden (Fig. 228). Einer Hummel, welche diese Blüte besucht, gewährt die Unterlippe einen bequemen Haltepunkt, von dem aus sie zur Honigdrüse am Grunde der Blumenblattröhre gelangen kann. Dabei stösst sie auf das Hebelwerk der Staubblätter (Fig. 228, 3) infolgedessen werden 
die vorher in der Oberlippe verborgenen Antheren herabgedrückt, und der Blütenstaub an dem Hinterleibe der Hummel abgestreift. Beim Anfliegen anderer Blüten kommt die aus der Oberlippe hervorragende zweiteilige Narbe mit jener Stelle der Hummel in Berïhrung, wo sich der Pollen befindet, wodurch dann die Fremdbestäubung erzielt ist.

Bei Aristolochia Clematitis (Fig. 229) können kleine Insekten leicht durch die mit nach abwärts gerichteten Haaren versehene Blütenröhre zur Narbe und zu den Antheren vordringen, sie können aber der Haare wegen nicht ohne weiteres wieder herauskriechen. Die Narbe hat die Form einer sechsteiligen Mütze, unter welcher die Antheren liegen. Wenn die Antheren reif sind und aufspringen, wird das Insekt mit Pollen beladen und aus der Blüte entlassen, indem die Haare der Blütenröhre vertrocknen. Kommt nun ein mit Pollen beladenes Insekt in eine andere Blüte, so vollzieht es dort die Bestäubung mit dem fremden Pollen. Die Narben sind früher empfängnisfähig, als die Antheren zu stäuben beginnen. Die Bestäubung kann durch fremden Pollen also schon von dem Insekt vollzogen sein, bevor die Antheren sich öffnen. Das

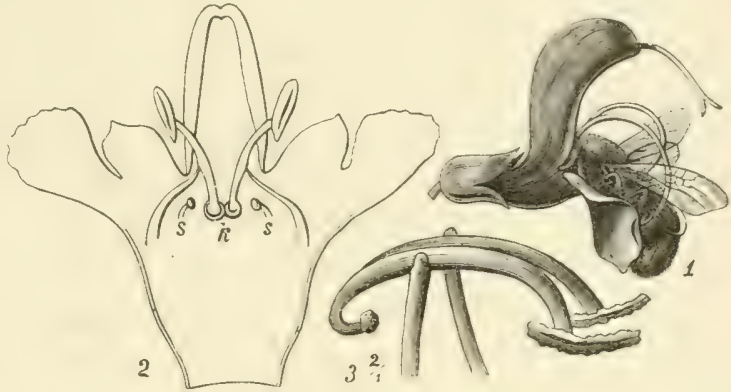

Fig. 228 .

Salvia pratensis, I Bestäubung durch eine Hummel, 2 Blüte aufgeschnitten, 3 Staubblätter. (Sch.)
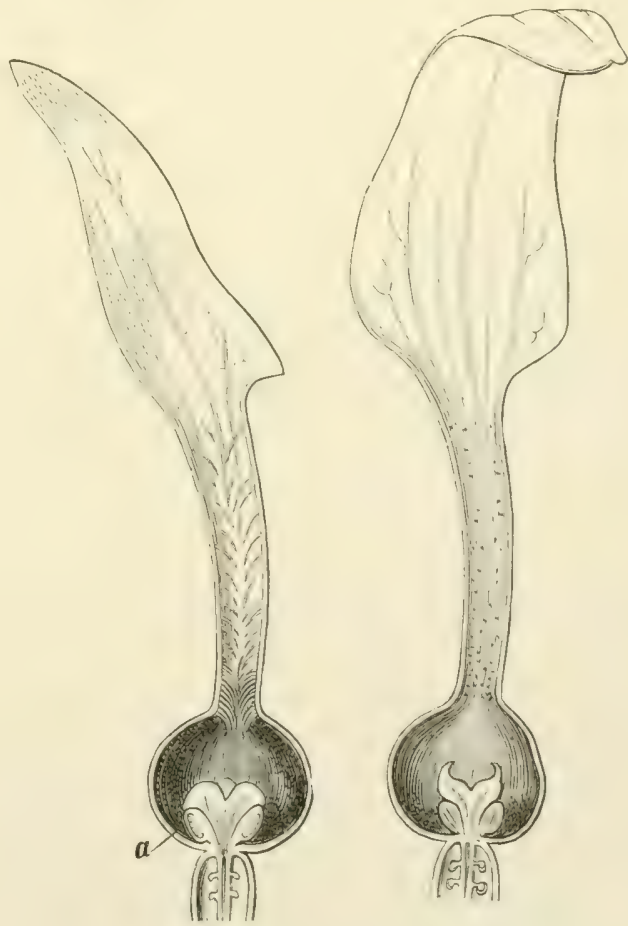

Fig. 229.

Aristolochia Clematitis, links unbestäubte, rechts bestäubte Blüte. a Anthere. (R.) den Pollen auf die Narbe bringende Insekt wird nicht früher entlassen, bevor die Antheren geöffnet sind, wird also vorher noch mit neuem Pollen beladen, den es auf weitere 
Bliiten iibertrïst. Durch Umbiegen des oberen Perigonlappens bei der schon bestäubten Blüte wird der Eingang zur Blütenröhre verschlossen und so ein weiterer Insektenbesuch hintangehalten.

Die Erscheinung der Heterostylie hänģ ebenfalls mit dem Insektenbesuche zusammen. Bei manchen Pflanzen giebt es kurzgriffelige und langsriffelige Blütenformen, deren Antheren ebenfalls in verschiedener Höhe angebracht sind, und zwar stehen die Staubgefässe der einen Blütenform in derselben Höhe als die Narben der anderen Form. Das Insekt muss daher mit derselben Körperstelle, mit welcher es das eine Mal die Antheren berührte, das andere Mal die Narben berühren, wodurch Kreuzbefruchtung herbeigeführt wird. Blüten mit zwei verschiedenen Formen heisson dimorph (Primula officinalis, IIottonia pahustris, Polyosonum Fagopyrum), mit drei Formen trimorph (Lythrum Salicaria, Oxalis gracilis).

Bei verschiedenen Blüten ist die Selbstbefruchtung durch die Lage von Narben und Antheren hintangehalten. Dasselbe wird durch die Monëcic und Diöcic erreicht, sowie durch ungleichzcitise Ausbilduns der Narben und Antheren (Dichogamie). Im letzteren Falle können die Antheren verstäuben, bevor die Narbe empfängnisfähig wird (protandrische Blüten), oder umgekehrt die Narben entwickeln sich vor den Antheren (protogynische Blüten).

Bei den nicht hinreichend besuchten Blüten ist Selbstbefruchtung die Regel (Malva rotundifolia, Cruciferen, Stellaria graminea, arktische und alpine Arten).

Blüten, welche geschlossen bleiben, demnach ausschliesslich aut Selbstbefruchtung angewiesen sind, werden als $\mathrm{kle}$ is to gam bezeichnet. Kleistogame und offene Blüten können an demselben Stocke vorkommen (Oxalis acetosella, Impatiens noli tangere). Bei vielen Blüten tritt bei unterbliebener Fremdbestäubung die Selbstbestäubung ein.

Die Ausbreitung von Samen und Früchten kann auf verschiedene Weise geschehen.

I. Durch den Wind. Die hierher gehörigen Samen und Früchte besitzen Flügel (Pinus, Picea, Acer), häutige Fortsätze (Ulmus, Ptelea, Thuja) haarförmige Anhänge (Populus, Salix, viele Compositen).

2. Durch Tiere. Bei fleischigen Früchten, Steinfrüchten, Beeren wird der fleischige Teil verzehrt, die harte Schale verhindert, dass die Samen im Verdauungskanal ihre Keimfähigkeit verlieren und so kann der Same mit dem Kote verschleppt werden (Sorbus, Ribes, Taxus, Viscum). Mäuse, Eichhörnchen sammeln nussartige Früchte als Wintervorrat ein und vergessen sie später (Corylus). Mit Widerhaken versehene Früchte bleiben an Federn, Haaren, Füssen hängen und werden auf diese Weise verbreitet ,Galiumarten, Lappa, die Klette, begrannte Gräser, Fagus und Castanea solange sie sich noch in der Cupula befinden).

3. Durch den Menschen. Mit dem Getreide werden Unkräuter 
verschleppt, in der Nähe von Eisenbahndämmen gehen Samen auf, die an den Wagen hängen geblieben waren etc.

4. Durch das Wasser werden namentlich Samen von Wasserpflanzen und Sumpfpflanzen weiter gespült (Menyanthes, Sagittaria, Alnus). Es können jedoch auch durch fliessendes Wasser Samen fortgeführt werden, wie die in den Isarebenen vorkommenden Alpenpflanzen beweisen.

5. Schleudervorrichtungen besitzen z. B. Momordica elaterium, Impatiens noli tangere und Impatiens parviflora. Beim Aufspringen der Früchte werden die Samen ausgestreut.

6. Einbohren in Erde und Felsspalten zeigen Trifolium subterraneum, Arachis hypogaea, Linaria cymbalaria.

Bei Waldbäumen fallen die schweren Samen in der Nähe des fruchttragenden Stammes zur Erde (Samenaufschlag), leichte und beflügelte Samen verbreiten sich in einem grösseren Umkreis (Samenanflug). Je höher die Früchte oder Zapfen an einem Baume entstehen, in desto grösserem Umkreise werden die Samen ausgestreut.

\section{@ 65. 1. Klasse. Monocotyledones, Einkeimblättrige. Typus.}

Verzweigung gering. Die Hauptaxe der Keimpflanze geht nicht selten zu Grunde, nachdem Seitenäste gebildet sind. Blätter häufig stengelumfassend, fast immer unverzweigt mit parallelen oder bogigen Nerven (Fig. 230), keine Nebenblätter. Blätter abwechselnd oder spiralig gestellt.

Die Sprossaxen und Wurzeln zeigen nur ausnahmsweise sekundäres Dickenwachstum (vgl. S. 85 und I I 8). Anordnung der Gefässbündel im Stamm vgl. S. 75. Keimling mit I Cotyledo (vgl. S. 25 I). Hauptwurzel meist klein, zahlreiche Adventivwurzeln. Keimling seitlich am relativ grossen Endosperm.

Der Bau der Blüte kann meist auf den Typus $\mathrm{P}_{3}+3 \mathrm{~A}_{3}+3 \mathrm{G} 3$ zurückgeführt werden, Reduktionen häufig.

\section{S. 66. 1. Ordnung. Helobieae.}

Sumpf- und Wasserpflanzen. Blüten actinomorph, nach dem Typus der Monocotyledonen, jedoch mit Vermehrung im Androeceum oder Gynaeceum. G, wenn oberständig, meist apocarp. Endosperm klein oder fehlend.

I. Fam. Alismaceae.

Blïten nach dem Typus $\mathrm{K}_{3} \mathrm{C}_{3} \mathrm{~A} 6-\infty \mathrm{G} 6-\infty$ Sagittaria sagittaefolia. Butomus umbellatus, Blumenbinse. Alisma Plantagso, grem. Froschlöffel (Fig. 230). 


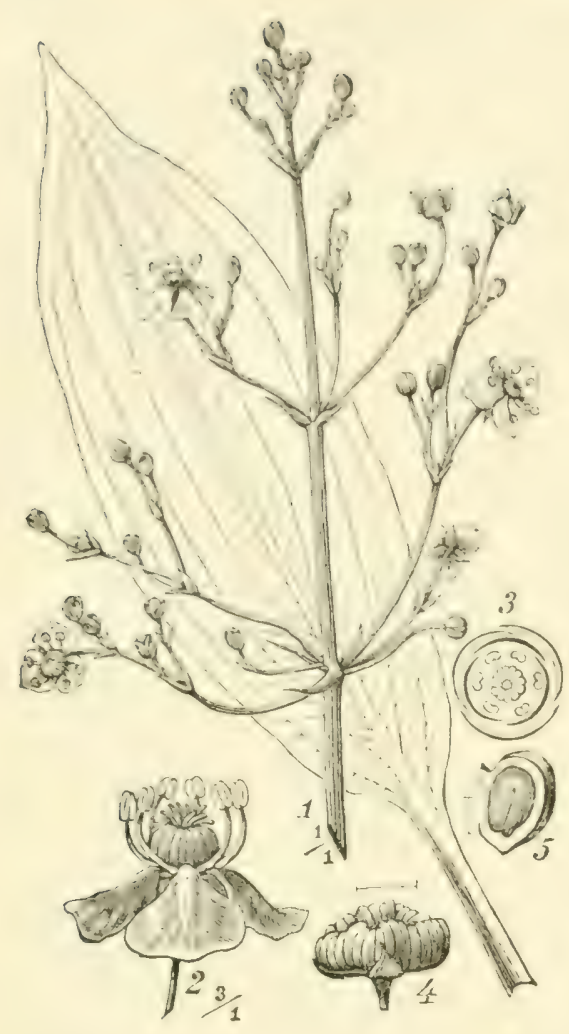

Fig. 230.

Alisma Plantago. (W.)

2. Fam. Juncasinaceac.

Bliiten meist $\mathrm{P}_{3}+3 \cdot \mathrm{A}_{3}+3$. $\mathrm{G} 3+3$. Perigon unscheinbar. Kcim gerade. Scheuchzeria, Triglochin.

3. Fam. Potamogetonaceac.

Untergetauchte oder auf Wasser schwimmende Blätter. Keim gekrümmt. Blüten meist nackt $\mathrm{A} \mathrm{I}-4 \mathrm{GI}-4$. Potamogeton natans, Laichkraut. Zostera marina, Seegras.

4. Fam. Hydrocharitaceae.

$\mathrm{K}_{3} \mathrm{C}_{3}$ oder o $\mathrm{A}_{3}-\infty \mathrm{G} \overline{(3-6)}$. Blüten eingeschlechtig. Fruchtknoten einfächerig. Hydrocharis morsus ranae, Froschbiss. Stratiotes aloides. Elodea canadensis, Wasserpest. Vallisneria spiralis.

\section{\$ 67.}

\section{Ordnung. Glumiflorae, Spelzblütige.}

Blütenstände ähren- oder rispenförmig. P. immer reduciert, unscheinbar. Ebenso Abort im Androeceum und Gynaeceum. Die Frucht von Spelzen eingehüllt, jeder Fruchtknoten mit einer Samenknospe. Stengel knotig, Blätter grasartig, lineal. Meist ๑) oder 9 Kräuter.

I. Fam. Cyperaceae, Halbgräser.

Blüten in der Achsel von Deckspelzen; blütenlose Vorspelzen, wie die Gramineen sie besitzen, fehlen. Sie stehen in arm- oder vielblütigen Ähren, welche zu Spirren (die Seitenaxen überragen die Hauptaxen) oder Trauben

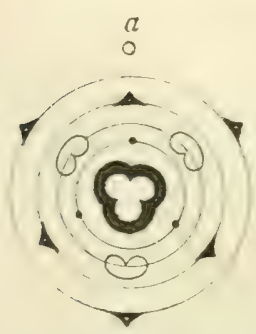

Fig. 231 .

Blütendiagramm von Scirpus, (K.) angeordnet sind. $\mathrm{P} 0$ oder borstenförmig, A 2 oder $3+\mathrm{o} G(2)$ oder (3). Halm häufig dreikantig. Blätter in der Divergenz $1 / 3$ mit meist geschlossenen Scheiden. Same rom Endosperm umschlossen. Circa 3000 Arten. I. Unterfam. Scirpeae, Binsen.

Blüten zweigeschlechtig. Blüten bei Scirpus $\mathrm{P}_{3}+3$ borstenförmig $\mathrm{A}_{3}+\mathrm{O} \mathrm{G}(\underline{3})$ (Fig. 23I), bei Heleocharis $\mathrm{P}_{3}+\mathrm{oA}_{3}+\mathrm{oG}(2)$. Bei Eriophorum besteht das Perigon aus zahlreichen Haaren. Scirpus palustris, S. silvaticus, Binsen. Eriophorum latifolium, E. vaginatum, Wollgras. Cyperus. 
2. Unterfam. Cariceae. Riedgräser, Seggen.

Blüten eingeschlechtig (vgl. Fig. 232 und 233). Die of Blüte besteht aus drei Staubblättern, welche in der Achsel eines Deckblattes stehen (Fis. $232 \mathrm{~A}$, Fig. 233 B, D), ein Perigon fehlt. Die $ᄋ$ Ähren bestehen aus Deckblättern (Deckspelzen), in deren Achsel ein oft stark verkürzter Spross steht (Fig. 233, $\Lambda, C$ ). Der letztere trägt eine zweikielige Vorspelze, den Utriculus oder Schlauch, in dessen Achsel sich die $\&$ Blüte befindet (Fig. 232 Bs und Fig. 233, As, Cs). Zwei oder drei Fruchtblätter verwachsen zu den Fruchtknoten, welcher auch später von dem Utriculus eingeschlossen ist.

Die Gattung Carex umfasst eine grosse Anzahl von Arten, von denen viele auf sumpfig feuchtem Terrain vorkommen (sog. saure Gräser): Doch sind manche Carices auch auf trocknerem Sandboden zu finden: C. ericetorum, C. praecox, C. arenaria (Fig. 8I).
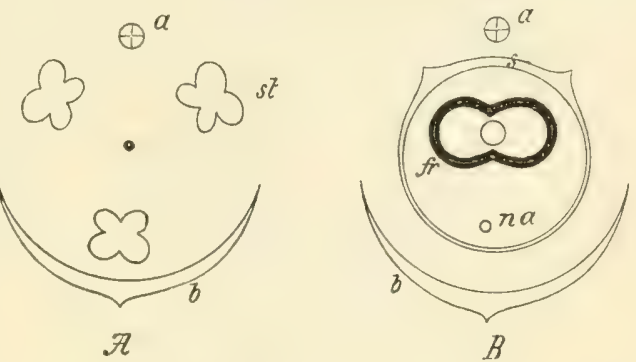

Fig. 232 .

Carex. A Diagramm der $ठ$ Blüte, B desgl. von der 0 Bliite. b Deckspelze, a Axe, na sekundäre Axe, st Staubblätter, s Utriculus, fr Fruchtknoten. (K.)
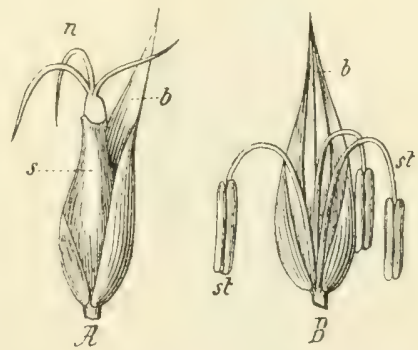
Gräser.

Runder oft hohler Stengel, mit Internodialknoten. Blätter meist zweizeilig (Divergenz 1/2), mit langen meist offenen Scheiden. Die Scheiden tragen an der Übergangsstelle zur Spreite oft einen häutigen Anhang (Ligula). Meh-

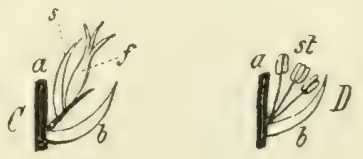

Fig. 233 .

Carex, A, C \& Blüte, B, D ơ Blïte. (K.) rere Blüten stehen in Ährchen zusammen, die wiederum zu grösseren Ähren oder Rispen vereinigt sind. Deckspelzen abwechselnd gestellt. Meist zweigeschlechtige Blüten. Fig. 234 zeigt eine schematische Darstellung der Grasähren. $\mathrm{h} h$ sind die beiden sog. Hüllspelzen, welche keine Blüten tragen, d sind die Deckspelzen (äusseren Blütenspelzen), in deren Achsel ein Seitenspross steht, welcher zunächst die eine Vorspelze (innere Blütenspelze) trägt, welche mit der Deckspelze zusammen die einzelne Blüte umschliesst. Dieselbe besteht hier aus zwei rudimen- 
tären, dïmnen Perigonblättern (p), den sog. Lodiculac, drei Staublättern und dem aus einem Fruchtblatt gebildeten, mit zwei federigen Narben versehenen Fruchtknoten. Die obersten Deckspelzen tragen häufig keine Blïten. Typus der Blüte Po oder $2 \mathrm{~A}_{3}+\mathrm{O}$, selten $3+3 \mathrm{G} \mathrm{I}$, selten G(2-3). Fruchtblatt nur mit einer Samenknospe, Keimling seitlich vom Endosperm. Frucht eine Karyopse, d. h. eine trockene Schliessfrucht, bei welcher Samenschale und Fruchthnotenwandung verwachsen sind. Circa 3 I 5 Gattungen mit mehr als 3500 Arten.

Von den einzelnen Gruppen der Gramineen ') mögen folgende erwähnt werden :

I. Maydeac. Zea mays, der Mais, j. Ährchen eingeschlechtig.

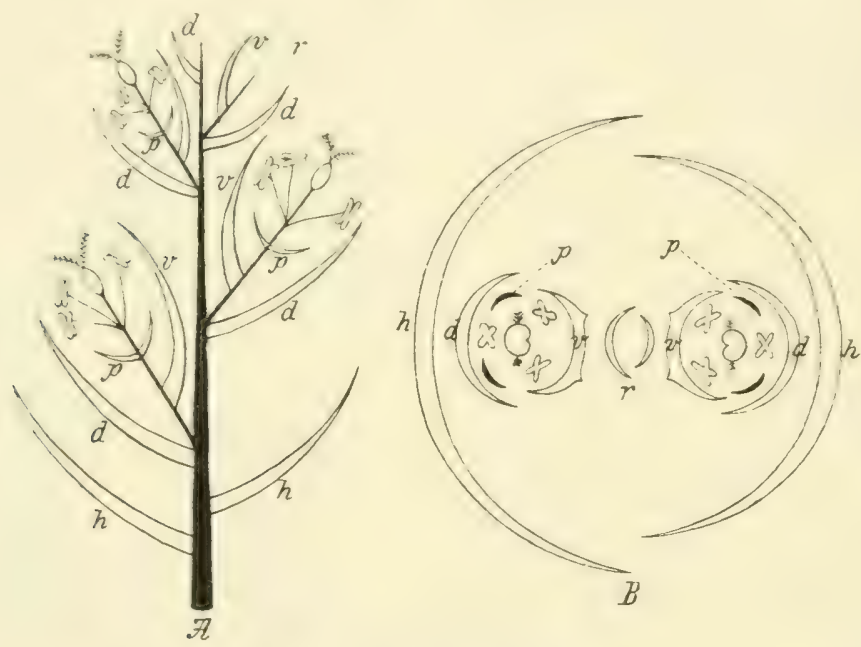

Fig. 234 .

Schematische Darstellung eines Grasährchens. A Dreiblüliges Ährchen im Längsschnitt. B Diagramm eines zweiblütigen Ährchens, h. Hüllspelzen, d Deckspelzen, v Vorspelzen, p Perigon, $r$ rudimentäre Bliiten. (K.)

2. Andropogoneae. Ährchen meist einblütig mit drei Hüllspelzen. Andropogon. Sorghum vulgare, j. Sorghum saccharatum, j. Sacharum officinarum, Zuckerrohr.

3. Paniceae, Ährchen einblütig oder aus einer $\Omega$ Blüte und einer ¡ Blüte bestehend. Drei Hüllspelzen. Panicum miliaceum, Hirse, j. Setaria italica, Kolbenhirse.

4. Oryzeae. Hüllspelzen zwei. Staubblätter häufig sechs. Oryza sativa, Reis.

1) Die als Futtergräser verwendeten Arten sind durch folgende Buchstaben bezeichnet. Es bedeutet: a auf armen Bodenarten zu verwenden, $b$ auf bindig festem Boden, $f$ auf feuchtem Boden, g gutes Futtergras, j jung auch als Grünutter verwendet, 1 auf leichtem Boden, m Futtergras von mittlerem Wert, $r$ auf reichem Boden, $t$ auf trocknem Boden, u unbrauchbar oder von geringem Wert. 


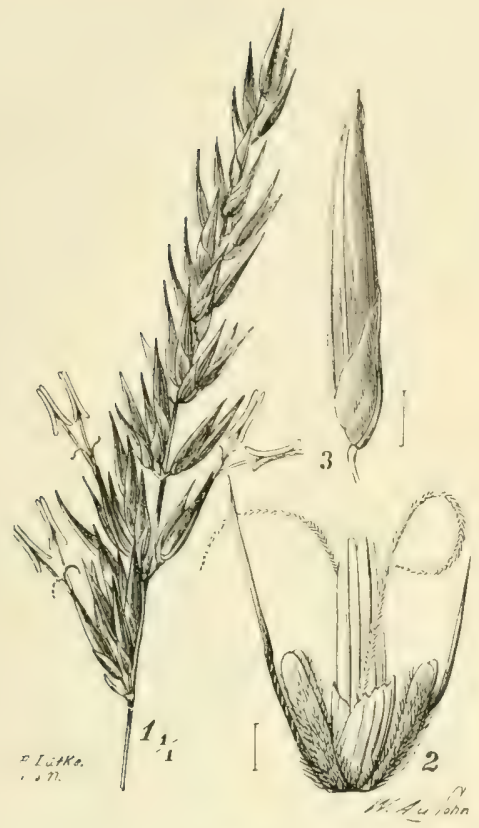

Fig. 235 .

Anthoxanthum odioratum (W.)

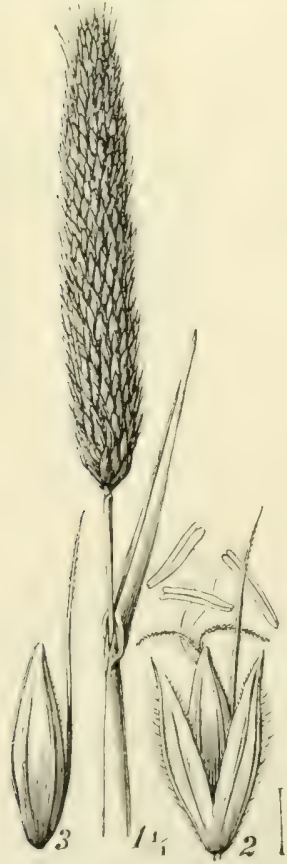

Fig. 237.

Alopecurus pratensis. (K.)

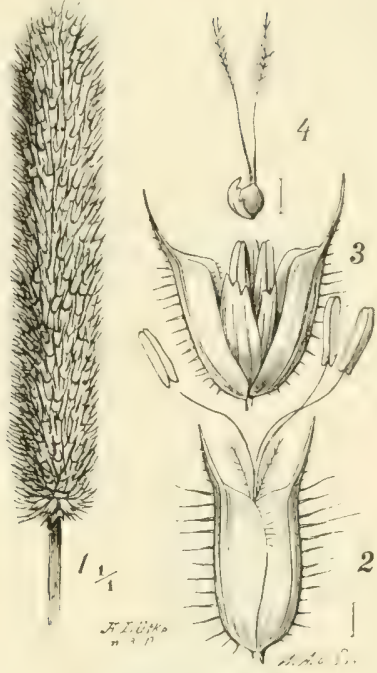

Fig. 236 .

Phleum pratense. (W.)

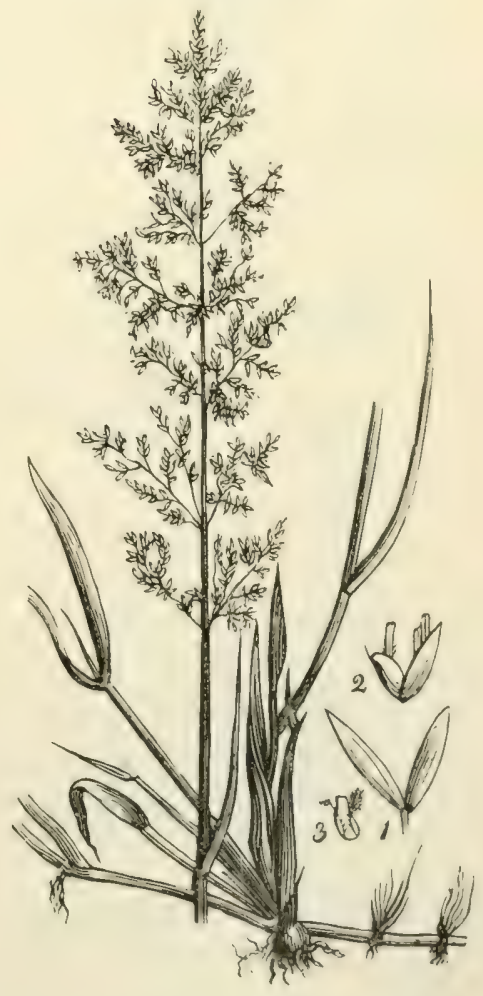

Fig. 238.

Agrostis alba, (K.) 
5. Phalarideac. Hüllspelzen vier, Deckspelzen und Vorspelzen cinander ähnlich. Anthoxanthum odoratum, Ruchgras, m (Fig. 235). Phalaris canariensis, Kanariengras, j. Phalaris arundinacea, schilfartiges Glanzgras, gf.

6. Agrostideac. Hüllspelzen zwei. Ährchen einblütig. Hüllspelzen meist so lang oder noch länger als die Deckspelzen. Milium effusum, m. Phleum pratense, Timotheegras, gf (Fig. 236). Alopecurus pratensis,

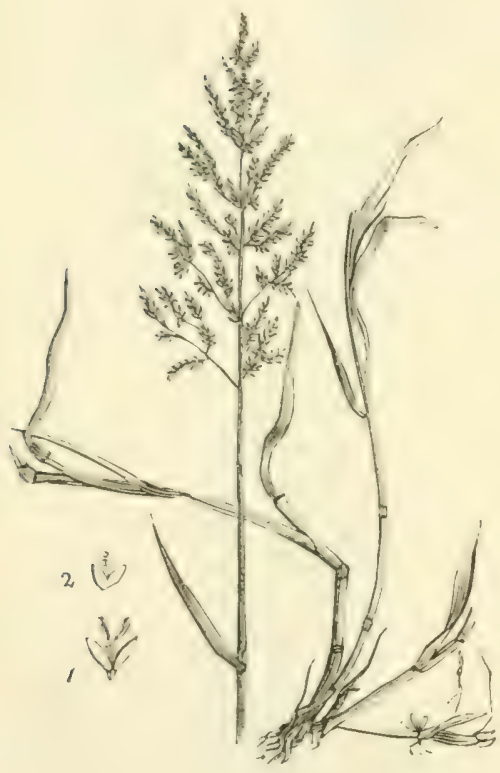

Fig. 239.

Agrostis vulgaris, (K.)

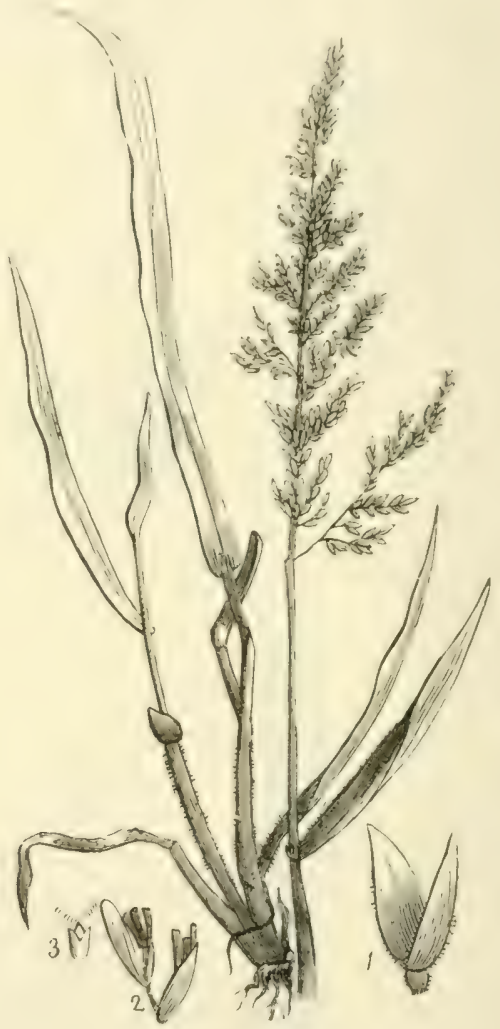

Fig. 240

Holcus lanatus. (K.)

Wiesenfuchsschwanz, g (Fig. 237). Agrostis alba, Fioringras, m (Fig. 238). Agrostis vulgaris, gemeines Straussgras, ma (Fig. 239). Calamagrostis epigeios, u. Ammophila (Psamma) arundinacea, Sandrohr, dient zur Befestigung von Flugsand. Stipa pennata.

7. Aveneae. Ährchen zwei- bis vielblütig. Hüllspelzen meist länger als Deckspelzen. Deckspelzen mit mehr weniger rückenständiger Granne. Holcus lanatus, Wollgras, wolliges Honiggras, ma (Fig. 240). Holcus mollis, u. Avena sativa, Hafer, j. Avena (Arrhenaterum) elatior, französisches Raygras, gb. Avena pubescens, grf. Avena flavescens, gr. Avena 
pratensis, mt. Avena fatua. Aira caespitosa, Schmiele, a (Fig. 241). Aira flexuosa (Fig. 242). Corynephorus (Aira) canescens, Silbergras.

8. Festuceae. Ährchen zwei- bis vielblütig. Hüllspelzen klein, kürzer als die Deckspelzen. Deckspelzen ohne Granne oder mit endständiger Granne. Phragmites

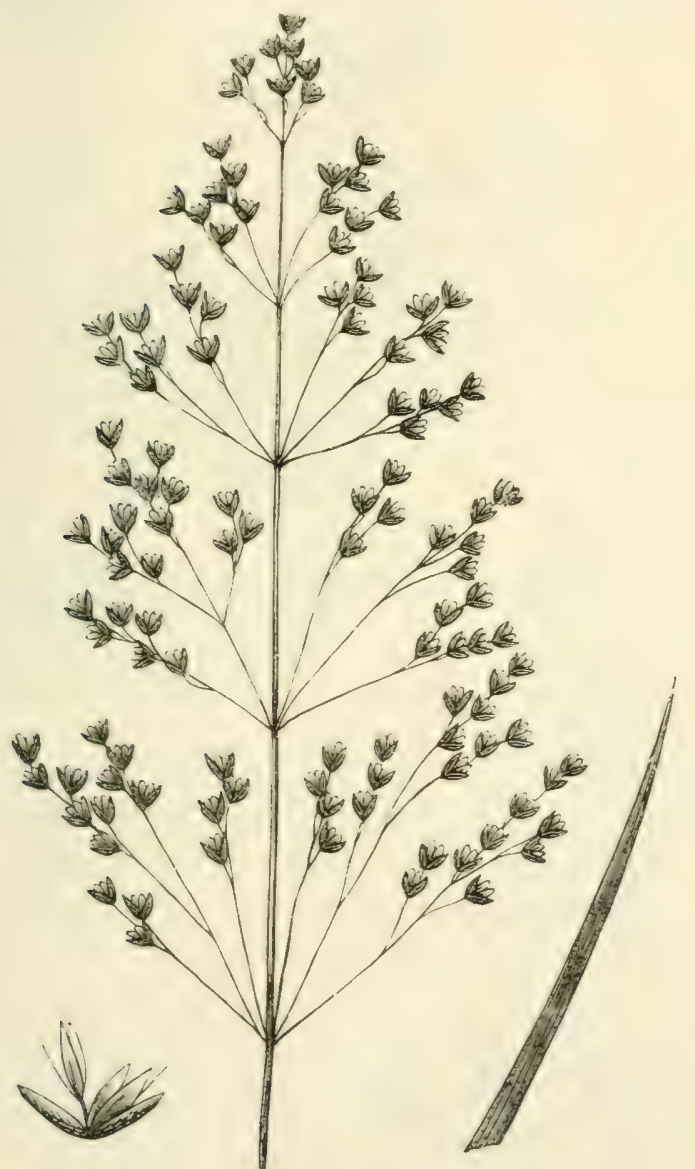

Fig. 24I.

Aira caespitosa.

(K.)

communis Trin. (syn. Arundo Phragmites L.), Schilfrohr. Molinia coerulea, Blau- oder Pfeifengras. Koeleria cristata. Melica nutans, Perlgras. Briza media, Zittergras, a (Fig. 243). Dactylis glomerata, Knäuelgras, g (Fig. 244). Cynosurus cristatus, Kammgras, g. Poa

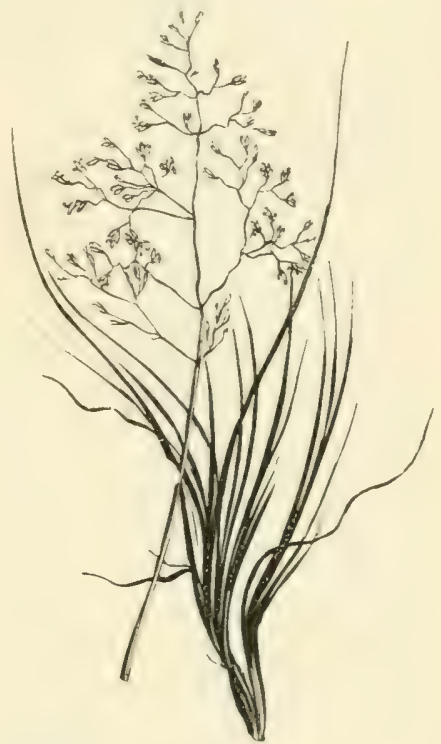

Fig. 242

Aira flexuosa. (K.)

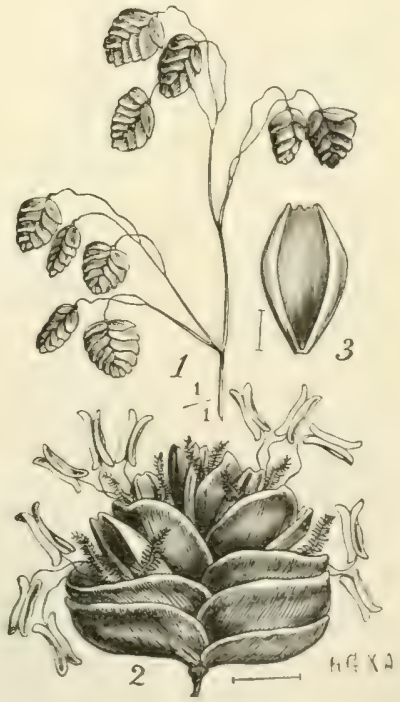

Fig. 243 .

Briza media. (W.) pratensis, Wiesenrispengras, $g$ (glatte Scheiden). Poa trivialis, rauhe Scheiden, gr. Poa annua, m, Rispenäste einzeln oder zu zwei (Fig. 245). 


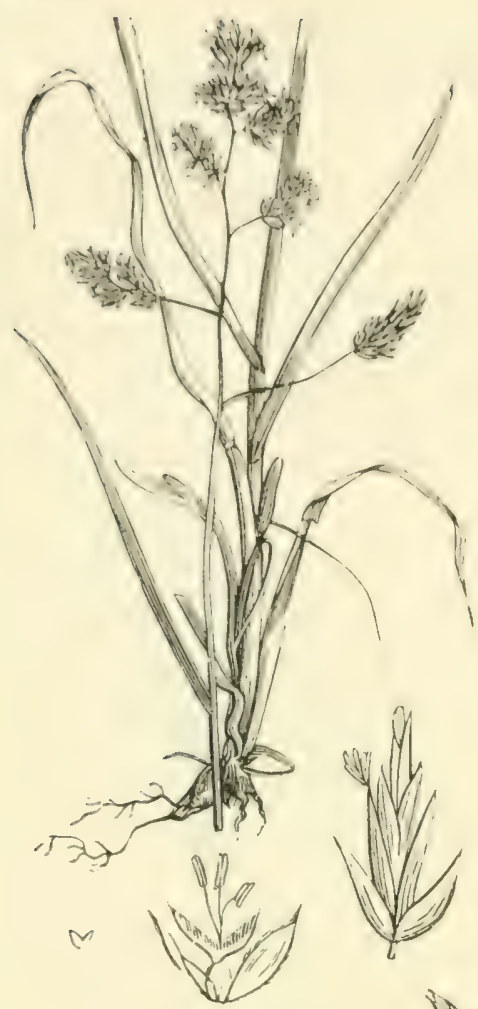

Fig. 244 .

Dactylis glomerata. (K.)
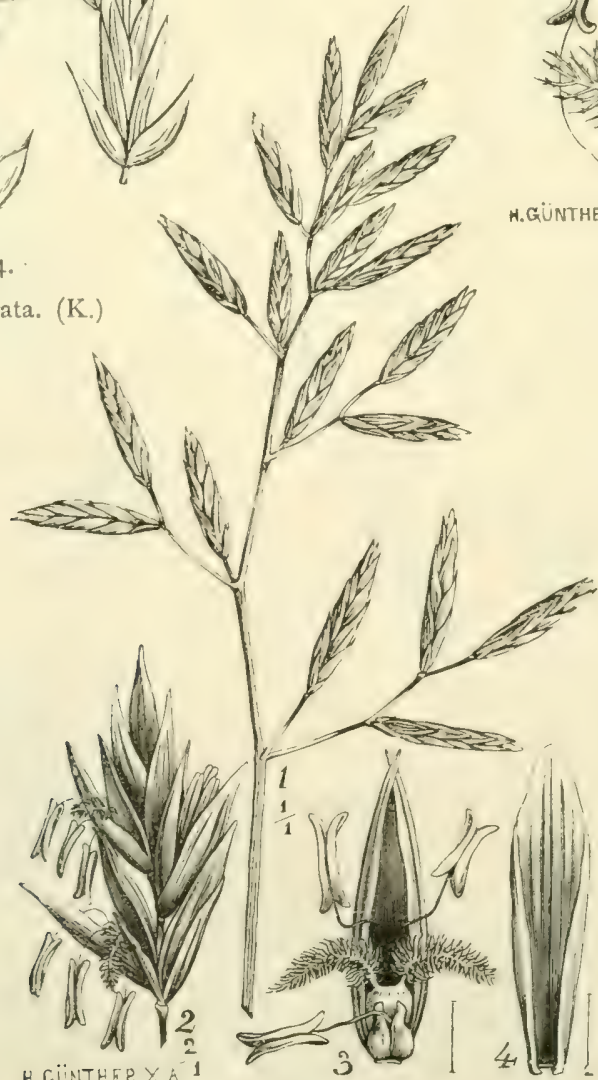

Fig. 246. Festuca elatior. (K.)

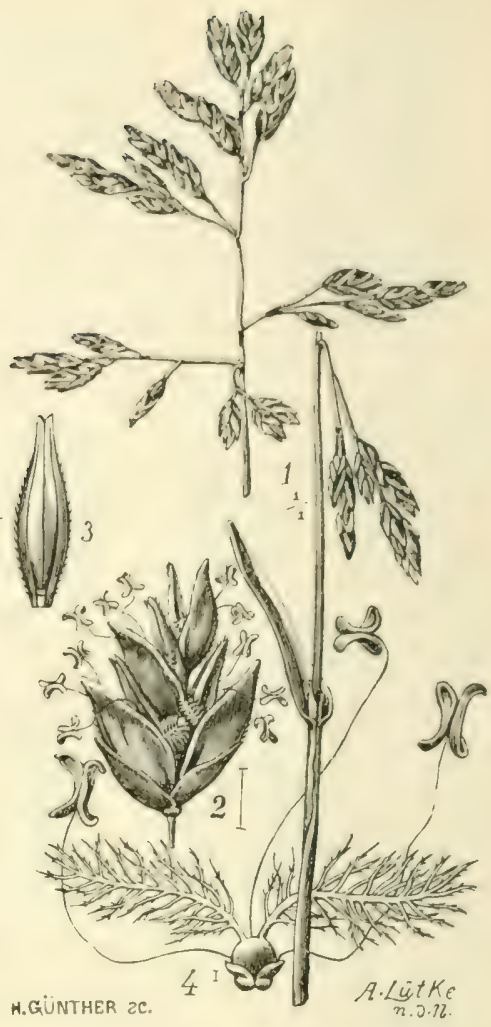

Fig. 245 .

Poa annua. (W.) 


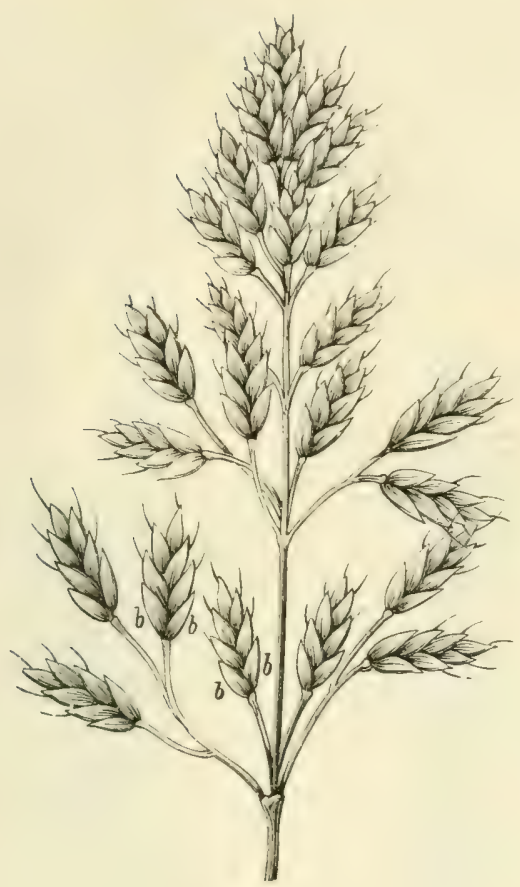

Fig. 247

Bromus mollis. (K.)

Poa nemoralis, $\mathrm{g}$, Rispenäste $\mathrm{zu}$ fünf, im ganzen zart. Poa compressa, mt. Poa palustris, gf. Festuca elatior, Wiesenschwingel, g (Fig. 246). Festuca ovina, glt. Festuca arundinacea, g; heterophylla, gr ; gigantea, m; rubra, m. Glyceria fluitans, gf. Bromus mollis, Weichhaarige Trespe (Fig. 247). Bromus secalinus, u; sterilis; tectorum; racemosus, $\mathrm{mbf}$; erectus, $\mathrm{t}$. Brachypodium pinnatum und silvaticum.

9. Hordeae. Ährchen ein-bis vielblütig (oberste dann unvollkommen), an den Auszähnungen einer Spindel sitzend, eine zusammengesetzte Ähre bildend. Lolium perenne, englisches Raygras, gb (Fig. 248). Lolium italicum, italienisches Raygras, glf. Lolium temulentum, Taumellolch, giftig. Triticum repens, Quecke (Fig. 249 und 82). Triticum monococcum, Einkorn. Triticum sativum, Weizen mit

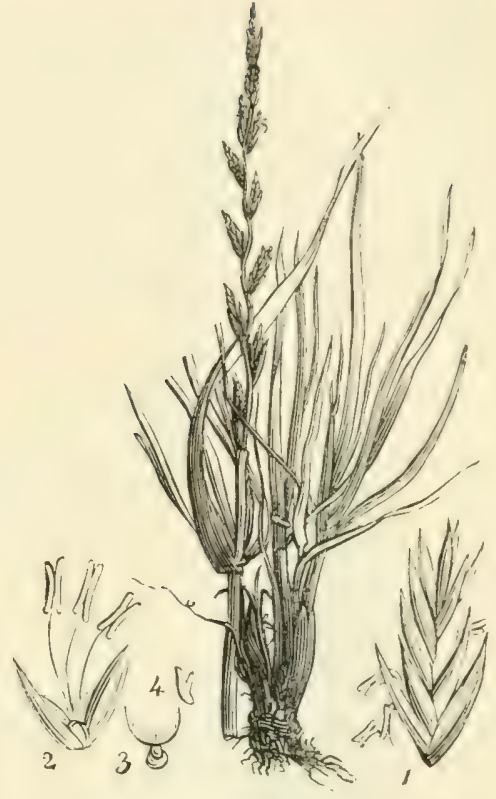

Fig. 248. Lolium perenne.

(K.)

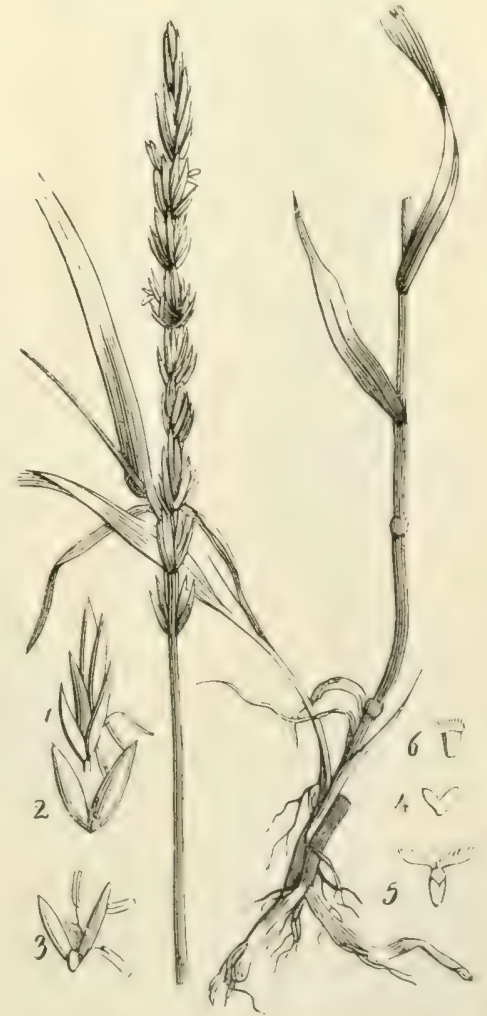

Fig. 249. Triticum repens. (K.) 
folgenden Varietïten, die auch als besondere Arten benamnt sind: Triticum sativum Spelta, Spelz, dicoccum, Emmer, vulgare, semeiner Weizen (Figr.250), compactum, Isel- oder Zwergweizen, turgidum, englischer Weizen, durum, Hart- oder Glasweizen. Triticum polonicum, polnischer Weizen. Secale cereale, Roggen, j (Fig. 251). Hordeum sativum, Gerste (j) mit den

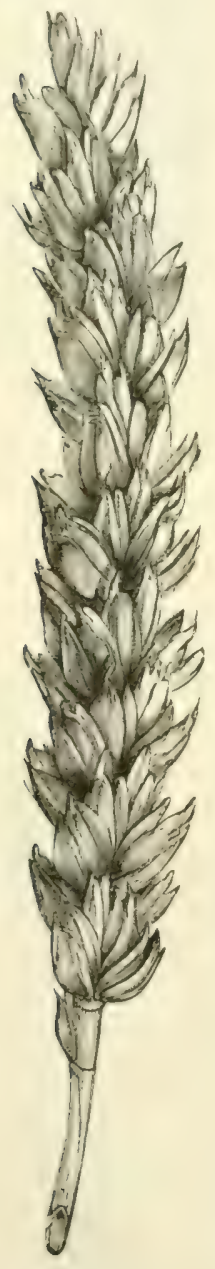

Fig. 250 .

Triticum vulgare.

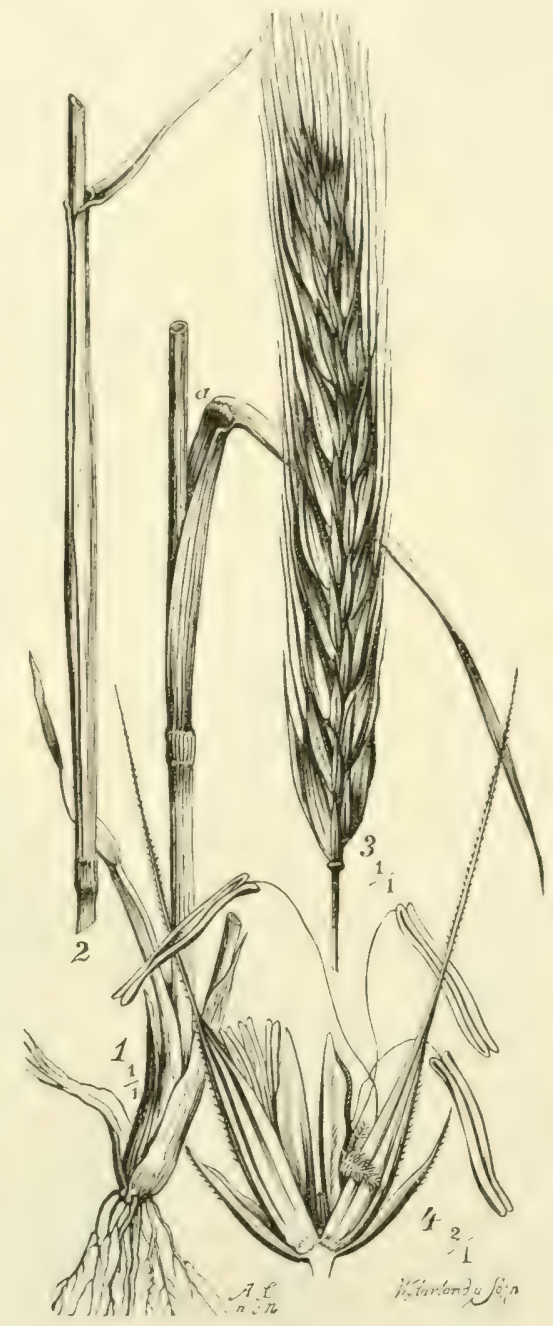

Fig. 251 .

Secale cereale. (W.)

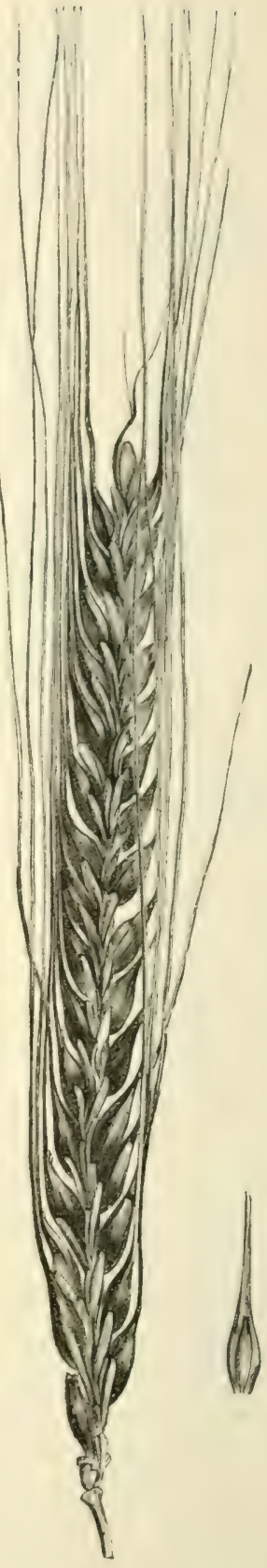

Fig. 252 .

Hordeum sativum var. distichum.

Varietäten: hexastichum, sechszeilige Gerste, vulgare, ungleichzeilige G. oder vierzeilige G., distichum, zweizeilige G. (Fig. 252). Hordeum murinum, 
Mäusegerste. Elymus arenarius, Strandhafer (Fig. 253), geeignet zur Bindung des Flugsandes.

IO. Bambuseae. Hohe Gräser der Tropen mit holzigem, kieselsäurehaltigem Halm. Bambusa arundinacea, vulgaris u. a.

\section{$\$ 68$.}

\section{Ordnung. Spadiciflorae.}

Blüten meist eingeschlechtig, mehr oder weniger reduciert. Blütenaxe bei einigen Familien fleischig (Spadix). Die dichten oft kolbigen Blütenstände sind bei Palmen und Araceen von einem grossen Hochblatt (Spatha) umhüllt. Blätter oft vom Monocotylentypus abweichend.

I. Fam. Palmae. Palmen.

Stamm meist unverzweigt, säulenförmig, mit Blattresten bedeckt. Blätter können durch Zerreissen der in der Knospenlage ungeteilten Spreite fiederoder fächerförmig werden. Blütenstand ein grosser, ästiger Kolben, ơ und f Blüten getrennt. Frucht eine Beere, Steinfrucht oder Nuss. Circa Iooo Arten.

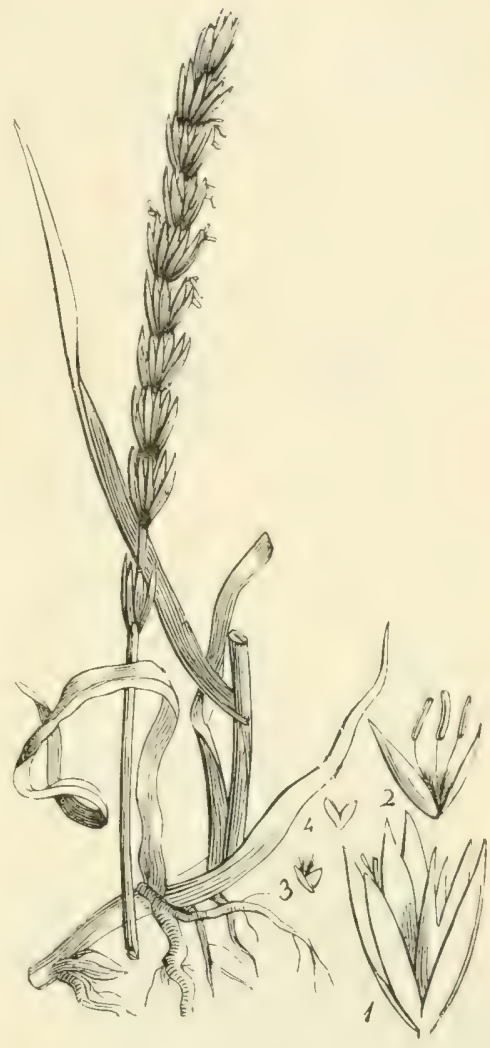

Fig. 253 .

Elymus arenarius. (K.)

Phoenix dactylifera, Dattelpalme.

Chamaerops humilis, Fächerpalme. Cocus nucifera, Kokosnuss. Elaeïs guineensis, Ölpalme. Attalea funifera. Metroxylon Rumphii, Sagopalme. Calamus Rotang, spanisches Rohr. Phytelephas macrocarpa. Das Endosperm liefert das sog. vegetabilische Elfenbein.

2. Fam. Pandanaceae.

3. Fam. Typhaceac.

Blüten eingeschlechtig, Blütenstände kolbig oder kopfig Po oder 3 oder haarförmig A I-3 G丷. Sumpfpflanzen mit kriechender Grundaxe und zweizeiligen, langen, linealen Blättern. Typha latifolia und angustifolia, Rohrkolben. Sparganium simplex und ramosum, Igelkolben.

4. Fam. Araceac.

Blïten ohne Vorblätter auf einem fleischigen Kolben sitzend, der häufig von einer auffallend gefärbten Spatha umgehen ist. Blüten s oder eingeschlechtig. Frucht eine Beere. Acorus Calamus, Kalmus. Calla palustris. Arum maculatum. Monstera deliciosa. Colocasia. Caladium. 
5. Fam. Lemnaceac, Wasserlinsen.

Blïten sehr reduciert. Der Blütenstand besteht aus zwei Staubblättern (2 je cinmännişen ơ Blüten) und einem einfächerigen Fruchtknoten (cine \& Blüte) und einer dünnen Spatha. Lemna minor, trisulca.

\section{4. Ordnung. Enantioblastac.}

Samenknospen nicht wie bei fast allen Monocotyledonen anatrop, sondern atrop. Typus verschieden. Tradescantia virginica, Commelina etc.

\section{5. Ordnung. Liliiflorae.}

Im allgemeinen nach dem Monocotylentypus gebaut, Reductionen sering (Iridaceen). Statt des typischen $\mathrm{P}_{3}+3 \mathrm{~A}_{3}+3 \mathrm{G}_{3}$ in einigen Fällen die Kreise zwei- oder vierzählig (z. B. Majanthemum, Paris). Fruchtknoten oberständig: Colchicaceae, Liliaceae, Convallariaceae, Bromeliaceae z. T. Fruchtknoten unterständig: Amaryllidaceae, Iridaceae, Bromeliaceae z. T., Dioscoraceae.

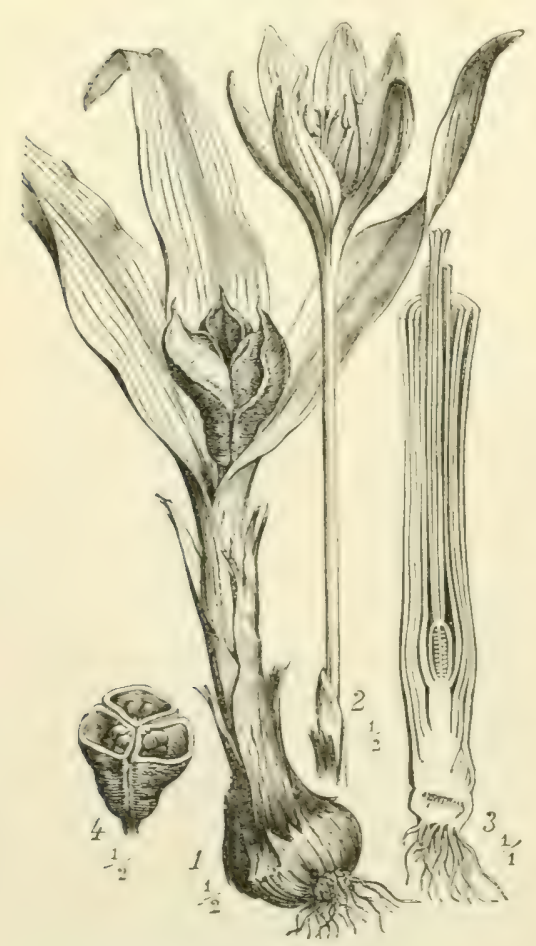

Fig. 254 .

Colchicum autumnale. (IV.)
I. Fam. Colchicaceac.

Frucht eine Kapsel, die scheidewandspaltig (septicid) aufspringt. Colchicum autumnale, Herbstzeitlose (Fig. 254) Blüte im Herbst, Blätter und Kapsel im Frühjahr, giftig. Veratrum album.

\section{Fam. Liliaceae.}

Die einzelnen Fächer (nicht die Scheidewände) der Kapselfrucht springen auf (loculicide Kapsel). Blütenstand endständig. Sprossaxe mit Zwiebelbildung. Tulipa Gesneriana. Gartentulpe. Fritillaria imperialis, Kaiserkrone. Lilium candidum, weisse Lilie, Lilium bulbiferum, Feuerlilie. Lilium Martagon, Türkenbund. Hyacinthus orientalis. Scilla. Hemerocallis fulva. Urginea maritima, Meerzwiebel. Allium cepa, Küchenzwiebel. A. sativum, Knoblauch. A. Schoenoprasum, Schnittlauch. Allium ursinum. Gagea lutea. Anthericum ramosum. Aloë. Yucca.

3. Fam. Convallariaceae.

Frucht eine Beere. Keine Zwiebel vorhanden. Convallaria majalis, Mai- 
glöckchen. Polygonatum multiflorum. Polygonatum officinale, Salomonssiegel. Najanthemum bifolium. Paris quadrifolia, Einbeere. Asparagus officinalis, Spargel. Ruscus aculeatus mit Phyllocladienbildung (Fig. So). Smilax Sarsaparilla. Dracaena Draco und indivisa.

4. Fam. Juncaceae.

Kelch wie bei den Liliaceen, das Perigon jedoch klein, trockenhäutig, spelzenartig. Blütenstände eine Spirre, ähnlich den Cyperaceen. Frucht

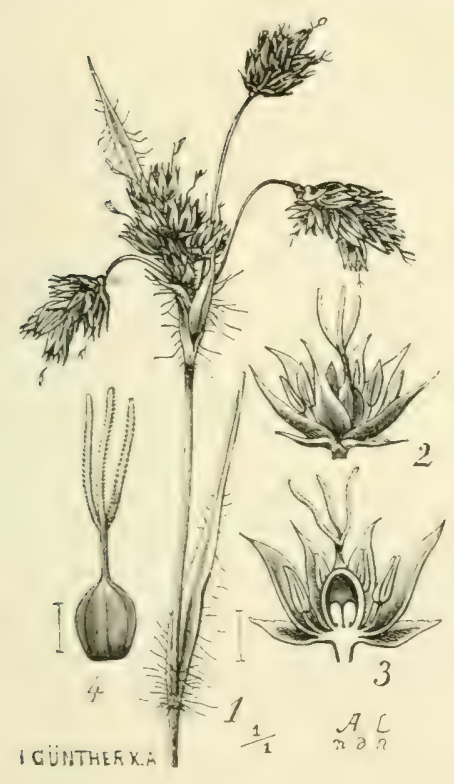

Fig. 255.

Luzula campestris. (IV.)

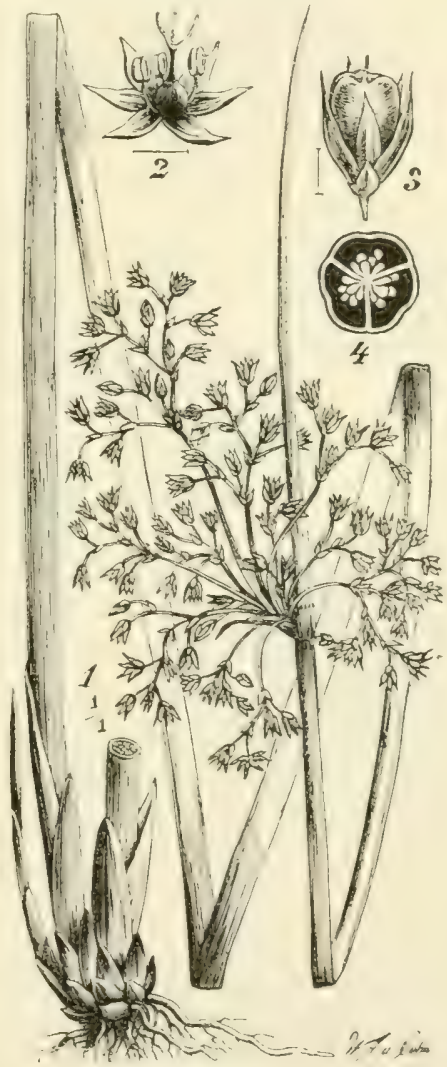

Fig. 256.

Juncus effusus. (IV.)

eine Kapsel. Habitus wie bei den Halbgräsern. Luzula, Hainsimse, am Grunde geschlossene Scheiden, Blätter am Rande meist behaart. Luzula pilosa. Luzula campestris (Fig. 255). Luzula albida. Sie zeigen lichten Stand in Buchenwäldern an. Juncus, Binse. Viele Arten mit blattlosen Halmen, mit blattlosen, aber offenen Scheiden, die Blütenstände zur Seite gedrängst, Juncus effusus, glaucus, conglomeratus u. a. Endständige Inflorescenzen haben J. bufonius, J. compressus, J. articulatus. Juncus lamprocarpus und silvaticus können als Varietäten von J. articulatus angesehen werden. 
5. Fam. Amaryllidaceac.

Typus wie bei den Liliaceen, doch Fruchtknoten unterständig. Galanthus nivalis, gem. Schneesgöckchen. Leucoüum vernum, grosses Schneerlöclichen. Narcissus pseudonarcissus und poüticus u. a. Amaryllis. Agave americana.

6. Fam. Bromeliaceac.

Perianth in Kelch und Krone geteilt. Frucht eine Kapsel oder Beere. Samen am Rande des Endosperms.

Ananas sativus. Tillandsia. Billbersia u. a.

-. Fam. Iridaceac.

Blütentypus $\mathrm{P}_{3}+3 \mathrm{~A}_{3}+\mathrm{OP}_{3}$. Fruchtknoten und Kapsel wie bei Fam. 2 und 4 . Iris germanica, florentina. Gladiolus communis. Crocus vernus. Crocus sativus Saffran.

S. Fam. Dioscoraceae.

Blüte meist diöcisch. Schlingende Stengel mit knolligen Rhizomen. Dioscorea Batatas und alata, Yamswurzel.

\section{6. Ordnung. Scitamineae.}

Blïten zygomorph oder asymmetrisch, von den Staubblättern meist nur eines entwickelt, die übrigen zu blattartigen Staminodien umgebildet. Kein Endosperm, aber grosses Perisperm.

Musa sapientum, paradisiaca, Banane. Musa textilis, Manilafasern liefernd. Zingiber officinale, Ingwer. Elettaria Cardamomum, Kardamom. Maranta arundinacea, Arrowroot. Canna indica.

\section{\$2. 7. Ordnung. Gynandrae.}

Blüten zwitterig, meist zygomorph nach dem Monocotylentypus, im Androeceum meist nur ein Staubblatt (5 unterdrückt). Das Staubblatt ist mit dem Griffel zu einer Säule verwachsen (daher Gynandrae). Fruchtknoten unterständig.

I. Fam. Orchid aceae.

Das hinterste Blatt des blumenkronartigen Perianths wird zum Labellum (Fig. $257 \mathrm{f}$ ), das in Form und Grösse von den anderen abweicht. Durch Drehung des Fruchtknotens (g) wird es oft nach vorn gekehrt. In Fig. 257, 2 s und 4 sehen wir die sog. Säule, $n$ die Narbe, $\mathrm{p}$ die Pollenmassen (Pollinien) des einen fruchtbaren Staubgefässes, $k$ das Connectiv zwischen den Staubbeuteln, q zwei verkümmerte Staubgefässe, die bei Cypripedium fruchtbar sind. In Fig. 257, 5 sind die Pollenmassen frei dargestellt, durch die Scheibe und werden sie den Insekten, welche die Kreuzbestäubung vermitteln, angeklebt. 
Der Embryo sehr klein, kein Endosperm. Über 6000 Arten. Orchis latifolia (Fig. 257), O. maculata, O. militaris, O. morio u. a. Listera ovata, Cephalanthera rubra, Epipactis latifolia und rubiginosa, Platanthera bifolia. Cypripedium calceolus. Neottia Nidus avis, Corallorhiza innata, Epipogum aphyllum. Viele tropische Arten.

\section{2. Klasse. Dicotyledones,}

Zweikeimblättrige. Typus.

Naturgemäss zeigt diese überaus grosse Klasse ausserordentliche Verschiedenheiten in Bezug auf $\mathrm{Ha}$ bitus, Verzweigung, Blattstellung. Blattformen sehr mannigfaltig, auch Nebenblätter können vorhanden sein. Die Nervatur meist netzförmig mit stärkeren Hauptrippen. Sprossaxen mit sekundärem Dickenwachstum (vgl. S. 83 und II 7 ). Anordnung der Gefässbündel weicht sehr bedeutend von den Monocotylen ab (vgl. S. 75). Keimling mit zwei Cotyledonen (Ausnahme Ranunculus

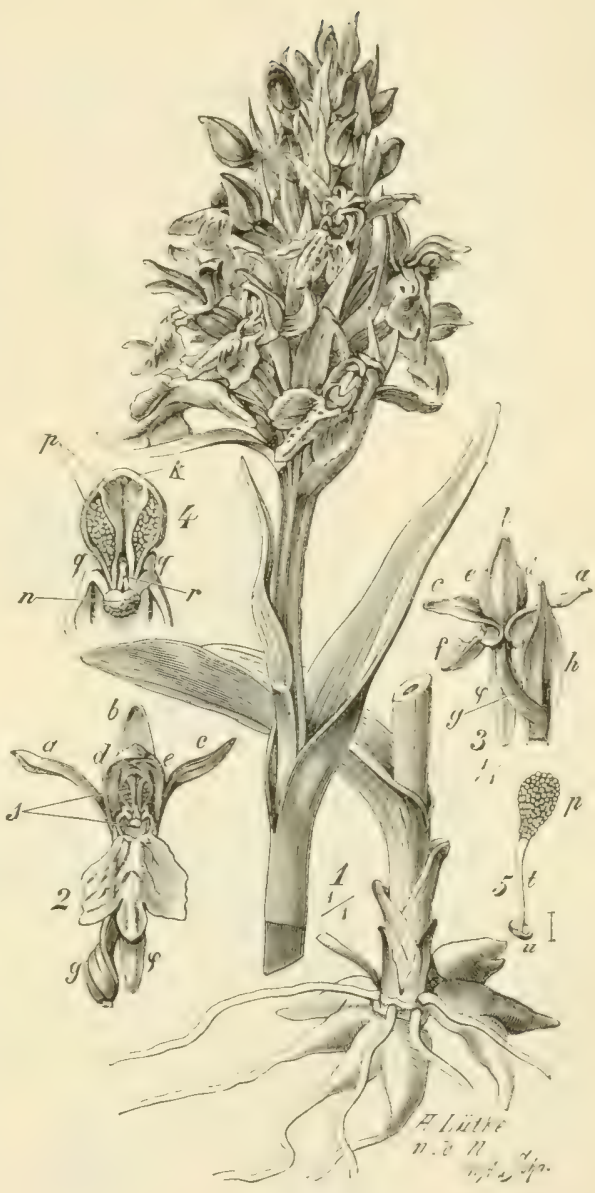

Fig. 257.

Orchis latifolia. (IV.) Ficaria, Cyclamen, Pinguicula mit einem Cotyledo, Monotropa, Orobanche, Pirola ohne Cotyledo). Primärwurzeln häufig erhalten.

Die Blüten sind sehr verschieden gebaut, lassen sich nicht auf einen gemeinsamen Typus zurückführen, vielfach fünf Kreise mit je vier oder fünf Gliedern, andere Zahlen kommen ebenfalls vor.

Die Unterklasse der Choripetalen umfasst ausser den freikronblättrigen Dicotyledonen auch noch jene Formen, welche gar kein Perianthium besitzen. In der Regel besitzen dieselben Samenknospen mit zwei Integumenten und einem grossen Knospenkern.

Die Unterklasse der Sympetalen zeichnet sich durch das vereintblättrige Perianthium und den bleibenden Kelch aus. Blïte cyclisch, $\mathrm{KnCnAnG}$ häufig 2 oder $\mathrm{KnCnAn}+\mathrm{nG}_{2}$. Samenknospe mit einem Integument und sehr kleinem Knospenkern. 


\section{1. Unterklasso. Choripotalao: 1. Ordnung. Saliciflorao.')}

Ordnungscharakter wie bei der einzigen Familic.

I. Fam. Salicaceac.

Blïten cingeschlechtig, diöcisch. Eigentliches Perianth fehlt, doch mit Diskusbildungen. $\mathrm{A}_{2}-\propto \mathrm{G}(2)$. Fruchtknoten einfächrig mit vielen Samenknospen. Frucht eine zweispaltige Kapsel. Blütenstände Kätzchen, d. h. Ähren oder Trauben, die nach der Reife und dem Abblïhen als

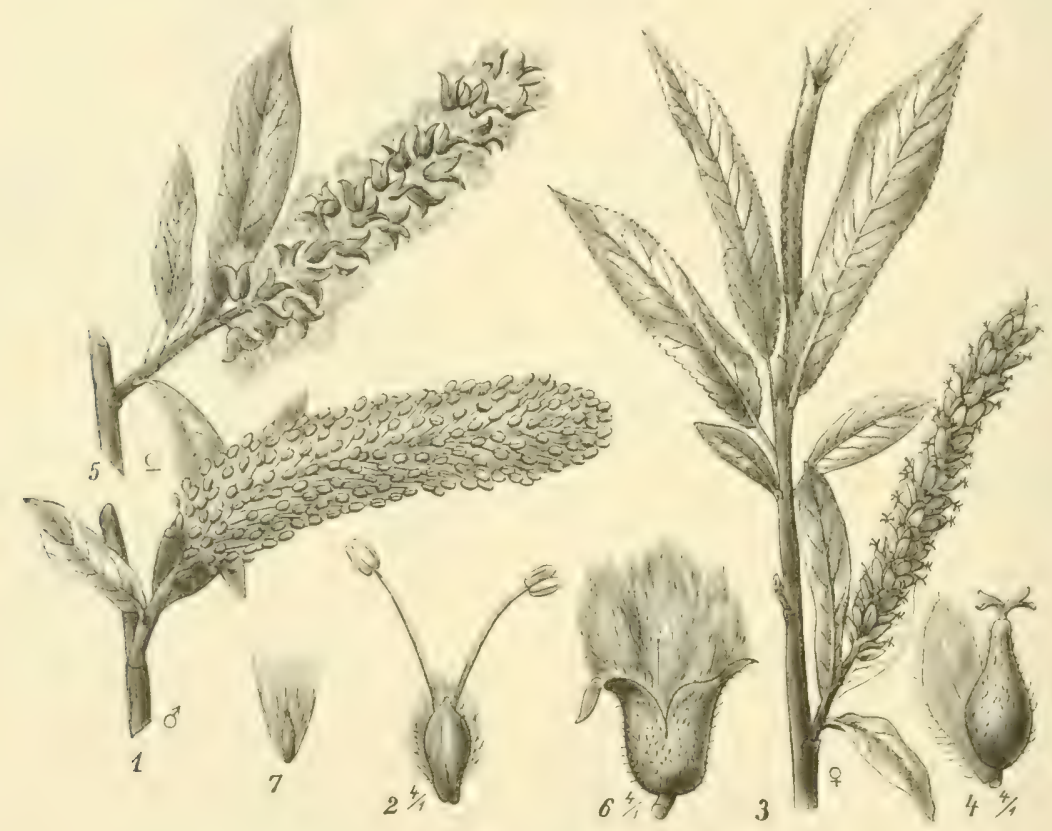

Fig. 258.

Salix alba. (Sch.)

Ganzes abfallen. Holzpflanzen mit einfachen Blättern, Nebenblätter häufis.

Circa I80 Arten der gemässigten und kalten Zone. Viele Bastarde.

Salix. Habitus strauchig oder baumartig. Blätter nicht oder nur kurz gestielt, ungeteilt, doch selten ganzrandig (vgl. Fig. 262 und 265). Die Blütenkätzchen entfalten sich entweder vor Laubausbruch, dann mit der Knospenschuppe am Grunde, oder sie erscheinen nach Laubausbruch, damn mit Laubblättern am Grunde (Fis. 258). Die 3 Kätzchen (Fig. 258, I) bestehen aus ganzrandigen, behaarten Schuppen, in deren Achsel meist

1) Die frühere Einteilung fasst unter der Ordnung der Amentaceen folgende Familien zusammen: Cupuliferae (mit den Unterfam. Betuleae, Coryleae, Fagineae), Juglandaceae, Myricaceae, Salicaceae, Casuarinaceae, Piperaceae, Engler sowie WVarming lassen die Ordnung der Amentaceen fallen. 
zwei Staubblätter stehen (Fig. 258, 2). An der Basis derselben befinden sich ein oder zwei sekundäre Drüsen (Fig. 259, 3), die man als sehr reduciertes Perianth, oder richtiger als Diskusbildungen, Diskuszähne (d. h. Vorwölbungen der Axe) deuten kann. Die analogen Gebilde sind auch bei der ㅇ Blüte vorhanden (Fig. 259, 4, 5). Die 오 Kätzchenschuppen tragen den aus zwei Fruchtblättern gebildeten, einfächrigen Fruchtknoten (Fig. 258, 4, 5). In der Kapselfrucht zahlreiche mit einem Haarschopf versehene Samen (Fig. 258, 5, 6,7 und Fig. 259, 5). Sie behalten ihre Keimfähigkeit nur kurze Zeit, Samenreife Mai, Juni.

Die Weiden zeichnen sich durch ihr ausserordentlich grosses Reproduktionsvermögen aus, weshalb sie leicht durch Stecklinge vermehrt und zum Kopfholzbetrieb verwendet werden können. Ausserdem ist die grosse Neigung zur Bastardbildung hervorzuheben.

Forstlich am wichtigsten: Salix viminalis, purpurea, triandra, acutifolia, Bastard von viminalis und purpurea.

Einteilung 1) nach $\operatorname{Pax}$ (in Engler-Prantl, die natürlichen Pflanzenfamilien.)

A In der ơ Blüte zwei Diskuszähne. Staubblätter zwei bis mehrere.

a. Sträucher oder Bäume, Deckschuppen einfarbig.

I. Sekt. Fragiles. Auch in der o Blüte zwei Diskus-

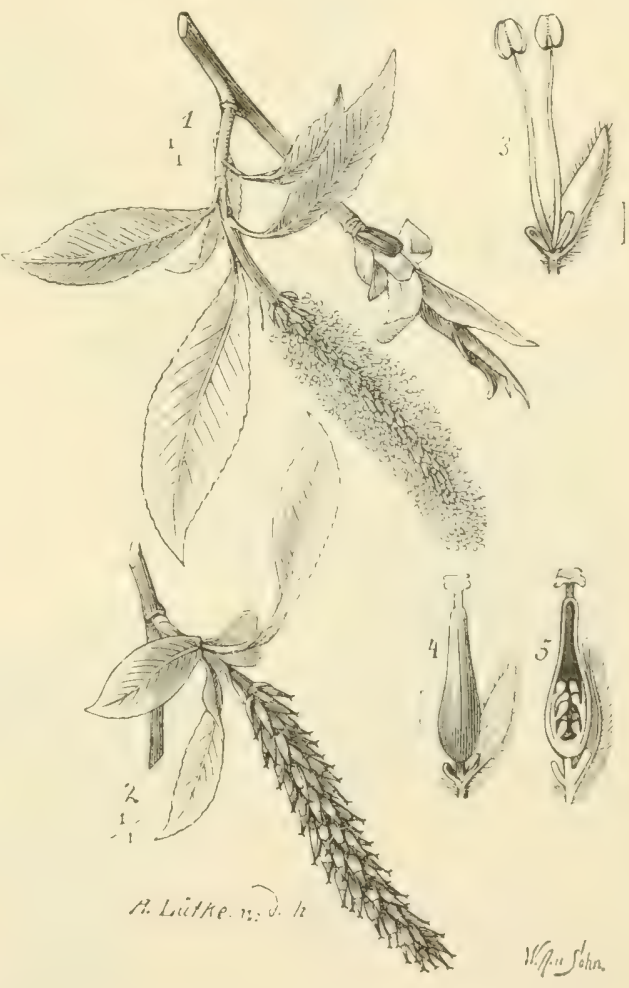

Fig. 259 .

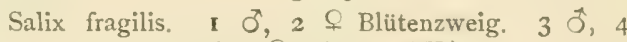
und 5 ㅇ Blüte. (W.) zähne. Blätter in der Jugend klebrig. S. pentandra, Lorbeerweide (Fig. 260), fün Staubblätter. S. fragilis, Knackweide (Fig. 26I), zwei bis vier Staubblätter. Baum II. Grösse.

II. Sekt. Triandrae. In der $q$ Blüte ein Diskuszahn. Blätter nicht klebrig. S. triandra (syn. S. amygdalina) Fig. 262, drei Staubblätter. S. alba, Silberweide, zwei Staubblätter (Fig. 258 und 263). S. alba var. vitellina, Dotterweide. S. babylonica, Trauerweide.

1) Zur näheren Unterscheidnng der einzelnen Arten vgl. die Tabelle zur Bestimmung der Laubholzgewächse. 
b. Niedrige Gletscherweiden.

1II. Sekt. Retusac. In der $f$ Blüte cin Diskuszahn. Arktisch-alpine Arten. S. retusa, S. herbacea.

IV. Sekt. Reticulatac. Diskus becherförmig. Arktisch-alpin. S. reticulata. B. In der or und $f$ Blüte je ein Diskuszahn. a Staubblätter mehr oder weniger vercinigt. Sträucher oder Båume.

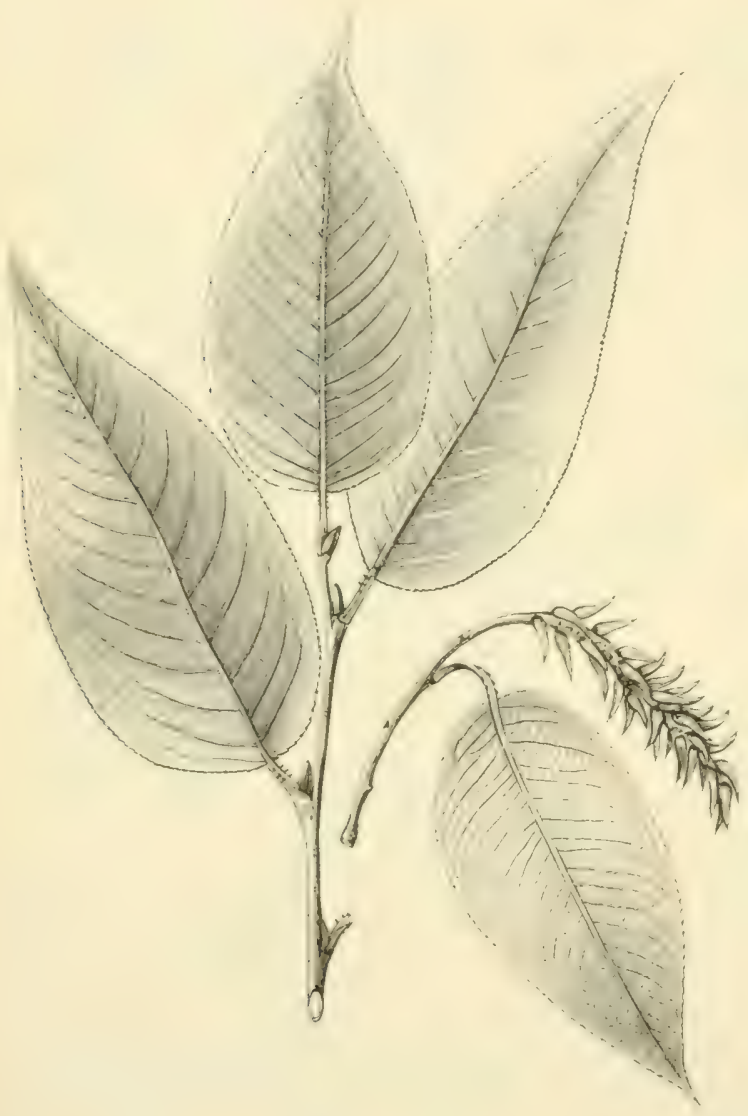

Fig. 260.

Salix pentandra.")

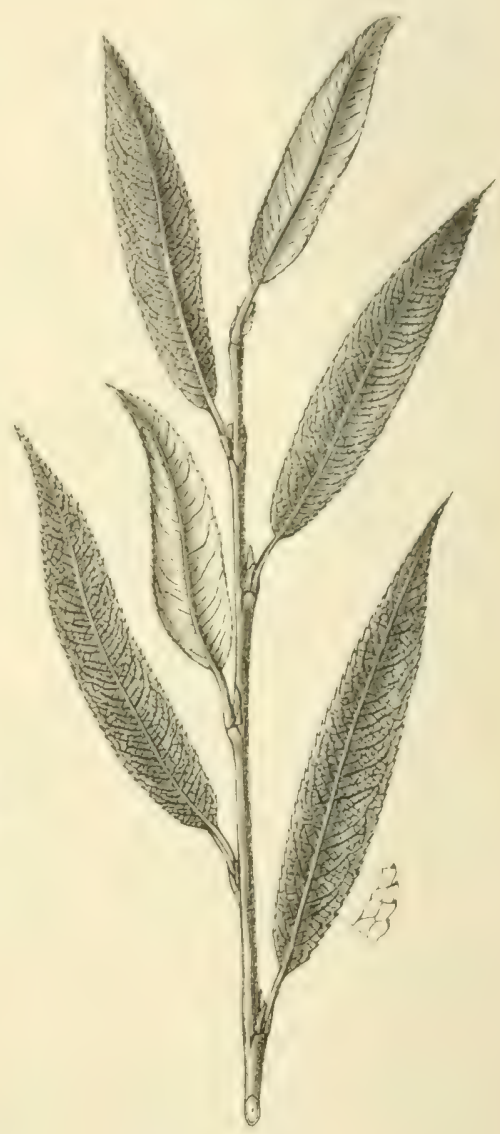

Fig. 26r.

Salix fragilis.

V. Sekt. Purpureae. Griffel kurz oder fehlend. S. purpurea. Purpur- Schlank- oder Bachweide (Fig. 264). Strauch oder Baum III. Grösse. Varietäten hiervon S. helix L. und S. rubra Huds. VI. Sekt. C a nae. Griffel lang und dünn. S. incana. b. Staubblätter frei. Kätzchenschuppen zweifarbig.

1) Die folgenden Abbildungen der Weiden sind $2 / 3$ der natürlichen Grösse. 


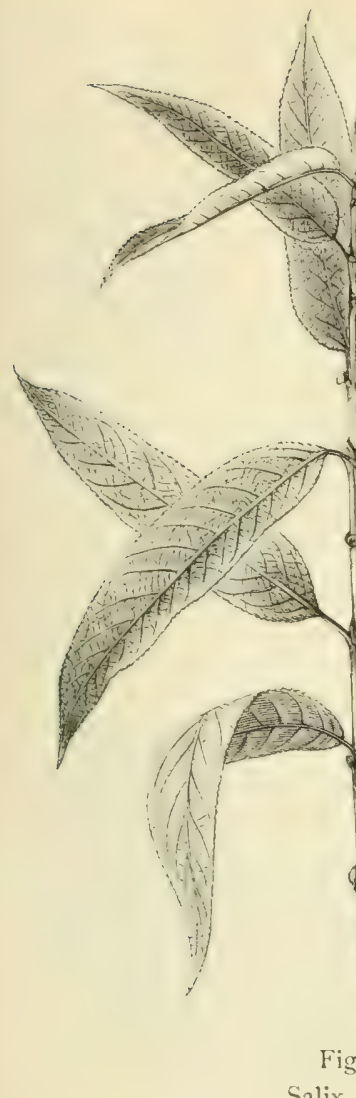

Fig. 262

Salix triandra.
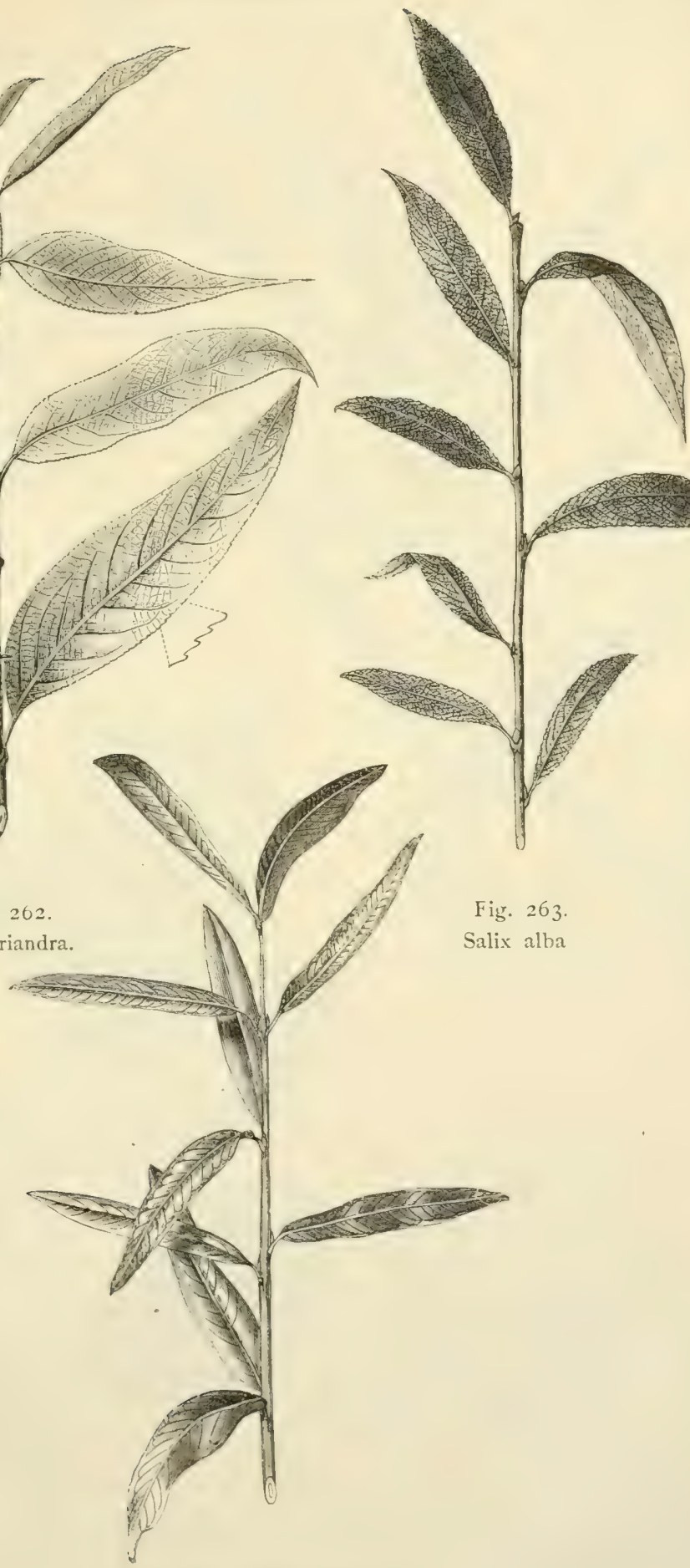

Fig. 263

Salix alba

Fig. 264. Salix purpurea. 


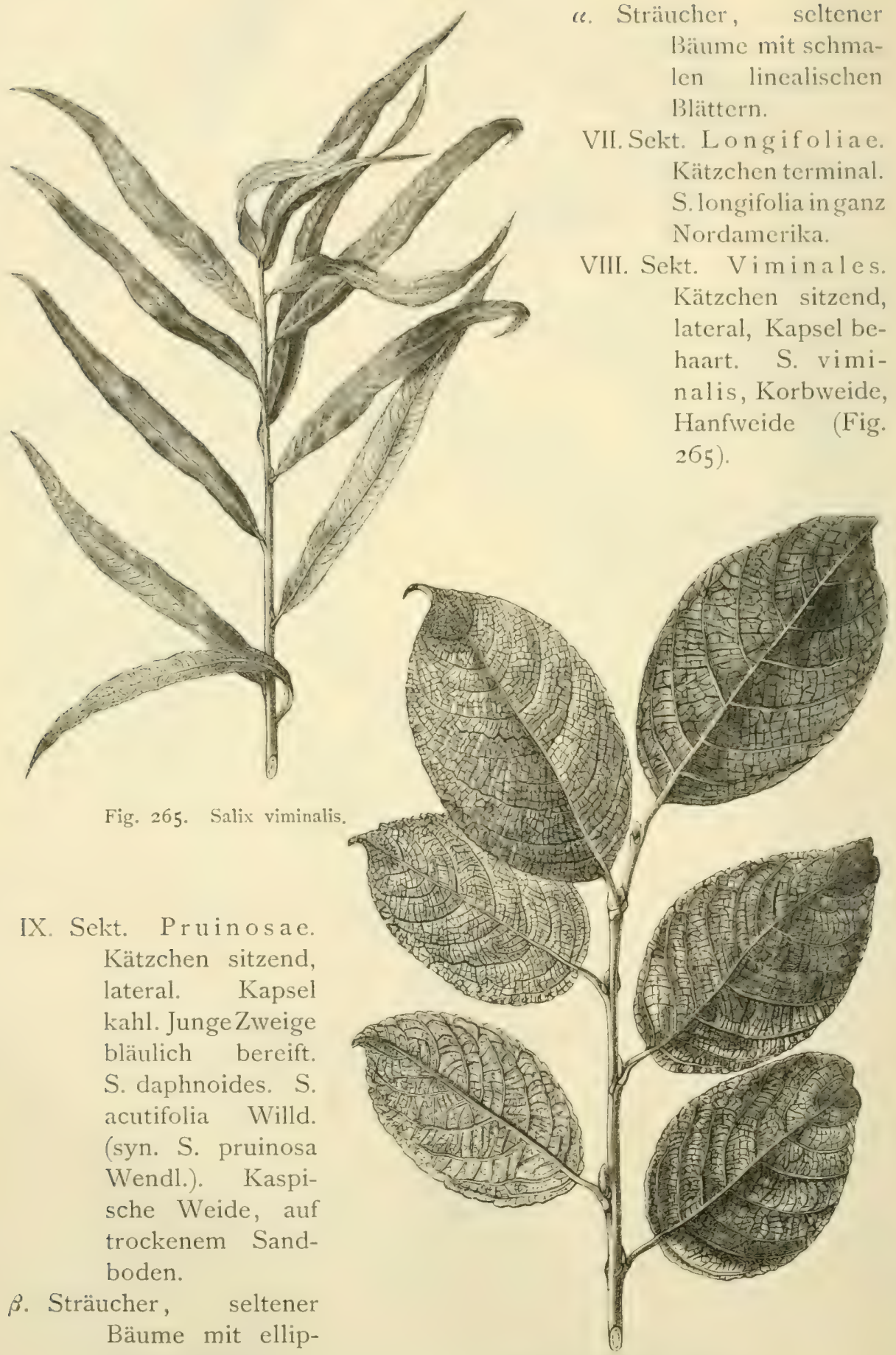

tischen Blättern.
Fig. 266. Salix caprea. 
X. Sekt. Capreae. Griffel kurz. Aderung der Blätter auf der Unterseite vorspringend. S. caprea, Saalweide (Fig. 267), S. aurita (Fig. 267), S. cinerea, unwichtiger S. silesiaca und S. grandifolia. $\gamma$. Niedrige Erdsträucher (wie Gletscherweiden).

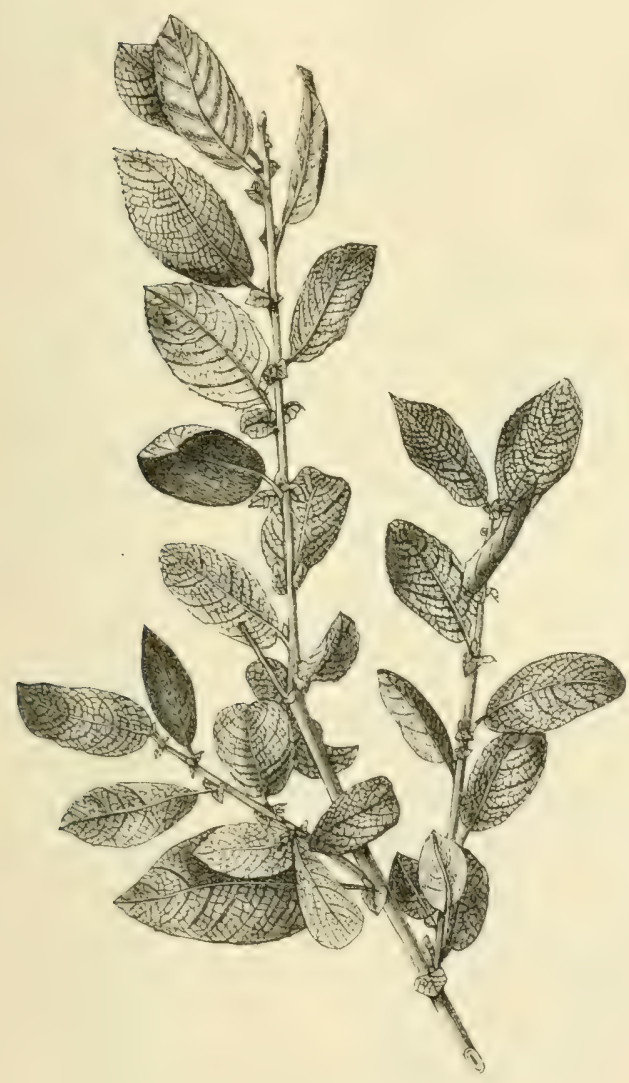

Fig. 267 .

Salix aurita.

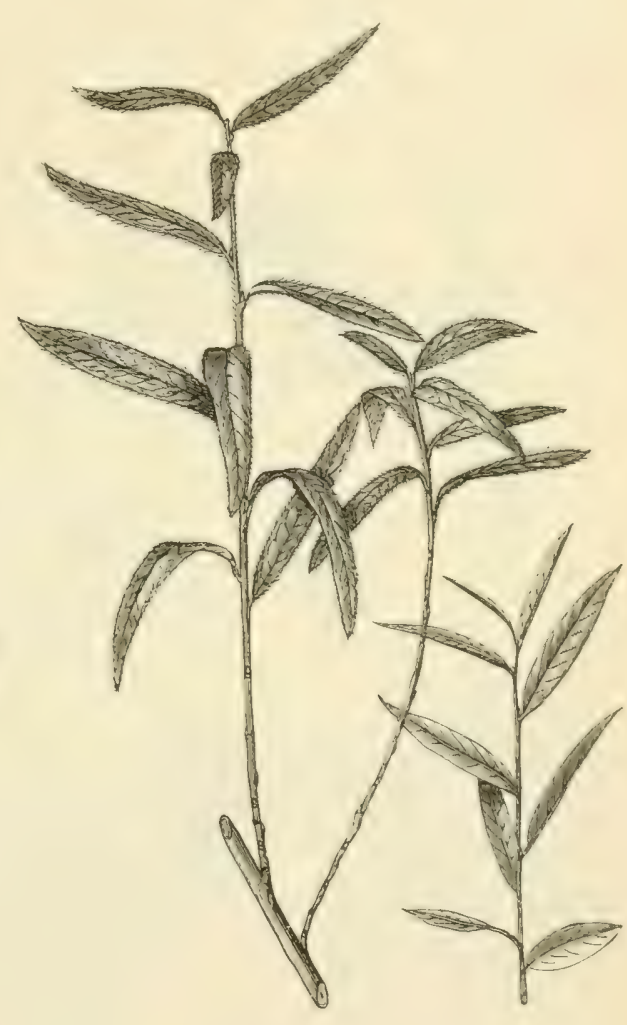

Fig. 268

Salix repens var. rosmarinifolia.

XI. Sekt. Repentes. Griffel kurz oder fehlend. S. repens. Meist auf moorig-torfigem Boden der Ebene. Sehr verschiedene Varietäten bildend; die eine Gruppe derselben, var. cylindrica, hat breite, elliptische Blätter, die zweite Gruppe, rosmarinifolia (Fig. 268), zeigt schmal lineale Blätter.

Populus. Raschwüchsige Bäume I. oder II. Grösse. Blätter lang gestielt, oft büschelig an kürzeren Seitentrieben. Blattspreite oft sta:k variierend. Nebenblätter häutig, abfallend. Kätzchenschuppen gezähnt 
oder seteilt (Fig. 269, I, 3, §, 4, \& Blüte), Staubblätter 4-30, sitzen auf dem ausgebreiteten Diskus (Fig. 269, 3). Um den Fruchtknoten (Fig. 269, 4, 5) ebenfalls ein becherförmiges Diskusgebilde. Kapsel und Samen wie bei Salix. An der Basis des reifen Fruchtkätzchens mehrere Knospenschuppen.

I. Aspen (Selition Leuce). Junge Triebe kurzhaarig. Blattstiel teilweise rund. Kätzchenschuppen langhaarig. A. 4-8 selten I 5. Rinde lange Zeit glatt.

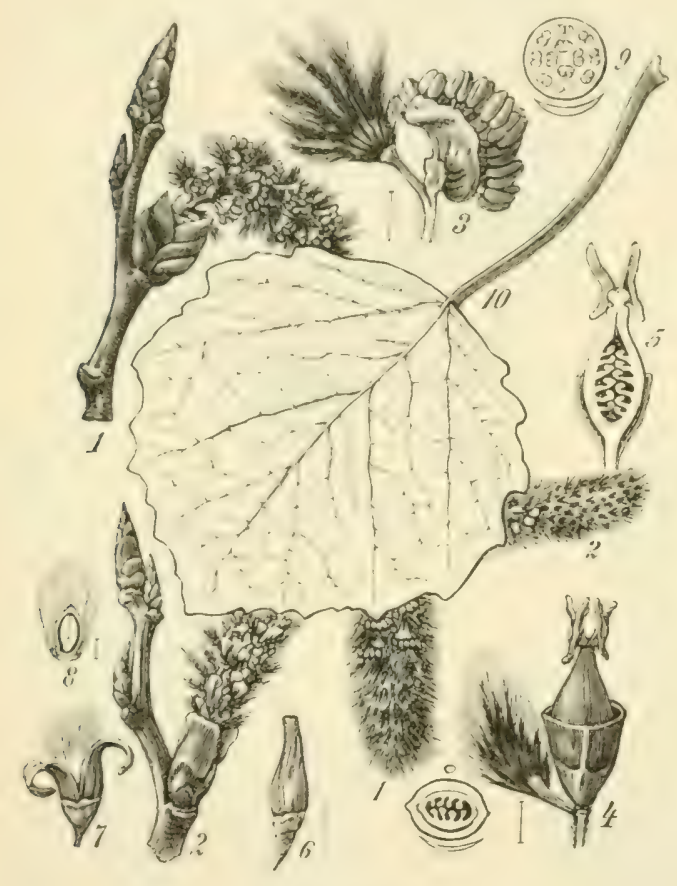

Fig. 269.

Populus tremula. (W.)

Populus tremula L. Espe, Aspe, Zitterpappel (Fig. 269). Baum II. Grösse. Diöcisch wic alle Pappeln. Blüht Ende März, Samenreife Mai, Juni. Sofortkeimfähig. Starke Wurzelbrut. In den Wäldern der Ebenen und des niederen Berglandes die verbreitetste Pappel. Im ganzen genügsam, fehlt auf sehr trocknem Sande. Unempfindlich gegen klimatische Einflüsse.

Populus alba L. Silberpappel (Fig. 270). Baum I. Grösse, lockere, reich belaubte Krone. In Flussthälern (Donau, Oberrhein) auf kräftigem, tiefgründigem Boden. Parkbaum.

Populus canescens Sm., Bastard von P. tremula $x$ alba; stcht zwischen beiden.

II. Echte Pappeln (Sektion Aigeiros). Junge Triebe klebrig. Blattstiele seitlich zusammengedrückt. Blattrand durchscheinend. Kätzchen-

schuppen kahl. A 16-30 (selten 6-I2). Narben deutlich gestielt.

Populus nigra L. Schwarzpappel (Fig. 27I, a). Baum I. Grösse. Krone umfangreich, mit abstehenden, besenförmigen Langtrieben und wenig Kurztrieben. Junge Triebe rundlich ohne Korkleisten. Staubblätter 6-8. Fruchtknoten eiförmig, kahl, grün, zweinähtig. Narben zurückgeschlagen, dreieckig, fast dreilappig, gelb. Liebt feuchten, sandigen Boden, Flussniederungen.

Populus nigra var. pyramidalis (syn. P. pyramidalis, P. italica, P. dilatata, P. fastigiata). Die Pyramidenpappel ist leicht an ihrem charakteristischen Wuchs zu erkennen. Bei uns nur o Individuen, die of 
Exemplare dagegen sehr selten. Das Absterben der oberen Baumkrone sehr häufig (durch Frost oder einen Pilz Dothiora sphaeroides Fr. bewirkt?).

Populus canadensis Desf. (syn. P. monilifera Ait., Fig. 27 I, b). Der Schwarzpappel sehr ähnlich. Unterscheidungsmerkmale oft unsicher.

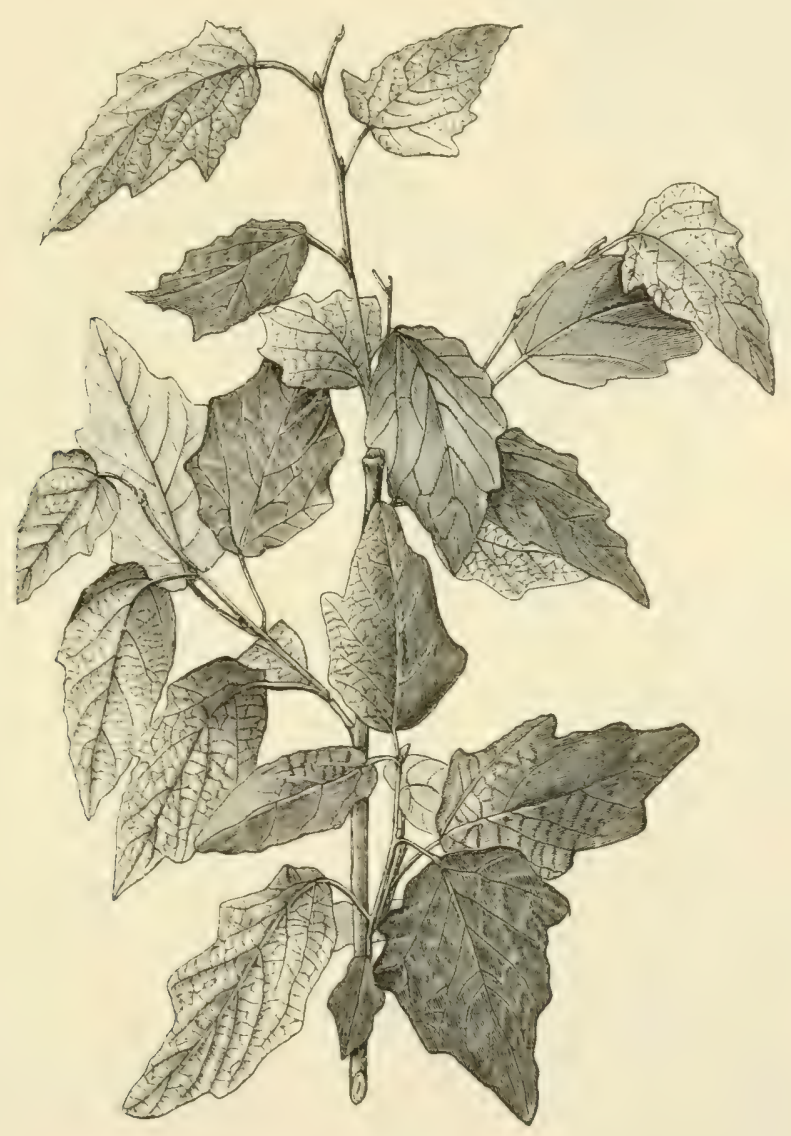

Fig. 270 .

Populus alba.

Krone wie bei P. nigra. Junge Triebe durch Korkrippen kantig. Staubgefässe 20-30. Fruchtknoten kürbisförmig, 3-4nähtig, oft zwischen den Nähten gefurcht. Narben nierenförmis, zweilappig, gelbgrün, am Rande purpurn. Als Varietät ist Populus canadensis var. serotina zu nennen, die Mitte Mai noch unbelaubt ist. Krone sperrig, zahlreiche Kurztriebe.

III. B als ampappeln (Sektion Tacamahaca). Junge Triebe klebrig, 


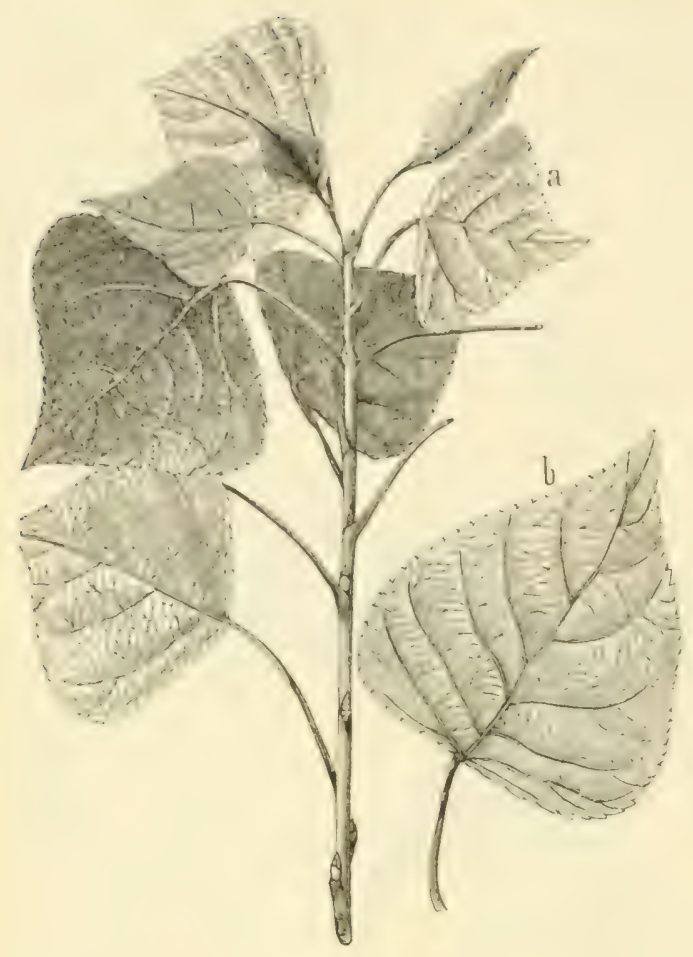

Fig. 271 .

Typische Blätter von a Populus nigra, b Populus caArten vor. nadensis. Es kommt jedoch jede Blattform an beiden

kahl. Blattstiele rundlich, Spreite bis zum äussersten Rand grün. Staubblätter 20-30. Langtriebe knotig, viele Kurztriebe.

Populus candicans Ait. (syn. P. ontariensis Desf.). Blätter sehr verschieden geformt, eiförmig zugespitzt oder dreieckig, jung klebrig, aromatisch riechend. Nordamerika.

Populus balsamifera L. Blätter eiförmig, viel länger als breit. Nordamerika. Populus laurifolia Ledeb. Blätter eiförmig zugespitzt. Junge Triebe scharf gerippt oder flügelkantig. Stammt aus Sibirien und dem Altai.

\section{§ 75.}

\section{Ordnung. Querciflorae.}

Bäume und Sträucher. Blätter abwechselnd oder spiralig gestellt. Nebenblätter hinfällis. Blüten cingeschlechtig, monöcisch. Die j Blüten, teilweise auch die $\subseteq$ Blüten in Kätzchen. Perianth vorhanden oder fehlend. A 2-20. G (2-3) selten mehr. Fruchtknoten gefächert, in jedem Fache eine oder zwei Samenknospen, von denen sich jedoch nur eine einzige weiter entwickelt. Die Frucht ist eine einsamige Nuss. Circa 368 Arten.

I. Fam. Betulaceae.

Die Frucht ist nicht von einer Cupula, d. h. einer durch die Verwachsung von Vorblättern entstandenen Hülle eingeschlossen. P in der $\checkmark$ Blüte entwickelt, bei der $\subseteq$ Blüte fehlend, G (2).

An der Kätzchenspindel stehen in spiraliger Anordnung die Deckblätter, welche in ihrer Achsel die einzelnen Blüten, sowie Vorblätter tragen. Die Anordnung der Blüten und Vorblätter bei den Betulaceen und ebenso bei den Corylaceen kann durch das in Fig. 272 dargestellte Diagramm verdeutlicht werden. Jedes Deckblatt (Fig. 272, d) trägt in der Achsel eine Mittelblüte (mb) mit den Vorblättern $\boldsymbol{a}, \boldsymbol{\beta}$, sowie zwei Seitenblüten (s b) mit den Torblättern $\iota^{\prime}$, . Bei den einzelnen Gattungen 
sind nur bestimmte Blüten und Vorblätter entwiclielt, während die übrigen unterdrückt sind.

Alnus glutinosa Gaertn. Schwarzerle, Roterle, klebrige Erle, Eller (Fig. 273). Baum II.-I. Grösse, selten bis $30 \mathrm{~m}$ hoch. Belaubung mässig dicht. Stockausschläge besonders nach Abhieb des Stammes. Blüten überwintern nackt (Fig. 273, I) entfalten sich Ende März, Anfang April. Die of Kätzchen langgestreckt (Fig. 273, I a), das Deckblatt der o Blüten trägt vier Vorblätter (Fig. 272, , $_{3}$, $y^{\prime} \gamma^{\prime} \mid$ und drei Blïten. Jede $\hat{\jmath}$ blïte hat ein vierteiliges Perigon (Fig. $273,2)$. Die \& Kätzchen stehen am Ende der Zweige (Fig. 273, I b , 3). Die Nittelblïte fehlt, es stehen daher nur je zwei \& Blüten mit ebenfalls vier Vorblättern in der Achsel einer Deckschuppe. Vorblätter und Deckblatt verwachsen zu einer holzigen Schuppe, diese Schuppen lösen sich bei der Reife nicht von der Spindel, sie bilden vielmehr ein holziges Zäpfchen (Fig. 273, 5). Frucht ein fünfechiges Nüsschen (Fig. 273, 6), das weniger breit geflügelt und etwas dunkler gefärbt ist, als die Frucht von Alnus incana. Abfall der Früchte December bis Frühahr. Keimung nach 4-6 Wochen.

Die Schwarzerle ist empfindlich gegen Trockenheit, gegen Schneebeschädigungen. Ihr Standort ist vorzüglich die Ebene, im Bergland bevorzugt sie West- und Nordhänge.

Alnus incana DC. Weisserle, Grauerle, nordische Erle (Fig. 274). Baum III.--II. Grösse. Wurzelbrut. Blüht

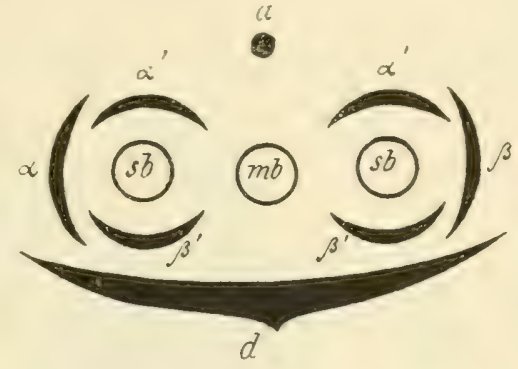

Fig. 272.

Schematisches Diagramm einer Blütengruppe der Betulaceen und Corylaceen. (K.)

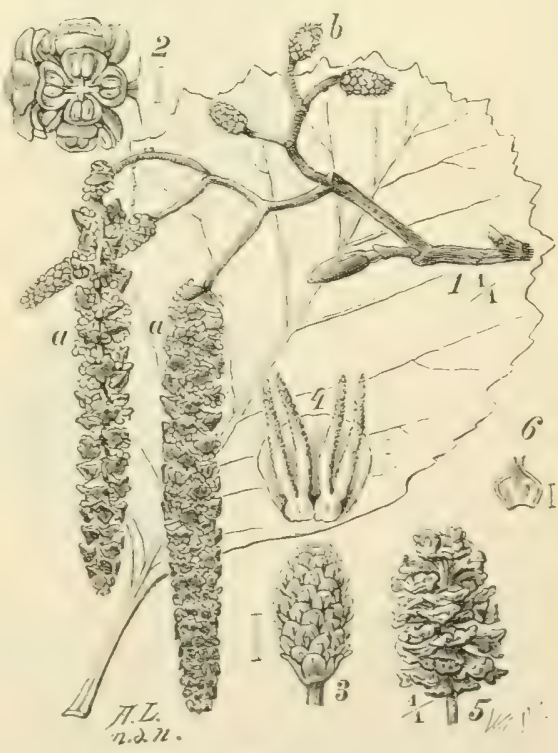

Fig. 273.

Alnus glutinosa. drei Wochen früher als die Schwarzerle (Ende Februar). Blütenbau wie bei A. glutinosa, die Kätzchenzapfen jedoch leiner. Früchte mehr plattgedrïclit, stärker geflügelt. Hat ein grosses Accomodationsiermögen an feuchten und trocknen Standort, kommt selbst auf Ödländereien vor. Liebt hartes, kalkhaltiges Mrasser. Bewohnt Niederungen und Vorberge, südlich mehr im Gebirge. 
Alnus pubescens Tausch. Bastard glutinosa $\chi$ incana. Alnus viridis DC. Grünerle, Alpenerle. Niedriger Stamm. o und $f$ Kätzchen an verschiedenen Zweigen. Blätter ciförmigs, spitz, doppelt sesägt. Im Schwarzwald und in der Knicholzregion der Alpen.

Betula rerucosa Ehrh. (syn. B. alba auct. non L.) gemeine

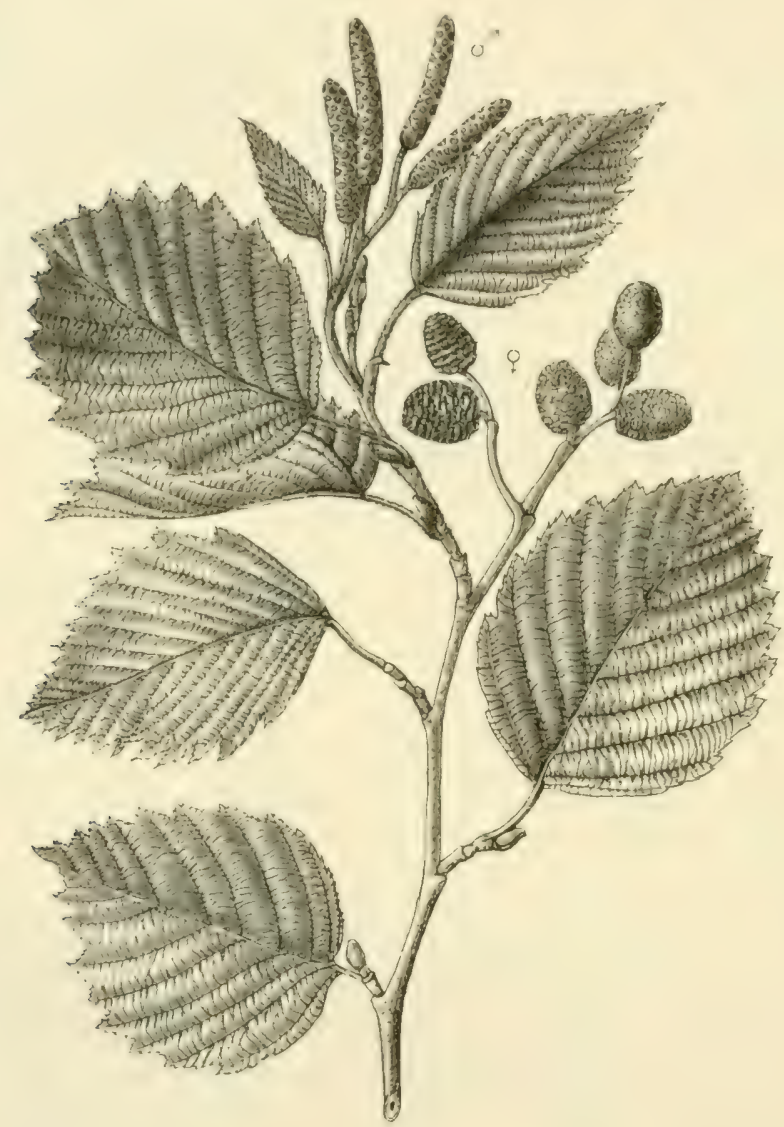

Fig. 274 .

Alnus incana (im August).

Birke, Weiss- Rauh- Harzbirke (Fig. 275). Schlanker, 22-25 m hoher Baum, mit feinen herabhängenden Ästen. Naserbildungen häufigs. Ausschlasvermögen gering. Die o Kätzchen überwintern am Ende der Zweige (Fig. 275, I, b), jede Kätzchenschuppe trägt drei of Blüten und zwei Vorblätter (Fig. 272, $\propto, \beta$ ). Das vierblättrige Perianthium meist reduciert, so dass oft nur je ein Perigonblatt vorhanden ist, vor dem die zwei gespaltenen Staubblätter stehen. Die $\subseteq$ Kätzchen (Fig. 275, I a) erscheinen im April oder Anfang Mai. In der Achsel jeder Deckschuppe stehen 
drei $\subseteq$ Blüten (Fig. 275, 3) mit den Vorblättern « und $\beta$. Das Deckblatt nnd die beiden Vorblätter verschmelzen zu einer dreilappigen schuppe, welche sich bei der Reife 14 lon der Kätzchenspindel loslöst. I)ie Früchte (5) sind sehr klein, breit geflügelt. Fruchtreife Juli, August, Abfall erst später, Bodenansprüiche sehr gering. Grosses Accomodationsvermögen an verschiedene Bodenfeuchtigkeit.

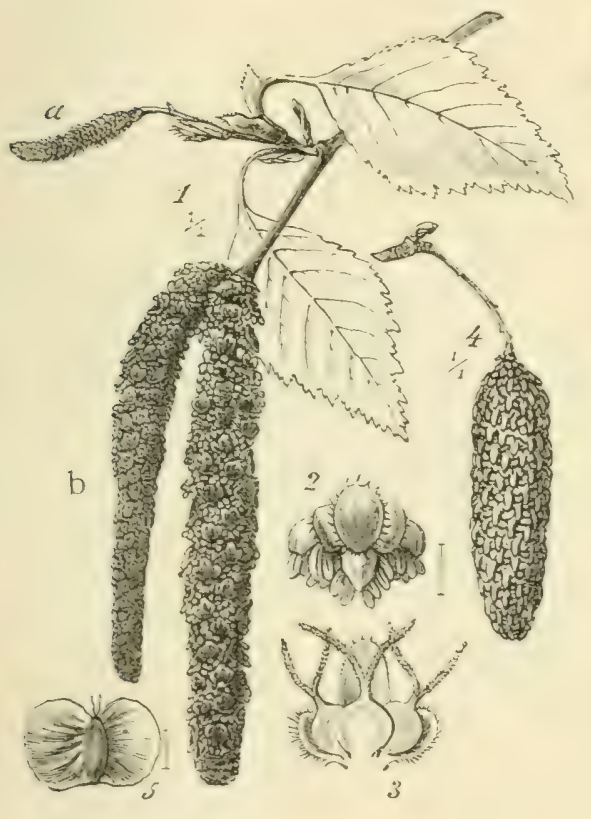

Fig. 275 .

Betula verrucosa. (W.)

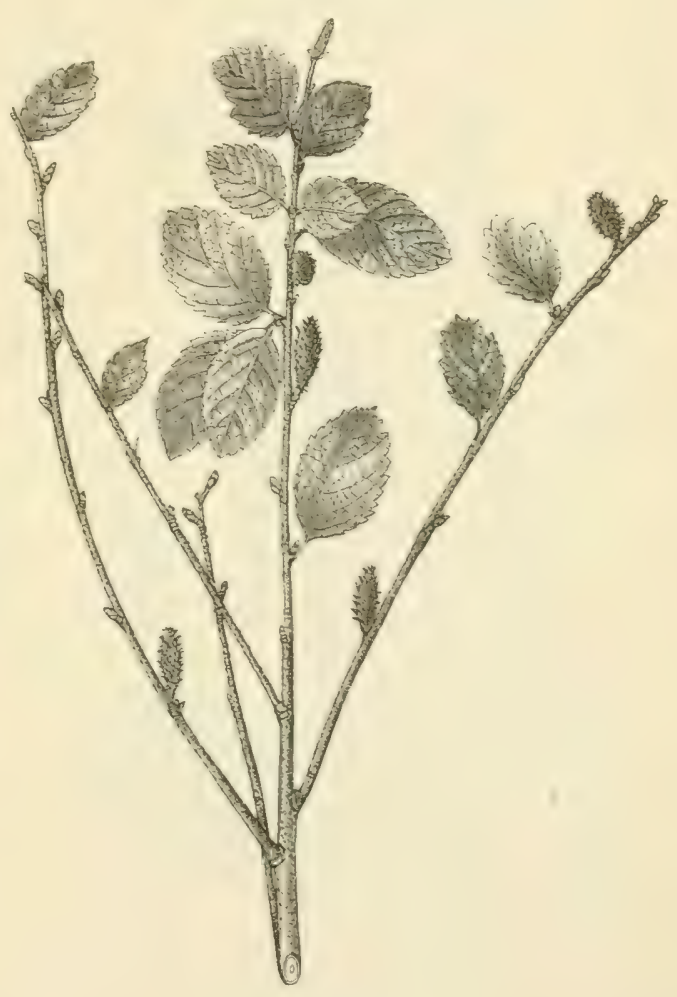

Fig. 276 .

Betula fructicosa.

Unempfindlich gegen atmosphärische Einflüsse. Ebenen, Vorberge, auch Gebirge.

Betula pubescens Ehrh. (syn. B. alba L., B. odorata Bechst., B. tomentosa Reitter, B. carpathica Willd.) Haar- Ruch- Schwarzbirke. Nordische Birke. Der rorigen Art sehr ähnlich, Zweige behaart, straffer. Früchte etwas dunkler, Flügel höchstens so breit als das Nüsschen. Beansprucht mehr Feuchtigkeit als B. verrucosa, kommt auch noch gut auf Noorboden fort. Variiert stark.

Betula lenta L. Blätter ähnlich wie bei Carpinus Betulus. Zweige nicht behaart, beim Zerkauen stark aromatisch. Holz ron hohem specifischen Gewicht. Diese nordamerikanische Art gedeiht auf frischem Boden 
auch in Deutschland. Sic wird zu forstlichen Anbauversuchen verwendet. Strauchbirken: Betula fructicosa Trautv. (syn. B. humilis Schrank). Kätzchen sehr zahlreich, Blätter (Fig. 276) $10-30 \mathrm{~mm}$ lang. Auf Torfmooren, sumpfigen Wiesen, in Gebirgen und in Nordeuropa. Betula nana, nicderliegender Strauch mit rundlichen, grobgekerbten Blättern. Torfmoore Westpreussens, Gebirge.

2. Fam. Corylaceac.

Jede einzelne Frucht ist von einer Blatthülle (Cupula) umgeben, die

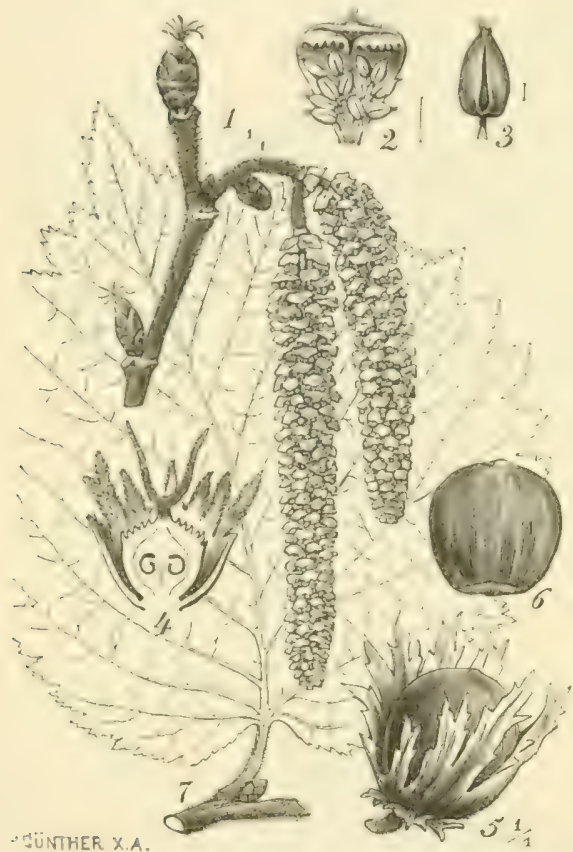

Fig. 277 .

Corylus avellana. (WV.)

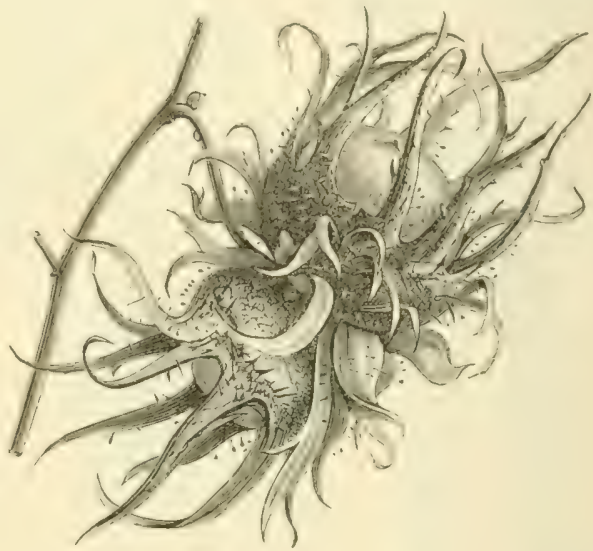

Fig. 278.

Cupula und Nuss von Corylus colurna. (DN.)

aus den Vorblättern $\alpha \alpha^{\prime} \beta^{\prime}$ resp. $\beta \alpha^{\prime} \beta^{\prime}$ (Fig. 272) besteht. Perianth der \& Blüte fehlt, bei der 올 Blüte vorhanden, doch rudimentär. G(2).

Corylus avellana L. Gem. Haselnuss (Fig. 277). Strauch, selten baumartig. Blüht Februar, März. Die ơ Kätzchen langgestreckt, überwintern frei (Fig. 277, I). In der Achsel jedes Deckblattes nur eine Blüte (dic Mittelblüte) mit vier tiefgespaltenen Staubblättern (Fig. 2\%テ, 2) und zwei Vorblättern $(\alpha \beta)$. Die o Blütenstände gleichen Laubknospen, sind jedoch an den hervorstehenden roten Narben zu erkennen (Figs. 277, 1). In der Achsel der Deckschuppen zwei $\odot$ Blüten mit je drei Vorblättern $\left(\alpha \alpha^{\prime} \beta^{\prime}\right.$ und $\beta$ c' $\beta^{\prime}$ ), welche zur Cupula werden. Beansprucht kräftigen Boden, kommt besonders an Waldrändern vor.

Corylus colurna, Türkische Hasel (Fig. 278). C. tubulosa, Lambertsnuss. Carpinus Betulus L. Hainbuche, Weissbuche, Hagebuche, Horn- 
baum (Fig. 279). Gewöhnlich nicht höher als 20-23 m. Stamm spannrückiss. Wird häufigs schon mit 120 Jahren wipfeldürr. Ausschlagrermögen vorzüglich. Blïht Ende April, Mai, anfangs Juni. Die 3 Kätzchen locker, walzenförmiç (Fig. 279, I), jede Deckschuppe trägt nur eine o Blïte mit 4-IO tiefgespaltenen Staubblättern, Vorblätter und Perianth fehlen. Dic q Kätzchen an der Spitze beblätterter Triebe (Fig. 279, I), erscheinen mit Laubausbruch. In der Achsel des Deckblattes zwei $q$ Blüten (Fig. 279, 4, 5) mit je drei Vorblättern, welche die dreiteilige Cupula bilden (Fig. 279, 6). Frucht riefig, vom rudimentären Perigon gekrönt. Keimung erfolgt erst im zweiten Frühjahr. Mannbar im 30-40. Jahr. Die Hainbuche liebt mehr das Tiefland und die Hügelregion, weniger das Gebirge. Sie ist wenig begehrlich, sehr frosthart, empfindlich gegen Hitze.

Carpinus duinensis im südlichen Ungarn und der adriatischen Zone. Cupula unsymmetrisch.

Ostrya carpinifolia Scop. (syn. Ostrya vulgaris Willd.). Hopfenbuche genannt wegen den hopfenartigen \& Kätzchen. $\mathrm{Cu}$ pula sackförmig. Ungarn, südliche Voralpen, adriatische Zone. Ostrya virginica. Nordamerika.

3. Fam. Cupuliferae.

Blütenstände erscheinen erst mit dem Laube, stehen in der

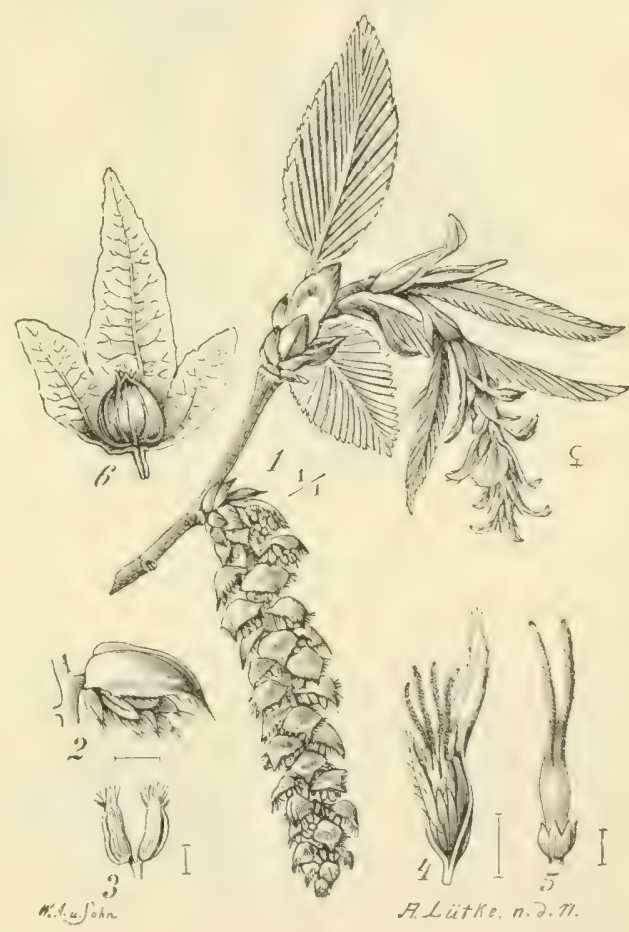

Fig. 279.

Carpinus Betulus. (W.) Achsel diesjähriger Blätter. Die Cupula verholzt, umgiebt cin bis mehrere Blüten resp. Früchte. Die Cupula hier eine Achsenwucherung und Blattbildung, verschieden ron den Vorblättern der Betulaceen und Corylaceen. $P$ bei of und $q$ Blüte vorhanden. $G \overline{(3-9)}$.

Fagus silvatica L. Gemeine Buche, Rotbuche (Fig. 280). Baum I. Grösse, bei freiem Stand sich IO-I5 $\mathrm{m}$ über der Erde verzweigend. Krone dichtblätterig. Herzwurzel. Ausschlagvermögen gering, Stockloden. VTird 200 Jahre alt und darüber. Blütezeit Nai, fast gleichzeitis mit der Belaubung. Die of Blüten stehen in Büscheln (Fig. 28o, I a): $\mathrm{P}$ fünf- bis sechs-spaltig, A 8 -I2. Je zwei 으 Blüten stehen zusammen in Form gestielter Köpfehen (Fig. 280, I b) umgeben von der mit zalnlreichen linealen Blättchen bedeckten Cupula. $G_{(3)}$, umhüllt von einem $4-6$ zijfeligen Perigon. 


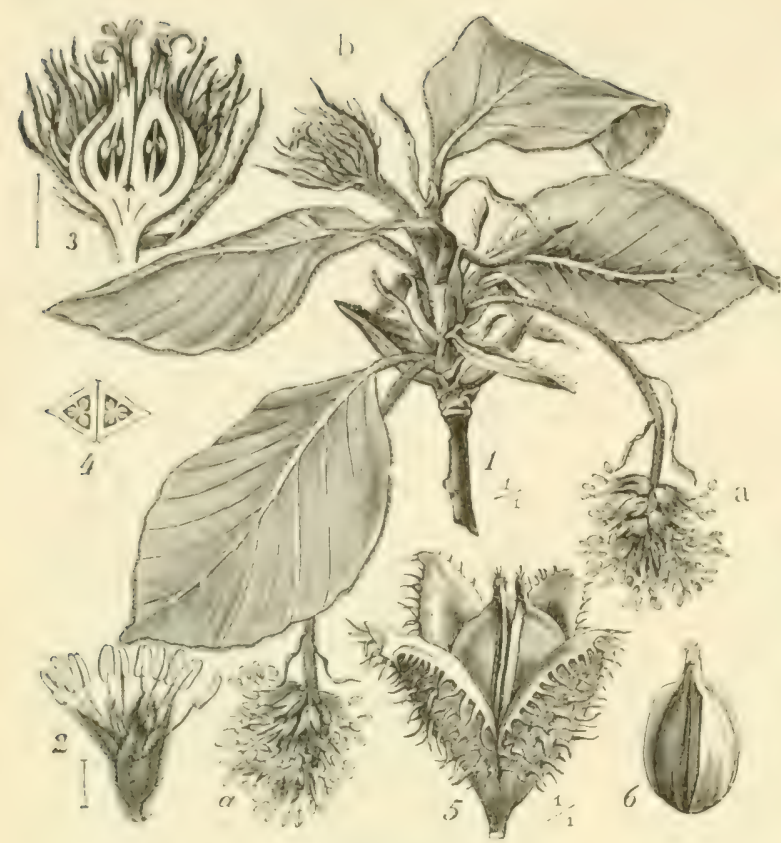

Fig. 2 So.

Fagus silvatica. (IV.)

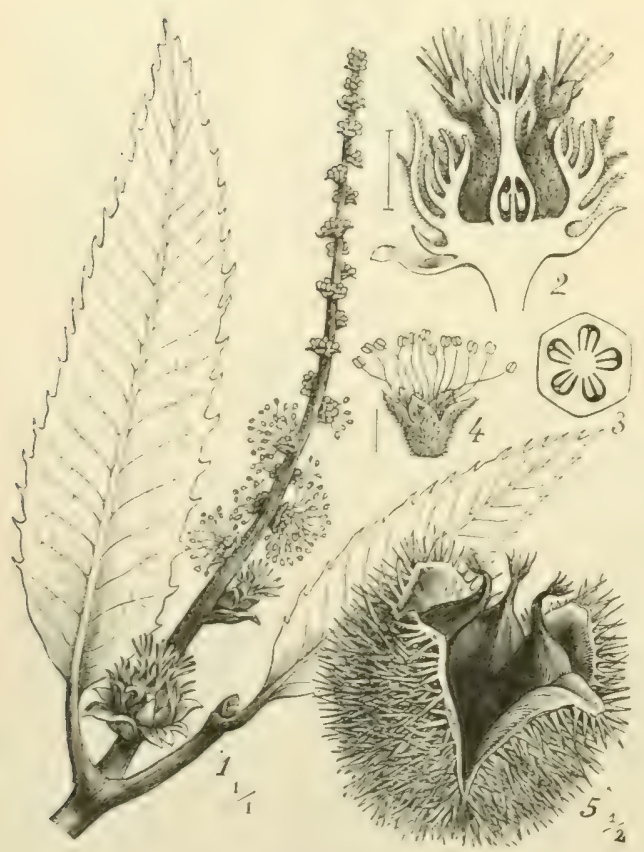

Fig. 28I.

Castanea vesca. (W.)
Dic Cupula schliesst die lirüchte ein (vgl. Figs. $280,3-5)$. Dic Früichte (Bucheln, Bucheckern) dreikantig, braun, glatt, bei der Reife einsamig (Fig. 280, 6), keimen im Frühjahr nach 4-6 Wochen. Mannbarkeit im freien Stande mit 40-50 Jahren, sonst mit $60-80$ Jahren.

Leidet unter Spätfrösten und Hitze. Verlangt frischen, kalkhaltigen, doch nicht besonders tiefgründigen Boden, verträgt keine stagnierende Nässe. Nicdere Gebirge, Vorberge und Ebene.

Castanea vesca Gaertn. (syn. C. vulgaris Lam.). Echte oder essbare Kastanie, Edelkastanie (Fig. 28I). Baum II. Grösse. Kätzchen aufrecht, lang, oben ơ unten \& (Fig. 28 I, I), einige ganz 0 . $G \overline{(6)}$, auch mehr oder weniger. Cupula ähnlich wie bei Fagus, vierklappig (Fig. 28I, 5). Früchte der Rosskastanienfrucht ähnlich, jedoch essbar, nicht bitter schmeckend. Meidet häufig Kalkboden, bedarf lockere, mineralisch kräftige Böden. Leidet sehr durch Früh- und Spätfröste, verlangt mildes Klima.

Quercus I. Sektion: Lepidobalanus. Narben kurz, glatt. Schuppen des Fruchtköpfchens angedrückt, grau. Schale der Eichel dünn, inwendig kahl, ohne einen Rest der Scheidewand, Samenreife einjährig.

Quercus pedunculata 
Ehrh. (syn. Q. robur a L.). Stieleiche, Sommereiche, Früheiche (Fig. 282 und 283 c). Baum I. Grösse, in der Regel nicht über $35 \mathrm{~m}$ hoch, ausnahmsweise über $50 \mathrm{~m}$ hoch. Äste unregelmässig gekrümmt, Wipfelzweige spitz, aufrecht. Pfahlwurzel. Wird sehr alt, bis 2000 (?) Jahre. Stockausschlag reichlich. Am Stamme bilden sich bei Freistellung Lichtreiser. Blüht Anfang Mai. Die c Blüten stehen sehr entfernt an herabhängenden Kätzchen (Fig. 2\$2, I $a b, 2$ ), jede Deckschuppe mit nur einer Blüte. $\mathrm{P} \quad 5-7$ blättrig, A 4-I2. Die \& Blüten sitzen zu I-5 auf einem langen Stiel an der Spitze der jüngsten Triebe (Fig, 282, I c, $3,4)$. P oberständig, unscheinbar (Fig. $2 \AA_{2}, 4, G_{3}$.

Die aus schuppenförmigen Blättchen gebildete Cupula umschliesst

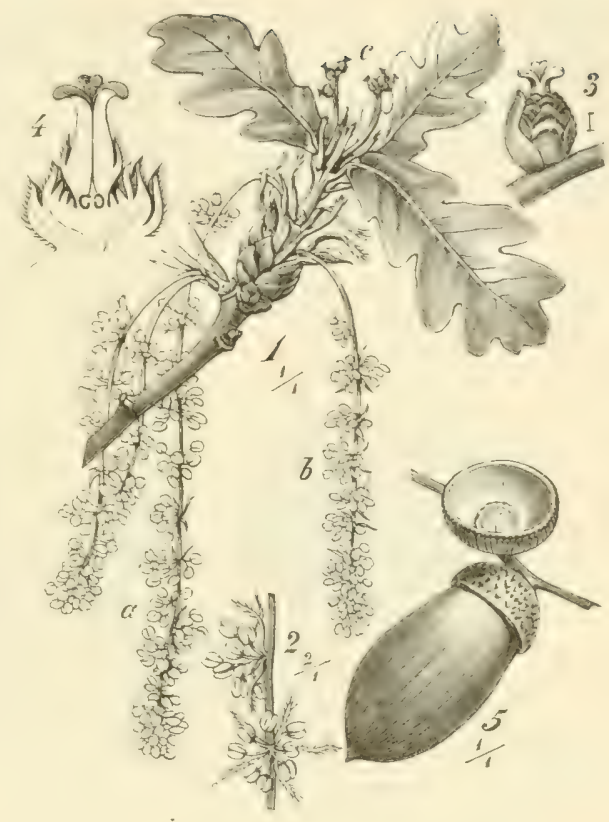

Fig. 282 .

Quercus pedunculata.

(IV.)

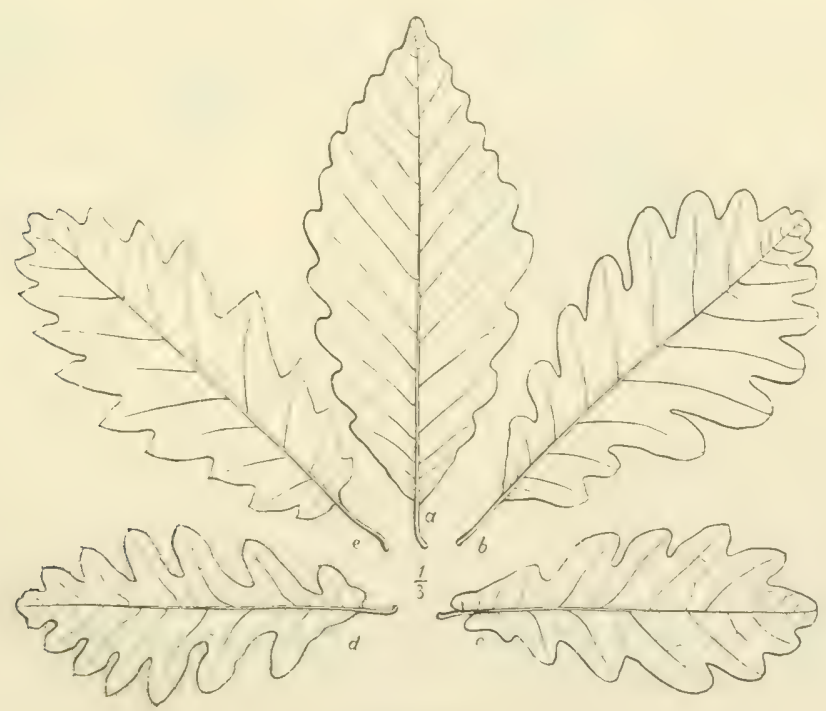

Fig. 283 .

Blätter von: a Quercus Prinos, b sessiliflora, c pedunculata, d pubescens, e cerris. (DN.)

die Frucht anfanıs vollständig, später bildet sie das Näpfchen. Früchte (Eicheln) einsamige Nüsse, länglich, an frischen Exemplaren mit grünlich- 
braunen Längsstreifen. Reife Ende September, Anfang Olitober. Keimung im Frühjahr nach +6 Wochen. Mannbarkeit mit 70 Jahren.

Empfindlich gegen Spätfröste, schlägt jedoch spät aus. Verlangt guten, tiefgründigen, warmen Boden. Erträgt ziemlich vicl Bodennässe. Ebene, Flussniederungen bevorzugt.

Quercus sessiliflora Sm. (syn. Q. robur Mill, Q. robur $\beta$ B.). Trauben-, Winter- oder Steineiche (Fig. 283 b). Baum I. Grösse, schlanker und durchschnittlich etwas weniger hoch als die vorige Art, Krone im

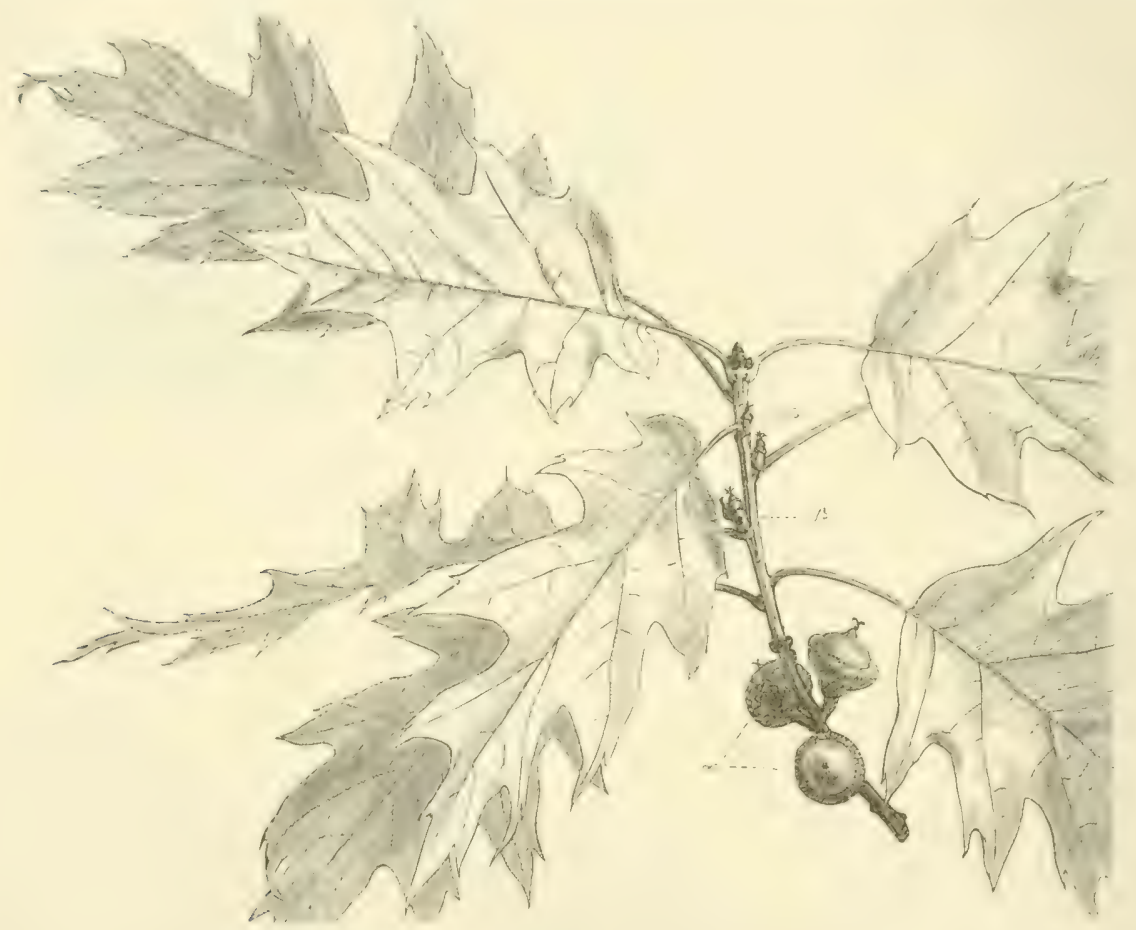

Fig. 284 .

Quercus rubra, Zweijähriger Spross, mit einjährigen ( $\beta$ ) und zweijährigen ( $\iota)$ Früchten im Juli. (DN.).

Umriss eiförmig, Äste gleichmässiger-verteilt. Die @ Blüten ohne Stiel. Die Eicheln sind meist kürzer und ohne Streifen, das Spitzchen am Scheitel mehr abgerundet, sie variieren jedoch ebenso wie die Eicheln von $Q$. pedunculata sehr bedeutend. Laubausbruch und Blütezeit Io bis I4 Tage später als bei der Stieleiche. Ausschlagvermögen ausgezeichnet. Etwas weniger begehrlich als $Q$. pedunculata, auch auf Buntsandstein gut gedeihend. Im Kalkgebirge durch die Stieleiche ersetzt. Hügelland. Hochebenen.

Quercus pubescens Willd. (Fig. 283 d). Steht Q. sessiliflora sehr nahe, unterscheidet sich von ihr durch die Behaarung von Blättern, Knospen, Zweigen. Südlicheres Europa. 
Quiercus hungarica. Ungarn, südöstl. Europa. Q. Ilex, immergrüne Stecheiche. Mittelmeergebiet. Q. Prinos (Fig. 283 a), alba, obtusiloba, macrocarpa; Nordamerika.

II. Sektion: Erythrobalanus. Narben verlängert, griffelförmig, lineal, oft zurückgekrümmt. Schuppen des Fruchtnäpfchens mit breiter

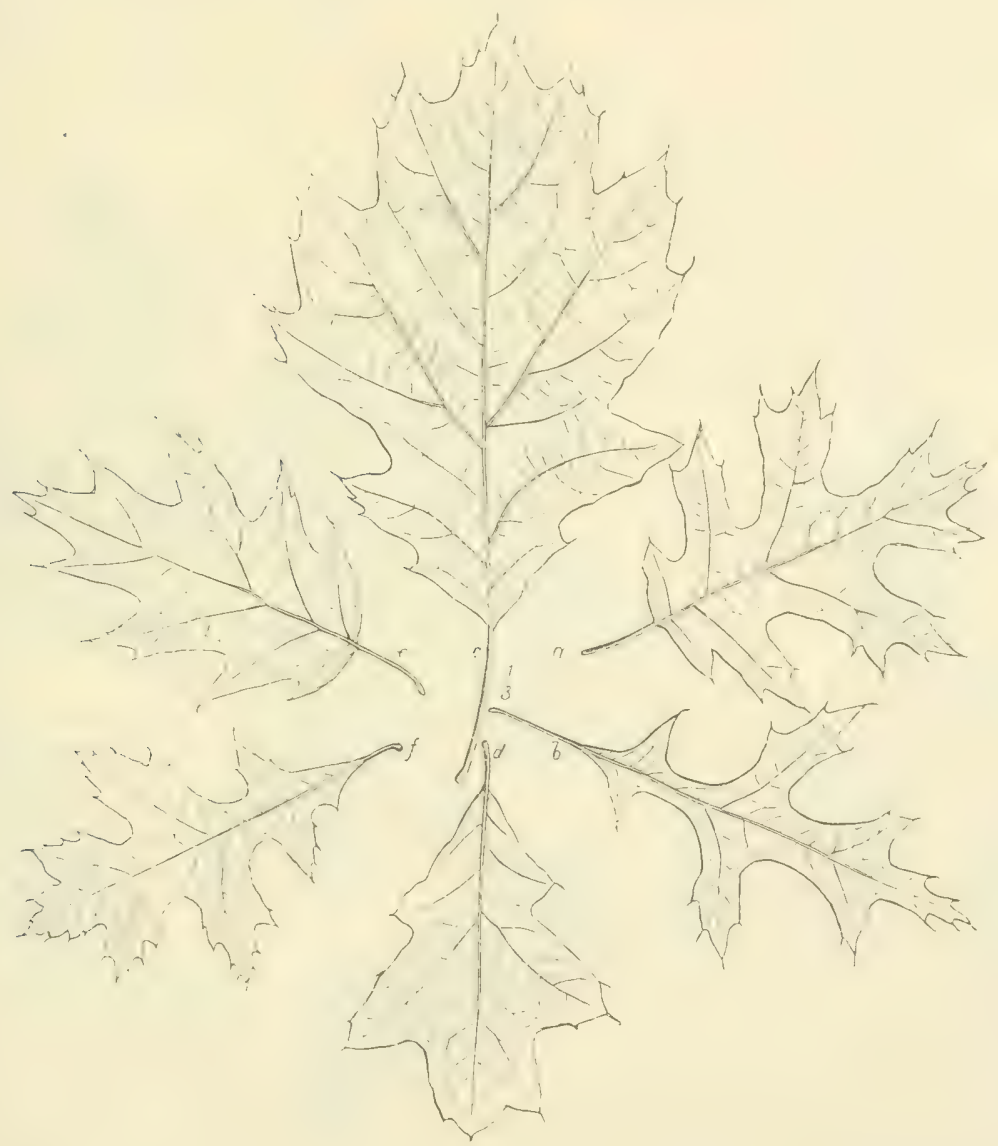

Fig. 285 .

Blattform von: a Quercus coccinea, b falcata, c tinctoria, d ilicifolia, e rubra, $f$ palustris. (DN.)

Basis, angedrückt, braun. Schale der Eichel dick, inwendig filzig, mit drei falschen Scheidewänden. Samenreife zweijähriş. Alles Nordamerikaner.

Quercus rubra L. Roteiche (Fig. 284). Baum bis $26 \mathrm{~m}$ hoch. Blätter im Herbst intensiv rot gefärbt. Eicheln rund, rotbraun. Stammt aus Nordamerika. In Deutschland mit Erfolg angebaut, bedarf jedoch humosen, frischen, tiefgründigen Boden.

Quercus palustris DR. Sumpfeiche (Fig. 285f). Q. coccinea (Fig. 285 a). Q. falcata (Fig. 285 b). Q. tinctoria (c). Die Rinde, sowie 
das Holz enthalten einen gelben Farbstoff, Quercitrongelb. Q. ilicifolia (d). Q. nigra, Blätter keilförmig, an der Spitze leicht gelappt.

Q. imbricaria (Fig. 286a), Q. phellos Q. sericea mit ungelappten Blättern.

III. Sektion: Cerris. Narben pfriemenförmig aufrecht oder zurücksebosen. Schuppen der Fruchtnäpfehen lineal, zurückgebogen oder ab-
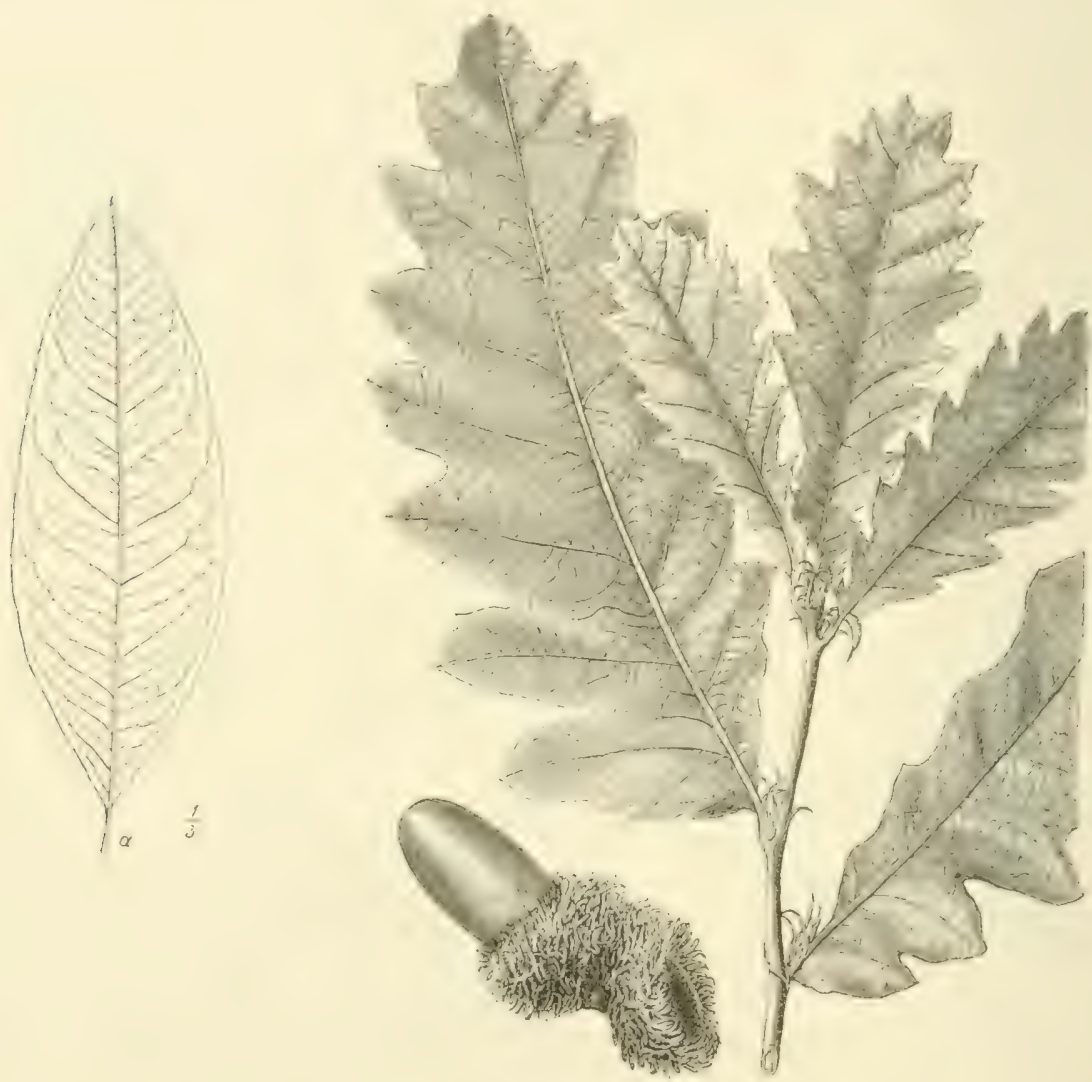

Fig. 286.

Blatt von Quercus imbricaria. (DN.)

Fig. 287 .

Quercus cerris.

stehend (Fig. 287), Eicheln mit dünner Schale, ohne Scheidewände. Samenreife zweijährig.

Quercus cerris L. (syn. Q. austriaca Willd.). Zerreiche, Burgunder-, Österreichische Eiche (Fig. 287). Baum II., selten I. Grösse, mit dickem Stamm und breitästiger Krone. Laubausbruch Mitte April, Anfang Mai. Eichel sehr schlank, mit rauh anzufühlender Oberfläche. Verlangt wärmeres Klima: Südösterreich, Ungarn, Mittelmeergebiet. Holz nicht so wertvoll als bei $Q$. pedunculata und sessiliflora. 
Q. suber, Korkeiche, Hauptsächlich in Spanien und Algier. Liefert den Flaschenkork. An Q. infectoria bilden sich durch Cynips gallae tinctoriae Gallen (Türkische Galläpfel, Knoppern).

\section{§ 76. 3. Ordnung. Juglandiflorae.}

Blüten eingeschlechtig, monöcisch. Blütenstände kätzchenartig. ơ Blüten $\mathrm{P}_{4}-\mathrm{OA}_{4}-\boldsymbol{\sim}$, \& Blüten $\mathrm{P}_{4}-\mathrm{OG}(2)$. Fruchtknoten einfächerig mit einer grundständigen geraden Samenknospe. Frucht gewöhnlich eine Steinfrucht. Endosperm fehlt.

I. Fam. Juglandacea e, Nussbäume.

Blätter spiralig gestellt, unpaarig gefiedert, Nebenblätter fehlen, reich an aromatischen Stoffen. Das Mark ist bei Juglans und Pterocarya gefächert, bei Carya dagegen nicht unterbrochen (Fig. 289).

Juglans regia L. Gem. Wallnussbaum (Fig. 288). Baum III. bis II. Grösse, mit gutem Ausschlagvermögen. Pfahlwurzel. Belaubt sich und blüht im Mai. Die of Kätzchen stehen an der Basis junger Triebe. Die Staubblätter sind auf eine Deckschuppe hinaufgewachsen (Fig. 288, 2), welche noch zwei Vorblätter und drei Perigonblätter trägt. A $6-20$. Die ㅇ Blüten vollständig um-

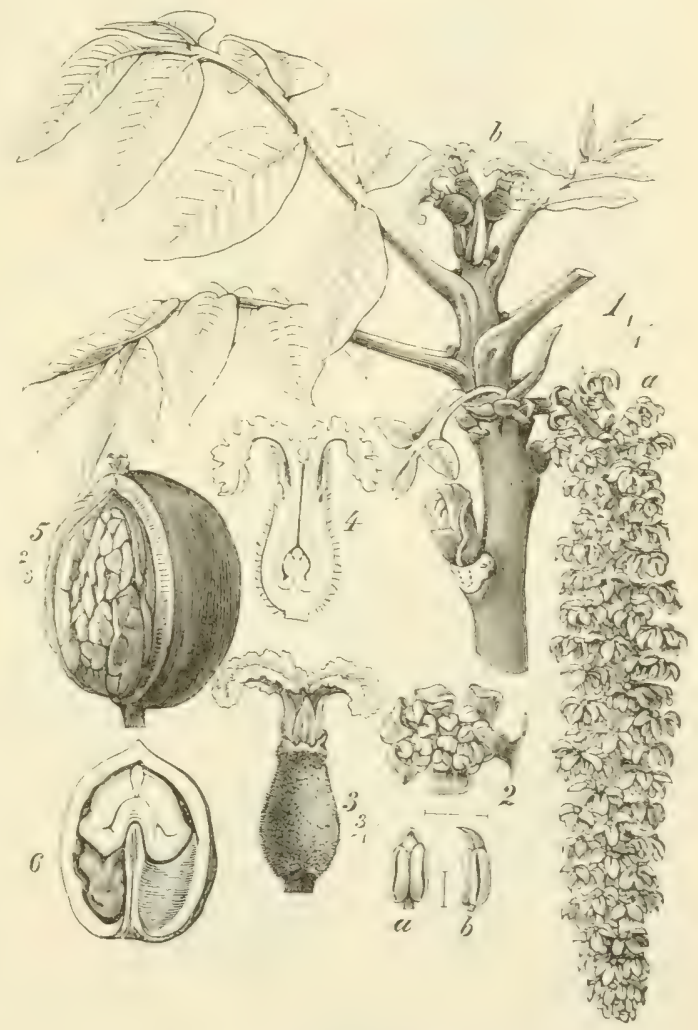

Fig. 288.

Juglans regia. (W.) geben von zwei verwachsenen Vorblättern, aus denen das vierblättrige Perigon und zwei dicke breite Narben hervorstehen (Fig. 288, 3, 4). Frucht eine Steinfrucht: die essbare Nuss ist der Embryo. Leidet unter Frost, verträgt keinen Bestandesschluss, als Waldbaum daher nicht zu verwenden.

Juglans nigra L. Baum II. Grösse mit sehr dickem Stamm. Früchte mit schwarzem, sehr unebenem Steinkern. Keimen spät, junge Pflanzen reifen daher nicht genügend aus und werden leicht durch Frost beschädist. Dic Blätter mit 13 - 2 I gesästen, nicht beharten Fiederblättchen. Die jüngeren Zweige sind graubraun behaart. Kann in I)eutschland mit gïnstisem Erfoles auf kiräftisem, mildem Boden ansebaut werden. Nordamerika. 
Juglans cinerea I. Ähnlich wie Juglans nisra, die Blätter behaart.

bei der Gattung Carya (Hickorynuss) fehlt sowohl in der of als of Blïte das Perigon oder ist nur durch ein Blättchen angedeutet. Alle Arten in Nordamerika heimisch.

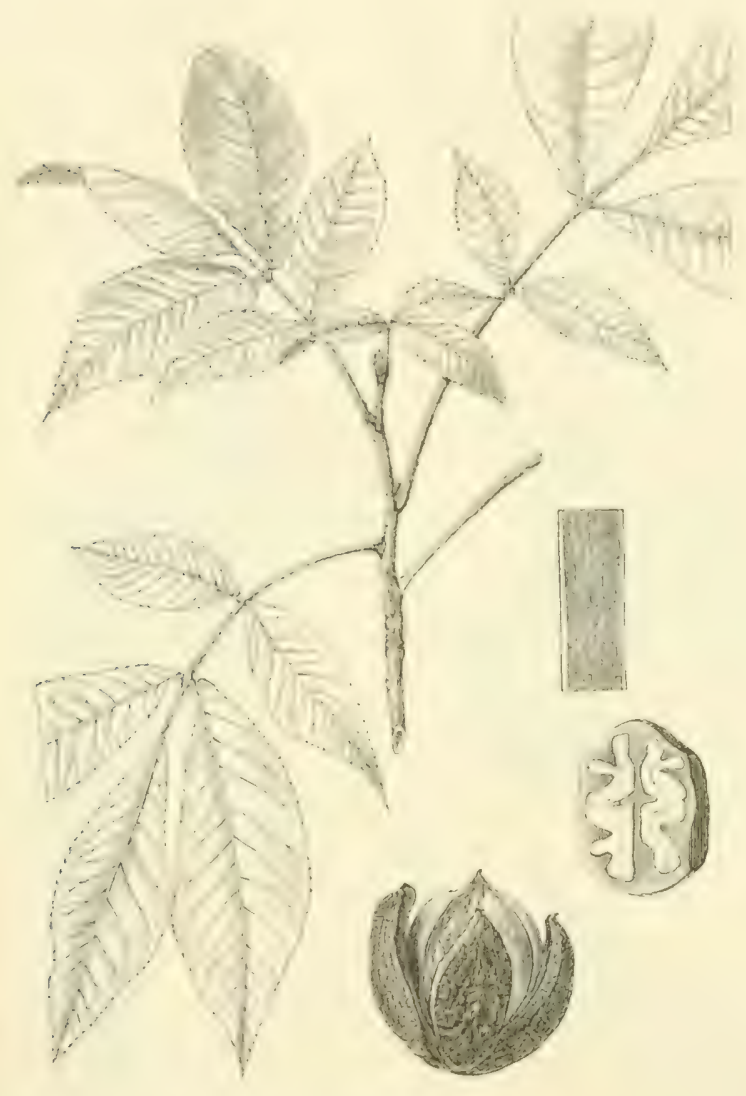

Fig. 289.

Carya alba.

( a l la alla Xitt Weisse Hickory (Fig. 289). Blitter mit fünf Fiederblättchen, von denen die drei oberen am grössten sind. Blattrand stumpf gesägt, immer behaart. Junge Triebe behaart. Endknospen sehr gross, länglich, mit cinigen abstehenden, braun behaarten Schuppen. Nuss I- I,5 cm lang, 4-6kantig, blassugelb, Kern schmackhaft.

Carya amara Nutt. Dic Bitternuss zeigt 7-I I Fiederblättchen, nur die Rippen und Blattstiele sind behaart. Knospen nackt, auffallend gelb gefärbt. Nuss ohne Rippen, Schale dünn, Kern bitter. Carya tomentosa Nutt. Spottnusshickory. Hat sieben lanzettliche, unterseits rauhhaarige Fiederblättchen, deren Randzähne nicht nach vorn gelrümmt sind.

Knospen kurz und dick, Knospenschuppen drüsig, filzig, junge Triebe völlig behaart. Nuss ziemlich gross, rundlich, dickschalig.

Carya porcina Nutt. Die Blätter zeigen 5-7 kahle Fiederblättchen. Die Zähne des kahlen Blattrandes sind nach vorwärts gekrümmt. Die Knospen sind kurz, eiförmig, mit braunen, kahlen Schuppen versehen. Junge Triebe unbehaart. Die Nüsse ähnlich wie bei Carya alba, doch dickschaliger und etwas kleiner, die Rippen erreichen meistens nicht das untere Ende der Nuss.

Carya sulcata Nutt. Fiederblättchen 4-9, die nach vorn gerichteten Zähne des Blattrandes behaart. Knospen ähnlich wie bei alba, junge 
Triebe jedoch nicht behaart. Die Frucht gross, länglich, der Kern mit vier Längsrippen versehen.

Die Caryaarten bedürfen sehr guten, frischen Boden, sind auch gegen Frost empfindlich. Sie liefern jedoch ausserordentlich wertvolles Holz, weshalb sie an geeigneten Stellen zu Anbauversuchen zu empfehlen sind. Carya porcina und sulcata haben sich in Norddeutschland nicht bewährt.

2. Fam. Myricaceae.

Blätter nicht zusammengesetzt, höchstens gelappt, Zweige mit Wachsdrüsen. Blüte eingeschlechtig, in kätzchenartigen Ähren. Myrica Gale, Gagelstrauch auf Torfmooren. Myrica cerifera, Nordamerika.

\section{4. Ordnung. Urticiflorae.}

Blüten meist eingeschlechtig, doch auch zwitterig. Blütenstände dicht gedrängt. P $4-5$ einfach, grün. A $4-5$ über den Perigonzipfeln. G(1-2). Frucht eine Nuss mit einem endospermhaltigen Samen, seltener eine Steinfrucht.

I. Fam. Ulmac ca e.

Meist $₫$ Blüten. $\mathrm{P} 4-6$. A 4-I 2 G(2) mit zwei Narben. Fruchtknoten meist einfächerig.

I. Unterfam. Ulmoideae. Frucht eine geflügelte Nuss, Staubbeutel nach aussen gewendet.

Ulmus campestris Sm. et auct., non L. (syn. U. glabra Mill., U. campestris « genuina Aschers., U. campestris a vulgaris Döll.). Feldrüster, Rotrüster, Korkulme (Fig. 290). Baum I. Grösse mit geradem Stamm, dicht belaubter Krone,

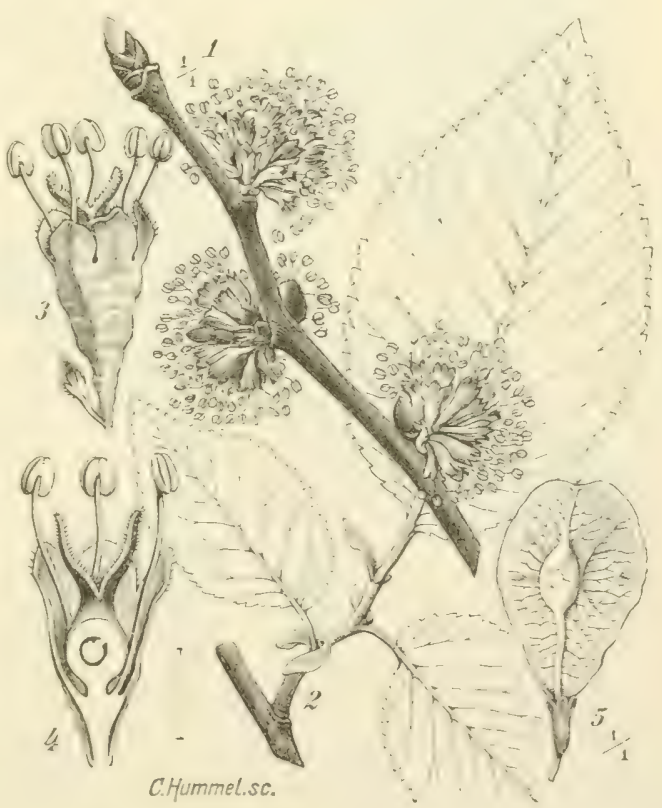

Fig. 290.

Llnus campestris. (WW.) oft besenförmig aufrecht stehenden Ästen. Rotrüster nach der Farbe des frischen Kernholzes genannt. Sehr lebhaftes Ausschlagvermögen, auch Wurzelbrut. Blüht vor Laubausbruch (März, April). Blüten in kleinen Knäueln (Fig̣. 290, I), sehr kurz gestielt. Fruchtreife Ende Mai, Anfang Juni. Frucht mit sellitichem Filiggel, das Nüsschen excentrisch in der Nähe des oberen Randes. Keimung zwei 
bis drei Wochen nach Aussaat. Nannbarkeit mit 30-40 Jahren. Samenjahre alle $2-3$ Jahre. Ulmus campestris var. suberosa an den Korkleisten der jungen Zweige kenntlich.

Die Ulme macht grosse Ansprüche an die mineralische Bodenbeschaffenheit. In südlichen Teilen Europas die herrschende Art, in Deutschland mehr dic Stromauen bewohnend.

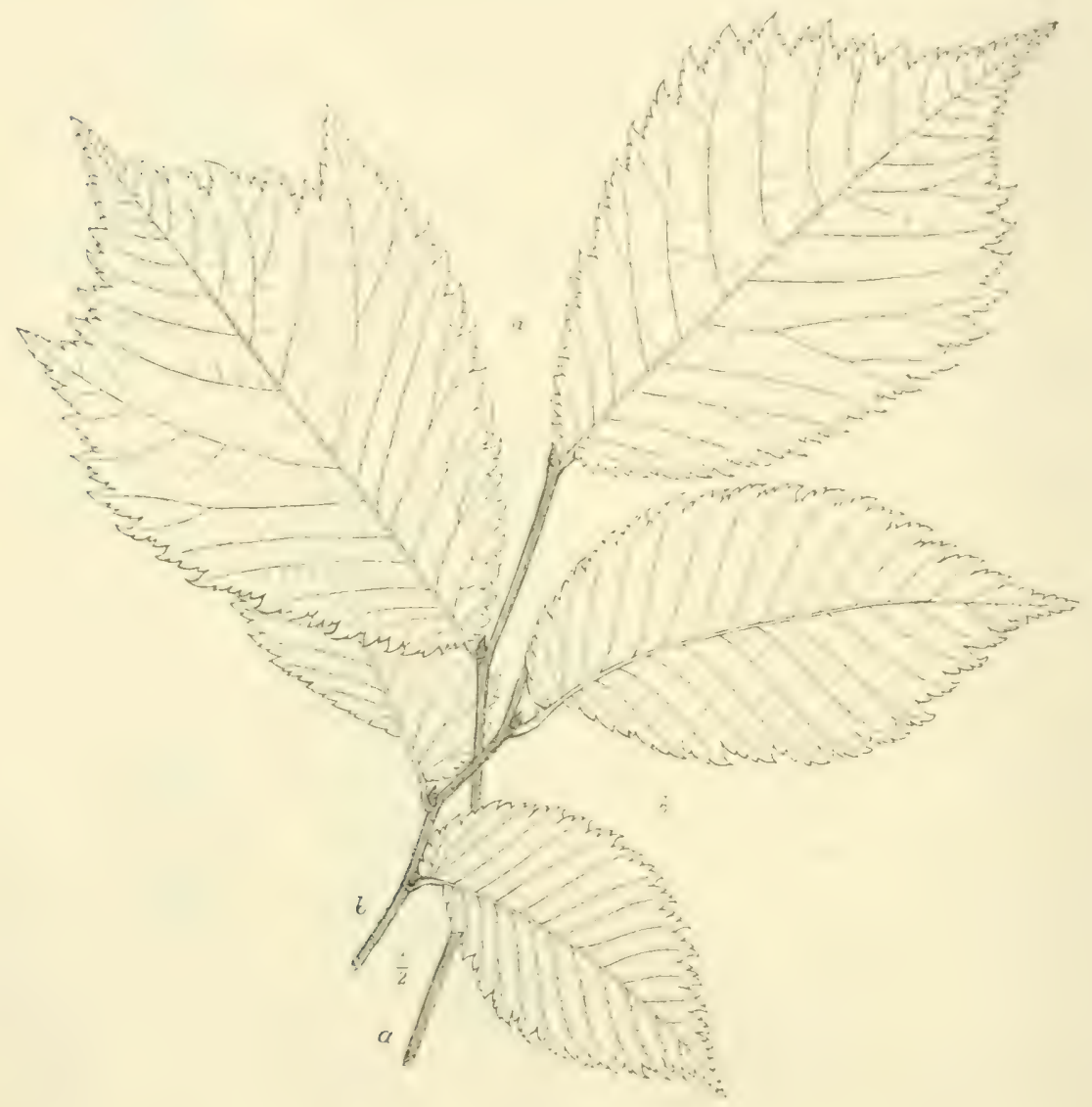

Fig. 29I.

a Ulmus montana. b Ulmus effusa. (DN.)

Ulmus montana Sm. (syn. U. campestris L., U. campestris $\beta$ montana Aschers. Döll., U. campestris var. scabra Pokorny) Berg- oder Haselrüster (Fig. 29I a). Holz bei der Fällung im Kern hell, erst später sich bräunend. Nüsschen in der Mitte des grünlichen Flügels. Samen liegen meist ein Jahr über. Es ist fraglich, ob die Bergrüster auch mit Korkleisten vorkommen kann. Nordwestliches Europa, Skandinavien, in Deutschland mehr im Gebirge, sonst wie U. campestris. 
Ulmus effusa Willd. (syn. U. ciliata Ehrh., U. pedunculata Foug., U. octandra Schk.) Flatterulme, Flatterrüster, Bastrüster (Fig. 29I b) Baum II-I. Grösse, mit schlankem Stamm, breitästiger unregelmässiger Krone. Blüten langgestielt, Früchte kleiner, am Rande gewimpert. Sogleich nach der Reife (Anfang Juni) keimfähig. In den nordöstlichen Teilen von Deutschland häufiger, wenig oder gar nicht im Gebirge.

Ulmus americana Willd. Früchte kleiner als bei $U$. effusa. Nordamerika.

2. Unterfamilie Celt o id e a e, Steinfrucht. Antheren nach innen gewendet.

Celtis australis, Zürgelbaum. Blätter sehr schief, eilanzettlich. Blumenblätter getrennt. Steinfrüchte erbsengross. Liefert das sog. Triester Holz. Nittelmeergebiet.

Zelkowa Keaki (syn. Z. acuminata [Lindl] Planch., Planera Kaki Hort.) Blätter ulmenartig, doch kleiner. Triebspitzen junger Pflanzen erfrieren bei uns, trotzdem zu weiteren Anbauversuchen verwendbar. Stammt aus den Gebirgen Japans.

2. Fam. Liticaceac.

Blüten in Knäueln, eingeschlechtig. Fruchtknoten nur mit einem Griffel. Samenknospen gerade. Ohne Milchsaft. Urtica urens und dioica, Brennessel. Parietaria erecta. Boehmeria nivea,

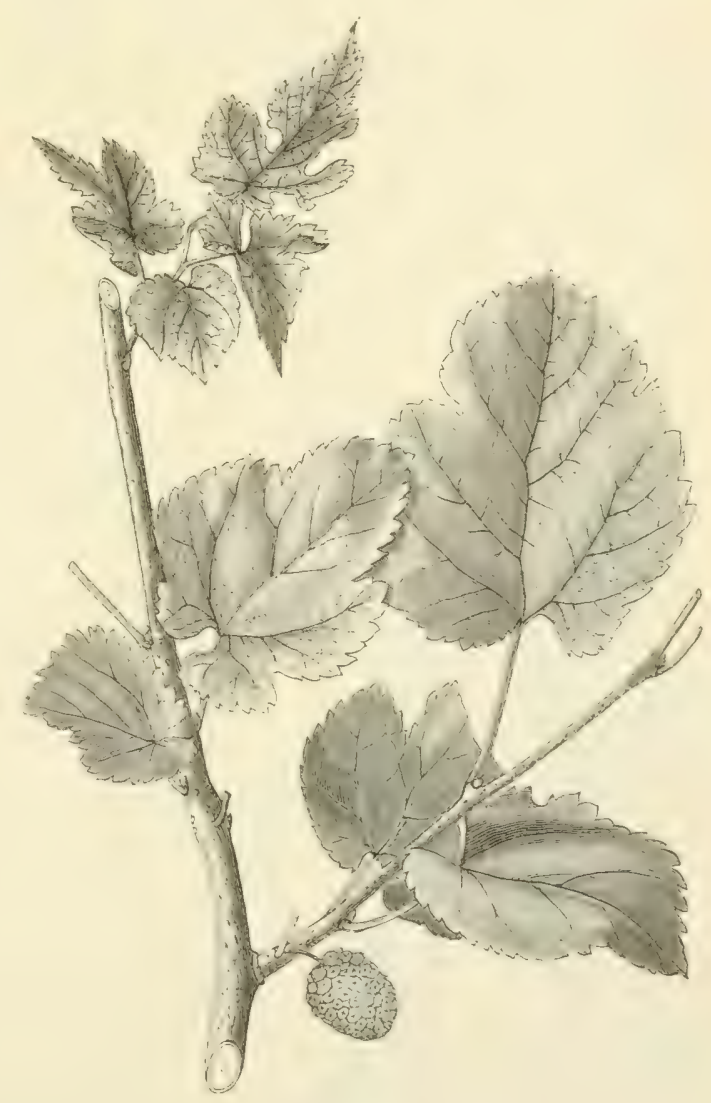

Fig. 292.

Morus alba. Ramié oder Chinagras.

3. Fam. Mor aceae.

Bäume und Sträucher mit Milchsaft. Blüten eingeschlechtig, in köpfchenartigen Ständen. P 2-6 meist 4, A ebensoviel. G 2 mit zwei Narben.

Morus alba L. Weisser Maulbeerbaum (Fig. 292) Baum III. Grösse. Blätter verschieden gestaltet, unterseits wenig behaart, sonst kahl. Blütenstände an blattachselständigen Kurztrieben. Die weisse oder rote Scheinfrucht Maulbeere) entsteht durch das Fleischigwerden des Perianths. Morus nigra L. Blätter behaart. Scheinfrüchte schwarz. Ficus carica, Feigen- 
baum, Ficus clastica, Gummibam, Ficus bengalensis und religiosa Banyan. Artocarpus incisa, Brodfruchtbaum. Broussonctia papyrifera, Papiermaulheerbaum.

4. Fam. Cannabincac.

Kräuter ohne Milchsaft, aber mit aromatischen Stoffen. Blüten diöcisch, in rispigen Ständen. Perianth niedrig, napförmig. G 2 mit zwei Narben.

Humulus Lupulus, Hopfen. Cammabis sativa Hanf.

5. Fam. Casuarinae.

Australische Holzpflanzen, die Zweige im Habitus den Equiseten ähnlich.

\section{5. Ordnung. Polygoniflorae.}

Blïten *, meist dreizählig, hypogyn oder schwach perigyn. Schliessen

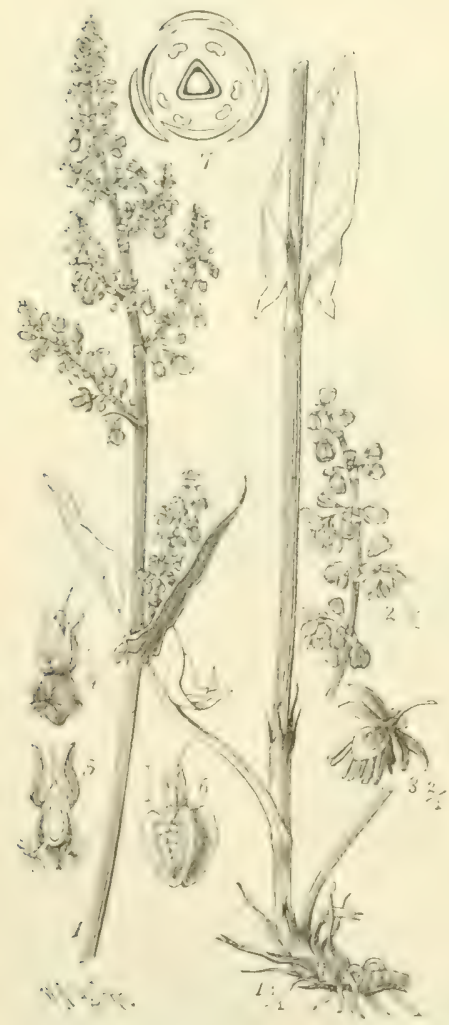

Fig. 293.

Rumex acetosa. (IV.) sich durch die grundständigen aufrechten, atropen Samenknospen den Urticaceen an. Blüten in Ähren oder Rispen.

I. Fam. Polygonaceac.

Stengel oft knotig, von der Blattscheide und den röhrenförmig verwachsenen Nebenblättern umgeben. Rheum officinale, $\mathrm{R}$. Rhaponticum, R. Emodi, Rhabarber. P $3+3$ $\mathrm{A}_{3} 2+3 \mathrm{G}(3)$. Rumex $\mathrm{P}_{3}+3 \mathrm{~A}_{3} 2+\mathrm{oG}(3)$. Dic Früchte vom inneren Perigon umschlossen. Rumex acetosa (Figur 293) und acetosella, Sauerampfer. R. obtusifolius, crispus u. a. Polygonum P 5 A 5-8. Polygonum bistorta, lapathifolium, Persicaria, aviculare. Polygonum fagopyrum, Buchweizen.

2. Fam. Piperaceac.

$\mathrm{PoA}_{3}+3 \mathrm{G}$ 3. Blütenstände traubig oder mit verdickter Axe (kolbig). Piper nigrum, schwarzer Pfeffer. Peperomia.

\section{S 79. 6. Ordnung. Curvembryae.}

Samen nierenförmig mit gekrümmtem Embryo, um den das mehlige Perisperm liegt. Samenanlagen an einer centralen Placenta. Blüten, meist 5 zählig, bei vollständigster Ausbildung $\mathrm{K}_{5} \mathrm{C}_{5} \mathrm{~A}_{5}+5 \mathrm{G}_{\underline{(2-3-5)}}$, reduziert bis auf $\mathrm{P}_{5} \mid \mathrm{A}_{5} \mathrm{G} \underline{(2)}$. 
I. Fam. Caryophyllaceae.

Krautige Pflanzen mit gegenständigen Blättern, oft etwas scheidenförmig verwachsen. Blüten $\&, * \mathrm{Kn} \mathrm{Cn} \mathrm{An}+\mathrm{n}$ (obdiplostemon) $\mathrm{Gn}$, wobei $\mathrm{n}=5$ oder 4 ist.

I. Unterfam. Alsineae. K freiblättrig, C meist vorhanden. Frucht eine vielsamige Kapsel. Stellaria media, Vogelmiere, sehr lästiges Unkraut. Arenaria serpyllifolia. Holosteum umbellatum. Spergula arvensis, Ackerspergel. Cerastium arvense. Malachium. Sagina.

2. Unterfam. Paronychieae. C fehlt sehr oft oder rudimentär, Fruchtknoten meist mit einem Samen. Frucht eine Nuss. Scleranthus annuus. Paronychia.

3. Unterfam. Sileneae. $\mathrm{K}$ verwachsenblättrig, C immer vorhanden. A. IO. Frucht eine vielsamige Kapsel.

G. 5 (selten 3-4): Melandryum album, Lichtnelke. Viscaria vulgaris, Pechnelke. Lychnis flos cuculi, Kuckucksnelke. Agrostemma Githago, Kornrade.

G 3: Silene inflata, Taubenkropf. Silene nutans, Leimkraut.

G 2: (zwei Griffel, vierzähnige Kapsel) Dianthus Carthusianorum, Karthäusernelke. D. deltoides, Heidenelke. D. caryophyllus, Gartennelke. Saponaria officinalis, Seifenkraut. Tunica prolifera, Felsnelke. Gypsophila muralis.

2. Fam. Amarantaceae: Amarantus. Celosia cristata.

3. Fam. Chenopodiaceae.

Krautige Pflanzen mit spiralig gestellten Blättern. Blïtenstände rispige Knäuel. P 5 - o (einfach, grün) A 5-I G (4-2). Frucht eine Nuss. Chenopodium album, Gem. Gänsefuss. Ch. murale, Ch. Vulvaria. Beta vulgaris, Runkelrübe, Mangold. Salsola Kali mit feischisen stachelspitzigen Blättern. Atriplex hastatum und patulum, Melden. Spinacia oleracea, Spinat.

4. Fam. Phytulaccaceac.

5. Fam. Portulaccaceae.

6. Fam. Nyctaginiaceae. Mirabilis Jalapa.

7. Fam. Aizoaceae. Nesembrianthemum crystallinum.

\section{S 80. 7. Ordnung. Cactiflorae.}

Ordnungscharakter wie bei der einzigen Familie.

I. Fam. Cactaceae.

$\mathrm{K}$ und $\mathrm{C} \propto$, spiralig gestellt. $\mathrm{A} \propto \mathrm{G} \overline{(3-\propto)}$ einfächerig mit zahlreichen wandständigen Samenknospen. Samen ohne Endosperm. Dickfleischige, meist blattlose Pflanzen, mit assimilirenden Sprossaxen. Stacheln und Haarbildungen häufig. Cereus. Epiphyllum. Echinocereus (Fig. 79). Phyllocactus. Opuntia. Nelocactus. Echinocactus. 


\section{8. Ordnung. Polycarpicae.}

Blitten $\unlhd$, sänzlich oder teilweise mit spiraliger Anordnung der Blütenteile (acyklisch) oder rariabel, teiheise noch apetal. Besonders charakteristisch die freien (apokarpen), oft zahlreichen Fruchtknoten. G in der Regel oberständig. Samen meist mit Endosperm.

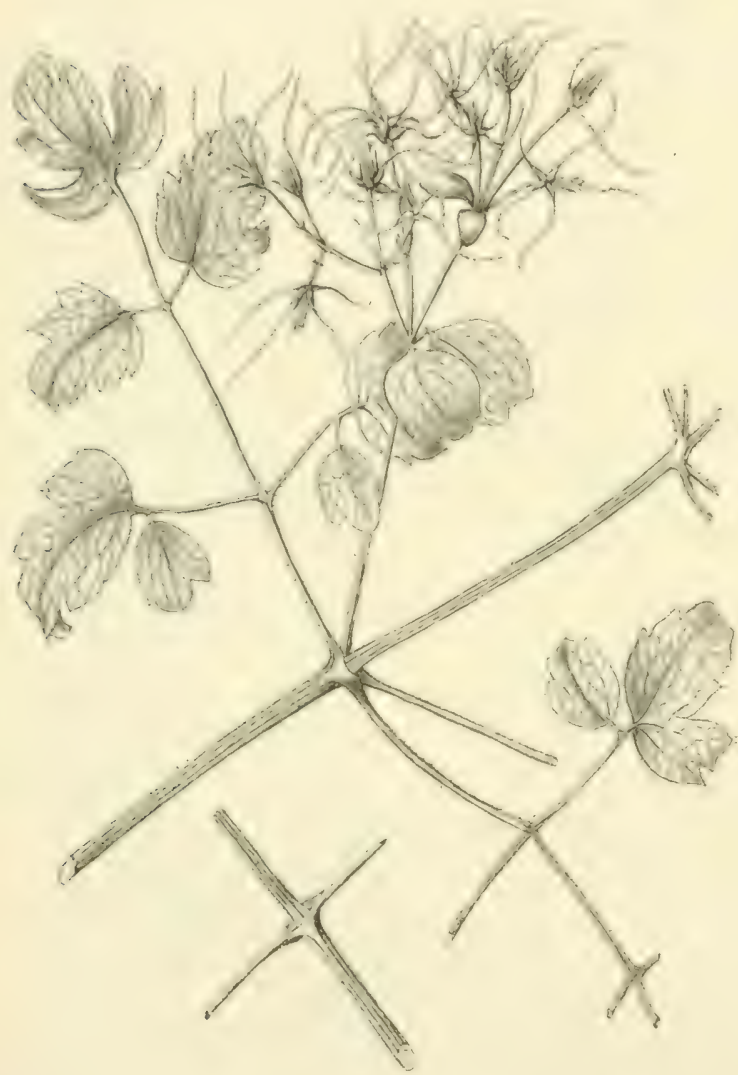

Fig. 294.

Clematis vitalba.

I. Fam. Ranuncul a c e a $\mathrm{c}$.

$\mathrm{K}_{5}(3-6) \mathrm{C}_{5}(\mathrm{O}-\boldsymbol{a})$ $A \propto G \underline{I-\infty}$. Dic Zahl der einzelnen Glieder variabel, Kelch und Krone nicht immer scharf getrennt.

I. Unterfam. Paeonieae. K grün, C gefärbt. Früchtchen mehrsamig. Paeonia arborea, P. officinalis, Pfingstrose.

2. Unterfam. Heleboreac. $\mathrm{K}$ ist blumenkronenartig $* \mathrm{~K}_{5} \mathrm{C}_{5}-\boldsymbol{x}$ Mehrsamige Balgfrucht. Caltha palustris. Trollius europaeus. Actaea spicata Christophskraut. Helleborus niger, schwarzer Nicswurz. Helleborus viridis, foetidus. Nigella arvensis. Aquilegia vulgaris.

3. Unterfam. Delphinieae. Blüte $y$. Aconitum napellus, Eisenhut. Delphinium consolida Ackerrittersporn.

4. Unterfam. Ranunculeae. K grün, C mit Honiggrübchen, Früchtchen nussartig. Ranunculus acer, repens, bulbosus, Ficaria, aquatilis u. a., Hahnenfuss. Myosurus minimus, Mäuseschwanz.

5. Unterfam. An emoneae. P einfach, A $\propto \mathrm{G} \propto$ Nussfrüchte. Anemone nemorosa, ranunculoides. Pulsatilla vernalis, vulgaris. Hepatica triloba (syn. Anemone Hepatica), Leberblümchen. Thalictrum flavum.

6. Unterfam. Clematideae. Blätter gegenständig, sonst wie vorige Unterfam. Clematis vitalba, Waldrebe (Fig. 294). Rankt mit Hilfe der 
Blattstiele. Stengel sechskantig, kletternd. Früchte sind Nüsschen mit federförmig ausgewachsenem Griffel. Andere Clematisarten häufig als Zierpflanzen verwendet. Atragene alpina, Alpenrebe.

2. Fam. Nymphae aceae.

Wasserpflanzen mit grossen schwimmenden Blättern $\mathrm{K} 3-5 \mathrm{C} 3-\boldsymbol{\alpha}$ A $6-\infty$ G 3- $\infty$. Nymphaea alba, weisse Seerose. Nuphar luteum, gelbe Seerose. Victoria regia Brasilien.

3. Fam. Ceratophyllaceae. Untergetauchte Wasserpflanzen. Ceratophyllum, Hornblatt.

4. Fam. Anonaceae. Tropische Holzpflanzen.

5. Fam. Magnoliaceae. Bäume oder Sträucher mit spiralig gestellten, oft lederartigen Blättern, meist mit Nebenblättern. $\mathrm{K}_{3} \mathrm{C}_{3}+3$ oder $\propto A \propto G \propto$. Magnolia conspicua, grandiflora, fuscata. Liriodendron tulipifera, Tulpenbaum. Drimys Winteri. Illicium anisatum, Sternanis.

6. Fam. Calycanthaceae. Ähnlich wie 5., doch perigyne Blüten. Sträucher. Calycanthus floridus, Blüten sehr wohlriechend, Nordamerika.

7. Fam. Berberideac. Berberitzen.

$\mathrm{K}$ in zwei oder mehreren, $C$ und $A$ in je zwei Quirlen. GI. Antheren meist mit zwei Klappen aufspringend. Frucht meist eine Beere.

Berberis vulgaris L. Berberitze, Sauerdorn.(Fig. 295). Strauch mit Blattdornen. Blïten gelb, $\mathrm{C}$ mit orangefarbigen Drüsen. $\mathrm{K}_{3}+3 \mathrm{C}_{3}+3 \mathrm{~A}_{3}+3 \mathrm{G}$ I. Endblïte des traubigen Blütenstandes häufig nicht dreizählig, sondern fünfzählig. Beeren rot. Findet sich besonders auf Kalkboden und in

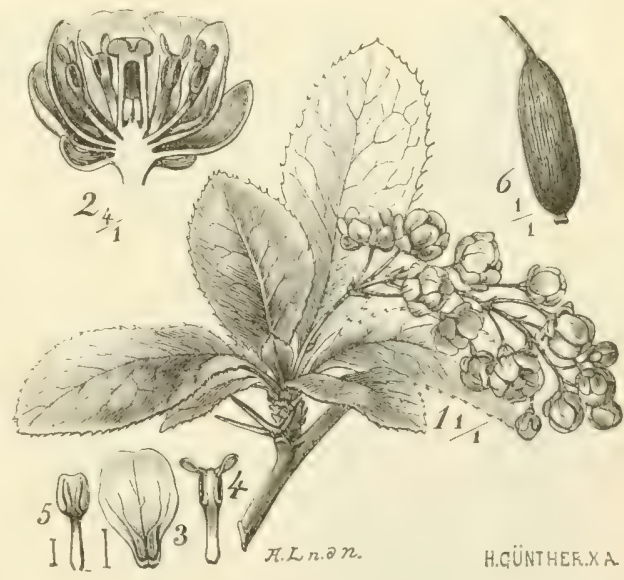

Fig. 295.

Berberis vulgaris. (IV.) Gebirgsthälern.

Mahonia aquifolium, Kelch aus drei Kreisen bestehend. Blätter immergrün, gefiedert. In Fasaneriegärten angepflanzt.

8. Fam. Men ispermaceae. Diöcisch. Menispermum canadense. Nordamerikanische Schlingpflanze.

9. Fam. Lauraceae.

Bäume und Sträucher. Blätter lederartig, ohne Nebenblätter, elliptisch. Blüte $s$, dreizählig (selten zweizählig) meist $\mathrm{P}_{3}+3 \mathrm{~A}_{3}+3+3+3 \mathrm{G}_{3}$. Frucht eine Beere oder Steinfrucht. Laurus nobilis, Lorbeer. Nittelmeergebiet. Camphora officinarum, Kampferbaum. Cinnamomum zeylanicum und aromaticum, Zimmt. Sassafras officinalis.

IO. Fam. Myristicaceae. Myristica fragrans, Muskatnuss. 


\section{\$ 82. 9. Ordnung. Rhooadinao.}

Krautige Pflanzen. Blüten cyklisch, $\$ * 2-$ oder vierzählig mit $\mathrm{K}$ und $\mathrm{C}$, $\mathrm{A}_{4}-\propto \mathrm{G}(2-\boldsymbol{x})$ cinficherig, mit wandständigen Samenknospen. Frucht cine Kapsel.

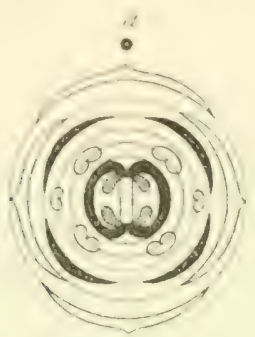

Fig. 296.

Diagramm der Cruciferenblüte. (K.)

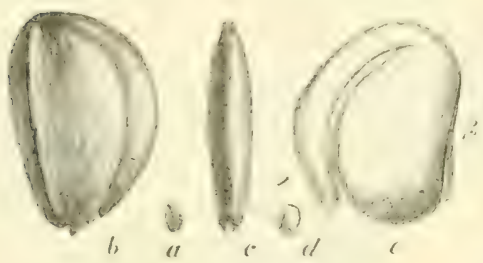

Fig. 297.

Iberic amara. I) X.

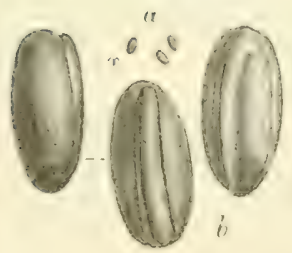

Fig. 298.

Camelina sativa, (DN.)

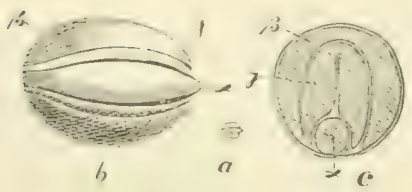

Fig. 299.

Brassica Napus var. oleifera. (DN.)

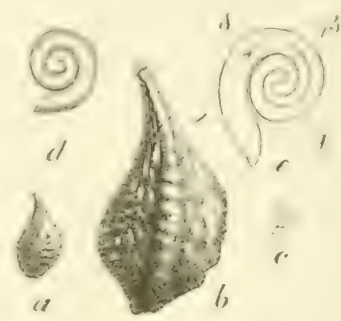

Fig. 300 .

liunias urientali: (I)

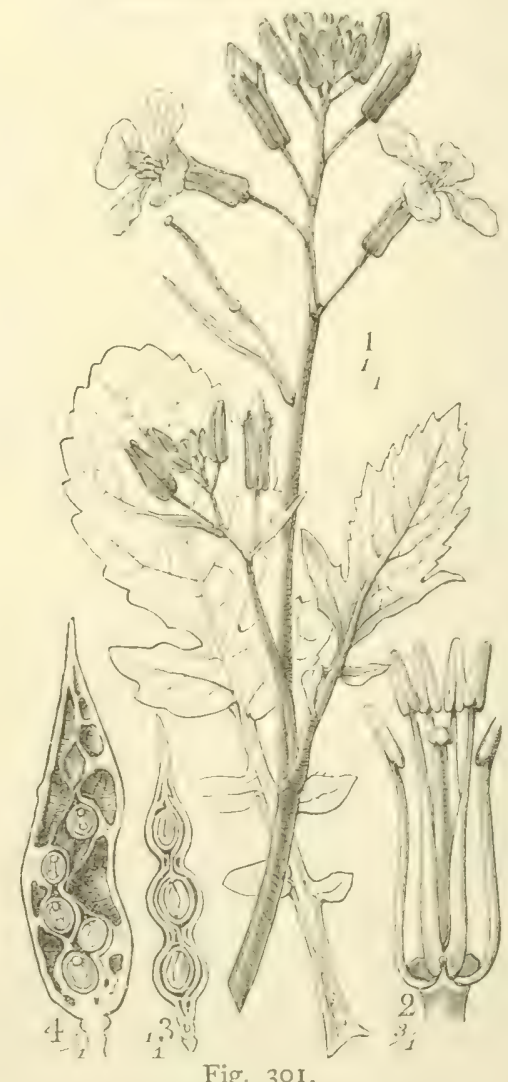

Raphanus Raphanistrum. (IV.)

I. Fam. Papaveraceae. Milchsaftführende Kräuter. * $\mathrm{K}_{2}-3 \mathrm{C}_{4}-6$ in zwei Quirlen $A x G(2-\infty)$. Papaver dubium, P. Argemone, P. Rhoeas, Mohn. Chelidonium majus, Schöllkraut. 
2. Fam. Fumariaceae. Blüte * oder y $\mathrm{K}_{2} \mathrm{C}_{2}+2 \mathrm{~A}_{2}{ }^{3}+\mathrm{OG}(2)$. Fumaria officinalis, Erdrauch. Corydalis cava. Dicentra spectabilis.

3. Fam. Cruciferae. Kreuzblütler.

Grosse, aus krautigen Gewächsen bestehende Familie. Blütenstand eine Traube. Blüten $s * \mathrm{~K}_{4} \mathrm{C}_{4} \mathrm{~A} 2+2{ }^{2} \mathrm{G}(2)$. Die äusseren Staubblätter kürzer als die vier inneren (Fig. 296). Frucht eine Schote, die durch eine falsche inicht durch die Ränder der Fruchtblätter sebildeter scheidewand in zwei Fächer geteilt wird. Embryo stets gekrümmt. Nan unterscheidet I) Pleurorhizae $\mathrm{O}=$, das Würzelchen liegt an der Kante der Cotyledonen (Fig. 297) Iberis. Cardamine. 2) Nothorhizae o $\mid$. Wurzel an dem Rücken des einen der beiden flach aneinander liegenden Cotyledonen (Fig. 298). Camelina. Sisymbrium. Capsella. 3) Orthoploceae o)) Wurzel in der Rinne der beiden dachförmig geformten Cotyledonen (Fig. 299). Brassica. Sinapis. 4) Spirolobeae o || Wurzel an der Seite des spiralig gerollten Embryos (Fig. 300), Bunias. 5) Diplecolobeae o $\mid\|\| \|$. Die Cotyledonen mehrmals hin und her gebogen, so dass sie ein Querschnitt mehrmals trifft, Senebiera, Heliophila.

I. Schotenfrïchtige, Schote mehrmals länger als breit: Brassica oleracea, Kohl, B. Napus, Raps, B. Rapa, Rübenkohl, B. nigra und Sinapis alba, Senf. Cardamine pratensis, impatiens, amara. Nasturtium officinale, Brumnenkresse. Sisymbrium officinale, Rauke. Erysimum cheiranthoides, Schotendotter, auch Hederich.

2. Schötchenfrüchtige, Schote nicht viel länger als breit: Draba verna. Alyssum calycinum, Berteroa incana. Camelina sativa, Leindotter. Teesdalea nudicaulis. Capsella bursa pastoris, Hirtentäschel. Lepidium sativum, Kresse, Cochlearia armoracea, Meerrettig. Cochlearia officinalis, Löffelkraut.

3. Gliederfrüchtige. Schote durch Querwände geteilt. Raphanus Raphanistrum, Hederich (Fig. 3OI), Raphanus sativus, Rettig. Cakile maritima.

4. Nussfrüchtige. Die Frucht ist eine einsamige, einfächerige Nuss. Isatis tinctoria, Färberwaid.

4. Fam. Capparideae.

Ähnlich wie Fam. 2. Staubfäden nicht verschieden lang, oft zahlreich. Capparis spinosa, Mittelmeergebiet. Die jungen Blïtenknospen liefern die Kappern.

\section{10. Ordnung. Cistiflorae.}

Androeceum und meist auch $\mathrm{K}$ und $\mathrm{C}$ cyklisch. Häufig $\mathrm{K}_{5} \mathrm{C}_{5} \mathrm{~A}_{5}+5$ oder a durch Spaltung quirlig angeordneter Staubblätter, G(3) oder mehr, mit oder ohne Fächerung.

I. Fam. Resedaceae. Blüten $r$, $K$ und $C$ 5-Szählig, A Io- $\mathbf{\alpha}$, $\mathrm{G}(2-6)$. Blumenblätter zerschlitzt. Diskus zwischen Krone und Staubblätter. Frucht eine Kapsel. Reseda luteola, Färberwau. Reseda odorata. 
2. Fam. Droseraceac. $\mathrm{K}_{5} \mathrm{C}_{5} \mathrm{~A}_{5}-20 \mathrm{G}(3)$. Drosera rotundifolia (Fig. 62), intermedia, longifolia auf Moorboden. Aldrovandia vesiculosa im Vasser. Dionaca muscipula, Fliegenfalle (Fig. 64).

3. Fam. Sarraceniaceac. Sarracenia. Darlingtonia.

4. Fam. Nepenthaceac. Kannenträser. Nepenthes (Fig. 66). Die Familien 2-4 enthalten dic meisten insektenfressenden Pflanzen.

5. Fam. Violaceac. Veilchensewächse. Blüten $\downarrow \mathrm{K}_{5} \mathrm{C}_{5} \mathrm{~A}_{5} \mathrm{G}(3)$. Viola canina, odorata, tricolor.

6. Fam. Tamaricaceac. Tamarisken. Myricaria germanica im Rhein- und Donaugebiet, sonst als Zierstrauch angeflanzt. Tamarix gallica.

7. Fam. Cistaceac. Blïten $* \mathrm{~K}_{5} \mathrm{C}_{5} \mathrm{Aa}$

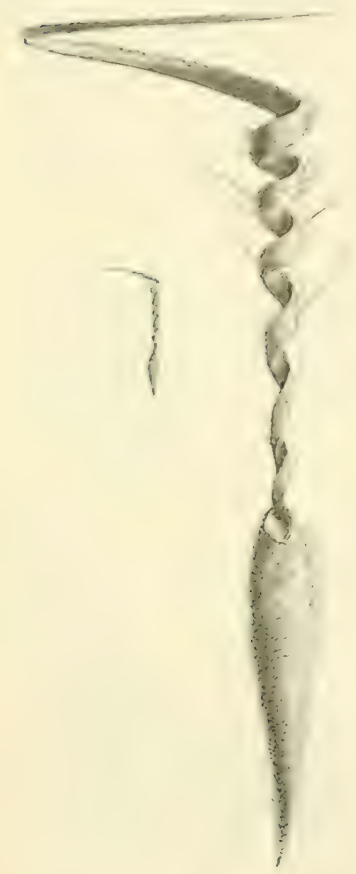

Fig. 302 .

Erridiun cicutarium. Reife Frucht mit Griffel. (DN.) G(3-5), Kelch und Krone in der Knospenlage gedreht. Sträucher und Halbsträucher besonders des Mittelmeergebietes.

Cistus salviacfolius, monspeliensis $u$. a. Helianthemum vulgare, Sonnenröschen und $H$. montanum, Ebene und Gebirge.

8. Fam. Hypericaceac. Blüte $* \mathrm{~K}_{5} \mathrm{C}_{5}$ $\mathrm{Ao}+3^{\infty}$ oder $\mathrm{O}+5^{\infty} \mathrm{G}(3-5)$. Staubblätter verzweigt. Hypericum perforatum, montanum u.a. Hartheu oder Johanniskraut.

Ausserdem gehören zu den Cistifloren verschiedene Familien der wärmeren Länder, die auch vielfach Holzpflanzen enthalten: Dilleniaceae, Clusiaceae, Marcgraviaceae, Dipterocarpaceac, Ternstroemiaceae. Zur letzten Familie gehört Thea chinensis, der Theestrauch und Camellia japonica, Kamellie.

\section{§ 84. 11. Ordnung. Gruinales.}

Blüten $₫$, meist * (Ausnahmen Pelargonium, Tropaeolaceae, Balsamineae) durchgehends fünfzählig, $\mathrm{K}_{5} \mathrm{C}_{5} \mathrm{~A}_{5}+5$ nder $5+0 \mathrm{G}_{5}$ oder 3. Die äusseren Staubblätter über C (obdiplostemon), G über C (epipetal). Teilweise Diskusdrüsen ausserhalb des Androeceums.

I. Fam. Oxalidaceae. A verwachsen, sonst wie Typus der Ordnung. Frucht eine Kapsel. Oxalis acetosella, Sauerklee.

2. Fam. Linaceae. A verwachsen. Die über C stehenden Staubblätter reduziert (unfruchtbar) oder ganz unterdrückt. Linum usitatissimum, Lein. Flachs ist der Bast der Stengel. L. catharticum, Purgierlein.

3. Fam. Geraniaceae. Storchschnabelgewächse. Die über der Blumenkrone stehenden Staubfäden alle oder teilweise steril, A ein wenig verwachsen. Fruchtknoten fünffächerig, Griffel sehr lang, rollt sich bei 
der Reife zusammen. Die Früchte lösen sich von einer Mittelsäule ab. Geranium pratense, Wiesenstorchschnabel, Ger. molle, pusillum, Robertianum. Erodium cicutarium, Reiherschnabel (Fig. 302). Pelargonium zonale Zierpflanze.

4. Fam. Tropaeolaceae. Blüte $\nmid$. Von den zehn typischen Staubblättern zwei unterdrückt. G(3). Tropacolum majus, Kapuzinerkresse.

5. Fam. Bals a minaceae. Blüte $\downarrow$. Ein Kelchblatt sehr gross, gespornt, zwei sehr klein oder unterdrückt $\mathrm{A}_{5}+\mathrm{oG}(5)$. Frucht aufspringend. Impatiens noli tangere, parviflora. Impatiens Balsamina, Gartenbalsamine.

\section{\$ 85. 12. Ordnung. Columniferae, Säulenblütler.}

Blïten cyklisch, zwitterig. Kelch in der Knospenlage klappig, C oft gedreht. A $5+5$, von denen der eine Kreis mehrweniger unterdrückt, der zweite häufig durch Spaltung mit geteilten Staubblättern versehen ist. Die Staubblätter mit Ausnahme der Tiliaceen zu einer Röhre (Säule) verwachsen. G2- $\infty$ mit vollständiger Fächerung, oberständig.

I. Fam. Tili a ceae. Staubblätter untereinander frei, sehr tief gespalten, so. dass die Blüte vielmännig erscheint. G(5).

Tilia parvifolia Ehrh. (syn. T. ulmifolia Scop., T. europaea L. z. Teil) Winterlinde, kleinblättrige Linde (Fig.303). Baum I. Grösse mit walzigem Stamm und reich verästelter Krone. Sehr

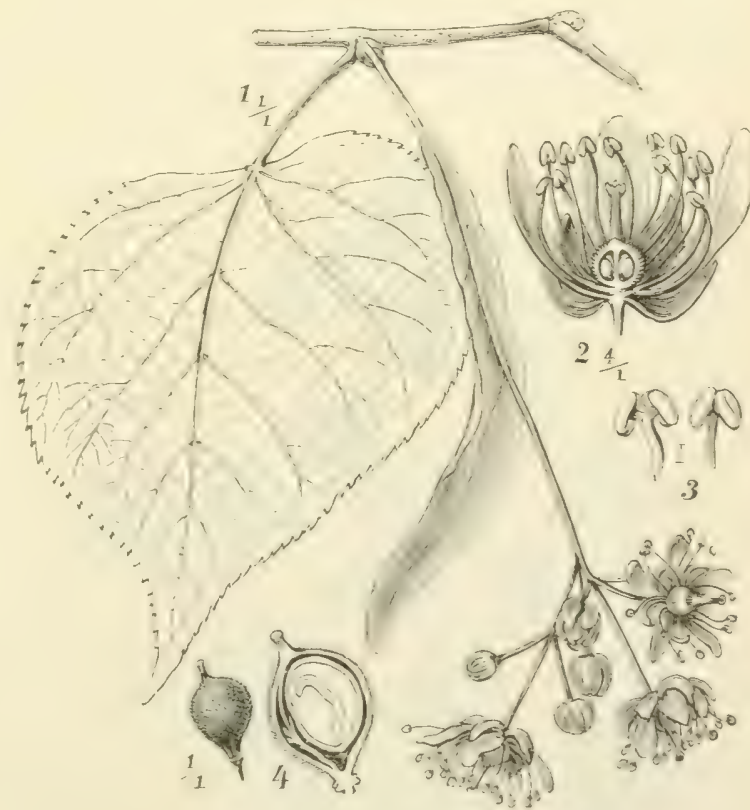

Fig. 303.

Tilia parvifolia. (IV.) gutes Ausschlagvermögen. Blüht Ende Juni, Anfang Juli. 5-7 Blüten in einer Trugdolde (Dichasium). Der Blütenstand ist mit dem grossen Tragblatte verwachsen, das beim Abfall der Früchte als Fallschirm dient. Blüten $*$ K5 $\mathrm{C}_{5} \mathrm{Ao}+5^{\infty} \mathrm{G}(\underline{5)}$. Jeder der fünf Fruchtknotenfächer trägt zwei Samenknospen, es entwickelt sich jedoch von allen Samenknospen nur eine, so dass die Frucht ein einsamiges, fünflilappiges Nüsschen ist. Frucht mit 
schwachen Rippen, rostrot, weniger behaart und kleiner als bei Tilia grandifolia. Fruchtreife Oktober. Abfall im Winter, Keimung im zweiten Frühjahr.

Leidet unter Trockenheit, empfindlich gegen Frost. Verlangt frischen tiefgründigen, mässig feuchten Boden. Vor- und Nittelgebirge bevorzugt.

Tilia grandifolia Ehrh. (syn. T. platyphyllos Scop. T. europaea L. 2. Teil, T. pauciflora Hayne) Sommerlinde, grossblättrige Linde. Der vorigen Art ähnlich. Blüten grösser, zu zwei bis drei in einem Stande. Blüht ein bis zwei Wochen früher als T. parvifolia. Früchte grösser, behaart, stark gerippt, graubraun. Etwas begehrlicher in Bezug auf Boden und Klima.

Tilia argentea Südeuropa. T. americana, pubescens Nordamerika. Corchorusarten liefern die Jute.

2. Fam. Malvaceac.

Kelch verwachsenblättrig. $\mathrm{C}$ und $\mathrm{A}$ an der Basis etwas verwachsen. A verzweigt zu einer Röhre vereinigt. Kapselfrüchtig: Gossipium herbacea, Baumwolle. Adansonia, Affenbrotbaum. Eriodendron, Wollbaum. Hibiscus syriacus. Spaltfrüchtig: Malva alcea, silvestris. Althaea officinalis, Eibisch. Lavatera arborea.

3. Fam. Sterculiaceae.

Sie zeigen zehn obdiplostemonische Staubblätter, die eventuell auch ungeteilt sind. Theobroma Cacao,

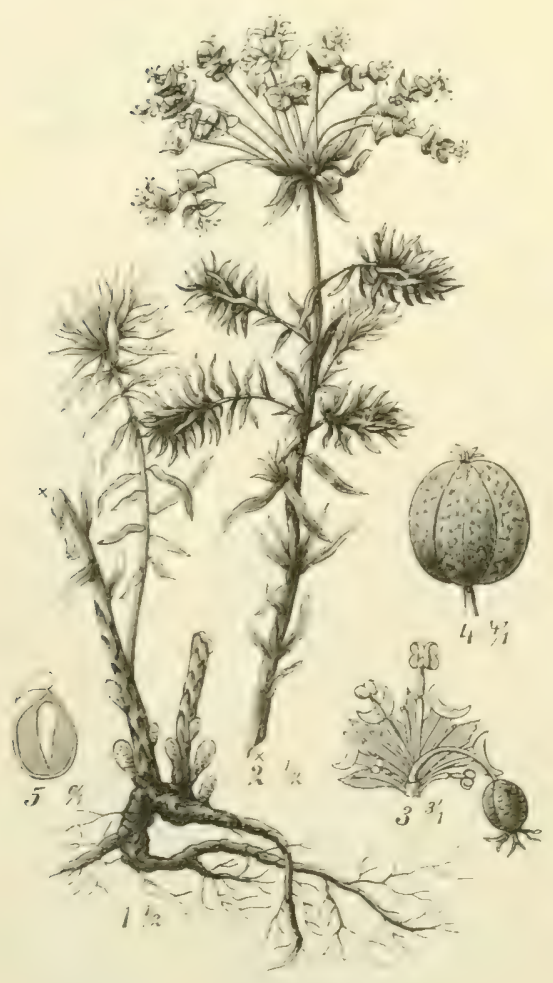

Fig. 304. Euphorbia cyparissias. Kakaobäume.

\section{§ 86. 13. Ordnung. Tricoccae.}

Eingeschlechtige, monöcische Blüten. Perianth einfach, seltener in $\mathrm{K}$ und $C$ gesondert. A I $-\infty$ oft verwachsen. $G(3)$, der dreifächerige Fruchtknoten oft tiefgefurcht (daher Tricoccae) mit ein oder zwei Samenknospen in einem Fach.

I. Fam. Euphorbiaceae, Wolfsmilchfamilie.

Die Blüten sehr verschieden, teilweise mit $\mathrm{K}$ und $\mathrm{C}$, oder wie bei Euphorbia nackt. Bei Euphorbia haben wir blütenähnliche Blütenstände (ein Cyathium Fig. 304, 3). Dieselben sind von einer Hülle umgeben, welche halbmondförmige Drüsen trägt. Innerhalb dieser Hülle eine grössere Anzahl von ô Blüten, deren jede nur aus einem Staubblatt besteht. An der Spitze steht eine 
\& Blüte, welche nur aus den Fruchtblättern gebildet ist. Euphorbia cyparissias (Fig. 304). E. Esula, E. helioscopia. Mercurialis annua und perennis Bingellkraut. Ricinus communis. Siphonia elastica u. a. A. liefern Kautschuk. Phyllanthus besitzt blattartige Zweige.

2. Fam. Buxaccae.

o Blüte $\mathrm{P}_{4} \mathrm{~A}_{4}$. \& Blüte $\mathrm{P} 6 \mathrm{G}_{3}$. Buxus sempervirens L. Gem. Buchsbaum. Immergrüner Strauch, bisweilen baumartig. Blüten blattwinkelständig in Knäueln. Kapselfrucht mit zwei bis drei Schnäbeln. Die Innenschicht löst sich elastisch von der Aussenschicht. Samen länglich, dreikantig schwarz. Besonders in den warmen Teilen Deutschlands und Österreichs, sowie in Südeuropa. Eine Zwergform dient zu Einfassungen. Holz sehr hart und gleichmässig.

3. Fam. Callitrichaceae.

Blüten mit zwei Vorblättern eingeschlechtig. P O. A I und PoG (2). Callitriche verna, Wasserstern.

4. Fam. Empetraceae.

$\mathrm{K}_{3} \mathrm{C}_{3}$, in den ô Blüten $\mathrm{A}_{3}$, in den $\AA_{i} \mathrm{G}(6-9)$. Samenknospen aufrecht. Empetrum nigrum, Rauschbeere.

\section{\$ 87. 14. Ordnung. Terebinthinae.}

Blüten ähnlich wie bei den Gruinales, meist vier- oder fünfzählig diplostemon, $* \mathrm{KnCnAn}+\mathrm{n} \mathrm{Gn}$. Meist fünf Fruchtblätter. Stets eine ring- oder napfförmige Discusbildung zwischen $\mathrm{A}$ und $\mathrm{G}$ vorhanden (Fig. 305, 2). Blätter spiralig gestellt, häufig gefiedert, reich an aromatischen Stoffen. Meist Sträucher und Bäume.

I. Fam. Meliaceae. Swietenia Mahagoni, Mahagoniholz, Westindien, Centralamerika. Cedrela odorata und guianensis, Cigarrenkistenholz.

2. Fam. Rutaceae. Blätter reich an Öldrüsen. Discus sehr stark.

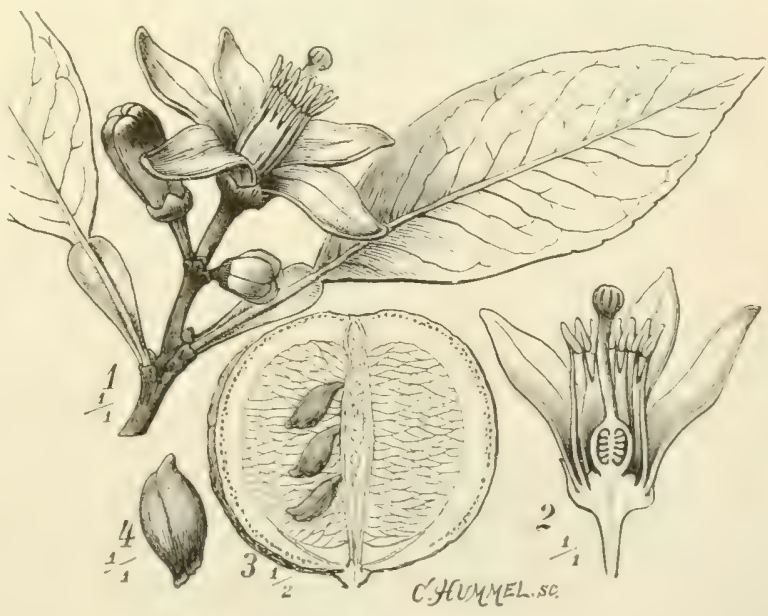

Fig. 305 .

Citrus Aurantium. (W.)

Ruta graveolens. Dictamnus albus. Citrus Limonum, Citrone. Citrus Aurantium Apfelsine (Fig. 305) und andere Citrusarten. Ptelea trifoliata. 
Blätter mit drei Fiederblättchen. Frucht Ulmen ähnlich, Flügel von derben Nerven durchzogen, an der Basis mit Perianthresten.

3. Fam. Burseraceac.

Commiphora Myrrha liefert Myrrhen, Boswellia sacra Weihrauch.

4. Fam. Zygophyllaceac.

Guajacum officinale, Pockholz, Franzosenholz. Immergrüner Baum Westindiens mit ausserordentlich festem, harzreichem Holz.

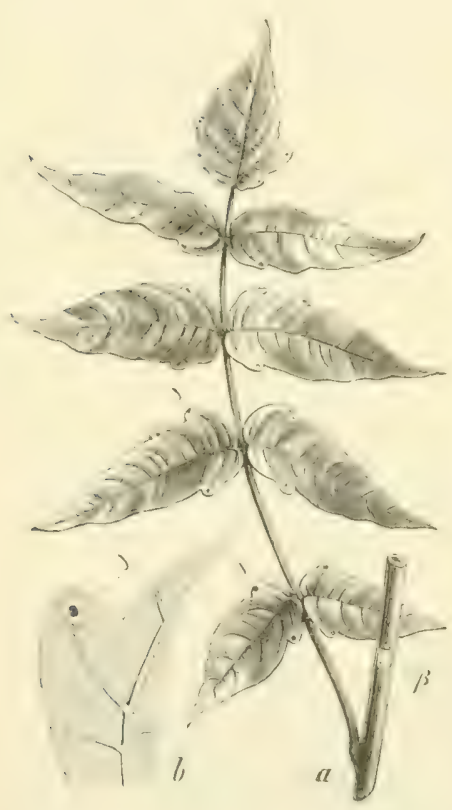

Fig. 306 .

Ailanthus glandulosa. (DN.)

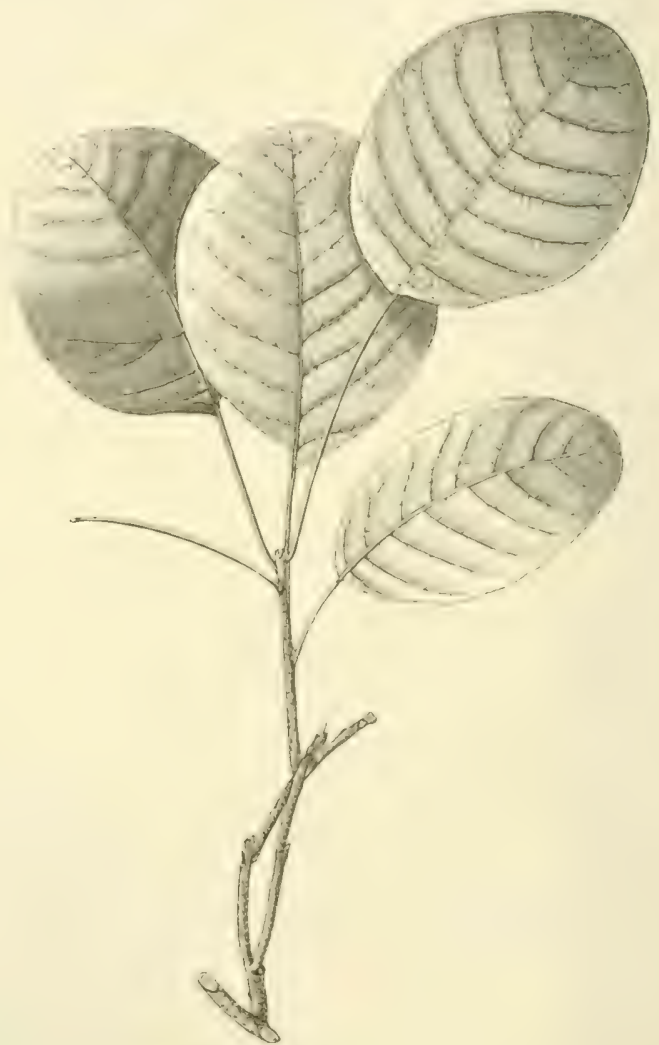

Fig. 307 .

Rhus cotinus.

5. Fam. Simarubaceae.

Ailanthus glandulosa Desf. Götterbaum (Fig. 306) besitzt grosse unparis gefiederte I 5 - 20 Fiederblättchen), drüsis ggezähnte Blätter. Flügelfrüchte länglich, an beiden Enden spitz. Stammt aus China und Japan, kommt in wärmeren Teilen Deutschlands gut fort. Quassia amara und Picraena excelsa liefern bitterstoffhaltiges Holz.

6. Fam. An a cardiaceae.

Rhus cotinus, Perückenstrauch (Fig. 307). Blätter stark aromatisch, bläulichgrün. Blütenstiele werden behaart. Liefert Gelbholz, Fisetholz. 
Laub stark gerbstoffhaltig. Südeuropäische Gebirge, sonst viel angepflfanzt. Rhus typhina Kolbensumach, Essigbaum. Pyramidale, später rote, filzige Fruchtstände. Ziergewächs. Rhus Toxicodendron Blätter dreizähliş. Kleinstrauch aus Nordamerika. Rhus coriaria Gerbersumach, Mittelmeergebiet. Pistacia vera, Pistazie, P. Terebinthus, P. Lentiscus, Mastixstrauch, nur Nittelmeergebiet. Schinus molle in Peru, liefert wertvolles Harz, erfriert in Norddeutschland.

\section{S 88. 15. Ordnung. Aesculinae.}

Typus ähnlich wie bei den Gruinales und Terebinthinae $\mathrm{K}_{5} \mathrm{C}_{5} \mathrm{~A}_{5}+5$ (einzelne Staubblätter abortiert) G meist (3) seltener (2-5). Discus, wenn

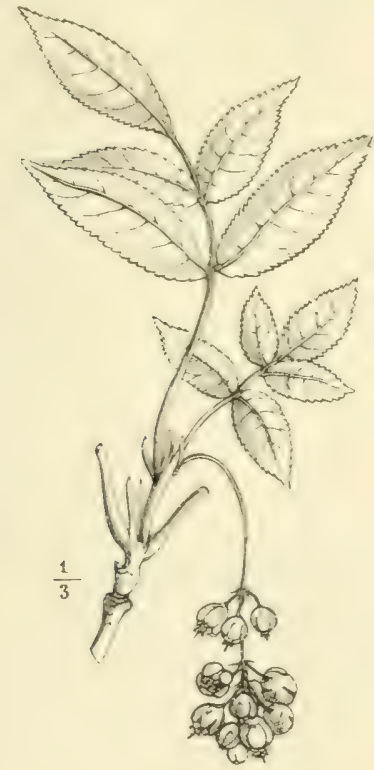

Fig. 308 .

Staphylea pinnata. (DN.)
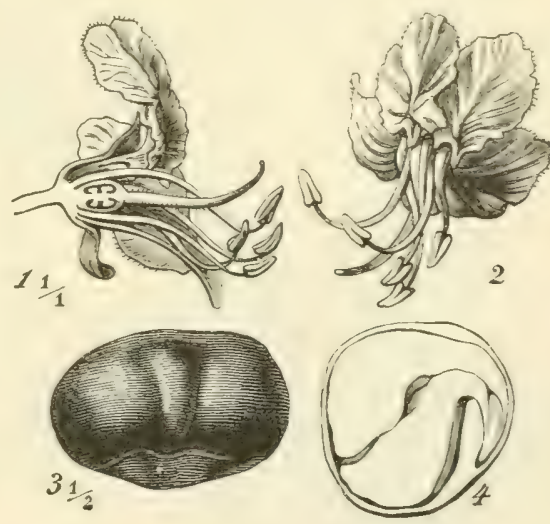

Fig. 309.

Aesculus Hippocastanum. (W.)

vorhanden, ausserhalb A. Zygomorphie häufig, in der Regel mit schräger Symmetrieebene. Aromatische Stoffe nicht vorhanden.

I. Fam. Staphyleaceae.

Staphyiea pinnata L., Pimpernuss (Fig. 308). Aufrechter Strauch. Blüte glockig, weisslich. Frucht eine aufgeblasene Kapsel. Süddeutschland, Rheingegenden. Staphylea trifoliata Nordamerika.

2. Fam. Sapindaceae.

Blüten $\downarrow \mathrm{K} 4-5 \quad \mathrm{C}_{4}-5$ A meist $5+2$ (drei fehlen) innerhalb des Discus G(3). Ohne Endosperm.

Aesculus Hippocastanum L., Rosskastanie (Fig. 309) Baum II. Grösse. Blüten in aufrechten Sträussen (Wickeltrauben), Kelch grün- 
lich, Blumenblïter genaselt, weisslich. Kapsel gross, stachelig. Cotyledonen sross, bitter. Heimat: Centralasiatisches Hochland oder Thessalien.

Aesculus carnea, Blumenblätter rosenrot, gelbgefleckt, nicht wellig. Pavia nur mit vier Blumenblättern. Pavia flava hat blassgelbe, Pavia rubra purpurrote Blüten. Bastarde zwischen den einzelnen Arten häufig.

Sapindus saponaria,

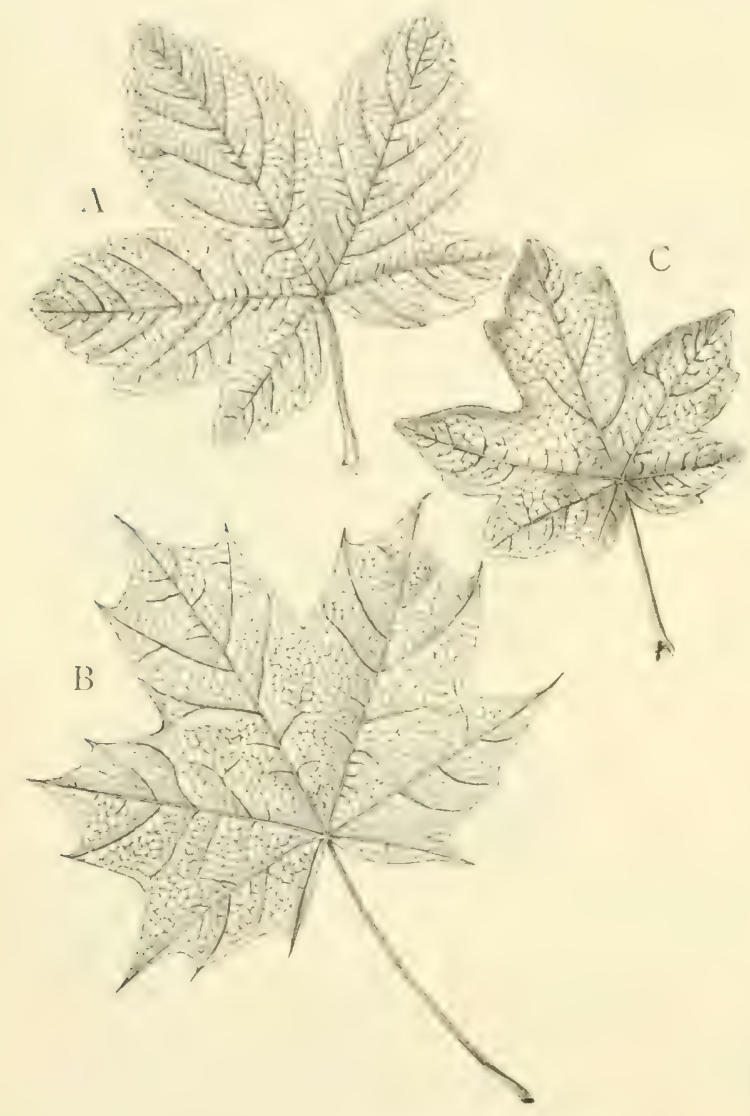

Fig. 310.

A Acer Pseudoplatanus, B Acer platanoides. C Acer campestre. Seifenbaum, Südamerika, Westindien. Paullinia cururu liefert Pfeilgift (Curare). Vicle andere tropische und subtropische Holzpflanzen, auch Lianen.

3. Fam. Acerineac. Blüten * $(2)$ sonst wie Fam. 2. Spaltfrucht mit zwei geflügelten, nussartigen Früchtchen.

Acer Pseudoplatanus L. Bergahorn, gemeiner, stumpfblättriger Ahorn (Fig.310A). Baum I. Grösse. Schaft vollholzig, Äste knickig. Herzwurzel. Ausschlagvermögen gering. Blüht Ende April oder Mai, nach Laubausbruch. Blïten in hängenden, aus Trugdolden zusammengesetzten Trauben. Ausser den $ڤ$ Blüten noch ô und $\Omega$. K grünlich-gelb, abfallend meist fünf (selten vier oder mehr als fünf), $\mathrm{C}$ soviel wie $\mathrm{K}, \mathrm{A}$ acht d. h. zwei Kreise zu fünf, von denen je ein Staubblatt fehlschlägt. Staubblätter in Gruben des Diskus inseriert (vgl. Fig. 3I4). Same sehr dick, die an der Basis bedeutend verschmälerten Flügel der Frucht sind an der Spitze einander genähert (Fis. 3I I). Abfall der Samen Oktober, November. Keimung bei Herbstaussaat im April, bei Frühjahrssaat nach längerer Ruheperiode. Mannbarkeit mit 40 bis 50 Jahren, an Stocklohden oft schon mit Io Jahren.

Nicht besonders empfindlich gegen Spätfrost und Hitze. Verlangt mineralisch kräftigen, frischen Boden. Mittelgebirge. 
Acer plat an oides L., Spitzahorn. Spitzblätteriger Ahorn (Fig. 3 IoB). Baum II.-I. Grösse. Dichte Krone, schlanker, gerader Stamm. Blüten

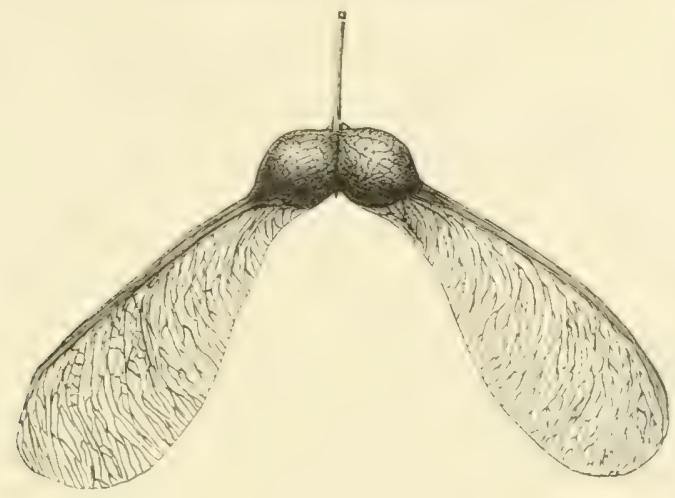

Fig. 3I I.

Frucht von Acer Pseudoplatanus.

in aufrechten, dichten Sträussen, gelblich-grün, erscheinen vor dem Laubausbruch. Früchte kahl, Flügel ausgebreitet, Samen flach (Fig. 3I2). Abfall Oktober. Mannbarkeit mit 30-40 Jahren.

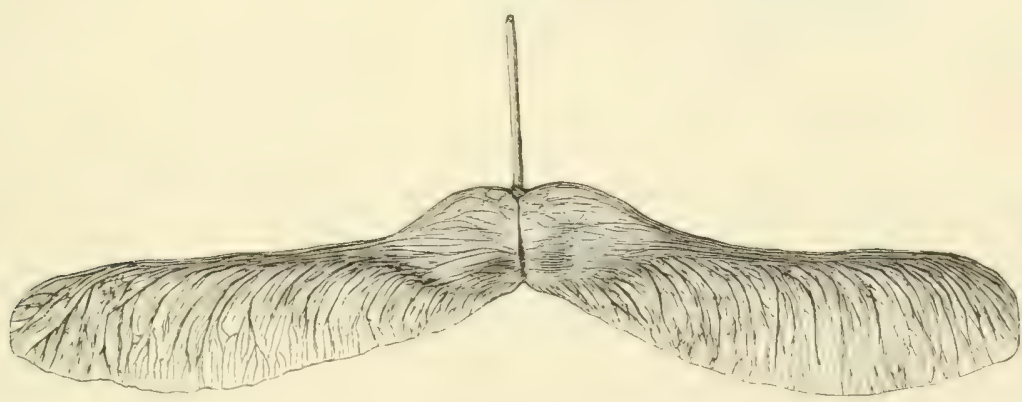

Fig. 312 .

Frucht von Acer platanoides.

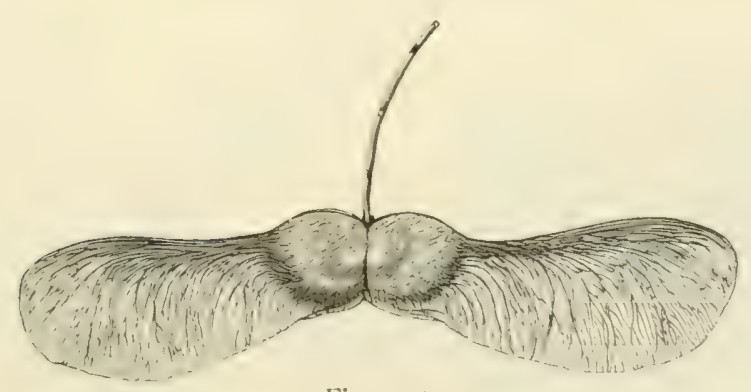

Fig. $3 I_{3}$.

Frucht von Acer campestre.

Macht etwas geringere Ansprüche an die Bodenbeschaffenheit, verträgt grössere Trockenheit und Feuchtigkeit als Acer Pseudoplatanus. Tiefland, niederes Bergland. 
Acer campestre L. Feldahorn, Massholder (Fiss. $310 \mathrm{C}$ und 314). Baum III. Grösse oder strauchig. Blïten in aufrechten, jedoch arm-

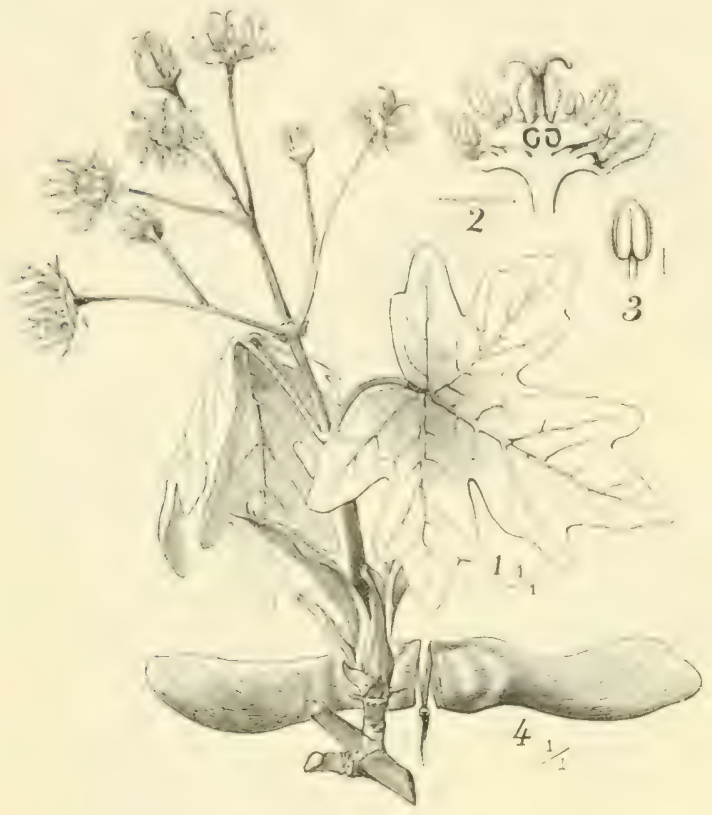

Fig. 314.

Acer campestre. (IV.) blïtiseren Trussolden. Die j) Blïten herrschen vor. Frucht mehr oder weniger behaart, kleiner als bei $\mathrm{A}$. platanoides, Samen flach (Fig. 313). Samenjahre seltener. Wegen seiner guten Ausschlagsfähigkeit im Mittel - und Niederwald. Weniger empfindlich als die beiden zuerst besprochenen Arten. Ebenen und Bergland, Waldränder, Bachufer.

Acermonspessulanum L. Französischer Ahorn, zeichnet sich durch seine sehr kleinen Blätter aus (ähnlich campestre). Süddeutschland, Südeuropa.

Acer saccharinum Wangh., Zuckerahorn. Blätter langgestielt, $5-7$ teilig, spitzlappig, ohne Milchsaft, unterseits bläulichgrün und wenig behaart. Stamme aus Nordamerikà. Iält in Deutschland sut aus, jedrich nicht in Irochlagen. Kann wegen seines wertvollen Holzes zum Anbau empfohlen werden.

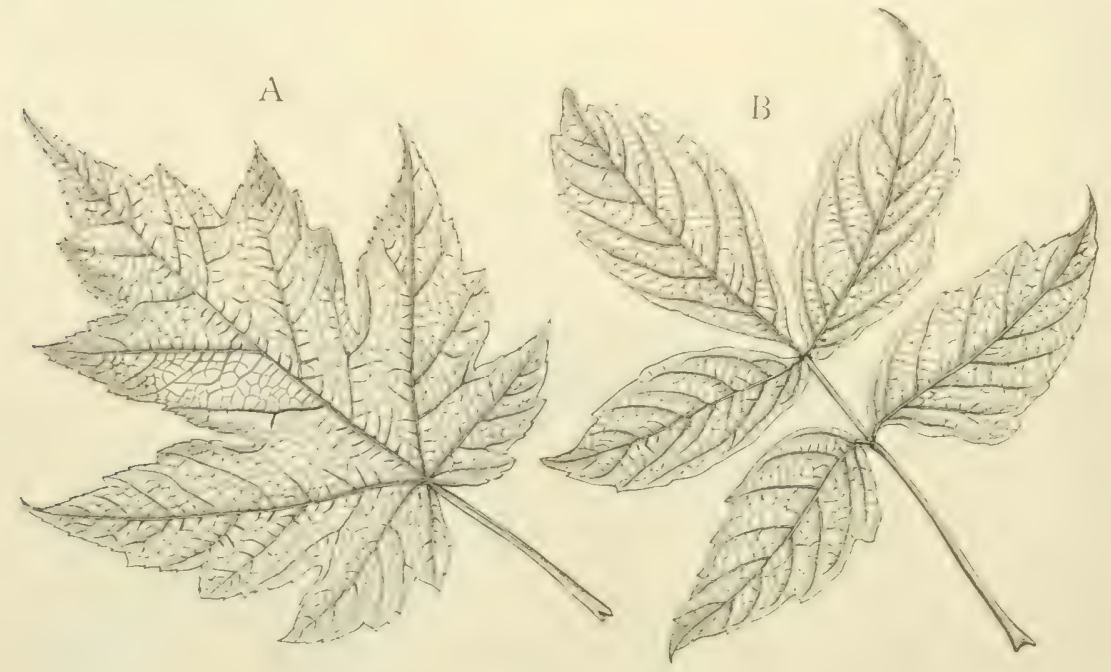

Fig. 315. A Acer dasycarpum. B Negundo aceroides. 
Acer dasycarpum Ehrh. (syn. A. saccharinum L.) Silberahorn, Weisser Ahorn (Fig. 3I5 A). Der Baum neigt zu strauchigem Wuchs. Blätter auf der Unterseite silberweiss glänzend. Cotyledonen bei der Keimung unterirdisch bleibend (im Gegensatz zu den anderen Ahornen). Sehr widerstandsfähig gegen Frost. Liefert geringwertiges Holz.

Acer italicum, rubrum, tartaricum, obtusatum, ohne forstliche Bedeutung.

Negundo a ceroides Mönch. (Negundo fraxinifolium Nutt., Acer Negundo L.). Eschenblättriger Ahorn (Fig. 3I5 B). Blätter mit I-2 Paaren gestielter Fiederblättchen. Weicht in der Blütenbildung sehr wesentlich von den Ahornen ab, indem weder Perianth noch Diskus vorhanden ist. Blüten mit langen, schlaff herabhängenden Stielen. Holz minderwertig. Der Anbau deshalb nicht zu empfehlen. Verträgt keinen trocknen Boden, verlangt frischen Boden, wächst auch noch auf Moorboden.

Negundo californicum Torrey et Gray. (syn. Acer californicum Koch). Ein nordamerikanischer, bis I $2 \mathrm{~m}$ hoher Baum, ähnlich Negundo aceroides, junge Zweige behaart, meist nur drei Fiederblättchen, forstlich wertlos.

4. Fam. Polygalaceae. Die zwei Kelchblätter sind kronblattartig ausgebildet. Blüten $\downarrow$. Polygala vulgaris.

\section{Sิ 89. 16. Ordnung. Frangulinae.}

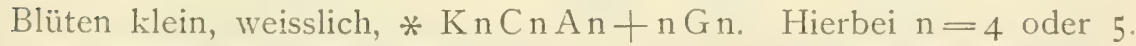
Von den zwei Kreisen im Androeceum schlägt immer einer fehl, so dass immer nur soviel Staubblätter als Kronenblätter vorhanden sind. Diskus verschieden, Fruchtknoten meist oberständig, mehrfächerig. Samenknospen anatrop. Bäume und Sträucher.

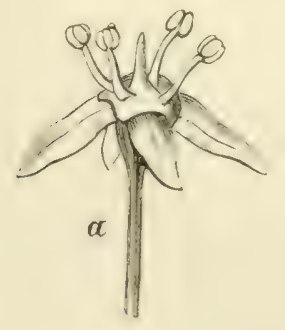

Fig. 316.

Evonymus europaeus a $\$$ Blüte, b $ᄋ$ Blüte.

(DN.)

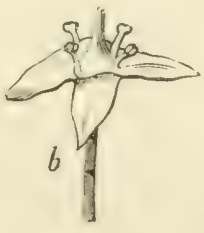

I. Fam. Celastraceac.

Blüte meist $\mathrm{K}_{4} \mathrm{C}_{4} \mathrm{~A}_{4}+\mathrm{OG}(4)$. Diskus vorhanden. Zwei Samenanlagen in jedem Fruchtknotenfach.

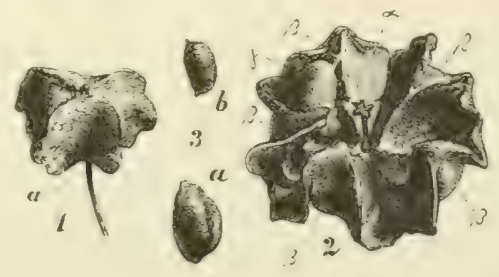

Fig. 317 .

Fruchtknoten und Samen von Evonymus europaeus. (DN.) 
Evonymus curopacus L. Pfaffenhütchen, Spindelbaum. Stranch mit gegenständigen Blättern. Die Staubblätter sitzen auf cinem fleischigen Diskus (Fig. 316). Frucht eine rote, vierklappige Kapsel (Fig. 3I7). Die Samen haben einen gelbroten Samenmantel (arillus).

Evonymus latifolius Scop. hat grössere Blätter.' Blüten meist fünfzählig. Kapseln an den Kanten schmal geflügelt. Celastrus scandens. Baumtöter.

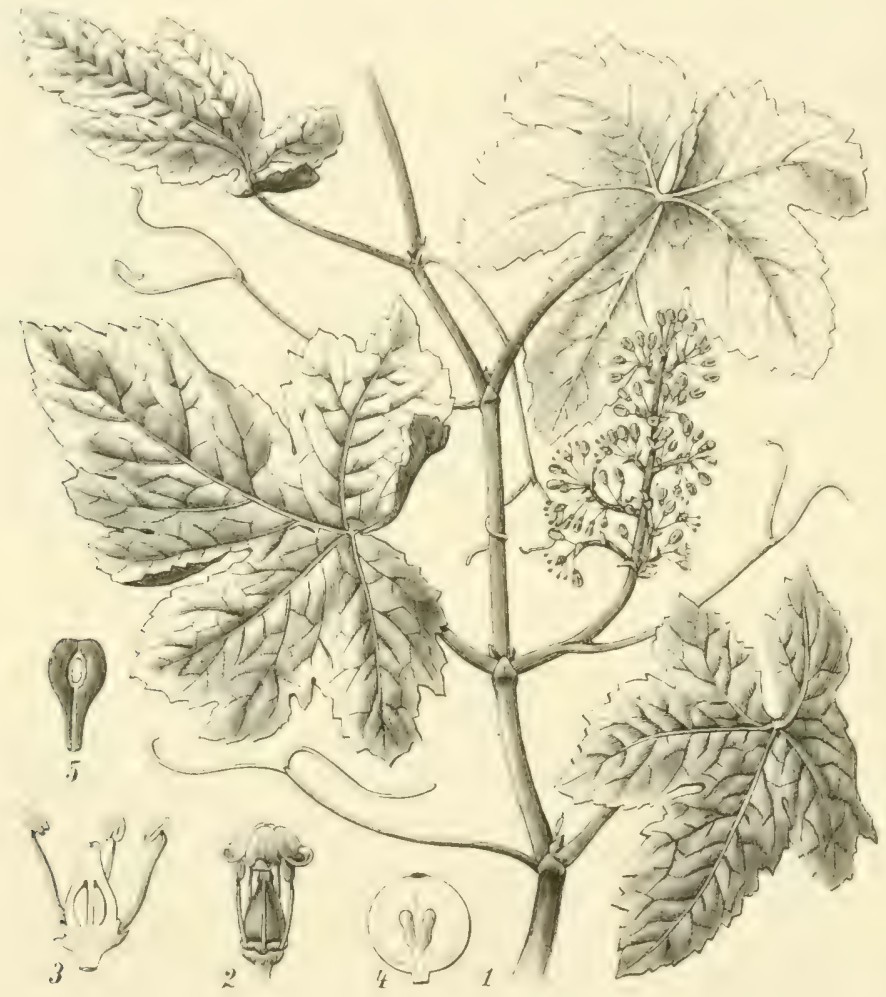

Fig. 318 .

Vitis vinifera. (Sch.)

2. Fam. Aquifoliaceae.

Diskus fehlt, $\mathrm{C}$ ein wenig vereintblättrig. Fruchtknoten kugelig. In jedem Fach nur eine Samenanlage.

Ilex aquifolium, Stechpalme. Immergrüne stachelige Blätter. Ist an das atlantische Seeklima von Europa gebunden.

3. Fam. Ampelidaceae.

Blüten meist $\mathrm{K}_{5} \mathrm{C}_{5} \mathrm{AO}+5 \mathrm{G}(2)$, auch vierzählig (Cissus), zwischen $\mathrm{A}$ und $G$ ein Diskus, der aber meist auf einzelne Drüsen reduciert ist. Rankende Sträucher. Frucht eine Beere.

Vitis vinifera, Weinstock (Fig.3 I8). Stammt aus dem Orient. Kelch 
sehr kurz, die Kronenblätter bleiben an der Spitze vereinigt und fallen als Haube ab. Vitis vulpina, V. Labrusca, nordamerikanische Reben. Ampelopsis hederacea, wilder Wein. Cissus discolor, Schlinggewächs.

4. Fam. Rhamnaceae.

Blüten $\mathrm{KnCnAo}+\mathrm{nG}(2-5)$. Dabei $\mathrm{n}=4$ oder 5 . Die kleinen Blumenblätter umhüllen häufig die davor stehenden Staubblätter (Fig. 319, 2, 3). Blütenaxe als Hypanthium becherartig gewölbt (Fig. 319).

Rhamnus frangula, Faulbaum, Pulverholz (Fig. 319). Blüten s. Blätter spiralig oder schief gegenständig.

Rhamnus cathartica Kreuzdorn, diöcisch. Zweige dornspitzig. Blätter gegenständig. Es sind kurzgriffelige und langgriffelige Blütenformen vorhanden (Fig. 320).

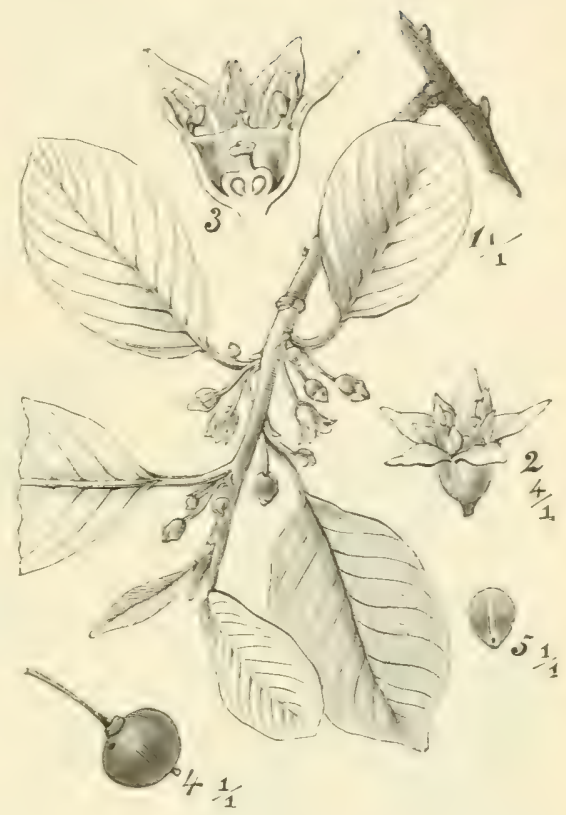

Fig. 319

Rhamnus frangula. (WV.)

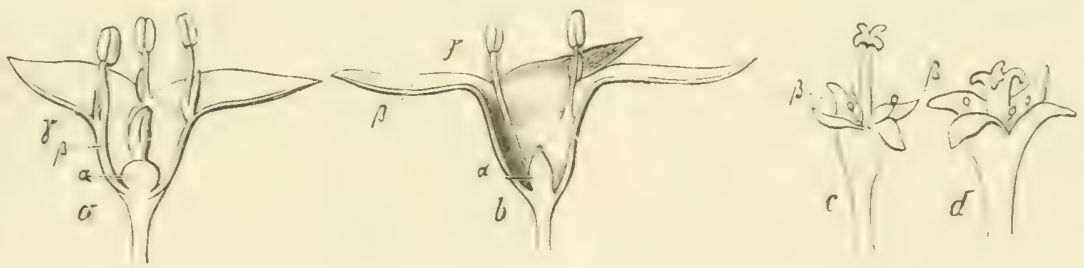

Fig. 320 .

Rhamnus cathartica. a langgriffelige, b kurzgriffelige ô Blüte. c langgriffelige, d kurzgriffelige O Blüte. " rudimentärer Fruchtknoten, $\beta$ Kelch, $\gamma$ Krone, n. Caspary. (DN.)

\section{\$ 90. 17. Ordnung. Thymelaeinae.}

Blüten vierzählig, perigynisch. $\mathrm{K}$ blumenkronartig, $\mathrm{C}$ fast immer fehlend. Dafür die Blütenaxe als Hypanthium entwickelt, auf welchem Kelch und Staubblätter inseriert sind. A mit einem oder zwei Kreisen, G I, im Grunde des Hypanthiums, meist mit einer Samenknospe.

I. Fam. Thymelaeaceae. Frucht eine Beere. $\mathrm{A}_{4}+4$ auf dem Hypanthium. 
Daphne Mezereum, Seidelbast (Figs. 321). Giftiger, keiner Strauch.

2. Fam. Elacagnaceac. $\mathrm{K} 2-6 \mathrm{CoAO}+4$ oder $4+4$. Frucht eine

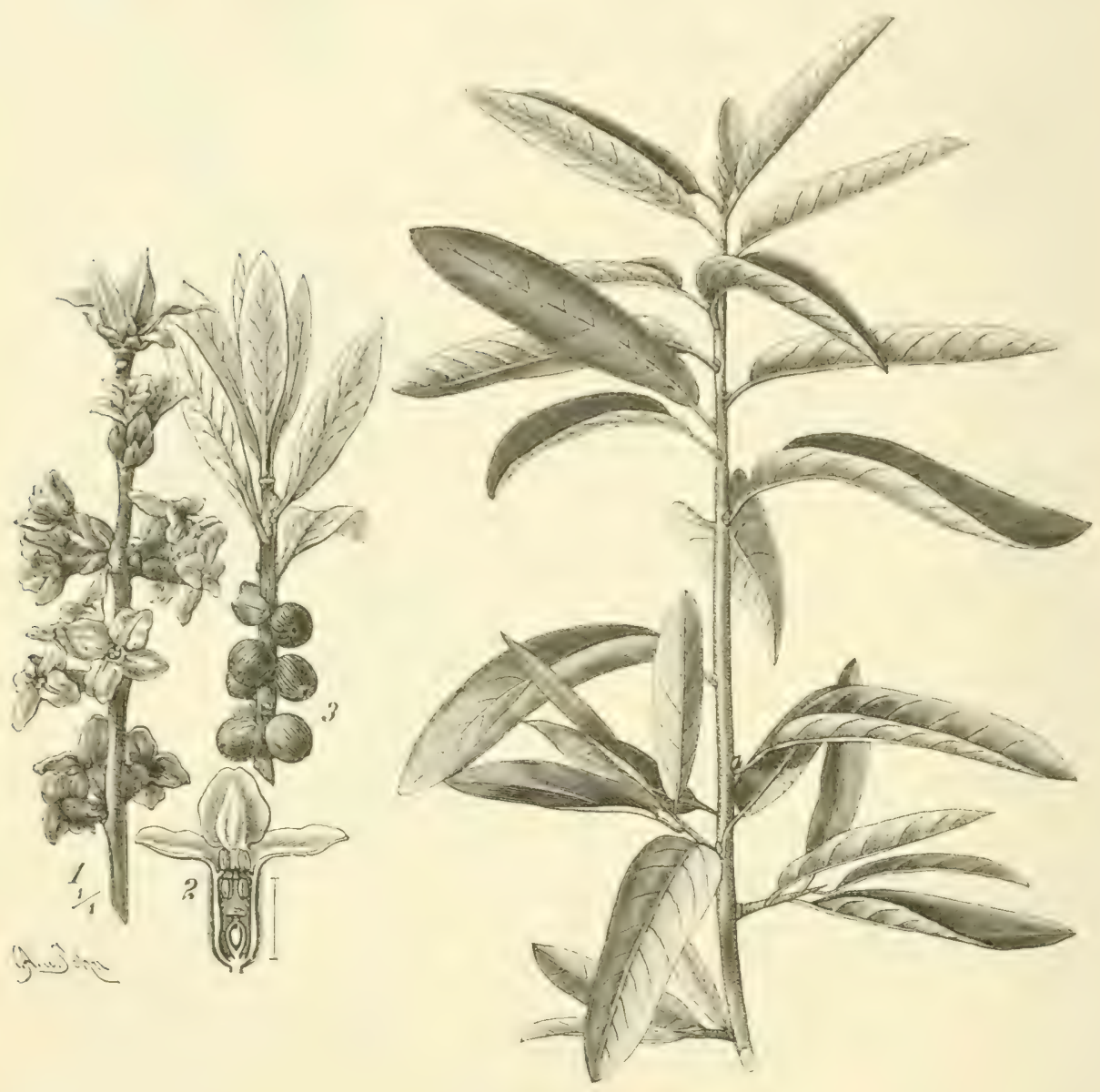

Fig. 321 .

Daphne Mezereum. (W.)
Fig. 322.

Elaeagnus angustifolia.

vom Hypanthium eingeschlossene Nuss, wird zu einer beerenartigen Scheinfrucht. Dic Elaeasnaceen zeiggen eisgentümliche, slänzende Sternhaare.

Elaeagnus angustifolia L. Ölweide (Fig. 322). Baum III. Grösse. Blüten \&. Scheinfrucht rotgelb. Stammt aus Vorderasien. Elaeagnus argentea. Nordamerika.

Hippophaë rhamnoides L. Sanddorn (Fig. 323). Strauch oder kleiner Baum. Scheinfrucht gelb. Auf Sand und Geröll besonders von Flussthälern und Küstengegenden. 
§ 91. 18. Ordnung. Saxifraginae.

Blüten peri- oder epigynisch, sehr häufig fünfzählig, sehr oft obdiplostemonisch: $\mathrm{KnCn} \mathrm{An}+\mathrm{n}$ oder $\mathrm{n}+\mathrm{OG} 2-5$ meist G2. Fruchtblätter frei oder teilweise verwachsen.

I. Fam. Crassulacea e.

Die Blüten nach dem Typus der Ordnung, wobei die Zahl n sehr verschieden sein kann, z. B. bei Sedum 4-7, Sempervivum 6-30, Bryophyllum 4, Echeveria 5. G steht über C. Fettpflanzen mit fleischigen Blättern und Sprossaxen. Sedum acre, Mauerpfeffer (Fig. 324), Sedum telephium, Fetthenne. Sempervivum tectorum, Dachwurz.

2. Fam. Saxifraga-

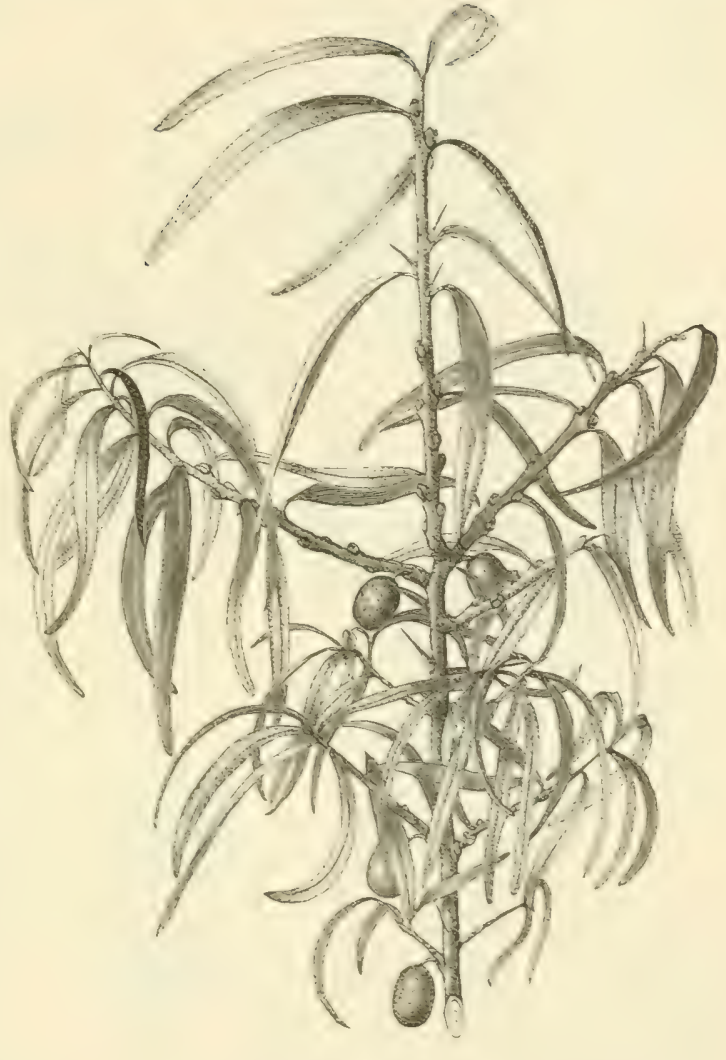

Fig. 323.

Hippophaë rhamnoides. ceae.

Blüten meist $\mathrm{K}_{5} \mathrm{C}_{5} \mathrm{~A}_{5}+5 \mathrm{G}_{2}$. Fruchtknoten halb oder ganz unterständig. Viele Saxifragaarten mit Kalkdrüsen. Saxifraga granulata, S. tridactylites, S. Aizoon und viele alpine Arten. Chrysosplenium alternifolium, Milzkraut. Parnassia palustris. Adoxa Moschatellina, Moschuskraut.

3. Fam. Ribesiaceae.

Blüte fünfählig, nur der epipetale Staubblattkreis entwickelt. Fruchtknoten unterständig, in der Verlängerung des Fruchtknotens ein becherförmiges Hypanthium, auf dem K, C und A inseriert sind. Frucht eine Beere.

Ribes grossularia L. Stachelbeere (Fig. 326). Ribes rubrum L., Gem. Johannisbeere (Fig. 327). Ribes nigrum L., Schwarze Johannisbeere. Ribes aureum. Ribes alpinum. Die Blüten sind bei der letzten Art diöcisch.

4. Fam. Hy drange a c a e.

Blüte vier- oder fünfzählig mit zwei Staubblattkreisen oder A $\boldsymbol{c}$ (durch Verzweigung). Frucht eine Kapsel. 


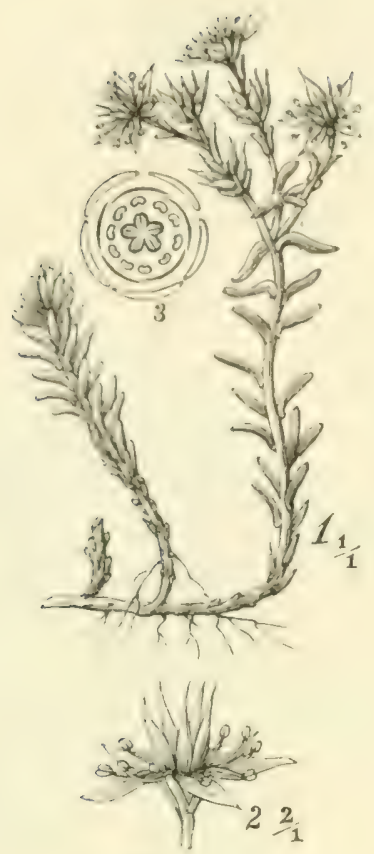

Fig. 324 .

Sedum acre. (W.)

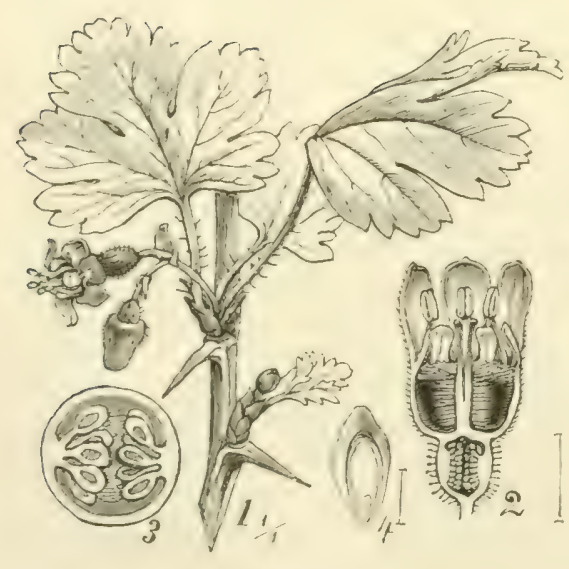

Fig. 326.

Ribes Grossularia. (W.)

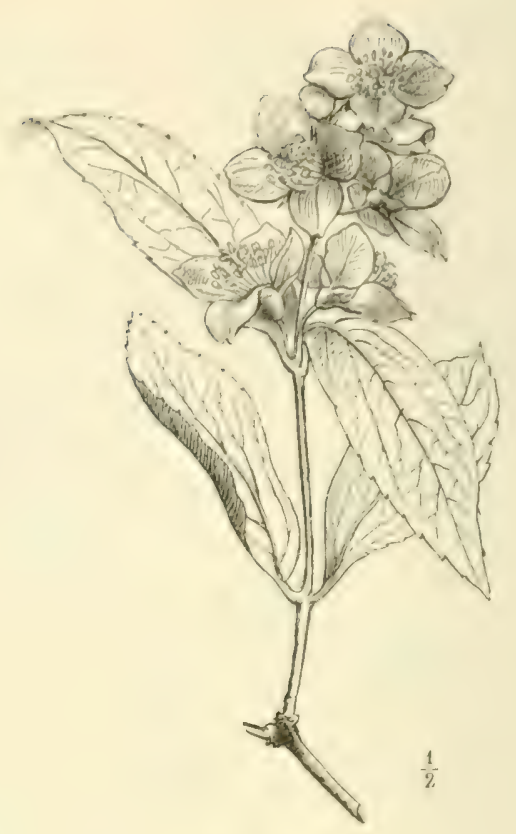

Fig. 325 .

Philadelphus coronarius. (DN.)

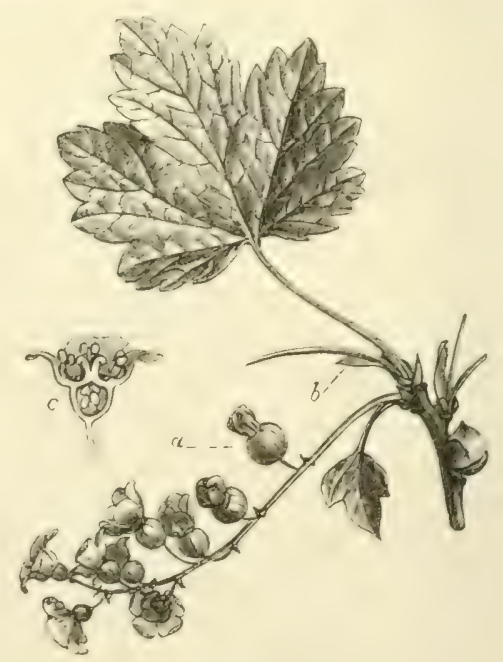

Fig. 327 .

Ribes rubrum. (DN.)

Philadelphus coronarius. Pfeifenstrauch, falscher Jasmin (Fig. 325). Blüten gross, weiss, in 5-9 blütigen Sträussen. Hydrangea Hortensia, Hortensie. 
5. Fam. (?) Platan a ceae, Platanen.

Anschluss dieser $\mathrm{Fa}$ milie fraglich (vielleicht zu der Urticinenreihe gehörig). Blüten monöcisch, in dichten, kugeligen Ständen, 2-4 an einem langen, hängenden Stiele. Kelch und Krone schuppenförmig. WenigeStaubblätter in der Achsel der Schuppen. G4. Frucht mit langen, braunen Haaren versehen. Fruchtstände kugelig (Fig. 328). Platanus occidentalis Baum II.-I. Grösse, wird sehr alt. Sehr gute Ausschlagsfähigkeit. Stammt aus Nordamerika. Kommt auch noch in Norddeutschland mit Ausnahme des Nordostens gut fort.

Platanus orientalis (Fig. 328). Verlangt etwas mehr Wärme. Stammt aus Westasien.

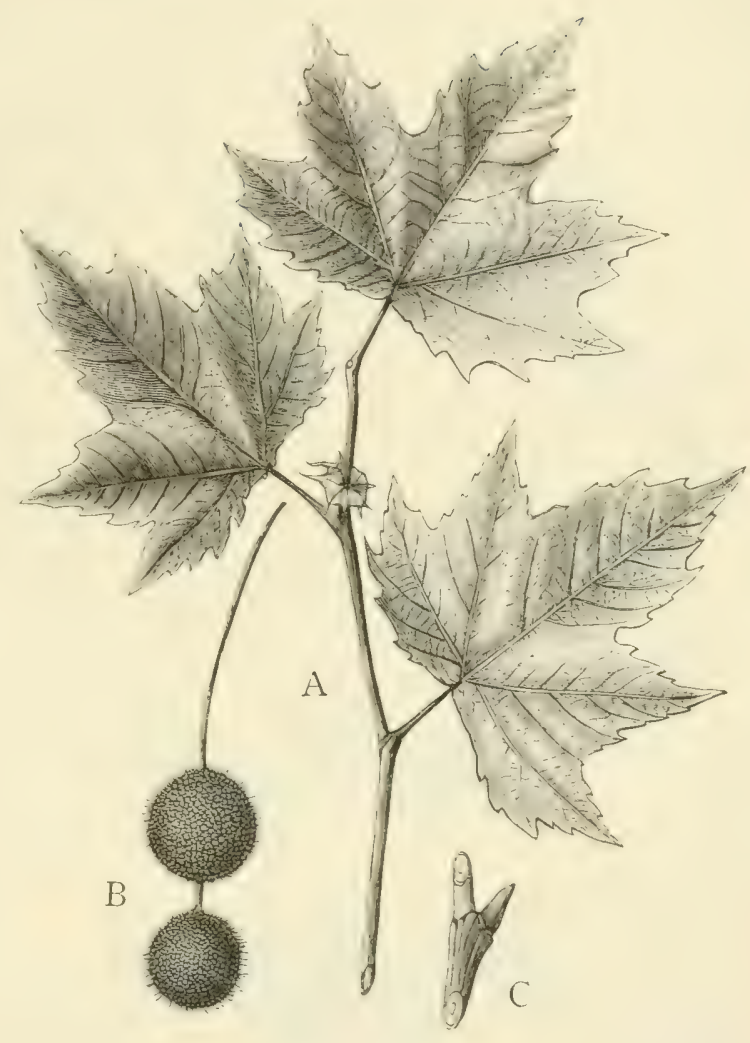

Fig. 328 .

Platanus vrientalis. A Beblätterter Zweig. B Fruchtstände. C Knospen.

\section{19. Ordnung. Rosiflorae.}

Blüten * (Ausnahme Chrysobalaneen), K und C fünf-, selten vierzählig. A $5-\infty$ immer in fünf- oder zehnzähligen Kreisen, häufig zwanzig in drei Kreisen $\left(\mathrm{AIO}_{\mathrm{IO}} 5+5\right) \mathrm{G}_{\mathrm{I}}-\infty$, frei oder nur teilweise verwachsen, so dass die Griffel frei bleiben. Gewöhnlich kein Endosperm. Die Bliitenaxe bei den einzelnen Familien in verschiedener Weise als Hypanthium ausgebildet (Fig. 329).

I. Fam. Ros a ceae.

Zahlreiche einblättrige Fruchtknoten (Sammelfrucht). Kräuter und Sträucher mit bleibenden Nebenblättern.

I. Unterfam. Spiraeeae.

Gewöhnlich fünf oberständige Fruchtblätter, die nicht von dem 
Hypanthium eingeschlossen sind. Frucht besteht aus vielsamigen Balgkapseln.

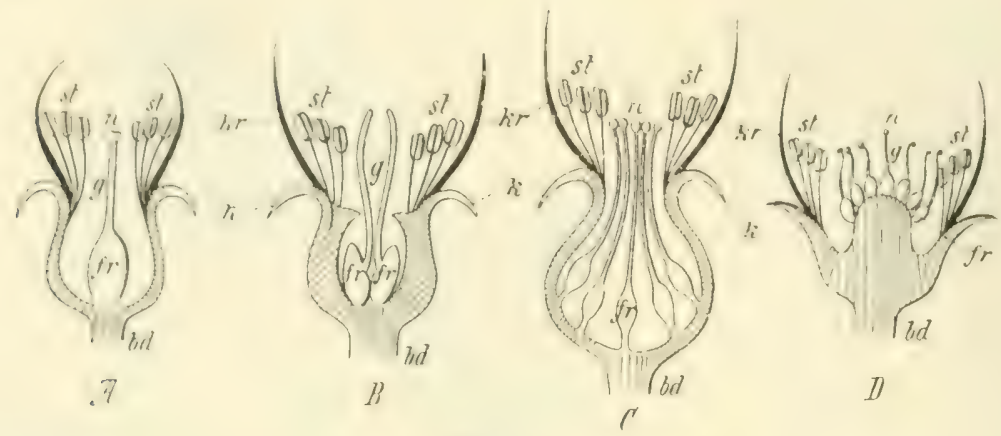

Fig. 329 .

Schematisierte Darstellung von Rosiflorenblüten. A Amygdalaceae, B Pomaceen, C Roseen, D Potentilleae. Die schraffierten Teile sind Axengebilde, bd Axengebilde. k Kelch. kr Krone. st Staubblätter. g Griffel. n Narbe. fr Frucht. (Sch.)

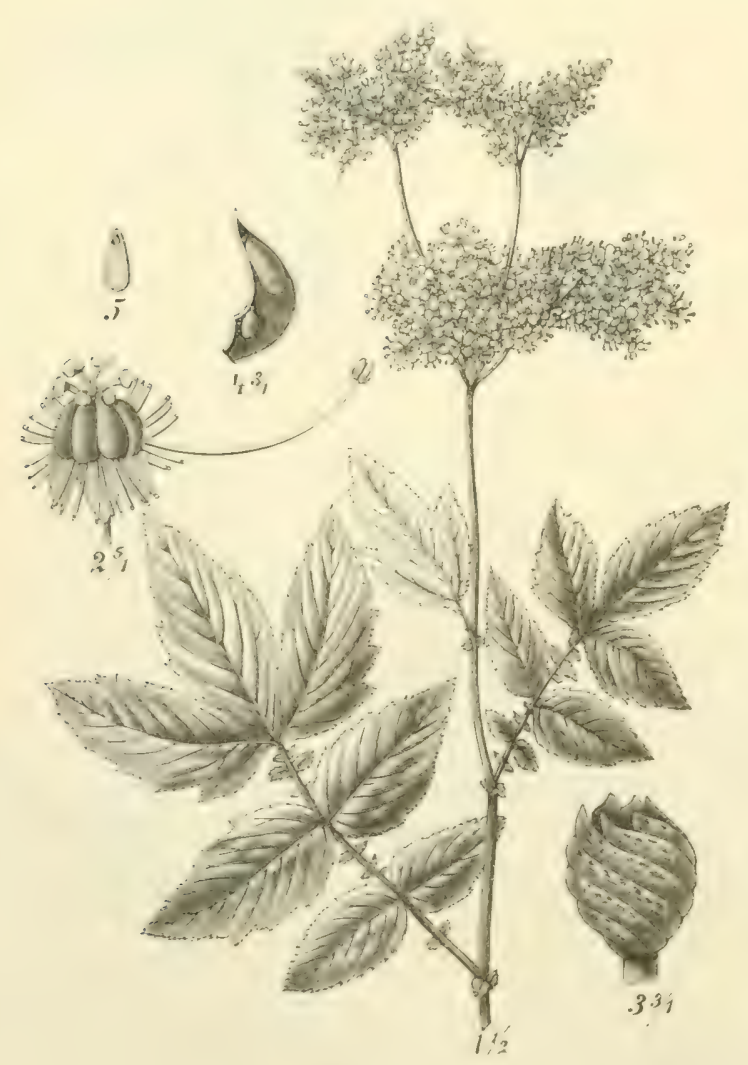

Fig. 330 .

Spiraea Ulmaria. (Sch.)

Spiraea Ulmaria (Fig. 330), Sp. Filipendula, Sp. Aruncus. Als Ziersträucher gepflanzt: Sp. salicifolia, sorbifolia, callosa, opulifolia u. a. Kerria japonica, Rhodotypus kerrioides.

2. Unterfam. Potentille ae.

Blüten mit einem Aussenkelch (Hochblättern) versehen. Die zahlreichen Früchtchen sitzen auf dem stark vorgewölbten Blütenboden (Fig. 329 D), der entweder fleischig oder holzig-lederig wird. Fragaria vesca, Fr. collina, Fr. elatior, Erdbeeren. Potentilla anserina, P. tormentilla, P. incana. Comarum palustre. Geum rivale und urbanum. Dryas octopetala.

3. Unterfam. Rubea e. Blüten ohne Aussenkelch. Die einzelnen Früchtchen werden saftig, bilden zusammen eine Scheinbeere, die sich von der Axe ablöst. 
Rubus Idaeus, Himbeere (Fig. 33I). Sprossaxen mit weichen Stacheln, oder stachellos. Scheinfrüchte rot. Sehr verbreitet in Wäldern. Rubus fructicosus (Fig. 332). Gemeine Brombeere. Scheinfrüchte schwarz. Rubus caesius, Kratzbeere. Die Zweige der beiden letzteren Arten sind mit derben Stacheln versehen. Rubus saxatilis mit nur wenigen roten Einzelfrüchten. Rubus chamaemorus, Torfbrombeere, Multbeere, wie $\mathrm{R}$. saxatilis mit krautigem Stengel, doch nur 8 - I $5 \mathrm{~cm}$ hoch. Die Gattung Rubus ist ausserordentlich vielgestaltig, die einzelnen Arten daher schwer zu bestimmen, besonders da auch viele Bastarde vorkommen.

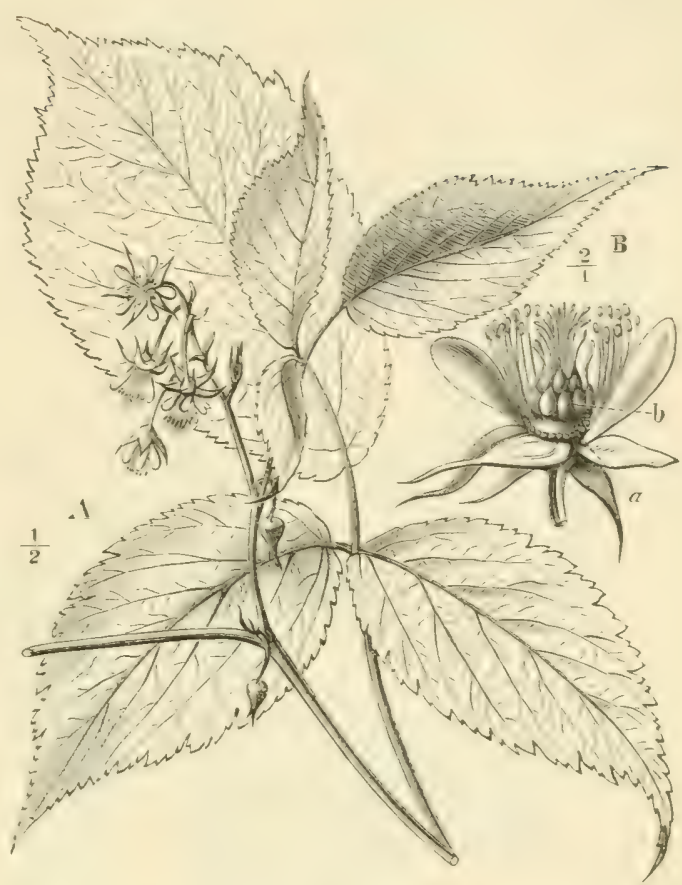

Fig. 33I. Rubus Idaeus. (Sch.)

4. Unterfam. Rosea e.

Das krugförmige Hypanthium umschliesst viele Früchtchen (Fig. 329 C), ist zuletzt fleischig und lebhaft gefärbt (Hagebutte).

\section{Rosa}

canina, Hundsrose, Rosa gallica, Essigrose, R. cinnamomea, Zimmtrose wild. Rosa centifolia, R. damascena kultiviert.

5. Unterfam. Agrimonieae.

Blütenboden trocken, umschliesst die nussartigen Früchtchen. Agrimonia Eu-

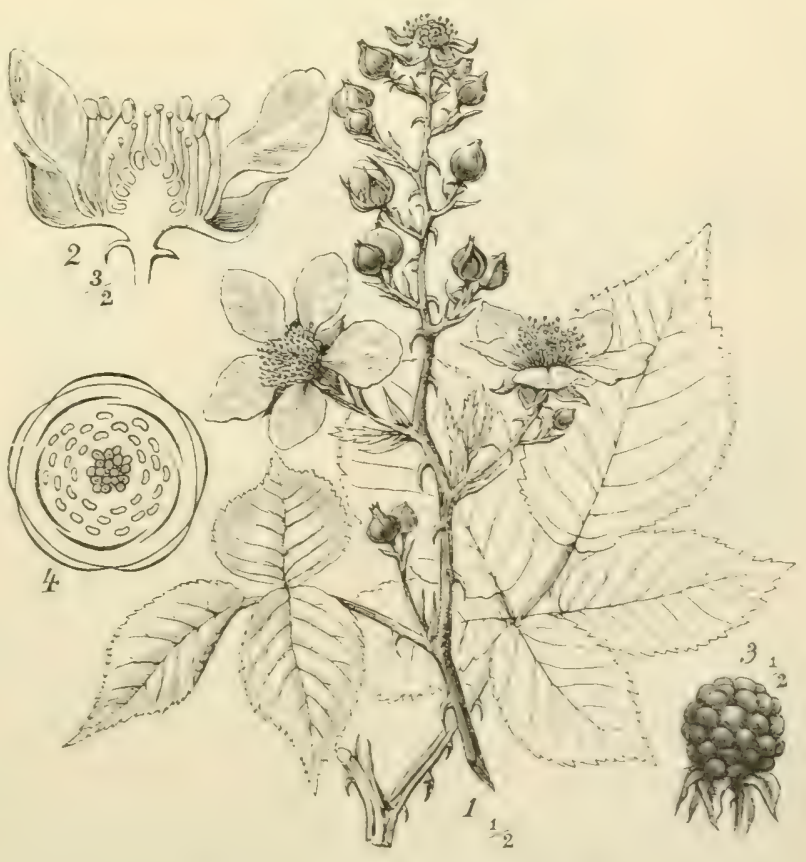

Fig. 332. Rubus fructicosus. (W.) 
patoria, Odermennig. Alchemilla vulgaris und arvensis. Sanguisorba officinalis und minor.

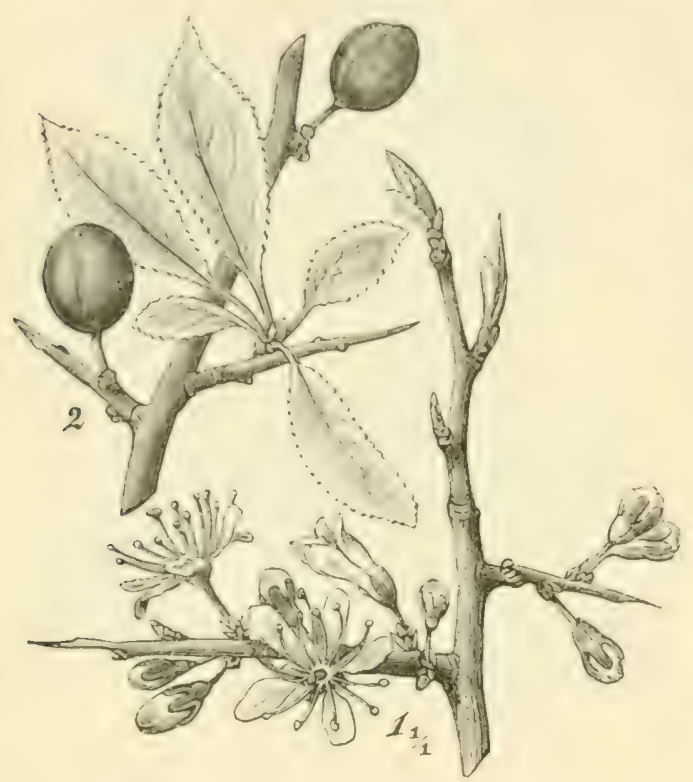

Fig. 333 .

I'runus spinusa. (W.)

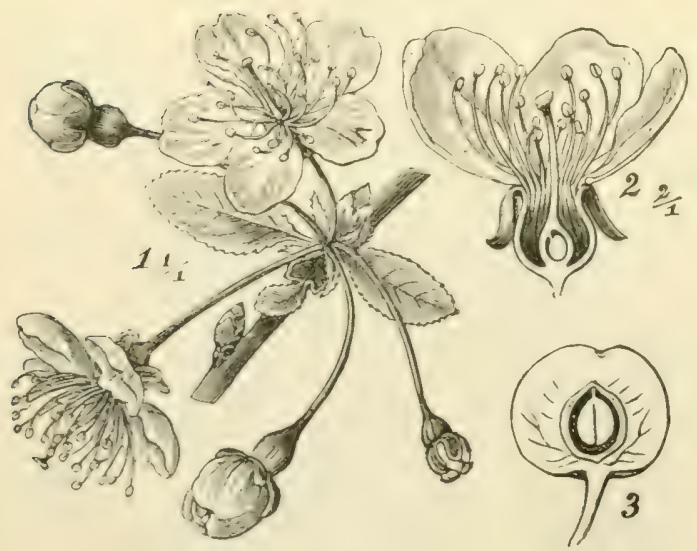

Fig. 334.

Prunus cerasus. (W.)

2. Fam. Amysdalaceac (oder Drupaceac).

Blätter cinfach, Nebenblätter abfallend. Blüten perigyn (Fig. 329 A). K5 $\mathrm{C}_{5} \mathrm{~A}_{2} \mathrm{O}$ -30GI. Der cinblättrige Fruchtknoten mit zwei Samenknospen. Die hier gebildete Steinfrucht ist eine echte Frucht, weil das hinfällige Hypanthium nicht an der Fruchtbildung beteiligt ist.

A m y g d a lus co m $\mathrm{m} u \mathrm{n}$ is L. Gem. Mandelbaum. Steinfrucht mit lederartiger Aussenschicht. Blüte gross. $\mathrm{C}$ hell rosenrot. Mittelmeergebiet, kommt noch in den wärmsten Teilen Deutschlands und Österreichs vor.

Persica vulgaris Mill. Pfirsichbaum. Kern der Steinfrucht grubig, gefurcht. Aussenfrucht fleischig. Blüten einzeln oder paarweise, C hellrosenrot. Gegen Kälte etwas weniger empfindlich als Amygdalus.

Prunus. Steinkern flachgrubig oder glatt. Äusserer Teil der Frucht fleischig.

I. Sektion Armeniaca. Blüten $\mathrm{zu} \mathrm{I}-2$, die sehr kurzgestielte Steinfrucht samtartig behaart. Prunus Armeniaca L. Aprikose. West- und Südeuropa. Wärmere TeileDeutschlands und Österreichs.

2. Sektion Prunophora,

Pflaumen. Blüten zu I-2, länger gestielt. Stein zusammengedrückt.

Prunus domestica L. Gem. Pflaume, Zwetschke, Zwetsche. Blumenblätter grünlich-weiss, April, Mai. Frucht schwarz und blau be- 
reift, länglich, niemals kugelig. In der Kultur ändert die Form und Farbe der Früchte sehr bedeutend ab. Besonders in Südwestdeutschland, Böhmen, Ungarn, Kroatien, Bosnien, dem Orient viel angebaut.

Prunus insititia L. Pflaume. Blüten auf behaartem Stiel. Früchte kugelig, eiförmig oder länglich. Urspünglich schwarz. Durch Kultur werden Reineclaudes, Mirabellen, damascener Pflaumen etc. erzielt.

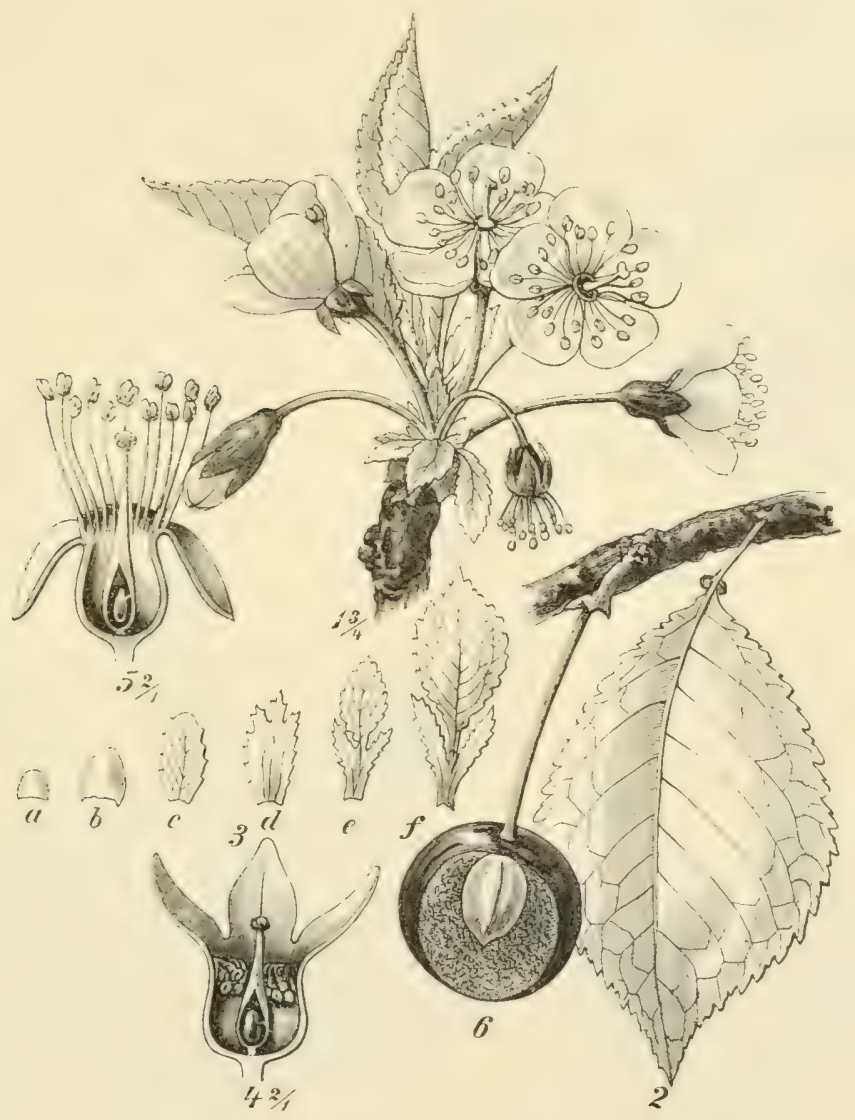

Fig. 335 .

Prunus avium. (Sch.)

Prunus spinosa L. Schlehdorn, Schwarzdorn (Fig. 333). Strauch meist mit dornigen, unregelmässig gebogenen Ästen. Früchte schwarzblau, kleiner als bei den vorigen Arten. Durch ganz Europa mit Ausnahme des Nordens verbreitet. Prunus cerasifera, Kirschenpflaume.

3. Selition Cerasus, Kirschen. Blüten langgestielt an beblätterten Kurztrieben, in einfachen Trugdolden. Kern der Frucht glatt.

Prunus cerasus L. (syn. P. acida Ehrh.). Sauerkirsche (Fig. 334). 


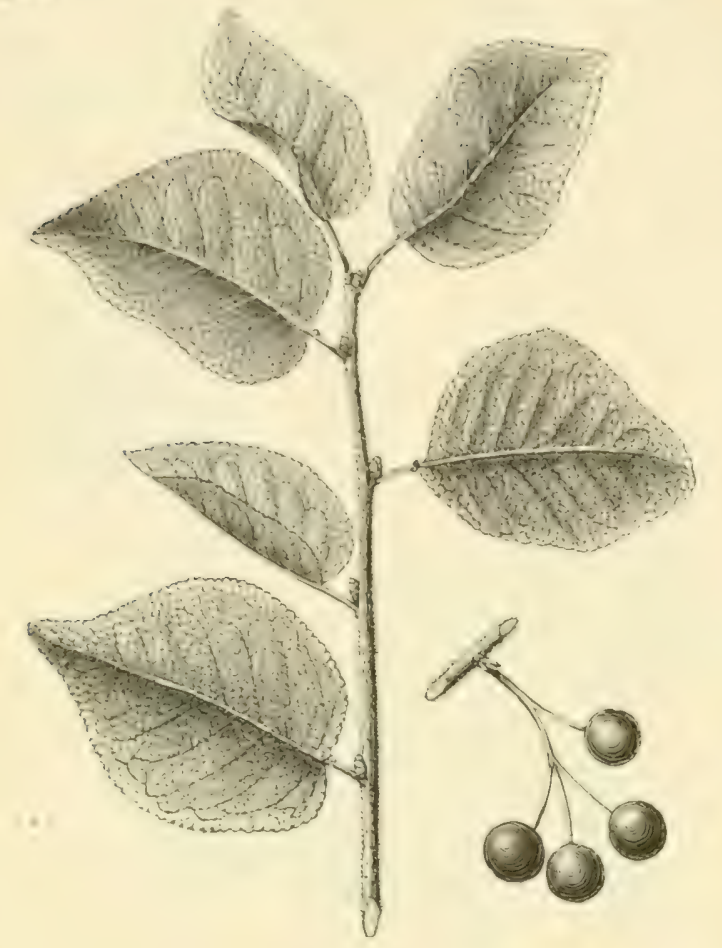

Blïten am Grunde von kleinen grünen Blättern umseben, erscheinen Ende April, Anfang Mai. Die als Ostheimer Kirsche bezeichnete, strauchige Varictät, mit reichlicher Wurzelbrut und Stockausschlag, eignet sich zur Aufforstung trockener Berghänge.

$$
\text { Prunus avium, }
$$

Süss- oder Vogelkirsche (Fig. 335). Wird im Bestandesschluss bis $2 \mathrm{I} \mathrm{m}$ hoch. Blüten schr gross, weiss, am Grunde mit häutigen Knospenschuppen, welche in kleine Laubblätter übergehen (Fig. 335, 3 a-f). P. chamaecerasus, kleiner Strauch.

Fig. 336.

Prunus Mahaleb.

4. Sektion. Padus, Traubenkirschen. Blïten in hängenden Trauben. Früchte kugelig, klein, beerenförmig.

$$
\text { Prunus Mahaleb L. }
$$
Felsenkirsche, echte Weichsel (Fig. 336). Blüten klein. Früchte erbsengross, schwärzlich. Reichlicher Stockausschlag (Weichselrohr). Im Klima des Weinstocks. Prunus Padus L. Ahlkirsche, gem. Traubenkirsche, auch Faulbaum (Fig. 337). Blïten klein, weiss, in reicheren. Trauben als bei P. Mahaleb. Reichlicher Stockausschlag. Auf frischem, hu-

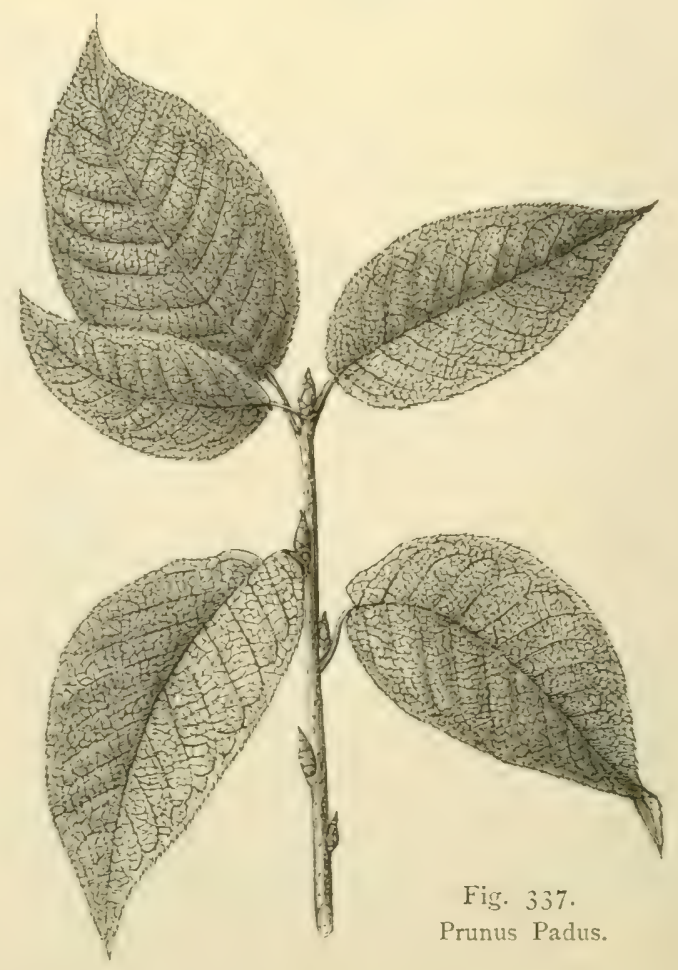


mosem Waldboden sehr verbreitet. Prunus serotina Ehrh. Glänzende, gesägte, steife, kahle, ziemlich langgestielte Blätter. Wird in der Heimat Nordamerika ein hoher Baum. Des guten Holzes wegen dürfte sich der Anbau in Deutschland lohnen. Prunus laurocerasus, Kirschlorbeer, Blätter immergrün, giftig. 3. Fam. Pom a ceae.

I - 5 Fruchtblätter, die ganz oder teilweise untereinander verwachsen und ausserdem mit dem Hypanthium zu einer Scheinfrucht vereinigt sind (Fig. 329 B). Die Wandung des Fruchtknotens wird entweder zum pergamentartigen

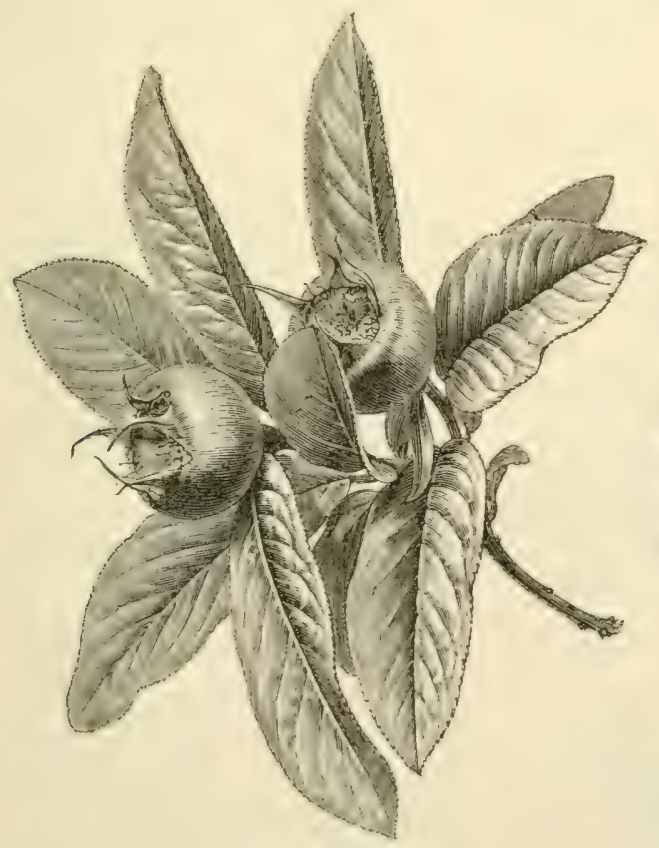

Fig. 339. Mespilus germanica. (K.)

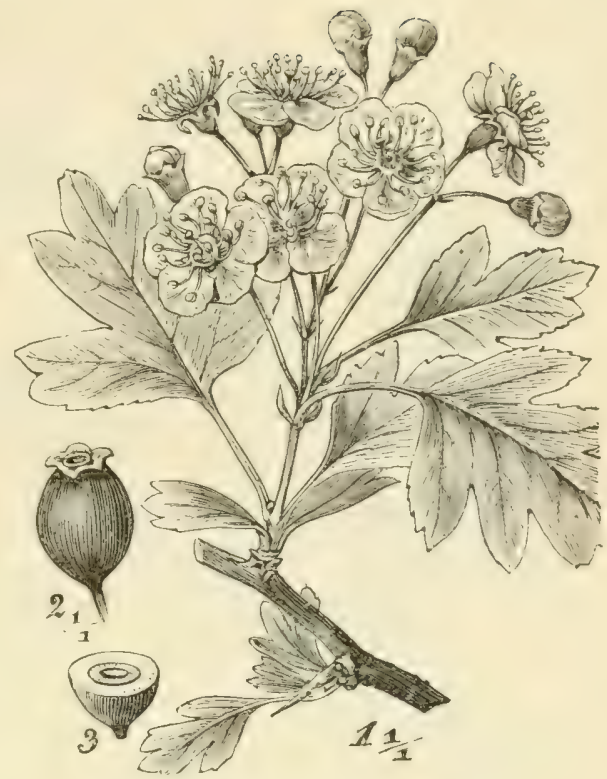

Fig. $33 \mathrm{~S}$.

Crataegus oxyacantha. (W.)

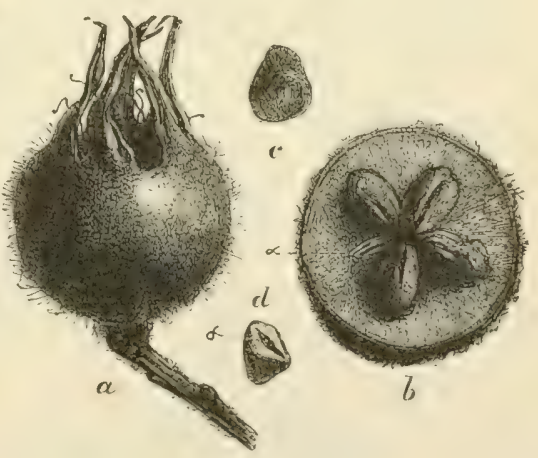

Fig. 340.

Mespilus germanica. (DN.)

„Kerngehäuse“ oder wird steinkernähnlich hart. Das Hypanthium wird fleischig; an der Spitze desselben bleiben Kelchreste erhalten. Blätter einfach, seltener gefiedert, Nebenblätter hinfällig. 


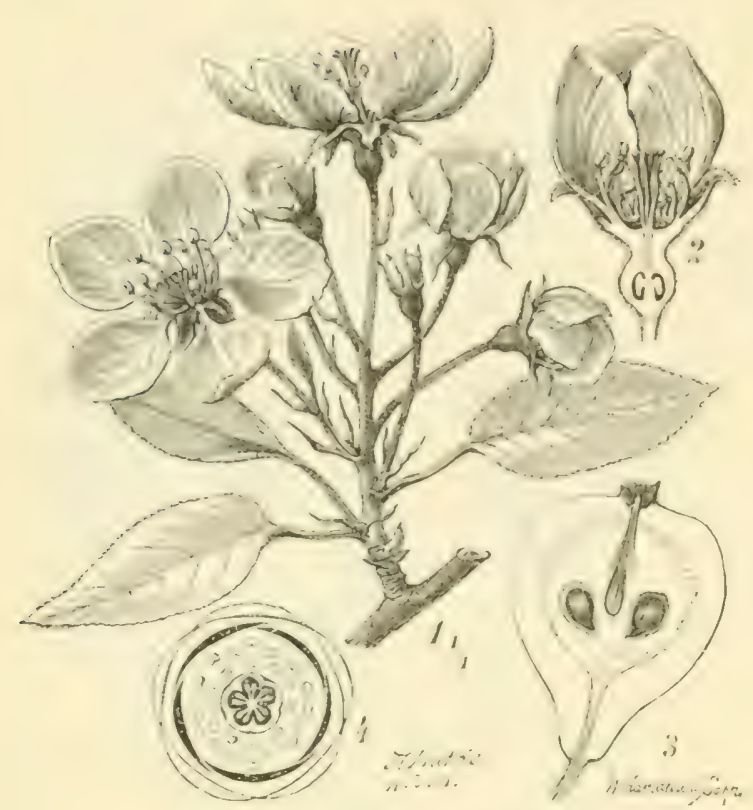

Fig. 34I. Pirus communis.

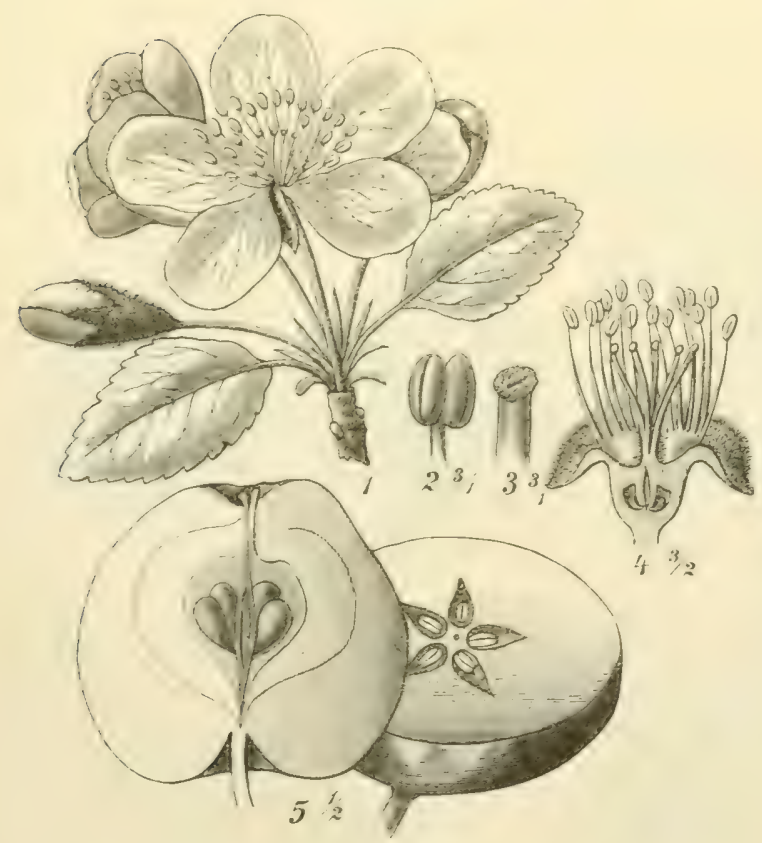

Fig. 342. Pirus malus, (Sch.)
I. Sektion. Mespileac. Scheinfrucht ein Steinapfel, Fruchtlenotenwandung hart.

Cratacous monosyna Jacqu. Strauch, seltener ein Baum. Blïten in Trusdolden stehend, weiss, besitzen nur einen Griffel. Früchte rot, mehlig, an der Spitze mit fünf Kelchzipfeln. Blätter besonders an den Langtrieben mit grossen Nebenblättern, variieren stark. Sehr verbreitet in lichten Wäldern an Waldrändern etc. Häufig in einer rotblühenden $\mathrm{Va}$ rietät als Zicrbaum angepflanzt, sowie zu Hecken verwendet.

Crataegus oxya cantha L. Gem. Weissdorn (Fig. 338). Sehr ähnlich der vorigen Art. $\quad 2-3$ Griffel, etwas kleinere, meist zweisteinige Früchte. In der nördlichen Hälfte Europas häufiger als monogyna. Ausserdem noch verschiedene Arten als Ziergehölze angepflanzt.

Mespilus germanic a L. Mispel. Strauch oder kleiner Baum. Blüte einzeln, gross (Fig. 339). Scheinfrüchte gelbbraun, sehr gross (Fig. 340), nach dem Gefrieren geniessbar. Cotoneaster vulgaris, Bergmispel. Niedriger

Strauch. Früchte klein, mehlig. An felsigen, sonnigen Orten, besonders auf Kalk. 
2. Sektion. Pireae. Scheinfrucht ein Kernapfel, Fruchtknoten pergamentartig.

Cydonia vulgaris Pers., Quitte. Blüten einzeln, gross, Scheinfrucht, gelb, wollig, filzig.

Pirus communis L. Birnbaum (Fig. 34I). Blüten in einfachen Trugdolden. Griffel frei, Antheren rot. Wilde Form mit holzigen Früchten. Blüht April bis Mai. Samen schwarzbraun. Pirus malus L. Apfelbaum (Fig. 342). Antheren gelb, Griffel bis zur Mitte verwachsen. Samen hellbraun. Die wilde Form, var. silvestris in den Früchten variabel, herb, süsslich, holzig, grünlich gelblich-rot. Noch grösser die Variabilität des zahmen Apfelbaums, var. sativa.

Bei Sorbus stehen die Blüten in schirmförmigen, zusammengesetzten Trugdolden.

$$
\text { Sorbus aucu - }
$$

paria L. Eberesche, Vogelbeere (Fig. 343). Baum II.-III. Grösse. Blüten klein, Griffel drei, Früchte rotglänzend, herb. Eine Varietät zeigt süsse Früchte. Sorbus domestica L. Zahme Eberesche, Speierling. Die Blätter wie bei Sorbus

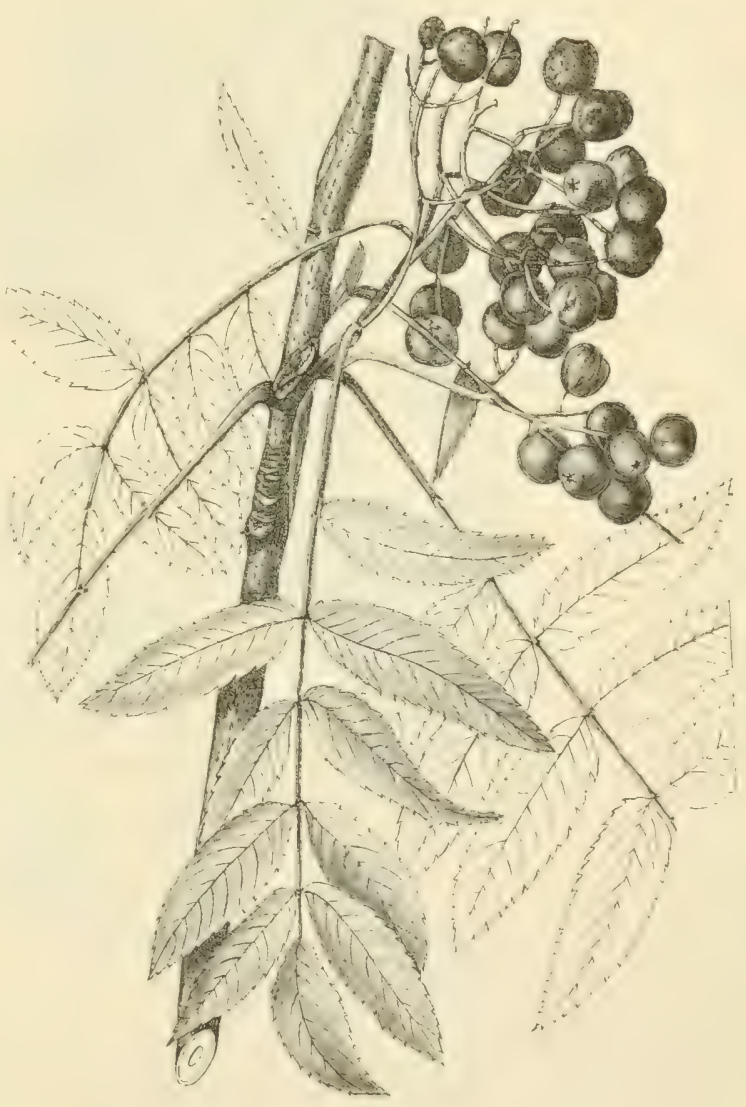

Fig. 343 .

Sorbus aucuparia. aucuparia unpaarig gefiedert mit gesägten Blättchen. Früchte birn- oder apfelförmig. Rheinund Donaugegenden. Sorbus torminalis Crantz. Elzbeere (Fig. 344). Blätter eiförmig, siebenlappig. Früchte anfangs bräunlich-grün, später rot-gelb und braun mit weissen Punkten. Sorbus Aria L. Mehlbeerbaum. Baum II. Grösse. Blätter eiförmig, gesägt oder mit kurzen, gesägten Lappen versehen, derb, unterseits filzig. Früchte rot, meist filzig. Sorbus scandica Fr. (syn. Sorbus intermedia Pers.). Blätter ähnlich wie bei S. Aria, doch stärker gelappt und tiefer eingeschnitten. Sorbus 
hybrida L. (syn. S. fennica C. Koch). Blätter am Grunde sefiedert, an der Spitze nur gelappt. Steht zwischen S. Aria und S. aucuparia.

Amelanchier rotundifolia C. Koch (syn. A. vulgaris Mönch. Felsenbirne. Strauch. Blumenblätter schmal. Früchte blauschwarz,

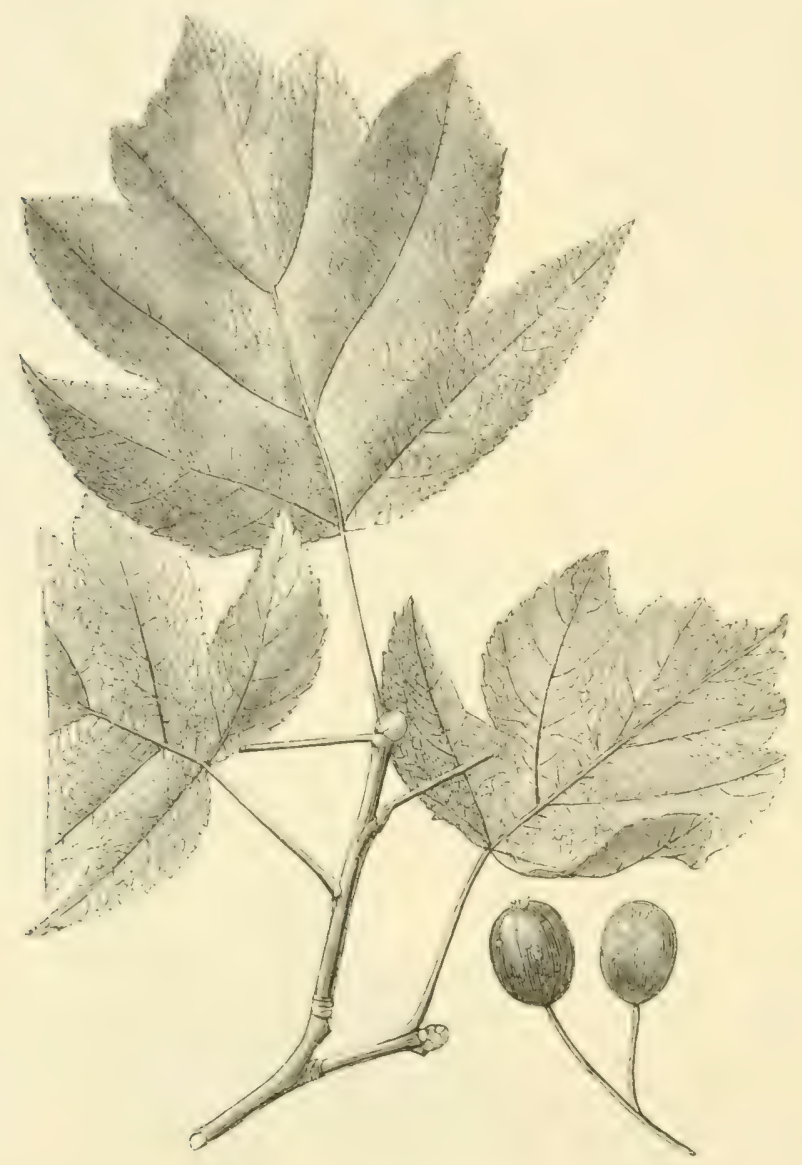

Fig. 344. Sorbus torminalis.

crbsengross. Auf Kalkboden. Fehlt im Nordosten Deutschlands. Amelanchier canadensis. Zierpflanze aus Nordamerika.

4. Fam. Chrysobalanaceae. Tropische Formen, welche mit ihren zygomorphen Blüten den Übergang zu den Leguminosen vermitteln.

\section{§ 93. 20. Ordnung. Leguminosae, Hülsenfrüchte.}

Blüten $\psi, \&$ kurz perigynisch. $\mathrm{K}_{5} \mathrm{C}_{5} \mathrm{~A}(5+5)$ oder 9 zu einem Bündel verwachsen, I frei, oder alle Io Staubblätter frei, $G$ frei. Frucht 
in den meisten Fällen eine Hülse (springt an der Rücken- und Bauchnaht auf). Blätter zusammengesetzt, mit Nebenblättern, spiralig gestellt.

I. Fam. Caesalpiniaceae.

Blätter nicht schmetterlingsförmig (vgl. Fam. 2) jedoch ein wenis zygomorph. Die vorderen Kronenblätter decken die hinteren, der Are zugewendeten Kronenblätter (aufsteigende Deckung). Zehn freie Staubblätter. Fast ausschliesslich tropische Bäume und Sträucher.

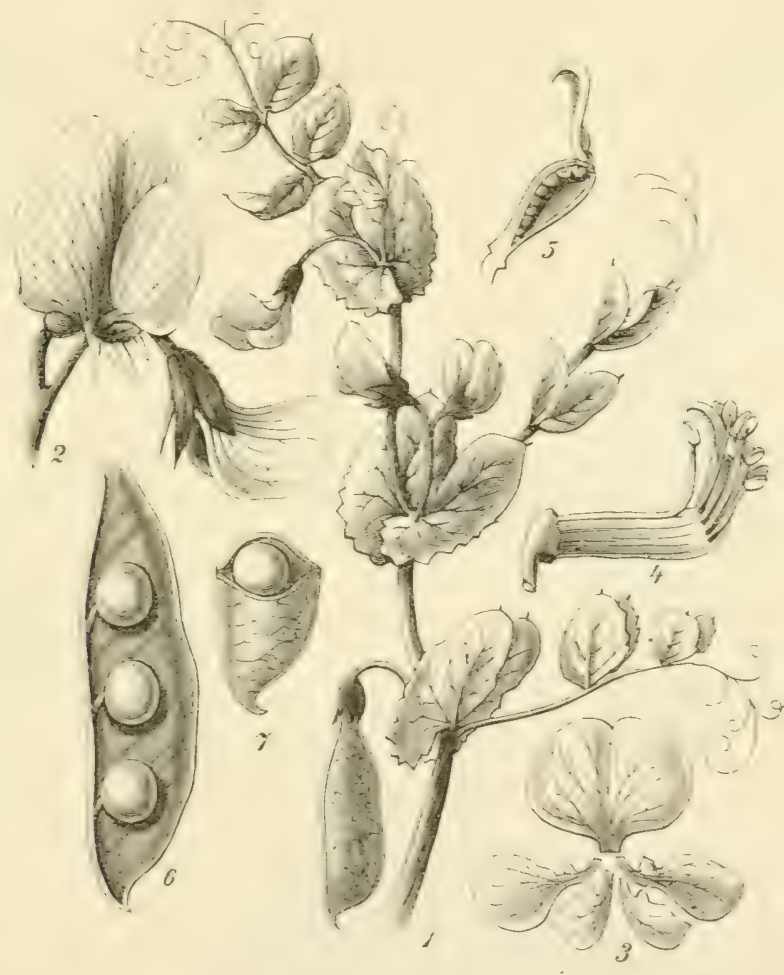

Fig. 345 .

Pisum sativum. (Sch.)

Als Ziergehölze angepflanzt: Cercis Siliquastrum L. Judasbaum. Blätter verkehrt herzförmig. Gleditschia triacanthos L. Christusdorn. Mit verzweigten Dornen. Blätter einfach oder doppelt gefiedert. Gymnocladus canadensis mit wenigen grossen Fiederblättchen.

Tropische Nutzpflanzen: Tamarindus indica, Tamarinde. Cassia acutifolia und ansustifolia liefert Sennesblätter. Copaiferaarten liefern Corainabalsam, Caesalpinia coriaria, Dividivi zum Gerben. Caesalpinia brasiliensis und echinata, Fernambuk- oder Rotholz. Caes. Sappan, Sappanholz. Haematoxylon campechianum, Campeche- oder Blauholz. Swartzia 
tomentosa, südamer. Eisenholz u. v. a. Ceratonia silicua, Johannisbrotbaum im Mittelmeersebiet.

2. Fam. Papilionaceac, Schmetterlingsblütler.

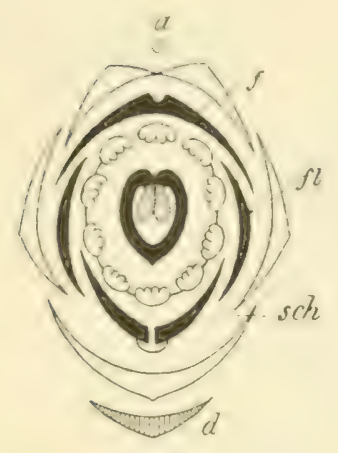

Fig. 346 .

Diagramm der Papilionaceenblïte. a Axe, of Fahne, f Flügel, sch Schiffchen. (K.)

Kelchblïtter verwachsen, Krone schmetterlingsförmig, mit absteigender Deckung. Sie besteht aus fünf Blättern, von denen das oberste als Fahne, vexillum (Fig. 345, 3 und 346 f), zwei seitliche als Flügel, alae (Fig. $346 \mathrm{fl}$ ) bezeichnet werden, während die beiden übrigen Kronblätter zum Schiffchen, carina, verwachsen (Fig. 346, sch). Die Staubblätter ein- oder zweibündelig $(9+1)$. Dic Samen enthalten kein Endosperm, die Cotyledonen reichliche Reservestoffe.

I. Unterfam. Sophoreac. Zehn freie Staubblätter. Sophora japonica. Cladrastis (Virgilia) lutea liefert eine Art Gelbholz. Myroxylon sansonatense liefert peruanischen Balsam. Baptisia (Sophora) tinctoria.

2. Unterfam. Astragaleac. Blätter meist unpaarig gefiedert, ohne Ranken. Blüten in Trauben oder Ähren.

Robinia Pseudacacia L. Robinie, falsche Akazic (Fig. 347). Baum II. Grösse. Sehr lebhafter Stock- und Wurzelausschlag. Blüht

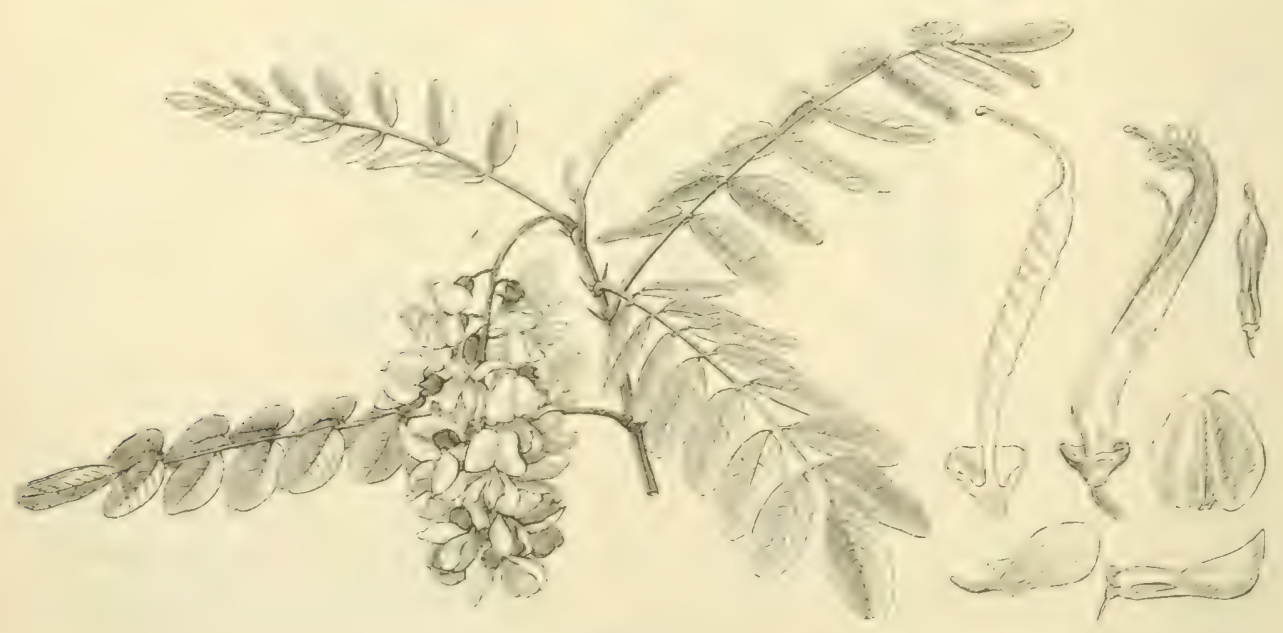

Fig. 347.

Robinia Pseudacacia. (DN.)

im Juni. Reife der Früchte Ende Oktober, Abfall vom Februar an. Samen an der Seite genabelt, schivärzlich, matt, flach.

Kommt auch noch auf sehr geringem Boden fort, Noor- und Thonboden sind ihr zuwider. Sie saugt den Boden jedoch stark aus (wegen 
des hohen Kalibedürfnisses?). Empfindlich gegen Frühfröste. Dürre schadet nicht. Ebenen und Vorberge. Robinia Pseudacacia var. umbraculifera, Kugelakazie.

Robinia hispida L. Blüten rosenrot, Dornen sehr kurz. Robinia viscosa. Blüten gebüschelt, rötlich weiss.

Amorpha fructicosa L. hat nur ein violettes Kronblatt. Nordamerika. Caragana arborescens Lam., Erbsenbaum. Blüten gelb, sehr zahlreich. Stacheln an der Basis der Blätter sehr fein. Aus Sibirien. Colutea arborescens L. Blasenstrauch. Blüten in aufrechten Trauben. Hülsen aufgeblasen. Wistaria (Glycine) frutescens DC., Blüten blau; Wistaria chinensis DC., Blüten rötlich; beide kletternd. Indigofera tinctoria Indigopflanze. Astragalus glycyphyllus, Traganth. Glycyrrhiza glabra, Süssholz.

3. Unterfam. Vicie a e. Blätter paarig gefiedert, Mittelrippe in eine Spitze oder Ranke auslaufend. A zweibündelig. Vicia sativa, Wicke. Vicia cracca, sepium, silvatica u. a. Vicia Faba, Saubohne. Pisum sativum, Erbse (Fig. 345). Lens esculenta, Linse. Lathyrus silvestris, pratensis, Aphaca, Platterbsen. Orobus vernus. Cicer arietinum, Kichererbse. Abrus precatorius, Paternostererbsen. Tropisches Asien.

4. Unterfam. Phaseoleae. Aufrechte oder ohne Ranken schlingende Kräuter. Blätter dreifingerig gefiedert. Blïtenstände zusammengesetzt. Phaseolus vulgaris, gemeine Schminkbohne. Phaseolus multiflorus, Feuerbohne.

5. Unterfam. Trifolieae. Blätter dreifiederig. Blüten in Köpfchen, Trau-
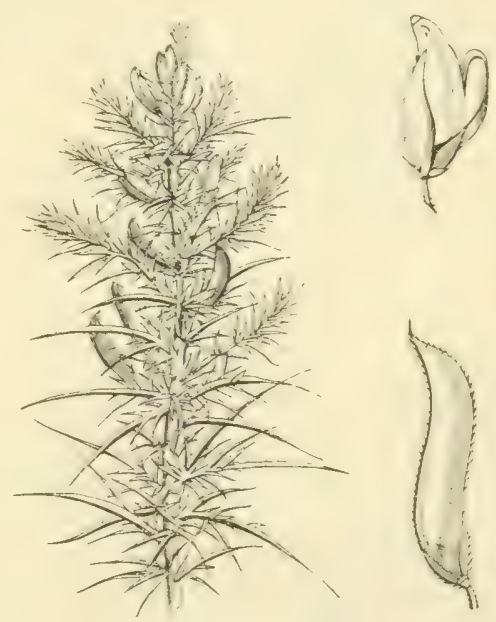

Fig. 348 .

Ulex etropaeus. (K.) ben oder Ähren. Frucht unregelmässig aufspringend oder eine Nuss. Trifolium pratense, hybridum, arvense, repens, montanum, procumbens, verschiedene Kleearten. Medicago sativa, Luzerne. Medicago falcata, schwedische Luzerne. Medicago lupulina, Schneckenklee. Melilotus officinalis und albus, Steinklee. Ononis spinosa, Hauhechel.

6. Unterfam. L otea e. Blätter gefiedert, dreifingerig oder unpaarig gefiedert, das unterste Fiederpaar bis an die Insertionsstelle des Blattes herabgerückt (nebenblattähnlich). Blütendolden oder Köpfchen.

Lotus corniculatus, Hornklee. Lotus uliginosus. Anthyllis vulneraria, Wundklee. Tetragonolobus siliquosus, Flügelerbse.

7. Unterfam. Genisteae. Blätter nur aus einem Endblättchen bestehend oder dreifingerig. Nebenblätter klein oder fehlend. A einbiindelig.

Cytisus Laburnum L. Goldregen, giftig. Grosse hängende Blüten- 
traube. Hülse seidenhaarig. Samen mit seitlichem Nabel, rundlich, glänzend schwar. Ulex europaeus L. Stecheinster, Hecksame (Fig. 348). Samen an der Spitze senabelt, selblich. Spartium scoparium L. (Sarothammus scoparius, Koch), Besenpfrieme. Blïten mit zusammengerolltem Griffel (Fig. 349). Einfache und dreiteilige Blätter (Fig. 350), gesellig wachsender, dichter Strauch. Samen an der Spitze genabelt, braun.
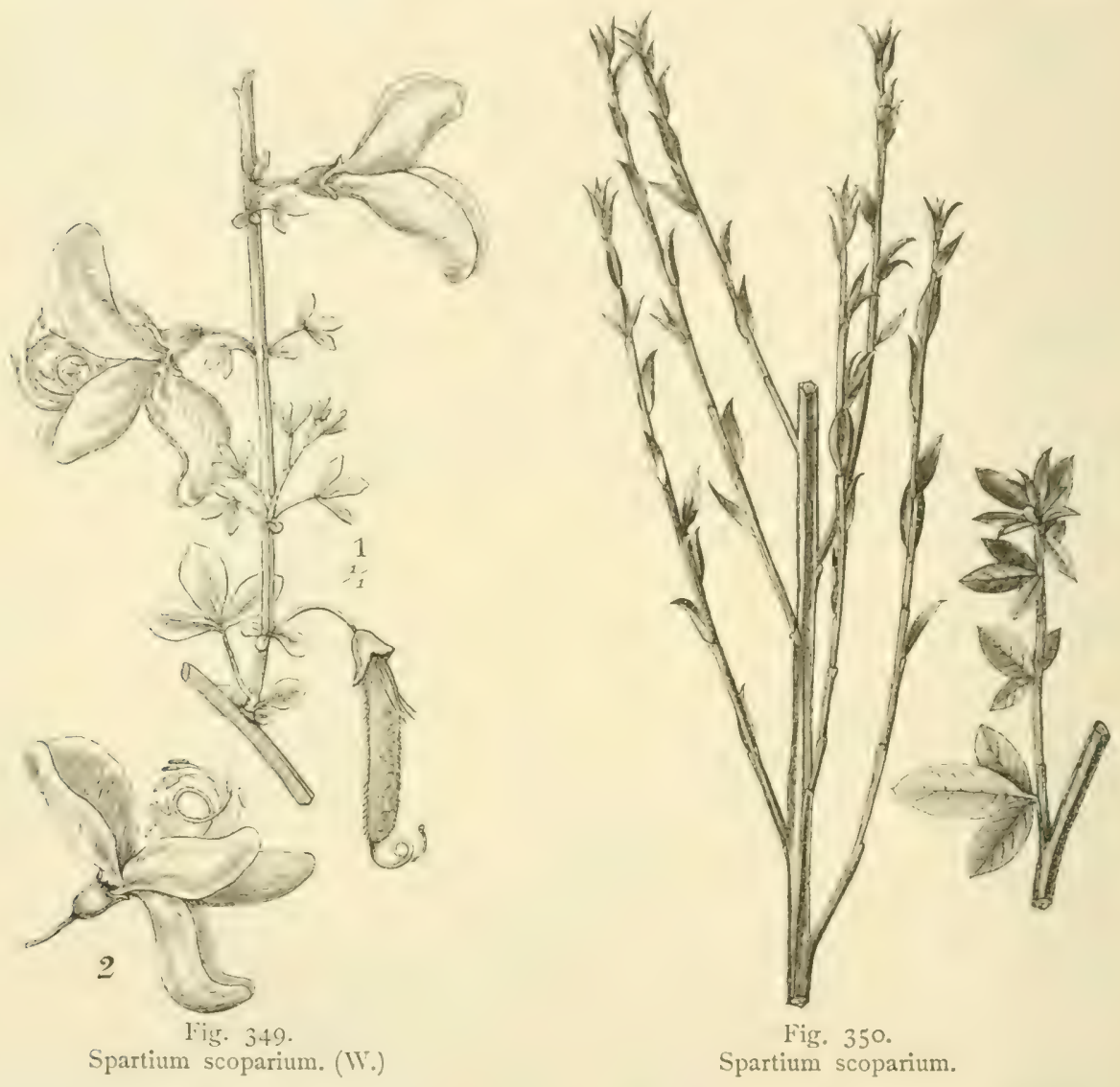

Genista pilosa, germanica, tinctoria, Ginsterarten. Lupinus luteus, angustifolius, einjährig, sowie verschiedene perennierende Lupinusarten.

S. Unterfam. Hedysareae. Fruchtknoten durch Querwände gefächert. Frucht eine Gliederhülse. Onobrychis sativa, Esparsette. Ornithopus sativus, Seradella. Ornithopus perpusillus, Vogelkralle. Hippocrepis comosa, Hufklee. Arachis hypogaea, Erdnuss. Hedysarum gyrans, Telegraphenpflanze (in Gewächshäusern kultiviert).

9. Unterfam. Dalbergieae. Frucht nicht aufspringend, eine Nuss oder Steinfrucht. Pterocarpus santalinus, liefert rotes Sandel- oder Caliaturholz. Ostindien. Dipteryx odorata. Die Samen (Tonkabohnen) sehr wohlriechend. Brasilien. 
3. Fam. Mimosaceae.

Blüten meist actinomorph. $\mathrm{K}$ und $\mathrm{C}$ meist vier- (seltener drei- oder fünfzählig), gewöhnlich vereintblätterig. $A_{3}-a G_{I}$. Blüten klein, in dichten Köpfchen oder Ähren. Meist tropische Pflanzen. Acacia verek u. a. liefern Gummi arabicum. Acacia catechu. Das Holz enthält viel Gerbstoff. Acacia lophantha, Zierpflanze. Mimosa pudica, Sinnpflanze.

\section{S 94. 21. Ordnung. Passiflorinae.}

Blüten * fünfzählig, cyklisch, epi- oder perigynisch. Charakteristisch ist der aus drei Fruchtblättern bestehende einfächerige Fruchtknoten mit drei parietalen Placenten. Griffel meist frei und zweiteilig.

I. Fam. Passifloraceae, Passionsblumen.

2. Fam. Papa y ceae. Carica Papaya, Melonenbaum. Die Früchte enthalten ein Verdauungsferment.

3. Fam. Turneraceae.

4. Fam. Loas aceae.

5. Fam. Datiscaceae.

6. Fam. B e goniace a e, Schiefblattgewächse.

7. Fam. (?) Cucurbitaceae.

Blüten eingeschlechtig, Fruchtknoten unterständig, oberhalb desselben ein napf- oder glockenförmiges Hypanthium. Antheren mit der vereintblätterigen Blumenkrone teilweise oder ganz verwachsen. Mit Ranken kletternde Pflanzen. Bryonia dioica und alba, Zaunrübe, giftig. Cucurbita Pepo, Kürbis. Cucumis sativus, Gurke. Cucumis Melo, Melone. Citrullus vulgaris, Wassermelone. Luffa acutangula. Sicyos angulata. Ecbalium officinale (syn. Momordica elaterium, und Cyclanthera explodens besitzen Schleudervorrichtungen zum Ausstreuen der Samen.

\section{§ 85. 22. Ordnung. Myrtiflorae.}

Blüten *, s, epi- oder perigynisch, meist 4- (seltener 2-6-) zählig, mit $\mathrm{K}$ und $\mathrm{C}$. Androeceum in zwei Kreisen oder $\boldsymbol{\alpha}$, G mehrblätterig mit vollständiger Fächerung und einfachem Griffel. Samenknospen häufig auf centralen Placenten. Blätter meist einfach, gegenständig.

I. Fam. Lythraceae.

Am häufigsten $\mathrm{K} 6 \mathrm{C} 6 \mathrm{~A} 6+6$ oder $6+\mathrm{o} \mathrm{G}(2-6)$, 2-6 fächerig. Lythrum Salicaria, Weiderich. Blüten trimorph.

2. Fam. Melastomaceae.

3. Fam. Oenotheraceae (oder Onagraceae). Meist $\mathrm{K}_{4} \mathrm{C}_{4} \mathrm{~A}_{4}+4$ oder $\mathrm{A}_{4}+\mathrm{O} \mathrm{G}_{(4)}$ auch 2-, 3-, 5 zählig. Griffel verwachsen. Epilobium angustifolium (Fig. 35I), parvifolium, montanum, Weidenröschen. Oenothera biennis, Nachtkerze. Circaea lutetiana, Hexenkraut. Trapa natans, Wassernuss. Fuchsia. 


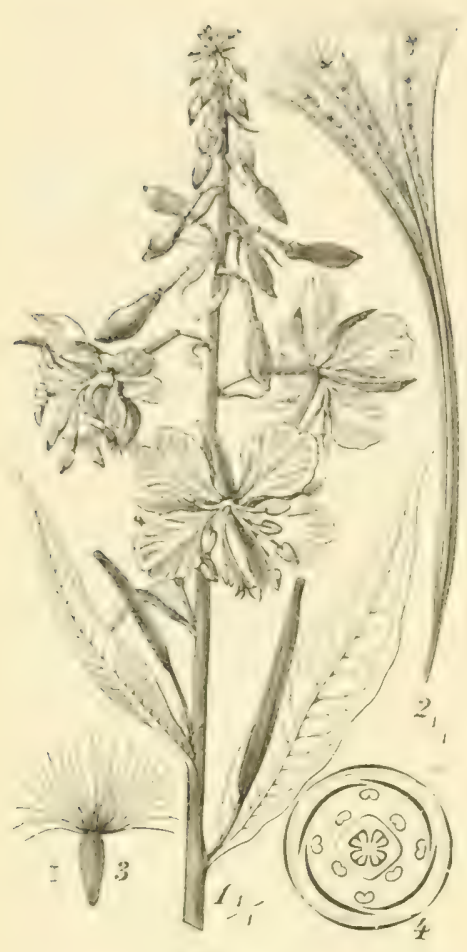

Figr. 351 .

Epilobium angustifolium. (WV.)
4. Fam. Haloragidaceac.

Wie lam. 3, aber Griffel setrennt, Fruchtknotenfächer nur mit einer Samenknospe. Reduktionen häufigs.

Myriophyllum verticillatum und spicatum. Hippuris vulgaris, Tannwedel.

5. Fam. Rhizophoraccac.

Rhizophora Mangle, Mangrove. Tropische Uferpflanzen.

6. Fam. Combretaceac.

7. Fam. Myrtaceac.

Mcist $\mathrm{K}_{4} \mathrm{C}_{4} \mathrm{~A} \propto$ (durch Spaltung aus 4 oder 8) $G_{(2-4)}$. Sträucher oder Bäume.

Eucalyptus globulus, blauer Gummibaum. Myrtus communis Nyrte. Caryophyllus aromaticus liefert Gewürznelken, Pimenta officinalis, Neugewürz oder Piment. Punica Granatum, Granatapfel. Bertholletia excelsa, die Früchte als Paranüsse bekannt.

\section{s 96. 23. Ordnung.}

\section{Umbelliflorae, Doldenpflanzen.}

$\mathrm{K}$ rudimentär, zahnförmig, $\mathrm{C}_{5}$ oder $4 \mathrm{~A}_{5}$ oder $4 \mathrm{G} \overline{(2)}$, selten mehr. An der Basis der freien Griffel ein Diskus. Fruchtknoten vollständig gefächert, in jedem Fach eine Samenknospe. Endosperm vorhanden. Blütenstand eine Dolde.

I. Fam. Cornaceae.

Blüten meist $\mathrm{K}_{4} \mathrm{C}_{4} \mathrm{~A}_{4} \mathrm{G}_{(2)}$. Frucht eine Beere oder Steinfrucht.

Cornus mas L. Gelber Hartriegel, Kornelkirsche, Dürlitze (Fig. 352 und 353). Grosstrauch oder kleiner Baum. Blüten am Ende seitenständiger Kurztriche in büschelförmigen Dolden, gelb, vor Laubausbruch erscheinend. Früchte eine dunkelrote Steinfrucht mit länglichem, zweisamigem Stein, essbar. Holz sehr hart.

Cornus sanguinea L. Gemeiner Hartriegel. Blütendolden langgestielt, schirmförmig, weiss, nach Laubausbruch. Reife Frucht glänzend schwarz.

Cornus suecica, krautig. Nordeuropa. Cornus alba und andere nordamerikanische Arten als Ziersträucher verwendet. Aucuba japonica.

2. Fam. Araliaceac. 
$\mathrm{K}_{5} \mathrm{C}_{5} \mathrm{~A}_{5}-\mathrm{IO} \mathrm{G} \overline{(2-\mathrm{IO})}$. Blütendolden meist traubig oder rispig zusammengesetzt. Steinfrucht oder Beere.

Hedera Helix, Epheu (Fig. 354). Stamm kriechend oder mit

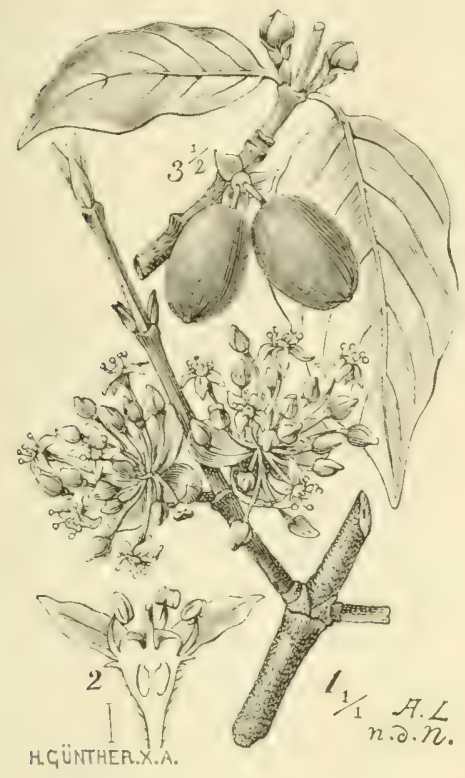

Fig. 352. Cornus mas. (W.)

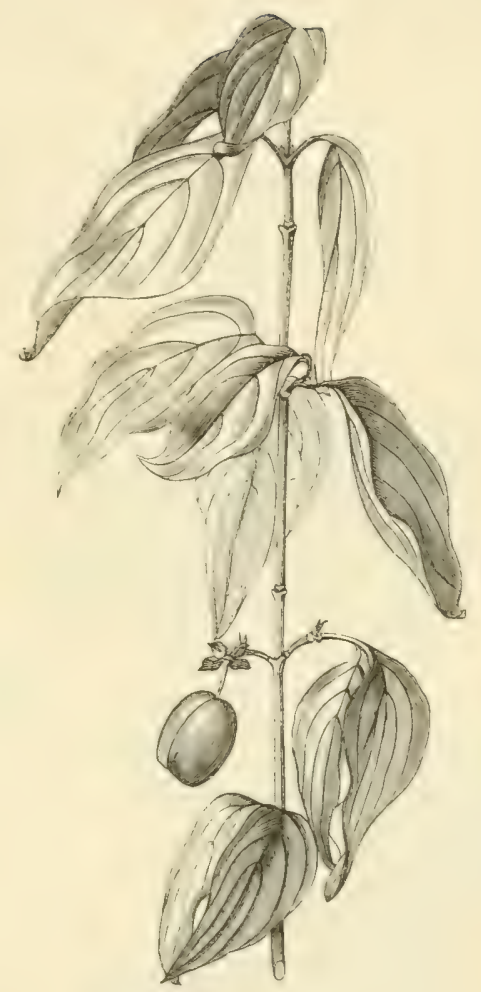

Fig. 353. Cornus mas.

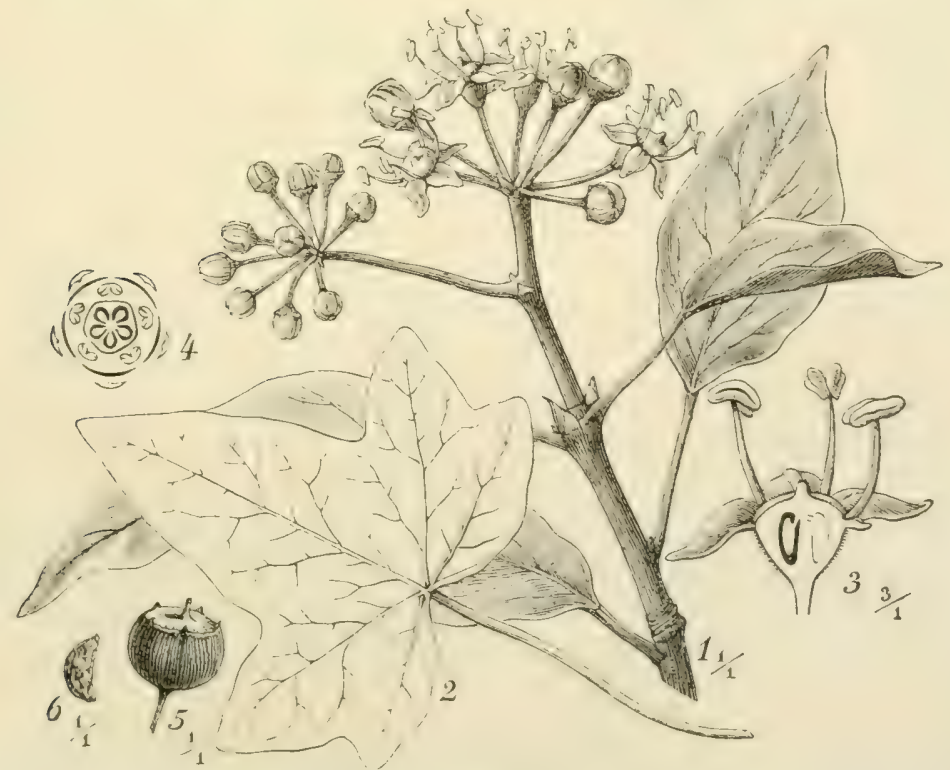

Fig. 354. Hedera Helix. (W.) 
Haftwroln kletternd. Blattform variiert stark. Dic reifen Beeren schwarz.

3. Fam. Umbelliferac.

Die Blïtendolden in der Regel (Ausnahme Hydrocotyleae) aus kleineren Döldchen zusammengesetzt. Dic Basis der zusammengesetzten Dolden wird häufig von Hochblättern umgeben (Hülle, involucrum), ähnliche Blättchen stehen am Grunde der Döldchen (das sog. Hüllchen, involucellum). $\left.\mathrm{K}_{5} \mathrm{C}_{5} \mathrm{~A}_{5} \mathrm{G}_{2}\right)$. Frucht eine zweiteilige Spaltfrucht. Die

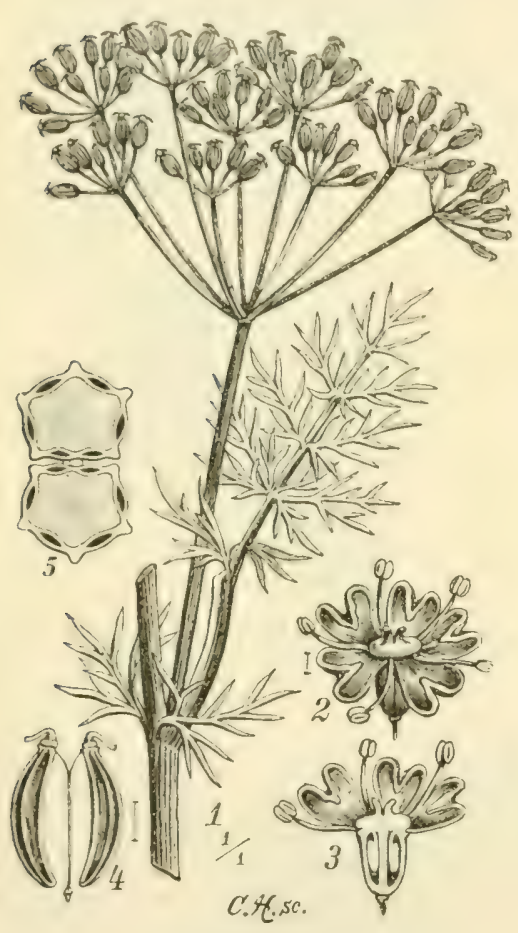

Fig. 355 .

Carum Carvi. (W.) nussartigen Teilfrüchte hängen eine zeitlang an einer Mittelsäule, dem Carpophor (Fis. 355, 4). An der Spitze des Fruchthnotens befindet sich der I)iskus mit zwei Griffeln (Fig. 355, 3). Jede Teilfrucht ist mit fünf Rippen versehen, zwischen welchen ebenso viel Thälchen (valleculae) mit Ölkanälen (Ölstriemen, vittae) liegen können (Fig. 355, 5).

I. Unterfam. Hydrocotyleae. Blüten in Köpfchen oder einfachen Dolden. Hydrocotyle vulgaris. Sanicula europaea. Astrantia major. Eryngium campestre, Männertreu.

2. Unterfam. Ammieae. Jede Teilfrucht mit fünf Rippen. Früchte von der Seite zusammengedrückt, mit einer Furche auf jeder Spaltebene. Cicuta virosa, Wasserschierling. Apium graveolens, Sellerie. Carum carvi, Kümmel (Fig. 355). Petroselinum sativum, Petersilie. Falcaria Rivini (siöides), Sichelwurz. Pimpinella Saxifraga, Bibernell. Aegopodium Podagraria Geissfuss. Conium maculatum, Schierling.

3. Unterfam. Sc andice a e. Frucht länglich oder lineal, von der Seite zusammengedrückt, oben meist in einen Schnabel ausgezogen. Anthriscus silvestris, Kerbel. Chaerophyllum temulum, Kälberkropf.

4. Unterfam. Seselineae. Frucht ellipsoïdisch oder länglich, im Querschnitt einigermassen stielrund. Foeniculum officinale, Fenchel. Aethusa Cynapium, Hundspetersilie. Oenanthe fistulosa, Rebendolde. Oenanthe aquatica (Oe. Phellandrium), Wasserfenchel. Meum athamanticum.

5. Unterfam. Peucedaneae. Frucht stark vom Rücken her zusammengedrückt. Meist geflügelte Seitenrippen. Angelica silvestris, 
Brustwurz. Archangelica officinalis, Engelwurz. Pastinaca sativa, Pastinak. Anethum graveolens, Dill. Heracleum Sphondylium, Bärenklaue.

6. Unterfam. Daucineae. Jede Teilfrucht hat fünf Haupt- und vier Nebenrippen, die oft weiter hervorragen als erstere. Die Ölkanäle liegen unter den Nebenrippen. Daucus carota, Möhre. Coriandrum sativum, Koriander. Torilis anthriscus, Klettenkerbel. Caucalis .daucoïdes, Haftkraut.

\section{\$97. 24. Ordnung. Hysterophyta.}

Meist Schmarotzerpflanzen (Ausnahme Aristolochiaceae), deren Verwandtschaft nicht sicher ist.

I. Fam. Aristolochiaceae.

Asarum europaeum, Haselwurz. Aristolochia Clematitis, Osterluzei (Fig. 229). Aristolochia Sipho.

2. Fam. Santalaceac.

Santalum album liefert wohlriechendes Sandelholz oder Ambraholz; Ostindien. Thesium pratense, montanum.

3. Fam. Olacaceae, den folgenden Familien verwandte tropische Holzpflanzen.

4. Fam. Loranthaceae.

Auf Bäumen schmarotzende Holzpflanzen. Viscum album,

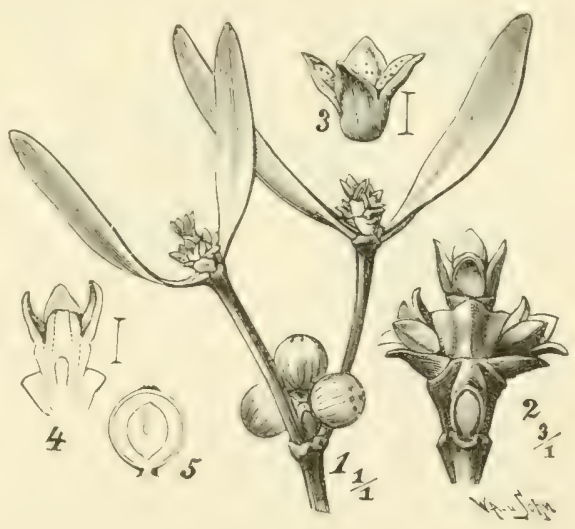

Fig. 356 .

Viscum album. (W.)

Mistel (Fig. 356) schmarotzt auf Kiefern, Tannen, Obstbäumen, besonders auf Pirus-, Sorbusarten, seltener auf Eichen, Birken (vgl. S. I Io). Loranthus europaeus auf Eichen.

5. Fam. Raphlesiaceae und

6. Fam. Balanophoreae, tropische chlorophyllfreie Humusbewohner und Schmarotzer mit grossen Blüten und Blütenständen.

\section{S 98. Sympetalae: 1. Ordnung. Bicornes.}

Blüten $\_$, *, fünf Kreise, 4-5-, selten mehrzählig. C frei oder verwachsen. A obdiplostemonisch oder die (epipetalen) Kronstaubblätter fehlend. Staubblätter in der Regel mit C gar nicht verwachsen, G mehrfächerig mit einem Griffel. Staubbeutel öffnen sich meist mit zwei Löchern (Fig. 358, 3).

I. Fam. Pirolaceae.

Fruchtknoten oberständig. Frucht eine fachspaltige Kapsel. C unter- 
einander meist frei, Antheren olne Anhängsel. Pirola secunda, rotundifolia, minor, uniflora, Wintergrün oder Birnkraut. Monotropa Hypopitys, Fichtenspargel.

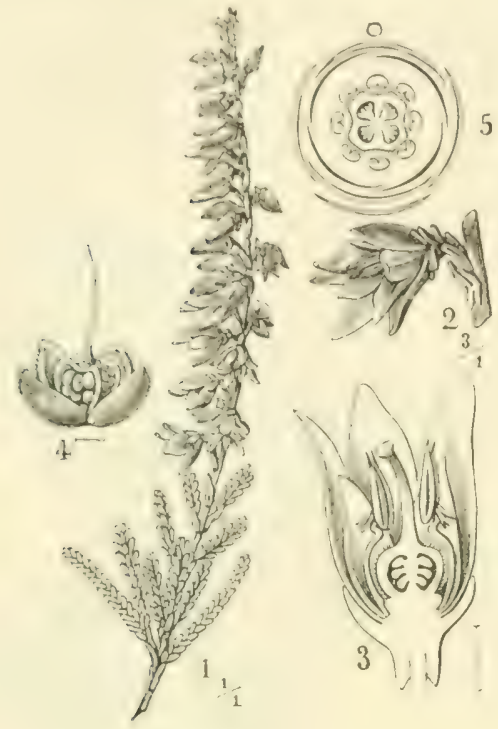

Fig. 357 .

Calluna vulgaris, (IV.)

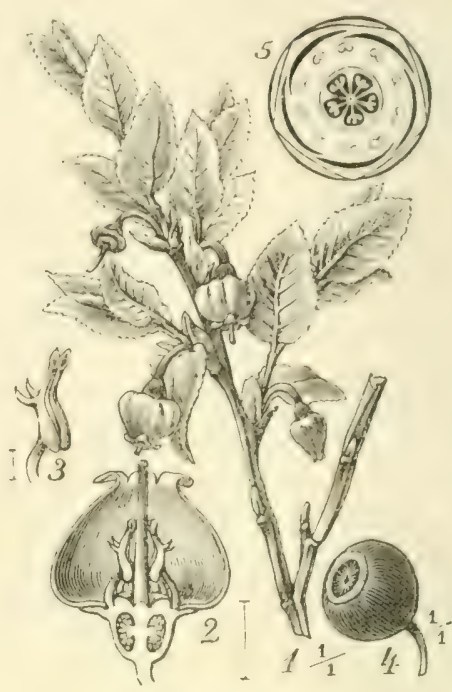

Fig. $35 \mathrm{~S}$.

Vaccinium Myrtillus. (W.)

2. Fam. Ericaceac.

Fruchtknoten oberständig, C vereintblätterig. Antheren zweihörnig. Immergrüne Halbsträucher und Sträucher. Calluna (Erica) vulgaris,

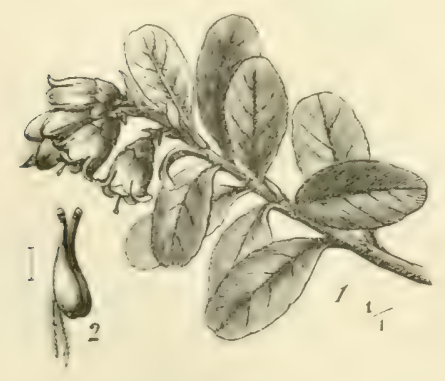

Fig. 359 . Heidekraut (Fig. 35\%). K gefärbt, doppelt so lang als C. Bei Erica Tetralix und E. carnea ist $\mathrm{K}$ kürzer als $\mathrm{C}$. Die Blüten vierzählig. Andromeda polifolia, Blüten fünfzählig. Arctostaphyllos uva ursi, Bärentraube. Arbutus Unedo, Erdbeerbaum.

3. Fam. Rhodoraceae.

Fruchtknoten oberständig, C tiefgeteilt oder freiblätterig. Antheren ohne Anhängsel. Kapsel scheidewandspaltig. Rhododendron hirsutum und ferrugineum, Alpenrose. Ledum palustre, Kienporst. Azalea procumbens.

4. Fam. Diapensiaceae.

5. Fam. Epacrideae.

6. Fam. Vacciniaceae.

Fruchtknoten unterständig. Frucht eine Beere. Antheren gewöhnlich gehörnt. Vaccinium Myrtillus, Heidel-, Bick-, Blaubeere (Fig. 358). 
Blätter sommergrün. V accinium Vitis Idaea (Fig. 359), Preisselbeere. Blätter immergrün. Vaccinium uliginosum, Rausch-, Trunkelbeere und Vaccinium Oxycoccus, Moos-, Krausbeere auf Torfsümpfen.

\section{\$ 99. 2. Ordnung. Diospyrinae.}

Blüten mit fünf Kreisen, $\mathrm{KnC}(\mathrm{n}) \mathrm{An}+\mathrm{nGn}$, wobei $\mathrm{n}$ meist 5 (4-6), seltener $3,7,8$ ist. Der äussere Staubblattkreis oft nur rudimentär. Fruchtknoten mehrfächerig, Frucht eine Beere. Samenanlagen wandständig. Meist tropische Bäume und Sträucher.

1. Fam. Sapotaceae. Milchsaftführend. Isonandra gutta liefert Guttapercha. Sideroxylon tenax und andere Arten, Eisenholz. Bassia butyraceae, Butterbaum.

2. Fam. Ebenaceae. Ohne Milchsaft. Diospyros ebenum, Ebenholz. Diospyros lotus, grünes Ebenholz. Diospyros kaki, chinesische Quitte. Eucleaarten liefern das sog. afrikanische Ebenholz.

3. Fam. Styraceae. Styrax officinalis und Benzoïn officinale liefern balsamische Harze. Halesia tetraptera, Zierstrauch aus Nordamerika.

\section{3. Ordnung. Primulinae.}

Blüte mit fünf Kreisen, $* \mathrm{~K}(\mathrm{n}) \mathrm{C}(\mathrm{n}) \mathrm{Ao}+\mathrm{nGn}$. Der äussere Staubgefässkreis teilweise noch durch Schuppen, Zähne angedeutet. Fruchtknoten einfächerig mit axiler Placenta.

I. Fam. Primulaceae.

Viele Samenanlagen an centraler Placenta. Ein ungeteilter Griffel. Meist fünfzählig. Primula elatior, officinalis, Primel, Himmelsschlüssel Hottonia palustris, Wasserfeder. Lysimachia Nummularia, vulgaris. Anagallis arvensis, Gauchheil. Soldanella montana. Glaux maritima. Trientalis europaea, Siebenstern. Cyclamen europaeum.

2. Fam. Myrsinaceae. Tropische Sträucher und Bäume.

3. Fam. Plumbaginaceae.

$\mathrm{K}_{5} \mathrm{C}_{5} \mathrm{Ao}+{ }_{5} \mathrm{G}(\mathbf{5})$. C fast freiblätterig. Fünf freie Griffel. Fruchtknoten einsamig. Armeria vulgaris, Grasnelke. Statice Limonium, Strandnelke.

\section{4. Ordnung. Tubiflorae.}

Blüten mit vier Kreisen (tetracyklisch). Fruchtknoten oberständig. $\mathrm{K}(5) \mathrm{C}(5) \mathrm{A}_{5} \mathrm{G}(2)$ seltener $\mathrm{G}(3-5)$ ohne Reduktionen.

I. Fam. Polemoniaceae.

2. Fam. Hydrophyllaceae. 


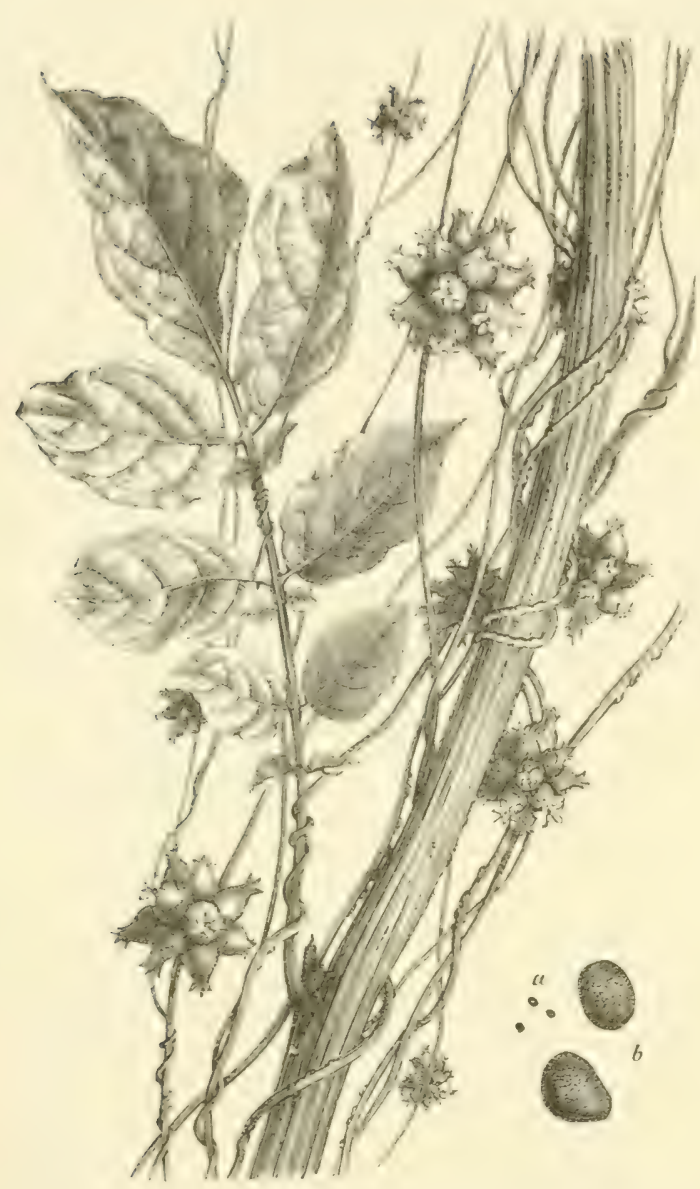

Fig. 360 .

Cuscuta europaea, a Samen in natürlicher Grösse, b Samen vergr. (DN.)

3. Fam. Convolvulaceac. Krone in der Knospenlage sedreht. Fruchtknoten zweifächerig mit I-2 Samenknospen. Meist windende Pflanzen. Convolvulus sepium und arvensis, Winde. Cuscuta epithymum, europaea und epilinum, Seide, Flachsseide, schmarotzende Schlinggewächse mit fadenförmiger Sprossaxe (Fig. 360) die besonders auf Kleefeldern sehr schädlich wirken.

$\$ 102.5$. Ordnung. Personatae.

Blüten tetracyklisch. $G$ oberständig. Aus dem Typus $\mathrm{K}(5) \mathrm{C}(5) \mathrm{A}_{5} \mathrm{G}_{2}$, der sich bei den actinomorphen Blüten findet, gehen zygomorphe Blüten hervor, bei welchen einzelne Glieder unterdrückt sind, so dass bestimmte Arten (Veronica, Plantago) anscheinend vierzählige Blüten haben. Der Fruchtknoten in der Regel zweifächerig, mit vielen Samenanlagen versehen.

\section{Fam. Solanaceac.}

Blüten *, Placenta central. Frucht eine Kapsel: Nicotiana Tabacum und rustica, Tabak. Datura Stramonium, Stechapfel. Hyoscyamus niger, Bilsenkraut. Frucht eine Beere: Solanum tuberosum, Kartoffel. Solanum Lycopersicum, Tomate, Liebesapfel. Solanum Dulcamara, bittersüsser Nachtschatten. Solanum nigrum, schwarzer Nachtschatten (Fig. 36I). Capsicum annuum, spanischer Pfeffer. Atropa Belladonna, Tollkirsche. Physalis Alkekengi, Judenkirsche, Blasenkirsche. Lycium barbarum, Bocksdorn (Fig. 362), Strauch mit dichten, sehr hell berindeten, überhängenden, bedornten oder unbewehrten Ästen. Blätter 5-10 cm lang. Blumenblätter hellviolett. Beeren länglich, scharlachrot. Vielfach angepflanzt. Lycium europaeum. Blätter $\mathrm{I}-2,5 \mathrm{~cm}$ lang. Beeren kugelig, Mittelmeergebiet, selten angepflanzt. 
2. Fam. Scrophulariaceae.

Blüten $\downarrow, \&, \mathrm{~K}_{5} \mathrm{C}(5) \mathrm{A}_{5}$ $\mathrm{G}(2)$, sehr häufig $\mathrm{A}_{4}$ zweimächtig (zwei länger, zwei kürzer) oder A noch weiter reduciert. Frucht eine zweifächerige, zweiklappige Kapsel mit centraler Placenta.

I. Unterfam. Antir rhineae. Absteigende Deckung der Kronzipfel (vgl. S. 345). Keine Schmarotzer. A 5 : Verbascum nigrum, Thapsus, thapsiforme Königskerze, Wollkraut. A4: Scrophularia nodosa, Braunwurz.

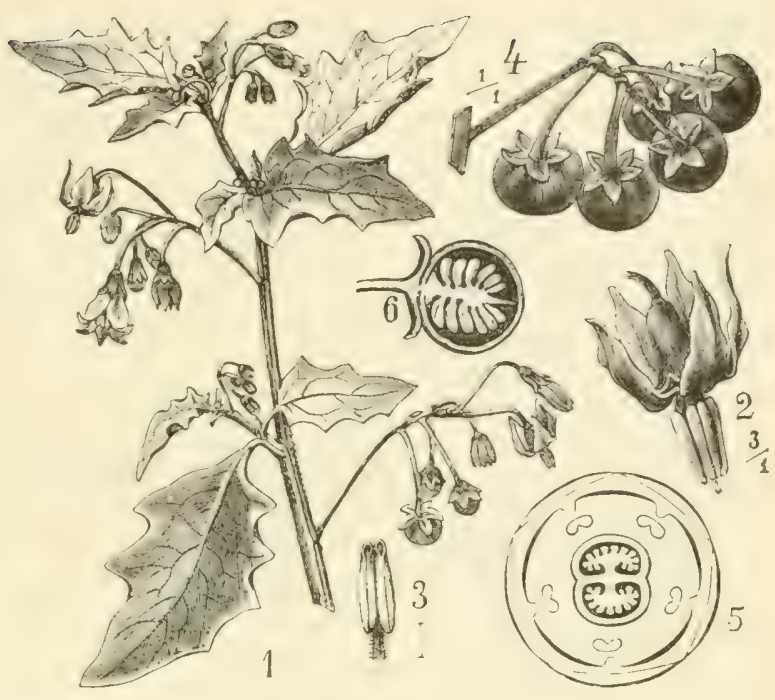

Fig. 361 .

Solanum nigrum. (W.)

Linaria Cymbalaria, vulgaris, Leinkraut, Frauenflachs(Fig.363). Digitalis purpurea, Fingerhut. Mimulus luteus. A 2: Gratiola officinalis, Gnaden-

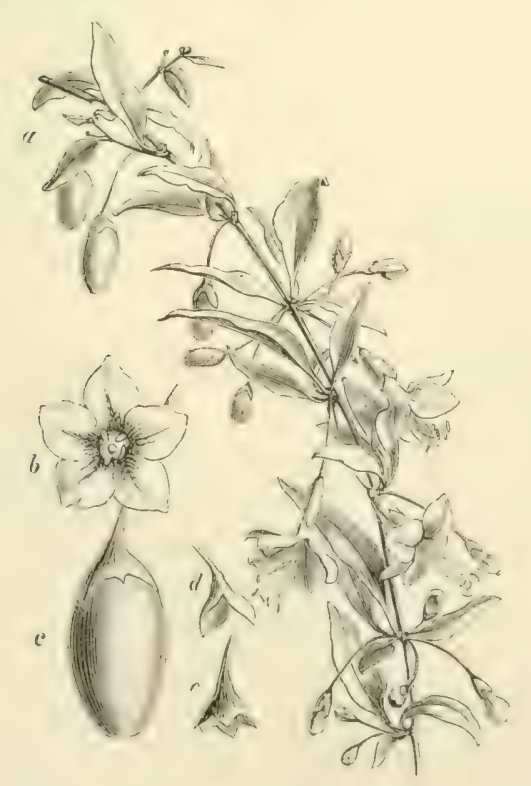

Fig. 362 .

Lycium barbarum. (DN.)

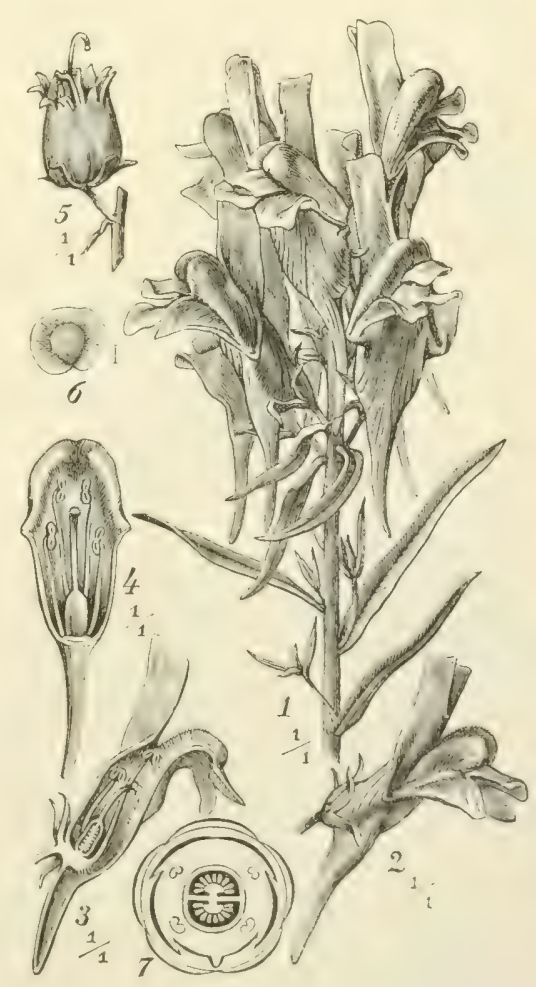

Fig. 363.

Linaria vulgaris. (W.) 
kraut. Veronica Chamaedrys, officinalis, arvensis, hederaefolia, Beccabunga, Ehrenpreis.

2. Unterfam. Rhinantheac. Aufsteigende Deckung der Kronzipfel. Schmarotzer auf Wurzeln von Gräsern und anderen krautigen Pflanzen. Melampyrum pratense, nemorosum u. a. Wachtelweizen. Pedicularis palustris, Läusekraut. Rhinanthus (Alectorolophus) minor und major, Klappertopf. Euphrasia officinalis, Augentrost. Euphrasia Odontites Zahntrost. Lathraea Squammaria schmarotzt auf Wurzeln von Corylus, Alnus etc.

3. Fam. Utriculariaceae.

A 2, Fruchtknoten cinfächerig. Insektenfressende Pflanzen. Pinguicula rulgaris, alpina, Fettkraut (Fig. 65). Utricularia vulgaris, Wasserschlauch.

4. Fam. Gesneraceac.

Parietale Placenten. Orobanche rubens und andere Arten, schmarotzen auf Wurzeln.

5. Fam. Bignoniaceac.

Fast alles Bäume und Sträucher warmer Länder. Sehr häufig kletternde Lianen. A zweimächtig, Blüten erinnern an Digitalis. Blätter gegenständig. Catalpa speciosa Warder. In Nordamerika Baum I. Grösse mit vorzüglichem Holz. Grosse unterseits behaarte Blätter. Früchte bis $50 \mathrm{~cm}$ lange Schotenkapseln. Zum Anbau empfohlen. Erträgt Bodennässe, leidet jung in Norddeutschland durch Frost. Catalpa syiringaefolia Sims. (syn. Catalpa bignonioides Walt., Bignonia Catalpa L.) leidet in Deutschland leicht durch Frost. Jacaranda brasiliana, Palisanderholz. Tecoma (Bignonia) radicans, rankender Zierstrauch.

6. Fam. Pedalin a ce a e. Sesamum orientale und indicum liefern Öl.

7. Fam. Acanthaceae.

8. Fam. Plantagin aceae.

$\mathrm{K}(4) \mathrm{C}(4) \mathrm{A}_{4} \mathrm{G}(2)$. Fruchtknoten zweifächerig. Plantago major, lanceolata, Wegerich. Litorella lacustris, Strandling.

\section{\$ 103. 6. Ordnung. Nuculiferae.}

Blüten tetracyklisch, $\gamma$, bis auf die Mehrzahl der Boraginaceae. $\mathrm{K}$ verwachsen, $\mathrm{C}$ zweilippig, $\mathrm{A}_{5}$ oder 4 (zweimächtig) oder 2. $\mathrm{G}(2)$, durch Einschnürung vom Rücken her entstehen vermittelst einer falschen Scheidewand im Fruchtknoten vier Fächer. Die Frucht eine vierteilise Spaltfrucht, mit vier nussartigen Teilfrüchten. Der Griffel steht in der Mitte der letzteren.

1. Fam. Boragin a ceae (Asperifoliaceae).

Blätter rauh behaart, Blüten in Wickeln, * (Ausnahme die $\downarrow$ Blüten ron Echium und Anchusa arvensis). $\mathrm{K}(5) \mathrm{C}(5) \mathrm{A}_{5} \mathrm{G}(2)$. Jedes der vier Fächer (Klausen) mit je einer Samenknospe. Pulmonaria officinalis, Lungenkraut. 
Lithospermum arrense, Steinsame. Echium vulgare, Natterkopf (Fis. 364). Cynouglossum officinale, Hundszunge. Borago officinalis, Borretsch, Gurkenkraut. Anchusa officinalis, Ochsenzunge. Symphytum officinale, Beinwell. Myosotis palustris, stricta u. a., Vergissmeinnicht.

2. Fam. Cordiaceac,

3. Fam. Verbenaceae.

Blütenstände Trauben, Ähren, Köpfchen, Dichasien. Blüten nicht so stark lippig. $\mathrm{K}(5) \mathrm{C}(5) \mathrm{A}_{4}$ oder $2 \mathrm{G}(2)$ Verbena officinalis, Eisenkraut. Vitex Agnus castus, Keuschbaum. Südeuropäischer Strauch. Tectona grandis, Teakbaum, Thekholz, vorzüglichstes Holz Ostindiens.

4. Fam. Labiatae,

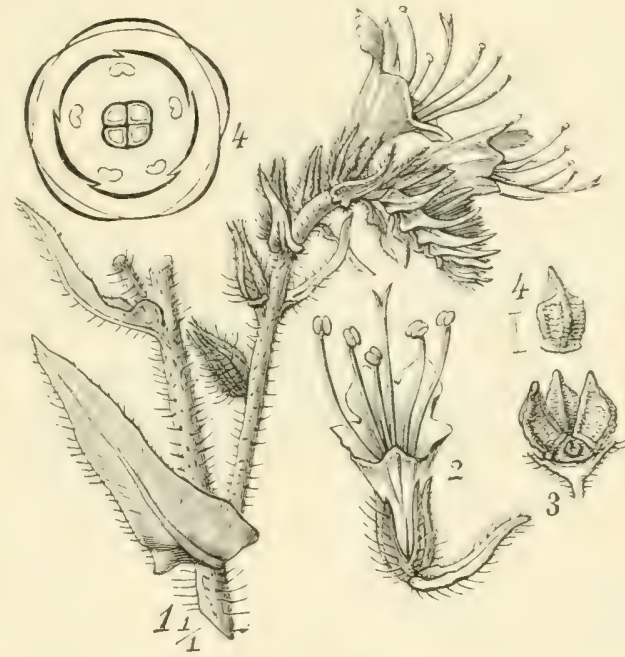

Fig. 364 .

Echium vulgare. (W.) Lippenblütler.

Stengel vierkantig, Blätter gegenständig, Blüten in Doppelwickeln (Schein-

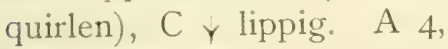
zweimächtig. Reich an ätherischen Ölen.

I. Unterfam. A jugoid eae. Lippenlos oder nur mit Unterlippe. Ajuga reptans, Günsel. Teucrium chamaedrys, montanum, Gamander.

2. Unterfam. Stachyd ea e. Oberlippe stark gewölbt. A4, die zweivorderen länger. Stachys palustris, silvatica, Ziest. Betonica officinalis. Ballota nigra. Galeopsis Tetrahit, versicolor, pubescens. Lamium

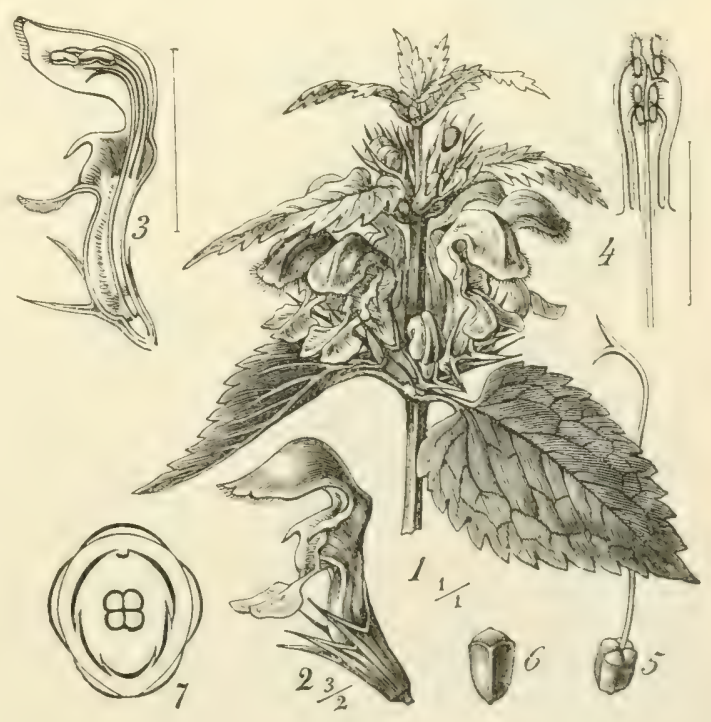

Fig. 365 .

Lamium album. (W.) album Figs. 365 , purjureum, maculatum, Taubnessel. Galeobdolon luteum. Marrubium rulgare. Scutellaria galericulata, Helmkraut. Brunella rulgaris. 
3. Unterfam. Nepeteac. Die hinteren zwei Staubblätter länger. Nepeta Cataria, Katzenminze. Glechoma hederacea, Gundermann.

4. Unterfam. Satureine a e. Oberlippe flach, eiförmig, ausgerandet. A 4, die vorderen Staubblätter länger. Lycopus europaeus. Mentha aquatica, Wasserminze. Mentha piperita, Pfefferminze. Mentha crispa, Krauseminze. Thymus serpyllum, Th. Chamaedrys, Thymian, Quendel. Origanum vulgare, Dost. Calamintha Acinos. Clinopodium vulgare. Lavandula Hysopus. Melissa officinalis, Citronenmelisse. Satureja hortensis, Bohnenkraut.

5. Unterfam. Monardeac. Nur zwei Staubblätter. Salvia pratensis, officinalis, Salbei. Rosmarinus officinalis, Rosmarin. Immergrüiner Strauch.

5. Fam. Selaginaceac.

6. Fam. Globulariaceac.

Blüitenstände ein kugeliges Köpfchen. Globularia vulgaris, Kugelblume.

\section{7. Ordnung. Contortae.}

Blïten tetracyklisch, $\mathrm{G}$ oberständig *, K und C fünf- oder vicrzählig. $\mathrm{A}_{4}$ - $\boldsymbol{x}$ oder $\mathrm{A}_{2} \mathrm{G}(2)$. Krone in der Knospe sehr oft gedreht. Um den

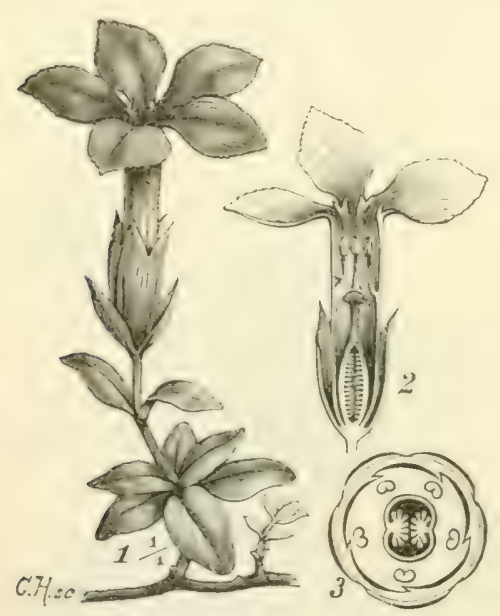

Fig. 366 .

Gentiana verna.

Grund des Fruchtknotens häufig ein Nectarium. Blätter gegenständig ohne Nebenblätter.

I. Fam. Gentianaceae.

Blüten in gabelzweigigen Dichasien. Fruchtblätter vollständig zu einem meist einfächerigen Fruchtknoten verwachsen. Kräuter ohne Milchsaft. Gentiana lutea, germanica, verna (Fig. 366), acaulis, ciliata u. a. Enzian. Erythraea Centaurium, Tausendgüldenkraut. Sivertia perennis. Menyanthes trifoliata, Fieberklee.

2. Fam. A pocynaceac.

Ein Griffel, aber nicht verwachsene Fruchtknotenteile. Frucht besteht aus zwei Balgkapseln. Kleine Sträucher oder Bäume mit Milchsaft. Vinca minor, Sinngrün. Nerium oleander L., Oleander. Blätter in dreigliedrigen Quirlen, dicklederig, lanzettlich, immergrün. Blumenkrone rosenrot. Ziergewächs. 3. Fam. Asclepiadaceae.

$\mathrm{K}_{5} \mathrm{C}(5) \mathrm{A}_{5} \mathrm{G}_{2}$. Fruchtknotenteile unten frei, die oberen Teile des $\mathrm{G}$. zu einem schildförmigen, fünfkantigen Kopf verwachsen. Alle Pollenkörner in einem Fache zu einer Masse verklebt (ähnlich wie bei den Orchideen). Vincetoxicum officinale (syn. Cynanchum Vincetoxicum), Schwalbenwurz. Asclepias syriaca. Periploca graeca. Hoja carnosa. 
4. Fam. Loganiaceae. Strychnos nux romica, Brechnussbaum enthält Strychnin, Stryohnos Castelnaeana, toxifera u. a. Curare.

5. Fam. Oleaceae.

$\mathrm{K}$ und $\mathrm{C}$ vierzählig, vereintblättrig oder frei, manchmal fehlend. C meist klappig. A reduciert, meist 2. G(2) mit zwei Samenanlagen in in jedem Fach.

I. Unterfam. Fraxineae.

Frucht eine Kapsel oder geflügelte Nuss.

Fraxinusornus L. (syn. Ornus europaea Pers.). Mannaesche, Blumenesche (Fig. 36\%). Blüten in reichverzweigten hängenden Sträussen. $\mathrm{K}_{4} \mathrm{C}_{4}$ (frei) $\mathrm{A}_{2}$ $G(2)$. Aus der Rinde fliesst in Südeuropa Manna aus. Südlich der Alpen und Ungarn. Angepflanzt auch im Rheinthal, Elsass.

Fraxinus excelsior L. Gemeine Esche (Fig. 368). Baum I. Grösse, mit einer kegelförmigen Krone. Pfahlwurzel mit umfangreichen Nebenwurzeln. Die Varietät monophylla zeigt keine gefiederten sondern einfache Blätter. Blüten in Büscheln oder trugdoldigen Sträussen erscheinen Ende April, Mai vor Laubausbruch.

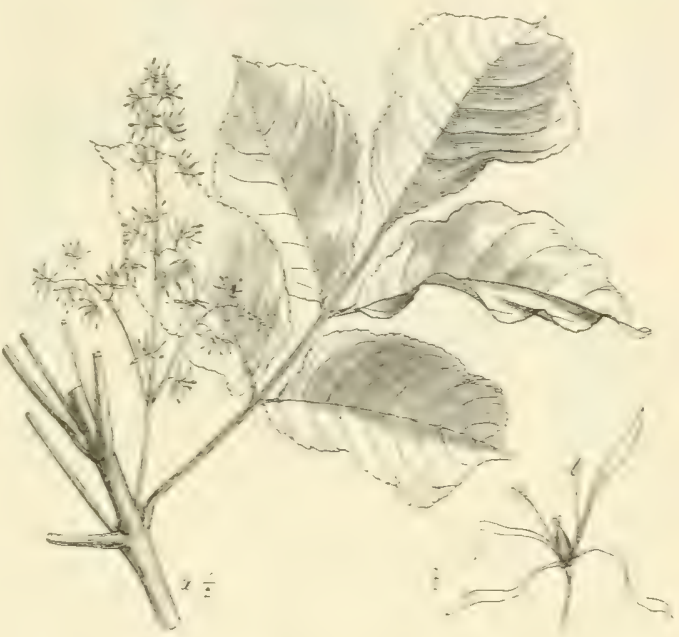

Fig. 360 .

Fraxinus ornus. (DN.)

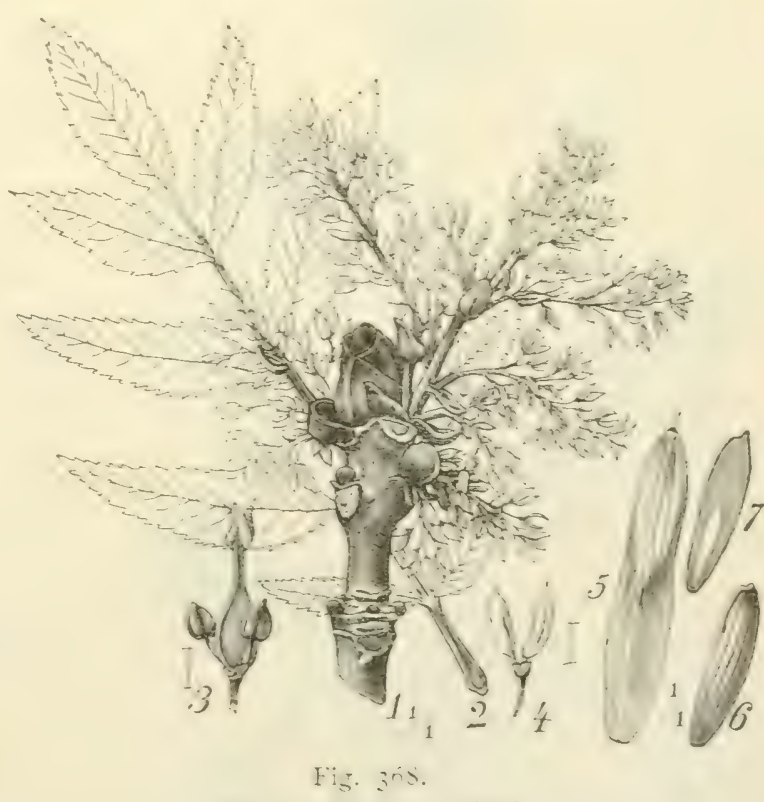

Fraxinus excelsior. (WV.) Polygam oder diöcisch.

$\mathrm{K}$ sehr klein oder fehlend. C fehlend. Die o Blüten bestehen nur aus zwei Staubblättern, die $\subseteq$ Blüten aus dem Fruchthnoten, die Zwitterblüten aus 


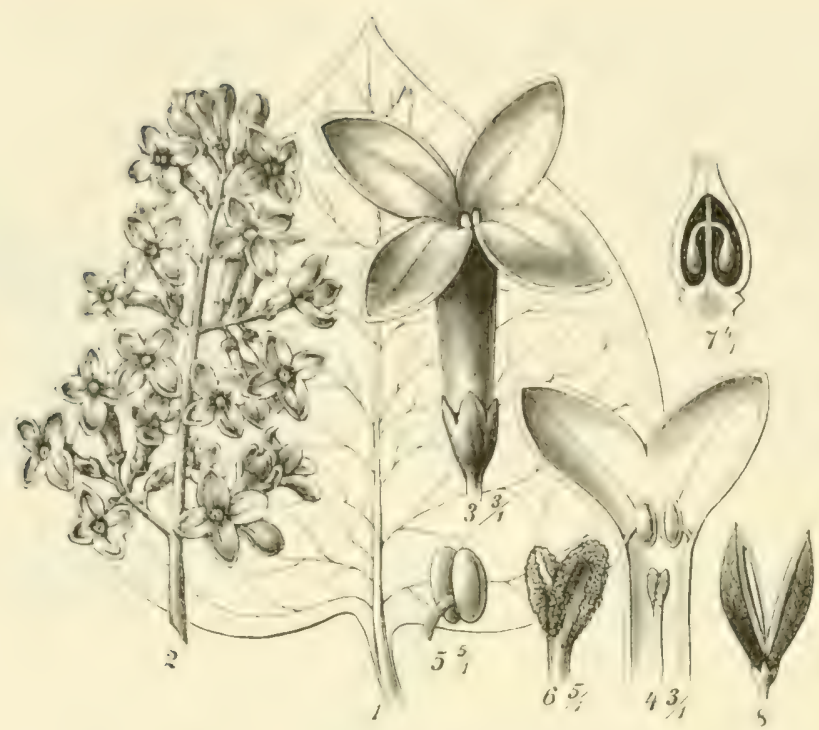

Fig. 369. Syringa vulgaris. (Sch.)

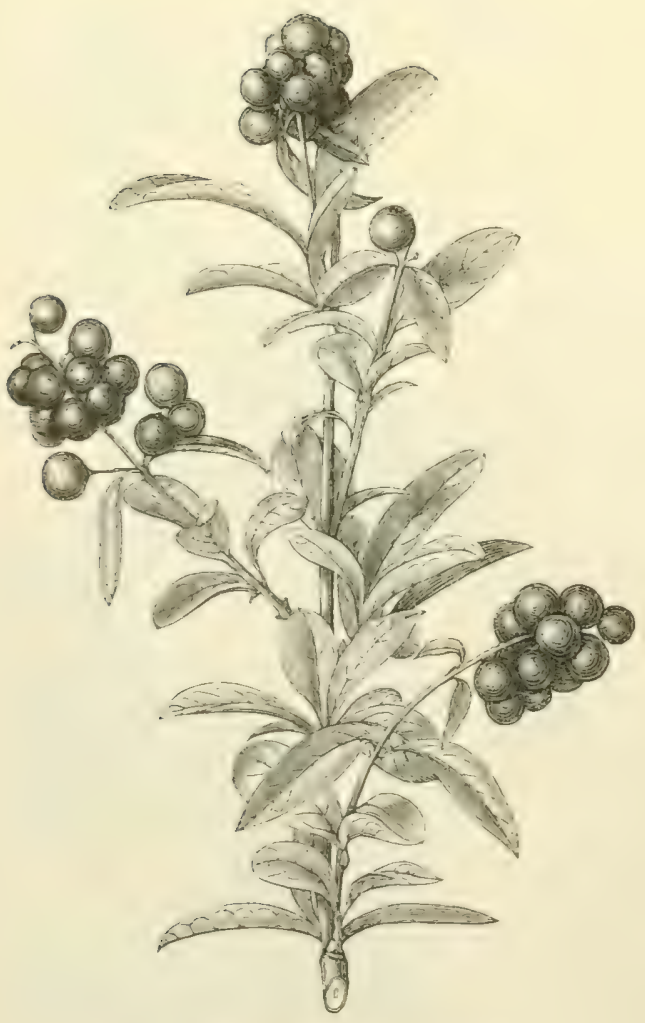

Fig. 370. Ligustrum vulgare. zwei Staubblättern und dem Fruchtknoten. Antheren dunkelviolett oder rot. Frucht eine geflügelte Nuss, durch Fehlschlagen des einen Fruchtknotenfachs und dreier Samenknospen einsamig. Reife September, Oktober. Abfall im Winter. Mannbar vom 40. Jahre ab. Dic Esche ist gegen Spätfrost sehr empfindlich, ebenso gegen Dürre. Verlangt sehr kräftigen, feuchten Boden. Flussniederungen, Auen, Vorberge Mitteleuropas.

Fraxinus americana L. Weissesche. Blätter gross, aus 7-9 Fiederblättchen bestehend, die letzteren gestielt, am Mittelnerv filzig. Frosthart, verträgt Nässe sehr gut. $\mathrm{Zu}$ Anbauversuchen empfohlen.

Fraxinus pubescens Lam. Blätter nur mit fünf Fiederblättchen, das endständige lang 
gestielt. Holz minderwertig, leidet durch Frost. Zum Anbau nicht zu empfehlen. Nordamerika.

Syringa vulgaris L., Gemeiner Flieder, auch Hollunder (Fig. 369). K klein, C vierlappig. Frucht eine zweiklappige Kapsel.

2. Unterfam. Ole in a e.

Frucht eine Beere oder Steinfrucht.

Ligustrum vulgare L., Liguster, Rainweide, Zaunriegel (Fig. 370). Strauch bis $3 \mathrm{~m}$ hoch werdend. Gutes Ausschlagvermögen. Blüten in aufrechten Sträussen. Beeren glänzend schwarz. In Mitteldeutschland häufig verwildert.

Olea europaea L., Ölbaum

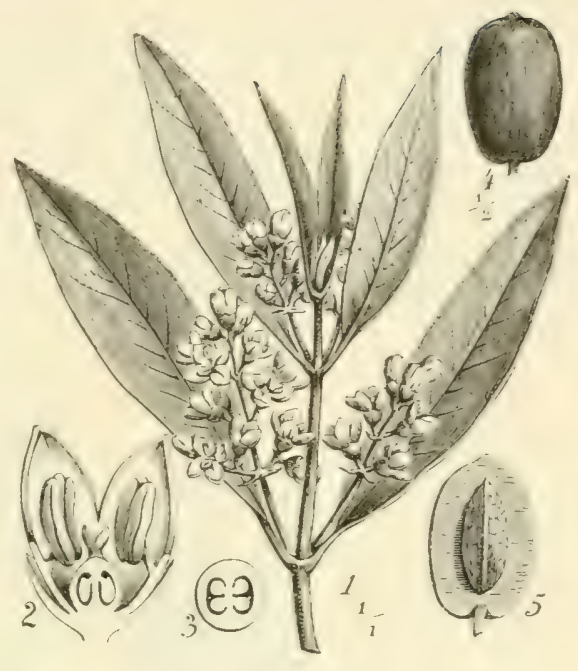

Fig. 371

Olea europaea. (W.) (Fig. 37r). Frucht eine Steinfrucht, liefert das Olivenöl. Mittelmeergebiet.

\section{\$ 105. 8. Ordnung. Rubiales.}

Blüten tetracyklisch, G unterständig. Gewöhnlich fünfzählig. $\mathrm{K}_{5}\left[\mathrm{C}(5) \mathrm{A}_{5}\right] \mathrm{G} \overline{(2-5)} \mathrm{K}$ klein, A teilweise reduciert. Blätter gegenständig oder, wo die Nebenblätter zu blattgleichen Gebilden verschmolzen sind, scheinbar quirlig.

I. Fam. Rubiaceae.

Blüten s, * vier- oder fünfzählig. $\mathrm{C}$ in der Knospenlage klappig. Fruchtknoten gewöhnlich zweifächerig. Blätter gegenständig mit meist verwachsenen Nebenblättern. Asperula odorata, Waldmeister. Galium MIolugo, Aparine, palustre u. a., Labkraut. Sherardia arvensis. Rubia tinctorum, Krapp. Ausserdem viele

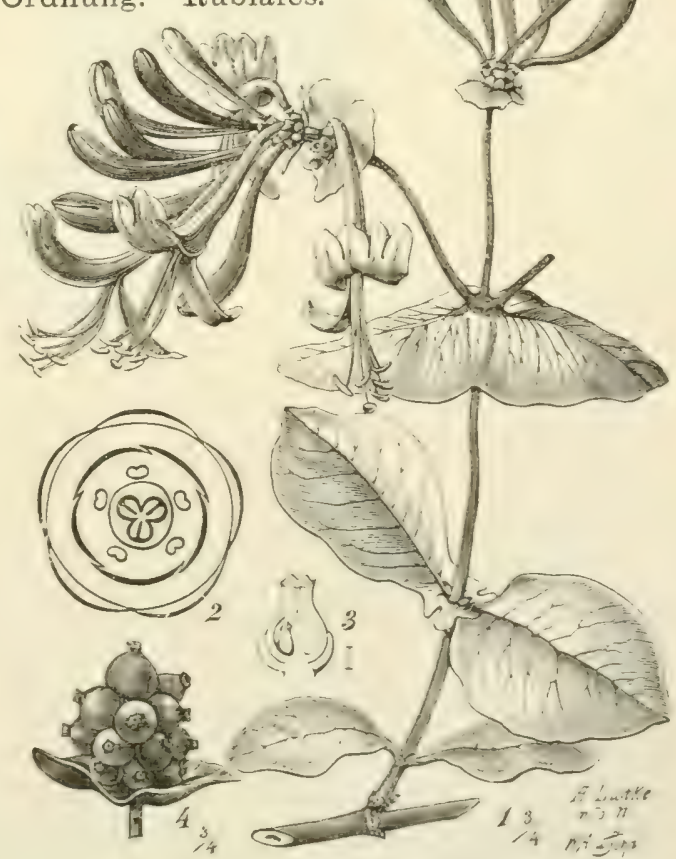

Fig. 372. Lonicera Caprifolium. (WV.) 
Gattungen warmer Länder: Cinchona Calisaya, succirubra, officinalis liefern Chinin und ähnliche Alkaloide haltige Rinden. Coffea arabica, Kaffecbaum.

2. Fam. Caprifoliaceac.

Blüten * oder $\downarrow \mathrm{G}_{(3-5)}$ meist $\mathrm{G}_{3}$. Frucht eine Becre oder Steinfrucht. Nebenblätter meist fehlend, wenn vorhanden, nur klein und nicht verwachsen. Meist Sträucher oder Bäume.

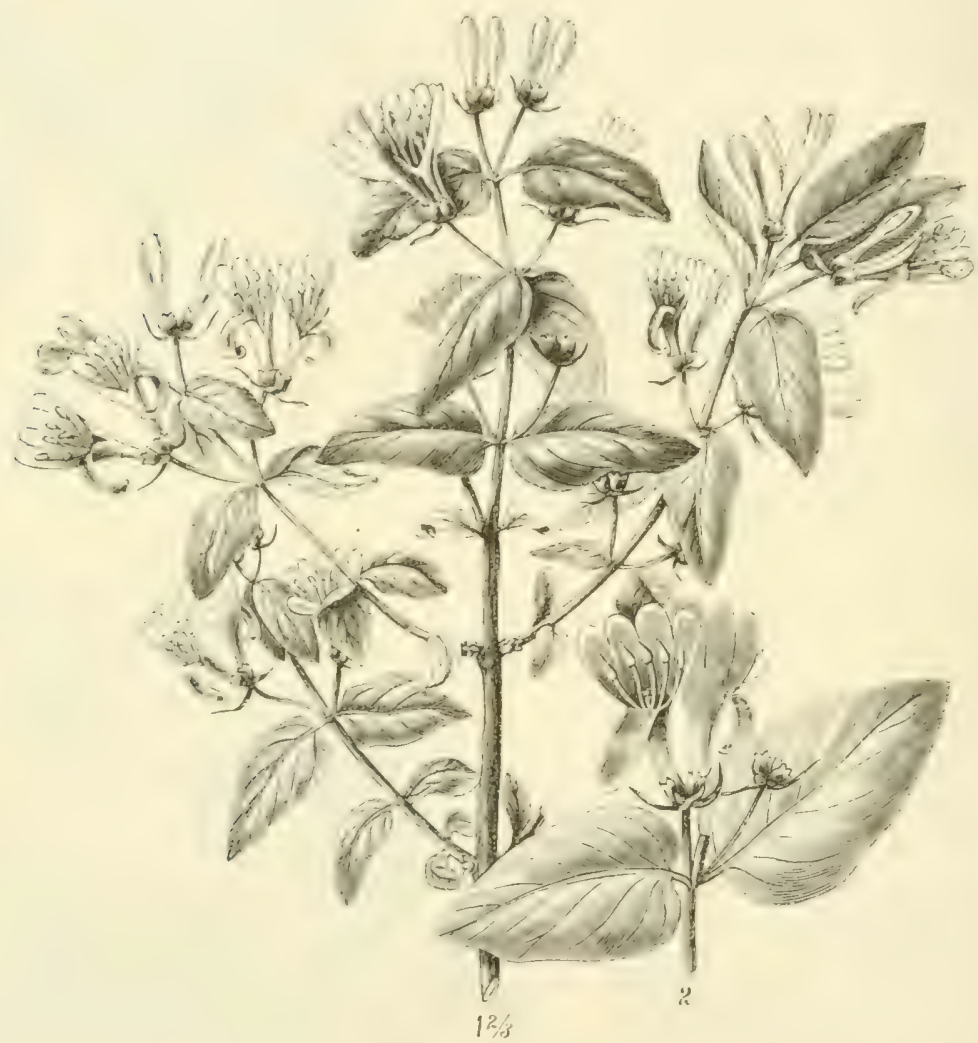

Fig. 373 .

Lonicera tartarica. (Sch.)

I. Unterfam. Lonicereae.

C röhrenförmig oder glockig, gewöhnlich $\downarrow$. Frucht meist eine Beere. In den Fruchtknotenfächern mehrere Samenknospen.

Lonicera Caprifolium L., Wohlriechendes Geissblatt, Jelängerjelieber (Fis. 3;2). Schlingender Strauch. Blïtenstände gedrängte Köpfchen, aus Dichasien bestehend. C mit vierlappiger Oberlippe und einlappiger Unterlippe. Beeren kugelig, scharlachrot, nicht verwachsen. Gartenpflanze, stellenweis verwildert.

Lonicera Periclymenum L., Gemeines Geissblatt. Der vorigen 
Art ähnlich. Schnürt jüngere Bäume ein (vgl. S. I30). Besonders auf feuchtem humosen Boden.

Lonicera Xylosteum L., Gemeine. Heckenkirsche, wie die folgenden Arten aufrechte Sträucher. Je zwei Blüten zusammenstehend (vgl. Fig. 373). Beeren rot, zur Hälfte verwachsen. Besonders auf Kalkboden häufig. Ähnlich Lonicera nigra, besonders in Gebirgswaldungen, Lonicera alpigena, und die in Gartenanlagen häufig angepflanzte Lonicera tartarica (Fig. 373). Bei Lonicera coerulea sind die Beeren ganz verschmolzen.

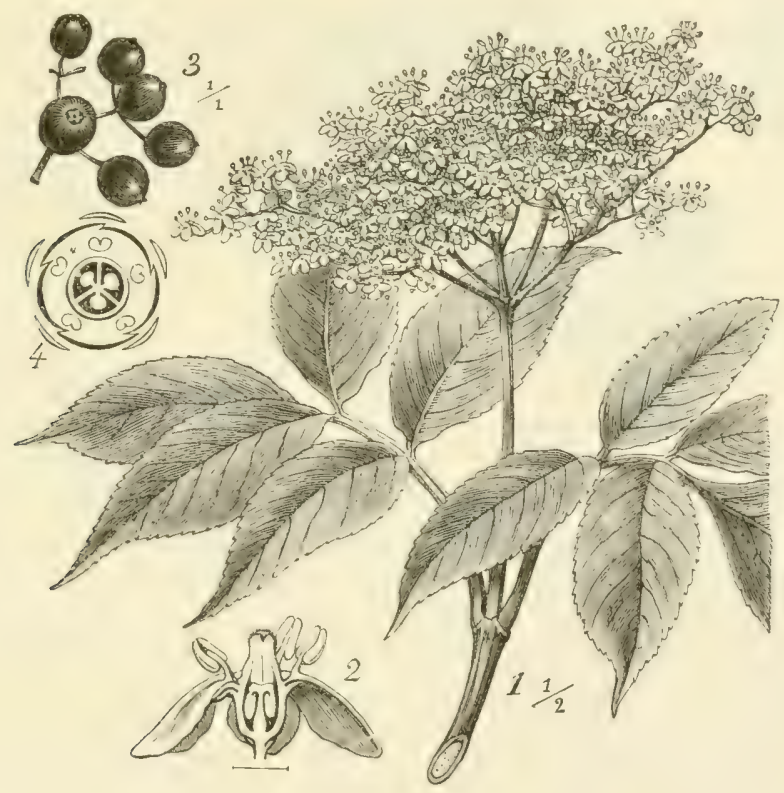

Fig. 374 .

Sambucus nigra. (W.)

Symphoricarpus racemosus Mich., Schneebeere und Diervilla (Weigelia) canadensis Willd. sehr häufig in Gärten angepflanzte Sträucher.

2. Unterfam. S a mbuc eae.

$\mathrm{C} *$, radförmig ausgebreitet. Inflorescenz eine Trugdolde. Beerenförmige Steinfrucht mit I-3 Steinen. In jedem der drei Fruchtknotenfächer eine Samenknospe.

Sambucus nigra L., schwarzer, gemeiner Flieder, Hollunder (Fig. 374). Grossstrauch oder Baum. Blüten in flachschirmigen Trugdolden. Früchte glänzend schwarz. Über das ganze Gebiet verbreitet.

Sambucus racemosa L. Roter Traubenhollunder. Blüten in kugeligen Trugdolden. Beeren scharlachrot. Licbt niedere Gebirge, besonders in West- und Süddeutschland zu finden. 
Viburmum Opulus L. Gemeiner Schneeball (Fig. 375). Strauch bis $4 \mathrm{~m}$ hoch. Die Kandblïten der Trugdolde ungeschlechtig mit grossen

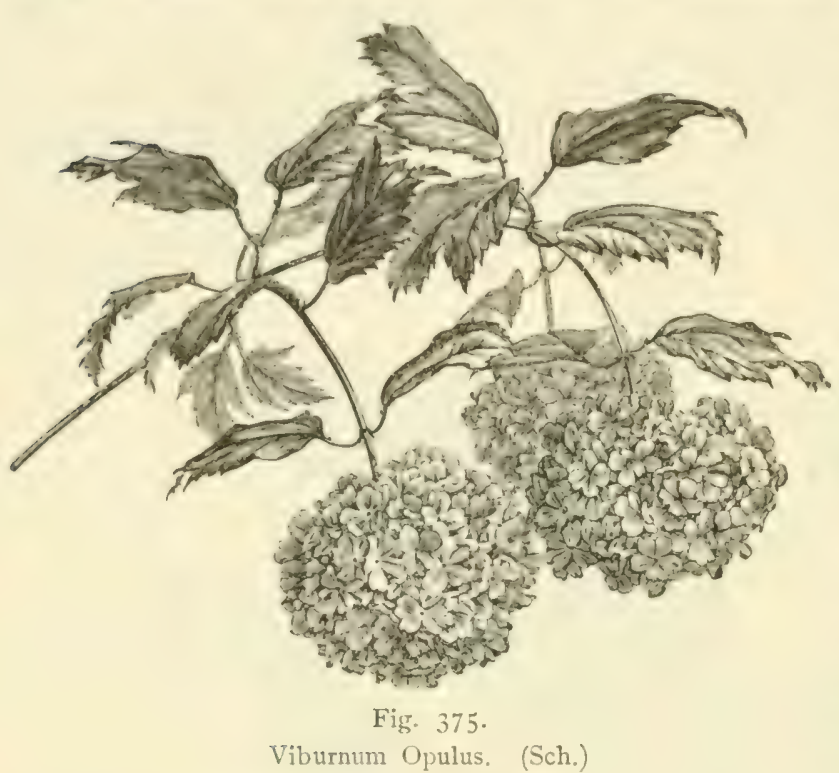

Kronenblättern, die inneren Blüten geschlechtig. Bei der Gartenvarictät (var. roseum) alle Blïten geschlechtslos. Früichte länglich, rotglänzend, mit herzförmig zusammengedrücktem Steinkern. Liebt Mergelboden, feuchten Laubwaldboden.

Viburnum Lantana L. Wolliger Schneeball. Blüten alle von gleicher Grösse, klein, in flachgewölbten Trugdolden. Liebt mehr Wärme als die

vorige Art. Auf Kalkboden in sonniger Lage.

Viburnum Tinus L., der sog. Laurustinus, eine immergrüne Zimmerpflanze.

3. Unterfam. Linn a e a e.

Vier Staubblätter, zweimächtig. Linnaea borealis. Im Moose kriechende Holzpflanze.

3. Fam. Valerianaceae.

Blüten ohne Symmetrieebene. $\mathrm{K}$ und $\mathrm{C}$ fünfzählig, der Kelch jedoch undeutlich, wird bei der Fruchtreife zu einem aus verzweigten Haaren bestehenden Pappus, A meist 3 (4-I) $\mathrm{G}_{(3)}$, von denen jedoch nur ein Fach eine Samenknospe trägt. Valeriana officinalis, Baldrian. Valeriana dioica und tripteris. Valerianella olitoria, Rapunzel.

\section{\$ 106. 9. Ordnung. Campanulinae.}

Blüten tetracyklisch, $G$ unterständig. $K(5) C(5)$ A $5 \mathrm{G} \overline{(3)}$ seltener $\overline{(2-5)}$. Kelch ïberall deutlich. A nicht mit $\mathrm{C}$ verwachsen. Antheren mehr oder weniger zu einer Röhre vereinigt. Fruchtknoten mehrfächerig, Frucht eine Kapsel.

I. Fam. Campanulaceae.

Blüten *. Staubbeutel schliessen lose zusammen, trennen sich nach der Verstäubung. Ein langer Griffel. Meist Kräuter mit Milchsaft und spiralig gestellten Blättern. Inflorescenz eine Traube oder Ähre, seltener ein Köpfchen. Campanula rapunculoides, Trachelium, rotundi- 
folia, patula, Rapunculus. Glockenblume. Phyteuma spicatum, Teufelskralle, Rapunzel. Jasione montana.

2. Fam. Lobeliaceae ähnlich wie erste Familie aber $\downarrow$, C mit dreiteiliger Ober- und zweiteiliger Unterlippe. Lobelia Dortmanna. Lobelia Erinus, Zierpflanze.

3. Fam. Goodeniaceae.

4. Fam. Stylidiaceae.

\section{10. Ordnung. Aggregatae.}

Blüten tetracyklisch, $\mathrm{G}$ unterständig. $\mathrm{K}_{5} \mathrm{C}(5) \mathrm{A}_{5} \mathrm{G}(2)$. Kelch reduciert, horstenfërmis, wulstis, als Haarkranz Pappus aussebildet oder fehlend. C zu einer Röhre verwachsen, vier- oder fünfzipfelig, * oder $\dot{\gamma}$, häufig nur die Randblüten $\downarrow$. A fünf oder durch Abort vier. $G$ ist immer einfächerig mit nur einer Samenanlage, eine Verminderung, die weiter als bei den Sambuceen und Valerianaceen geht. Blüten meist klein, zahlreich zu Köpfchen vereinigt, sie stehen auf einer gemeinsamen Blütenaxe, die entweder nackt oder mit Spreublättern und Haaren versehen ist. Meistens Kräuter. Nebenblätter fehlen.

I. Fam. Dipsaceae.

Jede Blüte hat einen aus Vorblättern gebildeten Aussenkelch. $\mathrm{K}$ oft in Borstenform. C bisweilen fünfteilig, zweilippig, meist vierteilig, indem zwei Lappen verschmolzen sind. A nie mehr als vier, Antheren frei. Frucht eine Nuss.

Dipsacus Fullonum, Weberkarde. Scabiosa columbaria, suaveolens, Scabiose, C fünfspaltig. Knautia arvensis, C vierspaltig. Succisa pratensis.

2. Fam. Compositae.

$\mathrm{K}$ rudimentär (Pappus), $\mathrm{C}(5) \mathrm{A}_{5} \mathrm{G}(\overline{2}), \mathrm{C} *$ fünfstrahlig oder $\checkmark$ zungenförmig, die Zipfel verteilt $\frac{0}{5}$ oder $\frac{\rho}{3}$, seltener zweilippig $\frac{2}{3}$. Die Antheren sind zu einer Röhre verbunden, welche den mit zwei Narben versehenen Griffel umgiebt. Die Frucht ist eine dünnwandige Nuss, welcher häufig der aus Haaren bestehende Kelch als Flugapparat dient. Sehr charakteristisch ist die Vereinigung zahlreicher Blüten zu einem Köpfchen, das ron schuppenförmigen Hochblättern umgeben ist.

I. Unterfam. Cynareae. Alle Blüten $s$, , mit röhrenförmiger Krone. Blütenboden mit Borsten. Das Blütenköpfchen ist ron zahlreichen dachziegeligen Hüllblättern umgeben. Griffel mit ringfürmiger Anschwellung unter der Narbe. Carduus nutans, Distel (Fig. 376). Cirsium arvense, palustre, lanceolatum, oleraceum, Distel. Cynara Scolymus, Artischocke. Onopordon Acanthium, Eselsdistel. Lappa minor, officinalis und tomentosa, Klette. Carlina acaulis und vulgaris, Eberwurz. Centaurea Cyanus, Kornblume. Centaurea jacea. Centaurea scabiosa. Serratula tinctoria. 


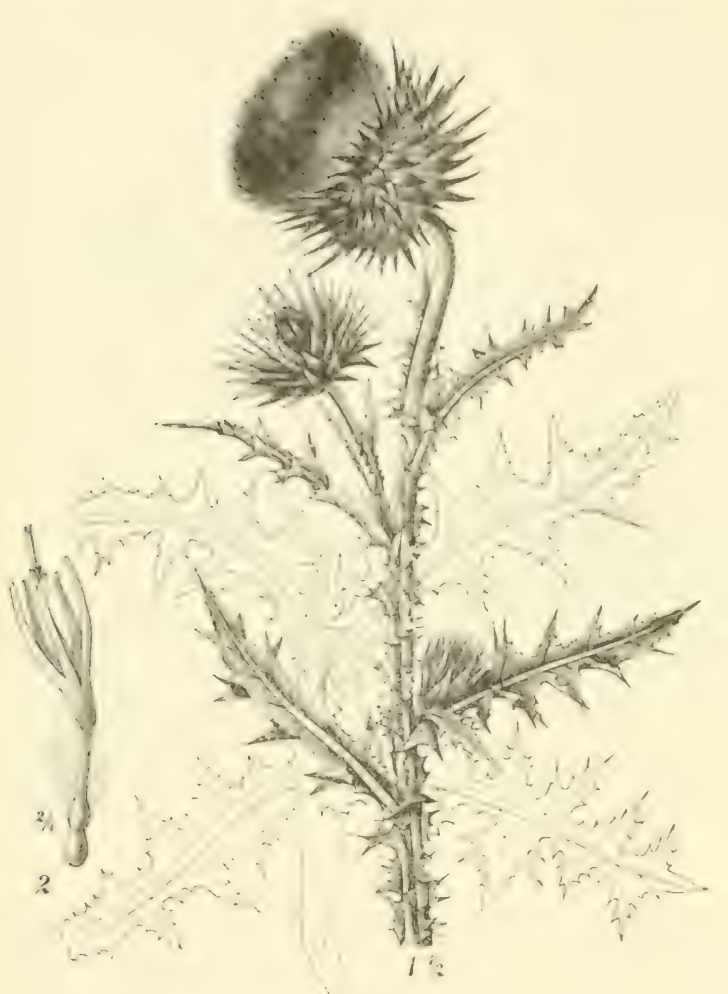

Fig. 376. Carduus nutans. (W.)

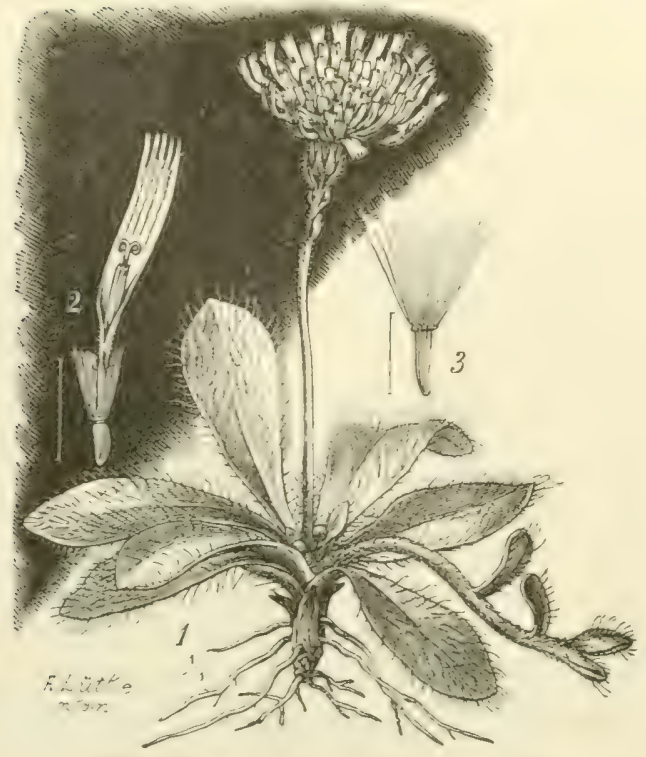

Fig. 377. Hieracium Pilosella. (W.)
2. Untcrfam. Mutisicac. I ippenblïtige $\left(\frac{4}{3}\right)$, tropische liormen.

3. Unterfam. Cichoricac. \%unsenblütler. Blïten alle $s$, mit zungenförmiger, fünfähniger Krone (!) Griffelästc verlängert, diinn, meist Milchsaft fïhrend.

A. Pappus nicht lang haarförmig. Cichorium Intybus, Wegewarte, Cichoric.

Lampsana communis, Milchkraut. Arnoseris minima, Lammkraut.

B. Pappus lang, haarförmig, nicht verzweigt. Taraxacum officinale (syn. Leontodon Taraxacum), Löwenzahn. Lactuca sativa, Salat, Lattich. Lactuca scariola, Compasspflanze. Lactuca muralis. Crepis tectorum, virens, paludosa, Pippau. Hieracium Pilosella, kleines Habichtskraut (Fig. 377). Hieracium vulgatum, silvaticum, umbellatum. Sonchus oleraceus, arvensis, Gänsedistel.

C. Pappus federig verzweigt, keine Spreublätter aufdem Blïtenboden. Tragopogon pratensis, major, Bocksbart. Scorzonera hispanica als SchwarzwurzelGemüse gebaut.. Leontodon auctumnalis, hispidus.

D. Pappus federig, Spreublätter lang, abfallend. Hypochaeris radicata, Ferkelkraut.

4. Unterfam. Eupa- 
torioideae. Alle Blïten meist $s$, röhrig, Hüllblätter nicht stechend, Blïtenboden ohne borstenförmige Spreublätter. Eupatorium cannabinum. Adenostyles albifrons. Petasites officinalis. Tussilago Farfara, Huflattig (Fig. 378).

5. Unterfam. Astereae. Randblüten $\subseteq$, zuweilen unfruchtbar, C meist $\frac{1}{\gamma}, \frac{0}{3}$ (Fig. 379, 4), Scheibenblüten *, röhrenförmig, $\subseteq$ (Fig. 379, 3). Griffelzweige gerade, mehr weniger kurz.

A. Dachziegelige, am Rande gewöhnlich häutige Hüllblätter. Kein Pappus, oder nur ein häutiger Rand. Achillea millefolium, Schafgarbe. Achillea Ptarmica. Bellis perennis, Gänseblümchen. Matricaria Chamomilla, echte Kamille (Fig. 379). Matricaria inodora. Anthemis arvensis. Chrysanthemum Leucanthemum, Wucherblume. Pyrethrum corymbosum. Tanacetum vulgare, Rainfarn. Artemisia vulgaris, Beifuss. Artemisia absinthium, Wermuth. Artemisia Dracunculus, Estragon.

B. Pappus nicht haarförmig, besteht aus Schuppen, Stacheln. Helianthus annuus, Sonnenblume. Helianthus tuberosus, Topinambur. Die unterirdischen Knollen

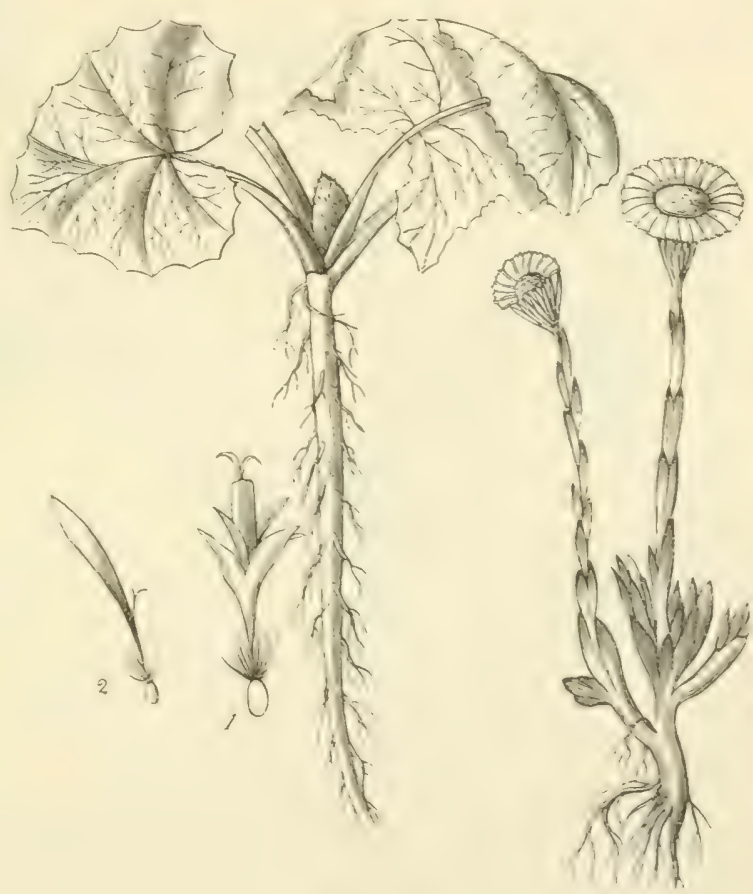

Fig. $37 \mathrm{~S}$.

Tussilago Farfara. (K.)

auch zur Wildfütterung verwendet. Dahlia variabilis, Georgine. Bidens tripartitus, Zweizahn.

C. Hüllblätter in ein bis zwei Reihen. Blütenboden nackt. Calendula officinalis, Ringelblume.

D. Pappus haarförmig, fein, weiss, Spreublätter fehlen, sonst wie bei A. Senecio Jacobaea, silvaticus, Fuchsii, vernalis (Fig. 380), vulgaris. Kreuzkraut, Baldgreis. Arnica montana, Wohlverleih. Doronicum Pardalianches, Gemswurz.

E. Pappus borstenförmig, unverzweigt, oft schmutzig bräunlich. Solidago Virga aurea, Goldrute. Aster alpinus, salicifolius, besonders 
aber viel cultivierte Arten. Erigeron canadense, Berufleraut. Inula Helenium, Alant. Gnaphalium uliginosum, silvaticum, Ruhrkraut. Heli-

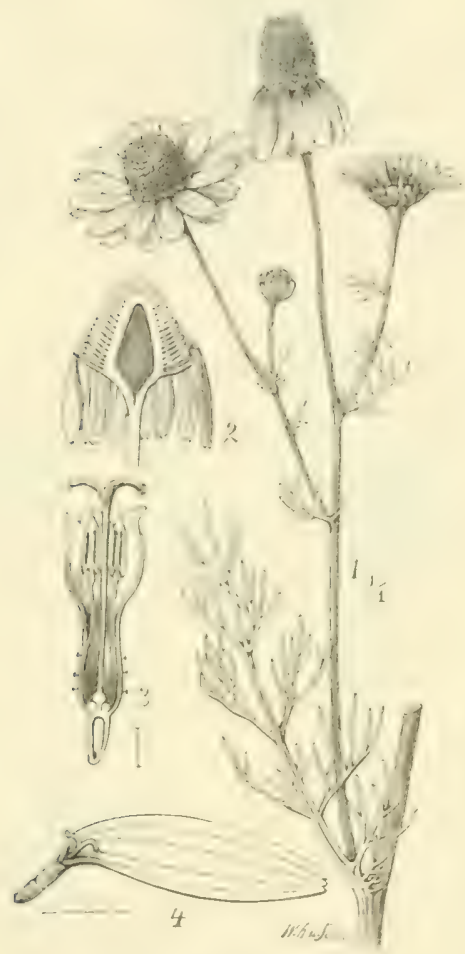

Fig. 379.

Matricaria Chamomilla. (IV.)

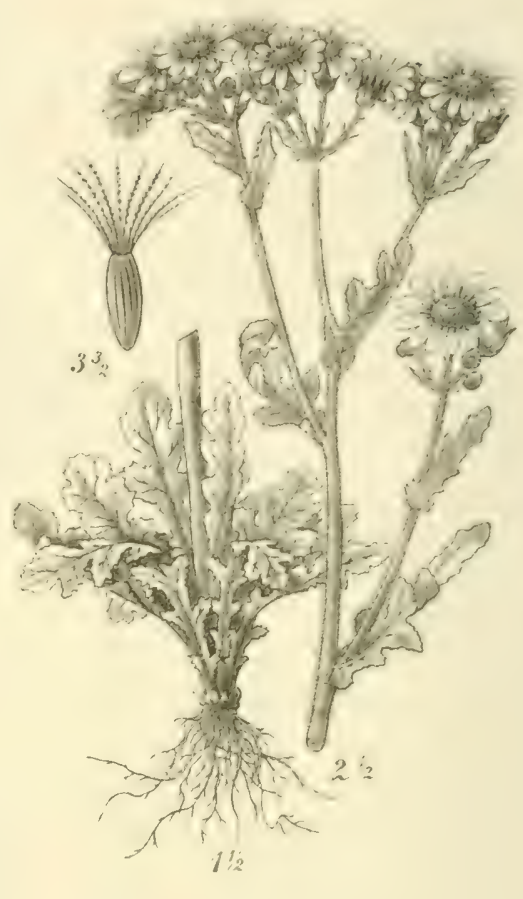

Fig. 350 .

Senecio vernalis. (Sch.)

chrysum arenarium, Sandstrohblume. Filago arvensis, Filzkraut. Leontopodium alpinum, Edelweiss.

F. Staubbeutel frei. Xanthium strumarium, Spitzklette. 


\section{Pflanzengeographie.}

\section{\$ 108. Die pflanzengeographische Einteilung der Erde in Florenreiche und Vegetationsformationen.}

Die Pflanzenwelt der Erde kann rom pflanzengeographischen Standpunkte aus in bestimmte Abteilungen und Gruppen gebracht werden. Dabei haben wir zunächst die sog. Florenreiche zu berücksichtigen. Man versteht darunter nach Drude die durch die Hauptmasse eigener Gattungen in bestimmten vorherrschenden Ordnungen ausgezeichneten Areale. Die Florenreiche werden wieder in Florengebiete geteilt, welche sich durch besondere Arten und das Vorherrschen verschiedener Gattungen auszeichnen. Diese systematische Übereinstimmung der Flora eines geographischen Gebietes wird durch die Entwickelungsgeschichte des Pflanzenreiches, soweit sich dieselbe durch lalärntelogische Funde aufdecken lässt, erklärt, indem die gegenwärtige Verteilung der Pflanzen auf der Erde von der Verteilung in früheren geologischen Epochen abhängig ist. Ausserdem beeinflussen die klimatischen Verhältnisse, Licht, Wärme, Feuchtigkeit, denen sich der Einfluss des Bodens anschliesst, die Verteilung der Pflanzen. Die Pflanzen verlangen zu ihrem Gedeihen eine gewisse Wärmemenge, Feuchtigkeit und Länge der Vegetationsperiode, welche ihnen nur in bestimmten Gegenden zur Verfügung stehen. Ebenso wird das Vorkommen vieler Pflanzen dadurch eingeschränkt, dass sie nicht im stande sind Perioden grösserer Kälte oder Trockenheit zu überstehen.

In alten Erdepochen bis etwa zum Jura aufwärts ist die Flora, nach den paläontologischen Resten zu urteilen, mehr gleichmässig verteilt gewesen. In der Miocänperiode war jedoch bereits eine Gliederung, in eine tropische und zwei gemässigte Zonen vorhanden. Die nördliche gemässigte Zone mit der arctotertiären Flora reichte bis in die höchsten Polargegenden, so dass man ihre Reste noch bei $S_{I^{0}} 4^{6}{ }^{4} \mathrm{n}$. Br. (GrinnellLand) nachgewiesen hat, sie besass zahlreiche Coniferen und mannigfaltige Laubhilzer. Die Abnahme der Temperatur hatte die Einschränkung der mit tropischen Pflanzen bedeckten Areale zur Folge. Durch den Wechsel der äusseren Lebensbedingungen wurde aber nicht allein eine Wanderung der vorhandenen Arten hervorgerufen, sie wurden vielmehr 
zugleich verändert, so dass sich neue Arten und Gattungen ausbildeten. Analoges Klima hat nun in geosraphisch weit auscinander liegenden, niemals direkt verbundenen Ländern keineswess dieselben Pflanzenspecies hervorgebracht, wir finden daher in seographisch getrennten Ländern, auch bei ähnlichem Klima, eine verschiedenartige Flora vorfinden.

Die klimatischen Veränderungen haben mancherlei Unterbrechungen erfahren, wie das Auftreten der Eiszeit in Mitteleuropa beweist, durch welche dic Flora von Gebieten zurückgedrängt wurde, die nach dem Schwinden der Vergletscherung mit einer Mischflora aus den benachbarten Ländern erfüllt wurde.

Den Wanderungen der Pflanzen werden durch Mecre, hohe Gebirge, Steppen Grenzen gesetzt, welche eine vollständige Mischung der Pflanzenformen unmöglich machen und die Ausbildung bestimmter an ein Land sebundener Arten begünstigen. Ist eine Familie, Gattung oder Art in einer früheren Erdepoche über ein grosses Areal zusammenhängend ausgebreitet gewesen, so können sich an den verschiedenen Stellen desselben neue Formen entwickeln, die bei späteren Veränderungen der Erdoberfäche isoliert werden; es entstehen auf diese Weise die endemischen Formen, d. h. Ordnungen, Familien etc., welche auf ein betimmtes Gebiet beschränkt sind. Vicariicrend oder korrespondierend werden jene Arten genannt, welche ähnliche Formen in einem anderen Gebicte vertreten. Die Florenreiche umfassen eine grössere Anzahl endemischer Familien und Gattungen, während die Florengebiete sich mehr durch die endemischen Arten auszeichnen.

In einem Florenreiche gehören alle Familien, Gattungen und Gattungsgruppen (Seltionen) einer bestimmten Auswahl von Ordnungen an, nach welchen der allgemeine Florenreichscharakter entweder tropisch, austral oder boreal sein kann.

Man unterscheidet demnach:

Tropische Florenreiche: I. Tropisches Afrika. 2. Ostafrikanische Inseln. 3. Indisches Florenreich. 4. Tropisches Amerika.

Australe Florenreiche: 5. Südafrika. 6. Melanesisch-neuseeländisches Florenreich. 7. Australien. 8. Andines Reich. 9. Antarktisches Reich.

Boreale Florenreiche: Io. Mittelmeerländer und Orient. I I. Innerasien. I2. Ostasien. I3. Mittleres Nordamerika. I4. Nordisches Florenreich.

Den Florenreichen des Landes steht gegenüber das ozeanische Florenreich, welches sämtliche fast ausschliesslich von den Meeresalgenfamilien besetzten Küsten und Meere einnimmt.

Selbstverständlich sind diese Florenreiche, die unten näher besprochen werden sollen, nur teilweise scharf begrenzt, wie denn auch Arten, welche denselben angehören, häufig in benachbarte Reiche übergreifen. 
Für die pflanzengeographische Betrachtung darf jedoch nicht einseitig die Verteilung der einzelnen Sippen und Arten des auf morpholosisch-entwickelungsseschichtlichen Principien beruhenden Pflanzensystems herangezogen werden. Es müssen vielmehr auch die Anpassungserscheinungen der Vegetationsformen an die äusseren Verhältnisse berïcksichtigt werden, welche ihren Ausdruck in der Bildung bestimmter Pflanzengesellschaften, der sog. Vegetationsformationen, finden. Diese Vegetationsformationen können zu srösseren Vecsetationsklassen vereinigt werden. die demnach eine grössere Anzahl von Einzelformation en umfassen. Derartige Vegetationsklassen bilden:

Die Waldformationen,

die Gebüsch- und Gesträuchformationen,

die Grasflur- und Staudenformationen,

die Noos- und Flechtenformationen,

die Formationen der Binnengewässer,

die ozeanischen Formationen.

Die Vegetationsklasse der Waldformationen umfasst:

I. Die Formation der tropischen immergrünen Regenwälder. Kein Frost und keine Trockenperioden stören die Vegetation dieser aus sehr verschiedenen Baumarten zusammengesetzten Wälder. Wie bei einem Mittelwalde breitet sich unter den höchsten Bäumen eine Vegetation etwas niedrigerer Arten aus, zwischen denen wieder kürzere Farnstämme oder kleinere Palmenformen vegetieren. Auf den Stämmen des tropischen Waldes leben zahlreiche Epiphyten, welche, ohne zu schmarotzen, mannigfaltige Anpassungen an dies luftige Leben aufweisen. Ein dichtes Gewirr von Lianen schlingt sich von Stamm zu Stamm.

2. Die tropischen Littoral-oder Mangrovenwälder breiten sich an flacher Küste im Bereich von Ebbe und Flut aus. Rhizophora

- Mangle, Brugiera, Kandelia, Avicennia, Sonneratia und andere Arten stellen einen 5- I5 m hohen Wald dar, dessen Zweige bogenförmig auf vielen Luftwurzeln ruhen und deren Stämme durch ein dichtes, den Speichen eines Regenschirmes ähnliches, niedrigeres Luftwurzelsystem in dem Schlamme verankert sind.

3. Die tropischen regengrünen Wälder. Die Ruheperiode dieser Wälder wird nicht durch verminderte Temperatur, sondern durch Perioden grösserer Trockenheit bewirkt. Die Mehrzahl der Bäume wirft das Laub ab, die immèrgrünen Formen zeigen lederartige Blätter. Die Lianen und Epiphyten gehören meist anderen Familien an, sind viel spärlicher vorhanden.

4. Subtropische Wälder mit immergrünen Laubbäumen. Die Bäume werfen ihr Laub periodisch ab oder zeigen vielfach mehr derbere oder lederartige Blätter, die in Grösse und Üppigkeit wesentlich hinter den Blattformen der tropischen Regenwälder zurückbleiben. Lianen, Epiphyten, mächtige Palmbäume und andere hohe Monocotylen gehören 
nicht mehr zum Bilde dieser Formationen, dafür treten die Nadelhölzer, die in den Tropen fast durchaus fehlen, bestandbildend auf. Lange oder strensere Winterkäle wird von den subtropischen Wäldern nicht mehr ertrasen, die zugleich hohe Sommertemperaturen verlangen.

Als Abteilungen der subtropischen Wälder ergeben sich: a) feuchte Subtropenwälder, sie schliessen sich mehr an die tropischen Regenwälder an, zeigen bestimmte subtropische Epiphyten, einige baumartige Liliaceen und Farne. Die Blätter besitzen keine Schutzvorrichtungen gegen Vertrocknen. b) trockene Subtropenwälder mit immergrünen, auch gegen Trockenheit geschützten Blättern. Baumfarne fehlen. Von dicotylen Familien sind besonders Oleaceen, Myrtaceen, Proteaceen vertreten. c) Subtropische Wälder mit reichlicher Beimischung von Bäumen, welche in der kithlen Jahreszeit ihr Laub abwerfen. Juglans, Morus, Platanus, Liquidambar, Ficus carica und gewisse Quercusarten treten hier auf.

5. Winterkahle Wälder mit periodischer Belaubung und immergrünen frostharten $\mathrm{Nadelh}$ özern. Die Frostempfindlichleit der hierher gehörigen Vegetationsformen ist eine verschiedene. Die frostunsicheren Gewächse der wärmeren Gegenden werden in höheren Breiten durch vollständig frostharte Arten vertreten. Der sommerheisse Gürtel im gemässigten Klima enthält eine Mischung immergrüner und sommergrüner Laubhölzer. Die Formen wärmerer Gegenden erhalten sich teilweise auch noch in den Landstrichen mit gemässigter Sommertemperatur und kalter Wintertemperatur und zwar besonders in dem Seeklima, dessen Winter durch den Einfluss warmer Neeresströmungen gemildert sind. Die nördliche Grenze der frostharten Wälder wird durch die Dauer und den Grad der Sommerwärme bestimmt. In den nördlichen Gegenden, wo sämtliche Nonate Mitteltemperaturen unter + IO ${ }^{\text {" }}$ C. aufweisen, hört auch das Vorkommen der am weitesten nach Norden gehenden Fichte, Lärche und Birke auf. Die Birke kommt in Klimaten vor, deren Januarmittel $\mathrm{O}^{0}$ (westliches Europa) und - $40^{\circ}$ bis $-48^{\circ} \mathrm{C}$. (Jakutsk, Gebiet der Lena) beträgt, während die Mitteltemperaturen des wärmsten Monats nur zwischen $+14^{\circ} \mathrm{C}$. und $+20^{\circ} \mathrm{C}$. schwanken. Beträgt die Verkürzung der Vegetationsperiode mehr als drei Monate, so fehlt der Baumwuchs.

Zwischen den bestandbildenden Bäumen entwickelt sich nun eine grössere Menge niederer Bäume und Sträucher, sowie Stauden, auf welche später näher eingegangen werden soll. Die Epiphytenvegetation der frostharten Wälder ist auf das Vorkommen von Moosen, Flechten sowie auf die parasitierenden Mistel- und Loranthusarten beschränkt.

Dic Gebüsch- und Gesträuchformationen. Als Gcbüsche bezeichnet Drude die Bestände höherer Sträucher mit aufrechtwachsenden, dicht stehenden Zweigen, während als Gesträuche die aus niederen Halbsträuchern gebildeten Bestände zusammengefasst werden. Auf verödetem Valdboden oder auf durch Viehweide zerstörten Kulturen können auch Stockausschlässe von Bäumen Gebüschformen annehmen. Ebenso können wald- 
bildende Bäume (z. B. Eichen, Fichten) unter ungünstigen Bedingungen zur Strauchform herabsinken.

Diese Formationen stellen sich namentlich unter äusseren Bedingungen ein, die nicht günstig genug sind, um einen kräftigen Baumwuchs aufkommen zu lassen, sei es nun dass die geringe Temperatur, länger andauernde Trockenperioden oder ungüunstige Bodenbeschaffenheit infolge lanser Freilase, das Vorkommen des Taldes ausschliessen. Wir sehen die Krummholzformen von Pinus montana in den höheren Lasen mitteleuropäischer Gebirge, die Zwergformen von Pinus cembra in Ostsibirien an die Stelle von Wäldern treten. In dem Mittelmeergebiete treten die sog. Maquis auf, d. h. Gebüsche aus Myrte, Lorbeer, Olive, Oleander, Phillyreen (Oleaceen), Erica arborea, Arbutus, Cistus, Pistacia und Buxus, welche gemischt oder auch, wie Cistus ladaniferus, für sich allein, grosse Flächen bedecken. Im gemässigten und kalten Klima sind es Calluna und Erica, Vacciniumarten, Rhododendron u. a., welche gesellig rorkommend, die Gesträuchformationen bilden. Auch die Gebüsche von Prunus, Rosa, Crataegus, Alnus viridis, Spartium scoparium, Ulex europaeus wären hier zu nennen.

Die Gebüsch- und Gesträuchformationen erlangen besonders in subtropischen Gegenden eine grosse Mannigfaltigkeit.

\section{Die Grasflur- und Staudenformationen.}

Diese Vegetationsklasse ist ausserordentlich mannigfaltig durch die grosse Anzahl der verschiedenen hier vereinigten Pflanzenarten, deren Gemisch je nach den klimatischen Verhältnissen und den lokalen Verschiedenheiten an Feuchtigleit und Bodenbeschaffenheit ausserordentlich stark wechselt. Beim Vorherrschen der Gramineen, Cyperaceen und Juncaceen wird der Ausdruck Grasflurformationen, bei dem grösseren Gehalt an Stauden mit lebhaft gefärbten Blüten der Ausdruck Staudenformationen gerechtfertigter erscheinen, doch lässt sich hierdurch keine allgemeinere schärfere Trennung herbeiführen. Nach dem Klima können wir besondere Abteilungen dieser Vegetationsklasse bilden:

I. Savannen, die Ruheperiode ist durch die trockene Jahreszeit gegeben. Besonders charakteristisch ist, dass zwischen den Gräsern von hohem üppigen Wuchs tropische Bäume und Sträucher vorkommen. Die letzteren sind gegen Trockenperioden geschützt. So bezeichnet Sargent als Prairien — sie gehören ebenfalls zur Savannenformation - jene grasbedeckten Gebiete, bei denen noch $10-20 \%$ der Bodenfläche von Bäumen bedeckt ist. Ähnliche Formationen finden sich nur in den Tropen und Subtropen.

2. Die Steppenformationen. Die Vegetation ruht im Winter, während sie in der heissen Zeit mehr oder weniger dem Vertrocknen ausgesetzt ist. Bäume enthält die Steppe nicht, da die Vegetationszeit für deren Entwickelung zu kurz ist. Hierher gehören Grassteppen mit gesellig wachsenden Gräsern, denen raschwïchsise Standen und Zwiebelgewächse beigemengt sind. Die Kraut- und Strauchsteppen zeigen eine 
srössere Menge ron Stauden und niederen Strätuchern, die sich alle durch weitgehende Anpassung an die Trockenperioden auszcichnen. Der Boden ist Weniser sleichmässiss rom Graswuchs bedeckt.

3. Die Wüstenformationen schliessen sich den Steppen an, die Vegetationszeit ist auf kurz andauernde Feuchtigkeitsperioden ansewiesen, wird aber von der Winterkälte nicht berïhrt.

4. Die Wiesenformationen zeigen eine vollständige, nicht unterbrochene Bedeckung des Bodens mit Gräsern, denen sehr mannigfaltige Stauden, sowie cinzelne Holzgewächse beigemengt sind. Die Vegetation ist nur durch die Kälte zu Ruheperioden gezwungen. Als hierhergehörige Einzelformationen sind nicht nur die Wiesen auf verschieden feuchtem Boden zu nennen, es bieten sich vielmehr auch Differenzen dar zwischen Gebirgs- und Thalwiesen, zwischen den im Walde liegenden und den starkbesonnten Formationen. Ebenso ist der Gehalt des Bodens an humosen und mineralischen Bestandteilen von Einfluss auf die Wiesenbildung.

5. Den Wiesenformationen schliessen sich andere Formationen an, welche eine bestimmte Beschaffenheit des Bodens voraussetzen, für welche es uns aber an einer gemeinsamen Bezeichnung fehlt. Als Beispiele seien angeführt die Formationen auf Felsen, Geröllhalden, armen Sandboden, die sog. Halophyten auf salzhaltigem Boden (Strandhalophyten und Binnenlandshalophyten), die Formation der Ruderalpflanzen auf unbebautem Boden, an Wegrändern oder auf Rohhumus. Ferner ist hierher die Vegetation der Moore zu rechnen, doch lassen sich diese Formationen häufig nicht scharf von den Wiesen- und Moosformationen trennen. Den hier genannten Formationen ist zumeist gemeinsam, dass eine continuierliche Grasdecke fehlt, die Gräser demnach nicht die herrschende Stellung einnehmen wie bei den Wiesen.

Selbstverständlich sind die genannten Formationen je nach dem Klima, aus sehr verschiedenen Arten zusammengesetzt.

\section{Die Moos- und Flechtenformationen.}

Die Moose und Flechten kommen, wie wir wissen, auf dem Boden der Wälder, auf der Borke von Holzpflanzen, auf feuchten. Wiesen zwischen Gras in grosser Menge vor, formationsbildend werden sic jedoch nur dann, wenn die übrigen Pflanzen im Vergleich zu den Moosen und Flechten zurücktreten.

Am prägnantesten sind diese Formationen in dem arktischen Gebiet, wo die sog. Noostundren auf feuchtem Boden, die Flechtentundren mehr auf trockenem Boden grosse Landesflächen bedecken. Cyperaceen, Luzula und einzelne andere arktische Blütenpflanzen sind diesen Tundren beigemischt.

In den etwas wärmeren Gebieten bilden die Moose, stärker gemischt mit Blütenpflanzen, die Moosmoore oder Torfsümpfe, in. Welchen die Flechten bei ihrer Vorliebe für einen trockenen Standort fehlen. 
Die Flechten bilden in wärmeren oder heissen Gegenden auf Felsen oder anderer zeitweise vollständig austrocknender Unterla ge besondere Formationen, denen kleine Nloose, welche das zeitweilige Austrocknen ebenfalls vertragen können, beigemischt sind.

\section{Die Formationen der Binnengewässer.}

I. Sümpfe und sehr flache Gewässer zeigen eine aus mannigfaltigen Familien zusammengesetzte Staudenvegetation, mit in Luft ragenden Blättern.

2. Wasserpflanzen. Hierher gehören einerseits Arten mit untergetauchten, anderseits mit schwimmenden Blättern. Dazu treten Algen, sowie einige Gattungen der Gefässkryptogamen, z. B. Salvinia, Azolla, Isoütes.

\section{Die ozeanischen Formationen.}

Sie bestehen fast ausschliesslich aus Algen und zwar herrschen Rhodophyceen und Phaeophyceen bei weitem vor. Blütenpflanzen sind sehr selten (z. B. Zostera).

\section{\$ 109. Die Florenreiche.}

Die tropischen Florenreiche zeichnen sich durch das Auftreten zahlreicher Baumformen aus, denen die mannigfaltigsten Lianen und Epiphyten beigemengt sind. Von den Gymnospermen sind nur die Cycadeen in grösserer Artenzahl vorhanden. Die Monccotylen sind für den Florencharakter bezeichnend und zwar besonders die Palmen, Araceen, Scitamineen, Orchideen und Bambuseen.

Von den Dicotyledonen spielen die baumartigen Vertreter folgender Familien und Ordnungen eine grosse Rolle: Rubiaceen, Bignoniaceen, Apacyneen, Loganiaceen, Oleaceen, Myrsinaceen, Diospyrinae, Combretaceen, Myrtaceen, Sapindaceen, Malpighiaceen, Terebinthinae, Euphorbiaceen, Columniferen, Dilleniaceen, Ternstroemiaceen, Clusiaceen, Bixaceen und Annonaceen. Besonders zahlreich sind die baumartigen Leguminosen, während von den Rosifloren nur die Chrysobalaneen, von den Umbelliferen nur die Araliaceen vorkommen. Ebenso sind in den Tropen besondere Sippen krautartiger Pflanzen vorhanden. Erwähnenswert ist die geringe Verbreitung der Compositen.

Die vier tropischen Florenreiche enthalten zusammen 36 I7 Gattungen. Von dieser grossen Anzahl sind in den Tropen der alten und neuen Welt allgemein verbreitet nur ISO Gattungen. Das tropisch-afrikanische Florenreich enthält 3 I2 endemische Gattungen, die ostafrikanischen Inseln (Madagaskar mit den Maskarenen und Seychellen) I 30, das indische Florenreich 870 , das tropische Amerika ${ }^{1}$ ) I 448 endemische

$\left.{ }^{1}\right)$ Diese Zahl enthält auch die Gattungen des andinen Florenreiches und des mexikanischen Hochlandes, ist also $\mathrm{zu}$ hoch. 
Gattungen. Die äbrigen Gattungen sind zwei oder drei tropischen Florenreichen semeinsam.

\%mm ersten Florenreich, dem tropischen Afrika, schören die Gebiete: I. Guinea, 2. Sansibar-Natal, 3. Ostafrika und Yemen, 4. die sïdliche Sahara und Hadramaut, 5. die Kalahari.

Zum ostafrikanischen Inselreich gehören I. Madagashar, 2. die Maskarenen mit Rodriguez, 3. die Seychellen.

Das indische Florenreich umfasst dic Gebiete: I. Dekhan, $\therefore$ südwestliches Indien (I und 2 die westliche Halbinsel von Indien), 3. Nepal-Birma, 4. Siam-Anam (3 und 4 Hinterindien ohne Malaklia), 5. Sundainseln mit Sumatra, Java, Borneo, den Philippinen und Malakka.

Das tropisch-amerikanische Florenreich umfasst I. das Paranasebiet, den südlichen Teil zwischen dem Gran Chaco und der atlantischen Küste, Paraguay und Parana bis zu deren nördlicher Wasserscheide. 2. Amazonas, Gebiet des Amazonenstroms mit dem Küstenstrich von Guyana. 3. Magdalena-Orinokogebiet mit dem inneren Hochland von Guyana und den tropischen Anden. 4. Antillengebiet mit den Inseln im mexikanischen Golf, 5. Mexiko, das südliche Nordamerika vom 12 " nördlicher Br. bis zum mexikanischen Hochplateau.

Dic australen Florenreiche umfassen die Gebiete südlich der tropischen Florenreiche. Sie sind zunächst durch negative Merkmale zu charakterisieren, d. h. durch das.Fehlen der Palmen, der epiphytischen Orchideen, Pandaneen und Cyclantheen, der Milchsaft liefernden Dicotyledonen, Clusiaceen etc., welche Gruppen in den australen Florenreichen nur vereinzelte Vertreter haben. Die geringe Menge allen australen Reichen gemeinsamer Gattungen erklärt sich durch die frühzeitige räumliche Trennung der einzelnen Florenreiche durch grosse Ozeane und die hiermit verbundene selbständige Entwickelung der einzelnen Reiche. Wir haben es daher hier hauptsächlich mit gemeinsamen Ordnungen zu thun, welche aber in verschiedenen Familien in den einzelnen Gebieten vorhommen. So ist die Ordnung der Bicornes im Kaplande durch zahlreiche Ericaceen vertreten, während in Australien keine Ericaceen, wohl aber sehr zahlreiche Epacrideen vorkommen. Etwas anders verhält sich die Familie der Proteaceen, welche über die australen Florenreiche verbreitet ist, sich jedoch nur durch die Verschiedenheit der Gattungen und Unterfamilien in den einzelnen Reichen unterscheidet. Von charakteristischen Familien sind zu nennen: Die Umbelliferen, Cruciferen, Oxalidaceen, Geraniaceen, Tropaeolaceen, Caryophyllaceen, von den Saxifrasaceen treten besendere Lnterfamilien Cunonieen, Escallonieen auf, cbenso erlangen Phaseoleen und Astereen eine grosse Bedeutung. Von Quercifloren sind ebenfalls Vertreter vorhanden (Fagus), von den Coniferen sind Unterfamilien der Cupressaceen bemerkenswert.

Die einzelnen subtropisch-australen Florenreiche sind nach dem oben Gesagten in höherem Masse verschieden, als die einzelnen tropischen 
und auch als die subtropisch-borealen Reiche. Eine grössere Verwandtschaft macht sich erst wieder bei dem antarktischen Reiche geltend, welches die südlichsten Teile von Südamerika und Australien und Neuseeland umfasst. Der Grund dieser Übereinstimmung ist noch nicht aufgeklärt.

Das südamerikanische Florenreich zerfällt in folgende Gebiete: I. südwestliches Kapland, 2. südöstliches Kapland, 3. inneres Kapland.

Das melanesisch-neuseeländische Florenreich geht von den Molukken (auch die Makassarstrasse bildet eine Grenzlinie) östlich bis zu den Marquesasinseln, von den Sandwichsinseln im Norden bis nach Neuseeland im Süden. I. Das Papuagebiet mit Celebes, Neuguinea, 2. Nordöstliches Australien, 3. Polynesien, 4. Sandwichsinseln, 5. Neuseeland.

Das australische Reich mit den Gebieten von West-, Süd-, Ostaustralien und Tasmanien.

Das andine Reich mit den Gebieten: I. tropische Anden, 2. chilenisches Gebiet, 3. argentinisches Gebiet.

Das antarktische Reich umfasst I. das pacifische Patagonien mit dem Feuerlande, 2. das atlantische Patagonien, 3. alle antarktischen Inseln, 4. die Südspitze und die Gebirge Neuseelands.

Die borealen Florenreiche, nördlich von den tropischen Reichen, zeigen in Bezug auf die herrschenden Systemgruppen einen einheitlichen Charakter. Dabei machen sich selbstverständlich bei der grossen Ausdehnung des Areals sehr verschiedene klimatische Verhältnisse geltend, welche bestimmend auf die äussere Physiognomie der Flora einwirken.

Wo das Klima das Vorkommen von Wäldern erlaubt, werden dieselben von Coniferen (Pinus, Abies, Picea, Larix), Salicifloren, Quercifloren, Ulmaceen, Aceraceen, Tiliaceen, Fraxineen, Amygdalaceen, Pomaceen gebildet, denen sich noch verschiedene Strauchformen zugesellen. Eine grosse Verbreitung besitzen ferner die krautigen Pflanzen aus den formenreichen Familien der Primulaceen, Plumbaginaceen, Umbelliferen, Saxifragaceen, Rosaceen, Caryophyllaceen, Cruciferen, Ranunculaceen, dazu wie überall Gramineen, Cyperaceen, Juncaceen, Liliaceen, Compositen, Labiaten, Personaten, Leguminosen, Chenopodiaceen. In den boreal-subtropischen Teilen treten ausserdem noch Platanaceen, Juglandaceen, Elaeagnaceen, Tamaricaceen, Cupressaceen auf.

Das mediterran-orientalische Florenreich erstreckt sich von Westen nach Osten ungefähr zwischen dem $30^{0}$ und $40^{\circ} \mathrm{n}$. Br. Es beginnt mit den atlantischen Inseln im Westen und endet mit den Bergwäldern des westlichen Himalaya. Gegen das nordische Reich wird es durch Gebirgszüge (Pyrenäen, Alpen, Balkangebirge südlich des $42^{0}$ und $43^{\circ}$ n. B., Kaukasus) gut abgegrenzt, während die Abgrenzung gegen das centralasiatische Reich (Südrand des caspischen Neeres, Turan und Kamm des Himalaya) weniger scharf ist. Im Süden geht die Grenze durch die Sahara, Arabien allmählich in das tropische Gebiet über. Es 
haben sich in diesen wasseramen, wüsten Gebieten besondere Vegetationsformationen heraussebildet, die sich durch die Verminderung der Blatterrösse, das Zuriektreten des Baum- und Strauchwuchses, den mannigfachen Schutz gegen Verdunstung auszeichnen.

Die einzelnen Gebiete des mediterran-orientalischen Florenreichs sind: I. Nördliche Sahara mit dem nördlichen Arabien. 2. Makaronesien (Canaren und Azoren). 3. Atlantisch-mediterrane Küstenländer (Marokko, Alsier, Tunis, Spanien, Italien, Griechenland, Küste von Kleinasien, Syrien und Nordafrilia). 4. Südwestasien (Plateau von Kleinasien, Kurdistan, Iran, Afghanistan bis zum westlichen Himalaya).

Einzelne Formen dieses Florenreichs sind auch in Frankreich, den Rheingegenden, in dem südlichsten Teile von England, in Kroatien, Ungarn, Sïdrussland verbreitet und greifen in das innerasiatische Florenreich über.

Das innerasiatische Florenreich umfasst die ganze regenlose Binnenlandsmasse Centralasiens und die westliche Hälfte Chinas. Es zeichnet sich durch Waldlosigkeit aus, sowie durch das Überwiegen von besonderen Chenopodiaceen, Polygonaceen, Astragalusarten, Phaseoleen und Plumbaginaceen. Die Gebicte sind: I. Turkestan. 2. Mongolei. 3. Tibet.

Das ostasiatische Florenreich ist subtropisch mit tropischen und nordischen Beimischungen. Hervorzuheben ist die ausserordentlich grosse Menge von Holzgewächsen, speciell von Bäumen, so dass die Mannigfaltigkeit derselben selbst eine grössere ist, als in Nordamerika. Von Coniferen, die hauptsächlich im nördlichen Teile herrschen, sind allein aus Japan mehr als 30 Arten bekannt. $\mathrm{Zu}$ erwähnen sind: Picea bicolor Mayr (syn. Picea Alcockiana Carr.), Picea polita, P. Ajanensis, Tsuga Sieboldii, T. diversifolia. Abies firma, A. Veitchii, A. Mariesii. Pinus chinensis, P. densiflora, P. Bungeana, P. Thunbergii, P. korvensis. Sciadopitys verticillata, Thujopsis dolobrata, Cupressus funebris, Podocarpusarten, Gingko biloba, Cryptomeria japonica, Biota orientalis, Larix leptolepis. Palmen sind in geringer Anzahl vorhanden (Sabaleen), ebenso Araceen, Dioscoreaceen. Eine reiche Entfaltung zeigen die Dicotylen, von denen besonders zu nennen sind: Lonicereen, Oleaceen, Sapotaceen, Styraceen, Ericaceen, Hydrangeaceen, Rosaceen, baumartige Leguminosen, Therebinthinen, Ternstroemiaceen (z. B. Camellia japonica, Thea viridis), Sapindaceen (besonders viele Aceraceen), Berberideen, Magnoliaceen, Menispermaceen, Lauraceen, Calycanthus, Celtoideen, (z. B. Zelkowa Keaki), Moraceen, Juglandaceen, Quercifloren, z. B. Fagus Sieboldii, Castanea japonica u. a.

Zwei Florengebiete: I. Inneres China. 2. Küste von China und Japan.

Das Florenreich vom mittleren Nordamerika ist boreal, der grössere Teil subtropisch. Die nördliche Grenze des Florenreiches beginnt an der atlantischen. Küste be̊im $40^{0}$ n. B., läuft von da in nordwestlicher Richtung bis zum $100^{\circ}$ westl. L. (von Green- 
wich) und geht dann, längs des $52^{0} \mathrm{n}$. Br., bis zu den Rocky Mountains und erreicht, in südwestlicher Richtung verlaufend, beim $42^{0}$ n. Br., die pacifische Küste. Auf den Alleghanies und den Rocky Mountains dringt das nordische Florenreich tief in das Florenreich des mittleren Nordamerika ein. Im Süden ist das Reich durch den Golf von Mexiko, die mexikanischen Hochlande begrenzt. Die südlichen Teile der californischen Halbinsel, sowie die Südspitze von Florida gehören schon zum tropischen amerikanischen Florenreich, doch handelt es sich hier mehr um eine Mischflora. Der tropische Wald von Südflorida liefert Guajacum sanctum, Swietenia Mahagoni, ferner treten Simaruba, Ximenia, Anona, Clusia, Capparis, Rhizophora auf, sowie Gattungen der Combretaceen, Myrtaceen, Rubiaceen, Myrsinaceen, Sapotaceen, Verbenaceen, Euphorbiaceen, mehrere Ficus- und Palmenarten. Das Florenreich des mittleren Nordamerika enthält vier Gebiete: I. Virginien (atlantischer Teil bis jenseits des Missisippi). 2. Montana und 3. Texas-Nordmexiko, mit den nördlich resp. südlich der Rocky mountains ein- und angelagerten Steppen oder Prairien. 4. Californien (pacifische Küste).

Virginisches Gebiet. Die südliche Hälfte bis etwa zum $36^{0} \mathrm{n}$. Br. ist ausgezeichnet durch Wärme (mittlere Temperatur des Winters $+12{ }^{\circ} \mathrm{C}$.) und grosse Feuchtigkeit. Die Wintertemperatur sinkt nur ausnahmsweise bis auf $-8^{\circ} \mathrm{C}$. Wir finden hier einen immergrünen Wald mit Magnolia grandiflora, Ilex, Aralia, Illicium, Smilax, Cliftonia, winterkahle Vitis, Orangen, von Palmen Sabal Palmetto und Sabal serrulata. Es gedeihen hier Kiefern mit ausserordentlich schwerem und dauerhaftem Holz, wie Pinus australis Mich. (syn. P. palustris) und cubensis Grieseb. (syn. P. Elliottii), von denen die erstere Art das einzige Kiefernholz ist, welches nach Europa importiert wird 1). Ausserdem sind $z u$ nennen Pinus clausa, Taeda, serotina, glabra, etwas weiter nördlich Pinus mitis. Die sumpfigen Stellen werden von Taxodium distichum eingenommen. Unter den Eichen ist die immergrüne Quercus virens zu nennen.

Weiter nördlich fällt die Temperatur im Winter bedeutend stärker (bis - I $5^{\circ} \mathrm{C}$ ), die mittlere. Temperatur des Winters beträgt $+7^{0} \mathrm{C}$, der Vegetationszeit $+24^{\circ} \mathrm{C}$. Es herrscht hier die Formation der winterkahlen Laubhölzer vor. Vor allen ist die grosse Anzahl von Eichen hervorzuheben (22 Arten), von denen Quercus alba, microcarpa, obtusiloba, Prinus, rubra, tinctoria genannt werden mögen. Ferner sind die Hickorys wegen ihres vortrefflichen Holzes forstlich wichtig (Carya alba, amara, tomentosa, sulcata, porcina), denen sich Juglans nigra und cinerea anschliessen.

Ferner kommen hier vor: Gleditschia triacanthos, Fagus ferruginea, Castanea americana, Liriodendron tulipifera, Platanus occidentalis, Pru-

1) In Europa, jedoch nicht in Amerika geht das Holz dieser beiden Arten unter dem Namen Pitch-Pineholz; dagegen werden Pinus rigida, mitis, resinosa auch in der nordamerikanischen Heimat als Pitch-Pine bezeichnet, sie liefern jedoch minderwertiges Holz. 
nus serotina, rerschiedene Weiden- und Pappelarten, neben Pinus mitis und Tacda noch P. inops, rigida, Chamaecyparis sphacroidea. Niedrige Holzowächse, Arten von Crataegus, Prunus, Rhus, Evonymus, Hamamaelis, Vitis sowie Andromeda, Kalmia, Vaccinium, Rhododendron vervollständigen das Bild dieser Waldunģen. Der nördlichste bedeutend kältere Teil des virginischen Gebietes bildet den Übergang zu dem nordischen Florenreich mit Pinus Strobus, Banksiana, resinosa, Tsuga canadensis und zahlreichen anderen an die deutsche Flora erinnernden Bäumen.

Die Gebicte von Montana und Texas-Nordmexilo entsprechen dem centralasiatischen Florenreich mit seinen weit ausgedehnten Steppen, die hier entsprechend der nördlicheren oder südlicheren Lagse eine verschiedene Zusammensetzung haben. Ungeheure Grasflächen bedecken die Erde,

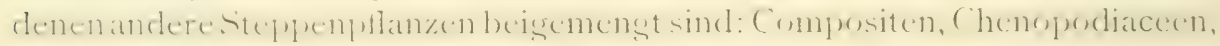
Hydrophyllaceen, Polemoniaceen, Scrophulariaceen, Astragalusarten u. a.

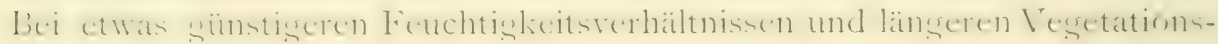
perioden stellen sich Sträucher und dornreiches Gestrüpp ein. In dem südlichen Gebiete von Texas-Nordmexiko finden wir Cacteen, z. B. kleine Opuntien, den baumartigen Cereus giganteus, ferner Agaven, Yuccas und Prosopis juliflora, den sog. Mesquit. Im nördlichen Gebiete Montanas treten Straucheichen, Kiefern und andere Pflanzen auf, welche im stande sind die hier auftretenden grossen Temperaturdifferenzen zu ertragen.

Ein grosser Teil der Prairien könnte bei künstlicher Bewässerung in fruchtbares Land verwandelt werden.

Das Florengebiet Kalifornien geht vom $34^{0} \mathrm{n}$. Br. bis zum $43^{0} \mathrm{n}$. Br. und reicht bis zu den westlichen Abhängen der Sierra Nevada. Temperatur hoch, Luft an der Küstenseite feuchter, zwischen dem Coast Range-Gebirge und der Sierra Nevada trocken, so dass sich dort Prärien einstellen. Der Hauptnutzbaum ist Sequoia sempervirens, welcher bis gegen $100 \mathrm{~m}$ hoch wird. Ferner charakteristisch Cupressusarten, z. B. Cupr. macrocarpa, Torreya californica, Pinus insignis, tuberculata, muricata, Parryana, Sabiniana, verschiedene Eichen, die in der trocknen Zeit ihre Blätter abwerfen, ferner Umbellaria californica, der sog. kalifornische Lorbeer und Castanopsis chrysophylla.

Das nordische Florenreich. Die nördlich von den vier vorher genannten boreal subtropischen Reichen liegenden Länder Amerikas, Europas und Asiens bilden ein weit ausgedehntes Florenreich, dessen südliche Teile jedoch eine Mischlingsflora aufweisen, in welcher sich je nach Wärme und Lage eine grosse Menge boreal-subtropischer Formen vorfinden. Die im nordischen Florenreich auftretenden Familien und Ordnungen sind dieselben, welche wir in Europa kennen. Von immergrünen Holzpflanzen kommen im allgemeinen nur Coniferen vor, während die Laubholzesewächse im Winter ihre Blätter abwerfen, Stauden in anderer Weise gegen den Frost geschützt sind.

Die zu diesem Florenreich gehörigen Gebiete sind: I. Columbien. 
2. Saskatchawan und Kanada. 3. Die ochotskischen Küstenländer. 4 . Mittelsibirien. 5. Osteuropäische Steppen. 6. Mitteleuropa. 7. Arktisches Gebiet.

Ich beginne mit dem Gebiet von Columbien, welches sich unmittelbar an das kalifornische Gebiet des vorigen Reiches (bei $42^{0} \mathrm{n}$. Br.) anschliesst, von da nördlich bis zum $60^{0} \mathrm{n}$. Br. geht und auch die westlichen Teile der Rocky-Mountains bedeckt. Es umfasst die Ebenen und Thäler von Oregon und Washington-Territory, die Küste von Britisch Columbia, die Insel Vancouver und die Küste bis zur Höhe von Sitka.

Im nördlichen Teile dieses Gebiets gedeihen vorzüglich Picea sitchensis, Pseudotsuga Douglasii, Tsuga Mertensiana und Thuja gigantea Nutt. (syn. Thuja Menziesii Dougl.), die besonders für den Anbau in Deutschland in Betracht kommen. Mittlere Sommertemperatur hier $15^{\circ} \mathrm{C}$, mittlere Jahrestemperatur + Io ${ }^{0} \mathrm{C}$., die niederste beobachtete Temperatur - I60 C., grosse Luftfeuchtigkeit. In den etwas südlicheren Gegenden mit geringeren Kältegraden erreicht Chamaecyparis Lawsoniana ihr Optimum. Zu den genannten Arten gesellen sich Quercus Garryana und Kelloggii, Fraxinus oregana, Populus trichocarpa, Acer californicum, Pinus ponderosa, Lambertiana, Jeffreyi, monticola, Coulteri, Abies grandis, concolor, bracteata, Sequoia gigantea. Librocedrus decurrens Torr. (syn. Thuja gigantea Carr.). Chamaecyparis nutkaensis Spach.

Das Gebiet von Saskatchawan und Kanada umfasst das übrige Nordamerika bis auf das arktische Gebiet. Wir haben hier gemässigt kühle Regionen, welche sich, wie schon oben angedeutet, auch auf dic höheren Lagen der Rocky Mountains, Alleghanies erstrecken, also in die Gebicte von Nontana und Virginien eingreifen und allmähliche Übergänge zu wärmeren Regionen aufweisen. Es herrscht der Nadelwald vor mit besonderen, jedoch nicht so mächtig grossen Arten, wie man sie z. B. an der pacifischen Küste in Menge findet. Im westlichen Teile dieses Gebietes sind zu erwähnen: Larix occidentalis, Pinus flexilis und Murrayana, Abies nobilis Lindl., Abies magnifica Murr. Abies amabilis, Picea pungens und Engelmannii. Diese Arten leben in einem Klima, welches dem Klima Deutschlands entspricht.

Im östlichen Teile des Gebietes herrschen sehr kalte Winter bei relativ warmen Sommern. In den günstigeren Klimaten sind verschiedene Laubhölzer zu finden, so fünf Birkenarten (Betula lenta, lutea, nigra, papyrifera, populifera), sechs Ahornarten (Acer saccharinum, rubrum, dasycarpum, Negundo u. a.), Fraxinus americana, viridis, sambucifolia, pubescens. Diesen schliessen sich Tsuga canadensis, Chamaecyparis sphaeroidea, Juniperus virginiana an. Bei Verwilderung des Bodens erobern sich Populus balsamifera, tremuloides, Weiden, Erlen das Terrain. An sandigen Orten herrscht ein umfangreicher Kieferngürtel mit Pinus Strobus, Banksiana, resinosa. In kälteren Teilen sind vorwiegend Picea alba, nigra, Abies Fraseri, balsamea zu finden. 
Der Kern des Gebietes der ochotskischen Küstenländer liegt am mittieren Amur, er reicht bis $55^{\prime \prime} \mathrm{n}$. Br. Es wechseln Laub- und Nadelhölzer, welche kïhle Sommer und kalte Winter crtrasen. Charakterschölze sind: Betula dahurica, Quercus mongolica, Evonymus Maachii, Corylus heterophylla, in Kamtschatka Betula Ermanni.

Das Gebiet von Mittelsibirien umfasst den nicht arktischen Teil Sibiriens und das nordöstliche Russland bis ungefähr zum $63^{\prime \prime} \mathrm{n}$. Br. Es zeigt sich hicr eine ärmere Waldflora, bestehend aus Abies Pichta, Picea obovata, Larix sibirica und dahurica, Betula pubescens, Pinus Cembra, von denen die Lärchen und Fichten der Larix europaea resp. Picea excelsa ausserordentlich nahe stehen, so dass sic besser als geographische Abarten aufgefasst werden.

Das osteuropäische Steppengebiet liegt im südlichsten Russland, wozu noch das ungarische Tiefland kommt. Dic Baumvegetation tritt zurück, dafür eine buntgemischte Wiesenflora (Stipa, Artemisien, Sanguisorba, Salvia, Nepeta, Verbascum) . Von diesem Gebiete aus sind viele Arten nach Mitteleuropa eingewandert und bevölkern unsere Wiesen und Triften.

Das Gebiet Mitteleuropa ist im Süden durch das atlantischmediterrane Gebiet begrenzt, umfasst die west- und centraleuropäischen Staaten, den südlichen Teil von Norwegen, ferner Schweden und Finnland bis zur Tornea-Lappmark und den westlichen und nordwestlichen Teil von europäisch Russland. Wir werden in den folgenden Paragraphen noch auf die nähere Gliederung dieses Gebietes eingehen, dessen Florenzusammensetzung auch schon aus den im systematischen Teil dieses Buches berücksichtigten Gattungen hervorgeht. Bemerkt sei, dass sowohl ron Süden als von Norden her Einwanderungen von Pflanzen aus anderen Reichen zu konstatieren sind. Besonders fallen die arktischen Formen in den hohen Gebirgen und teilweise auch in den sumpfig kalten Niederungen auf, die man als Relikten aus der Eiszeit aufzufassen hat. Nach dem Zurücktreten der Gletscher konnten sie sich an kalten Stellen halten, ohne dass jetzt ein kontinuirlicher Zusammenhang mit dem arktischen Gebiete bestehen würde. Ausser diesen Gebieten weisen jedoch die Gebirge des mitteleuropäischen Gebietes auch noch eigene, nicht arktische Florenelemente auf, die sich aus den übrigen Formen des eigenen Gebietes entwickelt haben.

Aus subtropischen Gebieten haben Einwanderungen stattgefunden, charakteristisch ist jedoch der Mangel an tropischen Formen.

Das arktische Gebiet ist durch das Auftreten circumpolarer Arten aussezeichnet, welche, absesehen won verschiedenartigen Lnterbrechungen, die nördlichsten Gegenden von Asien, Europa und Amerika bevölkern. Charakteristisch sind Erdsträucher, wie Andromeda hypnoides und tetragona, Loiseleura procumbens, Menziesia coerulea, Diapensia lapponica, ferner Rubus arcticus und chamaemorus, Empetrum, Vaccinium. Grosse 
Flächen bedecken die Tundrenformationen, welche in Sibirien mehr aus Moosen, in Nordamerika und Island aus Flechten bestehen. Die Baumgrenze ist nicht zugleich die Grenze des Gebietes, doch fehlen sämtliche Abiesarten, während Fichte, Birke (Betula pubescens und nana) und Lärche, wenn auch in Strauchform sehr hoch hinauf gehen. Eine grössere Artenzahl weist Salix auf, von denen hier Salix retusa, polaris, lanata, speciosa genannt sein mögen.

\section{§110. Vegetationslinien und Regionen.}

Im Folgenden soll sowohl die horizontale Ausbreitung der Pflanzen, als ihr Aufsteigen in den Bergen, soweit das mitteleuropäische Gebiet dabei in Betracht kommt, besprochen werden.

Vegetationslinien. Der horizontalen Ausbreitung einer Pflanze werden einerseits durch Meere, Steppen, hohe Gebirge, anderseits durch klimatische Verhältnisse Grenzen gesetzt. Diese Grenzen werden als Vegetationslinien bezeichnet. Sie fallen nicht unmittelbar mit den Grenzen der Florengebiete und Florenreiche zusammen, doch häufen sich in vielen Fällen an den Grenzen der letzteren auch die Vegetationslinien der einzelnen Arten.

Die Ausbreitung der wichtigsten Waldbäume ist aus den beigefügten Karten zu ersehen Dabei muss jedoch die Schwierigkeit hervorgehoben werden, derartige Grenzen genau zu fixieren, indem eine Art auch ausserhalb ihres natürlichen Verbreitungsbezirkes durch Kultur erhalten werden kann, so dass sich die Grenzen des natürlichen Vorkommens oft nur unsicher oder gar nicht feststellen lassen. So liegt das nordwestliche Deutschland nach den Angaben von Willkomm ausserhalb des Verbreitungsbezirkes der Fichte (vgl. Karte I), deren Grenze bei Danzig die Ostsee berührt und von da die Ostsee überspringend in das südliche Schweden eindringt und an der atlantischen Küste bis zum Vorgebirge Kunnen $\left(67^{\circ} \mathrm{n}\right.$. Br.) vordringt. Da jedoch auch in Mecklenburg, in Holstein und im nordöstlichen Frankreich die Fichte vorkommt, wäre es vielleicht richtiger, die Grenzlinie von den Vogesen aus weiter westlich zu ziehen und sie längs der Grenze von Holland und Deutschland, von Dänemark und Deutschland fortzuführen. Ähnlich verhält es sich mit der Lärche, deren natürliches Verbreitungsgebiet auf Karte II dargestellt ist, die jedoch auch in Norddeutschland kultiviert werden kann.

Über das natürliche Verbreitungsgebiet hinaus gelangen die Pflanzen nicht mehr zur Samenreife, sie sind oft gänzlich unfruchtbar oder nehmen verkrüppelte Zwergformen an.

Ein sehr auffallender Unterschied bezüglich der Ausbreitung macht sich in der Richtung von Westen nach Osten geltend, entsprechend dem Seeklima der westlichen und dem Kontinentalklima der östlichen 
Gesenden. An der Käste und den daran stossenden Ländern finden wir, verusacht durch den Golfstrom und feuchte Westwinde, relativ warme

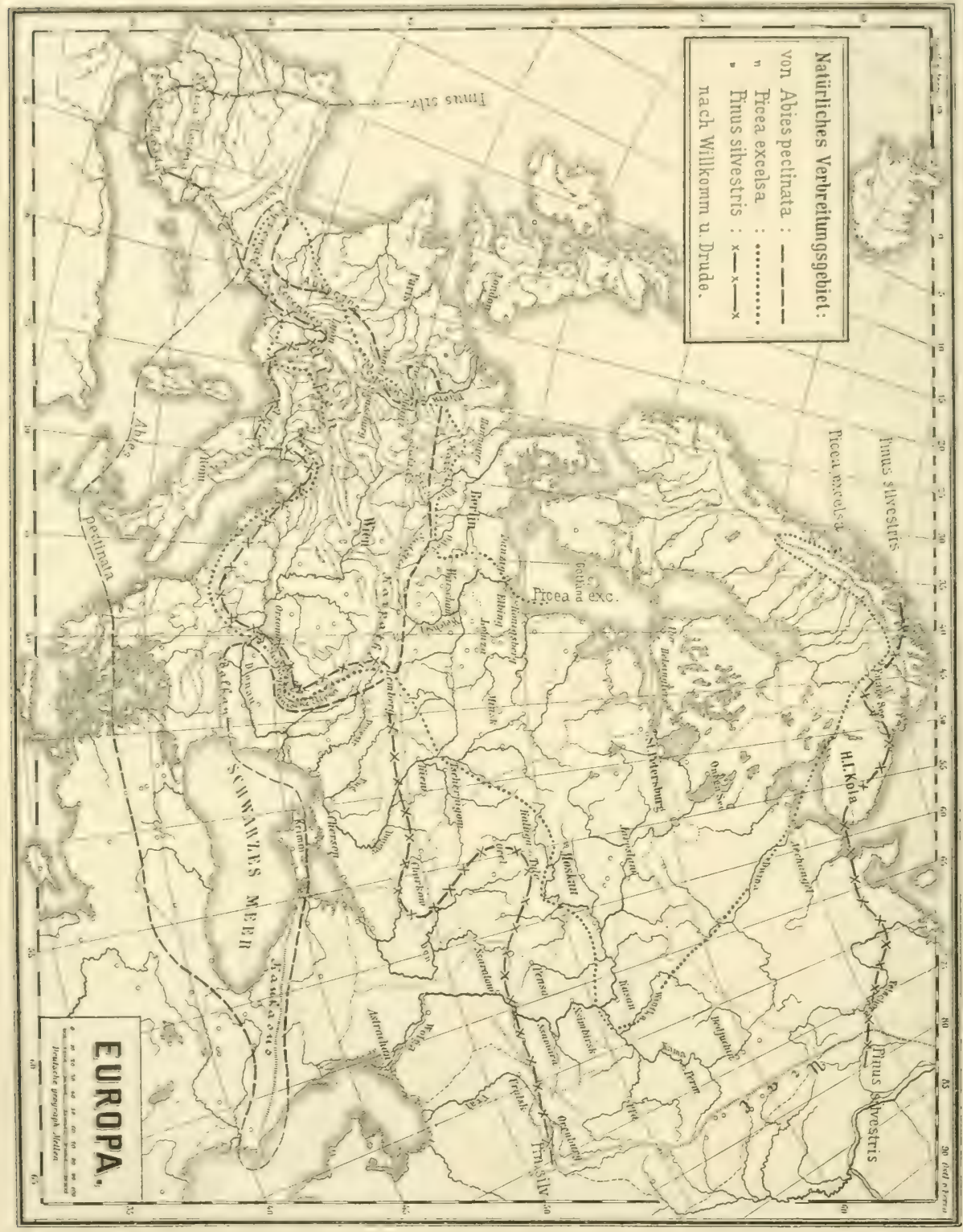

Karte I.

Winter und kühlere Sommer. Das Kontinentalklima dagegen zeigt im Zusammenhang mit den über weite Steppen gehenden, trockenen, polaren Ostwinden sehr kalte Winter und heisse Sommer. Zugleich wird durch 
das Kontinentalklima die der Pflanze zur Verfügung stehende Vegetationszeit verkürzt. So beträgt die Vegetationszeit in Bordeaux acht Monate,

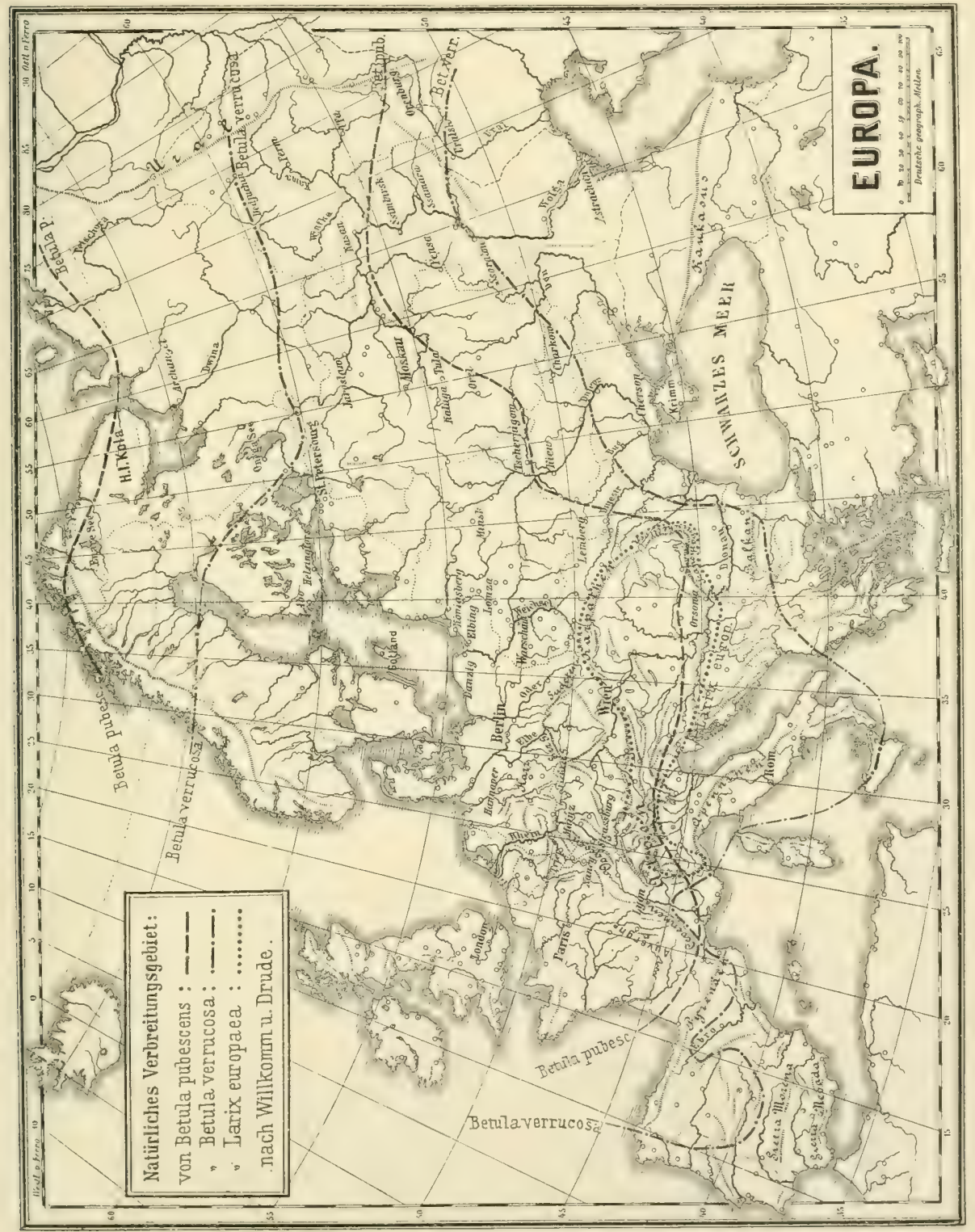

Karte II.

in Jakutsk nur drei Monate, wobei die Mittelwärme der acht Monate $\mathrm{I}_{7}, 4^{\text {" }} \mathrm{C}$., der 3 Monate $16,5^{\circ} \mathrm{C}$. beträgt. Ein prägnantes Beispiel bietet die Rotbuche, Karte III, welche eine Vegetationszeit ron mindestens fünf IIonaten 
verlanst. Thre istliche Grenze shneidet lie Küste Gstpreussens \%wi-chen Fibing und Königsbers. Schron östlich der Weichsel tritt vielfach dir.

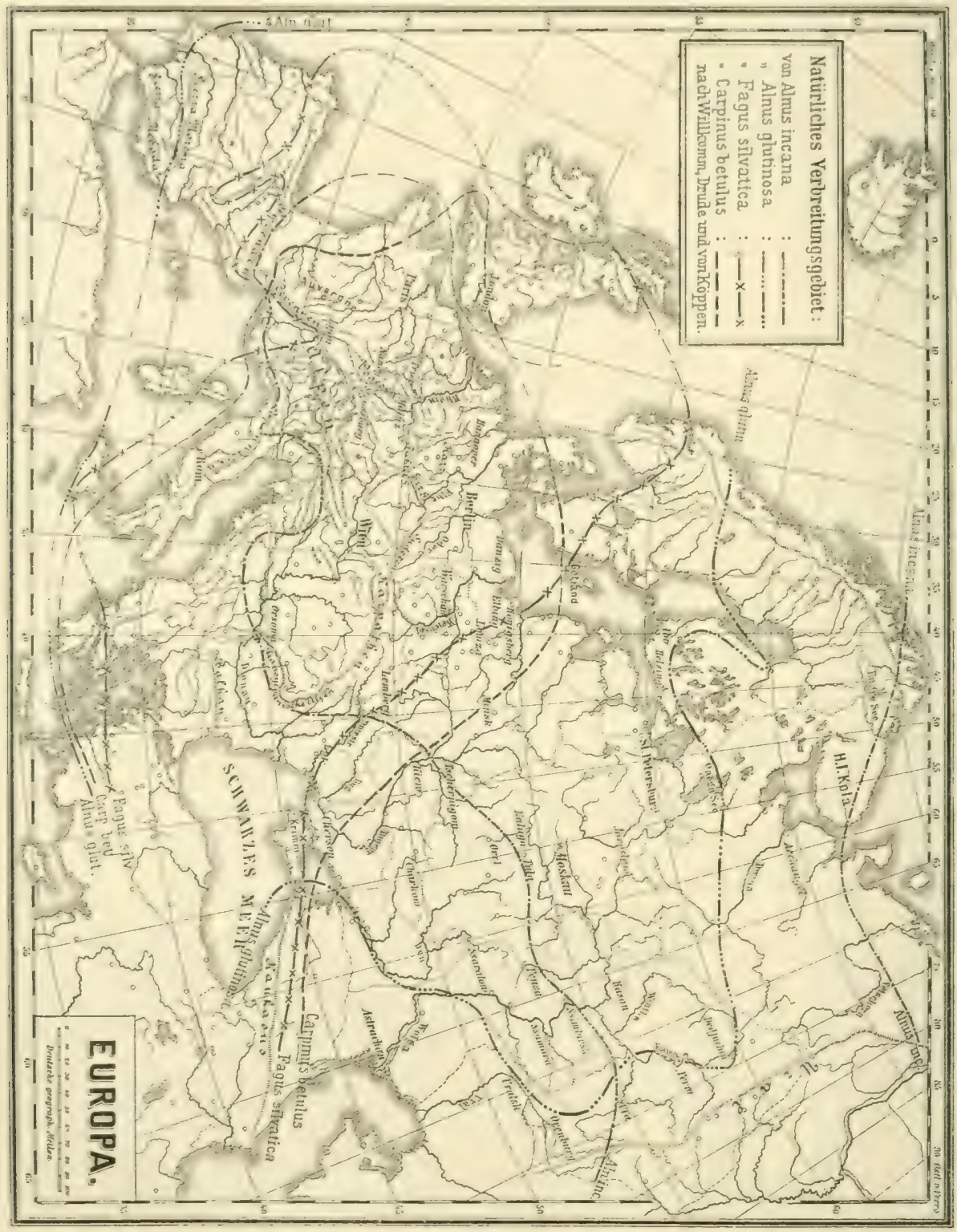

Karte III.

Hainbuche an Stelle der Rotbuche. Ähnliches gilt von Quercus sessiliflora, während Quercus pedunculata eine kürzere Vegetationszeit verträgt und dementsprechend viel weiter nach Osten ausbiegt (vgl. Karte IV). 
Die Anpassungsfähigkeit der einzelnen Bäume an die Kü̈ze der Vegetationszeit ist eine sehr verschiedene, so dass wir Pflanzen haben, wie z. B.

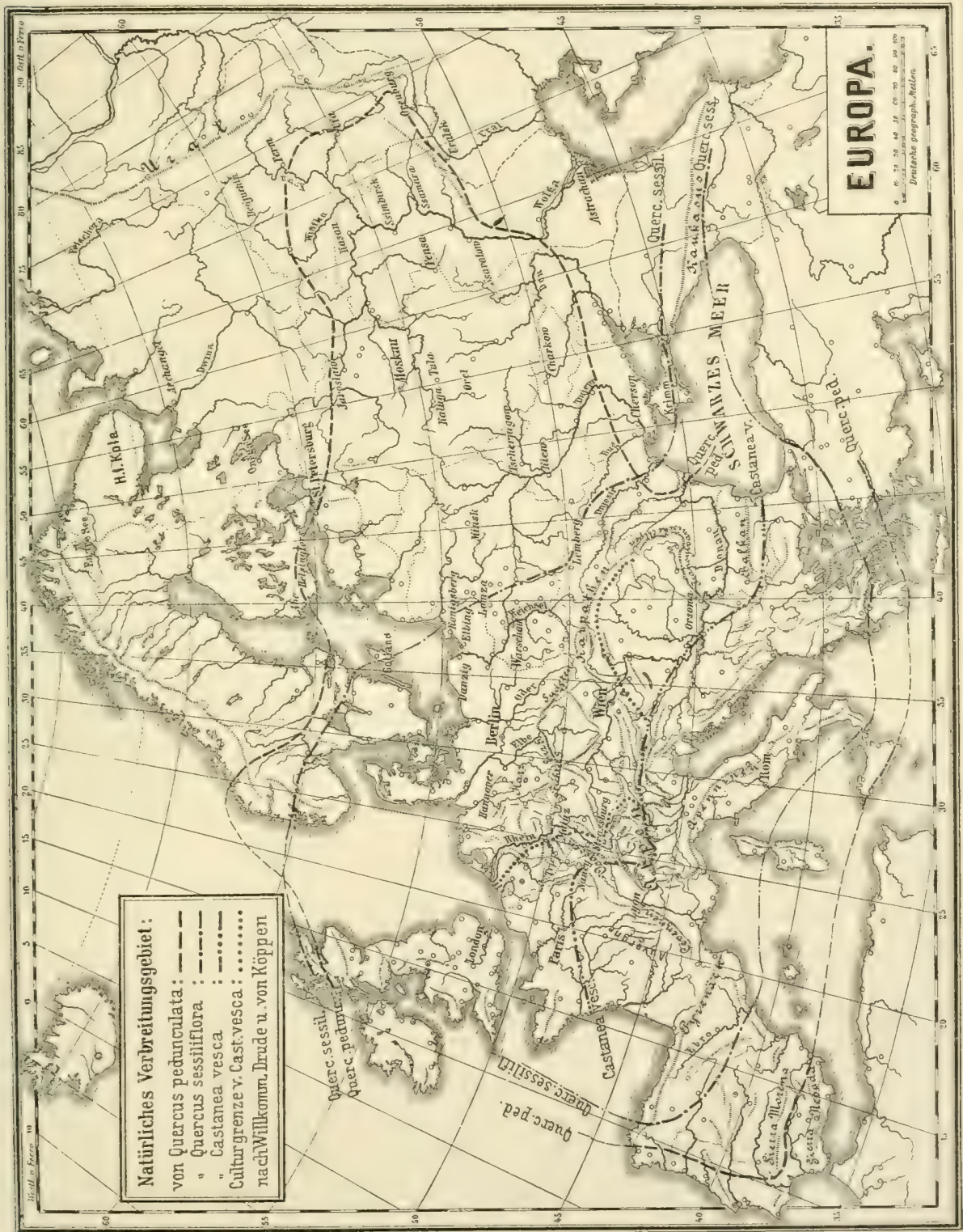

Karte IV

Pinus silvestris, welche sowohl in Bordeaux als in Jakutsk fortkommen können (vgl. Karte I). Selbstverständlich werden derartige Pflanzen mit weitgehender Anpassungsfähigkeit ein viel grösseres Areal bewohnen. 
Abseschen von der Dauer der Vegetationszeiten sind auch die Temperatur - und Feuchtigkeitsverhältnisse in dem Sec- und KontinentalLima zu beachten.

Es giebt Pflanzen, welche bei strenger Winterkälte erfrieren, aber sonst keine so hohen Ansprüche an die Sommerwärme machen. Dieselben sind auf die atlantischen Teile und den Süden Europas angewiesen, sic kommen meist noch im nordwestlichen Deutschland vor, sind aber doch an eine gewisse Entfernung von der Meeresküste gebunden. Selbstrerständlich sind auch die Ansprüche dieser Pflanzen graduell verschieden, so dass gewisse Arten (z. B. Quercus Ilex, Laurus nobilis) an die atlanticehe Kïste sebunden sind, in dem südlichen Ensland ihre Nordgrenze finden, während andere Arten weiter in die Ebenen Frankreichs und in das westliche und nordwestliche Deutschland vordringen. Charakteristisch ist in dieser Bezichung die Verbreitung von Ilex aquifolium, welche Pflanze der Nordseeküste entlang in Dänemark und bis nach Rügen vorkommt, aber in Mitteldeutschland, dem grössten Teile von Bayern und in Ostdeutschland fehlt, obgleich sie an der norwegischen Küste bis zum $62^{\circ} \mathrm{n}$. Br. hinaufgeht. $\mathrm{Zu}$ dieser Gruppe atlantischer Pflanzen gehören verschiedene Ericaarten, Erica tetralix, cinerea und ciliaris, ferner Ulex europaeus und nanus, Genista anglica, Buxus sempervirens u. a., von Bäumen namentlich Pinus maritima.

Im Gegensatz zu diesen atlantischen Pflanzen, welche Seeklima verlangen, stehen jene Arten des Kontinentalklimas, welche häufig aus dem Südosten Europas eingewandert sind und vor der Linie Danzig-BerlinErfurt Halt machen, weil ihnen die Sommerwärme weiter westlich nicht mehr genügt. Durch die nach Nordosten sich steigernde Verkürzung der Vegetationszeit ist einem Teil dieser Pflanzen zugleich eine nordöstliche Grenze gesetzt, so dass sie eventuell die Provinz Ostpreussen gar nicht mehr erreichen. Als Beispiele seien hier genannt: Cytisus capitatus, Cytisus ratisbonensis, Evonymus verrucosus, Salix incana, Salix livida, Salix myrtilloides, ferner Asperula Aparine, Centaurea austriaca.

Vergleichen wir das Gebiet nördlich der Alpen bis nach Lappland, so macht sich in regelmässiger Reihenfolge eine Abnahme in der Zahl der Pflanzenarten geltend. Während z. B. im Rheinthal von Schaffhausen bis Rheinbayern I362 Phanerogamenarten gezählt wurden, finden sich in Westfinnmarken auf einem etwa ebenso grossen Raume nur 402 Arten. I)iese geringere Mannisgaltigkeit der Pflanzendecke hänģt im allgemeinen mit der Abnahme der Wärmemenge zusammen, indem nur eine beschränkte Anzahl von Gewächsen die Verminderung der Wärmemenge erträgt, ganz abgesehen von der verschiedenen Verteilung der Wärme auf Sommer und Winter, sowie auf bestimmte Monate. Man hat versucht das Bedürfnis der einzelnen Pflanze an Wärme durch eine bestimmte Zahl auszudrücken, durch die sog. Wärmesumme, welche die einer Pflanze während einer Vegetationsperiode zur Verfügung stehende Wärmemenge enthält. Aus 
verschiedenen Gründen kann dieselbe nur ein unvollständiges Bild der thatsächlichen Abhängigkeit der Vegetation von der Wärme geben, da für die einzelnen Funktionen der Pflanze, Keimung, Laubentwickelung, Blütenansatz und Samenreife, das Temperaturminimum ungleich hoch liegt und weil die Funktionen der Pflanzen nicht einfach proportional der Temperaturerhöhung gesteigert werden. Ausserdem beziehen sich die meteorologischen Zahlen auf die diffuse Wärme der Luft, während die Pflanzenteile durch direkte Bestrahlung sich sehr verschieden erwärmen können.

An der nördlichen Grenze eines Verbreitungsbezirkes genügt häufig die Wärme zum Leben der Pflanzen, sie genügt jedoch nicht zur Ausbildung von reifen Früchten und Samen. In diesem Grenzgebiete kann demnach nur auf künstlichem Wesse, durch die Vermittelung des Menschen die betreffende Art erhalten werden. Je mehr wir uns diesem Grenzgebiete nähern, desto seltener werden z. B. bei den Holzgewächsen die Samenjahre eintreten.

Ebenso wie durch das Sinken der Wärme unter ein bestimmtes Minimum die Ausbreitung einer Art begrenzt wird, kann auch eine zu bedeutende Steigerung der Wärme die weitere Ausbreitung einer Pflanze hemmen.

Interessant sind die Vegetationslinien jener Pflanzen, welche eine rein nördliche, den Breitengraden paralle̊l verlaufende Grenze aufweisen. Als Beispiel sei die Höhe der Nordgrenzen von folgenden Pflanzen angeführt.

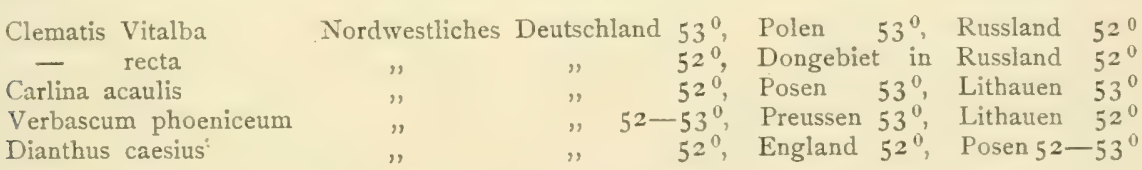

Die örtlichen Bedingungen des Vorkommens und zugleich auch die klimatischen Werte der okkupierten Gegenden weichen sehr bedeutend von einander $\mathrm{ab}$ und trotzdem bleibt die Polhöhe, bis zu welcher diese Pflanzen vorkommen, dieselbe. Grisebach nimmt daher an, dass diese Pflanzen von der durch direkte Insolation gewonnenen Erwärmung abhängiger sind als von den klimatischen Linien, deren Temperatur durch das Thermometer gemessen wird.

Andere Pflanzen, wie z. B. die Tanne (vgl. Karte I) und der Weinstock, verlausgen eine bestimmte Höhe der Sommertemperatur und zugleich eine gewisse Länge der Vegetationszeit. Ihre nördlichen Vegetationslinien verlaufen innerhalb Centraleuropas parallel den Isotheren (Linien gleicher Sommertemperatur) biegen aber im Osten Europas sehr weit nach Süden aus, weil ihnen nur im Süden eine hinreichend lange Vegetationszeit zur Verfügung steht.

Schliesslich möchte ich noch auf das Verhalten der Lärche verweisen, welche zu jenen Pflanzen gehört, die einen schnellen Übergang von der 
Wintertemperatur zur Sommertemperatur vorziehen. Wesen der für Spätfröste empfindlichen Benadelung findet die Lärche ein ihr zusagendes Klima sowohl in den Gebirgssegenden der Alpen und Karpathen als in den Ebenen Russlands und Sibiriens, weil sich dort die Sommertemperatur im Frïhjahr ziemlich unvermittelt, ohne für die jungen Blattorgane schädliche Schwankungen der Wintertemperatur anreiht. Auf unserer Tafel II ist nur der alpine Verbreitungsbezirk ausgeführt, da die in Russland rorkommende Lärche als besondere Abart betrachtet wurde.

Bei der Lösung ähnlicher pflanzengeographischer Fragen können die sog. pflanzenphänologischen Beobachtungen von Nutzen sein, welche vornehmlich die Tage des Laubausbiuchs, der Blütenentwickelung und Samenreife zusammenstellen. Je weiter wir nach Norden gehen, desto später tritt z. B. die Blüte ein, es machen sich jedoch auch hierbei Eigentïmlichkeiten des Sec- und Kontinentalklimas geltend, ebenso ist die Meereshöhe von Einfluss. Die cinzelnen Pflanzen reagieren bis zu einem gewissen Grade verschieden.

Die Wirkung der Feuchtigkeit auf die Verteilung der Pflanzen ist in unserem Gebiete mehr eine lokale, indem sich bei gleicher Regenmenge die Durchlïssigheit des Bodens und die Konfisuration desselben in hohem Masse geltend macht.

Abgesehen davon kann auch auf grosse Strecken durch Regenmangel und Trockenheit der Luft die Vegetation auf gewisse Formationen beschränkt werden. Die specifische Steppenvegetation ist hierfür der prägnanteste Ausdruck. Durch den Mangel an Regen, oder die Beschränkung des Regens auf gewisse Jahreszeiten wird die Vegetationszeit so verkürzt, dass Waldformationen nicht mehr aufzukommen vermögen. Die südliche Grenze vieler europäischer Gewächse ist durch die zu trockenen Sommer gegeben. Ebenso sind gewisse Pflanzen des mediterranen Gebietes auf die Küstenstriche beschränkt oder auf die Berge zurückgedrängt, da der übrige Teil dieser Gegenden eine zu geringe Menge von Regentagen im Sommer aufweist.

In Gebirgen herscht immer eine grössere Feuchtigkeit als in der Ebene. Da die Gebirge kühler sind, wird der Wasserdampf der Winde an denselben kondensiert. Der grösseren Regenmenge wirkt die grössere Intensität der Somnenwirkung entgesen, indem hierdurch die V'erdunstung des vorhandenen Wassers beschleunigt wird. In gemässigten Klimaten ist die Feuchtigkeit in den Thälern grösser, als an den Spitzen der Berge, da dort ein Teil der oben gefallenen Wassermenge zusammenfliesst. In den Tropen liegt es vielfach anders, da es hier überhaupt oft nur in den höheren Regionen des Gebirges regnet. Dementsprechend sind die höher gelegenen Strecken feuchter als die tieferen.

Regionen. In ähnlicher Weise wie in der Richtung von dem Äquator zu den Polen die Temperatur abnimmt, sehen wir auch bei steigender Erhebung des Landes über das Meeresniveau eine Temperaturverminde- 
rung eintreten. Dementsprechend kann man mehrere Schichten mit verschiedener Vegetation unterscheiden, die man als Regionen bezeichnet. Zwischen der Flora des Gebirges und der höheren Breiten besteht innerhalb eines pflanzengeographischen Gebietes noch die bemerkenswerte Beziehung, dass die Pflanzen der höheren Gebirgsregionen häufig in der Ebene höherer Breiten wiederkehren. Wenn nun auch die Temperaturverhältnisse und die Kürze der Vegetationszeit in den höheren Gebirgen und in den nördlichen Gegenden übereinstimmen, so bestehen doch auch Unterschicde bezüglich der Wirkung der Bestrahlung, der Intensität des Lichtes, der Dichtigkeit der Luft und der Konfiguration des Bodens.

Die Lage der Regionen und damit im Zusammenhang die Baumgrenze und die Grenze der übrigen Gewächse in vertikaler Richtung ist verschieden, je nach der geographischen Lage des Gebirges. Je weiter dasselbe nach Norden geht, desto weniger hoch liegen die einzelnen Regionen.

Wir können in Mitteleuropa folgende Regionen unterscheiden:

I. Ebene und Vorberge: Getreidekultur, speciell der Weizen gedeiht nur' in dieser Region. In wärmeren Teilen Weinbau und Mais. Verschiedene Laubhölzer und Nadelhölzer, unter denen die echte Kastanie und der Wallnussbaum dieser Region eigentümlich sind. In den Alpen bis $810 \mathrm{~m}$, in Nord- und Mitteldeutschland bis $450 \mathrm{~m}$.

2. Montane Region.

A. Buchenregion: Die Wälder sind durch Buchen und Eichen charakterisiert. Dabei Obst- und Getreidebau. In den Alpen von 810-I300 m, in Norddeutschland höchstens bis $650 \mathrm{~m}$.

B. Nadelwaldregion: Dic Laubhölzer treten mehr zurïck, Fichten, Lärchen bilden einen Gürtel von Nadelwäldern, der mit Zwergformen an der Baumgrenze aufhört. In den untersten Teilen dieser Region gedeihen noch Hafer, Gerste und Kartoffeln. In den Alpen von I300 - $1600 \mathrm{~m}$, in Nord- und Mitteldeutschland bis I $166 \mathrm{~m}$ (Riesengebirge) und $1037 \mathrm{~m}$ (Harz).

3. Alpine Region: Alpensträucher wie Rhododendron, ferner Erica, Vaccinium, Krummholzkiefern, ausserdem noch Waldbestände von Lärchen und Pinus Cembra. In den Alpen von 1620-2300 m. Auf dem Riesengebirge von I $66-1604 \mathrm{~m}$, im Harz die Brockenspitze von I037-I I $40 \mathrm{~m}$.

4. Nivale Region: Alpenkräuter wie Soldanella alpina, Saxifraga-, Gentiana-, Pedicularisarten etc. neben Flechten und Moosen. In den Alpen $2300 \mathrm{~m}$ bis zur Schneegrenze, die in den nördlichen Alpen etwa bei $2660 \mathrm{~m}$, in den Centralalpen bei $2800 \mathrm{~m}$ liegt.

Es existieren sehr viele Angaben über die Höhe, bis zu welcher unsere Waldbäume in den Gebirgen aufsteigen. Diese Angaben schwanken innerhalb eines grösseren Gebirgsstockes sehr bedeutend und zwar ist hierbei die Exposition der Gebirge nach den verschiedenen Himmelssergenden ron Bedeutung. Die Verschiedenheit der Sonnenbestrahlung. 
sowic die Feuchtigkeitsdifferenzen können bewirken, dass gegenüberliegende Thalgehänge sogar mit einer verschiedenartigen Vegetation bedeckt sind.

Für eine derartige Verschiebung der Höhengrenzen der Buche liefern die Angaben Sendtners (in bayrischen Fussen) ein gutes Beispiel.

\begin{tabular}{ll|c|c|c|c|c|c|c|c}
\hline Exposition gegen $\cdots$ & $\cdots$ & NO. & O. & SO. & S. & SW. & IV. & NW. & N. \\
\hline Höhe in den Alpen & $\cdot$ & 4200 & 4360 & 4485 & 4465 & 4405 & 4430 & 4300 & 4280 \\
Höhe im bayr. Walde & $\cdot$ & 3590 & 3885 & 3950 & 3850 & 3840 & 3820 & 3600 & 3625 \\
\hline
\end{tabular}

Verschiedene Bäume, so Abies, Picea, Fagus, Acer Pseudoplatanus, bevorzugen in den tieferen Lagen die nördlichen und östlichen Hänge, in den höheren Lagen die südlichen, südwestlichen oder südöstlichen Lagen. Von den mehr auf die Ebene angewiesenen Arten bevorzugen Pinus silvestris, Quercus pedunculata und sessiliflora, Betula verrucosa die südlichen und südöstlichen Hänge, während Carpinus, Fraxinus, Castanea, Tilia mehr die nördlichen und östlichen Hänge lieben. Es mag in dem letzteren Falle besonders die verschiedene Feuchtigkeit ins Gewicht fallen.

An der oberen Grenze des Vorkommens hören vielfach die Bestände auf, es kommen nur einzelne höhere Stämme fort, eventuell gemischt mit anderen Gehölzen, die eine höhere Lage vertragen. Schliesslich nehmen viele Bäume Zwergwuchs an, bis ihre Existenz überhaupt unmöglich wird.

Willkomm hat in seiner „Forstlichen Flora" eine grosse Menge von Angaben über die Baumgrenzen zusammengestellt, denen wir einige Beispiele entnehmen.

Picea excelsa: Norwegen $\left(67^{\circ}\right.$ n. Br. $) 227 \mathrm{~m}$, Harz und Thüringer Wald $1000 \mathrm{~m}$, Riesengebirge II70-I234 m, Erzgebirge 950 m, Schwarzwald $1400 \mathrm{~m}$, Bayrischer Wald I494 m, Karpathen $1527 \mathrm{~m}$, Steirische Alpen $1677 \mathrm{~m}$, Bayrische Alpen I798 m, Unterengadin 2 I I m m, Centralpyrenäen $1299-1624 \mathrm{~m}$.

Abies pectinata: Thüringer Wald und Erzgebirge $812 \mathrm{~m}$ im Mittel, Riesengebirge 747-I234 m, Schwarzwald und Nordschweiz 974-I300 m, Bayrischer Wald I2I6-1267 m, Karpathen 974-II69 m, Bayrische Alpen I486-I563 m (als Baum), Berner Oberland I624 m.

Pinus silvestris: Norwegen 227-940 m, Harz, Thüringer Wald, Erzgebirge, Riesengebirge 650-787 m im Nittel, Bayrischer Wald $923 \mathrm{~m}$, Bayrische Alpen $1600 \mathrm{~m}$, Engadin $1950 \mathrm{~m}$.

Larix europaea: Karpathen I500 m, Bayrische Alpen I833-1950 m, Tirol I $850 \mathrm{~m}$, Centralalpen und Berner Oberland 2000-2050 m, Unterengadin (Remüser Alpen) $2324 \mathrm{~m}$.

Fagus silvatica (Nittelwerte): Harz 650 m, Erzgebirge 81 2 m, Riesen- 
gebirge $650 \mathrm{~m}$, Böhmerwald II69 m, Bayrischer Wald I229 m, Jura I250 m, Bayrische Alpen 1497 m, Tiroler Alpen I 540 m, Aetna I965 m.

Quercus pedunculata: Südliches Skandinavien $313 \mathrm{~m}$, Thüringer Wald und Harz $487 \mathrm{~m}$, Schwarzwald $650 \mathrm{~m}$, Bayrischer Wald $968 \mathrm{~m}$, Bayrische Alpen $950 \mathrm{~m}$, Tirol $1000 \mathrm{~m}$.

Quercus sessiliflora: Harz ca. $500 \mathrm{~m}$, Thüringer Wald ca. $550 \mathrm{~m}$, Spessart, Erzgebirge $650 \mathrm{~m}$, Sudeten $505 \mathrm{~m}$, Schwarzwald 750-970 m, Centralalpen II 85 m., Südtirol I 106 m (als Strauch I359 m).

Obgleich die Eichen weiter nach Osten gehen und ein grösseres Areal einnehmen, gehen sie doch nicht so hoch wie die Buche. Quercus sessiliflora geht im allgemeinen höher als Quercus pedunculata.

Betula verrucosa: Norwegen $\left(60^{0} \mathrm{n}\right.$. Br. $) 908 \mathrm{~m}$, Harz $974 \mathrm{~m}$, Riesengebirge $1250 \mathrm{~m}$, Nordkarpathen I $234 \mathrm{~m}$, Erzgebirge $974 \mathrm{~m}$, Bayrischer Wald $1026 \mathrm{~m}$, Bayrische Alpen $1493 \mathrm{~m}$, Westliche Schweiz I750 m, Aetna $2050 \mathrm{~m}$.

Betula pubescens geht etwas höher hinauf als Betula verrucosa.

Carpinus Betulus: Harz $390 \mathrm{~m}$, Rhön ca. $600 \mathrm{~m}$, Bayrischer Wald $695 \mathrm{~m}$, Jura $800 \mathrm{~m}$, Bayrische Alpen $880 \mathrm{~m}$, Schweizer Alpen $900 \mathrm{~m}$. Geht weniger hoch als Fagus.

\section{111. Elemente der wichtigsten Vegetationsformationen Mitteleuropas.}

Durch das Zusammenwirken klimatischer Faktoren und lokaler Verschiedenheiten des Standortes ist das Bild, welches die einzelnen Vegetationsformationen darbieten, ein ausserordentlich mannigfaltiges. Die Struktur, d. h. die physikalische Beschaffenheit des Bodens, seine Durchlässigkeit, der Mineral- und Humusgehalt, sowie die Verwitterungsfähigkeit desselben können bestimmend auf die Vegetation eines Standortes einwirken. Ebenso ist der Wassergehalt des Bodens sowie die Beleuchtungsintensität von Wichtigkeit.

Die Vegetationsformationen sind demnach Pflanzengesellschaften, welche unter bestimmten äusseren Verhältnissen in ähnlicher Zusammensetzung wiederkehren. Im folgenden soll nun durch die Anführung von häufiger vorkommenden Pflanzen die Kenntnis der für uns wichtigsten Formationen in Mitteleuropa erleichtert werden.

Vegetation des sandigen Meeresstrandes und der Dünen. Der Boden ist sehr durchlässig, die oberflächlichen Schichten trocknen leicht aus. Beleuchtung intensiv. Der Salzgehalt hält die nicht zu den Halophyten gehörigen Arten zumeist fern, doch kommen auf den vom Neere nicht bespülten, durch Regen ausgelaugten Dünen auch verschiedene andere Pflanzen vor. Diese Formation zeigt daher eine grössere V'erwandtschaft mit der Vegetation des nicht salzhaltigen Sandes der Binnenländer. 
Ammophila arenaria.

Agrostis alba var. stolonifera.

Triticum junceum und pungens.

Elymus arenarius.

Salix daphnoides.

Salsola Kali.

Sagina maritima.

Honkenya peploides.
Cakile maritima.

Crambe maritima.

Cochlearia danica.

Hippophaë rhamnoides.

Eryngium maritimum.

Glatx maritima.

Hieracium umbellatum var. linariifolium.

Salzwicsen und Schlickgrund.

Triglochin maritima.

Scirpus parvulus.

Festuca thalassiana.

Hordeum maritimum.

Juncus bufonius var. ranarius.

Juncus balticus.

Salicornia herbacea.

Atriplex litorale.

Spergularia salina.

Cochlearia officinalis.

Cochlearia danica.
Althaea officinalis.

Melilotus dentatus.

Lotus corniculatus var. tenuifolius.

Apium graveolens.

Oenanthe Lachenalii.

Glaux maritima.

Armeria vulgaris var. maritima.

Statice limonium.

Plantago maritima.

Aster tripolium.

Artemisia maritima.

Süsswasserformation (Bäche, Teiche, tiefere Gräben).

Sagittaria sagittaefolia.

Potamogeton fluitans.

- perfoliatus.

- pusillus.

- crispus.

Stratiotes aloides.

Hydrocharis morsus ranae.

Polygonum amphibium.

Ranunculus aquatilis.

- fluitans.

Nymphaea alba.

Formation der $\mathrm{Sümpfe,} \mathrm{flachen} \mathrm{Gewässer} \mathrm{und} \mathrm{Bachränder.}$ Equisetum limosum.

- palustre.

Alisma Plantago.

Sagittaria sagittaefolia.

Butomus umbellatus.

Scirpus lacustris.

- silvaticus.

- palustris und andere Arten.

Carex paludosa.

- acuta.
Nuphar luteum.

Callitriche verna.

- auctumnalis.

Trapa natans.

Myriophyllum verticillatum.

- spicatum.

Ceratophyllum demersum.

Hippuris vulgaris.

Hottonia palustris.

Utricularia vulgaris.
Carex riparia und viele andere.

Arundo phragmites.

Glyceria fluitans.

Typha angustifolia.

- latifolia.

Sparganium ramosum.

- simplex.

Calla palustris.

Acorus calamus.

Iris pseudacorus. 
Juncus obtusiflorus.

Salix aurita.

Salix cinerea,

Alnus glutinosa.

Polygonum amphibium.

Rumex aquaticus.

- crispus.

- Hydrolapathum.

Ranunculus lingua.

Caltha palustris.

Nasturtium palustre.

- amphibium.

Epilobium hirsutum.

- parviflorum.

Lythrum salicaria.

Cicuta virosa.

Sium latifolium.

Oenanthe fistulosa.
Phellandrium aquaticum.

Archangelica officinalis.

Lysimachia vulgaris.

— thyrsiflora.

- nummularia.

Convolvulus (Calystegia) sepium.

Solanum dulcamara.

Symphytum officinale.

Myosotis palustris.

Mentha aquatica.

Stachys palustris.

Lycopus europaeus.

Menyanthes trifoliata.

Galium palustre.

Valeriana officinalis.

Eupatorium cannabinum.

Senecio paludosus.

Sonchus paluster.

Die Vegetation der Erlenbrüche ist ein specieller Fall der Sumpfformation, bei welcher durch die Beimischung von Bäumen und Sträuchern (Alnus glutinosa, Salix aurita, Rhamnus frangula, Viburnum Opulus u. a.) besonders die schattenertragenden Gewächse bevorzugt sind. Die Wurzelstöcke der Erlen sind mit dichten Moospoistern (Polytrichum, Sphagnum etc.) besetzt, zwischen denen sich Pflanzen der Wald- und Sumpfformation vorfinden. Gesellig vorkommende Rubussträucher und schlingender Hopfen und Lonicera Periclymenum vervollständigen das Bild.

Aspidium Thelypteris.

- spinulosum.

Phegopteris Dryopteris.

- polypodioides.

Lycopodium selago.

Carex echinata.

- elongata.

- canescens.

- caespitosa, grosse Polster (Kaupen) bildend.

Calla palustris.

Nalachium aquaticum.

Caltha palustris.

Moor und Torf. Wird die Zersetzung von Pflanzenresten durch Wasserbedeckung sehr verlangsamt, so häufen sich grosse Massen humoser Substanzen an, welche man je nach dem geringeren oder höheren Grade der Zersetzung als Torf oder Mloor bezeichnet. Die Vegetation dieser Moorflächen ist in hohem Grade von den im Wasser
Anemone nemorosa.

Spiraea ulmaria.

Geum rivale.

Lythrum salicaria.

Circaea alpina.

Lysimachia vulgaris.

Symphytum offinale.

Stachys palustris.

Menyanthes trifoliata.

Galium palustre.

Valeriana officinalis.

Crepis paludosa. 
gelösten Salze abhängig und man unterscheidet demnach zwischen Hochmooren, welche kalkarm sind und Grünlands-oder Wiesenmooren, welche sich durch Kalkgehalt auszeichnen. Aus Grünlandsmooren können Hochmoore entstehen, wenn die Moorschicht so mächtig geworden ist, dass von unten kein kalkhaltiges Wasser zu den oberen Schichten dringen kann oder die vorhandenen Kalksalze durch die tieferen Moorschichten gebunden werden. Dementsprechend finden wir auch zwischen der Flora der Hoch- und Grünlandsmoore Übergänge neben verschiedenen gemeinsamen Formen. Hochmoore tragen nur kümmerliche Erlen, Birken, Kiefern. Die Grünlandsmoore zeigen eine kräftigere Entwickeluns der senannten Holzarten, sobald sie ion fliessendem Wasser durchströmt sind.

Vegetation der Hochmoore. Der Torf der Hochmoore entstcht hauptsächlich durch die Iumifizierung von Morosen, d. h. Sphasnumarten (Torfmoosen) und Polytrichumarten sowie von Heidekraut, Calluna vulgaris und Erica tetralix. Charakteristisch sind folgende Pflanzen:

Scirpus multicaulis.

Eriophorum vaginatum.

Hypericum elodes.

Empetrum nigrum.

- gracile.

Carex pauciflora.

Sedum villosum.

- limosa.

Calla palustris.

Juncus squarrosus.

Salix repens var. rosmarinifolia.

- myrtilloides.

Betula nana.

Myrica Gale.

Drosera intermedia.

- rotundifolia.

Rubus chamaemorus.

Hydrocotyle vulgaris.

Cornus suecica.

Vaccinium uliginosum.

- oxycoccus.

Andromeda polifolia.

- calyculata.

Ledum palustre.

Calluna vulgaris.

Erica tetralix.

Vegetation der Grünlandsmoore. Von Moosen sind hauptsächlich Hypnum- und Mniumarten vorhanden (vgl. S. 235 und 236). Den Charakter dieser Moore bestimmen die zahlreich auftretenden Carexarten, welche zwar auch in den Hochmooren, doch nicht so zahlreich vorkommen (siehe unten). Den Grünlandsmooren eigentümlich:

Carex pulicularis.

- capitata.

- vulpina.

- distans.

- flava.

Scirpus silvaticus.

Aira caespitosa.

Orchis palustris.

Dianthus superbus.

Lotus uliginosus.

Gratiola officinalis.

Pinguicula vulgaris.

Taraxacum vulgare var. palustre.

Hochmooren und Wiesenmooren gemeinsame Pflanzen: Equisetum palustre.

Lycopodium inundatum.

-- limosum.

Aspidium Thelypteris. 
Scirpus caespitosus.

Eriophorum angustifolium. - latifolium.

Carex dioica.

- paniculata.

- echinata.

- canescens.

- stricta.

- caespitosa.

- Goodenoughii (=vulgaris).

- panicea.

- rostrata.

- vesicaria.

- paludosa u. a.

Nardus stricta.

Calamagrostis lanceolata.

- neglecta.

Alopecurus geniculatus.

Arundo phragmites.

Molinia coerulea.

Juncus filiformis.

Epipactis palustris.

Salix pentandra.

- cinerea.

- aurita.

Formationen der Wiesen. Ohne auf die grosse Nannigfaltigkeit dieser Formationen (vgl. S. 376) näher einzugehen, möchte ich hier nur auf die praktisch wichtige Unterscheidung von sauren und milden Wiesen hinweisen, zwischen denen selbstrerständlich zahlreiche L̈bergangsformen bestehen. Die Vegetation der sauren Wiesen schliesst sich, wie das bei ihrer relativ grossen Feuchtigkeit leicht erklärlich ist, näher an die Formation der Grünlandsmoore an, wenn auch einige neue Pflanzen hinzukommen, andere fehlen. Derartige saure Wiesen zeigen viele Carexarten, sowie Moose (vgl. S. 235), die verschwinden, sobald die Wiese entwässert oder durch Zufuhr von Dünger melioriert wird.

Auf den milden Wiesen, welche entweder einen frischen odẹr mehr trockenen Boden aufweisen, herrschen die Gramineen neben bestimmten, oft massenhaft auftretenden dicotylen Pflanzen. 1)

Auf feuchten Wiesen sind zu beobachten:

Equisetum palustre.

Triglochin palustris.

Scirpus paluster.

- compressus.

1) Die wertlosen oder schädlichen Pflanzen sind mit $\dagger$, die nützlichen Futterpflanzen mit $\because$ bezeichnet. 
"Carex vulpina.

$\uparrow$ - caespitosa.

$\dagger$ pallescens.

$\dagger$ - ampullacea.

$\leftarrow$ - hirta.

* Hierochloa odorata.

* Phalaris arundinacea.

* Phleum pratense.

* Avena pubescens.

Phragmites communis.

Molinia coerulea.

*Poa palustris.

*Glyceria fluitans.

* Bromus racemosus.

$\dagger$ †uncus lamprocarpus.

$\dagger$ - atratus.

†ris pseudacorus.

†Orchis latifolia.

$\uparrow$ - maculata.

*Polygonum bistorta.

†Stellaria glauca.

Auf mässig feuchten oder trockenen Wiesen:

Carex muricata.

*Anthoxanthum odoratum. ${ }^{1}$ )

*Alopecurus pratensis.

* Agrostis vulgaris.

* - alba.

*Holcus lanatus.

* Avena elatior.

* Koeleria cristata.

*Briza media.

*Dactylis glomerata.

*Cynosurus cristatus.

*Poa pratensis.

* - trivialis.

* - compressa.

*Festuca elatior.

*Lolium perenne.

$\dagger$ Allium acutangulum.

$\dagger$ - schoenoprasum.

$\uparrow$ Colchicum autumnale.

Orchis morio.
Stellaria uliginosa.

†Lychnis flos cuculi.

†Ranunculus acer.

$\dagger$ - repens.

Trollius europaeus.

Cardamine pratensis.

- amara.

Geranium palustre.

* Lathyrus pratensis.

Lysimachia nummularia.

$\dagger$ Euphrasia odontites.

- officinalis.

$\dagger$ Rhinanthus major.

- minor.

Ajuga reptans.

†Valeriana dioica.

Achillea ptarmica.

Cirsium oleraceum.

- palustre.

Crepis paludosa.
Orchis militaris.

Platanthera viridis.

Gymnadenia conopsea.

Rumex acetosa.

Cerastium arvense.

- triviale.

Ranunculus bulbosus.

Arabis arenosa.

- hirsuta.

$\uparrow$ Hypericum perforatum.

Geranium pratense.

Polygala vulgaris.

Potentilla anserina.

- reptans.

*Alchemilla vulgaris.

Sanguisorba officinalis.

* Nedicago lupulina.

*Trifolium pratense.

* - repens.

* - hybrida.

1) Über den Wert der Futtergräser vgl. S. 278 ff. 
* Lotus corniculatus.

*Vicia cracca.

- tetrasperma.

Carum carvi.

†Angelica vulgaris.

†Pastinaca sativa.

†Heracleum sphondylium.

†Daucus carota.

†Armeria vulgaris.

†Plantago major.

- lanceolata.

- media.

Mentha arvensis.

- pulegium.

†Salvia pratensis.

Brunella vulgaris.

Erythraea centaurium.

Galium mollugo.
†Galium verum.

Campanula patula.

Knautia arvensis.

Succisa pratensis.

†Bellis perennis.

Achillea millefolium.

Chrysanthemum leucanthemum.

Arnica montana.

Senecio Jacobaea.

†Centaurea jacea.

Serratula tinctoria.

†Cirsium acaule.

Taraxacum officinale.

Tragopogon pratensis.

Picris hieracioides.

Hieracium auricula.

- praealtum.

- pratense.

Formationen des trockenen Sandes und des geringeren Kiefernbodens. Die Flora des Sandbodens von geringerer Feuchtigkeit ist im allgemeinen eine sehr charakteristische. Bei steigendem Feuchtigkeitsgehalt, sowie bei grösseren Beimengungen von Humus und thoniglehmigen Boden wächst die Mannigfaltigkeit der vorkommenden Arten, die je nachdem ob der Sandboden Wiesen- oder Waldcharakter annimmt, verschieden sind.

Charakteristisch für den schlechtesten Boden (Kiefernboden V. Klasse) ist das Vorkommen von Cladonia rangiferina, einer Flechte, welche auch noch Beschattung gut aushält. Ferner sind für trockene Sandböden, etwa Kiefernboden IV. und V. Klasse zu erwähnen, ausser verschiedenen Moosen (vgl. S. 236):

Carex arenaria.

- praecox.

- obtusata.

Aira caryophyllea.

- praecox.

Corynephorus (Aira) canescens.

Festuca ovina.

- glauca.

- rubra.

Bromus sterilis.

- tectorum.

Rumex acetosella.

Salsola Kali.

Scleranthus annuus.
Scleranthus perennis.

Herniaria glabra.

Spergula arvensis.

Dianthus arenarius.

Draba verna.

Teesdalia nudicaulis.

Viola tricolor.

Helianthemum guttatum.

Sedum acre.

Trifolium arvense.

Astragalus arenarius.

Ornithopus perpusillus.

Calluna vulgaris.

Armeria vulgaris. 
Plantago arenaria.

Thymus serpyllum.

Anchusa arrensis.

Myosotis arenaria.

Verbascum thapsiforme.

Jasione montana.

Filago minima.

Helichrysum arenarium.
Senecio silvaticus.

- viscosus.

- vernalis.

Arnoseris minima.

Hypochaeris glabra.

Hieracium pilosella.

- umbellatum.

Auf besserem, etwas feuchterem Sandboden, der auch zersetzte Pflanzenstoffe in grösserer Menge enthält (Kiefernboden III., teilweise auch Il. Klasse) wird dic Flora eine mannigfaltigere. $\mathrm{Zu}$ erwähnen sind:

Hypnumarten.

Pteris aquilina.

Juniperus communis.

Anthoxanthum odoratum.

Agrostis vulgaris.

Dactylis glomerata.

Avena elatior.

- pubescens.

Poa pratensis.

Urtica dioica.

Polygonum convolvulus.

Rumex acetosa.

Hypericum perforatum.

Euphorbia cyparissias.

Rubus Idaeus.

Vicia sepium.

- silvatica.

- hirsuta.

Vaccinium Myrtillus.

- Vitis Idaea.

Convolvulus arvensis.

Kiefernboden I. und II. Klasse besitzt eine grössere Menge humusbedïrftiger Pflanzen und zeist eine ähnliche Bodenflora wie Buchenboden II. und III. Klasse.

In den auf trockenerem Boden stockenden Birkenwäldern tritt ungefähr. dieselbe Bodenflora auf wie in den Kiefernwäldern, da die Birke ähnliche Ansprüche an die mineralische Bodenkraft macht wie die Kiefer.

Die Fichten- und Tannenwälder erhalten einerseits durch ihren tiefen Schatten, andererseits ihrer Höhenlage entsprechend durch dic Beimengung montaner oder alpiner Arten ein eigentümliches Gepräge. Der aus Fichten und Tannen gebildete Vorgebirgswald beherbergt vielfach Pflanzen des Buchenwaldes. Die der Nadel- und Laubwaldregion 
gemeinsamen Arten der Bodenflora sind daher im Anschluss an die Laubwälder angeführt.

Im Schatten der Fichten- und Tannenwälder herrschen in ausgedehntem Masse die Moose und Pteridophyten. Von den letzteren sind hervorzuheben :

Asplenium filix femina.

- trichomanes.

Phegopteris Dryopteris.

- polypodioides.

Aspidium filix mas.

- montana.

- spinulosum.

An lichteren Stellen Pteris aquilina, Lycopodium clavatum.

Von den phanerogamen Schattenpflanzen des Nadelwaldes sind Taxus baccata, Goodyera repens und Monotropa hypopitys hervorzuheben.

Fiir lichtere Stellen sind zu nennen:

Carex pendula.

- digitata.

- ericetorum.

Calamagrostis arundinacea.

Veratrum album.

Luzula angustifolia.

Stellaria nemorum.

Helleborus niger.

Dentaria bulbifera.

- enneaphyllos.

Rhamnus alpina.

Ausserdem finden sich hier viele Pflanzen der besseren Klassen des Kiefernbodens.

Von den speciell in den Laubwäldern verbreiteten Pflanzen seien zunächst die Arten der schattigen Standorte genannt. Dieselben beanspruchen milden Humus, den sie in besonders reichem Masse auf stark kalkhaltigem Boden vorfinden, weshalb eine derartige Flora dort am üppigsten gedeiht. Phegopteris Dryopteris.

Aspidium filix mas.

Carex pilosa.

Melica nutans.

- uniflora.

Milium effusum.

Festuca gigantea.

Bromus asper.

Brachypodium silvaticum.

Elymus europaeus.

Arum maculatum.
Saxifraga decipiens.

- rotundifolia.

Ribes grossularia.

Atropa Belladonna.

Digitalis purpurea.

— ambigua.

Lamium maculatum.

Galeobdolon luteum var. montanum.

Petasites albus.

Mulgedium alpinum.
Galanthus nivalis.

Allium ursinum.

Paris quadrifolia.

Polygonatum multiflorum.

Cephalanthera grandifiora.

Neottia nidus avis.

Stellaria nemorum.

- holostea.

Cerastium silvaticum.

Malachium aquaticum.

Anemone nemorosa. 
Anemone ranuncoloides.

Hepatica triloba.

Ranunculus auricomus.

- lanuginosus.

- Ficaria.

Thalictrum aquilegifolium.

Aquilegia vulgaris.

Actaea spicata.

Corydalis cava.

— solida.

Dentaria bulbifera.

Alliaria officinalis.

Cardamine impatiens.

- hirsuta.

Euphorbia dulcis.

Mercurialis perennis.

Adoxa moschatellina.

Vicia dumetorum.
Vicia cassubica. silvatica.

Lathyrus vernus.

Circaea lutetiana.

- intermedia.

Hedera Helix.

Asarum europaeum.

Pirola minor.

Primula elatior.

Atropa Belladonna.

Lathraea squammaria.

Pulmonaria officinalis.

Stachys silvatica.

Asperula odorata.

Campanula latifolia.

Phyteuma spicatum.

Lampsana vulgaris.

Lactuca muralis.

Zwischen lichten Gebüschen, sowie an stärker besonnten Stellen des Laubwaldes, teilweise auch auf Schläsen sind zahlreiche Gräser der milden Wiesen zu finden (vgl. S. 400). Ausserdem fällt der Artenreichtum von Liliifloren, Labiaten und Compositen auf.

Von den vorzugsweise in lichten Laubwäldern vorkommenden Arten seien folgende angeführt:

Gagea lutea.

Lilium Martagon.

Erythronium dens canis.

Scilla bifolia.

Muscari tenuifolium.

Leucojum vernum.

Iris sibirica.

Orchis pallens.

Platanthera bifolia.

Cypripedium calceolus.

Arabis hirsuta.

Turritis glabra.

Viola odorata.

- hirta.

Hypericum montanum.

Geranium sanguineum.

Dictamnus albus.

Potentilla reptans.

Vicia pisiformis.
Lathyrus niger.

Aegopodium podagraria.

Sanicula europaea.

Primula officinalis.

Lithospermum officinale.

Origanum vulgare.

Melittis melissophyllum.

Lamium Galeobdolon.

Galeopsis versicolor.

Betonica officinalis.

Ajuga reptans.

Galium cruciatum.

Achillea ptarmica.

Senecio crucifolius.

Carduus crispus.

- defloratus.

Cirsium lanceolatum.

Lactuca quercina. 
Den Laubwäldern und den bessern Bodenklassen der Nadelholzwaldungen gemeinsame Arten.

A. Im stärkeren Schatten:

Equisetum pratense.

- silvaticum.

Verschiedene Filices (vgl. S. 239).

Carex remota.

- silvatica.

Poa nemoralis.

Festuca silvatica.

Majanthemum bifolium.

Luzula pilosa.

Epipactis latifolia.

Neottia nidus avis.

Rumex sanguineus.

Helleborus viridis.

— foetidus.
Geranium Robertianum.

Oxalis acetosella.

Impatiens noli tangere.

Chrysosplenium alternifolium.

Geum urbanum.

- rivale.

Fragaria elatior.

Pirola rotundifolia.

- media.

- uniflora.

Lysimachia nemorum.

Veronica montana.

Myosotis silvatica.

Senecio Fuchsii.

Aconitum Napellus.

B An lichteren, sowie stark beleuchteten Stellen, Schlägen, Waldrändern etc.:

Pteris aquilina.

Carex praecox.

- brizoides.

- leporina.

- obtusata.

Anthoxanthum odoratum.

Agrostis vulgaris.

— alba.

Calamagrostis epigeios.

- arundinacea.

Aira flexuosa.

Holcus lanatus.

Avena elatior.

Triodia decumbens.

Dactylis glomerata.

Festuca rubra.

Brachypodium pinnatum.

Convallaria majalis.

Luzula campestris.

Orchis maculata.

Cephalanthera rubra.

Urtica dioica.

Rumex conglomeratus.
Stellaria media.

Dianthus Carthusianorum.

- deltoides.

Viscaria vulgaris.

Silene inflata.

- nutans.

Melandryum rubrum.

Ranunculus acer.

- polyanthemus.

Viola odorata.

- canina.

Hypericum perforatum.

Polygala vulgaris.

- comosa.

Euphorbia cyparissias.

Sedum maximum.

Saxifraga granulata.

Fragaria vesca.

- collina.

Potentilla recta.

- verna.

- alba.

Agrimonia eupatoria. 
Spiraca ulmaria.

filipendula.

Trifolium montanum.

- rubens.

Astragalus glycyphyllus.

Coronilla varia.

Lathyrus silvestris.

montanus.

Spartium scoparium.

Epilobium spicatum. montanum.

Pimpinella saxifraga.

Bupleurum falcatum.

Peucedanum oreoselinum.

Heracleum sphondylium.

Laserpitium pruthenicum.

Torilis anthriscus,

Anthriscus silvestris.

Convolvulus sepium.

Cuscuta europaea.

Physalis Alkekengi.

Verbascum thapsus.

- thapsiforme.

- lychnitis.

Scrophularia nodosa.

Veronica chamaedrys.

- officinalis.

Melampyrum pratense.

Euphrasia officinalis.

Mentha aquatica.

Thymus Serpyllum.

Calamintha officinalis.

- clinopodium.

Glechoma hederacea.

Lamium maculatum.

Ajuga genevensis.

Der Artenreichtum ist am grössten im Mittelwald, da hier neben den schattigen Stellen auch feuchtere und trocknere lichte Lokalitäten zu finden sind. Ausserdem wird die Zahl der Arten besonders durch Kalkgehalt des Bodens vermehrt, der einerseits durch seine chemische Beschaffenheit, anderseits durch die reichliche Produltion von mildem Humus günstig einwirkt. Es treten hier auch eine grosse Anzahl von forstlich wichtigen Bäumen und Sträuchern auf, so dass in einem auf Kalkboden stehenden
Ajuga pyramidalis.

Vincetoxicum album.

Galium mollugo.

silvaticum.

saxatile.

Asperula tinctoria.

- cynanchica.

- glauca.

Valeriana officinalis.

- sambucifolia.

Campanula patula.

- rapunculus.

- Trachelium.

- rotundifolia.

Knautia silvatica.

Erigeron canadense.

Solidago Virga aurea.

Jnula salicina.

Gnaphalium dioicum.

— silvaticum.

Achillea millefolium.

Chrysanthemum leucanthemum.

- corymbosum.

Tanacetum vulgare.

Senecio Jacobaea.

Carlina acaulis.

Serratula tinctoria.

Centaurea phrygia.

- montana.

Scorzonera humilis.

Lactuca virosa.

Crepis succisifolia.

Hieracium pratense.

- murorum.

- vulgatum.

- tridentatum. 
Mittelwald unter Umständen fast sämtliche bei uns wild vorkommenden Holzpflanzen zu finden sind.

Die angeführten Formationen geben noch kein vollständiges Bild der einheimischen Flora, denn auch der kultivierte Boden, Geröllhalden, Felspartien, Dorfstrassen, Waldwiesen, sowie das Hochgebirge haben ihre eigenen Pflanzengesellschaften, deren Beschreibung uns jedoch zu weit führen würde. Auch die einzelnen grösseren Gebirgsketten weisen Eigentümlichkeiten auf, die teils von der geographischen Lage, teils von der geognostischen Beschaffenheit des Bodens abhängen.

Ich möchte schliesslich noch darauf hinweisen, dass die Pflanzenformationen keineswegs etwas beständiges sind. Es ist selbstverständlich, dass durch die Einwirkung des Menschen, der einen Wald in Kulturland überführt, auch eine andere Formation geschaffen wird. Doch auch in der Natur vollzieht sich ein Wechsel. Kahle Felstrümmer und Gesteinsmassen werden zunächst von Flechten überzogen, die als erste Ansiedler den Boden für kleine Moose bereiten, und ebenso wie die Flechten noch das zeitweilige Austrocknen vertragen können. Die Moose bilden eine Humusschicht, welche, sobald sie mächtiger geworden ist, soviel Wasser zurückhält, dass auch anspruchslosere Phanerogamen dort leben können. In Gesteinsrissen und Spalten sammeln sich genügsame Gräser an ( $\mathrm{z}$. B. Festuca ovina), die später anderen anspruchsvolleren Arten (z. B. Koeleria cristata, Brachypodium pinnatum, Briza media, Melica ciliata) weichen müssen. Doch auch diese treten in der Regel vor krautigen Gewächsen zurück (je nach der geognostischen Unterlage verschieden), es kommen Ononis spinosa, Juniperus communis, Crataegus oxyacantha, Viburnum Lantana hinzu. Der Boden ist schliesslich so weit zersetzt, dass anspruchsvollere Holzarten, sowie ein nutzbringender Wald kultiviert werden können.

\section{Bodenanzeigende Pflanzen. Nutzen und Schaden der Bodenflora.}

Wenn auch durch die im vorigen Paragraphen angeführten Pflanzenformationen die Beschaffenheit des Standortes bis zu einem gewissen Grade charakterisiert ist, sollen hier noch einige Angaben über das Verhalten der Pflanzen gegen die chemische und physikalische Beschaffenheit des Bodens gemacht werden. Man unterscheidet:

I. Bodenvage Pflanzen, welche ohne Unterschied auf den verschiedensten Bodenarten wachsen.

2. Bodenholde Pflanzen, welche mit Vorliebe auf einer bestimmten Bodenunterlage vorkommen, ohne auf anderen Böden ganz zu fehlen. Ein Beispiel ist die Kiefer, welche auf Kiesel-, Kalk- und Thonboden wächst, aber auf Sand-, d. h. Kieselboden am besten gedeiht. 
3. Bodenstete Pflanzen, welche nur auf einer bestimmten Bodenart wachsen, z. B. Globularia nudicaulis, Ophrys apifera, Saxifraga caesia, die nur auf Kalkboden zu finden sind. Streng durchzuführen ist diese Bodenstetigkeit nicht, da auch diese Pflanzen ausnahmsweise auf anderem Boden fortkommen.

Kalkanzeigende Pflanzen. Hierher gehören besonders Arten aus den Familien der Amygdalaceen, Pomaceen, Rosaceen, Labiaten, Papilionaceen. Unter den echten Gräsern nur wenige Arten, z. B. Stipa pennata, Melica ciliata; Briza media. Dagegen sind die Laubmoose dem Kalkboden entschieden abhold und verschwinden sogar, wenn moostragende Wiesen in entsprechender Weise gedüngt werden. Als Beispiele ron kalkanzeigenden Pflanzen seien angeführt:

A. Auf Kulturboden:

Agrostemma Githago.

Adonis vernalis.

Papaver Rhoeas.

Rubus caesius.

Lathyrus tuberosus.

Carum bulbocastanum.

Bupleurum rotundifolium.

Caucalis latifolia.

B. Auf Wiesen:

Koeleria cristata.

Briza media.

Sanguisorba minor.

Lathyrus pratensis.

Viccia cracca.

Trifolium pratense.

C. Im Walde :

Cephalanthera rubra.

Epipactis rubiginosa.

Cypripedium calceolus.

Orchis militaris und andere Orchideen.

Humulus lupulus.

Silene alpestris.

Clematis vitalba.

Thalictrum minus.

Viola canina.

Geranium sanguineum.

Polygala chamaebuxus.

Rhamnus frangula.

- cathartica.

Pirus communis.

- malus.
Falcaria Rivini.

Convolvulus arvensis.

Euphrasia odontites.

Teucrium botrys.

Asperula arvensis.

Sherardia arvensis

Centaurea cyanus.

Ononis repens.

Pastinaca sativa.

Daucus carota.

Carum carvi.

Rhinanthus major.

Amelanchier vulgaris.

Sorbus Aria.

- torminalis.

Cotoneaster vulgaris.

- tomentosa.

Rosa rubiginosa.

Anthyllis vulneraria.

Trifolium rubens.

Vicia dumetorum.

Peucedanum oreoselinum.

Bupleurum falcatum.

- longifolium.

Cyclamen europaeum.

Melampyrum cristatum.

Lithospermum officinale. 
Calamintha acinos.

Melittis melissophyllum.

Teucrium montanum.

Salvia glutinosa.
Stachys recta.

Viburnum lantana.

Lonicera periclymenum.

Scabiosa suaveolens.

Nach Hilgard muss der Kalkgehalt des Bodens um so grösser sein, je thoniger der Boden ist, soll eine „Kalkflora" auftreten. Auf sehr schwerem Thonboden findet man noch bei $0,5^{0}$." Kalkgehalt keine Kalkpflanzen, auf leichtem Lehmboden sind dieselben schon bei $0,25 \%$, auf Sandboden schon bei O, $5 \%$ Kalkgehalt vorhanden. Jeder Boden, der über $0,75 \%$ Kalkgehalt besitzt, zeigt charakteristische Kalkpflanzen.

Kalianzeiger.

A. Auf Kulturboden:

Spergula arvensis.

Sagina procumbens.

Fumaria officinalis.

Anagallis arvensis.
Veronica arvensis.

- triphyllos.

- hederaefolia.

Valerianella olitoria.

B. Auf Wiesen:

Die echten Gramineen der milden Wiesen.

C. Im Walde:

Das frische Gedeihen von Eichen, Eschen, Ulmen, Buchen deutet auf Kalireichtum des Bodens. Ferner

Pteris aquilina.

Polypodium vulgare.

Aspidium filix mas.

Asplenium filix femina.

Arum maculatum.

Urtica dioica.

Thonanzeiger.

Equisetum arvense.

Bromus arvensis.

Lathyrus tuberosus.

Carum Bulbocastanum.

Falcaria Rivini.

Euphrasia odontites.

Kieselsäureanzeiger.

Hierher gehören die meisten Pflanzen des Nadelwaldes und der Sandformation (vgl. Seite $4 \mathrm{OI}$ bis 403), ferner Moose, Equiseten Carices, Eriophorumarten und Gramineen, Calluna vulgaris und Erica tetralix. Von Bäumen sind sandliebend: Pinus, Picea, Populus, Betula, Quercus.

Kochsalzanzeiger, Halophyten.

Hierher gehören besonders die Pflanzen des Meeresstrandes. Sie gedeihen aber auch auf Bodenarten, welche mit unterirdischen Steinsalzlagern in Verbindung stehen.
Corydalis cava.

Epilobium angustifolium.

Atropa Belladonna.

Solanum nigrum.

Scrophularia nodosa.

Hieracium silvaticum.

Veronica opaca.

Antirrhinum orontium.

Tussilago Farfara.

Lactuca scariola.

Lappa tomentosa. 
Trislochin maritima.

Salicornia herbacea.

Honkenya peploides.

Salsola Kali.

Cochlearia officinalis.

Cakile maritima.

Crambe maritima.

Capsella procumbens.
Apium sraveolens.

Glaux maritima.

Plantago maritima.

Aster tripolium.

Lactuca saligna.

Atremisia rupestris.

Scorzonera parviflora.

Hum us anzeiger.

Die Bewohner des milden, weit zersetzten Humus finden wir im Schatten der Laubwälder (vgl. S. 403).

Saurer Humus wird durch die Pflanzen der Moore, speciell der Grünlandsmoore, sowie der sauren Wiesen angezeigt (vgl. S. 398-400).

Beim Abtrieb eines Hochwaldbestandes verschwindet die vorhandene Schattenflora, ebenso wird hierdurch die vollständige Zersetzung des Humus gehemmt. Es stellen sich demnach neue Pflanzen ein, die man als Schlagflora bezeichnet. Sie wachsen auf halbzersetzten, faserigen Pflanzenresten (Wildhumus).

Unter den in lichten Laub- und Nadelwäldern vorkommenden Pflanzen (S. 405) ist schon ein grosser Teil der Schlagflora angeführt, ich erwähne daher nur jene Arten, welche hier als verdämmende Unkräuter jungen Kulturen besonders gefährlich werden.

Festuca ovina.

- duriuscula.

- rubra.

Agrostis vulgaris.

Holcus mollis.

Aira flexuosa.

Calamagrostis Epigeios.

Urtica urens.

Rumex acetosella.

Chenopodium album.

- hybridum.

Je besser der Boden, desto stärker und gefährlicher ist der auf

Kulturen und Schlägen sich einstellende Graswuchs.

Ruderalflora.

Es handelt sich hier um eine Pflanzenformation, die eine bestimmte Bodenbeschaffenheit anzeist. Wo sich Zersetzungsprodukte von organischen und anorganischen Körpern befinden, auf Schutt, Gemülle, frischem Kompost etc. stellt sich diese Schutt- oder Ruderalflora ein.

Poa annua.

Bromus tectorum.

Urtica urens.

Chenopodium urbicum.

Epilobium angustifolium.

Calluna vulgaris.

Digitalis purpurea.

Galeopsis acuminata.

- pubescens.

- Tetrahit.

Senecio silvaticus.

- viscosus.

- vernalis.

Erigeron canadense. 
Polygonum aviculare.

Chenopodium vulvaria.

- album.

- rubrum.

Atriplex hastatum.

- patulum.

Sisymbrium officinale.

Lepidium ruderale.

Malva neglecta.

- rotundifolia.

Bryonia alba.

Anthriscus vulgaris.

Solanum nigrum.

Dieselben Pflanzen kommen vielfach auch im Walde auf verwandten Lokalitäten vor und sind oft von den Wildhumuspflanzen und der Schlagflora nicht scharf zu trennen.

Es bietet sich demnach durch die Betrachtung der Bodenflora Gelegenheit, ein Urteil über die Beschaffenheit des Bodens zu gewinnen. Je grösser die Zahl der vorkommenden Arten ist, je mannigfaltiger die auftretende Vegetation ist, desto besser wird im allgemeinen ein Boden sein. Ein anderes vielfach leichter anzuwendendes Mittel zur Beurteilung der Bodengüte ist durch die Betrachtung des Waldbestandes selbst gegeben, wobei besonders die Höhe der Bäume (vgl. S. I63) zu berücksichtigen ist.

Die Bedeckung des Bodens mit verschiedenen nicht zum Waldbestande grehörigen Pflanzen bietet auch gewisse wirtschaftliche Vorteile und Nachteile, ganz abgesehen von den Nebennutzungen, welche gewisse Sträucher an Holz und Früchten liefern.

Durch die Bodenflora wird die Beschaffenheit des Bodens selbst verändert, indem die organischen Bestandteile der Pflanzen mehr oder weniger zersetzt werden, die anorganischen Bestandteile in leicht aufnehmbarer Form dem Boden erhalten bleiben. Die Vegetation des Bodens ist demnach sowohl für die Humusbildung, als für die mineralische Aufschliessung des Bodens von Wichtigkeit.

Eine leichte Moos- und Grasdecke wird auf einem zur Erhitzung neigenden Boden von Vorteil sein. Doch kann auch durch Torfmoose, welche die Feuchtigkeit anzichen und Wasser festhalten, unter Umständen eine Versumpfung des Bodens herbeigeführt werden.

Undurchlässiger Boden kann durch Rhizome und ausgebreitete Wurzelmassen aufgelockert werden, Flussand durch Rhizome treibende Pflanzen (Ammophila arenaria, Elymus arenarius, Hordeum maritimum, Carex arenaria) befestigt werden.

Bei starker Bodenneigung wird das Abschlemmen der Erde von felsiger Unterlage, sowie das zu schnelle Ablaufen des Wassers durch die 
Bedeckung des Bodens mit holzigen oder krautigen Pflanzen mehr oder weniser verhindert. Ebenso sind Saatpflanzen durch benachbarte Kräuter ror der Entwurzelung und Verschlemmung durch starke Regengüsse, sowie vor dem Auffricren geschützt.

Während des Winters stehen bleibende Stengel können junge Kulturpflanzen vor Schnecdruck schützen.

Die schädliche Wirkung der Bodenflora liegt vor allem in dem Verdämmen junger Kulturen, das um so leichter eintreten wird, je besser der Boden ist.

Den jungen Baumpflanzen wird namentlich durch zu üppigen Graswuchs und jene schon früher genannte Schlagflora (vgl. S. 410) das zur Ernährung notwendige Licht entzogen, was dann eine ungenügende Ausbildung zur Folge hat, so dass diese Pflanzen gegen äussere Einflüsse empfindlicher sein können. Unter Umständen, z. B. bei zu starker Bestrahlung, kann jedoch ein derartiger Schutz erwünscht sein.

Verfilzung des Bodens durch Wurzelreste, Beerkräuter machen Bodenverwundungen notwendig, wodurch die Kulturkosten erhöht werden. In einem zu dichten Bodenfilz können sich die Wurzeln nicht genügend ausbilden, ganz abgesehen davon, dass die Keimung der Samen auf solchen Rohhumusschichten nicht genügend vor sich geht.

Starker Graswuchs befördert die Verdunstung und Wärmeausstrahlung des Bodens und dem entsprechend wird die Frostgefahr erhöht.

Eine zu dichte Bodendecke gewährt forstschädlichen Tieren, z. B. Näusen, Schutz und wirkt hierdurch indirekt nachteilig. Heidekraut und trockene Gräser sind als gefährliche Feuerleiter gefürchtet. 


\title{
Bestimmungstabellen.
}

\author{
§ 113. Bestimmung der wichtigsten Bäume und Sträucher \\ nach den Blättern. \\ Übersicht.
}

Tabelle I. Die Blätter sind nadel- oder schuppenförmig, Nadelhölzer.

I. Nadeln einzeln, nicht in Kurztrieben oder Büscheln.
A. Blattorgane spiralig inseriert, durch Drehungen der Blattbasis teil- weise kammförmig.
B. Blattorgane gegenständig oder quirlig.
2. Blätter nadelförmig, in Kurztrieben zu 2-5 oder zahlreich in büsche- ligen Kurztrieben.
A. Nadeln $z u 2$ in einem Kurztrieb.
B. Nadeln zu 5 in einem Kurztrieb.
C. Nadeln an den Kurztrieben gebüschelt, an den Längstrieben spiralig gestellt.

Tabelle II. Die Blätter sind laubartig, abwechselnd oder spiralig gestellt.

I. Blätter einfach (weder gelappt noch gefiedert), langgestreckt, d. h. mindestens dreimal so lang als breit, ganzrandig oder gesägt.
A. Die Blätter sind über $3 \mathrm{~cm}$ breit und dementsprechend lang.
B. Blätter sehr schmal, höchstens I $\mathrm{cm}$ breit.
C. Blätter circa $\mathrm{I}, 5-3 \mathrm{~cm}$ breit.

a. Blattrand ganz oder wellig, ohne Zähne.

b. Blattrand gezähnt.

2. Blätter einfach, höchstens doppelt so lang als breit, elliptisch, herzförmig, dreieckig, rautenförmig etc.

A. Blätter ganzrandig.

B. Blätter gesägt, gezähnt oder buchtig.

a. Spreite unsymmetrisch, d. h. die beiden Blatthälften laufen ungleich weit am Stiele herab.

b. Blätter ausgesprochen herzförmig, breit.

c. Blätter im Umriss rund oder eiförmig. Rand wellig oder buchtig. 
d. Blätter dreieckigs, mit serader oder herzförmiger Basis oder rautenförmigs.

c. Blätter verkehrt ciförmig, Spreite im vorderen Drittel breiter, in den Blattstiel keilförmisg verschmälert.

f. Blätter elliptisch, vorn zugespitzt oder abgerundet.

3. Blätter gelappt oder handförmig gespalten.

A. Spreite mindestens doppelt so lang als breit.

B. Spreite nicht wesentlich länger als breit.

a. Dic Sekundärnerven gehen spitzwinkelig von einem stärkeren Mittelnerv ab.

b. Der Hauptnerv geteilt, die Nerven gehen daher fingerförmig ron der Basis der Spreite aus.

4. Blätter zusammengesetzt, d. h. sie bestehen aus einzelnen Teilblättchen, die mehr oder weniger deutlich gestielt sind, drei- oder fünfzählig oder gefiedert.
A. Blätter drei- oder fünfzählig.
B. Alle Blätter einfach gefiedert.
C. Blätter teils doppelt, teils einfach gefiedert.

Tabelle III. Die Blätter sind laubartig und gegenständig.

I. Blätter einfach, weder gelappt noch gefiedert.
A. Blätter ganzrandig.
B. Blattrand gesågt.

2. Blätter gelappt.
A. Blattlappen in feine Spitzen ausgezogen.
B. Blattlappen mehr abgerundet.

3. Blätter handförmig zusammengesetzt.

4. Blätter unpaarig gefiedert.

A. Blattstiele ranken sich um andere Gegenstände.

B. Blattstiele ranken nicht.

\section{Tabelle I.}

Die Blätter sind nadel- oder schuppenförmig, Nadelhölzer.

\section{Nadeln einzeln, nicht in Kuratrieben oder Büscheln.}

A. Blattorgane spiralig inseriert, durch Drehungen der Blattbasis teilweise Kammformig.

a. Nadeln vierkantig.

Picea excelsa (Fis. 2I31. Nadeln rierkantis, stechend, Blattpolster an den Zweigen hervorragend.

Die übrigen Piceaarten vgl. S. 258 .

b. Nadeln flach, unterseits grün.

Taxus baccata (Fig. 2IO). Ende der Nadeln spitz, jedoch nicht stechend. Oberseite glänzend grün, Unterseite hellgrün ohne weisse Streifen. 
c. Nadeln flach, unterseits mit zwei weissen Längsstreifen.

Abies pectinata (Fig. 2I2). Nadeln an der Spitze eingekerbt, stehen kammförmig, scheinbar zweizeilig, junge Triebe sind behaart, ohne hervorragende Blattpolster.

Abies Nordmanniana. Nadeln an der Spitze eingekerbt, stehen am Rücken der Zweige bürstenförmig. Nadeln dicker und breiter als bei Abies pectinata.

Die übrigen Abiesarten vgl. S. 255.

Tsuga canadensis (Fig. 2I4), Nadeln an der Spitze eingekerbt, nur 6-I $4 \mathrm{~mm}$ lang, kürzer als bei Abies, Zweige nicht behaart.

Pseudotsuga Douglasii (Fig. 2 I5). Nadeln zugespitzt, nicht stechend, Zweige ohne erhabene Blattpolster.

B. Blattorgane gegenständig oder quirlig.

a. Blätter nadelförmig, am Zweige nicht herablaufend oder nur mit schmaler Basis angewachsen.

Juniperus communis (Fig. 226). Nadeln I-2 cm lang, stechend, spitz, abstehend, in Quirlen zu 3 beisammen, Oberseite blaugrün, Unterseite nicht gefurcht.

Juniperus virginiana. Nadeln abstehend oder schuppig angewachsen, auf der Unterseite mit buckeliger Öldrüse; sie stehen in dreigliedrigen Quirlen oder sind gegenständig. Die abstehenden Nadeln sind stachelspitzig, ungefähr halb so lang als bei Juniperus communis.

Juniperus Sabina. Nadeln anliegend, $\mathrm{O}, \mathrm{I}-\mathrm{O}, 2 \mathrm{~cm}$ lang, am Rücken mit eingedrückter länglicher Öldrüse.

b. Blätter schuppenförmig, am Zweige breit herablaufend, sich dachziegelig deckend. Zweige flach.

๙. Oberseite glänzend grün, Unterseite heller grün, nicht weiss gefärbt.

Thuja occidentalis (Fig. 225). Blattorgane auf dem Rücken mit buclieliger Öldrüse.

Biota orientalis. Blattorgane auf dem Rücken mit einer Längsfurche, sonst wie Thuja occidentalis.

3. Oberseite glänzend grïn, Unterseite weisslich.

Thuja gigantea, Thuja japonica vgl. S. 267.

c. Blätter wie bei b, die Zweige jedoch weniger zusammengedrückt oder annähernd vierkantig.

Chamaecyparis Lawsoniana, nutkaënsis (Figs. 224) und andere Chamaccyparisarten, vgl. S. 265.

2. Blätter nadelförmig, in Kurztrieben 2--5 oder zahlreich in büscheligen Kurstrieben.

A. Nadeln $\approx u$ in cinem l'uratrieb.

Pinus silvestris (Fig. 2I6). Nadeln meist 4-6 cm, mit zahlreichen sehr feinen weisslichen Längsstreifen versehen (Lupe), daher manchmal blaugrün aussehend. Knospen stumpflich.

Pinus montana. Nadeln meist nicht länger als $4 \mathrm{~cm}$, beiderseits grün, sonst wie die vorige Art. 
Pinus Laricio var. austriaen. Nadeln $8-16 \mathrm{~cm}$ lang, dunkelgrïn. Knospen zugespitzt mit silberweissen Schuppen bedeckt.

Die übrigen Pinusarten vgl. S. 26I.

1. Airdin an 5 in incm Limatrith.

Pinus Strobus. Nadeln sehr fein, weich, oberseits weisslich, meist 6-IO,5 cm lang. Einjährige Triebe kahl.

Pinus Combra. Nadeln starr, oberseits mit weissen Längsstreifen, meist $5-S \mathrm{~cm}$, breiter als bei Pinus Strobus. Einjährige Triebe mit rostbraunem Filz.

C. Nüdeln an den Kurstrietin sebüschelt, an den Längstrieben spiralig gestellt.

Larix europaea (Fig. 222). Ältere Nadeln reingrün, Kurztriebe schr kurz und dick, meist nur $0,3 \mathrm{~cm}$ lang, Nadeln sommergrün. Jüngste Zweige nicht behaart.

Cedrus Deodara. Nadeln blaugrün, immergrün, Kurztricbe etwas länger, $0,5 \mathrm{~cm}$ und darüber, oft zu Längstrieben auswachsend. Jüngste Zweige behaart.

\section{Tabelle II.}

Die Blätter sind laubartig, abwechselnd oder spiralig gestellt.

7. Blätter einfiach, äeder gelappt noch gefiedert, langgestreckt, d. h. mindestens dreimal so lang als breit, ganzrandig oder gesägt.

A. Die Blätter sind ïber $3 \mathrm{~cm}$ breit und dementsprechend lang.

Castanea vesca (Fig. 28I). Blätter $5-7 \mathrm{~cm}$ breit, gestielt, entfernt gezähnt, die Sekundärnerven verlaufen bis zum Rande und münden dort in einem Blattzahn.

Persica vulgaris. Blätter $3-4 \mathrm{~cm}$ breit, IO-I $6 \mathrm{~cm}$ lang, Blattstiel $1 / 2-\mathrm{I} \mathrm{cm}$ lang, Blattrand, fein gesägt, Sekundärnerven netzförmig verzweigt.

Man vgl. ferner Salix pentandra, Prunus avium.

B. Blätter sehr schmal, höchstens I cm breit.

a. Zweige dornigspitzig.

Hippophaë rhamnoides (Fiss. 323). Die einjährisen Triebe, die Knospen, sowic die jüngsten Blätter sind mit bronzefarbigen Sternhaaren versehen. b. Zweige niemals dornig.

Salix incana. Diesjährige Zweigse und junge Blätter grau behaart, bei älteren Blättern die Oberseite grün. Blätter 4-16 cm lang.

Salix repens var. rosmarinifolia (Fig. 268). Blätter nicht mehr als $4 \mathrm{~cm}$ lang, mehr oder weniger seidig behaart.

C. Blätter circa $1,5-3 \mathrm{~cm}$ breit.

a. Blattrand ganz oder wellig, ohne Zähne.

«. Zweige ohne Dornen.

Daphne. Mezereum (Fig. 32 I). Blätter kahl, am Ende der Zweige gebüschelt. Zweige ebenfalls unbehaart. 
Salix viminalis (Figs. 265). Blattoberseite srün, etwas runzelis, Unterscite weissfilzig behaart. Blattrand umgeschlagen. Einjährige Triebe kahl oder nur schwach, angedrückt behaart.

Salix viminalis $>$ purpurea. Blattrand ebenfalls umgeschlagen, mit oder ohne Zähne, die jedoch niemals scharf hervortreten. Ober- und Unterseite kahl. Knospen etwas länger als bei Salix viminalis, doch kürzer als bei Salix purpurea.

ß. Zweige meist mit Dornen.

Lycium barbarum (Fig. 362). Blätter unbehaart, beiderseits grün, häufig zu dreien gebüschelt. Zweige lang überhängend, rutenförmig. Die Dornen können auch fehlen.

Elaeagnus angustifolia (Fig. 322). Jüngere Blätter und Zweige mit weissen, silberglänzenden Sternhaaren bedeckt. Ältere Blätter oberseits grün, unterseits glänzend silberweiss. Ältere Zweige glänzend braun.

b. Blattrand gezähnt.

«. Blätter auf beiden Seiten oder doch auf der Unterseite seidenartig behaart.

Salix alba (Fig. 263). Zweige wie die Blätter zuerst weiss seidenhaarig, später grau, ohne Glanz.

Salix alba var. vitellina. Zweige dottergelb oder grünlich gelb, glänzend. Behaarung der Blätter schwächer als bei Salix alba.

B. Blätter kahl oder nur ganz unbedeutend behaart.

Salix purpurea (Fig. 264). Blätter an der Basis keilförmig verschmälert, die grösste Breite liegt im vordersten Drittel, unterseits blaugrün. Blätter sind ausnahmsweise gegenständig. Ältere Zweigteile glänzend graugrïn. Knospen gross und lang.

Salix daphnoides. Blätter an der Basis verschmälert oder elliptisch, oberseits stark glänzend, unterseits hellgrün. Ältere Zweige glänzend rotbraun, eventuell bereift. Knospen meist flach dem Zweige angedrückt.

Salix fragilis (Fiş. 26I). Blätter scharf gesäst, Zähne mit braunen Spitzen. Zweige glänzend gelbbraun, die älteren an der Basis leicht abbrechend. Knospen kurz, dick.

Salix triandra (Fig. 262). Blattrand ebenfalls drüsigs gesägt, Drüisen nicht so auffallend braun, Blattrand etwas umgeschlagen. Blätter an der Spitze weniger verschmälert als bei Salix fragilis. Nebenblätter länger erhalten. Einjährige Zweige glänzend grünbraun. Knospen mehr langgestreckt.

Salix acutifolia. Blattrand drüsigs gezähnt, Zähne sehr spitz, Blätter steif, etwas lederig. Oberseite glänzend mit unbedeutender Behaarung. Nebenblätter gross. Zweige glänzend, grünlich oder rot.

2. Blätter einfach, höchstens doppelt so lang als breit, elliptisch, herzförmig, dreieckig, rautenförmig etc.

A. Blätter gansrandig.

a. Blattunterseite filzig behaart.

Cydonia vulgaris. Blätter eiförmig oder rundlich, $3-5 \mathrm{~cm}$ breit, weich, 
kurz sesticlt. Junse Zweise spinnwebis behaart, ältere slänzend dunkelsriin oder braun.

Cotoneaster vulgaris. Blätter ciförmig oder elliptisch, kurz bespitzt, meist keiner als bei Cydonia vulgaris, derb, runzelig, sehr kurz gesticlt. Zweige rotbraun, nur an der Spitze feinfilzig.

b. Inlitter nur am Rande und auf der Unterseite der Rippen behaart.

Fagus silvatica (Fig. 280). Blätter elliptisch, kurz gestielt, glatt. Die Behaarung ist besonders an jungen Blättern deutlich.

c. Blätter kahl,

Rhus cotinus (Fig. 307). Blätter langgestielt, derb, auf der Unterseite blaugrün, mit ziemlich breitem durchsichtigem Rand. Beim Zerreiben stark aromatisch ricchend.

Rhamnus frangula (Fig. 319). Blätter kurz gestielt, nicht lederig derb, Unterseite grün. Sekundärnerven am Rande bogenförmig verbunden. Man vgl. ferner Salix caprea, Salix aurita, Salix cinerea.

b. Blïtter gesägt, gezühnt oder buchtig.

a. Spreite unsymmetrisch, d. h. die beiden Blatthälften laufen ungleich weit am Stiele herab.

r. Vom Blattstiel gehen drei gleich starke Nerven aus.

Celtis australis. Blätter sehr schief, derb, oberseits glänzend, rauh bchaart. Nark der Zweige eng, undeutlich gefächert.

3. Blätter mit einem Hauptnerv und spitzwinkelig inserierten Sekundärnerven.

Carpinus Betulus (Fig. 279). Blätter gezähnt, oberseits kahl, glatt, unterseits nur in den Blattwinkeln behaart. Asymmetrie nicht stark.

Ulmus effusa (Fig. 29I b). Blätter länglich, zugespitzt, nicht so derb, unterseits mehr weichhaarig. Sekundärnerven selten gegabelt, Knospen spitz.

Ulmus campestris (Fig. 290). Die Blätter rauhhaarig, meist in der Mitte am breitesten. Von den Sekundärnerven nur wenige gegabelt, meist die unteren. Die älteren Zweige etwas längsrissig oder mit Korkwülsten (var. suberosa).

Ulmus montana (Fig. 29I a). Grösste Breite der Blätter im oberen Drittel, auf beiden Seiten rauh behaart. Die Sekundärnerven in der Mehrzahl gegabelt. Zweige nicht längsrissig.

Man vgl. Tilia.

b. Blätter ausgesprochen herzförmig, breit.

r. Blattstiel kurz, bis $\mathrm{I} \mathrm{cm}$ lang.

Corylus avellana (Fis. 25T). Blätter doppelt gesäst, unterseits weichhaaris. Blattstiel und meist auch die jüngsten Triebe drüsig behaart.

$\beta$. Blattstiel länger.

Morus alba (Fig. 292). Blätter verschieden gestaltet, teils einfach, teils mit grossen Buchten. Blattfäche nicht rauh behaart. Zweige ohne Kurztriebe.

Morus nigra, ähnlich wie Morus alba, Blattfläche jedoch oberseits rauh behaart. 
Tilia parvifolia (Fig. 303). Blätter oft asymmetrisch. In den Blattwinkeln rostfarbige Behaarung, sonst kahl. Triebe mehr grünlichbraun.

Tilia grandifolia, wie die vorherugehende Art, Blätter meist etwas grösser, Haare in den Blattwinkeln weisslich. Zweige mehr rötlich grün.

Prunus Armeniaca. Blätter slänzend, beiderseits unbehaart, nicht länger als $6 \mathrm{~cm}$. Blattstiel und junge Zweige rot. Blattrand drüsig gesägt. Man vgl. ferner noch die annähernd herzförmigen Blätter von Alnus, Betula, Prunus Mahaleb, Populus nigra.

c. Blätter im Umriss rund oder eiförmig. Rand wellig oder buchtig.

Populus tremula (Fig. 269). Blätter rund, wenig buchtig, nicht behaart, mit langem, sehr beweglichem Stiel. Zweige kahl, glänzend.

Populus alba (Fig. 270). Junge Blätter und Triebe weiss behaart, ältere Blätter nur auf der Unterseite weiss. Blattspreite länglich, stark buchtig, in der Form sehr veränderlich.

Populus canescens steht zwischen den beiden vorhergehenden Arten, ist etwas behaart, weniger buchtig.

d. Blätter mit gerader oder herzförmiger Basis oder rautenförmig. r. Blattstiel flach, zusammengedrückt.

Populus nigra (Fig. 27 I a). Blattform sehr veränderlich (vgl. S. 298). Spreite häufig länger als breit, derb, glatt. Blatt nicht behaart. Zweige ausgebreitet.

Populus nigra var. pyramidalis, wie Populus nigra. Die Zweige stehen jedoch aufrecht und sind mit zahlreichen Kurztrieben versehen.

Populus canadensis (Fig. $27 \mathrm{I} \mathrm{b).} \mathrm{Blattrand,} \mathrm{besonders} \mathrm{an} \mathrm{jungen} \mathrm{Blättern,}$ sehr fein behaart. Zwei- bis dreijährige Zweige mit Korkleisten (nicht sehr charakteristisch, da dieselben auch bei Populus nigra vorkommen).

ß. Blattstiel rund.

Betula verrucosa (Fig. 275). Die Oberseite der Blätter mit Wachsdrüsen bedeckt, welche man leicht erkennt, sobald man mit dem Fingernagel darüber streicht. Die einjährigen Zweige sehr dünn, kahl oder mit Wachswarzen bedeckt, niemals behaart.

Betula pubescens, ähnlich der vorhergehenden Art, Blätter und junge Zweige jedoch behaart, ohne Wachsablagerungen.

e. Blätter verkehrt eiförmig, Spreite im vorderen Drittel breiter, an dem Blattstiel keilförmig verschmälert.

Myrica Gale. Blätter nur an der Spitze gesägt, mit kleinen goldgelben Drüsen versehen (Lupe), sonst kahl. Ohne Nebenblätter. Einjährige Zweige rotbraun, birkenähnlich.

Salix aurita (Fig. 267). Blätter runzelig, unterseits weichhaarig, stumpf gezähnt oder nur wellig, fast ganzrandig. Nebenblätter häufig stehenbleibend. Einjährige Zweige oft sehr feinfilzig.

Man vgl. auch Salix cinerea, Salix caprea, Prunus insititia. 
f. 13liatter elliptisch, vorn zugespizzt oder alggerundet

«. Blätter gekerbt, doppelt gresägt, Sägezaihne eventuell abgerundet (Alnus glutinosa).

Blitter relativ breit.

Sorbus Aria. Blätter dick, die Unterseite durch die Beharung silberweiss, Oberseite grïn, nicht behaart. Einjährige Triebe spinnwebig behaart.

Man vgl. S. 343 Sorbus scandica und Sorbus hybrida mit längeren und stärker gelappten Blättern.

Alnus incana (Fig. 274). Blätter zugespitzt, Sägezähne meist scharf. Unterseite nur in den Blattwinkeln behaart, etwas blaugrün. Einjährige Zweige behaart.

Alnus glutinosa (Fig. 273). Blätter an der Spitze eingebuchtet, im ganzen mehr rundlich, Sägezähne mehr unregelmässig. Nur in den Blattwinkeln behaart. Zweige unbehaart, mit Harzablagerungen, in der Jugend klebrig.

Blätter schmal, stark zugespitzt.

Prunus cerasus (Fig. 334). Blätter derb lederig, kahl, auf der Oberseite glänzend. Teilweise ist der Blattrand annähernd einfach gezähnt. An der Basis der Spreite, aber nicht auf dem Blattstiel, ein oder zwei dicke Drüsen, die jedoch auch fehlen können. Zweige schlank, etwas ïberhängend.

Prunus avium (Fig. 335). Blätter dünner, kahl, nur die Rippen der Unterseite schwach bchaart, Oberseite nicht glänzend. Zähne des Blattrandes spitz. Auf dem Blattstiel zwei dicke Drüsen. Zweige gedrungener, Knospen an dickeren Kurztrieben gehäuft.

3. Blattrand einfach gesägt, Seitennerven treten auf der Unterseite nicht hervor, Spreite daher glatt, Oberseite oft glänzend.

Berberis vulgaris (Fig. 295). Zweige mit stechenden Blattdornen. Blätter stehen gebüschelt, sie sind am Rande stachelspitzig oder buchtig gezähnt. Sind nur wenige Zähne vorhanden, erscheint das Blatt beinahe ganzrandig. Zweige lang überhängend.

Salix pentandra (Fig. 260). Blätter an der Spitze stark verschmälert, oberseits dunkelgrün glänzend. Blattstiel drüsig. Junge Triebe glänzend grünbraun, wie lackiert.

Pirus communis (Fig. 34I). Blätter sehr fein gesägt, hart, kahl, oberseits glänzend, langgestielt. Zweige oft dornig, glänzend braun, nicht behaart.

Prunus Mahaleb (Fig. 336). Blätter ähnlich wie bei Pirus communis, doch kürzer gestielt und auf der Oberseite weniger glänzend. Zweige dünn, niemals dornig.

$\gamma$. Blattrand einfach gesägt, die Sekundärnerven treten auf der Blattunterseite deutlich hervor, die Blätter daher mehr oder weniger runzelig. Oberseite gar nicht oder nur wenig glänzend.

: Zähne des Blattrandes abgerundet oder undeutlich, Spreite teilweise ganzrandig.

Salix caprea (Fig. 266). Blätter rundlich, Unterseite weisslich behaart. Nebenblätter nierenförmig, bleiben häufig erhalten. Junge Triebe schwach behaart oder kahl. 
Salix cinerea. Ähnlich wie Salix caprea, die Blätter jedoch mehr langgestreckt, teilweise verkehrt eiförmig. Junge Triebe mit dichter, später grauer Behaarung.

** Blattrand gleichmässig, meist schärfer gezähnt.

Pirus malus (Fig. 342). Blätter ziemlich derb, Oberseite etwas glänzend, Unterseite wollig behaart. Junge Triebe und Blattstiele angedrückt, weisslich behaart oder stellenweise glatt.

Prunus insititia. Blätter annähernd verkehrt eiförmig, Ober- und Unterseite etwas behaart. Blattpolster hervorragend. Junge Triebe und Blattstiele abstehend behaart. Zweige nicht dornig.

Prunus domestica. Ähnlich wie Prunus insititia, Blätter im unteren Drittel breiter, junge Triebe wenig oder gar nicht behaart, auf der Lichtseite rot, auf der Schattenseite grün. Zweige selten dornig.

Prunus spinosa (Fig. 333). Blätter wenig oder gar nicht behaart, kleiner als bei den anderen Prunusarten. Zweige unbehaart, oft dornig.

Prunus Padus (Fig. 337). Blätter stark zugespitzt, kahl, ziemlich dünn. Zweige unbehaart, nicht dornig.

3. Blätter gelappt oder handförmig gespalten.

A. Spreite mindestens doppelt so lang als breit.

a. Blattlappen, stachelspitzig, Blätter immergrün.

Ilex aquifolium. Blätter kurzgestielt, derb lederig, oberseits glänzend, unterseits heller grün, unbehaart.

b. Blattlappen nicht stachelspitzig, Blätter sommergriin.

r. Blïtter unterseits behaart.

Quercus cerris (Fig. 287). Blattlappen ziemlich spitz. Die pfriemenförmigen Nebenblätter bleiben länger erhalten und umgeben auch die Knospen.

Quereus pubescens (Fig. 283 d). Blattlappen stumpf, Behaarung dicht, die Knospen nicht von pfriemenförmigen Nebenblättern umhüllt.

3. Blätter unbehaart.

Quercus pedunculata (Fig. 283 c). Blätter kurzgestielt oder sitzend, Blattspreite am Grunde ohrförmig umgebogen. Knospen braunglänzend. Quercus sessiliflora (Fiss. 283 b). Blätter länger gestielt, Spreite am Grunde mehr keilförmig. Knospen weisslichbraun.

B. Spreite nicht wiesentich länger als breit.

a. Die Sekundärnerven gehen spitzwinkelig von einem stärkeren Mittelnerv ab.

«. Blätter auf der Unterseite silberhaarig.

Populus alba vgl. S. 4I9.

३. Altere Blätter kahl.

Crataegus oxyacantha (Fig. 338). Blätter 3-5lappig mit vorwärts gerichteten Lappen, glänzend, beiderseits fast gleichfarbig. Zweige mit Dornen. Am Grunde der kurzen Dornen steht seitlich je eine Knospe. Crataegus monogyna. Wie Crataegus oxyacantha, die Blattlappen mehr abstehend, unterseits etwas weisslich grün. 
Sorbus torminalis (Fis. 344). Blätter breit ciförmig, ziemlich langgestielt, 7 -9lappis, im erwachsenen Zustande beiderseits kahl. Zweige unbewehrt, Knospen rund, gelblich grïn.

b. Der IIauptnerv geteilt, die Nerven gehen daher fingerförmig, von der Basis der Spreite aus.

re. Blätter sehr gross, sommergrïn.

Platanus occidontalis. Blätter mehr dreilappig, wenn auch an der Basis noch ein kleinerer vierter und fünfter Lappen ausgebildet ist. Blattsticl später rotbraun.

Platanus orientalis (Fig. 328). Blätter 5-7 lappig, die Einschnitte tiefer. Blattsticl grün.

3. Blätter kleiner, sommergriin.

Zweige mit meist dreiteiligen Stacheln.

Ribes Grossularia ( Fis.s. 326). Blätter handfömis, 3-5 lappriss, unterscits am Rande und an den Nerven flaumig behaart.

Z: Zweige unbewehrt.

Ribes rubrum (Fig. 327). Blätter 3-5 lappig, unterseits wollig behaart, ohne Drüsen, geruchlos.

Ribes alpinum. Hlätter kurzesticlt, 3 lappis, unterscits slatt, glänzend, nicht behaart, geruchlos.

Ribes nigrum. Blätter 3-5lappig, oberseits kahl, glänzend, unterseits mit feinen goldgelben punktförmigen Drüsen, stinkend. Auch die jungen Triebe und Knospen zeigen die Drüsen.

\%. Blätter kleiner, immergrïn.

Hedera helix (Fig. 6I und 354). Blätter gelappt oder weniger geteilt, lederartig, oberseits glänzend dunkelgrün.

4. Blätter zusammengesetzt, d. h. sie bestehen aus einzelnen Teilblüttchen, die mehr oder weniger deutlich gestielt sind, 3-oder $5 z$ ählig oder gefiedert. A. Blättur 3-oder 5 zählig.

a. Zweige ohne Stacheln, Blätter 3 zählig.

Cytisus Laburnum. Unterseite der Blätter schwach behaart, einjährige Zweige, Blattstiele und Knospen weisshaarig, etwas ältere Zweigteile glatt grün, glänzend.

Pteiea trifoliata. Blatt und Blattstiel fast kahl. Zweigge unbehaart, ältere Zweige braun, durch Lenticellen rauh.

b. Zweige mit feinen oder derben Stacheln.

Rubus frueticosus (Figs. 332). Blätter an den Hauptaxen 3 zähliss, an den gebogenen Zweigen 5 zählig bis gefingert. Blätter flaumig behaart, oberseits dunkelgrïn, unterseits blassgrün. Seitenzweige aufrecht kantig, nur an der Spitze gebogen. Stacheln derb, zurückgebogen, sehr spitz.

Rubus caesius. Alle Blätter 3 zählig, die unteren Blättchen sitzend. Haupt- und Vebenaxen rund, nicht kantig, bläulich bereift, lang kriechend. Stacheln derb.

Rubus Idaeus (Fig. 33I). Obere Blätter 3 zählig, untere Blätter mit 5-7 
Teilblättchen. Oberseite kahl, grün, Unterseite weissfilzig. Haupt- und Nebenaxen bereift, mit feinen Stacheln versehen.

B. Alle Blätter einfach sefiedert.

a. Rand der Fiederblättchen nicht gesägt, glatt.

(4. Nark gefächert.

Juglans regia (Fig. 28S). Fiederblättchen gross, lederig derb, beim Zerreiben aromatisch duftend. Zweige dick.

3. Mark nicht gefächert.

Robinia Pseudacacia (Fig. 347). Blätter $10-22 \mathrm{~cm}$ lang, mit I I-2 I dünnen Fiederblättchen, deren jedes ungefähr $2-4 \mathrm{~cm}$ lang ist. Zweige unregelmässig gebogen, an der Blattbasis häufig zwei derbe Dorner. Knospen nicht sichtbar.

Colutea arborescens. Blätter $6-8 \mathrm{~cm}$ lang, mit 9-I I Fiederblättcher, deren jedes $\mathrm{I}-2 \mathrm{~cm}$ lang ist.. Blätter in der Jugend weissfilzig behaart. Junge Zweige grün, ältere Zweige längsstreifig, ohne Stachelr.

Caragana arborescens. Blätter $6-8 \mathrm{~cm}$ lang, paarig gefiedert mit 8 - IO deutlich stachelspitzigen. Fiederblättchen. Seitentriebe oft wulstig. An der Basis der Blätter zwei sehr feine Dornen. Die älteren Zweige grün mit Oberhautstreifen bedeckt.

b. Rand der Fiederblättchen gesägt.

(c. Mark gefächert.

Juglans nigra. Blätter sehr gross mit I 5-2 I Fiederblättchen, unterseits flaumig behaart. Zweige sehr dick, filzig.

3. Mark ungefächert.

Ailanthus glandulosa (Fig. 306). Blätter sehr gross mit 15-25 Fiederblättchen, welche an der Basis drüsige Zähne aufweisen. Zweige sehr dick, fein behaart, mit sehr weitem Mark.

Sorbus aucuparia (Fig. 343). Blätter mit II-I3 gleich grossen Fiederblättchen. Zweige unbehaart.

In diese Gruppe gehören auch die Caryaarten (S. 3 IO), Sorbus domestica und Rhus typhina.

C. Blätter teils doppelt, tcils einfach sefiedert.

Gleditschia triacanthos. An dem untern Teile der Äste stehen einfach gefiederte, an der Spitze doppelt gefiederte Blätter. Fiederblättchen schwach gekerbt, endigen in eine Spitze. Zweige mit einfachen oder dreiteiligen Dornen.

\section{Tabelle III.}

Die Blätter sind laubartig und gegenständig.

1. Blätter einfach, weder gelappt noch gefiedert.

A. Blätter ganzrandig.

a. Blätter schmal, 3-4 mal so lang als breit.

Ligustrum vulgare (Fig. 370). Blätter lanzettlich, kahl, etwas derb, sie 
bleiben im grünen Zustand bis in den Winter hinein an den Zweigen. Zweige dünn, unbehaart.

b. Blätter herzförmig.

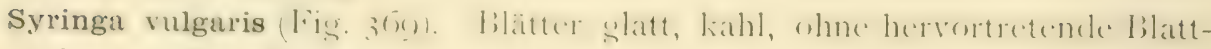
rippen. Die Zweige bilden Dichasien, sind grau, unbehaart.

c. Bilätter elliptisch, immergrün.

Buxus sempervirens. Blätter derb, lederartig, kahl, fast sitzend, Rand etwas umgebogen. Oberseite dunkelgrün glänzend, Unterseite heller grïin.

d. Blätter elliptisch oder zugespitzt, sommergrün.

r. Blattnerven bogenförmig zur Spitze laufend, so dass sie erst in der oberen Hälfte oder an der Spitze des Blattes den Blattrand erreichen.

Cornus mas (Fig. 353). Blätter länglich eiförmig, lang zugespitzt, jung zerstreut behaart, im Herbst sich gelb färbend. Zweige auf der Schattenseite grün, auf der Lichtseite violett, angedrückt behaart. Blütenknospen kugelig, abstehend.

Cornus sanguinea, ähnlich wie die vorige Art. Blätter jedoch kurz zugespitzt, im Herbst blutrot. Einjährige Triebe im Sommer schmutzig braunrot, im Herbst intensiv rot gefärbt. Knospen anliegend.

ß. Blattnerven nicht bogenförmig zur Spitze laufend.

Blätter weichhaarig.

Lonicera Xylosteum. Blätter cifürmis, länglich mit abgerundeter Basis (man vgl. Lonicera tartarica, Fig. 373). Mark der Zweige hohl, am Rande braun.

$*$ Blätter nicht behaart.

Lonicera nigra. Blattform ähnlich wie bei Lonicera Xylosteum, rein grün, dünn, Mark der Zweige voll, weiss.

Lonicera Caprifolium (Fig. 372). Blätter dick, etwas fleischig, blaugrün. Das oberste Blattpaar eines Zweiges an der Basis verwachsen. Nark hohl. Schlingpflanze.

Lonicera Periclymenum. Ähnlich wie I,onicera Caprifolium, die Blattpaare jedoch nicht verwachsen. Schlingpflanze.

B. Blattrand gesïgt.

a. Einjährige $Z$ weige mit krümeligen Sternhaaren besetzt.

Viburnum Lantana. Blätter dick, runzelig, 6-I $2 \mathrm{~cm}$ lang, oberseits wenig behaart, unterseits weisslich filzig.

b. Zweige unbehaart.

r. Zweige dornspitzig.

Rhamnus eathartica. Blätter lang sestielt, elliptisch oder eiförmig, kurz zugespitzt, bogennervig. Sie sind oft schief gegenständig. Neben der Dornspitze zwei schief gegenständige Knospen (vgl. Fig. 423). Zweige hellgrau oder braun.

$\beta$. Zweige nicht bedornt.

Evonymus europaeus. Blätter kurzosestielt, länglich elliptisch. An beiden 
Enden verschmälert. Jüngere $Z$ weige grün, meist vierkantig mit vier Korklängsleisten (vgl. Fig. 436 b).

Philadelphus coronarius (Fig. 325). Blätter sehr kurz gesticlt, mit auf der Unterseite stark hervortretenden Blattnerven. Jüngere Zweige glänzend braun, ohne Lenticellen. Knospen nicht sichtbar.

2. Blätter gelappt.

A. Blattlappen in feinere Spitzen aussezogen.

Acer platanoides (Fig. 3IOB). Blätter gross, 5 lappig, die einzelnen Lappen entfernt gezähnt. Unterseite der Spreite grün. Blattstiel grün oder rot.

Acer dasycarpum (Fig. $315 \mathrm{~A}$ ). Blätter ziemlich gross, meist 7 lappig, dic einzelnen Lappen grob gesägt. Unterseite der Spreite weissliçh glänzend. Blattstiel rot.

B. Blattlappen mekr abgernudet.

a. Blattstiel ohne Drüsen.

Acer Pseudoplatanus (Fig. 3IOA). Blätter gross, Blattspreite breiter als IO $\mathrm{cm}$, 5 lappig, runzelig. Die Blattlappen gesägt.

Acer campestre (Fig. 3IOC). Blätter klein, meist nicht breiter als $5 \mathrm{~cm}$, 5 lappig, doch die untersten Lappen klein. Blattstiel und die Unterseite der Rippen behaart.

b. Blattstiel mit Drüsen.

Viburnum Opulus (Fig. 375). Blätter 3 lappig, am Grunde abgerundet und ganzrandig, der obere Teil des Blattes gezähnt. Blätter unterseits flaumig behaart.

3. Blätter handförmig zusammengesetzt.

Aesculus Hippocastanum. Blätter 7 zählig, Blattgewebe zwischen den Primärnerven und Sekundärnerven etwas gewölbt. Zweige dick.

Die Gattung Pavia hat meist nur 5 zählige Blätter. Das Blattgewebe ist flacher.

4. Blätter unpaarig gefiedert.

A. Blattstiele ranken sich un andere Gegenstände.

Clematis vitalba (Fig. 294). Die 3-5 Fiederblättchen sind teilweise lang gestielt, herzförmig, eingeschnitten oder gesägt. Sprossaxe dünn, sechskantig, unregelmässig gebogen.

B. Blattstiele ranken nicht.

a. Fiederblättchen rundlich.

Fraxinus Ornus (Fig. 367). Blätter mit 5-9 Fiederblättchen, an der Basis und der Unterseite der Mittelrippe behaart. Zweige zusammengedrückt.

b. Fiederblättchen länglich, zugespitzt; ohne basale Anhängsel.

Fraxinus excelsior (Figs. 368). Blätter gross, aus 9-I 5 scharfgesägten Fiederblättchen zusammengesetzt. Blattpolster rorgewölbt, Zweige zusammengedrückt, glatt. 
Sambueus nigra (Fis. 374). Blätter mit 5 oder 7 spitzgesägsten Fiederblïtchen, Sägezähne nicht nach oben sewölbt. Mark, auch bei den älteren Zweigteilen weiss.

Sambucus racomosa, ähnlich wic Sambucus nicra, Fiederblättchen etwas stärker zugespitzt, Sägezähne nach oben gewölbt. Mark der älteren Zweigteile braun.

Negundo aceroides (Fig. 3 I5 B). Blätter mit 3 oder 5 Fiederblättchen, welche nur wenige Einschnitte zeigen, sonst ganzrandig sind. Rinde der cinjährigen Zweige glatt, grün, ohne Lenticellen.

c. Fiederblättchen länglich zugespitzt, an der Basis mit nadelformigen Anhängseln.

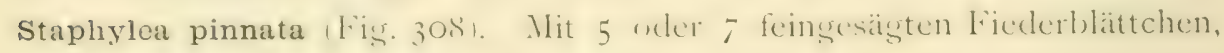
unbehaart. Zweige grünlich grau, glatt. 


\section{\$ 114. Bestimmung der Laubhölzer im Winterzustande.}

\section{Übersicht.}

Tabelle I. Die Knospen sind an den Langtrieben spiralig angeordnet.

I. Die Knospen sind in der Blattnarbe verborgen.

2. Knospen gestielt.

A. Eine grössere Schuppe umhüllt fast die ganze Knospe.

B. Mehrere Schuppen umgeben die Knospe spiralig.

3. Knospen von kleinen zusammengedrückten Blättchen gebildet (nackt).

4. Knospen sitzend, so klein, dass man die Stellung und Zahl der Schuppen nicht mehr deutlich wahrnehmen kann.

5. Knospen sitzend, Zahl der Schuppen gering, undeutlich, einjährige Zweige auffallend dick.

A. Nark gefächert.

B. Mark nicht gefächert.

6. Knospen sitzend mit I oder 2 Schuppen.

A. Knospen ausgesprochen kegelförmig, von der Blattnarbe ringförmig umgeben.

B. Knospen nicht kegelförmig, stehen über der Blattnarbe. Nur eine beiderseits kantige Schuppe (aus zwei Schuppen verwachsen).

7. Knospen sitzend, von mehreren Schuppen umgeben, Zweige auffallend schlank oder besenförmig.

A. Zweige rotbraun glänzend, mit deutlichen Lenticellen.

B. Zweige grünlich-hellgrau, dicker als bei der vorigen Gruppe.

8. Knospen sitzend, von mehreren Schuppen umgeben. Die Knospen stehen an der Spitze der Langtriebe einzeln, an den Kurztrieben einzeln oder gehäuft.

A. Zweige mit Stacheln, d. h. mit metamorphosierten Blatt- oder Haargebilden. Dornspitzige Zweige nicht vorhanden.

B. Zweige ohne Stacheln, mit oder ohne dornige Zweige.

a. Knospen glänzend weiss oder broncefarben.

b. Knospen grün, teilweise braun gerändert.

c. Knospen schwarz, gross. 
d. Knospen harzig slänzend, braun.

c. Knospen hell- oder dunkelbraun oder graubraun, behaart oder nicht behaart.

9. Knospen sitzend, von mehreren Schuppen umgeben, an der Spitze der Langtriebe gehäuft.

A. Knospen nicht von pfriemenförmigen Nebenblättern umgeben.

B. Knospen von pfriemenförmigen Nebenblättern umgeben.

Tabelie II. Die Knospen stehen an den Langtrieben abwechselnd, zweizeilig.

1. Knospen kugelig oder eiförmig mit zwei oder doch nur wenigen Schuppen.

A. Knospen äusserlich von einer grösseren umfassenden und einer kleineren Schuppe umgeben.

B. Knospen von mehreren Schuppen umgeben.

2. Knospen spitz, walzenförmig oder kegelförmig, mit zahlreichen Schuppen.
A. Schuppen spiralig angeordnet.
B. Schuppen abwechselnd stehend.

Tabelle III. Knospen gegenständig.

I. Die Knospen sind in der Blattnarbe verborgen.

2. Zweige auffallend dick, Endknospe sehr gross.

3. Die Zweige sind zumeist dornspitzig.

4. Zweige kletternd, dünn, mit stehenbleibenden, langen, rankenden Blattstielen.

5. Knospen von unausgebildeten Blättern, nicht von eisentlichen Schuppen umgeben.

6. End- und Seitenknospen von zwei Schuppen dicht umschlossen, so dass scheinbar nur eine Knospenschuppe vorhanden ist.
A. Knospenschuppen unbehaart, glänzend.
B. Knospenschuppen behaart.

7. Seitenknospen spindelig, fast senkrecht abstehend.

A. Windende und kletternde Sträucher.

B. Aufrecht wachsende, nicht schlingende Sträucher.

8. An den Seitenknospen nur wenige Schuppen (2 oder 3) sichtbar.
A. Seitenknospen abstehend kugelig.
B. Seitenknospen angedrückt.

9. An den Seitenknospen mehr als drei Schuppen sichtbar.

A. Knospen und Blattnarbe gross.

B. Knospen weniger gross, von den Schuppen sehr lose umhüllt; Blattnarbe ziemlich gross.

C. Knospen an der Spitze der Triebe gross, an der Basis klein, Blattnarbe klein.

D. Knospen und Blattnarbe klein. 


\section{Tabelle I.}

Die Knospen sind an den Langtrieben spiralig angeordnet.

\section{Die Knospen sind in der Blattnarbe verborgen.}

Robinia Pseudacacia (Fis. $38 \mathrm{I}$ ). Die Blattnarbe ist ziemlich gross, höckerig, wird zumeist von zwei derben geraden Stacheln flankiert. Die Stacheln können auch fehlen. Zweige sparrig, hin- und hergebogen, kantig, sehr lang. Rinde braun mit zahlreichen feinen Lenticellen, im Alter mehr grau. Mark unregelmässig, eckig, ziemlich weit.

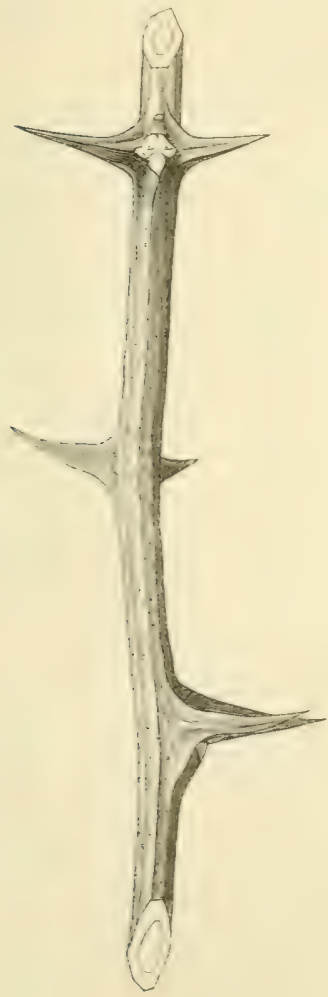

Fig. $38 \mathrm{r}$.

Robinia Pseudacacia.
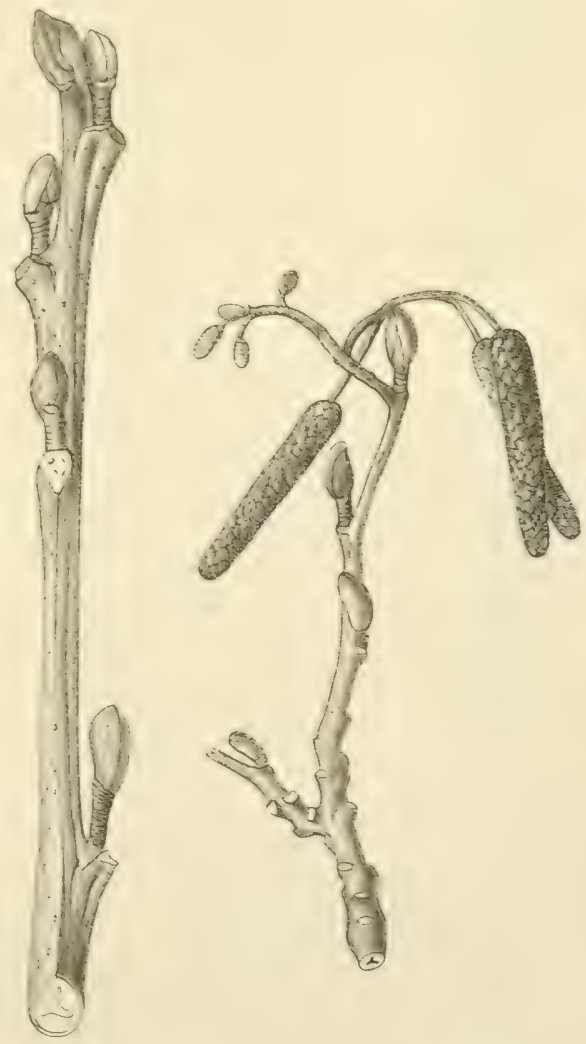

Fig. $3 \mathrm{~S} 2$. Alnus glutinosa.

2. Knospen gestielt.

A. Eine Grössere Schuppe umhiaillt fast die ganse Kinospe.

Alnus glutinosa (Fig. $3 \$ 2$ ). Knospen ziemlich gross, schwach gekrümmt, undeutlich dreikantig und besonders an der Spitze der Zweige langgestielt. Knospenschuppe violett, harzigs bereift. Zweisteile zwischen den 
cinzelnen Knospen häufig hin- und hergebogen, dreikantig oder rundlich. Die jünsten Teile der Zweige weisslich, harzig bereift, aber nicht behaart. Farbe der Zweige grïnlichbraun oder violettbraun, ältere duṇkelgrïn, Lenticellen deutlich, an den jungen Teilen der Triebe hellrot. Mark dreicckig.

Alnus incana. Zweise und Knospen ähnlich wie bei Alnus glutinosa. Die Knospenschuppen sind undeutlich behaart (nur mit Lupe erkennbar), bereift. Die jüngsten Teile der Triebe sind feinfilzig behart (Unterschied ron A. glutinosa), sie sind grau und lassen dic mehr weisslichen Lenticellen nicht so deutlich er-

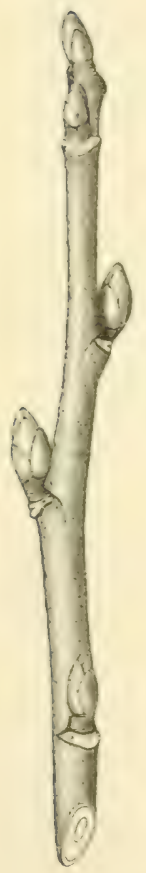

Fig. $3 s_{3}$. Ribes nigrum. kennen, welche Eigenschaften mit der erwähnten Behaarung zusammenhängen. An älteren Zweigen ist die Rinde glatt, glänzend graubraun.

B. Mehrere Schuppen ungeben die Knospe spiralig.

a. Die Zweige haben einen eigentümlichen Geruch.

Ribes nigrum (Fig. $3 s_{3}$ ). Knospen grünlich, den Zweigen angedrückt oder abstehend. Am Stiel und den Knospenschuppen lassen sich mit der Lupe punktförmige gelbglänzende Drüsen erkennen. Die Schuppen umschliessen lose die Knospe. Die Blattnarbe umfasst die Hälfte des Stengels. Die äusseren Peridermschichten geben den einjährigen Zweigen ein grauglänzendes Aussehen, nach dem Zerreissen derselben erscheint die Rinde hellbraun oder graubraun. Lenticellen sind erst an den älteren Zweigteilen sichtbar, man kann jedoch mit der Lupe an jüngeren Teilen feine schwarze Punkte (Drüsen) erkennen. Mark rund, ziemlich weit.

b. Die Zweige haben keinen specifischen Geruch.

Ribes rubrum. Knospen violettbraun, etwas weisslich bestaubt, mit dicht zusammenschliessenden Schuppen. Zweige hellgrau oder grünlich braun. Die äusseren Peridermschichten reissen auf und bleiben in Fetzen an den Zweigen hängen.

Ribes alpinum. Knospen etwas gebogen den Zweigen angedrückt. Schuppen häutig, hellviolett oder weisslich, mit mehr oder weniger deutlicher Stachelspitze. Junse Triche hellbraun slänzend, beim Absterben der äusseren Peridermschichten grau. Die letzteren reissen namentlich an den dickeren Zweigen längsstreifig auf, so dass dieselben mit faserigen Peridermschichten bekleidet sind.

Ribes Grossularia hat weniger deutlich gestielte Knospen, ist daher Tabelle $8 \mathrm{Ab}, \mathrm{S} .436$, beschrieben.

3. Knospen von kleinen zusammengedrückten Blättchen gebildet /nackt.

Rhamnus Frangula (Fis. 3s 4 ). Die Knospen sind filziss behaart, die Endknospe grösser als die Seitenknospen. Die obersten Seitenknospen 
sind der Endknospe oft sehr genähert. Die Zweige sind dünn, meist gebogen, an der Spitze fein behaart. Die jüngeren Zweige sind rötlichbraun mit sehr deutlichen, langgestreckten Lenticellen. Die älteren Zweige nehmen eine mehr graue Färbung an.

4. Knospen sitzend, so klein, dass man die Stellung und Zahl der Schuppen nicht mehr deutlich wahrnehmen kann.

Cydonia vulgaris. Knospen den Zweigen angedrückt, dreieckig, rotbraun, nur an der Spitze weisslich behaart. Stösst man die Spitze der Knospenschuppen ab, erscheint ein weisser Haarschopf. Die Zweige etwas hin- und hergebogen, die seitlichen sehr dünn. In der Jugend spinnwebig behaart, glänzend, grünlich oder schwarzbraun. Ältere Teile mit deutlichen, roten Lenticellen. Nark rund, ziemlich eng.

Rhus cotinus. Knospen abstehend, kurz zugespitzt, dreieckig, grünlich oder rotbraun, nicht behaart. Zweige gerade, schlank, unbehaart. Einjährige Triebe grün, rot oder braun, oft mit weissem Reif, ältere Triebe braun. Lenticellen sehr zahlreich, punktförmig. Mark rund, relativ weit.

Man vgl. ferner noch Populus alba, Elaeagnus angustifolia.

5. Knospen sitzend, Zahl der Schuppen undeutlich, einjährige Zweige auffallend dick. A. Mark gefächert.

Juglans regia (Fig. 385). Endknospe sehr viel grösser als die kugeligen

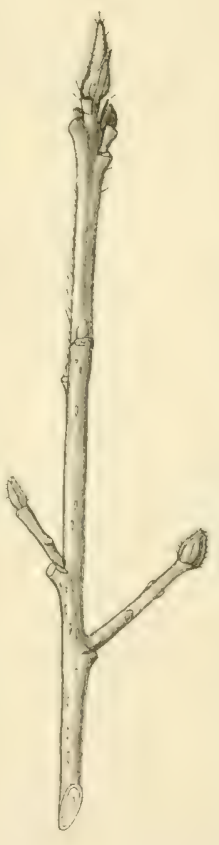

Fig. $3^{8} 4$. Rhamnus Frangula.

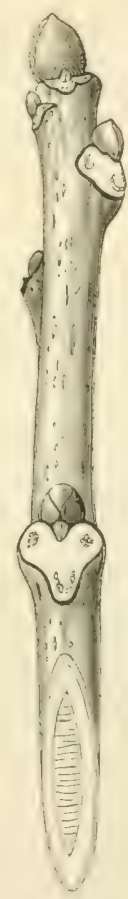

Fig. 385 . Juglans regia. Seitenknospen. Die Endknospe graufilzig behaart, die übrigen schwarz, kahl. Die Blattnarbe sehr gross, breit herzförmig. Zweige ziemlich dick, glänzend, glatt, ohne Behaarung, grünlich, später braun. Die Lenticellen erst an älteren Zweigen deutlicher. Mark weit, fünfeckig.

Juglans nigra. Die Knospen und Zweige ähnlich wie bei Juglans regia. Die einjährigen Triebe sind jedoch braunfilzig behaart. Die älteren Triebe sind unbehaart aber nicht so glänzend wie $e_{-i}^{\text {bei }}$ der vorhergehenden Art. B. Nark nicht gefachert.

Ailanthus glandulosa. Knospen sleich gross, relativ klein, halbliugelis. rot, weisslich behaart. Blattnarbe sehr gross. Zweige unregelmässig 
schosen. Die einjährigen Triebe seht fein und dicht behart, hellbraun, dic älteren srau bis braun. Mark sehr weit, rund.

Ähnlich ist Rhus typhina, jedoch mit klebrig drüsig beharten Zweigen.

6. Knospen sitzend, mit einer resp. zwei Schuppen.

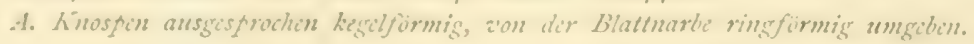

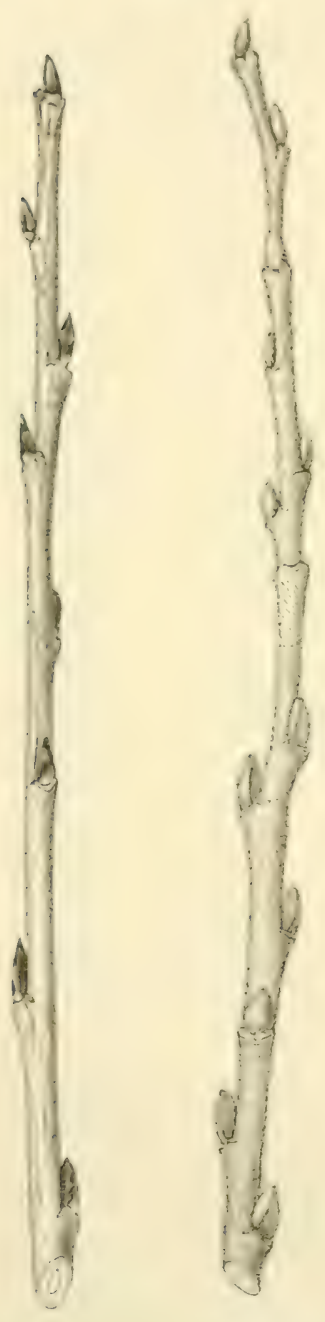

Fig. $386 . \quad$ Fig. 387 . Salix fragilis. Salix cinerea.

a. Zweige dottergelb.

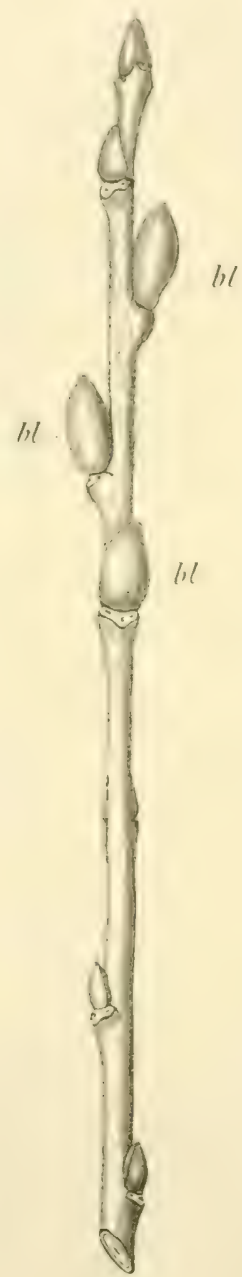

Fig. 388 .

Salix caprea.

Platanus occidentalis. Dic Knospen werden von zwei Schuppen umschlossen, die jedoch äusserlich nicht scharf getrennt erscheinen, Schuppen braun. Die Blattnarben schliessen an der Innenseite nicht vollständig zusammen. Bei der Anwesenheit von Blättern sind die Knospen nicht sichtbar, da sie von der Basis des Blattstieles eingeschlossen sind. Die Haupttriebe deutlich hinund hergebogen. Einjährige Zweige grünlichbraun, vorjährige graubraun mit weisslichem, abschabbarem Überzug. Die Spitzen kürzerer Triebe können wollig behaart scin, sonst die Zweige unbehaart. Mark rundlich oder wenig ausgezackt.

Platanus orientalis (Fig. $328 \mathrm{C}$ ) wie Platanus occidentalis, die Blattnarben bilden einen fast vollkommen geschlossenen Kreis um die Knospe.

B. Knospen nicht kegelförmig, stehen ïber der Blatmarbe. Nur eine beiderseits kantige Schuppe (aus zuei Schuppen verwachsen).

Salix alba var. vitellina. Knospen langgestrecht meist weisslich behaart. Die Knospen der Zweigbasis können jedoch auch unbehaart sein. Blattnarbe schmal. Die gelben Zweige können an der Spitze weisslich 
behaart sein, ältere Teile nehmen eine gelbrote Farbe an. Mark fünfeckig, ziemlich weit.

b. Einjährige Zweige braun glänzend, wie lackiert.

Salix fragilis (Fig. 386). Knospen länglich-eiförmig, an der Spitze abgerundet, wenig zusammengedrückt. Schuppe unbehaart, glänzend schwarz, an der Basis grünlichbraun. Zweige schlank, auf der Sonnenseite rötlich, auf der Schattenseite mehr grünlichbraun. Die älteren Zweige grünlichgrau. Die älteren Zweige brechen an der Basis leicht $\mathrm{ab}$, daher der Name Knackweide.

Salix pentandra. Knospen an der Spitze der Triebe grösser als an der Basis, eiförmig, dem Zweige angedrückt. Die Spitzenknospen erinnern in der Form etwas an die von Salix caprea. Schuppe glänzend braun, die unteren Teile bleiben längere Zeit grünlich. Einjährige Zweige braun, ältere grünlich bis grau.

(Man vgl. hier noch Salix triandra.)

c. Zweige nicht auffällig gefärbt, Knospen dick, eiförmig, doppelt gekielt. a. Zweige dichtfilzig behaart.

Salix cinerea (Fig. 387). Knospen graufilzig. Zweige fühlen sich infolge der dichten Behaarung ganz weich an, Färbung grau.

$\beta$. Zweige wenig behaart (nur an der Spitze).

Salix caprea (Fig. 388). Knospen ziemlich gross, gelblich, rötlich oder hellbraun, kahl. Das Blattpolster vorgewölbt. Blütenknospen (Fig. 388 bl) grösser. Zweigsspitzen behaart; Basis und ältere Zweige unbehaart, grün oder rötlich violett. Langtriebe dick.

Salix aurita. Knospen der vorhergehenden Art sehr ähnlich, doch weniger zugespitzt, dunkelbraun. Blattnarbe sehr schmal. Zweige dünner und kürzer. I jährige Zweige grau bereift, sonst bräunlich, ältere Zweige grünlichgrau.

d. Zweige nicht auffällig gefärbt, Knospen langgestreckt, schmal.

ж. Knospen nicht behaart, walzig.

Salix purpurea (Fig. 389). Die Knospen sind an der Spitze der Zweige kleiner als in der Mitte derselben. Die letzteren sind circa viermal so lang als breit, mit einer anfangs grünlichbraunen, später purpurroten oder schwarzen Schuppe, die sich leicht hülsenförmig von den Blättern ziehen lässt. Die Knospen stehen an den Zweigen sehr dicht. Blattpolster etwas vorspringend. Seitenzweige sehr dünn, gelblich bis grünlich grau, im ganzen hellgefärbt.

$\beta$. Knospen sehr wenig oder gar nicht behaart, zugespitzt.

Salix acutifolia. Knospen anliegend, flach gedrückt, selblich oder rot gefärbt. Zweige lang, glänzend rotbraun gefärbt.

$\gamma$. Knospen behaart, dem Stengel angedrückt.

Salix alba. Knospen sehr klein, dem Zweige angedrückt. Jüngere Zweigteile seidenhaarig, ältere rötlich grau, ohne Glanz. Zweige ziemlich düinn. 
Salix viminalis (Fiss. 390). Knospen sehr verschieden gross, dem Zweige dicht angedriickt, die Spitze etwas gebogen (besonders bei den grösseren Kinospen). Jüngste Zweigteile nur schwach behaart, ältere rotbraun glänzend. Zweige oft von grosser lënge.

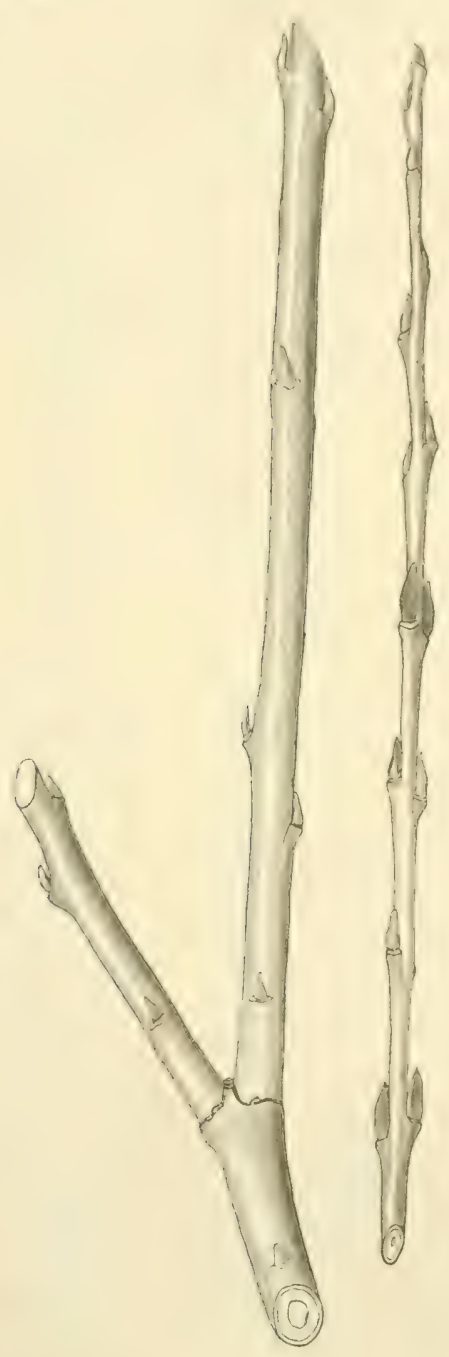

Fig. 389 .

Salix purpurea.

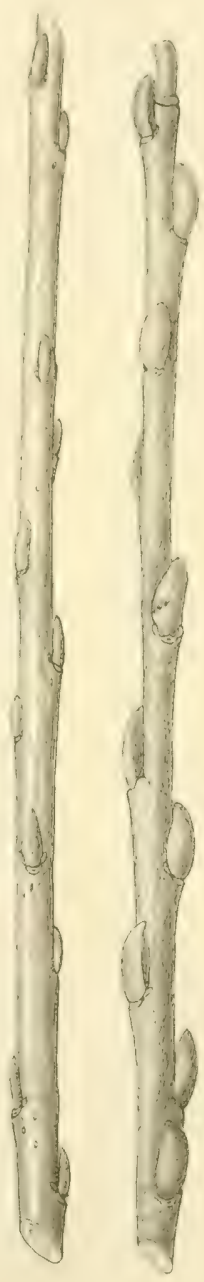

Fig. 390 . Salix viminalis.
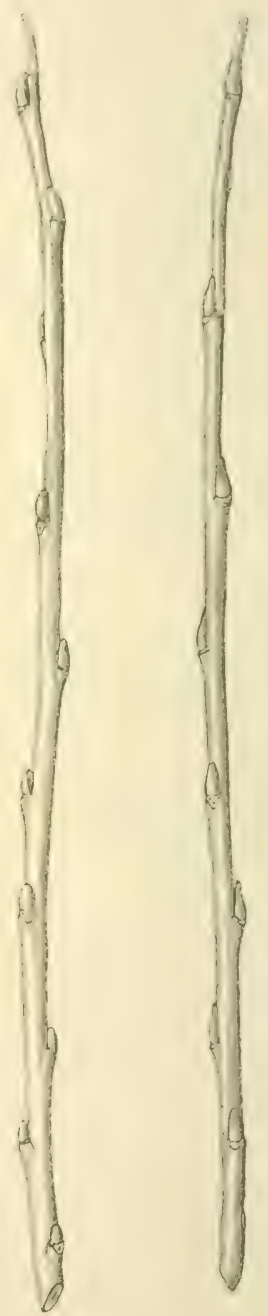

Fig. 391 . Salix triandra.

Ein häufig angebauter Bastard ist Salix viminalis $x$ purpurea. Die Knospen erinnern an Salix purpurea, sind jedoch häufig so flach zusammengedrückt wie bei Salix viminalis. Behaarung nur sehr schwach. Salix triandra. Knospen langgestreckt, zugespitzt, die Spitze sehr flach, häutig, oft etwas nach aussen gebogen. Behaarung nicht auffallend, 
Färbung grünlich oder hellbräunlich. Zweige oben kantig, nicht behaart, öfter glänzend. Seitenzweige weniger entwickelt.

7. Knospen sitzend, won mehreren Schuppen umgeben, Zweige auffallend schlank oder besenförmig.

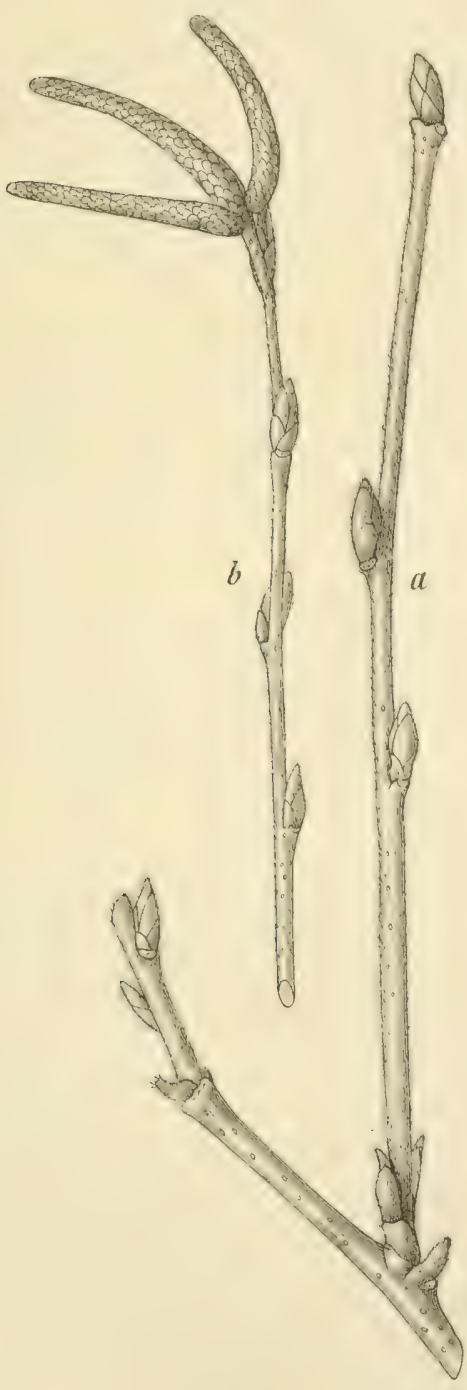

Fig. 392 .

Betula pubescens.

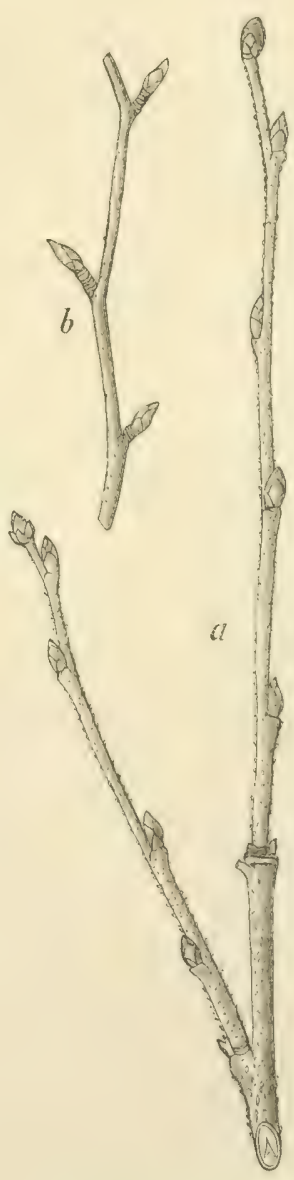

Fig. 393.

Betula verrucosa.

A. Zwenge rotbraun glänzend, mit deutlichen Lenticellen.

a. Einjährige Zweige behaart.

Betula pubescens (Fig. 392). Knospen ciförmig zugespitzt, etwas harzig. Schuppen am Rande gewimpert, sonst meist kahl, braun. Zweige an 
der Spitze mit grauer Behaarung, die mehrjährigen Zweige sind jedoch kahl, glänzend, gleichen den Zweigen der Betula verrucosa. Mark sehr eng, dreieckig.

b. Einjialırige Zweige nicht behaart.

Betula verrucosa (Fig. 393). Knospen eiförmig, zugespitzt, meist von feinen, weissen Wachsblättchen bedeckt, sonst bräunlich, unbehaart. Die schlanken Langtriebe sowie die langen, dünnen Seitentriebe herrschen vor, man findet jedoch auch durch Blattnarben eng geringelte Kurztriebe (Fig. 393 b). Die jungen Triebe sind sehr häufig (aber nicht immer) mit weissen Wachsdrüsen (Fig. 393 a) und Wachsschuppen bedeclit, so dass sie ein bräunlich graues Aussehen gewinnen. Ältere Triebe immer glänzend, mit scharf begrenzten Lenticellen. Mark sehr eng, unregelmässig dreieckig.

Myriea Gale. Knospen sehr klein, rund. Die braunen Schuppen sind weiss berändert, daher trotz der Kleinheit deutlich. Blattpolster vorspringend. Zweige sehr dünn, dunkel violettbraun oder rötlich, mit zahlreichen, derb hervortretenden Lenticellen. Mark sehr eng, dreieckig.

B. Zweige griunlich-hellgrant, dicker als bei der vorigen Gruppe.

Morus alba. Knospen dreicekig, den Zweigen angedrüickt, ungefähr eben so gross als die rundliche Blattnarbe, hellbräunlich oder rötlich. Die Seitenzweige sind lang, gerade, ohne wesentliche Kurztriebe. Die Lenticellen wenig in der Farbe von den Zweigen verschieden, daher nicht deutlich hervortretend. Mark weit, rund.

8. Knospen sitzend, won mehreren Schuppen umgeben. Die Knospen stehen an der Spitze der Langtriebe einzeln, an den Kurztrieben einzeln oder gehäuft. A. Zweeige mit Stachehn, do ho mit metamorphosierten Blatt- und Haargebilden. Domstittsige Zweige nicht vorhanden.

a. Je zwei gerade Stacheln neben den Knospen der Langtriebe.

Caragana arboreseens. Die Knospen stehen über dem konsolenförmigen Blattpolster. Knospenschuppen weisslich, häutig, die inneren am Rande behaart. Zweige aufwärts strebend, Peridermschichten in trocknen Streifen sich ablösend, darunter die glatte, grüne Rinde. Stacheln zart. Kurztriebe sehr dick, von häutigen Schuppen dicht umgeben. Mark eng.

b. Gerade, einfache oder verzweigte, 3-5 spitzige Stacheln unter der Knospe.

Ribes Grossularia (Fig. 394). Knospen schief abstehend, von dünnen, zugespitzten oder ausgefransten Knospenschuppen, aber nicht von Resten der Blattbasis umgeben. Die einjährigen Zweige sind hellgrau, die Oberhaut springt wie bei Ribes alpinum mit Längsrissen auf und lässt darunter die graubraune, glatte Rinde erkennen. Die Stacheln unter den Knospen meist zu drei beisammenstehend, seltener bloss ein Stachel vorhanden. Ausserdem können aber auch noch Stacheln auf der ganzen Fläche der Zweige vorkommen.

Berberis vulgaris (Fig. 395). Die Knospen sind von der stehenbleibenden 
Blattbasis mehrerer Blätter umgeben. Die braunen Knospenschuppen sehen wie vertrocknet aus. Zweige lang, rutenförmig, etwas hin- und hergebogen, hellbräunlich oder grau. Die Rinde nach dem Aufschneiden intensiv gelb gefärbt. Stacheln an der Spitze der Triebe in der Einzahl (Fig. 395a), an den übrigen Teilen verzweigt mit 3, 4 oder 5 Spitzen (Fig. 395 b). Stacheln nur unter den Knospen. Mark ziemlich weit, gelblich gefärbt.

c. Meist zwei nach rückwärts gebogene, derbe Stacheln unter jeder Knospe.

Rosa canina (Fig. 396). Die Knospen stehen in einiger Entfernung über den Stacheln und über der sehr

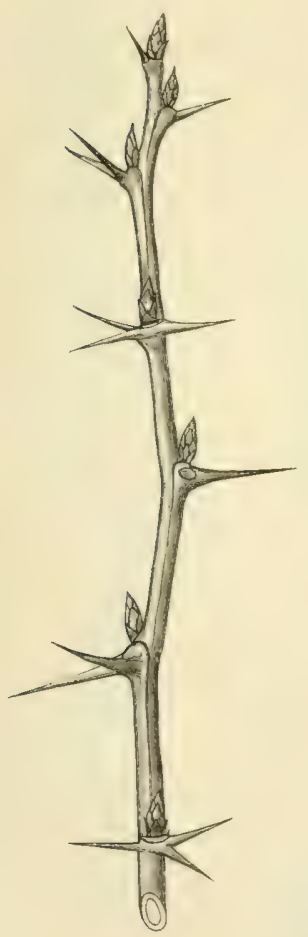

Fig. 394.

- Ribes Grossularia.

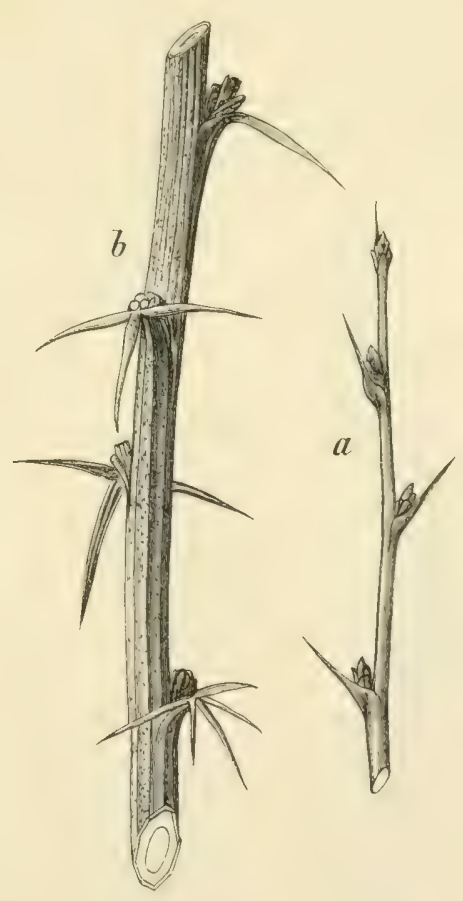

Fig. 395. Berberis vulgaris.

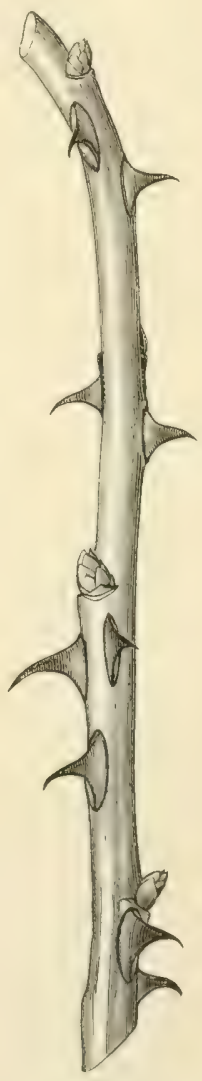

Fig. 396.

Rosa canina.

schmalen, den Stengel halb umfassenden Blattnarbe. Sie sind rundlich, stumpf, rötlich, schief abstehend. Zweige schlank, gebogen (Stocklohden gerade). Grün oder rötlichviolett gefärbt, im Alter mehr grau. Mark sehr weit.

(Ähnlich die anderen Rosenarten).

d. Zahlreiche derbe, zurückgebogene Stacheln, ohne Zusammenhang mit den Knospen.

Rubus frueticosus (Fig. 397). Knospen spitz, lang, von den behaarten Schuppen lose umhüllt. Sie stehen meist etwas über der stehen- 
bleibenden, vorgewülbten Blattsticlbasis. Dic Zweige lang, an der Spitze überhängend, kantig, grün, an der besonnten Seite violettrot. Die Blätter bleiben häufig den ganzen Winter an den Zweigen, Mark wcit.

Ähnlich Rubus eaesius. Dic Haupt- und Nebenaxen rundlich; diüner, kriechend, bläulich bereift.

e. Zahlreiche weiche Stacheln oder nur stachelige llöcker auf der ganzen Fläche der Zweige.

Rubus Idaeus (Fig. 398). Knospen ähnlich denen von Rubus fructicosus mit losen, hellbräunlichen Schuppen, auf der konsolenartigen Blattbasis stehend. Zweige lang, oft ziemlich dünn, braun oder hellbraun. Mark sehr weit.

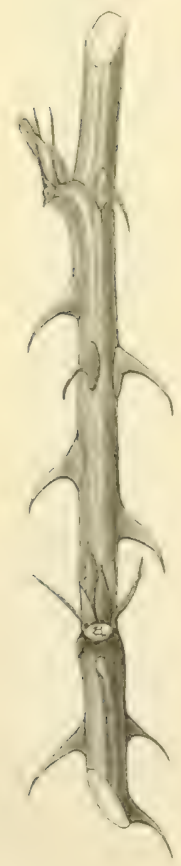

Fig. 397.

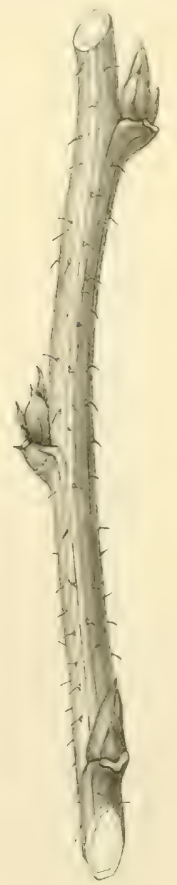

Fig. 398.

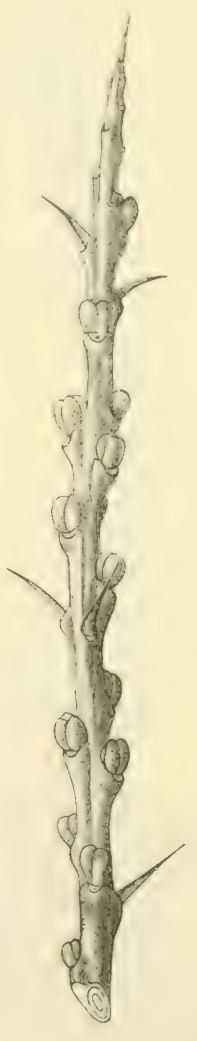

Fig. 399.

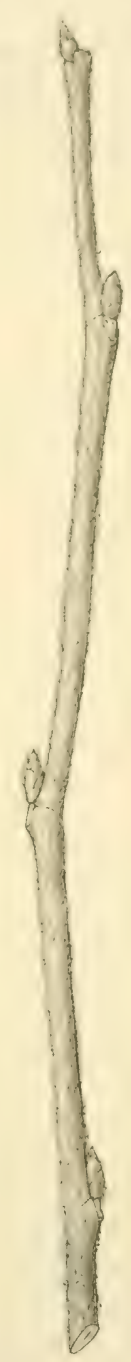

Fig. 400 .

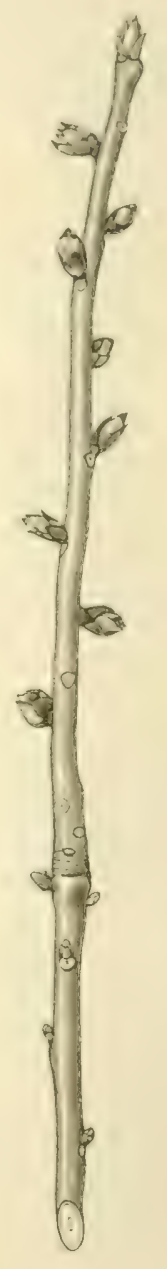

Fig. 40I.

Rubus fructicosus. Rubus Idaeus. Hippophaë rhamnoides. Populus alba. Daphne Mezereum

B. Zweige ohne Stacheln (mit oder ohne dornige Zuveige).

a. Knospen glänzend-weiss oder broncefarben.

«. Zweige teilweise dornspitzig, Haare schuppenförmig.

Elaeagnus angustifolia. Knospen rundlich, an der Spitze eingebuchtet. 
Knospenschuppen silberglänzend. Ausser den dornigen Langtrieben sind auch dornige Kurztriebe vorhanden, an deren Basis sich zumeist eine Knospe befindet (analog wie bei Crataegus oxyacantha). Langtriebe schlank. Im ersten Jahre sind die Zweige matt silberglänzend, ältere Zweige glänzend dunkelgrün oder rotbraun. Mark sehr weit.

Fippophaë rhamnoides (Fig. 399): Knospen rundlich, an der Spitze eingebuchtet, mit Trichomgebilden besetzt, welche der Knospe ein kupferbronciertes Aussehen verleihen. Knospen stehen dicht auf etwas vorgewölbtem Blattpolster. Unter Umständen sind an Stelle der Knospen auch gelbrote Früchte zu finden. Junge Zweigteile von der Farbe der Knospen, ältere dunkel oder weisslichgrau.

$\beta$. Zweige immer ohne Dornen. Haare filzig oder seidenglänzend.

Populus alba (Fig. 400). Inospen spitz, ähnlich wie bei Populus tremula an den Langtrieben abstehend, meist kleiner als bei den anderen Pappelarten. Dieselben sind wie die einjährigen Zweige von einem lockeren weissen Filz umgeben, die älteren Triebe grünlichgrau, Kurztriebe dünn, verschieden lang. Mark eng, fünfeckig.

Cytisus Laburnum. Die Schuppen umhüllen die Knospen locker, die Knospe rundlich, ziemlich gross, sitzt auf stark vorgewölbten Blattpolstern. Langtriebe schlank, die Kurztriebe - wenn, vorhanden dick, stark geringelt. Im ersten Jahre sind die Zweige silberweiss filzig behaart, die jungen Peridermschichten ebenfalls silberweiss. An etwas älteren Zweigteilen ist die Rinde glänzend grün. Mark rund, ziemlich weit.

(Man vergl. Cydonia vulgaris, Pirus malus.)

b. Knospenschuppen grün, teilweise braun gerändert.

«. Knospen, besonders die unteren Seitenknospen klein.

Daphne Mezereum (Fig. 4OI). Die oberen Knospen (Blattknospen) sind eiförmig, grün, mit brauner Spitze. Die unteren Seitenknospen (Blütenknospen) ausserordentlich klein, kugelig, braun. Zweige dünn, auch die älteren Zweigteile noch mit Knospen versehen, die ziemlich dicht stehen. Farbe der Zweige grau oder bräunlichgrau. Mark sehr eng, undeutlich dreieckig.

$\beta$. Knospen gross oder ziemlich gross.

Knospen kugelig.

Sorbus torminalis (rgl. Fig. 344). Die Form der Knospen sehr charakteristisch. Die Spitzenknospen grösser als die Seitenknospen. Die Schuppen sind glänzend grün, mit schmalem, braunem Rand, unbehaart. Langtriebe wenig gebogen, Kurztriebe verschieden lang, geringelt, nicht dornig, die kürzeren tragen meist nur eine Endknospe, keine Seitenknospen. Farbe der einjährigen Triebe glänzend braun, mit weisslichen Lenticellen, ältere Triebe graubraun. Mark ziemlich weit, etwas ausgerandet.

Knospen langgestreckt.

Sorbus Aria (Fig. 402). Knospen gross (besonders die Endknospen), 
Schuppen derb, gekiclt, hellbraun oder grün, mit braunem Rand oder brauner Spitze, schwach filzig behaart. Langtricbe gerade (Fig. $402 \mathrm{a}$ ),

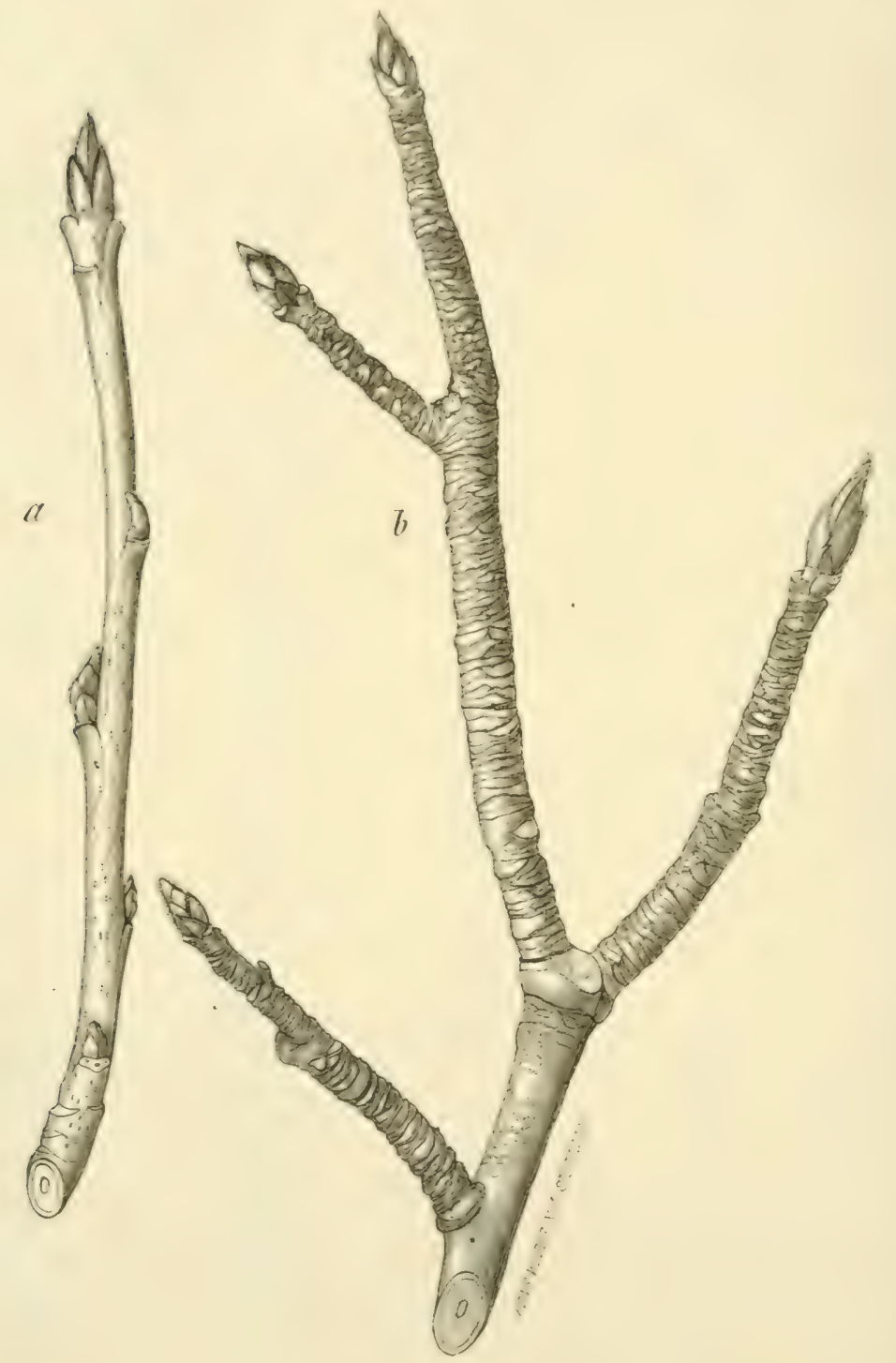

Fig. 402. Sorbus Aria.

Kurztriebe dick, stark geringelt iFigs. 402 b). Einjährige Zweige braun, ältere graubraun. Mark eng.

c. Knospen schwarz, gross.

Sorbus aucuparia. Die grossen Knospen in der Form ähnlich wie bei 
Sorbus Aria. Die äusseren Schuppen sind jdoch glänzend schwarz, wenig behaart, die inneren dicht filzig. Laugtriebe derb, gerade, Kurztriebe stark geringelt, beide dunkelbraun. Lenticellen deutlich, aber nicht zahlreich. Mark ziemlich weit.

d. Knospen harzig, glänzend braun.

Populus tremula (Fig. 403). Knospen sehr spitz,

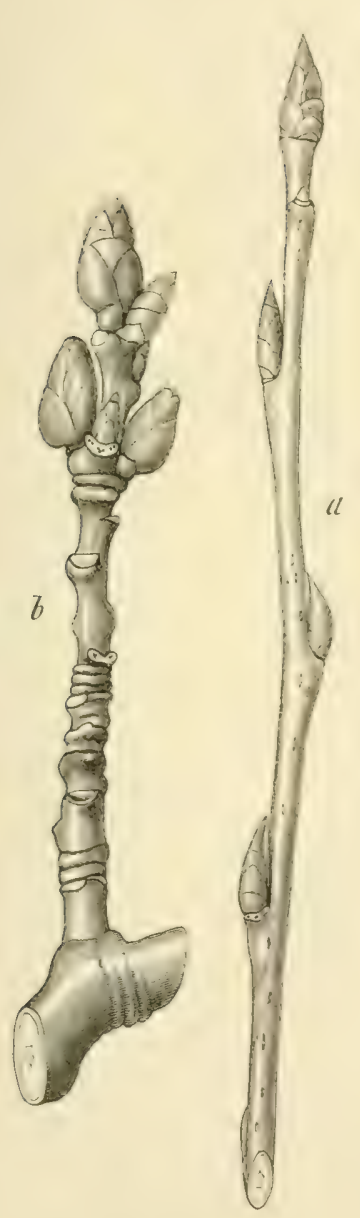

Fig. 403.

Populus tremula. gerade oder etwas nach innen gebogen, dreikantig bis eiförmig (Fig. 403 a). Blattpolster vorspringend. Blütenknospen dicker (Fig. 403 b).

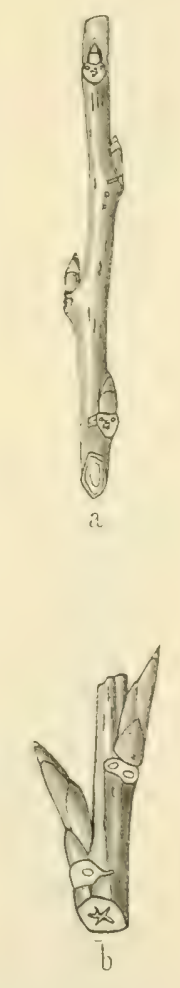

Fig. 404 .

b. Populus canadensis.

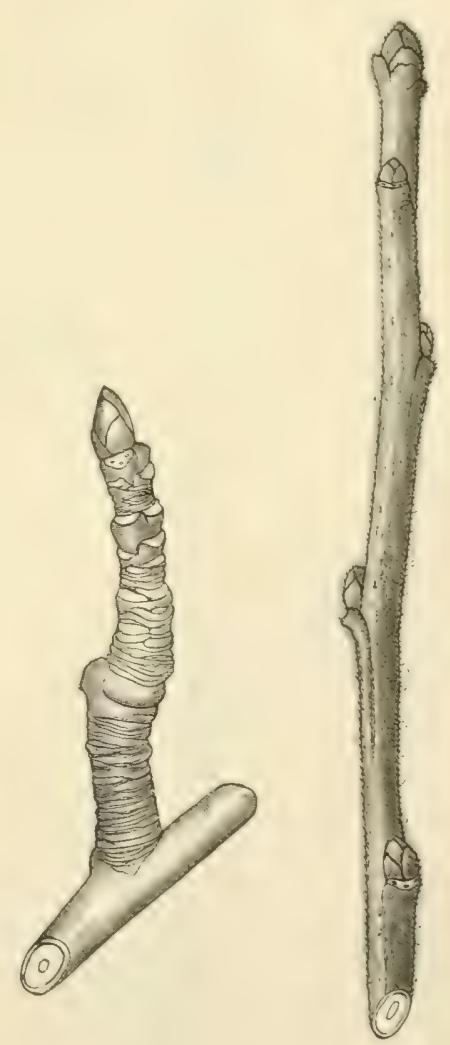

Fig. 405.

Pirus malus.

Schuppen glänzend braun. Langtriebe schlank, die Kurztriebe verschieden lang, die kürzeren knotig. Jüngere Zweige glänzendbraun oder rotbraun, ältere Triebe grau. Mark eng, fünfeckig.

Populus nigra (Fisg. fO4a). Knospen länglich, legelförmig, gerade oder die Spitze nach aussen gebogen (analog wie Fig. 404b). Die Endknospen der Kurztriebe, sowie die Blütenknospen wesentlich grösser 
als die Seitenknospen. Langtriebe rundlich, mit hervorgewölbten Blattpolstern, glänzend gelblich oder hellbraun, meist ohne Korkleisten.

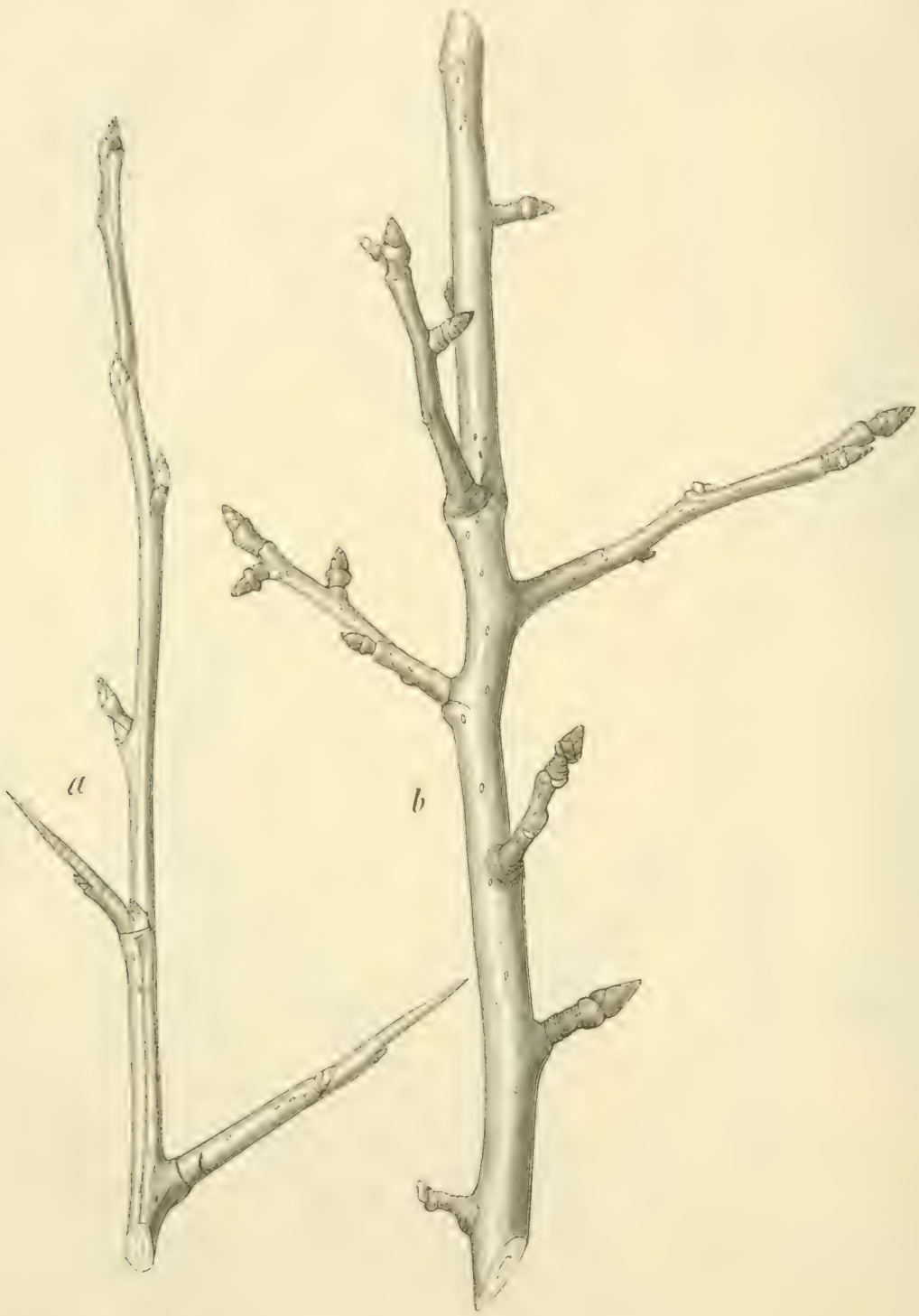

Fig. 406. Pirus communis.

Populus nigra var. pyramidalis. Wie P. nisgra, die Langtriebe sind jedoch alle nach aufwärts gebogen, die Kurztriebe meist zahlreich.

Populus canadensis (Fig. 404 b). Ähnlich wie P. nigra. Knospen jedoch noch grösser (besonders auffallend die Blütenknospen), Seitenknospen 


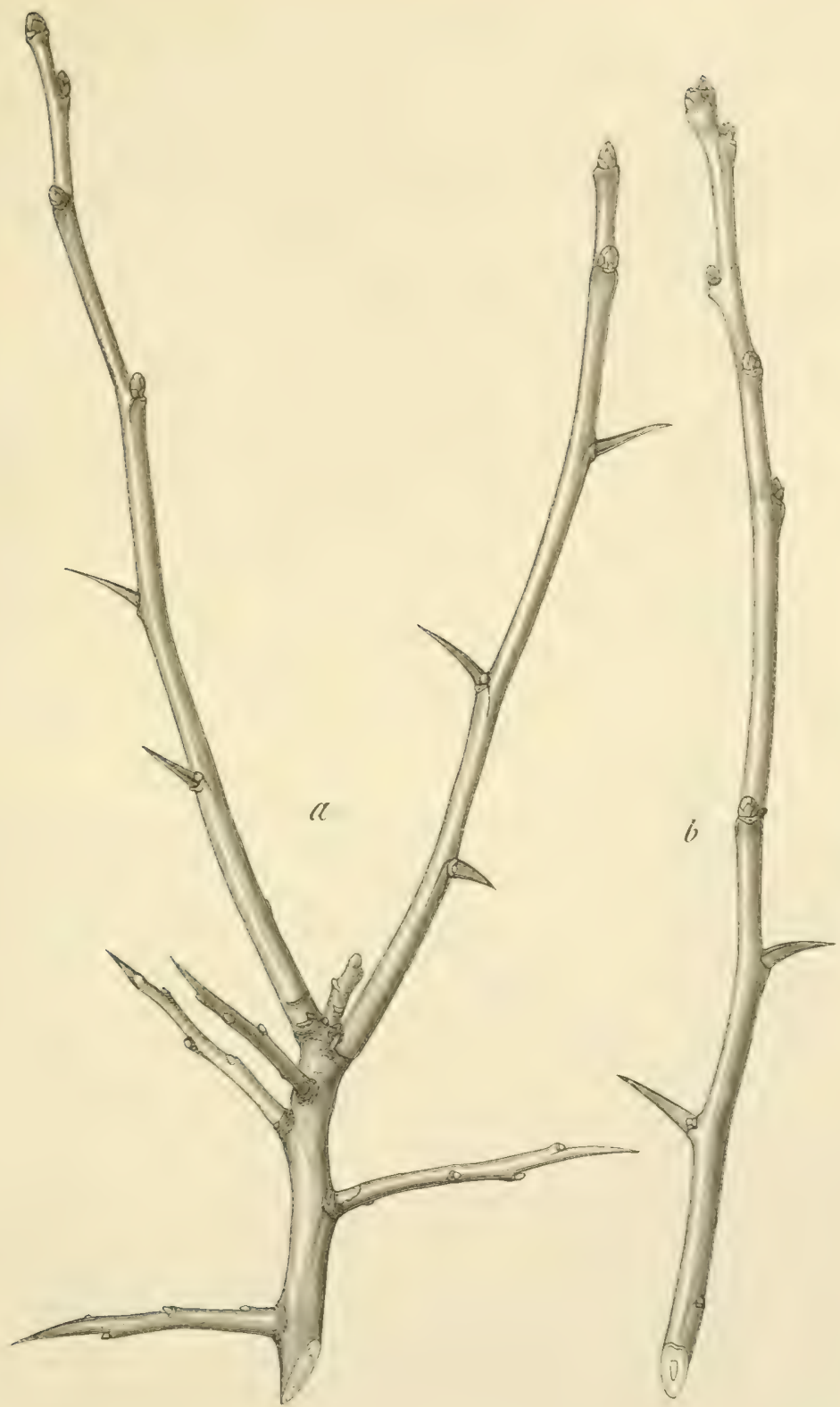

Fig. 407 .

Crataegus oxyacantha.

häufig an der Spitze stark nach aussen gebogen. Zweige derb, mehr kantig, öfter mit Korkleisten. Ist nur unsicher von Populus nigra zu unterscheiden. 
e. Knospen hell- odex dunkelbraun oder graubraun; behaart oder nicht behaart.

«. Blattnarbe halbmondförmig, schmal.

* Knospen behaart.

Pirus malus (Fig. 405). Knospen an den Langtrieben angedrückt, dreieckig, ziemlich klein, am Ende der Kurztricbe eiförmig, grösser. Die Schuppen sind rötlich oder braun mit filziger Behaarung, Zweige im ersten Jahre rotbraun, glänzend, mit geringer, unregelmässig haftenbleibender Behaarung. Kurztriebe zahlreich, stark geringelt, bei der wilden Form nicht selten dornig. Mark rundlich.

Cotoneaster vulgaris. Knospenschuppen rot-

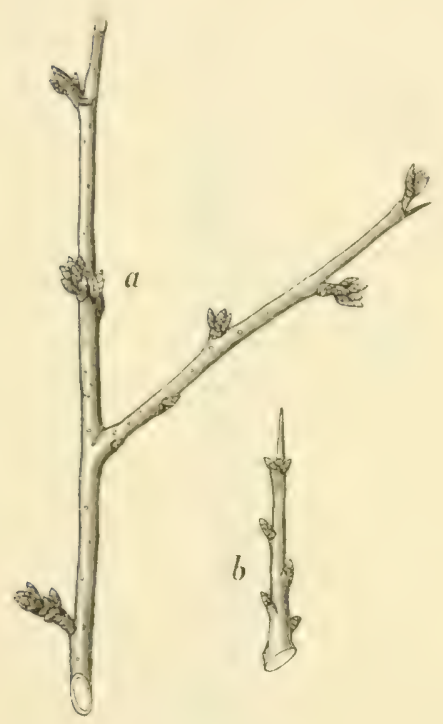

Fig. 408.

Prunus spinosa. braun, nicht oder nur wenig behaart. Zwischen denselben ragen zumeist die dicht filzig behaarten jungen Blättchen hervor, die von den Knospenschuppen nur lose umhüllt werden. Zweige gebogen, kurz, dünn, rotbraun, nur an der Spitze feinfilzig behaart (nicht spinnwebenartig, wie bei Cydonia, mit welcher die geschlossenen Knospen einige Ähnlichkeit haben). Ältere Zweige dunkel, schwärzlichbraun. Mark sehr eng. ** Knospen unbehaart.

Pirus communis (Fig. 406). Knospen dunkelbraun, schwärzlich oder rötlich, zu Beginn des Winters grünlich. Einjährige Zweige glänzend braun oder gelblichbraun, mit deutlichen Lenticellen, ältere Zweige graubraun oder dunkelgrau. Kurztriebe entweder in einen glatten Dorn umgewandelt (Fig. 406a) oder durch Blattnarben geringelt, mit einer Endknospe versehen (Fig. 406 b). Zweierlei Dornen wie bei Crataegus kommen hier nicht vor.

Crataegus oxyacantha und monogyna (Fig. 407). Knospen braun, die Schuppen manchmal etwas gekielt, wodurch die Knospe mehr eckig erscheint. An den Langtrieben stehen häufiger auf gleicher Höhe eine grössere und eine kleinere Knospe. Da sich die kleineren Knospen häufig nicht weiter entwickeln, finden wir seitlich, an der Basis der längeren Seitentriebe, immer kleine Knospen oder doch Reste davon vor. Ebenso ist charakteristisch, dass seitlich am Grunde der kürzeren Dornen je eine Knospe steht. Dịe Zweige meist mit kürzeren Dornen und längeren dornspitzigen Seitenästen besetzt, unregelmässig gebogen. Zweige grau, nicht glänzend. Mark sehr eng, rundlich.

$\beta$. Blattnarbe rundlich.

* Knospen sehr klein, kugelig.

Prunus spinosa (Fig. 408). Knospen sind kahl, circa I,5 mm lang. Die 
Knospen stehen häufig zu mehreren zusammen über einer Blattnarbe, namentlich sind öfter auch an den Kurztrieben die Knospen traubenartig vereinigt (Fig. 408a). Zweige sind unregelmässig gebogen, sehr oft mit Dornen versehen. Einjährige Sprosse grau oder bräunlich grau, etwas glänzend, ältere Zweige schwärzlich oder grau glänzend. Mark ziemlich eng.

* Knospen kegelförmig, etwas grösser.

Prunus domestica (Fig. 409). Die schwärzlichgrauen oder braunen Knospen stehen auf einem stark vorgewölbten, wulstigen Blatt-

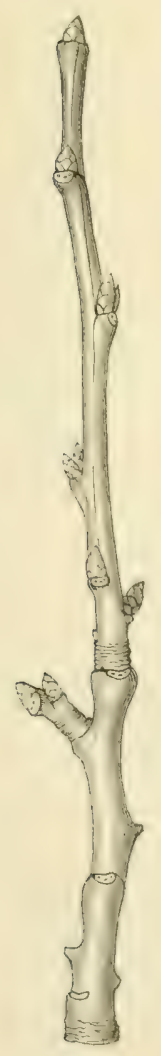

Fig. 409.

Prunus domestica.

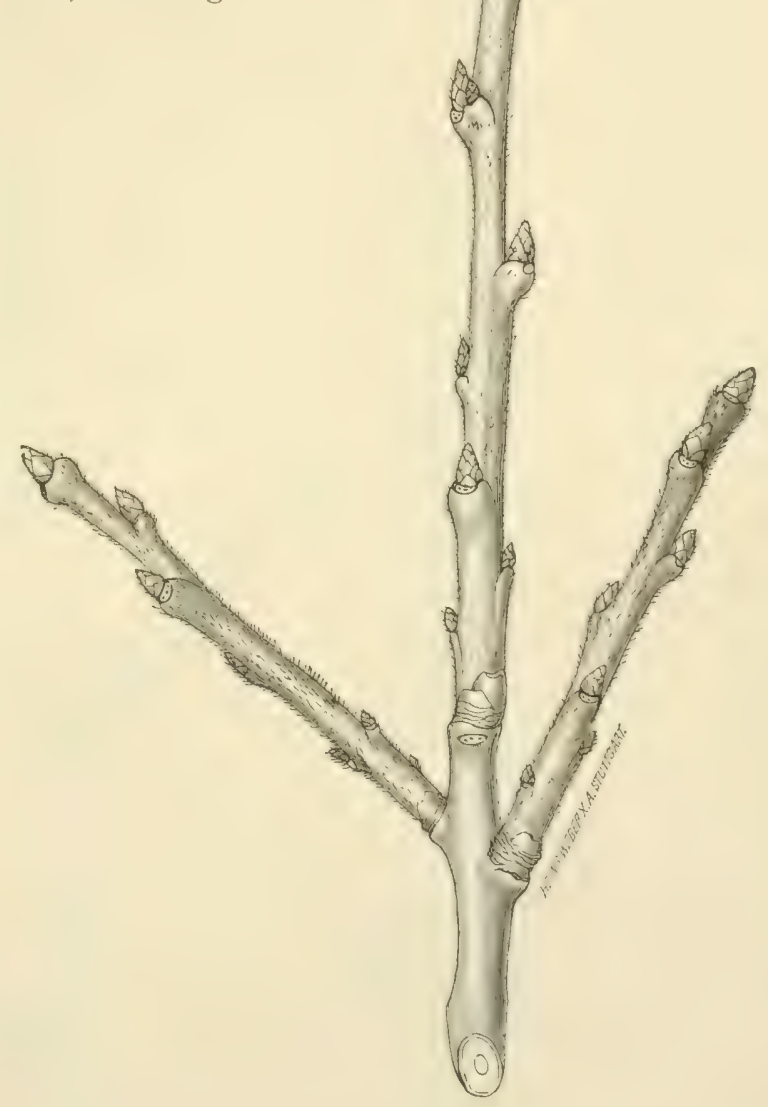

Fig. 4IO.

Prunus insititia.

polster. An den Langtrieben können 2-3 Knospen nebeneinander über einer Blattnarbe vorkommen. Die einjährigen Langtriebe sind rot, oder nur auf der besonnten Seite rot, auf der Schattenseite grün, manchmal bereift. Die älteren Zweige sind grau. Kurztriebe deutlich 


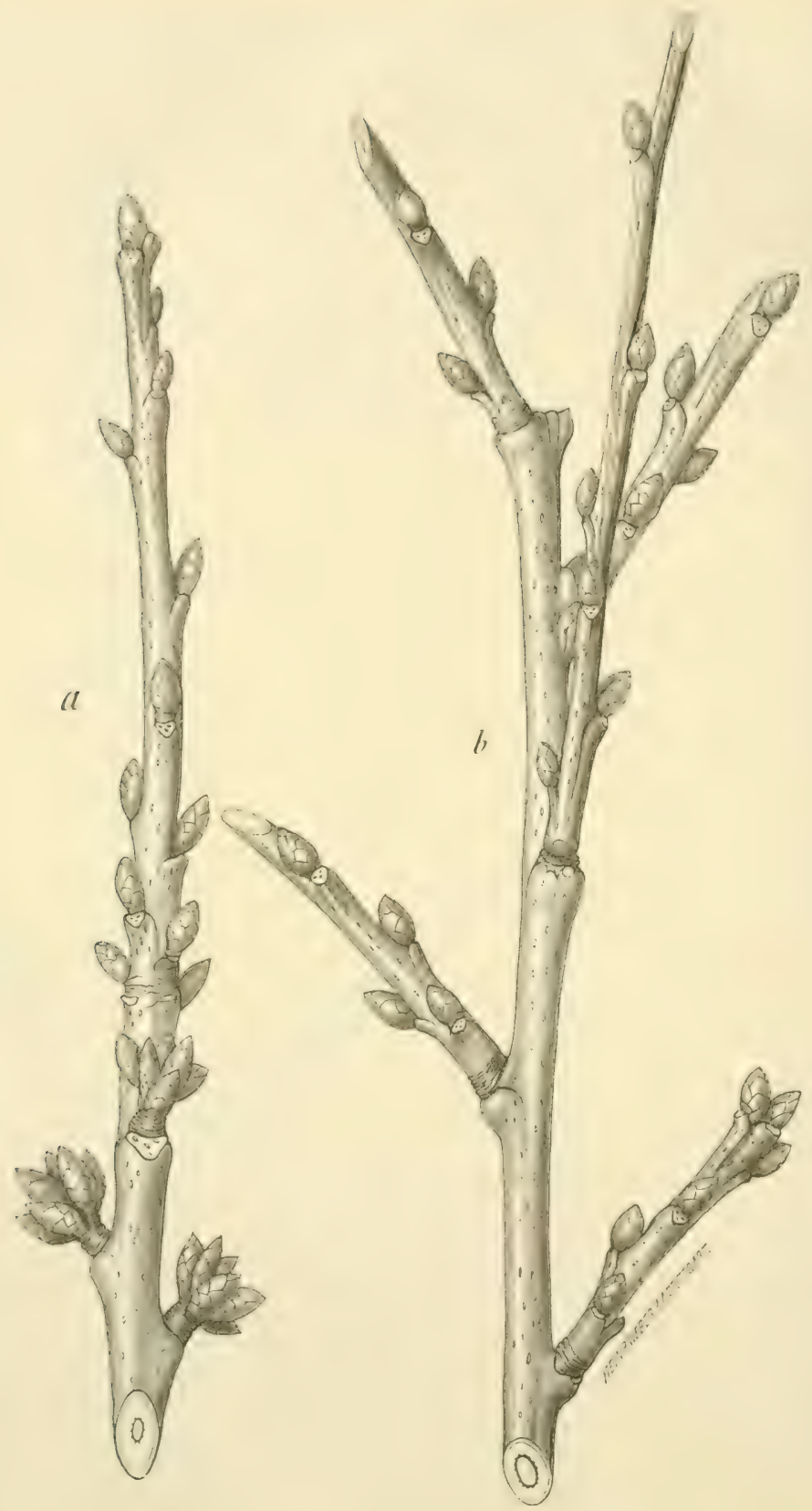

Fig. 4II. Prunus avium.

ausgebildet, durch die erhöhten Blattpolster knotig. Mark der Zweige eng.

Prunus insititia (Figs. 410). Knospen kegelförmig, abstehend auf stark 
emporgewölbtem Blattpolster, Schuppen grau behaart oder braun, mit grauer Behaarung. Langtriebe knotig, nicht sehr lang. Kurztriebe zahlreich. Einjährige Zweige dicht mit kurzen, grauen Haaren besetzt, ältere Zweige dunkelgrau. Mark rundlichechig.

Prunus armeniaca. Knospen ähnlich wie bei den zwei vorhergehenden Arten. Die Zweige sind stark glänzend, grau oder bräunlich oder grün, ältere Zweige besitzen eine feinrissige Oberhaut. * * Knospen eiförmig.

Prunus Padus (rgl. Fig. 337). Knospen ziemlich spitz (6-9 mm lang, $2 \mathrm{~mm}$ breit). Die Schuppen an der Basis dunkler, am Rande meist mit hellbraunem Saum, sie sind schwach gekielt, mit sehr kleiner Stachelspitze. Zweige schlank, fast kahl, in der Jugend violettbraun, im älteren Zustand grau. Sie zeichnen sich durch einen besonderen Geruch aus. Kurztriebe verschieden lang, ziemlich dünn.

Prunus Mahaleb (vgl. Fig. 336). Knospen kleiner (circa $3 \mathrm{~mm}$ lang) hellbraun, die Spitze fein behaart, schwach eingekerbt. Langtriebe dünn, Kurztriebe nicht auffälligs. Einjährige Triebe hellgrau, teilweise weisslich glänzend, ältere Zweige dunkel. Zweige wohlriechend. Mark eng.

Prunus avium (Fig. 4II). Knospen eiförmig (bis 6 mm lang), zugespitzt. Schuppen rotbraun, am Rande trockenhäutig. Blattpolster vorspringend. Langtriebe gerade, nicht dünn. Kurztriebe sehr kurz, eng geringelt, dick, meist mit 5-6 Knospen an der Spitze (Fig. 4II), Rinde nach dem Abschaben der dünnen, grauen Epidermisschicht rotbraun, glatt, ältere Zweige dunkler. Mark rund, ziemlich weit, fein ausgezackt.

Prunus cerasus. Knospen etwas kleiner als bei der vorhergehenden Art, sonst ähnlich. Die Zweige alle sehr schlank und dünn, oft überhängend. Die Seitentriebe sehr rerschieden lang, wesentlich länger als bei Prunus avium. Kurztriebe sind nicht so regelmässig vorhanden. Die Blattpolster treten wegen der Feinheit der Zweige nicht so deutlich hervor. Junge Triebe gelblichbraun oder grau, nach Abschürfung der weissen Epidermisschicht sehen die Zweige dunkelbraun aus.

9. Kirospen sitzend ion mehreren Schuppen umgeben, an der Spitse der Largtriebe gehäuft.

A. Knospen nicht von pfriemenförmigen Nebenblättern umgeben.

Quercus pedunculata (Fig. 4I2). Die Endknospe ist meist etwas grösser als die danebenstehenden und die übrigen Seitenknospen. Die Seitenknospen stehen häufig etwas schief über der Blattnarbe, folgen an den kürzeren Seitentrieben ziemlich dicht aufeinander. Die Knospen sind rundlich, zugespitzt, undeutlich fünfkantig. Knospenschuppen in fünt Reihen angeordnet. Die Knospenschuppen sind braun glänzend, un b eha art. Die Blattnarben dreieckig. Nebenblätter sind nicht erhalten geblieben.

Die Zweige sehr sparrig, ziemlich stark, die Kurztriebe sehr knotig. Die cinjührigen Zweige sind grünlich-ode" weisslichgrau, nicht behart, 


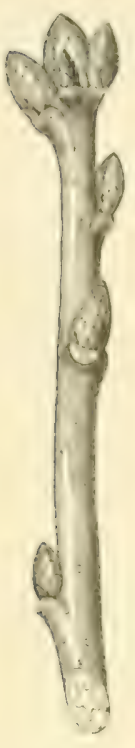

Fig. 412 . Quercus pedunculata.

dic älteren Zweige dunkelgrau oder graubraun. Mark unregelmässig ausgebuchtet.

Quorcus sossiliflora. Dic Knospen ähnlich wie bei der vorhergehenden Art, jedoch etwas mehr langgestreckt. Der Rand und die Spitze der Schuppen sind fein behart, wodurch die Knospen ein mehr weissliches, wie mehliges Ausschen erhalten und heller aber nicht glänzend erscheinen. Die jüngeren Zweige sehen aus wie weiss bereift, sind nicht behaart, im Ganzen den Zweigen von Quercus pedunculata ähnlich. Das dürre Laub bleibt oft den ganzen Winter an den Zweigen, was unter Umständen auch bei den anderen Eichenarten vorkommt.

B. Kunospen von pfriemenfömigen Nebenblättern ungeben.

Quercus pubescens. Die Knospen und behaarten Knospenschuppen wie bei Q. sessiliflora, doch weniger schief über der Blattnarbe stehend. Die Spitzen der jungen Triebe feinfilzig behaart, die älteren Triebe von rauhem, nicht glänzendem Aussehen.

Quereus cerris (vgl. Fig. 287). Die Knospen sind in sehr charakteristischer Weise von den stehen bleibenden, fädigen Nebenblättern eingehüllt. Die ganze Fläche der Knospenschuppen dicht feinfilzig behaart. Ebenso sind die Spitzen der jungen Triebe graufilzig, die älteren Teile grau, graubraun oder aschenfarbig.

\section{Tabelle II.}

Die Knospen stehen an den Langtrieben abwechselnd, zweizeilig.

1. Knospen kugelig oder eiförmig mit zwei oder doch nur wenigen Schuppen. A. Kunospen äusserlich von einer grösseren umfassenden und einer kleineren Schuppe umgeben.

Tilia grandifolia (Fig. +13). Knospen cifömis, zusespitzt, ziemlich gross, kahl, dunkel rotbraun, abstehend, schief über der Blattnarbe. Zweige etwas gebogen, lang. Die einjährigen Triebe sind im Winter dunkelrot, ältere Zweige grünlichgrau. Mark rundlich.

Tilia parvifolia. Wie die rorhersehende Art, doch die einjährişen Zweige glänzend gelbbraun.

B. Knospen von mehreren Schuppen umgeben.

Corylus avellana (Fig. fIf). Knospen eirund-kugelig, etwas zusammengedrückt, nur wenig schief über der Blattnarbe stehend (Fig. 4I4 a). Die Knospenschuppen hellbraun, am Rande behaart, sonst fast kahl. Zweige hellbraun, im ersten Jahre meist kurzhaarios, später grauglänzend. Häufig befinden sich männliche Kätzchen an den Zweigen (Fig. 4I4b). Mark ziemlich eng, unregelmässig dreieckig. 
Castanea vesca (Fig. 4I5). Knospen eiförmig, glänzend, rötlich oder grau bestäubt. Gipfelknospe grösser als die Seitenknospen. Blattnarbe

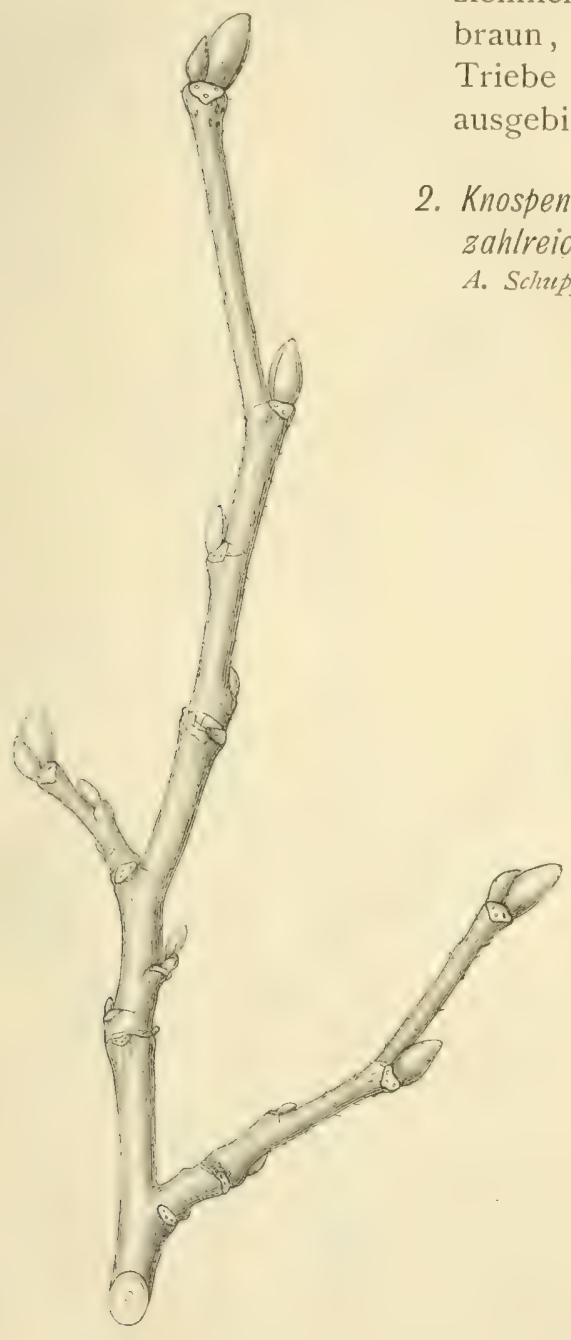

Fig. $4 \mathrm{I} 3$

Tilia grandifolia.

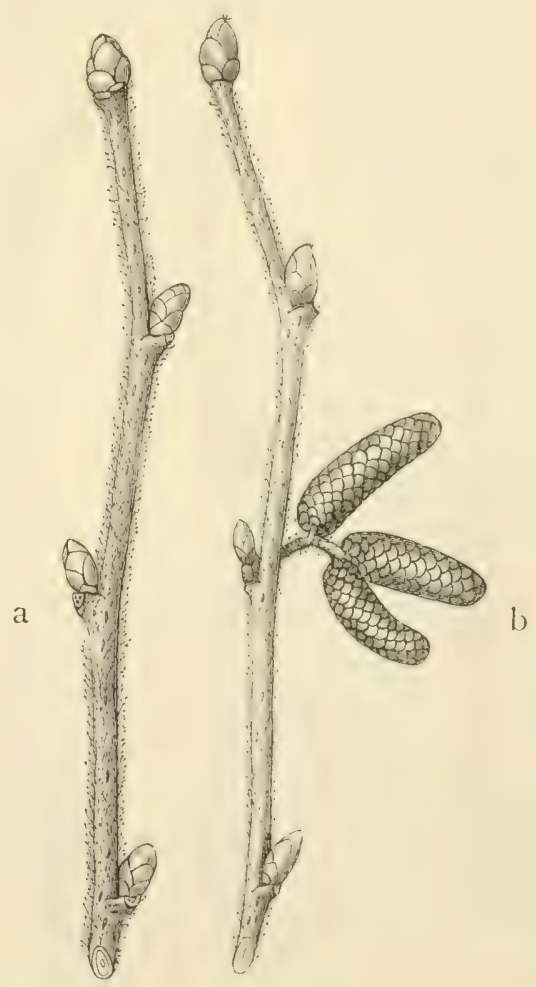

Fig. 414 .

Corylus avellana.

Fagus silvatica (Fig. 4I6). Knospen sehr langgestreckt, bis $2 \mathrm{~cm}$ lang, spitz, spindelförmig. Schuppen hellbraun, an der Spitze durch die undeutliche Behaarung grau gefärbt. Zweige schlank, etwas gebogen, glatt. Kurztriebe fein geringelt, in der Jugend hellbraun, später grau. Mark unregelmässig eckig.

Carpinus Betulus (Fig. 4I ). Knospen der vorhergehenden Art ähnlich, doch kleiner, nicht so rund, mehr vierkantig. Die Behaarung der 
Schuppen ebenfalls schwach, besonders an den Kanten deutlich. Langtricbe schlank, etwas hin und hergebogen. Kurztriebe durch die Blatt-

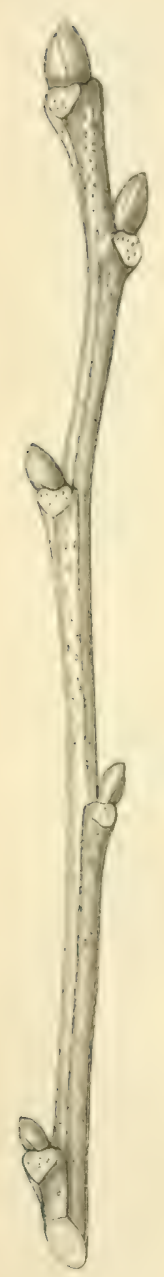

Fig. 415. Castanea vesca. Fagus silvatica. (DN.)

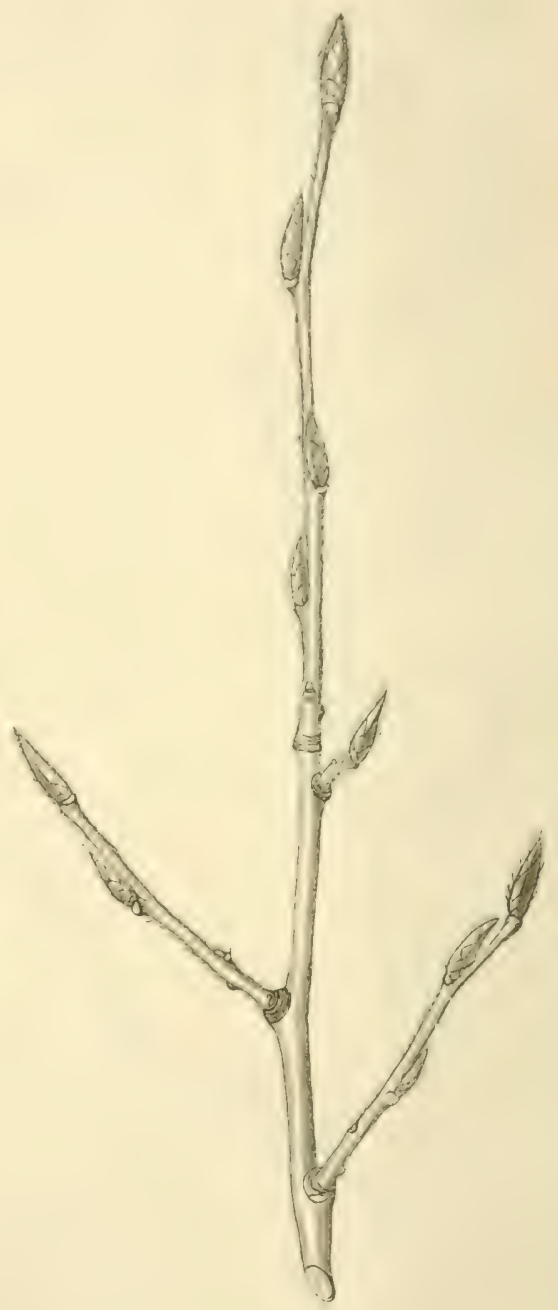

Fig. 417. Carpinus Betulus.

polster höckerig. Jüngere Zweige glänzend braun, ältere grau. Mark sehr eng, rundlich-eckig.

Ähnlich ist auch Ostrya vulgaris.

B. Schuppen abuechselnd stehend.

Ulmus eampestris (Fig. fIS). Knospen kegrelförmig bis eiförmig oder rund, stark abstehend, sehr schief über der Blattnarbe stehend (Fig. 4IS a, b). Schuppen schwärzlichbraun, am Rande mehr oder weniger behaart. Langtriebe hin und hergebogen (Fig. 4I 8 a). Die 
einjährigen Triebe kahl oder schwach behaart, dunkelbraun oder graubraun. Die mehrjährigen Triebe zeichnen sich durch kurze hellere Risse in der Epidermis aus (Fig. 4I 8 d), die sich bei der Varietät Ulmus campestris var. suberosa in dicke, lange Korkleisten verwandeln (Fig. 4I8, b, c). Mark sehr eng.

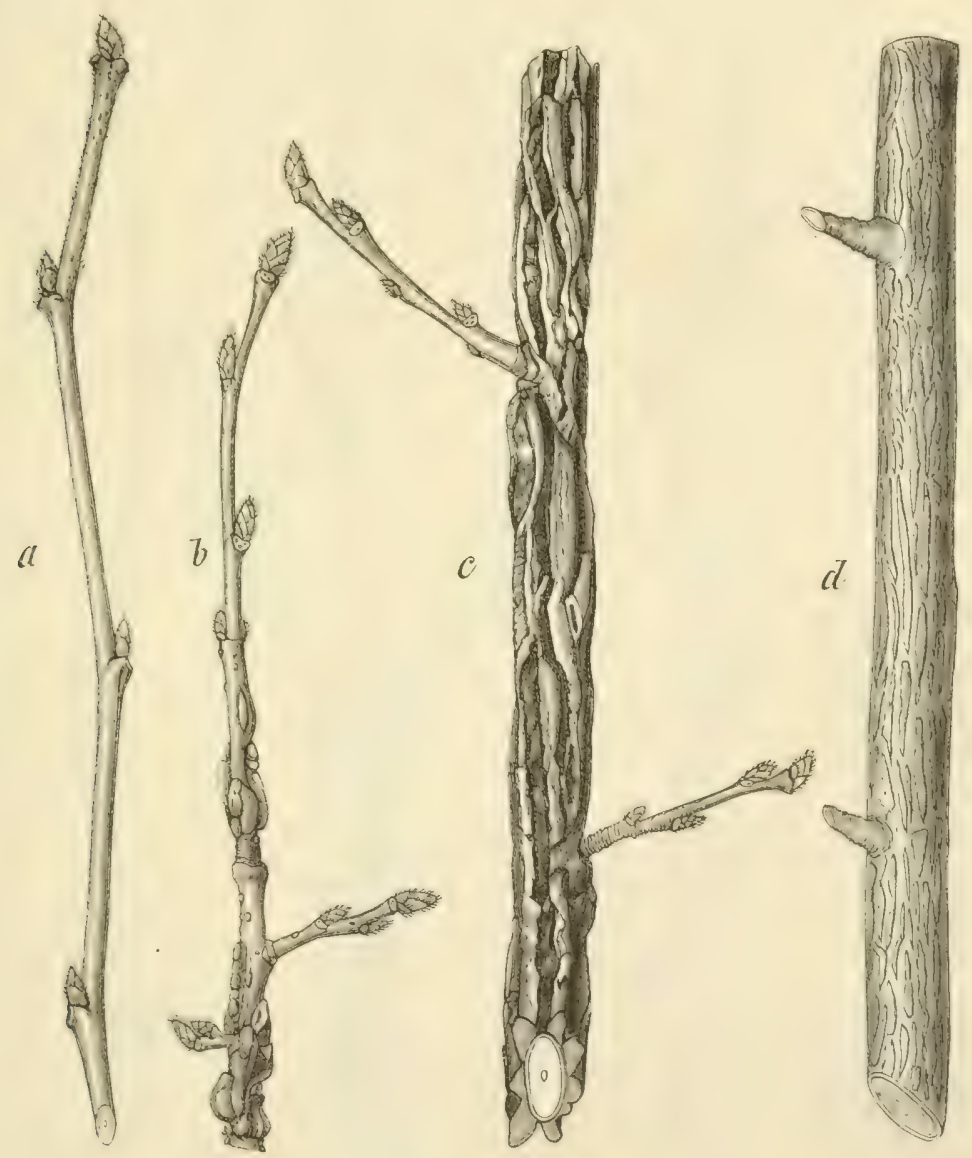

Fig. 4 I 8 .

a, d Ulmus campestris, b, c Ulmus campestris var. suberosa.

Ulmus montana (Fig. 4I9). Knospen ähnlich wie bei Ulmus campestris, doch zumeist grösser und stärker behaart, graubraun oder dunkel. Einjährige Triebe behaart, braun oder grau, fühlen sich etwas rauh an, mehrjährige Zweige mit Lenticellen, aber nicht mit jenen zahlreichen feinen Längsstrichen versehen wie bei Ulmus campestris. Mark ziemlich eng, rundlich.

Ulmus effusa (Fig. 420). Knospen langgestreckt, länger und mehr zugespitzt als bei den anderen Arten. Die Endknospen sind den 
Knospen von Carpinus ailnnlich. Die Scitenknospen etwas kürzer. Sic stehen schicf über den mässig grossen Blattnarben (Fig. 420a), dic wic bei den anderen Ulmenarten nur von der einen Seite der Zweige $7 u$ sehen sind. Knospenschuppen kahl, hellbraun und dunkel gerändert.

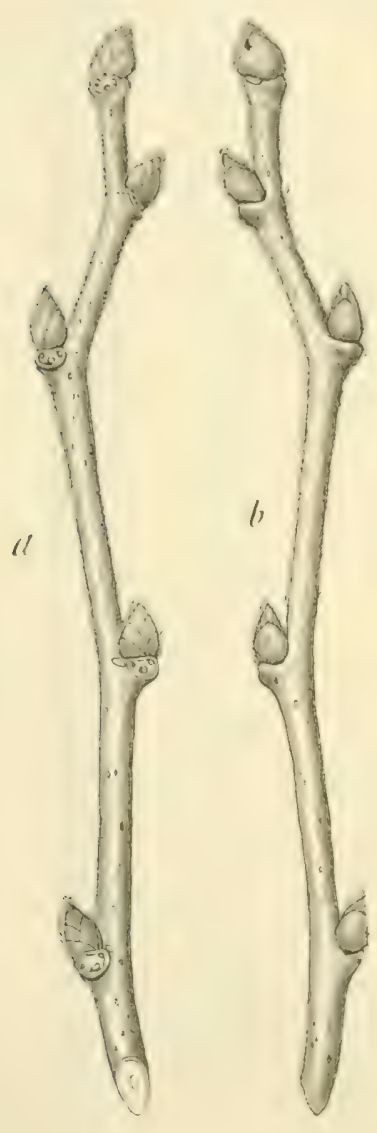

Fig. 419.

Ulmus montana.
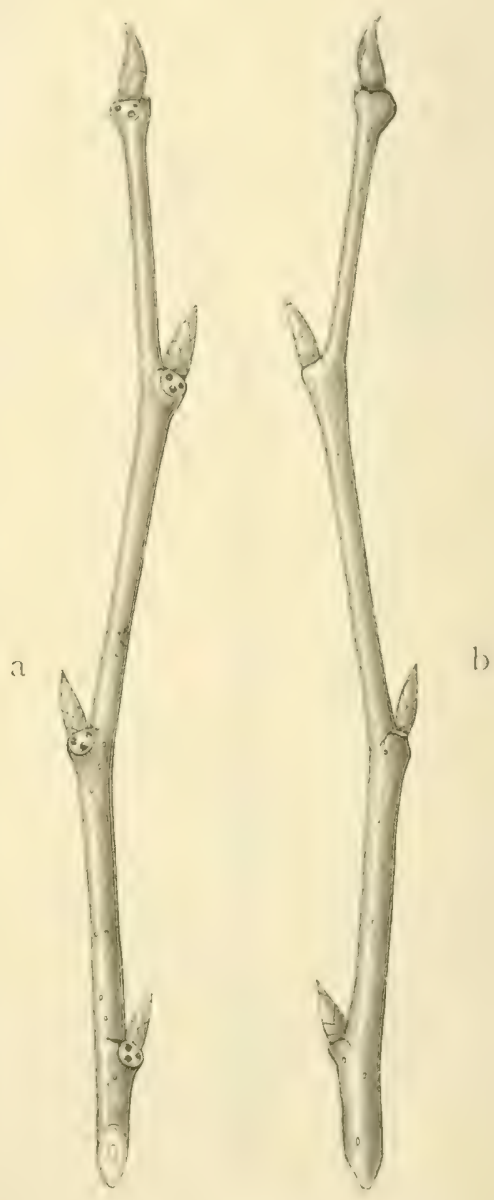

Fig: 420 .

Ulmus effusa.

Zweige dünner als bei den anderen Ulmen, nur an der Spitze oder garnicht behaart. An älteren Zweigen bleibt die Rinde glatt, etwas glänzend, ohne feine Längsrisse. Mark ziemlich eng, rundlich.

Nan vergleiche wegen der manchmal annähernd abwechselnd stehenden Seitenzweige noch Betula pubescens und Betula verrucosa. 


\section{Tabelle III.}

Knospen gegenständig.

1. Die Knospen sind in der Blattnarbe verborgen.

Philadelphus coronarius (Fis. 42I). Die helle Blattnarbe ist dreicckig,

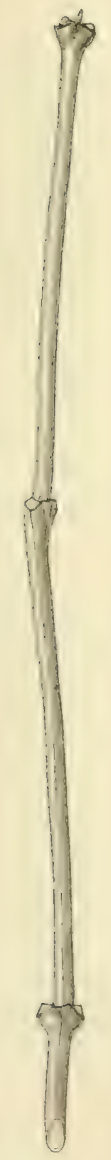

Fig. 421 .

Philadelphus coronarius.

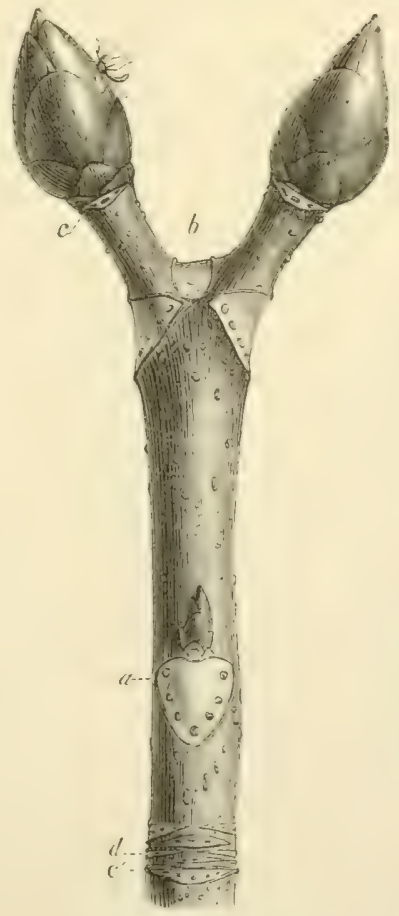

Fig. 422.

Aesculus Hippocastanum. (DN.)

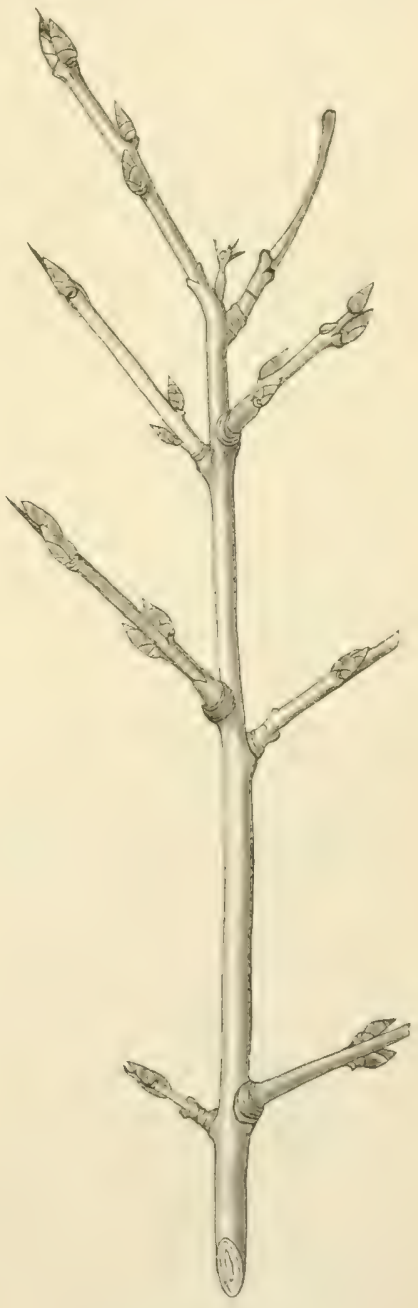

Fig. 423 .

Rhamnus cathartica.

etwas vorspringend, in der Mitte zeigt sie eine kleine. Vorwölbung, unter welcher die Knospe verborgen ist. Die Zweige sind schlank, gerade, entweder sehr lang, pfeifenrohrartig oder kürzer, dann schr dünn. In der Jugend sind die Zweige lebhaft braun gefärbt, 
die P'eridermschichten können sich bandförmigs ablösen, die Rinde wird grau, oder hellbräunlich. Mark weit.

2. Ziveige auffallend dick, Endknospe sehr gross.

Aoseulus Hippocastanum (Fig. 422). Die Seitenknospen sind entweder klein oder annähernd so gross wie die Endknospe. Beide braun, klebrig, harzig glänzend (besonders im Frühjahr). Blattnarbe schr gross. Zweige gerade, hellgrau oder graubraun, glatt, mit feinen aber deutlichen Lenticellen. Mark sehr weit.

\section{Die Zweige sind zumeist dornspitzig.}

Rhamnus eathartica (Fig. 423). Knospen ciförmig, zugespitzt, stehen sich oft schief gegenüber. Knospenschuppen dunkelbraun, kahl oder nux am Rande schwach behaart. Zweige gerade oder schwach gebogen, unbehaart, glatt, hellgrau gefärbt, ältere braun. Ausser den dornspitzigen Kurztrieben können noch unbedornte Kurztriebe vorhanden sein, die stark geringelt mit einer Endknospe abschliessen. Mark rund, weit.

4. Zàteige kletternd, dünn, mit stehenbleibenden, langen, rankenden Blattstielen.

Clematis Vitalba (Fig. 294). Knospen sehr klein, dicht filzig behaart, stehen in der Achsel der senkrecht abstehenden Blattstiele. Zweige dünn, sechskantig gefurcht, beinahe kahl. Internodien gerade oder unregelmässig gebogen, dem Klettern auf anderen Sträuchern und kleineren Bäumen entsprechend. Mark hohl, mässig weit.

5. Knospen won unausgebildeten Blättern, nicht von eigentlichen Schuppen umgeben.

Viburnum Lantana (Fig. 424). Knospen gross. Laubknospen langgestreckt, von den cingefalteten Blättern gebildet (Fig. 424a). Blütenknospen gestielt, diskusförmig (Fig. 424b Endknospe), wie die Laubknospen von zwei Blättern, ausserdem noch von kurzen Schuppen umschlossen. Die Blütenknospen können natürlich auch fehlen. Knospen hellgelblich grau, mehlig bestäubt. Zweige schlank, Seitenzweige abstehend, an der Spitze ähnlich wie die Knospen von gröberen abreibbaren Haaren bedeckt. Rinde sonst hellbraun. Mark ziemlich weit.

6. End- und Seitenknospen so von zwei Schuppen dicht umschlossen, dass scheinbar nur eine Knospenschuppe vorhanden ist.

A. Knospenschuppin unbehacurl, glänzenul.

a. Knospen gestielt.

Viburnum Opulus (Figs. 425 \%. Knosjen dem Stengel angsedrückt, auf der Aussenseite kugelig gewölbt, zugespitzt. Schuppen grünlich- oder rötlichbraun. Endknospe meist nicht vorhanden. Seitenzweige lang, nicht abstehend, mehr oder weniger kantig. Junge Triebe braun, ältere grau. Mark weit, eckig.

b. Knospen sitzend.

Staphylea pinnata. Knospen eikegelförmig, von aussen nach innen zusammengedrückt, beiderseits gekielt. Schuppen grün oder braun. Am 
Ende der Zweige stehen immer je zwei Knospen beisammen. Kurztriebe dünn, gerade, die Langtriebe stärker, kahl, im ersten Jahre grünlichbraun, später dunkelbraun, feinrissig. Mark relatir weit, rund.

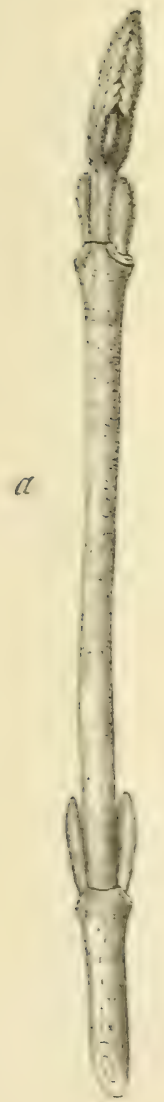

Fig. 424 .

Viburnum Lantana.

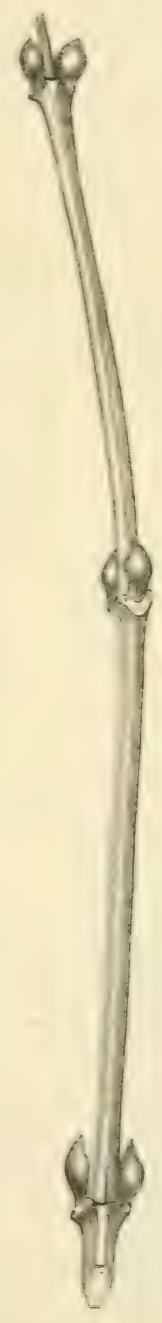

Fig. 425 ,

Viburnum Opulus.

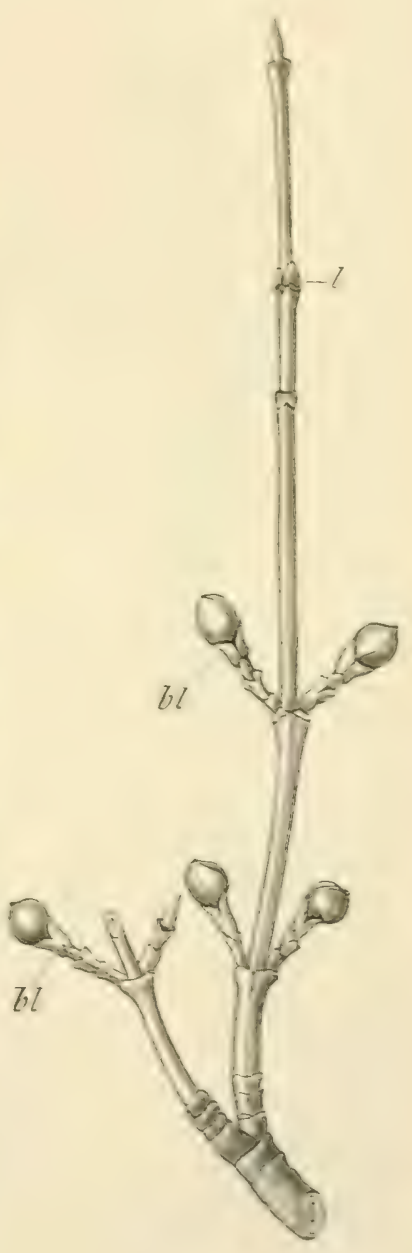

Fig. 420 .

Cornus mas.

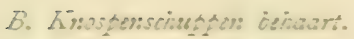

Cornus mas (Fig. 426). Laubknospen (Fig. +26 b) langgestreckt, sehr chmal, den Zweigen anliegend ader schief abstehend. Blutunknospen (Fig. +26 bl) kugelig, gestielt, grösser, mit mehr als ztrei Schuppen versehen. Schuppen grau oder gelblichgrau. Zweige gerade, dünn, Scitenzweige abstehend, vierhantig. Diesellen simd srün getäb: ade: an der Sonnenseite violettgrün, aber nicht rot. Mark eng. 
Cornus sanguinon. Laubknospen und Verzweigung wic bei Cornus mas. Die Zweige sind jedoch blutrot gefirbt, im Alter grau.

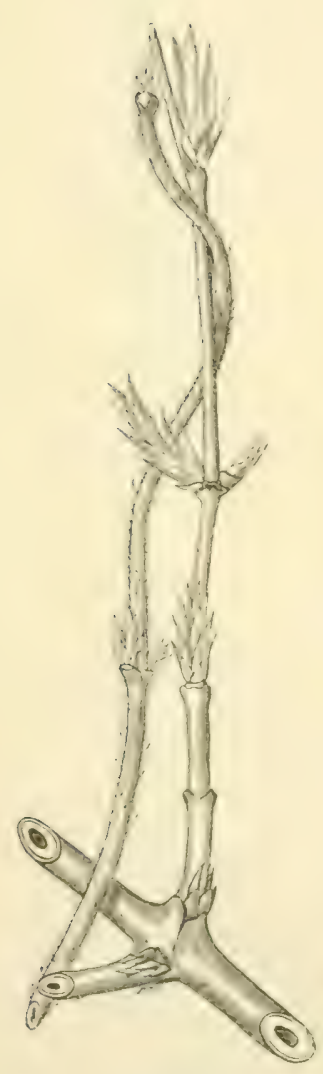

Fig. 427 .

Lonicera Caprifolium.

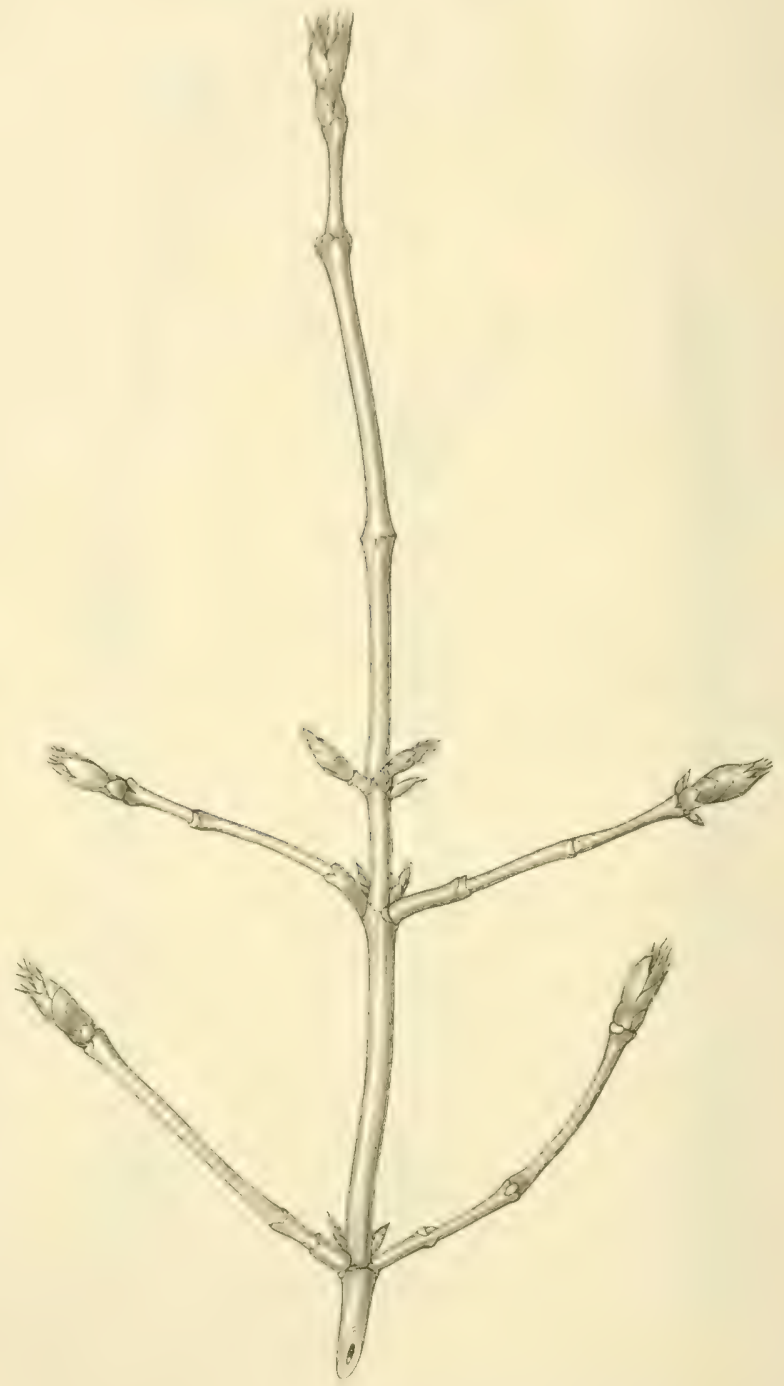

Fig. 428 .

Lonicera Xylosteum.

7. Seitenknospen spindelig, fast senkrecht abstehend.

A. Windende oder kletternde Sträucher.

Lonicera Caprifolium (Fig. 427). Knospen von den Schuppen lose umhüllt, am Ende der Zweige meist paarweis. Schuppen gekielt, bräunlich oder grünlich, trockenhäutig. Äste stark gebogen, glänzend, kahl 
oder wenig behaart, hellbraun, in der Nähe der jüngeren Knospen oft bläulich bereift. Nark hohl.

Lonicera Periclymenum. Habitus wie bei L. Caprifolium, Knospen meist etwas grösser, sehr locker beschuppt. Zweige mit Haaren mehr oder weniger besetzt, oder kahl und nur an der Spitze behaart. Sie sind hellgrau oder hellbräunlich oder violett. Mark hohl.

B. Aufrecht warchsende, nicht schlingende Sträzcher.

Lonicera Xylosteum (Fig. 428). Knospen locker beschuppt, Schuppen dicht filzig behaart, hellbräunlich. Endknospe einzeln. Zweige ziemlich dünn, hellgrau, unbehaart, die oberen Peridermschichten lösen sich in Fasern ab. Nark innen hohl, am Rande braun.

Lonicera nigra. Knospen kleiner, zugespitzt, kahl. Habitus sonst wie bei Lon. Xylosteum. Die einjährigen Triebe etwas glänzend, graubraun. Das Mark nicht hohl, weiss.

8. An den Seitenknospen nur wenige Schuppen (2 oder 3) sichtbar. d. Seitenknospen abstichend, kuyrelig.

Fraxinus excelsior (Fig. 429). Die Endknospen wesentlich grösser als die Seitenknospen. Die äusseren Schuppen der Endknospen sind derb, gekielt, wie die Seitenknospen in charakteristischer Weise schwarz oder schwarzbraun gefärbt. Die Seitenknospen, stehen auf vorspringendem Blattpolster über einer grossen Blattnarbe. Zweige derb, glatt,

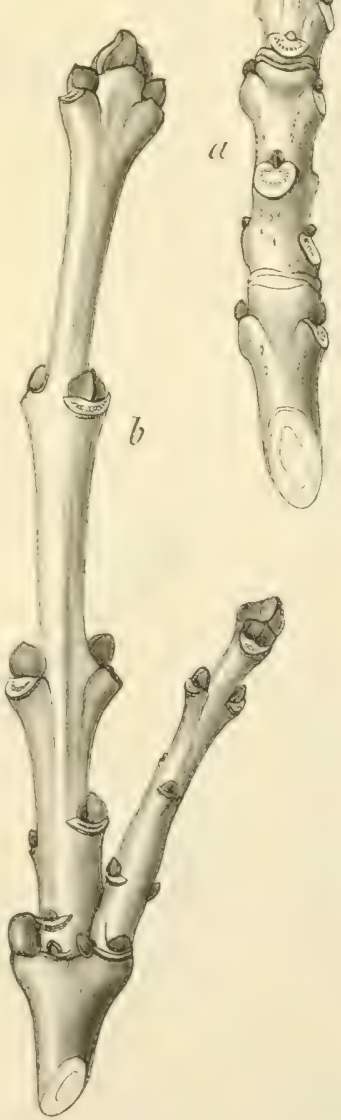

Fig. 429 .

Fraxinus excelsior.

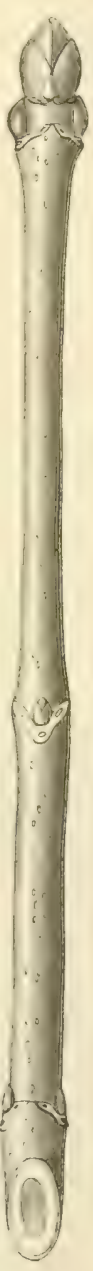

Fig. 430 . Acer platanoides. durch die vorspringenden Blattpolster uneben, besonders bei den kürzeren Seitentrieben (Fig. 429a), grünlichgrau gefärbt. Nark weit, kreisförmig oder elliptisch.

Fraxinus Ornus. Habitus der Knospen und Zweige wie bei Frax. excelsior. Die Knospen sind jedoch feinfilzig behaart, hell bräunlichgrau. 


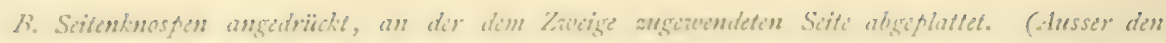

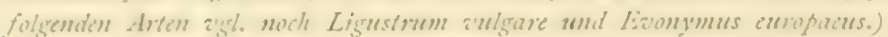

a. Zweige braun, rot oder grïnlichbraun.

Acer platanoides (Fig. +30). Knospen an der Spitze der Tricbe gehäuft, die Endknospe grösser. Knospenschuppen derb, gekielt, vollständig rotbraun oder an der Basis etwas gelbgrün. Blattnarben wenig hoch,

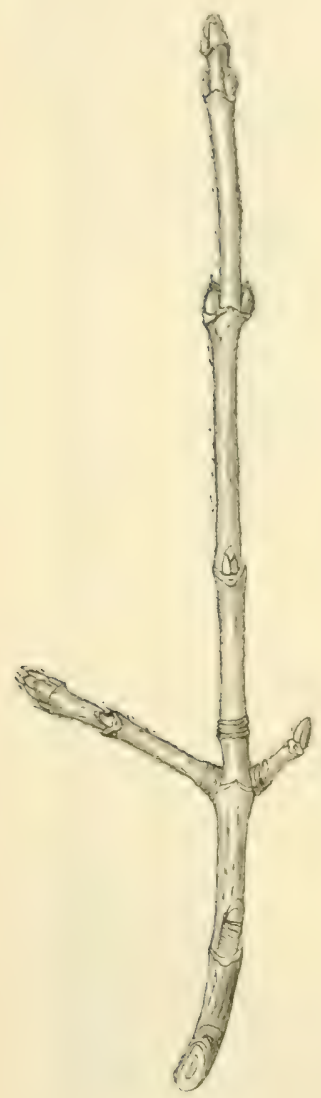

Fig. $43 \mathrm{I}$.

Acer campestre.

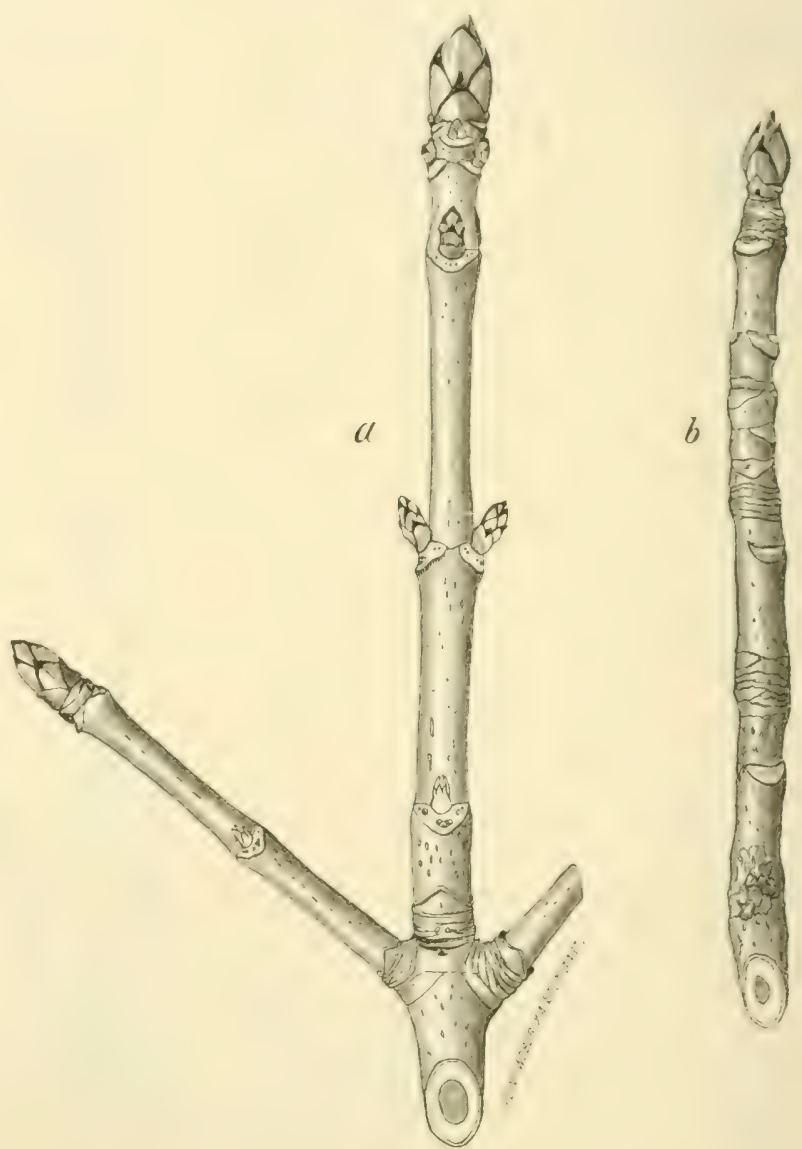

Fig. 432 .

Acer P'seudoplatanus.

doch breit, so dass sie die Hälfte des Stengels umfassen. Blattpolster nur am Ende der Triebe etwas stärker vorgewölbt. Langtriebe gerade, glatt, unbehaart, ziemlich dick, Seitentriebe dünn. Die Zweige im ersten Jahre braun oder rötlichgelb, später hellbraun, mit feinen Längsrissen. Mark weit, rund.

Acer dasycarpum. Endknospen spitz, nur von zwei kleinen Seitenknospen umgeben, nicht grösser als die Seitenknospen. Knospen sehr 
schmal, kurz gestielt, rot glänzend. An den stärkeren Trieben werden die Seitenknospen häufig noch von zwei sehr kleinen Knospen flankiert. Blattnarbe nicht so breit wie bei der vorhergehenden Art, nicht zusammenstossend. Zweige gerade, in der Jugend hellrotbraun, ältere braun, mit feiner Strichelung. Mark rund, ziemlich weit.

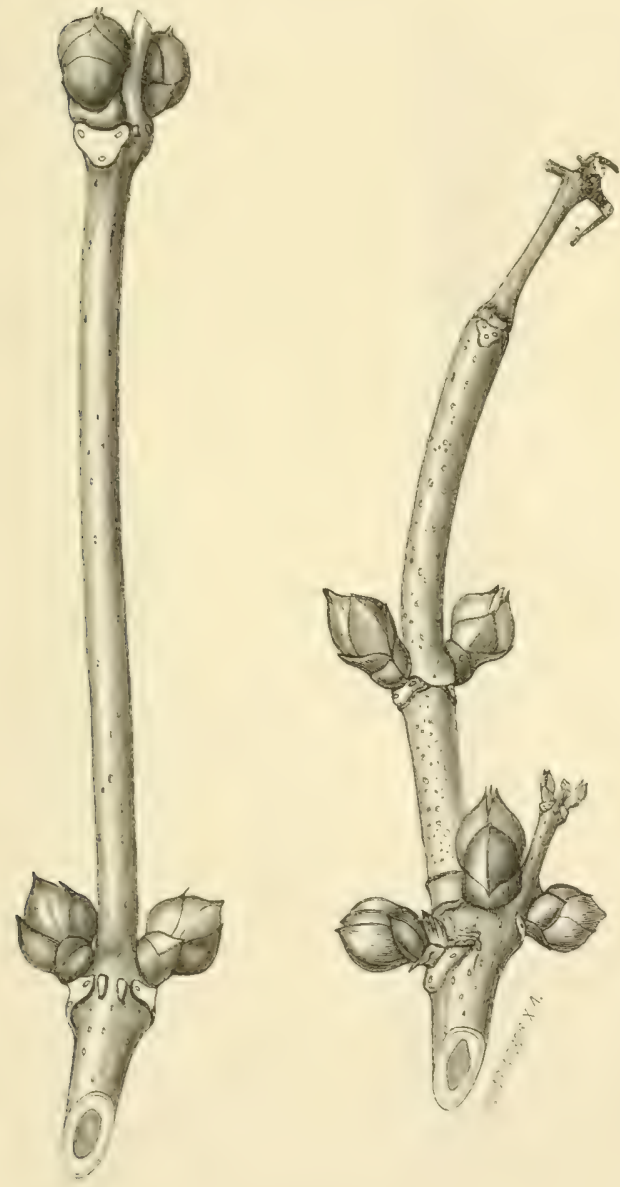

Fig. 433 .

Sambucus racemosa.

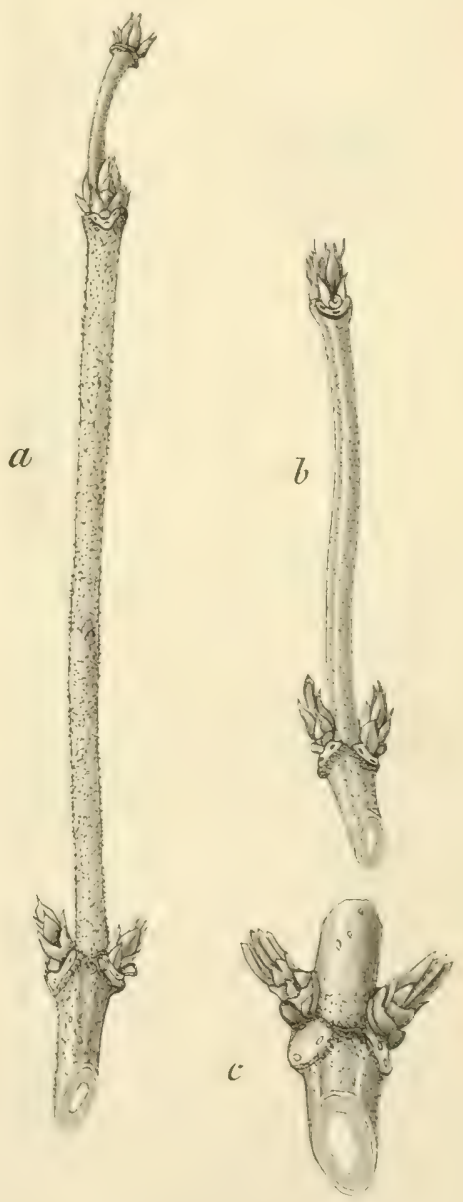

Fig. 434 .

Sambucus nigra.

Acer campestre (Fig. 43I). Endknospen nicht wesentlich grösser als die Seitenknospen. Knospenschuppen grünlichbraun, mit weisslicher, feiner Behaarung, die an der Basis der Schuppen eventuell fehlt. Zweige schlank, an der Spitze mehlig bestäubt, d. h. fein behaart, sonst durch helle feine Risse in den äusseren Peridermschichten ausgezeichnet, dic sich bei manchen Individuen in dicke Korkleisten verwandeln. Mark rund, ziemlich weit. 
b. Zweige glinzend grün, teilweise weiss hereift.

Nogundo aceroides. Endknospen nicht wesentlich grösser als die Seitenknospen. Knospen weiss behart. Blattnarben zusammenstossend. Blattpolster nicht hervortretend. Zweige lang, gerade, glatt. Mark ziemlich weit.

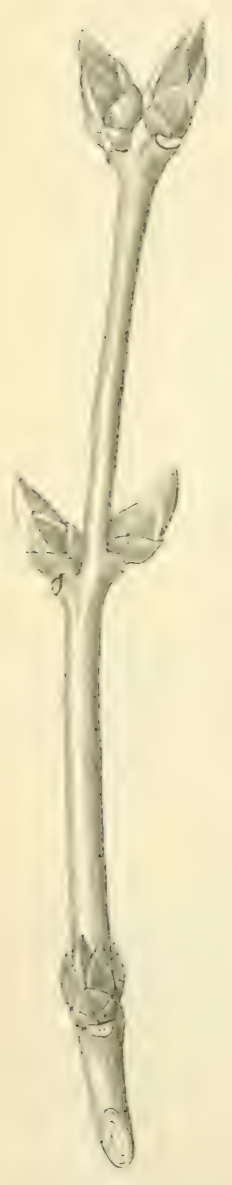

Fig. 435 . Syringa vulgaris.

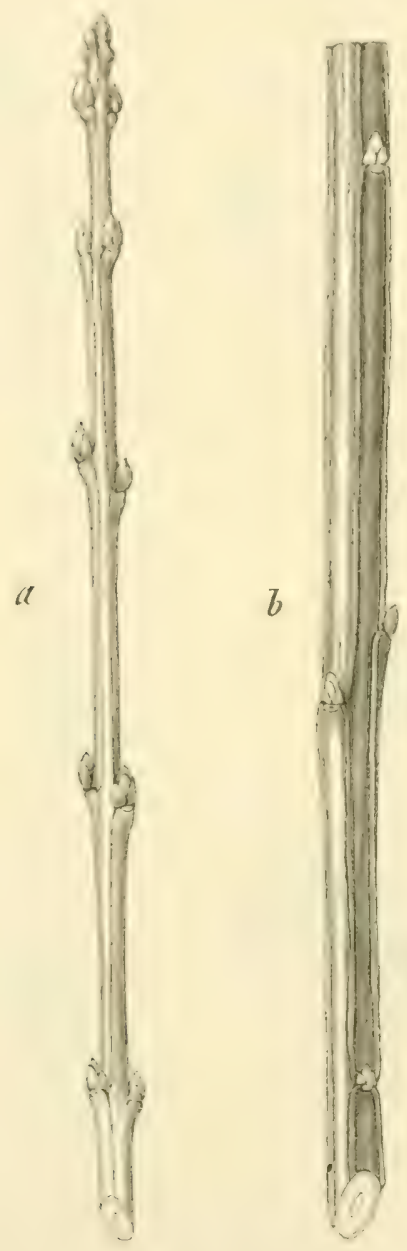

Fig. 436 . Evonymus europaeus.

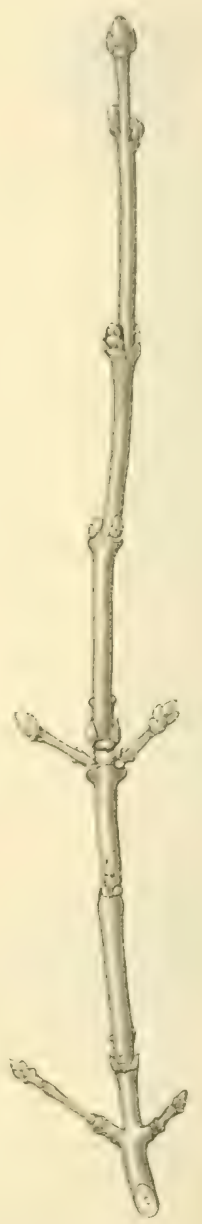

Fig. 437 .

Ligustrum vulgare.

9. An den Seitenknospen mehr als 3 Schuppen sichtbar.

A. Knospen and Blattnarbe gross.

Acer Pseudoplatanus (Fig. 432). Endknospe grösser als die Seitenknospen, von zwei kleineren Knospen umgeben, wird eventuell durch den Blütenstand ersetzt, Seitenknospen abstehend, eiförmig zugespitzt. Schuppen gelblichgrün, mit schwarzem Rand und schwarzer Spitze. 
Blattpolster nıcht vorspringend. Zweige ziemlich dick, braun, im Alter grau.

Sambueus racemosa (Fiss. 433). Knospen kugelig, gesticlt oder verkehrt eiförmig, rot bis violett gefärbt. Die zahlreichen Schuppen umgeben die Knospe ziemlich locker. Öfter stehen noch $\mathrm{I}-2$ Knospen unter der Hauptknospe. Zweige bogig gekrümmt, grau, mit deutlichen Lenticellen versehen. Mark bra un gefärbt.

B. Knospen weniger gross, von den Schutppen sehr lose umhiullt; Blattnarbe ziemlich gross.

Sambucus nigra (Fig. 434). Die Knospen sind rund oder länglich. Die Schuppen kurz und abstehend, trockenhäutig, braun oder rötlich gefärbt. Zweige gebogen an der Spitze etwas kantig, die Stockausschläge sehr lang und gerade. Die Zweige sind hellgrau, mit deutlichen Lenticellen und breitem, weissem Mark.

C. Kirospen an der Spitze der Triebe gross, an der Basis klein. Blattnarbe klein.

Syringa vulgaris (Fig. 435), Knospen am Ende der Triebe immer paarweise, eiförmig, Seitenknospen abstehend. Schuppen gekielt, grün, mit rotem oder braunem Rande, kahl. Zweige nur Langtriebe, hellgrau oder graubraun. Mark rundlich, ziemlich weit.

D. Knospen and Blattnarbe klein.

Evonymus europaeus (Fig. 436). Knospen entweder dem Stengel anliegend, dann auf der Stengelseite abgeplattet (Fig. 436b) oder mehr abstehend (Fig. 436a), dann von aussen nach innen zu etwas zusammengedrückt. Schuppen grün, mit rotem Rand oder roter Spitze. Zweige schlank, grün oder violettgrün gefärbt, teilweise vierkantig, mit vier herablaufenden Korkleisten (Fig. 436 b). Mark rundlich-viereckig. Ligustrum vulgare (Fig. 437). Knospen sehr klein, I-3 mm lang, zugespitzt, die Endknospe etwas grösser. Schuppen rund, schwärzlichbraun oder grünlich gefärbt. Zweige dünn, schlank, grau gefärbt, ohne Behaarung. Die grünen lanzettlichen Blätter fallen erst bei strenger Kälte ab. Mark rund, eng. 


\section{\$115. Bestimmung der wichtigsten Koimpflanzen.1)}

\section{Tabelle I. Nadelhölzer.}

Cotyledonen und Blätter nadelförmig, werden bei der Keimung durch Streckung des Hypocotyls über die Erde gehoben. Zwei bis mehrere Cotyledonen.

\section{Einjährige Keimpflanzen.}

Cotyledonen immer vorhanden. An den Sprossaxen sind keine Reste der Knospenschuppen zu beobachten, welche sich bei älteren Pflanzen an der Übergangsstelle zu einem neuen Jahrestriebe vorfinden. Die Nadeln stehen immer einzeln.

A. Cotyledonin flach.

Abies pectinata (Fig. 438 A). Die Tanne besitzt 4-8, (meist 5-6) sternförmig angeordnete Cotyledonen, welche auf der Oberseite (nicht wie die übrigen Nadeln auf der Unterseite) zwei weissliche Streifen zeigen. Im ersten Jahre bildet sich noch ein zweiter Quirl von Nadeln und die Knospe für den nächstjährigen Trieb, aber keine Sprossaxe.

(Abies Nordmanniana wie A. pectinata, die Keimpflanze der ersteren Art meist etwas grösser.)

Tsuga canadensis. Vier, seltener drei kürzere Cotyledonen.

Taxus sowie die Cupressaceen (Juniperus, Chamaecyparis, Thuja) besitzen zwei, Cryptomeria japonica drei flache Cotyledonen.

B. Cotyledonen rundlich oder kantig.

a. Cotyledonen und Plumulablätter gesägt.

Picea excelsa (Fig. 439 A). Die Fichte besitzt 6-Io kurze, steife, etwas nach aufwärts gebogene Cotyledonen. Dieselben sind dreikantig, an der oberen Kante fein gesägt. Die folgenden Blätter sind an beiden Seitenkanten gesägt. Hypocotyl grünlich oder grünlichbraun. Der Trieb des ersten Jahres ist ein bis wenige $\mathrm{cm}$ lang. Seitenknospen können schon im ersten Jahre angelegt werden.

Die übrigen Piceaarten ähnlich wie Picea excelsa, doch zeigt Picea sitchensis glatte, ungezähnte Cotyledonen und Nadeln.

1) Eine ausführlichere Darstellung der Keimpflanzen bietet K. v. Tubeuf, Samen, Früchte und Keimlinge, Berlin r89r. 
b. Cotyledonen und Plumulablätter nicht gezähnt.

Larix europaea (Fig. 440 A). Mit 5-7, meist 6, ziemlich kurzen Cotyledonen. Dieselben sind ebenso wie die jungen Blätter blaugrün und etwas fleischig. Die jungen Nadeln sind auf der Unterseite mit zwei weisslichen Streifen versehen. Das Hypocotyl meist auffallend rot ge-

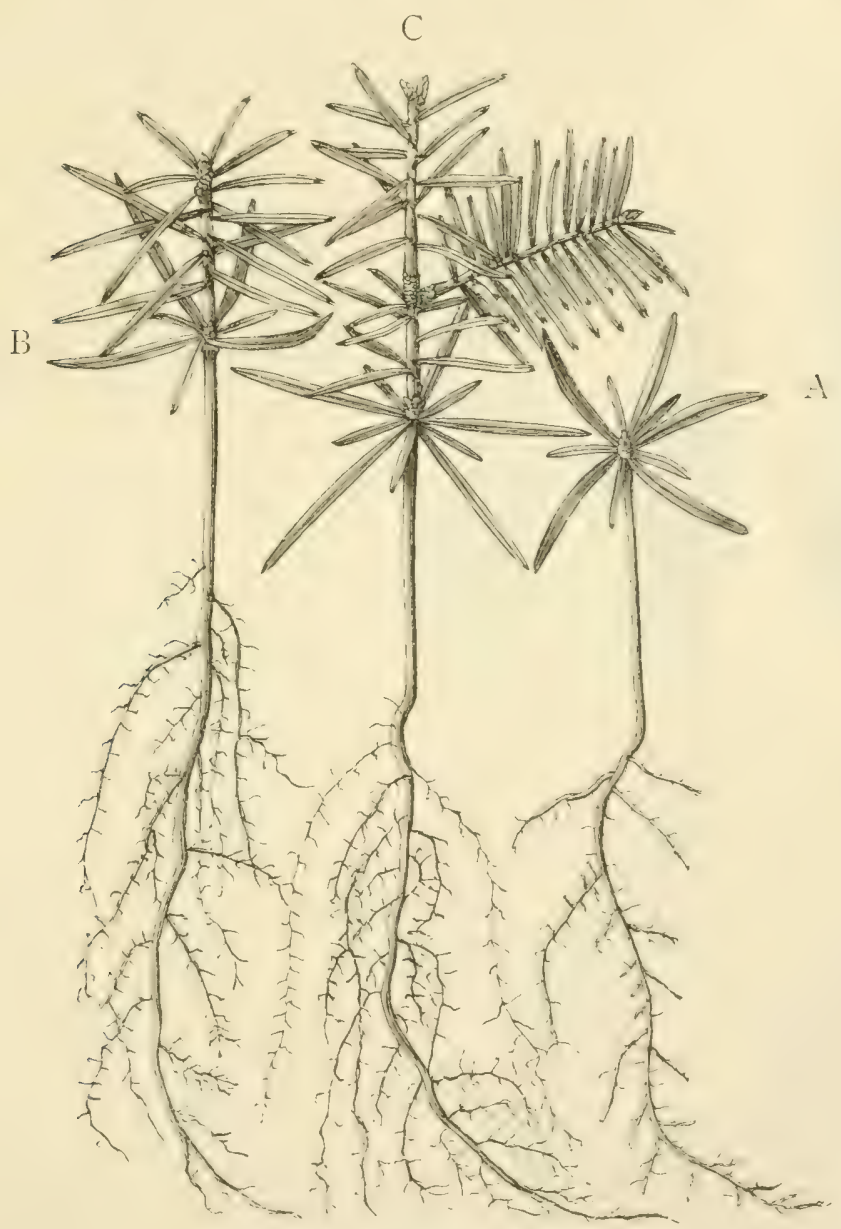

Fig. 438.

Abies pectinata. A einjährig, B zweijährig, C dreijährig. ${ }^{3 / 4}$ natürl. Grösse.

färbt. Länge des erstjährigen Triebes sehr verschieden, auf schlechtem Boden entwickelt sich nur ein langgestrecktes Nadelbüschel, unter günstigeren Verhältnissen ein Trieb von $6 \mathrm{~cm}$ Länge. Die im ersten Jahre gebildeten Nadeln bleiben den Winter über am Stämmchen, in ihren Achseln sitzen häufig junge Knospen.

Pseudotsuga Douglasii. Cotyledonen 5-7, dreikantig, I $5-20 \mathrm{~mm}$ lang, zugespitzt. Die erstjährigen Nadeln sind mit einer feinen Spitze vẻr- 
sehen, oberseits blaugrün, unterseits mit zwei weissen Streifen versehen. Hauptrieb des ersten Jahres $21 / 2-4 \mathrm{~cm}$ lang. An sehr kräftigen Exemplaren kann sich auch ein Seitentrieb entwickeln.

c. Cotyledonen glatt, die jungen Nadeln gesägt. Hypocotyl gellblichbraun oder schwach rötlich.

Pinus Laricio. In der Regel 5-8 nach oben sedrehte Cotyledonen, dic

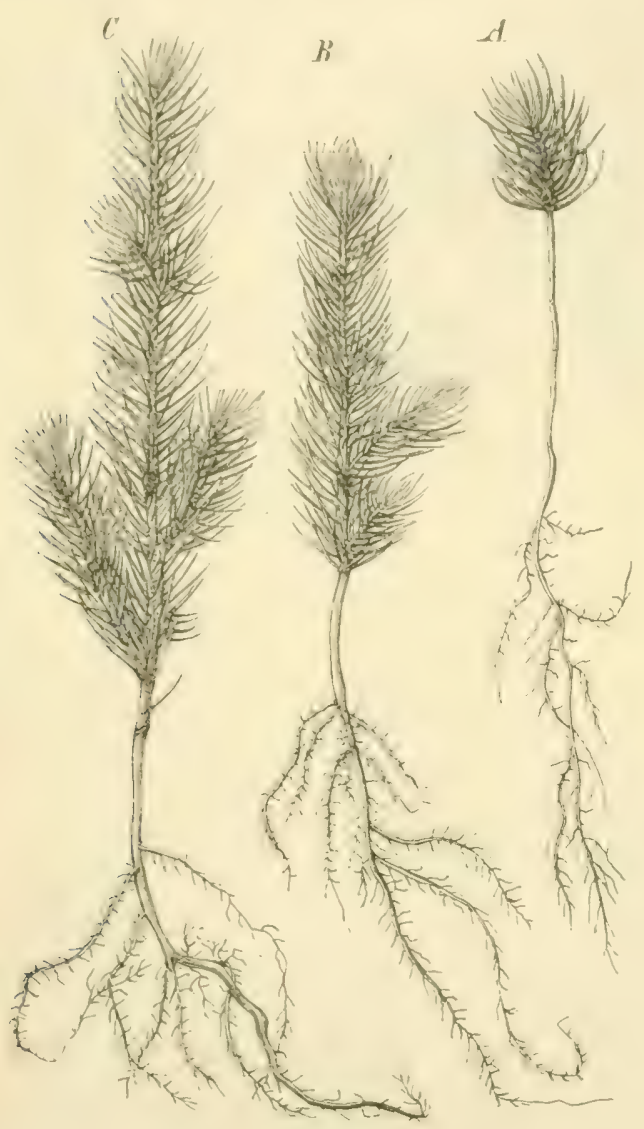

Fig. 439.

Picea excelsa, A einjährig, B zweijährig, C dreijährig. $2 / 3$ natürl. Grösse. etwas länger sind als bei der gemeinen Kiefer, circa $35 \mathrm{~mm}$ lang. Cotyledonen und Nadeln blaugrün. Hypocotyl häufig rötlich, mit bläulichweissem Überzug. Kurztriebe mit Doppelnadeln können schon am Ende des ersten Jahres auftreten. Pfahlwurzel nicht so stark als bei der remeinen Kiefer.

Pinus Strobus hat $7-9$, seltener bis I I reingrüne Cotyledonen, die auf der Innenkante häufig einige Sägezähne aufweisen. Die jungen einfachen Nadeln sind flach, auf der Oberseite mit weisslichen Längsstreifen, das Hypocotyl häufig etwas rötlich.

Pinus silvestris (Fig. Hf). Meist $6(4-7)$ Cotyledonen. Cotyledonen und Nadeln reingrün. An wasserschossartigen Ausschlägen, auf Torfboden, sowie in hesonders heissen sommern können auch schon im ersten Jahre Doppelnadeln gebildet werden. Die Regel ist, dass sich im ersten Jahre nur einfache Nadeln an dem ein bis mehrere Centimeter langen Sprosse bilden. Hypocotyl meist grünlichbraun.

Pinus cembra. Cotyledonen auf der Innenseite mit weissen Längsstreifen, lang, zugespitzt. Cotyledonen und erste Blätter nicht blau bereift.

2. Zwei- und mehrjährige Pflanzen.

Die einzelnen Jahrestriebe sind durch die Reste oder Narben der 
Knospenschuppen getrennt. Der jüngste Trieb besitzt zumeist eine hellere Rinde.

A. Nadeln glatt, an Rande nicht gesägt.

Abies pectinata (Fig. 438). Die Nadeln wie bei der erwachsenen Pflanze. Im zweiten Jahre entwickelt sich ein circa $2-4 \mathrm{~cm}$ langer Haupttrieb, welcher in der Regel mit einer Endknospe und einer daneben stehenden Seitenknospe abschliesst (Fig. 438 B). Im dritten Jahre entwickelt sich ausser dem Haupttrieb meist nur ein Seitentrieb (Fig. 438 C), während im vierten Jahre sehr häufig schon zwei neue Seitentriebe auf derselber? Höhe entspringen (Bildung des ersten Quirls).

Larix europaea (Fig. 440 B). Die Nadeln auch im zweiten Jahre meist einzeln, weich, etwas fleischig, ziemlich flach, blaugrün. Auf der Unterseite zwei weissliche Streifen. In den Achseln der einzeln stehenden Blätter im zweiten Jahre zahlreiche neue Knospen, die auch zu büscheligen oder relativ kurzen Seitentrieben auswachsen können. Vielfach wachsen auch die im ersten Jahre angelegten Knospen aus (Fig. 440 B). Im dritten Jahre treten deutliche Nadelbüschel auf, Quirlbildung unterbleibt. Wachstum in
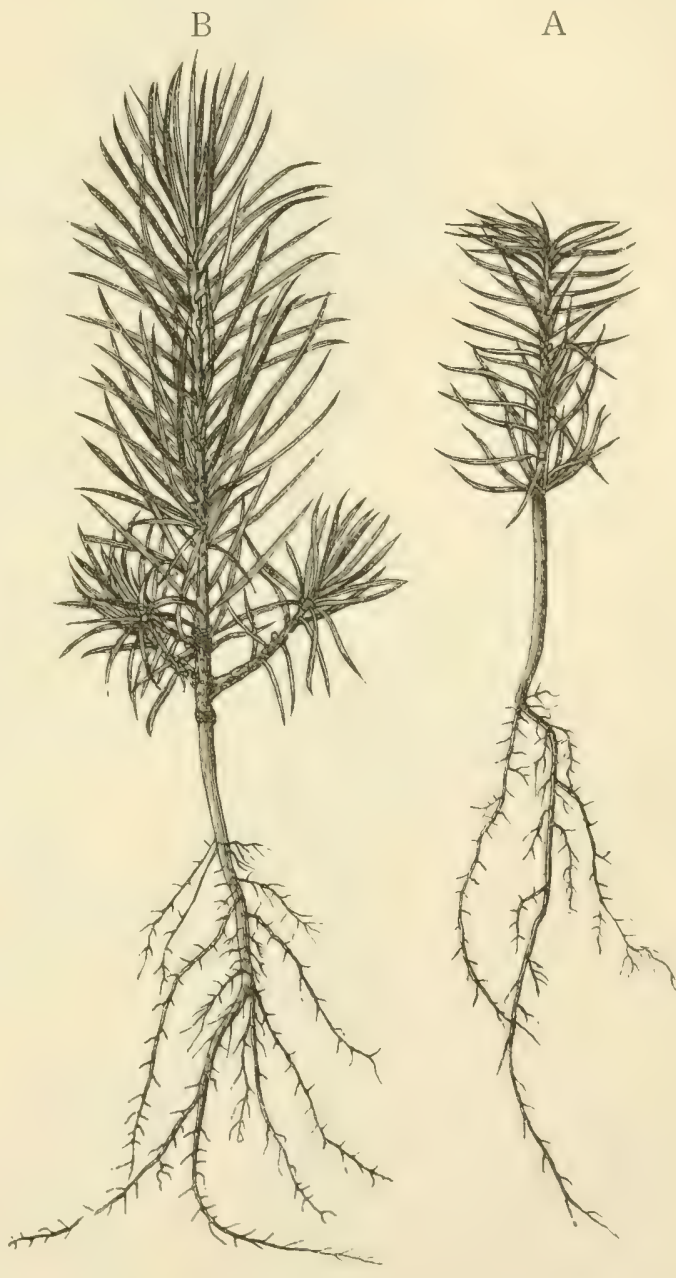

Fig. 440.

Larix europaea. A einjährig, B zweijährig. ${ }^{3} / 4$ natïrl. Grösse. den ersten Jahren sehr rasch.

Pseudotsuga Douglasii. Nadeln alle einfach, mit feiner weicher Spitze versehen, an der Basis verschmälert, niemals büschelig. Unterseits mit zwei weisslichen Streifen, blaugrün, oberseits wenig blaugrün. Der Haupttrieb erreicht im zweiten Jahre eine Länge von $5-8 \mathrm{~cm}$. 
E. . latibls firn gisuist.

a. Nadeln stehen einzeln, sind im Querschnitt vierkantig oder rundlich.

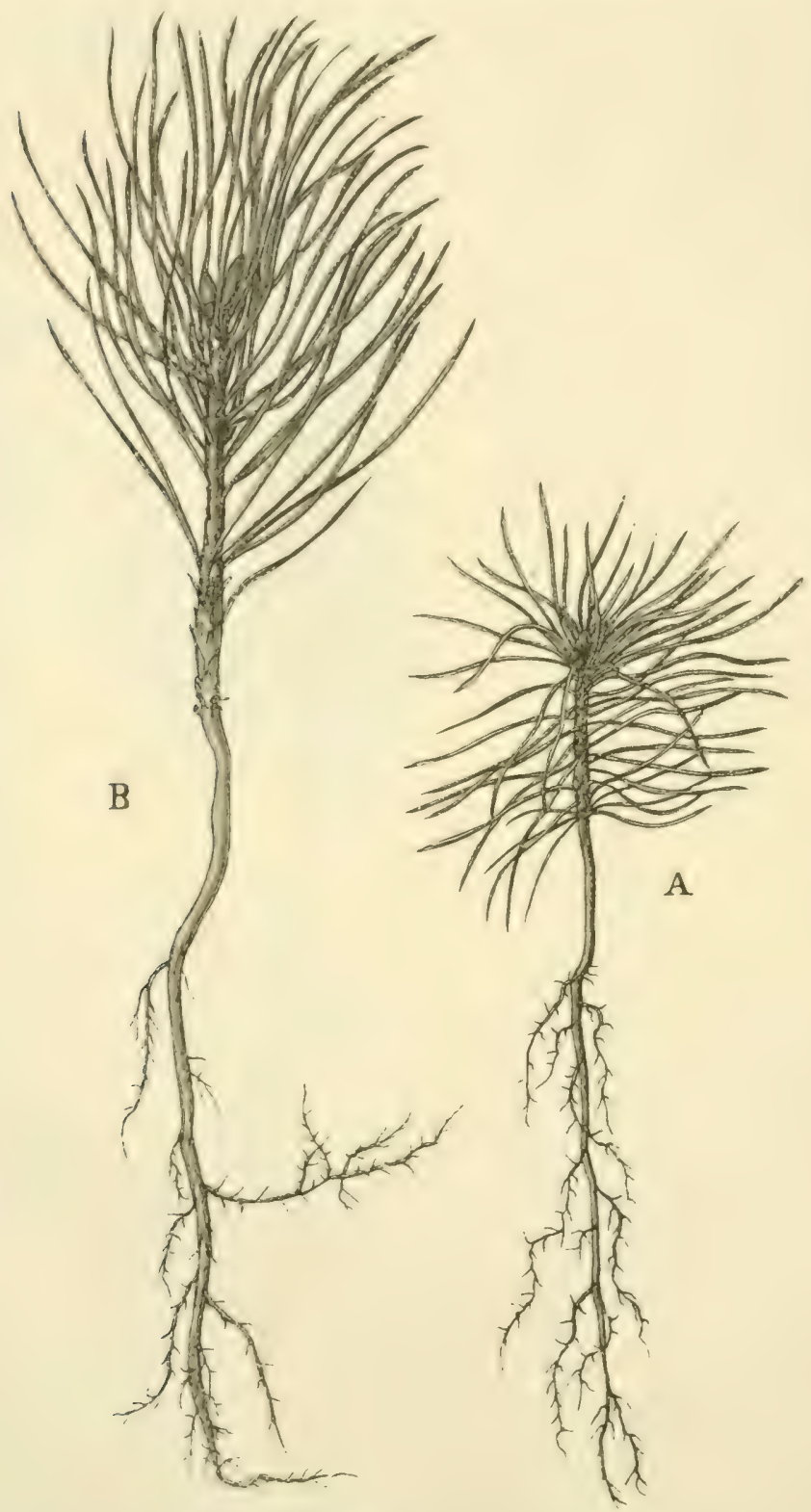

Fig. 441.

Pinus silvestris. A einjährig, B zweijährig. $2 / 3$ natürl. Grösse.

Picea excelsa (Fig. 439). Nadeln ziemlich starr, spitzig. Im zweiten Jahre sind dieselben immer gezähnt, im dritten Jahre werden auch 
ungezähnte Nadeln, wie an der älteren Pflanze gebildet. Der Trieb des zweiten Jahres ist auf genügend gutem Boden $4-7 \mathrm{~cm}$ lang. Seitenäste

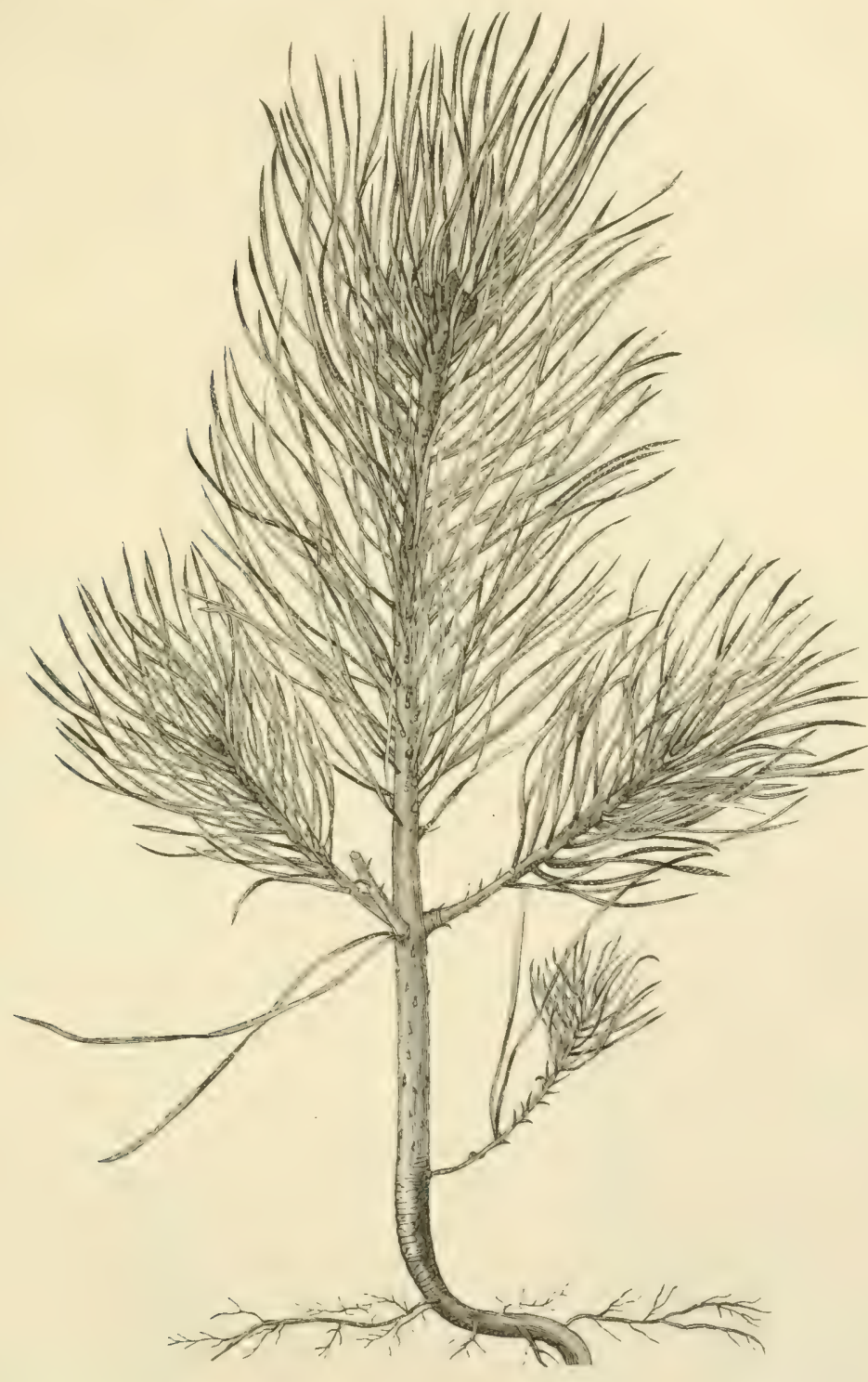

Fig. 442 .

Pinus silvestris, dreijährig. $\overbrace{/ 3}$ natürl. Grösse.

im zweiten Jahre fehlend oder wenig zahlreich (Fig. 439 B). Im dritten Jahre zahlreichere Seitenäste (Fig. 439 C). Die Quirlbildung beginnt mit dem vierten Jahre. 
b. Die Xadeln stehen in Kurztrichen, $2-5$ in einer Scheide.

«. Zwei Nacleln in einem Kurztrieles.

Pinus silvestris. Am Anfang des zweiten Jahres können noch einfache Nadeln gebildet werden, später treten die Kurztriebe auf. Seitenzweige fehlen im zweiten Jahre (Fig. HI B). Der erste deutliche Quirl aus 2-3 Scitenästen bestehend erscheint im dritten Jahre. (Fig. 442).

Pinus Larieio wie Pinus silvestris. Nadeln der Kurztriebe jedoch länger, bis zu IO cm. Kurztricbe gleich bei Beginn des zweiten Jahres gebildet. Die Knospen sind grösser und im Verhältnis zur Länge dicker.

3. Fünf Nadeln in einem Kurztriebe. Kurztriebnadeln auf der Oberseite mit zwei weissen Streifen.

Pinus Strobus. Die Nadeln der Kurztriebe ziemlich fein.

Pinus Cembra. Dic Nadeln der Kurztriebe derber.

\section{Tabelle II. Laubhölzer.}

Cotyledonen dickfleischig, unterirdisch oder laubartig, oberirdisch, nicht nadelförmig, Blätter laubartig. Immer nur zwei Cotyledonen. Die einzelnen Jahrestriebe sind auch hier an der Rinde oder an den gedrängten Narben der Knospenschuppen, manchmal auch an der Häufung unentwickelter Knospen zn erkennen.

7. Cotyledunen unterirdisch, nicht über die Erde emporgehoben. Sie bleiben im ersten Jahre zumeist mit der jungen Pflanze in Verbindung.

A. Laubblätter abrechselnd stehend.

Quercus pedunculata und sessiliflora. Cotyledonen derb, stoss, bleiben bis ins dritte Jahr erhalten. Bei der Keimung erscheinen zuerst kleine schuppenförmige Blättchen, sodann normale Eichenblätter. Vom zweiten Jahre ab verzweigt sich die Pflanze stark. Die einzelnen Jahrestriebe sind oft nicht so genau zu bestimmen, da sich häufig dem Frühjahrstrieb noch ein Johannistrieb anreiht.

Castanea vesca. Cotyledonen sehr dick, das erste Blatt ganzrandig, dic folgenden wie bei der erwachsenen Pflanze.

Corylus avellana. Cotyledonen dick, Blätter herzförmig, gesägt, den erwachsenen Blättern ähnlich.

Juglans- und Caryaarten besitzen ebenfalls unterirdische Cotyledonen.

B. Laubblätter gegenständig.

Aesculus Hippocastanum. Blätter wie bei der erwachsenen Pflanze.

Acer dasycarpum hat abweichend von den übrigen Acerarten unter der Erde bleibende Cotyledonen.

2. Cotyledonen durch Streckung des Hypocotyls ïber die Erde gehoben. Bei einem Teil der hier angefïhrten Holzarten fallen sie schon 6-8 Wochen nach der Entfaltung leicht ab.

A. Cotyledonen gross, fleischig, nierenformig.

Fagus silvatica (Fig. 443). Bei der Keimung sind die Cotyledonen zu- 


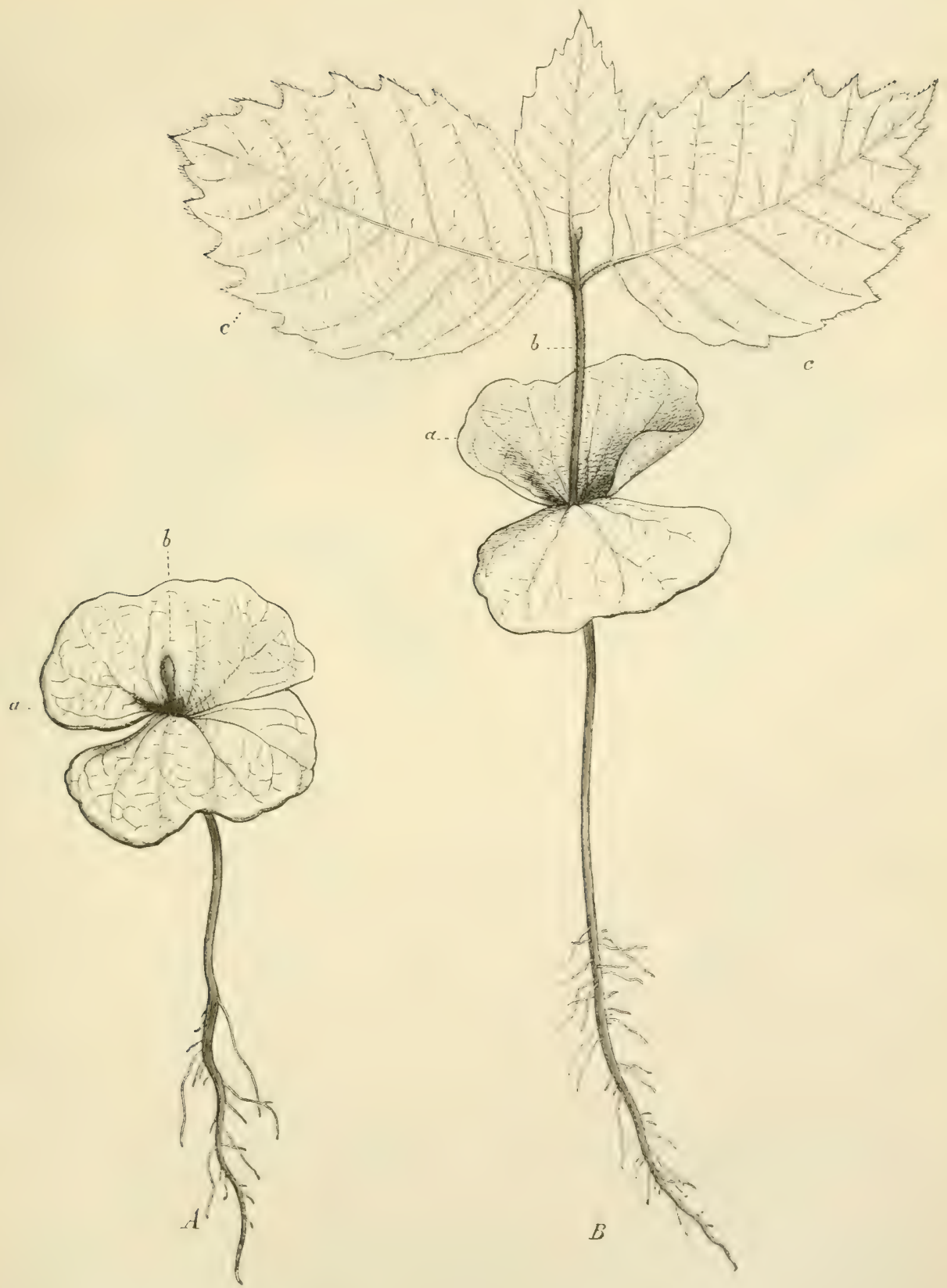

Fig. 443.

Keimling von Fagus silvatica. Natürliche Grösse. (DN.)

sammengefaltet. Die Oberseite ist grün, die Unterseite ist weisslich. Die ersten Buchenblätter sind gegenständig, sesïgt, die späteren stehen 
abwechselnd, sie sind wie bei der erwachsenen Pflanze ganzrandig und am Rande behart. Die Triebe der ersten $4-5$ Jahre sind sehr kurz.

f. Coryldench handformir sedith.

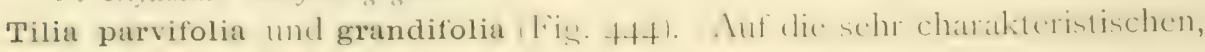

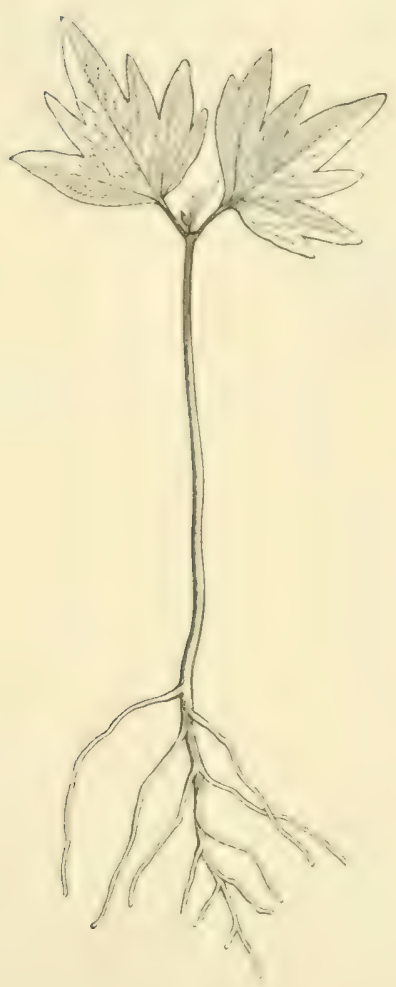

Fig. 444 .

Keimling von Tilia parvifolia. Natürl. Grösse. (DN.)

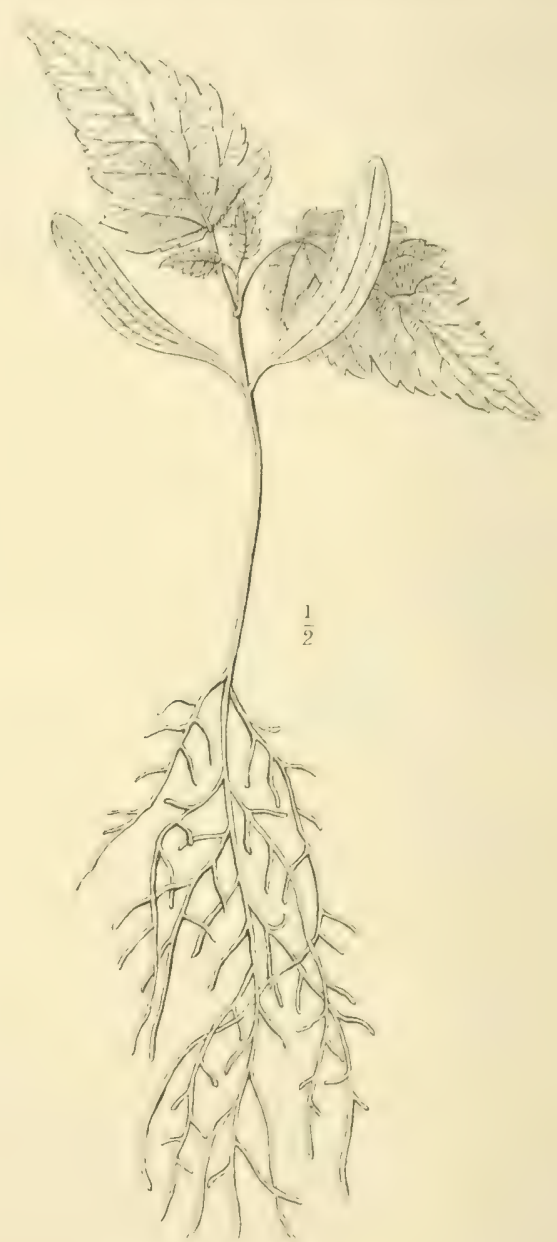

Fig. 445 .

Keimpflanze von Acer Pseudoplatanus. 1/2 der natürl. Grösse. (DN.)

dünnen Cotyledonen folgen länglich herzförmige, gesägte, zugespitzte Blätter. Dieselben erinnern an die ersten Blätter von Acer Pseudoplatanus, sie sind jedoch behaart und nicht gegenständig.

C. Cotyledonen langgestreckt, lanzettlich oder zungenförmig. Blätter durchweg gegenständig.

a. An den flach zungenförmigen etwas fleischigen Cotyledonen tritt die Mittelrippe nicht hervor. Die drei nicht besonders deutlichen Nerven laufen parallel.

Acer Pseudoplatanus (Fig. 445). Dic Cotyledonen fallen mehrere Wochen 
nach der Keimung ab. Die Primärblätter sind länglich herzförmig, zugespitzt, ungelappt aber gesägt. Die folgenden Blätter bilden den allmähligen Übergang zu den typischen Laubblättern.

Acer platanoides (Fig. 446). Die Cotyledonen sollen nach Tubeuf hier eine oder einige Querknickungen aufweisen, die bei A. Pseudoplatanus fehlen. Die Primärblätter sind herzeiförmig, etwas buchtig, dreilappig

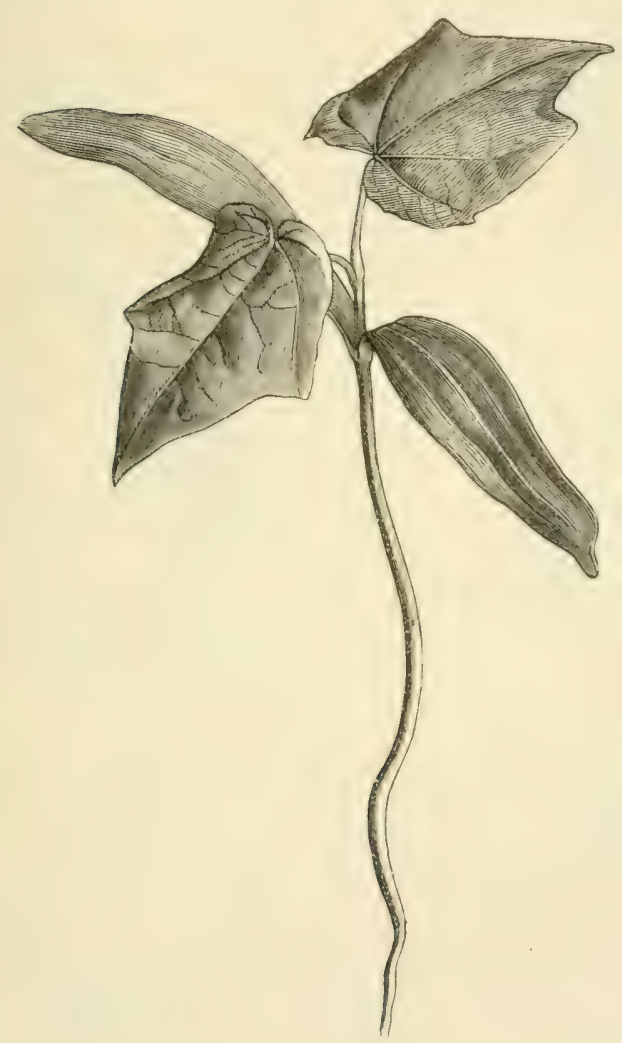

Fig. 446 .

Keimpflanze von Acer platanoides, wenig verkleinert (n. Willkomm).

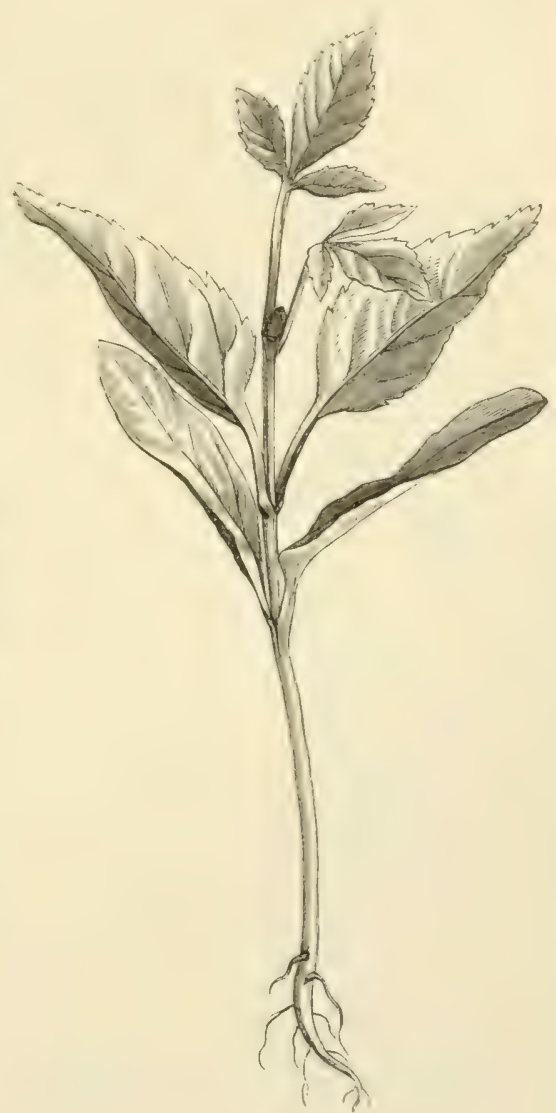

Fig. 447 .

Keimpflanze von Fraxinus excelsior, wenig verkleinert (n. Willkomm).

der Blattrand wenig oder gar nicht gezähnt. Es folgen typische Blätter mit zugespitzten Seitenlappen.

Acer campestre. Die Cotyledonen sind etwas kleiner als bei den vorhergehenden Arten. Die Primärblätter sind rundlich herzförmig, ganzrandig. Der Stiel, Rand und die Nerven der Unterseite behaart.

b. Cotyledonen lanzettlich, mit deutlichem Mittelnerv, von dem die Secundärnerven ausgehen.

Fraxinus excelsior (Fis. 447). Nach den Cotyledonen tritt ein Paar cin- 
facher, nicht gefiederter Blätter auf. Dieselben sind langgesticlt, eiförmig zugespitzt, am Rande gesägt. Es folgen Blätter mit wenigen Fiederblättchen, die Zahl der Fiederblättchen nimmt bei den später auftretenden Blättern zu. Im ersten Jahre erreicht der Trieb eine Länge ron circa 5 - $8 \mathrm{~cm}$.

D. Cotyldench rundlich, illiptisch, cifirmig, sihr kurs gesticth.

a. Cotyledonen rundlich oder verkehrt eiförmig, an der Basis in zwei Lappen oder Zähne auslaufend.

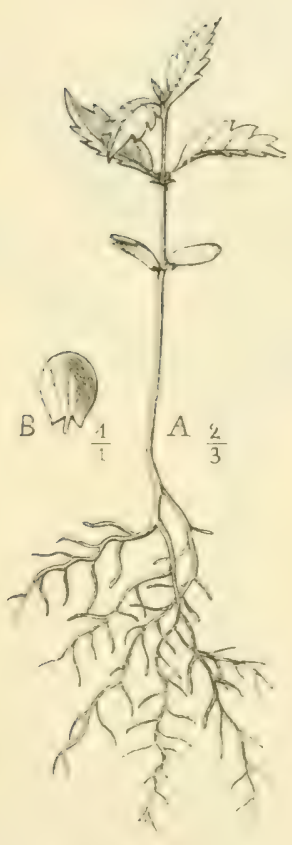

Fig. 448 .

Keimpflanze von Ulmus carnpestris. (DN.)

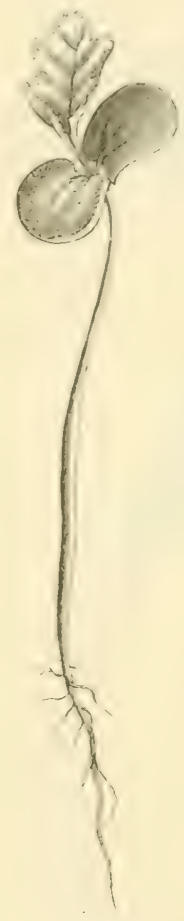

Fig. 449.

Keimpflanze von Carpinus Betulus, natürl. Grösse (n. Villkomm).

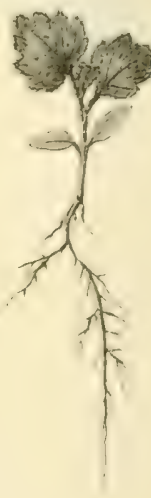

Fig. 450 .

Keimling von Betula verrucosa in natïrl. Grösse.

ฯ. Die Primärblätter gegenständig.

Ulmus campestris, montana und effusa Fis. f frí. Dic etwas fleischigen Cotyledonen sind an der Basis mit zwei spitzen Zähnen versehen, sie reiten gewissermassen auf dem kurzen Stiel. Die Blätter sind eiförmig, am Rande gesägt. Die einzelnen Ulmenarten unterscheiden sich nur wenig roneinander. Ulmus campestris hat etwas kürzer gestielte und kleinere Cotyledonen als U. montana. Bei U. effusa sind dieselben an der Spitze nicht so flach abgeschnitten und die Oberseite und Unterseite nicht so different gefärbt wie bei den anderen Arten. Der Trieb des ersten Jahres (nicht das Hypocotyl), scheint bei U. campestris am 
längsten zu sein, es folgt U. effusa, während U. montana am kürzesten bleibt. Nach mir vorliegenden, einer gleichmässigen Aussaat entstammenden Keimpflanzen betrug das Mittel des erstjährigen Triebes $50 \mathrm{~mm}$, resp. $30,7 \mathrm{~mm}$, resp. I $1,8 \mathrm{~mm}$. Bei Ulmus montana liegen die meisten Samen ein Jahr über, während die beiden anderen Arten im Jahre der Reife sofort auskeimen.

ß. Die Primärblätter abwechselnd gestellt.

Carpinus Betulus (Fig. 449). Die Cotyledonen ähnlich geformt wie bei Ulmus, die Zähne an der Basis sind jedoch abgerundet, die Oberfläche mehr runzelig. Die einzeln stehenden Primärblättter sind scharf gesägt, der erwachsenen Pflanze ähnlich.

b. Cotyledonen an der Basis in den Blattstiel verschmälert, ohne Zähne am Grunde.

«. Cotyledonen sehr klein, Blätter stark behaart.

Betula verrucosa und pubescens (Fig. 450). Die Cotyledonen sehr klein, fallen bald ab. Die zuerst auftretenden Blätter sind mehr rundlich, gezähnt bis gelappt. Ebenso wie die Blätter ist derSpross der beiden Arten im ersten und zweiten Jahre stark behaart. In den folgenden Jahren treten bei Betula verrucosa Wachsdrüsen auf.

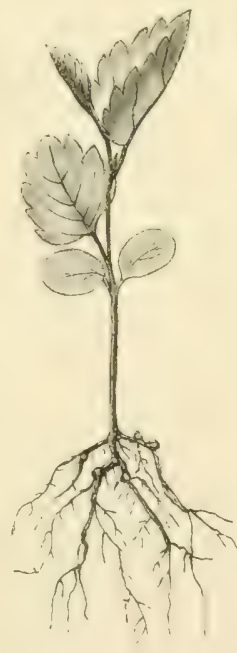

Fig. 45 I.

Keimling von Alnus glutinosa in natürlicher Grösse.

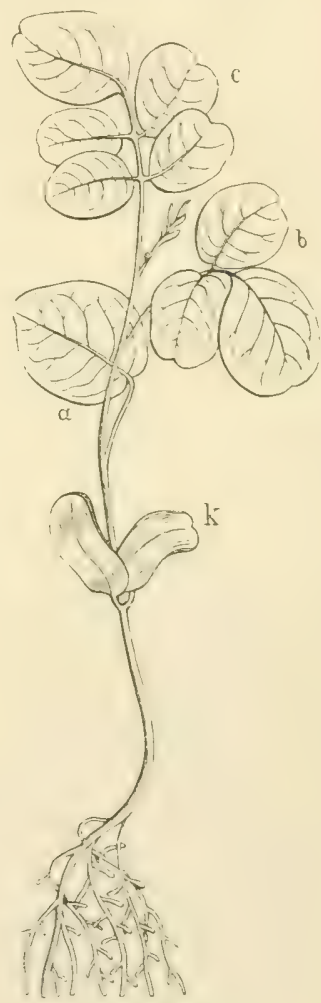

Fig. 452 .

Keimpflanze von Robinia Pseudacacia in natürl. Grösse. (DN.)

ß. Cotyledonen klein, Blätter nicht behaart. An den Wurzeln fast immer kleine Knöllchen.

Alnus glutinosa (Fig. 45I). Die Cotyledonen sind oval, kurz gestielt, wenig fleischig, die zuerst auftretenden Blättchen klein, eiförmig, scharf gesägt, auf der Unterseite grün. Die etwas später auftretenden Blätter sind elliptisch zugespitzt, in der Form den Blättern der erwachsenen Pflanze von Alnus incana ähnlich. Die Wurzelknöllchen durch einen 
Pilz veranlasst (vgl. S. 196), fehlen nur der ganz jungen Pflanze. Der Trieb des ersten Jahres wird bis $15 \mathrm{~cm}$ lang.

Alnus incana wie die vorige Art, die Unterseite der Blätter ist jedoch weisslichblaugrün.

$\%$ Cotyledonen grösser, circa I $\mathrm{cm}$ lang.

Robinia Pseudacacia (Fig. 452). Cotyledonen fleischig, eiförmig. Das erste Blatt (Fig. 452a) besteht aus einem sehr lang gesticlten, runden Blatt, demselben folgen Blätter mit wenigen Fiederblättchen. Der Trieb des ersten Jahres oft sehr lang. 
116. Bestimmung der Hölzer nach den mit freiem Auge sichtbaren Merkmalen.

\section{Übersicht.}

Tabelle I. Nadelhölzer.

Im sekundären Holz keine Gefässe, Markstrahlen sehr fein, nur bei stärkerer Lupenvergrösserung sichtbar. Grenze des Jahresringes scharf, meist breite Herbstholzzone. Harzgänge öfter als hellere Punkte im Herbstholz sichtbar.

I. Kein Kernholz oder letzteres nur sehr undeutlich.

2. Mit Kernholz.

Tabelle II. Laubhölzer.

Gefässe vorhanden. Dieselben erscheinen mit freiem Auge als feine Löcher oder helle Punkte, bei Anhäufung an einzelnen Stellen als helle Flecke, Linien, Bänder. Bei einer grösseren Anzahl von Hölzern sind die Gefässe erst mit der Lupe sichtbar. Markstrahlen verschieden breit.

I. Ein Teil der Markstrahlen oder wenigstens einzelne breit, häufig breiter als $0,2 \mathrm{~mm}$. Ausserdem sind noch sehr schmale, mit freiem Auge nicht mehr sichtbare Markstrahlen vorhanden. Fagus silvatica bildet die Grenze gegen die Gruppe 2.

A. Breite Markstrahlen in geringer Anzahl vorhanden, oft ganz vereinzelt. Zellgänge häufig. Gefässe nur mit der Lupe sichtbar.

B. Breite Narkstrahlen immer zahlreich. Keine Zellgänge. Gefảsse verschieden.

2. Alle Narkstrahlen fein, aber deutlich. Die Grenze gegen Gruppe 3 bilden Acer, Sambucus.

A. Die Gefässe teilweise sehr weit, d. h. die grösseren Gefässe auf dem Querschnitt als Löcher sichtbar (sog. grobporige Hölzer).

B. Die grössern Gefässe nicht als Löcher sichtbar. Das Frühlingsholz durch zahlreichere Gefässe und Holzparenchymzellen heller gefärbt als das Herbstholz. Kern vorhanden; Farbe des Kernholzes dunkel- oder hellbraun, rötlich oder gelblichbraun. 
C. Die Gefässe englumig, sind im ganzen Jahresringe ziemlich gleichmässig verteilt. Kern fehlt. Holz hellgelblich oder rötlichweiss. Markstrahlen sehr fein.

3. Markstrahlen so fein, dass sic mit freicm Auge gar nicht mehr sichtbar sind oder nur als undeutliche radiäre Strichelung wahrgenommen werden. An der Grenze der Sichtbarkeit stehen Ulmus, Fraxinus, Juglans, Castanca.

A. Holz auffallend gefäbt, im Kern rot oder grünlichbraun oder das ganze Holz hellgelb. Die grösseren Gefässe nicht als Löcher sichtbar.

B. Holz verschieden gefärbt, weiss, bräunlich oder gelblichweiss, hellbraun.

a. Ein Teil der Gefässe mit freiem Auge noch als Löcher sichtbar.

b. Gefässe zu helleren Bändern und Strichen vereinigt.

c. Gefässe, gleichmässig verteilt, erscheinen auf dem Querschnitt als hellere Punkte. Zellgänge zahlreich.

d. Gefässe ohne Lupe nicht mehr deutlich erkennbar. Jahresringe viclfach undeutlich, oder das Herbstholz nur um weniges dichter.

\section{Tabelle I.}

Nadelhölzer, vgl. Übersicht S. 475.

\section{Kein Kernholz oder letzteres nur sehr undeutlich.}

A. Keine Harzänge sichtbar.

Abies pectinata (Taf. I, Fig. 7). Farbe gelblich oder rötlichweiss, das Herbstholz erscheint meist etwas heller als bei der Fichte: Jahresringe scharf abgegrenzt. Vereinzelte Harzgänge nur mikroskopisch nachweisbar. An stark unterdrückten Stämmen kann das Holz verharzen, es bildet sich dann auch ein deutlicher Kern aus, der bei normalen Stämmen nur ganz schwach angedeutet ist oder fehlt. Rinde lange Zeit glatt, in der Jugend dunkelgrün, später hellgrau. An alten Stämmen eckige Tafelborke.

B. Mlit Harzä̈ringen.

Picea excelsa. Holz dem der Weisstanne sehr ähnlich. Harzgänge sehr fein, auf dem Querschnitt nicht immer sicher erkennbar. Auf dem Längsschnitt sind die Harzgänge als zarte, dunklere, eingeritzte Linien sichtbar, sie werden hier deutlicher, wenn man die glatte Schnittfläche etwas mit den Fingern reibt. Rinde in der Jugend rotbraun, von losselësten Korklamellen sehr feinschuppis, später runde Borkeschuppen.

2. Mit Kernholz.

1. Oline Hargänge.

a. Kern dunkelbraun, Splint hell.

Taxus baccata. Kern braunrot, Splint hellgelblich bis bräunlichweiss. 
Das sehr dunkle Herbstholz ziemlich breit (Unterschied von Juniperus virginiana). Jahresringe schmal, ungleich breit. Das Holz ist fest, sehr dicht und schwer spaltbar, widersteht der Fäulnis im hohen Grade. Rinde glatt, rotbraun, später Schuppenborke.

Juniperus virginiana. Kern braunrot oder mehr rosenrot, Splint gelblich bis bräunlichweiss, schmal (circa 5 Jahresringe breit). Herbstholz eine schmale, dunklere Linie, die besonders im Kern scharf hervortritt. Holz weich, ziemlich leicht, wohlriechend (Bleistiftholz). Rinde glatt, später sich faserig ablösend.

b. Kern hellbraun oder graubraun.

Juniperus communis. Kern hellbraun, rot-violett nuanciert. Die Farbe des Kernholzes rührt hauptsächlich von den dunklen Markstrahlen her, das übrige Gewebe heller. Splint gelblich bis bräunlichweiss. Grenze des Jahresringes eine sehr schmale, dunkle Linie. Holz ziemlich schwer und dicht, angenehm riechend. Rinde braunrot, faserig.

Thuja occidentalis und Biota orientalis. Kern graubraun, oft ungleichmässig gefärbt. Splintholz gelblich. Herbstholz durch eine schmale, dichtere Zone begrenzt. Holz sehr leicht und weich, schwer spaltbar, wenig glänzend. Rinde mit faseriger Borke.

\section{B. Nit Harsgängen.}

a. Herbstholz und Frühjahrsholz sind im Jahresringe scharf abgegrenzt.

Pinus silvestris. Kern rotbraun, mit oft sehr breitem, dunkel gefärbtem Herbstholz. Splint sehr breit, viele Jahresringe umfassend, hell gelblichweiss oder rötlichweiss. Der Kern tritt im frischen Zustande weniger hervor, färbt sich später dunkler und röter. Jahresringe oft sehr verschieden breit, unter günstigen Verhältnissen sehr breit. Jahresringgrenze deutlich. Harzgänge zahlreich, auf dem Querschnitt besonders im Herbstholz gut sichtbar. Mark häufig weit, bis $4 \mathrm{~mm}$ (vgl. Larix). Holz weich, gut spaltbar, dauerhaft. Die Rinde an den oberen Teilen des Stammes mit pergamentartig abblätternden, hellen, gelblichbraunen Borkeschuppen, an den älteren Teilen des Stammes befindet sich eine sehr dicke, rotbraune, tiefrissige Borke.

Pinus Laricio. Wie Pinus silvestris. Die Borke auch an den oberen Teilen des Stammes tiefrissig.

Pinus montana. Kern rot, rotbraun, Splint gelblich- bis bräunlichweiss, breit. Jahresringe meist alle sehr schmal (Unterschied von Pinus silvestris), stark gebogen, an den verschiedenen Seiten ungleich dick. Mark liegt häufig excentrisch. Harzgänge zahlreich. Holz schwerer und dichter als bei Pinus silvestris. Rinde erst glatt, später Borkeschuppen, niemals so dick wie bei der gewöhnlichen Kiefer.

Larix europaea (Taf. I, Fig. 4). Kern braunrot, etwas intensiver rot als bei Pinus silvestris, die Färbung tritt auch schon im frischen Zustande auf. Splint wenige Jahresringe breit, gelblich, immer deutlich rom Kern geschieden. Herbstholzzone breit, ausserordentlich scharf be- 
grenzt, oft in ein helleres und schmales dunkleres Band getrennt. Harzgänge kleiner und seltener als bei Pinus silvestris. Mark sehr eng. Holz mässig hart, glänzend, schr dauerhaft. Rinde anfangs glatt, grau, später sich in eine hellrote Borke umwandelnd. Diese schr charakteristische Farbe tritt besonders nach der Ablösung der obersten Borkeschichten hervor.

b. Herbstholz und Frühjahrsholz allmählich ineinander übergehend.

Pinus Strobus. Kern tritt nicht deutlich hervor, hell rotbraun. Splint schr breit, selblich. Jahresringe nicht so scharf hervortretend. Harzgänge ziemlich zahlreich, besonders an älteren Stämmen. Rinde lange Zeit glatt, rötlich glänzend. Schuppenborke erst in höherem Alter gebildet, nicht sehr dick.

\section{Tabelle II.}

Laubhölzer, vgl. Übersicht S. 475.

1. Ein Teil der Markstrahlen oder wenigstens cinzelne breit, häufig breiter als $0,2 \mathrm{~mm}$.

A. Brite Markstrahlen in seringer Anzahl vorhanden, oft ganz vereinzelt. Zellgänge häufig. Gefässe nur mit der Lupe sichtbar.

Alnus glutinosa. (Taf. I, Fig. I). Das frische Holz sieht weiss aus, beim Liegen wird es rötlich. Der Querschnitt von verschiedenen Seiten betrachtet sicht seidenglänzend weisslich oder mehr rötlich aus. Kern fehlt, Jahresringe nicht immer deutlich. Die Jahresringgrenze durch eine feine Linie markiert, die an den Seiten der breiten Markstrahlen etwas nach aussen ausgebuchtet ist, innerhalb der Markstrahlen selbst keilförmig nach dem Narke zu vorspringt, was jedoch nur mit dem Mikroskop gut wahrnehmbar ist. Ausserdem sind innerhalb des Jahresringes oft dunklere Zonen $\mathrm{zu}$ bemerken, welche das Erkennen der Jahresringgrenze erschweren. Die Markstrahlen sind meist zahlreicher wie bei Alnus incana. Zellgänge sehr zahlreich. Holz leicht, im Wasser dauerhaft. Rinde dunkel, anfangs glatt, reisst später scharfkantig auf, an älteren Stämmen wird eine dunkle Schuppenborke gebildet.

Alnus incana. Dem Holz von Alnus glutinosa sehr ähnlich, die breiten Narkstrahlen sind weniger zahlreich, an kleineren Stücken auch fehlend. Grenze des Jahresringes weniger ausgebaucht. Auf dem Längsschnitt sind die Spiegelfasern (Markstrahlen) deutlicher als bei A. glutinosa Zellgänge weniger zahlreich. Die Rinde ist heller, weisslich oder grau, bleibt sehr lange glatt.

B. Breite Markstrahlen inmer zahlreich. Kéine Zellgänge. Gefässe verschieden.

a. Gefässe weit, teilweise auf dem Querschnitt als Löcher sichtbar, Holz hellbraun oder dunkelbraun.

Quercus peduneulata und Qu. sessiliflora (Taf. I, Fig. 2). Kern dunkel- 
graubraun. Splint schmal, hellbraun. Jahresringgrenze sehr deutlich, im Frühjahrsholz eine oder mehrere Reihen weiter Gefässe. Im Sommerholz unregelmässig radial verlaufende, teilweise verzweigte und zusammenhängende hellere Streifen, die aus kleineren Gefässen, Tracheiden und Holzparenchym bestehen. Narkstrahlen verschieden breit, aber auch die feineren deutlich. Holz hart, schwer. Rinde nur anfangs glänzend, grau, reisst bald auf, sodann mit sehr harter, breiter tiefrissiger Borke.

Quercus cerris. Das Holz den eben erwähnten Eichen sehr ähnlich, der Splint jedoch breit, die sehr breiten Markstrahlen sind zahlreicher. Borke tiefrissig, grau bis rötlich grau.

Rosa (canina). Kern rötlichbraun. Splint schmal, heller gefärbt. Gefässe besonders an den alten Jahresringen als Löcher sichtbar. Helleres Parenchym und kleinere Gefässe im übrigen Jahresringe gleichmässig verteilt. Markstrahlen nach aussen bedeutend breiter werdend, Mark sehr weit. Rinde wulstig, glatt, ziemlich derb, später mit wenig tiefgehenden Längsrissen versehen.

b. Gefässe mit freiem Auge nicht mehr als Löcher sichtbar.

c. Holz intensiv gelb.

Berberis vulgaris. Kern gelb- oder rotbraun, Splint intensiv gelb. Jahresringgrenze nicht immer deutlich, die Gefässe im Frühlingsholz etwas grösser, dasselbe daher heller. Narkstrahlen häufig bogig, feinere Markstrahlen fehlen. Rinde dünn, hell, borkig.

3. Ein Teil der Markstrahlen wesentlich breiter, indem zahlreiche feine Markstrahlen zusammentreten.

Carpinus Betulus (Taf. I, Fig. 5). Kein Kern. Das ganze Holz hellgelblich weiss (daher Weissbuche). Jahresringgrenze nicht sehr scharf, teilweise nur an der helleren Frühjahrszone erkennbar. Die Jahresringe sehr stark grobwellig. Die Verlängerung der Markstrahlen schneidet sich häufig nicht im Centrum des Stammes (Spannrückigkeit). Holz schwer, hart, schwer spaltbar. Rinde mattgrau, grünlichgrau, ähnlich wie bei Fagus, reisst nicht auf.

Corylus avellana. Kein Kern. Die rötlichweisse Färbung des Holzes gleicht jener der Rotbuche. Die Jahresringgrenze eine feine, dunklere, sehr feinwellige Linie. Das Frühjahrsholz wegen der zahlreicheren Gefässe, heller gefärbt. Markstrahlen wie bei Carpinus Betulus. Holz ziemlich weich, nicht sehr dauerhaft, gut spaltbar, Rinde glänzendgrau, reisst nicht auf.

$\gamma$. Markstrahlen weniger breit, keine zusammengesetzten Markstrahlen.

Fagus silvatica (Taf. I, Fig. 8). Kein Kern. Holz rötlichweiss. Durch Zersetzungsprodukte eventuell weisslichvioletter Kern gebildet. Jahresringgrenze deutlich, durch eine schwach hellbräunliche Linie gebildet, die innerhalb der grösseren Markstrahlen eine Ausbuchtung nach innen zeigt. Bei der Ablösung der Rinde vom Holz bleiben daher an der Rinde den Markstrahlen entsprechende IVülste zurtick. Die Jahresringgrenze zwischen den grösseren Markstrahlen rerläuft halbkreisfürmig. 
dnch nicht so wellig wie bei Carpinus. Das Frühjahrsholz ist wegen der zahlreicheren Gefässe heller gefärbt. Die Markstrahlen sind sehr rerschieden breit, an der Grenze des Jahresringes manchmal etwas erweitert. Das Holz ist schwer, dicht, leicht spaltbar. Die Rinde mattgrau oder durch Flechten weisslich, springt für gewöhnlich nicht auf, nur bei der sog. Steinbuche springt sie etwas auf.

Platanus occidentalis. Holz selblich bis rötlichweiss, in der Farbe zwischen Hainbuche und Rotbuche stehend. Der Kern ist etwas dunkler, mehr bräunlich gefärbt. Jahresringgrenze nicht sehr deutlich. Das Herbstholz und Frühjahrsholz nur durch eine feine Linie getrennt. Im Herbstholz sind die Gefässe minder zahlreich, sonst gleichmässig verteilt. Dic Jahresringe rund, nicht wellig. Die Markstrahlen sind ausserordentlich zahlreich, nehmen fast eben soviel Raum ein wie das übrige Gewebe. Das Holz ziemlich schwer und fest. Die Rinde grau oder grünlichgrau, sehr charakteristisch durch die flachen, rundlichen, sich leicht loslösenden Borkeschichten. Unter den letzteren die Markstrahlen als Höcker sichtbar.

\section{Alle Markstrahlen fein aber deutlich.}

A. Die Gefässe teilu'zise sehr wieit, d. ho die grüsseren Gefösse auf dem Querschnith als Lücher sichtbar.

Morus alba (Taf. I, Fig. 6). Kern dunkelbraun, besonders bei längerem Liegen, frisch gelbbraun. Splint bräunlichweiss, sehr schmal, circa 5 Jahresringe breit. Im Frühjahrsholz mehrere Reihen weiter Gefässe, die häufig mit einem gummiartigen Sekret erfüllt sind. Im Herbstholz die feineren Gefässe als helles Netz zwischen dunklem Gewebe sichtbar, oder zu kurzen Strichen und Bändern vereinigt. Holz schwer, glänzend, dauerhaft. Rinde reisst bald auf, es wird eine tiefrissige Borke gebildet.

Gleditschia triacanthos. Kern rot oder braunrot. Splint gelblich hellbraun, mit schwach grünlicher Nuance. Fast im ganzen Jahresring weite Gefässe, die in der schmalen Herbstholzzone in helle Striche und Punkte übergehen. Jahresringe gut markiert. Holz schwer, hart. Rinde schwach runzelig, erst spät wird Schuppenborke gebildet. Auf dem Querschnitt erscheint die jüngere Rinde citronengelb.

Ailanthus glandulosa. Kern srau, rransefarbis, Sylint hellsclblich, breit. Weite Gefässe nur in wenigen (meist nur I-2) Reihen, im Herbstholz die helleren Flecke nicht $\mathrm{zu}$ Bändern und Binden vereinigt. Markstrahlen nicht vollständig gerade. Mark auffallend weit. Holz schwer, glänzend, hart. Rinde grau, nicht sehr dick, zeigt nur flache Risse.

B. Die grösseren Gefässe nicht als Löcher sichtbar. Das Frühjahrsholz durch sahlreichere Gefässe zund Holsparenchymzellen heller gefärbt als das Herbstholz. Kern vorhanden, Farbe dis Kérnholies dunkel oder hellbraun, rötlich oder gelblichbraun.

a. Frühjahrszone hẹll gefärbt durch das Auftreten grösserer, aber nicht zahlreicherer Gefässe.

Robinia Pseudacacia ,Taf. I, Fiss. 3!. Kern grünlichbraun oder im Alter 
braun. Splint gelblichweiss, sehr schmal, oft nur I-3 Jahresringe breit. Gefässe im Frühlingsholz weit, aber meist durch Füllzellen verstopft, sie erscheinen daher als helle Flecke auf dunklem Grunde. Dieselben treten auch noch im Herbstholz auf und vereinigen sich nur im äussersten Herbstholz zu kürzeren Strichen und Bändern. Markstrahlen sehr fein, aber infolge ihrer helleren Farbe sehr deutlich. Das Holz ist schwer, fest, dauerhaft. Rinde sehr dick, schon zeitig mit tiefen Längsrissen versehen.

Cytisus Laburnum. Kern dunkelbraun, Splint gelb. Frühjahrszone ziemlich schmal, im Herbstholz schief verlaufende, helle Bänder. Holz sehr hart, sehr schwerspaltig. Rinde glatt, glänzend gelbbraun, dünn, reisst nicht auf.

b. Frühjahrszone heller gefärbt durch das Auftreten zahlreicherer aber nicht wesentlich grösserer Gefässe.

Prunus domestica. Kern dunkelviolett oder rotbraun, Splint gelblichweiss. Frühjahrsholz etwas heller, in den äusseren Teilen des Jahresringes verschieden dunkle Partien. Die Markstrahlen sind bedeutend heller gefärbt als das umliegende Gewebe, nicht vollständig gerade. Das Holz ist schwer, leicht rissig. Rinde rötlichschwarz, dunkel gefärbt, lange Zeit glatt, später treten starke Längsrisse auf, die dazwischen liegenden Teile sind glatt und nur durch feinere Querrisse zerspalten.

Prunus Mahaleb. Kern rotbraun, ziemlich hell, Splint rötlichweiss. Die Gefässe des Herbstholzes verleihen dem Kern ein charakteristisches marmoriertes Aussehen. Die hellere Frühjahrszone sehr schmal. Die Jahresringgrenze durch eine dunklere Linie gebildet, tritt nicht scharf hervor. Holz von dauerndem, aromatischem Geruch, schwer, dicht. Rinde glatt, später bilden sich flache Borkenrisse.

Prunus Padus. Kern gelblichbraun. Splint gelblichweiss, nicht sehr different. Die Jahresringgrenze ist durch eine feine, dunklere Linie markiert. Das Frühlingsholz geht sehr allmählich in das Herbstholz über. Marmorierung durch hellere Gewebepartien nicht vorhanden. Holz nur im frischen Zustande riechend, dicht, schwer. Rinde glatt, dünn, dunkelbraun, mit grossen, helleren Korkwülsten.

Prunus spinosa. Kern rotbraun bis dunkelbraun, Splint hell rötlichbraun. Jahresringgrenze durch eine breite, dunkle Herbstholzzone gebildet. Frühjahrszone breit, ziemlich scharf ron der Herbstholzzone abgesetzt. Marmorierung nicht vorhanden. Holz gleichmässig, fein, sehr dicht und fest. Durchmesser meist gering. Öfters Zellgänge. Rinde dunkel, glatt.

Prunus avium und Cerasus. Kern rotbraun oder gelbbraun, Splint rötlichweiss. Herbstholzzone sehr breit, die helle Frühjahrszone hebt sich gut ab. Markstrahlen nicht so deutlich wie bei Prunus domestica und den anderen Prunusarten, doch viel deutlicher als bei Pirus malus 
und Pirus communis, auf dem Längsschnitt höher als bei Pirus. Holz leicht, wenig dauerhaft. Rinde lange Zeit glänzend, glatt, lösst sich bandförmig ab.

c. Die Gefässe englumig, sind im ganzen Jahresring ziemlich gleichmässig verteilt. Ilolz hellgelblich oder rötlichweiss. Markstrahlen sehr fein.

Acer Pseudoplatanus (Taf. 1, Fig. 9). Holz weiss oder gelblichweiss. Frühlings- und Herbstholz ziemlich gleich gefärbt. Jahresringe durch cine dunklere Linie begrenzt oder sich wenig deutlich abhebend, gewöhnlich ziemlich breit. Markstrahlen etwas deutlicher als bei den anderen Ahornarten. Markstrahlen auf dem Längsschnitt circa I mm hoch. Holz glänzend, nicht sehr schwer, ist hart, nur im Trocknen von grosser Dauer. Rinde grau, nicht glänzend, lange Zeit ohne Risse, später bilden sich der Platane ähnliche Borkeschuppen.

Acer platanoides. Holz gelblich ader rötlichweiss. Die Jahrestingsgrenze durch eine dunklere Linie ziemlich scharf markiert (deutlicher als bei A. Pseudoplatanus). Jahresringe ziemlich breit, wie bei der vorigen Art, kein konstantes Kennzeichen. Markstrahlen sehr fein, an der Grenze der Sichtbarkeit. Auf dem radialen Längsschnitt circa $1 / 2 \mathrm{~mm}$ hoch. Rinde, schon im jüngeren Alter mit rissiger Borke, ist hart, nicht korkig.

Acer campestre. Holz rötlichweiss. Jahresringe im allgemeinen schmäler als bei den vorhergehenden Arten, nicht so deutlich, da die Begrenzungslinie nicht so auffällt. Markstrahlen so fein wie bei A. platanoides, auf dem Längsschnitt $1 / 2 \mathrm{~mm}$ hoch. Rinde mit rissiger, heller Borke, die jedoch viel weicher und korkiger ist als bei Acer platanoides.

Sambucus nigra. Das Ho,lz durch seine gelbweisse Farbe ausgezeichnet. Jahresringe breit, durch eine helle Linie getrennt. Markstrahlen fein, auf dem radialen Längsschnitt sehr wenig hoch, wenig glänzend. Holz leicht, doch ziemlich fest. Rinde sehr hell, gelblichgrau oder bräunlichweiss mit rissiger, sehr schwammig-weicher Borke.

Tilia parvifolia und grandifolia. Holz weiss oder rötlich, auf dem Querschnitt seidenartig glänzend. Jahresringe treten sehr wenig scharf hervor. Markstrahlen sehr fein. Holz weich, sehr leicht. Rinde lange Zeit glatt, rotbraun, später mit flachrissiger schwärzlicher Borke. In der Rinde sind auf dem Querschnitt härtere franchenartige, sclerenchymatische Teile sichtbar.

3. Markstrahlen so fein, dass sie mit freiem Auge gar nicht mehr sichtbar sind oder nur als undeutliche radiale Strichelung wahrgenommen werden.

A. Holz auffallend gefärbt, im Kern rot oder grïnlichbraun, oder das ganze Holz hellgelb. Die grösseren Gefässe nicht als Löcher sichtbar.

a. Kein Kern, Holz hellgelb.

Evonymus europaeus. Holz eigentümlich hellgelb (Zahnstocherholz), sehr homogen, da weder Markstrahlen noch Gefässgruppen hervortreten, 
die Jahresringe auch nur durch eine breite, hellere Linie begrenzt sind. Markstrahlen auch auf dem Längschnitt nicht deutlich. Holz ziemlich schwer, hart, fest. Rinde hellgrau mit flachen Längsrissen.

Das Holz könnte mit dem von Aesculus Hippocastanum im frischen Zustande verwechselt werden, letzteres jedoch weich, wenig fest, nicht schwer, Jahresringgrenze undeutlich.

b. Kern vorhanden, rot oder orange.

Rhamnus eathartica. Kern orangerot, Splint gelb, schmal. Das Frühlingsholz stellt eine helle Binde dar, von derselben gehen in das dunklere Herbstholz sehr charakteristische flammenartige, verzweigte und Anastomosen bildende helle Gefässgruppen. Die Grenze der Jahresringe durch den helleren Frühjahrskreis sehr deutlich. Holz ziemlich schwer. Rinde lange Zeit glatt, glänzend, rotbraun, später treten flache Borkerisse auf.

Rhamnus frangula. Kern rot, seideglänzend, Splint hellgelb. Die Gefässe sind nicht zu flammenartigen Gruppen vereinigt, sondern gleichmässig verteilt, nur im Frühjahrsholz etwas lockerer. Jahresringe nicht scharf markiert. Holz leicht, weich. Rinde glatt, ohne Glanz, dunkel violettbraun oder grau.

c. Kern vorhanden, grünlichbraun.

Rhus cotinus. Kern grünlich bis gelblichbraun. Splint hellgelblich-weiss. Frühjahrsholz eine breite helle Zone darstellend, im Herbstholz nur wenige als helle Punkte erscheinende Gefässe. Holz ziemlich dicht, von schönem Glanz (sog. Fisetholz). Rinde hellbraun, mit kleinen Borkeschuppen.

B. Holz verschieden gefürbt, weiss, bräunlich oder gelblichweiss, hellbraun.

a. Ein Teil der Gefässe mit freiem Auge noch als Löcher sichtbar.

Castanea vesea. Kern hellbraun, Splint schmutzig gelblich. Gefässe schr weit, bilden im. Frühjahrsholz eine breite Zone. Im Herbstholz bilden die Gefässe feine, helle, unregelmässig radial verlaufende Linien. Jahresringgrenze scharf. Holz ziemlich fest und schwer. Rinde lange Zeit ohne Risse.

Fraxinus excelsior (Taf. II, Fig. II). Kern hellbraun, Splint bräunlichweiss, sehr breit. Gefässe im Frühjahrssholz wesentlich kleiner als bei Castanea, bilden ein mehrreihiges poröses Band. Das Herbstholz sehr dicht, Jahresringe scharf begrenzt. Markstrahlen sehr fein, aber noch stellenweise als feine Strichelung sichtbar. Auf dem radialen Längsschnitt deutlich, aber von sehr geringer Höhe. Holz schwer, fest, hart. Rinde grünlichgrau, erst sehr spät treten flache Längs- und Querrisse auf.

Juglans regia (Taf. II, Fig. I3). Kern graubraun, schwärzlich. Splint schmutzig gelblichweiss bis hellgrau. Gefässe bilden kleine Löcher, die gleichmässig im ganzen Jahresringe verteilt sind. Jahresringe sehr breit, nicht sehr scharf hervortretend: Markstrahlen sehr fein,-.aber noch als feine Strichelung wahrnehmbar. Holz schwer, hart, homogen. 
Kinde an jürendlichen Stämmen und Xsten slatt, mit weisslichen Lenticellen, bald in eine sehr derbe tiefrissige Borke verwandelt.

b. Gefisse zu helleren Bändern und Strichen vereinigt.

Ulmus campestris (Taf. II, Fig. I2). Kern dunkel- oder rötlichbraun (dunkler als bei den anderen Ulmenarten). Splint gelblich- oder bräunlichweiss. Frühjahrszone durch zahlreiche Gefässe hell, breit, im dunkleren Herbstholz bilden die letzteren sehr feine, kürzere Striche und längere Linien, welche vielfach geknickt und schief, seltener dem Jahresring parallel verlaufen. Gefässe sind auf dem Längsschnitt gut als vertiefte Linien sichtbar. Holz schwer, hart, etwas fester als bei den anderen Ulmenarten. Rinde dunkel, graubraun, zeigt derbe, nicht besonders tiefe Längs- und Querrisse.

Ulmus montana. Kern heller braun oder rötlichbraun. Splint scelblichweiss. Frühjahrs- und Herbstholz nicht so scharf getrennt. Herbstholz mit zahlreichen, sehr breiten helleren Linien. Die äusseren Linien feiner, als die an der Innenseite des Jahresringes, verlaufen dem Jahresringe parallel. Die Gefässe sind auf dem Längsschnitt nicht mehr gut als vertiefte Linien sichtbar. Das $\mathrm{Holz}$ erscheint jedoch längsgestreift. Holz etwas weniger fest als bei Ulmus campestris. Rinde mit ciefrissiger Borke.

Ulmus effusa. Kern hell bräunlich. Splint gelblichweiss, breit. Das Frühjahrsholz geht allmählich ins Herbstholz über. Die feineren Gefässe sind (besonders an der Innenseite der Jahresringe) zu breiten Linien vereinigt, welche innen mehr wellig, aussen parallel verlaufen. Auf dem Längsschnitt wie U. montana, mit der das Holz auch sonst srosse Ähnlichkeit hat. Holz von geringerer Festigkeit. Rinde nicht sehr dick, bleibt längere Zeit glatt, bis sich flache Borkeschuppen ablösen.

c. Gefässe gleichmässig verteilt, erscheinen auf dem Querschnitt als hellere Punkte. Zell. gänge zahlreich.

Betula verrucosa (Taf. II, Fig. I6). Kein Kern. Holz rötlich oder gelblichgrau. Jahresringe heben sich nicht sehr scharf $a b$, sind durch eine feine dunklere Linie begrenzt. Gefässe zahlreich, sehr fein. Zellgänge zahlreich. Rinde sehr charakteristisch, in der Jugend weiss, die äusseren Schichten sich bandförmig ablösend. An den älteren Stämmen eine unregelmässig tiefrissige schwärzliche Borke. Auf dem Querschnitt sind auch dann noch abwechselnd weisse und braune Schichten zu sehen.

d. Gefässe ohne Lupe nicht mehr deutlich erkennbar. Jahresringe vielfach undeutlich oder das Herbstholz nur um weniges dichter.

๔. Harte, schwerere Hölzer, Farbe rötlichweiss oder bräunlichweiss.

* Ohne Zellgänge.

Pirus communis. Holz hellbraun, rötlich, kein Kern, aber manchmal ein roter oder rotbrauner, falscher Kern. Die Herbstholzzone ist eine breite, um ein geringes dunklere Linie (breiter als bei Pirus malus). Das Holz hat ein sehr dichtes Gefüge, ist etwas glänzend, schwer, hart, schlecht spaltbar. Rinde grauschwarz oder bräunlichschwarz, zeigt 
hauptsächlich Längsrisse, die oft am Stamm einen schiefen Verlauf erkennen lassen.

Pirus malus. Kern vorhanden, doch nicht scharf hervortretend, ist rötlich hellbraun. Splint rötlichweiss, breit. Jahresringe durch eine feine, scharfe Linie begrenzt, sind immer deutlich geschieden. Holz etwas weniger hart als bei der Birne: Rinde wie bei dem Birnbaum gefärbt, löst sich infolge der zahlreicheren und stärkeren Querrisse leichter in Schuppen ab.

Syringa vulgaris. Kern hellbraun, mit violetten Rändern. Splint gelblich bis bräunlichweiss. Jahresringe durch die schmale, scharf abgesetzte Frühjahrszone gut markiert, das übrige Holz homogen. Holz sehr hart, fest und sehr schwer. Rinde ziemlich glatt, dunkelgrau, mit sehr flachen Rissen.

$$
\text { * Mit Zellgängen. }
$$

Crataegus oxyacantha. Kein Kern, Holz rötlichgelb. Jahresringe nicht sehr scharf markiert, doch meist eine dunklere Begrenzungslinie vorhanden, welche an das etwas dichtere Herbstholz stösst. Zellgänge sehr zahlreich. Holz sehr fest, schwer und zäh (zu Spazierstöcken vielfach verwendet). Rinde lange Zeit glatt, glänzend grau bis rötlichgrau, später wird eine kleinschuppige Borke gebildet.

Sorbus aucuparia (Taf. II, Fig. I4 und I5). Kern braun, Splint rötlich oder violettweiss, breit. Die hellere Frühjahrszone geht allmählich in die verschieden breite Herbstzone über. Die sehr langgestreckten Zellgänge treten meist nicht so deutlich hervor, da sie fast dieselbe Farbe wie das Herbstholz haben. Holz hart, fest, schwer. Rinde anfangs glänzend, glatt, rotbraun mit weisslichem Flechtenüberzug. An älteren Stämmen grau, nur stellenweise glänzend, ebenfalls mit dichtem, weisslichem Überzug von Krustenflechten.

Sorbus Aria. Kern braunrot, sehr zart weisslich marmoriert. Splint rötlichweiss oder weiss. Dem Apfelbaum sehr ähnlich aber mit Markflecken. Frühjahrszone hell, schmal, ziemlich scharf von der Herbstholzzone abgesetzt. Zellgänge langgestreckt. Rinde ähnlich wie Sorbus aucuparia.

Sorbus torminalis. Holz rötlich, dem Apfelbaum ähnlich. NIanchmal schwarzer, falscher Kern. Frühjahrsholz geht allmählich in die Herbstholzzone über. Holz fest, hart. Rinde mit flacher Schuppenborke, dem Apfelbaum ähnlich.

§. Weiche, leichte, meist weissliche oder gelblichweisse Hölzer, seltener (Salix caprea) rötlich seidenglänzend.

* Hölzer ohne Kern, Rinde bleibt lange Zeit glatt (Ist kein Kern sichtbar, so ist doch auch auf die folgende Gruppe ** zu prüfen, da bei der letzteren der Splint häufig sehr breit ist und nicht so scharf hervortritt).

Aesculus Hippocastanum. Holz gelblichweiss, rein weiss oder nach längerem Liegen an der Luft rötlichweiss. Jahresringe meist schmal, undeutlich geschieden, Frühjahrszone manchmal heller. Keine Zell- 
gäinge. Holz leichter als bei der vorigen Gruppe, doch etwas schwerer als bei Salix und Populus. Rinde glatt, hellgrau oder graubraun, ohne Glanz, später mit flachen Borkeschuppen, im ganzen dünn.

Populus tremula. Holz weisslich, mit schwach rötlichem Glanz, wird bei längerem Liegen an der Luft rötlich. Jahresringe durch feine, dunkle Herbstlinien begrenzt. Markstrahlen auf dem Querschnitt nicht sichtbar, auf dem genau radial gegangenen Längsschnitt stellen sie feine, dunklere Linien dar. In der Nähe des Markes häufig Zellgänge, sonst fehlen dieselben fast ganz. Holz leicht, weich. Rinde charakteristisch, hellgrau, glänzend, lange Zeit glatt, mit zahlreichen, dunkleren Korkwïlsten. Später hellgrau, mit flachen Borkerissen.

4. Hölzer mit Kern, Rinde mehr oder weniger rissig.

Populus nigra. Kern hellbräunlich bis bräunlichgrau. Splint weisslich oder gelblichweiss. Farbendifferenz nicht sehr deutlich. Jahresringe sehr breit, durch eine lichtbraune Linie begrenzt. Markstrahlen auf dem radialen Längsschnitt, als etwas glänzende, um weniges dunklere Linien sichtbar. Rinde graubraun, frühzeitig eine tiefrissige, dicke Borke bildend.

Populus alba. Kern selblich oder hellbräunlich, um weniges dunkler als der weissliche Splint. Rinde lange Zeit glatt, später Schuppenborke. Salix eaprea. Kern gelblich oder rötlichbraun, Splint gelblich oder rötlichweiss. Das ganze Holz rötlich seideglänzend. Jahresringe undeutlich von einander geschieden. Zellgänge öfter vorhanden. Rinde braun, etwas glänzend, bildet später eine tiefrissige Borke.

Salix alba, pentandra und andere Salixarten. Kern mehrweniger gelblich oder dunkler braun, Splint weiss. Im Holz eventuell Zellgänge. Rinde mit mehrweniger tiefen Längsrissen.

Salix fragilis. Wie die vorhergehenden Weiden, aber keine Zellgänge. 


\section{Register.}

Es bedeutet: B. Tabelle zur Bestimmung nach den Blättern; W. Tabelle zur Bestimmung in Winterzustand; K. Keimlingstabelle; H. Tabelle zur Bestimmung der Hölzer.

Abfall der Blätter 64 .

Abheben der Rinde durch Frost 176 .

Abies amabilis Forb. 255 .

- balsamea Mill. 255 .

- canadensis Mill. 259.

- concolor Lindl. et Gord. 255.

- Douglasii Lindl. 259.

- excelsa DC. 256.

- firma Sieb. et Zucc. 255.

- grandis 255.

- nobilis Lindl. 255.

- Nordmanniana Lk. 255. B. 4I5.

- pectinata DC. 255, B. 415 , K. 462,465, H. 476 .

- Pichta Forb. 256.

- Pinsapo 256.

- sibirica Ledeb. 256.

Abietaceae 254.

Abrus 347.

Abschlemmen der Erde 411 . Absorption des Lichtes 137 . Absprünge 164 .

Absterben der Wurzeln 108. Abwechselnde Stellung 50 . Abwerfen der Äste I64.

Acacia 349.

Acanthaceae $35^{8}$.

Acer californicum Koch 329.

- campestre L. 328, B. 425 , W. 459, K. $471, H .482$.

- dasycarpum Ehrh. 329, B. 425, W. 458, K. 468 .

- italicum 329.
Acer monspessulanum 328 .

- Negundo L. 329, B. 426, W. 460 .

- obtusatum 329.

- platanoides L. 327, B. 425, W. 458 , K. 47 I, H. 482 .

- Pseudoplatanus L. 326, B. 425 , W. 460 , K. 470 , H. 482 .

- rubrum 329.

- saccharinum Wangh. 328.

- saccharinum L. 329.

- tartaricum 329.

Acerineae 326.

Acetabularia 194.

Achillea 369.

Achlya 203.

Ackerspergel 313.

Aconitum 316.

Acorus 285 .

Actaea 316.

Actinomorph 269.

Actinomorphe Blüten 48 .

Acyklisch 268.

Adansonia 322.

Adenostyles 369 .

Adlerfarn 239.

Adoxa 333.

Adventivbildungen 44 .

Adventivembryonen $25 \mathrm{I}$.

Adventivwurzeln 108.

Aecidiosporen 216.

Aecidium Berberidis $2: 7$, 218.

- elatinum 223.

- Euphorbiae 2I8.
Aegopodium 352.

Aërotropismus 172 .

Aesculinae 325.

Aesculus Hippocastanum 325 , B. 425 , W. $454, \mathrm{~K}$. 468, H. 485 .

Aesculus carnea 326 .

Aethalium septicum 196.

Aethusa 352.

Affenbrotbaum 322 .

Afrika, tropisches 378 .

Agamae 186.

Agaricineae 229.

Agaricus 23r.

Agaricus melleus 230.

Agathis Dammara 264.

Agave 288.

Aggregatae 367 .

Agrimonia 337.

Agrimonieae 337 .

Agrostemma 315.

Agrostideae 280.

Agrostis 280.

Ähre 47.

Ahorn, eschenblättriger 329 .

- französischer 328.

- gemeiner 326 .

- spitzblättriger 327 .

— stumpfblättriger 326 .

- weisser 329.

Aigeiros 296.

Ailanthus 324, B. 423, W. 43 I,

H. 480 .

Aira 28I.

Aizoaceae 315 .

Ajuga 359 . 
Ajugoideac 359

Akazic 346, 349 .

Alac 346

Nlant 370 .

Alchemilla $33 \mathrm{~S}$.

Aldehyd 136 .

Aldrovandia 320 .

Alectorolophus $35^{\mathrm{S}}$

Aleppokiefer 26r.

Aleuronkörner 19.

Alisma 275 .

Alismaceae 275 .

Allium 286.

Allium cepa $7 \mathbf{I}$.

Alnus glutinosa 299, B. 420 , W. 429, K. 473, H. 478 .

- incana 299, B. $420, \mathrm{~W}$. 430 , K. 474, H. 478 .

- pubescens 300.

- viridis 300.

Aloë 286.

Alopecurus 280.

Alpenerle 300.

Alpenrebe 317 .

Alpenrose 354 .

Alsineae 315 .

Alternation 50, 268 .

Althaea 322.

Alyssum 319.

Amanita 23I.

Amarantus 315.

Amarantaceae 315 .

Amaryllidaceae 288 .

Amaryllis 288.

Amblystegium 236.

Ambraholz 353.

Amelanchier 344.

Amentaceae 290.

Amerika, tropisches 378 .

Ammieae $35^{2}$.

Ammoniakverbindungen I39.

Ammophila arenaria 7 I, 280.

Amöben 4, 196.

Amöboide Bewegung 7 .

Amorpha 347.

Ampelidaceae 330.

Ampelopsis hederacea $33 \mathrm{I}$.

Ampelopsisranken, Reizbarkeit 173 .

Amygdalaceae 338 .

Amygdalus communis 338 .

Amylum 20.
Anacardiaceac 324.

Anagallis 355 .

Analytische Processe $\times 36$.

Ananas 288.

Anatomic I.

Anatomic des Blattes 57 ff.

der Moose $3 \mathrm{~S}$.

- der Sprossaxen 7 I ff.

schuppenförmiger Blätter 64.

- der Wurzeln (primär) I I $1 \mathrm{ff}$.

Anatrope Samenknospen 244.

Anchusa 359.

Anden 379.

Androcceum 245.

Andromeda 354.

Andropogon 278 .

Andropogoneae 278 .

Anemone $3 \mathbf{I} 6$.

Anemoneae 316.

Anethum 353 .

Angelica 352 .

Angiospermae, Typus 268.

Angiospermen, Fortpflanzung $242 \mathrm{ff}$.

Anlegung von Organen, Lichteinfluss 167 .

Anlegung von Organen, Schwerkraftswirkung 167 .

Anonaceae 3 I 7 .

Anorganische Verbindungen I35.

Ansprüche an den Boden 145.

Antarktisches Reich 379.

Antennaria 208.

Anthemis 369.

Antheren 243.

Anthericum 286.

Antheridien der Algen I88.

- der Moose 232.

- der Pilze 197.

- der Pteridophyten $236 \mathrm{ff}$.

Anthoceros 234.

Anthochlor 16.

Anthocyan 16.

Anthoxanthin I6.

Anthoxanthum 280.

Anthriscus 352 .

Anthyllis 347 .

Antipoden 248.
Antirrhinaceac 357.

Apetal 269 .

Apfel 343 .

Apfelsine 323 .

Apiosporium 208.

Apium $35^{2}$.

A pocarp 269.

Apocynaceae 360.

Apophyse 260.

Apothecien 201.

Apposition 32.

Aprikose 338 .

Aquifoliaceae 330.

Aquilegia 316.

Araceae 285 .

Arachis 348 .

Araucariaceae 264.

Araucaria excelsa 264.

- imbricata 264.

Arbutus 354.

Archangelica 353.

Archegoniatae 237.

Archegonien der Gymnospermen 246.

- der Moose 23 I.

- der Pteridophyten 236 ff.

Arctostaphyllos 354 .

Arcyria 196.

Arktisches Gebiet 384 .

Arktotertiär 37 I.

Arillus 252, 330 .

Aristolochia 353 .

Aristolochia Clematitis, Bestäubung 273 .

Aristolochiaceae 353 .

Armeniaca 338.

Armeria 355 .

Armillaria 230.

Armleuchtergewächse 196.

Arnica 369.

Arnoseris 368 .

Arrowroot 288.

Art 182.

Artemisia 369.

Artischocke 367.

Artocarpus incisa 314.

Arum 285.

Arundo $28 \mathrm{r}$.

Arve 262.

Asarum 353.

Aschenbedürfnis 145,146 .

Aschenbestandteile $144 \mathrm{ff}$.

- Bedeutung 147. 
Aschengehalt des Holzes I46, I47.

- jüngerer Pflanzen 147 .

Aschenmengen 145.

Asci 201 .

Asclepiadaceae 360 .

Asclepias 360.

Ascolichenes 215.

Ascomycetes 204.

Ascosporen $20 \mathrm{r}$.

- Bildung ro.

Asparagin 17, 141.

Asparagus 287 .

Aspen 296.

Aspergilleae 207.

Aspergillus 207.

Asperifoliaceae 358

Asperula 363.

Aspidium 239.

Asplenium 240.

Assimilation 136 .

- Intensität 137 .

- Nachweis I36.

Assimilationsparenchym 62 .

Assimilierende Sprossaxen 68.

Äste, Abwerfen 164.

Aster 369 .

Astereae 369 .

Astragaleae 346.

Astragalus 347 .

Astrantia 352 .

Aststumpf 128 .

Ästung 128 .

Astverschluss 130 .

Astwunden 128.

Atemhöhle 58 .

Atlantische Pflanzen 390.

Atmung, Abhängigkeit von äusseren Faktoren I55.

- intramolecular 154.

- Nachweis 154.

- normal i 54.

Atmungsintensität 155 .

Atragene 317 .

Atriplex 315

Atropa 356.

Atrope Samenknospen 244.

Attalea 285.

Aucuba 350 .

Aufbau, radiärer 48 .

Auffrieren 175.

Auflockerung d. Bodens 4II
Aufrichten der Zweige 176 .

Auftauen 174.

Augentrost $35^{8}$.

Auriculariaceae 223.

Ausbreitung von Samen 274.

- der Wurzeln ro8.

Ausläufer 70.

Ausreifen der verholzten

Triebe 95 .

Aussaat, Tiefe 167 .

Ausschlagsfähigkeit 46 .

Austral 372.

Austrocknen 178 .

Austrocknen im Winter 174 .

Auswüchse am Holz I34.

Autobasidiomycetes 224 .

Autöcie 2 I 8 .

Autonome Bewegungen 168.

Auxosporen 194.

Avena 280.

Aveneae 280.

Axenbürtig 269.

Azalea 354.

Bachweide 292.

Bäche 396.

Bacillus I9I.

Bacterium aceti $\mathbf{1 9}$.

Bacterium Radicicola 140.

Bakterien I9I.

Balanophoreae 353 .

Baldgreis 369 .

Baldrian 366 .

Balgkapsel 270.

Ballota 359 .

Balsam, peruvianischer 346 .

Balsaminaceae $32 \mathrm{I}$.

Balsamine $32 \mathrm{r}$.

Balsampappeln 297.

Bambusa 285 .

Bambuseae 285 .

Banane 288 .

Bangia 195.

Banyan 314.

Baptisia 346.

Barbula 236.

Bärentatze 224 .

Bärenklaue 353 .

Bärentraube 354 .

Barfrost 174 .

Bärlappgewächse $24 \mathbf{I}$.

Bartflechte 2I 5 .
Basidie 200.

Basidiomycetes 223.

Basidiosporen 200.

Bassia 355.

Bast, sekundärer 104.

Bastfasern 25, 78, 105. 106.

Bastfaserähnliches System 89.

Bastkörper, sekundär ro4.

Bastparenchym 105.

Bastrüster $3^{\mathbf{I} 3}$.

Bastteil 77 .

Bauchkanalzelle 247 .

Bauchpilze 231.

Bauchseite 50.

Baum 66.

Baumgrösse 66 .

Baumtöter 330 .

Baumwolle 322.

Becherpilz 23I.

Beere 270, 27I.

Befruchtung, Angiospermen 248.

Befruchtung,Gymnospermen 245.

Beggiatoa 192.

Begoniaceae 349 .

Beifuss 369.

Beinwell 359 .

Bellis 369 .

Berberideae 317.

Berberis vulgaris 317, B. 420 ,

W. 436, H. 479 .

Bergahorn 326 .

Bergkiefer 260.

Bergmispel 342 .

Bergrüster 312 .

Berteroa 319.

Bertholletia $35^{\circ}$

Berufkraut 370.

Besenpfrieme 348 .

Bestandesbonitäten 160 .

Bestandeshöhen 160 .

Bestäubung 249, $27 \mathrm{rff}$.

Beta 315 .

Betonica 359.

Betulaceae 298.

Betula alba L. 301 .

- alba auct. non L. 300.

- carpathica $30 \mathrm{I}$.

- fructicosa 302.

- humilis 302.

- lenta zor. 
Betula nana \$02.

odorata $30 \mathrm{r}$.

pubescens Ehrh. 30I,

B. 419 , IV. 435 , K. 473 .

- tomentosa 301.

- verrucosa Ehrh. 300, B. 419, IV. 436 , K. 473 , H. 48.4 .

Bewegung, periodische 170 .

- spontane 168.

Bibernell 352 .

Bicornes 353 .

Bickbeere 354 .

Bidens 369 .

Biegungsfestigkeit 100.

Bierhefe 205.

Bignonia 358 .

Bignoniaceae 358 .

Bilaterale Organe 49.

Billbergia $2 S 8$.

Bilsenkraut 356 .

Bindung des Bodens $4 \mathrm{II}$.

Bingelkraut 323 .

Binnengewässerformation 377.

Binsen 276, 287.

Biota orientalis $267, \mathrm{~B} .415$, K. 462, H. 477 .

Birke 300.

- nordische 301 .

Birkenkork 122.

Birkenwälder, Bodenflora 402.

Birnbaum 343.

Birnenrost 218.

Birnkraut 354 .

Blasenkirsche 356 .

Blasenstrauch 347 .

Blatt 34, 5 I ff.

Blattadern 63.

Blattanlage 39.

Blattausbildung 166 .

Blätter, assimilierende $5 \mathrm{I}$.

- nicht assimilierende 55 .

Blätterschwämme 229 .

Blattfärbung $\mathrm{I} 5$.

Blattfläche 40.

Blattgrösse und Wassergehalt 167 .

Blattgrund 39.

Blattmosaik 52 .

Blattnerven 63 .

Blattranken 57
Blattrippen 63 .

Blattrosetten 52.

Blattscheide 39, 53 .

Blattspreite 40.

Blattspuren 74 .

Blattsteckling 45 .

Blattstellung 48,50 .

Blattstiel 40.

Blaubeere 354 .

Blaugras $28 \mathrm{r}$.

Blauholz 99, 345 .

Blechnum 240.

Bleichsucht 137 .

Bleistiftholz 267 .

Blitzschlag 180 .

Blumenbinse 275 .

Blumenesche $36 \mathrm{r}$.

Blutungsdruck 152,153 .

Bluten I 52, $244 \mathrm{ff}$.

Blüten, Morphologie 268.

- eingeschlechtige 245 .

- hermaphrodite 245 .

- nackte 269.

Blütenfarben $15,272$.

Blütenformeln 271 .

Blütengeruch 272 .

Blütenspelzen 277 .

Blütenstaub 243 .

Bocksbart 368 .

Bocksdorn 356 .

Bodenbildung durch Pflanzen 407.

Bodenflora, wirtschaftliche

Bedeutung $4 \mathrm{II}$.

Bodenfrische 146 .

Bodengüte und Bestandshöhe 163 .

Bodenhold 407 .

Bodenklassen $40 \mathrm{I}$.

Bodenstet 408.

Bodenvag 407 .

Boehmeria 313 .

Bohne 347.

Bohnenkraut 360 .

Boletus 229.

Bonität des Bestandes 163 .

Boraginaceae 358 .

Borago 359.

Boreal 372.

Borke 122.

Borretsch 359 .

Boswellia 324.

Botanik, allgemeine 2.
Botanik, specielle 2.

Botrychium 240.

Botrydium 194.

Botrytis $210,212$.

Bovist $23 \mathrm{I}$.

Brachypodium 283 .

Brandpilze 215.

Brandsporen 215.

Brassica 319.

Braunalgen 195.

Braunwurz 357.

Brechnussbaum 36 I.

Brennnessel 313

Briza 28I.

Brodfruchtbaum 314.

Brombeere 337 .

Bromeliaceae 288 .

Bromus $28_{3}$.

Broussonetia 314.

Brunella 359.

Brunnenkresse 319.

Brustwurz 353.

Brutzellen (Moose) 233 .

Bryonia 349.

Bryophyllum 333 .

Bryophyta 231.

Bryopogon 215.

Bryum 236.

Buche 303 .

Buchenfarn 239.

Buchenkeimlingskrankheit 202.

Buchenregion 393.

Büchse $27 \mathrm{I}$.

Buchweizen 314 .

Bulbochaete 193 .

Bulgaria 2r3.

Burgundereiche 308 .

Burseraceae 324.

Butomus 275 .

Butterbaum 355 .

Buttersäuregärung $\mathbf{I} 55$.

Buxaceae 323.

Buxus 323, B. 424 .

Cactaceae 315.

Cactiflorae 3 I 5 .

Caeoma 220.

Caesalpinia 345 .

Caesalpiniaceae 345 .

Cakile 3 I9.

Caladium 285 . 
Calamagrostis $2 \mathrm{So}$

Calamintha 360 .

Calamus 285 .

Calciumcarbonat, Vorkommen 30.

Calendula 366 .

Caliaturholz 99, 348 .

Calla 285 .

Callitriche 323 .

Callitrichaceae 323 .

Calluna 354 .

Callus 125 .

Caltha 3 I6.

Calycanthaceae 3 I 7 .

Calycanthus 3i7.

Calyptospora 220.

Calyptra 233 .

Calyx 245.

Cambiformzellen 77 .

Cambium 71, 83, 118

Cambiumring $\varsigma_{3}$.

Camelina 319.

Camellia 320.

Campanula 366.

Campanulaceae 366 .

Campanulinae 366 .

Campescheholz 99, 345 .

Camphora 317.

Canae 292.

Canna 288.

Cannabineae 314.

Cannabis $3 \mathbf{I} 4$.

Cantharellus 23 I.

Capillarkraft I5I.

Capnodium 208.

Capparideae 3 I9.

Capparis 319.

Capreae 295.

Caprifoliaceae 364 .

Capsella 319 .

Capsicum 356.

Caragana arborescens 347 , B. 423 , W. 436 .

Cardamine 319

Carduus 367 .

Carex 277.

Carex arenaria 68, 71 .

Carica 349.

Cariceae 277

Carina 346.

Carlina 367 .

Carpellbürtig 269.

Carpelle 243.
Carpinus Betulus 302, B. 418 , W. 449 , K. 473, H. 479 .

- duinensis 303 .

Carposporeen 189.

Carum 352.

Carya alba 3 Iо, K. 468 .

- amara .310.

- porcina 310.

- sulcata 310.

- tomentosa 310.

Caryophyllaceae 3 r5.

Caryophyllus $35^{\circ}$.

Cassia 345 .

Castanea vesca 304 , B. 4 I6, W. 449, K. 468, H. 483 .

- vulgaris 304 .

Casuarinae 3 I 4 .

Catalpa $35^{8}$.

Caucalis 353 .

Caulerpa 35, I94.

Ceder 264.

Cedrela 323.

Cedrus atlantica 264.

- Deodara 264, B. 4 I6.

- Libani 264.

Celastraceae 329.

Celastrus I3I, 330.

Cellulose $27 \mathrm{ff}$., I $4 \mathrm{I}$.

Celosia 3 I5.

Celtis australis $3 \mathrm{I} 3$, B. 4 I 8 .

Celtoideae $3 \mathbf{I} 3$.

Cembra 262.

Cenangium 212.

Centaurea 367.

Centralcylinder der Sprossaxen $4 \mathrm{I}, 76$.

Centralcylinder der Wurzeln I 7 .

Cephalanthera 289 .

Cephalotaxus 253.

Ceramium I95.

Cerastium 3 I 5 .

Cerasus 339 .

Ceratodon 236 .

Ceratonia 346.

Ceratophyllaceae 3 I 7 .

Ceratophyllum 317 .

Ceratozamia $25 \mathbf{I}$.

Cercis 345 .

Cereus 315

Cerris 308.

Cetraria 2 I 5 .

Chaerophyllum $35^{2}$.
Chaetocladiaceae 204.

Chalazaende 244.

Chamaecyparis Lawsoniana Parl. 265, K. 462 .

- nutkaënsis Spach. 266.

- obtusa Sieb. et Zucc. 266.

- pisifera Sieb. et Zucc. 266.

Chamaerops $2 S_{5}$.

Champignon $23 \mathrm{r}$.

Chantransia 195 .

Chara I96.

Characeae 196.

Chelidonium 3 I8.

Chemische Reize I7I.

Chenopodiaceae $3 \mathbf{I} 5$.

Chenopodium 3 I 5 .

China 380.

Chinagras 313 .

Chinin 364 .

Chlamydomonas 193.

Chlamydosporen 199, 20 I.

Chlor, schädliche Wirkung 179.

Chloroformwirkung 169.

Chlorophyceae 193.

Chlorophyllbildung 137 .

Chlorophyllfarbstoff $\mathbf{I} 37$.

ChlorophyllfreiePflanzen, Ernährung 142 .

Chlorophyllführende Gewebe 62 .

Chlorophyllkörper I3, I 4 .

- Bewegungen i 70.

Chlorophyllspectrum I 37 .

Chloroplasten I 3 .

Chloroplastin I4.

Chlorose 137.

Choripetal 269.

Choripetalae 289.

Christophskraut 3 I6.

Christusdorn 345.

Chromatin 9.

Chromatophoren 13.

Chromoplasten I 5 .

Chrysanthemum 369 .

Chrysobalanaceae 344 .

Chrysomyxa 223.

Chrysosplenium 333.

Chytridiaceae 203.

Chytridium 203.

Cicer 347.

Cichorieae 368 .

Cichorium 368. 
Cicuta 352.

Cigarrenkistenholz 323.

Cinchona 364 .

Cinnamomum 317 .

Circaea 349.

Circulation 7 .

Circumnutation I6S.

Cirsium 367.

Cissus 331 .

Cistaceae 320.

Cistiflorae 319.

Cistus 320 .

Citrone 323.

Citronenmelisse 360 .

Citrullus 349.

Citrus 251, 323.

Cladodien 68 .

Cladonia 215.

Cladophoraceae 194.

Cladothrix 19I.

Cladrastis 346.

Clavaria 224.

Clavarieae 224.

Claviceps 2 ro.

Cleistocarpae 235.

Clematideae 316 .

Clematis vitalba 316, B. 425 , IV. 454 .

Climacium 235.

Clinopodium 360.

Closterium 194.

Clusiaceae 320.

Cochlearia 319.

Cocus 285 .

Coelebogyne $25 \mathrm{I}$.

Coffea 364 .

Colchicaceae 286 .

Colchicum 286.

Coleochaetaceae 193.

Coleochaete, Fortpflanzung I 89.

Coleosporium $22 \mathrm{I}$.

Collema 215 .

Collenchym 24.

Colocasia 285.

Columbien 383 .

Columella (Moose) 234.

Columniferae $32 \mathrm{I}$.

Colutea arborescens 347 , B. 423 .

Comarum 336.

Combretaceae 350 .

Comellina 286.
Commiphora 324 .

Compassptlanze 365 .

Compositae 367 .

Confervaceac 193

Conidien 198, 199.

Conidienfrüchte 200 .

Conidienlager 199.

Conidienträger 199.

Coniferae 251 .

Coniferenzapfen 254 .

Coniferin 28.

Conium 352.

Conjugatae 194.

Connectiv 243.

Constantinea 36 .

Contactreize 172.

Contortae 360.

Convallaria 286.

Convallariaceae 286 .

Convolvulaceae 356 .

Convolvulus 356 .

Cora 215.

Corallorhiza 289.

Corchorus 322.

Cordiaceae 359 .

Cordiceps 2 ro.

Coriandrum 353.

Cornaceae 350.

Cornus alba 350.

- mas 35o, B. 424, W. 455.

- sanguinea 350 , B. 424 , W. 456 .

- suecica 350 .

Corolle 245.

Correlationswachstum 167 .

Corticium 224.

Corydalis 319 .

Corylaceae 302.

Corylus avellana 302, B. 418 ,

W. 448, K. 468, H. 479 .

- colurna 302.

- tubulosa 302.

Corynephorus $28 \mathrm{r}$.

Cosmarium 194.

Cotoneaster vulgaris 342 , B. 418, W. 444 .

Cotyledonen $38,251,289$.

Crassulaceae 333 .

Crataegus oxyacantha 342, B. $42 \mathrm{I}$, W. 444, H. 485 .

- monogyna 342 , B. $42 \mathrm{I}$, W. 444 .

Crenothrix 192.
Crepis 368.

Crocus 288.

Cronartium 222.

Cruciferae 319.

Cryptomeria japonica Don. 264, K. 462.

Cryptospora 209.

Cucumis 349.

Cucurbita 349.

Cucurbitaceae 349

Cupressaceac 264.

Cupressinae 265.

Cupressus Lawsoniana Murr. 265.

- sempervirens L. 266.

Cupula 302, 303.

Cupuliferae 303 .

Curare 361 .

Curvembryae 314.

Cuscuta IIo, 356 .

Cuticula 29.

Cutinisierung 29.

Cyanophyceae 193.

Cyathus 23I.

Cycadeae $25 \mathrm{I}$.

Cycas 251 .

Cyclamen 355 .

Cyclanthera 349 .

Cydonia vulgaris $343, \mathrm{~B} .417$, W. 431 .

Cyklisch 268.

Cymöse Verzweigung 47.

Cynanchum 360.

Cynara 367.

Cynareae 367 .

Cynoglossum 359.

Cynosurus 28r.

Cyperaceae 276.

Cyperus 276.

Cypripedium 289.

Cystopus 203.

Cytisus Laburnum 347, B.422,

W. 439, H. $48 \mathrm{I}$.

Cytoplasma 5, $6 \mathrm{ff}$.

Cytoplastin 7 .

Dachwurz 333.

Dacrydium 253.

Dacryomyceteae 224.

Dactylis $28 \mathrm{r}$.

Daedalea 228.

Dahlia 369. 
Dalbergieae 348 .

Daphne Mezereum 332, B 416, W. 439.

Darlingtonia 320.

Datiscaceae 349.

Dattelpalme 285 .

Datura 356.

Daucineae 353 .

Daucus 353.

Dauermycel 202.

Deckblätter 56 .

Deckschuppen, Pinoideae 254.

Deckspelzen 277 .

Decussierte Stellung 50.

Deformationen 134, I43.

Deformationen durch Taphrina 206.

Delesseria 195.

Delphineae 3 I6.

Delphinium 316.

Dematophora 208.

Dermatogen 4I.

Desinfektion 143.

Dextrin 17.

Diageotropismus I69.

Diagramm 48.

Diagramm der Blüten 269.

Diaheliotropismus der Blätter 170.

Dialypetal 269.

Dianthus 315 .

Diapensiaceae 354 .

Diaporthe 209.

Diatomeae 194.

Diatrype 209.

Dicentra 319.

Dichasium 47.

Dichogamie 274 .

Dichopodiale Verzweigung 46.

Dichotomie 46.

Dickenwachstum 157 .

- anormales 85 .

- Beginn 165.

- der Dicotylen 83.

- der Gymnospermen 83 .

- der Monocotylen 85 .

- normales 84.

- Periodicität 163 .

- sekundäres der Algen 37.

- - der Sprossaxen 83.

- _ der Wurzeln 117
Dickenwachstum der Zellwand 32 .

Dicotyledones, Typus 289.

Dicranum 236.

Dictamnus 323.

Dictyostelium 196.

Diervilla 365 .

Diffusion 22.

Digitalis 357 .

Dikarpisch 269.

Diklinische Blüten 245 .

Dill 353 .

Dilleniaceae 320.

Dimorph 274.

Diöcisch 245 .

Dionaea 54, 320 .

Dioon 25 I.

Dioscoraceae 288.

Diospyrinae 355 .

Diospyros 99, 355 .

Diplecolobeae 3 I9.

Diplodia 209.

Diplostemonisch 268.

Dipsaceae 367 .

Dipsacus 367 .

Dipteryx 348.

Discomycetes $21 \mathrm{I}$.

Diskus 29I.

Distel 367.

Divergenz $5 \mathrm{I}$.

Dividivi 345 .

Dolde 47 .

Doldenpflanzen $35^{\circ}$.

Dornen 57,69.

Dornfarn 240.

Doronicum 369.

Dorsiventrale Organe 49 .

Dost 360 .

Dothideaceae 2 II.

Dotterweide 291.

Douglasfichte 260.

Douglastanne 260.

Draba 319.

Dracaena 287 .

Dreikammerig 269.

Drimys 317 .

Drosera 54, 320.

Droseraceae 320.

Druckfestigkeit 100.

Drupaceae 338.

Drüsenhaare 6r.

Dryas $33^{6 .}$

Duftanhang I 80.
Dünen 395 .

Düngung 147 .

Durchlüftung des Bodensi 67 .

Dürlitze 350 .

Ebenaceae 355.

Ebene 393.

Ebenholz 99, 355.

Eberesche 343 .

Ebereschenrost 2 I9.

Ebermaiersche Theorie 177 .

Eberwurz 367.

Ecbalium 349.

Echeveria 333.

Echinocereus 67,315 .

Echium 359.

Ectocarpus 195.

Edelkastanie 304.

Edelreis 132.

Edeltanne 255 .

Edelweiss 370.

Ehrenpreis 358 .

Eiapparat 248.

Eibe 253.

Eibisch 322.

Eiche 304 .

- österreichische 308 .

Eichenfarn 239.

Einbeere 287 .

Einbohren von Früchten 275 .

Einfächerig 269.

Einhäusig 245 .

Einkeimblättrige, Typus 275 .

Einkorn 283.

Einzelformationen 373 .

Eisanhang 180.

Eisbildung 173 .

Eisen 147 .

Eisenholz 346, 355 .

Eisenhut $3 \mathbf{1 6}$.

Eisenkraut 359 .

Eiszeit 372.

Eiweisskrystalle 14, 16, 19.

Eizelle der Algen I88, 189.

- - Angiospermen 248 .

- - Gymnospermen 247.

Elaeagnaceae 332 .

Elaeagnus argentea 332 .

- angustifolia 332 , B. 417,

W. 438 .

Elaeïs 285 .

Elateren 233. 
Elementarorgane der Markstrahlen 02.

Elemente des sek. Holzes 89, 92.

Elettaria $28 S$.

Elfenbein 285 .

Eller 299.

Elodea 276 .

Elymus $36,71,285$.

Elzbeere 343 .

Embryo, Angiospermen 250, 251.

- Gymnospermen 247.

Embryosack 244, 248.

Emergenzen 60.

Emmer 284.

Empetraceae 323.

Empetrum 323.

Empfindlichkeit für Hitze I78.

Empusa 203.

Enantioblastac 286.

Endemisch 372.

Endodermis 117 .

Endogene Entstehung II 7 .

Endokarp 270.

Endosmose 22.

Endosperm (Angiospermen) $248,250$.

- (Gymnospermen) 246.

Endosporen 199, 200.

Endothecium 233.

Energiegewinnung $\mathbf{5} 5$.

Engelwurz 353.

Entomophtora 203

Entomophtoraceae 203.

Entwickelung, akropetale 44.

- basipetale 44.

- des Pflanzenreichs 182.

Entwickelungsreihen $\mathbf{1 8 7}$, I 90.

Enzian 360.

Epacrideae 354.

Ephedra 268.

Epheu 35 I.

Epicotyl 38.

Epidermis 57, 7 I.

Epigyn 270.

Epikarp 270.

Epilobium 349.

Epipactis 289.

Epipetal 269.

Epiphyllum 3 I 5.
Epiphyten 373.

Epipogum 289.

Episepal 268.

Equisetinae 240.

Equisetum 240.

Erbse 347.

Erbsenbaum 347.

Erdbeerbaum 354.

Erdbecre 336 .

Erdnuss 348 .

Erdrauch 319.

Erfrieren 174.

Erica 354.

Ericaceac 354.

Erigeron 370.

Eriodendron 322.

Eriophorum 276.

Erle 299.

- klebrige 299.

- nordische 299.

Erlenbruch 397.

Erlenwurzeln, Anschwellungen 196.

Erodium 321 .

Ersatzfasern $9 \mathbf{I}$.

Ersatzzellen 91.

Eryngium 352.

Erysimum 319.

Erysiphe 207.

Erysipheae 207.

Erythraea 360.

Erythrobalanus 307.

Esche $36 r$.

Eseisdistel 367 .

Esparsette 348.

Espe 296.

Estragon 369 .

Etiolement 137.

Eucalyptus 350.

Euclea 355.

Eucyklisch 268.

Eudorina 193.

Eupatorioideae 368.

Eupatorium 369.

Euphorbia 323.

Euphorbiaceae 322.

Euphrasia $35^{8}$.

Europa 384.

Evernia 215.

Evonymus europaeus 330,

B. 424 , W. $46 \mathrm{I}$, H. 482 .

- latifolius 330.

Exineblasen 254.
Exoasci 205.

Exoascus 206.

Exobasidium 224.

Exosmose 22.

Exosporen 199.

Expansion der Blattgelenke 169.

Exposition 394.

Fächel 48 .

Fächerpalme 285 .

Fagus silvatica 303, B. 418 ,

W. 449, K. 468, H. 479.

Falcaria 352.

Färberwaid 319.

Färberwau 3 I 9.

Farbstoffkrystalle 16 .

Färbung der Früchte 15.

- herbstliche 64 .

Farne 237.

Farnpflanzen 236.

Fasciation 134.

Fascicularcambium 83 .

Fasertracheiden 89.

Faulbaum 331, 340.

Fäulniss I 55 .

Fäulnissbakterien 192.

Fegetella 234.

Feigenbaum 3 I 3 .

Feldahorn 328.

Feldrüster 3 I I.

Felsenformationen 376 .

Felsenkirsche 340 .

Felsnelke 31.5.

Fenchel 352.

Ferkelkraut 368 .

Fermente 143.

Fernambukholz 99, 345.

Festigkeit des Holzes roo.

Festigkeitsmodul $3 \mathrm{I}$.

Festigkeitsverhältnisse der Zellen 31, 32.

Festigung der Blätter 63 .

Festigung der Sprossaxen 71,73 .

Festuca 283 .

Festuceae 28I.

Fette $2 \mathbf{I}$.

Fetthenne 333 .

Fettkraut 358 .

Feuchtigkeit und Pflanzenverteilung 392 . 
Feuchtigkeitsdifferenzen als Reiz 173.

Feuerbohne 347 .

Feuergefahr 4 I 2.

Feuerlilie 286.

Feuerschwamm 226.

Ficaria 316.

Fichte 256.

- sibirische 259.

Fichtennadelrost 223.

Fichtenspargel 354 .

Fichtenvarietäten 257 .

Fichtenwälder; Bodenflora 402.

Ficus carica $3 \mathbf{I} 3$.

- bengalensis 314.

- elastica 3I4.

- religiosa 314.

Fieberklee 360 .

Filago 370.

Filament 243 .

Filices 237.

Filicinae 237.

Filzkraut 370.

Fingerhut 357 .

Fioringras 280 .

Fischkrankheit 203.

Fisetholz 324.

Flächenwachstum I 57 .

- der Zellwand 32.

Flächenzuwachs 157 .

Flacherie 192.

Flachs 320.

Flachsprosse 68.

Flachsseide 356.

Flatterrüster $3 \mathrm{I} 3$.

Flatterulme 3 I 3 .

Flechten 2 I 3 .

Flechtenformationen 376 .

Fleischfressende Pflanzen 54, I 42 .

Flieder 363,365 .

Fliegenfalle 54,320 .

Fliegenpilz 23 I.

Florengebiete $37 \mathrm{I}, 378 \mathrm{ff}$.

Florenreiche $37 \mathrm{I}, 377 \mathrm{ff}$.

- antarktisches 379 .

- australe 378,379 .

- boreale 379 .

- mediterranes 379 .

- nordisches 382 .

- tropische 377 .

Florideae 195.
Flügel der Früchte 274 .

Flügelerbse 347 .

Foeniculum 352.

Föhre 260.

Folgemeristeme $7 \mathrm{I}$.

Fontinalis 235 .

Forche 260.

Formaldehyd 136 .

Formationen 373 ff.

Fortpflanzung der Algen 186.

- - Blütenpflanzen 242.

- - Moose 231.

- Pilze r96.

- Pteridophyten 236.

Fragaria 336.

Fragiles 291.

Frangulinae 329.

Franzosenholz 324 .

Frassgänge 132 .

Frauenflachs 357 .

Fraxineae 36I.

Fraxinus americana 362 .

- excelsior $36 \mathrm{I}$, B. 425 , W. 457 , K. 47 I, H. 483.

- excelsior var. monophylla 361 .

- Ornus 36 I, B.425, W. 457 .

- pubescens 362 .

Freikronblättrig 269.

Fremdbestäubung $27 \mathrm{I}$.

Fritillaria 286.

Froschbiss 276 .

Froschlöffel 275 .

Frostbeschädigungen 173 , 176.

Frostgefahr 412.

Frostkrebs 176 .

Frostleisten 175 .

Frostrisse 175 .

Frostspalten 175 .

Frostwirkung 173 .

Frucht, echte 270.

- Morphologie 268.

Früchte, Ausbreitung 274.

Fruchtblätter 243 .

Fruchtknoten 243, 269 .

Fruchtschuppen, Pinoideae 254.

Fruchtstände 270 .

Früheiche 305.

Frühfrost I74, I76.

Frühjahrsästung 130 .

Frühjahrsholz 94.
Frullania 234.

Fuchsia 349.

Fucus 195.

Fuligo 196.

Füllzellen I24.

Fumago 208.

Fumaria 3 I9.

Fumariaceae 319.

Funaria 236.

Funiculus 244.

Funkia $25 \mathrm{I}$.

Funktionen des Holzkörpers 87.

Fusicladium 209.

Gagea 286.

Gagelstrauch 3 II.

Gaisblatt 364 .

Gaisfuss 362 .

Galanthus 288.

Galeobdolon 359.

Galeopsis 359.

Galium 363.

Galläpfel 309 .

Gallertflechten 215 .

Gallertpilze 224.

Gamander 359 .

Gameten I 86 .

Gamopetal 269.

Gänseblümchen 369 .

Gänsedistel $36 S$.

Gänsefuss 315 .

Gartennelke 315.

Gärung 155 .

- alkoholische 155.

- durch Mucor 204.

- durch Hefe 205.

- faulige I55, I9I.

Gärungserreger I 55 .

Gase, schädliche, als Reiz 172.

Gasteromycetes 23 I.

Gattung 182.

Gauchheil 355 .

Gebůschformation 374 .

Gefässbündel $78, \delta_{3}, \delta_{5}$.

- Bau 77.

- bicollaterale 79 .

collaterale 78 .

- concentrische 79 .

_ des Blattes 63 .

- der Wurzeln 1 I 7 . 
Gefässbündel, Elemente des primären 77.

- geschlossene 85 . offene $S_{3}$.

- radiale 117.

- stammeigene 75 .

Gefässe 77.

- Bedeutung für Wassertransport 153.

- des sek. Holzes S9.

Gefässkryptogamen 236 .

Gefässzelle 25, 26.

- Länge 96.

Gefrieren 173.

Gegenfussler 248 .

Gehilfinnen $24 \mathrm{~S}$.

Geissblatt 364 .

Geissfuss $35^{2}$.

Gelbholz 324, 346.

Gelbkiefer 262.

Gemmen 199, 201.

Gemswurz 369.

Generative Zellen (Pollen) 245,248 .

Genista 348 .

Genisteae 347.

Gentiana 360.

Gentianaceae 360.

Genus I 82 .

Georgine 369.

Geotaxis 169.

Geotropismus 169.

- der windenden Pflanzen I 68.

Geraniaceae 320.

Geranium 32 I.

Gerbersumach 325 .

Gerbstoff 17, 18 .

Gerbstoffbehälter 8I.

Gerbstoffgehalt des Holzes 99.

- der Rinde 107.

Gerbstoffkugeln I 8 .

Gerbstoffschläuche $8 \mathbf{I}$.

Geröllhalden 376.

Gerste 284.

Geschlechtsgeneration der Algen 189.

Gesneraceae 358 .

Gesträuchformation 374 .

Getreidekultur 393.

Geum 336.

Gewässer 396.
Gewebe 43.

Gewebebildung 43 .

Gewebespannung 159.

Gewürznelken 350.

Gichtschwamm 231 .

Gifte 178 .

Ginkgo biloba 253 .

Ginster 348.

Gitterrost 2 I 8.

Gladiolus 288.

Glanzgras 280.

Glasweizen 284.

Glaux 355 .

Glechoma 360.

Gleditschia triacanthos 345 , B. 423 .

Gletscherweiden 292.

Glieder eines Blütenkreises 268.

Globoid I 9.

Globularia 360.

Globulariaceae 360 .

Glockenblume 366.

Gloeocapsa 193.

Glumiflorae 276.

Glyceria $28_{3}$.

Glycine 347 .

Glycocoll 141 .

Glycyrrhiza 347 .

Glykose I 7.

Gnadenkraut 357.

Gnaphalium 370.

Gnetaceae 268.

Gnetum 268.

Gnomonia 209.

Godlewskis Theorie der Wasserbewegung 153 .

Goldregen 347 .

Goldrute 369.

Golfstrom, Einwirkung des 386.

Gomphonema 195.

Gonium 193.

Goodeniaceae 367 .

Gossypium 322 .

Götterbaum 324 .

Gräben 396.

Gramineae 277.

Granatapfel $35^{\circ}$.

Graphis 215.

Grasähren 277.

Grasdecke 411 .

Gräser 277 .
Grasflurformation 375 .

Grasnelke 355.

Grassteppen 375.

Graswuchs 412.

Gratiola 357.

Graucrle 299.

Grenzhäutchen 26.

Grenzlinien, nördliche 390 , 391.

- nordöstliche 390 .

- nordwestliche 390 .

- südöstliche 390 .

Grimmia 236.

Grösse der Bäume 66 .

Gruinales 320.

Grünästung 128 .

Grünerle 300.

Grünlandsmoor 398.

Guajacum 324.

Gummi 29.

Gummi arabicum 349 .

Gummi des sekundären

Holzes 97.

Gummibaum 314, 350

Gummigänge 8 I .

Gummischleim 80

Gummosis 29.

Gundermann 360.

Günsel 359.

Gurke 349.

Gurkenkraut 359 .

Guttapercha 355.

Gymnoasceae 204.

Gymnocladus 345 .

Gymnocybe 235 .

Gymnospermae, Typus 25r.

- Fortpflanzung $242 \mathrm{ff}$.

- verglichen mit Kryptogamen 247 .

Gymnosporangium 218,219.

Gynaeceum 245, 269.

Gynandrae 288.

Gypsophila 315.

Haare 59.

Haarbirke 301 .

Habichtskraut 368 .

Haematoxylon 99, 345 .

Hafer 280.

Haftkraut 353 .

Haftscheiben der Algen 36 .

- der Wurzeln I Io. 
Hagebuche 302 .

Hagebutte 337 .

Hagel iso.

Hahnenfuss 316 .

Hainbuche 302 .

Hainsimse 287 .

Hakenkiefer $26 \mathrm{I}$.

Halbgräser 276 .

Halbschattenhölzer $\mathrm{I}_{3} \mathrm{~S}$.

Halbstrauch 66 .

Halesia 355.

Hallimasch 230 .

Halophyten 376, 409 .

Haloragidaceae 350 .

Halszellen 247.

Hanf 3 I 4 .

Hanfweide 294.

Hängefichte 257 .

Hängetanne 255 .

Haplostemonisch 268.

Harnstoff I 4 I.

Hartbast 78 .

Hartbovist $23 \mathrm{I}$.

Hartheu 320.

Hartriegel 350 .

Hartweizen $28_{4}$.

Harz im Plasma 2I.

Harzausscheidung $I_{3}$ o.

Harzbehälter 8I.

Harzbirke 300.

Harzfülle $23 \mathrm{I}$.

Harzgang $8 \mathrm{I}$.

Harzkanal $8 \mathbf{1}, 82$.

Harznutzung, Wunden 128 .

Harzsticken 23I.

Hasel, türkische 302 .

Haselnuss 302 .

Haselrüster 312.

Haselwurz 353.

Hauhechel 347.

Hauptwurzel ros.

Hausschwamm 228.

Haustorien I Io.

Heckenkirsche 365 .

Hecksame 348.

Hedera Helix 351, B. 422.

Hederich 319.

Hedwigia 236.

Hedysareae 348 .

Hedysarum 348 .

Hefepilze 204.

Heidekraut 354.

Heidelbeere 354 .
Heidenelke 315 .

Heleocharis 276 .

Helianthemum 320 .

Helianthus 369 .

Helianthus tuberosus $7 \mathrm{I}$.

Helichrysum 370 .

Heliotropismus 170 .

Helleboreae 316 .

Helleborus 316.

Helmkraut 359 .

Helobieac 275 .

Helvella 2 I 3 .

Helvellaceae 2r 3 .

Hemerocallis 286 .

Hemicyklisch 268.

Hemlockstanne 259.

Hepatica $3 \mathbf{1} 6$.

Hepaticae 233.

Heracleum 353

Herbstästung 130 .

Herbstholz 94.

Herbstzeitlose 286.

Hercospora 209.

Herpotrichia 208.

Heterobasidion 227.

Heteröcie 218.

Heterospor 236.

Heterostylie 274.

Hexenbesen der Tanne 223.

Hexenbesen durch Taphrina 206.

Hexenkraut 349.

Hibiscus 322 .

Hickorynuss 310.

Hieracium 368 .

Himbeere 337 .

Himmelsschlüssel 355 .

Hippocrepis 348 .

Hippophaë rhamnoides 332 , B. 4 I6, W. 439 .

Hippuris $35^{\circ}$.

Hippursäure I41.

Hirschschwamm 224.

Hirschtrüffel 208 .

Hirse 278 .

Hirtentäschel 319 .

Hochblätter $5 \mathrm{I}$.

Hochmoor 398 .

Höhencurven 162 .

Höhengrenzen der Waldbäume 394 .

Hoja 360.

Holcus $28 \mathrm{O}$.
Hollunder 363,365 .

Holosteum 315 .

Holzarten, begehrliche 145 .

- genügsame 145.

Holzelemente 85 , I I 9 .

Holzfasern 77 .

- des sekundären Holzes S9.

Holzgummi 28.

Holzkugeln I2 I.

Holzparenchym 77 .

Holzparenchym des sekundären Holzes $9 \mathrm{I}$.

Holzqualität roo ff.

- Abhängigkeit von äusseren Verhältnissen 102.

Holzstoffreaktionen 28 .

Holzsubstanzvolumen 102.

Holzteil 77

Holzzellen, Grösse 95.

- Verschiedenheiten 96.

Homalothecium 236.

Honiggras 280 .

Honigpilz 230.

Honigtau 208.

Hopfen 3 I 4.

Hopfenbuche 303 .

Hordeae $28_{3}$.

Hordeum 284 .

Hornäste I $2 S$.

Hornbaum 302.

Hornblatt 317.

Hornklee 347 .

Hortensie 334 .

Hottonia 355 .

Hufklee 348 .

Huflattig 369 .

Hülsspelzen 277 .

Hülse 270.

Hülsenfrüchte 344 .

Humus 142.

Humusanzeiger $4 \mathrm{IO}$.

Humulus 3 I 4 .

Hundspetersilie $35^{2}$.

Hundszunge 359 .

Hutpilze 224.

Hyacinthus 286.

Hydnaceae 225.

Hydrangea 334 .

Hydrangeaceae 333 .

Hydrocharis 276 .

Hydrocharitaceae 276 .

Hydrocotyle 352 . 
Hydrocotylene 35:

Hydrodictycac 194.

Hydrophyllaceac 355 .

Hydropterides 240.

Hymenium 199.

Hymenolichenes 215.

Hymenomycetes 22.4.

Hyoscyamus 356 .

Hypanthium 335 .

Hypericaceac 320 .

Hypericum 320 .

Hypnum 235,236 .

Hypochaeris 368 .

Hypocotyl $3 \mathrm{~S}$.

Hypocreaceac 209.

Hypoderma 63, 72 .

Hypogyn 269.

Hysteriacene $21 \mathrm{I}$.

Hysterium pinastri $21 \mathrm{I}$.

Hysterophyta 353.

Igelföhre $26 \mathbf{r}$.

Igelkolben 285 .

Igelweizen 284 .

llex aquifolium 330 , B. $42 \mathbf{I}$.

Illicium 317.

Imbibition 32.

Impatiens 321 .

Indien 378 .

Indusium 239.

Ingwer 288 .

Inkrustierende Substanz 28 .

Innerasien 3 So.

Inschriften auf Bäumen 128 .

Insektenblütler 272 .

Insektenfressende Pflanzen 54.

- Ernährung 142.

- Reizbarkeit I7I.

Insektenkrankheiten 192 , $203,205,210$.

Integumente 244 .

Interfascicularcambium 83 .

Intercellularräume $58,79,81$.

- der Markstrahlen 92.

Internodien 65 .

Intussusception 32 .

Inula 370.

Inulin 17 .

Involucellum $35^{2}$.

Involucrum 352 .

Iridaceae 288 .
Iris 285

Isatis 319 .

Islindisches Moos 215 .

Isoütes 242 .

Isogamac 186 .

Isoliren von Zellen 27 .

Isonandra 355 .

Isospor 236

Isothecium 236 .

Jacaranda 358 .

Jahresperioden $163,164,165$.

Jahresringbildung 95 .

Jahresringe der Wurzeln I 19 .

Jaminsche Kette $15 \mathrm{I}$.

Japan 380.

Jasione 366 .

Jelängerjelieber 364 .

Johannisbeere 333 .

Johannesbrotbaum 346 .

Johanneskraut 320 .

Johannistricbe 164 .

Judasbaum 345 .

Judasohr 223.

Judenkirsche 356 .

Juglandaceae 309 .

Juglandiflorae 309 .

Juglans cinerea 3 I0,

- nigra 309, B.423, W.43I, K. 468 .

- regia 309, B. $423, W$. $43 \mathrm{I}, \mathrm{K}, 468, \mathrm{H}, 483$.

Juncaceae 287 .

Juncaginaceae 276 .

Juncus 287.

Jungermannia 234 .

Juniperinae 267 .

Juniperus communis 267 , B. 415, K. $462, \mathrm{H} .477$.

- nana 267 .

- Sabina L. 267, B. 415.

- virginiana L. 267, B. 415 , II. 477 .

Jute 322 .

Kaffeebaum 364.

Kahmhaut 205.

Kaiserkrone 286.

Kaiserling 23I.

Kakao 322.

Kälberkropf 352 .
Kali 147

Kalianzeiger 409.

Kialifornien 382 .

Kalk $147,148$.

Kalkanzciger 408 .

Kalkflora 409.

Kalkgehalt und Ptlanzenverteilung 398 .

Kalmus 285.

Kamellic 320.

Kamille 369 .

Kammgras $28 \mathrm{I}$

Kampferbaum 317.

Kanada 383 .

Kanariengras 280.

Kannenträger 320 .

Kappern 319.

Kapsel 270, 271.

Kardamom 288.

Karthäusernelke 315 .

Kartoffel 7I, 356.

Kartoffelkrankheit 202.

Karyokinese 12.

Karyopse 278 .

Kastanic, echte 304.

Kätzchen 47, 290.

Katzenminze 360.

Kautschuk So, 323 .

Keimblätter 38 .

Keimung I4 I.

Kelch 245.

Kerbel $35^{2}$.

Kern, falscher 100.

Kerngehäuse 34 r.

Kerngerüst 9 .

Kernholz 97.

- Färbung 98 .

Kernkörperchen 9.

Kernmembran 9.

Kernplatte 1I.

Kernsaft 9.

Kernsegmente II.

Kernteilung II, 12 .

Kerria 336.

Keuschbaum 359.

Kichererbse 347 .

Kiefer, gemeine 260 .

Kiefer, österreichische 26I.

Kiefernboden 401 .

Kiefernschütte 176 .

Kiefernwälder, Bodenflora 401 .

Kienporst 354 . 
Kienzopf $22 \mathrm{x}$.

Kieselalgen 194.

Kieselguhr I95.

Kieselsäure 3 I.

Kieselsäureanzeiger 409 .

Kirsche, ostheimer 340.

Kirschen 339.

Kirschenpflaume 339 .

Kirschgummi $8 I$.

Kirschlorbeer $34 \mathrm{I}$.

Klappertopf 358 .

Kleberschicht 20.

Klee 347 .

Kleistogam 274 .

Klette 367 .

Klettenkerbel 353 .

Knackweide 29r.

Knäuelgras 28I.

Knnautia 367.

Knieholz 260.

Knoblauch 286.

Knollen 7 I.

Knollenbildung I2I.

Knoppern 309.

Knospen 40, 56 .

Knospenanhäufung $\mathbf{1 3 3}$.

Knospenbildung bei Verwundung 133 .

Knospengrund 244 .

Knospenkern 244.

Knospenschuppen $5^{6}$.

Kinoten 65.

Kochsalzanzeiger 409 .

Koeleria 28I.

Kohl 3 I9.

Kohlensäure, Abgabe I 54 .

- Assimilation I36.

- Aufnahme 136.

- Gehalt der Luft 138 .

Kohlenstoffverbindungen 135 .

Kohlhernie 196.

Kokkus I9I.

Kokosnuss 285.

Kolbenhirse 278 .

Kolbensumach 325 .

Königsfarn 240.

Königskerze 357 .

Konservierungsmethoden 143.

Kontinentalklima $3 S_{5}$.

Köpfchen 47.

Kopulation bei Algen IS6 ff.
Kopulation bei Pilzen 198.

Korbweide 294.

Koriander 353.

Korkcambium I 20.

Korkeiche 309.

Korkgewebe 120, 121 .

Korkleisten $12 \mathrm{I}$.

Korkreaktionen 29.

Korkulme 3 Ir .

Kornblume 367 .

Kornelkirsche 350 .

Kornrade 315.

Korrespondierende 372.

Kränkeln 173 .

Krapp 363 .

Kratzbeere 337 .

Krausbeere 35.5 .

Krauseminze 360 .

Krautsteppen 375 .

Kreatin I4I.

Krebs durch Frost I 76.

- der Kiefer $22 \mathrm{I}$.

- der Laubhölzer 209.

Kreise der Blüte 268 .

Kresse 319.

Kreuzbefruchtung 272 .

Kreuzbestäubung 27 I.

Kreuzblütler 3 I 9 .

Kreuzdorn 331.

Kreuzkraut 369 .

Krone 245.

Kronenblätter, Deckung 345 .

Krummholzkiefer 260.

Krystallbehälter S I.

Küchenzwiebel $2 \$ 6$.

Kugelblume 360 .

Kukuksnelke 3 I 5 .

Kümmel 352 .

Kürbis 349 .

Kurztriebe 67.

Kyanophyll 137.

Labellum $28 S$.

Labiatae 359.

Labkraut 363 .

Lactuca 368.

Laichkraut 276 .

Lambertsnuss 302 .

Lamellenschwämme 229 .

Laminaria 195.

Lamium 359.
Lammkraut 368 .

Lampsana 368 .

Längenwachstum 157,160 .

- Periodicität I59.

Längsschnitt, radial 85 .

- tangential 85 .

Längswunden $12 S$.

Langtriebe 67 .

Lappa 367.

Lärche 263 .

Larix decidua Mill. 263 .

- europaea DC. $26_{3}$, B. 4 I6, K. 463,465, H. 477 .

- - var. sibirica 264.

- japonica Carr. 264.

- leptolepis Murr. 264.

- pendula 264.

- rossica 264.

Lathraea $35 \mathrm{~S}$.

Lathyrus 347 .

Latsche 260 .

Lattich 368 .

Laubblätter $5 \mathrm{I}$.

Laubfall 64 .

Laubmoose 234.

Laubspross 34 .

Laubwaldpflanzen 403, 404.

Laubwälder, immergrüne 373.

- subtropische 373 .

- winterkahle 374 .

Laudatea 2 I 5 .

Lauraceae 3 I 7 .

Laurus 317 .

Laurustinus 366 .

Läusekraut $35^{8}$.

Lavandula 360 .

Lavatera 322.

Lebensbaum 267 .

Leberblümchen 316 .

Lebermoose 233 .

Lecanora 215.

Ledum 354.

Leguminosae 344 .

Leguminosenernährung $\mathrm{I} 39$.

Leimkraut 3 I5.

Lein 320.

Leindotter 319 .

Leinkraut 357.

Leitbündelkryptogamen 237.

Lejolisia 195.

- Fortpflanzung I9I.

Lemna 286. 
Lens 347 .

Lenticellen 823.

Leontopodium 368, 370.

Lepidium 3 rg.

Lepidobalanus 30.4 .

Lepidozia 234 .

Leptothrix buccalis $19 \mathrm{I}$.

Leuce 296.

Leuchten der P'llanzen 156.

Leuchtgas als Reiz 172.

Leucin 17,141 .

Leucobryum 236 .

Leucoïum 288 .

Leucoplasten 16 .

Lianen 373 .

Libanonceder 264 .

Libriformzellen 77 .

- des sek. Holzes 89.

- Länge 96.

Lichenes 213.

Lichtbedürfnis $\mathrm{I} 38$.

Lichtblätter 64 .

Lichteinfluss auf Wachstum I 66.

Lichterscheinung ${ }_{156}$.

Lichthölzer ${ }_{1} 38$.

Lichtintensität 138, I 70 .

Lichtintensitätswechsel I 70 .

Lichtlage der Blätter 170.

Lichtnelke 3 I5.

Lichtwirkung, Assimilation 137.

- Reizerscheinungen I69.

Liebesapfel 356.

Lignin 28.

Ligula 277 .

Liguster 363 .

Ligustrum vulgare ${ }_{3} 6_{3}, \mathrm{~B}_{4} 423$, W. $46 \mathrm{I}$.

Liliaceae 286.

Lilie 286.

Liliiflorae 286 .

Lilium 286.

Linaceae 320.

Linaria 357.

Linde $321,322$.

Linin 9.

Linnaea 366 .

Linnaeaceae 366 .

Linospora 209.

Linse 347.

Linum 320.

Lippenblütler 359 .
Liriodendron 317.

Listera 289.

Lithospermum 359.

Litorella 358 .

Littoralwälder 373 .

Loasaceac 349.

Lobelia 367 .

Lobeliaceae 367.

Löcherschwämme 226.

Loculicid 286.

Lodiculac 278 .

Löffelksaut 3 I9.

Loganiaceae $36 \mathbf{r}$.

Lohblüte 196.

Lolium 283.

Longifoliac 294.

Lonicereae 364.

Lonicera alpigena 365 .

- Caprifolium 364, B. 424, W. 456 .

- coerulea 365 .

- nigra 365, B. 424, W. 457.

- Periclymenum 131, 364 , B. 424, W. 457 .

- Xylosteum 365, B. 424, W. 457 .

Lophodermium brachysporum 212.

- juniperinum 212.

- laricinum 212.

- macrosporum $2 \mathrm{II}$.

- nervisequium 212.

pinastri 2 I 1 .

Loranthaceae 353.

Loranthus 353 .

Lorbeer 317 .

Lorbeerweide $29 \mathbf{I}$.

Lorcheln 213.

Loteae 347.

Lotus 347 .

Löwenzahn 368.

Luffa 349.

Luftdruckdifferenzen imHolz I 53.

Luftdruck und Wasserhebung $15 \mathrm{I}$.

Luftverdünnte Räume I 5 I.

Luftwurzeln 109, II 6 .

Lungenkraut 358 .

Lupinus 348 .

Luzerne 347.

Luzula 287.

Lychnis 315 .
Lycium 356, 13. 417

Lycogala 196.

Lycoperdon $23 \mathrm{I}$.

Lycopodiaceac 241 .

Lycopodinae $24 \mathrm{I}$.

Lycopodium 241.

Lycopus 360.

Lysigene Intercellularräume SI.

Lysimachia 355 .

Lythraceac 349.

Lythrum 349.

Macrocystis 195.

Magnesia 147.

Magnolia 317 .

Magnoliaceae $3 \times 7$.

Nahagoniholz 323 .

Nahonia 317 .

Maiglöckchen 286.

Mais 278 .

Maischwamm 23 I.

Majanthemum 287.

Makrosporen der Pteridophyten 236.

Makrozoosporen is6.

Malachium 3 I5.

Malva 322 .

Malvaceae 322 .

Mammuthbaum 264.

Mandelbaum 338 .

Mangold 315 .

Mangrove 350 .

Mangrovenwälder 373 .

Manilafasern 288 .

Manna $36 \mathbf{I}$.

Mannaesche $36 \mathrm{r}$.

Männertreu 352 .

Maquis 375 .

Maranta 288.

Marcgraviaceae 320 .

Marchantia 234.

Marginalwachstum 157 .

Mark, Bedeutung für Wachstum 159.

Markstrahlen 85, 86, 92.

- Bedeutung für Wassertransport 153 .

- der Rinde 107.

- Zahl ders. im Holz 97.

Markstrahlzellen 92.

Marrubium 359. 
Marsilea 240.

Maserung 134 .

Massaria 209.

Massenzunahme 157 .

Massholder 328 .

Mastixstrauch 325 .

Mastjahre I4r.

Matricaria 369.

Mauerpfeffer 333 .

Naulbeerbaum $3 \mathrm{I} 3$.

Mäusegerste 285 .

Maydeae 278 .

Mechanik des Wachstums 158.

Medicago 347 .

Meeresstrand 395 .

Meerrettig 319.

Neerzwiebel 286.

Mehlbeerbaum 343 .

Nehltaupilze 207 .

Mehrfächerig 269.

Mehrkammerig 269.

Melampsora 220, $22 \mathrm{I}$.

Melampyrum 358.

Melandryum 315.

Melanesien 379.

Melastomaceae 349 .

Melde 315.

Meliaceae 323 .

Melica $28 \mathrm{I}$.

Melilotus 347 .

Melissa 360 .

Melocactus 315.

Melone 349.

Nelonenbaum 349 .

Membranschichten 26.

Menispermaceae $3 \mathrm{I} 7$.

Menispermum 317 .

Mentha 360.

Menyanthes 360 .

Mercurialis 323 .

Nerulius 228 .

Nesembryanthemum 315 .

Nesokarp 270.

Mesophyll 62.

Mespileae 342.

Mespilus germanica 342 .

Netaxin I4.

Metroxylon 285.

Neum 352.

Micellen 32 .

Mikroconidien 200 .

Mlikrokokkus I9I.
Mikropyle 244,247 .

Mikrosomen 7 .

Mikrosphaera 207.

Mikrosporen, Pteridophyten 236.

Mikrozoosporen 186 .

Milchkraut 368 .

Milchröhren 79 .

Milchsaft So.

Milchsaftgefässe 79 .

Milchsäuregärung 155 .

Milchzellen 79 .

Milium 280.

Milzbrand I9I.

Milzfarn 240.

Milzkraut 333.

Mimosa 349.

- Reizbarkeit 172.

Mimosaceae 349 .

Mimulus 357.

Mineralische

Bestandteile I 44.

Minze 360 .

Mirabellen 339.

Mirabilis 315 .

Nischung von Holzarten 163.

Nispel 342.

Mistel I I0, 353 .

Mitteleuropa $38_{3}, 3{ }_{3}$.

Mittellamelle 26.

Mittelmeergebiet 380 .

Mitteltemperaturen 374 .

Mittelwald, Bodenflora 406 .

Inium 236.

Mohn 318.

Möhre 353.

Molecularkräfte $\mathbf{1 5 5}$.

Molinia 28I.

Momordica 349 .

Monardeae 360.

Monilia 205.

Monöcisch 245.

Monocotyledones, Typus 275.

Monokarpisch 269.

Monopodiale Verzweigung 46.

Monopodium 46.

Monotropa 354 .

Nonstera 285 .

Montana 382 .

Noor 397.
Moorformation 376 .

Moorkiefer 260.

Moosbeere 355 .

Mloosdecke 4 Ir.

Moose 23 I.

Moosformationen 376 .

Mooskapsel 233.

Moosmoore 376 .

Moospflanze 37, 23r.

Moosspore 233 .

Moosvorkeim 23I.

Noraceae 3 I 3 .

Norchella $2 \mathrm{I}_{3}$.

Morcheln $2 I_{3}$.

Morphologie 1 .

Morus alba 313, B. 418, W. 436, H. 480 .

- nigra 3I3, B. 4 I8.

Moschuskraut 333 .

Mousseron 23 I.

Mucor 37, 204.

Mucoraceae 204.

Nultbeere 337 .

Mundbesatz 235 .

Musa 288.

Muscardinenkrankheit 210.

Musci frondosi 234

Muscineae $23 \mathrm{I}$.

Muskatnuss 317.

Nutisieae 368 .

Mutterspross 47.

Nycel $37,20 \mathrm{I}$

Mycetozoën 196.

Mycoderma 205.

Mycomycetes I96, r98.

Mycorhizen II 2 .

Nycorhizenernährung I 42

Mycorhizenpilz 207

Nyosotis 359 .

Myosurus 316.

Myrica Gale 3II, B. 4I9, W. 436 .

Myricaceae 3 II.

Myricaria 320.

Myriophyllum $35^{\circ}$.

Myristica 3 I 7 .

Myristicaceae $3 \mathbf{I} 7$.

Myroxylon 346 .

Myrrhe 324.

Myrsinaceae 355 .

Myrtaceae 350.

Myrtiflorae 349 .

Myxomycetes 196. 
Nachtierze 349.

Nachtschatten 356 .

Nachtwachstum 166.

Nadelhölzer $25 \mathrm{r}$.

Nadelwald, Bodentlora 402.

Nadelwaldregion 393.

Nahrung, organische I4Iff.

Nahrungsstoffe der Pllanzen 1.5.

Nanismus 167.

Narcissus 288.

Nasturtium 310.

Natterkopf 359.

Natterzunge 240.

Navicula 195.

Nectria cinnabarina 209

- cucurbitula 209.

- ditissima 209

Nebenblätter $39,54$.

Negundo aceroides Mönch. 339, B. 426, W. 460 .

- californicum Torr. et Gray. 320

- fraxinifolium Nutt. 329.

Nelke 3 I 5 .

Neottia 289.

Nepenthaceae 320.

Nepenthes 54, 320 .

Nepeta 360.

Nepeteae 360.

Nerium 360.

Nervatur der Blätter 63 .

Netzgefässe 25 .

Neubildung 4.4.

Neugewürz 350 .

Neuseeland 379 .

Nicotiana 356 .

Niederblätter $5 \mathrm{r}$.

Nigella 3 I 6 .

Nitella ig6.

Nitrification 139.

Nivale Region 393.

Nodus 65 .

Nordamerilia $380 \mathrm{ff}$.

Norfolktanne 264.

Nostoc 193.

Nothorhizae 319.

Nucellus 244.

Nucleolus 9.

Nucleus 9.

Nuculiferae 358 .

Nuphar 317.

Nuss 270.
Nussbaum 309.

Nutation 168 .

Nyctaginaceae 315.

Nyctitropismus 170.

Nymphaea 317.

Nymphaeaceac 317.

Obdiplostemonisch 269 .

Oberblatt 39 .

Oberständig 269.

Ochotskische Küstenländer 384.

Ochsenzunge 359 .

Odermennig 338 .

Oedogoniaceae 193.

Oedogonium 36 .

Oenanthe 352 .

Oenothera 349 .

Oenotheraceae 349.

Öffnen der Blüten 173 .

Ö̈dienform 223.

Okulieren 132.

Öl 2I, I 4 I.

Olacaceae 353 .

Olbaum 363.

Ölbehälter 8 I.

Olea europaea 363 .

Oleaceae 36 I.

Oleander 360 .

Oleïnae 363 .

Olivenöl 363 .

Ölpalme 285 .

Ölstriemen 352 .

Ölweide 332 .

Onagraceae 349 .

Onobrychis 348 .

Onoclea 240.

Ononis 347 .

Onopordon 367 .

Oogamae isS.

Oogonien der Pilze 197.

Oogonium 188 .

Oomycetes 202.

Oospore IS8, 197.

Ophioglossum 240.

Opponierte Stellung 50.

Opuntia 315.

Orchidaceae 288.

Orchis 289.

Organographie 3 .

Orient 379.

Origanum 360 .
Ornithopus 348 .

Ornus curopaca 361.

Orobanche 358 .

Orobus 347.

Orthotrichum 236 .

Orthotrope Samenknospen 244.

Oryza 278

Oryzeae 278 .

Oscillaria 193.

Osmose 22.

Osmunda 240.

Ostafrikanische Inseln 378.

Ostasien 380 .

Osterluzei 353 .

Ostrya carpinifolia 303.

- virginica 303.

- vulgaris 303 .

Otthia 209.

Ovula $2+3$.

Oxalidaceae 320.

Oxalis 320 .

Oxalsäure I48.

Oxalsaurer Kalk 19.

- - der Rinde 107.

- Vorkommen 30

Pacifische Küste ${ }_{3} \$ 2$.

Padus 340.

Paeonia 316.

Paeonieae 316.

Paläontologische Funde $37 \mathrm{I}$.

Palisanderholz $35 \mathrm{~S}$.

Pallisadenzellen 62 .

Palmae 285 .

Palmella 193

Palmellaceae 193.

Palmen 285.

Pandanaceae $2 S_{5}$.

Pandorina 193.

Paniceae 278.

Panicum 278.

Papaver 3 I8.

Papaveraceae 3 I8.

Papayaceae 349.

Papiermaulbeerbaum 314 .

Papilionaceae 346.

Pappelrost 220.

Pappus 367 .

Paranuss $35^{\circ}$.

Parasitismus 142.

Parenchym 43. 
Parietaria 3 I 3.

Paris 287 .

Parmelia 2I 5 .

Parnassia 333.

Paronychia 315.

Paronychiaceae 3I5.

Passifloraceae 349 .

Passiflorinae 349 .

Passionsblumen 349.

Pastinak 353.

Pastinaca 353 .

Paternostererbse 347 .

Paullinia 326.

Pavia flava 326.

- rubra 326.

Pechkiefer 262.

Pechnelke 315.

Pechtanne 256.

Pedalinaceae 358 .

Pediastrum 36.

Pedicularis 338 .

Pelargonium 321 .

Pellia 234.

Peltigera 215.

Penicillium 207.

Peperomia $3 \mathbf{I} 4$.

Perianthium 245

Periblem 41.

Pericambium II 7 .

Periderm I 20.

Peridermium 22I.

Peridie 201.

Perigon 245.

Perigyn 270.

Perikarp 270.

Periode grosse I6o.

Periodicität des Wachstums I 59 ff.

Perisporiaceae 206.

Peristomium 235.

Perithecium 20I.

Perlgras $28 \mathbf{I}$.

Peronospora, Fortpflanzung I 97.

Peronosporaceae 202.

Persica vulgaris 338 , B. 4 I6.

Personatae 356 .

Pertusaria 215.

Perückenstrauch 324.

Pestalozzia 209.

Petasites 369 .

Petersilie 352 .

Petroselinum 352 .
Peucedanaceae $35^{2}$.

Pezizeae 2 I 2.

Peziza Willkommii 2 I 2.

Pfaffenhütchen 330 .

Pfahlwurzel ro8.

Pfeffer 3 I4.

- spanischer $35^{6}$.

Pfefferminze 360 .

Pfeifengras 28 $\mathbf{I}$.

Pfeifenstrauch 334 .

Pfifferling $23 \mathrm{I}$.

Pfingstrose 316.

Pfirsichbaum 338.

Pflanzengeographie $37 \mathrm{I}$.

Pflanzenphänologie 392 .

Pflanzenschlaf i 70.

Pflanzensubstanz 135 .

Pflanzung 178.

Pflaume 338,339 .

Pfropfen 132 .

Phacidieae 2I 2.

Phacidium 2 I 2.

Phaenologie 392.

Phaeoplasten I3.

Phaeophyceae $36, \mathbf{1 9 5}$.

Phalarideae 280.

Phalaris 280.

Phallus 23I.

Phascum 236.

Phaseoleae 347.

Phaseolus 347.

Phegopteris 239.

Phelloderm I 20.

Phellogenschicht $\mathbf{I} 20$.

Philadelphus coronarius 334 , B. 425 , W. 453 .

Philonotis 235 .

Phleum 280.

Phloëm 77, I1 7 .

- sekundär ro4.

- Elementarorgane 105.

Phloëmparenchymzellen 77 .

Phoenix 285.

Phoma 209.

Phosphorsäure 147.

Phosphorsaurer Kalk 17.

Phototaxis 171 .

Phragmidium 218.

Phragmites 281 .

Phycomycetes 196.

Phyllactinia 207.

Phyllanthus 323.

Phyllocactus 315 .
Phyllocladien 68

Phyllocladus 253.

Phyllosticta 209.

Physalis 356 .

Physcia 215.

Physocalymna 99.

Phytelephas 285 .

Phyteuma 366.

Phytolaccaceae 3I5.

Phytophthora omnivora 202.

- infestans 202.

Picea alba Lk 259.

- Alcockiana Carr. 259.

- bicolor Mayx 259.

- canadensis Lk. 259.

- Douglasii Lk. 259.

- Engelmannii Engelm. 258.

- excelsa Lk. 256, B. 414, K. 462,466, H. 476 .

- Menziesii Carr. 258.

— nigra Lk. 259.

- obovata Ledeb. 259.

- Omorica Panc. 259.

- orientalis Lk. et Carr. 259.

- Parryana Barron $25^{8}$.

- polita Carr. 259.

- pungens Engelm. 258.

- rubra Lk. 259.

- sitchensis Trautv. et Mey. 257.

Picraena 324.

Pilacreae 224.

Pillularia 195.

Pilobolus 204.

Pilularia 240.

Pilze, Ernährung I 43.

- Nutzen 143.

- Vegetationsorgane 201.

Pilzkulturen 143.

Pilzmycel 37, 201.

Pilzschütte 177 .

Piment 350.

Pimenta $35^{\circ}$.

Pimpernuss 325.

Pimpinella $35^{2}$.

Pinaster 260.

Pinguicula $54,35^{8}$.

Pinie 26r.

Pinoideae 253.

Pinselschimmel 207.

Pinus 260.

- abies L. 256.

- DR. 255 
Pinus australis 262 .

- austriaca llioss a6s.

- Banksiana lamb. 261 .

- canadensis L. 259.

- Cembra L. 262 , B. 4 r6, K. 464,468 .

- corsicana Poir. 26r

- Coulteri zriz.

- densiflora Sicl, et Zucc. $26 \mathrm{I}$.

- Douglasii Sab. 259.

- excelsa Lam. 256.

- Wall. 262.

- halepensis Mill. $26 \mathrm{I}$.

- Jefireyi Murr. 262.

Laricio Poir. 26I, B. 416 , K. 464,468, H. 477.

- var. austriaca 26 I.

- - cebennensis 26I.

- - Pallassiana 26r.

- - Poiretiana 26r.

-. -.- pyrenaica $26 \mathrm{I}$.

Larix L. 263.

- maritima Koch $26 \mathrm{r}$. - Poir. 26I.

- mitis 262 .

- montana Mill. 260. B. 4 I 5 , I1. $+7 ;$

- var. Mughus 26I.

- - Pumilio 26r.

- - uncinata $26 \mathrm{I}$.

- nigricans Host. 26 r.

-. Peuce Grieseb. 262.

- picea L. 255.

- Pinaster Besser $26 \mathrm{r}$.

- Sol. $26 \mathrm{I}$.

- Pinea L. $26 \mathrm{I}$.

- ponderosa Dougl. 262.

- pyrenaica La Peyr. 26 r.

- rigida Mill. 262.

-. Sabiniana 262.

- silvestris L. 260, B. 4I5, K. 464,468, H. $47 \pi$.

- Strobus L. 262, B. 416, K. 464,468, H. 478 .

- taeda 262.

- Thunbergii Parl. 26.I.

Piper 3 I4.

Piperaceae 314

Pippau 368.

Piptocephalideae 204.

Pireae 343.

Pirola 354 .
Pirolaceac 35.3 .

Pirus communis 34.3, B. 420 , IV. 4.4. H. 4.4.

- malus 343, B. 421, W. 444 , 11. 485 .

Pistacia 325.

Pisum 347.

P'itch-pine $262,38 \mathrm{I}$.

Placenta 244, 269.

I'lanera Kaki 313.

P'lantaginaceae 358 .

Plantago 358 .

Plasma 4, 5 ff.

- Bewegung 7.

- der Holzzellen 90, 91.

- Fixicrung 6.

- Reaktionen 5.

- Strulitur 7.

- Zusammenhang 8 .

Plasmodien 4.

Plasmodiophora 196.

Plasmolyse 22.

Platanaceae 335 .

Platane 335 .

Platanthera 289.

Platanus occidentalis 335 , H. 422, II. 4.32 . II. 475 .

- orientalis 335, B. 422, IV. 432 .

Plattenkork I 2 I.

Platterbse 347 .

Plerom 4I.

Pleurococcus 193.

Pleurorhizae 319.

Pleurosigma 195.

Plumbaginaceac 355 .

Plumula 39.

Poa $2 S_{1}, 2 S_{3}$.

Pockholz 324 .

Podocarpaceae 253 .

Podocarpus 253.

Podosphaera 207.

Polemoniaceae 355.

Pollenkörner $24 \hat{3}$.

Pollensäcke 242.

Pollenschlauch 245,$2 ; \mathrm{N}$

Pollinien $28 S$.

Polycarpicae 316.

Polychasium 47.

Polygala 329.

Polygalaceae 329 .

Polygam 245.

Polygonaceae 314 .
I'olygonatum $2 \$ 7$.

P'olygoniflorate $3 \mathrm{r}$ \&.

P'olygonum 314.

Polykarpisch 260.

I'olyphagus 203.

Polypodium 239.

Polyporeae 226.

Polyporus 226 ff.

Polysiphonia 195.

Polystigma $21 \mathrm{I}$.

Polytrichum 235,236 .

l'omaceac 341 .

Populus 295.

- alba 296, B. 419, IV. 439 , H. 486 .

- balsamifera 298 .

- canadensis 297, B. 4I9, IV. 442 .

- - var. serotina 297 .

-. candicans 298.

- dilatata 296.

- canescens 296, B. 419.

- fastigiata 296.

- italica 296.

- laurifolia 298. monilifera 297.

- nigra 296, B. 419, W 44I, H. 486 .

- nigra var. pyramidalis 296 , B. 419 , W. 442 .

- ontariensis 298.

- pyramidalis 296.

- tremula 296, B. 419, W. 44 I, H. 486.

Portulaccaceae 315 .

Porus 26.

- der Spaltöffnungen 58 .

Potamogeton 276.

Potamogetonaceae 276 .

Potentilla 336 .

Potentilleae 336 .

Prairien 375.

Preisselbeere 355 .

Primärwurzel Io8.

Primula 355.

Primulaceae 355 .

Primulinae 355 .

Procarpium der Algen I89.

Promycel 216.

Prosenchym 43.

Protandrisch 274.

Proteïnkörner 19.

Proteïnstoffe $14 \mathrm{r}$. 
Prothallium 236.

Protobasidiomycetes 223 .

Protococcaccae 194.

Protogynisch 274.

Protonema 23I.

Protoplasma s. Plasma.

Pruinosae 294.

Prunophora 338 .

Prunus 338 .

- acida 339.

- Armeniaca 338, B. 419, IV. 447 .

- $\operatorname{avium} 340$, B. 420 , W. 447 , H. 4 SI.

- chamaemorus 340.

- cerasifera 339.

- cerasus 339, B. 420, W. 447, H. $48 \mathrm{I}$.

- domestica 338 , B. $42 \mathbf{I}$, W. $445, \mathrm{H} .48 \mathrm{I}$.

- insititia 339, B. 421 , W.446.

- laurocerasus 34I.

- Nahaleb 340, B, 420, W. 447 , H. 48 I.

- Padus 340, B. 421, W. 447 , H. tisi.

- serotina 341 .

- spinosa 339, B. $421, W$. 444, H. $48 \mathrm{I}$.

Psamma 280.

Pseudoparenchym 36, 43.

- der Pilze 202.

Pseudotsuga Douglasii Carr. 259, B. 415, K. 463,465 .

Ptelea 323, B. 422.

Pteridophyta 236 .

Pteris 239.

Pterocarpus 99, 348.

Puccinia graminis 217,218 .

Pulmonaria 358 .

Pulsatilla 3 I6.

Pulverholz 33 I.

Punica 350.

Purgierlein 320

Purpureae 292.

Purpurweide 292.

Pusteln auf dürren Ästen 209.

Pycniden 200.

Pylaisia 236 .

Pyramidenpappel 296.

Pyrenäenkiefer 261.

Pyrenin 9.
Pyrenoide 15.

Pyrenomycetes 208.

Pyrethrum 369.

Pyronema 213.

Pythium 203.

Quassia 324.

Quaternaria 209.

Quecke 69, 7I, $28_{3}$.

Quellung 32.

Quendel 360.

Querciflorae 29 S.

Quercitrongelb 308.

Quercus 304.

-- alba 307.

- austriaca Villd. 308.

- cerris L. 308 , B. $42 \mathrm{I}$, W 448, H. 479

- coccinea 307 .

- falcata 307.

- hungarica 307.

- imbricaria 308.

- infectoria 309.

- ilex 307

— ilicifolia 308.

- macrocarpa 307 .

- nigra 308.

- obtusiloba 307.

- palustris 307 .

- pedunculata 304, B. $42 \mathrm{I}$, W. 447, K. 468, H. 478 .

- Phellos 308 .

- Prinos 307.

- pubescens Willd. 306, B. $42 \mathrm{I}$, W. 448.

- robur « L. 305.

- $-\beta$ L. 306.

- Mill. 306.

- rubra 307 .

- serricea 308 .

- sessiliflora 306, B. $42 \mathrm{I}$, IV 448, K. 468, H. 478 .

- suber 309.

- tinctoria 307.

Querschnitt 85 .

Quertracheïden 92.

Quetschwunden I33.

Quirle 50.

- der Blüte 268.

Quitte 343.

— chinesische 355 .
Racemöse Verzweigung 46 .

Radula 234.

Rainfarn 369.

Rainweide 363 .

Ramié 313 .

Randwachstum 157 .

Ranken 57, 70.

Ranken, Reizbarkeit 172 .

Ranunculaceae 316.

Ranunculeae 316.

Ranunculus 316.

Raphanus 319.

Raphlesiaceae 353 .

Rapunzel 366, 367 .

Rauchwirkung i 78 .

Rauhbirke 300.

Rauke 319.

Raupenkrankheiten 192, 203, 205, 210.

Rauschbeere $32,3,355$.

Raygras $280,2 S_{3}$.

Rebe 330 .

Rebendolde 352 .

Reduktion des Blattgewebes 64.

Regenmangel und Pflanzenverteilung 392 .

Regenwälder, tropische 373.

Regionen 392 ff.

Reiherschnabel 32 I.

Reineclaudes 339 .

Reinigung von Ästen $12 S$.

Reinzüchtung 143.

Reis 278 .

Reize I69.

- mechanische 172 .

Reizbarkeit 169.

Reizerscheinungen $169 \mathrm{ff}$.

Renntierflechte 215 .

Repentes 295 .

Rephuhnholz 225.

Reseda 319.

Resedaceae 3 I9.

Reservestoffe I4I.

Retusae 292.

Rhabarber $3 \mathbf{I} 4$.

Rhamnaceae $33 \mathrm{I}$.

Rhamnus cathartica 33I, B. 424, W. 454, H. $4 \delta_{3}$.

- frangula $33 \mathrm{I}$, B. $4 \mathrm{I} \delta$, W. $430, \mathrm{H} .483$.

Rheum 3 I 4 . 
Rhinanthaceac 358 .

khinanthus $35 \mathrm{~s}$

Rhipidonema 215 .

Rhizobium legruminosarum 1.40.

Rhizoiden 37 .

Rhizome 70.

Rhizomorphen 202.

Rhizophoraceae 350.

Khododendron 354 .

Rhodophyceae 36,195 .

Rhodoplasten 13 .

Rhodoraceae 354 .

Rhodotypus 336 .

Rhocadinae $3 \mathrm{I} 8$.

Rhus coriaria 325 .

- cotinus 324, B. $418, W$. 431 .

- toxicodendron 325 .

- typhina 325.

Rhytisma 212.

Ribes alpinum 333, B. 422, IV. 430

- aureum 333.

- Grossularia 333, B. 422, IV. 436 .

nigrum 333 , B. 422 , W. 430.

- rubrum 333, B. $422, \mathrm{IV}$ 430 .

Ribesiaceae 333 .

Riccia 234.

Richtung von Pflanzenteilen 169.

Ricinus 323 .

Riedgräser 277 .

Riesenstäubling $2 \hat{\mathrm{r}}$.

Rinde ohne Borke I2I.

Rindenbrand 177 .

Rindenbrandwunden 133 .

Rindenneubildung 126.

Rindenporen 123 .

Rindenwurzeln III.

Ring (Pilze) 230.

Ringelblume 369 .

Ringelborke 122.

Ringelschnitt 127 .

Ringfäule 227.

Ringgefässe 25 .

Rippenfarn 240.

Rispengras 281.

Rittersporn 316.

Ritzenschorf 2 II.
Robinia hispida 347 .

- P'seudacacia 346, B. 423, Rutaceae 323. IV. 429 , K. 474 , H. 480 .

- viscosa 347 .

Robinic 346 .

Roestelia $2 \mathrm{IS}$.

Roggen $2 S_{4}$.

Rohrkolben $2 \$ 5$.

Rohrzucker 17.

Rosa 337, W. 437.

Rosaceae 335 .

Roseac 33.7 .

Rosenholz 99.

Rosenrost 218.

Rosiflorae 335.

Rosmarinus 360 .

Rossellinia 208.

Rosskastanie 325 .

Rostpilze 216.

Rotalgen 195.

Rotation 7.

Rotbuche 303 .

Roteiche 307.

Roterle 299.

Rotfäule $226 \mathrm{ff}$.

Rotholz 99, 345.

Rotrüster 3 I I.

Rottanne 256.

Rubeae 336 .

Rübenkohl 3 I9.

Rubia 363.

Rubiaceae 363 .

Rubiales 363 .

Rubus caesius 337 , B. 422, W. 438 .

- chamaemorus 337 .

- fructicosus 337, B. 422, W. 437 .

- Idaeus 337 , B. $422, \mathrm{~W}$. 338 .

- saxatilis 337 .

Ruchbirke 301 .

Ruchgras 280.

Rückenseite 50 .

Ruderalflora 4 I 0.

Ruderalpfianzen 376 .

Ruheperioden 164.

Ruhrkraut 370.

Rumex 3 I 4 .

Runkelrübe 3 I 5 .

Runzelschorf 212 .

Ruscus 67, 287 .

Russtau 208.
Ruta 323

Säbelwuchs iso.

Saccharomyces 205.

Saccharomycetes 204 .

Saccharum 278 .

Sadebaum 267.

Saffran $28 S$.

Sagina 315.

Sagittaria 275 .

Sagopalme 285 .

Salat 368 .

Salbei 360 .

Salicaccae 290.

Salicitlorae 290.

Salisburia 253.

Salix $290 \mathrm{ff}$.

Salix acutifolia 294, B. 417 , IV. 433 .

- alba 29I, B. 417, W. 433 , H. 486 .

- alba var. vitellina $29 \mathrm{I}$, B. $417, \mathrm{IV}, 432$.

- amygdalina $29 \mathrm{I}$.

- aurita 295, B.419, W. 433 .

- babylonica $29 \mathrm{I}$.

- caprea 295, B. 420, IV. 433, H. 480

- cinerea 295, B. 42I, W. 433 .

- daphnoides 294, B. 417 .

- fragilis 29I, B. 4I7, W. 433, H. 486.

- grandifolia 295 .

- helix 292.

- herbacea 292.

-- incana 292, B. 416. longifolia 294.

- pentandra 29I, B. 420, W. 433, H. 486 .

- pruinosa 294.

- purpurea 292, B. 4r7, W. 433.

- repens 295 , B. 4 I 6.

- retusa 292.

- rubra 292.

- silesiaca 295.

- triandra 29I, B. 4I7, W. 434.

- viminalis $294, \mathrm{~B}, 4 \mathbf{I} 7, \mathrm{~W}$. 434. 
Salomonssiegel 287 .

Salpetersaure Salze I39.

Salsola 3 I 5 .

Salvia 360 .

Salvia pratensis, Bestäubung 272.

Salvinia 240 .

Salzwiesen 396.

Sambuceae 365.

Sambucus nigra 365 , B. 426 , W. $46 \mathrm{I}$, H. 482 .

- racemosa 365, B. 426, W. $46 \mathrm{I}$.

Samen 243.

- Angiospermen 250.

- Ausbreitung 274.

- Gymnospermen 247.

- Ruheperioden I65.

Samenanlagen 243.

Samenjahre I4I, 39I.

Samenknospen 243.

Samenmantel 252 .

Samenschale 247 .

Sammelfucht 270.

Sandbodenformation 376 , 401.

Sandelholz 99, 348, 353.

Sanddorn 332 .

Sandformation 376 , 40 I

Sandlulturen 144.

Sandrohr 280.

Sandsegge 68 .

Sandstrohblume 370.

Sanguisorba. 338 .

Sanicula 352 .

Santalaceae 353 .

Santalum 353.

Sapindaceae 325 .

Sapindus 326.

Saponaria 3 I 5 .

Sapotaceae 355.

Sappanholz 345.

Saprolegnia 203.

Saprolegniaceae 203.

Saprophyten 142 .

Saracenia 54, 320 .

Saraceniaceae 320 .

Sargassum 195 .

Sarothamnus 348 .

Sassafras 317 .

Satureinae 360.

Satureja 360.

Saubohne 347 .
Sauerampfer 314.

Sauerdorn 317 .

Sauerkirsche 339 .

Sauerklee 320.

Sauerstoff als Reiz $\mathbf{1} 72$.

- und Wachstum I67.

Sauerstoffausscheidung $\mathbf{I}_{3} 6$.

Sauerstoffentziehung 169 .

Sauerstoffverbrauch I 54.

Saugdruckwirkung der Markstrahlen $\mathbf{5 3}$.

Saugung der Blätter I5I.

Säule (Orchidaceae) 288.

Säulenblütler 32 I .

Säulenrost 220 .

Säureauscheidung der Wurzeln I 45 .

Savannen 375 .

Saxifraga 333 .

Saxifragaceae 333.

Saxifraginae 333 .

Scabiosa 367 .

Scandiceae 352 .

Schachtelhalm 240.

Schafgarbe 369 .

Schälen 128 .

Schälwunde I26.

Schattenblätter 64 .

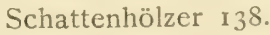

Schattenpflanzen 403, 405 .

Scheibenpilze 2 I I

Scheidewände, falsche 269.

Scheinaxe 48 .

Scheinfrucht 270.

Scheitelzelle 4I.

Scherfestigkeit I O I.

Scheuchzeria 276.

Schichtung der Zellwand 26. 27.

Schiefblatt 349 .

Schierling $35^{2}$.

Schierlingstanne 259 .

Schilfrohr 28 I.

Schinus 325 .

Schinzia Alni 196.

Schizocarpae 235.

Schizogene Intercellularräume $S I$.

Schizomycetes 191 .

Schizophyceae I9I.

Schlafende Augen 45.

Schlaffsucht der Raupen 192.

Schlagptlanzen 405 .
Schlangenfichte 257

Schlangentanne 255 .

Schlankweide 292.

Schlauch (Cariceae) 277.

Schlauchfrüchte 20 r.

Schlauchpilze 204.

Schlauchsporen 20 r.

Schlehdorn 339.

Schleier (Pilze) 230.

Schleimbehälter 80 .

Schleudervorrichtungen 275 .

Schleuderzellen 233.

Schlickgrund 396.

Schliessen der Blüten 173 .

Schliesshaut 25 .

Schliesszellen 58.

Schlingptlanzen $\mathbf{I} 3$ I.

Schmiele $28 \mathrm{I}$.

Schmierbrand $2 \mathrm{r} 6$.

Schminkbohne 347 .

Schmucktanne 264.

Schneckenklee 347

Schneeball 366 .

Schneebeere 365 .

Schneebruch 179.

Schneedruck 179.

Schneeglöckchen 288.

Schnittlauch 286

Schöllkraut 3 I 8 .

Schote 271 .

Schotendotter $3 \mathbf{I} 9$.

Schraubel 48.

Schubfestigkeit I I.

Schulzes Macerations-

gemisch 26.

Schuppenborke I 22.

Schütte der Kiefern 176 .

Schüttepilz 2 II.

Schutz der Blätter 52.

- der Sprossaxen 68.

Schutzholz Ioo.

Schwalbenwurz 360 .

Schwammbäume 229.

Schwämme 224.

Schwammkork I2I.

Schwammparenchym 62.

Schwärmsporen I 86 .

Schwärmzellen 196.

Schwarzbirke 30 I.

Schwarzdorn 339.

Schwarzerle 299.

Schwarzkiefer 26r.

Schwarzpappel 296. 
Schwarzwurzel 368 .

Schwefelsüure $1+7$.

Schweflige Süure 178 .

Schwerkraft, Einfluss auf Wachstum 167 .

Schwerkraftswirkung I69.

Schwimmbewegung 7 .

Schwinden 32.

Schwingel $2 S_{3}$.

Sciadopitys verticillata 264 . Scilla 286.

Scirpeae 276 .

Scirpus 276.

Scitamincac $28 S$.

Scleranthus 315.

Sclerenchymatische Zellen 24.

Scleroderma $23 \mathrm{I}$,

Sclerotinia 212 .

Sclerotium 202.

Scorzonera 368.

Scrophularia 357.

Scrophulariaceae 357 .

Scutellaria 359.

Secale $2 S_{4}$.

Sedum 333 .

Seegras 276 .

Seekiefer 26I.

Seeklima 385 .

Seerose 317 .

Seggen 277.

SekretbehäIter 79 .

Sekretschläuche $\delta$ I.

Selaginaceac 360 .

Selaginella 242 .

Selaginelleae $24 \mathrm{I}$.

Selbstbestäubung 271, 274.

Sellerie 352.

Seide 356 .

Scidelbast 332 .

Seifenbaum 326.

Seifenkraut 3 I5.

Seitenaxen 46.

Seitenwurzel ros.

Seitenwurzelbildung I 7 .

Sempervivum 333.

Senf 319 .

Senecio 369.

Sennesblätter 345 .

Septicid 286.

Septoria 209.

Sequoia gigantea Torr. 264 .

Seradella 348 .
Serratula 367 .

Scsamöl 35S.

Sesamum $35^{8}$.

Seselineac 352.

Setaria 278 .

Sevenbaum 267 .

Sherardia 363 .

Sibirien 383,384 .

Sichel 48 .

Sichelwurz 352.

Sicyos 349 .

Sideroxylon 355 .

Siebenstern 355 .

Siebröhren 26, 77, 107.

Sicbteil 77 .

Silberahorn 329.

Silbergras $28 \mathrm{I}$.

Silberpappel 296.

Silberweide 291 .

Silene 315 .

Sileneae 315.

Simarubaceae 324 .

Simultane Entstehung 50.

Sinapis 319.

Sinngrün 360 .

Siphoneen 35 .

Siphonia 323.

Sisymbrium 319.

Sklerenchymatische Zellen 24.

Smilax 287 .

Solanaceae 356 .

Solanum 356.

Solanum tuberosum 7 I.

Soldanella 355 .

Solidago 369.

Sommerästung 130.

Sommereiche 305 .

Sommerlinde 322 .

Sommerwärme und Pflanzenverteilung 390.

Sonchus 368 .

Sonnenröschen 320 .

Sonnenwirkung im Winter I 74 .

Sophora 346.

Sophoreae 346.

Sorbus Aria 343, B. 420, W. 439, H. 485 .

- aucuparia 343, B. 423 , IV. 440, H. 485 .

- domestica 343 .

- fennica 344.
Sorbus hybrida 344.

- intermedia 343.

- scandica 343.

- torminalis 343, B. 422 , W. 439, H. 485 .

Soredien 213.

Sorghum 27 S.

Sorus 238.

Spadicitlorac 285 .

Spadix 285 .

Spaltalgen 193.

Spaltöffnungen 58 .

Spaltpflanzen 191 .

Spaltpilzformen 191, 192.

Spanisches Rohr 285.

Spannung der Zellwand 22.

Sparassis 224.

Sparganium 285 .

Spargel 287 .

Spartium 348 .

Spätfrost I 74 .

Spatha 285.

Species 182.

Specifisches Gewicht der Zellwand $3 \mathrm{r}$.

SpecifischesTrockengewicht I I.

Speierling 343 .

Spelz 284 .

Spelzblütige 276 .

Spergel 315 .

Spergula 3 I 5 .

Spermakern $247,249$.

Spermaphyten 247.

Spermatien (Algen) r 89.

Spermatien (Pilze) 200.

Spermatozoiden der Algen I 88, I 89.

- der Mloose 232.

- der Pteridophyten 236.

- Reizbarkeit $17 \mathbf{I}$.

Spermogonien 200.

Sphaerella 209.

Sphaeriaceae 208.

Sphaeroblasten I 2 I.

Sphaerokrystalle 17 .

Sphaerophoron 21 5 .

Sphaeropleaceae 194.

Sphaerotheca 207.

Sphagna 235.

Sphagnum 235.

Spiegelrinde 107.

Spinacia 315. 
Spinat 315 .

Spindelbaum 330.

Spindelfasern $\mathrm{I} 2$.

Spiraea 336.

Spiraeeae 335.

Spirillum I9I.

Spirochaete I9I.

Spirogyra 194.

- Fortpflanzung I8S.

Spirolobeae 319.

Spirren 276.

Spitzahorn .327.

Spitzenwachstum I 57 .

Spitzklette 370.

Splint 97.

Spontane Bewegung I68.

Sporangien der Gymnospermen 248.

- der Pteridophyten 236.

- der Pilze 198, I99.

Sporangienstände 240, 24I, 242.

Sporenfrucht I 89 .

Sporidien 216.

Sporocarpium 189 .

Sporogon 233.

Sprossaxen 34, 65, 7I, $74 \mathrm{ff}$.

- oberirdische 66.

- unterirdische 70.

Sprosspilze 204.

Sprossranken 70.

Sprossung 202.

Sprossverkettung 46 .

Stachelbeere 333 .

Stacheln 60.

Stachelschwämme 225 .

Stachydeae 359 .

Stachys 359.

Stamina 242.

Stamm 65 ff.

Staphyleaceae 325 .

Staphylea pinnata 325 , 426, IV. 454.

- trifoliata 325 .

Stärke 20, I4I.

- in den Chlorophyllkörpern 14.

Stärkebildner 16.

Stärkebildung I 36 .

Stärkeherde I 5 .

Stärkereaktionen 20.

Starrezustände 169.
Statice 355 .

Staubbeutel 243.

Staubblätter $242,269$.

Staubbrand 216.

Staubfaden 243.

Staubgefässe 242 .

- Reizbarkeit 172.

Stauchlinge 66.

Stäubling 23 I.

Staudenformation 375 .

Stechapfel 356 .

Stecheiche 307.

Stechginster 348 .

Stechpalme 330.

Steckling 45.

Stegocarpae 235.

Steinapfel 342 .

Steinbrand 216.

Steineiche 306.

Steinfrucht 270, 271 .

Steinkern $27 \mathrm{I}$.

Steinklee 347

Steinpilz 229.

Steinzellen der Rinde 106.

Stellaria 3I 5 .

Stellung, gegenständige 50 .

- spiralige 50.

Stengel $65 \mathrm{ff}$.

Stephanosphaera 193.

Steppenformationen 375 .

Steppengebiet 384 .

Sterculiaceae 322 .

Stereum 225 .

Sternanis 317 .

Sternkiefer $26 \mathrm{I}$.

Stickstoffassimilation I $39 \mathrm{ff}$.

Stickstoffgehalt des Bodens 139, I4 I.

Stickstoffquellen I 39 .

Stieleiche 305 .

Stigmatea 209.

Stinkbrand 216 .

Stinkmorchel 23 I.

Stipa 280.

Stipulae 39.

Stockausschlag 46.

Stockloden 46.

Stoffleitung in den Sprossaxen 74 .

Stolones 70.

Stomata 58 .

Storchschnabel 321 .
Stossreize I $72 .^{2}$

Strahlende Wärme als Reiz I 73 .

Strandhafer 285 .

Strandkiefer 260, 26I.

Strandling $35^{8}$.

Strandnelke 355 .

Stratiotes 276 .

Strauch 66

Strauchsteppen 375 .

Straussgras 280 .

Streifung der Zellwand 27 .

Streu 146.

Strobus 262.

Stroma 199.

Struthiopteris 240 .

Strychnin $36 \mathrm{r}$.

Strychnos 36r.

Sturm 1 So.

Stylidiaceae 367 .

Styraceae 355 .

Styrax 355 .

Suberin 28 .

Subtropenwälder 374 .

Succedane Entstehung 50.

Succisa 367 .

Südamerika 379 .

Sumach 325 .

Sumpfcypresse 264 .

Sümpfe 396.

Sumpfeiche 307.

Sumpformation 377 .

Suspensor 247.

Süssholz 347 .

Süsskirsche 340 .

Süsswasserformation 396 .

Swartzia 345 .

Swertia 360 .

Swietenia 323 .

Symbiose 143 .

Symmetrische Organe 49 .

Sympetal 269.

Sympetalae 289, 353 .

Symphoricarpus 365 .

Symphytum 359 .

Sympodium 48 .

Syncarp 269.

Syncephalis 204.

Synchitrium 203.

Synthetische Processe 136 .

Syphoneae 194.

Syringa vulgaris $36_{3}$, B. 424 , IV. $46 \mathrm{I}, \mathrm{H} .485$. 
System, künstliches I $\$ 2$.

- matürliches I82.

Tabak .356.

labaschir 31.

Ticamahaca 297.

Tachaphantium 224.

Tiacda 262.

'iafelborke 123.

Tagesperioden 166.

Tagesuachstum I 66.

Tamaricaccac 320 .

Tamarinde 345 .

Tamarindus 345 .

Tamarix 320.

lanacetum 360.

Tanne, andalusische 256 .

- sibirische 256 .

Tannenwälder, Bodenflora 402.

Tannenwedel 350.

Taphrina 206.

Taraxacum 368.

Taubenkropf 315 .

Taubnessel 359 .

Taumeliolch $2 S_{3}$.

Tausendgüldenkraut 360 .

Taxaceae 253 .

Taxoideae 252.

Taxodiaceae 264.

Taxodium distichum 264.

Taxus baccata 253 , B. 414, K. 462, H. 476.

Teakbaum 359.

Tecoma 358 .

Tectona 359.

Teesdalea 3 i 9.

Teiche 396.

Telegraphenpflanze 348 .

Telephora laciniata 224.

- perdix 225.

Telephoreac 224.

Teleutosporen 216.

Temperatur, Einfluss auf Assimilation I38.

- Einwirkung auf Wachstum I66.

Temperaturdifferenzen als Reiz I 7 .

Temperatur der Pflanzen I 56.

Temperaturmaximum I 66.
Temperaturminimum 166.

Temperaturoptimum 166.

Temperatur und Reizbarkeit 169.

Terebinthinac 323 .

Ternstroemiaceac 320 .

Tetragonolobus 347 .

Teucrium 359.

Teufelskralle 366 .

Texas 382 .

Thalictrum 316 .

Thallus 37 .

Thea 320.

Thekholz 359.

Theobroma 322.

Thesium 353 .

Thonanzeiger 409.

Thuja gigantea Carr. 267 .

- Nutt. 267.

- japonica Maxim. 267. Menziesii Dougl. 267.

- occidentalis L. 267, B. 415 , K. 462 , H. 477 .

- Standishi Carr. 267.

Thujopsidinae 267 .

Thujopsis dolabrata 267 .

Thyllen 97, 127.

Thymelaeaceae 33I.

Thymelaeinae $33 \mathrm{I}$.

Thymian 360 .

Thymus 360 .

Tierblütler 272 .

Tiliaceae 321 .

Tilia americana 322.

- argentea 322.

- curopaca L. 321, 322.

- grandifolia Erh. 322, B 419, W. 448, K. $470, \mathrm{H}$. 482 .

- parvifolia Ehrh. 32I, B. Trespe $2 \delta_{3}$. 419, IV. 448, K. $470, \mathrm{H}$. $4 S_{2}$.

- pauciflora Hayne 322.

- platyphyllos Scop. 322.

- pubescens 322.

- ulmifolia Scop. $32 \mathbf{I}$.

Tillandsia 288 .

Tilletia 216.

Timotheegras 280 .

Tollkirsche 356 .

Tomate 356 .

Tomentelleae 224 .

Tonkabohnen 348 .
Topinambur 360

Torf 397.

Torfbrombecere 337.

Torfmoose 235 .

Torfsümpfe 376 .

Torilis 35.3 .

Torreya 253.

Torula pinophila 208.

Torus 26 .

Tötungstemperatur 177 .

Tracheales System 88

Tracheen 26, 77 .

- des sek. Holzes 89.

Tracheenlänge 96 .

Tracheïden 26, 77 .

- des sek. Holzes 89.

Tracheïdenlänge 96 .

Tradescantia 286 .

Traganth 347.

Tragblätter 56 .

Tragfähigkeit der Zellwand 3 I.

Tragholz 67.

Tragmodul $3 \mathrm{I}$.

Tragopogon 368 .

Trametes Pini 226.

- radiciperda 227.

Transpiration $\mathbf{1} 49$.

Trapa 349 .

Traube 47.

Traubeneiche 306 .

Traubenkirschen 340 .

Traubenkrankheit 207.

Traubenzucker 17 .

Trauerweide 291.

Tremellineae 224 .

Trennungsschicht an Blättern 65 .

Treppengefässe 25 .

Triandrae 291.

Trichogyn 189 .

Tricholoma $23 \mathbf{I}$.

Trichome 59.

Trichosphaeria 208.

Tricoccae 322.

Triebe, unverholzte 95 .

Trientalis 355 .

Triester Holz 313 .

Trifolieae 347 .

Trifolium 347.

Triglochin 276

Trimorph 274 . 
Triticum 283 .

- repens $69,7 \%$.

Trockengewicht des Holzes IoI.

Trockensubstanz I 49

Trockensubstanzabnahme I 54 .

Trollius 316.

Tropaeolaceae 32 I.

Tropisch 372 .

Trüffeln 207.

Trugdolde 48 .

Trunkelbeere 355 .

Tsuga canadensis Carr. 259, B. 415, K. 462 .

- Mertensiana Carr. 259.

- Sieboldii Carr. 259.

Tuber 207 .

Tuberaceae 207.

Tubercularia 210.

Tubiflorae 355 .

Tulipa 286.

Tulpe 286.

Tulpenbaum 3 I 7 .

Tundren 376 .

Tunica 315.

Tüpfel, einfache 25 .

- gehöfte 25 .

Tüpfelfarn 239.

Tüpfelhof 25 .

Turgor 22.

- Bedeutung für Wachstum 158.

- Schwankungen 153 .

Türkenbund 286 .

Turneraceae 349 .

Tussilago 369 .

Typha 285 .

Typhaceae 285 .

Überbrückungscambium $8_{3}$. Überliegen der Samen 165 . Übersicht über das System I $8_{3} \mathrm{ff}$.

- - Tabelle is;.

Überwallung I $28 \mathrm{ff}$.

Ulex 348.

Ulmaceae 3 II.

Ulmoideae 311 .

Ulmus americana Willd. 3 I 3 .

- campestris L. 312 .
Ulmus campestris Sm. et Valerianella 366. auct. non L. 3II, B. 4I8, Valleculae 352. IV. 450, K. 472, H. 484 . Vallisneria 276.

- $-\alpha$ genuina Aschers. 311. Valsa 209.

- $\beta$ montana Aschers. Vanillin 28.

Döll. 312.

— - « vulgaris Döll 3II.

- var. scabra Poth. 312.

- - suberosa $3 \mathrm{I} 2,45 \mathrm{I}$.

- ciliata Ehrh. 313 .

- effusa Willd. 313, B. 418 , W. $45 \mathrm{I}, \mathrm{K} .472, \mathrm{H} .482$.

- glabra. Nill. $3 \mathrm{II}$.

- montana Sm. 312, B. 4 I8, W. 45 I , K. 472, H. 484 .

- octandra Schk. 3 I3.

- pedunculata Foug. 3I3.

- suberosa 312, 45I.

Ulothrichaceae 193 .

Ulothrix, Fortpflanzung I 86.

Ulvaceae 193 .

Umbelliferae $35^{2}$.

Umbelliflorae 350 .

Umschnürung von Stämmen I 3 I.

Uncinula 207.

Unkräuter, verdämmende 410 .

Unterständig 270.

Uredineae 216.

Uredo linearis 218.

Uredosporen 216.

Urginea 286.

Urmeristem 4I.

Urocystis 216.

Uromyces Pisi 218.

Urtica 313 .

Urticaceae 313 .

Urticiflorae $3 \mathbf{I I}$.

Usnea 2 I 5 .

Ustilagineae 215 .

Ustilago 216.

Utricularia 54,358

Utriculariaceae 358 .

Utriculus 277 .

Vacciniaceae 354.

Vaccinium 354, 355 .

Vacuolen 6.

Valeriana 366.

Valerianaceae 366 .
Vaucheria 36, 194.

Vegetationsformationen $37 \hat{\mathrm{ff}}$.

- Veränderlichkeit 407 .

Vegetationsklassen 373 .

Vegetationslinien $385 \mathrm{ff}$.

Vegetationsorgane der Algen 35 .

- der Pilze 20 r.

Vegetationsperioden I64.

Vegetationspunkt 38 .

- der Algen 40, 4I.

- der Blüte 39, 40.

- der Gefässkryptogamen $4 \mathrm{I}$.

- der Laubsprosse 4 I.

- der Moose 40.

- der Wurzeln 42.

Vegetationszeit $3{ }_{3} \mathrm{ff}$.

Vegetative Zellen (Pollen) 245,248 .

Veilchen 320.

Velum 230.

Veratmung I 54 .

Veratrum 286.

Verbänderung I 34 .

Verbascum 357.

Verbena 359 .

Verbenaceae 359 .

Verbindungen, organische 135 .

Verbreitung, künstliche $39 \mathrm{I}$.

Verdämmung 4IO, 4I2.

Verdickung der Zellwand 23.

Verdickungsschicht, sekundäre 26.

Verdunstungsgrössen I 49 .

Vereintkronblättrig 269.

Verfärbung der Blätter 15 .

- von jungen Kiefern 177.

Verfilzung des Bodens 4I2.

Vergissmeinnicht 359 .

Verharzung 29.

Verholzung 28, 95.

Verkieselung $3 \mathbf{I}$.

Verkorkung 28.

Verletzung toter Gewebe i 26.

Veronica $35^{8}$. 
Verschleppung des Samen 274.

Verteiluner der P'tanzen 37 If.

Vertrocknen $17 \mathrm{~S}$.

Verwachsung holziger Teile 132.

Verwandtschaft der Pllanzen 182.

Verwundung als Reiz I33.

Verzweigung $44,46 \mathrm{ff}$.

Vexillum 346.

Viburnum Lantana 366, 13. $424, \mathrm{WV} .454$.

- Opulus 366, B. 425 , IV. 454.

- Tinus 366.

Vicariierend 372 .

Vicia 347.

Vicieae $3+7$.

Victoria 317.

Viminales 294 .

Vinca 360.

Vincetoxicum 360.

Viola 320.

Violaceae 320 .

Virgilia 346 .

Virginien $38 \mathrm{I}$.

Viscaria 315.

Viscum $110,353$.

Vitex 359.

Vitis Labrusca 331.

- vinifera 330.

- vulpina 33 I.

Vogelbeere 343 .

Vogelkirsche 340 .

Vogelkralle 348 .

Vogelmiere 3 I 5 .

Vollzellbildung 10.

Volva 230.

Volvocaceae 193.

Volvox 193.

Vorberge 393 .

Vorblätter 56 .

Vorkeim der Angiospermen 250.

- - Gymnospermen 247.

- Moose $23 \mathrm{I}$.

Vorspelze 277.

Vorwüchse 16I.

Wachholder 267.

Wachsablagerung 29.

Wachstum $156 \mathrm{ff}$.
Abhängigkeit von iusseren Falitoren 156.

- - inneren liaktoren 156 .

- basales 157.

gleitendes 44 .

- intercalares 157.

- Messung 157.

- des Stammes in verschicdenem Alter $16 \mathrm{r}$.

- der Wurzel 163,165 .

- der Zellwand 32.

- und Zellteilung 157.

Wachstumsgang einzelner Bäume 160 .

Wachstumsmaximum I60, I6I.

Wachstumsmechanik 158 .

Wachstumsperioden I59, I 60.

Wachstumsregistrierapparat I 57 .

Wachstumsstadien 157 .

Wachstumszonen 159 .

Wachtelweizen $35^{8}$.

Wahlvermögen 145 .

Waldbäume, Verbreitung ${ }_{3} 8 ; \mathrm{ff}$.

Wälder, winterkahle 374 .

- regengrüne 373 .

WValdformationen 373 .

Waldhaar 277 .

Waldmeister 363 .

Waldrebe 3 I 6.

Waldstreu I 46.

Wallnussbaum 309.

Wanderungen der Pflanzen 372.

Wanderung des Zellkerns 7,8 .

Wärmeeinfluss auf Wachstum I 66.

Wärmeentwickelung 156 .

Wärmesumme 390.

Warzenstäubling 231.

Wasser-Abgabe 149.

- Aufnahme i50.

- Ausfluss 152.

- Bedürfnis 149.

Wasserbewegung, Theorien $\mathrm{I} 50 \mathrm{ff}$.

Wasserblütler 272 .

Wasserfarne 240 .
Wasserfeder 355 .

Wasserfenchel 352 .

Wassergehalt 149 .

- Einfluss auf Assimilation 138.

- und Wachstum 167.

Wasserhebung 150.

Wasserkulturen 14.4 .

Wasserleitung 150.

Wasserlinsen 286.

Wassermelone 349 .

Wasserminze 360 .

Wassernuss 349 .

Wasserpest 276.

Wasserpflanzenformation 377.

Wasserreiser 45 .

Wasserschierling 352 .

Wasserschlauch 358 .

Wasserspalten 59 .

Wasserstern 323.

Wasserströmungen als Reiz I73.

Wasserverdunstung 149 .

- Abhängigkeit von äusseren Faktoren 150 .

Weberkarde 367.

Wechselwirkung verschiedener Organe 168.

Wegerich 358 .

Wegewarte 368 .

Weichbast 78 .

Weichsel 340.

Weide 290.

Weidenröschen 349.

Weidenrost $22 \mathrm{r}$.

Weiderich 349 .

Weigelia 365 .

Weihrauch 324 .

Wein, wilder $33 \mathrm{I}$.

Weinhefe 205.

Weinrebe 330.

Weinstock 330.

Weissbirke 300 .

Weissdorn 342.

Weisserle 299.

Weissesche 362 .

Weisstanne 255 .

Weizen 283.

Welken durch Frost 173 .

Welkwerden 22.

Wellingtonia gigantea Lindl. 264. 
Welwitschia 268 .

Wermuth 369.

Weymouthskiefer 262 .

Wicke 347 .

Wickel 48 .

Wiesenformationen 376 .

Wiesenmoor 398 .

Wiesenpflanzen 399.

Wiesenrispengras $28 \mathrm{I}$.

Wiesenschwingel 283 .

Wildling 132 .

Windblütler 272 .

Windbruch iso.

Winde 356 .

Winden der Pflanzen I68.

- der Sprossaxen 66.

Windwurf I8o.

Winterästung 130 .

Wintereiche 306 .

Wintergrün 354 .

Winterkälte 174 .

- und Pflanzenverteilung 390.

Winterlinde $32 \mathrm{I}$.

Winterruhe der Sprossaxen I64.

- Wurzeln 165:

Wintersonnenbrand $\mathbf{1 7 4}$.

Wirtel $5^{\circ}$.

Wistaria 347 .

Wohlverleih 369 .

Wolfsmilch 322 .

Wollbaum 322 .

Wollgras $276,280$.

Wollkraut 357 .

Wucherblume 369.

Wundklee 347 .

Wundkork 125 .

Wundparasiten 143.

Wundperiderm 125 .

Wundverschluss durch Callus I 27.

- durch Gummi 26.

- durch Harź 126.

- durch Kork 125.

Wurmfarn 239.

Wurzel 34, I $07 \mathrm{ff}$.

- der Humusbewohner I 12.

- der Schmarotzer I IO.

Wurzelanatomie I I I.

Wurzelbrut 45.

Wurzeldruck 152 .
Wurzelepidermis II $\mathbf{I}$.

Wurzelfäule I93.

Wurzelfunktionen 108 .

Wurzelhaare I I .

Wurzelhaube 42 .

Wurzelholz I 19 .

Wurzelknölichen 140.

Wurzelloden 46.

Wurzelrinde I I 5 .

Wurzelspitzen II 5 .

Wurzelverzweigung, abnorm I I 5 .

Wurzelwachstum $163,165$.

Wüstenformationen 376 .

Xanthium $37^{\circ}$

Xanthophyll I5, I37.

Xylarieae 2 ro.

Xylem 77.

Xylemstrahien der Wurzeln I 7 .

Yamswurzel 288.

Yucca 286.

Zahntrost $35^{8}$.

Zamia 251.

Zapfen (Coniferen) 254.

Zaserwurzeln 108.

Zaunriegel 363 .

Zaunrübe 349 .

Zea Mays 278 .

Zelkowa Keaki 3 I 3 .

- acuminata 313.

Zellbildung, freie $\mathbf{I}$.

Zelle 3 .

Zellen, mechanische 24,73 .

Zellenlehre 3 .

Zellfusionen 26 .

Zellgänge 132 .

Zellinhalt 3 .

Zellkern 9 .

- Bedeutung 12.

- Struktur 9.

Zelllumen 3.

Zellplatte 12 .

Zellsaft $4,6,17$.

Zellsaftfärbung 16 .
Zellteilung 9.

Zellwand $23 \mathrm{ff}$.

- Dehnbarkeit 158 .

- Falten 62.

- optische Eigenschaften 3 I.

- physikalische Eigenschaften $3 \mathbf{I}$.

- Verdickung 23.

- Wachstum 32.

Zerlegung von Stoffen I 36 . Zerreiche 308 .

Zersetzung organischerStoffe I 42 .

Ziegenbart 224 .

Ziest 359 .

Zimmt 317 .

Zingiber 288.

Zirbelkiefer 262.

Zittergras $28 \mathbf{I}$.

Zitterpappel 296.

Zoogloea 19 r.

Zoosporen i 86 .

Zostera 276 .

Zucker I $4 \mathrm{I}$.

Zuckerahorn 328 .

Zuckerrohr 278 .

Zugfestigkeit IOI.

Zunderschwamm 226.

Zürgelbaum 3 I 3 .

Zuwachsgrössen 160 .

Zuwachszonen 159.

Zweige, Abwerfen I64.

- Bewegungen durch Abkühlung 176 .

Zweihäusig 245 .

Zweikämmerig 269 .

Zweikeimblättrige, Typus 289 .

Zweimächtig 357 .

Zweizahn 369 .

Zwergwachholder 267 .

Zwergweizen 284 .

Zwetschke 338 .

Zwiebeln 57, 71, 286 .

Zwitterblüten 245 .

Zygnema I94.

Zygomorphe Blüten 49, 269.

Zygomycetes 204 .

- Fortpflanzung 197.

Zygophyllaceae 324 .

Zygospore I 86, I98. 


\section{Berichtigung.}

roseum.

Fig. 375 , S. 366 ist nicht der gemeine Schneeball sondern Viburnum Opulus var.

Seite 316 , Zeile 19 von oben lies Helleboreae statt Heleboreae.

" $322, \quad$ " 14 " " " Gossypium statt Gossipium. 



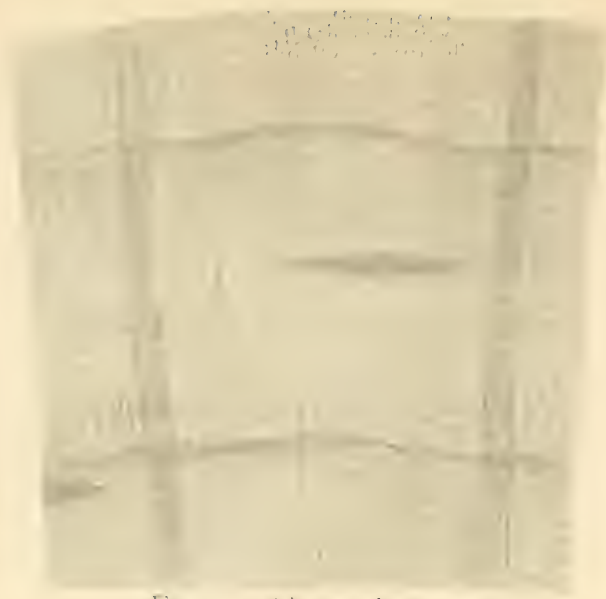

Fig. 1, Mlnus Eluturato

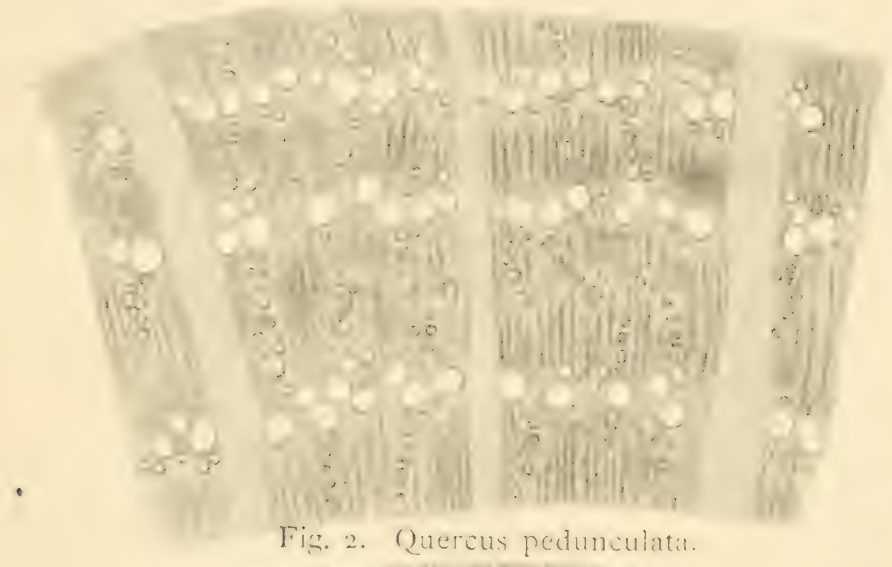

Fis. 2. Quercus nedunculati
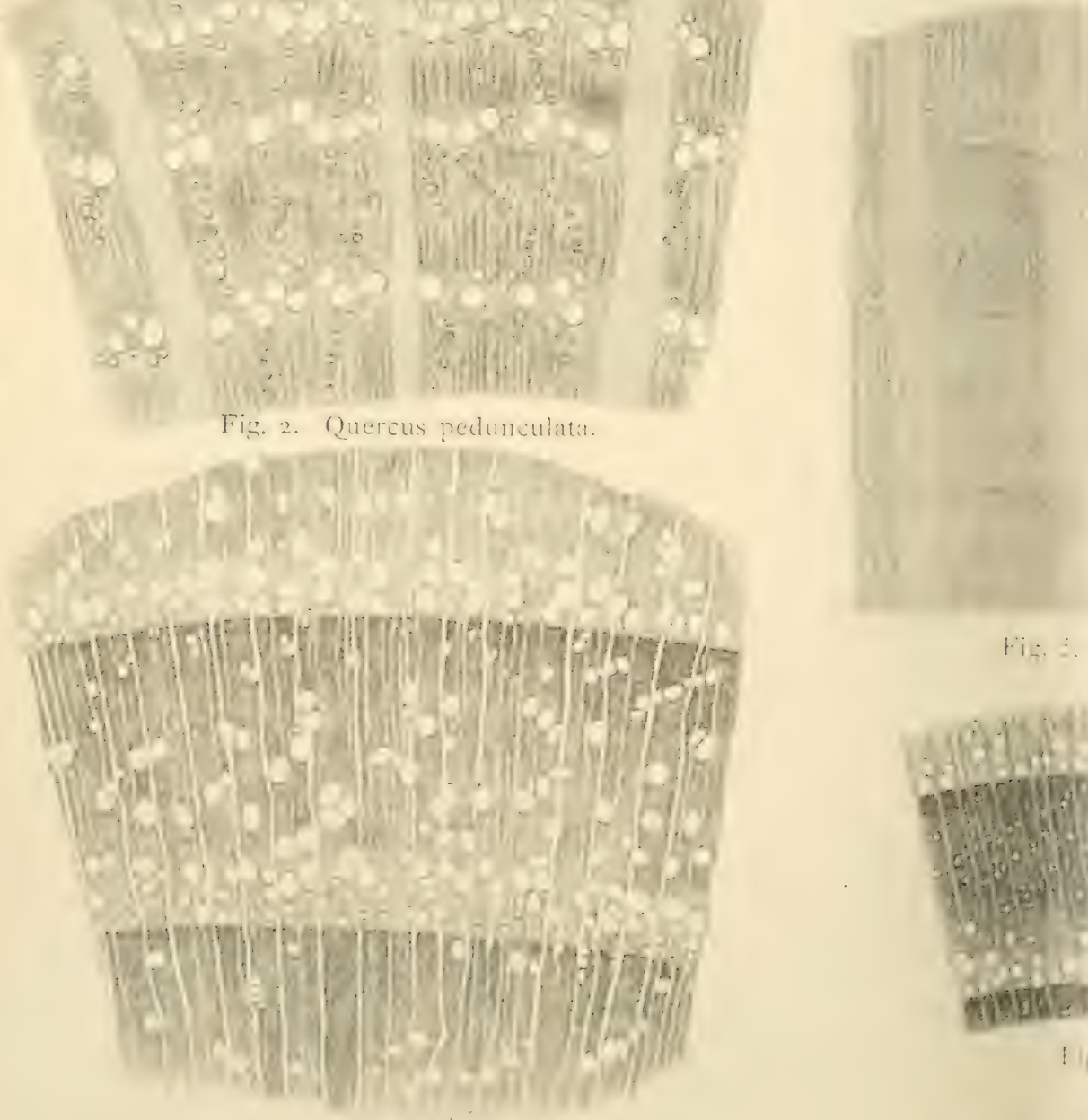

Fig. 3. Robinia Pseudacazia. 

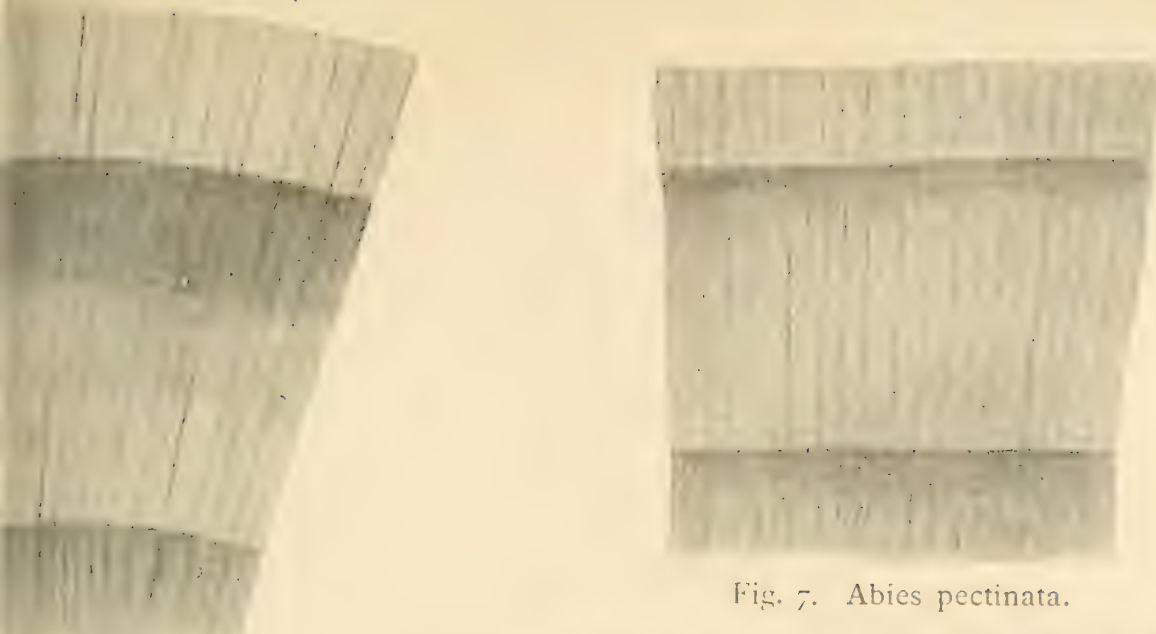

Fis. -7. Abies pectinata.

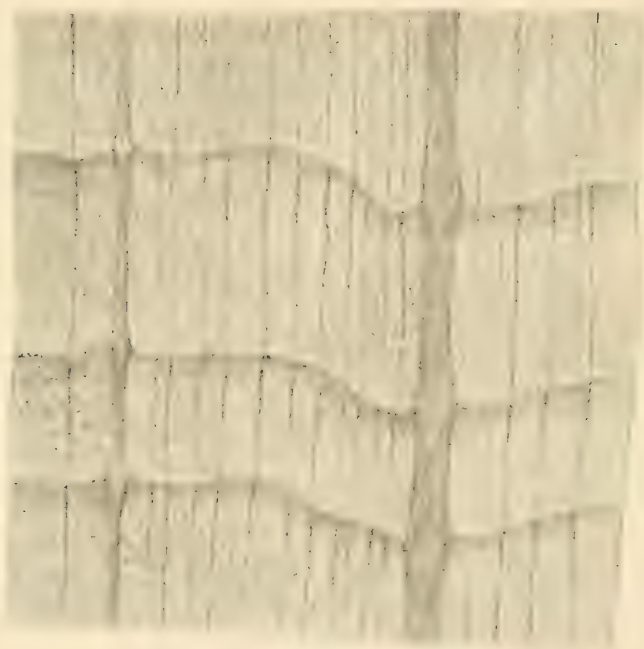

Fig. 8. Fagus silvatica.

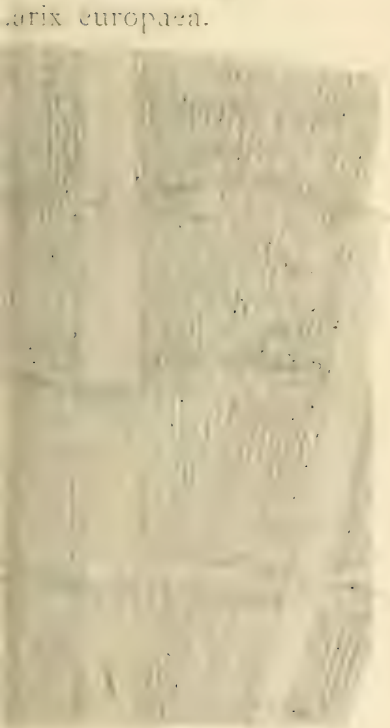

arpinus Batulus.

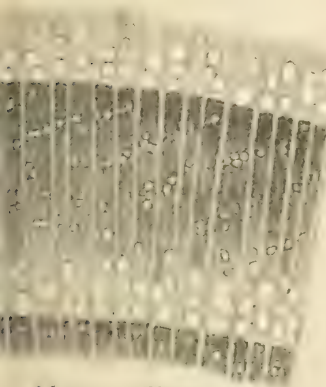

Morus alha.

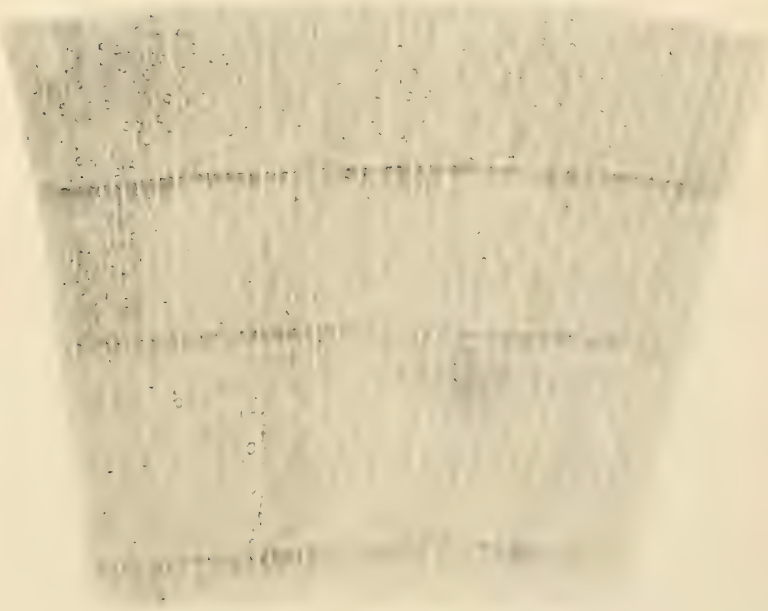

Fig. 9. Acer Pseudoplatanus. 




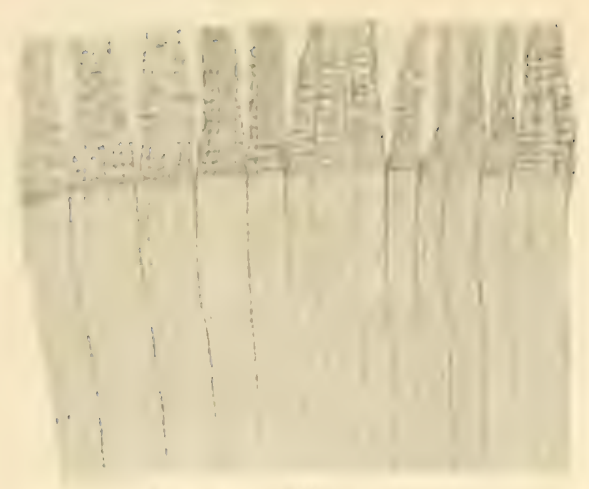

fiig. at Itha parvitolia.

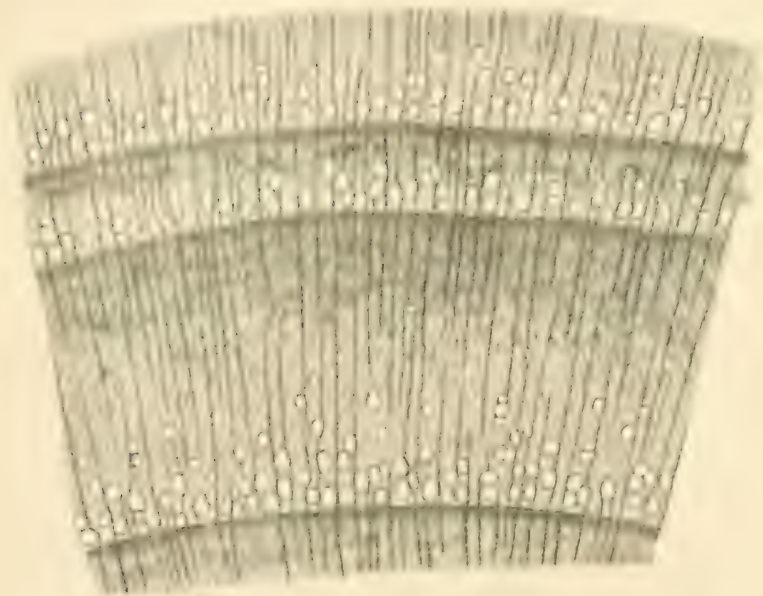

1.ic. 11. Fraxinus excelsior.

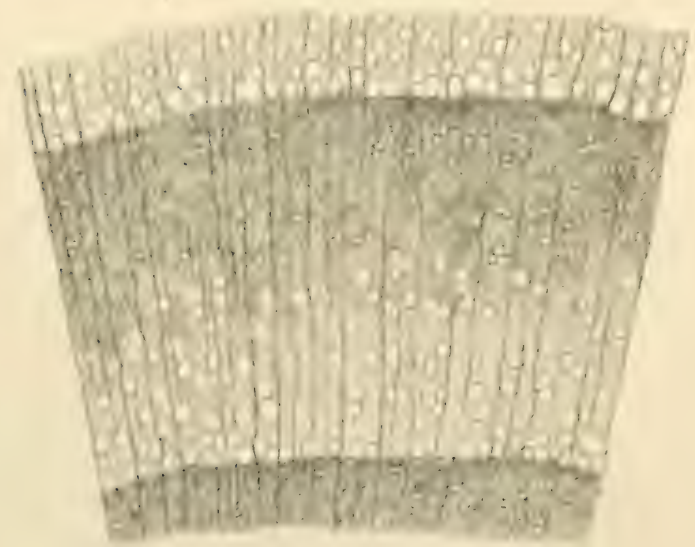

Fig. 12. Ulmus campestris.
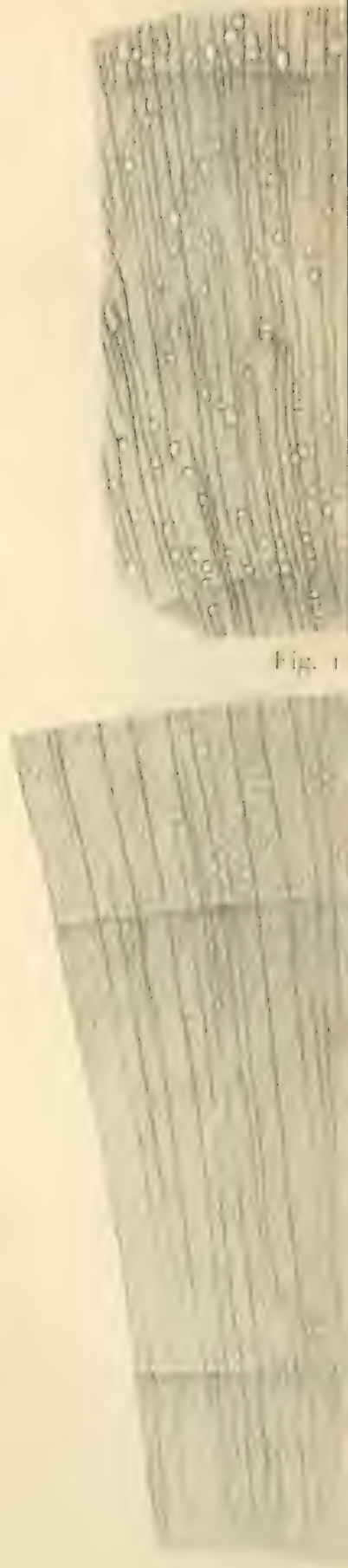

$1: \therefore 1$

Vergrösserung $12 \mathrm{fact}$ 

Döbner's

\section{Botanik für Forstmänner.}

Nebst einem Anhange:

Tabellen zur Bestimmung der Holzgewächse

während der Blüte und im winterlichen Zustande.

Vierte Auflage,

vollständig neu bearbeitet von

Dr. F. Nobbe,

Geh. Hofrat und Professor an der Königl. Sächs. Forstakademie zu Tharand.

Mit 430 Textabbildungen.

Preis 15 M. Gebunden 17 M.

\section{Botanik für Landwirte.}

Zum Gebrauch an landwirtschaftlichen Lehranstalten, sowie zum Selbstunterricht

Dr. F. Kienitz-Gerloff,

ord. Lehrer an der Landwirtschaftsschule in Weilburg a. L

Mit 532 Textabbildungen und einer Tafel in Farbendruck.

Preis 12 M.

\section{Lehrbuch der allgemeinen Botanik}

mit Einschluss der Pflanzenphysiologie.

Für den Gebrauch der Studierenden an Universitäten und Akademieen, sowie zum Selbststudium bearbeitet von

\section{Dr. J. Reinke,}

Professor der Botanik und Direktor des pflanzenphysiologischen Instituts der Universität Göttingen. Mit 295 Originalholzschnitten und einer Tafel in Farbendruck.

Preis 12 $\mathrm{M}$.

\section{Eigenschaften und forstliches Verhaiten}

der wichtigeren in

\section{Deutsehland vorkommenden Holzarten.}

Ein akademischer Leitfaden zum Gebrauche bei Vorlesungen über

\section{Waldbau}

von Dr. R. Hess, Professor in Giessen.

Preis $5 \mathrm{M}$.

\section{Gr'tundriss der lleteorologie unt Klimatologie,}

letztere mit besonderer Rücksicht auf Forst-und Landwirte.

Dr. R. Hornberger,

Prof. an der Kgl. Forstakademie Münden, Mitglied d. Kais. Leop. Carol. Akademie Deutscher Naturforscher. Mit 15 Textabbildungen und 7 lithogr. Tafeln.

Preis 6 M.

Zu beziehen dnoch jede Buchhaudlums. 


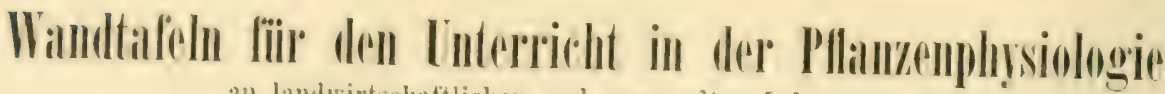

an limeirisehattichen und verwanden Lehranstalten
Dr. B. Frank,
von
Dr. A. Tschirch,
Professor in Berlin
Professor in Bern.

Farbendrucktafeln im Format von $69 \times 85 \mathrm{~cm}$ nebst Text.

1. Altcilung: Zehn Tafeln in Mappe, Preis 30 Mark. IT. Abceilung: Zehn Tafeln in Mappe, I'reis 30 Mlark. III. Ableilung: Zehn Tafehn in Mappe, Preis 30 Mark.

\section{Botanische Wandtafeln}

nebst erläuterndem Text.

\section{1.25}

In Farbeniruck ausgeführte Tafeln auf stärkstem Kartonpapier im Format von $69 \mathrm{~cm}$ Iöhe und $85 \mathrm{~cm}$ Breite.

\begin{tabular}{|c|c|}
\hline 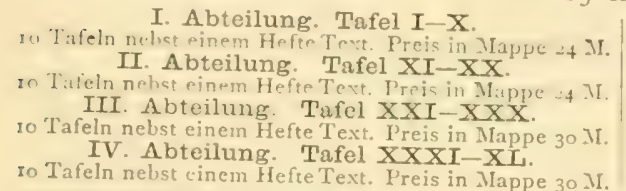 & 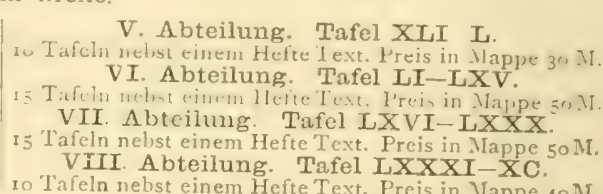 \\
\hline
\end{tabular}

\section{Anleitung zur Aufnahme des Holzyehaltes der Waldbestände.}

\author{
Dr. Max Friedrich Kunze, \\ Professor an der Forstakademie Tharand. \\ Zweite, durchgesehene Auflage. - Kartonniert, Preis $2 \mathrm{M}$.
}

\section{Das Forstrecht.}

Institutionen des preussischen und deutschen Civillechts, Verwaltungrsrechts, Strafrechts, Prozessrechts

in besonderer Beziehuner anf das Forstwesen.

Dr. Karl Ziebarth,

Geheimer Justizrat und ordentl. Prof. in der jurist. Fakultät der Univ. Göttingen.

Vier Teile in 1 Band gebunden. - Preis $12 \mathrm{M}$.

\section{HA NDBUCH \\ Staatsforstverwaltung in Preussen.}

Geordnete Darstellung der diesbezüglichen Gesetze, Kabinetts-Ordres

Verordnungen, Entscheidungen höchster Gerichtshofe, Regulative, Staatsministerialbeschlusse und

Ministerialverfügungen mit Quellenangabe.

E. Schlieckmann,

Kgl. preussischer Forstmeister in Frankfurt a $\mathrm{O}$

Zweite, vollständig umgearbeitete Auflage. - Gebunden, Preis $20 \mathrm{~m}$. 


\section{Illustriertes \\ Forst- und Jagd-Lexikon.}

\section{Unter Mitwirkung}

Professor Dr. Altum-Ebetswalde, Professor Dr. von Baur-München, Professor Dr. Bühler-Zürich, Forstmeister Dr. Cogho-Seitenberg, Forstmeister EsslingerAschaffenburg. Professor Dr. Gaycr-. München, Oberförster Frh. von NordenflychtSzittkehmen, Professor Dr. Prant l-Aschaffenburg, Forstmeister R unneba um-Eberswalde, Professor Dr. Weber-Münchcin, herausgegeben von Dr. H. Fürst, königl. Regierungs- und Forstrat, Direktor der kgl. Forstlehranstalt in Aschaffenburg.

Mit 580 in den Text gedruckten Abbildungen.

Ein Band in Gr.-Lexikon-Oktav.

Preis $20 \mathrm{M}$., gebunden $23 \mathrm{M}$.

\section{Der Waldbau. \\ Von}

Dr. Karl Gayer,

Professor der Forstwissenschaft an der Universität zu München.

Dritte, umgearbeitete Auflage.

Nit 88 in den Text gedruckten FIolzschnitten.

Gebunden, Preis $13 \mathrm{M}$.

\section{Die Forstbenutzung. \\ Von}

Dr. Karl Gayer,

o. ö. Professsor der Forstwissenschaft an der Universität zu München.

Siebente, vermehrle und verbesserte Auflage.

Mit 279 in den Text gedruckten IIolzschnitten.

Gebunden, Pieis $13 \mathrm{M}$.

\section{Handbuch der Waldwertberechnung.}

Mit besonderer Beriicksichtigung der Bedürnisse der forstlichen Praxis

bearbeitet von

Dr. Franz Baur,

o. ö. Professor an der Universität in München.

Gebunden, Preis $10 \mathrm{M}$.

\section{Die Holzmesskunde.}

Anleitung zur Aufnahme der Bäume und Bestände nach Masse, Alter und Zuwachs von

Dr. Franz Baur,

o. ö. Professor an der Universität in München.

Vierte, umgearbeitete Auflage. Mit 77 Holzschnitten.

Gebunden, Preis 1: M.

Vu bexiehen durch, iede IBuchhandlumg: 
Verlag von PAUL PAREY in BERLIN SW., so Hedemannstrasse.

\section{Handbuch der Nadelholzkunde.}

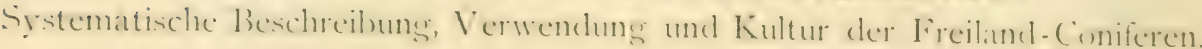
Für Gärtner, Forstleute und Botaniker

bearbitet von

1. Heissner.

Kgl. Garteninspelitor am botanischen Garten der Universitit Bonn und Lehrer für Gartenbau an rler Kigl. Landw. Akademie zu P'oppelsdorf.

Mit 138 nach dor Natur gezoichneton Abbildungen.

Ein sterlier Bund in Lexikon-Olike. Gebumlen, Preis $20 \mathrm{M}$.

\section{Handbuch der Laubholzkunde.}

Beschreibung der in Deutschland heimischen und im Freien kultivierten Bäume und Sträucher.

Für Botaniker, Gärtner und Forstleute bearbeitet yon

\section{Dr. Ieopold Dippel,}

Professor der Botanik und Direktor des Botanischen Gartens in Darmstadt.

Erster Teil: Monocotyleae und Sympetalae der Dicotyleae.

Mit sso Originalabbildmgen. - Preis $15 \mathrm{M}$.

Zweiter Teil: Dicotyleae, Choripetalae (einschliesslich Apetalae).

Urticinae bis Frangulinae.

Mit 2r: Textubbiliungen. - Preis 20 M.

Der dritte Teil (Schluss) erscheint 1892 .

\section{Handbuch der Pflanzenkrankheiten.}

Für Landwirte, Gärtner, Forstleute und Botaniker bearbeitet von

\section{Dr. Paul Sorauer,}

Dirigent der pflanzenphysiologischen Versuchsstation zu Proskau. Zweite, neubearbeitete Auflage.

Erster Teil: Die nicht parasitären Krankheiten. Mit 19 lithographierten Tafeln und 61 Textabbildungen. Gebunden, P'reis «O M.

Zweiter Teil: Die parasitären Krankheiten. Mit 18 lithographierten Tafeln und 21 Textabbildungen. Gebuuden, Ireis $14 \mathrm{M}$.

\section{Atlas der Pflanzenkrankheiten.}

\section{Dr. Paul Sorauer.}

Dirigent der pflanzenphysiologischen Versuchsstation zu Proskau.

Farbendruck-Tafeln im Format von $20>26 \mathrm{~cm}$ nebst Text.

Erste Folge. Taf. I-VIII. In Mappe. Preis 20 m. Dritte Folge. Taf. XVII-XXIV. In Mappe, Preis $20 \mathrm{M}$ Zweite Folge. Taf. IX-XVI. In Mappe. Preis 20 in. Vierte Folge. Taf.XXV-XXXII. In Mappe. Preis $20 \mathrm{M}$. Fünfte Folge. Taf. XXXIII-XL. In Mappe. Preis $20 \mathrm{M}$. 



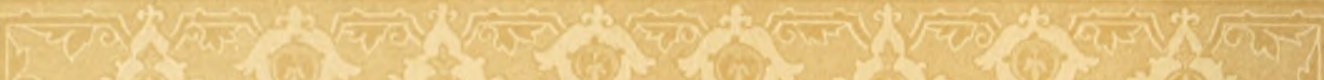

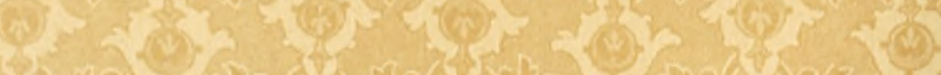

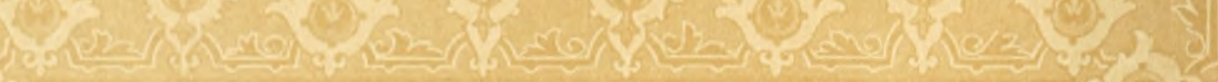

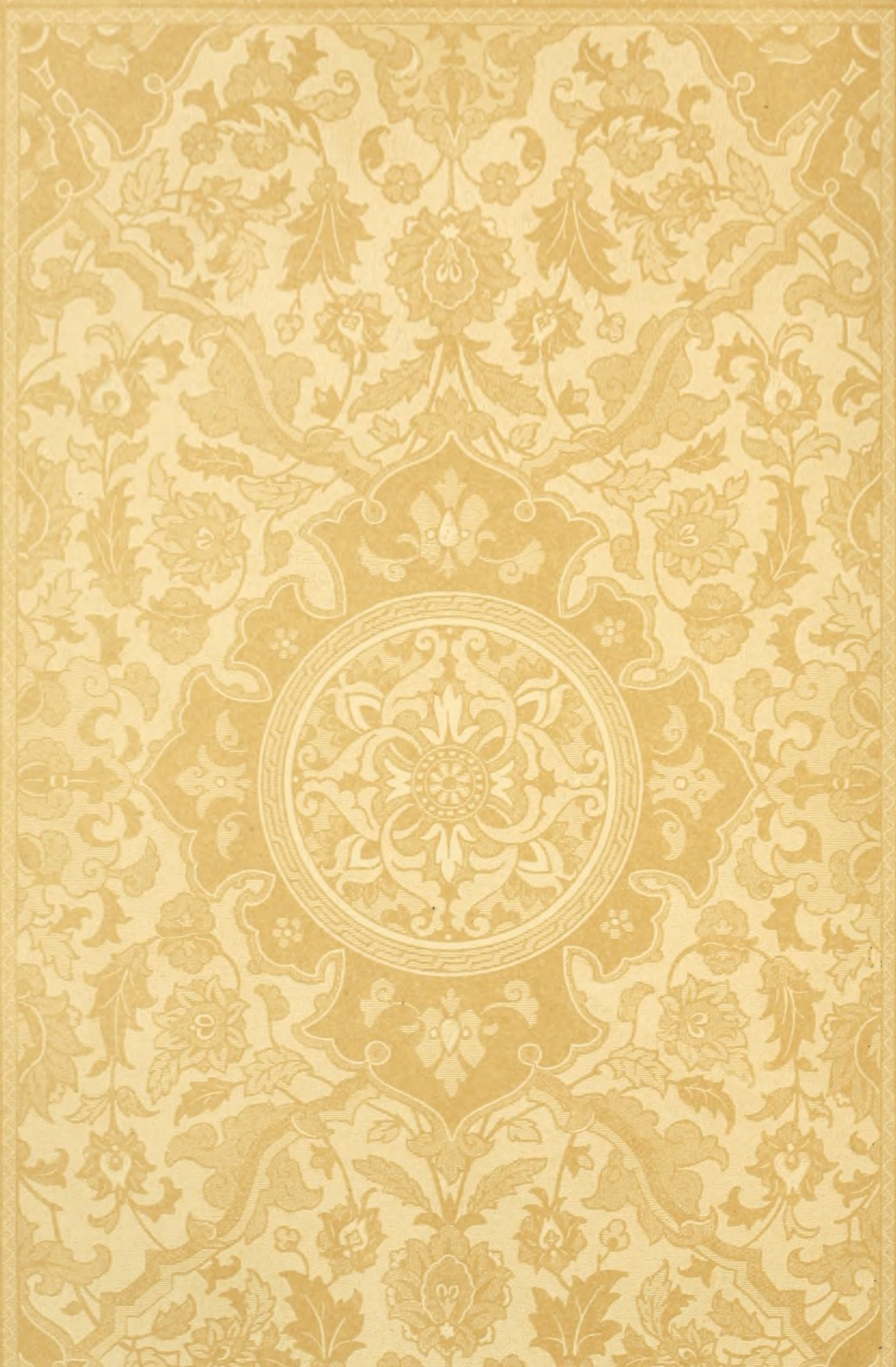

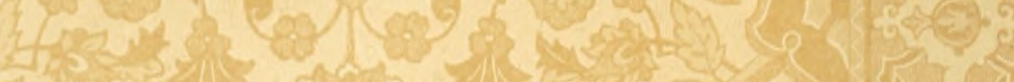

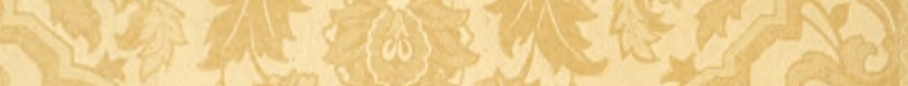
.

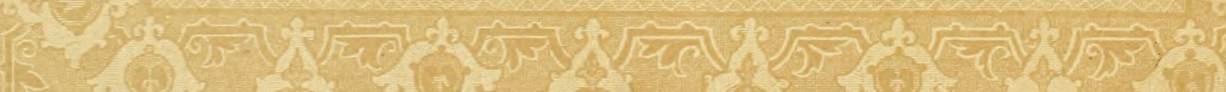
and 

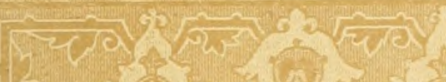

$-20$ (6) $)^{-1}$ (⿻)

seis
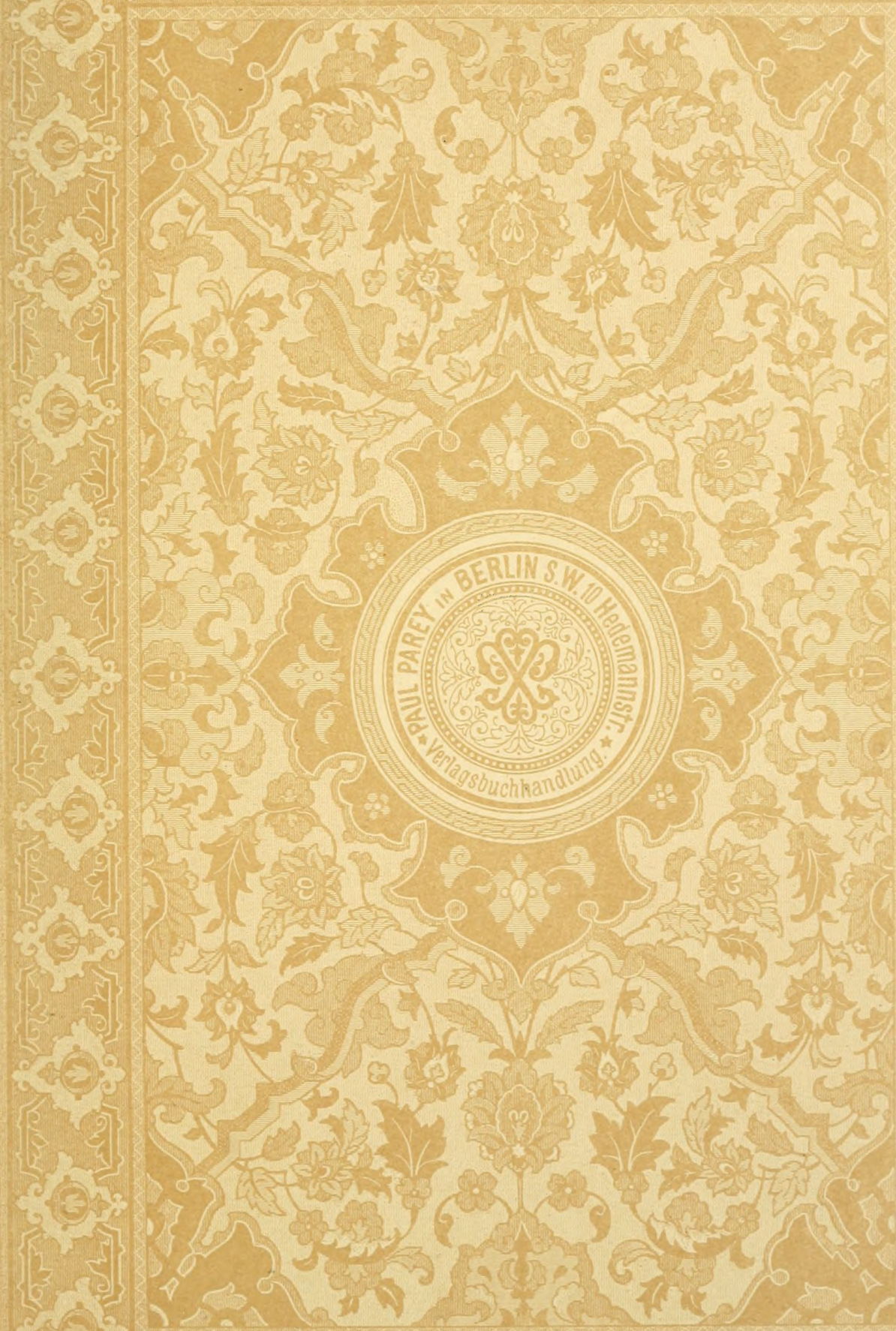

$15+2(2)$

विध

(c)

$(2)$

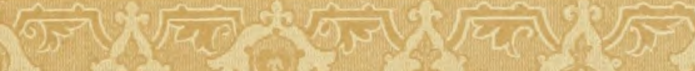

$\sqrt{a} \sqrt{2} \sqrt{\sqrt{2)^{3}}}$

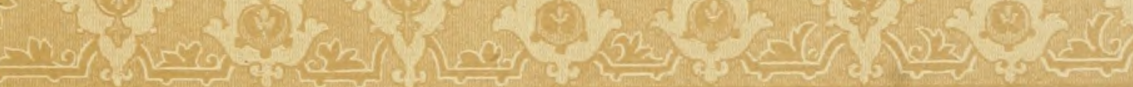




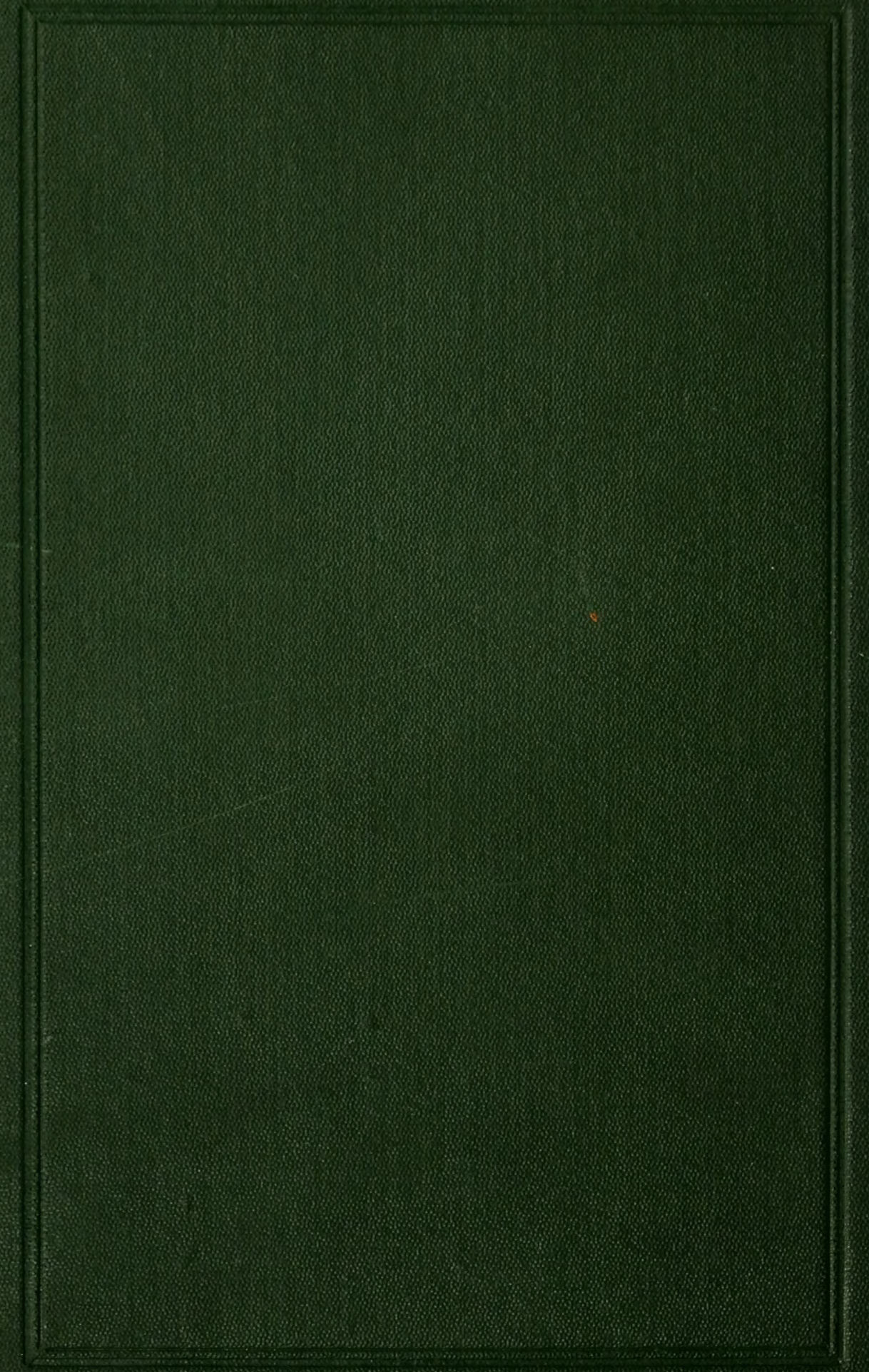

